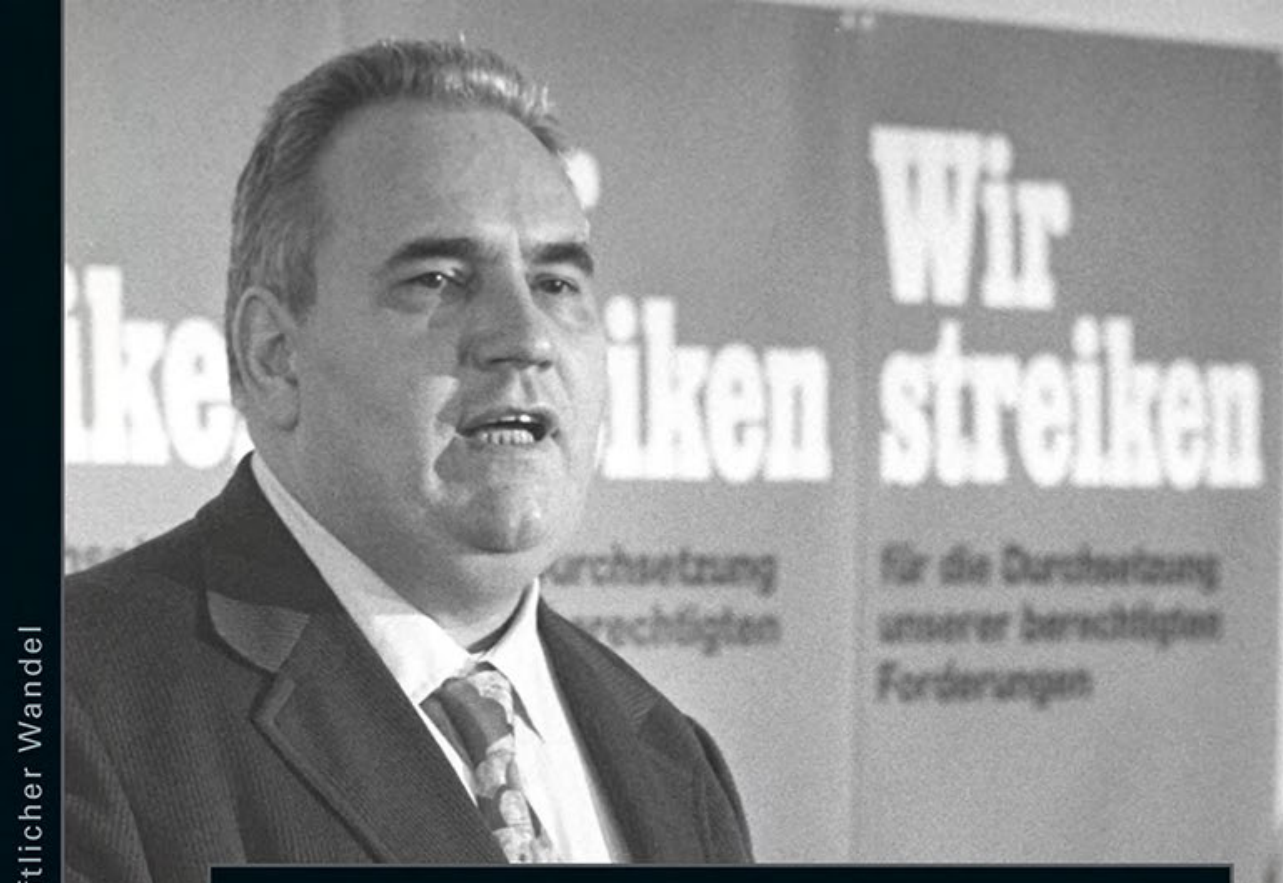

Karl Christian Führer

\title{
Gewerkschaftsmacht und ihre Grenzen
}

Die ÖTV und ihr Vorsitzender Heinz Kluncker 1964-1982

\section{[transcript] $\begin{gathered}\text { Hans Böckler } \\ \text { Stiftung }\end{gathered}$}


Karl Christian Führer

Gewerkschaftsmacht und ihre Grenzen 


\section{Editorial}

Die Reihe »Forschung aus der Hans-Böckler-Stiftung « bietet einem breiten Leserkreis wissenschaftliche Expertise aus Forschungsprojekten, die die HansBöckler-Stiftung gefördert hat. Die Hans-Böckler-Stiftung ist das Mitbestimmungs-, Forschungs- und Studienförderungswerk des DGB. Die Bände erscheinen in den drei Bereichen »Arbeit, Beschäftigung, Bildung«, »Transformationen im Wohlfahrtsstaat« und »Mitbestimmung und wirtschaftlicher Wandel«.

»Forschung aus der Hans-Böckler-Stiftung« bei transcript führt mit fortlaufender Zählung die bislang bei der edition sigma unter gleichem Namen erschienene Reihe weiter.

Karl Christian Führer, geb. I954, ist Historiker, außerplanmäßiger Professor an der Universität Hamburg und wissenschaftlicher Mitarbeiter am Historischen Seminar der Leibniz-Universität Hannover. Er publiziert zur deutschen Wirtschafts- und Sozialgeschichte, zur Mediengeschichte und zur Kulturgeschichte Deutschlands im 20. Jahrhundert. 2009 erschien die Biografie »Carl Legien I865-I92I. Ein Gewerkschafter im Kampf um ein >möglichst gutes Leben< für alle Arbeiter«. 
Karl Christian FüHrer

\section{Gewerkschaftsmacht und ihre Grenzen}

Die ÖTV und ihr Vorsitzender Heinz Kluncker 1964-1982

[transcript] 


\section{(C) Karl Christian Führer}

Erschienen im transcript Verlag 2017

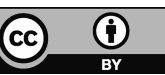

Dieses Werk ist lizenziert unter der

Creative Commons Attribution 4.0 (BY).

Diese Lizenz erlaubt unter Voraussetzung der Namensnennung des Urhebers die Bearbeitung, Vervielfältigung und Verbreitung des Materials in jedem Format oder Medium für beliebige Zwecke, auch kommerziell.

(Lizenztext: https://creativecommons.org/licenses/by/4.0/deed.de)

Die Bedingungen der Creative Commons Lizenz gelten nur für Originalmaterial. Die Wiederverwendung von Material aus anderen Quellen (gekennzeichnet mit Quellenangabe) wie z.B. Schaubilder, Abbildungen, Fotos und Textauszüge erfordert ggf. weitere Nutzungsgenehmigungen durch den jeweiligen Rechteinhaber.

\section{Bibliografische Information der Deutschen Nationalbibliothek}

Die Deutsche Nationalbibliothek verzeichnet diese Publikation in der Deutschen Nationalbibliografie; detaillierte bibliografische Daten sind im Internet über http://dnb.d-nb.de abrufbar.

Umschlagkonzept: Kordula Röckenhaus, Bielefeld

Umschlagabbildung: picture alliance / dpa / Lutz Rauschnick

Satz: Michael Rauscher, Bielefeld

Printed in Germany

Print-ISBN 978-3-8376-3927-8

PDF-ISBN 978-3-8394-3927-2

Gedruckt auf alterungsbeständigem Papier mit chlorfrei gebleichtem Zellstoff. Besuchen Sie uns im Internet: http://www.transcript-verlag.de

Bitte fordern Sie unser Gesamtverzeichnis und andere Broschüren an unter: info@transcript-verlag.de 


\section{Inhalt}

Einleitung | 11

I. Eine Gewerkschaft und ihr angehender Vorsitzender $\mid 21$

1. Die ÖTV: Ein einleitendes Porträt $\mid 21$

Vielfalt mit Lücken: Die ÖTV im System der bundesdeutschen

Gewerkschaften | 21

Neben- oder miteinander? Interne Spannungen in der ÖTV

und ihre Bedeutung für die Organisation | 37

Ungleiche Hälften: Frauen und Männer in der ÖTV | 51

Die »geliebte Farbe Rot«: Die ÖTV und die politischen Parteien | 58

2. Biografische Wendungen: Heinz Klunckers langer Weg in die ÖTV | 65

Kindheit und Jugend: Vom geborenen Sozialdemokraten

zum »einzigen Nazi in der Familie« 65

Umkehr, Neuanfang und biografische Umwege:

Die Jahre 1944 bis 1952 | 70

3. Gewerkschaftliche Lehrjahre: Heinz Klunckers Aufstieg in der ÖTV und deren Tarifpolitik bis $1964 \mid 86$

Gewerkschaftskarriere und erste tarifpolitische Grundsatzarbeiten für Arbeiter und Angestellte | 86

Unübersichtliche Fronten: ÖTV und Arbeitgeber des Öffentlichen

Dienstes im Wirtschaftsboom der Wiederaufbaujahre | 92

Probelauf mit Folgen: Der ÖTV-Streik in Hamburg von 1954 | 98

Der »umfassendste Streik in der deutschen Geschichte«: Der kurze Arbeitskampf der ÖTV von 1958 | 106

Die ÖTV im Kampf gegen ein »Tarifdiktat« der Bundesregierung und gegen Vorschläge zur »Versachlichung« der Tarifpolitik in den frühen 1960er Jahren | 113 


\section{Verschiedenartige Aufbrüche und Reformbemühungen Die ÖTV 1964 bis 1969 | 133}

1. Politische Aktivitäten des neuen Vorsitzenden: Der "geistige Beitrag der ÖTV« zur bundesdeutschen Außen- und Innenpolitik | 133

Die ÖTV im Ost-West-Konflikt | 133

Die Position der ÖTV im Streit um die Notstandsgesetze und Heinz Klunckers Verhältnis zur SPD | 147

2. Kein richtig grüner Zweig: Die internen Probleme der ÖTV $\mid 161$ Überalterung und Fluktuation $\mid 161$

Knauserige Mitglieder: Der Streit um den richtigen Beitragssatz | 165 Finanzielle Engpässe und ihre Folgen | 173

3. "Es muß uns gelingen, näher an die Betriebe heranzukommen«: Reformbemühungen, ein Rückschritt und tatsächliche Modernisierungen in der ÖTV $\mid 177$

Wie verbessert man die berufliche Betreuung in einem gewerkschaftlichen »Völkerbund «? | 177 Emanzipation ohne »Minderheitenschutz«? Der Verzicht der ÖTV auf eine Frauenquote und eigenständige Frauenkonferenzen | 184 Die neue Medien- und Werbearbeit der ÖTV $\mid 189$ Stärkung der Zentrale | 194

4. Nur ein Ritual? Einige allgemeine Bemerkungen zum strategischen Handeln in Tarifrunden | 197

Das schlechte Image von Tarifverhandlungen | 197 Kompromissfindung mit verschiedenen Akteuren. Wie Tarifverträge zustande kommen | 204

5. Tarifpolitik in turbulenten Zeiten:

Die Lohnrunden für den Öffentlichen Dienst in den Jahren der Großen Koalition 1966 bis 1969 | 220

Die Wirtschaftskrise von 1966/67, die Konjunkturpolitik der Bundesregierung und die Tarifrunde für den Öffentlichen Dienst 220

Fortsetzung mit neu verteilten Rollen: Der Streit um einen finanziellen Nachschlag für die Beschäftigten im Herbst 1968 | 239 "Wilde Streiks«, ein gültiger Tarifvertrag und die Bundestagswahl von $1969 \mid 256$ 
6. Tarifverträge als Gesellschaftspolitik: Veränderungen der sozialen Hierarchie im Öffentlichen Dienst durch die Tarifpolitik der ÖTV $\mid 268$

Der Ruhestand der Beamten als Modell: Die ÖTV und die Renten der staatlichen Arbeiter und Angestellten | 268

Laufbahnen für Angestellte durch den »Bewährungsaufstieg« und ein Monatssalär auch für Arbeiter | 279

\section{Die "eigentliche Macht im Staat»?}

Erfolge und vergebliche Mühen der ÖTV in den 1970er Jahren | 297

1. Politischer Konsens und Dissens: Positionen der ÖTV in allgemeinen politischen Fragen in der sozialliberalen Ära 297

Die Ostkontakte der ÖTV nach 1969| 297

Die Haltung der ÖTV im Streit um die »Berufsverbote« im Öffentlichen Dienst | 300

2. Geänderte Vorzeichen. Inflation und staatliche Konjunkturlenkung als neue Faktoren in der Tarifpolitik | 306

Sozial gerecht oder »nivellierend«? Die Inflation und die »Sockel«-

Strategie der ÖTV in den Lohn- und Gehaltsverhandlungen | 306

Die wirtschaftliche »Globalsteuerung« der Bundesregierung und die Tarifautonomie $\mid 321$

3. Ein gewerkschaftlicher Sieg zu viel?

Der Streik im Öffentlichen Dienst im Frühjahr 1974 | 339

Der Bundeskanzler als Tarifpolitiker: Die Ziele und Fehler

Willy Brandts in der Tarifrunde 1973/74 | 339

Warum und wie die ÖTV im Frühjahr 1974

den Streik organisierte $\mid 357$

Nach der Einigung: Reaktionen auf den Tarifabschluss in der ÖTV sowie in Politik und Medien | 380

4. Ein symbolischer Körper: Heinz Kluncker als »Gewerkschaftsboss«| 389

5. Gemischte Bilanz:

Die innere Entwicklung der ÖTV in den 1970er Jahren | 397

Ungelöste und gelöste Probleme:

Der Ertrag der organisatorischen Reformen | 397

Die neue soziale Struktur der Mitgliedschaft und ihre Konsequenzen für die ÖTV $\mid 408$ 
6. Begrenzte Handlungsmöglichkeiten:

Tarifverhandlungen für den Öffentlichen Dienst nach $1974 \mid 421$

Ungünstige Bedingungen und der Wunsch der ÖTV nach möglichst konfliktfreien Tarifrunden $\mid 421$

Verborgene Konflikte und Blockaden: Das tarifpolitische

"Moratorium « der Arbeitgeber und seine Folgen | 440

Noch einmal: »Sockel« oder nur Prozente? Der anhaltende Streit

um sozial ausgleichende Komponenten in der ÖTV-Tarifpolitik | 448

7. Rationalisierung und Privatisierung im Öffentlichen Dienst in den

1970er Jahren | 468

"Schreibdamen « und andere Opfer

betrieblicher Effizienzsteigerung | 468

Eine neue Epoche beginnt: Die frühe deutsche Privatisierungsdebatte und ihre Konsequenzen | 481

IV. Krise der Tarifpolitik

Die ÖTV in der letzten Phase der sozialdemokratischen Ära 1980 bis 1982 | 521

1. Eine verunsicherte Gewerkschaft: Die Stimmung in der ÖTV zu Beginn des neuen Jahrzehnts $\mid 521$

Umfassende Unzufriedenheit: Der Gewerkschaftstag 1980 als Ventil für die »Frustration mehrerer Jahre»| 521

Eine »Niederlage« der ÖTV? Der Lohn- und Gehaltsabschluss für 1980 in der Kritik des Gewerkschaftstages | 526

2. „Der Herr schütze uns vor unseren Freunden«:

Der Konflikt der ÖTV mit der SPD-Regierung Nordrhein-Westfalens in den Tarifverhandlungen für 1981 | 535

Verkehrte Welt in der Tarifpolitik | 535

Ein »blaues Auge« der ÖTV: Der tarifpolitische Kompromiss für $1981 \mid 548$

3. Der erste Abwehrkampf: Die Lohn- und Gehaltskürzungen im

Öffentlichen Dienst in der »Operation 82« und die ÖTV | 554

Ein ganz neuer Schachzug: Die Beamtenbesoldung als

tarifpolitischer Hebel der Arbeitgeber | 554

Ein gewerkschaftlicher »Triumph«? Der Ausgang der »Operation 82«und einige unangenehme Wahrheiten über die begrenzte Macht der ÖTV | 564 
4. Weichenstellungen unmittelbar vor dem Rücktritt: Heinz Klunckers gewerkschaftliche Arbeit in den letzten Monaten seiner Amtszeit | 578

Der »Neue Heimat«-Skandal und die Wahl des neuen

DGB-Vorsitzenden | 578

Ein Nachfolger oder eine Nachfolgerin? Der scheidende

Heinz Kluncker und die Wahl des neuen ÖTV-Vorsitzenden | 583

Schlussbetrachtung $\mid 591$

Literatur $\mid 603$

Abkürzungen | 647 



\section{Einleitung}

Der Begriff »Macht« lag für die Bundesbürger in den 1960er und 1970er Jahren sehr nah, wenn sie über die Gewerkschaft »Öffentliche Dienste, Transport und Verkehr« (ÖTV) und ihren Vorsitzenden Heinz Kluncker sprachen - und sie sprachen oft über die Organisation. Nach dem nahezu einhelligen Urteil von Presse und Politikern war die ÖTV seinerzeit eine Organisation, die bemerkenswerte tarifliche Erfolge aneinanderreihte, ohne Rücksicht auf andere Interessen zu nehmen. Ein größerer Streik im Öffentlichen Dienst, den die Gewerkschaft im Februar 1974 organisierte, verfestigte das Urteil. Mit diesem Arbeitskampf >besiegte die Organisation - einer fast allgemein akzeptierten Interpretation der Ereignisse zufolge - die Bundesregierung und Bundeskanzler Willy Brandt, weil sie schon nach wenigen Streiktagen einen Lohn- und Gehaltsabschluss durchsetzte, den die staatlichen Arbeitgeber mit dem Kanzler an ihrer Spitze zuvor vehement als überhöht und wirtschaftlich gefährlich abgelehnt hatten.

Selbst nach Abschluss dieses Tarifvertrages bezeichneten sozialdemokratische Finanzexperten die Abmachung noch als »unsinnig«, oder aber sie sprachen sogar von einer »Tragödie« für Staat und Bürger, die zu noch größeren Defiziten in den staatlichen Etats und zu höheren Steuern führen werde. ${ }^{1}$ Helmut Kohl, CDU-Ministerpräsident in Rheinland-Pfalz, klagte, mit ihrem erfolgreichen Streik habe die ÖTV demokratisch legitimierte Politiker zum Nachgeben gezwungen und so demonstriert, wer in der Bun-

1 | Zitiert werden Hans Wertz, der sozialdemokratische Finanzminister von Nordrhein-Westfalen, und sein hessischer Amtskollege und Parteigenosse Heribert Reitz: SPD und FDP über Tarifabschlüsse besorgt. In: FR, 15.2.1974; Minister Reitz: Die Gewerkschaften ÖTV und DAG haben versagt. In: Gießener Anzeiger, 4.3.1974. 
desrepublik »eigentlich die Macht in Händen halte.$^{2}$ Ein renommierter Professor für Verfassungsrecht sekundierte unter Hinweis auf die starke Stellung der Gewerkschaft in kommunalen Versorgungsbetrieben wie etwa der Stadtreinigung mit dem böse pointierten Satz: "Souverän ist, wer über die Müllabfuhr entscheidet«. Die ÖTV, so das Fazit des Juristen, missbrauche die Tarifautonomie als »Hebel zur Errichtung des Gewerkschaftsstaates ${ }^{3}{ }^{3}$

Da die Organisation als so übermächtig wahrgenommen wurde, galt auch Heinz Kluncker, der die Gewerkschaft in den Jahren zwischen 1964 und 1982 leitete, als ein Mann, an dem niemand vorbeikam. In der Presse erschien er als ein »Machtfaktor, neben dem es keinen gleichwertigen in der Bundesrepublik gibt«, als »umbo gewerkschaftlicher Potenz«, als politischer "Riese« oder auch als »die unbestritten stärkste Figur« unter den bundesdeutschen Gewerkschaftsführern. ${ }^{4}$ Überhaupt war der Chef der ÖTV nach dem Urteil von Journalisten ein »Gewerkschaftsboss aus dem Bilderbuch « und ein »Prototyp « für Männer mit dieser Funktion. ${ }^{5}$ Auch innerhalb der ÖTV herrschte Heinz Kluncker angeblich uneingeschränkt: So

2 | So Kohl auf einer Rede zum Abschluss des Landtagswahlkampfs in Hessen, zit. in: Mit Rückenwind nach Wiesbaden. In: FAZ, 25.10.1974.

3 I Josef Isensee: Der Tarifvertrag als Gewerkschafts-Staats-Vertrag. In: Walter Leisner (Hrsg.): Das Berufsbeamtentum im demokratischen Staat. Beiträge zum Dienstrecht und zur Dienstrechtsreform, Berlin 1975, S. 23-45, die Zitate in der Reihenfolge auf S. 35 u. 37. Isensee, Professor an der Universität Bonn, paraphrasierte hier den unter Juristen berühmten Satz: »Souverän ist, wer über den Ausnahmezustand entscheidet« des konservativen Verfassungsrechtlers Carl Schmitt aus dem Jahr 1922.

4 | In der Reihenfolge der Zitate: Leo Sievers: Wenn Kluncker will, stehen alle Räder still. In: Der Stern 29 (1976), H. 24, S. 77-80, hier: S. 79; Stefan Geiger: Der Hartnäckige mit der sanften Stimme. In: StZ, 3.6.1982; Horst Vetten: Der leise Riese. In: Der Stern 27 (1974), H. 5, S. 50-55; Erika Martens: Der Schreck in der Abendstunde. In: Die Zeit, 22.1.1982.

5 | In der Reihenfolge: Hermann Rudolph: Heinz Kluncker, der Gewerkschafter aus dem Bilderbuch. In: FAZ, 7.2.1974; Henk Ohnesorge: Wenn es um mehr Lohn geht, kennt Kluncker keine Freunde. In: Die Welt, 11.6.1976. Vgl. auch: Herbert Riehl-Heyse: An Kluncker kommt niemand vorbei. In: Playboy 9 (1980), H. 9, S. 108-110 u. 170-175; Horst Vetten: Ein Boss, kein Proletarier. In: Manager-Magazin 10 (1980), H. 9, S. 76. 
titulierten Medien die Gewerkschaft spöttisch als »Kluncker-Gesellschaft«, weil sie den Vorsitzenden für eine so »beherrschende Figur« hielten. ${ }^{6}$

Dieser Ruf überdauerte selbst Klunckers plötzlichen Amtsverzicht im Sommer 1982 aus gesundheitlichen Gründen im Alter von nur 57 Jahren. Noch 2005, als der ehemalige Gewerkschaftsvorsitzende nach längerer Krankheit starb, urteilte die linksalternative taz, Heinz Kluncker sei im historischen Rückblick "wohl der mächtigste Gewerkschaftsfunktionär, den es in Deutschland jemals gegeben hat". Die Stuttgarter Zeitung konstatierte: "Nie hatte die Organisation [die ÖTV - K.C.F.] mehr Macht als in seiner Amtszeit." Fünf Jahre zuvor, in einer Würdigung zu Klunckers 70. Geburtstag, hatte die konservative Frankfurter Allgemeine Zeitung (FAZ) den ehemaligen ÖTV-Chef »das personifizierte Durchsetzungsvermögen« genannt; 2005 erklärte sie deutlich kritischer, aber doch ähnlich stark personalisierend, der Name Heinz Kluncker sei ein »Synonym für eine überzogene Tarifpolitik«?

Die hier vorgelegte Untersuchung zur Geschichte der ÖTV in den Jahren, während derer Kluncker die Organisation führte, setzt an diesem doppelten Image von Macht oder sogar von Übermacht an. Sie fragt, wie es tatsächlich um die Durchsetzungskraft der Gewerkschaft bestellt war, wenn sie mit den Arbeitgebern über Tarifverträge stritt, die den Arbeitnehmern Vorteile bringen sollten. Stimmt das Bild von einer sehr dominanten Organisation, die Kompromisse verweigerte und ihre Verhandlungspartner rücksichtslos gegen die Wand drückte, das Politiker und Medien zeichneten? Wie entstand die Vorstellung, die ÖTV sei unbezwingbar? Daneben soll es aber auch um die Rolle gehen, die Heinz Kluncker innerhalb der ÖTV spielte. Beherrschte er die Gewerkschaft tatsächlich so uneingeschränkt, wie viele externe Beobachter meinten? Waren die demokratischen Strukturen der Organisation wirklich bedeutungslos, wenn konkret über die tarifpolitischen Forderungen der ÖTV, ihre Verhandlungsstrategie und über die mit den Arbeitgebern vereinbarten Abschlüsse entschieden wurde?

6 | Warten auf den DGB. In: Die Zeit, 20.6.1980.

7 | In der Reihenfolge der Zitate: Ralph Bollmann: Der Herrscher über die Tarifgespräche. In: taz, 23.4.2005; Symbolfigur für gewerkschaftliche Macht. In: StZ, 19.2.2005; Heinz Kluncker 75 Jahre. In: FAZ, 19.2.2000; Heinz Kluncker 80 Jahre. In: FAZ, 18.2.2005. 
Indem sie diese beiden Themen untersucht, leistet die Studie einen wichtigen Beitrag zur Geschichte der deutschen Gewerkschaften in der zweiten Hälfte des 20. Jahrhunderts. Mit etwas mehr als einer Million Mitgliedern war die ÖTV in den 1970er Jahren die zweitgrößte Organisation von Arbeitnehmern in der Bundesrepublik; darüber hinaus fand sie - wie schon die eben angeführten Zitate belegen - mit ihren Forderungen und Aktionen große öffentliche Aufmerksamkeit. Historiographisch ist sie jedoch bislang nur unzureichend erforscht. Die wenigen vorliegenden Arbeiten behandeln eher Nebenaspekte der Organisationsgeschichte, oder aber sie schürfen insofern nicht sehr tief, als sie auf kritische Fragen weitgehend verzichten und auch die verfügbaren internen Quellen nicht umfassend auswerten. ${ }^{8}$ Auch einige Regionalstudien liegen vor, deren Resultate aber selbstverständlich nur begrenzte Bedeutung beanspruchen können. ${ }^{9}$

8 | Als Spezialstudien vgl. etwa: Susanne Kreutzer: »Der Aufstieg findet nicht statt«. Frauen und Führungspositionen in der Gewerkschaft Öffentliche Dienste, Transport und Verkehr (ÖTV) in den 1950er und 1960er Jahren. In: Mitteilungsblatt des Instituts für Soziale Bewegungen 2006, S. 167-177; Brigitte Kassel (Hrsg.): ... letztlich ging es doch voran! Zur Frauenpolitik der ÖTV 1949-1989, Stuttgart 2001; dies.: Differenz und Gleichheit. Zur Zeitpolitik der Gewerkschaft ÖTV als Geschlechterpolitik 1948-1989. In: Karl Christian Führer (Hrsg.): Tarifbeziehungen und Tarifpolitik in Deutschland im historischen Wandel, Bonn 2004, S. 201-223; Susanne Kreutzer: »Eine Schwester schaut nicht auf die Uhr«. Zur Arbeitszeitpolitik der Gewerkschaft Öffentliche Dienste, Transport und Verkehr (ÖTV) in der Krankenpflege 1949-1960. In: Führer: Tarifbeziehungen, S. 175-200; Annette Rehbock: Soziologisches Wissen und gewerkschaftliche Organisation. Gewerkschaftliche Bildungsarbeit in den siebziger Jahren, Münster 1989; Sabine Schoefer: Strategie statt Notwehr. Organisationsentwicklung in den Gewerkschaften am Beispiel der ÖTV, Münster 2000. Eher zur Gruppe der Festschriften gehören etwa: Zehn Jahre ÖTV 1949-1959. Berichte, Bilder, Dokumente. Über Ziele und Wirken einer großen Gewerkschaft, Stuttgart 1959; Zwanzig Jahre ÖTV. Daten, Zeugnisse, Meinungen aus zwanzig Jahren Gewerkschaftsarbeit, Red. Bearb. v. Werner Haak, Stuttgart 1966; Franz Josef Furtwängler: ÖTV. Geschichte einer Gewerkschaft, 3. erw. Aufl., Stuttgart 1962; Walter Nachtmann: 100 Jahre ÖTV. Die Geschichte einer Gewerkschaft und ihrer Vorläuferorganisationen, Bd. 1: Geschichte, Bd. 2: Biographien, Frankfurt/Main 1996.

9 | Vgl. etwa: Hendrik Zörner: Die Gewerkschaft ÖTV in Wuppertal von 19451987, Wuppertal 1989; Beatrix Klein/Fritz Bilz/Klaus Ehlert: »Im Prinzip sind wir uns doch einig.« 50 Jahre ÖTV in Köln 1946-1996, Köln 1996; Karl Lauschke: 
Im Folgenden soll hingegen ein möglichst differenziertes Bild dieser großen und offensichtlich sehr erfolgreichen Gewerkschaft entstehen, das exemplarisch deutlich macht, wie eine Organisation dieser Art sowohl intern funktioniert als auch in der Auseinandersetzung mit ihren Tarifpartnern agiert. Zentral geht es mir dabei um den eigentlichen Auftrag (oder auch: die raison d'être) der Gewerkschaft: um ihre Bemühungen, sowohl die finanzielle Lage der Beschäftigten als auch deren Arbeitsalltag durch verbesserte Bestimmungen in Tarifverträgen positiv zu verändern. Unter welchen Umständen gelangen der Organisation Erfolge? Und ebenso wichtig: In welchen Situationen stieß die Gewerkschaft an die Grenzen ihrer Macht?

Gleichzeitig skizziert die Untersuchung die politische Biografie Heinz Klunckers, denn in den Augen der bundesdeutschen Öffentlichkeit symbolisierte er ganz persönlich nicht nur die ÖTV, sondern sogar den Gewerkschafter "an sich«. Glaubt man einer Münchner Boulevardzeitung, dann war das aus seinem Namen abgeleitete Verb »klunckern« bereits Ende der 1960er Jahre Teil der bundesdeutschen Alltagssprache - als ein Synonym für "Ärger machen « oder »Unruhe stiften $« .{ }^{10}$ Seine ungewöhnliche Prominenz und die ihm zugeschriebene fast schon absolutistische Macht über die ÖTV rechtfertigen es, Kluncker als Person eingehender darzustellen. Sieht man von einer Dokumentensammlung und einem umfangreicheren autobiografischen Zeugnis ab, gibt es auch in dieser Hinsicht keine Vorarbeiten. ${ }^{11}$

Im Zentrum der Studie steht jedoch eindeutig die tarifpolitische Tätigkeit der ÖTV. Diese Bemühungen und deren jeweiliger Ertrag sollen durchweg in einen weiten Kontext gestellt werden, weil sich nur so beurteilen lässt, welche Faktoren jeweils darüber entschieden, wie eine Tarifrunde zu Ende ging und wie viel die Arbeitnehmer mit dem neuen Vertrag wirklich

Die ÖTV in Dortmund. Lokale Gewerkschaftsgeschichte der Nachkriegszeit. Ein fälliger Perspektivenwechsel. In: Mitteilungsblatt des Instituts für Soziale Bewegungen 2000, S. 141-158; ders.: "Störenfriede«. Der Einfluss der 68er-Bewegung auf die betriebliche und gewerkschaftliche Interessenvertretung. Das Beispiel der Dortmunder ÖTV. In: Westfälische Forschungen 48 (1998), S. 333-358.

10 | »Jetzt zünden wir Ihnen das Haus an!«. In: Abendzeitung (München), 12.1.1970.

11 | Walter Eberhardt et al. (Bearb.): Heinz Kluncker. Ein Porträt zum siebzigsten Geburtstag. Hrsg. v. der Gewerkschaft Öffentliche Dienste, Transport und Verkehr, Stuttgart 1995; Hans-Otto Hemmer/Hartmut Simon (Hrsg.): Auf die Wirkung kommt es an. Gespräche mit Heinz Kluncker, Frankfurt/Main 2000. 
gewannen. Dazu ist es erforderlich, die Entscheidungen und Handlungen der Gewerkschaft sowie die Ziele, Angebote und Strategien ihrer tariflichen Verhandlungspartner sowohl in ihrer internen Vorgeschichte als auch in der Interaktion von Gewerkschaft und Arbeitgebern in den gemeinsamen Tarifverhandlungen jeweils synchron darzustellen und immer wieder neu aufeinander zu beziehen.

Selbstverständlich gehören daneben auch Analysen und Deutungen der allgemeinen wirtschaftlichen Entwicklung in diesen weiten Kontext. Da die ÖTV nicht mit privaten Arbeitgebern, sondern mit Ministern und anderen politischen Würdenträgern verhandelte, wenn es um die Beschäftigten des Öffentlichen Dienstes ging, interessierten sich zudem Politik, Parteien und Medien ungewöhnlich stark für diese Tarifrunden: Forderungen der Gewerkschaft konnten unmittelbar zu höheren staatlichen Personalausgaben führen und die Etatplanungen von Bund, Ländern und Gemeinden sowie auch die Preiskalkulationen staatlicher Dienstleistungsbetriebe berühren. In ihrer Rolle als »vierte Gewalt« beschäftigten sich die Medien deshalb vielfach sehr intensiv mit den Tarifstreitigkeiten der ÖTV. 1975 vermerkte Heinz Kluncker, die Journalisten hätten sich in diesen Beratungen mittlerweile »sozusagen als dritter Tarifpartner etabliert ${ }^{12}{ }^{12} \mathrm{Da}-$ her versteht die hier vorgelegte Studie auch Presseberichte und -kommentare als einen wichtigen Faktor im Kontext der Tarifgeschichte, in dem die Gewerkschaft agierte.

Durch diesen breiten Ansatz der Untersuchung trägt die nachfolgende Darstellung auch zur allgemeinen Politik- und Gesellschaftsgeschichte der Bundesrepublik bei. Erfasst wird dabei der Zeitraum zwischen den 1960er und frühen 1980er Jahren, in dem der Wiederaufbauboom erst seinen Höhepunkt erreichte und dann seit 1974/75 von strukturellen Wachstumsproblemen und Anpassungskrisen abgelöst wurde. In diesem historisch besonders bewegten Abschnitt der deutschen Geschichte nach 1945 fand parallel der Aufstieg der SPD zur politisch wichtigsten Kraft des Landes statt. Entsprechend groß ist die politikgeschichtliche Bedeutung einer Studie über die ÖTV für diese Jahre: Wie alle DGB-Gewerkschaften stand die Organisation der SPD einerseits sehr nahe; andererseits aber tangierten die Tarifverhandlungen für den Öffentlichen Dienst nun die wirtschafts- und finanzpolitischen Planungen einer SPD-geführten Bundesregierung. Der

12 | Schwergewicht auf leisen Sohlen. In: Bild am Sonntag, 2.11.1975. 
bereits erwähnte Streik von 1974, der das persönliche Renommee von Bundeskanzler Willy Brandt gravierend ramponierte, zeigt exemplarisch, wie unverzichtbar die Geschichte der ÖTV ist, wenn es darum geht, das widersprüchliche, sowohl von großen Hoffnungen wie auch von fast ebenso starken Enttäuschungen geprägte Profil dieses »sozialdemokratischen Jahrzehnts « (Bernd Faulenbach) politikgeschichtlich zu erfassen. ${ }^{13}$

Die Studie informiert ferner über den Einfluss der ÖTV auf die gesellschaftliche Entwicklung der Bundesrepublik, da der Öffentliche Dienst im Untersuchungszeitraum eine zentrale ökonomische und soziale Relevanz besaß. Mit insgesamt fast vier Millionen Beschäftigten gehörten die Staatsdienste und die öffentlichen Unternehmen zu den wirtschaftlichen Bereichen, in denen sich entschied, wie stark die große Masse der bundesdeutschen Bevölkerung an dem wachsenden Wohlstand des Landes partizipierte. Da die ÖTV und die staatlichen Arbeitgeber stets zentral verhandelten und bundesweit einheitlich geltende Tarifverträge abschlossen, stellten die Tarifpartner wichtige soziale und ökonomische Weichen. »Klunckers ÖTV sorgte in den sechziger und frühen siebziger Jahren dafür, daß von Ludwig Erhards Wohlstand alle eine Scheibe abbekamen« - diese retrospektive Feststellung der FAZ beschreibt den Zusammenhang zwar sehr pointiert (denn wichtige andere DGB-Gewerkschaften werden dabei ignoriert), aber im Kern durchaus treffend. ${ }^{14}$

Zugleich zeigten sich auch im Öffentlichen Dienst nach 1974/75 früh jene neuen Trends, die für die gesamte Epoche nach dem Ende der Wiederaufbaujahre charakteristisch sind. »Rationalisierungsmaßnahmen« zur wirtschaftlichen Effizienzsteigerung und »Privatisierung« zuvor staatlich erledigter Aufgaben sind dabei die entscheidenden Stichworte. Wie die Studie zeigen wird, dokumentiert und reflektiert die Arbeit der ÖTV exemplarisch diese grundlegend wichtige Wende in der bundesdeutschen Gesellschaftsgeschichte. ${ }^{15}$

Aus pragmatischen Gründen beschreibe ich die ÖTV im Folgenden nur als eine Gewerkschaft für die Beschäftigten des Öffentlichen Dienstes. Transport und Verkehr, die beiden anderen Wirtschaftsbereiche, für die sie

13 | Bernd Faulenbach: Das sozialdemokratische Jahrzehnt. Von der Reformeuphorie zur Neuen Unübersichtlichkeit. Die SPD 1969-1982, Bonn 2010.

14 | Rainer Hank: »Stell Dir vor, Verdi streikt ...«. In: Frankfurter Allgemeine Sonntagszeitung, 5.3.2006.

15 | Siehe dazu unten Kapitel III. 
gewerkschaftlich in begrenztem Umfang mit zuständig war, bleiben außen vor. Dieser Verzicht erscheint zwar bedauerlich, weil so kein vollständiges Bild der ÖTV-Geschichte entsteht. Aber es zeigte sich schon bei den Quellenarbeiten, wie komplex und wie aussagekräftig die Tarifpolitik für den Öffentlichen Dienst sowohl für die Entwicklung der Gewerkschaft als auch für die allgemeine Politik- und Gesellschaftsgeschichte der Bundesrepublik ist. Der Umfang der nachfolgenden Darstellung wäre enorm gewachsen, wenn man zusätzlich die Branchen Transport und Verkehr mit ihren ganz eigenen Strukturen und Problemen mit der erforderlichen Genauigkeit einbezogen hätte. Zudem stellten die Beschäftigten des Staates und der Staatsbetriebe im Untersuchungszeitraum durchweg rund 90 Prozent aller ÖTV-Mitglieder. ${ }^{16}$ Vor diesem Hintergrund erscheint es legitim, die kleine Minderheit der in privaten Transport- und Verkehrsbetrieben beschäftigten Mitglieder und deren spezielle Interessen in der nachfolgenden Untersuchung zu vernachlässigen.

Die Quellenlage für die so eingegrenzte Studie ist insgesamt sehr breit, weist jedoch mehrere problematische Züge auf. So gab es im Untersuchungszeitraum in der ÖTV kein professionell geführtes Archiv. Offensichtlich wurden nur die Protokolle der Hauptvorstandssitzungen systematisch gesammelt. Dagegen trugen die Mitarbeiter Presseberichte über die Gewerkschaft recht gründlich zusammen. Ansonsten aber blieb es wohl dem Zufall überlassen, was an Schriftstücken und anderen Dokumenten aufbewahrt wurde und was früher oder später verschwand. Ferner scheint Heinz Kluncker seine Geschäfte stark im persönlichen Gespräch (am Telefon oder auch in direkten Begegnungen) erledigt zu haben, ohne dazu Notizen festzuhalten. Korrespondenzen, die seine Innen- und Außenkontakte dokumentieren, fehlen. Dennoch finden sich sowohl im Archiv der ÖTV-Nachfolgeorganisation ver.di (Vereinte Dienstleistungsgewerkschaft) in Berlin sowie in den Beständen des Archivs der sozialen Demokratie (AdsD) in Bonn genügend Unterlagen der Gewerkschaft, die über ihre internen Diskussionen und Auseinandersetzungen informieren. Zusätzlich erwies sich ein Bestand im AdsD mit Dokumenten der ÖTV-Bezirksorganisation Nordrhein-Westfalen II als sehr nützlich. Dazu kommen die schon erwähnten und vollständig überlieferten Hauptvorstandsprotokolle, die ebenfalls in Bonn liegen. Die Seite der staatlichen Arbeitgeber ist für Bund, Länder und

16 | Siehe dazu genauer Kapitel I. 
Gemeinden vor allem in Beständen des Bundesarchivs Koblenz dokumentiert. Akten des Bundeskanzleramtes und diverser Ministerien konnten ebenso herangezogen werden wie Dokumente aus den dort aufbewahrten Beständen »Tarifgemeinschaft deutscher Länder« (TdL) und »Vereinigung der kommunalen Arbeitgeberverbände« (VKA). Weiteres Material fand sich unter den persönlichen Papieren der beiden sozialdemokratischen Bundeskanzler Willy Brandt und Helmut Schmidt (wiederum im AdsD in Bonn). Auch einige Interviews mit Zeitzeugen, die Heinz Kluncker persönlich kannten und in der ÖTV mit ihm zusammenarbeiteten, lieferten wertvolle ergänzende Informationen und Hinweise. Hinzu kommt die breite Berichterstattung der Presse, die von der ÖTV - wie gesagt - eifrig dokumentiert wurde. Von Quellenmangel lässt sich somit nicht sprechen, wenngleich die Untersuchung an einigen wenigen Punkten auf Mutmaßungen angewiesen ist, weil sich das Geschehen hinter den Kulissen nicht verlässlich rekonstruieren lässt.

Die Darstellung beginnt mit einem Kapitel (I), das zum einen die ÖTV und zum anderen den Lebensweg Heinz Klunckers bis zu dessen Wahl zum Gewerkschaftsvorsitzenden im Sommer 1964 vorstellt. In beiden Hinsichten geht es mir darum, die nachfolgende Untersuchung der Jahre ab 1964 pointiert vorzubereiten, indem Besonderheiten sowohl der Organisation als auch der Person Heinz Kluncker herausgearbeitet werden. Diese Informationen sollen es ermöglichen, den zentralen Fragen der Untersuchung nach der Macht der ÖTV sowie nach der Stellung Heinz Klunckers innerhalb der Gewerkschaft angemessen differenziert nachzugehen.

Es folgt eine im Wesentlichen chronologisch vorgehende Darstellung, die versucht, die Tarifpolitik der ÖTV, ihre inneren Veränderungen und die Handlungen der Arbeitgeber aufeinander zu beziehen. Die Einteilung in drei umfangreichere Kapitel ergibt sich aus wichtigen innenpolitischen Veränderungen, auf die der Gewerkschaftsvorsitzende und die ÖTV reagieren mussten. Zunächst werden die Jahre von 1964 bis zum Amtsantritt des sozialdemokratischen Bundeskanzlers Willy Brandt im Herbst 1969 untersucht; Jahre, in denen Heinz Kluncker als neu gewählter Vorsitzender die Gewerkschaft in vielerlei Hinsicht neu positionierte und gleichzeitig erste Erfahrungen als Chefunterhändler der Organisation sammelte (Kapitel II). Daran schließt sich ein Kapitel über die widersprüchlichen 1970er Jahre an (III). Trotz des Einschnitts durch den Konjunkturbruch von 1974/75 behandle ich das Jahrzehnt als Einheit, weil ÖTV und Arbeitgeber in dieser 
Zeit ungeachtet zahlreicher Streitigkeiten letztlich erfolgreich miteinander kooperierten. Der Arbeitskampf im Frühjahr 1974 soll als einzige Ausnahme von dieser Regel ausführlich analysiert werden. Kapitel IV schließlich untersucht den Zeitraum von 1980 bis 1982 separat, weil die Tarifverhandlungen für den Öffentlichen Dienst in diesen letzten Jahren der sozialliberalen Koalition kaum noch die Erträge erbrachten, die die ÖTV sich erhoffte. Zugleich entstand eine scharfe Frontstellung zwischen ÖTV und regierenden Sozialdemokraten, die es so zuvor nicht gegeben hatte.

Wie alle Autoren einer größeren wissenschaftlichen Arbeit bin auch ich zahlreichen Personen verpflichtet, die mir auf verschiedene Weise geholfen haben und die ich deshalb an dieser Stelle dankend erwähnen möchte. Hartmut Simon und Michaela Kuhnhenne halfen, aus meiner Idee, eine ÖTV-Geschichte zu schreiben, ein handhabbares Projekt zu machen, dessen finanzielle Förderung dann von der Hans-Böckler-Stiftung übernommen wurde. Für diese Unterstützung in der immer schwierigen Anfangsphase eines größeren Forschungsvorhabens bedanke ich mich noch einmal ausdrücklich. Auch der Hans-Böckler-Stiftung schulde ich selbstverständlich eine Danksagung - sowohl für die Förderung in der Bearbeitungszeit als auch für die Drucklegung des fertigen Textes. Die mehrfachen Diskussionen mit den Mitgliedern des Beirats, der die Durchführung des Projektes begleitete (wie es bei der Stiftung üblich ist), haben mir in vielen Punkten sehr geholfen. $\mathrm{Zu}$ diesem Gremium gehörten (in alphabetischer Reihenfolge): Knut Andresen, Stefan Berger, Karsten Burk, Hans-Otto Hemmer, Susanne Kreutzer, Michaela Kuhnhenne, Karl Lauschke, Stefan Müller, Hartmut Simon, Konrad Schneider, Michael Schneider, Hajo Graf Vitzthum und Klaus Weinhauer. Besonders danken möchte ich meinen Interviewpartnern: Siegfried Bußjäger, Walter Eberhardt, Elke Stierle, Hajo Graf Vitzthum und Monika Wulf-Matthies, die Heinz Kluncker persönlich kannten, waren so freundlich, mir in längeren Gesprächen von ihrer Arbeit in der ÖTV sowie von ihren Erinnerungen an den Gewerkschaftsvorsitzenden und an den privaten Heinz Kluncker zu erzählen. Mit Hartmut Simon, Hajo Graf Vitzthum und Klaus Weinhauer hatte ich drei aufmerksame und konstruktiv kritische Leser, die das gesamte Manuskript mit mir besprochen haben. Einzelne Abschnitte wurden von Kim Christian Priemel und Cornelia Rauh kommentiert und verbessert. Die Verantwortung für Lücken, Irrtümer und Fehlurteile liegt selbstverständlich trotz all dieser Unterstützung allein bei mir. 


\section{Eine Gewerkschaft und ihr angehender Vorsitzender}

\section{Die ÖTV: Ein einleitendes Porträt}

\section{Vielfalt mit Lücken: Die ÖTV im System der bundesdeutschen Gewerkschaften}

Der Kongress tanzte zwar nicht, aber er hörte Musik. Mit dem langsamen Satz aus der dritten Orchestersuite von Johann Sebastian Bach eröffnete die Gewerkschaft Öffentliche Dienste, Transport und Verkehr am 28. Juni 1964 ihren fünften Gewerkschaftstag. Für die fast 500 Delegierten, die rund 980.000 Mitglieder repräsentierten, bot die ÖTV in einem Saal auf dem Gelände der Dortmunder Westfalenhalle ein ganzes Symphonieorchester auf: Bachs sanft dahin strömendes "Air« wurde vom Orchester der Stadt Dortmund gespielt; die musikalische Leitung hatte dessen Chef, der Dirigent Wilhelm Schüchter. Erwähnenswert ist diese kulturelle Darbietung hier nicht wegen der vielleicht etwas überraschenden musikalischen Wahl, sondern weil sie einen ersten Hinweis liefert, wie bunt die Basis der ÖTV aussah: Schüchter, ein international renommierter Künstler, der den eindrucksvollen Titel »Generalmusikdirektor« führte, gehörte der Gewerkschaft als Mitglied an. Der ÖTV-Vorsitzende Adolph Kummernuss war »stolz darauf, das sagen zu können ${ }^{1}{ }^{1}$

Nach den in Gewerkschaften üblichen Umgangsregeln galt der hochbezahlte Dirigent damit als »Kollege« der Delegierten. Auch im Orchester

1 | Protokoll des 5. Ordentlichen Gewerkschaftstages der Gewerkschaft Öffentliche Dienste, Transport und Verkehr vom 28. Juni bis 4. Juli 1964 in Dortmund, Stuttgart 1965 (im Folgenden: Protokoll ÖTV-GT 1964), S. 15. Die feierliche Eröffnung mit klassischer Musik war seinerzeit keine Besonderheit der ÖTV: Fast alle DGB-Gewerkschaften machten es genauso. 
selbst mag es weitere "ÖTVler« gegeben haben, führte die Organisation doch eigens eine Fachgruppe "Kulturorchester ${ }^{2}$ Die Gemeinschaft der gewerkschaftlichen Kollegen, in der man in der Regel umstandslos miteinander "per Du« war, dürfte in der Dortmunder Westfalenhalle jedoch noch über den Kreis der Delegierten und der Musiker hinausgereicht haben. Mit hoher Wahrscheinlichkeit fanden sich unter den Arbeitern, die den Saal herrichteten, und auch unter den Putzfrauen, die ihn säuberten, zahlreiche weitere ÖTV-Mitglieder. Das Messe- und Tagungsgelände rund um die Westfalenhalle wurde von einer rein städtischen Firma betrieben, und Unternehmen dieser Art gehörten zum organisatorischen Rückgrat der ÖTV. ${ }^{3}$ Der Auftritt Wilhelm Schüchters illustriert daher treffend den schichten- und vielleicht sogar klassenübergreifenden Charakter dieser Gewerkschaft. Im Folgenden wird dieses besondere Wesen der ÖTV genauer beschrieben, wobei jeweils der Stand der Dinge in den frühen 1960er Jahren, also in der Zeit vor dem Amtsantritt Heinz Klunckers, im Fokus steht.

Zwar war die ÖTV keineswegs die einzige intern inhomogene DGBGewerkschaft. Nur in ihren Anfängen im 19. Jahrhundert definierten sich Gewerkschaften in Deutschland als eng gefasste Berufsverbände: In ihnen organisierten sich Arbeitnehmer (anfänglich waren es fast ausschließlich Männer) mit gleicher Berufsausbildung und gleicher Tätigkeit. Größere berufsübergreifende Verbände entstanden erst später in einem langwierigen und heftig umstrittenen Prozess, in dem sich die älteren, hochspezialisierten Organisationen zusammenschlossen, um ihre Verhandlungsposition gegenüber den Unternehmern zu stärken. Letztlich bildeten sich so Industrie- und Branchengewerkschaften. Gemeinsame oder doch zumindest eng miteinander verbundene Berufsidentitäten blieben aber auch in diesem Gefüge von Gewerkschaften wichtig. Die IG Bau - Steine - Erden oder auch die IG Bergbau können dafür als Beispiel dienen. ${ }^{4}$

2 | Sie zählte 1963 insgesamt 895 Mitglieder (ÖTV: Geschäftsbericht 1961-1963. Hrsg. v. der Gewerkschaft Öffentliche Dienste, Transport und Verkehr - Hauptvorstand, Stuttgart 1964 [im Folgenden: ÖTV-Geschäftsbericht 1961/63], S. 488).

3 | Siehe dazu genauer unten in diesem Kapitel S. 44.

4 | Als knappe, Epochen übergreifende Einführung vgl. Michael Schneider: Kleine Geschichte der Gewerkschaften. Ihre Entwicklung in Deutschland von den Anfängen bis heute, Bonn 1989. 
Bei der ÖTV verhielt sich das anders: Ihr fehlte ein vergleichbar einfach zu fassender Bezug auf ein bestimmtes Berufsfeld. Zeitgenössische journalistische Beschreibungen der Gewerkschaft begannen deshalb typischerweise mit einer Liste der in ihr vertretenen Berufe, die durch Aufzählung Anschaulichkeit anstrebte. »Gasmänner und Flugkapitäne, Schaffner und Schauerleute, Krankenschwestern und Stadtdirektoren, Fernfahrer und Polizisten « ist ein Beispiel dafür; "Müllmänner und Chefärzte, Straßenkehrer und Atomphysiker « ein anderes. ${ }^{5}$ Wer es noch etwas genauer wissen wollte, musste nur in einen der Bände schauen, in denen die ÖTV im Jahresrhythmus die Tarifverträge abdruckte, die sie in den jeweils letzten zwölf Monaten abgeschlossen hatte. Für 1964 enthält diese Dokumentation auf mehr als 1.500 Seiten 143 verschiedene Verträge für Dutzende höchst unterschiedliche Berufsgruppen. Neben einem Manteltarifvertrag für alle Angestellten von Bund, Ländern und Gemeinden mit der Kurzbezeichnung »BAT«, der als einer der wichtigsten Tarifverträge in der Geschichte der Bundesrepublik gelten darf, weil er - mit vielen kleineren Änderungen - noch jahrzehntelang weitergalt, finden sich hier auch Abmachungen für die »im Lochkartenwesen beschäftigten Angestellten der Deutschen Bundesbank«, für Taucher und Bergungsarbeiter, für die Angestellten von Sparkassen, Reisebüros und gesetzlichen Krankenkassen, für Arbeiter an Theatern, bei der Bundesanstalt für Arbeitsvermittlung und Arbeitslosenversicherung oder auch bei der »Einfuhrstelle für Zucker«, für die »Personenkraftwagenfahrer des Landes Hessen«, für das Personal der »Condor Flugdienst $\mathrm{GmbH}$ « oder der »Nordsee-Hochseefischerei GmbH« sowie für »Praktikantinnen im Öffentlichen Dienst der Länder«. ${ }^{6}$ Die Formulierung einer Journalistin, die ÖTV sei ein »Vielvölkerstaat«, ist offensichtlich keineswegs übertrieben. ${ }^{7}$

So unübersichtlich war die ÖTV vor allem deshalb, weil der Öffentliche Dienst in der Bundesrepublik sehr umfassend für das Wohl der Bevölkerung sorgte. Neben Bundes-, Landes- und Kommunalbehörden, Justiz,

5 | Bazillen im Bad. In: Der Spiegel 19 (1965), H. 29, S. 42; Vetten: Riese, S. 51.

6 | ÖTV: Wortlaut der überbezirklichen Tarifverträge des Jahres 1964, Stuttgart 1965 (im Folgenden: ÖTV-Tarifverträge 1964). Männliche Praktikanten scheint es seinerzeit nicht gegeben zu haben: Der entsprechende Tarifvertrag bezieht sich durchweg nur auf Frauen (S. 566-605). Zum BAT siehe auch unten S. $90 \mathrm{f}$.

7 | Erika Martens: Der Schreck in der Abendstunde. In: Die Zeit, 22.1.1982. 
Heer und Polizei als Kern des bundesdeutschen Staates (der »Eingriffsverwaltung «) existierte ein umfangreiches System von Wohlfahrtseinrichtungen und öffentlichen Betrieben, die Dienstleistungen verschiedenster Art erbrachten und daher oft als "Leistungsverwaltung « bezeichnet wurden. Die Versorgung mit Wasser, Strom und Gas war ebenso Teil dieses Systems wie der Transport von Personen und Waren in Bahn oder Flugzeug; Schulen und Universitäten gehörten dazu, Theater und Opernhäuser sowie die Müllabfuhr und -entsorgung, Kläranlagen, Straßenbahnen, Schlachthöfe, Messehallen, die Feuerwehr, Badeanstalten oder Friedhöfe.

Seine Ursprünge hatte dieses komplexe Ensemble, das neben behördenähnlichen Einrichtungen auch formal selbständige Aktiengesellschaften und "gemischt-wirtschaftliche« Unternehmen mit privaten Anteilseignern umfasste, im »langen" 19. Jahrhundert bis zum Beginn des Ersten Weltkriegs: Industrialisierung und Urbanisierung verwandelten in dieser Epoche nicht nur Gesellschaft, Landschaft und Raum, sondern auch den Staat auf radikale Weise. ${ }^{8}$

Parallel zum Siegeszug des Kapitalismus und in Reaktion darauf entstand vor allem auf lokaler Ebene ein Gefüge der staatlichen "Daseinsvorsorge«, das sozial und politisch stabilisierend wirken sollte. Zudem entdeckten die durchweg bürgerlichen Politiker, die all die eben genannten Dienstleistungen zu öffentlichen Aufgaben machten, rasch, wie verlässlich gerade Versorgungsbetriebe für Unverzichtbares wie Wasser oder Energie Geld in die Kassen von Kommune oder Staat spülten. In den letzten Friedensjahren des Kaiserreichs finanzierten deutsche Städte bis zu einem Viertel ihres Jahresetats mit den Gewinnen kommunaler Betriebe. ${ }^{9}$ Öffentliche

8 | Vgl. dazu als Überblick etwa: Jürgen Reulecke: Geschichte der Urbanisierung in Deutschland, Frankfurt/Main 1985, S. 109-118; Gerold Ambrosius: Regulierung öffentlicher Dienstleistungen in historisches Perspektive. In: Regulierung. Referate einer vom Wissenschaftlichen Beirat des Bundesverbandes Öffentlicher Dienstleistungen am 6./7. Februar 2008 veranstalteten Tagung, Berlin 2009, S. 18-38. Zu den "gemischt-wirtschaftlichen Betrieben«, in denen die Öffentliche Hand mit privaten Anteilseignern kooperierte, vgl. in systematischer Sicht: Gerold Ambrosius: Hybride Eigentums- und Verfügungsrechte. Öffentlich-private Kooperationen in systematisch-theoretischer und historisch-empirischer Perspektive, Berlin 2012.

9 | Vgl. etwa: Richard H. Tilly: Städtewachstum, Kommunalfinanzen und Munizipalsozialismus in der deutschen Industrialisierung. Eine vergleichende Perspek- 
Unternehmen ließen sich darüber hinaus als raum- und strukturpolitisches Instrument einsetzen, wenn es darum ging, wirtschaftlich schwache Regionen zu stärken, aus denen die Bevölkerung abwanderte. Auch diese Möglichkeit nutzten Politiker bereits im Kaiserreich. ${ }^{10}$

Das multifunktionale System der öffentlichen »Daseinsvorsorge« überstand die scharfen politischen Umbrüche in der deutschen Geschichte in der ersten Hälfte des 20. Jahrhunderts. Auch zwei Inflationen, zwei Währungsreformen und die epochale Wirtschaftskrise in den Jahren nach 1929 brachten die öffentlichen Unternehmen jeweils nur vorübergehend in Schwierigkeiten. Sowohl die Weimarer Republik als auch die NS-Diktatur bauten die Staatswirtschaft sogar noch weiter aus. Nach 1918 engagierte sich die Öffentliche Hand mit langwierig weiterwirkenden Folgen unter anderem erstmals auch im Wohnungsbau; die Nationalsozialisten gründeten verschiedene staatliche Großbetriebe, weil die Privatwirtschaft ihren ehrgeizigen industriepolitischen Zielen nicht in jedem Fall willig folgte. ${ }^{11}$

In den 1950er Jahren galten diese weit ausgebauten staatlichen Dienstleistungen nahezu unangefochten als zwingend notwendige soziale und kulturelle Errungenschaft der deutschen Gesellschaft. Ernst Forsthoff, ein

tive 1870-1913. In: Jürgen Reulecke (Hrsg.): Die Stadt als Dienstleistungszentrum. Beiträge zur Geschichte der »Sozialstadt« in Deutschland im 19. und frühen 20. Jahrhundert, St. Katharinen 1995, S. 125-152.

10 | Besonders wichtig war dieser Zusammenhang bei öffentlichen Investitionen in der Energiewirtschaft. Vgl. dazu umfassend: Bernhard Stier: Staat und Strom. Die politische Steuerung des Elektrizitätssystems in Deutschland 1890-1950, Ubstadt-Weiher 1999; als Zusammenfassung vgl.: ders.: Staat und Strom. Elektrifizierung in Preußen zwischen Staatswirtschaft und nationaler Strukturpolitik 1910-1940. In: Karl Heinrich Kaufhold/Bernd Sösemann (Hrsg.): Wirtschaft, Wissenschaft und Bildung in Preußen. Zur Wirtschafts- und Sozialgeschichte Preußens vom 18. bis zum 20. Jahrhundert, Stuttgart 1998, S. 111-137.

11 | Zur Einbeziehung der Wohnungsversorgung in den Bereich der staatlichen Daseinsvorsorge vgl. ausführlich: Karl Christian Führer: Mieter, Hausbesitzer, Staat und Wohnungsmarkt. Wohnungsmangel und Wohnungszwangswirtschaft in Deutschland 1914-1960, Stuttgart 1995, insbes. S. 117-164. Exemplarische Beispiele für die NS-Strategie sind etwa die Gründung von VW oder auch der Stahlwerke in Salzgitter. Vgl. dazu etwa: Hans Mommsen/Manfred Grieger: Das Volkswagenwerk und seine Arbeiter im Dritten Reich, Düsseldorf 1996; August Meyer: Hitlers Holding. Die Reichswerke »Hermann Göring«, überarb. u. aktualis. Aufl., München 1999. 
hoch angesehener Jurist, der den Begriff der "Daseinsvorsorge« geprägt hatte, fasste diesen Konsens 1957 exemplarisch zusammen: Um die Unsicherheit und Krisenanfälligkeit der privatkapitalistischen Gesellschaft auszugleichen, bedürften deren Bürger dringend der "Daseinsstabilisierung" durch staatliche Intervention. Öffentliche Unternehmen seien dabei von zentraler Bedeutung. Zugleich verstehe es sich von selbst, dass Wirtschaftlichkeit für diese Betriebe nachrangig sein müsse: »Die Daseinsvorsorge ist wesentlich auch eine soziale Funktion. ${ }^{12}$ Der Sozialdemokrat Max Brauer hatte es 1955 ganz ähnlich formuliert: Staatliches Wirtschaften sei »eine notwendige Ergänzung der privaten Marktwirtschaft«, ja in vieler Hinsicht "sogar eine entscheidende Voraussetzung für deren Funktionieren ${ }^{13}{ }^{13}$

Zwar umfasste der Bereich der öffentlichen Betriebe aus historischen Gründen seinerzeit auch zahlreiche Unternehmen, deren »soziale Funktion« doch recht fraglich war. Das Land Bayern etwa betrieb ein großes milchwirtschaftliches Unternehmen und auch eine staatseigene Bierbrauerei mit angeschlossener Gaststätte. Gewerbebetriebe wie Hotels, Kiesgruben, Kohlenhandlungen sowie zahlreiche weitere Brauhäuser befanden sich in kommunalem Besitz. ${ }^{14}$ Auch florierende Industriebetriebe wie die Stahlwerke in Salzgitter oder auch die VW-Werke gehörten wegen ihrer

12 | Ernst Forsthoff: Die Daseinsvorsorge und die Kommunen. Ein Vortrag, Köln 1958, S. 12 f. u. 14 (Zitat). Den Begriff der »Daseinsvorsorge«, der danach vielfach zitiert wurde, verwendet Forsthoff erstmals 1938 (Ders.: Die Verwaltung als Leistungsträger, Stuttgart und Berlin 1938, S. 6 f.). Forsthoffs Rolle als intellektueller Befürworter der NS-Diktatur, die ihn aus heutiger Sicht zu einer sehr fragwürdigen Figur macht, wurde in der Öffentlichkeit der frühen Bundesrepublik konsequent verschwiegen. Vgl. dazu etwa: Rainer Schuckart: Kontinuitäten einer konservativen Staatsrechtslehre. Forsthoffs Positionen in der Weimarer Republik, im Dritten Reich und in der Bundesrepublik. In: Stephan Alexander Glienke/ Volker Paulmann/Joachim Perels (Hrsg.): Erfolgsgeschichte Bundesrepublik? Die Nachkriegsgesellschaft im langen Schatten des Nationalsozialismus, Göttingen 2008, S. 85-114.

13 | Max Brauer: Grundfragen der öffentlichen Wirtschaft. In: Bekenntnis zur öffentlichen Wirtschaft. Kundgebung des Deutschen Gewerkschaftsbundes »Grundfragen der öffentlichen Wirtschaft« am 24. Juni 1955 im Städtischen Saalbau, Essen, Düsseldorf 1955, S. 7-26, hier: S. 14.

14 | Zu den kommunalen Betrieben vgl. im Überblick etwa: Hans-Jochen Vogel: Die kommunalen Unternehmen in der Marktwirtschaft, Köln 1962, S. 8 f. 
nationalsozialistischen Vorgeschichte nicht zu den Privatbetrieben. Die CDU als die dominierende politische Kraft in der frühen Bundesrepublik strebte aber selbst in Fällen wie diesen keineswegs konsequent nach Privatisierung, weil sie die Möglichkeit schätzte, mit solchen Staatsbetrieben auf den Arbeitsmarkt im wirtschaftlich schwachen »Zonenrandgebiet« einzuwirken. Ordnungspolitisch motivierte Kritik an dieser Strategie fand nur ein geringes öffentliches Echo; das widersprüchliche Profil der Staatswirtschaft galt vielmehr weitgehend als gegeben und als legitim. ${ }^{15}$

Die ÖTV als Gewerkschaft, die vor allem den Öffentlichen Dienst vertrat, wurde von dessen verwickelter Geschichte geprägt. Das Durch- und Nebeneinander höchst unterschiedlicher Berufe, Qualifikationen, Betriebsformen und Arbeitsverhältnisse, das im Laufe der Zeit im Ensemble der staatlichen Dienstleistungsunternehmen und Wohlfahrtseinrichtungen entstanden war, bestimmte sowohl die Abgrenzung der ÖTV gegenüber anderen Berufsverbänden als auch ihre inneren Strukturen - und beides bestimmte wiederum die Handlungsmöglichkeiten der ÖTV in Auseinandersetzungen mit den Arbeitgebern.

Wichtig ist mit Blick auf die Stellung der ÖTV im System der bundesdeutschen Gewerkschaften zunächst einmal: Die ÖTV warb weder um alle Beschäftigten im Staatsdienst der Bundesrepublik noch um alle Arbeitnehmer der Branchen Transport und Verkehr. Andernfalls hätte sie nämlich Konflikte mit gleich drei weiteren Gewerkschaften heraufbeschworen, die

15 | Vgl. exemplarisch den Streit um eine konsequente Privatisierung von VW und dazu: Rainer Nicolaysen: Der lange Weg zur VolkswagenStiftung. Eine Gründungsgeschichte im Spannungsfeld von Politik, Wirtschaft und Wissenschaft, Göttingen 2002. Zu dem inkonsequent verfolgten Projekt, Staatsbetriebe wie VW und die VEBA durch Ausgabe von »Volksaktien« an Belegschaft und Kleinanleger zu privatisieren, vgl. etwa: Heidrun Edelmann: Privatisierung als Sozialpolitik. »Volksaktien« und Volkswagenwerk. In: Jahrbuch für Wirtschaftsgeschichte 1999, Bd. 1, S. 55-72. Vgl. auch aus zeitgenössischer gewerkschaftlicher Sicht die kritische Darstellung: Kurt Hirche: Das Experiment der Volksaktie, Köln 1961. Anders als die VEBA und einige andere staatliche Industriebetriebe gehörte VW allerdings nicht zum Organisationsbereich der ÖTV, sondern in den der IG Metall, obwohl diese Zuordnung nicht als logisch gelten konnte. Einen knappen Überblick über die Industriebetriebe im Besitz des Bundes vgl. in: Heinz Oeftering: Die Unternehmungen des Bundes. In: Grundfrage der öffentlichen Wirtschaft. Ergebnisse einer Arbeitstagung, Stuttgart 1954, S. 70-87. 
ebenfalls zum DGB gehörten. Zum einen waren ausgerechnet die beiden größten staatlichen Unternehmen, die zugleich auch die wichtigsten Transportunternehmen des Landes darstellten, für die ÖTV tabu. Gemeint sind hier Bahn und Post, die als "Deutsche Bundesbahn« und »Deutsche Bundespost« beide seinerzeit noch zu hundert Prozent dem Staat gehörten und für die im DGB die »Gewerkschaft der Eisenbahner Deutschlands« (GdED) bzw. die »Deutsche Postgewerkschaft« (DPG) zuständig waren. Zusammen beschäftigten die beiden Unternehmen Anfang der 1960er Jahre etwas mehr als eine Million Menschen; rund 640.000 davon waren gewerkschaftlich organisiert. ${ }^{16} \mathrm{Zum}$ anderen existierte für alle »lehrenden und erziehenden Berufe« in Schulen und Hochschulen, die ein wichtiges Segment im Kernbereich des Öffentlichen Dienstes darstellten, im DGB eine eigenständige »Gewerkschaft Erziehung und Wissenschaft (GEW). ${ }^{17}$

Nach Logik und Zweckmäßigkeit hätten sowohl Bahn und Post als auch die Pädagogen in den Organisationsbereich der ÖTV gehört. Das Nebeneinander der vier Organisationen ergab sich aus der oben schon kurz skizzierten Geschichte der deutschen Gewerkschaften im Kaiserreich: In einigen Fällen widersetzten sich die damals entstandenen separaten Berufsverbände erfolgreich dem Trend, größere Gewerkschaften zu bilden. Dies galt etwa bei Bahn, Post und Lehrern. Ihre eigenständigen Gewerkschaften überlebten diverse Einigungsbemühungen in der Weimarer Republik sowie letztlich auch den scharfen Bruch in der deutschen Gewerkschaftsgeschichte in den Jahren der NS-Diktatur, weil alte Netzwerke und organisatorische Traditionen eine wichtige Rolle spielten, als die freien Gewerkschaften zwischen 1945 und 1949 neu gegründet wurden. Sogar neue Strukturen, die

16 | Zahlen aus: Folkert Schreiber: Personal und Personalausgaben. In: Der Städtetag 17 (1964), S. 534-535 (Beschäftigte); Hermann Bayer/Wolfgang Streeck/Eckbert Treu: Die westdeutsche Gewerkschaftsbewegung in Zahlen. Ein Datenhandbuch zur organisatorischen Entwicklung ausgewählter Industrie- und Berufsverbände 1960-1975, Königstein/Taunus 1981, S. 283 u. 311 (Gewerkschaftsmitglieder). Bahn und Post waren hinsichtlich der Zahl der Beschäftigten zudem die beiden größten bundesdeutschen Unternehmen überhaupt; dank des Postsparkassenamts war die Post zugleich auch noch das Geldinstitut mit den meisten Kunden. 17 | Die Gewerkschaft Erziehung und Wissenschaft. Ihr Aufbau, ihre Probleme, ihr Kampf und ihre Erfolge, Oberhausen 1954, S. 13. Wichtig ist dabei die Begrenzung auf Schulen und Hochschulen: Für Kindergärten war deshalb die ÖTV zuständig. 1963 zählte die GEW rund 90.000 Mitglieder. 
unmittelbar nach dem Ende der Diktatur in einzelnen Besatzungszonen entstanden, verschwanden daher wieder. Zwar bildeten sich politisch und religiös neutrale Einheitsgewerkschaften, die es zuvor in Deutschland nicht gegeben hatte. Ihren beruflichen Zuschnitt aber übernahmen die neuen Verbände vielfach von den alten Gewerkschaften aus der Zeit vor $1933 .^{18}$

Auch in den 1960er und 1970er Jahren vermied der DGB eine Debatte über die Frage, wie sinnvoll diese »ererbte« Struktur noch sei, obwohl sie eine einheitliche gewerkschaftliche Arbeit für die Beschäftigten des Öffentlichen Dienstes unmöglich machte. Weder in den Unternehmensgewerkschaften von Post und Bahn noch in der GEW waren die Funktionäre bereit, die »eigene« Organisation aufzugeben. Unter den Mitgliedern dieser drei Verbände dominierten Beamte, während die ÖTV vornehmlich Angestellte und Arbeiter vertrat. Dieser Unterschied zementierte die Separierung. Die ÖTV als die größte der vier Gewerkschaften schließlich tat gut daran, alles zu vermeiden, was nach dem Versuch einer feindlichen Übernahme aussah, denn kaum etwas erregte in den DGB-Führungsgremien so die Gemüter wie der Verdacht, eine der angeschlossenen Gewerkschaften wolle auf Kosten anderer Verbände wachsen. ${ }^{19}$

18 | Vgl. dazu ausführlich: Nachtmann: 100 Jahre ÖTV, S. 272-306. In der britischen Besatzungszone etwa organisierte die ÖTV nach 1945 auch die Beschäftigten von Bahn und Post; mit Entstehung der bundesweiten Organisation im Jahr 1949 aber wurde das aufgegeben. Vgl. dazu: [ÖTV]: Geschäftsbericht der Gewerkschaft Öffentliche Dienste, Transport und Verkehr für das Jahr 1949. Hrsg. v. Hauptvorstand, Stuttgart o. J. [1950] (im Folgenden: ÖTV-Geschäftsbericht 1949), S. 6 f. u. 34. Im Bereich der ÖTV blieben damit nur die wenigen »nicht-bundeseigenen«Bahnunternehmen, die in der BRD als Relikte einer lange zurückliegenden Vergangenheit existierten. Dabei handelte es sich um eine kleine Gruppe von Regionalbahnen, die weder untereinander noch mit der Bundesbahn in Konkurrenz standen.

19 | Vgl. als Beispiel dafür etwa den Streit um einen neuen Namen für die IG Bergbau in den 1950er Jahren: Die Gewerkschaft selbst wollte sich neu benennen, weil zunehmend klar wurde, dass der Bergbau in der Bundesrepublik künftig nur noch schrumpfen werde. Die angestrebte Bezeichnung als »IG Bergbau und Energiewirtschaft« rief jedoch ÖTV und IG Metall auf den Plan, die beide auch die Belegschaften von energieerzeugenden Betrieben vertraten und hinter der Änderung einen »Alleinvertretungsanspruch« der Bergbaugewerkschaft für die gesamte Energiebranche witterten. Man einigte sich schließlich auf »Bergbau und Energie«. Vgl. verschiedene Dokumente dazu in: Quellen zur Geschichte der 
So beteuerten die Verbandsleitungen von ÖTV und Bahn- und Postgewerkschaft stets ihr gutes tarifpolitisches Einvernehmen: Zielabsprachen und ein gemeinsames Vorgehen (bei dem die ÖTV stets Vortritt hatte) seien für sie selbstverständlich. ${ }^{20}$ Ohne Frage aber war die ÖTV als Gewerkschaft für den Öffentlichen Dienst und für die Verkehrswirtschaft wegen der fortdauernden Eigenständigkeit von drei anderen DGB-Gewerkschaften, die es ebenfalls mit staatlich Bediensteten zu tun hatten, weniger kopfstark und damit auch weniger finanzstark, als sie es eigentlich hätte sein können. Gleichzeitig aber musste sie ungefragt die Rolle eines tarifpolitischen Vorreiters für die »befreundeten" Organisationen spielen: Als von Beamten dominierte Verbände waren weder die beiden Betriebsgewerkschaften noch die GEW besonders starke Verhandlungspartner der öffentlichen Arbeitgeber. Ohne groß zu übertreiben, konnte man die ÖTV daher als »Tariframmbock« für die drei anderen Verbände bezeichnen. Wie noch gezeigt werden wird, konnte bei den ÖTV-Mitgliedern daher durchaus der Eindruck entstehen, sie müssten bei Arbeitskämpfen auch für kaum streikfähige Gewerkschaften die Kohlen aus dem Feuer holen. ${ }^{21}$

deutschen Gewerkschaftsbewegung im 20. Jahrhundert (im Folgenden: QGG), Bd. 12: Der Deutsche Gewerkschaftsbund 1956-1963. Bearb. v. Jens Hildebrandt (unter Mitarbeit v. Boris Schwitzer), Bonn 2005, S. 581-588 u. $609 \mathrm{f}$.

20 | Vgl. etwa die einvernehmlichen Erklärungen der drei Gewerkschaftsvorsitzenden vor dem DGB-Bundesvorstand am 11.6.1963 in: ebd., S. 913. Im Folgenden wird jedoch zu zeigen sein, dass es in der Realität auch anders zuging. Allein schon abweichende Laufzeiten von Tarifverträgen konnten dazu führen, dass bei Post und Bahn noch Friedenspflicht herrschte, während die ÖTV schon Kampfmaßnahmen ergriff und dabei auch die Beschäftigten in Verkehrsbetrieben zu Streiks aufrief. Aus dieser Struktur ergab sich 1974 Streit zwischen den an sich doch so eng befreundeten Gewerkschaften. Siehe dazu unten Kapitel II. Als Gewerkschaft, die vornehmlich Beamten vertrat, war die GEW nur für kleine Gruppen ihrer Mitglieder an Tarifverhandlungen beteiligt.

21 | Der zitierte Begriff aus: Egon Lutz: Ostpolitiker aus Passion: Heinz Kluncker. In: Werner Mühlbradt/Egon Lutz: Der Zwang zur Sozialpartnerschaft. Hintergründe der Zusammenarbeit von Gewerkschaften und Arbeitgebern, Neuwied und Berlin 1969, S. 104-109, hier: S. 107 f. Vgl. hierzu auch die nüchterne Selbsteinschätzung der Postgewerkschaft, sie verfüge wegen der fehlenden Möglichkeit, wirkungsvoll zu streiken, in Tarifverhandlungen kaum über »Bewegungsspielraum«. In: Die Tarifpolitik der Deutschen Postgewerkschaft. In: GM 24 (1973), S. 553-559, hier: S. 553. 
Zusätzlich beschränkten Gewerkschaften, die nicht zum DGB gehörten, Macht und Einfluss der ÖTV. Eine politisch und weltanschaulich motivierte Verbandskonkurrenz hatte die Entwicklung der deutschen Gewerkschaften seit ihren Anfängen im 19. Jahrhundert entscheidend geprägt. Zwar verlor dieser Wettbewerb nach 1945 mit der Gründung der neuen Einheitsgewerkschaften, die sich bewusst als politisch und religiös neutral definierten, stark an Bedeutung; ganz aus der Welt aber war er nicht. Insbesondere die Frage, ob es gemeinsame Interessen von Arbeitern, Angestellten und Beamten gebe, die eine solidarische gewerkschaftliche Arbeit sinnvoll und wünschenswert machten, wurde nach wie vor sehr unterschiedlich beantwortet.

Die ÖTV vertrat in diesem Meinungsstreit (wie bereits ihre Vorgängerorganisationen in der Weimarer Republik) das Prinzip, die drei Beschäftigtengruppen gehörten als lohnabhängige Arbeitnehmer zwingend zusammen. ${ }^{22}$ So wetterte der ÖTV-Vorsitzender Adolph Kummernuss 1964 gegen jede Form von gewerkschaftlicher »Eigenbrötelei«. Eine wirksame Interessenvertretung könne es nur geben, wenn die Arbeitnehmer sich ohne Rücksicht auf arbeitsrechtliche Unterschiede nach dem Prinzip »Ein Betrieb - eine Gewerkschaft« organisierten. Dies gelte auch für den Öffentlichen Dienst: „Wer das nicht einsehen will oder kann, betreibt mit oder ohne Absicht die Politik der Arbeitgeber. ${ }^{23}$

Mit der gewerkschaftlichen Einheit von Arbeitern, Angestellten und Beamten verfolgte die Gewerkschaft auch ein konkretes sozial- und tarifpolitisches Ziel: Bestehende soziale Privilegien von Beamten und Angestellten des Staates sollten ohne Unterschied allen Beschäftigten der Öffentlichen Hand zugute kommen und so gewissermaßen »demokratisiert« werden. Besonders Besserstellungen von Beamten galten der ÖTV als verwerflich. Soziale Gerechtigkeit, so sagte es Adolph Kummernuss, gebe es nur, wenn »Arbeiter und Angestellte genauso behandelt werden « wie die Beamten; "zweierlei Recht« im Öffentlichen Dienst sei unzeitgemäß und rückschrittlich. ${ }^{24}$

22 | Protokoll ÖTV-GT 1964, S. 69. Zur verwickelten Vorgeschichte der ÖTV vgl. den knappen Abriss in: Kassel: Frauenpolitik der ÖTV, S. 19-22, sowie ausführlich Nachtmann: 100 Jahre ÖTV.

23 | Protokoll ÖTV-GT 1964, S. 69.

24 | Ebd., S. 76f. Zu den konkreten Unterschieden zwischen den drei Gruppen siehe unten Kapitel II. 
Gesonderte Berufsorganisationen für Beamte und für Angestellte wie etwa der Deutsche Beamtenbund (DBB) und die Deutsche Angestellten-Gewerkschaft (DAG) als die größten Verbände dieser Art - vertraten hingegen ein ganz anderes Konzept. »Gleichmacherei« hielten sie für ein großes Übel, das die Freiheit der westlichen Welt beschädige. So pochte der Beamtenbund stets auf das "Gruppenbewußtsein« und »das spezifische Gruppeninteresse der Beamten«. Wer diese Separierung missachte, riskiere, »daß unser gesellschaftliches Leben in einer uniformen Massengesellschaft erstarrt $\ll .{ }^{25}$ Auch die DAG sah in sozialen Hierarchisierungen etwas Positives. »Die Nivellierung schafft kein soziales Gleichgewicht, sondern wesentliche Antriebskräfte in einem Volk werden vernichtet und die Gesellschaft wird ärmer«, formulierte es ihr Vorsitzender Rolf Spaethen im Jahr 1961. ${ }^{26}$

Beide Verbände konkurrierten als eher ständisch ausgerichtete Berufsorganisationen mit der ÖTV um Mitglieder. Zwar war die DAG zugleich auch ein Partner der ÖTV, denn beide Gewerkschaften führten die Tarifverhandlungen für den Öffentlichen Dienst in den 1950er und 1960er Jahren stets gleichzeitig, was sowohl eine gewisse Rücksichtnahme als auch Absprachen erforderte. Dennoch hielt die ÖTV die DAG für überflüssig: Sie sei nicht mehr als ein tarifpolitischer "Beifahrer«, der im Öffentlichen Dienst kaum einen wirkungsvollen Streik organisieren und daher in Konflikten mit den Arbeitgebern allein nichts durchsetzen könne. ${ }^{27}$ Höhnisch übersetzte Adolph Kummernuss die drei Buchstaben der DAG daher mit »Deutsche Abschreibergewerkschaft.$^{28}$

Als weitere gewerkschaftliche Konkurrenten der ÖTV außerhalb des Deutschen Gewerkschaftsbundes kamen zahlreiche kleinere Organisatio-

25 | Alfred Krause: Staat und Staatsdienst heute, Bad Godesberg 1968, S. 18 f. u. 20. Krause war Vorsitzender des DBB.

26 | Rolf Spaethen: Grundlagen einer modernen Sozialpolitik für Angestellte. Rede auf der Festveranstaltung aus Anlass des 1. Mai 1961 in der Beethoven-Halle in Bonn, Hamburg 1961, S. 8. Vgl. auch Spaethens Hinweise dort auf die Systemkonkurrenz von »Ost und West«als Hintergrund der DAG-Position S. 5 u. 24.

27 | Protokoll ÖTV-GT 1964, S. 75. Zur Verschärfung des Konfliktes zwischen ÖTV und DAG in den 1970er Jahren siehe unten Kapitel III. In dieser Auseinandersetzung beendete die ÖTV schließlich die Tarifgemeinschaft mit der DAG.

28 Protokoll des 3. Ordentlichen Gewerkschaftstages der Gewerkschaft Öffentliche Dienste, Transport und Verkehr vom 1. bis 6. Juni 1958 in München, Stuttgart 1959 (im Folgenden: Protokoll ÖTV-GT 1958), S. 53. 
nen für spezifische Berufsgruppen hinzu. Auch sie wollten nichts von dem Gedanken wissen, eine weit gefasste gewerkschaftliche Solidarität nütze sozial schwächeren Arbeitnehmern ebenso wie den Bessergestellten, und entstanden gerade für gut ausgebildete Arbeitnehmer mit besonderen Qualifikationen. Beispielhaft lassen sich hier etwa der Verband Deutscher Flugleiter (VDF), die Vereinigung Cockpit (VC) oder auch der Marburger Bund nennen. Der VDF organisierte die Fluglotsen, die den stark wachsenden Flugverkehr über der Bundesrepublik inklusive aller Starts und Landungen koordinierten; die Vereinigung Cockpit verstand sich als berufliche Interessenvertretung der Piloten bei der Deutschen Lufthansa (einem Staatsbetrieb); der Marburger Bund schließlich warb um Ärzte, die in öffentlichen wie auch in privaten Krankenhäusern angestellt waren. ${ }^{29}$

Zwar hatte der gewerkschaftliche Wettbewerb in kleinen bis kleinsten Expertengruppen für die Mitgliederbilanz der ÖTV zwangsläufig nur eine untergeordnete Bedeutung. Als Faktoren in einem Arbeitskampf konnten hoch qualifizierte und kaum ersetzbare Fachleute jedoch unter Umstän-

29 | In den 1960er Jahren definierten sich sowohl der VDF als auch die VC noch nicht als »tariffähige« Vereinigungen von Arbeitnehmern; bei der Aushandlung von Tarifverträgen waren sie - anders als ÖTV und DAG - dementsprechend nicht direkt beteiligt. Da sie über Kooperationsverträge mit den »richtigen« Gewerkschaften verbunden waren, prägten die internen Diskussionen in VDF und VC dennoch die Tarifpolitik für die beiden speziellen Berufsgruppen. Vgl. dazu am Beispiel des VDF, dem über 90 Prozent der Fluglotsen angehörten: Flugsicherungsangestellte wehren sich. In: FAZ, 13.3.1962. Ende der 1960er Jahre gehörten (bei unverändert starker Stellung des VDF) rund 40 Prozent der Fluglotsen zur DAG, zehn Prozent waren Mitglieder der ÖTV. Vgl.: Neuer Ärger bei den Fluglotsen. In: FAZ, 13.11.1969. Zum Marburger Bund vgl. in Ermangelung fundierter Untersuchungen: Kurt Gelsner: Der Marburger Bund. Chronik der organisierten Krankenhausärzte, Frankfurt/Main 1985. Die Frage, welche Vereinigungen von Arbeitnehmern »tariffähig " sind und welche nicht, war (und ist) in Deutschland nicht gesetzlich geregelt. De facto entscheiden im Streitfall die Arbeitsgerichte, die durch Interpretation des Tarifvertragsgesetzes verschiedene Kriterien entwickelt haben, die eine »tariffähige « Vereinigung erfüllen muss. Entscheidend wichtig sind dabei (neben intern demokratischen Strukturen und institutioneller Eigenständigkeit) der Wille und die Kraft, auch mit Streiks für die Interessen der Mitglieder zu kämpfen. Als Überblick über die komplexe Materie (mit kritischer Tendenz) vgl. etwa: Claus-Jürgen Bruhn: Tariffähigkeit von Gewerkschaften und Autonomie. Eine Kritik der Mächtigkeitslehre des Bundesarbeitsgerichtes, Berlin 1993. 
den von enormer Bedeutung sein. Die Anfang der 1960er Jahre nur wenig mehr als 500 Köpfe zählenden Fluglotsen können hier als Paradebeispiel dienen: Bei gemeinschaftlichem Handeln konnten sie unmittelbar den gesamten Flugverkehr in der Bundesrepublik stark behindern oder sogar ganz lahmlegen. Scharfe Kritik des VDF an den belastenden Arbeitsbedingungen der Berufsgruppe und ein zweitägiger Warnstreik erschreckten die Bundesregierung im Jahr 1962 daher so stark, dass sie aus Furcht vor einem eventuell drohenden ernsthaften Arbeitskampf zu einer höchst ungewöhnlichen Maßnahme griff: Sie schuf auf einen Schlag mehrere hundert neue Beamtenstellen nur für diese Berufsgruppe und bot den Lotsen, die bisher Angestellte der Bundesanstalt für Flugsicherung gewesen waren, die Übernahme in das Beamtenverhältnis an. Der VDF sah darin eine tarifpolitische Entmachtung der Fluglotsen und sprach von einer "Zwangsverbeamtung«. Die Mehrheit der Betroffenen aber akzeptierte das Angebot, sei es nun, weil sie es langfristig, mit Blick auf die Altersversorgung, tatsächlich als attraktiv empfanden, sei es, weil sie befürchteten, künftig als Angestellte bei Beförderungen übergangen zu werden. ${ }^{30}$

Einerseits demonstriert diese Episode eindringlich die potenziell große Bedeutung von beruflichen Experten in einem Arbeitskampf. Andererseits zeigt sich hier exemplarisch aber auch eine Gefahr: Wenn ein Streik einiger weniger Spezialisten das öffentliche Leben stark beeinträchtigte, galt ihr Arbeitskampf Politik und Öffentlichkeit unter Umständen rasch als moralisch verwerfliche »Erpressung «, die Gegenmaßnahmen rechtfertigte. Trotz dieser zu bedenkenden Schwierigkeit waren und blieben Beschäftigte, die an den Schaltstellen wichtiger öffentlicher Einrichtungen saßen, für die ÖTV als Machtfaktor und als eventuelles tarifpolitisches »Faustpfand « interessant. Gleichgültigkeit gegenüber kleinen Konkurrenten konnte sie sich daher nicht leisten. Wie noch gezeigt werden wird, sah sie sich bei Arbeits-

30 | Als knappen Abriss vgl.: William H. McPherson: Public Employee Relations in West Germany, Ann Arbor 1971, S. 174f.; den Rückblick des VDF in: "Das ganze System ist auf überhöhten Einsatz abgestellt«. In: FAZ, 12.5.1971; sowie die recht scharfen Debatten über die Angelegenheit in Fragestunden des Bundestages in: Verhandlungen des Deutschen Bundestages. 4. Wahlperiode. Stenographische Berichte, Bd. 50, Bonn 1962, S. 908-913, sowie Bd. 52, Bonn 1963, S. 2246-2248. Bis Ende 1962 hatten 463 Fluglotsen ein Angebot auf Verbeamtung erhalten; 101 lehnten es ab, 247 nahmen es an, in 88 Fällen lief die Erklärungsfrist bei Jahresende noch. Ebd., Bd. 52, S. 2246. 
kämpfen im Öffentlichen Dienst zudem ohnehin jedes Mal wieder neu mit dem Argument konfrontiert, der Streik schade nicht den Arbeitgebern, sondern »der Allgemeinheit« und gerade den einfachen Bürgern. ${ }^{31}$

Auf der Liste der organisatorischen Kontrahenten der ÖTV, die nicht zum DGB gehörten, ist schließlich auch noch die Gewerkschaft der Polizei (GdP) zu erwähnen. Sie warb sowohl unter den Polizisten als auch unter nicht-verbeamteten Mitarbeitern der staatlichen Ordnungsmacht um Mitglieder. Die ÖTV machte es genauso und führte für diese Beschäftigten des Öffentlichen Dienstes sogar eine eigene Hauptfachabteilung. Stärker noch als bei den Beamten meinte die ÖTV, sie leiste der bundesdeutschen Demokratie einen wertvollen Dienst, wenn sie sich bemühe, Polizisten in eine Einheitsgewerkschaft des Öffentlichen Dienstes einzubinden. Gerade bei diesen Staatsdienern sei eine selbstgewählte organisatorische Separierung bedenklich: Sie fördere einen Korpsgeist der staatlichen Ordnungsmacht, der in Deutschland in der Vergangenheit schon Übles bewirkt habe. Nur wenn man Polizisten in eine berufsübergreifende Gewerkschaft integriere, brauche man in der Bundesrepublik »nicht mehr über den Schutzmann zu reden [...], der über dem Volke steht «. ${ }^{32}$

Die GdP sah das anders. Zum einen gebe es eine »Eigenart des polizeilichen Dienstrechtes«, die eine separate Interessenvertretung für Polizisten

31 | Siehe dazu unten S. 98-113.

32 | Adolph Kummernuss: Gewerkschaft und Polizei. In: Der Bürger und seine Polizei. Vorträge im Rahmen der Arbeitstagung »Woche der Polizei«, veranstaltet von der ÖTV in der Michael-Rott-Schule Mosbach/Baden im Januar 1953, Stuttgart 1953, S. 76-94, hier: S. 94. Vgl. auch: Protokoll ÖTV-GT 1964, S. 82 f. Das Nebeneinander der beiden Organisationen hatte historische Gründe: Die Besatzungsmächte untersagten nach 1945 die Gründung separater Polizeigewerkschaften, weil sie der politischen Gesinnung der Polizisten misstrauten, die dem NS-Regime gedient hatten. So trat die ÖTV als berufsübergreifende Organisation an die Stelle der älteren Verbände von Polizisten. Als sich 1950 die GdP gründete, weil die alliierten Verbote nun nicht mehr galten, sah die ÖTV keinen Grund, auf ihre Polizeisparte zu verzichten. Als treffenden kurzen Abriss vgl. hierzu auch: Ernst Günther Vetter: Heimkehr der Polizeigewerkschaft in den Gewerkschaftsbund. In: FAZ, 10.12.1977. Ausführlicher vgl. aus Sicht der GdP: Friedrich Gniesmer: Der Weg zur und mit der GdP. In: Die deutsche Polizei. Ihre Geschichte, ihre Gewerkschaft. Daten, Fakten, Meinungen. 30 Jahre Gewerkschaft der Polizei 1950-1980, Hilden 1980, S. 1-59, hier: S. 36-43. 
notwendig mache; zum anderen sei die gewerkschaftliche Selbständigkeit einzelner Berufsgruppen ganz grundsätzlich »eine wesentliche Voraussetzung für den höchsten gewerkschaftlichen Effek $\kappa^{33}$ Da die GdP gezielt auch unter ÖTV-Mitgliedern warb, entwickelte sich ein Streit der beiden Gewerkschaften, in dem zeitweise mit harten Bandagen gekämptt wurde. So enthüllte die ÖTV 1957/58 in Nordrhein-Westfalen die frühere SS-Mitgliedschaft von etlichen höheren Kriminalbeamten des Landes. Damit wollte sie offensichtlich auch den Blick darauf lenken, dass einige der führenden Männer in der GdP eine »blutige« NS-Vergangenheit besaßen. ${ }^{34}$ Diese Konfrontation setzte sich noch fort, als eine neue, jüngere Führung der GdP wenig später auf Modernisierungskurs ging und intensiv für eine Integration der Polizeigewerkschaft in den DGB warb. Die ÖTV legte sich in dieser Frage jedoch quer und beharrte auf ihrer alleinigen "Zuständigkeit« für alle Mitarbeiter der Polizei im Rahmen des DGB. Das Verhältnis von ÖTV und GdP blieb daher bis 1977 feindschaftlich, obwohl beide Organisationen für die Berufsgruppe weitgehend die gleichen Ziele verfolgten. ${ }^{35}$

Die große Zahl von organisatorischen Konkurrenten, die teilweise (wie der DBB und die DAG) grundlegend andere sozialpolitische Konzepte ver-

33 | In der Reihenfolge der Zitate: Günther Schnapp: Zehn Jahre Arbeit und Kampf um die Rechte der Polizeibediensteten. In: Beginn und Aufstieg. 10 Jahre Gewerkschaft der Polizei 1950-1960, Hamburg 1960, S. 33-62, hier: S. 41; Werner Kuhlmann: Unser Weg. In: ebd., S. 15-21, hier: S. 19.

34 | Klaus Weinhauer: Sozialpartnerschaft, autoritärer Staat und Innere Sicherheit. Gewerkschaftliche Interessenvertretung in der nordrhein-westfälischen Polizei von den 1950er Jahren bis Anfang der 1970er Jahre. In: Karl Christian Führer (Hrsg.): Tarifbeziehungen und Tarifpolitik in Deutschland im historischen Wandel, Bonn 2004, S. 224-246, insbes. S. 230 f. 1962 startete die ÖTV noch einmal eine Kampagne gegen Polizeibeamte mit NS-Vergangenheit, die in der GdP aktiv waren. Vgl. Dietrich Strothmann: Kriminelle Kriminalisten? In: Die Zeit, 8.6.1962.

35 | Protokoll ÖTV-GT 1964, S. 73 f. Auch schon in den frühen 1950er Jahren hatte die ÖTV Versuche der GdP vereitelt, zum DGB-Mitglied zu werden. Vgl. die Dokumente dazu in: QGG Bd. 11: Der Deutsche Gewerkschaftsbund 1949 bis 1956. Bearb. v. Josef Kaiser, Bonn 1999, S. 190, 232 f. u. 305 f. Vgl. auch: Kuhlmann: Weg, S. 21 sowie S. 20 (zur Identität der gewerkschaftlichen Ziele von GdP und ÖTV). 
folgten und mitunter gezielt um spezielle, eng abgegrenzte Berufsgruppen warben, beeinflusste die Entwicklung sowohl der Mitgliederzahlen der ÖTV insgesamt wie auch ihrer inneren Strukturen. Die ÖTV musste eben nicht nur - wie alle Gewerkschaften - beständig damit kämpfen, dass viele Arbeitnehmer keine Bereitschaft zeigten, sich zu organisieren und einen finanziellen Beitrag zu leisten, der ihre kollektive Interessenvertretung möglich machte. Darüber hinaus war bei ihr die Gefahr von Abwanderungen zu anderen Gewerkschaften besonders groß, und ihr sehr uneinheitlicher Organisationsbereich bot besonders viele Möglichkeiten, mit Aussicht auf Erfolg eine neue berufliche Spartengewerkschaft zu gründen. In der weiteren Darstellung wird von diesen beiden Problemen noch die Rede sein. ${ }^{36}$

\section{Neben- oder miteinander? Interne Spannungen in der ÖTV und ihre Bedeutung für die Organisation}

Schaut man nach diesem Überblick zur Stellung der ÖTV im Gefüge der deutschen Gewerkschaften ergänzend auf ihre inneren Strukturen, so ist zunächst noch einmal an die Vielgestaltigkeit ihrer Basis zu erinnern. In der ÖTV fanden sich Arbeitnehmer zusammen, deren Qualifikationen, Bezüge und soziale Absicherung sich ebenso stark voneinander unterschieden wie ihr gesellschaftliches Prestige. Die Gewerkschaft verhandelte für höchst angesehene und exzellent bezahlte Beschäftigte wie beispielsweise die Piloten der Deutschen Lufthansa und die Manager dieser einzigen deutschen Airline, für Ingenieure in kommunalen Strom- und Wasserwerken sowie für den Generalmusikdirektor Wilhelm Schüchter und andere Musiker in den bundesdeutschen Symphonieorchestern. Allgemein respektiert oder sogar verehrt, im Vergleich aber doch schlecht bis sehr schlecht bezahlt waren demgegenüber etwa die ebenfalls von der ÖTV vertretenen Krankenschwestern oder Ärzte, die ihre Karriere als Mediziner direkt nach dem Studium an einem Klinikum begannen. Berufsgruppen wie den Müllmännern oder den Hafenarbeitern fehlte es zwar an einem vergleichbaren Sozialrenommee; die Wichtigkeit ihrer Arbeit für das Alltagsleben aller Bürger aber ließ sich kaum bestreiten. Im Kontrast dazu repräsentierten

36 | Vgl. unten die Ausführungen über den weiteren Konkurrenzkampf mit der GdP, den die ÖTV schließlich verlor, sowie über die Separierung der »Vereinigung Cockpit« für die Lufthansa-Piloten in Kapitel III. 
Putzfrauen, Fernfahrer, die Beschäftigten der städtischen Schlachthöfe oder die Arbeiter, die in Gummistiefeln und mit Schaufel in der Hand tief unten in der Kanalisation verstopfte Abwasserleitungen freimachten, jene von der ÖTV organisierten Beschäftigten, die unqualifizierte und gering geschätzte oder sogar missachtete Arbeiten verrichteten.

Diese Fraktionierung ihrer Basis behinderte und erschwerte die Arbeit der ÖTV an vielen Stellen. In der Tarifpolitik erlangten die stark unterschiedlichen Löhne und Gehälter besondere Bedeutung, zumal die Bandbreite zwischen hoher und niedriger Bezahlung unter ihren Mitgliedern ungewöhnlich weit ausfiel. So reichte die in Tarifverträgen geregelte Gehaltsskala bei der Lufthansa in den frühen 1960er Jahren in Leitungspositionen bis hinauf zu 20.800 DM pro Monat. Für die übergroße Mehrheit der Bundesbürger war das eine absolut fantastische Zahl: Über 80 Prozent von ihnen verdienten weniger als 1.000 Mark brutto. ${ }^{37}$ Auch Piloten der Luftlinie gehörten mit einem Monatsgehalt von bis zu 5.000 DM (bei freier Kost und freiem Logis während der Dienstzeiten) noch zu den Großverdienern. Gleichzeitig aber erhielt eine Stewardess (die sich bei der Einstellung darauf einlassen musste, spätestens mit 40 Jahren von ihrem Arbeitgeber als »zu alt« entlassen zu werden) als Anfängerin ein Grundgehalt von 435 Mark. ${ }^{38}$

Im Öffentlichen Dienst fiel die Verdienstspanne seinerzeit zwar nicht ganz so dramatisch aus, weil die Gehaltsspitzen weniger spektakuläre Höhen erreichten als bei der Lufthansa. Staatliche Angestellte aber kamen im

37 | Zahlen aus: Hans M. Bongers: Deutscher Luftverkehr. Entwicklung, Politik, Wirtschaft, Organisation. Versuch einer Analyse der Lufthansa, Bad Godesberg 1967, S. 146; Der private Haushalt in der Bundesrepublik Deutschland 1960/61. Statistische Daten zu ausgewählten Strukturdaten, Köln und Opladen 1965, nicht paginiert, Tabelle 20 .

38 | Bongers: Deutscher Luftverkehr, S. 146. Beim Blick auf die Bezahlung der Piloten sollte bedacht werden, dass diese seinerzeit einen »Eigenanteil« von 15.000 DM für die Kosten ihrer Ausbildung aufbringen mussten. Wer das nicht zahlen konnte, akzeptierte nach erfolgter Einstellung so lange Gehaltskürzungen, bis die Summe getilgt war (ebd., S. 139 f.). Erst 1974 setzte die ÖTV einen Tarifvertrag durch, der eine Beschäftigung der »Flugbegleiter« bis zum 55. Lebensjahr zuließ (ÖTV: Geschäftsbericht 1972-1975. Hrsg. v. der Gewerkschaft Öffentliche Dienste, Transport und Verkehr - Hauptvorstand, Stuttgart 1976 [im Folgenden: ÖTV-Geschäftsbericht 1972/75], S. 212). 
günstigsten Fall - in der Besoldungsstufe I A, als Verheiratete mit Kindern (die höhere Zulagen erhielten als Kinderlose und Ledige) - durchaus auf Summen von über 3.000 DM brutto pro Monat. Gleichzeitig betrugen die monatlichen Bezüge der unqualifizierten Arbeiterinnen und Arbeiter des Staates in der Regel zwischen 300 und 350 Mark - vor dem Abzug von Steuern und Sozialabgaben. ${ }^{39}$

Allerdings war die Zahl wirklich üppig entlohnter Stellen beim Staat wie bei der Lufthansa klein; zudem fand nur eine sehr überschaubare Gruppe unter den so hoch bezahlten Arbeitnehmern den Weg in die ÖTV. ${ }^{40}$ So handelte es sich bei dieser Gewerkschaft Anfang der 1960er Jahre eindeutig um eine Organisation von Normalverdienern und »kleinen Leuten«. 1961 zahlten fast 60 Prozent ihrer Mitglieder einen Monatsbeitrag bis maximal fünf Mark. Nach der ÖTV-Beitragstabelle lag ihr Brutto-Lohn damit unter 375 DM monatlich. ${ }^{41}$ Nicht weniger als 96 Prozent aller »ÖTVler« leisteten Beiträge, die einem Verdienst von bis zu 800 Mark entsprachen. Besserverdienende mit einem höheren Haupteinkommen, die sich in der gesamten Bevölkerung immerhin in 24 Prozent aller Haushalte fanden, waren an der Basis der Gewerkschaft stark unterrepräsentiert. ${ }^{42}$

Zwar dürften etliche Mitglieder mehr verdient haben, als sie es der Gewerkschaft gegenüber angaben, denn mit der Beitragsehrlichkeit vieler »Kollegen« stand es - wie noch gezeigt werden wird - zu dieser Zeit nicht zum Besten. Das Verfahren zur Berechnung und Eintreibung des individu-

39 | ÖTV: Geschäftsbericht 1964-1967. Hrsg. v. der Gewerkschaft Öffentliche Dienste, Transport und Verkehr - Hauptvorstand, Stuttgart 1968 (im Folgenden: ÖTV-Geschäftsbericht 1964/67), S. 643 (zur Gehaltsskala der Lufthansa); zu den Grundvergütungen nach BAT vgl. die Tabellen in: ÖTV-Tarifverträge. Wortlaut der überbezirklichen Tarifverträge des Jahres 1967, Stuttgart 1968 (im Folgenden: ÖTV-Tarifverträge 1967), S. 1059-1062 (Bund), 1083-1093 (TdL) und 1164-1168 (Bund).

40 | 1963 betrug die Organisationsquote unter den Beschäftigten in den Gehaltsstufen BAT III bis BAT I lediglich 0,2 Prozent (Protokoll der 7. Sitzung des HV, 26./27.6.1963. In: Archiv Ver.di, Bestand Kluncker 45).

41 | Die bundesdeutsche Einkommensstatistik verzeichnete lediglich 16 bis 18 Prozent aller Arbeiter und Angestellten in dieser Verdienstgruppe. Berechnet nach: Bayer/Streeck/Treu, Gewerkschaftsbewegung, S. 263; Der private Haushalt, Tabelle 20.

42 | Ebd. 
ellen Beitrags begünstigte solche Schummeleien. Dabei ging es jedoch in der Regel eher um bescheidene Summen. ${ }^{43}$ Es kann daher keinen Zweifel geben, dass die große Mehrheit der ÖTV-Mitglieder vom wirtschaftlichen Boom der Nachkriegsjahre nur gering profitiert hatte - und gerade deshalb verhielten sie sich gegenüber »ihrer« Gewerkschaft so knauserig. ${ }^{44}$

Dennoch - oder auch: deshalb - war die enorme Einkommensspanne in den Tarifverträgen, über die sie verhandelte, für die ÖTV ein Problem: Verlangte sie prozentuale Gehaltssteigerungen für alle Mitarbeiter des Öffentlichen Dienstes oder der Lufthansa, sorgte sie mit den entstehenden absoluten Zahlen für üppige Mehreinnahmen bei den Beschäftigten mit höherem Einkommen, während sie bei den schlechter Bezahlten kaum zusätzliche Kaufkraft schuf. Neun Prozent mehr Verdienst - um nur ein Rechenbeispiel anhand der oben genannten Zahlen für die Lufthansa zu nennen - von 20.800 DM sind nun einmal 1.872 Mark, bei 435 Mark aber nur magere neun DM. ${ }^{45}$ Selbst die höhere steuerliche Belastung, die Gutverdienende zu tragen hatten, schloss diese weite Kluft nur zum Teil. Im Folgenden wird deshalb stets auch der Frage nachgegangen, wie die Gremien der Gewerkschaft sowie die Arbeitgeber und die Öffentlichkeit mit dem Problem umgingen, dass eine prozentual gleiche Einkommensverbesserung in hierarchisch so stark gegliederten Betrieben wie der Lufthansa und dem Öffentlichen Dienst sehr unterschiedliche soziale Wirkungen entfalten konnte.

Vielfalt und Varianz ihrer Basis erschwerten die Tarifarbeit der Gewerkschaft ferner, weil kleine bis sehr kleine Mitgliedergruppen oft recht eigensinnig agierten, wenn sie ihre Erwartungen an die nächste Tarifrunde formulierten. Günter Stein, Mitglied der ÖTV-Angestelltenkommission, klagte im Herbst 1963 nach langwierigen Verhandlungen für diverse Technikergruppen: »Ich erlebe es immer wieder, desto kleiner die Gruppe, je schärfer die Forderungen. Je kleiner die Gruppe, desto weniger kompromissberei ${ }^{46}{ }^{46} \mathrm{Ko}-$

43 | Siehe unten Kapitel II.

44 | Vgl. den Delegierten Eugen Schackmann (Dortmund) in: Protokoll ÖTV-GT 1964, S. 234. Offiziell sollten die ÖTV-Mitglieder 1,33 Prozent ihres Brutto-Verdienstes als Beitrag zahlen; de facto wurden meist weniger als ein Prozent gezahlt (ebd.).

45 | Weitere Beispiele für diesen Effekt siehe unten Kapitel II.

46 | Protokoll der Sitzung der Großen Tarifkommission (GTK), 15.10.1963. In: Archiv Ver.di, Bestand Kluncker 12. 
ordinierungsprobleme kamen hinzu. »Wir führen so verschiedene Verhandlungen, daß die rechte Hand nicht weiß, was die linke tut« - diese Warnung eines Bezirksleiters aus dem Jahr 1960 blieb für die ÖTV dauerhaft gültig. ${ }^{47}$

Fliehkräfte, die an der organisatorischen Einheit der ÖTV zerrten, ergaben sich schließlich auch aus dem Ungleichgewicht zwischen dem sehr großen Segment »Öffentliche Dienste« und den deutlich kleineren Abteilungen für »Transport und Verkehr«. 1963 zählte die Gewerkschaft knapp 984.000 Mitglieder; nur rund zehn Prozent davon arbeiteten im privaten Transport- und Verkehrsgewerbe. ${ }^{48}$ Allerdings wird das an dieser Stelle nur noch der Vollständigkeit halber erwähnt. Wie eingangs angekündigt, konzentriert sich die folgende Darstellung aus pragmatischen Gründen auf die Tarifpolitik der ÖTV für den Öffentlichen Dienst. Die private Transportbranche bleibt daher unberücksichtigt; öffentliche Transportunternehmen wie die kommunalen Verkehrsbetriebe und die Deutsche Lufthansa aber finden Erwähnung, weil sie zum System der staatlich erbrachten Dienstleistungen gehörten.

Ohnehin war ein anderes internes Ungleichgewicht für die ÖTV sehr viel wichtiger als die Spannung zwischen den wenigen Mitgliedern, die in der sehr speziellen Welt der privaten Verkehrsbranche arbeiteten, und den Kollegen und Kolleginnen, die direkt oder indirekt »beim Staat « beschäftigt waren. Zwar warb die Gewerkschaft, wie erwähnt, um Beamte, Angestellte und Arbeiter gleichermaßen. Die solidarische Zusammenarbeit der drei Gruppen galt ihr als zentrale Aufgabe der Organisation, denn nur diese Gemeinsamkeit, so sagte es Heinz Kluncker auf dem Gewerkschaftstag 1964, sichere die »Schlagkraft wirksamer Interessenvertretung «. ${ }^{49}$ Auf Arbeiter, Angestellte und Beamte wirkte diese Strategie jedoch unterschiedlich überzeugend. Innerorganisatorisch dominierten - wie bereits in

47 | Protokoll der 9. Sitzung des Hauptvorstandes (HV), 9./10.11.1960. In: Archiv Ver.di, Bestand Kluncker 45.

48 | Bayer/Streeck/Treu geben die Zahl 104.741 an. Da hier jedoch auch die Luftfahrt einbezogen ist, die in der Bundesrepublik seinerzeit vor allem aus der Lufthansa, d.h. aus einem 100-prozentigen Staatsbetrieb bestand, muss diese Zahl als zu hoch gelten. Zieht man die 5.092 Mitglieder ab, die nach dem ÖTVGeschäftsbericht bei der Lufthansa arbeiteten (ÖTV-Geschäftsbericht 1961/63, S. 494), ergibt sich die Zahl von 99.649 Mitgliedern in privaten Transport- und Verkehrsbetrieben.

49 | Protokoll ÖTV-GT 1964, S. 412. 
den Vorläuferorganisationen der ÖTV - auch Anfang der 1960er Jahre eindeutig die Arbeiter. Obgleich die Gruppe der Angestellten im wirtschaftlichen Aufschwung des ersten Nachkriegsjahrzehnts kontinuierlich gewachsen war, stellten Arbeiter und Arbeiterinnen 1963 mit 607.000 der damals rund 984.000 ÖTV-Mitglieder immer noch 62 Prozent der Basis. Beamte waren nur schwach vertreten (91.000 bzw. 9,3 Prozent); 286.000 Angestellte bildeten die zweitgrößte Gruppierung (29 Prozent)..$^{50}$

Die Formel von der Interessenidentität aller Lohnabhängigen entfaltete bei Beamten offensichtlich nur sehr begrenzte Werbewirkungen: Als Beamtenorganisation konnte sich die ÖTV nicht mit dem DBB vergleichen, der im Jahr 1963 rund 900.000 Mitglieder zählte. Am erfolgreichsten war die ÖTV noch bei den Polizisten: Sie allein stellten knapp 35.000 der in der ÖTV organisierten Beamten (gleich 37 Prozent). ${ }^{51}$ Auch in dieser speziellen Berufsgruppe aber hielt sich die Mehrheit der unkündbaren Staatsdiener fern: Die mit der ÖTV verfeindete GdP war im Zwist der Organisationen mit rund 100.000 Beitragszahlern deutlich erfolgreicher. ${ }^{52}$

Bemüht, eine Schwäche als Vorteil erscheinen zu lassen, tat die ÖTV öffentlich so, als sei sie mit ihrem geringen Erfolg bei den Beamten durchaus ganz zufrieden, weil sie auf die fernbleibenden Staatsdiener gar keinen Wert lege: „Wir wollen nicht die alten, verknöcherten, sondern junge, moderne Beamte, die in den neuen, demokratischen Staat hineinpassen. ${ }^{53}$ Abgrenzungen dieser Art entfalteten auf den Gewerkschaftstagen der ÖTV sicher ihre Wirkung. Ob sie auch dazu dienen konnten, unter Beamten um neue Mitglieder zu werben, darf man aber bezweifeln.

Auch im Wettstreit mit der DAG blieb die ÖTV zweiter Sieger: Der standesstolze Konkurrent deklarierte 1963 knapp 474.000 Mitglieder. ${ }^{54}$

50 | Berechnet nach: Bayer/Streeck/Treu: Gewerkschaftsbewegung, S. 227.

51 | Berechnet nach: ÖTV-Geschäftsbericht 1961/63, S. 491.

52 | Weinhauer, Sozialpartnerschaft, S. 229. Neben der GdP gab es auch noch die zum DBB gehörende Deutsche Polizeigewerkschaft mit rund 10.000 Mitgliedern (ebd.).

53 | So der Leiter des Beamtensekretariats Karl Gröbing in: Protokoll des 2. Ordentlichen Gewerkschaftstages der Gewerkschaft Öffentliche Dienste, Transport und Verkehr vom 3. bis 7. Mai 1955 in Frankfurt/Main, Stuttgart 1956 (im Folgenden: Protokoll ÖTV-GT 1955), S. 321.

54 | Bayer/Streeck/Treu: Gewerkschaftsbewegung, S. 391. 
Schaut man etwas genauer hin, relativiert sich dieses Bild allerdings nicht unerheblich. In dem Bereich, in dem die beiden Organisationen direkt miteinander konkurrierten, im Öffentlichen Dienst, sah das Verhältnis anders aus: Die DAG kam hier auf 121.000 Mitglieder; die ÖTV aber zählte allein im unmittelbaren Öffentlichen Dienst von Bund, Ländern und Gemeinden sowie im Öffentlichen Verkehrswesen 144.000 organisierte Angestellte. Dazu kamen dann noch weitere Angestellte im staatlichen Gesundheitswesen und in der stark von öffentlichen Unternehmen geprägten Energiewirtschaft, deren Zahl sich aber nicht angeben lässt, weil die Mitgliederstatistik der ÖTV nicht besonders differenziert geführt wurde. ${ }^{55}$

Wegen der seit 1950 kontinuierlich steigenden Zahl von Angestellten in der ÖTV war die Gewerkschaft in dieser Berufsgruppe also durchaus erfolgreich und daher auch auf dem Weg dazu, stärker dem eigenen Anspruch gerecht zu werden, als Einheitsgewerkschaft berufliche und berufsständische Abgrenzungen zu überwinden. Unter den DGB-Gewerkschaften verzeichnete die ÖTV schon Anfang der 1960er Jahre die größte Zahl und den höchsten Anteil von Angestellten. Da Experten aus Wirtschaft und Wissenschaft allgemein ein weiteres starkes Wachstum dieser Beschäftigtengruppe prognostizierten und auch damit rechneten, ihr separates "Standesbewusstsein" werde zunehmend schwinden, durfte die Gewerkschaft mit Blick auf die Angestellten erwartungsvoll in die Zukunft schauen. Allerdings musste sie ebenso damit rechnen, dass unqualifizierte Beschäftigungen für Arbeiter wohl im gleichen Zuge zunehmend verschwinden würden. ${ }^{56}$ Diese prospektiven Prozesse ließen künftig nicht genau kalkulierbare Veränderungen erwarten - und das galt nicht nur für

55 | Zahlen aus: ebd., S. 399 (DAG), sowie berechnet nach den Angaben auf S. 230, 233, 236 u. 245. Die restlichen Mitglieder der DAG kamen aus den Bereichen "Handel, Banken, Versicherungen« sowie »Verarbeitendes Gewerbe«, in denen die ÖTV nicht aktiv war. Im Gesundheitswesen und in der Energiewirtschaft unterschied die ÖTV-Statistik nicht zwischen öffentlichen und privaten Unternehmen. 56 | Bei den kommunalen Verkehrsbetrieben war dieser Prozess bereits seit der zweiten Hälfte der 1950er Jahre in Gang. Vgl. etwa den Rückblick in: ÖTV-Geschäftsbericht 1964/67, S. $563 \mathrm{f}$. Zu der erwarteten weiteren Vermehrung der Arbeitsplätze für Angestellte vgl. etwa: Karl Valentin Müller: Die Angestellten in der hochindustrialisierten Gesellschaft, Köln und Opladen 1957; Ludwig Neundorfer: Die Angestellten. Neuer Versuch einer Standortbestimmung, Stuttgart 1961. 
die inneren Strukturen der ÖTV, sondern gerade auch für ihre Handlungsmöglichkeiten in Arbeitskämpfen.

Welche überragende Bedeutung das Verhältnis zwischen Arbeitern, Angestellten und Beamten für die Streikfähigkeit der Gewerkschaft hatte, belegt die Situation in den frühen 1960er Jahren. Bund, Länder und Gemeinden beschäftigten die drei Gruppen in sehr unterschiedlicher Zahl, und daher fiel auch die Macht der ÖTV mit ihrem starken Arbeiterblock gegenüber den drei öffentlichen Arbeitgebern recht ungleich aus.

Am stärksten war die ÖTV ohne Frage gegenüber den Kommunen, denn deren Belegschaften bestanden vor allem aus Arbeitern und Angestellten. Gleichzeitig hatte die Gewerkschaft hier besonders erfolgreich Mitglieder geworben: In den frühen 1960er Jahren gehörten 51 Prozent aller kommunalen Arbeiter zur ÖTV; auch bei den Angestellten lag die Organisationsquote noch bei 25 Prozent. ${ }^{57}$ In städtischen Versorgungsunternehmen für Strom, Gas und Wasser sowie in den Betrieben des öffentlichen Nahverkehrs, die für den städtischen Alltag überragend wichtig waren, zählte die ÖTV sogar die große Mehrheit aller Beschäftigten zu ihren Anhängern. Fast könnte man von »closed shops« sprechen, denn Organisationsquoten von 80 bis 90 Prozent aller Beschäftigten waren hier die Regel. Sogar Werte nah bei 100 Prozent kamen vor. ${ }^{58}$

Wie dieser große gewerkschaftliche Erfolg zustande kam, lässt sich nicht detailliert zeigen. Konvention und der Wunsch von neu dazukommenden Menschen, Teil der Gemeinschaft zu sein, dürften eine wichtige

57 | Bayer/Streeck/Treu: Gewerkschaftsbewegung, S. 261. 1963 waren 46 Prozent des gesamten städtischen Personals Angestellte; 33 Prozent waren Arbeiter und Arbeiterinnen. Diese Zahlen nach: Schreiber, Personal, S. 534-535.

58 | Diese Strukturen waren in vielen Betrieben schon in der Weimarer Republik entstanden. Vgl. etwa: Protokoll über die Verhandlungen der Gründungstagung des Gesamt-Verbandes der Arbeitnehmer der öffentlichen Betriebe und des Personen- und Warenverkehrs, Berlin 1929, S. 181; zu ihrer Fortdauer bis in die 1980er Jahre siehe unten Kapitel II. Zum Begriff des »closed shop« vgl.: Charles Hanson/Sheila Jackson/Douglas Miller: The Closed Shop. A Comparative Study in Public Policy and Trade Union Security in Britain, the US and West Germany, London 1982. In der Bundesrepublik untersagte die Rechtsprechung Tarifverträge, in denen sich der Arbeitgeber verpflichtete, nur Gewerkschaftsangehörige einzustellen. Insofern lässt sich für die Bundesrepublik nur in übertragener, nicht in wörtlicher Bedeutung von »closed shops« sprechen. 
Rolle gespielt zu haben: In diesen Unternehmen gehörte »man« (und auch: Frau) einfach zur Gewerkschaft. Wer sich verweigerte, der machte sich selbst zum Außenseiter. Überzeugungsarbeit mussten die ÖTV-Vertreter da kaum leisten. ${ }^{59}$

Bei Bund und Ländern herrschten deutlich andere Bedingungen als bei den Kommunen und den kommunalen Betrieben. Zum einen dominierten in ihren Belegschaften die Beamten, die nicht streiken durften. Bei den Ländern, die mit dem Bildungswesen, der Justiz und der Polizei für drei besonders kopfstarke Beamtenblöcke zuständig waren, stellten die auf Lebenszeit alimentierten Staatsdiener fast zwei Drittel aller Beschäftigten. Machtvolle Bastionen der ÖTV, die einen Vergleich mit den städtischen Versorgungs- und Verkehrsbetrieben erlaubt hätten, fehlten bei den Ländern vollständig, zumal die Anteile gewerkschaftlich organisierter Arbeiter und Angestellter hier mit 23 und zehn Prozent der jeweiligen Berufsgruppen auch noch deutlich magerer ausfielen als im Bereich der Kommunen. ${ }^{60}$

Für den Bund galt im Prinzip das Gleiche. Zwar gehörten fast 40 Prozent von dessen Arbeitern zur ÖTV. Diese recht hohe Quote verhalf der Gewerkschaft aber kaum zu besonderer Kampfkraft, weil der von der Bundesregierung bezahlte Arbeiter bzw. die Arbeiterin typischerweise einfache Hilfstätigkeiten in Ministerien und anderen Behörden verrichtete, die den Betriebszweck direkt kaum berührten. Arbeiter in typischen kommunalen Betrieben wie etwa bei der Straßenbahn, der Müllabfuhr oder im Wasser-

59 | Vereinzelt gab es allerdings auch offenen Druck. 1958 wurde ein solcher Fall in Nürnberg öffentlich bekannt: Die 90 Wagenpfleger der Städtischen Verkehrsbetriebe weigerten sich in diesem Jahr, mit einem neu eingestellten Kollegen zusammenzuarbeiten, der keiner Gewerkschaft angehörte und auch keiner beitreten wollte. Bekannt wurde das, weil der für den Betrieb zuständige ÖTV-Sekretär den Betroffenen brieflich darüber informierte und ihm vorwarf, er störe den »Arbeitsfrieden«. Der Mann (ein ehemaliges Mitglied der ÖTV) verklagte den ÖTV-Funktionär daraufhin wegen »Nötigung«. Der Prozess ging durch drei Instanzen und wurde schließlich wegen »Geringfügigkeit« eingestellt, nachdem zuvor zweimal unbedeutende Geldstrafen verhängt worden waren. Innerbetrieblich löste sich der Konflikt, als der klagende Arbeiter einer christlichen Gewerkschaft beitrat. Vgl. genauer zu der ganzen Angelegenheit: Wenn ein Funktionär droht. In: Die Zeit, 11.8.1961.

60 | Schreiber: Personal, S. 535; Bayer/Streeck/Treu: Gewerkschaftsbewegung, S. 261. 
werk waren demgegenüber betrieblich sehr viel wichtiger und damit auch gewerkschaftlich handlungsfähiger. ${ }^{61}$

Zudem waren die verschieden zusammengesetzten und verschieden großen Belegschaften von Bund, Ländern und Gemeinden auch unterschiedlich teuer. Die Länder wiesen wegen ihrer vielen Beamten anteilig die mit deutlichem Abstand höchsten Personalkosten auf: Im Jahr 1963 zahlten sie etwas mehr als 40 Prozent der Gesamtetats an ihre Bediensteten. Bei den Gemeinden betrug dieser Anteil hingegen nur 23 Prozent; beim Bund lag er (weil die zahlreichen Beschäftigten von Post und Bahn nicht dazu gerechnet wurden) mit etwa elf Prozent sogar noch niedriger. ${ }^{62}$

Lohn- und Gehaltssteigerungen für den Öffentlichen Dienst belasteten die Kassen von Bund, Ländern und Gemeinden also durchaus sehr unterschiedlich, und auch Streiks der ÖTV-Mitglieder trafen die öffentlichen Arbeitgeber jeweils sehr differenziert. Beides war für die Nachgiebigkeit gegenüber gewerkschaftlichen Forderungen bei den verschiedenen Vertretern der Öffentlichen Hand überragend wichtig. Verhandlungen mit der ÖTV aber führten die staatlichen Arbeitgeber grundsätzlich nur gemeinsam, um bundesweit möglichst vergleichbare Arbeitsbedingungen und Entgelte für vergleichbare Tätigkeiten zu sichern: Abwerbungen durch deutlich bessere Konditionen sollte es im Öffentlichen Dienst möglichst nicht geben. ${ }^{63}$

Tarifverhandlungen gingen deshalb stets mit komplizierten internen Abstimmungen auf der Seite der Arbeitgeber einher: Sowohl die Länder als auch die Gemeinden mussten sich jeweils zunächst einmal untereinander auf einen Kurs verständigen. Dies geschah in der TdL bzw. in der VKA. An-

61 | Ebd., S. 261. Zur relativen Machtlosigkeit der ÖTV gegenüber dem Bund siehe genauer unten Kapitel IV.

62 | Schreiber: Personal, S. 534.

63 | 1954 plante die Bundesregierung sogar eine gesetzliche Regelung, die es ihr erlauben sollte, Sonderregelungen der Länder für ihre Beschäftigten zu verhindern. Gleichzeitig klagte sie vor dem Bundesverfassungsgericht gegen eine Gehaltsregelung für die nordrhein-westfälischen Beamten, die über der Bezahlung des Bundes lag. Das Gericht wies diese Klage jedoch als juristisch unzulässig ab; daraufhin verzichtete die Regierung auch auf das geplante Gesetz. Vgl. dazu: Die Kabinettsprotokolle der Bundesregierung, Bd. 7: 1954. Bearb. v. Ursula Hüllbüsch/Thomas Trumpp, Boppard 1993 (im Folgenden: Kabinettsprotokolle Bundesregierung 1954), S. 258, 322, 361, 471. 
schließend ging es dann um eine weitere Absprache untereinander auch mit der Bundesregierung. Schon parteipolitische Differenzen zwischen CDUund SPD-geführten Ländern konnten hier Probleme schaffen; dazu kamen die erheblichen Unterschiede in der Finanzlage von reichen und armen Bundesländern, zwischen Stadtstaaten und Flächenländern sowie unter den Kommunen. ${ }^{64}$ Vereinheitlichend wirkte innerhalb der VKA allerdings die starke kommunalpolitische Stellung der SPD. Im Jahr 1960 gab es in der Bundesrepublik 50 Großstädte mit jeweils mehr als 100.000 Einwohnern; in 38 dieser Metropolen bekleidete ein Sozialdemokrat das höchste Amt. ${ }^{65}$

Gemeinsam war den in Amt und Würde stehenden Politikern auf allen staatlichen Ebenen allenfalls ihre Bereitschaft, die Beschäftigten der Öffentlichen Hand (und unter diesen insbesondere die Beamten) zumindest immer dann gezielt besser zu stellen, wenn in absehbarer Zeit wieder eine Wahl anstand. Gerade die Bundesländer mit ihren zahlreichen Beamten taten sich in dieser Hinsicht hervor, und sie bedachten dabei oft auch Arbeiter und Angestellte. Adolph Kummernuss nannte solche Geschenke, die parteipolitische Loyalität stiften sollten, 1964 etwas abschätzig »Wahlspeck, von dem wir mitunter gar nicht gewußt haben, daß er kommt«. Unter-

64 | Im Gefüge der öffentlichen Arbeitgeber bedeutete die Stellung der beiden Stadtstaaten Hamburg und Bremen ein besonderes Problem. Wegen ihrer großen kommunalen Versorgungsbetriebe (Energie, Wasser, Verkehr) unterschied sich die Beschäftigungsstruktur hier massiv von der der Flächenländer. Schon aus Prestigegründen gehörten beide Stadtstaaten jedoch zur TdL. Von 1956 bis 1958 gab es innerhalb der TdL massiven Streit um diese Mitgliedschaft, weil die Flächenländer meinten, beide Stadtstaaten seien - wie alle Kommunen - gegenüber den Gewerkschaften zu nachgiebig. Zeitweise wurde in diesem Streit sogar Bremen mit Mehrheitsbeschluss aus der Gemeinschaft ausgeschlossen. Am Ende stand ein Kompromiss: Bremen wurde wiederaufgenommen und auch Hamburg blieb in der TdL; für ihre Arbeiter durften die Stadtstaaten jedoch Regelungen vereinbaren, die von den TdL-Tarifverträgen abwichen. De facto richteten sich die beiden SPD-Hochburgen nach den Tarifverträgen der VKA, der sie selbst aber nicht angehörten. Vgl. etwa: Auszug aus der Mitgliederversammlung der TdL, 15.1.1958. In: Staatsarchiv Hamburg (StA HH), 131-11, 293. Hier auch umfangreiches weiteres Material zu dieser Angelegenheit.

65 | So das Resultat einer eigenen Auszählung für 1960, die auf den Angaben in den jeweiligen stadtgeschichtlichen Artikeln der Online-Enzyklopädie »Wikipedia«fußt. West-Berlin, Hamburg und Bremen sind in den oben genannten Zahlen nicht enthalten. 
schiedliche Haltungen bei Amtsinhabern aus CDU/CSU, SPD oder FDP sah er dabei nicht. ${ }^{66}$

Weiter unten wird genauer zu untersuchen sein, welche Strategien die ÖTV entwickelte, um tarifpolitisch auf diese ungleichen Strukturen und widersprüchlichen Rahmenbedingungen zu reagieren. Dabei ist vor allem zu fragen, ob die innere Fraktionierung, mit der die öffentlichen Arbeitgeber zu kämpfen hatten, der Gewerkschaft eher nützlich war, oder ob sich für die ÖTV auch Nachteile ergeben konnten, wenn Bund, Länder oder Gemeinden tarifpolitisch kein gemeinsames Ziel verfolgten, weil die drei Partner bei einem Streik der ÖTV-Mitglieder keineswegs gleich stark getroffen wurden.

Die Unterteilung des Öffentlichen Dienstes in Arbeiter, Angestellte und Beamte war für die ÖTV darüber hinaus bedeutsam, weil das Nebeneinander der drei Gruppen organisationsinterne Probleme mit sich brachte. So war die »Kragenlinie«, d. h. der Unterschied zwischen Beschäftigten »mit weißem Kragen«, die an Schreibtischen saßen, und den Handarbeitern, die bei der Arbeit schwitzten und schmutzig wurden, in der deutschen Gesellschaft seinerzeit noch höchst bedeutsam. Gemeinschaftliches gewerkschaftliches Handeln musste hier eine soziale Distanz überwinden, die ansonsten im Alltag allgegenwärtig war. Für die ÖTV bedeutete das eine Art Drahtseilakt. Georg Huber, der als zweiter Vorsitzender der Organisation in den frühen 1950er Jahren in der ÖTV eine wichtige Rolle spielte, hatte das zugrundeliegende Problem schon im Januar 1949 aufgespießt: Einerseits müsse die ÖTV das »Berufsethos" der einzelnen von ihr umworbenen und organisierten Gruppen intensiver beachten und pflegen, »als dies sonst allgemein üblich ist«, weil es für die Mitglieder nun einmal enorm wichtig sei. Andererseits aber dürfe dadurch keinesfalls der »Standesdünkel « gefördert werden. ${ }^{67}$

Dieser Kampf gegen die soziale Abgrenzung war durchaus auch bei Arbeitern eine Aufgabe. "Jemand, der einen weißen Kragen hatte, der wur-

66 | Protokoll ÖTV-GT 1964, S. 78. Vgl. auch: ÖTV-Geschäßtsbericht 1961/63, S. 369 .

67 | Protokoll des Vereinigungs-Verbandstages der Gewerkschaften des Öffentlichen Dienstes, Transport und Verkehr, Stuttgart, den 28. bis 30. Januar 1949, Stuttgart 1949, S. 32. Bis 1952 galten Huber und Kummernuss als gleichberechtigte Vorsitzende; 1952 beschloss der Gewerkschaftstag hier eine Hierarchisierung. Huber wurde zum Stellvertreter des Vorsitzenden Kummernuss. 
de schon komisch angeguckt « - so erinnert sich Walter Eberhardt, der in den späten 1970er Jahren in der ÖTV-Hauptverwaltung Karriere machte, an seine Kindheit und Jugend in einer Arbeiterfamilie in der nordrheinwestfälischen Kleinstadt Schwerte in den 1950er Jahren. Für das Arbeitermilieu in der frühen Bundesrepublik kann das als typisch gelten. Als Eberhardt nach einer Lehre bei der Kommune selbst erst zum städtischen Angestellten und dann sogar zum Beamten wurde, waren seine Eltern zwar einerseits stolz, andererseits aber auch skeptisch: Der Satz, "glaubst wohl, du wärst was besseres«, wurde ihm bei familiären Meinungsverschiedenheiten nun mehrfach entgegengehalten. ${ }^{68}$

In einer schichtenübergreifenden Organisation wie der ÖTV war innergewerkschaftliche Solidarität mithin alles andere als selbstverständlich, zumal sich die drei Gruppen unterschiedlich stark an der ehrenamtlichen Arbeit beteiligten, ohne die der Verband nicht funktionieren konnte. Arbeiter und Arbeiterinnen stellten zwar die Mehrheit der Mitglieder; Funktionen in der Gewerkschaft übernahmen sie aber nur selten. Die Gründe dafür waren umstritten: Sprachen die einen von mangelndem Selbstbewusstsein und Durchsetzungsvermögen, fühlten die Arbeiter selbst sich oft pauschal zurückgesetzt. 1958 klagte einer der Delegierten des Gewerkschaftstages: »Man hat als Arbeiter immer das Gefühl, daß in der Organisation die Kampfkraft des Arbeiters, das gute Organisationsverhältnis sehr wohl geschätzt wird, daß er auf der anderen Seite aber immer in den Hintergrund gespielt wird. $\ll^{69}$

Die nachfolgende Untersuchung für die Jahre nach 1964 wird deshalb beim Blick auf die Gewerkschaft immer auch fragen, wie Beamte, Angestellte und Arbeiter in der ÖTV miteinander umgingen. Wie sah es mit dem Einfluss der drei Gruppen auf Entscheidungsprozesse in der Gewerkschaft aus? Blieben Arbeiter und Arbeiterinnen in der innerverbandlichen Hierarchie unterrepräsentiert? Welche sozialen Interessen dominierten die Strategiedebatten der ÖTV und ihre praktische Tarifarbeit?

68 Interview des Verfassers mit Walter Eberhardt, 16.12.2013. Immer noch grundlegend zum proletarischen Milieu in der frühen Bundesrepublik: Josef Mooser: Arbeiterleben in Deutschland 1900-1970. Klassenlagen, Kultur und Politik, Frankfurt/Main 1984.

69 | Protokoll ÖTV-GT 1958, S. 141. 
Die beruflichen Disparitäten unter ihren Mitgliedern waren für die ÖTV in einer weiteren Hinsicht ein Problem: Sie prägten recht unübersichtliche innere Strukturen der Gewerkschaft. Anfang der 1960er Jahre gliederte sich die ÖTV auf komplizierte Weise in acht "Hauptfachabteilungen« mit einer Fülle von einzelnen »Fachgruppen«. Waren die einzelnen Fachgruppen beruflich noch recht präzise umrissen, wirkte ihre Zuordnung zu den Hauptfachabteilungen teilweise zufällig bis widersinnig. So war etwa der große Block der kommunalen Betriebe auf ganz verschiedene Abteilungen verteilt und innerverbandlich somit ohne koordinierende Leitung, während die Beschäftigten des Bundes und der Länder fast vollständig zur Hauptfachabteilung Eins gehörten. ${ }^{70}$

Neben den Hauptfachabteilungen und Fachgruppen existierte aus praktischen Gründen selbstverständlich eine regionale Gliederung der ÖTV, die von den unteren Ebenen der Betriebsgruppen sowie der Orts- und Kreisverwaltungen in den 1950er Jahren hinauf bis zu zwölf Bezirksverwaltungen führte. In beiden Strängen wurde separat ehrenamtlich gearbeitet; Mitgliederdiskussionen, Abstimmungen und Wahlen verliefen ebenfalls jeweils unkoordiniert parallel.

De facto wurden die Debatten und Entscheidungen der Organisation von den Spitzen der Hauptfachabteilungen dominiert, die alle in der ÖTVZentrale in Stuttgart verankert waren. Die Bezirke mit ihren durchaus recht unterschiedlichen Mitgliederzahlen und die anderen regionalen Gliederungen spielten als innerverbandlicher Machtfaktor hingegen nur eine untergeordnete Rolle. Das einfache Mitglied erlebte die ÖTV aber vor allem durch die jeweilige Betriebsgruppe sowie die lokale Orts- und Kreisverwaltung. Von diesen Ebenen führte jedoch nur eine schwach entwickelte Linie hinauf zur Verbandsführung. Als demokratisch aufgebauter Verein, der Mitglieder und Führung eng miteinander verbinden wollte, war die ÖTV Anfang der 1960er Jahre offensichtlich eher unpraktisch organisiert. ${ }^{71}$ Im Folgenden wird zu zeigen sein, welche Reformversuche nach 1964 unter dem Vorsitz von Heinz Kluncker unternommen wurden, um dieses Problem zu lösen.

70 | Vgl. die genaue Aufgliederung in: ÖTV-Geschäftsbericht 1961/63, S. 487-495. 71 | Zu den regionalen Gliederungen vgl. die Übersicht und Aufgliederung ebd., S. 467-483. 


\section{Ungleiche Hälften: Frauen und Männer in der ÖTV}

Wie in den meisten anderen deutschen Gewerkschaften, so stellten Frauen auch in der ÖTV nur eine Minderheit dar: Neben 808.000 Kollegen standen im Jahr 1963 rund 176.000 Kolleginnen. ${ }^{72}$ Dieser Anteil von 18 Prozent hatte sich trotz steigender Mitgliederzahlen seit Mitte der 1950er Jahre kaum nennenswert verändert. Zudem kämpfte die ÖTV (wie auch andere Gewerkschaften) unverändert mit dem Problem, dass Frauen die Organisation weitaus häufiger als Männer nach einigen Jahren wieder verließen, weil sie aus familiären Gründen ihren Beruf aufgaben. ${ }^{73}$

Solche individuellen Entscheidungen entsprachen dem damals gesellschaftlich noch dominierenden Verständnis von den komplementären männlichen und weiblichen Rollen: Der Mann hatte für seine Familie zu sorgen und ging deshalb zwischen Ausbildung und Rentenstand kontinuierlich einer Erwerbsarbeit nach. Das Leben der Frau kreiste nach der Heirat hingegen um ihren Mann, den Haushalt und die Kinder. Bezahlte Arbeit außerhalb des Familienheims konnte da nur stören. Teilweise galt sie sogar als Anzeichen für ein Versagen des Mannes, der nicht genug leiste. Im Leben der Frau prägte der Beruf so typischerweise nur die Jahre zwischen der Schule und der Eheschließung. ${ }^{74}$

Zwar sah die soziale Realität nach zwei Weltkriegen, nach Massenflucht und -vertreibungen vielfach ganz anders aus. Das Modell vom männlichen "Alleinversorger« aber herrschte noch in vielen Köpfen - auch in denen von Frauen. Mitglieder und Leitung der ÖTV waren hier keine Ausnahme. So verabschiedete beispielsweise der Gewerkschaftstag von 1958 vor den abschließenden Wahlen neben vielen männlichen Funktionsträgern, die nicht erneut für ein Amt kandidierten, auch Gertrud Rendel als bisheriges Mitglied des Hauptvorstandes. Während die Männer ausschieden, weil sie sich beruflich veränderten oder in den Ruhestand gingen, verließ Frau Rendel aus Gießen jedoch nicht nur den Vorstand, sondern gleich auch noch Gewerkschaft und Beruf, denn sie hatte geheiratet. Für Adolph

72 | Bayer/Streeck/Treu: Gewerkschaftsbewegung, S. 228.

73 | ÖTV-Geschäftsbericht 1964/67, S. 737.

74 | Vgl. etwa: Claudia Born: Das Ei vor Kolumbus. Frauen und Beruf in der Bundesrepublik Deutschland. In: Gunilla-Friederike Budde (Hrsg.): Frauen arbeiten. Weibliche Erwerbstätigkeit in Ost- und Westdeutschland nach 1945, Göttingen 1997, S. 46-61. 
Kummernuss war dies »das bessere Los«. Die ausscheidende Funktionärin kam hingegen nicht zu Wort. ${ }^{75}$

Der kleine weibliche Teil der ÖTV unterschied sich in einer Hinsicht deutlich von der großen Gruppe der Männer: Bei den Frauen sah die Gliederung in Beamte, Angestellte und Arbeiter ganz anders aus als bei den Kollegen. Die oben für die gesamte Mitgliedschaft beschriebene dreistufige Hierarchie gab es vor allem, weil sie bei den Männern bestand. Unter den ÖTV-Kolleginnen waren Angestellte hingegen fast genauso zahlreich wie die Arbeiterinnen; verbeamtete Frauen gab es hingegen kaum. ${ }^{76}$

Diese spezielle Struktur entstand zum einen, weil Männer und Frauen sich sehr ungleich auf die verschiedenen Berufsfelder und Wirtschaftssparten verteilten, die gemeinsam die bundesdeutsche Wirtschaft bildeten; zum anderen aber hatte sie auch mit der »Grenzziehung« zwischen den ÖTV und konkurrierenden Organisationen zu tun. Dieser zweite Zusammenhang erklärt zu einem guten Teil die geringe Zahl der Beamtinnen in der ÖTV: Für die größte Frauengruppe unter den auf Lebenszeit gesicherten Staatsbediensteten, für die Lehrerinnen, war unter den DGB-Gewerkschaften nun einmal nicht die ÖTV, sondern die GEW zuständig. Abseits der Schulen aber beschäftigten Bund, Länder und Gemeinden in den frühen 1960er Jahren nur wenige Frauen auf Beamtenstellen, und von diesen fand dann noch einmal nur eine kleine Gruppe den Weg in die ÖTV. So zählte die Gewerkschaft 1963 unter ihren Mitgliedern bei den Männern beispielsweise 1.247 Justizbeamte und 2.270 Beamte in Länderministerien - aber nur 56 bzw. 215 Frauen in entsprechenden Positionen. Auch in der Hauptabteilung II, die für kommunale Verwaltungen und städtische Betriebe zuständig war, gab es unter fast 43.000 weiblichen Mitgliedern lediglich 909 Beamtinnen. ${ }^{77}$

75 | Protokoll ÖTV-GT 1958, S. 364.

76 | ÖTV-Geschäftsbericht 1961/63, S. 474.

77 | Ebd., S. 486. Nur 1,2 Prozent der höheren Beamtenstellen und 1,7 Prozent der gehobenen Positionen waren im Jahr 1960 mit Frauen besetzt. Erst im mittleren Dienst (dazu gehörte der größte Teil des Schuldienstes) gab es mit 13,4 Prozent einen nennenswerten Frauenanteil (ÖTV: Geschäftsbericht 1958-1960. Hrsg. v. der Gewerkschaft Öffentliche Dienste, Transport und Verkehr - Hauptvorstand, Stuttgart 1961 [im Folgenden: ÖTV-Geschäftsbericht 1958/60], S. 541). 
Zugleich garantierte die ungeschriebene Alltagsregel, dass Frauen vor allem dort arbeiteten, wo sie es mit anderen Menschen zu tun hatten und wo es um soziale Dienste ging, eine fast unangefochtene männliche Dominanz in bestimmten anderen Sparten der ÖTV. Dies galt etwa für die Schifffahrt und die Hafenbetriebe. In der Hauptabteilung VI, die diese Berufsgruppen vereinte, lag der Anteil der weiblichen Mitglieder im Jahr 1963 unter zwei Prozent. Auch im privaten LKW- und Omnibusverkehr, im Bewachungsgewerbe sowie in den Versorgungsbetrieben für Strom, Gas und Wasser spielten Frauen im jeweiligen Berufsfeld und damit auch in der Gewerkschaft nur eine marginale Rolle. ${ }^{78}$ Ganz ähnlich sah es in den kommunalen Verkehrsbetrieben aus: Wo es um Technik ging, fehlten die Frauen. So waren im Jahr 1963 beispielsweise lediglich 18 der insgesamt 30.500 ÖTV-Mitglieder, die Fahrzeuge im öffentlichen Nahverkehr steuerten, weiblich. ${ }^{79}$

Vor allem in zwei Bereichen zählte die ÖTV viele Frauen: in den kommunalen Verwaltungen und Betrieben (Hauptfachabteilung II K) mit 52.000 weiblichen Mitgliedern sowie im Gesundheitswesen (Hauptfachabteilung IV) mit 46.000 Frauen. In der Gesundheitssparte gab es sogar eine weibliche Mehrheit unter den Beitragszahlern. ${ }^{80}$ An dritter Stelle folgte mit 37.000 organisierten Frauen die Abteilung I, in der die Verwaltungen von Bund und Ländern sowie der Sozialversicherungen und Krankenkassen zusammengefasst waren. Gemeinsam stellten diese drei Untergliederungen 77 Prozent aller ÖTV-Kolleginnen. ${ }^{81}$ Die Berufsgruppen der Angestellten und der Arbeiter waren bei den ÖTV-Frauen - anders als bei den Männern - fast gleichstark vertreten, weil es diese drei kopfstarken Abteilungen

\footnotetext{
78 | Ebd., S. 492, 494 u. 488.

79 | Ebd., S. 492.

80 | Ebd., S. 490. 1963 hatte die Abteilung 32.000 männliche Mitglieder. Zu den 46.000 Frauen in der Abteilung IV gehörten auch rund 13.000 Krankenschwestern. Für sie bestand als besondere Unterorganisation der ÖTV der »Bund freier Schwestern«. Vgl. dazu sowie umfassend zu den besonderen Problemen dieser Berufsgruppe: Susanne Kreutzer: Vom »Liebesdienst« zum modernen Frauenberuf. Die Reform der Krankenpflege nach 1945, Frankfurt/Main 2005 (S. 45-57 zum »Bund « und seiner Entstehung).
}

81 | ÖTV-Geschäftsbericht 1958/60, S. 486. 
gab. Bei den Kommunen sowie in der Abteilung I vertrat die Gewerkschaft sogar mehr weibliche Angestellte als Arbeiterinnen. ${ }^{82}$

Unter den Frauen, die sich der ÖTV anschlossen, stellten die vornehmlich mit Büro- und Schreibtischarbeit beschäftigten Angestellten somit anteilig einen viel größeren Block als bei den Männern. Dennoch darf die erhebliche Bedeutung der Handarbeit für die Beschäftigten - und folglich für die Gewerkschaft - auch bei den weiblichen Mitgliedern nicht übersehen werden. Die ÖTV war eben nicht nur für das Büropersonal zuständig, das in vielen Prognosen in den frühen 1960er Jahren die moderne Arbeitswelt schlechthin repräsentierte und dessen starke Vermehrung für die Zukunft allgemein als ausgemacht galt. Daneben gab es im Öffentlichen Dienst zahlreiche Arbeiterinnen, und gerade sie verrichteten meist unqualifizierte und besonders schlecht bezahlte Tätigkeiten: Sie putzten in Krankenhäusern sowie in Verwaltungsgebäuden und Schulen, sie arbeiteten als Hilfskräfte in Kantinen, Krankenhausküchen und -wäschereien.

Bei diesen Stellen zeigte sich bereits seit Mitte der 1950er Jahre ein neuer Trend, den die ÖTV mit Sorge betrachtete: Teilzeitbeschäftigungen ersetzten Verträge mit voller Arbeitszeit, weil der Staat als Arbeitgeber auf diese Weise Sozialversicherungsbeiträge einsparte und Arbeit billiger einkaufte. So wuchs zwar die Zahl der Hilfsarbeiterinnen; für die Gewerkschaft aber ergaben sich daraus nur Nachteile, denn Frauen, die lediglich wenige Stunden in der Woche einer Erwerbsarbeit nachgingen, waren nach den Erfahrungen der ÖTV »kaum ansprechbar für die gewerkschaftliche Organisation ${ }^{83}$

Wie es unter solchen Bedingungen gelingen konnte, den weiblichen Anteil in der Gewerkschaft auch in der Gruppe der "Arbeiter « weiter zu stärken, war unklar - zumal einige Behörden und staatliche Betriebe im Interesse reduzierter Personalkosten bereits einen Schritt weitergingen: Sie verzichteten ganz auf eigene Reinigungskräfte und vergaben Putzarbeiten en bloc an Privatfirmen. Solche Betriebe aber standen nicht nur außerhalb

82 | Besonders ausgeprägt war dies in Abteilung I mit rund 26.000 weiblichen Angestellten und 11.000 Arbeiterinnen (ebd., S. 486). Die Abteilung II K zählte 27.000 angestellte Frauen und 24.000 Arbeiterinnen (ebd., S. 488).

83 | ÖTV-Geschäftsbericht 1961/63, S. 646. Ähnlich auch schon: ÖTV-Geschäftsbericht 1958/60, S. 545 . 
des Organisationsbereiches der ÖTV; die fast ausschließlich aus Kleinunternehmen bestehende Branche war zudem fast gewerkschaftsfrei. ${ }^{84}$

Das Verhältnis zwischen qualifizierten Beschäftigungen und einfacher Arbeit war im Frauensegment der ÖTV daher bereits in den frühen 1960er Jahren sehr viel stärker in Bewegung als im männlichen Block der Organisation, in dem die Arbeiter so eindeutig dominierten, dass ihre Überzahl langfristig gesichert war. Die Arbeitsmarktentwicklung stellte die Frauenpolitik der ÖTV also schon zu dieser Zeit vor ein besonders Problem: Sie musste einerseits Beschäftigte verteidigen, die besonders leicht ersetzbar und daher verletzlich waren, und andererseits auch für Frauen attraktiv auftreten, die höher qualifizierte Arbeitsplätze besetzten.

Wie zu zeigen sein wird, verschärfte sich diese Spannung in den nachfolgenden Jahrzehnten noch ganz erheblich, denn Frauen übernahmen im Öffentlichen Dienst nach 1960 vielfach Positionen, die ihnen zuvor nicht zugänglich gewesen waren. Gerade dieses Arbeitsmarktsegment öffnete sich um so mehr für weibliche Beschäftigte, je stärker Büroarbeiten zunahmen und die sozialen Dienste ausgebaut wurden. Viele Bereiche der Industrie beschäftigten Frauen unverändert vornehmlich auf unqualifizierten und dementsprechend unattraktiven Arbeitsplätzen. Der Staat bot Frauen hingegen zunehmend auch qualifizierte Stellen, die Selbstverwirklichung im Beruf möglich machten und daher mehr sein konnten als eine »Brücke« zwischen den Jahren der Schulbildung und der Heirat bzw. der Geburt des ersten Kindes. Insbesondere das Bildungswesen und die sozialen Dienste als zwei Kernbereiche staatlicher Fürsorge und der Frauenarbeit im Öffentlichen Dienst expandierten stark. ${ }^{85}$

Zugleich aber stellten Frauen im gesamten Untersuchungszeitraum auch einen großen Teil der Beschäftigten, deren Arbeitsplätze durch Sparmaßnahmen, Rationalisierungen und Privatisierungen im Staatsapparat und in öffentlichen Unternehmen bedroht und abgebaut wurden. Die Versuche der ÖTV, diese Ökonomisierung der Arbeitsverhältnisse im Öffentlichen Dienst, die gerade in den 1970er Jahren ganz erheblich an Bedeutung gewann, zu stoppen oder doch zumindest einzudämmen, dienten daher zu einem großen Teil gerade dem Interesse von Frauen. Die Frage, wie erfolgreich der solidarische Bund zwischen Männern und Frauen sowie zwi-

84 | Ebd.

$85 \mid$ Ebd., S. 542. 
schen ganz verschieden qualifizierten Arbeitnehmern in dieser Hinsicht war, wird in der weiteren Darstellung eine wichtige Rolle spielen.

Neben diesen Aspekten ist beim Blick auf Männer und Frauen in der ÖTV auch ihre jeweilige Stellung in der Hierarchie der Gewerkschaft zu untersuchen. Für die frühen 1960er Jahre fällt das Urteil in dieser Hinsicht leicht: Frauen spielten in den internen Beratungen und bei Beschlüssen der Organisation eine ganz untergeordnete Rolle; sie agierten stets nur »im Vorfeld der Entscheidungen $\ll{ }^{86}$ Die Zahlen, die das belegen, sind eindeutig: Auf dem Gewerkschaftstag von 1964 stellten Männer 95 Prozent der Delegierten; die Rednerliste dominierten sie dann noch eindeutiger. ${ }^{87}$ Unter den zwölf Bezirksleitern der Organisation gab es zur gleichen Zeit keine Frau; der geschäftsführende Hauptvorstand ( $\mathrm{gHV}$ ) bestand aus zwölf Männern und Ingeborg Tönnessen, die dieses Amt schon seit 1952 bekleidete. Sie war innerhalb des Gremiums (selbstverständlich, muss man wohl sagen) für das Frauensekretariat und außerdem für »Bürobedarf und -einrichtungen« sowie für die Kantine zuständig. ${ }^{88}$ Im größeren Hauptausschuss kamen immerhin sechs Frauen auf 59 Männer, aber selbst diese Quote lag noch deutlich unter den 18 Prozent, die den Frauenanteil in der ÖTV numerisch adäquat repräsentiert hätten. ${ }^{89}$

Für spezifisch weibliche Angelegenheiten hatte die ÖTV - wie sich denken lässt - wegen dieser eindeutigen Machtverhältnisse fast kein Geld übrig: 1963 vermerkte der Kassenbericht der Gewerkschaft unter dem Posten »Frauenarbeit« Ausgaben von 89.845 DM. Das entsprach 0,18 Prozent der Gesamtausgaben und rund einem Zehntel der Summe, die für die Miete, Heizung und Reinigung aller ÖTV-Geschäftsräume gezahlt wurde..$^{90}$

86 | ÖTV-Geschäftsbericht 1961/63, S. 652.

87 | Im Verlauf des Kongresses, der (einschließlich der feierlichen Eröffnungssitzung am Abend des 28. Juni) sieben Tage dauerte, traten fünf der 26 anwesenden weiblichen Delegierten für jeweils kurze bis sehr kurze Beiträge an das Rednerpult (Protokoll ÖTV-GT 1964, S. 226, 300 f., 304 f., 309 f. u. 322). Geschätzt lag ihr Anteil an der Gesamtredezeit deutlich unter der Ein-Prozent-Marke.

88 | ÖTV-Geschäftsbericht 1961/63, S. 11-13. Zu ihrer Biografie vgl.: Rüdiger Zimmermann: 100 Jahre ÖTV. Die Geschichte einer Gewerkschaft und ihrer Vorläuferorganisationen. Biografien, Frankfurt/Main 1996, S. 122-125. Bei ihrer Wahl war Tönnessen die erste Frau überhaupt im gHV einer DGB-Gewerkschaft. 89 | Protokoll ÖTV-GT 1964, S. 425 f.

90 | Berechnet nach: ÖTV-Geschäftsbericht 1961/63, S. 705. 
Zumindest der ÖTV-Frauenausschuss meinte, es liege nicht an einem Mangel an geeigneten Kandidatinnen, dass Frauen in der Gewerkschaft weder eine eigene Stimme noch Durchsetzungskraft besaßen. Das Gremium beklagte 1964 vielmehr eine »Front der Männer«, die bei »der Verteidigung ihrer Vormachtstellung« in der Gewerkschaft von Jahr zu Jahr rücksichtsloser agierten. ${ }^{91}$ Adolph Kummernuss als Vorsitzender der Organisation teilte diese Sicht. Auf dem Gewerkschaftstag von 1964 mahnte er die männlichen Delegierten: »Ihr müßt den Graben zuschütten, der gleiches Recht und gleiche Pflichten in zwei ungleiche Hälften aufteilt.« ${ }^{92}$

Das klingt so, als habe der aus dem Amt scheidende Kummernuss die Sache tatsächlich ernst genommen und seine Mahnung als ein Art Vermächtnis verstanden. Allerdings ging seine Formulierung von den »Hälften" angesichts der oben genannten Zahlen sachlich in die Irre, und damit stellte sie die Aufgabe, vor der die Gewerkschaft stand, dramatisch kleiner dar, als sie es tatsächlich war.

Mit Blick auf die nachfolgenden Jahre ist somit das Verhältnis zwischen den beiden Geschlechtern als innerorganisatorisches Problem der ÖTV im Auge zu behalten. Wie veränderte sich der weibliche Anteil an der Mitgliedschaft der Gewerkschaft mit den Wandlungen, die sich auf den Arbeitsmärkten der Bundesrepublik für Frauen nach 1960 vollzogen? Blieb es bei der geringen Zahl von organisierten Frauen und bei der bislang »typisch weiblichen«stärkeren Fluktuation? Wie reagierte die Gewerkschaft auf die öffentlich vorgetragene Kritik, Frauen würden innerhalb des Verbandes benachteiligt? Und schließlich in weiter Perspektive, die schon das Ende des hier untersuchten Zeitraums ins Auge fasst: Was sagt uns die Tatsache, dass die ÖTV im Jahr 1982 nach dem Rücktritt von Heinz Kluncker als erste deutsche Gewerkschaft eine Frau in das höchste Amt der Organisation wählte, über diese Gewerkschaft, ihr Selbstverständnis und ihre inneren Strukturen? Ergab sich die Wahl von Monika Wulf-Mathies aus veränderten Machtverhältnissen zwischen Männern und Frauen in der ÖTV und in

91 | Ebd., S. 652.

92 | Protokoll ÖTV-GT 1964, S. 82. Schon auf dem GT von 1961 hatte Kummernuss gesagt, er sei »sehr, sehr traurig« über die geringe Zahl weiblicher Delegierter (Protokoll des 4. Ordentlichen Gewerkschaftstages der Gewerkschaft ÖTV vom 25. Juni bis 1. Juli 1961 in Berlin, Stuttgart 1962 [im Folgenden: Protokoll ÖTVGT 1961], S. 75). 
deren Gremien, oder handelte es sich eher um das Resultat von personalpolitischen Rangkämpfen unter führenden Funktionären, wie sie (auch) in den Leitungsetagen von Gewerkschaften durchaus häufig vorkommen??3

\section{Die "geliebte Farbe Rot«: Die ÖTV und die politischen Parteien}

Ein letzter Punkt bleibt noch anzusprechen, um dieses einleitende Porträt der ÖTV zu vervollständigen: das Verhältnis der Gewerkschaft zu den politischen Parteien und hier insbesondere zur SPD. Wie alle DGB-Gewerkschaften verstand sich die ÖTV selbstverständlich als parteipolitisch und religiös neutrale Einheitsgewerkschaft. Zwar äußerte sie sich oft zu politischen Fragen, aber das tat sie - wie der DGB insgesamt - stets im Interesse einer freien Gewerkschaftsarbeit: Angriffe von Rechts- und Linksradikalen auf die bundesdeutsche Demokratie etwa beantwortete die ÖTV stets mit scharfer Kritik und auch Entwicklungen in anderen Ländern wurden in diesem Sinne kommentiert. ${ }^{94}$

Gegenüber den demokratischen Parteien aber gab sich die Organisation betont neutral. Auf ihren Gewerkschaftstagen etwa sprachen vor Beginn der Beratungen meist sowohl Vertreter von CDU als auch SPD; 1964 trat erstmals auch noch ein Mitglied der FDP für eines dieser ritualisierten Grußworte an das Rednerpult. ${ }^{95}$ Bei solchen Reden dürften Christdemokraten und Liberale jedoch genau gewusst haben, dass sie vor allem vor Sozialdemokraten standen. Auf dem ÖTV-Gewerkschaftstag 1964 etwa waren nicht weniger als 419 der 516 Delegierten auch SPD-Mitglied; hingegen bekannte sich nur einer zu den Liberalen, 14 gehörten zu CDU und CSU. ${ }^{96}$ Im geschäftsführenden Hauptvorstand der ÖTV war die CDU in den frühen 1960er Jahren genauso schwach vertreten wie die Frauen gegenüber

93 | Siehe dazu unten Kapitel III.

94 | Vgl. etwa den scharfen Protest von Adolph Kummernuss gegen den »Neofaschismus« in der Bundesrepublik in: Protokoll ÖTV-GT 1958, S. 70 f., sowie als Überblick: Nachtmann: 100 Jahre ÖTV, S. 330-333.

95 | Protokoll ÖTV-GT 1964, S. 38-40 (FDP) sowie 31-38 (SPD und CDU).

96 | Parteipolitische Aufschlüsselung der Delegierten auf dem 5. Ordentlichen DGB-Gewerkschaftstag, Juli 1964. In: Archiv der sozialen Demokratie Bonn (AdsD), SPD-Parteivorstand, 0930. Da die Parteizugehörigkeit von 64 Delegierten nicht bekannt war, handelt es sich nicht um absolut verlässliche Angaben. 
den Männern: ein Christdemokrat hatte es dort mit zwölf Mitgliedern der SPD zu tun. ${ }^{97}$

Nun war diese sozialdemokratische Dominanz eigentlich nichts Besonderes. In allen DGB-Gewerkschaften gehörten seinerzeit aktive gewerkschaftliche Arbeit und Mitgliedschaft in der SPD zusammen: Wer sich so stark für seine Gewerkschaft engagierte, dass er (oder sie) in deren Gremien mitwirkte, der gehörte typischerweise auch zur SPD. Vergleichbar enge personelle Verflechtungen mit CDU und CSU gab es nicht (obwohl zumindest die CDU einen durchaus einflussreichen Arbeitnehmerflügel aufwies). ${ }^{98}$ Einerseits war die ÖTV mit den exemplarisch für 1964 genannten Zahlen also nur ein weiteres Beispiel für das enge Band zwischen Gewerkschaften und Sozialdemokratie, das in der frühen Bundesrepublik trotz der offiziellen Doktrin von der parteipolitisch neutralen Einheitsgewerkschaft allein schon aus historischen Gründen noch ganz selbstverständlich existierte. ${ }^{99}$

Andererseits aber bedeutete die große Zahl von SPD-Genossen unter den ehrenamtlichen und hauptamtlichen Funktionsträgern der Gewerkschaft für die ÖTV doch etwas anderes als bei den DGB-Gewerkschaften, die Industriearbeiter vertraten: Durch die häufigen Doppelmitgliedschaften und durch die Kombination von gewerkschaftlicher und politischer Aktivität standen etliche ÖTV-Kollegen sowohl auf der Seite der Arbeitnehmer, die solidarisch für ihre Interessen stritten, als auch auf der Seite der Arbeitgeber, mit denen die Gewerkschaft über die Lohn- und Arbeitsbedingungen im Öffentlichen Dienst verhandelte. Teilweise galt dies ganz unmittelbar, weil Gewerkschaftsmitglieder Führungspositionen in öffentlichen Unternehmen bekleideten; teilweise handelte es sich eher um einen

97 | Information des Büros für nationale Gewerkschaftsarbeit über die Vorbereitung des Kampfmonats März 1961 in Westdeutschland, 15.2.1961. In: BArch Berlin, SAPMO, DY 34, 29431. Karl Gröbing war seinerzeit der Christdemokrat in der Runde. Zu seiner Biografie vgl.: Zimmermann: ÖTV, S. 76-78.

98 | Zur politischen Rolle der "Sozialausschüsse« der CDU vgl. etwa: Herlind Gundelach: Die Sozialausschüsse zwischen CDU und DCG. Selbstverständnis und Rolle 1949-1966, phil. Diss., Universität Bonn 1983; Birgit Frese: Anstöße zur sozialen Reform. Hans Katzer, die Sozialausschüsse und ihre Vorschläge zur Schaffung einer partnerschaftlichen Wirtschaftsordnung, phil. Diss., Universität Düsseldorf 2000.

99 | Vgl. etwa: Faulenbach: Das sozialdemokratische Jahrzehnt, S. $324 \mathrm{f}$. 
versteckten Interessenskonflikt, weil »ÖTVler« für die SPD in Parlamenten saßen, die direkt oder indirekt über die finanzielle Ausstattung des Öffentlichen Dienstes und über die Angelegenheit der öffentlichen Unternehmen entschieden. ${ }^{100}$

Beispiele für Personen mit solch einer Doppelrolle musste man nicht lange suchen. 1958 verabschiedete die ÖTV auf ihrem Gewerkschaftstag etwa sowohl ihren langjährigen hessischen Bezirksleiter Karl Meißner als auch dessen ähnlich verdienten rheinland-pfälzischen Kollegen Edwin Will. Meißner hatte neben der hauptamtlichen Arbeit für die ÖTV seit 1946 als Sozialdemokrat nacheinander sowohl in der Frankfurter Stadtverordnetenversammlung als auch im Kreistag sowie dann im hessischen Landtag mit abgestimmt; Will war seit 1953 Mitglied des Stadtrats von Ludwigshafen gewesen. Der Vertreter der Hamburger ÖTV im Hauptvorstand der Gewerkschaft Willi Pingel schließlich, der nicht wieder kandidierte, war und blieb als Gewerkschafter zugleich auch Direktor der Hamburger Freihafen-Lagerhaus-Gesellschaft, die sich vollständig im Besitz der Hansestadt befand. Das Nebeneinander dieser Funktionen galt in der ÖTV nicht als problematisch. Adolph Kummernuss lobte den Hamburger Kollegen vielmehr ausdrücklich für seinen besonderen Einsatz: Seine Doppelrolle beweise, "mit welcher Energie und mit welchem Willen, der Arbeiterbewegung zu dienen, unser Kollege Willi Pingel gewirkt hat ${ }^{101}$

Der so gelobte Pingel bedankte sich mit launigen Worten: Künftig werde er häufiger in seinem Kleingarten arbeiten und dort vor allem Radieschen ziehen, weil dieses Gemüse beim Wachsen »die von mir so sehr geliebte rote Farbe« annehme. Selbstverständlich bleibe er auch nach sei-

100 Im Bundestag etwa war keine andere Gewerkschaft auch nur annähernd so stark vertreten wie die ÖTV: In der dritten Wahlperiode (1961-1965) gab es in Bonn 72 Abgeordnete, die der ÖTV angehörten (bei 521 Abgeordneten insgesamt). Der IG Metall - der größten bundesdeutschen Gewerkschaft - gehörten hingegen nur 27 Abgeordnete an. In beiden Fällen handelt es sich fast ausschließlich um Mitglieder der SPD-Fraktion. Kurt Hirche: Gewerkschafter im Bundestag. In: GM 12 (1961), S. 641-651, hier: S. 650.

101 | Alle Angaben nach: Protokoll ÖTV-GT 1958, S. 361-361. Vgl. allgemein zu diesem Problem auch: Johann Schneider: Gewerkschaften im öffentlichen Dienst. Interessen und Interessenkonstellationen. In: Joachim Bergmann (Hrsg.): Beiträge zur Soziologie der Gewerkschaften, Frankfurt/Main 1979, S. 111-142, hier: S. $139 \mathrm{f}$. 
nem Ausscheiden aus dem ÖTV-Vorstand »Gewerkschaftsgärtner [...] und hoffentlich färbt sich dann alles in der schönen Radieschenfarbe«. Die Delegierten des Gewerkschaftstages dankten Pingel anschließend mit freundlichem Applaus. ${ }^{102}$

Diese Episode sollte man selbstverständlich nicht überbewerten. Sie resultierte nicht zuletzt aus der besonderen, halb gelösten und halb erschöpften Stimmung kurz vor dem Ende langer und anstrengender Beratungen. Strikte politische Korrektheit konnte da leichter vergessen werden als sonst. Zugleich aber illustrieren die Abschiedsworte des Hamburgers treffend ein besonderes Problem der ÖTV: Wenn Gewerkschaft und SPD so stark und so selbstverständlich als Einheit gedacht wurden, dann richteten sich allerlei Hoffnungen an die politische Arbeit der Partei in Parlamenten, Rathäusern und Ministerien - aber deren Erfüllung war recht ungewiss. Wer Verantwortung als Volksvertreter oder in einem politischen Amt trug, der stand zwangsläufig vor komplexen Aufgaben, die es unmöglich machten, sich ausschließlich als Gewerkschafter zu verstehen. Entscheidungen mussten vor den eigenen Wählern, vor der Partei, den Medien und vor der Allgemeinheit der Bürger begründet werden; eventuell waren auch die Empfindlichkeiten eines Koalitionspartners zu berücksichtigten. Zudem entschied gerade im Öffentlichen Dienst kein Arbeitgeber für sich allein. Auch Sozialdemokraten hatten das komplizierte Gefüge innerhalb von VKA und TdL sowie allgemein zwischen Bund, Ländern und Gemeinden zu bedenken, wenn sie auf der Seite der Arbeitgeber mit der ÖTV verhandelten.

Zwar war dies in der ÖTV selbstverständlich bekannt, dennoch existierte offensichtlich eine Erwartungshaltung gegenüber Amtsinhabern aus Gewerkschaft und SPD - unter anderem, weil die beiden Rollen grundsätzlich nicht als Gegensatz verstanden wurden. Die lobenden Worte des Vorsitzenden Kummernuss für den Hamburger Willi Pingel, der einen staatlichen Betrieb leitete und zugleich dessen Belegschaft gewerkschaftlich vertrat, belegen diese harmonisierende Sicht: In einem öffentlichen Dienstleistungsunternehmen stritt ihr zufolge auch der Direktor für die Arbeiterbewegung.

Allerdings gab es innerhalb der Sozialdemokratie abweichende Ansichten. Walter Hesselbach etwa, einer der führenden Männer der gewerk-

102 | Protokoll ÖTV-GT 1958, S. 366. 
schaftlichen Gemeinwirtschaft in der Bundesrepublik und ein prominenter Vertreter der hessischen SPD, erklärte streng, es gebe keinen Auftrag der öffentlichen Unternehmen, für ihre Beschäftigten »Bahnbrecher auf sozialpolitischem Gebiet [zu] sein«. Deren Aufgabe sei es vielmehr, die "Kaufkraft der Masseneinkommen [...] durch preissenkende bzw. preisstabilisierende Effekte« zu steigern. Ungewöhnlich hohe Lohnkosten könnten den staatlichen Betrieben keineswegs helfen, diese Rolle zu übernehmen: "Ihre sozialpolitische Funktion ist gesamtwirtschaftlich orientiert und begründet sich nicht auf partikularen Interessen, ganz gleich, ob es sich dabei um die Interessen der Belegschaften der betreffenden Unternehmen handelt oder um die einer bestimmten Gemeinde, in der das Unternehmen seinen Sitz hat. ${ }^{103}$

Folgte man dieser Sicht, dann war die parteipolitische und gewerkschaftliche Orientierung des Betriebsleiters in einem öffentlichen Dienstleistungsunternehmen unwichtig: Selbst ein aktiver Sozialdemokrat und Gewerkschafter durfte sich in dieser Position nicht als Beauftragter der Beschättigten verstehen. Die Formulierung von der "geliebten roten Farbe«, der die ÖTV-Delegierten 1958 applaudierten, versprach jedoch genau das Gegenteil. Offensichtlich gab es innerhalb der Organisation eine große Bereitschaft, mögliche Interessenkonflikte zu verdrängen, die sich für die ÖTV ergeben konnten, wenn etliche ihrer Mitglieder gleichzeitig für Arbeitgeber und Arbeitnehmer im Öffentlichen Dienst sprachen.

Zwar klagte ebenfalls auf dem Kongress von 1958 eine Delegierte, die vielen »ÖTVler« im Bundestag und in anderen parlamentarischen Vertretungen leisteten keinen wirkungsvollen Beitrag zur Arbeit der Organisation: "Wo bleibt mitunter die Stimme unserer Kolleginnen und Kollegen, wenn es gilt? Mit einem simplen Zwischenruf ist es doch nicht abgetan! ${ }^{104}$ Diese Beschwerde aber blieb ohne Echo. Selbst Warnungen in der zeitgenössischen Gewerkschaftspresse, man dürfe die Kollegen, die in parlamentarischen Gremien saßen, keineswegs als »Gewerkschaftsblock« betrach-

103 | Walter Hesselbach: Die gemeinwirtschaftlichen Unternehmen im Wettbewerb. In: Kurt Nemitz/Richard Becker (Hrsg.): Gewerkschaft - Wirtschaft Gesellschaft. Beiträge zu wirtschaftlichen und sozialen Gegenwartsfragen, Köln 1963, S. 107-124, hier: S. 121.

104 | So die Delegierte Annemarie Keller (Mainz) in: Protokoll ÖTV-GT 1958, S. 140. 
ten, weil sie sich vor allem als Parteipolitiker verstünden, scheint in der ÖTV niemand wirklich ernst genommen zu haben. ${ }^{105}$ Die doppelte Rolle, die Funktionsträger der Gewerkschaft wie etwa Willi Pingel, Karl Meißner oder Edwin Will als Sozialdemokraten in Parlamenten oder öffentlichen Betrieben spielten, wurde jedenfalls weder 1958 noch auf einem der späteren Gewerkschaftstage grundlegend und selbstkritisch diskutiert.

Dabei gab es für eine solche Debatte spätestens seit 1959 besonders gute Gründe: Im November des Jahres gab sich die SPD in Bad Godesberg erstmals seit 1925 ein neues Parteiprogramm. Darin definierte sie sich auf neuartige Weise nicht mehr - wie bisher - als sozialistische Milieupartei für die Arbeiterklasse, sondern als Volkspartei, die für ein breites Spektrum von sozialen Gruppen und reformorientierten politischen Überzeugungen offen sein wollte. Vorstellungen von einer selbstverständlichen Interessenidentität zwischen Partei und Gewerkschaft waren damit noch fragwürdiger als zuvor. ${ }^{106}$

Zudem gewann die SPD dank ihrer ideologischen Wende in der Bundesrepublik in den 1960er Jahren zunehmend an innenpolitischer Macht. Ende 1966 übernahm sie als Koalitionspartner von CDU/CSU erstmals Regierungsverantwortung auf Bundesebene; fast zeitgleich bildete sie mit der FDP als kleinerem Partner ein Kabinett in Nordrhein-Westfalen, dem bevölkerungsreichsten und wirtschaftlich stärksten Bundesland; 1969 begann auch in Bonn die bis 1982 währende Epoche der sozialliberalen Koalition, in der die SPD den Kanzler stellte. Partei und ÖTV zogen in dieser Zeit jedoch keineswegs an einem Strang. Der in der Einleitung erwähnte Konflikt in der Tarifrunde von 1973/74 ist nur das bekannteste Beispiel, das zeigt, wie heftig die Gewerkschaft und regierende Sozialdemokraten zuweilen miteinander stritten.

Fragen nach dem Verhältnis zwischen ÖTV und Sozialdemokratie werden in der unten folgenden Untersuchung daher eine große Rolle spielen. Wie entwickelte sich die personelle Verflechtung zwischen Gewerkschaft und Partei in den 1960er und 1970er Jahren? Brachte die durch Doppelmit-

105 | Hirche: Gewerkschafter im Bundestag, S. 649 f.; ders.: Gewerkschafter im 5. Deutschen Bundestag. In: GM 16 (1965), S. 705-712, hier: S. 712.

106 | Vgl. ausführlich etwa: Kurt Klotzbach: Der Weg zur Staatspartei. Programmatik, praktische Politik und Organisation der deutschen Sozialdemokratie 1945-1965, Berlin 1982. 
gliedschaften verwischte Linie zwischen Arbeitgebern und Arbeitnehmern in dieser Zeit Vorteile für die ÖTV mit sich? Oder handelte es sich vielleicht eher um ein Handicap der Gewerkschaft, weil sie Rücksicht auf regierende Genossen nahm oder weil Medien und Öffentlichkeit die ÖTV für eine ungerecht begünstigte Gewerkschaft hielten?

Damit verbindet sich die Frage, wie sowohl innerhalb der Gewerkschaft als auch allgemein in Politik und Öffentlichkeit über den »Auftrag und die soziale Funktion staatlicher Dienstleistungsbetriebe diskutiert wurde. Stellten diese Unternehmen ihre Belegschaften besonders gut, weil sie sich als soziale »Bahnbrecher« verstanden, oder orientierten sich Löhne und Arbeitsbedingungen hier nur an dem, was auch in Privatbetrieben üblich war? Welche Bedeutung hatten die wirtschaftlichen Krisen seit den späten 1960er Jahren sowie die in den 1970er Jahren rasch zunehmenden Haushaltsnöte von Bund, Ländern und Gemeinden für den vielgestaltigen Öffentlichen Dienst, seine Beschäftigten und für die ÖTV als deren Gewerkschaft? Und schließlich: Wie veränderte sich in dieser Zeit das Verhältnis zwischen ÖTV und SPD?

Konkret waren es in dieser Krisenzeit ja vielfach sozialdemokratische Politiker, die Sparmaßnahmen, betriebliche Rationalisierungen und Privatisierungen bislang staatlicher Unternehmen beschlossen. Solche Entscheidungen fielen keineswegs nur auf Bundesebene unter dem zunehmenden Druck der weiter politisch nach rechts rückenden FDP, sondern auch in jenen Bundesländern und Kommunen, in denen die SPD als Regierungspartei keine Rücksicht auf ihren Koalitionspartner nehmen musste. Führte dieser Beginn der sogenannten neoliberalen Wende zu einer Entfremdung zwischen ÖTV und Sozialdemokratie oder war die Verbindung der beiden Organisationen stark genug, um - abgesehen von Einzelkonflikten - weiterhin ein prinzipiell gemeinsames Agieren von Gewerkschaft und Partei zu ermöglichen?

Zahl und Vielfalt der bislang aufgeworfenen Fragen mögen überraschend wirken. Geht es nicht "nur" um die Geschichte einer einzelnen Gewerkschaft in einem recht überschaubaren Zeitraum? Muss man dabei wirklich so viele verschiedene Aspekte berücksichtigen? Mir scheint das geboten zu sein, wenn man versucht, das komplexe soziale Wesen von Gewerkschaften als frei gebildete und selbstorganisierte Interessenvertretungen angemessen differenziert zu erfassen und dabei deutlich zu machen, 
wie stark sie von allgemeinen gesellschaftlichen Entwicklungen und Veränderungen geprägt wurden.

Eine multiperspektivische Herangehensweise ermöglicht es, über eine bloße Organisationsgeschichte hinauszugehen. Letztere wäre hier m.E. fehl am Platze, denn gerade bei der ÖTV liegt die Verbindung zwischen der Gewerkschaftsarbeit und der allgemeinen politischen, wirtschaftlichen und sozialen Geschichte der Bundesrepublik auf der Hand: Wenn der Öffentliche Dienst als Arbeitgeber zur Diskussion stand, ging es ja nicht um eine Auseinandersetzung zwischen der Gewerkschaft und den privaten Gewinninteressen einer kleinen Gruppe von Unternehmern. Vielmehr wurde immer auch über die Interessen der Allgemeinheit verhandelt. Für das Vorhaben, Gewerkschaftsgeschichte in einen breiten Kontext zu stellen und sie als Teil der Gesellschaftsgeschichte zu behandeln, kann die ÖTV daher wohl berechtigt als ein Glücksfall gelten.

\section{Biografische Wendungen: Heinz Klunckers langer Weg in die ÖTV}

\section{Kindheit und Jugend: \\ Vom geborenen Sozialdemokraten zum «einzigen Nazi in der Familie»}

Die Presse empfing den neuen Vorsitzenden mit sehr freundlichen Worten. Als Heinz Kluncker am 1. Juli 1964 auf dem fünften ÖTV-Gewerkschaftstag von den Delegierten mit großer Mehrheit zum Chef der Organisation gewählt wurde, durfte er sich über rundum positive Medienkommentare freuen: Vielfach war vom Beginn einer neuen Ära nicht nur für die ÖTV, sondern für die deutsche Gewerkschaftsbewegung insgesamt die Rede. Die $F A Z$ etwa meinte, mit Kluncker übernehme »die junge Gewerkschaftsgeneration« erstmals Führungsverantwortung; die Frankfurter Rundschau präsentierte ihn als »Prototyp des neuen Gewerkschaftsführers«, der - anders als »die alten Haudegen «, die in den neu gegründeten Berufsverbänden seit 1945 das Wort geführt hatten - »auf die Zukunft« schaue und »die trüben Erfahrungen der Vergangenheit« hinter sich lasse. Wie Klunckers Wahl zeige, sei die Zeit der von den politischen Spannungen des frühen 20. Jahrhunderts geprägten »Volkstribunen und Massenagitatoren« in den Gewerkschaften vorbei; auch hier brauche man mit Blick auf die Anforderungen 
der »Gegenwartsarbeit« nun »Persönlichkeiten mit Manager-Befähigung«. Für den Spiegel schließlich war Kluncker »der nüchterne Jung-Manager«, der »Konzilianz und Sachlichkeit« an die Stelle von ideologischer Emphase setze. ${ }^{107}$

Diese Wertungen hatten einerseits viel für sich. Selbst nach den Maßstäben unserer Zeit war Heinz Kluncker im Sommer 1964 mit seinen damals 39 Jahren als Vorsitzender einer großen Gewerkschaft ungewöhnlich jung. Zudem gehörte er zu der zwischen den beiden Weltkriegen geborenen Generation, und damit unterschied er sich deutlich von all den Männern, die das Gewerkschaftswesen in der Bundesrepublik nach dem Ende der NSDiktatur in Führungspositionen wieder aufgebaut hatten: Mehrheitlich handelte es sich bei diesen um ehemalige Aktivisten aus den Jahren der Weimarer Republik, die von den Nationalsozialisten kaltgestellt oder sogar verfolgt worden waren.

Klunckers Vorgänger als ÖTV-Vorsitzender repräsentierte diese Gruppe auf fast mustergültige Weise: Der 1895 geborene Adolph Kummernuss, ein ehemaliger Hamburger Hafenarbeiter, der 1964 wegen seines Alters abtrat, hatte schon von 1927 bis 1933 in einer der Vorläuferorganisationen der ÖTV als Funktionär gearbeitet; in der NS-Zeit wurde er als Mitglied einer Widerstandsgruppe, die Kontakte zu der internationalen Transportarbeitergewerkschaft ITF unterhielt, wegen »Hochverrats« für zwei Jahre ins Gefängnis geworfen. Die ÖTV hatte er seit 1949 geleitet und geprägt. ${ }^{108}$ Da lag es nahe, in der Wahl Klunckers einen Neubeginn zu sehen.

Andererseits aber überrascht aus heutiger Sicht doch, wie entschlossen die Zeitgenossen die Meinung vertraten, ein Mann wie Kluncker habe mit den Lasten der damals noch sehr nahen Jahre vor 1945 nichts zu tun. Hier war ganz offensichtlich der Wunsch der Vater des Gedankens. Zwar lief in Frankfurt am Main seit dem Dezember 1963 der Auschwitz-Prozess, der

107 | In der Reihenfolge der Zitate: Kluncker Nachfolger von Kummernuss. In: FAZ, 2.7.1964; Der neue Mann. In: FR, 2.7.1964; New Look in gleichen Jacken. In: Der Spiegel 18 (1964), H. 28, S. 34-36, hier: S. 35 f. Ähnlich vgl. ebenfalls noch: Chef der ÖTV Heinz Kluncker. In: Welt am Sonntag, 5.7.1964.

108 | Vgl. etwa den biografischen Abriss in: Zimmermann: ÖTV, S. 128-132, sowie kürzer auch: Streitbar und Marxist. In: Handelsblatt, 9.8.1979. Zu seiner NSHaft vgl. etwa: Willy Buschak: Edo Fimmen. Der schöne Schein von Europa und die Globalisierung. Eine Biografie, Essen 2002, S. 205. 
die bundesdeutsche Auseinandersetzung mit der NS-Vergangenheit langfristig grundlegend verändern sollte. Dennoch dominierte in den öffentlichen Debatten seinerzeit immer noch die Hoffnung, man könne einfach einen »Schlussstrich « unter die Katastrophen und Verbrechen der jüngsten deutschen Vergangenheit ziehen. ${ }^{109}$

Indem von Heinz Kluncker das Bild des nüchternen Jung-Managers, der in die Zukunft schaue, gezeichnet wurde, ersparte man sich die Frage, ob die Fronten und Brüche in der deutschen Geschichte zwischen 1918 und 1945 nicht auch noch für Klunckers Lebensweg entscheidend wichtig waren. Doch die folgenden Ausführungen werden zeigen, dass »die trüben Erfahrungen der Vergangenheit«, die für den neuen ÖTV-Vorsitzenden nach dem Urteil der Frankfurter Rundschau keine Bedeutung mehr besaBen, seine Biografie ganz im Gegenteil gravierend geprägt haben. Heinz Kluncker wäre vermutlich nicht der Gewerkschaftsführer geworden, der er in den Jahren 1964 bis 1982 war, wenn die allgemeine deutsche Geschichte sein Leben nicht zuvor wiederholt radikal aus der Bahn geworfen hätte. Dadurch entstand ein sein Leben prägendes biografisches Schlingern: Obwohl seine Herkunft ihn eigentlich zum Gewerkschafter geradezu prädestiniert hatte, brachten ihn die politischen Veränderungen ab 1933 erst einmal auf einen ganz anderen Pfad. Anschließend waren dann gleich mehrere plötzliche Wendungen erforderlich, um Kluncker erneut in die Arbeiterbewegung und speziell in die ÖTV zu bringen. Aus Platzgründen beschränke ich mich im Folgenden auf die entscheidenden Weichenstellungen, die Klunckers wechselhaftes Leben bestimmten und letztlich seine ÖTV-Karriere möglich machten.

Seine ersten Lebensjahre verbrachte der am 20. Februar 1925 geborene Heinz Kluncker in einem homogenen sozialdemokratischen Milieu. Er wuchs in Wuppertal auf, einer stark von Arbeitern geprägten Industriestadt. Sein Vater gehörte als Schlosser und Dreher nicht einfach nur zum Proletariat, sondern auch zu den berufsstolzen Facharbeitern, die in der Arbeiterbewegung eine dominante Rolle spielten: Friedrich Kluncker war

109 | Vgl. etwa: Detlef Siegfried: Zwischen Aufarbeitung und Schlußstrich. Der Umgang mit der NS-Vergangenheit in den beiden deutschen Staaten 1958 bis 1969. In: Axel Schildt/Detlef Siegfried/Karl Christian Lammers (Hrsg.): Dynamische Zeiten. Die 60er Jahre in den beiden deutschen Gesellschaften, Hamburg 2000, S. 77-113. 
ein überzeugter Sozialist, der als junger Soldat 1918 aktiv an der Novemberrevolution teilgenommen hatte. Er und seine ebenfalls aus Wuppertal stammende Frau Anna scheinen sogar Sozialdemokraten besonders fester Überzeugung gewesen zu sein.

Zwei Indizien sprechen für diese Vermutung: Ihr 1925 geborener Stammhalter (der das einzige Kind blieb) wurde nicht getauft, weil auch Eltern und Großeltern konfessionslos waren. Zudem ging das Kind mit Beginn der Schulpflicht nicht auf eine der normalen staatlichen Volksschulen, sondern in eine "Freie Schule«, die von einem Verein getragen wurde und den Schulalltag strikt religionsfrei hielt. Beide Entscheidungen waren nach den sozialen Standards der Zeit höchst ungewöhnlich und selbst für SPD-Wähler und aktive Gewerkschaftsmitglieder keineswegs typisch. Die Familie Kluncker gehörte damit zum engeren Kern der sozialdemokratischen Sphäre, die während der 1920er Jahre in vieler Hinsicht noch so etwas wie eine fast autarke »Gegengesellschaft« zur bürgerlichen Lebenswelt darstellte. ${ }^{110}$

Zudem schickten Friedrich und Anna Kluncker ihren Sohn im Alter von sechs Jahren auch noch zu den »Kinderfreunden«, einer Organisation, die sich dezidiert als sozialistischer Jugendverband definierte. Bei den Aktivitäten, die hier angeboten wurden (Wandern, Basteln, Gruppenspiele, Vorlesen), sollten die teilnehmenden Kinder lernen, »sich einzufügen, einzuordnen, mitzuhelfen, mitzuraten und mitzuverwalten«. Dieser starke Bezug auf die Gruppe und ihr »Wohl und Gedeihen« galt als Vorbereitung

110 | Vgl. allgemein: Peter Lösche/Franz Walter: Zur Organisationskultur der sozialdemokratischen Arbeiterbewegung in der Weimarer Republik. Niedergang der Klassenkultur oder solidargemeinschaftlicher Höhepunkt? In: GG 15 (1989), S. 511-536, hier: S. 534f.; speziell für Wuppertal vgl. den Überblick in: David Magnus Mintert: Distanz zum Unrecht durch Bindungen an das sozialistische Milieu und die Tradition der Sozialdemokratie am Beispiel Wuppertals. In: Rolf-Ulrich Kunze (Hrsg.): Distanz zum Unrecht 1933-1945. Methoden und Probleme der deutschen Widerstandsforschung, Konstanz 2006, S. 127-158, hier: S. 129-132. Wuppertal war eine der Hochburgen der »Freien Schulen«: Hier gab es zwölf solcher Einrichtungen, die von bis zu 16 Prozent eines Schülerjahrgangs besucht wurden. In ganz Preußen lag dieser Anteil unter einem Prozent (ebd., S. 132). Die Angaben zu Klunckers Biografie hier - wie auch im Folgenden - stets nach: Hemmer/Simon: Wirkung, insbesondere S. 24-98. Nur Zitate aus diesen autobiografischen Interviews sowie andere Quellen werden einzeln nachgewiesen. 
»für die Mitarbeit an der Gestaltung des gesellschaftlichen Lebens in der Richtung sozialistischer Aufbauarbeit «. ${ }^{111}$

Trotz solch intensiver weltanschaulicher Erziehung geriet der junge Heinz in den Jahren nach 1933 unter den Einfluss der NSDAP, deren Propaganda ja selbst auf Kinder und Jugendliche zielte und gerade sie vielfach besonders stark beeindruckte. Nach der Schließung der Wuppertaler "Freien Schule« im Jahr 1935 rückte der Zehnjährige, der sich in seiner neuen staatlichen Schule sofort als Außenseiter abgestempelt und ausgegrenzt sah, immer weiter von den Eltern und deren Überzeugungen ab, bis er schließlich nach seinen eigenen retrospektiven Worten als »einziger Nazi in der Familie « lebte. ${ }^{112}$

Diese opportunistische Einordnung in die Diktatur beschäftigte Heinz Kluncker während seines gesamten späteren Lebens. Anders als viele andere Deutsche seiner Altersgruppe betrachtete Kluncker seine politische Konversion nie als lässliche Jugendsünde. Vielmehr war die Erinnerung an die Zeit nach 1933 für ihn auch noch Jahrzehnte später »ein Vorwurf«, der sich gegen ihn selbst richtete. Im Rückblick erschrak er über seine Verführbarkeit: »daran leide ich heute noch, da habe ich heute noch Komplexe«. ${ }^{113}$ Einmal sprach Kluncker sogar von einem »Trauma, das mich jahrelang gequält hat «. ${ }^{114}$

111 | Wohlfahrtspflege und Gesundheitsfürsorge in Barmen. Hrsg. v. Städtischen Wohlfahrts- und Jugendamt Barmen, Düsseldorf 1929, S. 104. Die Organisation unterschied drei Altersgruppen: die "Küken« im Alter von sechs bis zehn Jahren, die »Jungfalken« (10-12 Jahre) und die »Roten Falken« (12-14 Jahre). In der Gruppe der Jüngsten überwogen spielerische Angebote; der weltanschauliche Charakter trat dann bei den Falken stärker hervor. Sie trugen auch eine Art Uniform und hatten sich an die »Falken-Gebote« zu halten. In diesem Gelöbnis ging es u. a. um Stolz auf die eigene Herkunft (»Wir sind Arbeiterkinder. Wir sind stolz darauf.«), um Hilfsbereitschaft, Ordentlichkeit sowie um Abstinenz bei Alkohol und Tabak (vgl. ebd., S. 105).

112 | Michael Berger: Zu Gast in Hannover: Der Dicke von der ÖTV. In: Hannoversche Allgemeine Zeitung, 13.10.1990.

113 | Hemmer/Simon: Wirkung, S. 41. Vgl. ähnlich auch: Michael Berger: Zu Gast in Hannover: Der Dicke von der ÖTV. In: Hannoversche Allgemeine Zeitung, 13.10.1990.

$114 \mid » \ldots$ und ich habe große Freude an alten Schrauben«. In: Kölner Stadt-Anzeiger, 10./11.1.1981. 
Umkehr, Neuanfang und biografische Umwege: Die Jahre 1944 bis 1952

Diese Selbstzweifel wurden bei Heinz Kluncker auch nicht dadurch gemildert, dass er seine Begeisterung für die NSDAP und Adolf Hitler nach langen Diskussionen mit seinem politisch stets antifaschistisch eingestellten Vater noch in der NS-Zeit auf dramatische Weise dementiert und damit gewissermaßen »zurückgenommen« hatte: Im Sommer 1944, als 19-jähriger Frontsoldat, desertierte er kurz nach dem Beginn der britisch-amerikanischen Invasion in der Normandie. Auf diese Befehlsverweigerung, die in mehrfacher Hinsicht große Gefahren für Leib und Leben mit sich brachte, war Kluncker nicht sonderlich stolz. Dies galt auch dann noch, als die Deutschen lange nach dem Krieg zögerlich begannen, ihre zuvor stark ablehnende Haltung gegenüber den Deserteuren des Zweiten Weltkriegs zu modifizieren. Nüchtern sah Heinz Kluncker in seiner Fahnenflucht eine schwache individuelle Geste, die zwar ihn selbst aus der Rolle befreite, den Krieg und die Diktatur »durch aktives Eintreten [...] noch zu verlängern«, die ansonsten aber kaum etwas bewirkte. ${ }^{115}$

Als "Überläufer«, der sich dem Feind kampflos ergeben hatte, war Kluncker nach dem Sommer 1944 erneut - diesmal aber durch eine eigene Entscheidung - ein isolierter Außenseiter. Am eigenen Leib erfuhr er erst in britischer, dann in amerikanischer Gefangenschaft, dass die übergroße Mehrheit der Deutschen "prisoners of war«-Deserteure entweder für Verräter oder - fast noch ehrenrühriger - für Feiglinge hielt. Er erlebte Anfeindungen und auch körperliche Angriffe von seinen eigenen Landsleuten. Wohl auch deshalb öffnete sich der junge Mann bereitwillig für die Angebote der US-amerikanischen "re-education", die den Deutschen die Grundprinzipien einer freien Gesellschaft vermitteln sollten. Da er zudem rasch recht gut Englisch sprach, machte Kluncker bis zu seiner Entlassung im Februar 1946 in den USA eine Art »Karriere«, die für einen deutschen Kriegsgefangenen recht ungewöhnlich war: Er besuchte verschiedene Fort-

115 | Ebd. Zu den Gefahren, denen sich ergebende deutsche Soldaten gerade in den ersten Tagen nach der Invasion ausgesetzt waren, vgl. etwa: Peter Lieb: Unternehmen Overlord. Die Invasion in der Normandie und die Befreiung Westeuropas, München 2014, S. 135-144. Erschießungen durch alliierte Soldaten waren offensichtlich durchaus häufig. Die Wehrmacht bestrafte ertappte Deserteure unnachgiebig mit dem Tod. 
bildungskurse, bediente amerikanische Offiziere in ihrem Club und durfte sich schließlich fast völlig frei bewegen.

Nach Kriegsende öffnete sich für ihn sogar eine Möglichkeit, das zerstörte Deutschland und die traumatisierte deutsche Gesellschaft mit all ihren dramatischen Problemen ganz einfach und ein für alle Mal hinter sich zu lassen. Ende 1945 war Heinz Kluncker mit einer Amerikanerin verlobt, deren Vater ein Hotel in Tampa am Golf von Mexiko im sonnigen Florida besaß. An diesem Punkt intervenierten per Brief jedoch offensichtlich sowohl sein Vater als auch andere Verwandte: "Seine Familie hat ihn in die Pflicht genommen« - so formuliert es Elke Stierle, die seit den späten 1980er Jahren seine Lebensgefährtin war, in Erinnerung an ihre Gespräche mit Heinz Kluncker. ${ }^{116}$

Näheres wissen wir nicht, und auch Klunckers Stimmung in dieser Zeit ist uns unbekannt. Nur das Resultat steht fest: Im Frühjahr 1946 kehrte er, der sich eben noch berechtigter Weise als hoffnungsvoller Hotelier im amerikanischen »sunshine state" gesehen hatte, in das vom Krieg schwer verwüstete, hungernde und frierende Deutschland zurück. Da in den deutschen Städten kaum etwas so knapp war wie Wohnraum, lebte Kluncker mit seinen nunmehr 21 Jahren zunächst wieder in der Wohnung der Eltern in Wuppertal-Barmen. Seine Mutter aber sah er nicht wieder: Sie hatte sich 1944, wohl kurz vor Klunckers Desertion, das Leben genommen. Schon als junge Frau hatte sie unter starken Stimmungsschwankungen und Depressionen gelitten. Im Krieg verschlimmerte sich dieses Leiden dann wohl auf gravierende Weise - vielleicht auch, weil sie wegen freundlicher Gesten gegenüber »Fremdarbeiterinnen« vorübergehend in Gestapo-Haft geriet und dort schwer misshandelt wurde. Der Sohn erfuhr erst jetzt von ihrem Tod. Die Rückkehr des jungen Mannes kann man sich unter diesen Umständen nur als äußerst belastend vorstellen.

Es folgte eine lange Suche nach einer Stellung, sowohl im wörtlichen Sinne im Beruf wie auch ganz allgemein im Leben, die letztlich erst 1952 endete, als Heinz Kluncker der Einstieg bei der Hauptverwaltung der ÖTV in Stuttgart gelang. Auf den entlassenen Kriegsgefangenen hatte in der Heimat niemand gewartet und Chancen eröffneten sich ihm, trotz exzellenter amerikanischer Referenzen, nicht einfach von selbst. Zwar hatte Kluncker in den Jahren 1939 bis 1942, vor seiner Zeit als Soldat der

116 | Interview Elke Stierle, 17.12.2013. 
deutschen Wehrmacht, erfolgreich eine dreijährige kaufmännische Lehre im Textilgroßhandel absolviert und anschließend auch einige Monate in dieser Branche gearbeitet. Die Stoffindustrie und damit auch der Textilhandel aber lagen im verarmten und zunächst vollständig vom Welthandel abgetrennten Nachkriegsdeutschland komplett danieder. Der Weg in den erlernten Beruf (den sich Kluncker ohnehin nicht selbst ausgesucht hatte) war daher verbaut.

Einige Monate lang versuchte sich der junge Mann in Wuppertal als Polizist. Die von den Siegermächten durchgesetzte Entnazifizierung der deutschen Behörden und Ämter machte diesen überraschenden Berufswechsel möglich. Schon im Dezember 1946 aber bat Kluncker um seine Entlassung. Hier passten Amt und Person offensichtlich überhaupt nicht zusammen. Erneut wissen wir nichts Genaues. Wenn Heinz Kluncker später spöttisch meinte, er wisse aus eigener Erfahrung, wie rasch bei Polizisten »kleinkariertes Denken« entstehen könne und wie oft bei der Ordnungsmacht "mangelnde Substanz durch einen Tschako ersetzt« werde, darf man diese Worte aber wohl als versteckte Erklärung für seine Flucht aus dem Staatsdienst deuten. ${ }^{117}$

Das sozialdemokratische Milieu Wuppertals, zu dem Klunckers Eltern und auch schon seine Großeltern vor 1933 gehört hatten, erwies sich in dieser persönlichen Krise als hilfreich: Der SPD-Kreisverband Wuppertal engagierte den jungen Mann als »Sekretär«, d.h. als Zuarbeiter für den Vorstand und alle sonst noch anfallenden politischen und organisatorischen Aufgaben. Dabei war wohl von vornherein klar, dass es sich um eine befristete Arbeit handeln würde, weil die Partei in dieser Zeit extremer Not aus sozialen Gründen zahlreiche junge Männer einstellte, die sie nur dadurch bezahlen konnte, weil die weitgehend wertlos gewordene Reichsmark vor der allgemein erwarteten Währungsreform noch sehr reichlich zur Verfügung stand. Parteimitglied war Kluncker offensichtlich schon seit dem Frühjahr 1946.

Kluncker diente der SPD bis zum Oktober 1949. Trotz magerer Bezahlung, der zeitweise katastrophal schlechten Ernährungslage und einer

117 | Referat von Heinz Kluncker »Das Zukunftsbild der ÖTV« für die Arbeitstagung des ÖTV-Bezirks Bayern, 10./12.2.1966. In: AdsD, Depositum Kluncker, Reden und Referate November 1964-September 1969. »Tschako« bezeichnet einen damals noch weit verbreiteten Polizeihelm. 
fehlenden Wohnung heiratete er in dieser Zeit: Seine Braut, die zwei Jahre jüngere Ilse Remy, stammte ebenfalls aus Barmen; auch sie gehörte zu den überzeugten Sozialdemokraten. ${ }^{118}$ Als SPD-Funktionär war der frisch gebackene Ehemann vor allem für die sozialdemokratische Jugendarbeit zuständig. So betreute er etwa die regionalen Gruppen der »Falken«, jener Organisation, der er selbst als Kind vor 1933 kurzfristig angehört hatte und mittels derer die SPD Kinder und Jugendliche nun erneut im sozialistischen Sinne zu erziehen versuchte.

Wie alle Verantwortlichen dieser »Sozialistischen Jugend Deutschlands« wird er versucht haben, die Rezepte der sozialdemokratischen Jugendarbeit aus den Jahren der Weimarer Republik wieder aufzugreifen, die stark auf eine proletarische Gruppenidentität und jugendlichen Idealismus setzten. Zugleich mag auch er erlebt haben, dass viele Heranwachsende in der moralisch tief verstörten deutschen Nachkriegsgesellschaft von den tradierten Werten und Formeln aus den Jahren vor 1933 nichts mehr wissen wollten. ${ }^{119}$

Allerdings sind das nur Vermutungen, die sich aus der allgemeinen Geschichte der Organisation ableiten. Ob Kluncker nach seinen amerikanischen Erfahrungen die Jugendarbeit nicht vielleicht doch anders verstand, wissen wir nicht. Seine knappe rückblickende Bemerkung, er sei dafür »berüchtigt« gewesen, freimütige Diskussionen zuzulassen, zeigt die engen Grenzen, die den Jugendgruppen auch im sozialdemokratischen Milieu seinerzeit gezogen wurden. ${ }^{120}$ Persönlich war Kluncker zudem in den USA zum Freund der Jazz-Musik geworden. Den meisten Deutschen aber galt Jazz - keineswegs nur wegen der rassistischen Hetze der Nazis - als abscheuliche »Negermusik«. Gerade auch im gewerkschaftlichen Milieu wehrte man sich ohnehin grundsätzlich voller Eifer gegen die amerikanische Unterhaltungskultur, der pauschal jeder künstlerische Wert abgesprochen wurde. ${ }^{121}$

118 | Interview Hajo Graf Vitzthum, 14.6.2014.

119 | Vgl. dazu allgemein: Bodo Brücher: Die sozialistische Jugendbewegung Deutschlands. Politisch-pädagogisches Konzept und Realität sozialistischer Jugend- und Erziehungsarbeit in den Nachkriegsjahren, Werther 1995; Rolf Schörken: Die Niederlage als Generationserfahrung. Jugendliche nach dem Zusammenbruch der NS-Herrschaft, Weinheim und München 2004.

120 | Hemmer/Simon: Wirkung, S. 91.

121 | Vgl. etwa: Uta G. Poiger: Jazz, Rock and Rebels. Cold War Politics and American Culture in a Divided Germany, Berkeley 2000. 
Wenn Heinz Kluncker in dieser Hinsicht eigene Wege ging, dann hat sein Arbeitgeber das zumindest geduldet, weil er mit der politischen Arbeit des jungen Mannes sehr zufrieden war. Zum Abschied Ende Oktober 1949 stellte der Vorstand des Kreisverbandes Kluncker ein sehr positives Zeugnis aus: Besonders seine "gedankliche Klarheit« und seine "geistigen Fähigkeiten « wurden gelobt. Er sei ein guter Versammlungsredner und habe zahlreiche Vorträge über wissenschaftliche und kulturelle Probleme gehalten, die »nach übereinstimmenden Zeugnissen sehr gut ansprachen «. ${ }^{122}$

Der talentierte junge Mann hatte offensichtlich Eindruck gemacht und so bot ihm die sozialdemokratische Arbeiterbewegung eine Chance zur Weiterbildung an der »Akademie für Gemeinwirtschaft« in Hamburg. Diese erst 1948 gegründete Institution der Erwachsenenbildung war mit ihrer Hoffnung auf einen gesellschaftlichen Neuanfang und eine grundlegende Reform der wirtschaftlichen Machtstrukturen ein typisches Kind der ersten Nachkriegszeit. Bekanntlich forderte damals ja selbst die CDU in ihrem Ahlener Programm, Bergbau und Stahlindustrie müssten sozialisiert werden. Die Hamburger Akademie bekannte sich programmatisch ebenfalls zur "Notwendigkeit eines ökonomischen und sozialen Neuaufbaus". Um diesen möglich zu machen, brauche man vor allem neuen Führungsnachwuchs auch aus Kreisen ohne höhere Schulbildung und Abitur. ${ }^{123}$

Die Gewerkschaften und verschiedene Genossenschaftsverbände hatten das Konzept der Schule entwickelt; das Geld, um die Idee Realität werden zu lassen, kam vor allem vom Hamburger Senat, der von der SPD geführt wurde. Vergleichbare Einrichtungen, die Erwachsene ausbildeten, gab es als Teil der sozialdemokratischen "Gegengesellschaft « zwar bereits in der Weimarer Republik. Mit der Hamburger Akademie aber entstand in Deutschland erstmals ein staatlich anerkannter und finanzierter zweiter Bildungsweg. ${ }^{124}$

Den Universitäten sollte die Akademie allerdings keine Konkurrenz machen. Trotz ihres wohlklingenden Namens verfolgte sie ein weitaus beschei-

122 | Hemmer/Simon: Wirkung, S. 83.

123 | Studienführer der Akademie für Gemeinwirtschaft Wintersemester 1948/49 und Sommersemester 1949, Hamburg o. J., S. 1.

124 | Grundlegend zur Geschichte der Einrichtung vgl.: Bärbel von Borries-Pusback: Keine Hochschule für den Sozialismus. Die Gründung der Akademie für Gemeinwirtschaft in Hamburg 1945-1955, Opladen 2002. 
deneres Bildungsziel als die traditionellen Hochschulen: Ihre Absolventen, so versprach sie, würden »den Abiturienten bei der Bewerbung für den gehobenen Dienst in der allgemeinen Verwaltung gleichgestellt « sein. ${ }^{125}$ Das Abschlusszeugnis öffnete also weder den Weg zu einem normalen Studium noch in den höheren Öffentlichen Dienst, d.h. dorthin, wo wirklich Führungsnachwuchs ausgebildet wurde.

Die Arbeitsanforderungen waren dennoch hoch. Von der akademischen Freiheit der Studenten, die seinerzeit im Studium weitgehend nach eigenem Ermessen über ihren Lehr- und Stundenplan entscheiden durften, konnten die »Lehrgangsteilnehmer" an der Hamburger Akademie nur träumen. Sie absolvierten den Unterricht im Klassenverband; ein für alle verbindlicher Stundenplan, der 32 Stunden Pflichtvorlesungen pro Woche vorsah, ließ kaum Luft für andere Aktivitäten. Unterrichtet wurden lediglich Volks- und Betriebswirtschaftslehre, Soziologie und Jura; zeitlich dominierten eindeutig die beiden ökonomischen Disziplinen. Allerdings durften die Teilnehmer (wenn sie denn die Kraft dazu aufbrachten) weitere frei gewählte Vorlesungen an der Universität Hamburg besuchen. ${ }^{126}$

Heinz Kluncker kam somit an eine »eiserne Schule«, als der DGB-Bundesvorstand ihn zum Wintersemester 1949/50 an die Hamburger Akademie »entsandte«. Diese noble Formulierung meinte die Tatsache, dass Kluncker ein Stipendium erhielt: Der DGB zahlte für ihn die durchaus nicht unerheblichen Studiengebühren; zudem erhielt der junge Mann sieben Monate lang weitere Gelder für seinen Lebensunterhalt. ${ }^{127}$ Nach Ablauf dieser

125 | Karl-Hermann Capelle: Wissenswertes von der Akademie und den ehemaligen Studenten 1951/52. In: Mitteilungen der Akademie für Gemeinwirtschaft in Hamburg, H. 1 (März 1952), S. 15-24, hier: S. 24.

126 | Wie wichtig die Ökonomie an der Akademie genommen wurde, zeigt sich schon daran, dass nur zugelassen wurde, wer Eingangsklausuren in »Doppelter Buchrechnung und in Wirtschaftsrechnen « bestanden hatte (Studienführer, S. 13). Als ausgebildeter Handelskaufmann dürfte Heinz Kluncker damit keine Probleme gehabt haben.

127 | DGB-Bundesvorstand an Heinz Kluncker, 26.10.1949. In: AdsD, Depositum Kluncker, Stehordner 78. Das Zitat von der »eisernen Schule« aus: Walter Meis: Einige Betrachtungen über die Leistungen der Absolventen der Akademie für Gemeinwirtschaft. In: Mitteilungen der Akademie für Gemeinwirtschaft in Hamburg, H. 2 (Dezember 1952), S. 27-33, hier: S. 31. Die Studiengebühr betrug 100 DM pro Semester; hinzu kamen 20 DM Semesterbeitrag (Studienführer, S. 14). 
Frist musste Kluncker Ausbildung und Broterwerb unter einen Hut bringen, denn ein »Lehrgang« an der Akademie dauerte jeweils vier Semester. Der klassische Hamburger Studentenjob, einzelne Schichten bei Entladearbeiten im Hafen zu übernehmen, half Kluncker aus dieser Not. Später fand er dann offensichtlich eine weniger anstrengende Aushilfsstelle im Hamburger Arbeitsamt.

Die »Entsendung« durch den DGB belegt noch einmal, wie erfolgreich sich Heinz Kluncker in den Jahren nach 1946 wieder in das sozialdemokratische Milieu integriert hatte. Sie zeigt zudem, wie eng die Verbindung zwischen SPD und Gewerkschaften seinerzeit war, denn Kluncker hatte soweit wir wissen - vor dem Herbst 1949 noch nie etwas mit dem DGBBundesvorstand zu tun gehabt und auch keine persönlichen Beziehungen in dessen »Lehrplanausschuss«, der Kluncker für die Weiterbildung auf Gewerkschaftskosten vorschlug. Empfehlungen in einem eng geknüpften Netzwerk von politischen Freunden scheinen dieses Manko aber problemlos überwunden zu haben.

Allerdings gehörte Kluncker unter den Stipendiaten der Akademie zu einer kleinen Minderheit, denn ansonsten handelte es sich bei den »Delegierten« (wie sie auch genannt wurden) fast ausnahmslos um Funktionäre einzelner Gewerkschaften. ${ }^{128}$ Heinz Kluncker war zwar seit 1946 Mitglied der ÖTV. Für einen sozialdemokratischen Polizisten kam selbstverständlich keine andere Gewerkschaft in Frage, nachdem sich die Besatzungsmächte widerwillig damit abgefunden hatten, auch Polizisten die Koalitionsfreiheit zuzugestehen. Eine aktive Rolle scheint er in der Organisation aber nicht gespielt zu haben - was angesichts seiner sehr kurzen Dienstzeit nicht überrascht.

Mit Blick auf die Zukunft bedeutete Klunckers schwache gewerkschaftliche Anbindung durchaus ein Problem: Während die anderen »entsandten« Schüler der Hamburger Akademie berechtigt darauf hoffen konnten, nach dem Abschluss wieder bei »ihrer« Organisation einsteigen zu können, fehlte es in seinem Fall an einer klaren Perspektive. Im Laufe des Lehrgangs entwickelte er deshalb einen eigenen Plan. In langer Sicht sah er sich selbst als Mitarbeiter des Arbeitsdirektors in einem Betrieb der bundesdeutschen

128 | Meis: Betrachtungen, S. 33. Die Stipendiaten stellten in den ersten Jahren der Akademie deutlich mehr als die Hälfte der jeweiligen Lehrgangsteilnehmer. Die anderen Schüler bezahlten ihre Ausbildung selbst. 
Stahl- und Eisenindustrie, d.h. als Unterstützung für das Vorstandsmitglied, das in der Unternehmensführung für die Personalplanung und die innerbetrieblichen Arbeitsbedingungen zuständig war. In der Schwerindustrie musste diese Position stets mit einem Gewerkschafter besetzt werden. Damit waren die Arbeitsdirektoren ein wichtiges Element in der Montanmitbestimmung, die nach 1945 auch unter dem Druck der Alliierten entstand, weil gerade diese Industrie als reaktionäre politische Kraft und als Hort des preußisch-deutschen Militarismus galt. Die ganz neuartige und weitreichende gewerkschaftliche Mitsprache in den Betrieben der Montanbranche sollte diesen unguten Traditionen ein Ende machen. ${ }^{129}$

Wahrscheinlich war Heinz Kluncker noch in anderer Hinsicht eine Ausnahme unter seinen Kommilitonen: Die jungen Männer um ihn herum (Frauen gab es an der Akademie nur in verschwindend geringer Zahl) hatten wohl alle der Wehrmacht treu und brav bis zur Kapitulation des »Dritten Reiches« gedient. Einige hatten sich militärische Ehren erworben. Auch im Lehrkörper dominierten Männer, die in der kriegführenden NSDiktatur einwandfrei funktioniert hatten. Heinz Oskar Vetter etwa (der spätere DGB-Vorsitzende), der ein Jahr vor Kluncker als Stipendiat an die Akademie gekommen war, zählte ebenso zu den hoch dekorierten Frontsoldaten wie Helmut Schelsky, der Dozent für Soziologie. ${ }^{130}$ Rechtswissenschaft unterrichtete ein Jurist, der in der NS-Zeit bis zum Richter am Oberlandesgericht Hamburg aufgestiegen war. Auch Schelsky blickte auf eine erfolgreiche Lehrtätigkeit an den nationalsozialistisch gleichgeschalteten Universitäten zurück. ${ }^{131}$

129 | Vgl. dazu etwa: Mark Roseman: Recasting the Ruhr, 1945-1958. Manpower, Economic Recovery and Labour Relations, New York 1992; Gloria Müller: Strukturwandel und Arbeitnehmerrechte. Die wirtschaftliche Mitbestimmung in der Eisen- und Stahlindustrie 1945-1975, Essen 1991. Anschauliches Material zur konfliktträchtigen Rolle der Arbeitsdirektoren vgl. etwa in: Alfred Horné: Der beklagte Sieg. Gespräche über die Mitbestimmung, Villingen 1959, S. 59-95. 130 | Vgl. etwa: Gerhard Schäfer: Soziologie zwischen Faschismus und Restauration. In: Rainer Waßner (Hrsg.): Wege zum Sozialen. 90 Jahre Soziologie in Hamburg, Opladen 1988, S. 147-168, hier: S. 158.

131 | Vgl. die genauen Angaben in: Studienführer, S. 8-11. Lediglich Walter Pohl, Dozent für Sozialpolitik, hatte die NS-Zeit im Exil verbracht. Vor 1933 hatte er für den sozialdemokratischen ADGB gearbeitet (ebd., S. 12). 
Wir wissen nicht, wie sich der Deserteur Heinz Kluncker in der Gesellschaft dieser Männer gefühlt hat und wie er mit ihnen umging. Mit Heinz Oskar Vetter verband ihn später in seiner Zeit als ÖTV-Vorsitzender eine tiefe, auf Gegenseitigkeit beruhende Abneigung - aber das mag auch ausschließlich persönliche Gründe gehabt haben. ${ }^{132}$ Der Zeitdruck des Lehrplans sowie die gemeinschaftliche gewerkschaftliche und sozialdemokratische Orientierung der Studierenden könnten zudem Erinnerungen an die Vergangenheit verdeckt haben: Als Genosse verhielt man sich selbstverständlich solidarisch gegenüber anderen Genossen.

Heinz Kluncker blieb in Hamburg - wie auch die anderen Stipendiaten - jedenfalls trotz seiner doppelten Belastung durch den Unterricht und die Nebenjobs politisch aktiv. Erneut engagierte er sich in der Jugendarbeit, sowohl bei der Hamburger SPD als auch bei der ÖTV. Diese Funktion brachte ihn in Kontakt mit jüngeren hanseatischen Sozialdemokraten wie Karl Schiller und Helmut Schmidt. Beide hatten bekanntlich noch eine lange politische Karriere vor sich; insbesondere Schmidt stritt sich als politischer Amtsinhaber später heftig mit der ÖTV und mit Heinz Kluncker.

Das aber war Zukunftsmusik und in keiner Weise vorgezeichnet, denn der junge Genosse aus Wuppertal interessierte sich damals eher für Erziehungsfragen und für Psychologie als für den Öffentlichen Dienst und sein Tarifrecht: Als Gasthörer an der Hamburger Universität informierte sich Heinz Kluncker intensiv über »Sozialpsychologie und Psychologie des Jugendalters «. ${ }^{133}$ Seine eigene Biografie spielte dabei sicher eine wichtige Rolle, boten ihm diese Veranstaltungen doch Stoff und Wissen, um einmal mehr über seine kindliche Verführbarkeit und Verblendung nachzudenken.

Bei dieser Schwerpunktsetzung blieb Heinz Kluncker, als er daran ging, die einzige umfangreichere Hausarbeit zu schreiben, die von den Lehrgangsteilnehmer der Akademie verlangt wurde: In der vorlesungsfreien Zeit zwischen ihrem zweiten und dritten Semester mussten sie sich schriftlich mit einem selbstgestellten soziologischen Thema beschäftigen, um zu zeigen, dass sie die "Anleitung zur Konkretheit« beherzigten, die Helmut Schelsky in seinen sozialwissenschaftlichen Lehrveranstaltungen

132 | Interview Walter Eberhardt, 16.12.2013; Interview Hajo Graf Vitzthum, 14.6.2014.

133 | Hemmer/Simon: Wirkung, S. 91. 
vermitteln wollte. ${ }^{134}$ Heinz Kluncker erfüllte diese Aufgabe mit einer Ausarbeitung über »Die Schwierigkeiten gewerkschaftlicher Jugendgruppenarbeit ${ }^{135}$

Den Text kennen wir nicht. Schelsky bewertete ihn als »voll befriedigend « und vermerkte zugleich, Klunckers mündliche Leistungen seien gerade im Fach Soziologie, auf die der Prüfling »seine Interessen etwas einseitig « konzentriert habe, sogar noch etwas besser gewesen. Insgesamt erhielt Kluncker als Abschlussnote dennoch nur ein »Ausreichend«, weil ihm zwei „Vierer« in den beiden stark theorielastigen ökonomischen Disziplinen sowie ein "Mangelhaft" für Jura den Durchschnitt verdarben. Selbstkritisch erinnerte sich Kluncker später: »Ich habe [...] nicht den besten Abschluss gemacht, weil ich ziemlich selektiv studiert habe«. ${ }^{136}$

Im Herbst 1951 endete Klunckers Zeit an der Hamburger Akademie, denn selbstverständlich duldete diese straff geführte Einrichtung keine Bummelstudenten. Mit einer schön gedruckten Urkunde (die keine Noten verzeichnete) in der Hand stand der jetzt 26 Jahre alte Ehemann vor der Aufgabe, einen Arbeitsplatz zu finden, der die investierte Zeit und Mühe rechtfertigte. Wie viele andere Lehrgangsabsolventen musste Kluncker allerdings erfahren, dass der Zweite Bildungsweg nicht zwingend in eine vielversprechende Karriere mündete. Viele Arbeitgeber kannten die Akademie und ihre Ausbildung gar nicht; andere bevorzugten schlicht die »richti-

134 | Helmut Schelsky: Die politische Bedeutung der soziologischen Studien an den sozialen Hochschulen. In: Die Akademie für Gemeinwirtschaft in Hamburg. Ihre Aufgaben und ihre Arbeitsweise, Hamburg 1952, S. 29-50, hier: S. 42.

135 | Karl-Hermann Capelle: Die Akademie für Gemeinwirtschaft an der Arbeit. In: Akademie für Gemeinwirtschaft in Hamburg. Ihre Aufgaben und ihre Arbeitsweise, Hamburg 1952, S. 63-80, hier: S. 62. Mit insgesamt 34 Seiten legte Kluncker hier einen recht kurzen Text vor. Heinz Oskar Vetter etwa hatte 168 Seiten über »Die soziale Problematik eines Bergarbeiterledigenheims im Ruhrgebiet« geschrieben (ebd., S. 58).

136 | Hemmer/Simon: Wirkung, S. 96. Die Noten aus: Bundesvorstand des DGB an die Landesbezirke, Abt. Schulung und Bildung, sowie an die Hauptvorstände der DGB-Verbände, 8.8.1951. In: AdsD, IGBE-Archiv, 11742. Für den Hinweis auf dieses Dokument danke ich Klaus Mertsching. In dem Lehrgang, zu dem Kluncker gehörte, gab es einmal ein »Sehr gut«, elfmal »Gut«, 27-mal »Befriedigend« und elfmal »Ausreichend«. Vier Kandidaten bestanden die Prüfung nicht (Capelle: Wissenswertes, S. 19). 
gen « Abiturienten und Universitätsstudenten. ${ }^{137}$ Der zweijährige Lehrgang schien sich für Kluncker daher zumindest für einige Zeit als Sackgasse zu erweisen.

Zwar erhielt er durch Vermittlung Helmut Schelskys zunächst problemlos eine dreimonatige Stelle als »Sozialpraktikant« in einem Dortmunder Stahlwerk. Hierbei handelte es sich um eine »informatorische Beschäftigung«: Der Praktikant (der immerhin bezahlt wurde) gewann Einblick in das Berufsfeld; der Arbeitgeber konnte sich währenddessen überlegen, ob der Betrieb den Aspiranten halten sollte. Schelsky brachte diesen Charakter einer Probe genau auf den Punkt, als er Kluncker von seiner erfolgreichen Fürsprache berichtete: "Was dann weiter wird, ist wahrscheinlich im wesentlichen Ihre eigene Sache. ${ }^{138}$

Ab November 1951 durchlief Heinz Kluncker somit in der DortmundHörder Hüttenunion eine Art Crash-Kurs im betrieblichen Alltag der Schwerindustrie. Er lernte alle Abteilungen des Unternehmens vom Kraftwerk über den Hochofen und das Thomaswerk bis hin zur Lohnbuchhaltung und Personalabteilung kennen. Die Unterschiedlichkeit der hier jeweils zu erfüllenden Aufgaben machte dieses Praktikum sicher äußerst anstrengend. Vertieftes Wissen aber kann Kluncker nicht gewonnen haben, denn seine einzelnen "Stationen« währten jeweils nur drei bis maximal vier Tage. Gerade in den Produktionsabteilungen dürfte der völlig branchenfremde Gast in dieser Zeit wohl bestenfalls gelernt haben, den Arbeitern nicht im Weg zu stehen. Ein »Ausbildungsbericht«, den Kluncker anschließend verfasste, blieb rein aufzählend und banal. ${ }^{139}$

137 | Vgl. dazu ausführlich: Borries-Pusback: Hochschule, S. 395-418.

138 | Helmut Schelsky an Heinz Kluncker, 21.8.1951. In: AdsD, Depositum Kluncker, Stehordner 78. Jahrzehnte später profilierte sich der im Alter politisch weit nach rechts gerückte Schelsky öffentlich als scharfer Kritiker der Gewerkschaften und gerade der ÖTV. Seine Polemik zielte auch persönlich auf Heinz Kluncker: Er sei ein »Berufsfunktionär« und stehe prototypisch für ein »wissenschaftlich-halbgebildetes, aber argumentationsfähiges Korps von Gewerkschaftsfunktionären«, dessen Macht die "Gemeinwohl-Stabilität« der Bundesrepublik bedrohe. Seine eigene Beteiligung an Klunckers angeblicher "Halbbildung « hat Schelsky nicht erwähnt (Helmut Schelsky: Funktionäre. Gefährden sie das Gemeinwohl?, Stuttgart 1982, Zitate: S. 135, 64 u. 130).

139 | Vorläufiger Ausbildungsbericht von Heinz Kluncker, o. D. [Januar 1952]. In: AdsD, Depositum Kluncker, Stehordner 78. Ob Kluncker nach diesem von 
Offensichtlich gelang es dem Sozialpraktikanten Heinz Kluncker nicht, den Arbeitsdirektor der Dortmunder Hüttenunion zu beeindrucken, der selbstverständlich aus der IG Metall kam und als eine Art Personalchef des Unternehmens für den Gast und dessen Weg durch das Unternehmen zuständig war: Kluncker durfte nach Ablauf des Praktikums wieder gehen und wurde erwerbslos. Der Akademieabsolvent Kluncker hatte dabei keinen Anspruch auf Arbeitslosengeld, denn drei Monate Beschäftigung nach zwei Jahren Ausbildung reichten dafür nicht aus. Bewerbungen bei anderen Betrieben der Schwerindustrie blieben erfolglos, selbst wenn es dabei nur um eine weitere »informatorische Beschäftigung« ging. Auch der DGB-Landesbezirk Nordrhein-Westfalen reichte eine Anfrage, ob man nicht eine »Nachwuchskraft« in der Bildungs- und Jugendarbeit brauche, umgehend zurück: Offene Stellen werde es in diesem Bereich »in absehbarer Zeit« nicht geben. Kluncker bemühte sich um einen Platz in einem Austauschprogramm zwischen DGB und US-amerikanischen Gewerkschaften, erhielt aber erneut eine Absage, weil das Stipendium nur an Ledige ging, die nicht älter als 25 Jahre sein durften. Beides traf auf Kluncker nicht zu. ${ }^{140}$

Geknickt kehrte der junge Mann zum zweiten Mal nach Wuppertal zurück. Das lokale Netzwerk der Sozialdemokraten versuchte zu helfen, konnte aber nicht viel bieten: Um überhaupt etwas Geld zu verdienen, akzeptierte Heinz Kluncker einen dreiwöchigen Aushilfsjob im Lager einer Konsumgenossenschaft. Gegenüber einem Bekannten in Hamburg zeigte sich Kluncker in dieser Zeit per Brief höchst frustriert: »Wie Du sieht, eine herrliche Scheiße!!! [...] Allmählich kotzt mich die ganze Situation an. [...] Drei Wochen ohne Einkommen und jetzt Aushilfsarbeiter, das haut den stärksten Mann um. ${ }^{141}$

ihm selbst so überschriebenen Text noch einen weiteren ausführlicheren Bericht verfasst hat, ist unklar. Unter seinen persönlichen Papieren, die gerade für diesen Zeitraum (und nur für diesen Zeitraum) recht vollständig wirken, findet sich keine zweite Version des Berichts.

140 | Heinz Kluncker an den Arbeitsdirektor des Bochumer Vereins, 27.2.1952; DGB-Landesbezirk Nordrhein-Westfalen an Heinz Kluncker, 7.4.1952; August Rathmann an Heinz Kluncker, 15.2.1952 (in Sachen des Stipendiums). Alle in: AdsD, Depositum Kluncker, Stehordner 78.

141 | Heinz Kluncker an Klaus [?], 23.3.1952. In: AdsD, Depositum Kluncker, Stehordner 78. Dieser Durchschlag eines maschinenschriftlichen Briefes nennt 
Heinz Kluncker hatte aktuell also keineswegs andere Eisen im Feuer, als er wenig später über den nordrhein-westfälischen DGB ein Angebot der ÖTV erhielt: In der Hauptverwaltung der Organisation in Stuttgart suchte man für ein Jahr einen Volontär. Kluncker sagte umgehend zu, trotz der Befristung und trotz der Notwendigkeit, erneut umzuziehen (was in dieser Zeit extremer Wohnungsnot unweigerlich erhebliche Mühen und Verdruss mit sich brachte). Schon Mitte April 1952 trat er seine Stelle an; wie fast alle Zugezogenen in einer deutschen Großstadt in dieser Zeit lebte er zunächst möbliert zur Untermiete. Da Ilse Kluncker schwanger war, erhielt das Ehepaar immerhin nach einiger Zeit eine eigene Wohnung - allerdings handelte es sich nur um eine "sehr unzureichende Dachgeschosswohnung" mit einem einzigen Wasserhahn an der Küchenspüle. Beengt und primitiv lebte die Familie nach der Geburt einer Tochter hier zu dritt. ${ }^{142}$

Anders als kurz zuvor im Dortmunder Stahlwerk verlief Klunckers »informatorische Beschäftigung « bei der ÖTV sehr zur Zufriedenheit beider Seiten. Der Neuling arbeitete rasch ausschließlich in der Tarifabteilung und unterstützte hier Karl Oesterle, den wichtigsten Tarifexperten der Gewerkschaft. Dabei entdeckte Kluncker nach seinen eigenen Worten zwar »einige juristische Lücken« in seinem Wissen, aber das war bei der Komplexität der Materie auch nicht verwunderlich. Er erlebte die Arbeit in der Tarifabteilung als "sehr vielseitig « und fühlte sich auch in Stuttgart rasch sehr wohl - trotz einiger Probleme mit dem »Verständnis der schwäbischen Urlaute «. ${ }^{143}$ In der Hauptverwaltung war man mit Kluncker ebenfalls sehr zufrieden: Noch vor Ablauf der zwölf Monate erhielt der junge Mann einen unbefristeten Arbeitsvertrag. Im 28. Lebensjahr befand sich Heinz Kluncker damit zum ersten Mal in einer Position, die ihm soziale Sicherheit und Perspektiven bot.

Es fällt auf, wie wenig der skizzierte Weg Heinz Klunckers mit der bis dato typischen Biografie eines deutschen Gewerkschaftsvorsitzenden gemein hatte. ${ }^{144}$ So war Kluncker gleich in doppelter Hinsicht kein »von der

den Adressaten nur beim Vornamen; Anschrift und vollständiger Name fehlen. Aus dem Text ergibt sich, dass der Angeschriebene in Hamburg lebt.

142 | Hemmer/Simon: Wirkung, S. 99.

143 | Heinz Kluncker an die Akademie für Gemeinwirtschaft, 14.11.1952. In: AdsD, Depositum Kluncker, Stehordner 78.

144 | Als treffende Zusammenfassung vgl.: Karl Lauschke: Weder Kämpfer noch Bürokrat oder Dienstleister. Zum Wandel der Gewerkschaftsfunktionäre in der 
Pike auf« gelernter Gewerkschafter: Zum einen verlief seine berufliche Sozialisation weitgehend außerhalb des Berufsfeldes, für das die ÖTV zuständig war. Vor seiner Anstellung in Stuttgart hatte der spätere Vorsitzende der Gewerkschaft nur wenige Monate im Öffentlichen Dienst gearbeitet und dabei wohl so negative Erfahrungen gemacht, dass er freiwillig wieder ausschied. Die Branchen Transport und Verkehr waren ihm völlig fremd. Zum anderen absolvierte Kluncker nie die klassische »Ochsentour« durch die verschiedenen Ebenen der Gewerkschaftsorganisation, bei der sich ein junger Mann stufenweise hinauf diente, Kontakte knüpfte und Erfahrungen sammelte, die ihn schließlich befähigten, das Amt des Vorsitzenden zu übernehmen. Bis 1952 war Heinz Kluncker nur in der Jugendarbeit der ÖTV aktiv gewesen, also auf einem Feld, das mit dem Kern gewerkschaftlicher Arbeit nichts zu tun hatte und in der Organisation - jenseits allgemein üblicher Lippenbekenntnisse - auch als nicht besonders wichtig galt. Dieses Manko hat er in Stuttgart aber offensichtlich in kurzer Zeit überwunden, schließlich arbeitete er nun just in der Abteilung, die den Spielraum der Gewerkschaft auszuloten hatte, wenn sie sich aufmachte, die materiellen und beruflichen Interessen der Mitglieder durchzusetzen.

Als Sonderfall steht Heinz Kluncker mit seinem Lebensweg zwischen zwei Typen der Berufsbiografie gewerkschaftlicher Führungskräfte, die beide jeweils längere Abschnitte der Gewerkschaftsgeschichte geprägt haben: Weder gehörte er zu der älteren Kohorte, deren Mitglieder typischerweise als einfache Arbeiter aus der Mitte ihrer Kollegen kamen und die sich dann mit und in der Gewerkschaft einen höheren sozialen Status erarbeiteten; noch war er ein Vertreter der neuen Generation von Gewerkschaftsführern, die seit den 1980er Jahren als akademisch ausgebildete Quereinsteiger in den Berufsverbänden Karriere machten und sich daher oft nicht mehr so bedingungslos mit »ihrer « Organisation identifizierten wie Vertreter des älteren Typs. ${ }^{145}$

zweiten Hälfte des 20. Jahrhunderts. In: Till Kösler/Helke Stadtland (Hrsg.): Vom Funktionieren der Funktionäre. Politische Interessenvertretung und gesellschaftliche Integration in Deutschland nach 1933, Essen 2004, S. 221-238.

145 | Ebd., S. 236-238. Diese Generationenfolge ist eine Generalisierung. Einzelfälle durchbrechen sie. Franz Steinkühler etwa, der 1986 zum Vorsitzenden der IG Metall gewählt wurde, absolvierte noch eine fast klassische Karriere nach dem ersten Muster. Die Stufen seiner Gewerkschaftskarriere waren beinahe mustergül- 
Umso bemerkenswerter erscheint es, wie stark Heinz Kluncker dann in seiner Zeit als Vorsitzender auf ungewöhnlich eindringliche Weise die gesamte Organisation verkörperte. Spätestens seit den frühen 1970er Jahren war er die ÖTV, sowohl in den Augen der Mitglieder als auch für die breite Öffentlichkeit. In der Presse firmierte die Organisation teilweise nur noch als »Kluncker-Gesellschaft«. ${ }^{146}$

Diese repräsentative Rolle musste sich der Vorsitzende wohl besonders schwer erarbeiten, weil er beruflich eigentlich wenig "Stallgeruch" mitbrachte. Die weitere Darstellung wird zeigen, wie es ihm gelang, dennoch - sowohl in einer positiven wie auch in einer negativen Sicht - zur Symbolfigur für die ÖTV und für den Öffentlichen Dienst der Bundesrepublik zu werden. Auch dabei spielte Klunkers Individualität eine Rolle: Wie zu zeigen sein wird, funktionierte die Stilisierung seiner Person zur Inkarnation eines Gewerkschaftsführers, die stark von den Medien ausging, der ÖTV aber durchaus nicht ungelegen kam, gleich aus verschiedenen Gründen besonders gut.

Angesichts mangelnder biografischer Informationen bleibt es selbstverständlich Spekulation, in welcher Art und Intensität sich die erwähnten Erfahrungen in Kindheit und Jugend auf Verhalten und Charakter des späteren Gewerkschaftsführers auswirkten. Mit großer Wahrscheinlichkeit haben aber die kindliche Konversion zur NS-Ideologie und deren spätere (in Klunckers Augen: verspätete) Korrektur durch die Desertion seine Person entscheidend geprägt. Der erwachsene Mann verstand diese für ihn schmerzliche Erinnerung offensichtlich sehr grundsätzlich als Warnung vor einem allzu schnellen Einverständnis. Nach dem einhelligen Zeugnis von Mitarbeitern, die ihn persönlich genauer kannten, und von Journalisten, die ihn als Vorsitzenden begleiteten, schätzte Heinz Kluncker Widerspruch und Oppositionsgeist; habituelle Ja-Sager waren ihm suspekt.

Nach den Worten Hajo Graf Vitzthums, der seit 1971 als persönlicher Referent für Kluncker arbeitete, hatte sein Chef einen »Faible für Leute, die nicht stromlinienförmig waren« und »hohen Respekt vor Leuten, die persön-

tig: Jugendvertreter, Betriebsrat, Sekretär in einer Ortsverwaltung, Bezirksleiter, zweiter Vorsitzender, schließlich erster Vorsitzender. Vgl.: Berthold Huber: Franz Steinkühler - einer von uns. In: Hans-Joachim Schabedoth/Peter Schaaf (Hrsg.): Franz Steinkühler. Einer von uns, Marburg 2012, S. 8-12.

146 | Warten auf den DGB. In: Die Zeit, 20.6.1980. 
lich Position bezogen haben«. Bei innerverbandlichen Streitigkeiten strebte der Vorsitzende stets nach einer »sehr konstruktiven Auseinandersetzung«. Siegfried Bußjäger, der in der ÖTV ab 1966 langjährig für die Öffentlichkeitsarbeit zuständig war, formuliert es ganz ähnlich: Heinz Kluncker legte »keinen Wert auf Ja-Sager« und »konnte eine andere Meinung ertragen« ${ }^{147}$

Überhaupt zeigte sich Kluncker - ganz im Gegensatz zu seiner zunehmend immer bulliger wirkenden Erscheinung - im persönlichen Gespräch leise, voller Interesse am Gegenüber und einfühlsam. ${ }^{148}$ Walter Eberhardt etwa, der seit Mitte der 1970er Jahre zu Klunckers engsten Mitarbeitern zählte, hatte dank der vielen Fernsehauftritte des ÖTV-Vorsitzenden eine genaue Vorstellung, wie Kluncker sei, als er sich - mit einem Universitätsabschluss in der Tasche - Ende 1974 in Stuttgart um einen Job bewarb. Kluncker war in seiner Sicht ein Gewerkschafter, »der alle Politiker auffrisst« und »ein harter Hund«; dementsprechend erwartete er schon im Vorstellungsgespräch »ein relativ raues Klima«. Überraschenderweise nahm sich der Vorsitzende dann nicht nur stundenlang Zeit für ein Gespräch mit dem jungen Mann. Er interessierte sich auch sehr für dessen Erfahrungen und Ansichten. Beeindruckt kam Eberhardt zu dem Ergebnis: »der hört zu, wenn ich ihm was sage«. Ganz ähnlich erzählt auch Hajo Graf Vitzthum von seiner ersten Begegnung mit Heinz Kluncker. ${ }^{149}$ Diese Charakterzüge erscheinen nicht zuletzt auch als eine persönliche Lehre aus eigenen Kindheits- und Jugenderfahrungen, weil Kluncker retrospektiv so intensiv über seine Vergangenheit nachdachte. Unter den Männern seiner Generation stand er mit dieser Nachdenklichkeit genauso isoliert da wie als ehemaliger Deserteur.

Allerdings existierte daneben noch ein ganz anderer Heinz Kluncker: einer, der sehr laut werden konnte (auch gegenüber seinen engsten Mit-

147 | Interview Hajo Graf Vitzthum, 14.6.2014; Interview Siegfried Bußjäger, 1.4.2014. Vgl. auch die zeitgenössischen Presse-Porträts: Vetten: Riese, S. 50-55; Georg Heller: Der sanfte Buhmann. In: Wirtschaftswoche 35 (1981), H. 13, S. 46 u. 50; Erika Martens: Der Schreck in der Abendstunde. In: Die Zeit, 22.1.1982; Frank Bünte: Für eine humane Arbeitswelt verschlissen. In: Deutsches Allgemeines Sonntagsblatt, 13.6.1982.

148 | Interview Walter Eberhardt, 16.12.2013. Ähnlich auch: Interview Siegfried Bußjäger, 1.4.2014.

149 | Interview Walter Eberhardt, 16.12.2013; Interview Hajo Graf Vitzthum, 14.6.2014. 
arbeitern), der eitel und sehr machtbewusst war, dominant auftrat und sich sowohl in der Öffentlichkeit als auch in Tarifverhandlungen stets unnachgiebig präsentierte. Ohne diesen "zweiten Mann« gleichen Namens hätte sich die ÖTV mit Sicherheit nicht zu der »Kluncker-Gesellschaft» entwickelt, die sie in den 1970er Jahren wohl tatsächlich war. Da hier keine Biografie des Vorsitzenden, sondern eine Geschichte der Gewerkschaft unter seinem Vorsitz zu schreiben ist, wird dieser »offizielle« Kluncker im Folgenden sehr viel häufiger auftreten als der andere, sensiblere Mann. Der Zwiespalt zwischen dieser in vieler Hinsicht sehr stereotypen politischen Figur und dem Heinz Kluncker, der als gebranntes Kind aus Deutschlands dunkelster Vergangenheit kam, verdient es dennoch, im Bewusstsein gehalten zu werden. Der nüchterne Manager ohne Bezug zur Vergangenheit, als der Kluncker bei seiner Wahl zum ÖTV-Vorsitzenden von der Presse begrüßt wurde, war er jedenfalls nicht.

\section{Gewerkschaftliche Lehrjahre: Heinz Klunckers Aufstieg in der ÖTV und deren Tarifpolitik bis 1964}

\section{Gewerkschaftskarriere und erste tarifpolitische Grundsatzarbeiten für Arbeiter und Angestellte}

Rund zwölf Jahre liegen zwischen Heinz Klunckers Einstellung als Volontär in der Hauptverwaltung der ÖTV in Stuttgart und seiner Wahl zum Vorsitzenden der Gewerkschaft. In der Öffentlichkeit spielte Kluncker in dieser Zeit kaum eine Rolle. Auf den Gewerkschaftstagen der ÖTV etwa, den auch von den Medien beobachteten Hauptversammlungen der Organisation, gab es für ihn keine Gelegenheiten zu glänzen. 1955 war er nicht dabei, 1958 durfte er mit einem einzigen standardisierten Satz seine Wahl zum Arbeitersekretär annehmen. 1961 äußerte er sich zweimal nur ganz kurz zu Spezialfragen der Arbeitertarifverträge, obwohl er auf diesem Kongress in den Geschäftsführenden Hauptvorstand (gHV) gewählt wurde und damit in den engsten Führungskreis der Organisation aufrückte. Die grundlegenden gewerkschaftspolitischen Reden vor dem »Parlament« der ÖTV kamen 1961 von Hans Koschnik, der als Delegierter aus Bremen engagiert für eine umfassende gesellschaftspolitische Reformstrategie der Gewerkschaft warb und insgesamt sechsmal auf dem Podium stand. 1964 berichtete Heinz 
Kluncker dann zwar recht ausführlich über das Tarifgeschehen in den vorangegangenen Jahren; eine Kandidatenrede, mit der er sich den Delegierten als Bewerber für das Amt des Vorsitzenden vorgestellt hätte, sah die Tagesordnung jedoch nicht vor (auch weil es keinen Konkurrenten gab). ${ }^{150}$

Offensichtlich ergab sich das Vertrauen, das die Organisation ihren neuen Leiter entgegenbrachte, ausschließlich aus der Alltagsarbeit, die er in den zwölf Jahren zwischen 1952 und 1964 geleistet hatte. Einige der zentralen Themen und Probleme dieser Tätigkeit werden im Folgenden kurz angerissen, um deutlich zu machen, wie die gewerkschaftliche Expertise zustande kam, die den Außenseiter Heinz Kluncker auf dem Gewerkschaftstag von 1964 an die Spitze der ÖTV brachte.

Die Arbeit in der Tarifabteilung, die der Volontär 1952 aufnahm, führte Kluncker direkt in das strategische Zentrum der ÖTV. Formal handelte es sich lediglich um eine vorbereitende und beratende Tätigkeit. Entscheidungen, was die Gewerkschaft in kommenden Tarifverhandlungen fordern könne und solle, fielen nicht in der Abteilung, sondern zunächst einmal im gHV und verbindlich dann - nach dessen Vorschlag - in der Großen Tarifkommission. Ohne ein Votum dieses ehrenamtlichen Gremiums, das mit mehr als 100 Delegierten groß besetzt war, gab es keine offiziellen Forderungen der Organisation. Die Tarifsekretäre sammelten Material, das bei der Entscheidungsfindung helfen konnte, und sie formulierten Entwürfe. Konkret bedeutete das unendlich viel »Kleinarbeit«, die ausgefeiltes Expertenwissen über die Bestimmungen in den geltenden Tarifverträgen erforderte, und »Teamarbeit«, weil die Abstimmung zwischen den verschiedenen Berufsgruppen innerhalb der ÖTV anders nicht zu leisten war. ${ }^{151}$

De facto tat das Tarifsekretariat deutlich mehr, als nur gewerkschaftspolitisch nützliche Informationen zusammenzutragen. Ihre Mitglieder

150 | Protokoll ÖTV-GT 1958, S. 360; Protokoll ÖTV-GT 1961, S. 429 f. u. 445; Protokoll ÖTV-GT 1964, S. 108-116. Die beiden wichtigsten Reden Koschniks: Protokoll ÖTV-GT 1961, S. 127-130 u. 328 f., letztere zu der Frage, wer denn 1964 Nachfolger von Kummernuss werden könne. Koschnik plädierte hier für Erich Raabe, der 1961 als zweiter Vorsitzender kandidierte und auch gewählt wurde, allerdings nur 247 Ja-Stimmen bei 473 abgegebenen Stimmen erhielt. Wie Raabe selbst sagte, war das eine »recht schmale Basis des Vertrauens« (S. 333).

151 | So die Formulierungen von Adolph Kummernuss in: Protokoll ÖTV-GT 1955, S. 319. Die Abkürzung gHV (statt: GHV) wurde im Untersuchungszeitraum durchgehend in der ÖTV benutzt und wird deshalb hier übernommen. 
hielten beständig Kontakt mit den Tarifsekretären in den ÖTV-Bezirksverwaltungen, und sie leiteten Arbeitstagungen dieser Funktionäre, auf denen über konkrete soziale Anliegen der einfachen Mitglieder gesprochen wurde. Die Tarifforderungen entstanden insofern eher in einem kontinuierlichen kommunikativen Prozess innerhalb der Organisation als durch eine Abfolge von Abstimmungen in separaten Gremien. Wer als Experte im Zentrum dieser Gespräche saß, der verfügte fast zwangsläufig über besonderen Einfluss. Die Große Tarifkommission war zwar die demokratische Instanz, deren Zustimmung es zu gewinnen galt; in der Realität aber trat dieses Gremium stets erst dann zusammen, wenn es durch viele Gespräche und Beratungen hinter den Kulissen inhaltlich "ausgerichtet« war. ${ }^{152}$

Der erste große Schritt in seiner Gewerkschaftskarriere gelang Heinz Kluncker deshalb, als er auf dem Gewerkschaftstag von 1958 zum »Bundesarbeitersekretär« der Organisation berufen wurde. Die Delegierten bestätigten damit eine Entscheidung, die der Hauptvorstand einige Zeit zuvor getroffen hatte. ${ }^{153}$ Wie diese doppelte Wahl zeigt, genoss der ehemalige Volontär in den ÖTV-Gremien dank seiner Arbeit seit 1952 offensichtlich großes Vertrauen, denn wenn man nach dem in Gewerkschaften so wichtigen beruflichen "Stallgeruch« fragte, dann hätte Kluncker ausgerechnet als Sprecher von Arbeitern eigentlich als Fehlbesetzung gelten müssen: Der ausgebildete Handelskaufmann und kurzzeitige Polizist hatte nie zu dieser Berufsgruppe gehört. Dennoch erhielt er nun die Aufgabe, alle Tarifverhandlungen der ÖTV für Arbeiter und Arbeiterinnen vorzubereiten und zu koordinieren. ${ }^{154}$

Erstaunlicherweise handelte es sich bei dem Bundesarbeitersekretär um einen neu geschaffenen Posten, denn bislang hatte es in der ÖTV nur einen Angestellten- sowie einen Beamtensekretär gegeben. Anregungen, diese Lücke zu schließen, waren bereits älter; der gHV aber zögerte lange. Offiziell ging es darum, eine »Überorganisation« zu vermeiden, denn der neue Sekretär sollte - genau wie seine beiden Kollegen - ein System von Orts- und Bezirksausschüssen für die Berufsgruppe leiten, die er vertrat.

152 | So die offensichtlich keineswegs kritisch, sondern rein beschreibend gemeinte Feststellung des Bezirksleiters in: Kurzprotokoll der Bezirksvorstandssitzung NRW II, 3.11.1961. In: AdsD, ÖTV-NW II, 5/ÖTVC022005.

153 | Protokoll ÖTV-GT 1958, S. 53 u. 360.

154 | ÖTV-Geschäftsbericht 1958/60, S. 206. 
Die ohnehin komplizierte Verwaltungsstruktur der ÖTV drohte damit noch unübersichtlicher zu werden. ${ }^{155}$

Inoffiziell mag die Furcht dazu gekommen sein, die kopfstarke Gruppe der Arbeiter könne die Angestellten und Beamten innerhalb der Organisation übertönen, wenn man ihr das Recht einräumte, sich als Block zu artikulieren. Um diese Gefahr zu bannen, wurde der Bundesarbeitersekretär ausdrücklich dem Tarifsekretariat und dessen Leiter unterstellt, als der Posten schließlich doch entstand. Doch auch mit dieser Einschränkung handelte es sich um eine Funktion, die der Amtsinhaber nur erfüllen konnte, wenn er intensiven Kontakt mit allen Ebenen der ÖTV hielt. Heinz Kluncker hat diese Präsenz gezeigt: Fast zwei Drittel seiner Arbeitszeit als Arbeitersekretär verbrachte er außerhalb seines Stuttgarter Büros, weil er mit den Arbeiterausschüssen der Organisation oder auch mit Gremien des DGB konferierte und an Tarifverhandlungen teilnahm. ${ }^{156}$

Wer in der ÖTV aktiv war, so darf man schließen, der lernte Heinz Kluncker in den Jahren nach 1958 früher oder später fast zwangsläufig kennen. So erklärt sich wohl die auf den ersten Blick recht überraschende Tatsache, dass Kluncker auf dem Gewerkschaftstag 1964 von den Delegierten mit eindeutiger Mehrheit gewählt wurde, obwohl er im »Parlament« der ÖTV erst kurz vor seiner Wahl zum ersten Mal eine richtige Rede gehalten hatte.

Die Bemühungen der Gewerkschaft, im Interesse der Arbeiter zu handeln, die Heinz Kluncker spätestens seit 1958 an zentraler Stelle mitgestaltete, konzentrierten sich in den 1950er Jahren für den Öffentlichen Dienst stark darauf, die soziale Ungleichheit unter den Beschäftigten des Staates abzubauen. Als historisches Erbe, das teilweise sogar noch aus dem Kaiserreich datierte, galten im Öffentlichen Dienst und in staatlichen Dienstleistungsbetrieben seinerzeit etliche tarifvertragliche Regelungen, die Arbeiter deutlich schlechter stellten als Angestellte. Solche Differenzen gab es etwa bei der Lohnfortzahlung im Krankheitsfall, bei den Kinder- und Ortszu-

155 | So Kummernuss in: Protokoll ÖTV-GT 1958, S. 51-53. Eine der Anregungen lautete, das Arbeitersekretariat analog zu den Abteilungen für Angestellte und Beamte aufzubauen, damit es zu »einer echten tragenden Säule« der Organisation werden könne, vgl. etwa in: Protokoll ÖTV-GT 1955, S. 239 f. Zu den Streitigkeiten um die Einrichtung des Sekretariats vgl. ausführlich: Nachtmann: 100 Jahre ÖTV, S. 339-343.

156 | ÖTV-Geschäftsbericht 1958/60, S. 206. 
schlägen sowie auch beim Urlaubsanspruch. Als Markierung der »Kragenlinie« symbolisch hoch bedeutsam war zudem der Unterschied zwischen dem »Gehalt« der Angestellten (wie auch der Beamten), das stets im Voraus für einen Monat gezahlt wurde, und dem »Lohn« der Arbeiter, der jeweils pro Woche und erst im Nachhinein abgerechnet wurde. ${ }^{157}$ In solchen sozialen Hierarchisierungen sah die ÖTV eine »Diskriminierung« der Arbeiter, die in der modernen leistungsorientierten Arbeitswelt keinerlei Berechtigung mehr habe und deshalb verschwinden müsse. ${ }^{158}$

In diesem Zusammenhang wollte die Gewerkschaft generell alle Manteltarifverträge für die Beschäftigten des Öffentlichen Dienstes neu verhandeln, in denen die allgemeinen Arbeitsbedingungen, die Eingruppierungen der verschiedenen Tätigkeiten in die Lohntabellen sowie Lohnstrukturen und -zuschläge geregelt wurden. Im Kern entsprachen diese Abmachungen sowohl für Arbeiter als auch für Angestellte nämlich immer noch weitgehend den "Arbeitsordnungen«, die das NS-Regime nach 1933 auch im Öffentlichen Dienst erlassen hatte, um die Tarifverträge aus den Jahren der Weimarer Republik abzulösen. Aus praktischen Gründen hatten sich die Tarifparteien nach 1945 weitgehend darauf beschränkt, diese Bestimmungen der nationalsozialistischen »Treuhänder der Arbeit« nun als Tarifvertrag weiterhin gelten zu lassen, weil arbeitsrechtlich kein vertragsloser Zustand entstehen sollte, eine Neuregelung aber viel Zeit brauchte. Allein schon wegen des Wandels der Technik und der Arbeitsorganisation passten diese alten Formulierungen gerade bei den Beschreibungen und Eingruppierungen der verschiedenen Berufe zunehmend schlecht zum betrieblichen Alltag in den Staatsbetrieben und im Öffentlichen Dienst. Die notwendige Aktualisierung wollte die ÖTV nutzen, um Höherstufungen für möglichst viele Beschäftigte durchzusetzen. ${ }^{159}$

In dieser komplizierten Angelegenheit erreichte die Gewerkschaft einige Erfolge. Das Vorhaben, neue Manteltarifverträge für alle Arbeiter in Staatsdiensten auszuhandeln, konnte 1960 abgeschlossen werden; ein Jahr später folgte nach neunjährigen Auseinandersetzungen mit dem BAT ein

157 | Vgl. etwa: ebd., S. 31 u. 39 sowie 202-205.

158 | Ebd., S. 202.

159 | Vgl. dazu ausführlich: ÖTV: Geschäftsbericht 1952-1954. Hrsg. v. der Gewerkschaft Öffentliche Dienste, Transport und Verkehr - Hauptvorstand, Stuttgart 1954 (im Folgenden: ÖTV-Geschäftsbericht 1952/54), S. 20-27. 
einheitlicher Manteltarifvertrag für alle Angestellten von Bund, Ländern und Gemeinden, welcher, wie erwähnt, dieses wichtige Segment der bundesdeutschen Arbeitswelt für Jahrzehnte prägte. Eine zentrale Bestimmung all dieser Abmachungen war die einheitlich gesicherte Unkündbarkeit von langjährigen Beschäftigten des Staates: Wer mehr als 15 Jahre im Öffentlichen Dienst gearbeitet hatte, konnte nicht mehr entlassen werden. Auch beruflich gering qualifizierte Arbeiter und Arbeiterinnen wie etwa Straßenfeger oder Putzfrauen genossen damit nach Ablauf der Frist einen beamtenähnlichen Status. ${ }^{160}$

Besonders den körperlich Arbeitenden zugute kam die Bestimmung in den neuen Manteltarifverträgen, dass nachlassende Leistungen bei Beschäftigten, die älter als 55 waren, nicht zu einer individuellen Herabstufung und niedrigerem Lohn führen durften. Gemeinsam bedeuteten diese beiden Regelungen eine "Sicherung des erkämpften Lebensstandards" gerade für die Beschäftigten, die in der Hierarchie des Öffentlichen Dienstes eher unten standen. Auf diese soziale Errungenschaft war die ÖTV sehr stolz. ${ }^{161}$

Gleiches galt für einen im Oktober 1963 durchgesetzten Tarifvertrag, der die Lohnzuschläge für (etwa durch Schmutz) erschwerte Arbeiten oder für Nacht- und Schichtdienste für die Arbeiter von Bund, Ländern und Gemeinden nicht einfach nur erhöhte, sondern auch von der Praxis abwich, sie in festen Beträgen zu fixieren. Stattdessen wurde der aktuell geltende Stundenlohn bei solchen Arbeiten um verschiedene Prozentsätzen erhöht. Dadurch stiegen die Zulagen nun automatisch mit jeder der jährlichen Lohnrunden, während es zuvor oft langfristig keine Anpassung gegeben hatte. Auch hier diente die Tarifpolitik der Gewerkschaft insbesondere den Handarbeitern im Öffentlichen Dienst. ${ }^{162}$

160 | Ebd., S. 22 (für den hier als Modell dienenden Manteltarifvertrag für Gemeindearbeiter); Günter Stein: Der Bundesangestelltentarifvertrag (BAT) im öffentlichen Dienst. In: Die Quelle 12 (1961), S. 111-112. Kürzere Fristen als die 15 Jahre waren möglich und gerade in großen öffentlichen Dienstleistungsbetrieben auch eher die Regel als die Ausnahme. Bei schweren persönlichen Verfehlungen konnte - genau wie bei Beamten - der Kündigungsschutz im Einzelfall allerdings wirkungslos werden. Vgl. dazu: ÖTV-Geschäftsbericht 1952/54, S. 38.

161 | Ebd., S. $22 \mathrm{f}$.

162 | ÖTV-Geschäftsbericht 1961/63, S. 233 f. Die Zuschläge variierten zwischen 5 und 31 Prozent des jeweils zugrundeliegenden Stundenlohns. 
In anderer Hinsicht fiel die Erfolgsbilanz der Gewerkschaft wegen starker Widerstände der Arbeitgeber eher durchwachsen aus. Die komplexe Frage etwa, wie Berufe und Tätigkeiten in Anpassung an den technologischen Wandel neu zu beschreiben und in einer Besoldungspyramide zu ordnen seien, wurde in den neuen Manteltarifverträgen kaum zur Zufriedenheit der ÖTV gelöst. Höhergruppierungen für Arbeiter blieben selten; der BAT übernahm in dieser Hinsicht Bestimmungen aus den Vorkriegsjahren sowie aus noch älteren Phasen der deutschen Geschichte, weil der Abschluss des Vertrages nicht noch weiter hinausgezögert werden sollte. ${ }^{163}$

Die anschließenden Nachverhandlungen erwiesen sich für die ÖTV als ausgesprochen unerquicklich, weil die Arbeitgeber kein Interesse daran hatten, ein Gesamtkonzept zu entwickeln: Sie konzentrierten sich auf einzelne Berufsgruppen mit spezieller Expertise, die im Verwaltungsablauf als besonders wichtig galten. Solche Teilreformen, die Gehaltsaufbesserungen mit sich brachten, weckten Begehrlichkeiten bei den noch nicht Berücksichtigten - und viele von diesen nahmen die ÖTV in die Pflicht. 1963 berichtete das Tarifsekretariat der Gewerkschaften von zahlreichen »Pressionen « durch Telegramme und Telefonanrufe mit der Drohung "wir treten aus«, wenn ihr nicht endgültig auch bei uns mal Eingruppierungen macht«. Da ein Vertrag immer zwei Unterschriften braucht und die Arbeitgeber bei ihrer Strategie blieben, konnte die Gewerkschaft diesen ultimativen Forderungen jedoch nicht nachkommen. ${ }^{164}$ An unerledigten Aufgaben herrschte bei den Manteltarifverträgen also durchaus kein Mangel, als Heinz Kluncker im Jahr 1964 die Leitung der ÖTV übernahm.

\section{Unübersichtliche Fronten: ÖTV und Arbeitgeber des Öffentlichen Dienstes im Wirtschaftsboom der Wiederaufbaujahre}

Neben der Arbeit an den langfristig geltenden Rahmenverträgen stand das gewerkschaftliche Alltagsgeschäft der jährlichen Lohnrunden an. In diesem Bereich sammelte der junge Heinz Kluncker in seinen gewerkschaftlichen Lehrjahren offenkundig die ihn am stärksten prägenden Erfahrungen. Für

163 | Ebd., S. 234.

164 | Protokoll der 7. Sitzung des HV, 26./27.6.1963. In: Archiv Ver.di, Bestand Kluncker 45. Ähnlich auch noch: Protokoll der 1. Sitzung des HV, 29.9./1.10.1964. In: ebd. 
die Beschäftigten und ihre Organisation war die Lohnfrage eine Angelegenheit von höchster Dringlichkeit, lebten die Mitarbeiter von Bund, Ländern und Gemeinden in den frühen 1950er Jahren doch mehrheitlich ausgesprochen kärglich: Ihr Lebensstandard fiel zu dieser Zeit deutlich dürftiger aus als 1938 oder 1928. Vielfach galten immer noch die niedrigen Löhne und Gehälter, die auf dem Höhepunkt der Weltwirtschaftskrise in den Jahren 1931/32 durch Notverordnungen dekretiert worden waren. Der Lohn- und Gehaltsstop, den das NS-Regime 1936 verhängt hatte, zementierte diesen Tiefstand in Staatsbetrieben und Behörden, während die schwieriger zu kontrollierenden Privatbetriebe im Aufrüstungsboom der letzten Vorkriegsjahre oft besser zahlten. So entwickelte sich zwischen vergleichbar ausgebildeten und eingruppierten Beschäftigten des Staates und der Industrie ein Lohnabstand, der spätestens mit der Währungsreform von 1948 zu einem echten sozialen Problem wurde, weil die Lebenshaltungskosten nun wieder schneller stiegen. Für Arbeiter im Öffentlichen Dienst lag der Reallohn im Jahr 1950 um fast ein Drittel unter dem Stand von 1938. Fast 90 Prozent von ihnen verdienten monatlich weniger als $250 \mathrm{DM}$ brutto - und damit lag ihr Verdienst »weit unter dem Existenzminimum«, wenn nicht ergänzend anderes Einkommen dazu kam. ${ }^{165}$

Dazu kam die Frage der Arbeitszeit als zweites zentrales Thema der jährlichen Lohn- und Gehaltsrunden. Die ÖTV stand hier vor einer drängenden Aufgabe, die sich zudem auch noch dynamisch veränderte. So stellte die 48-Stunden-Woche mit sechs Arbeitstagen in Industrie und Gewerbe inzwischen den tarifvertraglichen Standard dar, während sie für eine große Gruppe der von der ÖTV vertretenen Beschäftigten immer noch nicht mehr als ein angenehmer Traum war: Im bundesdeutschen Gesundheitswesen war seinerzeit die 60-Stunden-Woche üblich; viele Krankenschwestern arbeiteten sogar bis zu 80 Stunden - und das selbstverständlich im Schichtbetrieb ganz nach den Bedürfnissen der Klinik. ${ }^{166}$ Für die ÖTV galt

165 | K.[arl] Osterkamp: Die wirtschaftliche Lage der Arbeitnehmer im öffentlichen Dienst. In: Öffentlicher Dienst, Transport und Verkehr 2 (1950), S. 250-251. 166 | Vgl. dazu: Kreutzer: »Liebesdienst«, S. 183 f. Allgemein zur Entwicklung der tariflich vereinbarten Arbeitszeit in den 1950er Jahren vgl.: Günter Scharf: Geschichte der Arbeitszeitverkürzung. Der Kampf der deutschen Gewerkschaften um die Verkürzung der täglichen und wöchentlichen Arbeitszeit, Frankfurt/ Main 1987, S. 604-654. 
es aber nicht nur, diesen sozialen Anachronismus so rasch wie möglich zu überwinden. Parallel musste sie auch die weitere Entwicklung der Arbeitszeit in der Privatwirtschaft im Auge behalten. Denn dort kämpften die Gewerkschaften bereits dafür, die 48 Stunden bei vollem Lohnausgleich zu verkürzen und gleichzeitig den Samstag zum zweiten arbeitsfreien Tag in der Woche zu machen.

Wirtschaftlich entwickelten sich die 1950er Jahre für die Bundesrepublik bekanntlich ausgesprochen positiv. Die Zeitgenossen sahen in diesem Aufschwung ein spezifisch deutsches "Wirtschaftswunder«, obwohl nüchtern betrachtet - andere westliche Länder seinerzeit durchaus vergleichbare Wachstumsraten verzeichneten. ${ }^{167}$ Diese umfassende Prosperität sollte - so könnte man denken - der ÖTV bei der Durchsetzung ihrer Forderungen geholfen haben. Ganz so einfach entwickelten sich die Dinge allerdings nicht.

Zwar wirkte der Mangel an Arbeitskräften, der in einzelnen Industriebranchen bereits in den Jahren 1953/54 auftrat und dann zügig zur Anwerbung der ersten ausländischen »Gastarbeiter« führte, zweifellos zum Vorteil aller Gewerkschaften. Für den Öffentlichen Dienst hatte die wachsende Lücke auf dem Arbeitsmarkt insofern Konsequenzen, als alle Politiker in verantwortlichen Positionen im Laufe der 1950er Jahre die Furcht entwickelten, der Staat als Arbeitgeber könne im Wettbewerb mit der Industrie zunehmend unattraktiv werden. Bundeskanzler Konrad Adenauer sah bereits 1951 die Gefahr, es werde in der Bundesrepublik bald nur noch »Zweitklassige Beamte « geben, »was grundlegenden staatspolitischen Interessen widerstreiten würde«. Ohne eine adäquate Bezahlung der Beschäftigten sei ein leistungsstarker Staatsapparat unmöglich. ${ }^{168}$

Bezog sich das zunächst vornehmlich auf besonders qualifizierten Nachwuchs, so erweiterte sich diese Furcht in dem Maße, in dem der Arbeitskräftemangel wuchs. Bereits 1954 klagte das Verkehrsministerium ganz all-

167 | Vgl.: Ludger Lindlar: Das mißverstandene Wirtschaftswunder. Westdeutschland und die westeuropäische Nachkriegsprosperität, Tübingen 1997.

168 | Die Kabinettsprotokolle der Bundesregierung, Bd. 4: 1951. Bearb. v. Ursula Hüllbüsch, Boppard 1988 (im Folgenden: Kabinettsprotokolle Bundesregierung 1951), S. 238 (Kabinettssitzung v. 16.3.1951). 
gemein für Bahn und Post, es gebe immer größere »Schwierigkeiten bei der Einstellung von neuem Personal, da geeignete Kräfte fehlen«. ${ }^{169}$

An politischen Bekenntnissen zu dem Grundsatz, der Staat müsse als Arbeitgeber die Entwicklungen in Industrie und Handel beachten und nachvollziehen, fehlte es in den Folgejahren daher nicht. Bundesinnenminister Hermann Höcherl postulierte 1964 als Gastredner auf dem ÖTV-Gewerkschaftstag sogar expressis verbis ein »Anrecht« der beim Staat beschäftigten Arbeitnehmer, "genauso behandelt zu werden, wie die allgemeine Entwicklung ist ${ }^{170}$

Wenn es darum ging, solchen Worten Taten folgen zu lassen, gab es dennoch regelmäßig Streit zwischen Gewerkschaft und Arbeitgebern. Das zentrale Argument, das zumal der Bund und die TdL in diesen Auseinandersetzungen immer wieder lautstark vortrugen, war weder neu noch besonders originell: Die Haushaltslage lasse - leider - nur Lohnsteigerungen zu, die weit hinter den Forderungen der ÖTV zurückblieben. Auch andere Sozialleistungen und bessere Arbeitsbedingungen der Beschäftigten könne sich der Staat wegen seiner knappen Mittel nur in ganz bescheidenen Umfang erlauben. ${ }^{171}$

Finanzprobleme gab es trotz zunehmend boomender Wirtschaft in der Tat. Allein schon die Versorgung der Millionen von Kriegsopfern sowie der dringend nötige massive Wohnungsbau, der fast vollständig aus öffentlichen Geldern finanziert werden musste, bedeuteten erhebliche zusätzliche Lasten für alle öffentlichen Etats. Staatsschulden aber galten seinerzeit als absolutes politisches Tabu; der ausgeglichene Haushalt - oder besser noch: Überschüsse - musste in jedem Fall erreicht werden. Zudem wollte insbesondere die Bundesregierung Löhne und Preise auch im Aufschwung möglichst stabil halten. Nur »Stabilität« galt als wirtschaftspolitisch »gesund«; wurde sie verfehlt, witterten die führenden Männer von CDU und CSU stets sofort eine weitere Inflation. Vor allem der ungemein populäre Wirt-

169 | Kabinettsprotokolle Bundesregierung 1954, S. 472 (Kabinettssitzung v. 23.6.1954).

170 | Protokoll ÖTV-GT 1964, S. 66.

171 | Vgl. etwa nur für 1950: Finanzminister Württemberg-Baden an TdL, 28.2.1950. In: Archiv Ver.di, Bestand Kluncker 44; Finanzminister Schleswig-Holstein an TdL, 31.1.1950. In: ebd.; Bericht des Personalamtes Hamburg über die Tarifvertragsverhandlungen mit der ÖTV, 3./4.4.1950. In: StA HH, 131-11, 294. 
schaftsminister Ludwig Erhard profilierte sich bei diesem Thema beständig als politische Kassandra. ${ }^{172}$

Paradoxerweise skandalisierte die Bundesregierung dabei immer wieder ihr größtes innenpolitisches Pfand: den Wohlstandszuwachs, den auch Normalverdiener dank des wirtschaftlichen Aufschwungs und dank gewerkschaftlicher Erfolge spätestens in der zweiten Hälfte der 1950er Jahre nach und nach genießen konnten. 1957 sprach Erhard im Kabinett empört über eine »Preis-Lohn-Spirale«, die dringend gestoppt werden müsse, wenn es wirtschaftlich weiter bergauf gehen solle. Ein Jahr später kommentierte er die Meldung, die Arbeitszeit für mehr als elf Millionen Beschäftigte der bundesdeutschen Industrie betrage nach den in der letzten Zeit ausgehandelten Tarifverträgen nur noch maximal 45 Stunden pro Woche, mit der schwarzseherischen Warnung: »Die Bundesrepublik sei auf dem Wege, den Boden zu zerstören, auf dem sie steht. ${ }^{173}$

Zwar richteten sich diese Warnungen immer auch an die Arbeitgeber; viele führende Christdemokraten aber hielten doch die Gewerkschaften für den wahren wirtschaftlichen Störenfried. Bundeskanzler Adenauer machte da keine Ausnahme. Im Frühjahr 1963 konstatierte er auf einer Kabinettssitzung, die von einer »kleinen Gruppe der Funktionäre« geführten Gewerkschaften seien in der Bundesrepublik so mächtig, dass sie »in Wirklichkeit die Geschicke des Landes in der Hand hielten. Dies könne auf die Dauer nicht hingenommen werden«. Die Bundesregierung brauche dringend gesetzlich gesicherte Möglichkeiten, »diesen endlosen Mehrforderungen entgegenzutreten« ${ }^{174}$

Dieser vehemente Vorstoß scheiterte zwar rasch an verfassungsrechtlichen Bedenken. Wegen der tief sitzenden Inflationsangst bemühte sich das

172 | Vgl. etwa: Volker Hentschel: Ludwig Erhard. Ein Politikerleben, München 1996, S. 235-243; Alexander Nützenadel: Stunde der Ökonomen. Wissenschaft, Politik und Expertenkultur in der BRD 1949-1974, Göttingen 2005, S. 264-278.

173 | In der Reihenfolge der Zitate: Die Kabinettsprotokolle der Bundesregierung, Bd. 10: 1957. Bearb. v. Ulrich Enders/Josef Henke, München 2000 (im Folgenden: Kabinettsprotokolle Bundesregierung 1957), S. 177 (Kabinettssitzung v. 7.3.1957); Die Kabinettsprotokolle der Bundesregierung, Bd. 11: 1958. Bearb. v. Ulrich Enders/Christoph Schawe, München 2002 (im Folgenden: Kabinettsprotokolle Bundesregierung 1958), S. 91 (Kabinettssitzung v. 22.1.1958).

174 | Die Kabinettsprotokolle der Bundesregierung, Bd. 16: 1963. Bearb. v. Ulrich Enders/Christoph Seemann, München 2006 (im Folgenden: Kabinettsprotokolle Bundesregierung 1963), S. 218 (Kabinettssitzung v. 7.5.1963). 
Kabinett aber dennoch kontinuierlich um eine Lohn- und Gehaltspolitik des »Maßhaltens«. Zwischen der Ankündigung, der Staat werde sich als Arbeitgeber selbstverständlich an dem orientieren, was in der Privatwirtschaft üblich sei, und der politischen Praxis klafften daher erhebliche Lücken. Insbesondere die Beamten, deren Gehälter und Arbeitsbedingungen per Parlamentsbeschluss dekretiert werden konnten, wurden lange mit einem zögerlich umgesetzten Ausgleich der aktuellen Inflationsrate abgespeist. Ein Besoldungsgesetz, das die im Wesentlichen noch aus dem Jahr 1927 stammenden Regelungen für diese Gruppe der Staatsbediensteten reformieren sollte, brauchte nach seiner Ankündigung im Jahr 1951 sieben Jahre bis zur Verabschiedung durch den Bundestag. Die Wirkung blieb bescheiden: Selbst unter Einrechnung bereits vorher gewährter Übergangszahlungen erreichte die reale Kaufkraft der Beamtengehälter nach dem Inkraftreten des Gesetzes lediglich den Stand von 1927. ${ }^{175}$

Kürzere Arbeitszeiten lehnte das Kabinett ebenfalls ab: Noch Anfang 1958 beschloss die Bundesregierung unter dem Vorsitz von Kanzler Konrad Adenauer kategorisch, es müsse bei der 48-Stunden-Woche im Öffentlichen Dienst bleiben. Damit sollte ausdrücklich ein Zeichen für »die Beendigung des Zuges zur Arbeitsverkürzung« in der bundesdeutschen Wirtschaft gesetzt werden. ${ }^{176}$

Angesichts dieser Haltung des Bundeskanzlers und seiner Minister waren die Tarifverhandlungen für die Arbeiter und Angestellten im Öffentlichen Dienst für die ÖTV sogar mitten im "Wirtschaftswunder« alles andere als ein Spaziergang; ja, teilweise nahmen sie sogar »sehr, sehr häßliche Formen« an, weil die Vertreter der Bundesregierung wiederholt versuchten, auch Länder und Kommunen auf die harte Linie des Kabinetts festzulegen. ${ }^{177}$

175 | Hans-Joachim Hülsbruch: Die Gestaltung der Beamtengehälter seit der Währungsumstellung. Eine volkswirtschaftliche Untersuchung, wirtschaftswiss. Diss., Hochschule für Wirtschafts- und Sozialwissenschaften Nürnberg 1961, S. $141 \mathrm{f}$. Vgl. dazu auch: Das Besoldungsgesetz war kein Wahlgeschenk. In: Die Quelle 8 (1957), S. 397-398.

176 | Kabinettsprotokolle Bundesregierung 1958, S. 93 f. (Kabinettssitzung v. 22.1.1958).

177 | A. Kummernuss in: Protokoll ÖTV-GT 1958, S. 67. 


\section{Probelauf mit Folgen: Der ÖTV-Streik in Hamburg von 1954}

Solche Bemühungen der Bundesregierung führten allerdings selten tatsächlich zum Erfolg, denn gerade die Gemeinden und ihr tarifpolitischer Dachverband VKA gaben der ÖTV in lohnpolitischen Fragen wiederholt weitaus bereitwilliger nach, als es sich die Bundesregierung wünschte. Diese Kompromissbereitschaft der Kommunalvertreter hatte die Gewerkschaft aktiv erkämpft, indem sie in den 1950er Jahren zweimal eindrucksvoll demonstrierte, wie stark ihre Streikmacht in den Städten war. 1954 organisierte sie einen achttägigen lokalen Ausstand in Hamburg; 1958 rief sie ihre Mitglieder auf kommunaler Ebene dann erstmals bundesweit zu einem Streik auf, der allerdings schon nach 24 Stunden sein Ende fand. Diese Arbeitskämpfe gehören an zentraler Stelle zu den Erfahrungen, die Heinz Kluncker im Zuge seiner gewerkschaftlichen Professionalisierung in und mit der ÖTV sammelte. ${ }^{178}$

Die Gewerkschaftsfunktionäre erlebten bei diesen Streiks allerdings nicht nur, wie wirkungsvoll ein Ausstand der Beschäftigten im Öffentlichen Dienst sein konnte. Sie lernten zugleich, wie rasch die Gewerkschaft im Zentrum der öffentlichen Aufmerksamkeit stand, wenn sie einen Arbeitskampf leitete, und wie scharf Politik und Medien die ÖTV als streikende Organisation kritisierten. Oft wurde dabei das Streikrecht für Arbeiter und Angestellte des Staates gleich grundsätzlich in Frage gestellt, obwohl die Gewerkschaft nach 1950 doch nur diese beiden Arbeitskämpfe

178 | Vor den beiden genannten Streiks hatte die ÖTV nur einen bedeutsameren Arbeitskampf geführt: Im Oktober 1950 organisierte sie einen siebentägigen Streik von Arbeitern und Angestellten an Schleusen, der die Binnenschifffahrt treffen sollte. Sie wollte so die Bundesregierung zu Zugeständnissen im Streit über einen Teuerungsausgleich für den Öffentlichen Dienst zwingen. Vgl. dazu ausführlich: Nachtmann: 100 Jahre ÖTV, S. 316-322. Der Streik führte zwar zu einem Erfolg, erwies sich aber offensichtlich nicht als so effektiv wie von der ÖTV erhoff, weil Beamte an die Stelle der kleinen Gruppe von Streikenden traten. Als neu gegründete Organisation, die keinen nennenswerten Streikfonds besaß, war jedoch für die ÖTV seinerzeit offensichtlich nur ein personell eng begrenzter Expertenstreik möglich, den die allgemeine Öffentlichkeit nur am Rande wahrnahm. Negative politische Reaktionen und Pressekommentare, die von »Erpressung « und "Schädigung der Allgemeinheit« sprachen, gab es allerdings auch schon bei dieser Gelegenheit. Vgl. etwa: Die dunkle Nordsee. In: FAZ, 10.10.1950; Stoßtrupp Kummernuss. In: Die Zeit, 12.10.1950. 
ausfocht. Insofern gehörte sie zu den ausgesprochen friedlichen Organisationen im DGB. Gleichwohl war wegen der harschen öffentlichen Reaktionen ein Streik für die ÖTV offensichtlich eine in doppelter Hinsicht problematische Waffe: Der Arbeitskampf kostete sie nicht nur viel Geld. Zugleich ging mit einem Ausstand der ÖTV immer gleich eine öffentliche politische Debatte um ein gewerkschaftliches Grundrecht einher.

Diese widersprüchlichen Effekte zeigten sich schon beim Hamburger Streik von 1954. Da es sich dabei um den ersten wirklich großen Arbeitskampf im Öffentlichen Dienst in Deutschland seit den Jahren 1931/32 handelte (als sich Beschäftigte sowohl der Hamburger als auch der Berliner Verkehrsbetriebe in "wilden Streiks« jeweils vergeblich gegen Lohnkürzungen gewehrt hatten), fand dieser rein lokale Ausstand in der ganzen Bundesrepublik breite öffentliche Aufmerksamkeit. ${ }^{179}$

Konkret ging es in der Hamburger Tarifauseinandersetzung um die Haustarife der städtischen Verkehrsbetriebe sowie der Wasser- und Gaswerke. Die ÖTV forderte unter Hinweis auf gestiegene Preise, die generell hohen Lebenshaltungskosten in Hamburg und die Einkommensdifferenz zwischen Privatindustrie und Öffentlichem Dienst deutliche Lohn- und Gehaltserhöhungen, insbesondere für die Arbeiter. Der Senat der Hansestadt bot für die Arbeiter ungefähr ein Drittel dessen, was die Gewerkschaft verlangte. Die Löhne der drei Staatsbetriebe, so erklärten die Senatoren, lägen im Vergleich mit anderen öffentlichen Unternehmen in der Bundesrepublik ohnehin ungewöhnlich hoch. Weitere Steigerungen würden in Hamburg zu höheren Preisen für Wasser, Gas sowie für Bahn und Bus führen und damit die Interessen der »überwältigenden Mehrheit der arbeitenden Bevölkerung schädigen $« .{ }^{180}$

179 | Vgl.: Theo Pirker: Die blinde Macht. Die Gewerkschaftsbewegung in Westdeutschland. Zweiter Teil: 1953-1960. Weg und Rolle der Gewerkschaften im neuen Kapitalismus, München 1960, S. $105 \mathrm{f}$.

180 | Presseerklärung des Hamburger Senats, 15.7.1954. In: StA HH, 135-1 VI, 1639. Für die ÖTV vgl.: ÖTV, Bezirksverwaltung Hamburg an die Hamburger Hochbahn AG, 22.6.1954. In: StA HH, 131-1 II, 1326. Zum Berliner Streik von 1932, der von der Gewerkschaft nicht unterstützt wurde, vgl. etwa Detlef Lehnert: Kommunale Politik, Parteiensystem und Interessenkonflikte in Berlin und Wien 1919-1932. Wohnungs-, Verkehrs- und Finanzpolitik im Spannungsfeld von städtischer Selbstverwaltung und Verbandseinflüssen, Berlin 1991, S. 442-449. 
Trotz längerer Verhandlungen fanden Gewerkschaft und Senat in dieser Auseinandersetzung keinen Kompromiss, der beide Seiten zufrieden stellte. Dabei dürfte auch die besondere politische Konstellation eine Rolle gespielt haben: Der Stadtstaat wurde 1954 erst seit kurzer Zeit nicht mehr von der SPD regiert, die in Hamburg bislang seit dem Ende der NS-Diktatur stets klar dominiert hatte. Nach dem knappen Wahlsieg, den ein von CDU und FDP geführter »Bürgerblock« im Herbst 1953 errungen hatte, lag die politische Führung Hamburgs erstmals seit den Jahren der Weimarer Republik wieder in konservativ-liberaler Hand. Offensichtlich sah der neue Senat in den Tarifstreitigkeiten eine Gelegenheit, sich politisch zu profilieren. Gleichzeitig mag es in der Hamburger ÖTV, die mit der lokalen SPD eng verflochten war, durchaus Kräfte gegeben haben, die eine Konfrontation mit CDU und FDP eher suchten als scheuten. Verifizieren lassen sich diese politischen Spekulationen allerdings nicht.

Der Streik, der am 4. August 1954 begann, bewies jedenfalls eindringlich die Macht der ÖTV in einer Großstadt wie Hamburg. Bei der Hochbahn AG, dem städtischen Verkehrsunternehmen, legten 98 Prozent der Belegschaft die Arbeit nieder; auch in den Gas- und Wasserwerken streikten mehr als 80 Prozent der Beschä̈tigten. ${ }^{181}$ Der öffentliche Nahverkehr lag daher vollständig still (nur die von der Bundesbahn betriebenen S-Bahnen fuhren weiter); der Druck in den Gasleitungen sank so stark, dass Gasherde kaum noch funktionierten. Da seinerzeit ungefähr die Hälfte der Hamburger Verkehrsampeln noch mit Gas betrieben wurde, fielen auch sie aus - was die Verkehrsprobleme der Stadt begreiflicherweise erheblich intensivierte. Die Wasserversorgung lief bei deutlich verringertem Druck in den Leitungen weiter; allerdings schlossen - mitten im Hochsommer alle Badeanstalten. ${ }^{182}$

In enger Kooperation mit den Betriebsleitungen organisierte die ÖTV in allen drei Betrieben einen Notdienst, der die Betriebstechnik vor Schäden bewahrte und - bei Wasser und Gas - eine Art Minimalversorgung der

181 | Aktenvermerk von Senator Luigs über die wirtschaftlichen Auswirkungen des Streiks, 16.2.1955. In: StA HH, 131-1 II, 1326.

182 | Vgl. etwa: Aktenvermerk der Senatskanzlei, 5.8.1954. In: StA HH, 131-1 II, 1326; Bewegter Freitag. In: Hamburger Echo, 7.8.1954; Quo vadis, Kummernuss? In: HAB, 7.8.1954; Versorgungslage in Hamburg spitzt sich zu. In: FR, 7.8.1954; Streik-Ende? Wenig Hoffnung. In: Die Welt, 8.8.1954. 
Bevölkerung sicherstellte. So wurde etwa der Gasdruck seit dem dritten Streiktag jeweils in den Mittagsstunden kurzzeitig erhöht, damit die Besitzer von Gasherden wieder kochen konnten. ${ }^{183}$

Wie die Hamburger diesen Arbeitskampf beurteilten, der vielfach stark in ihren Alltag eingriff, lässt sich nicht sagen. Zwar berichtete die Presse von heftigen Unmutsbekundungen, die Repräsentativität solcher Stimmen aber bleibt fraglich. Die vielen, fast durchweg stark gewerkschaftsfeindlichen Protestbriefe von einzelnen Bürgern, die während der Streiktage im Hamburger Rathaus eingingen, taugen ebenfalls nicht, um eine mehrheitlich ablehnende Haltung der betroffenen Bevölkerung zu belegen, denn schließlich konnte man ja auch den Senat dafür verantwortlich machen, dass eine Einigung ausblieb. ${ }^{184}$

Einen Druck, aufeinander zuzugehen, scheint jedenfalls keine der beiden Seiten empfunden zu haben. In dieser verfahrenen Situation waren zwei fast direkt aufeinander folgende Schlichtungsverfahren erforderlich, um den Arbeitskampf zu beenden. Die erste Empfehlung unparteiischer Experten scheiterte in einer Urabstimmung der ÖTV an 90 Prozent NeinStimmen - was insofern bemerkenswert ist, als die Gewerkschaft vor der Abstimmung keine klare Empfehlung gegen eine Annahme abgegeben hatte. ${ }^{185}$ Auch in der zweiten Woche stand die Streikfront offensichtlich noch fest. Einen Vorschlag des Senats, beide Seiten sollten die Entscheidung ganz in die Hände von unabhängigen Schlichtern legen, wiesen die

183 | Pressemitteilung der Hamburger Gaswerke, 6.8.1954. In: StA HH, 131-1 II, 1326. Bei den Gaswerken stellte die ÖTV immerhin 13 Prozent der Belegschaft für den Notdienst ab; im Wasserwerk lag dieser Anteil sogar bei 19 Prozent. Lediglich im städtischen Verkehrsbetrieb (der Hochbahn AG) blieb der Notdienst mit zwei Prozent der Belegschaft sehr klein. Alle Angaben nach: Aktenvermerk von Senator Luigs über die wirtschaftlichen Auswirkungen des Streiks, 16.2.1955. In: StA HH, 131-1 II, 1326.

184 | Eine Sammlung solcher Briefe findet sich in: StA HH, 131-1 II, 1326; zugleich enthält diese Akte aber auch eine Entschließung des Betriebsrates des Hamburger Gesamthafenbetriebs (datiert vom 10.8.1954), die den Senat dafür verantwortlich machte, dass der Arbeitsweg der Hafenarbeiter wegen des Streiks mühsam war.

185 | Vgl.: Flugblatt der ÖTV-Bezirksverwaltung Hamburg, 6.8.1954; Bekanntmachung der ÖTV-Bezirksverwaltung Hamburg, 8.8.1954. Beide in: StA HH, 131-1 II, 1326. 
Betriebsräte der drei Unternehmen jedenfalls empört als »Provokation« zurück. ${ }^{186}$

Es folgte eine zweite Schlichtung unter dem Vorsitz eines prominenten Hamburger Juristen. Der Einigungsvorschlag dieses Gremiums, den schließlich beide Seiten annahmen, enthielt im Wesentlichen die Zahlen, die der ÖTV-Vorsitzende Adolph Kummernuss kurz zuvor öffentlich als gerade noch akzeptabel bezeichnet hatte. Der Lohnzuschlag für die Arbeiter der drei Unternehmen lag nun doppelt so hoch wie zunächst von der Stadt angeboten. Die Experten, zu denen der Hamburger Sozialdemokrat Karl Schiller gehörte, erklärten ergänzend, sie seien der Gewerkschaft so weit entgegengekommen, um den Streik endlich zu beenden, obwohl die Lohnsteigerung zwingend zu höheren Preisen für Wasser, Gas und Nahverkehr in Hamburg führen werde. ${ }^{187}$

Politik und Presse griffen dieses Urteil bereitwillig auf. Hamburgs Erster Bürgermeister Kurt Sieveking (CDU), der sich ansonsten gerne betont liberal gab, meinte, er habe dem »Druck einer Minderheit" nachgeben müssen, die »ihre Monopolstellung in den lebenswichtigen Betrieben « ausnutze, um eigennützige Forderungen auf Kosten der Allgemeinheit durchzusetzen. Für die Zukunft müsse es gesetzliche Regelungen geben, die einen ähnlichen Streik verhinderten. ${ }^{188}$ Sein Stellvertreter Edgar Engelhard (FDP) rückte die ÖTV sogar in die Nähe von Putschisten, weil sie gegen »die frei gewählte Regierung« der Hansestadt gekämpft habe: Arbeitsnie-

186 | Mitteilung der ÖTV-Bezirksverwaltung Hamburg, 10.8.1954. In: StA HH, 131-1 II, 1326.

187 | Schiedsspruch der Schlichtungskommission, 12.8.1954. In: StA HH, 131-1 II, 1326; Mitteilung des Senats, 12.8.1954. In: ebd. (Zitat). Hatte der erste Schiedsspruch eine Erhöhung des Arbeiterstundenlohns um fünf Pfennige sowie drei Prozent mehr Gehalt für die Angestellten vorgeschlagen, so sah der zweite Schiedsspruch sieben Pfennige bzw. 3,5 Prozent vor. Genau diese Zahlen hatte Kummernuss bei einem Besuch in Hamburg am 9. August als das Ergebnis benannt, unter dem die ÖTV keinesfalls abschließen werde. Ursprünglich hatte die ÖTV zehn Pfennige gefordert; der Senat hatte 3,5 Pfennige angeboten (Stichworte über die Pressekonferenz der ÖTV, 9.8.1954. In: ebd. Vgl. auch: Versteifung in Hamburg. In: FAZ, 10.8.1954).

188 | Kurt Sieveking: Nach dem Streik. In: HAB, 14.8.1954. 
derlegungen in öffentlichen Versorgungsbetrieben seien »anachronistisch, ja frivol. Hier darf nicht mehr gezögert werden. ${ }^{189}$

Die vorwiegend bürgerliche Presse der Bundesrepublik sah das mehrheitlich ganz ähnlich. Auch Zeitungen außerhalb Hamburgs und überregionale Blätter berichteten ausführlich über den Arbeitskampf an der Elbe. Die Stuttgarter Zeitung etwa sah »den kleinen Mann« als Leidtragenden des Streiks und der neuen Löhne; Die Zeit sprach von einem »Warnsignal« vor einer allzu großen Macht der Gewerkschaften und titulierte die Hamburger Bürger als »Zwangsgeschädigte« der ÖTV; die FAZ befürchtete sogar einen Inflationsschub und kommentierte den Streik mit den Worten, er zeige »an welchen Abgründen eine Demokratie wandelt, wenn sie nicht in jedem Augenblick ganz genau die politischen Auswirkungen ihrer Lohnpolitik überprüft«. ${ }^{190}$ Auch der öffentlich-rechtliche Rundfunk, der zu dieser Zeit noch ein Sendemonopol im Äther besaß, verurteilte die Tarifautonomie mit scharfen Worten: Bei Streiks im Öffentlichen Dienst litten "ganz Unbeteiligte" so "wie etwa die Zivilbevölkerung im modernen Luftkrieg«. Schiedsgerichte mit dem Recht, verbindliche Entscheidungen zu fällen, seien für die Zukunft unerlässlich. ${ }^{191}$

Wirtschaftlich war all diese Aufregung völlig unberechtigt. Die gewährten Lohnsteigerungen hatten für die drei staatseigenen Betriebe nur geringe Auswirkungen. Zwar musste die Hamburger Hochbahn mit acht Prozent höheren Personalkosten rechnen; Gas- und Wasserwerk kamen auf jeweils fünf Prozent. In der Gesamtrechnung der Unternehmen ergaben sich dadurch aber nur geringe Verschiebungen: Die Hochbahn verzeichnete 2,5 Prozent höhere Aufwendungen; bei Gas und Wasser betrug die Steigerung sogar nur ein Prozent aller anfallenden Kosten. Betrieb-

189 | Edgar Engelhard: Nach dem Streik. In: HAB, 14.8.1954.

190 | In der Reihenfolge der Zitate: Lohn der Angst. In: StZ, 7.8.1954; Modellfall Hamburg. In: Die Zeit, 19.8.1954; Die Sackgasse des Streiks in Hamburg. In: Die Zeit, 12.8.1954; Teils, teils. In: FAZ, 13.8.1954.

191 | Abschrift des Rundfunk-Kommentars von Friedrich Friedländer, 14.8.1954. In: StA HH, 131-1 II, 1326. Gesendet wurde dieser Text wohl im Programm des NWDR, der damals noch bestehenden Rundfunkanstalt für Nord- und Westdeutschland, die 1956 in NDR und WDR aufgegliedert wurde. Friedländer, der bis 1950 stellvertretender Chefredakteur der Zeit gewesen war und seitdem als freier Publizist arbeitete, gehörte seinerzeit zu den prominentesten deutschen Journalisten. 
liche Rationalisierungsmaßnahmen, die ohnehin geplant gewesen waren, konnten diese zusätzlichen wirtschaftlichen Belastungen problemlos ausgleichen. ${ }^{192}$

Der Streik selbst hinterließ in den Bilanzen der drei Unternehmen keine dramatischen Spuren, weil sich die Einnahmeausfälle mit den nicht gezahlten Löhnen verrechnen ließen. Sogar der vollständig stillgelegte Verkehrsbetrieb konnte so rund 60 Prozent seiner Mindereinnahmen ausgleichen. Zwar blieb mit einem Minus von 850.000 DM dennoch ein erheblicher Verlust zurück; auch diese Summe aber war für ein Unternehmen, das im gleichen Jahr eine Gewinnabgabe von 5,75 Millionen DM in die Kassen des Hamburger Staates zahlte, letztlich kein ernsthaftes Problem. Für das Wasserwerk bedeutete der Arbeitskampf sogar ein recht gutes Geschätt, weil die besonders personalintensiven Badeanstalten in der Streikwoche geschlossen blieben, während der Wasserverbrauch kaum sank. Aus diesen Zahlen schloss der Wirtschaftssenator der Stadt im Frühjahr 1955 in einem internen Memorandum, weder der Lohnabschluss noch der Streik machten es nötig, die Preise für Gas, Wasser und Verkehr zu erhöhen. ${ }^{193}$

Davon erfuhr die Öffentlichkeit allerdings nichts: Die Senatskanzlei strich die nüchternen Schlussfolgerungen des Senators, als sie offiziell über die Auswirkungen der Tarifstreitigkeit berichtete, und ersetzte sie durch ein ganz anderes Fazit: Die Mehrausgaben der drei Staatsbetriebe müssten mit Preiserhöhungen auf die Kunden »abgewälzt« werden, um Defizite zu vermeiden. ${ }^{194}$ Noch 1955 zahlten die Hamburger per Beschluss der Bürgerschaft deshalb tatsächlich höhere Tarife im Nahverkehr und für Gas, denn eine Flucht der Kunden zu anderen, günstigeren Anbietern mussten die städtischen Monopolunternehmen und die Politiker, die deren Preise bewilligten, damals nicht fürchten, und auch die Pkws galten seinerzeit offensichtlich noch nicht als ernst zu nehmende Konkurrenz für U-Bahn, Bus und Straßenbahn. Bei den städtischen Verkehrsmitteln fiel die Preis-

192 | Aktenvermerk von Senator Luigs über die wirtschaftlichen Auswirkungen des Streiks, 16.2.1955. In: StA HH, 131-1 II, 1326. Beim Gaswerk entstand durch den Streik ein finanzieller Schaden von 91.000 DM, beim Wasserwerk hingegen ein Gewinn von 110.000 DM.

193 | Ebd. Die Höhe der Gewinnabgabe nach: Hochbahntarife sind genehmigt. In: HAB, 4.4.1955.

194 | Drucksache für die Senatssitzung, 16.2.1955. StA HH, 131-1 II, 1326. 
erhöhung mit Verteuerungen zwischen 25 und neun Prozent (je nach Fahrkarte) sogar ausgesprochen üppig aus. Gerade in diesem Fall aber argumentierten Senat und Regierungsparteien mit dem angeblich so stark kostentreibenden Tarifabschluss. ${ }^{195}$

Überregionale Bedeutung hatte der Ausstand an der Elbe von 1954 darüber hinaus, weil er Politiker in anderen Bundesländern und Kommunen von der Macht der ÖTV überzeugte. Bei den zentralen Tarifverhandlungen, die kurz nach dem Ende des Hamburger Arbeitskampfes begannen, plädierte etwa der nordrhein-westfälische Innenminister Franz Meyers (CDU) entschieden dafür, der ÖTV ohne längere Streitigkeiten weit entgegenzukommen, weil die Industrie an Rhein und Ruhr unter einem Streik im Öffentlichen Dienst schwer leiden würde: »Jede Störung in den Versorgungs- und Verkehrsbetrieben könnte zu unabsehbaren Folgen im Industriegebiet führen.« Ähnlich argumentierten auch Vertreter der Großstädte in der VKA. ${ }^{196}$ Zwar folgte dann doch eine längere Verhandlungsrunde, weil sich die Bundesregierung gegen allzu eilige Zugeständnisse wehrte. In zwei Urabstimmungen bewies die ÖTV aber die Streikwilligkeit ihrer Mitglieder. Die damit errichtete Drohkulisse sorgte schließlich für ein friedliches Ende. Die ohne einen weiteren Streik abgeschlossenen Tarifverträge näherten sich der Regelung für die Beschäftigten der Hamburger Staatsbetriebe stark an: Die Lohnsteigerung für Arbeiter lag in ihnen doppelt so hoch wie das erste Angebot der Arbeitgeber. ${ }^{197}$

195 | Vgl.: Anfang April: Höhere Fahrpreise. In: HAB, 25.3.1955; Hochbahntarife sind genehmigt. In: HAB, 31.3.1955; Großzügiger Gasmann. In: HAB, 24.6.1955. Die Erhöhungen sind nach den Angaben im ersten dieser Artikel berechnet. Um 25 Prozent (von 40 auf 50 Pfennige) verteuerte sich ein Einzelfahrschein, der zum Umsteigen zwischen verschiedenen Linien und Verkehrsmitteln berechtigte. Um 20 Prozent verteuerten sich Schüler-Monatskarten (eine Erhöhung von fünf auf sechs DM); die neun Prozent betrafen »Umsteiger-Monatskarten« (von 16,50 DM auf $18 \mathrm{DM})$.

196 | Bericht über die Lohnverhandlungen zwischen TdL und VKA sowie ÖTV und DAG, 12./13.8.1954. In: StA HH, 131-1 II, 1326.

197 | Vgl. den Überblick in: ÖTV-Geschäftsbericht 1952/54, S. 68-73. 


\section{Der "umfassendste Streik in der deutschen Geschichte«: Der kurze Arbeitskampf der ÖTV von 1958}

Beim zweiten branchenübergreifenden Arbeitskampf, den die ÖTV organisierte, wiederholte sich im März 1958 in größerem Maßstab vieles von dem, was sich im Hamburger Streik vier Jahre zuvor ereignet hatte. Die Reaktionen in Politik und Medien fielen ähnlich aus: Wieder sah sich die ÖTV mit dem Vorwurf konfrontiert, sie handle »willkürlich«, »unverantwortlich« oder »erpresserisch «. ${ }^{198}$ Neu war nur: Solche Kritik kam nun selbst von SPD-Politikern, denn dieser ÖTV-Streik traf auch Großstädte wie West-Berlin, München oder Frankfurt am Main, die alle von sozialdemokratischen Bürgermeistern regiert wurden. Werner Bockelmann etwa, der Frankfurter Oberbürgermeister, klagte, unter der Arbeitsniederlegung leide die Frankfurter Bevölkerung gleich doppelt, durch Erschwernisse des Alltags während des Streiks, und - wichtiger noch - auch nachfolgend, weil der von der ÖTV erzwungene höhere Lohn die städtischen Dienstleistungen und die Versorgung mit Gas, Wasser und Strom verteuern werde. ${ }^{199}$ Da die ÖTV zudem in West-Berlin zum Streik aufrief, musste sie sich sogar noch als national unzuverlässig beschimpfen lassen. Den Zeitungen des Verlegers Axel Springer galt ein Streik bei den öffentlichen Verkehrsmitteln und in den Gas- und Stromwerken in der Teilstadt mitten im Kalten Krieg gleich als »härteste Belastungsprobe« für die Berliner seit der sowjetischen Blockade von 1948/49. ${ }^{200}$

In der DDR-Führung herrschte derweil eine ganz andere Furcht. Einerseits missverstand das Ministerium für Staatssicherheit selbstverständlich auch diesen Streik als Vorboten einer antikapitalistischen "Massenbewegung«, die dem Sozialismus in der Bundesrepublik zum Sieg verhelfen wer-

198 | Vgl. als Beispiele nur: Ein unpopulärer Streik. In: FAZ, 18.3.1958; Willkür. In: FAZ, 19.3.1958; Mittwoch Streik der Gemeindearbeiter. In: HAB, 17.3.1958. Vgl. die umfangreiche Sammlung weiterer Pressestimmen in: Archiv Ver.di, Bestand Kluncker, 45.

199 | »Unerfüllbar«sagen die kommunalen Arbeitgeber. In: FAZ, 25.2.1958; Harte Probe. In: FAZ, 7.3.1958; Der Streik triff unsere Stadt besonders hart. In: FAZ, 18.3.1958; Privatbusse befahren die wichtigsten Straßenbahnlinien. In: FAZ, 19.3.1958.

200 | Auch Berlin betroffen. In: HAB, 18.3.1958. Vgl. auch: Streik in Berlin! In: BZ am Mittag, 18.3.1958. 
de. Andererseits aber sorgte sie sich ernsthaft, der West-Berliner Ausstand könne vielleicht auch Ost-Berliner auf die Idee bringen, von ihrem Streikrecht Gebrauch zu machen - schließlich waren die beiden Teilstädte seinerzeit noch nicht durch die Mauer, den »antifaschistischen Schutzwall«, voneinander getrennt, und die S-Bahn, die von der DDR-eigenen Reichsbahn betrieben wurde, verkehrte auch in West-Berlin. In diesem Zusammenhang beschloss das oberste Gremium des Stasi-Apparates unter dem Vorsitz von Erich Mielke, »die operative Arbeit gegenüber der ÖTV [zu] überprüfen. Diese Gewerkschaftsorganisation wurde bisher nicht bearbeitet, aber der vergangene Streik erfordert das. $\aleph^{201}$

Das Ziel dieses politisch so stark beachteten Arbeitskampfes war bescheiden: Die ÖTV wollte mit dem Streik eine "gerechte Relation" der Einkommen zwischen Gemeindearbeitern und kommunalen Angestellten erreichen. Vor allem wegen anders gestalteter Zulagen, die sich auch am Familienstand orientierten, standen sich die letzteren oft deutlich besser als die Arbeiter der Kommunen. Mit Erhöhungen der Stundenlöhne, die bis zu 23 Pfennige betragen sollten, wollte die ÖTV hier gezielt Abhilfe schaffen. Die VKA bot hingegen maximal neun Pfennige. ${ }^{202}$ Da mehrere Verhandlungsrunden keine Annäherung brachten, setzte die ÖTV das Prozedere in Gang, das einem Streik nach ihren Statuten und auch nach den Gesetzen vorauszugehen hatte. Bei einer Urabstimmung beteiligten sich 197.000 von 225.000 Gemeindearbeitern, die Mitglied der ÖTV waren; 95 Prozent der abgegebenen Stimmen befürworteten einen Streik. ${ }^{203}$

Der Ausstand, der von vornherein als nur eintägiger »Proteststreik« angekündigt wurde, fand am 19. März 1958 statt und erwies sich als äußerst wirksam. Nach Angaben der ÖTV gab es im Bundesgebiet und in West-Ber-

201 | Protokoll der Kollegiumssitzung [des Ministeriums für Staatssicherheit], 26.3.1958. In: BStU, Archiv der Zentralstelle, MfS SdM, 2838. Einen Solidaritätsstreik bei der S-Bahn gab es bezeichnenderweise zwar nicht; die Züge hielten aber während des Ausstandes nicht auf den West-Berliner Bahnhöfen. Vgl. dazu etwa: Auch Berlin betroffen. In: HAB, 18.3.1958; SED-Störversuche in Berlin schlugen fehl. In: HAB, 19.3.1958. Zur praktischen Umsetzung des Beschlusses, die ÖTV stärker »operativ« zu beobachten, siehe unten S. 299.

202 | Das Zitat aus: Am Mittwoch stehen die Straßenbahnen still. In: FAZ, 18.3.1958. Zu den Details vgl. ausführlich: Tarifgespräch im öffentlichen Dienst. In: FAZ, 12.2.1958; ÖTV-Geschäftsbericht 1958/60, S. 159 f.

203 | ÖTV-Geschäftsbericht 1958/60, S. 158. 
lin insgesamt rund 250.000 Streikende; der Arbeitskampf war damit trotz seiner kurzen Dauer »der umfassendste Streik [...], der in Deutschland je geführt wurde ${ }^{204}$ Wie schon in Hamburg trat zumal in den großstädtischen Verkehrs- und Versorgungsbetrieben jeweils fast die gesamte Belegschaft in den Ausstand. Der öffentliche Nahverkehr lag in den Großstädten und selbst in den meisten mittelgroßen Kommunen komplett still; vielfach blieb der Müll liegen und der Schulunterricht fiel aus, weil die Hausmeister die Gebäude nicht heizten. Zwar gab es durchweg - wie schon in Hamburg Notdienste, die trotz der Arbeitsniederlegung eine Grundversorgung mit Wasser, Gas und Strom für die Bürger sicherstellten. Industriebetriebe, die sich nicht selbst mit Energie versorgten, konnten in einzelnen Fällen den Betrieb jedoch nicht fortführen. So schlossen in Kiel die Howaldtswerke (eine Werft); in Hannover schickte der Reifenhersteller Continental seine Arbeiter nach Hause; in Köln stoppte Ford die Pkw-Produktion. ${ }^{205}$

Da die ÖTV-Führung mit einem unbefristeten Streik drohte, führten neue Verhandlungen mit der VKA, die unmittelbar nach dem Ende des Warnstreiks begannen, innerhalb weniger Tage zu einer Einigung. Die Stundenlöhne der Gemeindearbeiter wurden um 14 Pfennige erhöht; Großstädte wie West-Berlin, Frankfurt oder München zahlten 15 Pfennige mehr. Prozentual entsprach das einem Plus von etwa sieben Prozent für die vergleichsweise gut bezahlten Arbeiter in großstädtischen Versorgungsbetrieben; bei geringeren Entgelten ergaben sich Zuschläge von zehn Prozent und mehr. Dazu kam eine Pauschalsumme von 50 DM für die drei Monate, in denen es für die Gemeindearbeiter keinen gültigen Tarifvertrag gegeben hatte. Dies wirkte sozial zusätzlich ausgleichend. ${ }^{206}$

Ob die ÖTV-Mitglieder, die sich sicher noch an die deutlich höheren Ausgangsforderungen der Verbandsführung erinnerten, mit diesem Resul-

204 | Ebd., S. 101. Nur den politisch motivierten Generalstreik gegen den KappPutsch im Jahr 1920 hielt die ÖTV für noch größer. Vgl.: Nach dem Streik wird wieder verhandelt. In: HAB, 20.3.1958.

205 | Vgl.: Warnstreik der ÖTV lähmt Berufsverkehr in Westdeutschland. In: HAB, 19.3.1958; Nirgends Zwischenfälle. In: HAB, 19.3.1958; Nach dem Streik wird wieder verhandelt. In: HAB, 20.3.1958; Nach dem Warnstreik wird verhandelt. In: FAZ, 20.3.1958. Lediglich in Hamburg und Bremen gab es keine Streikaktionen, weil die beiden Stadtstaaten der VKA nicht angehörten.

206 | ÖTV-Geschäftsbericht 1958/60, S. 160. 
tat zufrieden waren, wurde nicht geprüft. Da es sich lediglich um einen »Proteststreik" gehandelt hatte, musste die Gewerkschaft keine zweite Urabstimmung durchführen: Das positive Votum der Großen Tarifkommission reichte aus, um den ausgehandelten Kompromiss anzunehmen. Wenige Wochen später schlossen ÖTV und Arbeitgeber ohne großen Streit gleichlautende Verträge auch für die Arbeiter der Länder und des Bundes. $^{207}$

In der Öffentlichkeit galt die Gewerkschaft damit als eindeutiger Sieger. Allerdings zog sie gerade deshalb Kritik auf sich: Der Triumph der ÖTV, so kommentierte etwa das zum Springer-Konzern gehörende Hamburger Abendblatt, belaste die städtischen Haushalte und gehe somit »auf Kosten der Pflege öffentlicher Anstalten, eines Schwimmbades oder gar eines Kinderheimes ${ }^{208}$ Kommunalpolitiker aller Parteien betonten, sie hätten unter dem Zwang der Gewerkschaft wider die ökonomische Vernunft gehandelt. Der Stuttgarter OB Arnulf Klett (CDU) erklärte als Vorsitzender der VKA, man habe »eine staatspolitische Entscheidung« getroffen, weil es in der vom kommunistischen Osten bedrohten Bundesrepublik keine innere Unruhe geben dürfe. In Berlin meinte Finanzsenator Joachim Lipschütz (SPD), die rasche Einigung nach dem Warnstreik sei »eine nationalpolitische Aufgabe " gewesen. ${ }^{209}$

Dieses vielfach in grellen Farben gemalte Bild von rücksichtslos eingesetzter und fast unbegrenzter gewerkschaftlicher Macht auf der einen und allgemeiner Wehrlosigkeit auf der anderen Seite hatte nur wenig mit der Realität zu tun. Tatsächlich zog die ÖTV weder bedenkenlos noch ohne Sorgen in den Arbeitskampf von 1958 - und bei nüchterner Betrachtung wäre dieses Zögern eigentlich auch für einen Außenstehenden recht leicht zu erkennen gewesen. Aufregung aber fiel Politik und Medien in der Bundesrepublik generell immer viel leichter als Nüchternheit, wenn gestreikt wurde. Ohne es zu erkennen, erleichterten die Politiker und die Journalisten damit gerade der ÖTV ihr Geschäft, das so leicht nämlich gar nicht war, obwohl sie im Öffentlichen Dienst doch ohne Frage wirkungsvolle Streikaktionen organisieren konnte.

207 | Ebd.

208 | Kauft Kerzen! In: HAB, 20.3.1958.

209 | In der Reihenfolge der Zitate: Kein Streik in den Gemeinden. In: HAB, 22./23.3.1958; Senator Lipschütz warnt. In: Telegraf, 23.3.1958. 
Jeder Ausstand bedeutet für eine Gewerkschaft, die dazu aufruft, die Arbeit niederzulegen, zunächst einmal vor allem Kosten, denn selbstverständlich erwarten die Mitglieder die ihnen nach den Verbandsstatuten zustehende Streikunterstützung als Ausgleich für den ausbleibenden Lohn. Gerade große Streiks sind rasch sehr teuer. Da es im Tarifstreit von 1958 um einen für alle deutschen Kommunen geltenden Lohnvertrag ging, konnte die ÖTV keinen regionalen Arbeitskampf ausrufen. Sie musste bundesweit agieren und war gerade deshalb unsicher, ob sie sich diesen Streik finanziell überhaupt leisten konnte. Bei vorbereitenden Beratungen mit den Bezirksleitern am 12. März 1958 warnte der gHV ausdrücklich vor einem sofortigen flächendeckenden Ausstand: »Auf keinen Fall dürften wir uns verausgaben.«Der gHV fürchtete in Erinnerung an die Reaktionen auf den Hamburger Streik zudem politische Gegenmaßnahmen: Radikale Aktionen wie eine Unterbrechung der Wasser-, Gas- und Stromlieferung seien völlig ausgeschlossen, weil man der Bundesregierung keine Handhabe geben dürfe, um nach der Technischen Nothilfe zu rufen oder »irgendwelche gegen den Streik gerichteten Gesetze zu beschließen «. ${ }^{210}$

In historischer Perspektive war diese Furcht sehr verständlich: In den ersten Jahren der Weimarer Republik hatte der sozialdemokratische Reichspräsident Friedrich Ebert gleich mehrere Notverordnungen erlassen, die Streiks in »lebenswichtigen Betrieben " untersagten und bei Verstößen gegen dieses Verbot mit Gefängnis drohten. Zudem gründete die Republik die »Technische Nothilfe« (»TeNo«), eine Art Einsatztruppe, die über das Know-how und die Technik verfügte, um die Produktion in »lebenswichtigen Betrieben« in Gang zu halten. Ihre Rechtfertigung fanden diese Maßnahmen in "wilden Streiks « etwa bei der Reichsbahn oder in großstädtischen Elektrizitätswerken, mit denen die Beschäftigten - ohne Unterstützung der Gewerkschaften - Lohn- und Gehaltserhöhungen durchsetzen, die den galoppierenden Wertverlust der Mark durch die Inflation zumindest vorübergehend ausglichen. Dabei wurden Betriebe mitunter vollstän$\operatorname{dig}-$ d.h. ohne jeden Notdienst - stillgelegt. ${ }^{211}$

210 | Protokoll der Sitzung des gHV mit den Bezirksleitern, 12.3.1958. In: Archiv Ver.di, Bestand Kluncker, 45.

211 | Vgl. dazu als knappen Überblick etwa: Petra Weber: Gescheiterte Sozialpartnerschaft - Gefährdete Republik? Industrielle Beziehungen, Arbeitskämpfe und der Sozialstaat. Deutschland und Frankreich im Vergleich (1918-1933/39), 
Zwar war all dies in der Bundesrepublik Vergangenheit, und mit gewerkschaftlichem Handeln hatte es ohnehin nie etwas zu tun gehabt. Aber ÖTV-Funktionäre wie Adolph Kummernuss, die schon vor 1933 gewerkschaftlich aktiv gewesen waren, dürften sich noch gut an diese Regelungen erinnert haben, die bei den Gewerkschaften seinerzeit auf scharfe Kritik gestoßen waren, weil sie die Koalitionsfreiheit gerade der Staatsarbeiter und der Staatsangestellten massiv einschränkten. Dementsprechend vorsichtig wollte der Hauptvorstand bei dem Streik von 1958 vorgehen.

Konkret dachte sich der Vorstand den Ausstand als "Springerstreik«, der »mit wenig Einsatz« große Wirkung haben könne, weil er »heute hier, morgen dort« stattfinden sollte. Bei den Bezirksleitern stieß dieses Konzept jedoch auf Widerstand. Albert Fink, der den Bezirk NRW II vertrat, fürchtete, solche punktuellen Aktionen seien mit den ÖTV-Mitglieder nicht verlässlich zu organisieren: "Sie wollten in der Masse anonym bleiben und seien nur dann bereit, ein Opfer zu bringen, wenn alle mitmachen.« Karl Meissner (Bezirk Hessen) sah hingegen eher die Gefahr, dass "wir in unseren Reihen das Kommando verlieren könnten«, weil Betriebsgruppen mit besonders engagierten Kollegen auf eigene Faust streiken könnten. Erich Raabe aus dem Bezirk Niedersachsen hielt ganz generell nichts von begrenzten Arbeitsniederlegungen: »Ein Paukenschlag am Anfang hätte eine große Wirkung." Damit erntete er Zuspruch von verschiedenen Seiten, auch weil eine weithin wahrnehmbare Aktion der ÖTV viele neue Mitglieder bringen könne. Paul Leichsenring (Bezirk Baden-Württemberg) hielt jedoch gerade dieses Argument für frivol: »Auf keinen Fall dürfte ein Streik als Werbemittel betrachtet werden. $\ll^{212}$

Diese sehr kontroverse Debatte klärte sich erst, als der Vorsitzende Adolph Kummernuss plötzlich die vorherrschende Stimmung gegen einen »Springerstreik« aufgriff und damit den bisherigen Kurs des gHV verließ: »Lieber mutig ins Zeug greifen und einige Millionen ausgeben, als zaghaft

München 2010, S. 524-527; Robert Hill: Streiks in gemeinnützigen Betrieben. In: Walter Kaskel (Hrsg.): Koalitionen und Koalitionskampfmittel, Berlin 1925, S. 149-156. Zur »TeNo« vgl. etwa: Heinrich August Winkler: Von der Revolution zur Stabilisierung. Arbeiter und Arbeiterbewegung in der Weimarer Republik 1918 bis 1924, Berlin und Bonn 1984, S. 407-412.

212 | Protokoll der Sitzung des gHV mit den Bezirksleitern, 12.3.1958. In: Archiv Ver.di, Bestand Kluncker, 45. 
sein und nachher eine Schlappe einstecken, die nicht so leicht wiedergutgemacht werden kann « - so lautete jetzt seine Parole. Die Furcht vor finanziellen Lasten aber blieb bestehen. Ohne formellen Beschluss einigten sich die führenden Männer der ÖTV und gHV-Mitglied Ingeborg Tönnessen daher auf den eintägigen Warnstreik. Sofort zeitlich unbefristet zu streiken, galt als viel zu kühn, ein kurz erwogener Proteststreik nur in den Vormittagsstunden hingegen dann doch wieder als zu zaghaft. ${ }^{213}$

Hinter dem vermeintlich so machtvollen Auftrumpfen der ÖTV am 19. März 1958 stand mithin tatsächlich eine skeptische Selbsteinschätzung der Organisation: Ihr Führungspersonal hielt die Gewerkschaft keineswegs für unbesiegbar. Der geschäftsführende Hauptvorstand und die Bezirksleiter waren sich zudem recht unsicher, wie verlässlich die Mitglieder einem Streikaufruf folgen würden. Bei einer Organisation, die so gut wie keine Streikerfahrung besaß, war das eigentlich nicht weiter verwunderlich. Eher erstaunt es im Rückblick, wie wenig sich Politik und Medien für eventuelle Unstimmigkeiten im öffentlichen Bild der ÖTV interessierten. Selbst die keineswegs besonders günstige finanzielle Situation der Gewerkschaft, die in ihren Geschäftsberichten offen lag, wurde nicht wahrgenommen. Zwar konnte die Gewerkschaft die rund 1,4 Millionen DM, die der Warnstreik an ausgezahlten Streikunterstützungen kostete, problemlos verkraften. Bei einem längeren Arbeitskampf aber hätte das schon nach wenigen Tagen ganz anders ausgesehen, denn die Bankguthaben der Organisation, die - anders als weitere Vermögenswerte - rasch verfügbar waren, beliefen sich insgesamt auf nicht mehr als 20 Millionen DM. ${ }^{214}$ Ein hart geführter Streik, an dem viele Mitglieder teilnahmen, bedeutete für die ÖTV bei diesem finanziellen Polster ein erhebliches finanzielles Risiko.

Wie die rasche Einigung nach dem kurzen Warnstreik im März 1958 zeigt, zog die Gewerkschaft großen Vorteil daraus, dass sich Politiker und

213 | Ebd.

214 | Angaben nach: ÖTV-Geschäftsbericht 1958/60 (Nachtrag: Geschäftsbericht der Hauptkasse der Gewerkschaft ÖTV), S. 19 (ausgezahlte Streikunterstützung); ÖTV: Geschäftsbericht 1955-1957. Hrsg. v. der Gewerkschaft Öffentliche Dienste, Transport und Verkehr - Hauptvorstand, Stuttgart 1958 (im Folgenden: ÖTVGeschäftsbericht 1955/57), S. 673 (Bankguthaben Ende 1957). Der eben zitierte Nachtrag erschien separat, weil der Kassenbericht später erstellt wurde als der umfangreiche restliche Geschäftsbericht. 
Öffentlichkeit so wenig für Zahlen und Fakten interessierten. Wer als ausgesprochen stark gilt, der muss seine Kraft eben oft gar nicht mehr wirklich beweisen. Bei der ÖTV trat dieser Effekt in den 1950er Jahren wohl tatsächlich ein - und darauf zielte die Bemerkung eines Delegierten auf dem Gewerkschaftstag von 1964, die tarifpolitischen Erfolge der ÖTV seien jenseits rhetorischer Streitigkeiten mit den Arbeitgebern »zu plötzlich, zu reibungslos, zu schnell« gekommen, um die Basis der Organisation deutlich zu verbreitern: Eine Organisation, die weitgehend ohne Streiks auskomme, müsse sich nicht wundern, wie viele "Trittbrettfahrer« es unter den Beschäftigten des Öffentlichen Dienstes gebe. ${ }^{215}$

\section{Die ÖTV im Kampf gegen ein "Tarifdiktat" der Bundesregierung und gegen Vorschläge zur "Versachlichung" der Tarifpolitik in den frühen 1960er Jahren}

Tatsächlich bestimmte die für 1958 beschriebene Nachgiebigkeit der Kommunalpolitiker gegenüber Forderungen der ÖTV immer wieder den Verlauf von Tarifstreitigkeiten für den Öffentlichen Dienst. Die Warnstreiks in diesem Jahr intensivierten die gravierende Uneinigkeit unter den Arbeitgebern nur, schufen sie aber nicht. In einer tarifpolitischen Frage, die der Bundesregierung als sehr wichtig galt, bei der Arbeitszeit, hatte die VKA bereits ein Jahr vor dem 24-stündigen bundesweiten Ausstand der Gemeindearbeiter frühzeitig den Widerstand aufgegeben, den Kanzler und Bundesminister von allen öffentlichen Arbeitgebern verlangten. Damit setzte sich der "Zug zur Arbeitszeitverkürzung«, den die Regierung grundsätzlich aufhalten wollte, auch im Öffentlichen Dienst in Bewegung, denn der ÖTV gelang es im Sommer 1957, mit den Kommunen den Übergang auf 45 Wochenstunden zu vereinbaren - bei vollem Lohnausgleich für die nun fehlenden drei Stunden. Die VKA ließ sich auf diese Abmachung ein, weil die Gewerkschaft in der kurz zuvor ausgefochtenen Lohnrunde im Frühjahr 1957 eine siebenprozentige Erhöhung akzeptiert hatte, obwohl mit Blick auf die Tarifabschlüsse in der Privatwirtschaft vermutlich eine Steigerung um neun Prozent möglich gewesen wäre. ${ }^{216}$

215 | Delegierter Rudolf Pfeiffer (Mannheim) in: Protokoll ÖTV-GT 1964, S. 134. 216 | So die Mitteilungen des VKA-Vorsitzenden, des Stuttgarter Oberbürgermeisters Arnulf Klett. In: Aktenvermerk des Personalamtes Hamburg über die 
Dieser bewusste Verzicht, der die Kommunen aus einer zuvor geschlossenen Abwehrfront der Arbeitgeber herauslöste, brachte reichen Ertrag. Schon wenige Monate nach der Abmachung über die Arbeitszeitverkürzung unterschrieb der Stadtstaat Hamburg als erstes Bundesland einen gleichlautenden Vertrag für die Beschäftigten der Hansestadt. Die Flächenländer folgten kurz darauf; der Bund schließlich strich im März 1958 die Segel, um stark voneinander abweichende Arbeitsbedingungen im Öffentlichen Dienst zu vermeiden. Ab Oktober 1958 galt im Öffentlichen Dienst dann schließlich ganz allgemein die 45-Stunden-Woche. Auch Beamte profitierten von dieser ersten Arbeitszeitverkürzung für die Beschäftigten des Staates seit 1918. ${ }^{217}$

Ebenfalls im Frühjahr 1958 gaben die öffentlichen Arbeitgeber endlich der Forderung nach, die Beschäftigten in den Krankenhäusern zeitlich zu entlasten. Eine völlige Gleichstellung gelang zwar nicht, weil es auf dem bundesdeutschen Arbeitsmarkt kaum qualifiziertes Personal für neue Stellen in der medizinischen Pflege gab. Immerhin aber sank die von den Krankenschwestern verlangte Wochenarbeitszeit dank neuer Tarifverträge auf 51 Stunden; für den Oktober 1960 wurde zudem die 48-Stunden-Woche fest vereinbart. Auch dieser soziale Erfolg stand in direkter Verbindung mit dem kurz zuvor durchgeführten Warnstreik der kommunalen Arbeiter und Arbeiterinnen. ${ }^{218}$

Mitgliederversammlung der TdL, 21./22.5.1957. In: StA HH, 131-11, 294. Der Tarifvertrag über die 45-Stunden-Woche wurde Mitte Juni 1957 unterzeichnet; in Kraft trat er zum 1. Oktober des Jahres. Vgl.: Kürzere Arbeitszeit. In: HAB, 15.6.1957.

217 | Vgl.: Heinz Kluncker: Arbeitszeitverkürzung auch im öffentlichen Dienst. In: Die Quelle 9 (1958), S. 453-454; Jetzt noch 45 Stunden. In: HAB, 14.9.1958 (für Hamburg); Ab 1. Oktober für Beamte. In: HAB, 28.7.1958.

218 | Vgl. etwa: Kreutzer: »Liebesdienst«, S. 204-207. Vorangegangen war im Juli 1956 eine Verkürzung auf 54 Stunden. Sie galt allerdings nur in kommunalen Krankenhäusern (ebd., S. 195). Die Bestimmungen der Tarifverträge - auch die über die Arbeitszeit - galten allerdings grundsätzlich nicht für Krankenschwestern, die einem der sogenannten »Mutterhäuser" angehörten. Ihre Arbeitsbedingungen wurden von den »Mutterhäusern«, die Ähnlichkeit mit einem christlichen Orden hatten, weitgehend frei festgelegt. Zu diesen archaischen Strukturen vgl. etwa: Elisabeth Zimmermann: Der Beruf der Krankenschwester. Seine Entwicklung in den letzten 80 Jahren unter besonderer Berücksichtigung Bayerns und seiner Probleme in der Gegenwart, München 1961, S. 36-43. 
Ebenfalls schrittweise scheiterten 1961 und 1962 die Versuche der Bundesregierung, die bislang weitgehend vergeblich gepredigte Politik des »Maßhaltens« mithilfe einer lohnpolitisch betont harten Haltung im Öffentlichen Dienst doch noch auf breiter Front durchzusetzen. Die ÖTV empfand die Haltung der Regierung als höchst bedrohlich und reagierte mit ungewöhnlich scharfer Kritik. Diese tarifpolitische Zuspitzung, die in mancher Hinsicht die Konfrontation zwischen der Gewerkschaft und Bundeskanzler Willy Brandt im Jahr 1974 vorwegnahm und an der Heinz Kluncker als der frisch bestellte verantwortliche Tarifsekretär der ÖTV entscheidend beteiligt war, resultierte aus verschiedenen Faktoren.

So trat die ÖTV in den frühen 1960er Jahren deutlich fordernder auf, als sie das zuvor getan hatte. Adolph Kummernuss erklärte intern im Frühjahr 1960, die Organisation müsse lohnpolitisch »ein Stück Schüchternheit« aus früheren Jahren ablegen. Wenn man eine Lohnsteigerung von zehn Prozent anstrebe, »dann darf ich nicht 12\%, sondern muß 15\% verlangen. $\mathrm{Ob}$ uns dies schmeckt, ist eine andere Sache. ${ }^{219}$ Dementsprechend konfrontierte die Gewerkschaft Politiker und Öffentlichkeit sowohl 1960 als auch 1961 mit der Forderung nach einer fünfzehnprozentigen Steigerung der Löhne und Gehälter. ${ }^{20}$

Mit dieser Zahl fällten Hauptvorstand und Große Tarifkommission indirekt ein negatives Urteil über die Tarifabschlüsse der ÖTV seit 1950: Trotz der erreichten Zuwächse und ungeachtet des großen Warnstreiks von 1958 verdienten Staatsbeschäftigte in den frühen 1960er Jahren immer noch deutlich weniger als vergleichbare Arbeitnehmer in Industrie und Gewerbe. Mit ihrer Lohnpolitik war es der ÖTV nicht gelungen, hier eine Angleichung durchzusetzen; auf jeweils höherem Niveau bestand die vor dem Zweiten Weltkrieg entstandene Diskrepanz fast unverändert fort. Noch 1961 bezifferte das Bundesinnenministerium den Lohnabstand zwischen Arbeitern in staatlichen Unternehmen und in Industriebetrieben auf

219 | Protokoll der 7. Sitzung des HV, 8./9.4.1960. In: Archiv Ver.di, Bestand Kluncker, 45.

220 | Die Kabinettsprotokolle der Bundesregierung, Bd. 14: 1961. Bearb. v. Ulrich Enders/Jörg Filthaut, München 2004 (im Folgenden: Kabinettsprotokolle Bundesregierung 1961), S. 31. Vgl. auch: Zwanzig Jahre ÖTV, S. 43. Das SED-Organ Neues Deutschland berichtete in seiner Ausgabe vom 25.2.1960 über diese ÖTVForderung sogar auf der Titelseite. 
durchschnittlich 33 Prozent. ${ }^{221}$ Im gleichen Jahr konstatierte die Gewerkschaft, das »so viel gepriesene Wirtschaftswunder« sei bei den Staatsdienern bislang noch nicht angekommen. ${ }^{222}$

Anders als die ÖTV hielten die öffentlichen Arbeitgeber diese schlechtere Bezahlung allerdings nicht für ungerecht und unsozial. Vielmehr sahen sie darin eine Selbstverständlichkeit. Der Öffentliche Dienst, so hatte das Bundesarbeitsministerium bereits 1953 erklärt, privilegiere seine Beschäftigten ja durch den besonderen Kündigungsschutz und daneben auch noch durch ein besseres Krankengeld: »Ein Anspruch auf gleiche Entlohnung sei daher nicht berechtigt. ${ }^{223}$ Auch die TdL meinte, der Lohnabstand gegenüber der Industrie lasse sich wegen der »sozialen Schutzbestimmungen« im Öffentlichen Dienst, zu denen die bereits erwähnte zusätzliche Altersrente gehörte, nicht kritisieren. ${ }^{224}$

Mit dieser Argumentation setzte sich die ÖTV unter der Führung von Adolph Kummernuss nicht offensiv auseinander. Sie stellte sich vielmehr auf den Standpunkt, »gerecht entlohnt« würden die Beschäftigten des Staates erst dann, wenn die Arbeitgeber Löhne und Gehälter zahlten, die denen der Privatindustrie entsprachen. ${ }^{225}$ Zudem erklärte sie - wie alle DGB-Gewerkschaften - immer wieder, eine »Stärkung der Massenkaufkraft« durch Reallohnzuwächse sichere den weiteren ökonomischen Aufschwung und

221 | Kabinettsprotokolle Bundesregierung 1961, S. 126 (Kabinettsprotokoll v. 16.3.1961). In absoluten Zahlen betrug der durchschnittliche Stundenlohn für Industriearbeiter hiernach 3,01 DM, während im Öffentlichen Dienst 2,26 DM gezahlt wurden.

222 | ÖTV-Geschäftsbericht 1961/63, S. 371.

223 | Die Kabinettsprotokolle der Bundesregierung, Bd. 6: 1953. Bearb. v. Ulrich Enders/Konrad Reiser, Boppard 1989 (im Folgenden: Kabinettsprotokolle Bundesregierung 1953), S. 258 (Protokoll der Beratungen über Lohnerhöhungen im Öffentlichen Dienst, 10.4.1953). Da das Arbeitsministerium mit den Tarifverhandlungen für den Öffentlichen Dienst direkt nichts zu tun hatte (sie lagen allein in der Zuständigkeit des Innenressorts), stellt diese klare Positionierung eine politische Ausnahme dar. Typischerweise hielten sich die amtierenden Arbeitsminister in dieser Sache sehr zurück, um keine Ressortkonkurrenz aufkommen zu lassen. 224 | Vermerk der VKA-Geschäftsstelle über die Besprechungen mit der TdL und den Gewerkschaften, 2.8.1954, StA Hamburg, 131-1 II, 1326.

225 | Heinz Kluncker: Der Lohn- und Gehaltsstreit im Öffentlichen Dienst. In: Die Quelle 11 (1960), S. 106-107. 
diene daher auch den Interessen der bundesdeutschen Wirtschaft. ${ }^{226}$ Die 15-Prozent-Forderungen von 1960 und 1961 entsprachen exakt diesen Prämissen.

$\mathrm{Zu}$ ihrer neuen Rolle als lohnpolitisch lautstark auftrumpfende Gewerkschaft kam die ÖTV allerdings nicht ganz freiwillig. Vielmehr stand sie in dieser Sache unter starkem Druck, weil andere DGB-Gewerkschaften dank des Wirtschaftsbooms schon seit Mitte der 1950er Jahre teilweise groBe Erfolge für die Lohnabhängigen erringen konnten. In stark florierenden Branchen wie der Metallindustrie und der Bauwirtschaft kam es in der zweiten Hälfte des Jahrzehnts zu Tarifabschlüssen, die den Beschäftigten zu einem spürbar höheren Lebensstandard verhalfen. Bekannt ist insbesondere das hartnäckige Ringen der IG Metall um ein Urlaubsgeld und die Gleichstellung von Arbeitern und Angestellten bei der Lohnfortzahlung im Krankheitsfall. Ein 16 Wochen dauernder Streik in Schleswig-Holstein zwang die Arbeitgeber 1957, diese Forderungen zu akzeptieren. Sozialpolitisch kann dieser Abschluss als ein echter Meilenstein gelten, weil er zum Vorbild für viele andere Tarifverträge und für gesetzliche Regelungen wurde. ${ }^{227}$ Oft übersehen werden hingegen die fast zeitgleichen Erfolge der Baugewerkschaft, mit denen sie sowohl deutliche Lohnzuwächse als auch teilweise völlig neue Sozialleistungen wie Betriebsrenten und ein "Schlechtwettergeld« durchsetzte. ${ }^{228}$

226 | Vgl. etwa: ÖTV-Bezirksverwaltung Hamburg an die Hamburger Hochbahn AG, 22.6.1954. In: StA HH, 131-1 II, 1326; Vermerk der VKA-Geschäftsstelle über die Besprechungen mit der TdL und den Gewerkschaften, 2.8.1954. In: ebd.; Höhere Löhne und Gehälter im öffentlichen Dienst. In: Die Quelle 7 (1956), S. 9-10. 227 | Friedrich Stamp: Arbeiter in Bewegung. Die Geschichte der Metallgewerkschaften in Schleswig-Holstein, Malente 1997, S. 213-254. Als Überblick vgl. auch die Zusammenfassung des Bearbeiters in: Jürgen Peters (Hrsg.): In freier Verhandlung. Dokumente zur Tarifpolitik in der Metallindustrie 1945 bis 2002. Bearb. u. eingel. v. Holger Gorr, Göttingen 2003, Bd. 2, S. 145-163.

228 | Vgl. dazu etwa den Überblick des Gewerkschaftsvorsitzenden Georg Leber in: Protokoll über den 6. Ordentlichen Gewerkschaftstag der Industriegewerkschaft Bau - Steine - Erden für die Bundesrepublik Deutschland, Kongreßhalle Berlin vom 24. bis 29. Juni 1963, Frankfurt/Main o. J. (im Folgenden: Protokoll GT IG Bau 1963), S. 225 f. Das "Schlechtwettergeld « glich die Lohnausfälle aus, die entstanden, wenn Bauarbeiter wegen Frost oder Dauerregen nicht arbeiten konnten. 
Zwar argumentierte die ÖTV in Tarifverhandlungen und vor der Öffentlichkeit selbstverständlich mit Hinweisen auf diese Entwicklungen außerhalb des Öffentlichen Dienstes: Um die Staatsbediensteten sozial nicht zu benachteiligen und die Arbeit für Bund, Länder und Gemeinden weiterhin attraktiv zu gestalten, müssten sich die öffentlichen Arbeitgeber hier anpassen. ${ }^{229}$ Zugleich aber fürchtete die ÖTV den Vergleich. Im Frühjahr 1963 erregte sich Adolph Kummernuss vor dem Hauptvorstand sehr grundsätzlich über die Tarifpolitik der IG Bau. Den konkreten Anlass dafür bot der jüngste Tarifvertrag der Branche, der eine zusätzliche Altersrente einführte, die vollständig von den Arbeitgebern gezahlt wurde. Für die ÖTV hatte das große Bedeutung, denn eine ergänzende Rente gab es schon seit langem auch im Öffentlichen Dienst - nur mussten Arbeiter und Angestellte sie anteilig mit eigenen Beiträgen finanzieren. Die Beschäftigten der Baubranche standen in dieser Hinsicht nun deutlich besser da. Es bestehe die Gefahr, so Kummernuss, dass die gewerkschaftliche Basis solche Vereinbarungen als »Musterbeispiel« verstehen könnte: »Das ist eine Auswirkung auf die Gewerkschaftspolitik, eine Auswirkung auf die Mentalität der Gewerkschaftsmitglieder, die ich für äußerst gefährlich halte." Jetzt habe die ÖTV einmal mehr »die Schweinerei«, weil Mitglieder nun erneut mit Austritt drohen würden. ${ }^{230}$

Gleichzeitig begegnete die Gewerkschaft in den Tarifrunden von 1961 und 1962 jedoch Verhandlungspartnern, die weitaus unnachgiebiger auftraten als im ersten Jahrzehnt der bundesdeutschen Geschichte. Dafür war Bundeswirtschaftsminister Ludwig Erhard verantwortlich: Er wollte den Lohnabschluss für den Öffentlichen Dienst gezielt als allgemeines konjunkturpolitisches Instrument einsetzen und verlangte daher strikte Sparsamkeit.

Aus heutiger Sicht wirkt der wirtschaftliche Hintergrund dieser Bemühungen fast schon exotisch: In den frühen 1960er Jahren erreichte der Nachkriegsboom in der Bundesrepublik und in den anderen westlichen Industrienationen seinen Höhepunkt; die Wachstumsraten und Investi-

229 | Vgl. etwa: ÖTV-Geschäftsbericht 1961/63, S. 120 f.

230 | Protokoll der 6. Sitzung des HV, 17./18.4.1963. In: Archiv Ver.di, Bestand Kluncker 45. Zu der zusätzlichen Altersversorgung für die Arbeiter und Angestellten des Bundes und der Länder und zu deren Ausbau nach 1964 siehe genauer unten Kapitel II. 
tionsquoten übertrafen selbst ausgesprochen optimistische Prognosen. In diesem ökonomischen Schlaraffenland herrschte jedoch keineswegs eitel Sonnenschein, sondern die Sorge, eine "Überhitzung« der Konjunktur könne unversehens in eine schwere wirtschaftliche und soziale Krise umschlagen. Umso intensiver bemühte sich die Bundesregierung um Stabilität bei den Löhnen - und der Öffentliche Dienst sollte dafür Beispiel und Maßstab sein. ${ }^{231}$

1961 betätigte sich Ludwig Erhard deshalb erstmals selbst aktiv als Tarifpolitiker: Eine der Beratungen in der Lohnrunde für den Öffentlichen Dienst, die jeweils in Stuttgart stattfanden, musste im März des Jahres eigens für fünf Stunden unterbrochen werden, weil der Minister unversehens persönlich teilnehmen wollte und deshalb per Hubschrauber aus Bonn einschwebte. Vor Ort warnte er sprichwörtlich als deus ex machina dann vor einer Gefährdung der deutschen Industrieexporte, die drohe, wenn der Öffentliche Dienst mit einem hohen Abschluss eine weitere Umdrehung der »Lohn-Preis-Spirale« in Gang setze und so die preisdämpfenden Wirkungen der kurz zuvor beschlossenen DM-Aufwertung konterkariere. ${ }^{232}$ Auch eine konkrete Zahl hatte Erhard parat: Keinesfalls dürfe der Anstieg bei Löhnen und Gehältern über acht Prozent hinausgehen. Eine darüber hinausgehende Lohnsteigerung, so erklärte Erhard mehrfach sowohl im Kabinett als auch öffentlich, sei nicht mehr stabilitätsgerecht. ${ }^{233}$

Dieser überraschende Besuch düpierte nicht nur den eigentlich zuständigen Innenminister Hermann Höcherl von der CSU. Auch die ÖTV reagierte sehr verstimmt und protestierte scharf gegen »das politische Eingreifen der Bundesregierung «, das die Tarifautonomie in Frage stelle. Adolph Kummernuss verwahrte sich sogar gegen »die politische Diktatur der Bundesregierung«, die er mit dem lohnpolitischen Handeln der SED

231 | Vgl. zum wirtschaftspolitischen Hintergrund allgemein etwa: Nützenadel: Stunde, S. 279-283.

232 | Erhard greift ein. In: HAB, 24.3.1961. Zum Zusammenhang dieser Strategie mit der DM-Aufwertung und deren erhofften Stabilitätseffekten vgl. etwa: Wolfgang Krüger: Der Schlüssel in der Hand der Gewerkschaften. In: Die Zeit, Nr. 13 vom 24.3.1961.

233 | Vgl. etwa: Kabinettsprotokolle Bundesregierung 1961, S. 126 (Kabinettssitzung v. 16.3.1961); ebd., S. 144f. (Kabinettssitzung v. 12.4.1961); Erhard greift ein. In: HAB, 24.3.1961. 
gegenüber den machtlosen DDR-Gewerkschaften verglich. Eine Einigung nach Erhards Gusto blieb daher aus. ${ }^{234}$

Ähnlich wie einige Jahre zuvor in der Frage der Arbeitszeit, so gingen die Gemeinden zum großen Ärger des Wirtschaftsministers jedoch auch in der Lohnrunde von 1961 einen eigenen tarifpolitischen Weg: Nur wenige Tage nach dem Stuttgarter Eklat vereinbarten sie mit der ÖTV eine neunprozentige Gehaltserhöhung für ihre Angestellten und eine Steigerung von zwölf Prozent für die Arbeiter. Gerade dieser soziale Ausgleich, der gering entlohnten Beschäftigten zugutekam, war der ÖTV sehr wichtig. Dieses Resultat, das die Gewerkschaft angesichts der vorangegangenen dezidierten Einwände des Wirtschaftsministers als großen Erfolg werten durfte, rechtfertigte die VKA mit dem Argument, man habe einen Streik im öffentlichen Nahverkehr, bei der Müllabfuhr oder in den kommunalen Versorgungsbetrieben unbedingt verhindern müssen. ${ }^{235}$

Ludwig Erhard aber beharrte auf seiner Position. Unterstützung fand er sowohl bei der FDP, dem Koalitionspartner von CDU und CSU, als auch bei den großen Wirtschaftsverbänden. Mit dem Bundesverband der Deutschen Industrie (BDI) und dem Deutschen Industrie- und Handelstag (DIHT) forderten gleich zwei besonders einflussreiche Arbeitgeberorganisationen nach der Einigung zwischen den Kommunen und der ÖTV eine unnachgiebige Haltung von Bund und Ländern. ${ }^{236} \mathrm{Im}$ Bemühen, Fakten zu schaffen, begab sich die Bundesregierung sogar auf rechtlich äußerst dünnes Eis: Sie kündigte öffentlich an, die angeblich allein akzeptable Entgeltverbesserung von acht Prozent einseitig auszuzahlen, ohne den Abschluss eines neuen Tarifvertrages abzuwarten. Entrüstet drohte die ÖTV mit juristischen Schritten: Ein solches "Diktat der Bundesregierung« für die Arbeiter und Angestellten im Öffentlichen Dienst werde sie keines-

234 | In der Reihenfolge der Zitate: Heinz Kluncker: Die Tarifsituation im öffentlichen Dienst. In: Die Quelle 12 (1961), S. 152-153; A. Kummernuss auf der Bundesvorstandssitzung des DGB am 9.5.1961. In: Der Deutsche Gewerkschaftsbund 1956-1963. Bearb. v. Jens Hildebrandt unter Mitarbeit v. Boris Schweitzer, Bonn 2005, S. 680. Ähnlich scharf auch die Formulierungen in: Protokoll der 11. Sitzung des HV, 18./19.4.1961. In: Archiv Ver.di, Bestand Kluncker, 45.

235 | Vgl. Nachtmann: 100 Jahre ÖTV, S. 315 f. u. 326.

236 | Kabinettsprotokolle Bundesregierung 1961, S. 163 (Kabinettssitzung v. 3.5.1961). 
falls hinnehmen. ${ }^{237}$ Der Hauptvorstand hielt die Angelegenheit für extrem wichtig: Es gehe dabei »nicht mehr um die ÖTV, sondern um die freie Gewerkschaftsbewegung überhaupt ${ }^{238}$

In dieser Situation fand die Gewerkschaft unerwartet einen neuen Bündnispartner, denn Innenminister Höcherl suchte nun die Konfrontation mit dem unnachgiebigen Wirtschaftsminister. Trotz aller ökonomischen Bedenken, so erklärte Höcherl im Bundeskabinett, sei es politisch klug, der Gewerkschaft nachzugeben. Unterschiedliche Lohn- und Gehaltsentwicklungen bei Bund, Ländern und Gemeinden würden die benachteiligten Beschä̈tigten der Öffentlichen Hand verärgern; auch gebe es in der TdL bereits eine Mehrheit, die bereit sei, den Tarifabschluss der Gemeinden zu übernehmen. Entscheidend war dabei die Haltung der allein von der CDU gestellten Landesregierung von Nordrhein-Westfalen: Erst ihr Votum stabilisierte diese Mehrheit. Wenn die Bundesregierung nun immer noch hart bleibe, dann, so Höcherl, habe sie »mit einem ärgerlichen Prestigeverlust zu rechnen«, denn im Endeffekt werde sie doch unterliegen: »Eine Härte im falschen Augenblick sei geeignet, ein Stück Staatspolitik zu beeinträchtigen. « $^{239}$

Widerspruch kam sowohl von Erhard selbst als auch von Justizminister Wolfgang Stammberger (FDP) und Arbeitsminister Theodor Blank (CDU). Sie warnten, ein Zurückweichen liefere »der Wirtschaft eine Legitimation für Zugeständnisse«. Da Bundeskanzler Adenauer schwieg und er keine Anstalten machte, den Dissens kraft seiner Richtlinienkompetenz zu entscheiden, kam es schließlich zu einer der seltenen Abstimmungen des Kabinetts. Mit neun gegen fünf Stimmen ergab sich dabei eine klare Mehrheit für die Haltung von Hermann Höcherl. Bereits eine Woche später unter-

237 | Kummernuss: Diktat der Bundesregierung. In: HAB, 13.4.1961; ÖTV: Das darf die Bundesregierung nicht. In: HAB, 19.4.1961.

238 | Protokoll der 11. Sitzung des HV, 18./19.4.1961. In: Archiv Ver.di, Bestand Kluncker, 45.

239 | Kabinettsprotokolle Bundesregierung 1961, S. 168 u. 170 (Kabinettssitzung v. 10.5.1961). Zum Umschwenken der NRW-Regierung vgl.: Niederschrift über die Bezirksvorstandssitzung der ÖTV-NRW II, 8.5.1961. In: AdsD, ÖTV-NW II, 5/ ÖTVC022005. Hiernach handelte es sich in der TdL nur um »eine kleine Mehrheit«. Inwiefern die Entscheidung im Düsseldorfer Kabinett »nicht ohne unseren Einfluß« gefallen sei, hat der Berichterstatter nicht erläutert. 
zeichneten Bund und Länder einen Lohn- und Gehaltstarifvertrag, der exakt die Bestimmungen übernahm, die auch die Gemeinden akzeptiert hatten. ${ }^{240}$

Die ÖTV-Führung dürfte diese Entwicklung erleichtert registriert haben, weil sie die Kampfbereitschaft der Mitglieder skeptisch beurteilte: Da Erhards Parolen von der wirtschaftlichen Weisheit des »Maßhaltens" gut in die Vorstellungswelt vieler Bundesbürger passten, hielten es die Mitglieder des Hauptvorstandes für "sehr fraglich", ob bei einer Urabstimmung das erforderliche Quorum von 75 Prozent für einen Streik erreichbar sei. ${ }^{241}$ Das sukzessive Einlenken der Arbeitgeber ersparte den Gewerkschaftsfunktionären jedoch den Test, ob ihre Empörung über den Kurs des Wirtschaftsministeriums von der Basis geteilt wurde.

Trotz seiner eindeutigen Niederlage in der Tarifrunde von 1961 zog der Wirtschaftsminister ein Jahr später erneut in den Kampf gegen die ÖTV. Noch eindeutiger als zuvor wollte er die Lohnrunde für den Öffentlichen Dienst im Frühjahr 1962 nutzen, um »eine neue Norm für die Tariferhöhungen zu setzen«. Konkret fiel das Ziel nun sogar noch ambitionierter aus: Mehr als ein Ausgleich der Inflationsrate von 3,5 Prozent, so meinte Erhard, dürfe der ÖTV keinesfalls gewährt werden, um so indirekt auch die angeblich in Industrie und Gewerbe herrschende »Disziplinlosigkeit in Lohnfragen« zu bekämpfen. ${ }^{242}$ Zwar warnte Hermann Höcherl, auf die Standfestigkeit von Ländern und Gemeinden könne man nicht setzen. Da der Kanzler seinem Wirtschaftsminister diesmal ausdrücklich den Rücken stärkte, beschloss das Kabinett jedoch nach Erhards Vorschlag »hart zu verhandeln«. ${ }^{243}$

Dies geschah dann auch. Erhard nahm zusammen mit Finanzminister Starke nun von Anfang an an den Tarifverhandlungen teil. Dabei zogen die beiden Minister nach einem Bericht Heinz Klunckers »alle Register: Verteidigungslasten, Hochwasserschäden, Entwicklungshilfe, EWG-Auswir-

240 | Ebd., S. 168 (Zitat) u. S. 170 (das Abstimmungsergebnis). Zum Tarifvertrag vgl. etwa: Höhere Löhne und Gehälter. In: HAB, 19.5.1961.

241 | Protokoll der 11. Sitzung des HV, 18./19.4.1961. In: Archiv Ver.di, Bestand Kluncker, 45.

242 | In der Reihenfolge der Zitate: Die Kabinettsprotokolle der Bundesregierung, Bd. 15: 1962. Bearb. v. Uta Rössel/Christoph Seemann, München 2005 (im Folgenden: Kabinettsprotokolle Bundesregierung 1962), S. 181 (Kabinettssitzung v. 9.3.1962) u. S. 145 (Kabinettssitzung v. 8.2.1962).

243 | Ebd., S. 184f. (Kabinettssitzung v. 16.3.1962) u. S. 181 (Zitat). 
kungen und andere finanzpolitische Probleme wurden aufgetischt«, um zu begründen, warum im Öffentlichen Dienst lediglich ein Ausgleich der Inflationsrate möglich sei. Auch das Prozedere wollte Erhard grundlegend verändern: Der Lohn- und Gehaltszuwachs für die Staatsbediensteten sollte nicht mehr ausgehandelt, sondern von einer unabhängigen "Sachverständigenkommission « bestimmt werden. Für die ÖTV, die in dieser Tarifrunde zwar nicht mehr 15, aber doch immer noch zwölf Prozent mehr Lohn und Gehalt forderte, waren diese Leitlinien des Wirtschaftsministers - wie sich denken lässt - völlig inakzeptabel. ${ }^{244}$

Es folgte ein mehrere Monate währender Streit, in dem viele Vorwürfe und Drohungen ausgesprochen wurden. Der Finanzminister sprach von Rücktritt, um seinen lohn- und haushaltspolitischen Warnungen mehr Nachdruck zu verleihen; die ÖTV begann mit Streikvorbereitungen. Schließlich vollzog sich exakt die gleiche Entwicklung wie im Vorjahr: Zunächst kam es zu einem neuen Vertrag zwischen den Gemeinden und der ÖTV (diesmal wurden Lohnsteigerungen von sechs Prozent vereinbart). Dann bröckelte die Front der Bundesländer (diesmal lenkten Hessen sowie Hamburg und Bremen zuerst ein). Zum Schluss sah sich die Bundesregierung gezwungen nachzugeben, weil sie letztlich doch keinen Streik riskieren wollte und der Finanzminister nun die Ansicht vertrat, Zugeständnisse nach einem Arbeitskampf seien für die Bundesregierung »außerordentlich unglücklich «. ${ }^{245}$

Stolz resümierte Heinz Kluncker diese Tarifrunde in einer internen DGB-Publikation mit den Worten, die ÖTV habe im Interesse aller Gewerkschaften den Versuch des Wirtschaftsministers vereitelt, eine »Norm» für Lohnerhöhungen zu setzen und damit erneut die "Angriffe auf die Tarifautonomie abgewiesen «. ${ }^{246}$ Später beschlossen das Kabinett und die Regierungskoalition im Parlament einen Nachtragshaushalt, der die Ausgaben des Bundes für die Wohnungsbauförderung sowie für Bürgschaften

244 | Heinz Kluncker: Tarifautonomie im öffentlichen Dienst bleibt gewahrt. In: Die Quelle 13 (1962), S. 300-301. Ähnlich auch Klunckers interner Bericht in: Kurzprotokoll der Sitzung des Lohnpolitischen Ausschusses des DGB (kleiner Kreis), 30.3.1962. In: Archiv Ver.di, Bestand Kluncker, 51.

245 | Zum Ablauf vgl.: Kabinettsprotokolle Bundesregierung 1962, S. 268 (Zitat - Kabinettssitzung v. 16.5.1962), S. 279 (Kabinettssitzung v. 30.5.1962), S. $282 \mathrm{f}$. (Kabinettssitzung v. 6.6.1962) u. S. 292f. (Kabinettssitzung v. 13.6.1962).

246 | Kluncker: Tarifautonomie, S. 301. 
und Kredite an die Privatwirtschaft kürzte, um die Mehrkosten auszugleichen, die durch den sechsprozentigen Lohn- und Gehaltszuwachs entstanden. Diese Entscheidung ließ die ÖTV unkommentiert. ${ }^{247}$

Abermals ein Jahr später erwies sich die Bundesregierung als lernfähig. Zwar wollte Erhard öffentlich verkünden, Lohnzuwächse im Öffentlichen Dienst wie auch in der Privatwirtschaft dürften im Interesse der Preisstabilität »keinesfalls über 4\% hinausgehen «. Mit Mehrheitsbeschluss aber strich das Kabinett diese Zahl aus der offiziellen Prognose für die ökonomischen Aussichten im Jahr 1963 und ersetzte sie durch die vage Formulierung, Verbesserungen der Besoldung müssten sich »im Rahmen des Produktivitätszuwachses halten«. Derart ausgebremst, verzichtete der Wirtschaftsminister auf einen weiteren Versuch, die Tarifverhandlungen mit der ÖTV durch konkrete Vorgaben zu beeinflussen. ${ }^{248}$

Damit aber war der Streit um ökonomische Orientierungsdaten und "Normen" für die Lohnentwicklung noch nicht abgeschlossen, denn die ÖTV musste sich in dieser Sache in den Jahren 1963/64 auch mit sozialdemokratischen Experten und mit anderen Gewerkschaftern auseinandersetzen. In vielerlei Hinsicht können die 1960er Jahre als eine Phase der Planungseuphorie gelten: Die Idee, wirtschaftliche und gesellschaftliche Entwicklungen ließen sich zielgerichtet und rational lenken, bestimmte seinerzeit viele Debatten. Gerade auch Sozialdemokraten begeisterten sich für eine Planungspolitik dieser Art, die stark auf die Aussagekraft wirtschaftswissenschaftlicher Expertise setzte. ${ }^{249}$

Es entsprach daher dem Zeitgeist, wenn Ludwig Preller, als Leiter der "Akademie der Arbeit« einer der allgemein respektierten tarifpolitischen Experten in der SPD und im DGB, in den frühen 1960er Jahren verlangte, gewerkschaftliche Lohnforderungen müssten künftig vor allem »makroökonomische Erwägungen « berücksichtigen. Gewerkschaftliches Handeln, das sich nicht an der "gesamtwirtschaftlichen Situation « orientiere, hielt Preller

247 | Kabinettsprotokolle Bundesregierung 1962, S. 451 (Kabinettssitzung v. 4.10.1962).

248 | Kabinettsprotokolle Bundesregierung 1963, S. 127-129 (Kabinettssitzung v. 20.2.1963).

249 | Vgl. allgemein dazu: Nützenadel: Stunde, S. 233-244 u. 306. 
für »problematisch « ${ }^{250}$ Wenn Politiker öffentlich »Richtwerte« für Lohnerhöhungen nannten, die sich aus gesamtwirtschaftlichen Daten ableiteten, so sah Preller darin kein Problem. Im Gegenteil: Solche Vorgaben ergäben sich »aus der immer zu respektierenden politischen Führungsrolle des Staates«; es liege im Interesse der Allgemeinheit, darauf hinzuwirken, dass Tarifverträge sich »möglichst im Rahmen dieser Richtwerte bewegen« ${ }^{251}$

Die IG Bau, die von dem populären Sozialdemokraten Georg Leber geführt wurde, griff dieses Konzept, das Tarifverhandlungen "versachlichen" sollte, bereitwillig auf. In Absprache mit den Bauunternehmen orientierten sich die Lohnabschlüsse der Branche seit 1963 konsequent an statistischen Zahlen wie etwa der Teuerungsrate und dem allgemeinen Produktivitätszuwachs in der deutschen Wirtschaft. Leber begründete dieses Vorgehen mit dem Argument, Preisstabilität sei »ein vordringliches Anliegen der Arbeitnehmer«. Deshalb sei es sinnvoll, »an die Stelle des Streites am Verhandlungstisch [...] einmal den Versuch zu setzen, von sachlichen Erwägungen auszugehen ${ }^{252}$ Auch Ludwig Rosenberg, der DGB-Vorsitzende, machte sich für Prellers Modell stark. Im Frühjahr 1964 warb er dafür als Gastreferent vor dem ÖTV-Hauptvorstand. ${ }^{253}$

250 | Ausarbeitung von Ludwig Preller zur Lohnpolitik, November 1962. In: Archiv Ver.di, Bestand Kluncker, 51. Ähnlich auch Prellers Ausführungen in: Protokoll der Sitzung des Wirtschaftspolitischen Ausschusses beim Parteivorstand der SPD, 14./15.12.1965. In: ebd.

251 | Ludwig Preller: Lohnpolitik in gesamtwirtschaftlicher Betrachtung. In: Kurt Nemitz/Richard Becker (Hrsg.): Gewerkschaft - Wirtschaft - Gesellschaft. Beiträge zu wirtschaftlichen und sozialen Gegenwartsfragen, Köln 1963, S. 206217, hier: S. 215. Inhaltlich ähnlich auch: Theo Pirker: Die Gewerkschaft als Versicherungsbetrieb. In: Alfred Horné (Hrsg.): Zwischen Stillstand und Bewegung. Eine kritische Untersuchung über die Gewerkschaft in der modernen Industriegesellschaft, Frankfurt/Main 1965, S. 7-17, hier: S. 17.

252 | Protokoll GT IG Bau 1963, S. 239 u. 235. Vgl. auch: Geschäftsbericht der IG Bau - Steine - Erden für die Bundesrepublik Deutschland [19]63/65, Frankfurt/ Main 1966 (im Folgenden: Geschäftsbericht IG Bau - Steine - Erden 1963/65), S. 22 f.; Christian Zentner: Das Verhalten von Georg Leber, analysiert unter dem Aspekt seiner macht-politischen Bedeutung für die deutsche Gewerkschaftsbewegung und die Sozialdemokratische Partei Deutschlands, Mainz 1966, S. 191-197. 253 | Protokoll der 6. Sitzung des HV, 17./18.4.1963. In: Archiv Ver.di, Bestand Kluncker, 45. 
Überzeugen konnte er dabei allerdings nicht. Das Gremium verwahrte sich vielmehr ausdrücklich gegen eine Tarifpolitik, die auf wirtschaftswissenschaftlichem Expertenwissen und auf statistischen Angaben beruhte, denn beides sei keineswegs »objektiv«. Heinz Kluncker etwa erklärte, hinter den Formeln von der "Versachlichung" der Lohnpolitik und den angeblich so nützlichen gesamtwirtschaftlichen Rahmendaten verberge sich eine »zweckbewußte Interessenpolitik« der privaten Arbeitgeber und der Bundesregierung. Eine Gewerkschaft, die ihren Namen verdiene, müsse so etwas »auf das schärfste zurückweisen«. Überhaupt sei es unsinnig, die Tarifparteien für die Währungsstabilität und das Wirtschaftswachstum verantwortlich zu machen: Regierung und Parlament wollten sich damit aus ihrer eigenen Verantwortlichkeit stehlen. ${ }^{254}$

Offensichtlich fühlte sich die ÖTV in dieser Sache erneut stark bedroht. Dafür gab es gute Gründe, denn die Tarifautonomie für Arbeiter und Angestellte des Staates gehörte keineswegs so selbstverständlich zur Grundausstattung einer freien Gesellschaft, wie die ÖTV es immer wieder darstellte. In etlichen westlichen Demokratien galten seinerzeit ganz andere Regeln. So kannte beispielsweise das sozialdemokratische Musterland Schweden kein Streikrecht für die Beschäftigten des Staates, weil das Recht der Bürger auf uneingeschränkte öffentliche Dienstleistungen als höherrangig galt. Ein Expertengremium entschied einmal pro Jahr verbindlich darüber, was die Öffentliche Hand als Arbeitgeber zu bieten und zu zahlen hatte. Dabei stützten sich die Fachleute in ihren Beschlüssen auf genau die makroökonomischen Daten, die in der Bundesrepublik der IG Bau als Richtschnur für ihre Tarifverträge dienten und die auch dem lohnpolitischen Konzept

254 | Protokoll der 7. Sitzung des HV, 26./27.6.1963. In: ebd. Auch die IG Metall wehrte sich gegen das Konzept von Preller und Leber: 1963 führte sie einen harten Arbeitskampf (in dem die Unternehmen zu einer Flächenaussperrung griffen), weil die Arbeitgeber verlangten, auch die Lohnabschlüsse für die Metaller sollten sich künftig an »neutralen Daten« orientieren. Die Gewerkschaft hielt demgegenüber das Prinzip hoch, die »innere Dynamik« der Tarifrunde müsse entscheiden. Eine pointierte Zusammenfassung aus Arbeitgebersicht vgl. in: Hanns Martin Schleyer: Arbeitgeber-Maßnahmen beim Lohnkonflikt in der Metallindustrie. In: Die gesamtwirtschaftliche Koordinierung der Lohn- und Sozialpolitik. Geschäftsführerkonferenz der Bundesvereinigung der Deutschen Arbeitgeberverbände am 17. und 18. Mai 1963 in Baden-Baden, Düsseldorf 1963, S. 38-44 (die beiden Zitate oben: S. 39). 
Ludwig Prellers zugrunde lagen. ${ }^{255}$ Ähnlich war die Situation in den Niederlanden und in der Schweiz: In beiden Ländern untersagte es ein Gesetz nicht nur den Beamten, sondern auch den übrigen Staatsbediensteten, mit Streiks für die eigenen Interessen zu kämpfen. ${ }^{256}$

Großbritannien behandelte die Mitarbeiter der Öffentlichen Hand nicht ganz so streng, aber doch deutlich anders als Arbeiter und Angestellte der Privatwirtschaft. Zwar verhandelten Staat und Gewerkschaften über die Löhne im Öffentlichen Dienst. Dabei orientierten sie sich jedoch an den Empfehlungen einer unabhängigen Kommission, die zu ermitteln hatte, was für vergleichbare Arbeiten in der Privatwirtschaft gezahlt wurde. Für Streitfälle existierte eine Schlichtungsinstanz, das »Civil Service Arbitration Tribunal«, das nicht verbindlich entscheiden durfte, dessen Empfehlungen die Tarifpartner aber doch meist einvernehmlich akzeptierten. Streiks im Öffentlichen Dienst waren nicht verboten; die Regierung konnte sie jedoch im Interesse der öffentlichen Ordnung sowohl einschränken als auch für bis zu 60 Tage ganz suspendieren. Ziel dieser Regelungen war es, die Bezahlung der Staatsbediensteten an dem Grundsatz eines »fairen Vergleichs« mit der Privatwirtschaft zu orientieren, anstatt sie von der Durchsetzungsmacht von Gewerkschaften und öffentlichen Arbeitgebern abhängig zu machen. ${ }^{257}$

255 | Vgl. etwa den Rückblick in: Walter Leisner: Beamtenstreik? Das »Schwedische Modell« auf dem Prüfstand. Hintergründe und Lehren des schwedischen Beamtenstreiks 1971, Bonn-Bad Godesberg 1971, S. 26. Allerdings vollzogen die regierenden Sozialdemokraten in dieser Hinsicht 1965 einen radikalen Kurswechsel: Nach wachsender öffentlicher Kritik an der unzureichenden Bezahlung für Beamte gewährten sie allen Beschäftigten des Staates - auch den Beamten - das Streikrecht. Bereits 1971 wurde dies allerdings wieder zurückgenommen, nachdem es erstmals tatsächlich zu größeren Beamtenstreiks gekommen war. Vgl. dazu: ebd., S. $26 \mathrm{f}$. et passim.

256 | Wolfgang Däubler: Der Streik im öffentlichen Dienst, Tübingen 1970, S. 31-35.

257 | George A. Campbell: The Civil Service in Britain, London 1965, S. 53 u. 204; Norman M. Hale: Großbritannien. In: Josef H. Kaiser/Franz Mayer/Carl Ule (Hrsg.): Recht und System des öffentlichen Dienstes. Frankreich, Großbritannien, Italien, Japan, Niederlande, Baden-Baden 1973, S. 93-154, hier: S. 116-120 u. 143145. Zur Entstehung dieser Regelungen 1955/56 und zur Bedeutung des Prinzips des »fair comparison« darin vgl. den Rückblick in: Civil Service Pay Research 
In den USA schließlich galten Streiks von Staatsbeschäftigten als politisch verwerflich. Franklin D. Roosevelt etwa, der Demokrat, der die USA durch die Weltwirtschaftskrise und den Zweiten Weltkrieg geführt hatte, vertrat in dieser Frage einen ganz rigiden Standpunkt, obwohl er ansonsten als ein Präsident in die Geschichte einging, der sich intensiv um die Belange der Arbeiter und der Gewerkschaften bemühte. Arbeitsniederlegungen im Öffentlichen Dienst waren für Roosevelt aber »unthinkable and intolerable«, weil sie darauf hinausliefen, die Entscheidungen von demokratisch gewählten Politikern zu unterlaufen oder zu korrigieren: Eine solche "paralysis of Government« dürfe es nicht geben. Mit dieser Sicht prägte er Politik und Rechtsprechung in Amerika auf Jahrzehnte hinaus. ${ }^{258}$

Die leitenden hauptamtlichen Funktionäre der ÖTV dürften zu den wenigen Bundesbürgern gehört haben, die über die eingeschränkten gewerkschaftlichen Rechte für staatliche Arbeiter und Angestellte in anderen westlichen Demokratien informiert waren. Wenn die ÖTV-Führung so scharf darauf beharrte, in Tarifverhandlungen für den Öffentlichen Dienst dürfe es - mit Adolph Kummernuss' Worten - immer nur darum gehen, "wer die stärkeren Nerven, wer den längeren Arm hat", so ist diese Position wohl nicht zuletzt vor diesem Hintergrund zu sehen: Die Gewerkschaft wusste genau, dass die das Streikrecht einschließende Tarifautonomie für die von ihr vertretenen Arbeitnehmer im Öffentlichen Dienst politisch keineswegs so gesichert war wie für Beschäftigte der Privatwirtschaft. ${ }^{259}$

Unit: First Annual Report 1957, London 1958, S. 3-6. Allerdings entzündete sich um das System in den frühen 1960er Jahren Streit zwischen Regierung und Gewerkschaften: Die Regierung forderte, die Lohnerhöhungen für den Öffentlichen Dienst sollten sich stärker an der Zunahme der allgemeinen industriellen Produktivität orientieren (was die Zuwachsraten nach unten gedrückt hätte); die Gewerkschaften beharrten auf dem Grundatz, nur die Bezahlung vergleichbarer Tätigkeiten dürfe als Maßstab dienen. Vgl. dazu etwa: 2 Per Cent Offer Angers Civil Servants' Leaders. In: The Times, 27.3.1962.

258 | Manfred Löwisch: Zulässiger und unzulässiger Arbeitskampf im öffentlichen Dienst. Ein Vergleich der Rechtslage in den USA und in der Bundesrepublik Deutschland, Heidelberg und Karlsruhe 1980, S. 9-11 (Zitat: S. 10 f.). Zu den konkreten (sehr unterschiedlichen) Verfahren, wie die Löhne für den Öffentlichen Dienst gebildet wurden, vgl. am Beispiel der Bundesstaaten ebd., S. 14-22.

259 | Protokoll der 7. Sitzung des HV, 8./9.4.1960. In: Archiv Ver.di, Bestand Kluncker, 45. 
Nun hätte selbstverständlich jede Gewerkschaft, die ihren Namen verdiente, gegen Handlungen und Überlegungen opponiert, die sie als Einschränkung ihrer Handlungsfreiheit betrachtet. Die ÖTV aber reagierte in dieser Hinsicht ganz besonders empfindlich, weil sie sich als sehr verletzlich ansah - und dabei machte es keinen Unterschied, wer auf der anderen Seite stand. Schließlich stieß der Tarifpolitiker Ludwig Erhard genauso auf den Widerstand der ÖTV wie Ludwig Preller, Ludwig Rosenberg oder auch Georg Leber, die sich als Interessenvertreter der Arbeitnehmer verstanden und politisch doch eigentlich zu den engsten Verbündeten der Gewerkschaft zählten.

So gesehen war der Verlauf der Tarifrunde von 1973/74, die das Ansehen des sozialdemokratischen Kanzlers Willy Brandt ramponierte, alles andere als überraschend, denn die von Heinz Kluncker geführte Gewerkschaft handelte in dieser Auseinandersetzung exakt nach den gleichen Prinzipien wie in den Jahren 1961 und 1962 unter dem Vorsitz von Adolph Kummernuss im Streit mit dem konservativen Wirtschaftsminister. Weiter unten wird zu zeigen sein, warum es 1974 dennoch zu einer heftigen Konfrontation zwischen Brandt und der ÖTV kommen konnte.

Die Erfahrungen, die Heinz Kluncker in seinen gewerkschaftlichen Lehrjahren zwischen 1952 und 1964 in und mit der ÖTV sammelte, waren durchaus ambivalent - und gerade darin lag wohl ihre Bedeutung. Der Vorsitzende in spe erfuhr in dieser Zeit vor allem, wie naiv und abwegig die weit verbreitete Vorstellung war, Gewerkschaften seien strikt hierarchisch aufgebaute Organisationen, in denen machtvolle Funktionäre die Mitglieder nach eigenem Gutdünken wie Marionetten bewegten.

Tatsächlich fielen Entscheidungen in der Führung der ÖTV stets mit Blick auf die Basis. Dabei erlebte die Leitung das Kollektiv der Mitglieder sowohl als fordernd und antreibend wie auch als unsicher und unberechenbar. Tarifpolitische Forderungen der Gewerkschaften antworteten stark auf die Stimmung in den Betriebs- und Ortsgruppen, und diese Stimmung bildete sich offensichtlich auf komplexe und schwer zu kalkulierende Weise unter dem Einfluss zahlreicher divergierender Faktoren.

Wie der sorgenvolle Blick der ÖTV auf die Tarifpolitik der IG Bau beweist, scheinen Erfolge anderer Gewerkschaften dabei eine große Rolle gespielt zu haben. Trotz spezieller wirtschaftlicher Voraussetzungen wirkten Tarifabschlüsse in einer bestimmten Branche damit unter Umständen weit über ihren eigentlichen Geltungsbereich hinaus. Vorbilder dieser Art 
konnten eine Gewerkschaftsleitung erheblich unter Stress setzen, weil sie die Loyalität und die Beiträge von Mitgliedern zu verlieren drohte, wenn es ihr nicht gelang, vergleichbare Ergebnisse auszuhandeln.

Zugleich waren die Kollegen und Kolleginnen an der Basis der Organisation aber selbstverständlich auch normale Bürger, deren Wertvorstellungen und Ziele nicht vollständig von ihrer Identität als Gewerkschafter bestimmt wurden. Diese Einbindung der Mitglieder in die allgemeine Öffentlichkeit mit ihren politischen und medialen Debatten erschwerte vor allem die Planung gewerkschaftlicher Kampfmaßnahmen. 1961 etwa fürchtete die öffentlich heftig gegen das versuchte »Diktat« der Bundesregierung wetternde ÖTV-Führung, bei einer Urabstimmung werde es kein positives Votum für einen Streik geben, weil Erhards Slogan vom "Maßhalten« auch ÖTV-Mitglieder beeindruckte. 1958 hingegen streikten die Beschäftigten der Öffentlichen Betriebe selbst in West-Berlin sehr geschlossen, obwohl die Medien - und hier insbesondere die Zeitungen des Verlegers Axel Springer - den Ausstand als schwere Krise der politisch gefährdeten Teilstadt darstellten und damit indirekt Anti-Streik-Propaganda betrieben. Offensichtlich waren Vorhersagen über das Verhalten der Basis im Konfliktfall eine schwierige Angelegenheit. Insofern erfüllte Heinz Kluncker als Mann, der die Skepsis schätzte, wohl eine der wichtigsten Voraussetzungen für erfolgreiche Gewerkschaftsarbeit.

Sowohl an den Streiks von 1954 und 1958 als auch an der Debatte über die »Versachlichung« der Tarifverhandlungen durch ökonomische Richtwerte in den frühen 1960er Jahren zeigte sich zudem ein besonderes Problem der ÖTV: Ihr Verhältnis zu politischen Amtsinhabern und Parlamentariern trug fast schizophrene Züge. Einerseits fürchtete sie politische Entscheidungen, die das Arbeitskampfrecht in lebenswichtigen öffentlichen Betrieben beschneiden könnten. Das fehlende oder stark eingeschränkte Streikrecht für Beschäftigte der Öffentlichen Hand in anderen westeuropäischen Staaten förderte diese Angst ebenso wie die Erinnerung an die Notverordnungen der Weimarer Republik, die Streiks in Unternehmen von wirtschaftlich zentraler Bedeutung verhindern sollten. Hinzu kam die durchweg negative, teilweise fast hysterische Reaktion von Politik und Medien auf die beiden isolierten und kurzen Arbeitsniederlegungen, die in den 1950er Jahren im Öffentlichen Dienst der Bundesrepublik stattfanden. Der dabei sofort wieder laut gewordene Ruf nach einem besonderen Arbeitskampfrecht für Beschäftigte des Staates vertiefte zwangsläufig 
das Misstrauen, das die ÖTV politischen Würdenträgern entgegenbrachte. Andererseits aber führte die enge personelle Verflechtung zwischen ÖTV und SPD auch zu einem ganz anderen Blick auf Politiker: Von »Kollegen«, die als Sozialdemokraten politische Ämter übernahmen, erwartete die Gewerkschaft aktive Unterstützung.

Diese Widersprüche prägten die ÖTV und ihr Verhalten bei der Interessenvertretung der Mitglieder. So neigte die Gewerkschaft dazu, sehr scharf zu reagieren, wenn ihre Verhandlungspartner in den Tarifrunden Strategien benutzten, die in privatwirtschaftlichen Lohnstreitigkeiten allgemein üblich waren. Wenn Wirtschaftsminister Erhard etwa öffentlich Höchstgrenzen für Lohnerhöhungen nannte, die er für noch akzeptabel hielt, tat er ja nichts anderes als ein Unternehmer, der erklärte, sein Betrieb könne nur weiter florieren, wenn der Lohnzuwachs eine bestimmte Größenordnung nicht überschreite. Zum »Diktat" wurde diese Erklärung erst in der Wahrnehmung einer Gewerkschaft, die um die besonderen politischen Handlungsmöglichkeiten ihrer Tarifpartner wusste und ihnen deshalb tief misstraute.

Zugleich aber konnte sich die eigentlich so furchtsame ÖTV wegen ihrer widersprüchlichen Beziehung zu politischen Amtsinhabern auch überschätzen, weil sie von sozialdemokratischen Politikern - und zumal solchen, die selbst zur Gewerkschaft gehörten - eine besondere Offenheit für ihre Forderungen erwartete. Die Frustrationen, die entstehen konnten, wenn diese Erwartung enttäuscht wurde, hielten sich dank der günstigen wirtschaftlichen Entwicklung der Bundesrepublik in den 1950er Jahren in Grenzen. Wie sich dies unter anderen ökonomischen Vorzeichen entwickeln würde, war eine offene Frage.

Die Tarifrunden der Jahre 1952 bis 1964 demonstrierten schließlich, wie unübersichtlich und hoch politisch Verhandlungen für die Beschäftigten des Öffentlichen Dienstes ausfallen konnten. Hier handelte es sich nicht um einen Streit zwischen zwei Parteien, sondern um eine multilaterale Angelegenheit mit vielen verschiedenen Akteuren. Diese Struktur war für die ÖTV insofern von großem Vorteil, als es den Arbeitgebern fast durchweg nicht gelang, gemeinsam gegen die Forderungen der Gewerkschaft zu agieren. Die intensive Streikfurcht bei den Kommunalpolitikern führte ebenso zu interner Uneinigkeit wie unterschiedliche Urteile über die schwierig zu entscheidenden Fragen, was der Staat als Arbeitgeber bieten müsse, um 
in der Konkurrenz mit der Privatwirtschaft weiterhin für qualifizierte Beschäftigte attraktiv zu sein, und wie das alles zu finanzieren sei.

Vor diesem Hintergrund spielten politische Überlegungen in den Tarifauseinandersetzungen für den Öffentlichen Dienst eine ungleich größere Rolle als in den Verhandlungsrunden zwischen Gewerkschaften und privaten Unternehmern. Im Vergleich können solche Streitigkeiten in Industrie und Gewerbe fast als ein Muster für Klarheit und Überschaubarkeit gelten: In diesen Tarifrunden standen die sozialen und ökonomischen Interessen der Lohnabhängigen gegen die wirtschaftlichen Ansprüche und Ziele der Unternehmer. Der Staat als Arbeitgeber, der von gewählten Amtsinhabern vertreten wurde, orientierte sich hingegen keineswegs nur an betriebswirtschaftlichen Gesichtspunkten. Die verantwortlichen Politiker standen etwa vor der Entscheidung, ob sie bei einer raschen Einigung mit der ÖTV den Vorwurf riskieren wollten, auf Kosten der Allgemeinheit nicht hart genug verhandelt zu haben, oder ob sie einen Streik in Kauf nahmen, was Wähler wegen der damit entstehenden Störungen des Alltagslebens verärgern konnte.

Indirekt wurde in Tarifrunden für den Öffentlichen Diensteben auch über die öffentlichen Haushalte und die öffentlichen Ausgaben sowie über die politisch festgesetzten Preise staatlicher Dienstleistungen debattiert. Parlament und Regierung konnten in Reaktion auf einen Tarifabschluss mit der ÖTV etwa Etatkürzungen oder -umschichtungen beschließen, ohne dass die Gewerkschaft darauf noch Einfluss nehmen konnte. Auch die Preise für Gas, Wasser und Strom oder für den öffentlichen Nahverkehr konnten durch politische Entscheidungen erhöht werden. Wie sich am Beispiel Hamburgs in den Jahren 1954/55 zeigt, konnten solche Verteuerungen aus politischem Kalkül selbst dann beschlossen werden, wenn sie wirtschaftlich gar nicht nötig waren - in der Öffentlichkeit aber galt die ÖTV dennoch als verantwortlich.

Wer die Arbeitsbedingungen und die Bezahlung von Arbeitern und Angestellten des Staates verbessern wollte, der begab sich daher fast zwangsläufig in eine politische Auseinandersetzung. Die Frage, wie Heinz Kluncker als Vorsitzender und Chefunterhändler der Organisation in den so deutlich politisch geprägten Tarifverhandlungen für den Öffentlichen Dienst agiert hat, wird sich wie ein roter Faden durch die folgende Darstellung der »Ära Kluncker« ziehen. 


\section{Verschiedenartige Aufbrüche und Reformbemühungen}

Die ÖTV 1964 bis 1969

\section{Politische Aktivitäten des neuen Vorsitzenden: Der "geistige Beitrag der ÖTV« zur bundesdeutschen Außen- und Innenpolitik}

\section{Die ÖTV im Ost-West-Konflikt}

Ende September 1964 trat der Hauptvorstand der ÖTV erstmals unter dem Vorsitz von Heinz Kluncker als Chef der Organisation zusammen. Das fast 70 Personen umfassende Gremium hörte dabei die politische Grundsatzerklärung des neu gewählten Vorsitzenden, die es auf dem Gewerkschaftstag im Sommer dieses Jahres nicht gegeben hatte. Kluncker setzte in dieser Rede zwei Schwerpunkte: Zum einen zeichnete er ein wenig schmeichelhaftes Bild vom organisatorischen Zustand der ÖTV und forderte grundlegende Reformen. Sie seien dringend nötig, um die Gewerkschaft stärker zu machen. Zum anderen kritisierte er - ohne den Namen zu nennen - seinen Vorgänger Adolph Kummernuss wegen dessen »Zurückhaltung [...] in lebenswichtigen Fragen der Gesellschaftspolitik, Innen- und Wirtschaftspolitik«. Bei der öffentlichen Diskussion über diese Themen sei »ein geistiger Beitrag der ÖTV nicht feststellbar«. Künftig müsse sich die Organisation politisch stärker profilieren. ${ }^{1}$

Dafür sei unter anderem eine aktive Pressearbeit nötig. Für die Pressestelle der Gewerkschaft bedeutete diese Vorgabe des frisch gewählten Vorsitzenden eine völlige Neuausrichtung: Hatte sie sich bisher eher als »Presseabwehrstelle« gesehen, so galt für sie nun eine »Politik der offenen Tür«

1 | Protokoll d. 1. Sitzung des HV, 29.9./1.10.1964. In: Archiv Ver.di, Bestand Kluncker, 45. Der HV tagte in jeweils dreimonatigen Abständen. 
gegenüber Journalisten aller Medien als neue Richtschnur. ${ }^{2}$ Allein der Wille zur Öffentlichkeitsarbeit führte allerdings noch nicht sehr weit. Um in Presse, Hörfunk und Fernsehen präsent zu sein, musste man Journalisten etwas bieten, das sie als interessant genug empfanden, um es zu melden.

Die Aufgabe, für solchen Nachrichtenstoff zu sorgen, übernahm Heinz Kluncker, indem er die ÖTV gezielt auf politischen Feldern profilierte, die nichts mit den jährlichen Tarifrunden zu tun hatten. Zwei Themen lagen ihm dabei besonders am Herzen: die »Ostpolitik«, d.h. das Verhältnis der Bundesrepublik zu den kommunistisch beherrschten Ländern in Osteuropa, sowie die von der Bundesregierung geplanten »Notstandsgesetze«, die festlegen sollten, wie die Bundesrepublik im Kriegsfall und in anderen schweren Krisensituationen regiert wurde. Mitte der 1960er Jahre handelte es sich in beiden Fällen um hochbrisante Fragen, über die sehr emotional gestritten wurde. Wenn die ÖTV sich dazu mitten im »Kalten Krieg« zwischen den beiden Militärblöcken, die von den USA und von der UdSSR geführt wurden, zu Wort meldete, konnte sie mit Aufmerksamkeit rechnen.

Die »Ostpolitik« berührte ein breites Themenspektrum, zu dem unter anderem die Grenzziehungen nach dem Zweiten Weltkrieg, die Legitimität der kommunistischen Diktaturen jenseits des »Eisernen Vorhangs« sowie die ungelöste »Deutsche Frage« gehörten. Als Heinz Kluncker wenige Wochen nach seinem ersten Auftritt vor dem ÖTV-Hauptvorstand ankündigte, er wolle sich konkret für "gewerkschaftliche Kontakte« in den »Ostblock « einsetzen, betrat er eine politische Arena, in der sehr viele Gefahren lauerten. Man müsse in Europa »über den Status quo des politischen $\mathrm{Zu}$ standes hinauskommen«, so begründete Kluncker seine damalige Initiative. Wer nicht auf die sozialistischen Staaten zugehe, fügte er hinzu, der könne in diesen Gesellschaften auch »keine gesellschaftspolitischen Wirkungen auslösen «. ${ }^{3}$

Kluncker nutzte mit diesem Vorstoß den Gestaltungsspielraum, den das Amt des Gewerkschaftsvorsitzenden mit sich brachte, denn einen Auftrag aus der Organisation, die ÖTV auf das Feld der »Ostpolitik« zu führen, gab es nicht. Weder der Hauptvorstand noch der gHV war in dieser Angelegenheit aktiv geworden; keiner der Anträge für den Gewerkschaftstag

2 | ÖTV-Geschäftsbericht 1964/67, S. 40.

3 | Protokoll der 1. Sitzung des HV, 29.9./1.10.1964. In: Archiv Ver.di, Bestand Kluncker, 45. 
von 1964 hatte sich damit beschäftigt. ${ }^{4}$ Allerdings stand Kluncker politisch selbstverständlich keineswegs allein: Sowohl die SPD-Führung wie auch Gremien der Evangelischen Kirche plädierten seinerzeit ebenfalls dafür, mit offiziellen Vertretern der »Ostblock«-Staaten zu sprechen, um das tiefe Misstrauen zwischen den beiden Blöcken zu überwinden. »Wandel durch Annäherung« lautete die Formel hinter dieser »neuen Ostpolitik«, die ausdrücklich nur »kleine Schritte « vorsah, um Ost und West überhaupt wieder in Kontakt zu bringen. ${ }^{5}$

In der bundesdeutschen Gesellschaft gab es dennoch viele Kritiker dieser Strategie. Selbst der DGB war trotz seiner generellen politischen Nähe zur SPD Mitte der 1960er Jahre noch keineswegs bereit, der Partei in dieser Frage zu folgen. Führende Männer der bundesdeutschen Einheitsgewerkschaften und ihres Dachverbandes hielten wenig bis gar nichts von politischen Kontakten zu offiziellen Stellen und Amtsinhabern in »Ostblock«-Staaten, weil man so diese Diktaturen bestätige und stärke. Zwar sah der DGB diese Angelegenheit schon nicht mehr ganz so dogmatisch wie der »Internationale Bund Freier Gewerkschaften«, der kategorisch darauf bestand, es dürfe keinerlei Kontakte zu Regierungsvertretern und Gewerkschaftern in Diktaturen geben. Der westdeutsche Verband wollte immerhin Ausnahmen von dieser Regel zulassen. Diese brauchten aber einen ausdrücklichen Beschluss des Bundesvorstandes, der nur aus besonders wichtigen politischen Gründen erteilt werden sollte. ${ }^{6}$ De facto bestanden die Beziehungen der DGB-Gewerkschaften mit Ländern jenseits

4 | Die allgemeinpolitischen Anträge finden sich in: Protokoll ÖTV-GT 1964, Anträge und Entschließungen, S. 159-170. Sie befassten sich mehrheitlich mit Abrüstungsfragen. Lediglich ein Antrag forderte den HV auf, bei der Bundesregierung und den Parteien für eine Politik einzutreten, die »eine Verminderung der Spannungen zwischen Ost und West« erreichen könne. Von eigenen Initiativen der ÖTV und gewerkschaftlichen Kontakten in den »Ostblock« war dabei jedoch nicht die Rede (ebd., S. 165). Ähnlich auch schon das Bild auf dem GT von 1961 (Protokoll ÖTV-GT 1961, Anträge und Entschließungen, S. 139-152).

5 | Vgl. etwa: Christoph Kleßmann: Zwei Staaten, eine Nation. Deutsche Geschichte 1955-1970, 2. überarb. u. erw. Aufl., Bonn 1997, S. 82-98. Vgl. als knappen Überblick zum »Kalten Krieg« insgesamt etwa: Carole K. Fink: Global Cold War. An International History, Boulder 2014.

6 | Der Deutsche Gewerkschaftsbund 1964-1969. Bearb. v. Wolther von Kieseritzky, Bonn 2006, S. 98 . Vgl. ausführlich auch: Jens Hildebrandt: Gewerkschaften im 
des »Eisernen Vorhangs« in den Jahren 1964/65 lediglich aus Fahrten von Jugendgruppen nach Auschwitz und in andere Erinnerungsstätten an die NS-Verbrechen im Zweiten Weltkrieg. Die DDR wurde dabei ausdrücklich ausgespart, um jeden Verdacht zu zerstreuen, der DGB habe sich mit der deutschen Spaltung abgefunden. ${ }^{7}$

Heinz Klunckers Plan, die ÖTV solle eine eigene aktive Rolle in der Verständigungspolitik gegenüber dem »Ostblock« übernehmen, war daher selbst innergewerkschaftlich durchaus riskant. Eine erste Gelegenheit zu testen, wie weit er als außenpolitischer Vorbote der bundesdeutschen Gewerkschaften gehen konnte, ergab sich dank einer Einladung aus der Tschechoslowakei bereits im Frühjahr 1965. Gemäß der Politik der »kleinen Schritte« ging es dabei noch nicht um ein direktes Treffen zwischen ost- und westeuropäischen Gewerkschaftern, sondern um eine Einladung zu einem Fachkongress, den die »Internationale medizinische Gesellschaft für das Studium der Lebensbedingungen und der Gesundheit» für den September in dem tschechischen Kurort Karlovy Vary (Karlsbad) plante. Allerdings kam die Einladung vom Zentralvorstand der "Gewerkschaft für das Gesundheitswesen der CSSR «. So ergab sich doch ein offizieller Kontakt zwischen der ÖTV und einer der politisch strikt gegängelten osteuropäischen Gewerkschaften. Zudem handelte es sich bei dem Kongress eher um eine Propagandaveranstaltung zum Lob der medizinischen Versorgung in den Ostblock $\ll$-Staaten als um ein Forum der freien wissenschaftlichen Diskussion. $^{8}$

Trotz dieser politischen Dimension der Einladung beschloss der ÖTVHauptvorstand, Heinz Kluncker solle als Gast nach Karlsbad reisen, und

geteilten Deutschland. Die Beziehungen zwischen DGB und FDGB vom Kalten Krieg bis zur Neuen Ostpolitik 1955 bis 1969, St. Ingbert 2010.

7 | Der Deutsche Gewerkschaftsbund 1964-1969, S. 87 (Sitzung des Bundesvorstandes, 6.10.1964).

8 | Die Feststellung, die "International Medical Association for the Study of Living Conditions and Health" sei eine »kommunistische Angelegenheit« findet sich in: Kluncker: Gespräche in Karlsbad. In: WAZ, 17.9.1965. Zu den Vorträgen der zwischen 1961 und 1965 jährlich veranstalteten Kongresse vgl. die vier Ausgaben der Zeitschrift "Acta Medica et Sociologica« 1 (1961) bis 4 (1965). Auf dem vierten Kongress etwa beschäftigten sich 13 der insgesamt 19 Referate mit sozialistischen Ländern. Nach 1965 scheint die Gesellschaft keine Kongresse mehr veranstaltet zu haben. 
auch der DGB-Vorstand gab dafür im März 1965 sein Plazet. Das Protokoll dieser Sitzung vermerkt zwar, der Bundesvorstand habe die Erlaubnis erst nach »lebhafter Diskussion« erteilt, was nach Streit klingt. Details kennen wir aber nicht. ${ }^{9}$ Öffentlich erklärte Kluncker, die ÖTV wolle selbstverständlich »keine eigene Außenpolitik« betreiben, mit ihrer Initiative aber »Ansätze einer flexiblen Ostpolitik« unterstützen. ${ }^{10}$ Konkret ging es ihm um die »Hallstein-Doktrin«, nach der die Bundesrepublik Deutschland keine diplomatischen Beziehungen zu Ländern unterhielt, die ihren Alleinvertretungsanspruch ignorierten und die DDR als eigenständigen Staat anerkannten. Dieser außenpolitische Grundsatz beschränkte nicht nur die direkten Beziehungen der Bonner Republik in Osteuropa allein auf die Sowjetunion. Er bedrohte in den 1960er Jahren zunehmend auch die diplomatischen Kontakte zu den »Entwicklungsländern« in der »Dritten Welt«, strebten doch etliche dieser »blockfreien« Staaten (die weder zur Nato noch zum »Warschauer Pakt « gehörten) nach Verbindungen auch in die DDR. Wie viele andere Sozialdemokraten hielt der ÖTV-Vorsitzende die »Hallstein-Doktrin« daher politisch für dysfunktional und überflüssig: Diese Selbstbindung der bundesdeutschen Außenpolitik stehe »außerhalb der Realität «. ${ }^{11}$ Wer weiter daran festhalte, der könne »keine fortschrittliche deutsche Politik« machen und müsse auf »kulturelle, menschliche Beziehungen« mit Osteuropa verzichten, »die für die Aufrechterhaltung des Friedens und normaler Beziehungen unerläßlich seien «. ${ }^{12}$

Zudem ging es Kluncker auch um eine spezielle politische Parität innerhalb der Bundesrepublik: Es störte ihn, dass einige führende Industrielle und Manager - allen voran Berthold Beitz, der mächtigste Mann des Krupp-Konzerns - teilweise schon seit Mitte der 1950er Jahre intensive

9 | Der Deutsche Gewerkschaftsbund 1964-1969, S. 177 (Sitzung des Bundesvorstandes, 4.3.1965).

10 | Kontakte zu osteuropäischen Gewerkschaften. In: FAZ, 25.9.1965.

11 | So Kluncker auf einer öffentlichen Diskussionsveranstaltung in Düsseldorf Mitte Dezember 1965. Zit. nach: Ernst-Otto Maetzke: Bei Ostkontakten nicht zu simpel. In: FAZ, 16.12.1965. Ihren Namen hatte die 1955 erstmals öffentlich formulierte »Hallstein-Doktrin« nach Walter Hallstein, dem Staatssekretär im Auswärtigen Amt von 1953 bis 1958.

12 | H. Kluncker in: Protokoll über die 4. Sitzung des HV, 11.3.1965. In: AdsD, 5/ÖTVB130011. Vgl. ferner: Heinz Kluncker: Gewerkschaftliche Ostkontakte. In: ÖTV-Magazin 1966, H. 1, S. 29-32. 
Kontakte in die osteuropäischen Länder unterhielten und dort mit offenen Armen empfangen wurden, während sich die westdeutschen Gewerkschafter an eine selbstverhängte Kontaktsperre hielten. "Was gut ist für Beitz, das ist auch gut für Kluncker«, äußerte der ÖTV-Vorsitzende vor der bundesdeutschen Presse - und bewies damit nebenbei, wie gut entwickelt sein politisches Ego bereits war. ${ }^{13}$ Allerdings betonte Kluncker seine diplomatischen Ambitionen gelegentlich auch weniger selbstbezogen: »Der ansteckende Bazillus der Freiheit kann doch im Osten auch durch Gewerkschaftler verbreitet werden, nicht nur durch Industrielle«, sagte er noch vor seiner Reise in die CSSR. ${ }^{14}$

Diese Reise fand vom 2. bis zum 5. September 1965 statt. Heinz Kluncker war damit der erste bundesdeutsche Gewerkschaftsführer, der in eines der sozialistischen Länder hinter dem »Eisernen Vorhang« fuhr. Da sich die ÖTV seit seinem Amtsantritt um eine aktive Öffentlichkeitsarbeit bemühte, reiste ihr Chef nicht allein: Zu seiner Begleitung gehörten sowohl ein Journalist vom Hamburger Nachrichtenmagazin Der Spiegel als auch ein Fernseh-Kamerateam. Für Medienecho war somit gesorgt. ${ }^{15}$

Den hoch spezialisierten Fachvorträgen, die es auf dem Medizinischen Kongress in Karlovy Vary zu hören gab, hat Heinz Kluncker nach eigener Aussage »interessiert zugehört«. Wichtiger waren für ihn jedoch die Begeg-

13 | Tut nicht weh. In: Der Spiegel 19 (1965), H. 37, S. 64-66, hier: S. 64. Zu den Ostkontakten von Beitz, die von der Bundesregierung anfänglich stark missbilligt wurden, vgl. ausführlich: Joachim Käppner: Berthold Beitz. Die Biographie, Berlin 2010, S. 221-260.

14 | Bazillen im Bad. In: Der Spiegel 19 (1965), H. 29, S. 42. Im Rückblick sagte Kluncker, er habe die Formulierung von dem "Bazillus der Freiheit« von Willy Brandt übernommen (Hemmer/Simon: Wirkung, S. 165). Klunckers Fahrt nach Karlsbad wurde nach Presseangaben vorab mit dem Auswärtigen Amt besprochen (vgl. etwa: Heinz Kluncker reist nach Prag. In: Die Welt, 20.7.1965). Bei Recherchen im Politischen Archiv des Auswärtigen Amtes konnten allerdings keine Akten ermittelt werden, die Informationen über Beratungen in dieser Sache enthalten. Ein Hinweis auf eine Besprechung zwischen der ÖTV und dem Auswärtigen Amt vor einer weiteren Osteuropa-Reise Klunckers findet sich auch in: Kluncker reist nach Moskau. In: Die Welt, 16.9.1965.

15 | Vgl. etwa den eben genannten Spiegel-Artikel sowie eine umfangreiche Zusammenstellung von Zeitungsberichten in einer Broschüre der ÖTV »Gewerkschaftliche Ostkontakte« (ein Exemplar in: Archiv Ver.di, Bestand Kluncker, 48). 
nungen am Rande des offiziellen Programms, über die er öffentlich und intern mehrfach berichtete: Mit Hilfe von Dolmetschern führte Kluncker eine Reihe von »Kontaktgesprächen« (so seine eigene Formulierung) mit Vertretern tschechischer, polnischer und russischer Gewerkschaften für die Beschäftigten des Gesundheitswesens sowie für den Öffentlichen Dienst in den jeweiligen Ländern. ${ }^{16}$

In diesen Gesprächen vereinbarte der ÖTV-Vorsitzende jeweils weitere Kontakte, etwa durch einen Austausch der Verbandszeitungen und durch gegenseitige Einladungen zu »Studienreisen«. Die Gesprächspartner legten damit die Basis für eine offizielle institutionelle Zusammenarbeit von Gewerkschaften in Ost und West, die Gleichberechtigung und gegenseitige Anerkennung voraussetzte. Als Kluncker im Oktober 1965 dem DGB-Bundesvorstand über seine Reise berichtete, betonte er, es gehe ihm bei solchen Abmachungen um »Aussöhnung« und um eine Überwindung des »Eisernen Vorhangs ${ }^{17}{ }^{17}$

Von diesem Ziel waren nicht alle führenden Männer des DGB überzeugt. Bernhard Tacke etwa, der stellvertretende Vorsitzende des Bundes (und das einzige CDU-Mitglied im DGB-Vorstand), kritisierte Kluncker mit scharfen Worten: Hoffnungen, im »Ostblock« werde sich durch Kontakte mit westlichen Demokratien etwas ändern, seien völlig illusorisch. Ähnliches sei erfolglos schon in den 1930er Jahren mit dem nationalsozialistischen »Dritten Reich« versucht worden, das aus solchen Begegnungen nur gestärkt hervorgegangen sei.

Aus anderen Gründen urteilte auch der DBG-Vorsitzende Ludwig Rosenberg negativ über die von Kluncker eingeschlagene Politik der »kleinen Schritte«: Verbindungen zu osteuropäischen Gewerkschaften seien gefährlich, denn die dabei stets so freundlich auftretenden osteuropäischen Kommunisten wollten die freien westlichen Verbände in Wirklichkeit politisch unterwandern. Kluncker aber blieb unbeeindruckt: »Wir sollten zur Kenntnis nehmen, daß sich ein Wandel im Ostblock vollzieht. Es sei zwar eine kommunistische Wandlung, aber eine Wandlung. Die geistige Isolation

16 | Hemmer/Simon: Wirkung, S. 164.

17 | Der Deutsche Gewerkschaftsbund 1964-1969, S. 218f. Vgl. auch: Heinz Kluncker: Hintergründe einer Reise. In: Die Quelle 16 (1965), S. 438-439; Das alte Tabu ist durchlöchert. In: FR, 17.9.1965. 
dieser Länder sei verderblich, vielmehr müsse der Bazillus der Freiheit in die Diktaturen getragen werden. ${ }^{18}$

Der ÖTV-Vorsitzende spielte damit auf verschiedene Ereignisse in Osteuropa an, die »im Westen« vielfach als Vorboten einer politischen Lockerung verstanden wurden. In Moskau war im Oktober 1964 der alternde starke Mann der UdSSR, Nikita Chruschtschow, gestürzt worden. Mit Leonid Breschnew und Andrey Kossygin standen seitdem zwei deutlich jüngere Politiker an der Spitze von Partei und Staat, von denen viele westliche Beobachter sowohl innere Reformen als auch einen pragmatischeren außenpolitischen Kurs erwarteten. Zudem zeigten sich in einigen anderen »Ostblock«-Staaten Ansätze für eine politische Eigenständigkeit, die es so zuvor nicht gegeben hatte: Die CSSR und Ungarn etwa suchten Kontakt zu internationalen Institutionen wie der Weltbank und dem Internationalen Währungsfonds, die Kommunisten bislang stets als imperialistische Herrschaftsinstrumente der USA geschmäht hatten. Darüber hinaus reagierten einige der Staatsparteien im kommunistischen »Warschauer Pakt» betont zurückhaltend auf die Palastrevolution im Kreml, die so gar nicht zu den elaborierten Ritualen passte, auf deren Inszenierung der »real existierende Sozialismus « ansonsten doch so große Mühen verwandte. ${ }^{19}$

Im Kreis der DGB-Gewerkschaftsvorsitzenden wurden diese Ereignisse jedoch sehr unterschiedlich beurteilt. Klunckers Hoffnung auf eine »Wandlung« teilten nur wenige. Nach erneuten Beratungen in den Führungsgremien der Einzelgewerkschaften fasste der Bundesvorstand Anfang November 1965 auf einer eigens einberufenen außerordentlichen Sitzung schließlich einen Beschluss, der salomonisch einen offenen Konflikt vermied: Offizielle Begegnungen zwischen Funktionsträgern der DGB-Verbände und Gewerkschaftern aus den staatssozialistischen osteuropäischen Ländern waren danach weiterhin grundsätzlich »nicht zulässig«; die ÖTV aber durfte ihre bereits geknüpften Kontakte dennoch weiterpflegen. ${ }^{20}$

18 | Ebd., S. 218 f. Vgl. auch ausführlich: Hildebrandt: Gewerkschaften im geteilten Deutschland, S. 514-521.

19 | Vgl. zum letzten Punkt etwa: Podest und Rinnstein. In: Der Spiegel 18 (1964), H. 45, S. 117-118; ansonsten: Helmut Altrichter: Kleine Geschichte der Sowjetunion 1917-1991, 4. aktualis. u. erw. Aufl., München 2013, S. 151-171.

20 | Der Deutsche Gewerkschaftsbund 1964-1969, S. 227 (Bundesvorstandssitzung, 2.11.1965). 
Die damit ausgesprochene widerwillige Duldung weiterer Versuche der ÖTV, zur »Aussöhnung« mit dem Osten beizutragen, wäre im DGB-Vorstand mit Sicherheit gescheitert, wenn die Mitglieder des Gremiums gewusst hätten, dass Heinz Kluncker in Karlsbad insgeheim auch einen Gewerkschafter aus der "Sowjetzone« getroffen hatte: Eines seiner »Kontaktgespräche» führte er mit Martin Döring, dem stellvertretenden Vorsitzenden der »Gewerkschaft Gesundheitswesen« im »Freien Deutschen Gewerkschaftsbund « (FDGB) der DDR. Offensichtlich plante Kluncker in dieser Unterredung sogar schon die Zukunft: Für 1966 avisierte er eine weitere Reise in die CSSR, auf der es dann erneut ein geheimes Treffen mit Vertretern des FDGB geben sollte. ${ }^{21}$

Mit diesem Gespräch nahm sich Kluncker politisch sehr viel heraus: Handlungen, die - wie vermittelt auch immer - als Anerkennung der DDR und ihrer Institutionen gedeutet werden konnten, waren in der Bundesrepublik seinerzeit strikt tabuisiert. An diese politische Linie hielten sich auch die Gewerkschaften und der DGB. Im Oktober 1964 untersagte der Bundesvorstand des Dachverbandes einmal mehr ausdrücklich jeden offiziellen Kontakt mit Vertretern der SED, des FDGB oder auch der FDJ (dem Jugendverband der DDR). ${ }^{22}$

Mit dieser Abgrenzung betonte der DGB seine eigene gewerkschaftliche Identität: Er sah im FDGB keine Gewerkschaft, sondern ein Herrschaftsinstrument der SED und damit letztlich der russischen Kommunisten in der "Sowjetzone«. 1962 hieß es in einer offiziellen Stellungnahme des DGB-Bundesvorstandes betont giftig, der FDGB sei ganz im Gegensatz zu seinem Namen »weder frei noch deutsch $« .{ }^{23}$ Rigorismus dieser Art erklärt sich nicht nur aus antikommunistischen Überzeugungen und Emotionen. Die DGB-Verbände durften die straff am Gängelband der SED geführten

21 | Hildebrandt: Gewerkschaften im geteilten Deutschland, S. 600.

22 | Der Deutsche Gewerkschaftsbund 1964-1969, S. 98 (Bundesvorstandsitzung, 6.10.1964).

23 | Der FDGB. Erfüllungsgehilfe der SED. Hrsg. v. Bundesvorstand des Deutschen Gewerkschaftsbundes, Frankfurt/Main 1962, S. 1. Trotz ihrer ähnlichen Namen waren FDGB und der bundesdeutsche DGB ganz unterschiedlich aufgebaut. Der FDGB war letztlich eine einheitliche Gewerkschaft; die Unterteilung in verschiedene, berufliche Untergliederungen hatte eher formale Bedeutung. Der DGB war hingegen ein Dachverband von eigenständigen Gewerkschaften, in dem nur die jeweiligen Verbandsleitungen miteinander berieten. 
DDR-Gewerkschaften mit Recht als eine direkte Bedrohung verstehen, denn diese betrieben alle eine intensive "Westarbeit«, um insgeheim politisch in den DGB hineinzuwirken. ${ }^{24}$

Es ist nicht bekannt, warum sich Heinz Kluncker in Karlsbad dennoch mit einem hochrangigen DDR-Gewerkschafter zusammensetzte. Möglicherweise handelte er aus purer Neugier; vielleicht bewies er auch nur politische Naivität, denn das geheime Treffen hätte ihm persönlich schwer schaden können, wenn die Öffentlichkeit seinerzeit davon erfahren hätte. Sowohl intern im DGB als auch im Gespräch mit Journalisten hat der ÖTV-Vorsitzende sein verbotenes Gespräch stets verschwiegen. Er erläuterte sogar, warum solche Kontakte undenkbar seien: »Mit Helfershelfern von Mördern gibt es für mich keine Gespräche«, sagte er nach seiner Reise wörtlich dem gewerkschaftlichen Wochenblatt Welt der Arbeit. ${ }^{25}$ Für die gewerkschaftliche »Ostpolitik« blieb diese merkwürdige Episode ohne Folgen. Vor dem Hintergrund der völlig offenen »Deutschen Frage« war ein anderer Ausgang auch gar nicht möglich.

Selbst in den nachfolgenden Jahren hat es keine offiziellen Treffen zwischen bundesdeutschen Gewerkschaften und den FDGB-Organisationen gegeben. 1967 unternahm Heinz Kluncker in dieser Sache zwar einen neuen Vorstoß - und diesmal tat er das sogar öffentlich. In einem Radio-Interview plädierte er im August für eine ergebnisoffene Debatte im DGB über gewerkschaftliche Kontakte auch in die DDR. Wenig später erklärte er im DGB-Bundesvorstand, es gehe ihm darum, mit solchen Verbindungen »zu einem geordneten Nebeneinander der beiden Deutschland[s] beizutragen «. Es sei absurd und politisch kontraproduktiv, die DDR auf Dauer unter eine umfassende Quarantäne zu stellen: »Wer in dieser Welt entspannen wolle [sic], kann es nicht an der DDR vorbei tun. ${ }^{26}$

Mit diesen Ansichten gehörte Kluncker zu der damals noch recht überschaubaren Gruppe von bundesdeutschen Politikern, die das ritualisierte Denken und Handeln des auf strikte Abgrenzung setzenden »Kalten Krieges« überwinden wollten und deshalb nicht mehr vor der Konsequenz zu-

24 | Vgl. allgemein: Hildebrandt: Gewerkschaften im geteilten Deutschland, S. $173-260$.

25 | Kluncker: Gespräche in Karlsbad. In: WdA, 17.9.1965.

26 | Der Deutsche Gewerkschaftsbund 1964-1969, S. 514 (Bundesvorstandssitzung, 5.9.1967). Zu Klunckers Radio-Interview vgl. die Angaben ebd., S. 512. 
rückschreckten, die SED als Gesprächspartner zu akzeptieren. Angst vor den politisch revolutionären Absichten und den subversiven Methoden der Kommunisten hatte er nicht. Eher hielt er eine offene Auseinandersetzung für lehrreich: »Es sei nicht zu bestreiten, daß wir es verlernt hätten, uns mit den Kommunisten auseinanderzusetzen und zu leben. $\ll^{27}$ Das zuvor öffentlich auch von Kluncker benutzte moralische Argument, Kontakte zur DDR dürfe es nicht geben, solange der "Schießbefehl« an der deutsch-deutschen Grenze gelte, fiel dabei aus realpolitischen Gründen stillschweigend unter den Tisch.

Seine öffentliche politische Initiative für gewerkschaftliche Kontakte mit der DDR verband Heinz Kluncker mit einem neuerlichen Versuch, als Geheimdiplomat einen Weg nach Ost-Berlin zu finden. Über tschechische Gewerkschaftsfunktionäre unterbreitete er dem FDGB bereits im Juli 1967 das Angebot, zwischen der ÖTV und ihren gewerkschaftlichen Pendants in der DDR eine "schriftliche Kontaktaufnahme" zu beginnen, um den Besuch einer ÖTV-Delegation unter seiner Leitung in Ost-Berlin vorzubereiten. Nach den Worten der tschechischen Mittelsmänner hatte Kluncker ihnen gegenüber angegeben, diese Selbsteinladung der Gewerkschaft sei mit Willy Brandt abgesprochen, der mittlerweile in der Bundesregierung das Amt des Außenministers bekleidete. Verifizieren lässt sich das nicht. ${ }^{28}$

Wie schon 1965 verpuffe auch diese geheime Aktion des ÖTV-Vorsitzenden. In der Machtelite der DDR erweckte Klunckers Kontaktstreben eher Misstrauen als Interesse. Beziehungen zwischen einzelnen Gewerkschaften standen auf dem politischen Programm der SED ohnehin nicht obenan: Sie strebte schon aus Prestigegründen sowie im Interesse umfassender Kontrolle zunächst einmal nach Begegnungen auf möglichst hoher Ebene, bei denen politisch nichts Unvorhersehbares geschehen konnte. Kluncker hatte insofern falsch kalkuliert: Nach seinem erneuten Vorstoß zog sich der FDGB gegenüber der ÖTV und den anderen DGB-Gewerkschaften auf »eine risikoscheue Abgrenzungspolitik« zurück. ${ }^{29}$

27 | Ebd., S. 514.

28 | Ebd., S. 620 f. Auch hier gilt für das Politische Archiv des Auswärtigen Amtes das oben Gesagte. Im Willy Brandt-Archiv im Archiv der sozialen Demokratie in Bonn konnten ebenfalls keine Akten ermittelt werden, die Informationen über Beratungen in dieser Sache enthalten.

29 | Ebd., S. 622. 
Klunckers »Ostpolitik«, so hieß es in einem internen FDGB-Papier zur Rechtfertigung dieser abwehrenden Strategie, sei nichts anderes als ein »Antikommunismus moderner Art«, der auf eine innere Zersetzung der DDR abziele: ÖTV-Funktionäre »der mittleren und örtlichen Ebene« suchten "mit Wissen Klunckers« Kontakt zu DDR-Gewerkschaftern und träfen diese auf privaten Reisen. Solche Begegnungen galten politisch offensichtlich als hoch riskant, weil sie den westdeutschen Gewerkschaftern die Gelegenheit boten, ihre »überholte bürgerliche Gewerkschaftstheorie« zu vertreten. ${ }^{30}$ So schalteten die Kommunisten 1967 alle Signale für einen gewerkschaftlichen Austausch zwischen der DDR und der Bundesrepublik auf Rot - und diese Verweigerungshaltung zielte durchaus auch persönlich auf den ÖTV-Vorsitzenden: »Einer politischen Aufwertung Klunckers im DGB und in der Öffentlichkeit ist entgegenzutreten. ${ }^{31}$ Heinz Bartsch, der Vorsitzende der DDR-Gewerkschaft für den Öffentlichen Dienst, forderte den ÖTV-Chef daher 1968 öffentlich auf, er solle von seinem »Vorhaben der Liberalisierung « in den sozialistischen Staaten ablassen und lieber gegen die angeblich bereits weit fortgeschrittene »Renazifizierung« der Bundesrepublik kämpfen. ${ }^{32}$

Darüber hinaus scheiterte der "Ostpolitiker" Heinz Kluncker nicht nur gegenüber den DDR-Gewerkschaftern, sondern einmal mehr auch im DGB-Bundesvorstand. Ludwig Rosenberg wandte sich als Vorsitzender des Dachverbandes eindeutig gegen die von der ÖTV gewünschte Kurskorrektur gegenüber der DDR und der SED: Eine »Aufwertung« der Parteidiktatur jenseits der Elbe durch die bundesdeutschen Gewerkschaften dürfe es nicht geben. Mit großer Mehrheit bestätigte der Vorstand im September

30 | Vorlage des Zentralvorstandes der Gewerkschaft für die Mitarbeiter der Staatsorgane und der Kommunalwirtschaft für das Sekretariat des FGBD-Bundesvorstandes zur Einschätzung der Führung der Gewerkschaft ÖTV, 11.10.1966. In: BArch Berlin, SAPMO, DY 34, 24912.

31 | Taktik des FDGB-Bundesvorstandes und seiner Verbände zum Kontaktstreben der Gewerkschaft ÖTV, 23.8.1967. In: BArch Berlin, SAPMO, DY 34, 24913.

32 | Heinz Bartsch: Die Aufgaben der Gewerkschaft der Mitarbeiter der Staatsorgane und der Kommunalwirtschaft bei der Gestaltung des entwickelten gesellschaftlichen Systems des Sozialismus in der DDR. Referat auf der III. Zentraldelegiertenkonferenz, Ost-Berlin 1968, S. 7 f. 
1967 diese Position und seine früheren Beschlüsse über die politische Quarantäne gegenüber den ostdeutschen Kommunisten. ${ }^{33}$

In der Folge entwickelte die ÖTV nur Kontakte in andere Länder jenseits des »Eisernen Vorhangs«. Klunckers erster Besuch in der CSSR öffnete ihm und »seiner« Gewerkschaft dort viele Türen. Rasch folgten Reisen des Vorsitzenden in die UdSSR, nach Polen und Ungarn sowie nach Jugoslawien, das im sozialistischen Lager erfolgreich eine Sonderrolle für sich beanspruchte und deshalb nicht zum »Warschauer Pakt « gehörte. Rasch beteiligten sich Ebenen unterhalb der obersten Leitung in der ÖTV an den Kontakten: Jugend- und Frauengruppen traten als Gastgeber auf, oder sie gingen selbst auf Reisen. Zumindest mit der CSSR entwickelten sich dabei intensive Beziehungen: Allein 1967 empfing die ÖTV fünf verschiedene Delegationen aus der Tschechoslowakei. Dazu kam je einmal offizieller Besuch aus der UdSSR, aus Ungarn und aus Jugoslawien. ${ }^{34}$

Ob es der Gewerkschaft gelang, bei solchen Kontakten den »Bazillus der Freiheit« zu übertragen, lässt sich nicht sagen. Selbstverständlich begegneten den ÖTV-Mitgliedern im Rahmen solcher Veranstaltungen als Besucher oder Gastgeber direkt jeweils nur Menschen, die sich in ihrem Land ideologisch und politisch vielfach als treue Gefolgsleute der herrschenden Kommunisten bewährt hatten. Zudem traf man immer in Gruppen aufeinander; die Notwendigkeit, Dolmetscher einzusetzen, schuf weitere Kontrollmöglichkeiten. Wenn überhaupt, dann mag sich das metaphorische Bakterium insgeheim im Kopf einzelner »Ostblock«-Gewerkschafter eingenistet haben.

Das jähe Ende des »Prager Frühlings« bewirkte im August 1968 das ebenso abrupte Ende der stets prekären und komplizierten Beziehungen zwischen west- und osteuropäischen Gewerkschaften. Als sich der Reformkommunismus in der CSSR unversehens so rasch und dynamisch entwickelte, dass eine offene politische Diskussion und freie Wahlen möglich zu werden schienen, intervenierte bekanntlich die Sowjetunion: Mit militärischer Hilfe fast aller Staaten des »Warschauer Paktes« besetzte die Rote

33 | Der Deutsche Gewerkschaftsbund 1964-1969, S. 513 (Zitat Rosenberg) u. S. 517.

34 | Aufstellung von Gastdelegationen aus sozialistischen Ländern nach Westdeutschland, 14.6.1967. In: BArch Berlin, SAPMO, DY 34, 24913. Diese Liste verzeichnet auch verabredete Besuche für das zweite Halbjahr. Vgl. auch: ÖTV-Geschäftsbericht 1964/67, S. $17 \mathrm{f}$. 
Armee die Tschechoslowakei und erzwang so ein Ende der Reformen. Dieser Gewaltakt machte weitere Treffen mit Repräsentanten der »Ostblock«Staaten, die einer »Versöhnung« zwischen Ost und West dienen sollten, politisch unmöglich. Der DGB forderte umgehend den Abzug der »Okkupationsmächte « und beschloss, jeden Kontakt zu den Gewerkschaften dieser Länder abzubrechen. Besonders Otto Brenner, der einflussreiche Vorsitzende der IG Metall, der einer gewerkschaftlichen »Ostpolitik« ohnehin skeptisch gegenüberstand, hielt dies für alternativlos. ${ }^{35}$

Heinz Kluncker plädierte zwar selbst in dieser Situation noch dafür, den Gesprächsfaden nicht abreißen zu lassen: Der Sicherheit der Bundesbürger und »dem leidgeprüften tschechoslowakischen Volk« könne es nur nützen, wenn "wir unsere Bemühungen um Entspannung ohne falsche Anbiederungsversuche entschlossen fortsetzen«. Als Kluncker erkannte, wie wenig er seine Kollegen im DGB-Bundesvorstand mit diesen Statements beeindruckte, beugte er sich jedoch der Mehrheitsmeinung. Zwar galt der Beschluss erklärtermaßen nur »vorläufig«. Unter welchen Bedingungen er revidiert werden könnte, blieb jedoch offen. ${ }^{36}$

Abgesehen von dem Fazit, dass die Handlungsmöglichkeiten westlicher Demokraten gegenüber dem »real existierenden Sozialismus« in Osteuropa, der sich zur Herrschaftssicherung aller Machtmittel moderner Staaten bedienen konnte, zwangsläufig sehr gering ausfielen, bleibt als Resultat der gewerkschaftlichen »Ostpolitik«, die Heinz Kluncker 1965 einleitete, somit nur ein persönlicher Erfolg - der aber war unbestreitbar: Der ÖTV-Vorsitzende hatte sich mit seinen außenpolitischen Initiativen und Reisen fraglos als reformorientierter Gewerkschaftsvorsitzender profiliert, der öffentliche Debatten anstieß und bestimmte. ${ }^{37}$

35 | Jens Becker/Harald Jentsch: Otto Brenner. Eine Biografie, Göttingen 2007, S. 317; Klaus Kemper: Eugen Loderer und die IG Metall. Biografie eines Gewerkschafters, Filderstadt 2003, S. 180-185.

36 | Heinz Kluncker: Kommt es zu einer Neuorientierung der gewerkschaftlichen Ostpolitik? In: Der Volkswirt 22 (1968), H. 35, S. 23. Der DGB-Beschluss in: DGB 1964/69, S. 732 (Bundesvorstandssitzung, 28.8.1968). Bei einer Vorabstimmung hatte nur die ÖTV dafür plädiert, Kontaktmöglichkeiten aufrecht zu erhalten; anschließend stimmte sie dann mit der Mehrheit (ebd.). Da Rumänien sich an der Besetzung der CSSR nicht beteiligt hatte, hatte der DGB-Beschluss für dieses »Ostblock«-Land keine Bedeutung. Vgl.: Müller: DGB, S. 225.

37 | Vgl. etwa zusammenfassend: Lutz: Ostpolitiker aus Passion, S. 104-109. 
Diese Feststellung will keineswegs die zynische Schlussfolgerung nahelegen, es sei Heinz Kluncker bei seinen Gesprächen mit osteuropäischen Gewerkschaftern vor allem darum gegangen, einen persönlichen Effekt in der Bundesrepublik zu erzielen. Nichts im Denken und Handeln Klunckers lässt daran zweifeln, dass ihm die "Versöhnung« mit den von deutschen Soldaten verwüsteten Ländern jenseits des »Eisernen Vorhangs« wirklich wichtig war, weil es seiner Überzeugung zufolge nur so gelingen konnte, Europa auf Dauer zu einem friedlichen Kontinent zu machen. Dennoch ist Politik zu einem guten Teil immer auch symbolisches Handeln - und dieser symbolische Anteil ist im Bereich der Außenpolitik besonders groß, wenn es dabei nicht gerade um handfeste Regelungen wie Zölle oder Grenzkontrollen geht. Wenngleich es Kluncker in dieser außenpolitischen Frage erkennbar nicht zentral um persönliche Profilierung ging, so demonstrierte er mit der ÖTV-Ostpolitik doch seine außergewöhnlichen Fähigkeiten im politischen Geschäft, zu dem es eben auch gehört, auf der Klaviatur der Symbolpolitik zu spielen.

\section{Die Position der ÖTV im Streit um die Notstandsgesetze und Heinz Klunckers Verhältnis zur SPD}

Auch in der Frage der Notstandsgesetze vertrat Heinz Kluncker in den Jahren nach 1964 Positionen, mit denen er im DGB aneckte. Diese eigensinnige Haltung, die er wiederum gezielt öffentlich vortrug, prägte sein politisches Profil und seine Wahrnehmung durch die politisch interessierten Zeitgenossen aus zwei Gründen vielleicht noch stärker als sein Engagement für eine Entspannung zwischen Ost und West. Zum einen korrigierte der neu gewählte Vorsitzende in dieser Sache offizielle Beschlüsse der ÖTV; zum anderen handelte es sich bei den Notstandsgesetzen um ein Thema, das die bundesdeutsche Gewerkschaftsbewegung über Jahre hin stark erregte. Um die politische Bedeutung von Klunckers Verhalten deutlich zu machen, sei vorab der Kontext etwas ausführlicher skizziert.

Die im Mai 1968 vom Bundestag verabschiedeten Notstandsgesetze sind heute weitgehend unbekannt und vergessen, obwohl sie nach wie vor geltendes Recht sind. In der Bundesrepublik gehörte dieses Gesetzespaket, das im Parlament eine verfassungsändernde Zweidrittel-Mehrheit brauchte, um in Kraft zu treten, für lange Zeit - zwischen den späten 1950er Jahren und 1968 - zu den politisch am stärksten umstrittenen Themen. Die oft 
leidenschaftlich geführte Debatte prägte das innenpolitische Klima; ohne sie hätte sich die studentische Revolte, die unter der Chiffre $\$ 68$ « heute als epochemachender Einschnitt in der Entwicklung der bundesdeutschen Gesellschaft gilt, nicht so entwickelt, wie sie es tat. Eine ausführliche Darstellung dieser Streitigkeiten ist hier nicht möglich. Kurz gesagt ging es um den Versuch der Bundesregierung, die Arbeit von Legislative und Exekutive gesetzlich auch für den Ausnahmezustand zu regeln, in denen das normale Prozedere nicht mehr funktionieren konnte oder aber zu langwierig sein würde. Krieg (das heißt in der Bundesrepublik nach der Verfassung: die Verteidigung gegen Angreifer) und schwere Naturkatastrophen galten als solche »Notstände«, dazu kam dann aber noch ein so unpräzise definiertes Phänomen wie »innere Unruhen «. ${ }^{38}$

Diese Planungen der Bundesregierung wurden in den frühen 1960er Jahren vielfach scharf kritisiert. Vergleiche mit der legal verbrämten »Machtergreifung« der Nationalsozialisten im Jahr 1933 gehörten dabei zu den Standardargumenten. Gerade in den DGB-Gewerkschaften war die Empörung groß, denn in den Gesetzentwürfen gab es unter anderem Bestimmungen, die es erlaubten, das Streikrecht einzuschränken und eine "Dienstpflicht" für bestimmte Arbeitnehmer zu verfügen. Als Gewerkschaft für die Beschäftigten öffentlicher Versorgungsunternehmen fühlte sich die ÖTV von solchen Überlegungen ganz besonders betroffen: Es lag auf der Hand, dass gerade solche Betriebe in Krisenzeiten überragend wichtig waren. ${ }^{39}$

38 | Als knappe Zusammenfassung nützlich: Kleßmann: Zwei Staaten, S. 245250. Vgl. auch: Wolfgang Kraushaar: Die Furcht vor einem »neuen 33«. Protest gegen die Notstandsgesetzgebung. In: Dominik Geppert/Jens Hacke (Hrsg.): Streit um den Staat. Intellektuelle Debatten in der Bundesrepublik 1960-1980, Göttingen 2008, S. 135-150; Boris Spernol: Notstand der Demokratie. Der Protest gegen die Notstandsgesetze und die Frage der NS-Vergangenheit, Essen 2008. Als detaillierteste Darstellung vgl. nach wie vor: Michael Schneider: Demokratie in Gefahr? Der Konflikt um die Notstandsgesetze: Sozialdemokratie, Gewerkschaften und intellektueller Protest (1958-1968), Bonn 1986.

39 | Vgl. zu diesem Zusammenhang etwa A. Kummernuss in: Protokoll ÖTV-GT 1961, S. 85. Vgl. ebd., S. 86 u. 88, auch den Vergleich mit der NS-Machtergreifung. Die Frage der Notstandsgesetze besaß für die ÖTV auch insofern besondere Bedeutung, weil sie seit 1965 (d.h. praktisch seit dem Amtsantritt von H. Kluncker) für das Recht stritt, auch Berufssoldaten zu organisieren. Im August 1966 gestattete ein Erlass des Verteidigungsministeriums solche Mitgliedschaften. Vgl. 
Die ÖTV gehörte daher - neben der IG Metall - zu den DGB-Gewerkschaften, die sich nach 1960 offiziell darauf festlegten, den Überlegungen der Bundesregierung ein radikales »Nein« entgegenzusetzen: Gesetzliche Regelungen für »Notstände« seien schlicht überflüssig, weil das geltende Recht voll und ganz ausreiche, um auch solche schwierigen Situationen zu bewältigen. Bleibe die Regierung trotzdem bei ihrem Vorhaben, beweise sie damit ihre autoritären politischen Absichten; als gewerkschaftliche Reaktion müsse deshalb selbst ein politischer Streik in Betracht gezogen werden, um die bedrohte Demokratie zu verteidigen. ${ }^{40}$ Die Delegierten des DGB-Bundeskongresses verzichteten im Oktober 1962 zwar auf eine Streikdrohung; die Gesetzentwürfe aber verwarfen sie dennoch in Bausch und Bogen als Gefährdung der demokratischen Grundrechte. ${ }^{41}$

Wie das Beispiel der ÖTV zeigt, empörten sich keineswegs nur die leitenden gewerkschaftlichen Funktionäre über die Gesetzentwürfe. 1961 lagen dem Gewerkschaftstag zu diesem Thema insgesamt 14 Entschließungsanträge vor, die von einzelnen Bezirks- und Kreisverwaltungen sowie von mehreren Konferenzen verschiedener Hauptabteilungen stammten und den Plan der Bundesregierung sämtlich verwarfen. Keine andere Frage hatte die Organisation bei der Vorbereitung des Kongresses so breit beschäftigt. Einige dieser Resolutionen, die der Gewerkschaftstag alle pauschal und ohne Diskussion annahm, verlangten ausdrücklich, die ÖTV solle »mit allen Mitteln« oder auch »mit schärfsten Mitteln« gegen die »drohende Vergewaltigung des Grundgesetzes« kämpfen. Mehrfach wurden Streiks empfohlen. ${ }^{42}$

Die SPD verfolgte hingegen einen ganz anderen Kurs: Sie hielt den Grundgedanken, die Bundesrepublik brauche besondere gesetzliche Regelungen für Notsituationen, durchaus für richtig. Dementsprechend beteiligte sie sich nach einem Beschluss des Parteitages von 1960 im Bundestag

zu diesem seinerzeit heftig umkämpften Thema ausführlich: Wilhelm Trottenberg: Bundeswehr und Gewerkschaften (1945-1966). Ende einer hundertjährigen Feindschaft, Hamburg 1995, insbes. S. 304-32 u. 351-387.

40 | Schneider: Demokratie, S. 60 f. u. 73-77.

41 | Vgl.: ebd., S. 95-98.

42 | Protokoll ÖTV-GT 1961, Anträge und Entschließungen, S. 142-148, Zitate: S. 144 (Entschließung der Konferenz der Hauptabt. V) u. S. 147 (Entschließung der Kreisverwaltung Mainz). 
und in seinen Ausschüssen konstruktiv an der Ausarbeitung der Gesetzentwürfe - unter anderem, um sie so umzuformulieren, dass die Bedenken des DGB entfielen. ${ }^{43}$

In dieser Auseinandersetzung ging es verdeckt auch sehr grundsätzlich um das Verhältnis zwischen der Partei und den politisch und personell mit ihr so eng verbundenen DGB-Gewerkschaften. Das Stichwort "Godesberger Programm" bezeichnet die damals noch ganz neue Wandlung in dieser Beziehung, die den Streit anheizte: Als selbst deklarierte »Volkspartei«, die gezielt und planvoll nach Regierungsmacht strebte, beanspruchte die SPD deutlich größere politische Handlungsspielräume und Entscheidungsfreiheiten. In den Planungen der Parteiführung genossen die Belange der Gewerkschaften damit zwangsläufig nicht mehr den gleichen Rang wie zuvor. Konflikte waren so gleich auf doppelte Weise programmiert: Zum einen immer dann, wenn organisatorische Eigeninteressen der Gewerkschaften zur Debatte standen; zum anderen dadurch, dass traditionell linke Sozialdemokraten Gewerkschaftskongresse nutzen konnten, um »ihre wahre Meinung zur Politik der Partei aus[zu]drücken«, ohne dabei »den eigentlichen Adressaten offen anzusprechen «. Die scharfen Resolutionen gegen die Notstandsgesetze, die etwa die IG Metall und die ÖTV auf ihren Kongressen in den Jahren 1960 und 1961 verabschiedeten, lassen sich wohl berechtigt in diesem Sinne deuten. ${ }^{44}$

Erst in diesem Kontext gewinnen die Äußerungen, mit denen sich Kluncker seit dem Sommer 1965 in die Debatten über die Notstandsgesetze einschaltete, ihre Bedeutung. Für sich selbst betrachtet, wirken sie nämlich einfach nur unspektakulär und fast prosaisch nüchtern. Im DGBBundesvorstand sprach sich der ÖTV-Vorsitzende mehrfach dagegen aus, den Dissens zwischen SPD und Gewerkschaften weiterhin so stark zu betonen, wie das bisher geschehen war. So hielt er nichts von öffentlichen Kundgebungen der Gewerkschaften oder von Unterschriftensammlungen gegen die Gesetzentwürfe. Der DGB, so sein Rat, tue besser daran, über deren Details mitzureden, als immer nur pauschal seine Ablehnung zu erklären. Ohnehin widme der gewerkschaftliche Dachverband dem Thema viel Energie, »obwohl es zur Zeit wichtige ökonomische Fragen gibt, die be-

43 | Ebd., S. 68-73 u. 84-89.

44 | Otto Stolz: Kummernuss macht der SPD Kummer. In: Christ und Welt, 3.6.1961. 
antwortet werden müßten. Nach seiner Auffassung wird in den Betrieben und Verwaltungen über andere Fragen als Notstandsgesetze diskutiert. «" ${ }^{45}$

Im Oktober 1965 machte Kluncker in einer Rede in West-Berlin dann erstmals öffentlich deutlich, dass er beim Blick auf die Gesetzesvorhaben in Sachen Notstand weder einen Angriff auf das Grundgesetz noch die Gefahr entdecken konnte, Gewerkschafter könnten wieder in KZs geworfen werden. Zwar sei es die Aufgabe des Gesetzgebers, Regelungen zu verabschieden, die »keinen Argwohn hervorrufen und nicht von vornherein zu einem Nein zwingen«. An der Notwendigkeit der Notstandsgesetze gebe es aber keinen Zweifel. ${ }^{46}$ Der ÖTV-Vorsitzende nahm damit eine Position ein, die der DGB-Bundesvorstand bislang stets verworfen hatte. Auf Nachfragen der Presse erklärte Kluncker, im DGB und seinen Verbänden müsse es »eine Versachlichung der Diskussion« über die Notstandsgesetze geben. Bleibe sie aus, bestehe »die Gefahr, daß die Entwicklung an uns vorübergeht «. ${ }^{47}$

Anders als viele andere führende Gewerkschaftsfunktionäre zweifelte Kluncker zudem nicht an der demokratischen Einstellung der CDU: Es gebe keinen Grund zu glauben, dass die Christdemokraten es darauf anlegten, eine Notstandsregelung "gegen den Widerstand der Gewerkschaften durch[zu]peitschen ${ }^{48}{ }^{4}$ Als die Delegierten des DGB-Bundeskongresses im Mai 1966 dennoch erneut mit klarer Mehrheit jede gewerkschaftliche Mitarbeit an den Gesetzentwürfen ablehnten, ging Kluncker öffentlich auf Distanz: Der Beschluss entspreche »nicht den Realitäten«, denn alle drei im Bundestag vertretenen Parteien bejahten im Prinzip gesetzliche Bestimmungen, wie Legislative und Verwaltung bei gravierenden Notständen funktionieren sollten. Konstruktive Mitarbeit sei daher der bessere Weg, die eigenen Interessen zu wahren, als sture Ablehnung. ${ }^{49}$

45 | Der Deutsche Gewerkschaftsbund 1964-1969, S. 205 (Bundesvorstandssitzung v. 1.6.1965), S. 297 (Bundesvorstandssitzung v. 13.6.1966), Zitat: S. 361 (Bundesvorstandssitzung v. 25.11.1966). Vor dem ÖTV-HV sagte Kluncker im Frühjahr 1967, vier Fünftel der für Beratungen in den DGB-Gremien zur Verfügung stehenden Zeit werde mit Debatten über die Notstandsgesetze verbracht. Protokoll über die 11. Sitzung des HV, 16./17.3.1967. In: AdsD, 5/ÖTVB130014.

46 | ÖTV-Vorsitzender Kluncker durchbricht das Notstands-Tabu. In: Handelsblatt, 14.10.1965.

47 | Ändern die Gewerkschaften ihre Haltung? In: Die Welt, 2.3.1966.

48 | Notstand - mehr Ja als Nein. In: Die Welt, 22.3.1966.

49 | Kluncker: Beschluss des DGB unrealistisch. In: Die Welt, 20.6.1966. 
Für diese pragmatische Einstellung, die im DGB seinerzeit nur von einer Minderheit der Gewerkschaftsführer geteilt wurde, öffneten sich im weiteren Verlauf dann allerdings doch die meisten Mitglieder im DGBBundesvorstand. Die von Heinz Kluncker bislang vergeblich angemahnte konstruktive Mitarbeit der Gewerkschaften an den Gesetzentwürfen intensivierte sich 1967 und 1968 rasch, je näher die Verabschiedung der Notstandsgesetze im Bundestag rückte. Entscheidend gefördert wurde diese Wende durch die Bildung der Großen Koalition zwischen CDU/CSU und SPD im November 1966: Da die Sozialdemokraten Regierungsverantwortung übernahmen und der Koalitionsvertrag sie eindeutig auf eine positive Haltung gegenüber den Notstandsgesetzen festlegte, ließ sich kaum noch darauf hoffen, man könne die notwendige Zweidrittel-Mehrheit im Bundestag verhindern, indem man auf die SPD-Fraktion einwirkte. ${ }^{50}$

Auch in der letzten Phase der langwierigen Streitigkeiten über die Notstandsgesetze fanden die DGB-Verbände jedoch nicht zu einer wirklich einheitlichen Haltung: Insbesondere die IG Metall und ihr Vorsitzender Otto Brenner beschworen nach wie vor »die tödlichen Gefahren« der Notstandsgesetze für die bundesdeutsche Demokratie. ${ }^{51}$ Die Metallgewerkschaft beteiligte sich aktiv an den Protestaktionen und Demonstrationen, die während der abschließenden parlamentarischen Beratung der Gesetzentwürfe immer zahlreicher und lautstärker wurden. Auf ihrem Höhepunkt, im Mai 1968, führten diese Proteste bundesweit etwa 150.000 Menschen auf die Straßen. ${ }^{52}$

Wenn Heinz Kluncker in dieser Phase der politischen Zuspitzung an seiner Überzeugung festhielt, bei den Notstandsgesetzen gehe es nicht um eine grundsätzliche Entscheidung für Demokratie oder Diktatur, und wenn er im DGB zudem davor warnte, Gewerkschafter dürften ihren »Abwehrkampf« in dieser Sache nicht »mit den falschen Verbündeten« (nämlich: mit selbst undemokratisch denkenden Linksradikalen) führen, dann formte er damit entscheidend das politische Profil, das ihn in seiner Kar-

50 | Vgl.: Schneider: Demokratie, S. 190-195; speziell zum Beitrag der ÖTV etwa auf Anhörungen verschiedener Bundestagsauschüsse vgl.: ÖTV-Geschäftsbericht 1964/67, S. 16 f.; Sachverständig zum Bundeswehr-Einsatz bei innerem Notstand. In: FAZ, 1.12.1967.

51 | Vgl. Becker/Jentsch: Brenner, S. 264-275, Zitat: S. 266.

52 | Vgl. ausführlich: Schneider: Demokratie, S. 239-267. 
riere fortan begleiten sollte: Kluncker stand in dieser Sache im politischen Spektrum des DGB in der öffentlichen Wahrnehmung eindeutig nicht bei der IG Metall und damit auf der »linken « Seite, sondern »rechts«. ${ }^{53}$

Wie hilfreich diese Label grundsätzlich sind, muss hier nicht diskutiert werden. $\mathrm{Zu}$ betonen ist jedoch, dass der ÖTV-Vorsitzende stets entschieden darauf pochte, nur eine rechtsstaatlich einwandfreie Fassung der Notstandsgesetze sei akzeptabel. Gravierende Einschränkungen der bürgerlichen Grundrechte - etwa durch eine staatlich verhängte "Dienstpflicht« - dürfe es nicht geben. Kluncker argumentierte dabei auch mit dem außenpolitischen Projekt, den osteuropäischen Staaten die Hand zur "Versöhnung" zu reichen: Diese Friedenspolitik könne nicht vorankommen, wenn es im Ausland ernsthafte Zweifel an der zivilen Ordnung der Bundesrepublik gebe. $^{54}$

Im Endeffekt unterschieden sich die verabschiedeten Notstandsgesetze deutlich von den vorangegangenen Entwürfen, weil viele Bestimmungen auf Druck der SPD und der Gewerkschaften anders gefasst wurden. Ob diese reformierte Version wirklich keine antiliberalen und verfassungsrechtlich fragwürdigen Elemente mehr aufweist, ist dennoch schwer zu beurteilen und stark umstritten. ${ }^{55}$

Kaum zu bestreiten ist jedoch, dass es die erreichten Änderungen ohne die gewerkschaftliche Kritik an den Planungen der Bundesregierung nicht gegeben hätte - und diesen Beitrag leisteten sowohl »rechte « Gewerkschafter wie Heinz Kluncker als auch »linke« wie Otto Brenner, denn erst gemeinsam erreichten sie ihre Wirkung. Rückblickend kann der interne Streit im DGB, wie man auf die autoritären Tendenzen in den ersten Gesetzentwürfen reagieren solle, daher eher als ein gemeinsamer Kampf mit verteilten Rollen denn als unversöhnlich ausgetragene Kontroverse gelten. Die zeitgenössische Wahrnehmung allerdings sah anders aus: Gerade enga-

53 | Das Zitat aus: Der Deutsche Gewerkschaftsbund 1964-1969, S. 494 (Bundesvorstandssitzung v. 5.7.1967).

54 | Vgl. etwa: Referat H. Kluncker auf der außerordentlichen Bundes-Jugendkonferenz der ÖTV, 18.6.1966. In: AdsD, Depositum Kluncker, Reden und Referate November 1964-September 1969; Der Deutsche Gewerkschaftsbund 19641969, S. 494 (Bundesvorstandssitzung v. 5.7.1967).

55 | Unterschiedlich abwägende Urteile vgl. etwa in: Schneider: Demokratie, S. 273-280; Becker/Jentsch: Brenner, S. 273-275; Spernol: Notstand, S. 88-92. 
gierte Kritiker, die jede Form der Notstandsgesetzgebung für überflüssig und politisch gefährlich hielten, empfanden sich am Ende als gescheitert, ja als »betrogen«, weil die IG Metall im Mai 1968 trotz ihrer stets scharf formulierten Resolutionen doch nicht zum politischen Streik aufgerufen hatte..$^{56}$

Der Streit über die Notstandsgesetze hinterließ ein recht ambivalentes politisches Erbe. So kann diese langwierige Auseinandersetzung zwar berechtigt als »Reifeprüfung« der bundesdeutschen Demokratie gelten, weil sich der Gesetzgeber ernsthaft bemühte, abweichende Meinungen nicht nur zu hören, sondern auch zu bedenken. ${ }^{57}$ Aber in dieser Debatte hatten sich argumentative und rhetorische Muster gebildet und stabilisiert, die noch lange fortlebten und das politische Klima in der Bundesrepublik auf ungute Weise beeinflussten: Der bedenkenlose Vergleich des Landes mit dem »Dritten Reich«, den so viele Kritiker der Notstandsgesetze gezogen hatten, verschwand selbst dann nicht in der Abstellkammer für unbrauchbare politische Polemik, als sich nach dem Mai 1968 zeigte, dass die bundesdeutsche Demokratie trotz der neuen Regelungen unangefochten fortbestand. Im Gegenteil: Gerade im linken Milieu verfestigte sich das Bild, es fehle nicht mehr viel für eine neue Diktatur. ${ }^{58}$

Die komplexen Ursachen für diese Entwicklung stehen hier nicht zur Debatte. Wer über die politischen Leistungen Heinz Klunckers in seiner Zeit als ÖTV-Vorsitzender urteilen möchte, sollte sich jedoch daran erinnern, dass Kluncker in der Debatte über die Notstandsgesetze früh dazu geraten hat, die Kritik an den Gesetzentwürfen weniger emotional und dramatisierend vorzutragen. Der politischen Kultur des Landes hätte es sicher gutgetan, wenn der DGB und die ihm angeschlossenen Verbände diesen Rat rascher und konsequenter beachtet hätten.

Mit dieser Bemerkung könnte man hier abbrechen, da die Notstandsgesetze mit den zentralen gewerkschaftlichen Aufgaben der ÖTV nur sehr vermittelt zu tun hatten. Dennoch lohnt sich ein zweiter Blick auf Klunckers Kurs in dieser Sache, weil er sich als Gewerkschafter und Politiker dadurch noch genauer beschreiben lässt: Er zeigt sich als gewiefter Taktiker,

56 | Schneider: Demokratie, S. 271.

57 | Ebd., S. 280.

58 | Vgl.: ebd., S. 244 f.; Kraushaar: Furcht, S. 147-149. 
der innerhalb der Organisation souverän die politischen Möglichkeiten nutzte, die sein Amt mit sich brachte.

Um Kluncker in der Sache der Notstandsgesetze als politischen Strategen zu erkennen, muss man sich nur an die scharf ablehnenden Beschlüsse des ÖTV-Gewerkschaftstages von 1961 zu dieser Frage erinnern. Der Kongress von 1964 bestätigte dieses Votum noch einmal. ${ }^{59}$ Wenn der neue Vorsitzende etwa ein Jahr später eine andere Haltung einnahm und allgemein den Gewerkschaften empfahl, sich konstruktiv an der Beratung der Notstandsgesetze zu beteiligen, dann wich er damit von der demokratisch ermittelten Position seiner eigenen Organisation ab. Politisch wurde das möglich, weil Kluncker rückblickend entdeckte, dass der Kongress von 1961 nicht sehr sorgfältig gearbeitet hatte. Zu den 14 damals pauschal angenommenen Anträgen gegen die Notstandsgesetze gehörte auch eine Entschließung, die bei genauer Lektüre nicht zu den anderen Texten passte: Sie forderte nämlich die Gremien der ÖTV auf, "geeignete Maßnahmen« zu ergreifen, »damit eine Notstandsgesetzgebung zustande kommt, die die sozialen und demokratischen Grundrechte der Arbeitnehmer und Gewerkschaften nicht zerstört«. Mit den Appellen in den 13 weiteren Anträgen, »mit allen Mitteln« und eventuell auch mit Streiks gegen die Gesetzentwürfe zu kämpfen, hatte dieser politische Auftrag zu Verhandlungen nichts gemein. ${ }^{60}$

Bei den Beratungen im Sommer 1961 war dieser Widerspruch entweder niemandem aufgefallen, oder aber Antragskommission und Kongressleitung war es ganz recht gewesen, dass er unentdeckt blieb, weil sie so eine kontroverse und politisch heikle Debatte kurz vor dem Ende der Veranstaltung vermeiden konnten. Diskussionsbedarf hatte jedenfalls niemand gesehen - und auch auf dem Gewerkschaftstag von 1964 blieb es dabei. Insofern war es doch recht überraschend, dass Heinz Kluncker im Oktober 1965, mehr als vier Jahre nach den ersten Beschlüssen der ÖTV zu den Notstandsgesetzen, im geschäftsführenden Hauptvorstand plötzlich forderte, man müsse die Position der ÖTV in dieser Frage »klären«, weil das Votum

59 | Protokoll ÖTV-GT 1964, S. 397; Anträge und Entschließungen, S. 161. Dieser Antrag bezog sich auf die ebenfalls scharf ablehnende Resolution des DGB-Bundeskongresses von 1962; er wurde ohne Debatte angenommen.

60 | Protokoll ÖTV-GT 1961, Anträge und Entschließungen, S. 142 f. (Antrag 260, beschlossen von der Konferenz der Hauptabt. I). 
von 1961 nicht eindeutig sei. Wie der Vorsitzende es vorschlug, revidierte das Gremium daraufhin nach kurzer und kaum strittiger Debatte die Mehrheitsbeschlüsse von gleich zwei Gewerkschaftskongressen. ${ }^{61}$ Politisch gab es gute Gründe für diese Entscheidung. Ob sie auch als Teil gelebter gewerkschaftlicher Demokratie gelten kann, darüber lässt sich aber wohl trefflich streiten.

Wenn Klunckers Kurswechsel in der ÖTV zu Protesten führte, dann hat das keine großen Wellen verursacht. Auf dem Gewerkschaftstag von 1968 - als die Notstandsgesetze bereits verabschiedet waren - spielte diese Angelegenheit keine Rolle mehr. ${ }^{62}$ Zwar äußerte der sozialdemokratische Bundestagsabgeordnete Fritz Bütter im Mai 1968 in einem Brief an Kluncker, die Erklärungen des ÖTV-Vorsitzenden zu den Notstandsgesetzen seien für viele Mitglieder der Organisation »Anlaß gewesen [...], der ÖTV den Rücken zu kehren ${ }^{63}$ In der Mitgliederstatistik lassen sich solche Abwanderungen jedoch nicht nachweisen. Wenn es sie gab, handelte es sich offensichtlich nur um ein begrenztes Phänomen. Auch Resolutionen und Beschlüsse von Untergliederungen der Organisation, die den Kurs der Verbandsführung offen kritisierten, sind nur in Einzelfällen dokumentiert. ${ }^{64}$ Klunckers Urteil, die Notstandsgesetze seien in den Betrieben kein wichtiges Thema, wirkt wegen dieser Lücke durchaus überzeugend.

Zudem zeigt sich an der Politik des ÖTV-Vorsitzendenden mit Blick auf die Notstandsgesetzgebung, wie er über das politische System der Bundesrepublik dachte. Klunckers Strategie einer pragmatischen Mitarbeit war anders motiviert als bei einigen seiner Kollegen im Kreis der DGB-Gewerkschaftsführer, die schon frühzeitig ähnlich argumentierten. Bei Georg Leber etwa liegt es auf der Hand, dass der Vorsitzende der IG Bau Spannungen zwischen den DGB-Gewerkschaften und der Sozialdemokratie vermeiden

61 | ÖTV-Geschäftsbericht 1964/67, S. 14 f.

62 | Schneider: Demokratie, S. 270.

63 | Fritz Bütter an Heinz Kluncker, 17.5.1968 (Abschrift). In: AdsD, Helmut Schmidt-Archiv (HSA), 1/HSAA 005357. Bütter war diesem Schreiben zufolge selbst ÖTV-Mitglied.

64 | Schneider: Demokratie erwähnt etwa einen Beschluss der ÖTV-Gruppe in den Stadtwerken Offenbach, der im Mai 1968 für Streiks plädierte (S. 258). Die wenigen Streiks, die tatsächlich stattfanden (vgl. ebd., S. 259 f.), berührten offensichtlich keine staatlichen Einrichtungen oder Betriebe. 
wollte. Leber saß selbst als SPD-Abgeordneter im Bundestag; zudem war er Mitglied des Parteivorstandes. Walter Arendt, Vorsitzender der IG Bergbau, sowie Philipp Seibert, der die Gewerkschaft der Eisenbahner leitete, gehörten ebenfalls zur sozialdemokratischen Fraktion in Bonn. ${ }^{65}$ Wenn die Mehrheit im DGB die Notstandsgesetze grundsätzlich ablehnte, so mussten diese drei Gewerkschaftsführer schon deshalb widersprechen, weil die parlamentarische Fraktionsdisziplin sie auf eine andere Linie festlegte. ${ }^{66}$

Heinz Kluncker fühlte sich der SPD zwar ohne Frage eng verbunden. Er war ihr 1946 »aus Überzeugung« beigetreten und beteiligte sich auch noch in den frühen 1950er Jahren aktiv am Parteileben. 1954 schickte ihn die Stuttgarter SPD als einen ihrer Delegierten auf den Bundesparteitag, und dort stritt er sich mit dem Hamburger Professor Karl Schiller, der sich bemühte, die Partei von ihrem traditionellen sozialistischen Dogmatismus in Fragen der Wirtschaftspolitik abzubringen. ${ }^{67}$ Spätestens seit seiner Berufung zum ÖTV-Arbeitersekretär im Jahr 1958 beschränkte sich Kluncker jedoch auf die Rolle eines einfachen Parteimitglieds. ${ }^{68}$

Die persönliche politische Glaubwürdigkeit stand in seinem Fall daher - anders als bei Leber, Arendt oder Seibert - nie zur Debatte, wenn er über die »richtige« gewerkschaftliche Haltung zu den Notstandsgesetzen sprach. Wenn er die Empörung der engagierten Kritiker nicht teilte, so ergab sich das zu einem guten Teil wohl schlicht aus einem weniger aufgeregten Blick auf die komplizierten juristischen Formulierungen, um die gestritten wurde. Dazu kam ein insgesamt positives Urteil über die demokratische

65 | Hirche: Gewerkschafter im 5. Deutschen Bundestag, S. 710.

66 | Schneider: Demokratie, S. $96 \mathrm{f}$.

67 | Zitat: Hemmer/Simon: Wirkung, S. 146. Zu Klunckers Auftritt auf dem Parteitag vgl. Nützenadel: Stunde, S. 240. Allerdings wird Kluncker hier als »Gewerkschaftsführer« bezeichnet, was er 1954 definitiv noch nicht war.

68 | Als ÖTV-Vorsitzender war er allerdings selbstverständlich per se kein wirklich »einfaches« Parteimitglied. Zweimal - 1969 und 1979 - übertrug ihm die Partei ein politisches Ehrenamt: Sie entsandte ihn in die Bundesversammlung, die den Bundespräsidenten wählt (vgl.: Die Bundesversammlungen 1949-1994. Eine Dokumentation aus Anlaß der Wahl des Bundespräsidenten am 23. Mai 1999, Bonn 1999, S. 158 u. 240). Auch an Versammlungen des SPD-Kreisverbandes Stuttgart hat Kluncker wohl zumindest gelegentlich teilgenommen. Vgl. etwa den Bericht über eine Diskussion mit Helmut Schmidt in: Die SPD wirbt um Verständnis. In: FAZ, 5.12.1966. 
Stabilität der jungen Bundesrepublik. So verstehe ich Klunckers oben angeführte Bemerkung, es gebe keinen Grund, der CDU pauschal undemokratische Absichten zu unterstellen; so deute ich auch seinen Wunsch an den DGB, dieser möge sich bei Stellungnahmen zu den Gesetzentwürfen auf die Fragen beschränken, »die wir als Arbeitnehmer primär, mit anderen Worten aus dem Sozialauftrag, zu vertreten haben ${ }^{6}{ }^{6}$

Wenn die Gewerkschaften also nicht Kontrolleure des gesamten politischen Prozesses in der Bundesrepublik waren, sondern daran teilhatten, indem sie die sozialen Interessen ihrer Mitglieder vertraten, dann mussten sie die politische Prärogative der Parteien und des Bundestages akzeptieren: Die Selbstermächtigung gegenüber dem Parlament, die in vielen der radikal ablehnenden Stellungnahmen gegen die Notstandsgesetze auch von gewerkschaftlicher Seite anklang, war Heinz Kluncker offensichtlich suspekt.

Hierin sehe ich den Kern seiner pragmatischen Politik gegenüber den Gesetzentwürfen - und dabei spielte sein Alter, das ihn in den 1960er Jahren zu einem »jungen« Gewerkschaftsvorsitzenden machte, vielleicht doch eine wichtige Rolle. Adolph Kummernuss und Otto Brenner etwa, die beide deutlich älter waren, bezogen sich mit ihren dramatischen Warnungen vor den Regierungsplänen ja expressis verbis immer wieder auf das Jahr 1933, in dem alle bürgerlichen Parteien Deutschlands den Nationalsozialisten auf schmähliche Weise zur Macht verholfen hatten. Kluncker gehörte hingegen zu einer Generation, für die das Ende der Weimarer Republik nicht mehr Teil der bewussten persönlichen Erfahrung war - und damit fiel es ihm wohl leichter, die Emotionalität zu vermeiden, mit der Kummernuss und Brenner über die Notstandsgesetze sprachen.

Für das politische Profil Klunckers als ÖTV-Vorsitzender ist all dies wichtig, weil man seine Haltung gegenüber den Gesetzentwürfen nicht als gezielte Annäherung an die SPD deuten sollte. Generell hielt Kluncker wenig davon, gewerkschaftliches Engagement eng mit politischer Arbeit für eine Partei zu verbinden. So kritisierte er in einem intern gebliebenen Vortrag mit dem gewichtigen Titel »Das Zukunftsbild der ÖTV« im Februar 1966 dezidiert die mangelnde parteipolitische Neutralität vieler Funktionsträger in der Organisation: Vor allem bei Kommunalwahlen

69 | Der Deutsche Gewerkschaftsbund 1964-1969, S. 494 (Bundesvorstandssitzung v. 5.7.1967). 
neigten ÖTV-Ortsverwaltungen zu »überbetontem Engagement für eine Partei« - und damit war selbstverständlich die SPD gemeint. Stärker noch als bei anderen DGB-Gewerkschaften sei parteipolitische Neutralität jedoch für die ÖTV unerlässlich. Als »Interessenwahrer« der Beschäftigten des Öffentlichen Dienstes müsse die Gewerkschaft in der Lage sein, mit allen politischen Gruppierungen zusammenzuarbeiten, die »Rathausfraktionen« stellten: Deshalb gehöre die ÖTV nicht »an das Gängelband einer Partei ${ }^{70}$

Eine konsequente Haltung in dieser Sache fiel allerdings auch dem Vorsitzenden der Gewerkschaft nicht ganz leicht. Er musste sie sich selbst offensichtlich erst erarbeiten. Ende 1968 nämlich berichtete Helmut Schmidt als damaliger Fraktionsvorsitzender der SPD im Bundestag dem Parteivorsitzenden Willy Brandt erfreut von einem politischen Coup, der für die Sozialdemokraten »ein außerordentlicher Gewinn« sei: In einem persönlichen Gespräch mit Heinz Kluncker habe sich gezeigt, dass der ÖTV-Chef »in keiner Weise abgeneigt wäre, ein Bundestagsmandat in Baden-Württemberg anzunehmen«. Da ein Direktmandat wegen Klunckers zeitlicher Belastung im Beruf nicht in Frage komme, solle ihn die baden-württembergische Parteiorganisation »in einer sicheren Stellung auf der Landesliste platzieren ${ }^{71}$

Wie es zu dieser überraschenden Entwicklung kam, konnte im Rahmen dieses Projektes nicht geklärt werden. Klar ist nur, dass sich Kluncker fast unmittelbar nach seiner Unterhaltung mit Schmidt vehement korrigiert haben muss. In Schriftstücken des SPD-Landesverbandes Baden-Württemberg, die detailliert beschreiben, wie die Parteigliederung im Frühjahr 1969

70 | Referat von Heinz Kluncker »Das Zukunftsbild der ÖTV« für die Arbeitstagung des ÖTV-Bezirks Bayern, 10./12.2.1966. In: AdsD, Depositum Kluncker, Reden und Referate November 1964-September 1969.

71 | Helmut Schmidt an Willy Brandt u. Heinz Bühringer, 20.12.1968. In: AdsD, HSA, 1/HSAA 005357. Bühringer war Vorsitzender des SPD-Landesverbandes Baden-Württemberg. Kluncker hat rückblickend für die Zeit nach 1969 von einer „Wunschvorstellung « Erwin Schoettles, des SPD-Abgeordneten für den Wahlkreis Stuttgart I, berichtet, Kluncker solle den Wahlkreis »übernehmen«. Er habe abgelehnt, "weil ich nicht daran dachte, mich in der Fraktion von Herbert Wehner disziplinieren zu lassen« (Hemmer/Simon: Wirkung, S. 145). Wehner übernahm den SPD-Fraktionsvorsitz mit dem Wechsel Schmidts in die Bundesregierung bei Bildung der ersten sozialliberalen Koalition nach der Bundestagswahl von 1969. 
ihre Kandidatenliste für die anstehende Bundestagswahl zusammenstellte, ist von einer möglichen Kandidatur der ÖTV-Vorsitzenden mit keinem Wort und an keiner Stelle die Rede. ${ }^{72}$

Tatsächlich hat Heinz Kluncker weder 1969 noch in einer der nachfolgenden Wahlen für den Bundestag kandidiert. Es sei dahingestellt, ob Schmidts Schreiben ein simples Missverständnis dokumentiert, oder ob Kluncker für einen Moment doch über eine aktive politische Rolle in der SPD nachgedacht hat. Nur wenig später bezog er in dieser Sache eindeutig Position gegen eine doppelte Rolle des ÖTV-Vorsitzenden. Im Dezember 1969, als die SPD mit Willy Brandt erstmals den Bundeskanzler stellte, ließ Kluncker in einer Rede vor der Großen Tarifkommission der Gewerkschaft keinen Zweifel daran, dass die ÖTV die sozialen Interessen ihrer Mitglieder auch gegenüber »einer von vielen Gewerkschaftsmitgliedern erhofften Regierungskonstellation" entschlossen vertreten werde: "unser Selbstverständnis verbietet jede Art von Disziplinierung - und damit verbot sich für ihn logischer Weise auch eine parlamentarische Tätigkeit. $^{73}$

Wenn Heinz Kluncker im Jahr 1968 wirklich darüber nachgedacht haben sollte, für die SPD in den Bundestag zu gehen, dann kann es sich dabei nur um eine politische Versuchung gehandelt haben, aus der er gestärkt hervorging, weil sie ihm half, eine knifflige Frage zu klären. Ob die ÖTV den Anspruch, als Gewerkschaft für den Öffentlichen Dienst gegenüber regierenden Sozialdemokraten genauso zu handeln wie gegenüber konservativen Politikern, in den Tarifverhandlungen auch konsequent verwirklicht hat, ist allerdings eine andere Frage, der weiter unten nachgegangen wird.

72 | Vgl. die entsprechende Sammlung von Schriftstücken im Nachlass von Alex Möller, der seinerzeit zum Landesvorstand gehörte. In: BArch Koblenz, N 1369, 1721.

73 | Sitzung der Großen Tarifkommission (GTK), 4.12.1969. In: AdsD, Depositum Kluncker, Reden und Referate November 1969-Februar 1972. 


\section{Kein richtig grüner Zweig: Die internen Probleme der ÖTV}

\section{Überalterung und Fluktuation}

Die Gewerkschaft, deren Leitung Heinz Kluncker im Sommer 1964 übernahm, war auf den ersten Blick ohne Frage eine eindrucksvolle Organisation: Rund 980.000 Mitglieder machten die ÖTV zur zweitgrößten bundesdeutschen Gewerkschaft (nur die IG Metall zählte noch mehr Köpfe). Ihr Jahresetat betrug mehr als 55 Millionen DM; etwa 1.100 Beschäftigte standen in ihren Diensten; das Gesamtvermögen summierte sich auf fast 61 Millionen DM. ${ }^{74}$ Alle Daten, die Organisationsstärke messen können, hatten sich seit 1950 kontinuierlich positiv entwickelt. So wuchsen etwa die Beitragseinnahmen allein von 1961 bis Anfang 1964 um 23 Prozent; im gleichen Zeitraum nahm die Gewerkschaft fast 200.000 neue Mitglieder auf. ${ }^{75}$ Bei den Betriebsratswahlen ließ sie problemlos alle mit ihr konkurrierenden Verbände wie die etwa die DAG hinter sich: 1965 stellte die ÖTV 81 Prozent der gewählten Betriebsräte im Öffentlichen Dienst und in der privaten Verkehrsbranche; die DAG kam nur auf magere 4,5 Prozent. ${ }^{76}$

Zahlen können allerdings auch dann einen falschen Eindruck vermitteln, wenn sie korrekt erhoben und wiedergegeben werden. Das Bild einer florierenden, starken ÖTV, das die eben angeführten Daten entwerfen, zeigte etliche Schönheitsfehler und Risse, wenn man etwas genauer hinsah und nach weiteren Informationen suchte. Heinz Kluncker tat genau dies in den ersten Wochen nach seiner Amtsübernahme. Was er dabei entdeckte, missfiel ihm. Vor dem Hauptvorstand fällte er im Oktober 1964 daher ein überraschend negatives Urteil über den organisationalen Zustand der Gewerkschaft.

Nicht falsch, aber in mancher Hinsicht doch recht irreführend war bereits die Zahl der organisierten Mitglieder, denn sie umfasste auch zahl-

74 | Der Vermögensbestand nach: Protokoll der 6. Sitzung des HV, 17./18.4.1963. In: Archiv Ver.di, Bestand Kluncker, 45. Rund die Hälfte des Gesamtvermögens bestand aus Bargeld auf Bankkonten.

75 | Protokoll ÖTV-GT 1964, S. 95. Die Zahlen gelten für die drei Jahre 1961 bis Ende 1963.

76 | ÖTV-Geschäftsbericht 1964/67, S. 484 f. Die auf 100 Prozent fehlenden Sitze gingen vor allem an unorganisierte Bewerber. Insgesamt gab es im Zuständigkeitsbereich der ÖTV 5.342 Betriebe mit Betriebs- und Personalratsgremien. 
reiche Pensionäre und Rentner. Für die gewerkschaftlichen Kernaufgaben waren solche Mitglieder eher unwichtig: Sie zahlten lediglich geringe Beiträge und konnten bei Arbeitskämpfen bestenfalls Hilfsdienste leisten. Die ÖTV aber hatte im Jahr 1964 rund 120.000 Mitglieder im Ruhestand, d.h. als Kampforganisation war sie bei weitem nicht so stark, wie es bei einem oberflächlichen Blick scheinen konnte. ${ }^{77}$

Fasste man das Bild noch etwas weiter, dann ließ sich unschwer ein weiteres Problem erkennen: Die ÖTV war insgesamt eine recht »alte« Organisation, die Schwierigkeiten damit hatte, Nachwuchs anzuwerben. 1963 gehörten 42 Prozent aller Mitglieder in die Altersgruppen jenseits des 50. Lebensjahres; die Gruppe der wirklich jungen ÖTVler (d.h. derjenigen, die unter 25 Jahres alt waren) war mit 93.000 Köpfen deutlich kleiner als die der Rentner und Rentnerinnen. Selbst der offizielle Geschäftsbericht der Gewerkschaft konstatierte eine "Überalterung unserer Organisation" oder - zugespitzter formuliert - einen »Vergreisungsprozess « ${ }^{78}$

Zwar konnten die Anmeldezahlen an sich durchaus als erfreulich gelten. Allerdings verzeichnete die ÖTV jedes Jahr auch zahlreiche "Abgänge«: Mitglieder starben oder wechselten den Wohnort, ohne ihre neue Anschrift mitzuteilen; andere traten aus oder zahlten einfach ihre Beiträge nicht mehr. All dies gehörte für jede freiwillige Vereinigung zum Alltagsgeschäft es erreichte bei der ÖTV jedoch problematische Größenordnungen. Die fast 200.000 Neuaufnahmen der Jahre 1961 bis Ende 1963 etwa schrumpften auf einen effektiven Gewinn von nur 22.000 neuen Kollegen und Kolleginnen zusammen, wenn man alle Verluste abzog. 31.000 »ÖTVler" waren in diesen drei Jahren gestorben; zudem strich die Organisation

77 | Protokoll der 1. Sitzung des HV, 29.9./1.10.1964. In: Archiv Ver.di, Bestand Kluncker, 45.

78 | In der Reihenfolge der Zitate: ÖTV-Geschäftsbericht 1961/63, S. 499 (die Zahlen der Rentner und Mitglieder unter 25 Jahren: ebd., S. 616); ÖTV-Geschäftsbericht 1955/57, S. 337. Die im Folgenden skizzierten Probleme der ÖTV waren keine Besonderheit dieser Organisation: Die bundesdeutschen (Industrie-) Gewerkschaften hatten in den 1960er Jahren mit ähnlichen und teilweise identischen Problemen zu kämpfen; auch sie reagieren mit organisationalen Reformen. Vgl. dazu am Beispiel der Gewerkschaften Bau, Bergbau, Chemie, Handel, Banken und Versicherungen, Metall und Textil: Wolfgang Streeck: Gewerkschaftliche Organisationsprobleme in der sozialstaatlichen Demokratie, Königstein/Taunus 1981. 
1963 nach einer großangelegten Überprüfung sämtlicher Beitragskonten mehr als 12.000 Namen aus ihren Listen, weil diese Mitglieder ihre Zahlungen schon seit längerem eingestellt hatten. Somit muss es im gleichen Zeitraum 155.000 weitere »Abgänge « durch Austritt gegeben haben. ${ }^{79}$

Eine Zuwachsrate in dieser Höhe war zu gering, um die ungünstige Altersstruktur der Mitgliedschaft zu verbessern; die ÖTV musste folglich Anfang der 1960er Jahre schon aus biologischen Gründen damit rechnen, dass sich das Verhältnis zwischen Verlusten und erfolgreich neu geworbenen Beitragszahlern in der Zukunft weiter verschlechtern werde. In seiner ersten Rede als Chef der Organisation vor dem Hauptvorstand verwies Heinz Kluncker eindringlich auf das Problem: Die Zahl der Neuaufnahmen sei viel zu klein - vor allem auch, weil der effektiv erreichte Gewinn an Mitgliedern »dem Zuwachs der Beschäftigten in unserem Organisationsbereich bei weitem nicht entspricht $«{ }^{80}$ Die drohende »Vergreisung« der ÖTV bedrohte ihre Position als Interessenvertretung von Arbeitnehmern also gleich auf mehrfache Weise.

Besonders bedenklich wirkte dabei die Tatsache, dass gerade die starken Bezirke der Organisation zwischen 1961 und 1963 mehrheitlich fast stagnierten. Weniger als ein Prozent betrug der effektive Zuwachs an Mitgliedern etwa in Baden-Württemberg, im Bezirk Nordrhein-Westfalen I und in Berlin; Hessen lag mit einem Plus von 1,15 Prozent nur knapp darüber. Hamburg verzeichnete sogar einen leichten Verlust. ${ }^{81}$

Eine Gewerkschaft, die ihre Basis in drei Jahren der Hochkonjunktur ausgerechnet in den wirtschaftlichen Zentren der boomenden Bundesrepublik nur noch so gering verstärken konnte, hatte offensichtlich ein

79 | Berechnet nach: ÖTV-Geschäftsbericht 1961/63, S. 6 (Zahl der Toten) u. S. 502; zur Überprüfung der Mitgliedschaft durch einen Austausch der Beitragshefte, der die Beschäftigten der ÖTV »außerordentlich in Anspruch« nahm, vgl. Protokoll ÖTV-GT 1964, S. 93-96 (Zitat: S. 93).

80 | Protokoll der 1. Sitzung des HV, 29.9./1.10.1964. In: Archiv Ver.di, Bestand Kluncker, 45.

81 | Berechnet nach: ÖTV-Geschäftsbericht 1961/63, S. 475-483. Als einziger der mitgliederstarken Bezirke wuchs »Nordrhein-Westfalen II «, die größte Teilorganisation der ÖTV, die vor allem das Ruhrgebiet umfasste: Mit fünf Prozent (ein Plus von 6.371 Mitgliedern) gab es hier sogar einen besonders starken Zuwachs (ebd., S. 479). Eine Erklärung für diese Sonderentwicklung (gerade auch im Vergleich mit NRW I) bietet der Geschäftsbericht nicht an. 
ernsthaftes Problem. Selbst ein aufwendiger Versuch, die vorhandenen Mitglieder als aktive »Werber« für die Gewerkschaft zu rekrutieren, führte 1963 trotz ausgelobter Geldprämien und attraktiver Preise (wie etwa mehrtägiger Reisen nach London) nur zu bescheidenen Ergebnissen. Frustriert kommentierte die Verbandsleitung, bei den meisten Kollegen sei die Bereitschaft, sich aktiv für die eigene Gewerkschaft einzusetzen, leider »immer noch zu gering, viel zu gering ${ }^{8}$.

Nun war das Nebeneinander von Neuaufnahmen und Mitgliederverlusten durch Austritt oder schlichtes Desinteresse und Verweigerung der Beiträge weder eine Besonderheit der ÖTV noch historisch neu. Im Gegenteil: Die Anwerbung neuer Beitragszahler war für Gewerkschaften seit eh und je Sisyphusarbeit gewesen, denn keineswegs jedes Mitglied, das der Organisation beitrat, blieb ihr auch auf Dauer treu. Über diese »Fluktuation" und ihre Ursachen sowie über mögliche Abhilfe hatten sich schon Generationen von engagierten Gewerkschaftern den Kopf zerbrochen; Neues gab es in dieser Debatte wohl beim besten Willen nicht mehr zu sagen. ${ }^{83}$

Letztlich ließ sich das ganze Problem darauf zurückführen, dass der Beitritt zu einer Gewerkschaft vielfach nicht als das grundsätzliche Bekenntnis zum Gedanken der Solidarität verstanden wurde, der er nach dem Selbstverständnis der Gewerkschaften eigentlich sein sollte. Daher fürchteten die Organisationen den Eigensinn ihrer Mitglieder; vielfach agierten sie äußerst vorsichtig, wenn es darum ging, mit Forderungen und Ansprüchen an diejenigen heranzutreten, für deren Interessen sie stritten.

Bei der ÖTV lässt sich diese Scheu exemplarisch belegen. So war eine Kündigung der Mitgliedschaft nach ihrer Satzung jeweils sofort wirksam: Termine und Fristen mussten dabei nicht eingehalten werden. 1964 diskutierte der Gewerkschaftstag ausführlich über die Frage, ob es nicht sinnvoll sei, dies zu ändern. Kündigungsfristen gab es bei den meisten anderen DGB-Gewerkschaften; in der ÖTV-Satzung hatte man sie bei der Gründung der Organisation 1949 offenbar schlicht vergessen. Die zusätz-

82 | ÖTV-Geschäftsbericht 1961/63, S. 544.

83 | Vgl. nur für das Kaiserreich etwa: Klaus Schönhoven: Expansion und Konzentration. Studien zur Entwicklung der freien Gewerkschaften im Wilhelminischen Deutschland 1890 bis 1914, Stuttgart 1980, S. 150-221; ders.: Selbsthilfe als Form der Solidarität. Das gewerkschaftliche Unterstützungswesen im Deutschen Kaiserreich bis 1914. In: Archiv für Sozialgeschichte 20 (1980), S. 147-193. 
liche Hürde, so hofften die Antragsteller, werde die Zahl der »Abgänge« deutlich reduzieren: Fehle sie, dann seien »die Austrittsschleusen der ÖTV unbewacht und weit offen«. Ausgerechnet die Antragskommission, d.h. letztlich die Verbandsführung, aber widersprach. Die vorgeschlagene Satzungsänderung sei »psychologisch unklug«: Sie werde die Mitglieder stärker verärgern und verschrecken als binden. Nach langer Diskussion blieb daher (zunächst einmal) alles beim Alten. ${ }^{84}$

Die ÖTV ignorierte damit Erfahrungen anderer Verbände. So hatte etwa die Gewerkschaft Textil und Bekleidung 1960 eine dreimonatige Kündigungsfrist eingeführt und zugleich auch damit begonnen, Mitglieder zu mahnen, wenn ihre Beitragszahlungen ausblieben (auch dies gab es bei der ÖTV nicht). Wie die Verbandsführung 1963 berichtete, gelang es so, zahlreiche Kollegen wieder an die Organisation zu binden, die schon auf dem Absprung gewesen waren: Es wirke sich positiv aus, "wenn unsere Mitglieder in allen Phasen ihrer Mitgliedschaft spüren, daß die Organisation nichts Anonymes ist, sondern ihr Tun und Handeln beachtet ${ }^{85}$

\section{Knauserige Mitglieder: Der Streit um den richtigen Beitragssatz}

Noch kniffliger und umstrittener als die Kündigungsfrist waren alle Fragen, die mit den Beiträgen der »ÖTVler« und deren Höhe zu tun hatten. Auch bei diesem Thema behandelte die Organisation ihre Mitglieder mit Samthandschuhen, weil sie Austritte fürchtete. Sie nahm daher finanzielle Nachteile in Kauf und duldete es, dass die eigene Basis die demokratisch beschlossene Satzung unterlief.

Bei ihrer Gründung hatte sich die ÖTV ein ehrgeiziges Ziel gesetzt: Wer ihr angehörte, sollte pro Woche den Bruttolohn einer Arbeitsstunde

84 | Vgl. zu diesem Problem: Protokoll ÖTV-GT 1964, S. 224-232, Zitate S. 225 u. 226; die Abstimmung S. 232.

85 | Protokoll des 8. Ordentlichen Gewerkschaftstages der Gewerkschaft Textil Bekleidung vom 16. bis 20. September 1963 in Hannover, Düsseldorf 1963, S. 75. Auch die IG Bau führte 1960 eine Kündigungsfrist ein und berichtete später, es handele sich um eine wirkungsvolle Maßnahme, um »Mitglieder in der Organisation zu halten« (Geschäftsbericht IG Bau - Steine - Erden 1963/65, S. 125). 1968 fügte dann auch die ÖTV eine Kündigungsfrist in ihre Satzung ein. Das Problem der Fluktuation beschäftigte die Organisation dennoch weiter. Siehe dazu unten Kapitel III. 
als Beitrag zahlen. Bei einer Wochenarbeitszeit von 48 Stunden, wie sie seinerzeit in den meisten Bereichen des Öffentlichen Dienstes üblich war, entsprach das einem Beitragssatz von rund zwei Prozent auf den Bruttoverdienst. Allerdings handelte es sich bei dieser Bestimmung um ein auf längere Sicht angelegtes Projekt. Viele der Regionalverbände und Teilorganisationen, die sich 1949 zur ÖTV zusammenschlossen, hatten deutlich weniger verlangt; teilweise gab es einen vom individuellen Verdienst unabhängigen Einheitsbeitrag von einer DM pro Monat. Von den zwei Prozent für Alle war das denkbar weit entfernt. Die neue Gewerkschaft musste ihre Mitglieder also davon überzeugen, deutlich mehr zu zahlen als zuvor: Aus der Sicht der Verbandsführung war dies »die dringendste Aufgabe unserer Bezirkskassierer und Orts- und Kreisverwaltungen $« .{ }^{86}$

Über die Fragen, was geschah, um diese Aufgabe zu bewältigen, und welche Erfolge dabei gelangen, hat die ÖTV in den nachfolgenden Jahren kaum gesprochen, geschweige denn kontrovers diskutiert. Sowohl die Ausführungen des Hauptkassierers Fritz Müllé auf den Gewerkschaftstagen als auch die langen Abschnitte in den Geschäftsberichten, die teilweise pedantisch genau über die Finanzlage der Gewerkschaft informierten, können in dieser Beziehung als Muster detail- und wortreicher Unklarheit gelten. ${ }^{87}$

Dabei stand fest, dass die Gewerkschaft Beiträge in satzungsgemäßer Höhe nur erreichen konnte, wenn die Mitglieder ihr Einkommen ehrlich selbst deklarierten. Zwar befand sich die ÖTV in dieser Sache - im Vergleich mit den Industriegewerkschaften - grundsätzlich in einer günstigen Position: Der Öffentliche Dienst kannte keine individuell bemessenen übertariflichen Zahlungen und damit keine Differenz zwischen den Tarifentgelten und dem effektiven Verdienst der Beschäftigten ${ }^{88}$ Zumindest für

86 | ÖTV-Geschäftsbericht 1949, S. 36. 1955 bekannte sich auch der DGB zu einem Beitrag von zwei Prozent des Bruttolohns und empfahl allen angeschlossenen Verbänden, soviel zu verlangen. Vgl. dazu: ÖTV-Geschäftsbericht 1955/57, S. $140-144$.

87 | Vgl. beispielhaft etwa: ÖTV-Geschäftsbericht 1952/54, S. 542-575, vor allem S. $544 \mathrm{f}$., wo vage »Bemühungen um Herbeiführung der Beitragsehrlichkeit« erwähnt werden, sowie ÖTV-Geschäftsbericht 1955/57, S. 124-140, wo die Frage gar nicht mehr erwähnt wird.

88 | In Industrie und Gewerbe war die »Lohndrift« hingegen so weit verbreitet, dass die effektiv gezahlten Löhne teilweise erheblich über den Tariflöhnen lagen. Vgl. zu diesem Phänomen auch oben S. $333 \mathrm{f}$. 
ihre Mitglieder, die »beim Staat« arbeiteten, hätte die ÖTV also einfach auf Lohn- und Gehaltstabellen zurückgreifen können, um festzustellen, ob jeweils der »richtige« Beitrag gezahlt wurde. Aber der Gewerkschaft fehlte schlicht das Personal, um das bewährte Prinzip "Vertrauen ist gut, Kontrolle ist besser" auch innerorganisatorisch anzuwenden.

Auf Hilfe der Arbeitgeber konnte die ÖTV nicht hoffen. Die Bundesrepublik war in den 1950er Jahren und im größeren Teil der nachfolgenden Dekade ein Land fast ohne EDV und ohne bargeldlosen Zahlungsverkehr; Lohnbuchhaltung gehörte zu den aufwendigsten Verwaltungsarbeiten. ${ }^{89}$ Schon aus Zeitgründen hatten die Lohnbüros von Behörden und staatlichen Betrieben daher Besseres zu tun, als auch noch die Beiträge der ÖTV auszurechnen und einzubehalten. Da nur wenige Bundesbürger ein Girokonto besaßen, spielten Daueraufträge und Einzugsermächtigungen ebenfalls nur eine ganz untergeordnete Rolle. Im Wesentlichen musste die Gewerkschaft also ihr Geld selbst eintreiben. Bei diesen Transaktionen in bar war die ÖTV vollständig darauf angewiesen, dass sich die Beitragszahler in der Tabelle der Einkommen und Monatsbeiträge wahrheitsgemäß einordneten. ${ }^{90}$

89 | Vgl. die Klage darüber in: Protokoll ÖTV-GT 1964, S. 161. Anfang der 1970er Jahre konnte sich die individuelle Bezahlung im Öffentlichen Dienst aus bis zu 80 verschiedenen »Teilelementen« ergeben (Wilhelm Bierfelder: Personalführung und Personalverwaltung in alten Gleisen? In: Hans-Dietrich Genscher et al.: Der öffentliche Dienst am Scheideweg, Bonn 1972, S. 77-121, hier: S. 106).

90 | Anfang 1963 überwiesen rund 46.000 Mitglieder der ÖTV (4,7 Prozent) ihren Beitrag per Dauerauftrag (Protokoll der 6. Sitzung des HV, 17./18.4.1963. In: Archiv Ver.di, Bestand Klunker, 45). Gewerkschaftsmitglieder kauften (meist einmal im Monat) »Beitragsmarken« in den Geschäftsstellen oder auch bei Kassierern, die sie im Auftrag der Organisation entweder zu Hause oder auch am Arbeitsplatz besuchten. Erst diese in ein Heft geklebten Marken machten den Angeworbenen oder die Angeworbene wirklich zum Mitglied der Organisation. Noch 1963 stammten 96 Prozent der ÖTV-Beitragseinnahmen aus dem Verkauf solcher Marken (Protokoll ÖTV-GT 1964, S. 95). Bezeichnenderweise sah es in den Industriegewerkschaften, in deren Organisationsbereich Großbetriebe dominierten, teilweise schon ganz anders aus, weil diese Firmen ihre Lohnbuchhaltung bereits modernisiert hatten. Dank der Kooperation der Betriebe kamen etwa bei der Textilgewerkschaft im gleichen Jahr bereits 42,5 Prozent der Beiträge durch das »Lohnabzugsverfahren« in die Gewerkschaftskasse (Protokoll des 
Vor diesem Hintergrund ist es erstaunlich, wie konsequent das Thema "Gewerkschaftsbeitrag«, das für die Organisation und ihre Handlungsmöglichkeiten von großer Bedeutung war, sowohl auf den Gewerkschaftstagen als auch in den Beratungen von Hauptvorstand und gHV über Jahre hinweg kleingehalten wurde.

Im Jahr 1961 brach dieses Schweigen erstmals auf. Dabei zeigte sich, dass die Realität mit den Bestimmungen in der ÖTV-Satzung wenig bis gar nichts zu tun hatte. Bei ihrer Vorbereitung auf den Gewerkschaftstag im Sommer 1961 formulierten nicht weniger als 15 Untergliederungen der Organisation Anträge, die sich mit der »Beitragsordnung« der ÖTV befassten. Sie alle ließen kaum ein gutes Haar an den geltenden Regelungen, die ganz offenbar nur auf dem Papier standen: „Der Großteil der Mitgliedschaft ist nicht bereit, die bisher festgelegten Beitragssätze zu zahlen«, so hieß es etwa im Antrag der Bezirksverwaltung Uelzen; die Konferenz des Bezirks Nordrhein-Westfalen I erklärte, der verlangte Beitrag sei viel zu hoch und führe bei der Mitgliederwerbung zu »unüberwindlichen Schwierigkeiten«; der Bezirk Baden-Württemberg verlangte "realistischere Monatsbeiträge" und dachte dabei an Werte um ein Prozent. ${ }^{91}$

Auch die Beratungen des Kongresses bestätigten den Eindruck, dass mit diesen Anträgen ein lange aufgestauter Ärger losbrach. Ein Delegierter aus Kassel, der die Resolutionen zusammenfassend begründete, klagte, die "Beitragsfrage« sei in allen unteren Gliederungen und Gremien der ÖTV jahrelang immer wieder "Gegenstand heftigster Debatten" gewesen: Viele Mitglieder zahlten der ÖTV de facto lediglich einen »Anerkennungsbeitrag " und weigerten sich, davon abzugehen. Man könne das kritisieren, erreiche damit aber nichts: »Aus der mangelnden Beitragsehrlichkeit kann man schließen, daß die Beiträge einfach zu hoch sind.« Bezeichnender-

9. Ordentlichen Gewerkschaftstages der Gewerkschaft Textil - Bekleidung vom 11.-15.10.1965 in der Liederhalle in Stuttgart, Düsseldorf 1966 [im Folgenden: Protokoll GT Textil 1965], S. 60). Dieser hohe Anteil ist insofern bemerkenswert, als die Bundesvereinigung der Deutschen Arbeitgeberverbände das Lohnabzugsverfahren als »Begünstigung der Gewerkschaften« ablehnte (Jahresbericht der Bundesvereinigung der Deutschen Arbeitgeberverbände 1. Dezember 1963-30. November 1964. Vorgelegt der Mitgliederversammlung in Bad Godesberg am 2. Dezember 1964, Düsseldorf 1964, S. 66).

91 | Protokoll ÖTV-GT 1961, Anträge, S. 6-16, hier in der Reihenfolge der Zitate S. 15 u. $12 f$. 
weise seien es insbesondere gutverdienende Kollegen, denen die ÖTV mit ihrem offiziell geltenden Beitragssatz viel zu teuer sei. Wenn die ÖTV auch höhere Beamte und beruflich qualifizierte Angestellte binden wolle, dann dürfe sie Änderungen in dieser Sache nicht aufschieben. ${ }^{92}$

Da die so lange verborgene Katze damit endlich aus dem Sack war, hielt plötzlich auch die Verbandsführung eine Reform für unerlässlich. Allerdings gelang es ihr doch, dem Zorn der Basis die Spitze zu nehmen. Obwohl mehrere Anträge vorlagen, die eine umfassend ausgearbeitete neue Beitragsordnung enthielten, wurde eine Entscheidung vertagt: Mit dem Argument, man müsse den Kongress wohl »um acht Tage verlängern«, wenn es eine Sachdiskussion über die »richtige« Beitragshöhe gebe, erreichte die Antragskommission ein sofortiges Ende der Debatte. Die Mehrheit der Delegierten legte die Frage in die Hände einer Kommission, die der gHV »im Benehmen mit den Bezirksleitern« berufen sollte. Der Gewerkschaftsbeirat sollte dann bis zum April 1962 über eine neue Beitragsordnung der ÖTV beschließen. ${ }^{93}$

Wegen fehlender Dokumente lässt sich nicht sagen, wie daraufhin im engeren Kreis der leitenden Funktionäre diskutiert und gestritten wurde. Am Ende standen jedenfalls grundlegend neue Bestimmungen, die zum 1. April 1963 in Kraft gesetzt wurden: Die ÖTV-Mitglieder sollten nun in der Regel 1,3 Prozent ihres monatlichen Bruttoverdienstes als Obolus an die Gewerkschaft abführen. ${ }^{94}$ Zwar lag dem Gewerkschaftstag von 1964 ein Antrag vor, noch weiter zu gehen und nur noch ein Prozent vom Bruttoverdienst zu verlangen. Er wurde jedoch abgelehnt, weil die Verbandsleitung erfolgreich argumentierte, es sei besser, in dieser Frage nach der gerade erst in Kraft gesetzten Reform »Ruhe eintreten« zu lassen, »damit sich die Mitgliederverhältnisse konsolidieren ${ }^{9}{ }^{95}$

92 | Ebd., S. 362 f. (Heinz Mayfarth).

93 | Ebd., S. 361 f. u. 364 (Zitate). Zu Funktion und Kompetenzen des Gewerkschaftsbeirats vgl. die Bestimmungen in der Satzung: Protokoll ÖTV-GT 1964, S. 234.

94 | Ein verwaltungstechnisch orientierter Abriss der Kommissionsarbeit findet sich in: ÖTV-Geschäftsbericht 1961/63, S. 692-695.

95 | Protokoll ÖTV-GT 1964, S. 232 f., u. ebd., Anträge, S. 10 (der Antrag stammte von der Kreisverwaltung Uelzen). Die neue Beitragstabelle in: ebd., S. 217. Lediglich besonders schlecht entlohnte Mitglieder (bis $250 \mathrm{DM}$ brutto monatlich) 
Die Debatte über interne Defizite und Schwachstellen der ÖTV wurde damit allerdings nicht beendet, sondern nur in eine andere Richtung gelenkt: Fast einstimmig beauftragten die Delegierten die Verbandsführung, über »erstrebenswerte innerorganisatorische Verbesserungen« nachzudenken und bis spätestens Ende 1966 darüber zu berichten. Der für den Sommer 1968 angesetzte nächste Gewerkschaftstag sollte dann über eventuell nötige Änderungen der Satzung beschließen. Bis dahin wollte man mit einem Urteil über die neue Beitragsordnung warten. ${ }^{96}$

Errechnet man für die Beitragszahlungen aller ÖTV-Mitglieder einen Durchschnittsbetrag, dann lag dieser im Jahr 1964 bei 4,88 DM pro Monat. 1962 - vor der Reform - waren es 4,46 DM gewesen. Ob damit die bislang so unzulänglich entwickelte »Beitragsehrlichkeit» der Organisierten bereits erreicht war, konnte niemand sagen. Kurzfristig verzeichnete die Gewerkschaft jedenfalls keine auffällig höheren Einnahmen, nachdem sie ihre finanzielle Forderung an das einzelne Mitglied abgesenkt hatte: Die Zuwachsraten von 1962 auf 1964 beim Durchschnittsbeitrag sowie auch bei den Einnahmen insgesamt unterschieden sich nicht signifikant vom Niveau der vorangegangenen Jahre. ${ }^{97}$

Unbestreitbar leisteten die Mitglieder der ÖTV finanziell deutlich weniger für ihre Gewerkschaft als die Beitragszahler anderer DGB-Gewerkschaften. 1964 betrug die durchschnittliche Monatszahlung der Mitglieder in der Textilgewerkschaft etwa 5,17 DM, in der Gewerkschaft Handel, Banken und Versicherungen 5,85 DM sowie in der IG Metall 6,20 DM. ${ }^{98}$ Selbst

zahlten mit 1,2 Prozent etwas weniger; ähnliche Sätze galten auch für besonders gut Verdienende (ab 1.050 DM monatlich).

96 | Protokoll ÖTV-GT 1964, S. 267-274, u. ebd., Anträge, S. 37 (die Zuständigkeit der kommenden Gewerkschaftstage wurde erst auf Antrag eines Delegierten Teil des Antrags). 1968 wurden mit dem gleichen Argument dann erneut verschiedene Anträge abgelehnt, die eine Reduzierung des Beitragssatzes auf ein Prozent des Bruttolohns forderten (Protokoll 6. Ordentlicher Gewerkschaftstag München 1968 [der Gewerkschaft Öffentliche Dienste, Transport und Verkehr], 2 Bde., Stuttgart 1968 [im Folgenden Protokoll ÖTV-GT 1968], Bd. 1, S. 190).

97 | ÖTV-Geschäftsbericht 1964/67, S. 760; ÖTV-Geschäftsbericht 1961/63, S. 699. 98 | Protokoll GT Textil 1965, S. 59; Protokoll des 7. Ordentlichen Gewerkschaftstages der Gewerkschaft Handel, Banken und Versicherungen 15. September bis 20. September 1968 in Bremen, Bochum 1969, S. 150; Geschäftsbericht 1962, 1963 und 1964 des Vorstandes der IG Metall für die Bundesrepublik Deutschland, 
die Gewerkschaft Nahrung, Genuss, Gaststätten verzeichnete mit 5,44 DM im Jahr 1964 einen Durchschnittsbeitrag, der deutlich über dem Resultat der ÖTV lag - und im Organisationsbereich dieses Verbandes gab es überhaupt keine Beamten und erheblich weniger qualifizierte Beschäftigte. ${ }^{99}$

Dies war der Stand der Dinge, als Heinz Kluncker die Leitung der ÖTV übernahm. Die Beitragsfrage sprach er bei seiner kritischen Bestandsaufnahme des organisationalen Zustandes der Gewerkschaft nicht direkt an. Nach dem Beschluss des Gewerkschaftstages von 1964 hielt er das wohl für vergebliche Mühe. Gleichzeitig aber hielt er die Art und Weise, wie der Verband bisher mit seinen Mitgliedern über einen angemessenen Beitragssatz kommuniziert hatte, offensichtlich für falsch. Seine Bemerkung auf der Vorstandssitzung Ende September 1964, in der ÖTV fehle »das für eine demokratische Organisation vielleicht lebensnotwendige Element der Gewaltenteilung«, lässt sich so deuten. ${ }^{100}$ Etwas später klagte er sehr viel deutlicher, in der ÖTV gebe es bei internen Beratungen »noch zu viele obrigkeitliche Züge ${ }^{101}$

Frankfurt/Main 1965, S. 394. Noch höher lag der Durchschnittsbeitrag bei der IG Bau: 1965 betrug er 8,33 DM (für 1964 konnte keine Angabe ermittelt werden; Protokoll über den 7. Ordentlichen Gewerkschaftstag der Industriegewerkschaft Bau - Steine - Erden für die Bundesrepublik Deutschland, Stadthalle Bremen vom 20. bis 25. Juni 1966, Frankfurt/Main 1966, S. 93). Allerdings verteilte sich, wie bereits in Kapitel I erwähnt, die Basis der ÖTV in der Verdienstskala auch anders als in den meisten Industriegewerkschaften: Sie hatte besonders viele Mitglieder in den niedrigsten Einkommens- und Beitragsklassen, für die selbst geringe Summen hohe Belastungen darstellten. Lässt man Sonderbeiträge für Lehrlinge und Rentner beiseite, dann begann die Beitragstabelle der IG Metall bezeichnenderweise erst bei 5,20 DM - die der ÖTV jedoch bei 2,50 DM. Sicher ergab sich diese spezielle Struktur auch aus dem stark abweichenden Lohngefüge und -niveau des Öffentlichen Dienstes. Die Frage, ob bei der Beitragszahlung eventuell auch eine besonders stark entwickelte habituelle Knausrigkeit der ÖTV-Kollegen eine Rolle spielte, lässt sich nicht eindeutig beantworten.

99 | Jahrbuch 1964/65. Geschäftsbericht der Gewerkschaft Nahrung, Genuss, Gaststätten, Hamburg 1966, S. 255.

100 | Protokoll der 1. Sitzung des HV, 29.9./1.10.1964. In: Archiv Ver.di, Bestand Kluncker, 45.

101 | Referat von Heinz Kluncker »Das Zukunftsbild der ÖTV« für die Arbeitstagung des ÖTV-Bezirks Bayern, 10./12.2.1966. In: AdsD, Depositum Kluncker, 
Nun war Kluncker spätestens seit seiner Wahl zum Arbeitersekretär 1958 selbst Teil der Führungsmannschaft, die diese hierarchische und unfreie Diskussionskultur verantwortete. Offensichtlich hat er sich als Nachwuchskraft in der ÖTV-Zentrale und dann nach 1961 auch als Mitglied im geschäftsführenden Hauptvorstand konsequent strategisch verhalten und kritische Gedanken stets für sich behalten. Wenn sich Adolph Kummernuss bei seinem Abschied auf dem Gewerkschaftstag 1964 selbst dafür lobte, dass es im gHV unter seinem Vorsitz in 15 Jahren keine einzige Abstimmung gab, weil man sich stets so gut verstand, »daß es nicht erforderlich war«, dann kennzeichnet dies treffend die internen Strukturen der Organisation, in der Heinz Kluncker Karriere gemacht hatte: Die Einigkeit, auf die Kummernuss so stolz war, existierte nur deshalb, weil die Leitung wichtige, aber konfliktträchtige Fragen einfach nicht besprach. Auch Kluncker, der sich persönlich mit dem alternden Vorsitzenden wohl eher schlecht verstand, hat sich hier eingeordnet. ${ }^{102}$ Immerhin ging der junge Mann als neuer Vorsitzender der ÖTV dann zügig daran, die interne Diskussion offener zu gestalten - und diese Initiative war für die Geschichte der Gewerkschaft letztlich sehr viel wichtiger als sein vorheriges taktisches Schweigen. ${ }^{103}$

Reden und Referate November 1964-September 1969. Ähnlich auch: ÖTV-Geschäftsbericht 1964/67, S. 23 f.

102 | Protokoll ÖTV-GT 1964, S. 368 f. Ein kritischer Hinweis auf die große Macht leitender Funktionäre über die Karrieren von Nachwuchskräften, der für die Gewerkschaften typisch sei, findet sich in: Klaus Dörre: Gewerkschaftseliten nach 1945 - Kontinuität und Wandel der Führungsgruppen deutscher Gewerkschaften: Das wiederbelebte Interesse an den gewerkschaftlichen Führungsgruppen. In: Mitteilungsblatt des Instituts für soziale Bewegungen, Bd. 35 (2006), S. 7-27, hier: S. 17-f.

103 | Um nur ein Beispiel zu nennen: Bereits im April 1963 konstatierte Hauptkassierer Müllé vor dem HV unmissverständlich, der jährliche Vermögensgewinn der ÖTV sei »bei unseren Größenverhältnissen in diesem Umfang absolut unzureichend «. Nachfragen und eine Diskussion blieben jedoch aus (Protokoll der 6. Sitzung des HV, 17./18.4.1963. In: Archiv Ver.di, Bestand Kluncker, 45). Zum persönlichen Verhältnis Kummernuss - Kluncker vgl.: Hemmer/Simon: Wirkung, S. 104 f.; Interview Hajo Graf Vitzthum, 14.6.2014. 


\section{Finanzielle Engpässe und ihre Folgen}

Da es nicht sinnvoll war, die Frage der Beitragshöhe sofort wieder auf die Tagesordnung zu setzen, beschränkte sich Heinz Kluncker bei seiner ÖTVkritischen Bilanz auf Bemerkungen zu den Ausgaben der Organisation, denn sie entwickelten sich seit Anfang der 1950er Jahre deutlich dynamischer als die Beitragsleistungen der Mitglieder. Schon drei Zahlen belegen das damit verbundene Problem: 1952 hatte die Gewerkschaft 86,5 Prozent ihrer gesamten Einnahmen noch im gleichen Jahr wieder ausgegeben; 1961 betrug dieser Anteil 91,8 Prozent und 1964 bereits 98,3 Prozent. Nur der verbliebene kleine Rest wurde noch einbehalten, um die Rücklagen für Arbeitskämpfe und langfristig angelegte Investitionen zu stärken. Diese Entwicklung hielt Kluncker für »ungesund«. Der erste unter seiner Ägide erstellte Geschäftsbericht formulierte es daher ganz eindeutig: „Die Finanzlage bedarf der Konsolidierung «. ${ }^{104}$

Ein vergleichender Blick auf die IG Metall, die einzige DGB-Gewerkschaft mit mehr Mitgliedern als die ÖTV, zeigt, wie berechtigt dieses Urteil war. Der erwirtschaftete Überschuss, den die ÖTV am Ende des Jahres an ihre Vermögensverwaltung überweisen konnte, betrug 1964 lediglich zwei Millionen DM - gegenüber etwas mehr als 25 Millionen bei der IG Metall. Hier lagen finanzielle Welten zwischen den beiden Organisationen, die sich nicht aus den unterschiedlichen Mitgliederzahlen erklären konnten, denn die Metallgewerkschaft war ja »nur« doppelt so kopfstark wie ihre gewerkschaftliche "Schwester «. Zudem handelte es sich bei den genannten Zahlen nicht um Zufallsergebnisse für ein besonders ungünstig bzw. günstig verlaufenes Jahr: In nur drei Jahren, zwischen 1962 und 1964, bildete die IG Metall neue Rücklagen von 76,2 Millionen DM - und diese Summe übertraf das gesamte Vermögen der ÖTV, das sie seit 1949 angesammelt hatte. Im Vergleich kam die ÖTV daher nur auf »eine extrem niedrige Rückstellungsquote pro Mitglied «. ${ }^{105}$

104 | ÖTV-Geschäftsbericht 1952/54, S. 544 (die Zahl für 1952); ÖTV-Geschäftsbericht 1958/60, Nachtrag, S. 18 (die Zahl für 1960); Niederschrift über die gemeinsame Sitzung von Hauptvorstands- und Beiratsmitgliedern, des Bezirksvorstandes und der Bezirkssekretäre NRW II, 18.5.1965. In: AdsD, ÖTV-NW II, 5/ ÖTVC022005; ÖTV-Geschäftsbericht 1964/67, S. 23.

105 | Lutz: Ostpolitiker aus Passion, S. 105. Die Zahlen für die ÖTV aus: ÖTVGeschäftsbericht 1964/67, S. 803; die Jahresangabe von 25 Millionen DM für die 
Wenn die ÖTV immer stärker von der Hand in den Mund lebte, dann lag das zum Teil an allgemeinen Kostensteigerungen, die es selbstverständlich auch im westdeutschen Wirtschaftswunderland gab. Die Produktion von Zeitschriften, Broschüren und Werbematerial etwa verteuerte sich in den 1950er Jahren ganz erheblich durch stark steigende Papierpreise und höhere Gebühren der Nachrichtenagenturen sowie durch höhere Löhne für das Personal der Druckereien. Allein von 1958 bis 1960 wuchsen die Ausgaben der ÖTV für ihr Mitgliedermagazin und andere Druckprodukte um nicht weniger als 66 Prozent, von 1,53 Millionen auf 2,55 Millionen DM. 1963 waren es dann schon 3,5 Millionen DM. Diese enorme Verteuerung ergab sich allerdings auch aus Bemühungen, das Magazin attraktiver zu gestalten, etwa durch eine größere Zahl von Abbildungen und durch mehrfarbigen Druck. ${ }^{106}$

Kaum Einfluss hatte die ÖTV hingegen auf einen anderen großen Ausgabenposten: auf ihre eigenen Beiträge, die an den DGB sowie - in deutlich geringerem Umfang - an jene internationalen gewerkschaftlichen Organisationen gingen, denen sie sich angeschlossen hatte. Die Beitragszahlungen wuchsen automatisch mit der Mitgliederzahl und stiegen daher zwischen 1958 und 1963 von 5,5 Millionen auf 7,7 Millionen DM. ${ }^{107}$

Ein weiterer großer, allerdings anders gearteter Ausgabenblock im Budget bestand aus den Unterstützungen, die einzelnen Mitgliedern in sozialen Notlagen gewährt wurden. Solch eine aus den normalen Beitragseinnahmen finanzierte Hilfe hatte nichts mit der Streikunterstützung zu tun. Vielmehr kannten diese Solidarmaßnahme alle Gewerkschaften schon

IG Metall berechnet nach: Geschäftsbericht IG Metall 1962/64, S. 353 (es handelt sich hierbei um einen Durchschnittswert für die Jahre 1962 bis 1964); ebd. auch die Angabe zum gesamten Vermögenszuwachs.

106 | ÖTV-Geschäftsbericht 1958/60, Nachtrag, S. 20; ÖTV-Geschäftsbericht 1961/63, S. 705. Um Kosten zu sparen, wurde das »ÖTV-Magazin« seit 1963 auf Papier aus Finnland gedruckt, was der Gewerkschaft scharfe Proteste sowohl der IG Druck und Papier als auch der IG Chemie eintrug: Es sei unverantwortlich, dass die ÖTV »bei dieser hohen Auflage vom deutschen Papier weggegangen ist« (Protokoll der 6. Sitzung des HV, 17./18.4.1963. In: Archiv Ver.di, Bestand Kluncker, 45).

107 | Ebd. Die beiden wichtigsten internationalen Gewerkschaftsbünde, denen die ÖTV angehörte, waren die IÖD (für Gewerkschaften des Öffentlichen Dienstes) sowie die ITF (für Gewerkschaften der Transportbranchen). 
seit dem Kaiserreich. Leistungen und Anspruchsvoraussetzungen waren in den jeweiligen Satzungen detailliert festgelegt. Meist handelte es sich um Zahlungen an kranke sowie an invalide Kollegen; auch ein "Sterbegeld« (d.h. ein Zuschuss zu den Bestattungskosten, der an die Angehörigen ging) wurde gezahlt. Im Kern handelte es sich um versicherungsähnliche Leistungen, denn den vollen Anspruch erwarb immer nur das Mitglied, das der Gewerkschaft langfristig treu blieb. ${ }^{108}$

Die ursprünglich starken Hoffnungen, mit der Einführung solcher Unterstützungen werde die leidige »Fluktuation« der Mitglieder verschwinden oder zumindest stark zurückgehen, hatten sich zwar nicht erfüllt, dennoch standen diese Extraleistungen nie ernsthaft zur Disposition, weil sie als praktizierte gewerkschaftliche Solidarität galten. Die Delegierten auf Gewerkschaftskongressen diskutierten und beschlossen sogar ausgesprochen gern Verbesserungen dieser Hilfen. Die »ÖTVler« machten da keine Ausnahme: 1952 etwa lagen dem Verbandskongress 56 verschiedene Anträge vor, in denen es durchweg darum ging, den Bezug der Hilfen zu erleichtern und sie großzügiger zu gestalten. Zwar konnte die Verbandsführung bremsend eingreifen, die offensichtlich starken Erwartungen innerhalb der Organisation auf entsprechende Beschlüsse aber waren damit nicht aus der Welt. ${ }^{109}$

Auf den nachfolgenden Gewerkschaftstagen wiederholte sich daher das Spiel. Schrittweise kam es zu einem Ausbau der Hilfsangebote, obwohl die Verbandsführung mehrfach über die Bereitschaft der Delegierten klagte, höhere Ausgaben zu beschließen, ohne gleichzeitig auch über deren Finanzierung zu sprechen. ${ }^{110}$ So wuchsen die Unterstützungszahlungen der ÖTV an Mitglieder kontinuierlich von 2,7 Millionen DM 1952 über 5,4 Millionen im Jahr 1959 auf 6,7 Millionen $1963 .^{111}$

108 | Vgl. grundlegend: Schönhoven: Selbsthilfe.

109 | Die Anträge finden sich in: Protokoll des 1. Ordentlichen Gewerkschaftstages der Gewerkschaft Öffentliche Dienste, Transport und Verkehr vom 18. bis 22. Februar 1952 in Hamburg, Stuttgart 1952 (im Folgenden: Protokoll ÖTV-GT 1952), S. 363-407. Sie wurden vorwiegend als »Material« an den Hauptvorstand überwiesen. Auf die Frage, wie die Mehrleistungen zu finanzieren seien, ging keiner der Anträge ein.

110 | Vgl. etwa (auch im Rückblick auf die vorherigen Kongresse): Protokoll ÖTV-GT 1964, S. 232 f. (Gert Kasch als Sprecher der Antragskommission).

111 | ÖTV-Geschäftsbericht 1952/54, S. 553; ÖTV-Geschäftsbericht 1958/60, Nachtrag, S. 20; ÖTV-Geschäftsbericht 1961/63, S. 705. 
Den größten Einzelposten in der Wirtschaftsrechnung der ÖTV bildeten jedoch mit 16,3 Millionen DM (1963) die Personalkosten: Sie allein verschlangen rund ein Drittel der gesamten Ausgaben. ${ }^{112}$ Dabei zahlte die Gewerkschaft keine besonders üppigen Gehälter. Angesichts des damaligen Mangels an Verwaltungsfachleuten und qualifizierten Bürokräften konkurrierte die ÖTV mit allen anderen Arbeitgebern der Republik, konnte aber mit ihren begrenzten finanziellen Mitteln in diesem Wettbewerb nicht wirklich mithalten. In ihrem Geschäftsbericht für die Jahre 1964 bis 1967 deutete sie dies an: »In einer Reihe von Fällen« sei das Gehaltsniveau, das die Gewerkschaft bieten könne, »zu niedrig [...], um eine bessere Personalauslese zu ermöglichen ${ }^{113}$

Bei einfachen Tätigkeiten sah es offensichtlich noch schlechter aus: Intern hatte die Verbandsführung den Hauptvorstand schon 1961 informiert, teilweise sei die ÖTV als Arbeitgeber von der allgemeinen Lohnentwicklung abgehängt und daher »heute nicht mehr konkurrenzfähig «. ${ }^{114}$ Anteilig waren Personal und Verwaltung der ÖTV zudem seit Mitte der 1950er Jahre nicht deutlich teurer geworden. In absoluten Zahlen hatten sich diese Kosten zwar seit dem Jahr 1955 glatt verdoppelt; prozentual aber waren sie nur geringfügig gewachsen.

Dennoch setzte die ÖTV genau bei diesen Ausgaben an, als sie sich Mitte der 1960er Jahre endlich eingestand, dass sie dringend etwas tun musste, um ihre prekäre Finanzsituation zu verbessern. "Straffung und Rationalisierung « des Apparates und aller Verwaltungsarbeiten, so lautete die Devise, die Heinz Kluncker der Gewerkschaft nach der Bestandsaufnahme vorgab, mit der er seine Arbeit als Vorsitzender begann. Entlassungen oder verordnete Umsetzungen, die den Betroffenen widerstrebten, sollte es dabei allerdings nicht geben. ${ }^{115}$

Geschuldet war dieser Umbau des eigenen Stabes organisationalen Zwängen und unternehmenspolitischen Überlegungen, denn alle anderen wichtigen Etatposten waren entweder dem Willen der Führung entzogen

112 | ÖTV-Geschäftsbericht 1961/63, S. 705.

113 | ÖTV-Geschäftsbericht 1964/67, S. 23.

114 | Protokoll der 11. Sitzung des HV, 18./19.4.1961. In: Archiv Ver.di, Bestand Kluncker, 45. Konkret bezieht sich diese Bemerkung auf Service- und Hilfskräfte in den vier Erholungsheimen der Gewerkschaft.

115 | ÖTV-Geschäftsbericht 1964/67, S. 22. 
oder aber sie dienten dazu, die Gewerkschaft attraktiv zu präsentieren und Mitglieder zu binden. Die ÖTV war sich allerdings bewusst, dass eine dauerhafte Konsolidierung über eine bloße Senkung der Verwaltungskosten kaum möglich sein würde, und strebte gleichzeitig danach, die Einnahmen zu verbessern. So setzte sie die Werbung neuer Mitglieder und die Klärung der Frage, wie eine korrekte Beitragszahlung erreicht werden könnte, mit gleicher Dringlichkeit auf die Agenda.

Für den frisch gewählten Gewerkschaftsführer Heinz Kluncker bedeutete die notwendige Reform der Gewerkschaft die eigentliche Bewährungsprobe, denn eine erfolgreiche interne Neuaufstellung war für die Zukunft der ÖTV letztlich weitaus wichtiger als Stellungnahmen des Vorsitzenden zu politischen Themen wie der Entspannungspolitik oder den Notstandsgesetzen.

\section{3. „Es muß uns gelingen, näher an die Betriebe heranzukommen«: Reformbemühungen, ein Rückschritt und tatsächliche Modernisierungen in der ÖTV}

\section{Wie verbessert man die berufliche Betreuung in einem gewerkschaftlichen „Völkerbund»?}

Da recht unterschiedliche Probleme hinter dem geringen Wachstum der ÖTV und ihrer unbefriedigenden finanziellen Situation standen, waren Lösungen schwierig und kaum rasch zu erreichen. Heinz Kluncker versuchte deshalb, zunächst die interne Diskussion in der Gewerkschaft neu zu beleben, die unter Adolph Kummernuss offensichtlich weitgehend eingeschlafen war. Im Oktober 1964 initiierte Kluncker eine breit angelegte Beratung über die aktuelle Situation der ÖTV. Da der vorangegangene Gewerkschaftstag die Leitung beauftragt hatte, innerorganisatorische Reformen vorzubereiten, bildete der Hauptvorstand zwölf »Sachkommissionen«, die jeweils einen wichtigen Aspekt der gewerkschaftlichen Arbeit kritisch betrachteten. Auch Funktionäre anderer Verbandsgremien und -ebenen wurden zu diesen Debatten hinzugezogen. Gemeinsam hatten die Kommissionen nach Klunckers Worten keine geringere Aufgabe als die, eine »neue Ordnung« der ÖTV zu entwerfen, um ihre Stagnation zu überwinden. Damit legte er den Antrag, den die Delegierten auf dem Kongress im Juli 1964 angenommen hatten, denkbar weit aus. Bei den Mitgliedern 
des Hauptvorstandes fand dieses Projekt viel Beifall. ${ }^{116}$ Als koordinierende Instanz entstand dort ein besonderer Ausschuss. Der dazugehörige Geschäftsbericht der ÖTV vermerkte, Kluncker habe sich dessen Leitung »selbst vorbehalten «. ${ }^{117}$

Die folgenden Beratungen zeigten allerdings, dass gute Vorsätze oft mit banalen Alltagsproblemen kollidieren, wenn sie realisiert werden sollen. So konnten sich die ehrenamtlichen Mitglieder im Hauptvorstand nicht so regelmäßig und intensiv an der Arbeit der Sachkommissionen beteiligen, wie sie das selbst wünschten, weil sie beruflich stark eingebunden waren. Gleichzeitig klagten hauptamtliche Funktionäre wie etwa die Bezirksvorsitzenden über die zusätzliche Arbeit. Zentrale Elemente der »neuen Ordnung « scheinen daher doch eher im engsten Kreis der ÖTV-Führung in Stuttgart als in einer wirklich breiten innerverbandlichen Debatte entstanden zu sein. Die Basis der Organisation hat so oder so offensichtlich kaum mitgeredet. ${ }^{118}$

Als zentrales Problem der ÖTV galt bei dieser kritischen Revision des Status quo die berufsfachliche Betreuung der Mitglieder. Die ÖTV, so ließe sich ein Fazit formulieren, wisse als Gewerkschaft zu wenig darüber, was den Beschäftigten an ihren Arbeitsplätzen wirklich wichtig sei und welche konkreten Verbesserungen sie sich erhofften: Sie sei zu sehr eine Gewerkschaft für abstrakte Gebilde wie »Öffentlicher Dienst« oder »Transport und Verkehr« und zu wenig eine Gewerkschaft für einzelne Berufsgruppen mit ihren spezifischen Sorgen. Ohne eine »stärkere Bindung der Organisation an berufsfachliche Anliegen«, so resümierte Heinz Kluncker, werde es wohl kaum gelingen, die ÖTV wieder zu einer dynamisch wachsenden Gewerkschaft zu machen, die effektiv für die Interessen der Beschäftigten

116 | Protokoll der 1. Sitzung des HV, 29.9./1.10.1964. In: Archiv Ver.di, Bestand Kluncker, 45.

117 | ÖTV-Geschäftsbericht 1964/67, S. 671.

118 | Vgl.: Niederschrift über die gemeinsame Sitzung von Hauptvorstands- und Beiratsmitgliedern, des Bezirksvorstandes und der Bezirkssekretäre NRW II, 18.5.1965. In: AdsD, ÖTV-NW II, 5/ÖTVC022005 (H. Kluncker spricht hier mit Blick auf die Sachkommissionen von »entmutigenden Erfahrungen«); ÖTV-Geschäftsbericht 1964/67, S. 671 (hier heißt es, die Debatte habe "weniger beim Mitglied als bei den [...] Vertrauensleuten, Funktionären und Vorständen regionaler wie auch fachlicher Gliederungen« stattgefunden). 
eintreten könne: »Wir tun so, als seien wir [eine] Bewegung und sind eine nicht immer gut funktionierende Verwaltung. «119

Da Interessenvertretungen von Arbeitnehmern nun einmal als Organisationen mit festen internen Strukturen arbeiten, führte diese Problemanalyse zwingend zu einer Reformdebatte, in der es im Wesentlichen um den institutionellen Aufbau der ÖTV ging. Dieser Streit um die Organisationsstruktur der Gewerkschaft war jedoch kein Selbstbeschäftigungsprogramm der Funktionäre. Verhandelt wurde dabei vielmehr die Frage, wie die ÖTV als Gewerkschaft attraktiver werden konnte, um mit mehr Mitgliedern und besseren Finanzen erfolgreicher für die sozialen Belange von Arbeitnehmern eintreten zu können. Optimierte bürokratische Strukturen waren ein unerlässliches Mittel für diesen Zweck.

In mehreren Regionalkonferenzen, auf denen Heinz Kluncker ab dem Frühjahr 1965 die Probleme der Organisation mit haupt- und ehrenamtlichen Funktionären der einzelnen ÖTV-Bezirke diskutierte, gab der Vorsitzende jeweils sehr klar den Kurs vor, der bei einer internen Reform nach seiner Meinung einzuschlagen war: »Es muß uns gelingen, näher an den Betrieb heranzukommen und mehr in den Betrieb hineinzugelangen." Dafür sei es unerlässlich, die eigene Organisation fachlich klarer zu gliedern. $^{120}$

Konkret hielt Kluncker die oben in der Einleitung kurz vorgestellten acht Hauptfachabteilungen der ÖTV schlicht für »entbehrlich«. Ihre Abgrenzung gegeneinander sei teilweise willkürlich, ja unlogisch und daher ein Hindernis bei der tarifpolitischen Arbeit. ${ }^{121}$ Spöttisch fragte der Vorsitzende, welchen konstruktiven Beitrag zur internen gewerkschaftlichen Diskussion denn wohl eine Fachabteilung leisten solle, die unter anderem Feuerwehrleute, Sparkassenangestellte und Friedhofsgärtner gleicherma-

119 | In der Reihenfolge der Zitate: ebd.; Protokoll über die 7. Sitzung des HV, 20./21.1.1966. In: AdsD, 5/ÖTVB130014.

120 | Niederschrift über die gemeinsame Sitzung von Hauptvorstands- und Beiratsmitgliedern, des Bezirksvorstandes und der Bezirkssekretäre NRW II, 18.5.1965. In: AdsD, ÖTV-NW II, 5/ÖTVC022005.

121 | Ebd. 
ßen zu vertreten habe: So etwas sei ein »Wischi-Waschi-Völkerbund«, aber keine funktionsfähige Organisationseinheit. ${ }^{122}$

Wie bei anderen Großorganisationen mit eingespielten internen Strukturen waren grundlegende Veränderungen jedoch auch bei der ÖTV eher zähe Angelegenheiten. Jedenfalls setzte sich in der langwierigen Debatte, in der auch radikale Reformvorschläge diskutiert wurden, ${ }^{123}$ schließlich die Überzeugung durch, eine Reform könne »nur schrittweise« erfolgen. Die »neue Ordnung« der ÖTV, deren Details schließlich Ende 1966 ausgearbeitet vorlagen, unterschied sich scheinbar sogar nur unwesentlich von den alten Strukturen: Aus den acht Hauptfachabteilungen wurden neun »Hauptabteilungen«.

Als Resultat mehrjähriger Beratungen mag das zunächst eher lächerlich als eindrucksvoll wirken. Die Bedeutung der Reform zeigt sich aber bei einem genaueren Blick. So bildeten die Beschäftigten von Bund, Ländern und Gemeinden nun jeweils eine eigene separate Sparte, während die zuvor bestehende Hauptfachteilung I gleichzeitig für den Bund und für die Länder zuständig gewesen war. Logischer geordnet und untereinander abgegrenzt waren auch die nachfolgenden neuen Sektionen für die Beschäftigten der Sozialversicherungsträger, der Polizei, des Gesundheitswesens, der Energie- und Wasserversorgung, des Nahverkehrs und von »Transport und Verkehr «. ${ }^{124}$ Diese Umorganisation allein hätte allerdings nicht ausgereicht, um dem eigentlichen Ziel der Reformbemühungen - die Mitglieder intensiver und betriebsnäher betreuen zu können - näherzukommen. Zu-

122 | Referat von Heinz Kluncker »Das Zukunftsbild der ÖTV« für die Arbeitstagung des ÖTV-Bezirks Bayern, 10./12.2.1966. In: AdsD, Depositum Kluncker, Reden und Referate November 1964-September 1969.

123 | Erneut fehlen Quellen, die uns detaillierte Einblicke in die internen Debatten der Gewerkschaft bieten könnten. Offensichtlich diskutierten die Funktionäre untereinander durchaus auch radikale Neuordnungspläne wie etwa den Vorschlag einer "regionalen Reform «, die ganz auf den Versuch verzichten wollte, die verschiedenen Berufsgruppen in der ÖTV auf überregionaler Ebene zu größeren organisatorischen Einheiten zusammenzufassen. Damit hätte man die Bezirks- und Kreisverwaltungen enorm aufgewertet - aber sie zugleich mit neuen anspruchsvollen Aufgaben belastet. Ob das praktikabel sei, daran zweifelte offensichtlich nicht nur die Verbandsspitze. Einen Abriss der internen Debatten vgl. in: ÖTV-Geschäftsbericht 1964/67, S. 671-680, Zitat: S. 673.

124 | Ebd., S. $679 \mathrm{f}$. 
gleich wollte die ÖTV mit der neuen Struktur bewusst künftig auf einen kosten- und zeitintensiven Strang der internen Beratungen verzichten: Bislang hatten die Hauptfachabteilungen bei der Vorbereitung der Gewerkschaftstage eine wichtige Rolle gespielt, indem sie darüber in jeweils 96 regionalen Fachabteilungskonferenzen und acht weiteren Hauptkonferenzen berieten. De facto hatte die ÖTV damit eine gewisse Doppelstruktur etabliert, denn parallel diskutierte man auch noch in den Ortsvereinen, Kreis- und Bezirksverwaltungen und stimmte dort ab. ${ }^{125}$ Dieser überaus komplizierte Meinungsbildungsprozess war eingeführt worden, um das nur alle vier Jahre kurzfristig tagende »Parlament« der ÖTV besser an die Organisation zu binden; er sollte nun aber weitaus straffer verlaufen und im Wesentlichen nur noch in den regionalen Gremien stattfinden. Vor allem ließ sich so Zeit sparen - und zwar die Zeit der ehrenamtlichen und hauptberuflichen Funktionäre, die innerhalb der Organisation oft genug Doppelt- und Dreifachrollen übernommen hatten. Diese Zeit (sowie auch die Gelder, die durch den Verzicht auf die vielen Konferenzen frei wurden) wollte die ÖTV nutzen, um die »berufliche und fachliche Betreuung«ihrer Mitglieder zu optimieren. ${ }^{126}$

Wie wichtig diese Sache genommen wurde, zeigte sich, als der Gewerkschaftsbeirat den zweiten Teil der Reform bereits im Dezember 1966 »vorläufig" in Kraft setzte. Die Funktionäre der ÖTV trafen sich in der Folge bereits weitaus seltener, um den Gewerkschaftstag von 1968 vorzubereiten, als dies bei den früheren Kongressen der Fall gewesen war. ${ }^{127}$ Kritik, die eine Einschränkung der innerverbandlichen Diskussion beklagte, kam kaum auf. Vielmehr bestätigte der Gewerkschaftstag, der im politisch stürmischen Sommer 1968 tagte, trotz intensiver Detaildiskussionen, die den Kongress insgesamt 17 Stunden lang beschäftigten, mit großer Mehrheit die gesamte »neue Ordnung« der ÖTV und den vorgezogenen Beschluss des Beirats. ${ }^{128}$

125 | Vgl. ebd., S. 674.

126 | Ebd., S. 674 (Zitat) u. S. 678.

127 | Ebd., S. 675-679.

128 | Die Diskussion ist dokumentiert in: Protokoll ÖTV-GT 1968, Bd. 1, S. 148235. Die neue Satzung ist abgedruckt in: Protokoll ÖTV-GT 1968, Bd. 2, S. 489508. Vgl. auch Nachtmann: 100 Jahre ÖTV, S. $368 \mathrm{f}$. 
Beim zentralen Reformziel, die Mitglieder stärker an die Gewerkschaft zu binden und so die Fluktuationsrate zu verringern, handelte es sich um ein Langzeitprojekt, dessen Wirkungen sich nicht kurzfristig beurteilen lieBen. Unmittelbar veränderte sich mit dem Umbau der internen Strukturen das innere Machtgefüge der ÖTV, was allerdings nicht offen zutage trat: Mit den alten Hauptfachabteilungen verschwand auch das Wahlverfahren für deren Leiter, denn die Spitzen der neuen Hauptabteilungen wurden vom ÖTV-Hauptvorstand berufen. Infolgedessen gewannen die Bezirksvorsitzenden in der Führung der Gewerkschaft stark an Gewicht, denn sie besaßen nach wie vor ein direktes Votum »ihrer« jeweiligen Basis, während das für die Hauptabteilungsleiter nicht mehr galt. Die beiden nordrheinwestfälischen Bezirke, die allein ein Viertel aller ÖTV-Mitglieder stellten, konnten nach der Reform von 1966/68 bei internen Debatten eine "gewisse Dominanz« für sich beanspruchen, denn gerade im Ruhrgebiet lag der Organisationsgrad der ÖTV in den Kommunen und Kommunalbetrieben besonders hoch. Wie es um die Streikfähigkeit der Gewerkschaft stand, das entschied sich zu einem guten Teil in dieser Region. Bayern, Baden-Württemberg und Hessen waren weitere "Schwergewichte« mit besonderem innerverbandlichen Einfluss. ${ }^{129}$

Zugleich und ebenso unmittelbar stärkte die »neue Ordnung« auch die eigentliche Führung der ÖTV, d.h. vor allem den geschäftsführenden Hauptvorstand und dessen Vorsitzenden. Da das starre Schema der zwingend vorgeschriebenen Fachkonferenzen obsolet wurde und die neuen Hauptabteilungen intern nur noch unregelmäßig über konkrete Sachthemen berieten, konnten Heinz Kluncker, der gHV und der Hauptvorstand zwischen den Gewerkschaftstagen politisch freier agieren als zuvor. ${ }^{130}$ Mitten im Jahr 1968, in dem Jugendproteste auch in der Bundesrepublik so viele Autoritäten grundlegend in Frage stellten, verwandelte sich die ÖTV also in eine deutlich straffer geführte Organisation.

129 | Interview Walter Eberhardt, 16.12.2013 (Zitat); die Zahlen für das Jahr 1967 nach: ÖTV-Geschäftsbericht 1964/67, S. 849. Auf Bayern entfielen 16 Prozent der ÖTV-Mitglieder, auf Baden-Württemberg 11,7 Prozent und auf Hessen 10,4 Prozent.

130 | Vgl. zu diesem Zusammenhang H. Kluncker in: Protokoll ÖTV-GT 1968, Bd. 1, S. $68 \mathrm{f}$. 
Heinz Kluncker hatte mit diesem Verstoß gegen den Zeitgeist kein Problem, ja er sah in der Stärkung der Verbandsführung sogar einen ausgesprochen positiven Nebeneffekt der neuen Satzung. Bei einem Gewerkschafter, der zeitgleich über »obrigkeitliche Züge« im Verhalten vieler »ÖTVler« klagte und sich für die politisch seinerzeit teilweise recht radikal auftretende Gewerkschaftsjugend ausdrücklich ein »Optimum an Freiheit« wünschte, mag das inkonsequent und widersprüchlich wirken. ${ }^{131}$

Dennoch sollte man den jungen Vorsitzenden nicht für einen verkappten Gegner der innergewerkschaftlichen Demokratie halten. Kluncker war vielmehr ein Freund klar definierter Rollen. Um als Gewerkschaft erfolgreich zu sein, brauchte die ÖTV aus seiner Sicht ebenso offene Diskussionen, freie Abstimmungen und Wahlen wie auch die Arbeit einer zielbewussten Führung, die klare Vorgaben machte: »Die ÖTV bedarf einer starken zentralistischen Leitung «, so formulierte er es ganz unmissverständlich im Mai 1965 auf einer Funktionärstagung in Nordrhein-Westfalen. Einmal dabei, Rollen und Funktionen innerhalb der Organisation abzugrenzen, nannte Kluncker gleich noch eine Zahl: »80\% der Gewerkschaftspolitik« lagen nach seiner Überzeugung in der Verantwortung der Verbandsleitung. ${ }^{132}$

Wie diese Ziffer zustande kam, hat er nicht erläutert. Ihr Wert ist sicher fragwürdig und retrospektive Kritik daran wohlfeil. Die Vehemenz, mit der Kluncker an dieser Stelle argumentierte, beweist jedoch, wie stark ihn die Furcht umtrieb, die beruflich so heterogene ÖTV könne in der Öffentlichkeit als uneinig und ziellos erscheinen. Den »Wischi-Waschi-Völkerbund« hielt er offensichtlich für eine reale Gefahr - und damit hatte er insofern fraglos recht, als mit der 1968 in Kraft gesetzten Strukturreform nicht das Problem beseitigt wurde, dass die ÖTV gleichzeitig für höchst unterschiedliche Berufsgruppen einzutreten hatte. Konkret gab es etwa nach wie vor eine Hauptabteilung, in der Feuerwehrmänner, Sparkassenangestellte und Friedhofsgärtner zugleich beraten und betreut werden sollten. ${ }^{133}$

131 | DGB 1964/68, S. 709 (H. Kluncker auf der DGB-Bundesvorstandssitzung v. 19.6.1968).

132 | Niederschrift über die gemeinsame Sitzung von Hauptvorstands- und Beiratsmitgliedern, des Bezirksvorstandes und der Bezirkssekretäre NRW II, 18.5.1965. In: AdsD, ÖTV-NW II, 5/ÖTVC022005.

133 | Dies war die neue Hauptabteilung »Gemeinden«. ÖTV-Geschäftsbericht 1964/67, S. 680 . 
Gerade dieses Beispiel aber hatte Kluncker in den Beratungen zur »neuen Ordnung« der ÖTV benutzt, um sein negatives Urteil über die bislang bestehende Organisation der Gewerkschaft zu begründen. Deren Klientel war nun einmal beruflich höchst disparat - und dies ließ sich auch durch eine noch so ausgeklügelte interne Reform nicht aus der Welt schaffen. Eine zentrale Führung, die den Verband zwischen den Gewerkschaftstagen politisch klar dominierte, galt dem ÖTV-Vorsitzenden unter diesen Voraussetzungen offensichtlich als unerlässlich. Für ebenso selbstverständlich hielt er allerdings das Recht der Mitglieder, im »Parlament« der Organisation rückblickend über den Kurs der Leitung zu urteilen und - wenn nötig - auch personelle Konsequenzen zu ziehen. ${ }^{134}$

\section{Emanzipation ohne »Minderheitenschutz»? Der Verzicht der ÖTV auf eine Frauenquote und eigenständige Frauenkonferenzen}

Mit Verabschiedung der neuen Satzung 1968 gab es einen weiteren Nebeneffekt: Die Gewerkschaft verzichtete fortan auf spezielle Frauenkonferenzen und Frauenausschüsse auf allen Ebenen der Organisation. Diese Maßnahme verfolgte ebenfalls das Ziel, den Aktivisten des Verbandes - inklusive den weiblichen - mehr Zeit für die Betreuung der Mitglieder zu geben. ${ }^{135}$ Doch damit befand sich die ÖTV erneut gar nicht im Einklang mit dem Zeitgeist, denn im Kontext der Studentenrevolte dieser Jahre entstand in der Bundesrepublik eine neue Frauenbewegung, die selbstbewusst begann, die im Grundgesetz postulierte Gleichheit der Geschlechter aktiv einzufordern. Separate Diskussionen ohne männliche Mitwirkung und eigene Frauenorganisationen galten dabei als die ersten, unverzichtbaren Schritte, um Frauen aus ihrer gesellschaftlich inferioren Stellung zu befreien. ${ }^{136}$

Diese Entscheidung, auf einen autonomen weiblichen Bereich und gleichzeitig auch auf jede Frauenquote für ihre Gremien zu verzichten, sollte nicht als Anti-Feminismus gedeutet werden. Vielmehr handelte es sich um einen Ausdruck von Ratlosigkeit: Die Gewerkschaft wollte etwas

134 | Siehe dazu auch unten S. 521-535.

135 | Protokoll ÖTV-GT 1968, Bd. 1, S. 70.

136 | Als knappen Überblick vgl. etwa: Axel Schildt/Detlev Siegfried: Deutsche Kulturgeschichte. Die Bundesrepublik - 1945 bis zur Gegenwart, München 2009, S. 379-383. 
Neues auszuprobieren, weil die gutgemeinten alten Regelungen sich nicht bewährt hatten. Gleichwohl muss diese Maßnahme in historischer Perspektive wohl als politischer und institutioneller Rückschritt gelten.

Wie erwähnt spielten Frauen in den Gremien der ÖTV eine marginale Rolle, obwohl sie doch fast 20 Prozent der Mitglieder stellten. Auf dem Gewerkschaftstag im Sommer 1968 konstatierte Heinz Kluncker, die bislang geltende Vorschrift in der Satzung, Frauen sollten »ihrem Anteil entsprechend « an allen Konferenzen beteiligt sein und auch in allen Beschlussgremien mindestens je einen Sitz erhalten, habe seit der Gründung der ÖTV "weder den Frauen noch der Gewerkschaftsorganisation Vorteile gebracht«. Schon ein Blick in den Saal bewies das: Frauen stellten nur noch drei Prozent der Delegierten, die Versammlung war damit männlicher als je zuvor. ${ }^{137}$

Der Vorsitzende plädierte daher dafür, in der neuen Satzung auf jede "Minderheitenprivilegierung« der Frauen zu verzichten: So vermeide man die »Isolierung« der ÖTV-Kolleginnen in der Organisation, die es wegen der speziellen Frauenkonferenzen und der verschiedenen Frauenausschüsse in den Kreisen und Bezirken der Gewerkschaft bis dato gegeben habe. ${ }^{138}$

Dieser Vorschlag resultierte aus den Debatten über die inneren Strukturen der ÖTV, die nach dem Gewerkschaftstag von 1964 begonnen hatten. Frauen spielten bei diesen Beratungen aber lediglich eine Nebenrolle: Nur in vier der zwölf "Sachkommissionen«, die der Hauptvorstand im Herbst 1964 zur Vorbereitung der Reform bildete, saß jeweils eine Frau neben sechs bis acht Männern; acht Kommissionen waren rein männlich. Zwar vertrat Ilse Brieke als Hauptvorstands-Mitglied die ÖTV-Frauen im achtköpfigen koordinierenden Ausschuss, den Heinz Kluncker leitete; von einer angemessenen Beteiligung der Kolleginnen kann insgesamt dennoch nicht die Rede sein. ${ }^{139}$

137 | Protokoll ÖTV-GT 1968, Bd. 1, S. 70 f.; der Prozentsatz der weiblichen Delegierten nach ebd., S. 81; die Satzung zit. nach: Protokoll ÖTV-GT 1961, Anträge, S. 215.

138 | Ebd., S. 71. Ausführlich zu der im Folgenden skizzierten Debatte vgl.: Kassel: Frauenpolitik der ÖTV, S. 56-69.

139 | Vgl. die Namenslisten der Kommissionen und des Ausschusses in: ÖTV-Geschäftsbericht 1964/67, S. 827-830. Bei den Kommissionen mit Frauenbeteiligung handelte es sich um die Kommission für Sozialpolitik (Ingeborg Tönnessen), für "gewerkschaftliche Verwaltungs- und Organisationsfragen" (Hertha Peters), für Personalpolitik (Ilse Brieke, Herne) sowie für Werbung (Rosemarie Nemitz, die 
Für die wenigen Frauen, die in den speziell weiblichen Ausschüssen und Konferenzen der Gewerkschaft aktiv waren, bedeuteten die weitgehend nicht mit ihnen, sondern über ihre Köpfe hinweg geführten Gespräche der ÖTV-Reformer eine schwere Enttäuschung. Selbst der offizielle Geschäftsbericht vermerkte rückblickend "schockierende, sogar deprimierende Auswirkungen« der Debatte, in der die dominierenden Männer sich offenbar sehr rasch auf das Ergebnis einigten, die Frauengremien seien entbehrlich. ${ }^{140}$

Immerhin entwickelte sich auf dem ÖTV-Kongress im Sommer 1968 ein kurzer Streit zumindest über den Plan, in der Gewerkschaft zukünftig auch auf jede Quote für die Frauen zu verzichten. Allerdings handelte es sich um einen Streit mit vertauschten Rollen: Ausgerechnet eine der 15 anwesenden Frauen begrüßte den Vorschlag der Verbandsführung, und ausgerechnet einer der 499 stimmberechtigten Männer kritisierte ihn. Die Delegierte Marie-Luise Smeets aus Düsseldorf hielt die neue Regelung für emanzipatorisch: Frauen seien so selbstverständlich Teil der ÖTV, dass sie »keinen Minderheitenschutz mehr nötig« hätten. Von einer Gleichberechtigung der beiden Geschlechter ließe sich erst dann sprechen, "wenn es bei Wahlvorgängen wirklich keine Rolle mehr spielte, ob Männer oder Frauen zur Wahl stehen, sondern wenn allein die Tüchtigkeit entscheiden [...] würde ${ }^{141}$ Widerspruch kam vom Delegierten Gert Kasch aus Uelzen: Verschwinde die Vorschrift, jeweils mindestens eine Frau in jedes Beschlussgremium der Gewerkschaft zu berufen, dann würden die Frauen in der ÖTV jeden Einfluss verlieren, denn bei ganz freien Wahlen seien Kandidatinnen gegenüber Männern de facto chancenlos. ${ }^{142}$

Eine damit drohende Grundsatzdebatte über den »richtigen« Weg zur Gleichberechtigung war jedoch nicht im Sinne der Verbandsführung: Heinz Kluncker intervenierte mit der Erklärung, die neue Regelung sei keineswegs als emanzipationspolitisches Statement gedacht. Es gehe lediglich

allerdings bereits im August 1965 ausschied, ohne dass eine Ersatzfrau nachrückte). Rein männlich besetzt waren damit u.a. die thematisch zentralen Bereiche »Finanz- und Vermögensfragen der ÖTV«, Tarifpolitik sowie »Gewerkschaftsund Gesellschaftspolitik«. Biografische Angaben zu Ilse Brieke finden sich in ihrem Nachruf in: Trauer um engagierte Hernerin. In: WAZ, 27.1.2009.

140 | ÖTV-Geschäftsbericht 1964/67, S. 743.

141 | Protokoll ÖTV-GT 1968, Bd. 1, S. 85.

142 | Ebd., S. 104. 
darum, »einmal einen anderen Weg zu versuchen«, weil das bislang geltende Privileg die weibliche »Aktivität« in der Gewerkschaft leider nicht »auf eine breitere Basis gestellt« habe. ${ }^{143}$

Nun ist die Frage, die Marie-Luise Smeets und Gert Kasch auf dem ÖTV-Kongress von 1968 so unterschiedlich beantworteten, bis heute heftig umstritten: Die Auseinandersetzung in Politik und Gesellschaft, ob eine Quote für Frauen in den Führungsetagen von Unternehmen nötig und nützlich sei, hat es kürzlich wieder gezeigt. Insofern ist es zu einfach, die interne Reform der ÖTV, die der Gewerkschaftstag 1968 mit so großer Mehrheit beschloss, nur als Resultat einer Männerherrschaft zu deuten. Das von der Verbandsleitung vorgeschlagene Experiment, ob Frauen besser in die Organisation integriert werden könnten, wenn sie eben keinen garantierten Sonderstatus genossen und nicht separat berieten, war sicher gut gemeint. Doch gerade deshalb hätte eine verbindliche Erfolgskontrolle dieser Neuorientierung nahegelegen. Da ein solcher Beschluss ausblieb, verschwanden die speziellen Frauenkonferenzen und -ausschüsse der Gewerkschaft, ohne dass neue Foren für spezifisch weibliche Anliegen in der ÖTV entstanden.

Zumindest vereitelten die Delegierten den Plan der Verbandsführung, einen neuen, verkleinerten geschäftsführenden Hauptvorstand wählen zu lassen, in dem keine Frau mehr sitzen sollte. Anders als die Verbandsführung hielten sie auch in einem weniger kopfstark besetzten gHV eine "deutlich sichtbare Repräsentanz« des weiblichen Geschlechts für unverzichtbar. ${ }^{144}$ Erstmals in der Geschichte der Organisation gab es eine Kampfabstimmung um einen der Plätze in der ÖTV-Führung, die Hanna Simon als kurzfristig aufgestellte Kandidatin mit klarer Mehrheit für sich entschied. Der geschlechterpolitische »Rollback«, den die ÖTV mit ihrer

\section{3 | Ebd., S. 145.}

144 | Protokoll ÖTV-GT 1968, Bd. 1, S. 123. Über die fehlende Nominierung einer Frau für den neuen gHV hatte der Hauptvorstand vor dem Kongress kontrovers diskutiert: Willi Kuhlmann hatte den Vorschlag kritisiert; die Mehrheit aber folgte Klunckers Vorschlag. Allerdings erregte das Thema bei den HV-Mitgliedern bei weitem keinen so großen Diskussionsbedarf wie die Nominierung von Karl Heinz Hoffmann als dem neuen CDU-Vertreter im gHV, der als Person stark umstritten war. Protokoll über die 14. Sitzung des HV, 1.2.1968. In: AdsD, 5/ÖTVB130015. 
organisatorischen Reform vollzog, fiel daher doch nicht ganz so radikal aus, wie es die Leitung geplant hatte. ${ }^{145}$

Die ÖTV demonstrierte damit aber vermutlich nur ihre grundsätzliche Aufgeschlossenheit für Minderheitenschutz. So privilegierten die Delegierten parallel auch eine andere Minderheit unter ihren Mitgliedern (die wahrscheinlich noch deutlich kleiner war als die Gruppe der Frauen): Der Gewerkschaftstag entsandte Karl Heinz Hoffmann ebenfalls in den gHV und dies geschah eindeutig vor allem deshalb, weil Hoffmann als Hauptgeschäftsführer der »Christlich-Demokratischen Arbeitnehmerschaft« ein prominentes CDU-Mitglied war. Besonderes Engagement in der ÖTV hatte er bislang nicht gezeigt. Innerhalb der Organisation gab es verdiente Funktionäre, die meinten, Hoffmann fehlten "wesentliche Voraussetzungen« für sein neues Amt wie etwa "Kenntnis der ÖTV und notwendige Erfahrungen im Organisationsbereich «. Dennoch wurde er nicht nur in den gHV gewählt, sondern zugleich zum Stellvertretenden Vorsitzenden bestellt. ${ }^{146}$

Ob sich die ÖTV mit dem Verzicht auf ihre Frauenkonferenzen einen Gefallen tat, darf man mit Blick auf den Aufschwung, den die neue Frauenbewegung in der Bundesrepublik in den 1970er Jahren erlebte, bezweifeln. Gerade für selbstbewusste Frauen präsentierte sich die Gewerkschaft in ihrer neuen Gestalt in diesem Jahrzehnt alles andere als modern und fortschrittlich. Der Versuch, die Mitgliederbetreuung zu verbessern, forderte daher durchaus einen Preis. Zwar blieb das zentrale Frauensekretariat bestehen und auch auf den unteren Ebenen der Organisation gab es nun spezielle Anlaufstellen für weibliche Anliegen. Die männliche Dominanz in der Hierarchie der ÖTV tangierte das jedoch kaum: 1972 waren lediglich fünf der insgesamt zwölf »Frauensekretäre« in den Bezirksverwaltungen

145 | Vgl. dazu: Kassel: Frauenpolitik der ÖTV, S. 66-68; die Formulierung vom »Rollback« ebd., S. 56.

146 | Protokoll ÖTV-GT 1968, Bd. 1. S. 517-523; das Zitat aus: Niederschrift der Bezirksvorstandssitzung NRW II, 3.5.1968. In: AdsD, ÖTV-NW II, 5/ÖTVC02002. $\mathrm{Zu}$ den Vorbehalten gegenüber Hoffmann, der angeblich nur »wegen des Prinzips der Einheitsgewerkschaft [...] eingekauft" werde, vgl. auch schon: Protokoll über die 14. Sitzung des HV, 1.2.1968. In: AdsD, 5/ÖTVB130015. Auf Kritik stieß nicht so sehr seine Nominierung für den gHV, sondern vornehmlich der Vorschlag, Hoffmann gleich auch zum Stellvertretenden Vorsitzenden zu wählen. 
der Gewerkschaft weiblich; sieben dieser Positionen wurden von Männern besetzt. $^{147}$

\section{Die neue Medien- und Werbearbeit der ÖTV}

In den ersten Jahren seiner Amtszeit initiierte Heinz Kluncker ein ganzes Bündel an Neuerungen und Reformen, die die ÖTV stärken und dynamisieren sollten. Dabei kümmerte er sich selbst um Kleinigkeiten. So empörte er sich etwa darüber, dass zahlreiche Orts- und Kreisverwaltungen der Gewerkschaft auf das offizielle Logo der ÖTV verzichteten, wenn sie Flugblätter, Pressemitteilungen oder andere Drucksachen herausbrachten. Teilweise benutzten sie sogar eigene Embleme, was Kluncker scharf verurteilte: "Jede Markenartikelfirma legt Wert auf ein geschlossenes Erscheinungsbild, nur eine Gewerkschaft kapiert das nicht. ${ }^{148}$

Eine solche Aussage, in der die hehre Sache einer Arbeiterorganisation mit den schnöden Geschäften eines Wirtschaftsunternehmens verglichen wurde, hätte ältere Gewerkschafter wie etwa Adolph Kummernuss wohl sprachlos zurückgelassen. Heinz Kluncker aber dachte pragmatisch und zeitgemäß: Er forderte eine aktive Pressearbeit, gezielte Werbung und ein einheitliches öffentliches Auftreten der ÖTV ein. Zu den im Herbst 1964 eingerichteten »Sachkommissionen « gehörte folgerichtig ein spezielles Gremium nur für Werbung. ${ }^{149}$

Bereits im Sommer 1965 verabschiedete diese Kommission eine Art Grundsatzbeschluss: Zentrales Ziel der künftigen Öffentlichkeitsarbeit sollte es sein, »ein ÖTV-Erscheinungsbild (Image)« zu schaffen. Um das zu erreichen, müssten »Öffentlichkeitsarbeit, Werbung und Information« bewusst voneinander unterschieden, aber doch koordiniert werden. Ferner beschloss die Kommission inhaltliche Vorgaben für die zu intensivierende Mitgliederwerbung: Der »Charakter des `Service«, der Dienst am Mitglied«,

147 | Kassel: Frauenpolitik der ÖTV, S. 68f. Zur Entwicklung des Frauensegments in der ÖTV nach 1968 siehe unten S. 411-420.

148 | Referat von Heinz Kluncker »Das Zukunftsbild der ÖTV « für die Arbeitstagung des ÖTV-Bezirks Bayern, 10./12.2.1966. In: AdsD, Depositum Kluncker, Reden und Referate November 1964-September 1969.

149 | ÖTV-Geschäftsbericht 1964/67, S. 830. Im Mai 1966 übernahm Heinz Kluncker persönlich die Leitung der Kommission. 
sollte »stärker betont« werden; daneben wünschten sich die Vorstandsmitglieder bei Werbeaktionen einen genaueren Bezug auf einzelne Berufsgruppen und ihre Belange. Zudem sollte die ÖTV dazu beitragen, dass der Öffentlichen Dienst und die beim Staat beschäftigten Arbeitnehmer allgemein »mit Mitteln der Werbung aufgewertet werden«. Um dieses Konzept zu realisieren, wurden sogar zusätzlich Gelder in Höhe von immerhin 200.000 DM bereitgestellt. ${ }^{150}$

Darüber hinaus engagierte die ÖTV-Hauptverwaltung im Frühjahr 1966 mit dem damals 37-jährigen Siegfried Bußjäger eigens einen neuen Mitarbeiter, der sich vor allem um das "Erscheinungsbild« der Organisation kümmern sollte. Bußjäger hatte zuvor in München die Pressestelle des DGB-Landesbezirks Bayern geleitet und besaß Erfahrungen, wie man Gewerkschaften, ihre Anliegen und ihre Arbeit öffentlich präsentieren konnte. ${ }^{151}$ Bei der Gestaltung der ÖTV-Werbung arbeitete er eng mit Fachleuten der »Reklame« zusammen: Eine Werbeagentur mit Sitz in Köln, die auch für den DGB arbeitete, entwickelte zwischen 1966 und 1969 verschiedene ÖTV-Werbematerialien, die sie unter dem Titel »Werbung für eine Gewerkschaft« schließlich »voll Stolz« in einer eigenen Hochglanzbroschüre zusammenfasste. Nicht ganz uneigennützig dekretierte die Agentur darin, Werbung sei »ein wesentlicher Bestandteil aktiver Gewerkschaftspolitik. Sie ist ein Führungsmittel und verlangt vorausschauende Planung, Konzentration, adäquate Mittel und versierte Fachleute. ${ }^{152}$

Als Blickfänge benutzten diese selbsternannten Experten der »Creativität« [sic] etwa Fotos von Menschen in sofort zu identifizierender Berufskleidung (der Polizist, die Krankenschwester, die Schaffnerin). Die ÖTV insgesamt wurde als »Tarif-Lokomotive« bezeichnet - und dementsprechend fand sich direkt

150 | Ebd., S. 718 f.

151 | Interview Siegfried Bußjäger, 1.4.2014.

152 | ACON[-Gesellschaft für Werbung und Kommunikation]: Werbung für eine Gewerkschaft, Köln o.J. [Zitat S. 1 - die Broschüre ist nicht paginiert]. Ein Exemplar dieser wohl nicht in den Buchhandel gebrachten Publikation findet sich in der Bibliothek der Ver.di-Hauptverwaltung in Berlin. Die meisten der hier abgebildeten Motive wurden als Plakate, die in Betrieben aushingen, als Broschüren sowie als Flugblätter eingesetzt. Anzeigen in Publikumszeitschriften wie etwa dem "Spiegel« schaltete die ÖTV erstmals 1971 (ÖTV: Geschäftsbericht 1968-1971. Hrsg. v. der Gewerkschaft Öffentliche Dienste, Transport und Verkehr - Hauptvorstand, Stuttgart 1972 [im Folgenden: ÖTV-Geschäftsbericht 1968/71], S. 41). 
unter diesem Wort das Bild einer Lokomotive, die aus starker Untersicht gezeigt wird und daher kraftvoll und dynamisch wirkt. Dabei tat es offensichtlich nichts zur Sache, dass die ÖTV gar nicht für die Bahn zuständig war. Entsprechend den disparaten Berufsgruppen der ÖTV waren einzelne Motive bewusst nur für Beamte, für Angestellte oder für Arbeiter gestaltet. Auch für Frauen gab es speziell gestaltete Plakate, Anzeigen oder Broschüren. ${ }^{153}$

Durchgängig erschien die Mitgliedschaft in der Gewerkschaft als ein Ausdruck von Selbstbewusstsein und Selbstbestimmung, als etwas, das für einen »modernen« Menschen selbstverständlich sein sollte. »Frauen von heute« etwa hatten nach den Worten der ÖTV-Werber »wenig Sinn für fruchtlose Umwege. Frauen handeln praktisch« - und deshalb würden sie Mitglied der Gewerkschaft. Materielle Vorteile wurden teilweise ganz handfest versprochen und illustriert (eine Hand streckt dem Betrachter drei 100-DM-Geldscheine entgegen); die Gewerkschaft kämpfe aber um so etwas nur, weil es sich um ein wohlerworbenes Recht der Berufstätigen handele. ${ }^{154}$

Besonders modern gab sich die ÖTV bei der Werbung für junge Mitglieder: Für sie gestalteten die Kölner Werber 1969 gleich mehrere Motive in dem grell-bunten »Flower-Power«-Look, der seinerzeit in der ganzen westlichen Welt die aktuelle Jugendkultur symbolisierte. Auch eine Comic-Figur, die an Superman erinnert, tauchte auf; der damit symbolisierte ÖTV-Jugendvertreter wurde für seine »Fighter- und Tischcrackerqualitäten $\ll[$ sic $]$ gelobt. ${ }^{155}$

Wie wirkungsvoll diese neuartigen Werbebemühungen waren, lässt sich zwar im Nachhinein nicht mehr eruieren, aber in ihrem Streben nach Professionalität und Zielgenauigkeit gehörte die ÖTV zu den gewerkschaftlichen Vorreitern auf diesem Gebiet. Bis dato hatten sich alle DGB-Verbände auf traditionelle Weise vor allem als Gesinnungsgemeinschaften verstanden. Professionell gestaltete »Reklame«, wie sie von gewinnorientierten Unternehmen betrieben wurde, galt in dieser Welt nicht als legitimes Mittel, um potenzielle »Kunden« auf sich aufmerksam zu machen, sondern als Betrug und Täuschung, auf die man selbst nicht angewiesen sei. ${ }^{156}$

153 | ACON: Werbung, S. 27 u. 5.

154 | Ebd., S. 26 (Zitat) u. S. 7.

155 | Ebd., S. 21 f. u. 15 (Zitat).

156 | Vgl. etwa: Willi Bongard: Männer machen Märkte. Mythos und Wirklichkeit der Werbung, Oldenburg und Hamburg 1963, S. 35 f. 
Erst nach 1962 öffneten sich die Gewerkschaftsführer zunehmend für den Gedanken, eine gute Sache brauche auch gute Werbung. So plädierte der DGB-Kongress von 1962 ausdrücklich für eine »zeitgerechte Propaganda« und für eine Zusammenarbeit mit »Fachkräften« der Werbebranche. ${ }^{157}$ Vor allem eine allgemeine "Sympathiewerbung" galt als wichtig, sowohl um neue Mitglieder zu werben als auch um Austritte zu verhindern: »Das Gefühl, einer Institution anzugehören, die respektiert wird und angesehen ist, gibt den Mitgliedern ein zusätzliches Maß an Vertrauen und Rückhalt.« Die Imagewerbung der Gewerkschaften müsse daher »in besonderem Maße modern sein ${ }^{158}$

Bewusst auf die bundesdeutsche Gesellschaft als moderne Mediengesellschaft bezog sich die Arbeit von Siegfried Bußjäger im Dienst der ÖTV in einer weiteren Hinsicht: Wie er selbst rückblickend formuliert, hat er, gemeinsam mit Rudi Wörl, der nach der Ära Kummernuss Pressereferent der Gewerkschaft blieb, »die ÖTV in der Person Kluncker personalisiert, weil Gremien [den Massenmedien - K.C.F.] ja nicht zu verkaufen sind, und ich denke, wir haben mit einigem Erfolg gearbeitet ${ }^{159}$

In der bundesdeutschen Presse hatte schon in den 1950er Jahren eine zunehmende Personalisierung in der Berichterstattung eingesetzt. Der gewaltige Erfolg der 1952 gestarteten Bild-Zeitung von Axel Springer, die bereits 1962 täglich rund vier Millionen Exemplare verkaufte und damit wohl mehr als zehn Millionen Leser und Leserinnen erreichte, prägte den Markt, ob das den Redaktionen und Journalisten der anderen Blätter nun passte oder nicht. Ein stärkerer "human touch « (auch durch die fotografische Abbildung von Personen) war eines der Rezepte, die viele Zeitungen benutzten, um ihre Auflage trotz der neuen Konkurrenz hoch zu halten. ${ }^{160}$

157 | Protokoll 6. Ordentlicher Bundeskongress [des Deutschen Gewerkschaftsbundes], Hannover, 22. bis 27. Oktober 1962, Düsseldorf 1963, S. 280 u. 925 f. (der Text der angenommenen Entschließung).

158 | Geschäftsbericht des Bundesvorstandes des Deutschen Gewerkschaftsbundes 1962 bis 1. Halbjahr 1965, Düsseldorf 1965, S. 89.

159 | Interview Siegfried Bußjäger, 1.4.2014.

160 | Vgl. zu diesen Zusammenhängen etwa: Karl Christian Führer: Medienmetropole Hamburg. Mediale Öffentlichkeiten 1930-1960, Hamburg 2008, S. 523531 u. 570-580. Bei einer Würdigung von »Bild« sollte stets bedacht werden, dass der Erfolg des Blattes nach seiner Gründung die positive Auflagenentwicklung bei anderen Tageszeitungen keineswegs pauschal schwächte oder umkehrte. 
Engagierte Gewerkschafter - wie generell alle »Linken« in der Bundesrepublik - fürchteten gerade Bild als mächtigen publizistischen Feind, obwohl sich die Zeitung in mancher Hinsicht keineswegs in ein simples »Rechts-Links«-Schema einordnen ließ. ${ }^{161}$ Politische Themen waren für Bild vor allem dann interessant, wenn sie auch emotionalen "Stoff « boten. Über die Gewerkschaften und deren Arbeit berichtete das Blatt eher selten; allerdings machte es sich die Parolen der Bundesregierung zu eigen, »Maßhalten" sei wirtschaftspolitisch geboten, und für Streiks fand Bild stets kritische Worte. ${ }^{162}$

Die führenden Männer im DGB und in den einzelnen Gewerkschaften revanchierten sich mit geballter Abneigung. Auch in der ÖTV schaute die Leitung äußerst skeptisch auf Springers so enorm erfolgreiche Boulevardzeitung. Adolph Kummernuss etwa spottete 1964, der "geistige Inhalt« von Bild bestehe "zu einem großen Teil aus fetten Überschriften«. Heinz Kluncker klagte zwei Jahre später etwas konkreter, wenn mittlerweile auch Gewerkschaftsmitglieder der Meinung seien, steigende Preise gingen auf steigende Löhnen zurück, so handele es sich um »das Ergebnis einer un-

Der Niedergang der SPD-nahen Tagespresse vollzog sich zwar zeitlich parallel, hatte aber andere Gründe. Vgl. dazu etwa grundlegend: Stefan Appelius: Heine. Die SPD und der lange Weg zur Macht, Essen 1999.

161 | So kann man »Bild« in den 1950er und 1960er Jahren eine wichtige Rolle bei der Kritik antisemitischer Tendenzen zuschreiben; zugleich tat das Blatt viel für die öffentliche Erinnerung an die NS-Verbrechen. Vgl. dazu: Karl Christian Führer: Schuld und »Selbstbesinnung«. Axel Springers Bild-Zeitung und die Juden in den 1950er und 1960er Jahren. In: Fritz Backhaus/Dimitrij Belkin/Raphael Gross (Hrsg.): Bild dir dein Volk! Axel Springer und die Juden, Göttingen 2012, S. 17-25. Auch Heinz Kluncker hielt grundsätzlich Distanz gegenüber »Bild« und den anderen Springer-Zeitungen: »Es gibt seriöse Zeitungen und es gibt die Springer-Presse - das sagte er im Sommer 1966 vor dem ÖTV-HV (Protokoll über die 8. Sitzung des HV, 30.6./1.7.1966. In: AdsD, 5/ÖTVB130014).

162 | Vgl. dazu etwa den Abriss eines Konflikts zwischen »Bild « und der IG Bau im Frühjahr 1962 in: Zentner: Georg Leber, S. 181 f. Die Gewerkschaft agierte dabei recht ungeschickt, weil sie versuchte, die Zeitung mit "getürkten« Leserbriefen zu beeinflussen - was aufflog und von »Bild« prompt enthüllt wurde. 
informierten Gesellschaft [...], die ihre Informationsquellen aus der Bildzeitung liest $[!] \ll{ }^{163}$

Dennoch reagierte die ÖTV seit 1966 auf die Veränderungen des publizistischen Marktes und auf die besondere Stellung von Bild, indem sie ihren Vorsitzenden nun so oft es ging gezielt ins Rampenlicht rückte. Heinz Kluncker eignete sich dafür allein schon wegen seiner auffälligen Erscheinung - und er sperrte sich auch nicht gegen eine profilierte öffentliche Rolle: "Eitel war er schon«, konstatiert nüchtern sein enger Mitarbeiter Walter Eberhardt. ${ }^{164}$ Wenn Kluncker in den 1970er Jahren in den Medien unangefochten als Symbol für die ganze ÖTV und oft sogar für alle bundesdeutschen Gewerkschaften galt, so war dies auch ein Ergebnis bewusster PR-Arbeit (wie man heute vielleicht sagen würde), bei der ein Plan, Talent und Einsatz erfolgreich zusammenwirkten.

\section{Stärkung der Zentrale}

Im Rahmen seines Bemühens, die ÖTV durch ein professionelleres Auftreten und eine leistungsfähigere Organisation wieder zu einer dynamisch wachsenden Gewerkschaft zu machen, forderte der neue Vorsitzende im Herbst 1964, die in Stuttgart angesiedelte Hauptverwaltung zu stärken. Bislang war diese äußerst schwach besetzt: Noch 1966 füllte die Liste der Beschäftigten und ihrer Telefonnummern nur eine DIN-A4-Seite. ${ }^{165}$ Zwangsläufig fand die Verwaltungsarbeit der Organisation im Wesentlichen in den 175 Kreis- und zwölf Bezirksverwaltungen statt. Dort wurden die Mitgliederlisten geführt und die Beiträge eingetrieben; erst diese Zuarbeit und die Informationen der unteren Gliederungen machten die ÖTV-Zentrale als Verwaltung des Verbandes handlungsfähig. Heinz Kluncker hielt diesen Zustand für völlig falsch. Analyse und Zielvorgabe formulierte er denkbar knapp: Wenn man ihn frage, ob die Verwaltung der ÖTV rationell arbeite - so erklärte er im Frühjahr 1966 -, dann »muß ich dreimal Nein sagen«,

163 | Referat von Heinz Kluncker »Das Zukunftsbild der ÖTV« für die Arbeitstagung des ÖTV-Bezirks Bayern, 10./12.2.1966. In: AdsD, Depositum Kluncker, Reden und Referate November 1964-September 1969.

164 | Interview Walter Eberhardt, 16.12.2013. Siehe dazu unten ausführlicher auch den Abschnitt über Kluncker als »symbolischen Körper«.

165 | Interview Siegfried Bußjäger, 1.4.2014. 
denn von Effizienz könne in dieser Beziehung erst gesprochen werden, wenn die ÖTV »eine zentrale Mitgliederkartei, einen zentralen Materialversand und ein zentrales Beitragsinkasso« habe. ${ }^{166}$

Nun lässt sich die interne Verwaltung einer Organisation mit fast einer Million Mitgliedern wohl selbst dann nicht kurzfristig umkrempeln, wenn alle Beteiligten an einem Strang ziehen und Geld keine Rolle spielt. Da die ÖTV finanziell sehr limitiert war, konnte sie sich intern allein aus diesem Grund lediglich schrittweise modernisieren. Zudem leuchtete das Projekt, entscheidende Teile der Verwaltungsarbeit in Stuttgart zu zentralisieren, keineswegs allen Funktionären und Angestellten ein. Der Gedanke, finanziell zukünftig ganz von Abrechnungen und Überweisungen der Zentrale abhängig zu sein, beunruhigte gerade die kopf- und finanzstarken Ortsund Bezirksverwaltungen, obwohl die Hauptverwaltung damit lockte, man wolle die Kollegen und Kolleginnen in den unteren Gliederungen ja vor allem deshalb entlasten, damit sie sich "besser und intensiver dem speziellen Anliegen der Mitgliederwerbung und Mitgliederbetreuung widmen können«. ${ }^{167}$

Es passte nach dem Selbstverständnis vieler engagierter »ÖTVler« nicht zum Wesen einer Gewerkschaft, wenn die Mitglieder ihre Beiträge an eine anonyme Zentralkasse leisteten: Mit den Kassierern und den Kassen vor Ort verschwinde ein wichtiges Band zwischen den einfachen Gewerkschaftern und der Organisation. ${ }^{168}$ Selbst das für die Gewerkschaft enorm kostensparende "Lohnabzugsverfahren«, bei dem der Arbeitgeber den Obolus der gewerkschaftlich Organisierten einbehielt und weiterleitete, stieß bei ÖTV-Funktionären auf Bedenken: Damit mache sich die Organisation ja von ihren Kontrahenten abhängig. Heinz Kluncker weigerte sich, diese Sorgen ernst zu nehmen: Es handle sich um den untauglichen Versuch, in einer Frage »Ideologie zu machen«, die rein pragmatisch zu prüfen sei. Wer

166 | Referat von Heinz Kluncker »Das Zukunftsbild der ÖTV« für die Arbeitstagung des ÖTV-Bezirks Bayern, 10./12.2.1966. In: AdsD, Depositum Kluncker, Reden und Referate November 1964-September 1969.

167 | ÖTV-Geschäftsbericht 1964/67, S. 698.

168 | Gerhard Weiß: Die ÖTV. Politik und gesellschaftspolitische Konzeptionen der Gewerkschaft ÖTV von 1966 bis 1976, 2. Aufl., Marburg 1978, S. 30 f. 
die Finanzlage der ÖTV verbessern wolle, der müsse bereit sein, auch ganz neue Wege zu gehen. ${ }^{169}$

Zwar setzte sich diese Position letztlich gegen die Einwände der Bedenkenträger durch. Dennoch blieb die Zentralisierung der ÖTV-Verwaltung ein auf lange Sicht angelegtes Projekt. Die im Sommer 1967 gegründete "Abteilung Zentrale Datenverarbeitung« in Stuttgart übernahm zunächst nur die Beitragsabrechnung für die Kreisverwaltung Ludwigsburg-Waiblingen in Baden-Württemberg. Durch eine kontinuierliche Expansion sollten nach fünf bis maximal sieben Jahren etwa zwei Drittel der Mitglieder zentral erfasst werden. ${ }^{170}$

Eine eigene Computeranlage kaufte die ÖTV allein schon deshalb nicht, weil sie die hohen Anfangsinvestitionen nicht stemmen konnte. Sie verpflichtete daher zunächst IBM als Dienstleister und benutzte seit dem Sommer 1969 dann das Rechenzentrum der gewerkschaftlichen Bank für Gemeinwirtschaft. Finanziell erwies sich die neue Technik rasch als einträglich: Betrugen die Verwaltungskosten pro Mitglied bei den herkömmlichen Verwaltungsmethoden im Durchschnitt jährlich 13,32 DM, so schrumpfte dieser Betrag auf ein Drittel zusammen, wenn der Computer benutzt wur$\mathrm{de}$ - und weitere Einsparungen waren fast sicher zu erwarten, weil die Leistungsfähigkeit der elektronischen Geräte rasch zunahm. ${ }^{171}$ Nachrichten dieser Art konnte die hart geplagte Finanzabteilung der ÖTV gut gebrauchen.

In vielerlei Hinsicht hat die ÖTV also nach 1964 unter ihrem neuen Vorsitzenden einen Reformkurs eingeschlagen, um die Organisation zu stärken. Ein »schwerer Tanker« nahm damit wieder Fahrt auf - und das tat er zunächst immer noch mit Musik: 1968 wurde der Gewerkschaftstag, wie bislang alle Kongresse der ÖTV, erneut feierlich mit dem Auftritt eines Symphonieorchesters eröffnet. Mit der »Oberon«-Ouvertüre von Carl-Maria von Weber spielten die Musiker dieses Mal ein wesentlich schwungvolleres Stück, als 1964 mit dem »Air« von Bach auf dem Programm gestanden hatte. ${ }^{172} 1972$ allerdings brach die Verbandsleitung mit

169 | Referat von Heinz Kluncker »Das Zukunftsbild der ÖTV« für die Arbeitstagung des ÖTV-Bezirks Bayern, 10./12.2.1966. In: AdsD, Depositum Kluncker, Reden und Referate November 1964-September 1969.

170 | ÖTV-Geschäftsbericht 1964/67, S. 705-708.

171 | ÖTV-Geschäftsbericht 1968/71, S. $486 \mathrm{f}$.

172 | Protokoll ÖTV-GT 1968, Bd. 1, S. 10. 
dieser Tradition. Der Kongress begann nun ganz nüchtern, indem Heinz Kluncker an das Mikrophon trat und die Delegierten begrüßte. Man geht wohl nicht fehl, wenn man auch diesen Verzicht den von Heinz Kluncker angestoßenen Bemühungen zuordnet, die ÖTV moderner zu machen, als sie bislang gewesen war. ${ }^{173}$

\section{Nur ein Ritual? Einige allgemeine Bemerkungen zum strategischen Handeln in Tarifrunden}

\section{Das schlechte Image von Tarifverhandlungen}

Gewerkschaftliche Tarifpolitik vollzieht sich auf zwei Ebenen: intern als ein Prozess, in dem Forderungen formuliert und Verhandlungsergebnisse geprüft werden, sowie extern in Form von Verhandlungen mit den Arbeitgebern, den Partnern der Tarifverträge. Im Folgenden geht es vor allem um diese zweite Ebene, über die viele negative Urteile im Umlauf sind. Solche Beratungen galten (und gelten) vielfach als ein Ritual, das mit großem Aufwand jedes Jahr neu wieder zu vorhersehbaren Resultaten führt. In den 1960er und 1970er Jahren bezog sich diese Kritik vielfach expressis verbis gerade auf die Lohn- und Gehaltsrunden für den Öffentlichen Dienst.

Zumal langwierige Streitigkeiten, die sich über mehrere Runden erstreckten und erst in einer finalen Marathonsitzung endeten, firmierten in der Presse etwa als »Klamauk«, als »Theater« oder eben als sinnloses »Ritual«. An anderer Stelle finden sich Vergleiche mit einem Poker-Spiel, bei dem bekanntlich das "Bluffen« der Kontrahenten eine große Rolle spielt, oder auch mit Verhandlungen auf einem Bazar, bei denen mit allen nur denkbaren Finten und Tricks "gefeilscht« werde. ${ }^{174}$

173 | Mit diesem Verzicht auf die feierliche Kongress-Eröffnung mit klassischer Musik ging die ÖTV durchaus eigene Wege: Die IG Metall etwa hielt bis 1988 an einem klassischen Musikprogramm vor Kongressbeginn fest. Auf dem Gewerkschaftstag von 1992 trat dann erstmals eine Pop-Musik-Band auf.

174 | Wolfgang Krüger: Lohnpolitik ohne Klamauk. In: Die Zeit, 18.1.1963; »In der Liebe und im tariflosen Zustand ist alles erlaubt«. In: FAZ, 19.2.1975 (der Theater-Vergleich); Wozu der Unfug? In: Handelsblatt, 8.2.1982 (dito); Kurt Pentzlin: Die organisierte Unzufriedenheit. Eine »Rolle« der Gewerkschaften, Stuttgart 1973, S. 82 (hier die Formulierung vom »Ritual«); Klaus Müller-Münter: Tarifpoker beendet. In: StZ, 14.2.1974; Sieg der Vernunft. In: NRZ, 18.2.1975 (auch 
Ähnliche Vokabeln finden sich aber auch, wenn ganz allgemein von der Tarifautonomie die Rede ist. Auf einer wissenschaftlichen Tagung des renommierten "Vereins für Socialpolitik« etwa klagte einer der Diskussionsteilnehmer im Jahr 1968 über »das unwürdige Gesellschaftsspiel [...], das sich zwischen den Tarifparteien herausgebildet hat «: Erst nach langen und oft theatralisch inszenierten Streitigkeiten einigten sich Arbeitgeber und Gewerkschaften auf einen Kompromiss, der stets »ungefähr in der Mitte liege, und deshalb schon vor Verhandlungsbeginn problemlos zu erkennen gewesen sei. ${ }^{175}$ Fast zur gleichen Zeit konstatierte ein ehemaliges Vorstandsmitglied der IG Druck und Papier, in Deutschland gelte die Auseinandersetzung der Tarifparteien um Löhne und Arbeitsbedingungen allgemein als weitgehend sinnlose »Zeit- und Kraftvergeudung«; der Daimler-Benz-Manager Hanns-Martin Schleyer, ein wichtiger Mann in den Arbeitgeberverbänden, hatte schon einige Jahre zuvor geklagt, die Bundesbürger benutzten stets "Schlagworte vom orientalischen Teppichhandel«, wenn von Tarifverhandlungen die Rede sei. ${ }^{176}$

hier der Poker-Vergleich); Kraftprobe zwischen Schmidt und Kluncker. In: SZ, 15.1.1975 (dito); In der Klemme. In: Bonner Generalanzeiger, 17.2.1975 (dito); Wie Maihofer im Tarif-Poker gegen das Umfallen kämpft. In: Die Welt, 26./27.2.1977; Tarif-Poker wie eh und je. In: Saarbrücker Zeitung, 28.3.1980; Den Rückzug vorbereiten. In: Die Zeit, 9.4.1982 (mit der gleichen Formulierung); Arndt mahnt Gewerkschaft zur Vernunft. In: Handelsblatt, 9.10.1970 (der Bazar-Vergleich).

175 | Helmut Arndt (Hrsg.): Lohnpolitik und Einkommensverteilung. Verhandlungen auf der Tagung des Vereins für Socialpolitik, Gesellschaft für Wirtschaftsund Sozialwissenschaften, in Berlin 1968, Berlin 1969, S. 179. Zitiert wird hier ein Dr. Pentzlin. Er selbst präsentierte sich dem Kongress als jemand, der 40 Jahre »Lohnpolitik praktisch betrieben« habe, aber dennoch ein »Amateur« sei (ebd., S. 174). Wahrscheinlich handelt es sich um den Unternehmer Kurt Pentzlin, den Inhaber eines Maschinenbauunternehmens, der auch zu Fragen der technischen Rationalisierung und zu allgemeinen wirtschaftspolitischen Themen publizierte. Vgl. etwa die würdigenden Beiträge in: Burkhardt Huch/Carl Martin Dolezalek (Hrsg.): Angewandte Rationalisierung in der Unternehmenspraxis. Ausgewählte Beiträge zum 75. Geburtstag von Kurt Pentzlin, Düsseldorf und Wien 1978.

176 | Egon Lutz: Zwischen Kampf und Kooperation - Kritische Bemerkungen aus gewerkschaftlicher Sicht. In: Mühlbradt/Lutz: Zwang, S. 145-167, hier: S. 154; Hanns-Martin Schleyer: Tarifautonomie in der Praxis. In: Tarifautonomie in gesamtwirtschaftlicher Verantwortung. Geschäftsführerkonferenz der Deutschen Arbeitgeberverbände vom 4.-6. Juni 1964 in Berlin, Düsseldorf 1964, S. 16-29, 
Diese negative Sicht auf die praktizierte Tarifautonomie wird in der vorliegenden Literatur zur Gewerkschaftsgeschichte vollständig ignoriert, und auch in anderen Disziplinen wie etwa in der Soziologie und in den Wirtschaftswissenschaften, die sich mit den Aktionen von Gewerkschaften und deren Konsequenzen beschäftigten, gerät sie nicht in den Blick. ${ }^{177}$ Dabei gibt es meiner Meinung nach gute Gründe, genauer zu fragen, was hinter solchen abschätzigen Urteilen steht - gerade wenn man sich für Gewerkschaften und ihre Erfolge oder auch Misserfolge im Streit mit den Arbeitgebern interessiert.

Da Tarifverhandlungen in der Regel so verlaufen, dass Vertreter von Arbeitnehmern etwas von den Arbeitgebern fordern, das dann fast durchweg nur teilweise erfüllt wird, war es vor allem ihre Arbeit, die mit den zitierten negativen Begriffen kritisiert wurde. ${ }^{178}$ Zudem galten Tarifverhandlungen offensichtlich auch bei gestandenen Gewerkschaftern als ein

hier: S. 27. Egon Lutz war 1967 als geschäftsführendes Vorstandsmitglied der IG Druck ausgeschieden; seitdem arbeitete er als politischer Redakteur bei den »Nürnberger Nachrichten«.

177 | Als Beispiele für die bemerkenswerte Fähigkeit von modellhaft denkenden Soziologen und mathematisch arbeitenden Wirtschaftswissenschaftlern, Tarifverhandlungen so abstrakt zu behandeln, dass jeder konkrete ökonomische oder soziale Bezug fehlt, vgl. etwa: Bernhard Külp: Tarifverhandlungen: Strategie und Taktik. In: Arndt: Lohnpolitik, S. 157-173; ders.: Streik und Streikdrohung. Ihre Rolle in der Volkswirtschaft und im Sozialprozeß, Berlin 1969; Heinz-Dieter Harden/Hans Friedrichs: Das Collective-Bargaining-Modell von Pen. In: Wirtschaftswissenschaftliche Studien 11 (1982), S. 145-151; Walter B. Nelson/Gerald W. Stone/J. Michael Swint: An Economic Analysis of Public Sector Bargaining and Strike Activity. In: Journal of Labor Research 2 (1981), S. 77-98. Einen kritischen Überblick speziell für Tarifverhandlungen im Öffentlichen Dienst bietet: Lothar Pelz: Theorie und Empirie des Collective Bargaining und die Verdienstdynamik des öffentlichen Sektors, Oldenburg 1984 (Arbeitskreis Sozialwissenschaftliche Arbeitsmarktforschung, Arbeitspapier 1984/8).

178 | Zwar gewährt die Tarifautonomie selbstverständlich auch den Arbeitgebern die Freiheit, einen Tarifvertrag zu kündigen und für die neue Abmachung Lohnkürzungen zu verlangen. In den 1960er Jahren stellte dies aber nur noch eine historische Erinnerung dar; die Wahrscheinlichkeit, dass es noch einmal (wie in den Jahren der Weltwirtschaftskrise nach 1929) zu solchen Forderungen komme könne, galt wegen der optimistischen Konjunkturerwartungen allgemein als äuBerst gering. Konkret musste die ÖTV im hier untersuchten Zeitraum nur einmal 
unerfreuliches Geschäft. Entsprechende Äußerungen sind zwar nicht gerade zahlreich zu finden (vielleicht auch, weil sich bislang niemand die Mühe gemacht hat, systematisch danach zu suchen), aber doch aussagekräftig genug.

Auf dem Gewerkschaftstag der IG Druck etwa kritisierten im Jahr 1965 gleich mehrere Delegierte die Tatsache, dass die öffentlich genannten Forderungen der Gewerkschaft offensichtlich gar nicht ernst gemeint seien. "Entweder ist unsere Forderung gerechtfertigt oder sie ist nicht gerechtfertigt«, so formulierte es einer der Basisvertreter. Eine Organisation, die zwölf Prozent mehr Lohn verlange, dann aber 7,1 Prozent akzeptiere (wie die IG Druck es im Frühjahr 1965 getan hatte), handle »unwahr«. Einer seiner Kollegen schlug in die gleiche Kerbe: Wer zwölf Prozent als sein Ziel nenne, der solle für dieses Ergebnis kämpfen, anstatt geduldig mit den Arbeitgebern zu diskutieren, um dann fast auf die Hälfte seiner Forderung zu verzichten, wenn die andere Tarifpartei ihr Ausgangsangebot (4,5 Prozent) um 2,6 Prozent erhöhte: »Wir lassen mit uns 19 Stunden verhandeln. Ist das nicht schmählich? Ist das nicht schändlich? « ${ }^{179}$

Die oben zitierte Bemerkung von Adolph Kummernuss aus dem Jahr 1960, die ÖTV müsse mit einer 15-Prozent-Forderung in die Verhandlungen gehen, wenn sie zehn Prozent mehr Lohn durchsetzen wolle, und sein nachfolgender Satz, es sei »eine andere Sache", ob »uns dies schmeckt«, thematisierten das gleiche Problem, boten als Reaktion darauf aber nur ein resigniertes Achselzucken. ${ }^{180}$

Auf der eben schon erwähnten Tagung des "Vereins für Socialpolitik" von 1968 störte sich ein Funktionär der DAG an den »Fensterreden«, mit denen Arbeitgeber wie Gewerkschafter Tarifverhandlungen in die Länge zögen und an dem fehlenden »Mut«, den in der Regel doch recht einfach zu findenden Kompromiss auch zügig anzusteuern. Im Kern gehe es bei sol-

(bei der Tarifrunde 1981/82) auf eine solche Forderung (die sie als unerhörten Tabubruch empfand) reagieren. Siehe dazu genauer unten in Kapitel IV.

179 | In der Reihenfolge der Zitate: Protokoll des 7. Ordentlichen Gewerkschaftstages [der IG Druck und Papier] 1965, vom 26. September bis 2. Oktober 1965 in Berlin, Berlin o.J., S. 249 (der Delegierte Konrad Keller aus Neuwied) u. S. 250 (der Delegierte Franz Rotter aus Augsburg). Ähnlich auch noch der Delegierte Werner Hansen aus Hamburg (ebd., S. 256f.).

180 | Siehe oben S. 115. 
chen Streitigkeit gar nicht um die Sache, sondern für beide Seiten nur um die Frage: "Wie bekomme ich die Kuh vom Eis, ohne nach links und rechts das Gesicht zu verlieren. ${ }^{181} 1972$ schließlich rechtfertigte die Führung der IG Bau das von ihr nach wie vor verfolgte Konzept, die Tarifverhandlungen mit statistischen Daten »zu versachlichen« (das oben schon erwähnt wurde), mit dem Argument, Lohnpolitik solle und dürfe »kein raffiniertes Pokerspiel sein «. ${ }^{182}$ Fünf Jahre später berichtete eine Funktionärin der Gewerkschaft Nahrung - Genuss - Gaststätten, die zur Tarifkommission des Verbandes gehört hatte, im Rückblick, Tarifverhandlungen seien von ihr und ihren Kollegen »oft als ein slevantinischer Teppichhandek bezeichnet« worden. $^{183}$

Wenn selbst Gewerkschaftsfunktionäre und engagierte Verbandsmitglieder Tarifverhandlungen als ein so anrüchiges Geschäft ansahen oder gleich ganz an ihrem Sinn zweifelten, dann lohnt es sich im Rahmen einer Gewerkschaftsgeschichte, nach den Gründen für diese Abneigung zu fragen. In gewisser Hinsicht ist dies im Fall der ÖTV vielleicht sogar besonders sinnvoll, denn Heinz Kluncker kann fast als eine Art Kronzeuge für all jene gelten, die den Aushandlungsprozess von Tarifverträgen grundsätzlich für moralisch suspekt halten.

»Gauner betrügen einander nicht« - diesen Satz hat der ÖTV-Vorsitzende in internen Beratungen wohl im Herbst 1965 dem damaligen Bundesinnenminister Hermann Höcherl entgegengehalten. 1982 wurde dieser Ausspruch, der zuvor offensichtlich in Gewerkschaften und Parteien vielfach mündlich kolportiert wurde, durch einen Presseartikel öffentlich bekannt. Journalisten haben ihn danach gern zitiert, wenn es um Kluncker, die ÖTV und ihre Tarifverhandlungen ging. ${ }^{184}$

181 | Arndt: Lohnpolitik, S. 194f. (Herr Bormeister von der DAG).

182 | So der Vorsitzende Rudolf Sperner in: Protokoll über den 9. Ordentlichen Gewerkschaftstag der Industriegewerkschaft Bau - Steine - Erden für die Bundesrepublik Deutschland, Rheingoldhalle Mainz vom 25. bis 30. September 1972, Frankfurt/Main o.J., S. $72 \mathrm{f}$.

183 | Irmgard Tiemann: Mehr Frauen in die Tarifkommissionen. In: Frauen und Arbeit (1977), H. 2, S. 6-7, hier: S. 6. Die Autorin, die mittlerweile die Frauenabteilung im DGB-Landesbezirk Niedersachsen-Bremen leitete, äußerte zugleich, die Verhandlungen seien »heute« nicht mehr so stark taktisch geprägt »wie früher« (ebd.).

184 | Erika Mertens: Der Schreck in der Abendstunde. In: Die Zeit, 22.1.1982. 
Nun handelte es sich hierbei selbstverständlich um einen Scherz, der die Atmosphäre auflockern sollte und von Höcherl auch so verstanden wurde. ${ }^{185}$ Etliche der Vorgänger und Nachfolger des Ministers hätten wahrscheinlich anders reagiert. Selbst als spaßige Randbemerkung, die ein konkretes kommunikatives Ziel verfolgte, gehört der Satz von den Gaunern und ihrer speziellen Ehre - zumindest auf den ersten Blick - jedoch zu den oben zitierten negativen Wertungen der Tarifverhandlungen: Er setzt sie voraus und treibt sie auf die Spitze, um einen komischen Effekt zu erreichen. Allerdings lässt sich der Satz auch anders verstehen - nur muss man sich paradoxerweise von der grundsätzlich negativen Sicht lösen, Tarifverhandlungen seien ein »unwürdiges Gesellschaftsspiel«, um diesen verborgenen Sinn zu erkennen.

Im Kern störten sich die zitierten Kritiker der Tarifrunden, so scheint es mir, durchweg vor allem daran, dass diese Beratungen so stark strategisch geprägt sind: Die Gewerkschaften beginnen sie mit unrealistisch hohen Forderungen, und die Arbeitgeber antworten darauf mit ebenso unrealistisch niedrig angesetzten Angeboten, weil beide Seiten hoffen, so in der letztlich ausgehandelten Einigung »ungefähr in der Mitte einen Vorteil zu erringen.

Unter den vielen zitierten Metaphern für Tarifverhandlungen ist daher wohl der Vergleich mit dem, was zwischen Käufer und Verkäufer auf einem Bazar geschieht, noch am treffendsten: Auch diese Protagonisten ringen in einem "psychologischen Duell« um einen für beide Seiten akzeptablen ökonomischen Kompromiss und operieren dabei in einem dramatischen "Spiel der Über- und Unterbewertung« mit Offerten, die sie gar nicht ernst meinen, weil sie genau wissen, dass der Geschäftspartner darauf nicht eingehen wird (was beiden Seiten selbstverständlich durchweg bewusst ist). Dieses diskursive Aushandeln eines Vertrages durch "Feilschen" spielt in der stark geordneten Welt westlicher kapitalistischer Gesellschaften kaum

185 | Die beiden Männer verstanden sich offensichtlich persönlich sehr gut und blieben auch nach Höcherls Ausscheiden aus dem Amt des Innenministers freundschaftlich verbunden (Interview Walter Eberhardt, 14.12.2013). Nach den Angaben von Höcherls Biograf war auch Wirtschaftsminister Erhard anwesend, als der zitierte Satz fiel: Erhard sei so verärgert gewesen, »daß er den Saal verlassen hätte - wäre er nicht von Höcherl in seinen Sessel zurückgedrängt worden« (Reiner Vogel: Hermann Höcherl. Annäherungen an einen politischen Menschen, Regensburg 1988, S. 33). 
noch eine Rolle, obwohl es in vormoderner Zeit selbstverständlich auch in Europa den Alltag dominierte - und gerade in dieser Feststellung sehe ich einen sinnvollen Ansatz, um das schlechte Image von Tarifverhandlungen zu erklären. ${ }^{186}$

Thesenhaft und zunächst einmal sehr allgemein gesagt hat der moderne Kapitalismus gemeinsam mit dem modernen Verwaltungs- und Fürsorgestaat das freie Verhandeln weitgehend in ziemlich genau abgegrenzte soziale Segmente und Nischen abgedrängt. ${ }^{187} \mathrm{Da}$ es zunehmend nicht mehr gebraucht wurde, war der Weg frei, diese traditionsreiche soziale Interaktion falsch zu verstehen und sie als moralisch fragwürdig oder sogar als "fremd $«$ zu deklarieren. ${ }^{188}$

In Tarifverhandlungen aber wurde und wird "gefeilscht" - mit enormen ökonomischen und sozialen Folgen. Mitte der 1960er Jahre verhandelten Arbeitgeber und Gewerkschaften in der Bundesrepublik jedes Jahr neu über rund 5.000 Tarifverträge. Gemeinsam regelten diese Abmachungen die Löhne und Beschäftigungsbedingungen von fast 20 Millionen Arbeit-

186 | Laurence Fontaine: Bemerkungen zum Kaufen als soziale Praxis. Feilschen, Preise festlegen und Gütern ersteigern in frühneuzeitlichen Europa. In: Historische Anthropologie 14 (2006), S. 334-348, hier: S. 337.

187 | Für das »unternehmerische Selbst« blieb die Fähigkeit, eigene Interessen in freien Verhandlungen selbst zu verfechten, selbstverständlich zentral. Vgl. dazu grundlegend: Ulrich Bröckling: Das unternehmerische Selbst. Soziologie einer Subjektivierungsform, Frankfurt/Main 2007. Geradezu als Synonym für das »Feilschen« und dessen angeblich moralisch fragwürdiges Wesen diente vielfach der Viehhandel. Real spielte Vertrauen allerdings auch bei Verhandlungen in diesem speziellen ökonomischen Segment eine zentrale Rolle. Vgl. dazu ausführlich am konkreten Beispiel: Stefanie Fischer: Ökonomisches Vertrauen und antisemitische Gewalt. Jüdische Viehhändler in Mittelfranken 1919-1939, Göttingen 2014, insbes. S. 94-199.

188 | So beklagte etwa Fritz Paeplow, der Vorsitzende des sozialdemokratischen Bauarbeiterbundes, 1920 seine Rolle in Tarifverhandlungen u.a. auch mit den Worten, er müsse als Gewerkschafter in solchen Runden "ja leider immer noch so handeln wie der Jude, dass wir immer mehr fordern, als wir haben wollen«. Der Vergleich mit dem Bazar fällt im europäischen Kontext nicht ganz so diskriminierend aus, funktioniert aber doch nach demselben Schema. Das Zitat nach: Karl Christian Führer: Tarifbeziehungen und Tarifpolitik als Gegenstand der Geschichtswissenschaft. In: ders. (Hrsg.): Tarifbeziehungen und Tarifpolitik, S. 7-25, hier: S. 17. 
nehmern. Die gesamte Lohnsumme, um die es in den jährlichen Tarifrunden ging, überstieg 200 Milliarden DM. ${ }^{189}$

Das Unbehagen, das zum Ausdruck kommt, wenn Tarifstreitigkeiten als »Theater«, »Klamauk« oder auch als »Gesellschaftsspiel« bezeichnet werden, erwächst - so denke ich - aus der Spannung zwischen dieser großen Bedeutung des Geschehens und dem vormodernen Charakter der dabei benutzten Verhandlungsmethoden: Mit unseriösen Tricks, so mag es scheinen, werden in diesen Beratungen in einem irrationalen "Geschachere" Entscheidungen gefällt, die für die weitere Entwicklung der kapitalistischen Gesellschaft grundlegend wichtig sind.

\section{Kompromissfindung mit verschiedenen Akteuren. Wie Tarifverträge zustande kommen}

Dabei gibt es - nüchtern betrachtet - keinen Grund, das »Feilschen « für moralisch anrüchig zu halten. Kurz gesagt sind freie Verhandlungen, in denen rhetorisches Talent und strategisches Denken eine wichtige Rolle spielen können, auf allen Märkten unverzichtbar, auf denen nicht-standardisierte Waren gehandelt werden und Kunde wie Produzenten und Verkäufer nur über sehr lückenhafte Informationen verfügen. ${ }^{190}$

Anders als das negativ konnotierte deutsche Wort es suggeriert, geht es beim "Feilschen" in der vormodernen Gesellschaft nicht darum, den Partner »über den Tisch zu ziehen«. Das Verkaufsgespräch wird von beiden Seiten vielmehr in der Erwartung geführt, mit der konkret berede-

189 | Arndt: Lohnpolitik, S. 185. Vgl. auch: Bernhard Külp: Lohnbildung im Wechselspiel zwischen politischen und wirtschaftlichen Kräften, Berlin 1965, S. $340 \mathrm{f}$.

190 | Vgl. hierzu grundlegend: Clifford Geertz: Suq: The Bazar Economy in Sefrou. In: ders./Hildred Geertz/Lawrence Rosen: Meaning and Order in Marroccan Society, Cambridge/MA u.a.O. 1979, S. 123-244. Der Kaufinteressent verzichtet daher auf den (weitgehend aussichtslosen) Versuch, einen Marktüberblick zu gewinnen, und lotet seine Optionen stattdessen intensiv mit einem einzelnen Anbieter oder mit einer sehr begrenzten Zahl von Anbietern aus. Auf dem Bazar gibt es also keinen wirklich nennenswerten Wettbewerb zwischen den verschiedenen Produzenten oder den Verkäufern: Der »competitive stress" entfaltet sich vielmehr zwischen dem einzelnen Kunden und dem Händler, dem der Interessent gerade gegenübersitzt (ebd., S. 223). 
ten Transaktion eine dauerhafte Geschäftsbeziehung zu stiften oder fortzuschreiben: Bazarhandel fußt auf stabilen sozialen Beziehungen und auf dem unausgesprochenen Vertrauen, dass beide Verhandlungspartner bereit sind, die Kerninteressen der jeweils anderen Seite zu respektieren, obwohl sie versuchen, den eigenen Vorteil durchzusetzen. ${ }^{191}$ Klunckers Satz von den »Gaunern« und ihrer speziellen Ehre scheint mir - recht verstanden genau diesen Kodex zu postulieren.

Um Kompromisse durch ein gegenseitiges Geben und Nehmen zu erleichtern, geht es im Verkaufsgespräch auf dem Bazar typischerweise gleichzeitig um viele verschiedene Aspekte der angestrebten Abmachung. In dieser Form dient das freie Verhandeln beiden Seiten: Es macht Geschäfte auf einem Markt möglich, der wegen der fehlenden Normierung der gehandelten Waren und der Geschäftsbedingungen ansonsten von Misstrauen und Unsicherheit gelähmt würde. ${ }^{192}$

Diese kurze Skizze enthält indirekt bereits die Erklärung, warum das »Feilschen« in modernen westlichen Gesellschaften kaum noch alltagsrelevant ist: Standarisierung, Normierung und eine immer genauer werdende Verrechtlichung des sozialen Lebens gehören zu den Grundprozessen, die den Siegeszug der kapitalistischen Wirtschaftsweise, die das jeweilige Verhältnis von Kunden und Verkäufern zunehmend unpersönlich gestaltet, ermöglicht und vorangetrieben haben. Details sind an dieser Stelle entbehrlich. Wichtig ist nur das Resultat: Moderne Märkte sind eben keine "Welt des Ungefähren« mehr, sondern weitgehend vereinheitlicht, transparent (bzw.: zur Transparenz verpflichtet), rechtlich exakt kodifiziert und damit weitgehend rational berechenbar. ${ }^{193}$

191 | Ebd., S. 217-219 u. 260f. Daraus ergibt sich allerdings zwingend, dass Außenseiter - wie etwa Auswärtige und Reisende aus anderen Ländern - als Kunden auf dem Bazar strukturell massiv benachteiligt sind.

192 | Geertz spricht von einem "multidimensional character« der Verhandlungen (ebd., S. 223). Sie beziehen sich also nicht nur auf den Preis, sondern auch auf alle überhaupt nur denkbaren Konditionen der Lieferung sowie vor allem auch auf die Zahlungsbedingungen. Deshalb wird der Kauf fast immer durch einen Kredit des Verkäufers finanziert.

193 | Fontaine: Bemerkungen, S. 334. Der hoch komplexe Prozess der Warenund Marktnormierung als Teil der europäischen Modernisierungsgeschichte bleibt historiographisch noch darzustellen. Einige grundlegende Bemerkungen dazu finden sich etwa schon in: Max Weber: Wirtschaft und Gesellschaft. Sozio- 
Spätestens seit Beginn des 20. Jahrhunderts sorgten in Deutschland auch die Gewerkschaften dafür, dass persönlich geführte Verhandlungen um den eigenen Vorteil gesellschaftlich immer seltener wurden. Die Tarifverträge, für die sie stritten (und die sie zumindest in einigen Branchen auch schon vor 1914 durchsetzen konnten), befreiten Arbeitnehmer von dem Zwang, den Preis für ihre Arbeitskraft selbst zu vereinbaren, bzw. sie ermöglichten es ihnen, nur noch über individuelle Abweichungen »nach oben « zu verhandeln. ${ }^{194}$ Seit dem November 1918 garantierte der deutsche Staat die Kollektivverträge, die Gewerkschaften und Arbeitgeberverbände aushandelten. Gleichzeitig schuf er mit der »Allgemeinverbindlichkeitserklärung« sogar die Möglichkeit, auch Unternehmer auf die Tariflöne zu verpflichten, die keiner Arbeitgebervereinigung angehörten. ${ }^{195}$

logie. Unvollendet 1919-1920. Hrsg. v. Knut Borchardt/Edith Hanke/Wolfgang Schluchter, Tübingen 2013 (Max Weber-Gesamtausgabe I/23), S. 627 f. Vgl. auch (mit einem Fokus auf Globalisierungsprozesse): Jürgen Osterhammel: Die Verwandlung der Welt. Eine Geschichte des 19. Jahrhunderts, München 2009, S. 1012-1055. Aus wirtschaftswissenschaftlicher Sicht vgl. grundlegend etwa: Hubert Menze: Markttransparenz in Theorie und Wettbewerbsrecht. In: Wirtschaft und Wettbewerb 13 (1963), S. 578-590; Arno Sölter: Der unvollständige Wettbewerbsbegriff. Zur Bedeutung von Markttransparenz und Marktinformationsverfahren für den Wettbewerbsprozess, Heidelberg 1975.

194 | Vgl. grundlegend: Thilo Ramm: Die Parteien des Tarifvertrags, Stuttgart 1961. Konkret zur Tarifsituation vor 1914 vgl.: Klaus Schönhoven: Arbeitskonflikte in Konjunktur und Rezension. Gewerkschaftliche Streikpolitik und Streikverhalten der Arbeiterschaft vor 1914. In: ders.: Arbeiterbewegung und soziale Demokratie in Deutschland. Ausgewählte Beiträge. Hrsg. v. Hans-Jochen Vogel/ Michael Ruck, Bonn 2002, S. 165-182, hier: S. 168-172.

195 | Vgl. dazu etwa am Beispiel der Chemieindustrie: Werner Plumpe: Tarifsystem und innerbetriebliche Konflikte in der Weimarer Republik. In: Karl Christian Führer (Hrsg.): Tarifbeziehungen und Tarifpolitik in Deutschland im historischen Wandel, Bonn 2004, S. 26-63; zur "Allgemeinverbindlichkeitsverklärung«, deren Bedeutung in der Weimarer Republik in der Literatur massiv unterschätzt wird, vgl. einige Angaben in: Karl Christian Führer: Von der Selbstbestimmung der Tarifparteien zur staatlichen Verantwortung für die Lohnbildung. Das tarifliche Schlichtungswesen des Baugewerbes in der Weimarer Republik 1924-1932. In: ebd., S. 64-113, hier: S. 98-110. Kurz gesagt konnte das Arbeitsministerium die Allgemeinverbindlichkeit auf Antrag der Tarifparteien verfügen, wenn der in Rede stehende Tarifvertrag mehr als 50 Prozent der Arbeitnehmer der jeweili- 
Dank der gesetzlich abgesicherten Tarifautonomie fügte sich somit auch der Arbeitsmarkt in den allgemeinen gesellschaftlichen Trend, die ökonomische Sphäre möglichst transparent, geordnet und exakt berechenbar zu gestalten. Bei den Tarifverhandlungen, auf kollektiver Ebene, aber blieb das "Feilschen« wichtig. Wenn dies als irritierend und fragwürdig wahrgenommen wurde, so zeigt sich daran nur, wie weitgehend das rationalisierte und reglementierte Wesen moderner wirtschaftlicher und sozialer Beziehungen als selbstverständlich und »normal« galt.

Verabschiedet man sich von darin enthaltenen, nicht explizit gemachten moralischen Wertungen, dann hilft das Bild vom Bazar, auf dem "gefeilscht« wird, jedenfalls durchaus dabei, Tarifverhandlungen ganz allgemein und auch speziell für den Öffentlichen Dienst genauer zu beschreiben und zu verstehen - gerade auch deshalb, weil die Metapher (wie fast alle Vergleiche) bei bestimmten Aspekten nicht mehr funktioniert. Auf einige dieser Ähnlichkeiten und Abweichungen möchte ich im Folgenden kurz hinweisen.

Frei verhandelt wird bei Tarifverhandlungen, weil beide Parteien - ähnlich wie Käufer und Verkäufer auf dem Bazar, wie er auch heute noch etwa in der arabischen Welt existiert - nur über unsichere und unvollständige Informationen verfügen: Sie reden ja über die Zukunft, denn Tarifverträge legen die Löhne und Arbeitsbedingungen jeweils prospektiv, aber doch bindend fest, meist für zwölf Monate bei der Bezahlung, teilweise auch für deutlich längere Zeiträume bei Manteltarifverträgen, die grundsätzliche Fragen des Beschäftigungsverhältnisses regeln. Die Arbeitgeber »kaufen« sich dabei kalkulatorische Sicherheit für die Laufzeit des Vertrages und Schutz vor Streiks, indem sie den Beschäftigten einen fixen Anteil an dem prognostizierten wirtschaftlichen Zuwachs zusagen.

Allerdings gibt es bei diesen Beratungen keine vollständige Freiheit der Akteure. Spätestens seit dem Erlass der Tarifvertragsverordnung im Dezember 1918, die das Prinzip der Tarifautonomie in Deutschland rechtlich zweifelsfrei etablierte, können die Verhandlungen von Arbeitgebern und Gewerkschaften als ein Musterbeispiel der »regulierten Selbstregulierung« gelten. Dieser Begriff mag sperrig klingen; er ist aber doch hilfreich, um das Geschehen systematisch zu erfassen. In Bereichen der regulierten Selbstregulation verzichtet der Staat auf konkrete Entscheidungskompetenzen und delegiert

gen Branche oder der Region erfasste. »Tarifflucht« einzelner Unternehmer wurde dann juristisch unzulässig. 
sie an nichtstaatliche Institutionen, fixiert per Gesetz oder in Verordnungen gleichzeitig aber den Rahmen, in dem diese Organisationen und Gremien zu handeln haben, und das Prozedere ihrer Auseinandersetzungen. ${ }^{196}$

Darüber hinaus wirken die Gerichte darauf ein, wie Arbeitgeber und Gewerkschaften miteinander umgehen. Vor allem die Fragen, wer unter welchen Voraussetzungen mit welchen Methoden wie intensiv streiken darf und wie die Arbeitgeber darauf reagieren dürfen, können juristisch geprüft und entschieden werden. Dabei spielt auch die Auslegung nicht exakt definierter Begriffe eine wichtige Rolle. Zudem regeln die Gewerkschaften diese für sie zentral wichtigen Entscheidungen sehr genau in ihren eigenen Satzungen. ${ }^{197}$ So sind die Kontrahenten in Tarifverhandlungen bei ihren Beschlüssen vielfältig gebunden. Kündigungsfristen und die Friedenspflicht bei einem noch laufenden Vertrag müssen gewahrt werden; bei Arbeitskampfmaßnahmen ist jeweils zu prüfen, ob sie juristisch zulässig sind und auch satzungsgemäß beschlossen wurden.

Für den Inhalt ausgehandelter Verträge aber sind allein die letztlich unterzeichnenden Parteien zuständig. Insofern genießen sie eben doch groBe Freiheiten. ${ }^{198}$ Das rhetorische "Spiel der Über- und Unterbewertung«, das die Verhandlungspartner bei solchen Beratungen inszenieren, bezieht sich bei Tarifverhandlungen im Kern auf die Zukunft und nur vermittelt auf Gegenwart und Vergangenheit (weil diese selbstverständlich die Prognose prägen). Grundsätzlich tendieren die Vertreter der Gewerkschaften bei diesem »Spiel« dazu, im Interesse ihrer Mitglieder von maximal positi-

196 | Vgl. dazu grundlegend etwa: Hansjörg Weitbrecht: Effektivität und Legitimität der Tarifautonomie. Eine soziologische Untersuchung am Beispiel der deutschen Metallindustrie, Berlin 1969; Gerd Bender: Tarifautonomie, Regulierte Selbstregulation, Korporatismus. Eine Skizze. In: Peter Collin et al. (Hrsg.): Regulierte Selbstorganisation im frühen Interventions- und Sozialstaat, Frankfurt/ Main 2012, S. 53-67.

197 | Zur deutschen Streik-Rechtsprechung nach 1945 vgl. als Überblick: Michael Kittner: Arbeitskampf. Geschichte, Recht, Gegenwart, München 2005, insbes. S. 596-629; zu den gewerkschaftlichen Regelungen vgl. etwa: ebd., S. 629-647.

198 | Gesetzliche Regelungen gelten dabei selbstverständlich genauso wie bei allen anderen Vertragsabschlüssen. Als ein Beispiel lässt sich etwa anführen, dass Tarifverträge, die einen "closed shop" schaffen, in Deutschland rechtlich nicht zulässig sind, weil solche Abmachungen u.a. als Verstoß gegen das Grundrecht der Koalitionsfreiheit gelten. Siehe dazu oben S. 44. 
ven Entwicklungen auszugehen, um sich dann schrittweise auf realistischere Werte »herunterhandeln« zu lassen. ${ }^{199}$ Spiegelbildlich scheint das dem Beginn eines Verkaufsgesprächs auf dem Bazar zu entsprechen. ${ }^{200}$

Gerade in diesem Punkt hilft der Vergleich allerdings doch nur begrenzt weiter: Eine Gewerkschaft, die Tarifverhandlungen beginnt, indem sie ihre Forderungen formuliert, verfügt keineswegs über jene Freiheit, auch mit willkürlich oder vielleicht sogar provokativ gewählten Zahlen zu operieren, die Händler auf dem Bazar besitzen. Zwar existiert die populäre Vorstellung, Gewerkschaftsarbeit sei eigentlich ganz einfach: Sie erschöpfe sich darin, "mehr« zu verlangen. ${ }^{201}$ Tatsächlich ist die Sache jedoch deutlich komplizierter. Vor der Großen Tarifkommission der ÖTV hat Heinz Kluncker im Jahr 1969 die Anforderungen aufgelistet, die an sinnvolle Tarifforderungen zu stellen seien: Sie müssten »den Erwartungen der Mitglieder entsprechen, sie müssen für die Betroffenen überschaubar sein, sie müssen in der öffentlichen Auseinandersetzung darstellbar und vor allem realisierbar sein«. Ausdrücklich warnte der Vorsitzende vor gut klingenden Maximalforderungen: Gemessen werde die ÖTV von ihren Mitgliedern wie von der Öffentlichkeit »nicht an der Höhe der Forderungen, sondern an den Ergebnissen. Und dabei spielt auch die Spanne zwischen Forderung und Ergebnis eine Rolle. ${ }^{202}$

199 | Vgl. etwa die Angaben eines Tarifexperten der IG Metall (Dipl.-Volkswirt Schmidt): Arndt: Lohnpolitik, S. $188 \mathrm{f}$.

200 | Spiegelbildlich, weil auf dem Bazar das erste Gebot nach den ungeschriebenen sozialen Gesetzen dieses Marktes stets vom Kaufinteressenten kommt - das dementsprechend so niedrig wie möglich angesetzt wird. Erst dann nennt der Verkäufer den Preis, den er (angeblich) verlangt. Vgl. Geertz: Suq, S. 227.

201 | Der legendäre US-amerikanische Gewerkschaftsführer Samuel Gompers, Vorsitzender des Dachverbandes »American Federation of Labor« von 1886 bis 1924, hat die Tätigkeit von Gewerkschaften und ihren Funktionären tatsächlich einmal so definiert. Das vollständige Zitat (aus einer Rede in Louisville vom Mai 1890) lautet: »We do want more, and when it becomes more, we shall still want more. [...] And we shall never cease to demand more until we have received the results of our labor." (Samuel Gompers: The Samuel Gompers Papers. Vol. 2: The Early Years of the American Federation of Labor, 1887-90. Edited by Stuart B. Kaufman, Urbana and Chicago 1987, S. 313)

202 | Protokoll der Sitzung der GTK, 4.12.1969. In: AdsD, Depositum Kluncker, Reden und Referate November 1969-Februar 1972. 
Vor allem dieser komplizierte und kaum systematisch zu fassende Außenbezug, der in verschiedener Form Rücksichtnahme erzwingt, unterscheidet das "Feilschen" der Tarifunterhändler von der »reinen" Form solcher Verhandlungen auf dem Bazar, bei der beide Parteien jeweils nur für sich selbst und ganz direkt in eigener Sache agieren. Schon die Abstimmung mit der jeweils »eigenen« Klientel ist kompliziert genug. Nach den Worten Hermann Höcherls befindet sich ein Unterhändler bei Tarifverhandlungen durchweg mindestens »in doppelter Frontstellung«: Beide Seiten müssen eben nicht nur den Tarifpartner im Auge behalten, sondern sich bei taktischen Entscheidungen auch »nach innen « absichern. ${ }^{203}$

Konkret brauchte Heinz Kluncker als Verhandlungsführer der ÖTV stets ein positives Votum der Großen Tarifkommission, in der mehr als einhundert vornehmlich ehrenamtliche Funktionäre saßen, bevor er Abstriche an den ursprünglichen Forderungen des Verbandes verbindlich zusagen konnte. Um die Beratungen zu beschleunigen, gab es zusätzlich noch eine »Verhandlungskommission« mit nur 16 Mitgliedern, in der vorläufige Abstimmungen stattfanden. Darin waren - anders als in der Große Tarifkommission - alle Bezirke der ÖTV gleichberechtigt mit je einer Stimme vertreten. Ein positives Votum der »Verhandlungskommission« bedeutete daher keineswegs zwingend ein gleiches Ergebnis auch in dem größeren Gremium, das von den kopfstarken Bezirken der Organisation dominiert wurde. ${ }^{204}$ Bei den Arbeitgebern mussten Bund, Länder und Gemeinden ihre keineswegs einheitlichen Interessen so weit auf einen Nenner bringen, dass sie gemeinsam auftreten konnten. Ging es um Kompromisse, entstand in diesen drei Delegationen zudem rasch die Notwendigkeit, sich zusätzlich intern neu zu beraten. ${ }^{205}$

Gerade in ihrer Endphase verliefen Tarifverhandlungen für den Öffentlichen Dienst daher typischerweise nach dem »Stop-and-go«-Prinzip: Beratungen in paritätisch besetzten kleineren Gremien oder im engsten Kreis der wichtigsten Männer beider Seiten wurden mehrfach unterbrochen, um den Tarifparteien die Möglichkeit zu geben, sich den jeweils aktuel-

203 | Zit. nach: Vogel: Höcherl, S. 33.

204 | Beschlussprotokoll der Sitzung der GTK, 30.5.1967. In: Archiv Ver.di, Bestand Kluncker, 12. Neben den Vertretern der zwölf Bezirke saßen in der »Verhandlungskommission « noch vier Mitglieder des Hauptvorstandes.

$205 \mid \mathrm{Zu}$ diesen Interessengegensätzen siehe schon oben Kapitel I. 
len Verhandlungsstand erst einmal »innen« absegnen zu lassen. ${ }^{206}$ Zählt man die Beteiligten auf beiden Seiten zusammen, so waren in den 1960er und 1970er Jahren in der Schlussphase von Tarifverhandlungen für den Öffentlichen Dienst insgesamt fast 300 Personen mit jeweils sehr unterschiedlichen Rechten und Aufgaben an diesen Abstimmungen beteiligt, weil durchweg gleichzeitig für Bund, Länder und Gemeinden verhandelt wurde. ${ }^{207}$

Die gewerkschaftliche Basis konnte auch in solchen Endrunden durchaus noch sehr präsent sein: Zumindest bei kontrovers verlaufenden Verhandlungen versuchten häufig einzelne Gliederungen der ÖTV auch noch in letzter Minute, mit Telefonanrufen und Telegrammen auf die Tarifkommission und auf die Verbandsführung einzuwirken. In der Regel erhoben sie in solchen Einreden die Forderung, »hart zu bleiben ${ }^{208}$

Die Frage, wann welche Informationen über den Verlauf der Beratungen jeweils der »eigenen Seite« mitgeteilt wurden, gehörte daher zu den strategisch wichtigsten Entscheidungen, über die der enge Kreis der Verhandlungsführer befinden musste. Monika Wulf-Mathies, die 1982 zur Nachfolgerin Heinz Klunckers wurde und die auch dessen Rolle in den Tarifverhandlungen der ÖTV übernahm, formuliert dies im Rückblick so: »Sie führen auch Tarifverhandlungen mit der eigenen Kommission und

206 | Um ein konkretes Beispiel zu nennen: In der Tarifrunde für den Öffentlichen Dienst 1968/69 wurde die fünfte (und vorletzte) Verhandlungsrunde, die vom 17. Januar, 11 Uhr vormittags, bis zum 18. Januar, 4 Uhr 35 morgens, dauerte, insgesamt dreimal für längere separate Besprechungen unterbrochen. Die GTK beriet dabei etwa von 1 Uhr 15 bis 3 Uhr morgens offensichtlich sehr kontrovers allein darüber, ob die Angebote der Arbeitgeber eine ausreichende Basis für weitere Verhandlungen böten (Bericht des Tarifsekretariats über die Tarifvertragsverhandlungen, 17./18.1.1969. In: Archiv Ver.di, Bestand Kluncker, 13).

207 | Ralf Krumsiek: Alle Jahre wieder. In: Der Städtetag 31 (1978), S. 332-335, hier: S. 323. Krumsiek nahm seit 1969 für die VKA an den Tarifverhandlungen für den Öffentlichen Dienst teil; seit 1975 war er deren Verhandlungsführer.

208 | Siehe dazu beispielhaft: Zweikampf zwischen Klett und Kluncker. In: StZ, 26.9.1969, sowie auch die Ausführungen zum Streik im Februar 1974 in Kapitel III. Die Möglichkeit einer »Inszenierung« ist selbstverständlich nicht von der Hand zu weisen, d. h. auch der Druck »von außen« mag mit der Gewerkschaftsführung abgesprochen sein. Diese Unsicherheit zeigt einmal mehr, wie problematisch es ist, das Handlungsgefüge von Tarifverhandlungen zu schematisieren. 
müssen die Mitglieder von den Träumen über wunderbare Ergebnisse langsam in die Realität zurückholen.« Die Rücksprache mit den Vertretern der Basis war daher genau zu überlegen: Deutete sich die Möglichkeit an, mit den Arbeitgebern eine ausgewogene Gesamtlösung zu erreichen, dann »hat man eher Zwischenschritte vermieden, die Nervosität hätten verursachen können. Wenn man den Arbeitgebern zeigen wollte, das geht gar nicht, da gibt's Ärger, dann hat man das auch in der Großen Tarifkommission entsprechend kommuniziert. ${ }^{209}$

Dazu kommt noch eine weitere Dimension des Außenbezugs speziell von Tarifverhandlungen für den Öffentlichen Dienst: In diesem Segment der Arbeitswelt geht es keineswegs zwingend so zentral oder ausschließlich um die ökonomischen Interessen der Tarifpartner wie bei Lohnverhandlungen in der Privatindustrie. Wird für die Beschäftigten des Staates verhandelt, so übernehmen Politiker die Rolle der Arbeitgeber, die nur als Mitglied einer gewählten politischen Führung in diese Position gekommen sind. Anders als Unternehmer (oder deren professionelle Vertreter in den Arbeitgeberverbänden), die jeweils direkt "pro domo " handeln, verfolgen diese politischen Würdenträger nicht nur ökonomische und betriebswirtschaftliche Ziele. Sie haben vielmehr zugleich - oder vielleicht sogar: vor allem - eine politische Agenda und stehen bei den Wählern sowie bei der Partei im Wort, der sie angehören. Auch mit den Medien müssen sie zurecht kommen. Dieser indirekte, zugleich aber doch sehr starke Außenbezug konnte eine Einigung der Verhandlungspartner sowohl erheblich erschweren als auch beschleunigen. ${ }^{210}$

Besonders deutlich wird dieser Zusammenhang, wenn ein Streik droht. Im Öffentlichen Dienst hat dieses stärkste Kampfmittel einer Gewerkschaft nicht ganz den gleichen Charakter wie bei Tarifstreitigkeiten in Industrie und Gewerbe. In der Privatwirtschaft verlieren Unternehmer unmittelbar Geld, wenn die Beschäftigten ihre Arbeit niederlegen. Bei einem längeren Ausstand können produzierende Betriebe Lieferverträge nicht einhalten, was Kunden verärgert und auf Dauer vertreiben kann. In der Industrie führen Gewerkschaften und Arbeitgeber bei Streiks (und auch bei Aus-

209 | Interview Monika Wulf-Mathies, 7.4.2015.

210 | Das Musterbeispiel dafür bietet nach wie vor die Tarifrunde für den Öffentlichen Dienst von 1973/74, die in dem ÖTV-Streik gipfelte. Siehe dazu ausführlich Kapitel III. 
sperrungen durch die Unternehmer) ihren Streit daher letztlich nur noch mit wirtschaftlichen Mitteln: Es geht um die Frage, ob ein Ausstand für die Unternehmer so »teuer" sein kann, dass sie die bislang abgelehnten gewerkschaftlichen Forderungen trotz der langfristigen ökonomischen Folgen als das kleinere Übel akzeptieren. Zwangsläufig wird dieses Spiel auch mit sehr hohen Einsätzen gespielt, weil die Gewerkschaften nur so hoffen können, mit einer kurzfristigen Kampfmaßnahme langfristig weiterwirkende Zugeständnisse zu erringen. ${ }^{211}$

Arbeitsniederlegungen in einem Ministerium oder einer anderen Behörde verursachen demgegenüber zunächst einmal überhaupt keinen präzise zu benennenden wirtschaftlichen Schaden, weil sich der »Betriebszweck« ökonomisch gar nicht oder allenfalls sehr grob messen lässt. ${ }^{212}$ Auch bei öffentlichen Versorgungsunternehmen haben Streiks nicht die gleichen Konsequenzen wie bei Privatfirmen, die ohne regelmäßigen Absatz nicht existieren können: Als Monopolbetriebe müssen sie keine Abwanderung verärgerter Kunden fürchten; vielfach laufen ihre Einnahmen auch dann weitgehend unverändert weiter, wenn sie die Produktion deutlich drosseln. Wegen der fehlenden Konkurrenz können sie steigende Arbeitskosten

211 | Vgl. als ein Beispiel den Streik (mit nachfolgender Aussperrung) in der baden-württembergischen Metallindustrie im März 1978: Er verursachte einen Lohnausfall von 450 Millionen DM, einen Umsatzausfall von geschätzt 4,5 Milliarden DM (aus dem sich dann ein Steuerausfall von ebenfalls geschätzten 390 Millionen DM ergab). Die IG Metall zahlte 130 Millionen DM Streikunterstützung; die drei beteiligten Arbeitgeberverbände unterstützten bestreikte und aussperrende Betriebe mit 252 Millionen DM aus ihren Arbeitskampffonds. Alle Zahlen aus: Florian Schilling: Der Einigungsprozess bei Tarifverhandlungen. Eine Darstellung am Beispiel der Tarifrunde 1978 in der bundesdeutschen Metallindustrie, Berlin 1984, S. 86.

212 | Dies galt zumal in der hier untersuchten Periode, in der betriebswirtschaftliche Methoden zur Kostenkontrolle, die auch Verwaltungsvorgänge ökonomisch zu bewerten versuchen, noch unbekannt waren. Vgl. zum Beginn dieser konsequenten Ökonomisierung auch des Öffentlichen Dienstes in der Bundesrepublik, der sich auf die späten 1980er Jahre datieren lässt, etwa die Beiträge in: Jürgen Weber/Otto Tylkowski (Hrsg.): Controlling - eine Chance für öffentliche Unternehmen und Verwaltung, Stuttgart 1988. 
zudem relativ einfach und gefahrlos durch Preiserhöhungen ausgleichen. Dafür braucht es »nur« das Plazet der zuständigen politischen Gremien. ${ }^{213}$

Gleichzeitig aber tangieren solche Arbeitsniederlegungen in öffentlichen Dienstleistungsbetrieben den Alltag der Bürger ganz unmittelbar. Damit geht es kurzfristig ganz konkret um »Ordnung« und die Fähigkeit von Ministern und/oder Bürgermeistern, diese zu sichern; längerfristig geht es auch um die Preise, die von den Bürgern für öffentlich erbrachte Dienstleistungen gefordert werden, und um die Verantwortung, die Politiker dafür tragen - das heißt, es geht auf doppelte Weise um Politik. Dieser besondere Zusammenhang kann für die Tarifstrategie der öffentlichen Arbeitgeber so unterschiedliche Folgen haben, dass ein Versuch, Generalisierungen zu formulieren, meiner Meinung nach nur untaugliche Resultate liefern kann. ${ }^{214}$

Festzuhalten ist jedoch der spezielle, oft stark und vielschichtig politisch geprägte Charakter speziell von Tarifverhandlungen für den Öffent-

213 | Zusammenfassend zu der vergleichsweise guten ökonomischen Position von öffentlichen Versorgungsbetrieben bei Streiks vgl. etwa: Berndt Keller: Lohnbestimmung im öffentlichen Dienst. In: Hans-Georg Wehling (Hrsg.): Arbeitskonflikte in der Bundesrepublik. Fachwissenschaftliche Analysen, Unterrichtsempfehlungen, Opladen 1978, S. 44-52, hier: S. 45 f. Wegen der Notdienste, denen die ÖTV zustimmte, kam eine völlige Stilllegung im hier untersuchten Zeitraum gar nicht vor. Lediglich Verkehrsbetriebe, die vor allem Einzelfahrkarten verkaufen, sind durch einen Streik unmittelbar ökonomisch zu treffen. Ansonsten sinken die Einnahmen wegen der üblichen langfristigen Lieferverträge (mit Monatszahlungen der Kunden) nur geringfügig. Erinnert sei an die Hamburger Wasserwerke, die beim Streik der ÖTV 1954 während der Arbeitsniederlegung einen zusätzlichen Gewinn verzeichneten, weil sie die hohen Personalkosten sparten. Siehe oben S. 66.

214 | Vgl. als unzulänglichen Versuch in dieser Richtung etwa: Berndt Keller: Arbeitsbeziehungen im öffentlichen Dienst. Tarifpolitik der Gewerkschaften und Interessenpolitik der Beamtenverbände, Frankfurt/Main und New York 1983, insbes. S. 255-284. In dieser rein modellhaften Argumentation bleibt etwa die Möglichkeit, dass ein Politiker bei Streiks gerade deshalb »hart« bleibt, um Wähler zu binden, völlig unberücksichtigt. Dabei können Politiker wie Margaret Thatcher (seit Mai 1979 britische Premierministerin) und François Mitterrand (seit Mai 1981 französischer Präsident) als fast zeitgleiche Extrembeispiele dafür dienen, wie stark politische Programme das konkrete Verhalten in Tarifstreitigkeiten für den Öffentlichen Dienst und in Gewerkschaftsangelegenheiten allgemein prägen können. 
lichen Dienst. Wenn ein Kompromiss bei Tarifstreitigkeiten (wie im Verkaufsgespräch auf dem unreglementierten Bazar) immer beiden Seiten die Möglichkeit geben muss, selbst dann »ihr Gesicht zu wahren«, wenn sie nachgeben, dann muss dieser Prozess zwangsläufig umso komplexer und unberechenbarer werden, je stärker es dabei nicht nur um ökonomische Interessen geht.

Möglichkeiten, Kompromisse zu schließen, um einen neuen Tarifvertrag möglich zu machen, gab es zwar viele. Tarifverhandlungen waren (und sind) in der Regel multidimensionale Verhandlungen: Es geht dabei stets um viele Bestimmungen gleichzeitig, da diese Abmachungen seit ihrer Erfindung im späten 19. Jahrhundert im Laufe der Zeit immer detaillierter und genauer wurden. ${ }^{215}$ In dieser Beziehung funktioniert der Vergleich mit Verhandlungen auf dem Bazar wieder sehr gut, denn auch dort wird ja stets »multidimensional« beraten.

Allerdings handelt es sich bei Tarifverträgen vielfach um eine so komplexe und unübersichtliche Materie, dass die schiere Fülle der potenziellen "Stellschrauben« eine Einigung vermutlich eher erschwert als erleichtert. Ein Beispiel mag genügen, um das Problem zu illustrieren: In der Tarifrunde für den Öffentlichen Dienst von 1968/69 verhandelte die ÖTV eben nicht nur über eine allgemeine Lohn- und Gehaltserhöhung von acht Prozent (das darauf antwortende Angebot der Arbeitgeber betrug vier Prozent). Gleichzeitig ging es auch noch um die Höhe der Zuschläge für Überstunden, für Bereitschaftsdienste und erschwerte Arbeiten (die für Arbeiter und Angestellte jeweils getrennt geregelt waren), um die Dienstalterszulagen (sie gab es in fünf Stufen, ebenfalls separat für Arbeiter und Angestellte) sowie um eine Abstufung des Sozialzuschlages (der in den verschiedenen Ortsklassen unterschiedlich hoch bemessen war) je nach der Kinderzahl sowie darüber hinaus auch noch um die »Lohngruppenspannen « zwischen beruflich verschieden qualifizierten Personengruppen der beim Staat be-

215 | Schon in der Weimarer Republik konstatierte ein Experte, Tarifverträge seien in Deutschland mittlerweile so "fein ausgebaut" und "bis ins letzte durchdachte Instrumente zur Regelung der Arbeitsbedingungen, dass sie nur noch in "minuziöser und angespannter Arbeit" neu auszuhandeln seien (Richard Sternberg-Raasch: Die Bedeutung der Kommunen als Arbeitgeber und ihre besonderen Probleme, Berlin 1928, S. 11). 
schäftigten Arbeiter. ${ }^{216}$ Nur »ausgezeichnete Kenner« der Materie konnten bei solchen Beratungen sinnvoll mitreden. ${ }^{217}$

Die Öffentlichkeit nahm diese Komplexität jedoch nicht zur Kenntnis - und konnte dies auch gar nicht. Gewerkschaften und Arbeitgeber präsentierten ihre Verhandlungen vielmehr fast ausschließlich als Streit um Lohn- und Gehaltsprozentpunkte, der dann in der Tat »in der Mitte" (1968/69 konkret mit einer Einigung auf sechs Prozent) gelöst wurde und dementsprechend banal wirkte. ${ }^{218}$ Solche Simplifizierungen waren in mancher Hinsicht ohne Frage sinnvoll: Sie machten komplexe Tarifverhandlungen für die Medien fassbar und halfen gerade den Gewerkschaften, ihre Mitglieder für eine »überschaubare« Forderung zu mobilisieren. Andererseits aber mussten Funktion und Wert der Tarifautonomie wohl zwingend unklar bleiben, wenn sie als soziale Praxis stets nur so grob vereinfacht dargestellt wurde. ${ }^{219}$

Verhandlungsrunden von 19 Stunden Dauer (oder auch mehr), die bei Tarifauseinandersetzungen nicht selten sind, haben also keineswegs nur den rein symbolisch-performativen Charakter, der ihnen oft nachgesagt wird. ${ }^{220}$ Sie ziehen sich vielmehr auch deshalb so in die Länge, weil es den Arbeitge-

216 | Bericht des Tarifsekretariats über die Tarifvertragsverhandlungen, 17./ 18.1.1969; Bericht des Tarifsekretariats über die Tarifvertragsverhandlungen, 28./ 29.1.1969. Beide in: Archiv Ver.di, Bestand Kluncker, 13.

217 | So schon die resignierte Feststellung des Bezirksvorsitzenden für Bayern, Christoph Friedrich (Protokoll über die 9. Sitzung des HV, 9./10.11.1960. In: Archiv Ver.di, Bestand Kluncker, 45).

218 | ÖTV-Geschäftsbericht 1968/71, S. 79; eine Aufstellung der ergänzend vereinbarten, durchweg sehr unterschiedlich bemessenen Veränderungen bei den verschiedenen Zuschlägen findet man ebd., S. 78-91.

219 | Als rare Beispiele für Versuche, die Komplexität der Verhandlungen journalistisch genau zu beschreiben, vgl. etwa: Zweikampf zwischen Klett und Kluncker. In: StZ, 26.9.1969; Hermann Rudolph: Langwierige Einleitung eines Milliarden-Vergleichs. Stuttgarter Nächte - Die Tarifverhandlungen für den öffentlichen Dienst. In: FAZ, 8.2.1975.

220 | Vgl. als ein Beispiel für diese Sicht die Formulierung der FAZ von 1967, Marathonsitzungen gehörten nur mit Blick auf die jeweils »eigene« Seite "zur tarifpolitischen Etikette. Wer es kürzer macht, setzt sich anscheinend dem Vorwurf aus, zu weich verhandelt zu haben.« (Der öffentliche Dienst bleibt vom Streik verschont. In: FAZ, 4.12.1967) 
bern schwer fällt, die finanziellen Konsequenzen einzelner Zugeständnisse abzuschätzen, und die Gewerkschaften Mühe haben, angebotene Vergünstigungen so gegeneinander abzuwägen, dass möglichst viele Mitglieder möglichst stark profitieren. Die Aushandlung einer »Paket«-Lösung aber ist der Königsweg, um einen Kompromiss zu finden, der Gewerkschaft wie Arbeitgeber zufrieden stellt. In den 1960er und 1970er Jahren, als sich Informationen noch nicht mit ein paar Klicks im Internet abrufen ließen und komplizierte Rechenoperationen nicht in Sekundenschnelle elektronisch gelöst wurden, agierten beiden Seiten wohl zwangsläufig sehr im Vagen, wenn sie von ihren Ausgangsforderungen abgingen, um einen Abschluss möglich zu machen. ${ }^{221}$

Wenn exakt durchdachte und rationale Entscheidungen aber so erschwert sind, dann gewinnt die Taktik der Verhandlungspartner stark an Bedeutung: Sie kann helfen, die zögerliche Haltung der Gegenseite aufzubrechen, und Entscheidungen fördern, die eben noch als ein zu großes Risiko galten. Bei einer Befragung der Unterhändler beider Seiten in der württembergischen Metallindustrie hat ein Soziologe in den späten 1970er Jahren ermittelt, dass Verhandlungserfolge in Tarifrunden zentral vom "timing « abhängen. Gerade in der Endphase einer Tarifrunde, in der Gewerkschaft wie Arbeitgeber zunehmend unter dem Druck stehen, sich »zu bewegen«, entscheide vielfach der Zeitpunkt, zu dem bestimmte Angebote gemacht werden, über Annahme oder Ablehnung. ${ }^{222}$

Dabei erfüllt auch die Nachtsitzung, die pausenlos bis in den frühen Morgen fortgeführt wird, eine wichtige Funktion: Müdigkeit und Erschöpfung sowie der Stress, stundenlang in stark verräucherten Konferenzräumen (denn bei solchen Beratungen durfte seinerzeit - wie allgemein in der deutschen Öffentlichkeit - selbstverständlich geraucht werden) mit den gleichen Leuten über die gleichen Fragen zu streiten, können auf beiden Seiten Bedenken überwinden, die einer Einigung hartnäckig im Weg stan-

221 | Vgl. die Klage, die verfügbaren "Personalstrukturdaten« seien in der Regel mehr als ein Jahr alt und damit überholt. In: BMdI and BKA, 19.1.1972. In: BArch Koblenz, B 136, 5107. Monika Wulf-Mathies erinnert sich, dass selbst in den 1980er Jahren teilweise keine präzisen Angaben darüber vorlagen, wie viele Beamte und Angestellte es in einzelnen Beschäftigtengruppen gab (Interview Monika Wulf-Mathies, 7.4.2015).

222 | Schilling: Einigungsprozess, S. 169 f. 
den. Diesen »Sieg des Hinterns über den Geist« akzeptierten Gewerkschaften wie Arbeitgeber, weil es um ihre Erfolgsaussichten bei diesem speziellen finalen Wettstreit grundsätzlich gleich gutstand. ${ }^{223}$

Heinz Kluncker als der Chefunterhändler der ÖTV war offensichtlich sehr versiert darin, gegen Ende einer langen Verhandlungsrunde psychologisch auf die Vertreter der Arbeitgeber einzuwirken. Als er nicht mehr selbst mit Kluncker beraten musste, lobte Hermann Höcherl anerkennend die »darstellerische Kraft« des ÖTV-Vorsitzenden: Dieser könne das Verlassen des Verhandlungsraumes (und damit das Ende der Einigungsversuche) in mindestens $» 28$ Stufen " zelebrieren, die sich vom »Rascheln mit dem Papier" und "Papier in die Tasche stecken und wieder herausnehmen" schrittweise steigerten, bis schließlich "gemessenes Schreiten zur Tür in Erwartung eines weiteren Kompromißangebots« das letzte Warnsignal aussandte. ${ }^{224}$

Auch Monika Wulf-Mathies betont rückblickend die Bedeutung solch kleiner Gesten gerade in der Schlussphase der Beratungen: »Natürlich belauert man sich auch. Man guckt, welche Wirkung welche Bemerkung hat, und versucht, daraus seine Schlüsse zu ziehen.« Dabei gehe es darum, auch noch auf die »Körpersprache und Nebensätze« zu achten. Die Nachtsitzung und die Müdigkeit aller Beteiligten sei als Element der Kompromissfindung von großer Bedeutung: »Es gehört ein gewisses Maß an Erschöpfung dazu, sich selbst zu prüfen, was kann man denn noch anbieten, damit man zu einem Ergebnis kommt«. Zudem entscheiden ja nicht allein die Verhandlungsführer: »Es müssen auch die Kommissionen das Gefühl haben, nun geht wirklich nichts mehr - und das ist eben mittags um Zwölf nicht so. " ${ }^{225}$

Strategie spielt bei Tarifverhandlungen offensichtlich eine zentral wichtige Rolle. Berücksichtigt man dazu das Resultat der eben zitierten empirischen Studie, die sachlichen Argumente der Gegenseite seien in Tarifverhandlungen weder für die Gewerkschafter noch für die Arbeitgeber wirklich wichtig, weil ihre jeweiligen Grundüberzeugungen nicht zu erschüttern sind, dann mag sich doch wieder ein negatives Urteil über diese Beratungen aufdrängen. ${ }^{226}$

223 | Ebd., S. 175 f. (Zitat: S. 176).

224 | Zit. nach: Vogel: Höcherl, S. 34.

225 | Interview Monika Wulf-Mathies, 7.4.2015.

226 | Schilling: Einigungsprozess, S. 212. 
Die vorangegangenen Seiten sollten jedoch gezeigt haben, wie verfehlt pauschalisierende abschätzige Schlagworte in diesem Zusammenhang sind. Tarifverhandlungen sind ein Prozess der Kompromissfindung, in dem beide Seiten keine »Exit«-Option haben: Auf dem Bazar steht es Verkäufern wie Käufern frei, auf ein Geschäft zu verzichten, um es mit anderen Partnern neu zu versuchen. Gescheiterte Verhandlungen sind im Tarifgeschäft aber nur der Beginn weiterer Beratungen in gleicher Konstellation: Keine Gewerkschaft kann auf Dauer einen tariflosen Zustand wollen, und auch den Arbeitgebern liegt ihre kalkulatorische Sicherheit sehr am Herzen. ${ }^{227}$ Wer um Löhne und Arbeitsbedingungen »feilscht«, der übernimmt daher eine hochkomplexe Aufgabe, die nur dann erfolgreich bewältigt werden kann, wenn großes Wissen, Geduld, Einsatzbereitschaft und Stehvermögen zusammenkommen. Die konservative britische Tageszeitung The Times hat 1964 Tarifverhandlungen in einem Artikel über Lohnverhandlungen für den Öffentlichen Dienst entsprechend respektvoll als »more an art than a science« - »eher eine Kunst als Wissenschaft« - bezeichnet. ${ }^{228}$

227 | Heinz Kluncker hat durchweg stark betont, dass es bei Tarifverhandlungen - und sogar beim Streik - immer darum gehe, einen Konflikt friedlich durch einen Kompromiss beizulegen. Vgl. etwa: Wenn Richter über Streiks urteilen ... In: Die Zeit, 30.7.1971 (ein Interview mit dem ÖTV-Vorsitzenden); Heinz Kluncker: Tarifautonomie im Widerstreit der Interessen. In: Heinz Flohr/Klaus Lompe/Lothar F. Neumann (Hrsg.): Freiheitlicher Sozialismus. Beiträge zu seinem heutigen Selbstverständnis, Bonn 1973, S. 213-216, hier: S. 214. Ob auch die ÖTVMitglieder einen Streik so beurteilten, ist eine andere Frage. Siehe dazu in Kapitel III die Ausführungen zum Streik von 1974.

228 | What is the cost? In: The Times, 25.7.1964. Der englische Begriff »science» bezeichnet - anders als das sehr viel weiter zu verstehende Wort »Wissenschaft « im Deutschen - nur die Naturwissenschaften. 


\section{Tarifpolitik in turbulenten Zeiten: Die Lohnrunden für den Öffentlichen Dienst in den Jahren der Großen Koalition 1966 bis 1969}

\section{Die Wirtschaftskrise von 1966/67, die Konjunkturpolitik der Bundesregierung und die Tarifrunde für den Öffentlichen Dienst}

Ein ganzer Tag war für die Beratungen der Tarifparteien eingeplant; tatsächlich aber dauerten sie nur wenige Minuten. Bundesinnenminister Paul Lücke (CDU) hatte kaum das zentrale Lohnangebot der Arbeitgeber - ein Plus von zwei Prozent, das erst nach einer Wartezeit von mehr als einem Jahr wirksam werden sollte - vorgestellt, als Heinz Kluncker ihn unterbrach: Diese Offerte sei eine »Provokation«, sagte er; Gespräche darüber werde es nicht geben. Dann verließ der ÖTV-Vorsitzende gemeinsam mit den anderen anwesenden Gewerkschaftern den Saal - ohne diesen Abgang auf die sonst übliche Weise mimisch oder gestisch irgendwie vorbereitet zu haben. Verblüfft blieben die versammelten Vertreter von Bund, Ländern und Gemeinden allein zurück. Da sie nach einer internen Debatte mitteilten, es werde kein anderes Angebot geben, erklärte die ÖTV die Tarifverhandlungen für den Öffentlichen Dienst umgehend für gescheitert. Gleichzeitig wurde ein Termin für die Urabstimmung über einen Streik bekannt gegeben. ${ }^{229}$

So ungewöhnlich dieser Vorgang, der sich am 17. November 1967 in Köln ereignete, auch war - wirklich bemerkenswert wurde er erst durch die anschließende Reaktion des Innenministers. Im Bundeskabinett fand Lücke nur freundliche und anerkennende Worte für die ÖTV: Seit Anfang Juni sei ein neuer Lohn- und Gehaltstarif für den Öffentlichen Dienst nun schon überfällig; die Gewerkschaft aber habe sich dennoch stets »vernünftig und staatsbewußt« verhalten. Selbst der Eklat in Köln und die bevorstehende Urabstimmung über einen Streik der ÖTV mitten in der Vorweihnachtszeit irritierten den Minister der Großen Koalition, die seit dem Dezember 1966 in Bonn regierte, nicht. Lücke hielt die brüske Reaktion der Gewerkschaft auf das von ihm vorgetragene Angebot vielmehr für »absolut verständlich«. Unzufrieden war er hingegen mit den Vertretern der

229 | Streikgefahr im öffentlichen Dienst, FR, 18.11.1967. Vgl. auch: Vorschuß auf den Mai. In: Der Spiegel 21 (1967), H. 49, S. 32-34; ÖTV-Geschäftsbericht 1964/67, S. $57 \mathrm{f}$. 
Länder und der Kommunen, mit denen er gemeinsam als Kontrahent der Gewerkschaft zu agieren hatte: Deren Verhalten sei unflexibel und kontraproduktiv. So habe die VKA etwa "trotz dringender Bitten« keinen Vertreter zu einer Besprechung entsandt, auf der Lücke über ein gemeinsames besseres Angebot von Bund, Ländern und Gemeinden an die Gewerkschaft beraten wollte, und dadurch einen Beschluss torpediert, mehr als die mageren zwei Prozent zu offerieren, die zudem erst 1969 ausgezahlt werden sollten. $^{230}$

Auch der Wirtschaftsminister sympathisierte mit der ÖTV. Ein Plus von 3,5 Prozent bereits für 1968, so erklärte der Sozialdemokrat Karl Schiller, sei »wirtschaftspolitisch richtig«. Wenn TdL und VKA für das kommende Jahr und rückwirkend für die Monate seit Juli 1967 eine lohnpolitische Nullrunde für den Öffentlichen Dienst forderten, weil die Etats von Ländern und Kommunen in ihrer Sicht kaum noch finanziellen Spielraum ließen und bei größeren Zugeständnissen ihre Investitionen bedroht seien, dann handelten sie »konjunktur- und zinspolitisch falsch«. Schließlich sei es allen Gebietskörperschaften problemlos möglich, durch »die weitere Aufnahme von Krediten [...] die Investitionsausgaben trotz Erhöhung der Löhne und Gehälter aufrechtzuerhalten«. Leider aber machten Länder und Gemeinden »von dieser Möglichkeit nur zögernd Gebrauch «. ${ }^{231}$

In der Tarifrunde für den Öffentlichen Dienst von 1967/68 galten offensichtlich besondere Bedingungen: Vertreter der Bundesregierung, die für die staatliche Lohn- und Gehaltspolitik entscheidend wichtig waren, solidarisierten sich mit den Forderungen der ÖTV und haderten mit ihren Kollegen in den Bundesländern und in den Gemeinden, die sich ausgesprochen knauserig gaben, während doch ansonsten gerade die Kommunen bei einem drohenden Streik im Öffentlichen Dienst stets als allzu nachgiebig galten. Die große Bedeutung der Politik und deren enge Verbindung mit der aktuellen wirtschaftlichen Situation in den Tarifverhandlungen der ÖTV wird in dieser Tarifrunde im ersten Jahr der Großen Koalition besonders gut sichtbar. Dies gilt im Prinzip ebenfalls für die unter den Vorzeichen von »Wilden Streiks« durchgeführten Lohnverhandlungen im

230 | Die Kabinettsprotokolle der Bundesregierung, Bd. 20: 1967. Bearb. v. Walter Naasner/Christoph Seeman, München 2010 (im Folgenden: Kabinettsprotokolle Bundesregierung 1967), S. 553 u. 551 (Sondersitzung des Kabinetts v. 27.11.1967).

231 | Ebd., S. $553 \mathrm{f}$. 
Sommer 1969, wenngleich sie unter anderen ökonomischen Rahmenbedingungen mit entsprechend differenzierten politischen Prägewirkungen stattfanden. Im Folgenden steht deshalb die jeweilige politische Dimension der Tarifverhandlungen für den Öffentlichen Dienst im Fokus der Darstellung. Gleichzeitig wird gezeigt, wie stark sich das öffentliche Image des ÖTV-Vorsitzenden Heinz Kluncker - und damit auch das Bild der von ihm geführten Organisation - entscheidend gerade in diesen beiden Lohnverhandlungen formte, weil sie für eine im Prinzip so friedfertige Gewerkschaft wie die ÖTV jeweils ungewöhnlich konfrontativ verliefen.

1967 erlebte die Bundesrepublik ihre erste echte wirtschaftliche Krise: Die Konjunktur brach ein, das Bruttosozialprodukt sank. Die Zahl der beschäftigten Arbeitnehmer schrumpfte um 800.000; zum ersten Mal seit 1950 ging es zwischen Rhein und Elbe nicht mehr wie bisher immer weiter wirtschaftlich bergauf. So klaffte etwa im Bundeshaushalt unversehens ein Milliardenloch. Nach dem langen ökonomischen Aufschwung empfanden Politik, Medien und Öffentlichkeit diese Probleme als dramatischen Einschnitt. Sowohl der Sturz des glücklosen Bundeskanzlers Ludwig Erhard durch seine eigene Partei wie auch die Bildung der Großen Koalition zwischen CDU/CSU und den Sozialdemokraten mitten in der Legislaturperiode gehörten bereits zu den Auswirkungen der sich spätestens seit Herbst 1966 stark zuspitzenden ökonomischen Krise. Zu einem guten Teil entstand sie durch mangelnde wirtschaftspolitische Koordination zwischen einer Bundesregierung, die im Wahljahr 1965 großzügig Wahlgeschenke verteilt hatte, und der Bundesbank, die mit ihren Instrumenten restriktiv gegensteuerte. $^{232}$

Die SPD übernahm also im Dezember 1966 erstmals politische Verantwortung im Bonner Kabinett - und sie ging zügig daran, ein grundlegend neues wirtschaftspolitisches Konzept umzusetzen. Ihr ehrgeiziger Wirtschaftsminister Karl Schiller setzte nicht einfach nur auf aktive konjunkturpolitische Maßnahmen des Staates; er entwickelte gleich ein umfassendes Modell, das eine dauerhaft möglichst krisenfreie wirtschaftliche Aufwärtsentwicklung zur zentralen politischen Aufgabe der Bundesregierung und aller staatlicher Institutionen erklärte. Der um eine einprägsame Formulierung ebenso wie um eindrucksvoll klingende englische Vokabeln nie verlegene Minister sprach von einer "Globalsteuerung « des wirtschaft-

232 | Vgl. zusammenfassend etwa: Kleßmann: Zwei Staaten, S. 197-209. 
lichen Geschehens, in deren Zentrum eine klug geplante und stets antizyklisch angelegte »fiscal policy« zu stehen habe. ${ }^{233}$

So sollte aus der »früheren, naiven Marktwirtschaft« der Bundesrepublik, die vor allem »mit Appellen, Seelenmassagen, Maßhaltebeschwörungen und ähnlichem« gearbeitet hatte, eine »aufgeklärte Marktwirtschaft« werden, deren Steuerung auf der Basis der »volkswirtschaftlichen Gesamtrechnung « fast wissenschaftlichen Charakter trug. ${ }^{234}$ Ohne Frage setzte Schiller mit dieser Strategie eine "Zäsur in der Wirtschaftspolitik der Bundesrepublik«. CDU und CSU saßen - anders als man vielleicht denken könnte - dabei mit im Boot: Ihre wichtigsten Männer teilten den Planungsoptimismus der Sozialdemokraten; auch sie glaubten, nur eine statistisch informierte und aktiv lenkende staatliche Wirtschaftspolitik entspreche den »Erfordernissen einer hochentwickelten Industriegesellschaft «. ${ }^{235}$

Konkret brauchte die Bundesrepublik nach dem Urteil Karl Schillers im Jahr 1967, "auf der Talsohle eines Konjunkturtiefs«, vor allem staatliche Investitionen (für die auch Schulden gemacht werden durften) sowie zusätzlich eine »Stärkung der Massenkaufkraft«, damit die Konjunktur wie-

233 | So Schiller vor dem Bundesrat am 2.6.1967 (Verhandlungen des Bundesrates 1967. Stenographische Berichte von der 304. Sitzung am 10. Februar 1967 bis zur 318. Sitzung am 15. Dezember 1967, Bonn 1967 [im Folgenden: Verhandlungen BR 1967], S. 103). Zum Konzept der »Globalsteuerung« insgesamt vgl.: Johann Welsch: Globalsteuerung in der Bundesrepublik Deutschland, Köln 1980; Tim Schanetzky: Die große Ernüchterung. Wirtschaftspolitik, Expertise und Gesellschaft in der Bundesrepublik Deutschland 1966 bis 1982, Berlin 2007, S. 55-160; Ulfried Weißer: Die Bundesrepublik Deutschland. Ein Erfolgsprojekt, Berlin 2015, S. 249-252.

234 | Karl Schiller: Gewerkschaften als Verbündete der Wirtschaftspolitik. In: ders.: Wachstum, Stabilität, Gleichgewicht. Vorträge, Reden, Aufsätze. Hrsg. v. Detlef W. Prinz, Berlin 2007, S. 207-243, hier: S. 220. Es handelt sich hier um eine Rede, die Schiller am 18.5.1968 auf der Landesbezirkskonferenz der Gewerkschaft HBV hielt.

235 | So der baden-württembergische Ministerpräsident Werner Schwarz (CDU) vor dem Bundesrat am 2.6.1967 (Verhandlungen BR 1967, S. 96). Vgl. im Rückblick selbstkritisch auch: Hans Filbinger: Regierungsplanung - Euphorie und Wirklichkeit. In: Robert Schwebler (Hrsg.): Jahre der Wende 1968-1978. Bestandsaufnahme eines Jahrzehnts. Alex Möller zum 75. Geburtstag, Karlsruhe 1978, S. 95-105. 
der ansprang. ${ }^{236}$ Letzteres fiel stark in die Zuständigkeit der Tarifparteien und auch sie gehörten selbstverständlich in Schillers Großen Plan.

Regelmäßige Konsultationen von Gewerkschaftern, Arbeitgebern und Vertretern der Bundesregierung, für die das Wirtschaftsministerium die Bezeichnung »Konzertierte Aktion« erfand, sollten helfen, ein "gleichzeitiges aufeinander abgestimmtes Verhalten« aller drei Gruppen zu erreichen. Einerseits wurden die Tarifparteien so offiziell an der »Vorformung der Wirtschafts- und Finanzpolitik" beteiligt; andererseits erhielt das Wirtschaftsressort ein Forum, um Arbeitgebern und Gewerkschaftern »Orientierungsdaten « für eine ökonomisch positiv wirkende Lohn- und Gehaltspolitik an die Hand zu geben. ${ }^{237}$ Begeistert lobte sich der Minister selbst, er habe mit der »Konzertierten Aktion" und seinen öffentlichen Erklärungen für eine höhere Massenkaufkraft eine "negative Lohnpolitik« in der Krise verhindert: "Wann ist das früher gewesen? Ich glaube nie. Jede Lohnbewegung wurde früher von der Obrigkeit und von der Regierung als sSünde gegen den heiligen Geist der Marktwirtschaft angesehen. « $^{238}$

Die ÖTV stimmte Schiller hier zu: Heinz Kluncker äußerte, die Zusammenarbeit mit dem sozialdemokratischen Wirtschaftsminister biete »ein völlig neues Gefühl für uns Gewerkschafter - nach all den Jahren mit Erhard«, der bekanntlich gerade die Organisationen der Arbeitnehmer immer nur zum »Maßhalten« gedrängt hatte. ${ }^{239}$ Karl Schiller wollte die Zahlungsfähigkeit der Lohnabhängigen hingegen gezielt auch durch Lohn- und Gehaltserhöhungen für den Öffentlichen Dienst steigern: Bei

236 | So Schiller im Rückblick auch auf 1967 in: Protokoll des 8. Ordentlichen Gewerkschaftstag der Industriegewerkschaft Druck und Papier, Koblenz 1968, Frankfurt/Main 1968 (im Folgenden: Protokoll GT IG Druck 1968), S. 254.

237 | Karl Schiller: Konjunkturpolitik auf dem Wege zu einer Affluent Society. In: Robert Schwebler/Walter Föhrenbach (Hrsg.): Jahre der Wende. Festgabe für Alex Möller zum 65. Geburtstag, Karlsruhe 1968, S. 61-72, hier: S. 70 f. Zur »Konzertierten Aktion « allgemein vgl.: Christian Kaiser: Korporatismus in der Bundesrepublik Deutschland. Eine politikfeldübergreifende Übersicht, Marburg 2006, S. 169-234.

238 | Schiller: Gewerkschaften, S. 216.

239 | Heinz Kluncker in: Protokoll ÖTV-GT 1968, Bd. 1, S. 57. Deutlich distanzierter hingegen die Wertung Schillers in: Geschäftsbericht des Bundesvorstandes des Deutschen Gewerkschaftsbundes 2. Halbjahr 1965 bis 1968, Düsseldorf 1968 (im Folgenden: Geschäftsbericht BV DGB 1965/68), S. 251-256. 
der Planung des Etats für 1968 setzte das Wirtschaftsressort 724 Millionen DM ein, die eine »tarifliche und besoldungsmäßige Verbesserung« für alle Beschäftigten des Bundes finanzieren sollten. Grob gerechnet entsprach das einem Lohn- und Gehaltsaufschlag von etwa vier Prozent für 1968. Für das dann nachfolgende Jahr hielt das Ministerium sogar ein Plus von fünf Prozent für wirtschaftspolitisch sinnvoll. ${ }^{240}$

Unter diesen Voraussetzungen durfte die ÖTV eigentlich eine recht entspannte Tarifrunde erwarten - es kam dann aber doch ganz anders. Die Verhandlungen, die erst im Sommer 1967 begannen, weil der im Frühjahr 1966 abgeschlossene Lohntarif für die Staatsbediensteten ungewöhnlicher Weise über eine Laufzeit von anderthalb Jahren galt, verliefen zunächst ausgesprochen schleppend. Bei den ersten Besprechungen machten die Arbeitgeber kein konkretes Angebot; die ÖTV aber verhielt sich abwartend, ja fast passiv. Diese Untätigkeit hatte einen doppelten Hintergrund. Zum einen fuhr die unerwartet hereinbrechende Wirtschaftskrise allen Gewerkschaftern gehörig in die Knochen: Da es erstmals seit Beginn des "Wirtschaftswunder« in den frühen 1950er Jahren wieder eine wirklich nennenswerte Zahl von Arbeitslosen gab, hatten die Gewerkschaften in den Tarifverhandlungen der Privatwirtschaft für 1967 nur die bescheidene Hoffnung, "wenigstens die bestehenden Einkommen zu sichern «. ${ }^{241}$

240 | Vermerk v. Referat I/3 für die Kabinettssitzung, 11.9.1967. In: BArch Koblenz, B 136/5202.

241 | So Heinz Kluncker rückblickend in: Protokoll ÖTV-GT 1968, Bd. 1, S. 57 f. (Zitat: S. 58). Zum Ziel der Lohnsicherung vgl. auch: Geschäftsbericht BV DGB 1965/68, S. 253. Die Zahl der registrierten Erwerbslosen erreichte im Januar 1968 auch durch saisonale Effekte - mit etwa 673.000 ihren Höhepunkt. Bis Ende April 1968 ging sie aber bereits auf 331.000 zurück. Vgl. Hans Hofbauer/Lothar Schuster/Werner Dadzio: Die Arbeitssuchenden in der Bundesrepublik Deutschland im Frühjahr 1968. In: Mitteilungen aus der Arbeitsmarkt- und Berufsforschung 1 (1968) 4, S. 177-197, hier S. 181. Ein größerer Anstieg blieb aus, weil in der Krise rund 500.000 »Gastarbeiter" wieder aus der Bundesrepublik abwanderten. Arbeitslose: Im Jahresmittel 1967 waren es offiziell nur knapp 460.000, 1968 nur noch etwa 323.500 (Geschäftsbericht BV DGB 1965/68, S. 242). Die lange Laufzeit des Tarifvertrags vom März 1966 stand im Zusammenhang mit der gleichzeitig vereinbarten Einführung des »Bewährungsaufstiegs« für Angestellte. Siehe dazu S. 281-286. 
Zwar tangierte der Konjunktureinbruch die öffentlichen Betriebe und Unternehmen nicht so stark wie zentral wichtige privatwirtschaftliche Branchen. Die Furcht vor der zuvor fast vergessenen Arbeitslosigkeit aber prägte die Stimmung auch der ÖTV-Mitglieder: »Die Kollegen sprechen z. Zt. nicht so sehr über Lohnerhöhungen, desto sorgenvoller aber über den Erhalt der bislang gewährten Leistungen und über den Erhalt ihrer Arbeitsplätze « - so berichtete ein Betriebsvertreter im Hauptvorstand. ${ }^{242}$ Expansive Lohnforderungen mochte die ÖTV deshalb nicht entwickeln, zumal die Arbeitgeber öffentlich betonten, wie privilegiert die Beschäftigten des Öffentlichen Dienstes mit ihren vielfach unkündbaren Arbeitsverhältnissen in einer Wirtschaftskrise doch seien. ${ }^{243}$

Zum anderen nahm die Gewerkschaft offensichtlich bewusst Rücksicht auf die neu gebildete Regierung, die mitten in einer Krise einen grundlegenden Kurswechsel vollzog: Wie Heinz Kluncker sagte, sollte die Große Koalition eine »faire Chance« bekommen, »um die Trümmer der Erhardschen Wirtschaftspolitik zu beseitigen «. ${ }^{244}$ So konnte die Gewerkschaft der erstmals in Bonn mitregierenden SPD helfen, ohne sich gleich dem Vorwurf auszusetzen, sie vernachlässige die Interessen ihrer Mitglieder. Die Verhandlungen über den am 1. Juli 1967 ausgelaufenen Lohn- und Gehaltstarifvertrag dümpelten daher über Monate träge vor sich hin. Die Tarifparteien trafen sich nur in weiten zeitlichen Abständen und gingen dann jeweils unverrichteter Dinge wieder auseinander. ${ }^{245}$

Gleichzeitig aber formierte sich in VKA und TdL Widerstand gegen die Planungen der Bundesregierung. Besonders die im Etatentwurf enthaltenen konkreten Zahlen für 1968 erregten bei den Haushaltspolitikern der Länder und der Gemeinden heftigen Unwillen. Zum Teil ging es dabei

242 | Erich Rüttel (Dortmund) in: Protokoll über die 11. Sitzung des HV, 16./17.3.1967. In: AdsD, 5/ÖTVB130014. Ähnlich auch Willi Kuhlmann (Düsseldorf) in: ebd. Beide gehörten zu den ehrenamtlichen Mitgliedern des HV.

243 | Vgl. etwa den schleswig-holsteinischen Finanzminister Hans-Hellmuth Qualen (FDP) in: Qualen: Kein Grund zum Streik. In: FAZ, 22.11.1967. Wegen dieser sicheren Arbeitsplätze, so Qualen, sei den Beschäftigten des Öffentlichen Dienstes »ein gewisses Abwarten« bis zur nächsten Lohn- und Gehaltserhöhung ja wohl zuzumuten.

244 | Rede Heinz Kluncker auf der ÖTV-Protestkundgebung in München, 14.11.1967. In: Archiv Ver.di, Bestand Kluncker, 12.

245 | Vgl.: ÖTV-Geschäftsbericht 1964/67, S. 57. 
ums Prinzip: Landes- und Kommunalpolitiker fühlten sich in einer finanziell höchst bedeutsamen Angelegenheit schlicht »überfahren«, weil die oben genannten Vorgaben ohne Konsultationen mit TdL und VKA allein im Bonner Regierungsapparat entstanden waren.

Als Sprecher der Länder erklärte der niedersächsische Finanzminister Alfred Kubel (SPD) im Oktober 1967 im Bundesrat: »Wir müssen verlangen, daß sich der Bund, bevor er Besoldungserhöhungen in dieser Form in Aussicht stellt, vergewissert, wie weit Länder und Gemeinden überhaupt zu folgen in der Lage sind. ${ }^{246}$ Mit ähnlichen Worten verwahrten sich auch die Gemeinden gegen eine indirekte Einschränkung ihrer Haushaltsrechte durch Bonner Planungen. ${ }^{247}$

Da die Bundesregierung fast zeitgleich versprach, sie werde künftig über Lohn- und Gehaltsfragen des Öffentlichen Dienstes nur noch »im engsten Einvernehmen« mit Ländern und Gemeinden entscheiden, wäre dieser Konflikt eigentlich leicht beizulegen gewesen. ${ }^{248}$ Tatsächlich aber eskalierte er zu einem gravierenden wirtschaftspolitischen Streit, als der Bundesrat am 13. Oktober 1967 ebenso überraschend wie konkret für eine radikal andere Lohnpolitik der Öffentlichen Hand votierte: Die Länder wollten die im Bundeshaushalt für eine bessere Bezahlung der Staatsdiener vorgesehenen 724 Millionen DM um nicht weniger als 674 Millionen DM kürzen. De facto forderten sie damit, in den beiden kommenden Jahren

246 | Verhandlungen BR 1967, S. 191. Vgl. ebd., S. 160 f. u. 168 f., auch die ähnlichen Klagen Kubels schon am 1.9.1967.

247 | Bericht des BMdI zur tarifpolitischen Lage im Öffentlichen Dienst, 23.11.1967. In: BArch Koblenz, B 136, 5202; Gemeinden erwarten Finanzhilfe vom Bund. In: Frankfurter Neue Presse, 29.11.1967. Hinter diesen Positionen stand auch die Vorstellung, die Gemeinden seien - anders als der Bund - allein schon wegen fehlenden Fachwissens grundsätzlich nicht für die Konjunkturpolitik zuständig. Vgl. grundlegend dazu sowie zu neuen Konzepten, die Konjunkturpolitik als eine gesamtstaatliche Aufgabe definierten, etwa: Ernst Helmut Wilms: Probleme einer konjunkturgerechten Gestaltung der Gemeindefinanzen, rechts- u. staatswiss. Diss., Universität Freiburg/Breisgau 1968; Alfons Schmidt: Entwicklung und Bedeutung der Gemeindefinanzen in der BRD mit einem Vergleich dreier strukturtypischer Gemeinden: 1950-1968, rechtswiss. Diss., Universität Freiburg (Schweiz) 1971.

248 | Das Zitat aus der Rede von Bundesfinanzminister Franz Josef Strauß schon am 1.9.1967 im Bundesrat (Verhandlungen BR 1967, S. 169). 
auf jede Lohn- und Gehaltsverbesserung für Beschäftigte des Staates zu verzichten. ${ }^{249}$

Die in der VKA zusammengeschlossenen Gemeinden sekundierten: Ihr Hauptziel sei es, in der aktuellen Wirtschaftskrise Defizite in den kommunalen Haushalten zu vermeiden. Deshalb gehe es nicht an, die Personalkosten der Städte gerade jetzt zu erhöhen. ${ }^{250}$ Komme es 1968 und 1969 dennoch zu Lohn- und Gehaltsverbesserungen, dann müsse man unweigerlich die kommunalen Sachinvestitionen kürzen. ${ }^{251}$

Wie oben schon zitiert wurde, reagierte das Bundeswirtschaftsministerium auf diese Kritik mit dem Hinweis, wer Kredite aufnehme, der könne sehr wohl gleichzeitig investieren und die Kaufkraft der beim Staat beschäftigten Menschen stärken: In der gegebenen ökonomischen Situation sei dieses staatliche »deficit-spending " genau das richtige Rezept. Wenn die Öffentliche Hand in der Krise sparsam agiere, verstärke sie hingegen den wirtschaftlichen Einbruch; die Angst vor Schulden entspringe »einem nicht-adäquaten gesellschaftlichen Bewusstsein ${ }^{252}$ Ergänzend betonten sowohl Wirtschaftsminister Schiller als auch der Finanzminister Franz Josef Strauß (CSU), für die von allen Seiten gewünschte konjunkturelle Belebung sei der vorgesehene Lohn- und Gehaltszuschlag für den Öffentlichen Dienst eine »notwendige Voraussetzung «. ${ }^{253}$

Die Gemeinden aber wollten von diesem wirtschaftspolitischen Rezept der Großen Koalition nichts wissen. Weitere kommunale Schulden, so er-

249 | Vgl. die Empfehlungen der BR-Ausschüsse: Drucksache 480/1/67, S. 24. In: Drucksachen des Bundesrates 1967 (451/67-500/67); Einigungsvorschläge der Länderfinanzminister. In: FAZ, 6.10.1967; Der Bundesrat will Änderungen im Haushaltsentwurf. In: FAZ, 14.10.1967; Harter Dienstherr. In: FR, 20.10.1967. Die verbliebenden 50 Millionen DM sollten für zusätzliche Stellen verwandt werden. 250 | Vgl. etwa: Realistisch. In: Der Städtetag 20 (1967), S. 683; Bericht des ÖTVTarifsekretariats Nr. 94/67, 26.9.1967. In: AdsD, 5/ÖTVB130015 A.

251 | Bericht des BMdI zur tarifpolitischen Lage im Öffentlichen Dienst, 23.11.1967. In: BArch Koblenz, B 136, 5202; Gemeinden erwarten Finanzhilfe vom Bund. In: Frankfurter Neue Presse, 29.11.1967.

252 | Schiller: Gewerkschaften, S. $210 \mathrm{f}$.

253 | So Strauß am 24.10.1967 im Bundestag. In: Verhandlungen des Deutschen Bundestages. 5. Wahlperiode. Stenographische Berichte, Bd. 65, Bonn 1966, S. 6429. Vgl. auch: Das Kabinett hält an höherer Beamtenbesoldung fest. In: FAZ, 19.10.1967. 
klärten zahlreiche Bürgermeister und die VKA, könnten nicht akzeptiert werden, denn leider seien die bundesdeutschen Städte bereits »am Ende ihrer Verschuldungsmöglichkeiten«: Die laufenden Kosten für die Verzinsung und Tilgung von Krediten dürften nicht noch weiter steigen. ${ }^{254}$

Tarifpolitisch wirklich aktiv wurde die ÖTV im Jahr 1967 erst, als dieser Streit unter den Arbeitgebern voll entbrannt war. Bis zu dem demonstrativ radikalen Kürzungsbeschluss des Bundesrates vom Oktober scheint die Gewerkschaft immer noch gehofft zu haben, die Gegenseite werde sich schon "zusammenraufen" und den Vorschlägen der Bundesregierung folgen. Nun aber begann sich die ÖTV zu wehren. Mit einer Serie von öffentlichen Protestveranstaltungen in 15 größeren Städten der Republik warb sie um öffentliche Aufmerksamkeit. Mit starken Worten stützte Heinz Kluncker dabei etwa in München die Bundesregierung. Er kritisierte »die falsche Analogie von Staatswirtschaft und privatem Haushalt«, die vor allem die VKA benutze, wenn sie sich gegen den Vorschlag wehre, Kredite aufzunehmen: Nötig sei ein Abschied von dieser »überholten Fiskalpolitik«, die "gegen alle wirtschaftliche Vernunft« verstoße. ${ }^{255}$

Insbesondere die Bundesregierung sah Kluncker in der Verantwortung: Ihre »Globalsteuerung« wie auch die mit so viel Selbstlob auf den Weg gebrachte »Konzertierte Aktion" sei doch nichts weiter als eine »Farce", wenn es Wirtschaftsminister Schiller noch nicht einmal gelinge, die öffentlichen Arbeitgeber auf seine konjunkturpolitischen »Orientierungsdaten« festzulegen. 256

In einem Beitrag für die Gewerkschaftszeitung Welt der Arbeit argumentierte der ÖTV-Vorsitzende noch grundsätzlicher, der Hinweis auf »leere Kassen« des Staates sei für die von ihm geführte Organisation unerheblich: »Die Tarifpolitik kann und darf sich deshalb nicht an den Haushalten orientieren. Sie wird vielmehr von den Notwendigkeiten bestimmt, die sich aus der sozialen und wirtschaftlichen Lage der Arbeitnehmer er-

254 | Aus den Haushaltsreden 1968. In: Der Städtetag 21 (1968), S. 26-31, hier: S. 30. Vgl. auch: Die Gemeindefinanzmasse muß um vier Milliarden DM verstärkt werden. In: ebd. 20 (1967), S. 527-530.

255 | Rede Heinz Kluncker auf der ÖTV-Protestkundgebung in München, 14.11.1967. In: Archiv Ver.di, Bestand Kluncker, 12. Zu der Serie von 15 Protestversammlungen vgl. auch: Lücke folgt Klunckers Ultimatum. In: FAZ, 7.11.1967. 256 | Streik im öffentlichen Dienst? In: StZ, 18.11.1967. 
geben. Die Arbeitgeber müssen dafür in den Haushalten genauso Mittel bereitstellen wie für alle anderen Aufgaben.« Im Übrigen seien die Kassen von Ländern und Gemeinden »keineswegs leer. Es ist durchaus Geld da, aber es wird für andere Zwecke verwendet. « $^{257}$

Politisch waren diese gewichtigen Formulierungen wohl alles andere als geschickt. Die darin implizit enthaltene Aufforderung, der Staat - d.h. Regierung und Parlament - sollten doch bitte andere öffentliche Ausgaben einschränken, um die Beschäftigten des Öffentlichen Dienstes besser zu bezahlen, war zumal in einer ökonomischen Krisensituation wohl kaum geeignet, die Sympathiewerte der ÖTV in der allgemeinen Öffentlichkeit zu verbessern. Zudem verdeckten die zitierten Worte, wie stark sie sich auf die konkrete ökonomische Situation des Jahres 1967 bezogen, in der ein konjunktureller Anstoß durch »deficit-spending « der Öffentlichen Hand in der Tat als höchst sinnvoll gelten durfte. Sie postulierten daher gar kein ehernes tarifpolitisches Konzept der ÖTV, wurden in der Presse teilweise aber dennoch gerade in diesem Sinne verstanden und negativ als selbstgerechte Ignoranz gegenüber den Folgen des eigenen Tuns vermerkt. ${ }^{258}$ Für Klunckers öffentliches Image als Gewerkschaftsführer hatte dieses Missverständnis - wie noch zu zeigen sein wird - langfristige Folgen, handelte es sich doch um die erste offen konfrontative Tarifrunde für den Öffentlichen Dienst seit seinem Amtsantritt.

Wenn die ÖTV im Herbst 1967 - scheinbar - ihre grundsätzliche finanzpolitische Gleichgültigkeit erklärte, dann verhielt sie sich auch deshalb ungeschickt, weil bei näherem Hinsehen deutlich zu erkennen war, dass die öffentlichen Arbeitgeber untereinander im Kern gar nicht über das Prinzip stritten, staatliche Ausgaben unter Umständen auch mit Krediten zu finanzieren.

Das Argument von den angeblich ohnehin schon »zu hohen« öffentlichen Schulden, das vor allem die Kommunen ins Feld führten, verschleierte vielmehr das wahre politische Ziel, das VKA und TdL im Herbst 1967 verfolgten: Sie verstellten der konjunkturpolitisch tatendurstigen Großen

257 | Heinz Kluncker: Der Haushalt des Staates ist keine heilige Kuh. In: WdA, 17.11.1967.

258 | Vgl. als scharf negativen Kommentar etwa: Klunckers Polit-Logik. In: SZ, 18.11.1967. Hier werden die zitierten Formulierungen als »blanke Dummheit« bewertet. 
Koalition den Weg, um die Bundesregierung zu zwingen, im Finanzausgleich günstigere Regelungen für Länder und Gemeinden zu akzeptieren. Deshalb agierte der Bundesrat ausgerechnet im Jahr 1967 als Gegenspieler der Bonner Regierung, als das zum ersten Mal geschmiedete Bündnis von CDU/CSU und SPD eine oppositionelle Haltung der Länder politisch ganz unwahrscheinlich machte.

In der Bundesrepublik wurde (und wird) das Steueraufkommen nach äußerst komplizierten Regeln auf Bund, Länder und Gemeinden verteilt. Da die Steuerhoheit fast ausschließlich beim Bund liegt, sitzen Länder und die Kommunen in diesem System grundsätzlich am kürzeren Hebel. Politisch wurde über den Finanzausgleich nahezu permanent gestritten, seitdem er in den bis heute gültigen Grundzügen in den ersten Jahren der Weimarer Republik entstand, denn Länder und Gemeinden fühlten sich finanziell stets benachteiligt. ${ }^{259}$ Die Geschichte des Systems ist daher eine Geschichte vieler kleinerer Korrekturen und einiger weniger "großer« Reformen. Die bundesdeutsche Politik setzte eine solche umfassende Überarbeitung, die den Finanzausgleich gerechter machen sollte, bereits 1957 auf die Agenda. 1967 wurde in dieser Angelegenheit immer noch beraten. Ein Abschluss, der auch eine Veränderung des Grundgesetzes (für die im Bundestag eine Zwei-Drittelmehrheit der Stimmen erforderlich war) umfassen sollte, war aber für 1969 geplant und damit fast zum Greifen nah. ${ }^{260}$

Vor diesem Hintergrund enthüllt sich die plötzliche lohnpolitische Knauserigkeit von Ländern und Gemeinden in den Tarifverhandlungen für den Öffentlichen Dienst als der Versuch, die Bundesregierung finanzpolitisch unter Druck zu setzen. So sagte der oben bereits zitierte niedersächsische Finanzminister Kubel im Bundesrat ganz offen, die Länder würden sich so lange gegen Lohn- und Gehaltszuschläge für die Beamten und alle anderen Staatsbediensteten im Jahr 1968 sperren, solange sie keine

259 | Als Überblick vgl. etwa: Manfred Schüler et al.: Zur Finanzreform in der Bundesrepublik Deutschland. Tatsachen, Probleme, Möglichkeiten, Hannover 1964, S. 15-40; Alex Möller: Neuordnung des Finanzausgleichs zwischen Bund, Ländern und Gemeinden. In: Kommunale Finanzreform, Hannover 1962, S. 49-62.

260 | Vgl. als Zusammenfassung etwa: Fritz Neumark: Probleme und Aspekte einer Finanzreform. In: Die Finanzreform und die Gemeinden, Stuttgart u. a.O. 1966, S. VII-XVI; Schüler et al.: Finanzreform. 
Zusagen hätten, „wie weit der Bund bereit ist, einer neuen Entwicklung $\mathrm{zu}$ folgen und einen besseren Ausgleich [d.h.: einen besseren Finanzausgleich - K.C.F.] aufzubauen «. ${ }^{261}$

Für die finanziellen Wünsche von Ländern und Gemeinden gab es gute Gründe. So hatten Bundesregierung und Bundestag in den frühen 1960er Jahren gleich mehrfach staatliche Leistungen für Bürger erhöht oder neu eingeführt, deren Kosten die Länder mitzutragen hatten. Drängende politische Aufgaben wie etwa die Anpassung der bundesdeutschen Infrastruktur an die rasch wachsende Zahl von Privatautos oder der Ausbau der Krankenhäuser und des Bildungswesens mussten in beträchtlichem Umfang von den Ländern finanziert werden. Gleichzeitig gingen verschiedene Steuerreformen, die Unternehmen und Privathaushalte besserstellten, aber vor allem zu Lasten der Länderkassen. ${ }^{262}$

Da sie zudem durchschnittlich etwas mehr als 40 Prozent ihrer Etats für Personalkosten aufwandten (statt nur elf Prozent wie der Bund), ließ sich kaum bestreiten, dass die von der Bundesregierung für 1968 geplante Lohn- und Gehaltsverbesserung die Finanzpolitiker der Länder vor ein echtes finanzielles Problem stellte. ${ }^{263}$ Zwar sah es mit den Geldnöten im Einzelnen durchaus sehr unterschiedlich aus. Die Finanzminister der ökonomisch und finanziell schwächsten Länder - das waren seinerzeit Bayern, Niedersachsen, Rheinland-Pfalz und Schleswig-Holstein - setzten sich mit ihrem Widerstand gegen die Haushaltsplanung der Bundesregierung im Bundesrat jedoch gegen ihre Kollegen aus den florierenden Regionen der Bundesrepublik durch: Die 724 Millionen DM, die Wirtschaftsminister

261 | Verhandlungen BR 1967, S. 206.

262 | Vgl. etwa den knappen Überblick durch Finanzminister Kubel in: ebd., S. 192 f., sowie: Bayern erwartet mehr Geld vom Bund. In: FAZ, 9.11.1967. Ein Beispiel für diese neuen Sozialleistungen ist etwa das 1961 eingeführte Wohngeld für finanziell schwache Mieter: Seine Kosten mussten zu 50 Prozent von den Ländern getragen werden. Vgl. dazu: Jens Alber: Der Sozialstaat in der Bundesrepublik 1950-1983, Frankfurt/Main 1989, S. 63 u. 68-76. Die Ausgaben für das Wohngeld stiegen durch die allgemeine Erhöhung der Mieten in den 1960er Jahren stark an, vgl. Bruno Felberg: Das Wohngeld. Eine Untersuchung seiner wirtschaftlichen und sozialen Bedeutung und ein Vergleich mit anderen Subventionen, Bonn 1972, S. 71. Zu den Investitionsaufgaben vgl. etwa: Schüler et al.: Finanzreform, S. 53-58.

263 | Zu diesen Unterschieden siehe schon S. 46. 
Schiller ausgeben wollte, sollten fast ganz gestrichen werden, um die Länder vom politischen Zwang zu befreien, ihre Beschäftigten ebenfalls besser zu stellen. ${ }^{264}$

Auch die Gemeinden sahen sich finanziell stark bedrängt. Sie waren im Finanzausgleich ohnehin die »Stiefkinder" und mussten machtlos mit ansehen, wie ihr prozentualer Anteil am gesamten deutschen Steueraufkommen immer weiter schrumpfte. ${ }^{265}$ Die erwähnten dringenden Investitionsaufgaben der 1960er Jahre aber betrafen sie ebenfalls: Zumal in den Großstädten stammten zentrale Elemente der städtischen Infrastruktur sowie die Ausstattung von Ämtern und öffentlichen Versorgungseinrichtungen oft noch aus dem Kaiserreich oder aus den 1920er Jahren. ${ }^{266}$ Nach den damals geltenden finanziellen Regeln und Kriterien war ihr Kreditspielraum zudem tatsächlich ausgeschöpft. Die dramatische Feststellung des Deutschen Städtetages von 1968, die bundesdeutschen Kommunen hätten "jeden finanziellen Spielraum verloren«, war also keine Übertreibung. ${ }^{267}$

264 | Der Stadtstaat Hamburg hatte eine 50-prozentige Kürzung vorgeschlagen, konnte sich damit aber nicht durchsetzen (Verhandlungen BR 1967, S. 198 u. 209). 265 | Dieser Anteil sank von 37,2 Prozent im Jahr 1913 über 25,2 Prozent 1932 auf nur noch 13,5 Prozent im Jahr 1959. So die Angaben des CDU-Bundestagsabgeordneten Walter Eberhardt in: In letzter Stunde. Reden, Diskussionen und Beschluß der außerordentlichen Hauptversammlung des Deutschen Städtetages am 26. November 1968 in Bonn, Stuttgart und Berlin 1968, S. 34. Vgl. auch: Willi Albers: Aufgabe und Stellung der Gemeinden im Finanzsystem der gesamten Öffentlichen Hand. In: Finanzarchiv N. F. 19 (1958/59), S. 399-426, hier: S. 402-424. 266 | Vgl. etwa: 157 Milliarden. In: Der Städtetag 15 (1962), S. 229-230; Das Kind beim Namen genannt. In: Der Städtetag 17 (1964), S. 469-470. Ausführlicher: Bruno Weinberger: Das quantitative Problem der Gemeindefinanzreform. In: Die Finanzreform und die Gemeinden, Stuttgart u.a. O. 1966, S. 71-109, insbes. S. 76-84.

267 | Alfred Dregger: Die Forderungen des Deutschen Städtetages. In: In letzter Stunde, S. 27-32, hier: S. 29. Der CDU-Politiker Dregger war seinerzeit Oberbürgermeister von Fulda und Vizepräsident des DStT. Nach heutigen Kriterien war der Schuldenstand der Gemeinden gering: Noch 1968 entfielen nur 4,2 Prozent ihrer gesamten Ausgaben auf Zinsen und Tilgung (Hermann Elsner: Das Gemeindefinanzsystem. Geschichte, Ideologie, Grundlagen, Köln u.a.O. 1979, S. 106). Die Bundesbank erklärte die öffentlichen Haushalte der Bundesrepublik 1967 ausdrücklich für solide (Die Kreditfinanzierung der öffentlichen Hand aus der Sicht der Deutschen Bundesbank. In: Der langfristige Kredit 18 [1967], S. 487-488). Vor 
Da die »Konjunkturbelebung« gleichzeitig das zentrale politische Ziel der Großen Koalition in Bonn darstellte, nutzten Länder und Gemeinden die Tarifverhandlungen für den Öffentlichen Dienst durchaus sehr geschickt als »Druckmittel gegenüber der Bundesregierung. Die Sparsamkeit der VKA war nach dem Urteil des Bundesinnenministeriums "sehr stark, wenn nicht sogar ausschließlich" durch die Hoffnung der Kommunalpolitiker zu erklären, mit diesem Hebel im Finanzausgleich einen größeren Gemeindeanteil am Steueraufkommen durchzusetzen. Weil die Bundesregierung die öffentlich bereits angekündigte bessere Besoldung für die Staatsbediensteten im Herbst 1967 als eine Frage ihrer eigenen »Glaubwürdigkeit« betrachtete, stand sie politisch in dieser Sache unter starkem Druck. ${ }^{268}$

Wirtschaftsminister Schiller bekräftigte nach dem eingangs geschilderten Eklat bei den Tarifverhandlungen in Köln entschieden seine Ansicht, ohne eine echte Gehaltsaufbesserung für den Öffentlichen Dienst noch 1968 sei »das projektierte wirtschaftliche Wachstum nicht zu er-

dem Hintergrund der sehr restriktiven Vorschriften der Deutschen Gemeindeordnung, die de facto eine strenge »Schuldendienstgrenze« enthielt und die Aufnahme von Krediten nur zuließ, wenn der Etat fortlaufend mit einem Gewinn abschloss, konnte allerdings auch schon der oben genannte Wert als bedenklich gelten, weil solche Überschüsse zunehmend sanken oder auch schon ganz fehlten. Zudem waren noch 1965 nur 2,5 Prozent der Ausgaben auf den Schuldendienst entfallen. Zu den Details vgl. etwa: Alfons Schreml/Josef Dietl: Die Berechnung der gemeindlichen Schuldengrenze, München 1960, insbes. S. 10 f u. 43 f.; die Zahl für 1965 nach: Elsner: Gemeindefinanzsystem, S. 106. Eine Geschichte der öffentlichen Schuldenwirtschaft in der Bundesrepublik ist noch zu schreiben. Vgl. als knappen Abriss etwa: Roland Sturm: Staatsverschuldung. Ursachen, Wirkungen und Grenzen staatlicher Verschuldungspolitik, Opladen 1998; Marc Hausmann: Vor dem dritten Staatsbankrott? Der deutsche Schuldenstaat in historischer und internationaler Perspektive, 2. durchges. Aufl., München 2012.

268 | In der Reihenfolge der Zitate: Vermerk v. Referat I/3 für die Kabinettsitzung, 21.11.1967. In: BArch Koblenz, B 136/5202; Bericht des BMdI zur tarifpolitischen Lage im Öffentlichen Dienst, 23.11.1967. In: ebd.; Vermerk v. Referat I/3 für die Kabinettsitzung, 11.9.1967. In: ebd. Zum Hintergrund vgl. auch: Mirko Abresch/Sven Leunig: 1962-1969: Dominanz föderaler Konflikte. In: Sven Leunig/ Hendrik Träger (Hrsg.): Parteipolitik und Landesinteressen. Der deutsche Bundesrat 1949-2009, Münster 2012, S. 79-106. 
reichen ${ }^{269}{ }^{26}$ Zugleich aber erklärte er, ein "Junktim« zwischen den Lohntarifen für den Öffentlichen Dienst und bestimmten Regeln im Finanzausgleich dürfe "nicht hingenommen werden [...], da dieses Problem keinesfalls zur Tarifpolitik gehöre ${ }^{270}$

Weil sich keine Seite bewegte, sah es im November 1967 eine Zeit lang tatsächlich so aus, als werde die ÖTV von den Arbeitgebern quasi zum Streik gezwungen, weil Bund, Länder und Gemeinden unfähig zu sein schienen, ihre interne Uneinigkeit ohne Druck von außen zu überwinden. ${ }^{271}$ Die Basis der ÖTV war zu diesem Zeitpunkt ohne Frage streikbereit: Fast 95 Prozent Ja-Stimmen bei der Urabstimmung am 29. und 30. November dokumentierten dies. ${ }^{272}$

Die Perspektive, die Bürger ausgerechnet in der Vorweihnachtszeit mit stillgelegten öffentlichen Verkehrsmitteln und nicht geleerten Mülltonnen zu konfrontieren, bewog jedoch zumindest die VKA zum Einlenken, die sich noch am Tag vor der Urabstimmung ganz unnachgiebig gezeigt hatte. Zudem drohte die Bundesregierung, sie werde anderenfalls allein weiterverhandeln. Öffentlich bezeichnete ein Regierungssprecher die bislang so rigide lohnpolitische Haltung von TdL und VKA als »schwer verständlich und unfreundlich ${ }^{273}$

So kam es am 2. Dezember 1967 nach 22-stündigen Verhandlungen, die immer wieder für interne Beratungen der Arbeitgeber unterbrochen wurden, schließlich doch noch zu einer Tarifeinigung, die den Angestellten und Arbeitern des Staates fast unverzüglich höhere Löhne und Gehälter

269 | Kabinettsprotokolle Bundesregierung 1967, S. 553 (Sondersitzung des Kabinetts v. 27.11.1967).

270 | Ebd.

271 | Vgl. etwa: Länder und Kommunen sollen ihre Haltung überprüfen. In: FAZ, 22.11.1967; Spitze der Unpopularität. In: FAZ, 22.11.1967; Bonn dringt auf neues Angebot für öffentlichen Dienst. In: FAZ, 24.11.1967; Noch kein neues Angebot im öffentlichen Dienst. In: FAZ, 27.11.1967.

272 | ÖTV-Geschäftsbericht 1964/67, S. 57. Der Anteil der abstimmenden Mitglieder betrug 84 Prozent bei den Arbeitern und Arbeiterinnen sowie 82 Prozent bei den Angestellten.

273 | Kein gemeinsames Angebot mehr im öffentlichen Dienst? In: FAZ, 26.11.1967; Gemeinden erwarten Finanzhilfe vom Bund. In: Frankfurter Neue Presse, 29.11.1967. Zur scheinbar unnachgiebigen Haltung der VKA vgl.: Klett im Kreuzfeuer. In: StZ, 28.11.1967. 
bescherte: Ihre Bezahlung stieg mit Beginn des nachfolgenden Jahres um 3,5 Prozent. Zudem vereinbarten die Tarifpartner für 1969 eine einstündige Arbeitszeitverkürzung, der zum 1. Januar 1972 eine weitere Reduzierung auf dann insgesamt nur noch 42 Stunden pro Woche folgen sollte. ${ }^{274}$ Wenig später verzichtete der Bundesrat ganz offiziell auf weiteren Widerstand gegen die Haushaltsplanung der Bundesregierung; die 724 Millionen DM für die Besoldungsverbesserung blieben als Etatposten daher unangetastet. $^{275}$

Damit hatte die ÖTV zwar einen Lohn- und Gehaltsstopp im Jahr 1968 verhindert. Zudem war der Öffentliche Dienst auf mittlere Sicht nun nicht mehr der »Naturschutzpark für überlange Arbeitszeiten«, über den Heinz Kluncker zuvor gespottet hatte. ${ }^{276}$ Der eindeutige Gewinner dieser Tarifrunde war jedoch die Bundesregierung: Sie erhielt fast genau den Abschluss, den sie sich gewünscht hatte. Lediglich die fest zugesagte zweite Stufe der Arbeitszeitverkürzung behagte ihr nicht, weil solche Zukunftsabsprachen zwangsläufig den künftigen konjunktur- und tarifpolitischen Verhandlungsspielraum einengten. ${ }^{277}$ Gleichzeitig war es ihr aber gelungen, Länder und Gemeinden mit dem vagen Versprechen abzuspeisen, ihre finanziellen Interessen würden im System des kommenden Finanzausgleichs selbstverständlich angemessen gewürdigt. ${ }^{278}$

274 | ÖTV-Geschäftsbericht 1964/67, S. 58. Die zweistufige Verkürzung galt auch für das Gesundheitswesen; sie bezog sich aber auf die dort bislang übliche 48-Stunden-Woche.

275 | Bundesrat unterstützt die Finanzpolitik der Regierung. In: FAZ, 16.12.1967. 276 | Rede Heinz Kluncker auf der ÖTV-Protestkundgebung in München, 14.11.1967. In: Archiv Ver.di, Bestand Kluncker, 12. In der Privatwirtschaft arbeiteten im Jahr 1967 bereits vier Fünftel aller Beschäftigten weniger als 44 Stunden pro Woche.

277 | Vgl. dazu BMdI Lücke in: Kabinettsprotokolle Bundesregierung 1967, S. 553 (Sondersitzung des Kabinetts, 27.11.1967).

278 | So Finanzminister Franz Josef Strauß schon am 1.9.1967 im Bundesrat (Verhandlungen BR 1967, S. 169). Zu der 1969 verabschiedeten Finanzreform, die Länder und Gemeinden tatsächlich stärkte, von diesen aber doch nur als halber Erfolg gewertet wurde, vgl. etwa: Franz Josef Strauß: Die Finanzreform 1969. In: Robert Schwebler (Hrsg.): Jahre der Wende 1968-1978. Bestandsaufnahme eines Jahrzehnts. Alex Möller zum 75. Geburtstag, Karlsruhe 1978, S. 43-53. 
Allerdings blieben auch die Länder nicht ganz erfolglos: Ungewöhnlicher Weise wurden die Bestimmungen des Tarifvertrages nicht umgehend auf die Beamten übertragen. Deren Bezüge stiegen wegen einer Absprache von Bund und Ländern vielmehr erst ab dem 1. Juli 1968; die Gehaltsaufbesserung betrug für sie demnach lediglich zwei Prozent, wenn man sie für das ganze Jahr berechnete. Damit wurde de facto nur die Teuerung ausgeglichen. Bei den Beschäftigten des Staates, die sich nicht mit einem Streik wehren konnten, kam die Bundesregierung den finanziellen Interessen der Länder also durchaus entgegen. ${ }^{279}$

In der ÖTV gab es im Dezember 1967 keine Triumphgefühle. Die Große Tarifkommission stimmte dem Verhandlungsergebnis erst nach stundenlangen Beratungen zu. Offensichtlich waren etliche ihrer Mitglieder der Ansicht, mit einem Streik könne die Organisation ein noch deutlich besseres Ergebnis erreichen. Letztlich setzte sich der gHV, der einen Arbeitskampf vermeiden wollte, aber durch. ${ }^{280}$ Was dafür den Ausschlag gab, muss mangels aussagekräftiger Quellen offen bleiben. Die Furcht, das Image der ÖTV könne durch einen Arbeitskampf in der Adventszeit Schaden nehmen, mag sich mit der Abneigung vermengt haben, der neuen, an so prominenter Stelle mit Sozialdemokraten besetzten Regierung genau zu dem Zeitpunkt Probleme zu bereiten, an dem sich die Hoffnung breitmachte, die staatliche »Konjunkturankurbelung« könne Erfolg haben.

An der Basis der Organisation stieß der neue Tarifvertrag jedoch auf recht breite Skepsis: Von den Arbeitern und Arbeiterinnen, auf deren Schultern der gerade eben noch vermiedene Streik der ÖTV gelegen hätte, stimmten in der zweiten Urabstimmung 46 Prozent gegen die Vereinbarung vom 2. Dezember 1967. Offensichtlich störten sich gerade unter den Arbeitern viele Mitglieder an der Tatsache, dass die Lohnerhöhung nicht

279 | Scharfe Kritik daran, die auch stark konjunkturpolitisch argumentiert, findet sich etwa in: Entschließung des ÖTV-HV auf seiner 15. Sitzung, 24.4.1968. In: AdsD, 5/ÖTVB130015 A; Geschäftsbericht BV DGB 1965/68, S. 651-665, insbes. S. $658 \mathrm{f}$.

280 | Vgl. dazu die Hinweise in: Der öffentliche Dienst bleibt vom Streik verschont. In: FAZ, 4.12.1967. Wichtig für die Zustimmung der GTK war offensichtlich die Zusage der Arbeitgeber, noch 1968 den Lohnzuschlag und Sozialzuschlag für Arbeiter und Arbeiterinnen neu zu verhandeln. Die beiden Zuschläge wurden daher ab dem 1.7.1968 heraufgesetzt. Vgl. dazu: ÖTV-Geschäftsbericht 1968/71, S. 78. 
auch rückwirkend für die Zeit galt, die seit dem Ablauf des alten Lohntarifs vergangen war. ${ }^{281}$

Gleichzeitig aber stand die Gewerkschaft in den Medien einmal mehr am Pranger. Wie bereits bei den Streiks von 1954 und 1958 meldeten Zeitungen und Rundfunk auch diesmal fast unisono, die ÖTV treibe mit ihrer Tarifpolitik die Gebühren für öffentliche Dienstleistungen in die Höhe. ${ }^{282}$ Material dafür lieferten die VKA und der Deutsche Städtetag, die selbst nach dem Abschluss des Tarifvertrages vom Dezember 1967 nicht davon abließen, ihre Forderungen für die Finanzreform mit den Personalkosten des Öffentlichen Dienstes zu begründen. Die Lohn- und Gehaltserhöhung, so erklärte es das Präsidium des Städtetages, zwinge die Gemeinden zu Mehrausgaben von 350 Millionen DM allein im Jahr 1968. Damit habe sich ihre Finanzlage "aufs schärfste " verschlechtert; "Steuer-, besonders aber Gebührenerhöhungen« seien unabwendbar, wenn nicht der Bund einspringe. ${ }^{283}$ Widerspruch von Wirtschaftsminister Schiller oder Finanzminister Strauß, die als Konjunkturpolitiker eben noch so entschlossen für die Besoldungsverbesserung gestritten hatten, blieb jedoch aus. Ausgerechnet eine Tarifrunde, in der die ÖTV kaum mehr getan hatte, als den Vorgaben der Bundesregierung zu folgen, förderte also ihr negatives öffentliches Image.

Politik, so lehrt es die Soziologie, ist zu einem guten Teil »Komplexitätsreduktion«: Amtsinhaber und Parteivertreter erklären komplizierte Probleme und Aufgaben so stark vereinfacht, dass alle politisch überhaupt interessierten Bürger und Wähler bei Wahlen und Abstimmungen in der Lage sind, als rational und legitim empfundene Entscheidungen zu treffen,

281 | Das Abstimmungsergebnis in: ÖTV-Geschäftsbericht 1964/67, S. 58. Wie fast immer lag die Beteiligung auch bei dieser zweiten Urabstimmung deutlich niedriger als beim ersten Votum: Es beteiligten sich 70 Prozent der Arbeiter und 67 Prozent der Angestellten (ebd.). Zur Mitgliederkritik an dem Vertrag vgl. die Hinweise des Delegierten Franz Drucks (Kreisverwaltung Osnabrück) sowie den Antrag der Bezirkskonferenz Hessen in: Protokoll ÖTV-GT 1968, Bd. 1, S. 93, u. Bd. 2, S. 317.

282 | Vgl. die umfangreiche Presseschau in: Geht den Städten die Luft aus? In: Der Städtetag 21 (1968), S. 39-40.

283 | Der Bund soll die Städte entlasten. In: Der Städtetag 21 (1968), S. 25-26, hier: S. 25. 
obwohl ihre Sachkenntnisse doch meistens nicht sehr weit reichen. ${ }^{284}$ Dieser Zusammenhang stellte eine so politik- und staatsnahe Gewerkschaft wie die ÖTV vor echte Probleme.

Gerade wenn es um in der Tat sehr schwierige Fragen wie etwa um den Finanzausgleich, die Gründe für die finanziellen Nöte der Gemeinden oder um das "vertretbare« Maß an öffentlichen Schulden ging, konnten Politiker anklagend auf die ÖTV und ihre Forderungen verweisen, um Etatprobleme auf ganz einfache Weise zu erklären. Bei diesem Hang zur Simplifizierung gab es keine parteipolitischen Unterschiede: Sozialdemokratische Bürgermeister trugen die Kampagne des Städtetages von 1967/68 für einen anderen Finanzausgleich, die mit Klagen über die Personalkosten operierte, ebenso wie konservative und liberale Kommunalpolitiker. ${ }^{285}$ Sie alle wiesen der Gewerkschaft damit öffentlich mehr oder weniger direkt die Verantwortung für gravierende Problemen zu, die in Wirklichkeit auf ganz verschiedene und teilweise weit in der Vergangenheit liegende politische Entscheidungen zurückgingen. Die Möglichkeiten der ÖTV, dieses Bild zu korrigieren, waren jedoch gering, weil sie der wirkungsvollen »Komplexitätsreduktion« der Politiker keine vergleichbar schlüssigen Erklärungen entgegensetzen konnte. ${ }^{286}$

\section{Fortsetzung mit neu verteilten Rollen: Der Streit um einen finanziellen Nachschlag für die Beschäftigten im Herbst 1968}

Die in vieler Hinsicht ungewöhnliche Tarifrunde des Jahres 1967 war auch insofern ein Fall für sich, als sie noch im Jahr 1968 zu einem Nachspiel führte, das die Lohn- und Gehaltserhöhung von 3,5 Prozent korrigierte, obwohl der darüber abgeschlossene Tarifvertrag noch lief. Bei den Arbeitgebern waren die Rollen dabei wieder anders verteilt als im Herbst 1967. Ei-

284 | Vgl. etwa: Niklas Luhmann: Politische Soziologie. Hrsg. v. André Kieserling, Berlin 2010, S. 415.

285 | Vgl. beispielhaft die Stellungnahmen des Frankfurter Oberbürgermeisters Willi Brundert (SPD) in: Am Beispiel Frankfurts. In: FAZ, 30.11.1967; Ohne Rücksicht auf Verluste. In: FAZ, 1.12.1967.

286 | Vgl. etwa die defensiv formulierte Entschließung des HV vom Dezember 1967, die Gemeinden machten es sich "zu einfach«, wenn sie nach der Einigung im Tarifstreit höhere Preise für öffentlichen Dienstleistungen ankündigten (Entschließung des ÖTV-HV, 12./13.12.1967. In: AdsD, 5/ÖTVB130015 A). 
nige Dokumente, die uns über diese besonderen Tarifverhandlungen informieren, illustrieren zudem einen Aspekt des Begriffs »Tarifpolitik«, der in den Quellen ansonsten schwer zu fassen ist: Sie belegen, dass ein Gewerkschaftsvorsitzender, der in zentralen Verhandlungen mit den Arbeitgebern selbst als Chefunterhändler seiner Organisation agiert, durchaus so etwas wie eine eigene Tarifpolitik verfolgen kann, die sich von den Vorgaben der Gewerkschaftsgremien löst. Auch deshalb lohnt sich ein genauerer Blick auf das tarifpolitische Nachspiel von 1968.

Die Gelegenheit (oder auch: die Notwendigkeit) für diese zweite Runde entstand, weil die bundesdeutsche Wirtschaft nach dem Dezember 1967 überraschend schnell und überraschend einheitlich auf den Wachstumspfad zurückfand, von dem sie nach dem Amtsantritt von Bundeskanzler Ludwig Erhard abgekommen war. Unversehens bot sich damit der ÖTV die Chance, einen »Nachschlag« zu den Tariflöhnen zu verlangen, die sie mit den Arbeitgebern in der letzten Phase des konjunkturellen Einbruchs vereinbart hatte. Da die Abmachung über die Löhne und Gehälter noch bis Ende 1968 lief, musste sie dazu allerdings auf ein anderes tarifliches Feld ausweichen. Dafür kam nur das »Weihnachtsgeld« in Frage, das Bund, Länder und Gemeinden jeweils im Dezember an ihre Beschäftigten zahlten: Der Tarifvertrag darüber lief nach mehrjähriger Dauer zufällig im Herbst 1968 ab. Die Gewerkschaft kündigte die Abmachung fristgerecht und gewann damit die Möglichkeit, das Einkommen der beim Staat beschäftigten Arbeitnehmer auf einem Umweg noch 1968 ein weiteres Mal zu verbessern.

Öffentlich trat die Gewerkschaft in dieser Sache sehr fordernd auf: Hatten die Beschäftigten des Staates seit 1964 jeweils ein Drittel ihrer individuellen monatlichen Bezüge gegen Jahresende als zusätzliche besondere "Zuwendung" erhalten, so sollten es künftig - und erstmals auch noch im laufenden Jahr - zwei Drittel sein. Diese Forderung begründete die ÖTV ausdrücklich mit der kurzfristig geänderten wirtschaftlichen Lage: Der 3,5-Prozent-Abschluss vom Dezember 1967 sei durch die seitdem eingetretene und »damals nicht vorhersehbare günstige wirtschaftliche Entwicklung [...] überholt«. Deshalb gebe es bei den Mitarbeitern des Öffentlichen Dienstes einen "Nachholbedarf« für 1968, den das erhöhte "Weihnachtsgeld« decken müsse. ${ }^{287}$ Die Industriegewerkschaften, die mehrheitlich erst

287 | Bericht des BMdI über die tarifpolitische Lage im öffentlichen Dienst für den Chef des Bundeskanzleramtes, 17.10.1968. In: BArch Koblenz, B 106, 37702. 
im Frühjahr mit ihren Tarifverhandlungen begannen, erreichten in diesen Auseinandersetzungen in der Tat bessere Zahlen: Die durchschnittliche Lohn- und Gehaltserhöhung für Arbeiter und Angestellte betrug 1968 in der Bundesrepublik rund fünf Prozent. ${ }^{288}$

Zwar hätten Heinz Kluncker und die anderen gHV-Mitglieder wegen dieser Diskrepanz durchaus auf sich selbst zeigen können, denn schließlich hatten sie viel dafür getan, um Ende 1967 einen Streik des Öffentlichen Dienstes zu vermeiden, mit dem wohl ein höherer Lohnabschluss möglich geworden wäre. Da Selbstkritik bekanntlich schwer fällt, schimpfte die ÖTV-Führung aber lieber über Karl Schiller. Im internen Gespräch mit Vertretern des Innenministeriums, der TdL und der VKA sagte Heinz Kluncker im Oktober 1968, für ihn und alle anderen ÖTV-Funktionäre sei »der Gedanke unerträglich «, noch einmal in die Situation zu kommen, in der man jetzt stecke: Die Gewerkschaftsführung habe den Prognosen des Wirtschaftsministers vertraut und müsse sich nun sagen lassen, sie habe den lohnpolitischen »Spielraum« für 1968 nicht ausgeschöpft. Umso wichtiger sei für die ÖTV ein Erfolg beim »Weihnachtsgeld« noch im laufenden Jahr. $^{289}$

Bevor die damit eingeleitete Auseinandersetzung skizziert wird, lohnt sich ein kurzer Blick auf die Geschichte dieser besonderen Form des Einkommens von lohnabhängigen Arbeitnehmern: An ihr zeigt sich, wie stark der Öffentliche Dienst trotz der zahlreichen dienstrechtlichen Unterschiede zwischen Beamten, Angestellten und Arbeitern schon in den 1950er und 1960er Jahren ein einheitliches System darstellte, in dem sich soziale Verbesserungen kaum auf nur ein Segment beschränken ließen.

Zudem hatte der Gewerkschaftstag im Sommer 1968 mehrere Anträge angenommen, die ein höheres Weihnachtsgeld forderten (Protokoll ÖTV-GT 1968, Bd. 2, S. 315 f.).

288 | Geschäftsbericht BV DGB 1965/68, S. 290. In dieser Zahl ist der ÖTV-Abschluss vom Dezember 1967 mit enthalten.

289 | Vermerk betr. Verhandlungen über die gesamte tarifpolitische Lage, 7.10.1968. In: BArch Koblenz, B 106, 37702. Schiller trat im Herbst 1968 öffentlich mehrfach mit dem Argument auf, die Gewerkschaften hätten bislang lohnpolitisch zu zurückhaltend agiert. Das Zitat von dem nicht ausgeschöpften »Spielraum« stammt aus einer Rede des Ministers vor dem Gewerkschaftstag der IG Druck und Papier (Protokoll GT IG Druck 1968, S. 253). 
Der Ursprung der besonderen »Zuwendung«, für die sich im alltäglichen Sprachgebrauch rasch der Begriff »Weihnachtsgeld« einbürgerte, liegt in den frühen 1950er Jahren. In dieser Zeit versuchte die Öffentliche Hand mehrfach, die unbestreitbar vorhandene Diskrepanz zwischen dem Lohnund Gehaltsniveau in Industrie und Gewerbe einerseits sowie dem Öffentlichen Dienst andererseits durch einmalig gewährte Zulagen für ihre Beschättigten zu verringern. Die erste Zahlung dieser Art gehört zu den frühen tarifpolitischen Erfolgen der ÖTV: Sie wurde im Herbst 1950 zunächst mit den Ländern ausgehandelt und für die vier Monate von Oktober bis Ende Januar 1951 gezahlt. Der Bund übernahm diese Abmachung und dehnte sie zudem auf die Beamten aus. Zwar gab es im Kabinett durchaus Bedenken gegen diesen zweiten Schritt, der die Sonderzahlung wegen der zahlreichen verbeamteten Staatsdiener im Personal des Bundes deutlich in die Höhe trieb. Zulagen dürften Beamten, so monierte Innenminister Gustav Heinemann (damals noch CDU-Mitglied), nach dem geltenden Dienstrecht nicht pauschal, sondern »nur bei Erfüllung bestimmter Tatbestände« gezahlt werden. Damit aber setzte er sich nicht durch: Bundeskanzler Adenauer und die Mehrheit der Minister stimmten für eine allgemeine Sonderzahlung auch an die Beamten, weil es sich ja nur »um eine einmalige Übergangsmaßnahme« handle. ${ }^{290}$

Es folgten jedoch weitere Zulagen, weil der Öffentliche Dienst immer wieder neu den Anschluss an die allgemeine Entwicklung der Löhne und Preise zu verlieren drohte, die im beginnenden Wirtschaftsboom teilweise deutlich stiegen. So setzte die ÖTV als »Ausgleich für die gestiegenen Lebenshaltungskosten« bereits im Frühjahr 1952 ein zusätzliches »einmaliges halbes Monatsgehalt« durch - und diesmal kamen nach dem Tarifabschluss nicht nur die Beamten, sondern durch Beschluss der öffentlichen Arbeit-

290 | Die Kabinettsprotokolle der Bundesregierung, Bd. 2: 1950. Bearb. v. Ulrich Enders/Konrad Reiser, Boppard 1984, S. 759 (Kabinettssitzung v. 4.10.1950). Die Tarifverträge über die Zulage veröffentlicht in: Geschäftsbericht der Gewerkschaft Öffentliche Dienste, Transport und Verkehr 1949-1951, Stuttgart 1952 (im Folgenden: ÖTV-Geschäftsbericht 1949/51), Bd. 2, S. 208-213. Die Zulage war sozial gestaffelt: Arbeiter der Öffentlichen Hand erhielten pauschal eine Zulage von 9 Pfennigen zu ihren jeweiligen Stundenlöhnen (die seinerzeit zwischen 75 und 85 Pfennigen gestaffelt waren). Angestellte mit einem Gehalt bis zu 350 DM monatlich erhielten durchweg $20 \mathrm{DM}$ »Sonderzulage« pro Monat; höhere Gehälter durften nur auf maximal 370 DM aufgestockt werden. 
geber auch noch die Pensionäre und Rentner des Staates in den Genuss der Sonderzahlung. ${ }^{291}$

Da sich der Preisauftrieb weiter fortsetzte, beschlossen Bund und Länder kaum ein halbes Jahr später eine nun offiziell so genannte »Weihnachtszuwendung«. Dabei liefen die Beratungen mit den Gewerkschaften und die politischen Entscheidungen über die Behandlung der Beamten bereits parallel. Einerseits gab es in der von CDU und CSU geprägten Bundesregierung große Sympathien gerade für eine Zuwendung an die Beamten. Die Bundestagsfraktion der beiden konservativen Parteien verlangte im Herbst 1952 gleich eine ganze Reihe von "Notstandsmaßnahmen« für Staatsdiener, weil es nach ihrem Urteil in Deutschland keine andere Bevölkerungsgruppe gab, »die relativ so stark hinter den Teuerungsverhältnissen zurückgeblieben ist, wie es bei der Beamtenschaft und bei den öffentlich Angestellten der Fall ist «. ${ }^{292}$ Auch Bundeskanzler Adenauer erklärte, er »halte sich im Gewissen verpflichtet, etwas für die Beamten zu tun«. Andererseits gab es jedoch erneut Bedenken: Der Finanzminister sorgte sich wegen der Kosten; Adenauer fürchtete - Gewissen hin, Gewissen her -, es könne »ein Gewohnheitsrecht« entstehen. ${ }^{293}$

Die schließlich einheitlich für alle Beschäftigten des Öffentlichen Dienstes gezahlte "Zuwendung« bestand aus Festbeträgen von 30 DM für Ledige und 50 DM für Verheiratete; dazu kam ein Zuschlag von 15 DM pro Kind. Es handelte sich also um eine sozial stark ausgleichend wirkende Maßnahme, die den Beziehern kleiner Einkommen sowie kopfstarken Familien besonders nützte, "um die Eltern in die Lage zu versetzen, den Kindern [zu Weihnachten - K. C.F.] eine besondere Freude zu bereiten «. ${ }^{294}$

291 | Die Kabinettsprotokolle der Bundesregierung, Bd. 5: 1952. Bearb. v. Kai von Jena, Boppard 1989 (im Folgenden: Kabinettsprotokolle Bundesregierung 1952), S. 177 f. (Kabinettssitzung v. 18.3.1952) u. S. 356 f. (Kabinettssitzung v. 27.5.1952).

292 | So der CDU-Abgeordnete Franz-Josef Wuermling im Bundestag am 26.11.1952. In: Verhandlungen des Deutschen Bundestages. Stenographische Berichte Bd. 13, S. 10973.

293 | Kabinettsprotokolle Bundesregierung 1952, S. 655 f. u. 658 (Kabinettssitzung v. 5.11.1952).

294 | So Staatssekretär Alfred Hartmann vom BMF in: ebd., S. 493 (Kabinettssitzung v. 1.8.1952). Die entsprechenden Tarifverträge veröffentlicht in: ÖTV: Wortlaut der überbezirklichen Tarifverträge des Jahres 1952, Stuttgart 1953 (im Folgenden: ÖTV-Tarifverträge 1952), S. 356-359. 
Erklärtermaßen ging es um eine »Überbrückungsmaßnahme«, die als eine Art Abschlag auf die kommende und seit langem versprochene "große Besoldungsreform « für den ganzen Öffentlichen Dienst und insbesondere für die Beamtenschaft gedacht war. ${ }^{295}$

Ein Jahr später war diese "große" Reform wegen anhaltender Streitigkeiten aller Beteiligten zwar immer noch nicht beschlossen. Dennoch unternahm der Bundesrat im Herbst 1953 den ernsthaften Versuch, am Jahresende keine weiteren Sonderzulagen mehr zu zahlen. Die von der Ländervertretung angeführten, ausschließlich finanziellen Argumente überzeugten nicht nur den Bundesfinanzminister, sondern auch die ganze Bundesregierung. Anfang November beschloss das Kabinett, 1953 werde es keine "Weihnachtszuwendung" geben: Sie sei erstens wegen der zwischenzeitlich erfolgten Lohn- und Gehaltserhöhungen auch im Öffentlichen Dienst nicht mehr nötig und zweitens bei den Beamten unzulässig, weil diese keine pauschale »Gratifikation« erhalten dürften. ${ }^{296}$

Politisch stand dieser Beschluss allerdings auf wackeligen Beinen. So hatten sich die Gemeinden schon 1952 vertraglich verpflichtet, die Zulage auch in den nachfolgenden Jahren zu zahlen. ${ }^{297}$ Zudem wusste Bundeskanzler Adenauer, es gebe im Bundestag in allen Fraktionen »wenig Verständnis für den Gedanken der Nichtzahlung von Weihnachtszuwendungen ${ }^{298}$ Die scheinbar entschlossene Haltung von Bundesregierung und Bundesrat hatte daher nicht lange Bestand.

Als die Landtage von Bayern und Hessen (d.h. die Fraktionen der regierenden CSU bzw. der SPD) mit den Stimmen der jeweiligen Opposition fast einstimmig beschlossen, das "Weihnachtsgeld « auch im laufenden Jahr zu zahlen, griff die Bundesregierung zwar noch zu einem scharfen Mittel: Sie beantragte beim Bundesverfassungsgericht den Erlass einer Einstweiligen Verfügung gegen die beiden Landesregierungen. Deren Alleingang

295 | So Bundesfinanzminister Fritz Schäffer im Bundestag am 26.11.1952 (Verhandlungen des Deutschen Bundestages. 1. Wahlperiode. Stenographische Berichte, Bd. 13, Bonn 1952, S. 10975.

296 | Kabinettsprotokolle Bundesregierung 1953, S. 476-478 (Kabinettssitzung v. 3.11.1953).

297 | ÖTV-Tarifverträge 1952, S. 366f. ( $\$ 9$ des Vertrages).

298 | Kabinettsprotokolle Bundesregierung 1953, S. 477 (Kabinettssitzung v. 3.11.1953). 
führe zu ungleichen Beamtengehältern und das verletze »ein legitimes Bundesinteresse«. Die höchsten Richter wiesen diesen Antrag jedoch umgehend ab: Es gehe nicht an, ein juristisches Instrument zu nutzen, um dem Verfassungsgericht die Entscheidung in einem politischen Streit zwischen Bund und Ländern »zuzuschieben«. Das Bundeskabinett gab daraufhin rasch nach. ${ }^{299}$

Zwar erreichte der um die öffentlichen Finanzen besorgte und auf Wahrung seines politischen Renommees bedachte Finanzminister eine deutliche Reduzierung der Zulage: Sie wurde 1953 nur noch an Beschäftigte mit Kindern gezahlt. ${ }^{300}$ Dieser Beschluss war jedoch nichts anderes als ein politisches Rückzugsgefecht: Unabhängig von der konkret gezahlten Summe wurde das Weihnachtsgeld mit der Entscheidung vom Dezember 1953 für den Öffentlichen Dienst zu dem »Gewohnheitsrecht«, vor dem Konrad Adenauer ein Jahr zuvor gewarnt hatte.

Mehrere Bundesländer zahlten die Zulage bereits 1953 auf eigenen Beschluss in alter Form weiter. 1954 ging die TdL insgesamt zu dieser Praxis über; die Kommunen gewährten im gleichen Jahr sogar etwas mehr Geld. ${ }^{301} 1955$ schließlich konnte die ÖTV auch mit dem Bund einen Tarifvertrag aushandeln, der die besondere »Zuwendung« gegen Jahresende dauerhaft als Teil der Löhne und Gehälter im Öffentlichen Dienst sicherte. ${ }^{302}$

299 | In der Reihenfolge der Zitate: Weihnachtsgeld auf eigene Gefahr der Länder. In: FAZ, 12.12.1953; Entscheidungen des Bundesverfassungsgerichts 3 (1954), S. 52-58, hier: S. 52. Zu den Details vgl.: Kabinettsprotokolle Bundesregierung 1953, S. 565. (Kabinettssitzung v. 11.12.1953); S. 569f. (Kabinettssitzung v. 18.12.1953). Zum Verfahren vor dem Bundesverfassungsgericht vgl. auch: Das Weihnachtsgeld vor dem Zweiten Senat. In: FAZ, 10.12.1953.

300 | Pro Kind gab es 15 DM. Ausgeschlossen waren alle Beschäftigten, deren Lohn oder Gehalt mehr als 420 DM betrug (ebd., S. 570).

301 | ÖTV-Geschäftsbericht 1952/54, S. 67; ÖTV: Wortlaut der überbezirklichen Tarifverträge des Jahres 1954, Stuttgart 1955. (im Folgenden: ÖTV-Tarifverträge 1954), S. $131 \mathrm{f}$. (für die TdL); ebd., S. 100-102 (hier vereinbarten ÖTV und VKA Zulagen von 40 DM für Ledige und 60 DM für Verheiratete. Der Kinderzuschlag betrug unverändert $15 \mathrm{DM}$ pro Kind).

302 | ÖTV-Geschäftsbericht 1955/57, S. 196; ÖTV: Wortlaut der überbezirklichen Tarifverträge des Jahres 1955, Stuttgart 1956 (im Folgenden: ÖTV-Tarifverträge 1955, S. 410 f. (wie bei der TdL wurden hier weiterhin 30 bzw. 50 DM vereinbart). 
Die ursprünglich als befristete Notmaßnahme gedachte Sonderzahlung war damit unter tätiger Mithilfe der politischen Parteien sowie der Länder und Gemeinden zum sozialen Besitzstand aller Beschäftigten geworden, die für den Staat arbeiteten. Zwar durfte sich die ÖTV diese soziale Verbesserung durchaus mit einigem Recht an die eigene Fahne heften: Ihre Durchsetzungskraft gegenüber den Gemeinden half entscheidend, die Zulage im Herbst 1953 auf Dauer zu sichern. Zugleich aber ging es bei dieser Sache immer auch um die Interessen der Beamten und um die Bemühungen von Politikern sowohl der CDU/CSU wie auch der SPD, die eigene politische Gruppierung als Wohltäter dieser Staatsdiener und ihrer Familien zu profilieren. ${ }^{303}$ Insofern hatte die ÖTV in ihrem gewerkschaftlichen Kampf nicht nur einflussreiche, sondern auch noch mit eigener Entscheidungskompetenz ausgestattete Verbündete, die den Industriegewerkschaften fehlten.

Bei ihren Zugeständnissen an die Beamten reagierten die Politiker zudem auf ein gravierendes ökonomisches und arbeitsmarktpolitisches Problem. Mit dem Wirtschaftsboom der 1950er Jahre entwickelte sich in der bundesdeutschen Privatwirtschaft eine erhebliche »Lohndrift«: Die meisten Beschäftigten erhielten übertarifliche Löhne, weil die Betriebe stark um Arbeitskräfte konkurrierten. Der Öffentliche Dienst kannte hingegen keinen Unterschied zwischen Tariflohn und effektiver Bezahlung: Löhne und Gehälter wurden mit all ihren Bestandteilen exakt nach den dafür geltenden Tabellen berechnet. ${ }^{304}$ Wenn der Staat als Arbeitgeber dennoch

303 | Diese Gemeinsamkeit zeigt sich exemplarisch etwa an der Bundestagsdebatte über die Zulage im November 1952, in der sich die Sprecher aller Parteien (inklusive der damals noch im Bundestag vertretenen KPD) bemühten, einander mit beamtenfreundlichen Forderungen und Formulierungen zu übertreffen (Verhandlungen des Deutschen Bundestages. 1. Wahlperiode. Stenographische Berichte, Bd. 13, Bonn 1952, S. 10973-10992. Konkrete Forderungen an die Bundesregierung, gezielt die Beamtenschaft besser zu stellen, finden sich etwa in: CDU-Landtagsfraktion Schleswig-Holstein an den Bundesminister des Innern, 13.9.1962; Beschluss der CSU-Landesgruppe im Bundestag, 29.9.1962. Beide in: BArch Koblenz, N 1407, 10.

304 | Vgl. grundlegend: Bruno Gleitze: Die Lohndrift als Konjunkturindikator. In: Kurt Nemitz/Richard Becker (Hrsg.): Gewerkschaft, Wirtschaft, Gesellschaft. Beiträge zu wirtschaftlichen und gesellschaftlichen Gegenwartsfragen, Köln 1963, S. 81-92; Harald Gerfin: Ausmass und Wirkung der Lohndrift. In: Lohnpolitik 
attraktiv bleiben wollte, musste er nach Kompensationsmöglichkeiten suchen, und dafür eignete sich das Weihnachtsgeld, obwohl es - wie gesagt gerade bei den Beamten überhaupt nicht zu den »hergebrachten« Regeln ihrer Bezahlung passte.

Da der Arbeitskräftemangel weiter zunahm, entwickelte sich die Sonderzahlung zum Jahresende im Öffentlichen Dienst schon in den frühen 1960er Jahren vollends zu einem eigenständigen Teil der Löhne und Gehälter. Anfang 1964 beschloss der Bundestag im Einvernehmen aller Parteien, auf das bis dahin praktizierte Ritual zu verzichten, das Weihnachtsgeld für die Beamten des Bundes jedes Jahr neu erst kurz vor dem Zahlungstermin zu beschließen. ${ }^{305}$ Noch im gleichen Jahr vereinbarten ÖTV und Arbeitgeber außerdem einen separaten Tarifvertrag, mit dem sich der soziale Charakter der Zulage grundlegend wandelte. Die bislang gewährten festen Summen, die besonders den Interessen der Geringverdiener gedient hatten, verschwanden. Stattdessen erhielten Arbeiter und Angestellte jetzt im Dezember jeweils ein Drittel ihrer individuellen Bezüge zusätzlich. ${ }^{306}$

Darüber hinaus versprachen die Arbeitgeber, dies sei erst der Anfang: Auf mittlere Sicht werde die Zulage zu einem vollen 13. Gehalt ausgebaut. Nur die weiteren Etappen bis zu diesem Ziel blieben offen. Der Tarifvertrag enthielt sogar noch ein weiteres Zugeständnis, denn es gelang der ÖTV, einen Paragrafen durchzusetzen, in dem sich die Arbeitgeber verpflichteten, die für Arbeiter und Angestellte ausgehandelte Regelung ohne Abstriche auf die Beamten zu übertragen. Für die Gewerkschaft war dieser Part der Abmachung ein Triumph: Erstmals hatte sie mit einem Tarifvertrag »beamtenrechtliche Bestimmungen präjudiziert «. ${ }^{307}$ In ihrer Werbung um Beamte strich die Organisation diesen Erfolg groß heraus: Wer sich

und Einkommensverteilung. Verhandlungen auf der Tagung des Vereins für Socialpolitik, Gesellschaft für Wirtschafts- und Sozialwissenschaften in Berlin 1968, Berlin 1969, S. 472-522.

305 | Weihnachtsgeld für Bundesbeamte. In: FAZ, 29.10.1963; Bundesbeamte erhalten Weihnachtsgeld. In: FAZ, 23.1.1964.

306 | ÖTV-Geschäftsbericht 1964/67, S. 51. Vgl. dort auch Angaben zu den komplizierten Details, welche Zulagen und Zuschläge bei der Berechnung des Weihnachtsgeldes einbezogen bzw. ausgeschlossen wurden. Der Kinderzuschlag von $20 \mathrm{DM}$ pro Kind blieb erhalten.

307 | Sechs Prozent mehr Lohn und Gehalt im öffentlichen Dienst. In: FAZ, 26.11.1964. Vgl. auch: Grund zur Zufriedenheit. In: StZ, 27.11.1964. 
immer noch frage, ob die Einheit von Arbeitern, Angestellten und Beamten in der ÖTV auch den nicht streikberechtigten Beamten nütze, der habe jetzt den Beweis, wie positiv die gewerkschaftliche Solidarität der drei Gruppen wirke. ${ }^{308}$

Nüchtern betrachtet verdankte sich der Tarifvertrag vom November 1964 jedoch einer besonders günstigen Situation. Zum einen kann dieses Jahr als einer der Höhepunkte des Nachkriegsbooms gelten. Damit verschärfte sich die Lohndrift in der Privatwirtschaft; dementsprechend wuchs die Sorge der staatlichen Arbeitgeber, in der Konkurrenz um qualifizierte Beschäftigte abgehängt zu werden. ${ }^{309}$ Deshalb verschwand die bislang stark sozial orientierte Sonderzahlung gerade in diesem Jahr; deshalb trat eine lineare Lohn- und Gehaltserhöhung an ihre Stelle, die Besserverdienende bevorzugte. ${ }^{310}$ Der vergleichende Blick auf die Privatwirtschaft enthüllt die arbeitsmarktpolitische Funktion des Tarifvertrags. Dort war ein Weihnachtsgeld zur gleichen Zeit nach wie vor »eher Ausnahme als Regel«. Juristisch verbindlich gesichert hatte es nur die Gewerkschaft Handel, Banken und Versicherungen. ${ }^{311}$

Zum anderen ging die Großzügigkeit der Arbeitgeberseite stark auf das Konto der Bundesregierung. Die Koalition von CDU/CSU und FDP bereitete sich im Herbst 1964 schon auf die nächste Bundestagswahl vor, die im September 1965 anstand. Die CSU wünschte sich in dieser Situation einen handfesten und langfristig weiter wirkenden Beweis für die beam-

308 | Vgl. etwa das speziell für Beamte formulierte Flugblatt »Ein offenes Wort«, das wahrscheinlich aus dem Dezember 1964 stammt. Ein Exemplar in: Archiv Ver.di, Bestand Kluncker, 45. Vgl. auch: ÖTV-Geschäftsbericht 1964/67, S. 323.

309 | Vgl. zusammenfassend etwa: ÖTV-Geschäftsbericht 1964/67, S. 47.

310 | Die Steuerprogression konnte diesen Effekt allerdings deutlich dämpfen. Genauere Informationen, die es erlauben würden, diesen Effekt präziser zu bestimmen, liegen allerdings nicht vor.

311 | Wahlpolitik statt Wirtschaftspolitik. In: FAZ, 28.11.1964. Zu den Regelungen für die Beschäftigten von Banken und Versicherungen (die deutlich großzügiger ausfielen als im Öffentlichen Dienst) vgl. als Überblick: Banken zahlen bis zu 15 Gehälter. In: FAZ, 8.12.1964. Vertraglich vereinbart war zu diesem Zeitpunkt eine Sonderzahlung von 1,5 Monatsgehältern, die in drei Raten, verteilt über das Jahr, ausgezahlt wurde. Durch zusätzliche gewinnabhängige Vergütungen kamen viele Beschäftigte aber auf noch größere Summen. 
tenfreundliche Haltung der christlichen Parteien. ${ }^{312}$ Wie die konservative FAZ kritisch kommentierte, war die Umwandlung der Weihnachtszulage sowie das Versprechen, sie in der Zukunft noch weiter auszubauen, gleich auf doppelte Weise ein »Wahlgeschenk«, das die Etats dauerhaft belaste. ${ }^{313}$ Auch das Wirtschaftsblatt Industriekurier klagte über die finanziellen Folgen und warnte, die öffentlichen Arbeitgeber würden mit ihrer Entscheidung »eine Bresche für das tarifliche Weihnachtsgeld in der gesamten Wirtschaft schlagen ${ }^{3} .14$

1968, als die ÖTV mit dem Auslaufen der Vereinbarung vom Herbst 1964 erstmals die Chance erhielt, erneut über das Weihnachtsgeld zu verhandeln, war der vertraglich abgesicherte Zuschlag zum Jahresende jedoch immer noch eine Besonderheit des Öffentlichen Dienstes und der Banken. ${ }^{315}$ Gerade auch deshalb stieß die Gewerkschaft mit ihrer Forderung, die Sonderzahlung weiter aufzustocken, auf Widerstand. Von einflussreicher Seite wurde der Bundesinnenminister gewarnt, in dieser Angelegenheit nachzugeben: Die Bundesvereinigung der Deutschen Arbeitgeberverbände entsandte zweimal eigens hochrangige Vertreter nach Bonn, um »dringend um Zurückhaltung der öffentlichen Hand« bei einer Erhöhung des Weihnachtsgeldes zu bitten. Werde dieser Wunsch ignoriert, sei mit Kompensationsforderungen der Industriegewerkschaften zu rechnen, insbesondere bei der »Vermögensbildung« für die Arbeitnehmer, um die es dankenswerter Weise - mit der Wirtschaftskrise von 1967 »öllig still geworden« sei. ${ }^{316}$

312 | Vgl.: Der Vorsitzende der CSU-Landesgruppe im Bundestag, Franz Josef Strauß, an Bundeskanzler Ludwig Erhard, 5.3.1964. In: BArch Koblenz, N 1407, 10. 313 | Wahlpolitik statt Wirtschaftspolitik. In: FAZ, 28.11.1964.

314 | Vorreiter. In: Industriekurier, 26 11.1964.

315 | Vgl. den Überblick in: Am Weihnachtsgeld wird nicht gespart. In: FAZ, 2.12.1970. Zwar zahlten de facto offensichtlich mittlerweile viele Betriebe ein Weihnachtsgeld. Dabei handelte es sich aber nicht um tarifvertraglich gesicherte Leistungen, sondern um freiwillige Zahlungen, die jeder Arbeitgeber frei gestalten konnte. Üblich waren wohl nach Dauer der Betriebszugehörigkeit und auch nach dem Alter gestaffelte Zahlungen. Offizielle Statistiken über diese Bestandteile des Einkommens gibt es nicht.

316 | Vermerk von StS Gumbel über die Besprechung mit dem Hauptgeschäftsführer u. Geschäftsführer der BDA, 21.3.1968. In: BArch Koblenz, B 106, 37702. Ähnlich auch: Vermerk über das Gespräch StS Gumbel mit Vertretern der BDA, 
Im mehrmonatigen Verhandlungsprozess, in dem die öffentlichen Arbeitgeber und die Gewerkschaft im Sommer und Herbst 1968 über ein höheres Weihnachtsgeld stritten, akzeptierte die ÖTV am Ende einen Kompromiss: Die Sonderzuwendung für die Beschäftigten des Staates stieg nicht auf zwei Drittel der jeweils individuellen Bezüge, sondern nur auf 40 Prozent. Allerdings wurde sie noch 1968 in dieser Höhe ausgezahlt, d.h., der Lohn- und Gehaltsabschluss des Vorjahres wurde in der Tat nachträglich korrigiert, obwohl sich die Arbeitgeber dagegen anfangs noch heftig wehrten. $^{317}$

Wie oben schon angedeutet wurde, verteilten sich die tarifpolitischen Rollen im Lager der Arbeitgeber in dieser Verhandlungsrunde ganz anders als 1967. Beim Bund war die ungewöhnliche Aktionseinheit von Innen-, Wirtschafts- und Finanzminister zerbrochen, die in der Krise des Vorjahres noch gemeinsam dafür gestritten hatten, den Öffentlichen Dienst trotz leerer staatlicher Kassen finanziell besser zu stellen. Franz Josef Strauß profilierte sich nun vielmehr in der klassischen Rolle eines Finanzministers, d.h. als Hüter des Etats und Prediger staatlicher Sparsamkeit. Auch der Innenminister zog nicht mehr mit dem Wirtschaftsminister an einem Strang. Vielmehr beklagte er sich, Karl Schiller bringe ihn »in eine äußerst mißliche und politisch schwierige Lage«, weil dessen volkswirtschaftlich orientierte Prognosen und Rezepte die staatlichen Finanznöte ignorierten. Die ökonomische Entwicklung schlage sich nun einmal »nicht sofort in den Kassen der öffentlichen Hand nieder«, d. h., Schillers »Orientierungs-

2.5.1968. In: BArch Koblenz, B 106, 37703. Zwischen diesen beiden Gesprächen wechselte die Amtsführung im Innenministerium, weil Paul Lücke von seinem Amt zurücktrat, als eines seiner politischen Lieblingsprojekte - die Einführung eines Mehrheitswahlrechts - scheiterte. Sein Nachfolger wurde der CDU-Politiker Ernst Benda. Auswirkungen auf die Verhandlungsführung in der Tarifrunde hatte dieser Wechsel nicht.

317 | Vgl. dazu: Bericht des Tarifsekretariats über die Tarifverhandlungen für den Öffentlichen Dienst, 7.10.1968; Bericht des Tarifsekretariats, 16./17.10.1968. Beide in: Archiv Ver.di, Bestand Kluncker, 13. Nach Angaben des Innenministers entsprach die Anhebung des Weihnachtsgeldes einer weiteren Lohn- und Gehaltserhöhung für 1968 von 0,6 Prozent (BMdI an den Chef des Bundeskanzleramtes, 17.10.1968. In: BArch Koblenz, B 106, 37702). 
daten« für die Lohnfindung seien gerade für den Staat eher ein tarifpolitisches Problem als eine Hilfe. ${ }^{318}$

Länder und Gemeinden hingegen verzichten auf einen weiteren Versuch, gegenüber der ÖTV eine betont »harte« Linie zu fahren. Gerade in der Endphase der Tarifverhandlungen zwangen sie vielmehr den widerstrebenden Bundesinnenminister, die Erhöhung auf 40 Prozent noch für $1968 \mathrm{zu}$ akzeptieren, weil sie intern wissen ließen, man werde der ÖTV in separaten Verträgen mehr gewähren, wenn kein einheitlicher Vertrag zustande komme. Der Ablauf des Vorjahres wiederholte sich also mit vertauschten Rollen. Angesichts dieser Drohung fügte sich der Minister, obwohl er überzeugt war, es sei »ein Fehler«, der Gewerkschaft nachzugeben. Trotz einiger Kritik stimmte auch das Kabinett dem Verhandlungsergebnis zu, und es akzeptierte zugleich einen Stufenplan, der das bislang ganz vage Versprechen, die Zulage zu einem vollen 13. Gehalt auszubauen, etwas konkreter machte: 1971 sollten bereits zwei Drittel des individuellen Gehalts gezahlt werden. ${ }^{319}$

Nach kurzer Verzögerung wurden alle diese Bestimmungen wiederum auf die Beamten und die Ruhegeldempfänger ausgedehnt, obwohl die Angelegenheit zumal für Bund und Länder damit erst richtig teuer wurde. Wie schon einmal in den 1950er Jahren spielte dabei eine inoffizielle Ko-

318 | In der Reihenfolge der Zitate: BMdI an Bundeskanzler Kurt-Georg Kiesinger, 20.3.1968. In: BArch Koblenz, B 106, 37702; Bericht des Tarifsekretariats über die Tarifverhandlungen für den Öffentlichen Dienst, 7.10.1968. In: Archiv Ver.di, Bestand Kluncker, 13. Vgl. auch: Vermerk von Referat D II 2 für das Spitzengespräch über die tarifpolitische Lage im öffentlichen Dienst, 17.9.1968. In: BArch Koblenz, B 106, 37702. Zur Position des BFM vgl. etwa: Die Kabinettsprotokolle der Bundesregierung, Bd. 21: 1968. Bearb. v. Christian Fabian/Uta Rössel, München 2011 (im Folgenden: Kabinettsprotokolle Bundesregierung 1968), S. 405 (Kabinettssitzung v. 16.10.1968).

319 | Das Zitat aus: Stefan Marx (Bearb.): Der Kreßbronner Kreis. Die Protokolle des Koalitionsausschusses der ersten Großen Koalition aus CDU, CSU und SPD, Düsseldorf 2013, S. 194. Vgl. auch: BMdI an den Chef des Bundeskanzleramtes, 17.10.1968. In: BArch Koblenz, B 106, 37702 (hiernach wollte die TdL eine Erhöhung auf 50 Prozent akzeptieren; in der VKA seien die Vertreter der Großstädte sogar bereit, bis zu zwei Drittel zu zahlen); Kabinettsprotokolle Bundesregierung 1968, S. 418 f. (Kabinettssitzung v. 23.10.1968). Ende 1969 stieg das Weihnachtsgeld auf 50 Prozent der jeweiligen Bezüge. Auch dieser Schritt wurde im Tarifvertrag von 1968 fest vereinbart. 
alition der hessischen SPD mit der CSU in Bayern eine wichtige Rolle: Auf Antrag der jeweiligen Regierungspartei (aber wiederum mit den Stimmen der Opposition) beschlossen die beiden Landtage die Gleichstellung der hessischen und bayerischen Landesbeamten, während die Bundesregierung sich noch bemühte, einer solchen Kostensteigerung zu entgehen und daraufhin gab der Bund dann auch in diesem Fall seinen Widerstand auf. ${ }^{320}$ Dabei hatten die Postbeamten wirkungsvoll geholfen: Sie praktizierten aus Protest gegen die restriktive Haltung der Regierung in Bonn einen »Dienst nach Vorschrift«, der an den Schaltern zu langen Schlangen führte. Die Vorstellung, dafür in der beginnenden Adventszeit verantwortlich gemacht zu werden, behagte Bundeskanzler Kurt Georg Kiesinger und seinen Ministern offensichtlich so wenig, dass sie alle finanziellen Bedenken beiseite schoben. ${ }^{321}$

Wie dieser Ablauf zeigt, herrschte in der Tarifrunde von 1968 - im Vergleich zum Vorjahr - auf der Seite der Arbeitgeber wieder der politische Alltag. Innen- und Finanzministerium des Bundes übernahmen ihre traditionellen Rollen offensichtlich sowohl aus wirtschaftlichen wie auch aus politischen Gründen. Da die Wirtschaftskrise überwunden war, hielten die beiden Ressortleiter weitere Konjunkturanstöße durch eine Expansion der staatlichen Ausgaben für entbehrlich. Wirtschaftsminister Schiller aber war damit beschäftigt, die Instrumentarien der ökonomischen »Globalsteuerung« dauerhaft zu etablieren. Anders als im Vorjahr enthielt er sich deshalb jeder direkten Intervention in den Tarifkonflikt zwischen ÖTV und Staat. Dazu kamen die parteipolitischen Spannungen innerhalb der Großen Koalition, die ja nur als Übergangs- und Notlösung entstanden war: Mit der im Spätsommer 1969 anstehenden Bundestagswahl wollten sowohl die Konservativen als auch die Sozialdemokraten das Experiment wieder beenden. Wenn CDU und CSU wieder auf eine sparsame Haushaltsführung pochten, bereiteten sie damit vermutlich schon den kommenden Wahlkampf vor. ${ }^{322}$

320 | Vgl.: Weihnachtsgeld für hessische Beamte. In: FAZ, 30.10.1968; Weihnachtsgeld. In: FAZ, 19.11.1968; Bayern zahlt höheres Weihnachtsgeld. In: FAZ, 20.11.1968; Höheres Weihnachtsgeld für alle Beamten. In: FAZ, 26.11.1968.

321 | Vgl. Theodor Eschenburg: Dienst nach Vorschrift. In: Die Zeit, 29.11.1968. 322 | $\mathrm{Zu}$ den wachsenden Spannungen innerhalb der Koalition vgl. allgemein: Klaus Schönhoven: Wendejahre. Die Sozialdemokratie in der Zeit der Großen Ko- 
Ländern und Gemeinden schließlich scheint in den Streitigkeiten des Vorjahres die Lust vergangen zu sein, Tariffragen mit dem Problem des Finanzausgleichs zu vermengen. Insofern dominierte bei diesen Akteuren - zumal bei den Gemeinden - nun wieder die traditionsreiche Furcht, das öffentliche Leben werde schwer gestört, wenn die Beschäftigten des Staates die Arbeit niederlegten. Die in dieser Tarifrunde wieder zu verzeichnende Bereitschaft von TdL und VKA, der ÖTV schon nach kurzem, hinhaltendem Widerstand nachzugeben, ist insofern bemerkenswert, als die Gewerkschaft - in Gestalt ihres höchsten Repräsentanten Heinz Kluncker - bei den Verhandlungen von 1968 erneut keineswegs massiv fordernd oder drohend auftrat. Sie hielt sich sogar eher noch stärker zurück als im Herbst 1967.

So erklärte der Gewerkschaftsvorsitzende im Juli 1968 bei einer inoffiziellen Besprechung mit Bundesinnenminister Ernst Benda ausdrücklich und ungefragt, die von der ÖTV verlangte Aufstockung des Weihnachtsgeldes auf einen Zwei-Drittel-Lohn noch im laufenden Jahr sei »nicht als >unabdingbar anzusehen. Verhandlungsspielraum sei durchaus gegeben. ${ }^{323}$ Im September sagte Kluncker bei einem »Spitzengespräch« mit Vertretern von Bund, TdL und VKA zur Vorbereitung der offiziellen Verhandlungen noch etwas deutlicher, »daß die Forderung auf Erhöhung auf zwei Drittel für 1968 nur eine Maximalforderung sei - womit er eigentlich schon mehr erklärt habe, als er eigentlich dürfe ${ }^{324}$

Das mit diesen Einladungen zu einem Kompromiss erreichte Angebot der Arbeitgeber, das Weihnachtsgeld auf 40 Prozent des Entgelts zu erhöhen, beeindruckte viele Mitglieder der Großen Tarifkommission überhaupt nicht. Nach dem Bericht des Tarifsekretariats über den Verlauf dieser Beratungen wurde »sehr kritisch" diskutiert: Der Aufschlag sei zu gering, der ursprünglich verlangte Zwei-Drittel-Satz werde zudem erst 1971 und damit viel zu langsam erreicht. Mit einem solchen Abschluss würden »die

alition 1966-1969, Bonn 2004, S. 429-486; Edgar Wolfrum: Die 60er Jahre. Eine dynamische Gesellschaft, Darmstadt 2006, S. 16f. u. 45; Arnulf Baring (in Zusammenarbeit mit Manfred Görtemaker): Machtwechsel. Die Ära Brandt-Scheel, Stuttgart 1982, S. 27-62.

323 | Vermerk des Referats D II 2 über die Besprechung von BMdI Benda mit dem ÖTV-Vorsitzenden Heinz Kluncker, 12.7.1968. In: BArch Koblenz, B 106, 37702.

324 | Vermerk über das Spitzengespräch in Bonn, 19.9.1968. In: ebd. 
Erwartungen der Kollegen nicht erfüllt«. Als Heinz Kluncker auf den finanziell motivierten Widerstand der Arbeitgeber verwies, hielten ihm die Delegierten genau das Argument von der politischen Formbarkeit der staatlichen Etats entgegen, das der Vorsitzende im Vorjahr in einer ganz anderen ökonomischen Situation formuliert hatte: »Es wurde betont, daß eben die Haushalte von vornherein anders hätten aussehen müssen oder aber Nachtragshaushalte eingebracht werden müßten. « 325

Dennoch erreichte Heinz Kluncker schließlich ein mehrheitlich positives Votum. Eine Ablehnung des Vertrages durch die Große Tarifkommission, so warnte er, werde die Arbeitgeber nicht zu einem besseren Angebot bewegen. Dann müsse die Gewerkschaft zwangsläufig einen Streik organisieren - es sei aber doch sehr fraglich, wie stark die Kollegen sich daran beteiligen würden, wenn die Arbeitgeber gleichzeitig das Weihnachtsgeld in alter Höhe auszahlten. Da der Widerspruch auch nach diesen skeptischen Worten des Vorsitzenden noch nicht verstummte, schob Kluncker ein tarifpolitisches Versprechen nach: Er werde die Arbeitgeber auffordern, bereits 1969 die "Anspruchsvoraussetzungen« für das Weihnachtsgeld neu auszuhandeln. Erst daraufhin akzeptierte die Kommission das von Kluncker vereinbarte Ergebnis. ${ }^{326}$

Anschließend bat der Gewerkschaftsvorsitzende das Innenministerium tatsächlich um die Vorbereitung solcher Beratungen, wobei er betonte, es sei ihm »nur mit großer Mühe« gelungen, eine »ablehnende Haltung« der Großen Tarifkommission zu verhindern. Gleichzeitig aber trug er seine Forderung in einer Art und Weise vor, die wohl kaum den Beifall der Tarifkommission gefunden hätte. Es sei ihm klar, sagte Kluncker nach den Aufzeichnungen eines Ministerialbeamten, dass für 1969 »keine Änderung der Bemessungsgrundlage erreicht werden könne«, weil die Arbeitgeber dazu frühestens 1970 bereit seien. Verhandeln aber müsse man, damit »die Bedingung der Großen Tarifkommission als erfüllt anzusehen« sei. Das

325 | Bericht des Tarifsekretariats über die Tarifverhandlungen für den Öffentlichen Dienst, 16./17.10.1968. In: Archiv Ver.di, Bestand Kluncker, 13.

326 | Ebd. Im Kern sollte es bei den verlangten Zusatzverhandlungen um die "Bemessungsgrundlage " gehen, d.h. um die Frage, welche Bestandteile der jeweils individuellen Bezüge in die Berechnung des Weihnachtsgeldes eingingen und welche nicht. 
Ministerium möge deshalb bitte darauf verzichten, die gewerkschaftliche Forderung öffentlich schon vorab eindeutig abzulehnen. ${ }^{327}$

Der Vorsitzende vereinbarte also ein Vorgehen, das den Auftrag »seiner« Organisation nur formal erfüllte. Dieses Verhalten mag man befremdlich finden. Die oben gemachten Ausführungen über die Kunst des freien Verhandelns sollten allerdings helfen, moralisierende Urteile dieser Art zu relativieren. In der Tarifrunde um das Weihnachtsgeld, so denke ich, sehen wir, wie Heinz Kluncker versuchte, jenes Vertrauen zwischen den Tarifpartnern zu stiften und zu bestärken, das für die Suche nach Kompromissen in Tarifverhandlungen entscheidend wichtig ist. Offensichtlich räumte er der Erhöhung des Weihnachtsgeldes und stärker noch der Frage, wie dessen »Bemessungsgrundlage « aussehen solle, tarifpolitisch eine eher geringe Bedeutung ein, während diese Angelegenheit an der Basis der Organisation und auch in der Großen Tarifkommission als ziemlich wichtig galt. Dementsprechend nutzte er die Gelegenheit, um sich den Arbeitgebern als flexibler Partner zu präsentieren, der im internen Gespräch unter Umständen souverän von den Vorgaben der ÖTV-Gremien abweichen konnte.

Die Quellen sagen uns nicht, warum Heinz Kluncker so dachte und handelte. Möglicherweise ging es ihm darum, den Verhandlungsspielraum für die kurz bevorstehende eigentliche Lohn- und Gehaltsrunde möglichst nicht einzuschränken. 1969 wollte die ÖTV nicht einfach nur eine weitere Erhöhung: Sie verlangte vielmehr den Monatslohn für Arbeiter und Arbeiterinnen - und diese bereits ältere Forderung gehörte zu den zentralen strukturellen Zielen der Organisation. ${ }^{328}$ Möglicherweise fürchtete Kluncker grundsätzlich, der Öffentliche Dienst könne in die Kritik geraten, wenn er der Privatwirtschaft beim Ausbau des tariflich gesicherten Weihnachtsgeldes weit vorauseilte. Deutlich wird in jedem Fall der Drahtseilakt, den ein gewerkschaftlicher Verhandlungsführer zu bewältigen hatte, der tarifpolitisch hinter den Kulissen eigenmächtig handelte: Die Gremien der Organisation saßen ihm im Nacken; ihre Zustimmung zu Verhandlungsergebnissen war keinesfalls sicher.

327 | Vermerk des Unterabteilungsleiters Abteilung D II über das vertrauliche Gespräch mit dem ÖTV-Vorsitzenden Heinz Kluncker, 23.10.1968. In: BArch Koblenz, B 106, 37702.

328 | Siehe dazu genauer unten S. 307-312. 
Insofern besaß ein Gewerkschaftsvorsitzender wie Heinz Kluncker, der in zentral geführten Tarifrunden selbst mit den Arbeitgebern beriet, einerseits beträchtliche Gestaltungsmöglichkeiten. Andererseits aber musste er Eigenmächtigkeiten doch genau überlegen und planvoll dosieren, denn bei Konflikten drohte ein Gesichtsverlust nicht nur innerhalb der »eigenen« Organisation, sondern auch gegenüber den Tarifpartnern, denen der Vorsitzende unter der Hand entgegengekommen war. In Tarifverhandlungen war ein Gewerkschaftsvorsitzender daher paradoxerweise ein Autokrat, der sich schon im eigenen Interesse selbst streng zu kontrollieren hatte.

\section{"Wilde Streiks", ein gültiger Tarifvertrag und die Bundestagswahl von 1969}

Der SPD-Kanzlerkandidat war sehr besorgt. "Wenn es im öffentlichen Dienst zu Streiks kommt, dann kann das die SPD noch den Sieg kosten«, so klagte Willy Brandt im September 1969, nur wenige Tage vor der Bundestagswahl, für die alle Demoskopen ein knappes Resultat voraussagten, weil SPD und CDU/CSU bei Umfragen nahe beieinander lagen. ${ }^{329}$ Kurz vor dem Ziel fürchtete Brandt, der zum dritten Mal kandidierte, die Eskalation eines Konfliktes, den es nach den Regeln des Tarifrechts gar nicht geben durfte: In mehreren bundesdeutschen Städten ignorierten kommunale Arbeiter und Angestellte die Friedenspflicht, die ein gültiger Tarifvertrag mit sich bringt. Sie legten auf eigene Faust die Arbeit nieder, um ad hoc Lohnforderungen durchzusetzen; eine Ausweitung dieser »wilden Streiks« galt als möglich.

Diese Perspektive erschreckte nicht nur die SPD, die um ihren Wahlsieg bangte, weil allgemein erwartet wurde, Störungen der öffentlichen Ordnung durch große Streiks etwa bei der Müllabfuhr, den kommunalen Versorgungsbetrieben oder auch im Nahverkehr würden unentschlossene Wähler zu den konservativen Parteien treiben. Die ÖTV fürchtete ebenfalls weitere spontane Arbeitsniederlegungen. Sie fürchtete sie als Gewerkschaft, deren Legitimität litt, wenn Arbeiter und Angestellte einen Ausstand ohne »ihre« institutionalisierte Interessenvertretung begannen; sie fürchtete sie als Organisation, die in all ihren Instanzen eng mit der SPD verflochten war und daher selbstverständlich einen Sozialdemokraten im Kanzleramt sehen wollte.

329 | Gut für Rechts. In: Der Spiegel 23 (1969), H. 39, S. 100. 
Unversehens stand die ÖTV deshalb im Spätsommer 1969 vor der Aufgabe, ihre eigene Basis gleichzeitig zu disziplinieren und materiell zufriedenzustellen. Dieser Zwickmühle entkam die Gewerkschaft allerdings rasch und ohne Schaden zu nehmen. Die Verflechtung der Organisation und ihrer gewerkschaftlichen Arbeit mit der Politik, die das Problem der "wilden« Streiks im September 1969 so besonders gewichtig machte, sorgte für dieses glimpfliche Ende: Die Arbeitgeber agierten uneiniger als je zuvor - und das nutzte der Gewerkschaft. Damit erlebte die ÖTV zum dritten Mal seit 1967 Tarifverhandlungen, in denen sich die Gegenseite aus politischen Gründen anders gruppierte als im Jahr zuvor.

Die nicht gewerkschaftlich organisierten "September-Streiks" von 1969 waren keine Besonderheit des Öffentlichen Dienstes. Sie begannen vielmehr in der Privatwirtschaft und waren dort fast schon wieder vorbei, als auch Beschäftigte des Staates "wild« die Arbeit niederlegten. Die Zeitgenossen haben diese Welle spontaner Streiks, die niemand erwartet hatte, sehr ernst genommen. Sahen konservative Kreise die Bundesrepublik schon am Rande von Krawall und Chaos, so meinten viele Linke (gerade an den Universitäten und unter den Studenten), sie erlebten die Wiedergeburt der revolutionären Arbeiterklasse. Tatsächlich war diese doppelte Aufregung jedoch schlicht voreilig. Die »September-Streiks" zwangen zwar die Gewerkschaften, ihre Methoden der Interessenvertretung zu überdenken. Eine neue Phase in der bundesdeutschen Sozialgeschichte markierten sie jedoch nicht. Sie entstanden, weil viele Arbeiter dank der Hochkonjunktur und des Arbeitskräftemangels sehr selbstbewusst auftraten und weil das Gefühl um sich griff, nicht angemessen an den jüngsten wirtschaftlichen Erfolgen der Unternehmer beteiligt zu werden, während gleichzeitig die Lebenshaltungskosten stiegen. ${ }^{330}$

330 | Vgl. zu den Streiks in der Privatwirtschaft: Peter Birke: Wilde Streiks im Wirtschaftswunder. Arbeitskämpfe, Gewerkschaften und soziale Bewegungen in der Bundesrepublik und Dänemark, Frankfurt/Main und New York 2007, S. 218249; zu Veränderungen in den Gewerkschaften nach den Streiks vgl. etwa: Karl Lauschke: Der Wandel in der betrieblichen und gewerkschaftlichen Interessenvertretung nach den westdeutschen Septemberstreiks. In: Bernd Gehrke/GerdRainer Horn (Hrsg.): 1968 und die Arbeiter. Studien zum »proletarischen Mai« in Europa, Hamburg 2007, S. 76-91. 
Diese spontanen Arbeitsniederlegungen, an denen sich insgesamt rund 140.000 Arbeiter vor allem in Betrieben der Metallindustrie sowie im Bergbau in Nordrhein-Westfalen und in Baden-Württemberg beteiligten, fanden ein rasches Ende, weil Arbeitgeber und Gewerkschaften gemeinsam sehr flexibel reagierten: Die Gewerkschaften übernahmen die materiellen Forderungen der Streikenden; die Industriellen erklärten ihre Bereitschaft, in Lohnverhandlungen einzutreten, obwohl damit die laufenden Tarifverträge gebrochen wurden. Einzelne Betriebsleitungen (insbesondere in der florierenden Metallbranche) gewährten sogar umgehend mehr Geld, ohne groß zu verhandeln. Der »wilde« Protest wurde so erfolgreich besänftigt. ${ }^{331}$

Diese Entwicklung war - wie gesagt - bereits weit fortgeschritten, als am 10. und 11. September 1969 in Duisburg und Essen erstmals auch Beschäftigte des Öffentlichen Dienstes auf eigene Faust in den Streik traten. In Essen legten mehrere Hundert Mitarbeiter der städtischen Verkehrsbetriebe die Arbeit nieder; in Duisburg streikte die Mehrheit der Müllmänner. In beiden Fällen verlangten die Ausständigen eine sofort wirksam werdende Aufstockung ihrer Löhne um 100 oder auch 150 DM pro Monat. ${ }^{332}$ Die ÖTV wurde von diesen Aktionen überrascht, obwohl es vergleichbare spontane Streiks in der Industrie schon seit mehr als einer Woche gab. Rückblickend konstatierte Heinz Kluncker, die Organisation habe - wie schon die Industriegewerkschaften - »die wirkliche Stimmung in den Betrieben« nicht gekannt: Weder von einem der Bezirksleiter noch von einer

331 | Längere Ausstände blieben eine Ausnahme. Fast die einzigen Beispiele waren in den Stahlwerken von Klöckner in Bremen sowie bei der Howaldtswerft in Kiel zu verzeichnen. Vgl.: Birke: Streiks, S. 229.

332 | Vgl. zusammenfassend den Bericht in: Protokoll über die gemeinsame Sitzung des HV und der GTK, 18.9.1969. In: AdsD, 5/ÖTVB130016 B. Anfang 1969 war für den Öffentlichen Dienst eine lineare Lohnerhöhung um sechs Prozent vereinbart worden. Nach den Angaben des Bundesinnenministers waren die in den Bundesetat eingestellten »Personalverstärkungsmittel « für Neueinstellungen und Besoldungsverbesserungen damit bereits »nahezu ausgeschöpft" (Die Kabinettsprotokolle der Bundesregierung, Bd. 22: 1969. Bearb. v. Walter Naasner/ Christoph Seemann, München 2012 [im Folgenden: Kabinettsprotokolle Bundesregierung 1969], S. 76 (Kabinettssitzung v. 22.1.1969). Zu den zahlreichen weiteren Punkten, die darüber hinaus in dieser Tarifrunde verhandelt worden waren, siehe bereits S. $215 \mathrm{f}$. 
Betriebsgruppe habe es eine »Alarmmeldung« an die Verbandsführung gegeben. ${ }^{333}$

Allerdings reagierte die ÖTV sofort. In den beiden Ruhrgebietsstädten machte sie sich die Forderungen der Streikenden zu eigen, mahnte gleichzeitig aber zu gewerkschaftlicher Disziplin. In Essen ging der Streik damit zu Ende. Zeitgleich kündigte der gHV an, die ÖTV werde in Kürze die öffentlichen Arbeitgeber auffordern, zentral über einen Lohnzuschlag zu beraten. Eine außerplanmäßige Sitzung von Hauptvorstand und Großer Tarifkommission wurde angesetzt, um einen Forderungskatalog zu entwickeln; zudem begannen Gespräche mit der DAG über ein gemeinsames Vorgehen. ${ }^{334} \mathrm{Um}$ zu beweisen, wie ernst sie die »Stimmung « der Beschäftigten nahmen, verlangten die Vorsitzenden der beiden Gewerkschaften am 16. September 1969 in einem »Spitzengespräch« mit Bundesinnenminister Benda zügige Verhandlungen mit Bund, Ländern und Gemeinden, ohne sich dabei auf konkrete Zahlen festzulegen. Gäbe es keine raschen Gespräche, so sagte Heinz Kluncker, dann lehne die ÖTV »jede Verantwortung für die entstehenden Folgen $a b$ «. Der Minister aber verwies abwehrend auf die geltenden Tarifverträge, die erst zum Jahresende ausliefen und - wie fast alle Lohn- und Gehaltsverträge - keine außerordentliche Kündigung zuließen. Zudem könne die Bundesregierung so kurz vor der Parlamentswahl, die am 28. September anstand, keine Beschlüsse mehr fällen, die das nachfolgende Kabinett finanziell banden. ${ }^{335}$

Diese juristische Begründung hielt die Gewerkschaften jedoch nicht davon ab, ihr Vorhaben zu konkretisieren. Am 18. September beschlossen Hauptvorstand und Tarifkommission der ÖTV gemeinsam, eine Lohnaufbesserung von pauschal $100 \mathrm{DM}$ pro Monat für jeden Beschäftigten des Staates zu verlangen; die DAG, die nichts von "nivellierenden« Tarifforderungen hielt, legte sich hingegen auf ein lineares Plus von 15 Prozent fest. ${ }^{336}$ Diese insistierenden Forderungen fielen den Organisationen keines-

333 | Wortprotokoll der HV-Sitzung, 9.12.1969. In: AdsD, 5/ÖTVB130016 B.

334 | ÖTV-Tarifgespräch am Dienstag. In: FAZ, 13.9.1969.

335 | Stichwort-Protokoll des Tarifgesprächs im BMdI, 16.9.1969. In: Archiv Ver.di, Bestand Kluncker, 17. Vgl. auch Bendas zusammenfassenden Bericht in: Kabinettsprotokolle Bundesregierung 1969, S. 257 f. (Kabinettssitzung v. 23.9.1969). 336 | Jetzt Streikwelle im öffentlichen Dienst? In: FAZ, 19.9.1969. Zahlungsbeginn sollte jeweils der 1. Oktober 1969 sein. 
wegs leicht. So gab es in den Beratungen der ÖTV-Gremien gleich mehrere Warnungen, die Gewerkschaft müsse mit Schadensersatzklagen rechnen, wenn sie trotz eines gültigen Tarifvertrages offiziell mehr Geld für die Beschäftigten verlange und es gleichzeitig zu weiteren Streiks im Öffentlichen Dienst komme. Andere Mitglieder des Hauptvorstandes und der Tarifkommission meinten jedoch, die ÖTV habe, wenn sie »in den nächsten Wochen bestehen « wolle, gar keine andere Handlungsoption, als sich »hinter die in Ausstand stehenden Kollegen zu stellen«. Einige Delegierte hegten sogar die Hoffnung, mit den spontanen Streiks entstehe eine neue Arbeiterbewegung: „Dies ist der Zeitpunkt, endlich eine aktive Mitgliedschaft im öffentlichen Dienst zu bekommen«, rief voller Enthusiasmus etwa Günter Noack als Vertreter des Bezirks Berlin. ${ }^{337}$

Nach kontroverser Debatte billigten Hauptvorstand und Große Tarifkommission die Forderung nach der pauschalen Zulage mit deutlicher Mehrheit. Vorschläge, den Arbeitgebern zugleich ein Ultimatum zu stellen und eine Urabstimmung anzusetzen, wurden jedoch abgelehnt. Auffälliger Weise hat sich Heinz Kluncker in diesen Streitigkeiten ganz bedeckt gehalten: Das Protokoll der Beratungen vermerkt keinen inhaltlich substanziellen Redebeitrag des Vorsitzenden. ${ }^{338}$ Der Konflikt mit den öffentlichen Arbeitgebern so kurz vor der Bundestagswahl, den die ÖTV nach den ersten "wilden« Streiks zu ihrer Sache machte, war - so scheint es - keine Herzensangelegenheit des Vorsitzenden.

In einigen größeren Städten kam es unmittelbar nach dem offiziellen Beschluss der ÖTV-Gremien zu weiteren Arbeitsniederlegungen von kommunalen Beschäftigten. In West-Berlin etwa streikten 1.200 Beschäftigte der Müllabfuhr sowie weitere Arbeiter der Straßenreinigung und Fahrer von U-Bahnen und Omnibussen. In Offenbach, der Industriestadt vor den

337 | Protokoll über die gemeinsame Sitzung des HV und der GTK, 18.9.1969. In: AdsD, 5/ÖTVB130016 B. Die Furcht vor juristischen Folgen bezog sich auf ein Urteil des Bundesarbeitsgerichts vom Dezember 1963, das "wilde Streiks« als "nicht sozialadäquat« bewertete, sowie auch auf eine bereits ältere Entscheidung dieses Gerichts vom Dezember 1958, wonach es bei Verstößen gegen die Friedenspflicht eine "gesamtschuldnerische Haftung« der Ausständigen für entstehende Schäden gebe. Vgl. dazu in kritischer Perspektive: Thilo Ramm: Der wilde Streik. In: Arbeit und Recht 12 (1964), S. 353-362.

338 | Ebd. 
Toren von Frankfurt am Main, verursachte schon ein einstündiger Ausstand von 4.000 Arbeitern und Angestellten fast aller Bereiche des Öffentlichen Dienstes ein Verkehrschaos, wie es die Stadt noch nicht erlebt hatte, weil die Ampelanlagen abgeschaltet und Müllfahrzeuge sowie die Maschinen der Straßenreinigung in einem Demonstrationszug zum Rathaus gefahren wurden. Kleinere Aktionen gab es in Nürnberg, Kaiserlautern, Mannheim, Wanne-Eickel und Witten; in Duisburg verweigerten viele Müllmänner nach wie vor die Arbeit. In einigen Fällen wurden dabei sehr weitreichende Forderungen erhoben, etwa nach der sofortigen Einführung der 40-Stunden-Woche und nach einem Pensionsalter von 60 Jahren. ${ }^{339}$ $\mathrm{Zu}$ diesem Zeitpunkt fielen die oben zitierten sorgenvollen Worte Willy Brandts.

Die Frage, wie "wild« diese Streiks waren, die alle erst nach der ÖTVVorstandssitzung vom 18. September 1969 begannen, ist wohl durchaus berechtigt. Öffentlich bestritt die Gewerkschaft zwar jede organisatorische Mitwirkung. ${ }^{340}$ Andererseits aber hatte Günter Noack bei den eben zitierten internen Beratungen erklärt, es sei die Aufgabe aller ehrenamtlichen und hauptberuflichen Funktionsträger, so auf »die Bewegung in den Betrieben« einzuwirken, »daß die ÖTV sie in die Hand bekommt«. Da Kritik daran ausblieb, war dies offensichtlich die Ansicht der gesamten ÖTVFührung. Im Dezember 1969 sprach auch Heinz Kluncker im Rückblick intern von einer »Unruhe [...], die von uns gewerkschaftlich gewollt und organisiert war». 341

339 | Vgl.: Benda warnt den öffentlichen Dienst vor wilden Streiks. In: Berliner Morgenpost, 18.9.1969; Auf dem Kurfürstendamm verkehrte kein Bus mehr. In: Der Tagesspiegel, 19.9.1969; Die Männer von der Müllabfuhr bereiten Duisburgs Stadtvätern schwere Stunden. In: Die Welt, 18.9.1969; Wilde Streiks breiten sich aus. In: Handelsblatt, 19./20.9.1969; Wilder Streik des BVG-Personals verursachten ein Verkehrschaos. In: Die Welt, 19.9.1969; Streik führt in Offenbach zu Verkehrschaos. In: SZ, 20./21.9.1969; Mehr Geld auch im Staatsdienst? In: HAB, 19.9.1969; Jetzt Streikwelle im öffentlichen Dienst? In: FAZ, 19.9.1969; Ausstand in Duisburg und Witten. In: FAZ, 19.9.1969.

340 | Vgl. etwa das Interview mit Heinz Kluncker in: »Wir sind keine Bremsklötze«. In: Der Spiegel 23 (1969), H. 40, S. 38.

341 | In der Reihenfolge der Zitate: Protokoll über die gemeinsame Sitzung des HV und der GTK, 18.9.1969; Wortprotokoll der HV-Sitzung, 9.12.1969. Beide in: AdsD, 5/ÖTVB130016 B. 
Offensichtlich versuchte sich die Gewerkschaft in der Woche vor der Bundestagswahl in einer Doppelrolle: Sie präsentierte sich als vertragstreue Organisation, die ihre Friedenspflicht »sehr, sehr ernst« nahm, und mahnte die Arbeitgeber gleichzeitig, trotz gültiger Tarifverträge mit ihr zu verhandeln, um größere Streiks und Störungen der öffentlichen Ordnung zu verhindern. ${ }^{342}$ Gerade auf kommunaler Ebene entstand so eine wirkungsvolle Drohkulisse. In Frankfurt am Main etwa warnte der lokale ÖTV-Vorsitzende, er habe einen Streik der Gewerkschaftsmitglieder »nur mit Mühe verhindert«: Unter den Kollegen in den Betrieben und Ämtern herrsche "starke Erregung«. Die Stadt solle daher "guten Willen zeigen" und wenigstens den Lohn- und Gehaltszuschlag von 100 DM sofort zusagen. ${ }^{343}$

Diese Doppelstrategie war für eine Gewerkschaft, die eben gerade von ihrer eigenen Basis überrascht worden war, zwar nicht ohne Risiko. Auftrumpfende Forderungen der "wild« Streikenden wie etwa der Ruf nach der 40-Stunden-Woche, der einen weiteren gültigen Tarifvertrag korrigieren wollte, zeigen die Gefahr. Hilfe aber kam von der Seite, die in der gegebenen Situation am meisten zu verlieren hatte, nämlich von den mitten im Wahlkampf stehenden Sozialdemokraten. Der SPD-Parteivorstand verabschiedete eine scharf formulierte Erklärung, in der er Innenminister Benda und damit den Koalitionspartnern CDU/CSU unmissverständlich widersprach: Sofortige Verhandlungen über einen Lohnzuschlag für den Öffentlichen Dienst seien trotz der bevorstehenden Wahl selbstverständlich. Willy Brandt vertrat diese Position in seiner Rolle als Vizekanzler: Er reiste eigens kurzfristig aus den USA nach Bonn zurück, um im Bundeskabinett für solche Beratungen zu werben. Fast gleichzeitig schufen die Stadtstaaten Berlin, Hamburg und Bremen, in denen die SPD dank einer absoluten parlamentarischen Mehrheit jeweils keine Rücksicht auf einen Koalitionspartner nehmen musste, bereits Fakten: Sie gewährten ihren Beschäftigten die zusätzlichen 100 DM für die Monate Oktober bis Dezember. In der VKA schließlich setzten die mehrheitlich von Sozialdemokraten geführten Großstädte separate Tarifverhandlungen der Vereinigung mit den Gewerkschaften durch, weil sich der Bund und die Mehrheit der Länder in der TdL

342 | »Wir sind keine Bremsklötze«. In: Der Spiegel 23 (1969), H. 40, S. 38.

343 | Brundert soll zahlen. In: FAZ, 20.9.1969. 
nach wie vor mit juristischen Begründungen dagegen wehrten, von den gültigen Lohn- und Gehaltsverträgen abzugehen. ${ }^{344}$

Im Bundeskabinett stritten derweil die Minister. Franz Josef Strauß wandte sich strikt dagegen, den Forderungen der ÖTV nachzugeben. Dabei argumentierte er mit den konjunkturpolitischen Begriffen, die Karl Schiller als Wirtschaftsminister in die bundesdeutsche politische Debatte eingebracht hatte. Anders als Ende 1966, mitten in der Rezession, war eine Stärkung der Massenkaufkraft nach Strauß’ Meinung in der aktuellen Situation völlig verfehlt: »Die Anerkennung gesamtwirtschaftlich nicht vertretbarer Lohnforderungen sei dem Ziel einer antizyklischen Finanzpolitik diametral entgegengesetzt und würde letztlich die Aufgabe der bisherigen Regierungspolitik bedeuten. ${ }^{345}$ Wirtschaftsminister Schiller sah das etwas anders. Zwar befand sich die bundesdeutsche Wirtschaft auch nach seinem Urteil in einer »Phase des überschäumenden Booms«, in der es gefährlich sein konnte, einen »allzu starken« zusätzlichen Konsumanreiz zu schaffen. Das rechte Maß lasse sich aber problemlos wahren, etwa indem man einen Teil der 300 DM, die nach dem Willen der ÖTV pauschal für Oktober bis Dezember 1969 zusätzlich gezahlt werden sollten, als »vermögenswirksame Leistung " gewähre. ${ }^{346}$

Diese Debatte endete mit einem Sieg der Sozialdemokraten, weil überraschender Weise auch Bundeskanzler Kurt Georg Kiesinger für sofortige Beratungen mit der ÖTV plädierte, um »den Arbeitsfrieden zu wahren«.347 Allerdings reichte die Entscheidungskraft der auseinanderstrebenden Gro-

344 | Vgl.: Koalitionsparteien uneinig über Zeitpunkt der Tarifverhandlungen im öffentlichen Dienst. In: FAZ, 22.9.1969; Letzte Belastungsprobe für die Große Koalition. In: FAZ, 23.9.1969; Vorschuß auf höhere Löhne und Gehälter. In: HAB, 24.9.1969; 300 Mark mehr im Staatsdienst. In: HAB, 25.9.1969.

345 | Kabinettsprotokolle Bundesregierung 1969, S. 358 (Kabinettssitzung v. 23.9.1969).

346 | »Lohnerhöhungen sind die Folgen des Booms«. In: StZ, 23.9.1969 (das Zitat zur konjunkturellen Lage); Kabinettsprotokolle Bundesregierung 1969, S. 359 (Kabinettssitzung v. 23.9.1969). Konkret dachte Schiller an $100 \mathrm{DM}$, die als langfristig gebundenes Sparguthaben gewährt werden sollten.

347 | Kabinettsprotokolle Bundesregierung 1969, S. 359 f. Nur zwei Tage zuvor hatte Kiesinger noch öffentlich erklärt, es werde »keine Wahlgeschenke« für die Beschäftigten des Öffentlichen Dienstes geben (Ruhe vor dem Sturm im öffentlichen Dienst. In: StZ, 22.9.1969). 
Ben Koalition nicht mehr so weit, den Innenminister auch mit einem konkreten Verhandlungsmandat auszustatten. Heinz Kluncker fühlte sich deshalb durch den Kabinettsbeschluss »verschaukelt«: Es handle sich um eine »Hinhaltetaktik«, die nur provozierend wirke. In mehreren Großstädten kam es daraufhin zu weiteren »wilden« Streiks im Öffentlichen Dienst (vornehmlich bei der Müllabfuhr). ${ }^{348}$ Bild, das seinerzeit täglich von fast zwölf Millionen Deutschen gelesene Boulevardblatt des Axel Springer-Verlages, warnte mit dramatischen Worten, der Bundesrepublik drohe in den letzten Tagen vor der Bundestagswahl »das totale Chaos«. ${ }^{349}$

Nur mit der VKA konnte die ÖTV noch vor dem Wahlgang tatsächlich verhandeln. Nach 14 Stunden kontroverser Diskussionen kam es dabei am 25. September 1969 zu einer Einigung, die der Verhandlungsführer der Kommunen, der parteilose Stuttgarter Oberbürgermeister Arnulf Klett (der auch Mitglied der ÖTV war), anschließend scharf kritisierte: Er sprach von "Zugeständnissen, die schwer erträglich « seien und meinte, der »Kaufpreis«, den die Kommunen gezahlt hätten, um weitere Streiks zu verhindern, müsse als »teuer« gelten. Konkret erhielten alle Arbeiter und Angestellten der Gemeinden jeweils eine pauschale »Überbrückungszahlung« von 300 DM für die Monate Oktober bis Dezember 1969, die vollständig in bar ausgezahlt wurde. Insgesamt kostete das die Stadtkämmerer rund 180 Millionen DM. ${ }^{350}$

348 | Handel ohne Angebot. In: Der Spiegel 23 (1969), H. 40, S. 36. Zu den neuen Streikaktionen (in München sowie noch einmal in Nürnberg) vgl. etwa: Müllabfuhr-Streik in München. In: FAZ, 25.9.1969; Wieder wilde Streiks. In: Bonner Rundschau, 25.9.1969.

349 | 5 Tage vor der Wahl: Drohung mit wilden Streiks. In: Bild, 23.9.1969.

350 | In der Reihenfolge der Zitate: Dreihundert Mark für jeden Arbeitnehmer der Gemeinden. In: FAZ, 26.9.1969; Gemeinde-Bedienstete erhalten 300 Mark. In: SZ, 26.9.1969. Die genannte Summe nach: Teures Experiment. In: FAZ, 26.9.1969. Die DAG stimmte dem Abschluss zwar zu, bemängelte aber zugleich, die Pauschalzahlung widerspreche dem Prinzip, »die Ordnung der Bezahlung nach Leistung zu bewahren«. Zit. nach: Dreihundert Mark für jeden Arbeitnehmer der Gemeinden. In: FAZ, 26.9.1969. Arnulf Klett war als Parteiloser unter den bundesdeutschen Oberbürgermeistern eine Ausnahme. Er war im Frühjahr 1945 von der französischen Besatzungsmacht ohne eine demokratische Abstimmung eingesetzt worden. Spätere Wahlen entschied er dann durchweg mit großen Mehrheiten für sich, so dass er das Amt bis zu seinem Tod im Jahr 1974 bekleidete. Zu 
Die ÖTV feierte dieses Resultat als großen Erfolg, der besonders Geringverdienern nütze und jeden weiteren »wilden« Streik überflüssig mache. Wie sich denken lässt, sah die Gewerkschaft in der ausgehandelten Summe zudem »einen Maßstab « für die noch kommenden Verhandlungen mit Bund und Ländern. Der Abschluss beweise, wie falsch Vorwürfe von linksradikaler Seite seien, die Organisation habe nach dem 10. September die Kampfbereitschaft der Beschäftigten geschwächt: »Durch die Gewerkschaft ÖTV werden die Interessen der Arbeiter, Angestellten und Beamten nicht manipuliert, sondern tatkräftig und wirksam vertreten. ${ }^{351}$

Auf den ersten Blick schien sich die ÖTV bei der Abmachung von Stuttgart tatsächlich ohne Abstriche durchgesetzt zu haben. Das öffentliche Image des Vorsitzenden Heinz Kluncker als harter Kontrahent der Arbeitgeber verfestigte sich damit noch stärker. Das Handelsblatt etwa titulierte ihn nun schon als »starken Mann im Staate«, von dem es abhänge, »ob die politische Ordnung gesprengt wird oder nicht«: Kluncker habe die Beschäftigten des Öffentlichen Dienstes zu den angeblich spontanen Streiks »ermuntert" und auf diese Weise die Interessen »seiner Leute auf Kosten der Gesamtheit « durchgesetzt. ${ }^{352}$

Bei genauerer Prüfung des Resultats und des Ablaufs hätten allerdings andere Urteile nahegelegen. Schaut man auf die Details, so zeigt sich etwa, dass es der ÖTV keineswegs gelungen war, die Vorgaben der Großen Tarifkommission und der »wild « Streikenden exakt umzusetzen: Die 300 DM kamen nämlich nicht durch eine Erhöhung der monatlichen Bezüge zustande. Vielmehr handelte es sich um eine Einmal-Zahlung, d.h. mit Beginn des Jahres 1970 erhielten alle Beschäftigten des Öffentlichen Dienstes wieder ihr vorheriges Gehalt. Damit bezogen sich auch die im neuen Jahr beginnenden regulären Tarifverhandlungen auf das niedrigere Lohnniveau. Bei diesem unscheinbaren, finanziell aber doch bedeutsamen

seiner Person vgl.: Paul Sauer: Arnulf Klett. Ein Leben für Stuttgart, Stuttgart 2003; dort (S. 262) auch der Hinweis auf seine ÖTV-Mitgliedschaft. 1972 erhielt er die »Ehrennadel« der ÖTV für 25 Jahre Mitgliedschaft.

351 | Flugblatt »ÖTV-Tariferfolg«, о.D. [September 1969]. Ein Exemplar in: Archiv Ver.di, Bestand Kluncker, 13.

352 | Antonius John: Bendas zweite Linie. In: Handelsblatt, 25.9.1969. 
Unterschied handelte es sich eindeutig um ein gut verstecktes Zugeständnis der Gewerkschaft an die Interessen der VKA. ${ }^{353}$

Noch weniger eindrucksvoll wirkt der Vertrag vom September 1969 bei genauerer Betrachtung, weil die ÖTV-Führung in dieser Sache de facto vor allem mit politisch Gleichgesinnten verhandelt hatte. Arnulf Klett als Verhandlungsführer der VKA kommentierte das Resultat nicht zuletzt deshalb so böse, weil er im Laufe der Beratungen realisieren musste, dass es keine einheitliche Verhandlungsposition der kommunalen Arbeitgeber gab: Diese war "gefährdet, wenn nicht [sogar] zerschlagen", weil sich viele Bürgermeister fest entschlossen zeigten, ohne jeden Verzug einen Tarifvertrag zu vereinbaren, der weitere Streiks unwahrscheinlich machte. Warnmeldungen von ÖTV-Betriebsgruppen, in Essen, Braunschweig und Frankfurt am Main seien ganze Belegschaften von städtischen Betrieben entschlossen, schon am nächsten Tag nicht zu arbeiten, wenn es bis dahin keine für sie zufriedenstellende Vereinbarung gebe, steigerten die Nervosität der Kommunalpolitiker. Offensichtlich gingen bei der VKA während der Verhandlungen in Stuttgart Nachrichten ein, wonach Magistrat und Stadtverordnetenversammlung die $300 \mathrm{DM}$ - nach dem Vorbild der drei Stadtstaaten - in mehreren Großstädten bereits fest zugesagt hatten. ${ }^{354}$

Politisch wäre es naiv, an dieser Stelle nicht an die sozialdemokratischen Oberbürgermeister von Städten wie etwa München, Frankfurt am Main, Düsseldorf, Essen, Hannover oder Nürnberg zu denken. Wenn die ÖTV unmittelbar vor der Bundestagswahl warnte, es könne »in den nächsten Tagen große Erschütterungen« geben (etwa durch Streiks im öffentlichen Nahverkehr), falls die Bediensteten der Kommunen nicht sofort materiell besser gestellt würden, konnten diese Politiker unter den besonderen Bedingungen des Jahres 1969 wohl nicht mehr als tarifpolitische Kontrahenten der Gewerkschaft gelten. ${ }^{355}$ Der Abschluss trotz Friedensplicht taugte daher kaum, um eine übermächtige Position der ÖTV zu belegen. Er bewies vielmehr ein weiteres Mal eindringlich, wie stark politische Interessen unter Umständen die Tarifverhandlungen für den Öffentlichen Dienst prägen konnten.

353 | Vgl. zu den Details: Gemeinde-Bedienstete erhalten 300 Mark. In: FAZ, 26.9.1969; Zweikampf zwischen Klett und Kluncker. In: StZ, 26.9.1969.

354 | Vgl.: ebd.

355 | So zitiert durch Arnulf Klett in: Gemeinde-Bedienstete erhalten 300 Mark. In: FAZ, 26.9.1969. 
1969 nutzte dieser Zusammenhang sowohl der ÖTV und den Beschäftigten des Staates als auch den Sozialdemokraten und konkret dem Kanzlerkandidaten Willy Brandt. Die Bundestagswahl am 28. September, die zur Bildung der ersten Koalitionsregierung von SPD und FDP führte, ging ruhig über die Bühne, ohne von Streiks im Öffentlichen Dienst gestört zu werden. Anschließend gelang es der ÖTV, ihre Abmachung mit der VKA auch bei Bund und Ländern durchzusetzen: Das nur noch geschäftsführend amtierende Kabinett der Großen Koalition übernahm die Regelung ebenso wie die TdL, weil die Kommunen nach den Worten von Bundeswirtschaftsminister Schiller ja ohnehin schon die »Preisführerschaft« übernommen hatten. Damit waren Beschlüsse, den Beamten ebenfalls eine »Überbrückungszahlung« zu gewähren, nur noch eine Formsache. ${ }^{356}$

Ende 1969 schaute die ÖTV-Führung daher sehr zufrieden zurück. Der Schreck der ersten, wirklich »wilden« Streiks im September war gründlich vergessen. Vor dem Hauptvorstand betonte Heinz Kluncker sogar, wie geschlossen die Organisation agiert habe. ${ }^{357}$ Die Gewerkschaft fühlte sich offenbar sehr stark, nachdem sie in zwei aufeinander folgenden Jahren trotz laufender Verträge zusätzliche materielle Erfolge für alle Beschäftigten des Staates erreicht hatte. Damit verblasste auch die Erinnerung an die Tarifverhandlungen von 1967, in denen sich gerade sozialdemokratische Landes- und Kommunalpolitiker aus politischen Gründen entschieden gegen die Forderungen der ÖTV gestellt hatten. Das Warnsignal, wie wenig die Verflechtung von Gewerkschaft und Partei bedeuten konnte, wenn die Löhne und Gehälter des Öffentlichen Dienstes in einer ökonomischen Krise neu verhandelt wurden, hat die ÖTV-Führung deshalb nicht wirklich ernst genommen.

356 | Zwar versuchte die Bundesregierung, nach Familienstand differenzierte Zahlungen durchzusetzen. Die ÖTV aber lehnte das strikt ab, obwohl diese Variante nach den Angaben des Innenministeriums für fast 90 Prozent der Arbeiter und Angestellten des Bundes höhere Zahlungen bedeutet hätte. Vgl. dazu: Kabinettsprotokolle Bundesregierung 1969, S. 370 (Kabinettsprotokoll v. 8.10.1969 - hier auch das Zitat); Überbrückungs-Zulage auch für Bundesbedienstete. In: FAZ, 10.10.1969. Bayern, Baden-Württemberg und Rheinland-Pfalz gewährten wenig später allerdings den Landesbeamten zusätzliche Kinderzuschläge. Nach dem Urteil Heinz Klunckers zeigte dieser Beschluss »einen bemerkenswerten Mangel an Fairneß« (Sitzung der GTK, 4.12.1969. In: AdsD, 5/ÖTVB130016 B). Vgl. auch: Der »Weiße Riese« im Beamten-Express. In: ÖTV-Beamten-Nachrichten 15 (1970), S. 6-7.

357 | Wortprotokoll der HV-Sitzung, 9.12.1969. In: AdsD, 5/ÖTVB130016 B. 


\section{Tarifverträge als Gesellschaftspolitik: Veränderungen der sozialen Hierarchie im Öffentlichen Dienst durch die Tarifpolitik der ÖTV}

\section{Der Ruhestand der Beamten als Modell: Die ÖTV und die Renten der staatlichen Arbeiter und Angestellten}

Ende der 1960er Jahre durfte sich die ÖTV nicht nur deshalb gewerkschaftlich stark fühlen, weil sie 1968 und 1969 Lohnzuschläge durchgesetzt hatte, die indirekt oder direkt jeweils einen laufenden Tarifvertrag korrigierten. Vielmehr war die Organisation seit 1964 unter dem Vorsitz von Heinz Kluncker auch einem ihrer tarifpolitischen Hauptziele deutlich nähergekommen. Seit ihrer Gründung agitierte die ÖTV kontinuierlich gegen die Kluft in der sozialen Ausstattung zwischen Beamten einerseits und Arbeitern und Angestellten andererseits: Von »zweierlei Recht« für die Beschäftigten des Staates wollte sie nichts wissen. ${ }^{358}$ Auf dem Weg zur angestrebten Vereinheitlichung von Dienst- und Personalrecht kam die Gewerkschaft in den Jahren 1965 bis 1969 in drei separaten Schritten deutlich voran: Sie konnte Tarifverträge durchsetzen, die den sozialen Besitzstand der öffentlich beschäftigten Arbeiter und Angestellten stärker an das Niveau anglichen, das die staatlichen Arbeitgeber den Beamten gewährten. Zugleich handelte es sich um Abmachungen, die langfristig weiterwirkten, weil sie das innere Gefüge des Öffentlichen Dienstes strukturell veränderten. Das Bild von der tarifpolitischen Arbeit der ÖTV wäre unvollständig, wenn dieser Teil ihrer Erfolgsbilanz unerwähnt bliebe.

1965 ging es in der ersten dieser drei Vereinbarungen gleich darum, ein besonders gewichtiges soziales Vorrecht der Beamten, nämlich die Konditionen ihrer Alterssicherung, auf die übrigen Staatsdiener auszuweiten. Deutsche Beamte wurden (und werden) von ihrem Arbeitgeber bis an ihr Lebensende alimentiert, weil der Eid, den sie bei der Verbeamtung schwören, ein auf Gegenseitigkeit beruhendes »Dienst- und Treueverhältnis« stiftet. Seinerzeit erhielten sie bei langer Beschäftigung im Ruhestand 75 Prozent der individuell zuletzt erhaltenen Bezüge, ohne dafür in der aktiven Dienstzeit eine Eigenleistung erbracht zu haben. Typischerweise errechnete sich diese »Pension« aus dem höchsten Verdienst, den der Beamte

358 | Siehe dazu schon S. $31 \mathrm{f}$. 
in seinem Berufsleben erreicht hatte. ${ }^{359}$ Die »Rente« für Arbeiter und Angestellte funktionierte nach ganz anderen Prinzipien: Hier entstand der Anspruch über Jahre und Jahrzehnte hinweg durch Beitragszahlungen der Beschäftigten und ihrer Arbeitgeber; ihm lag also die gesamte Erwerbsbiografie des einzelnen Versicherten zugrunde. Wiederholte Perioden von Erwerbslosigkeit oder Krankheit minderten die Rente ebenso wie niedrige Löhne in Zeiten nachlassender Arbeitskraft. Selbst bei kontinuierlicher Beitragsleistung in 40 Berufsjahren und mehr entstanden so Altersbezüge, die (gestaffelt nach Einkommenshöhe) maximal 60 bis 55 Prozent des jeweils letzten Verdienstes ausmachten. ${ }^{360}$

Im Öffentlichen Dienst standen sich Arbeiter und Angestellte in dieser Hinsicht allerdings schon seit den 1920er Jahren etwas besser als die Beschäftigten in der Privatindustrie. Zwar galten auch sie grundsätzlich als normale versicherungspflichtige Arbeitnehmer, d. h. ihre Renten errechneten sich nach den eben skizzierten Regeln. Zugleich aber existierte für die Nicht-Beamten im Öffentlichen Dienst - wie bereits erwähnt wurde - eine zusätzliche »Versorgungskasse«, deren Zahlungen die individuell bezogene gesetzliche Rente aufstockten. Auch sie arbeitete nach dem Versicherungsprinzip; allerdings übernahm der Arbeitgeber in diesem Fall zwei Drittel der Beiträge (nicht 50 Prozent wie in der gesetzlichen Rentenversicherung). ${ }^{361}$ Die Entstehungsgeschichte dieser zweiten Rente, die nur Arbeitern und Angestellten des Staates zugänglich war, zeigt exemplarisch, wie

359 | Der Satz von 75 Prozent wurde nach 35 Dienstjahren erreicht. Bei kürzerer Beschäftigung gab es Abzüge: Nach zehn Dienstjahren waren es 35 Prozent, für jedes weitere bis zum 25. Dienstjahr erhöhte sich der Satz um zwei Prozentpunke, danach pro Dienstjahr um einen Punkt. Zum »Laufbahnprinzip«, das dafür sorgte, dass die Bezüge von Beamten mit dem Alter stiegen, siehe das Folgende. Als Zusammenschau der Beamtenrechte vgl. Winfried Benz: Beamtenverhältnis und Arbeitsverhältnis, Stuttgart 1969, S. 60-89.

360 | Vgl. etwa: Dagmar Hilpert: Wohlfahrtsstaat der Mittelschichten? Sozialpolitik und gesellschaftlicher Wandel in der Bundesrepublik Deutschland (19491975), Göttingen 2012, S. 114f. Der erreichbare Anteil sank mit der Höhe von Lohn und Gehalt.

361 | In den frühen 1960er Jahren betrug der Beitragssatz 6,9 Prozent der Bezüge; ein Drittel davon (2,3 Prozent) entfiel auf den Arbeitnehmer. Der von Arbeitgeber und -nehmer gemeinsam zu tragende allgemeine Rentenversicherungsbeitrag betrug sechs Prozent (Geschäftsbericht der Versorgungsanstalt des Bundes und der 
stark der gesamte Öffentliche Dienst von den Beamten her gedacht wurde, obwohl alle staatlichen Instanzen und Betriebe schon seit dem Kaiserreich auch zahlreiche Nicht-Beamte beschäftigten. Auch sie gehört daher zu dem hier verhandelten Thema.

Der Nukleus der "Zusatzversorgung« entstand durch einen Tarifvertrag, den die Postgewerkschaften im Dezember 1925 mit der Reichspost vereinbarten. Obwohl es überraschend klingen mag, kann man diese Abmachung als ein nachgeholtes Ergebnis des verlorenen Weltkriegs bezeichnen: Sie entstand, um die Konsequenzen zu mildern, die der Versailler Vertrag für das Staatsunternehmen und dessen Personal mit sich brachte. Ähnlich wie auch die Bahn beschäftigte die Reichspost eine Fülle von Beamten, die gering qualifizierte und oft sogar vornehmlich körperliche Arbeiten erledigten. Dieser »einfache" Dienst hatte mit dem ursprünglichen Konzept der Beamtenschaft wenig bis gar nichts tun, denn hier agierten keine staatlichen "Hoheitsträger" mit wichtigen Entscheidungskompetenzen, deren Unabhängigkeit durch die lebenslange Stellung gesichert werden musste. Der Beamtenstatus dieser Beschäftigten hatte vielmehr politische Funktionen: Um sich gegen die sozialistische Arbeiterbewegung zu wappnen und die Funktionsfähigkeit von Post und Eisenbahn auch im Kriegsfall oder in innenpolitischen Krisen zu sichern, ließ das wilhelminische Kaiserreich in diesen staatlichen Betrieben auch simple Tätigkeiten von Beamten erledigen. Vielfach arbeiteten diese direkt neben Nicht-Beamten. ${ }^{362}$

Daran änderte sich in der Weimarer Republik nichts. Anders verhielt es sich jedoch mit den Chancen der Postarbeiter, zum Beamten »aufzusteigen «, wenn eine solche Stelle frei wurde oder neu entstand. Vor 1914 scheinen solche Karrieren häufig gewesen zu sein, da das Unternehmen un-

Länder 1967, Karlsruhe 1970 [im Folgenden: Geschäftsbericht Versorgungsanstalt Bund-Länder 1967], S. 3).

362 | Diese Betriebsbeamten von Bahn und Post zählten entsprechend zur »unteren Klasse« im Kaiserreich. Vgl.: Hans-Peter Ullmann: Das Deutsche Kaiserreich, 1871-1918, Frankfurt/Main 1995, S. 115 f. Zur politischen Funktion der Beamten vgl.: Hans-Ulrich Wehler: Deutsche Gesellschaftsgeschichte, Bd. 3: Von der Deutschen Doppelrevolution bis zum Beginn des Ersten Weltkrieges, München 1995, S. 702-712. Zur Entwicklung des numerischen Verhältnisses zwischen Beamten und Nicht-Beamten in den Jahren 1910 bis 1926 bei der Post vgl.: Ernst Metzler: Die Arbeiter und Angestellten der Deutschen Reichspost in ihrer besonderen Rechtsstellung, Diss., Leipzig 1928, S. 2 f. 
ablässig expandierte. Nach 1918 aber befand sich das Deutsche Reich und damit auch die staatliche Post in einer ganz anderen Situation: Deutschland verlor mit dem Friedensvertrag größere Teile seines Territoriums; die zahlreichen Beamten, die in den abgetretenen Gebieten für die Reichspost gearbeitet hatten, aber blieben dem Unternehmen erhalten. Auch wirtschaftlich blühte Deutschland nicht mehr. Damit schwanden die Aussichten aller Nicht-Beamten auf eine wirklich lebenslange Stellung bei der Post und auf die mit dem Beamtenstatus verbundene vergleichsweise großzügige Altersversorgung. Die "Zusatzversorgung« war die Antwort auf dieses Problem, das innerbetrieblich offensichtlich einigen Ärger verursacht hatte: Sie sollte die Arbeiter der Reichspost damit versöhnen, dass sie nur noch in Ausnahmefällen zu Beamten werden konnten. Letztlich entstand sie also deshalb, weil sich auch die junge Republik, die das wilhelminische Herrschaftssystems beerbte, den Luxus leistete, Beamte weiterhin für Tätigkeiten einzusetzen, die nichts mit der staatlichen »Hoheit« und ihrer Durchsetzung zu tun hatten. ${ }^{363}$

Es braucht kaum Fantasie, um den weiteren Weg zu erahnen: Der neue soziale Anspruch, den die Reichspost ihren Arbeitern zugestanden hatte, wurde rasch zur Forderung auch in den anderen Bereichen des Öffentlichen Dienstes. Schon 1927 schlossen Reich und Länder einerseits und die Gewerkschaften andererseits einen Tarifvertrag, in dem sie die Errichtung einer eigenen »Zusatzversorgungskasse« für Arbeiter vereinbarten. Seit

363 | Vgl. etwa: Matthäus Hotz: Die soziale Betätigung der Deutschen Reichspost, Berlin 1926, S. 55-60; Metzler, Arbeiter und Angestellten der Deutschen Reichspost, S. 102-104. Ausgespart bleibt hier die spezielle Altersversorgung für die Arbeiter der deutschen Staatsbahnen: Sie entstand bereits im Kaiserreich in Gestalt einzelner Pensionskassen, die 1922 zu einem Verband und 1934 dann zu einer einheitlichen »Versicherungsanstalt« zusammengeschlossen wurden. Es würde den Rahmen des hier behandelten Themas sprengen, die Ähnlichkeiten und Unterschiede dieser Sonderversicherung mit der »Zusatzversorgung « für die Post und den übrigen Staatsdienst auszubreiten. Vgl. als Überblick: Werner Haustein: Fragen der allgemeinen und betrieblichen Sozialpolitik bei der Reichsbahn. In: Archiv für Eisenbahnwesen 66 (1944), S. 165-224, hier: S. 174-182, sowie: Sigrid Amedick: Altersversorgung in einer Leistungsverwaltung: das Beispiel der bayerischen Staatseisenbahnen 1844-1914. In: Bernd Wunder (Hrsg.): Pensionssysteme im öffentlichen Dienst in Westeuropa (19./20. Jh.), Baden-Baden 2000, S. 55-75, hier: S. $72-75$. 
1933 versicherte die Kasse dann auch staatliche Angestellte. ${ }^{364}$ Zwar fehlte eine solche Einrichtung für die Beschäftigten der Gemeinden. Teilweise gab es aber vergleichbare Regelungen durch einzelne Kommunen; zahlreiche Städte schlossen sich zudem nach einiger Zeit doch der von Reich und Ländern betriebenen Kasse an. ${ }^{365}$ Wie die meisten anderen Institutionen der deutschen Sozialversicherung überstand diese "Zusatzversorgungskasse« alle wirtschaftlichen und politischen Stürme der nachfolgenden Jahrzehnte. 1966 zählte sie rund 900.000 Versicherte; ihre Einnahmen beliefen sich auf 660 Millionen DM. Im gleichen Jahr wurden Leistungen von insgesamt 161 Millionen DM ausgeschüttet; fast 230.000 Rentner und Rentnerinnen kamen so zu höheren Bezügen. ${ }^{366}$

Die soziale Bedeutung dieser Zusatzrenten war umstritten. Nach Angaben des ÖTV-Vorstandssekretärs Heinrich Jacobi, der die Gewerkschaft im Verwaltungsrat der Kasse repräsentierte, betrug die tatsächlich ausgezahlte Zusatzrente im Jahr 1960 in der Regel etwa 25 Prozent des individuell unmittelbar vor der Verrentung erhaltenen Entgelts. Das damit erreichte Versorgungsniveau fiel allerdings sehr unterschiedlich aus, weil lange Beschäftigungszeiten - und damit hohe gesetzliche Renten - entgegen populären

364 | Zusammenfassend vgl.: Georg Heubeck: Entwicklung der Beamtenpensionen im Vergleich zu anderen Arten der Alters- und Hinterbliebenenversorgung, Bad Godesberg 1970, S. 34f.; Alfred Jahnz: Die Neuregelung der zusätzlichen Alters- und Hinterbliebenenversorgung im öffentlichen Dienst. Kommentar zur Satzung der Versorgungsanstalt des Bundes und der Länder (VBL), 3. neu bearb. Aufl., Stuttgart 1971, S. 9 f. Anders als für die Arbeiter bestand für Angestellte zunächst keine Versicherungspflicht in der Zusatzversorgung. Sie wurde erst 1944 verfügt (Heubeck: Beamtenpensionen, S. 34f.). Die Kasse trug seit 1949/50 den Namen »Versorgungsanstalt des Bundes und der Länder« (VBL).

365 | Ende 1966 hatten sich 1.741 »kommunale Verwaltungen« mit rund 115.000 Beschäftigten der VBL angeschlossen. Unter diesen Begriff fasste die Kasse auch einzelne öffentliche Betriebe und formal selbständige Unternehmen wie etwa die kommunalen Sparkassen (Geschäftsbericht der Versorgungsanstalt des Bundes und der Länder [VBL], Karlsruhe, für die Geschäftsjahre 1963 bis 1966, Karlsruhe 1967, S. 10).

366 | Ebd., S. 11. Die Versichertenzahl der Anstalt schwankte im Verlauf ihrer Geschichte allerdings enorm: Noch 1934 lag sie unter 80.000, stieg bis 1939 aber auf rund 290.000 und bis 1944 dann auf 870.000. 1946 gab es hingegen nur noch 113.000 Beitragszahler; danach wuchs die Zahl kontinuierlich (ebd., S. 19). 
Klischees von der stets »sicheren« Arbeit für den Staat auch im Öffentlichen Dienst keineswegs die Norm darstellten: Von rund 3.400 stichprobenartig genauer untersuchten »Versorgungsfällen« erreichten 27 Prozent selbst dann keine 50 Prozent des jeweils letzten Verdienstes, wenn man gesetzliche Rente und Zusatzversorgung zusammenrechnete. Insgesamt 60 Prozent des Samples kamen auf eine Gesamtversorgung von weniger als 60 Prozent ihrer früheren individuellen Bezüge. Immerhin in fast einem Drittel der Fälle aber erhielt der Rentner jeweils jene 75 Prozent, die einem langgedienten Beamten maximal zustanden, oder sogar noch mehr. ${ }^{367}$

Da Rentner seinerzeit noch kostenlos krankenversichert waren und ihre Bezüge nur gering versteuern mussten, entsprachen 75 Prozent des letzten Bruttoverdienstes weitgehend der Summe, die der Rentner oder die Rentnerin unmittelbar vor dem Ausscheiden aus dem Erwerbsleben netto erhalten hatte. Abstriche an dem gewohnten Lebensstandard waren in solchen Fällen kaum nötig oder so gering, dass sie keine wirklich spürbare Einschränkung bedeuteten. ${ }^{368}$ Bei Beschäftigungszeiten von über 45 Jahren konnte das real verfügbare Einkommen im Ruhestand sogar höher ausfallen als in der Zeit vor der Verrentung. Die Mehrheit der Arbeiter und Angestellten, die beim Staat gearbeitet hatten, erreichte jedoch deutlich

367 | Alle Zahlen nach Jacobis Angaben in: Protokoll über die 9. Sitzung des HV, 9./10.11.1960. In: Archiv Ver.di, Bestand Kluncker, 45. Ob diese Stichprobe auf Initiative der ÖTV oder sogar von ihr selbst durchgeführt wurde, geht aus dem Protokoll nicht hervor. Auch bleibt unklar, ob - und wenn ja: wie - ein repräsentativer Charakter der Stichprobe sichergestellt wurde. Separate Angaben für Männer und Frauen fehlen. Jacobi macht hier allerdings Angaben, wie die Zusatzversorgung im Einzelfall berechnet wurde. Diese Regeln waren so kompliziert, dass nach seiner Überzeugung kaum ein Versicherter in der Lage war, seinen individuellen Anspruch vorab zu berechnen. Grob gesagt bezog sich die Zusatzrente zum einen anteilig auf die individuellen Bezüge in den letzten fünf Jahren vor Rentenbeginn, zum anderen prozentual auf die »allgemeine Bemessungsgrundlage« (d. h. auf den durchschnittlichen Verdienst aller Versicherten).

368 | Vgl. zu den komplizierten Details - gerade im Vergleich mit den Beamten - zusammenfassend etwa: Georg Heubeck: Die Versorgung im öffentlichen Dienst - gestern - heute - morgen, Bad Godesberg 1974, S. 32-34. Hier (S. 13 f.) auch Angaben zur Besteuerung von Renten. De facto zahlten die meisten Rentner keine Steuern. 
niedrigere Summen: Ihre Bezüge lagen »weit unter der Versorgung eines vergleichbaren Beamten ${ }^{369}$

Aus dieser komplizierten und widersprüchlichen Sachlage leitete die ÖTV Anfang der 1960er Jahre den Auftrag ab, sie müsse die »Versorgungslücke« gegenüber den Beamten grundsätzlich schließen. Zugleich wollte sie einen Mangel der bislang bestehenden Zusatzversorgung beseitigen: Deren Zahlungen wurden nicht an die Teuerung angepasst, während die gesetzliche Sozialversicherung seit der grundlegenden Rentenreform von 1957 »dynamische Renten« zahlte. Wer lange lebte, musste als Rentner des Öffentlichen Dienstes also nach wie vor effektive Wertverluste seiner Bezüge hinnehmen. ${ }^{370}$ In der »Überversorgung « einer kleinen Minderheit von Ruheständlern, die aus der Kombination von gesetzlicher Rente und Zusatzzahlung entstehen konnte, sah zwar auch die ÖTV »eine unangenehme Erscheinung«. Änderungen, etwa durch Einführung einer Kappungsgrenze, aber lehnte sie ab: Es handle sich schließlich um Versicherungsansprüche, die auf eigenen Beiträgen und einem besonders langen »Dienst« beruhten. ${ }^{371}$

Seit 1961 stritten Gewerkschaft und Arbeitgeber über diese Fragen in offiziellen Tarifverhandlungen, ohne eine Einigung zu finden. Zeitlich parallel nahm der Arbeitskräftemangel in der Bundesrepublik immer gravierendere Formen an. Im Sommer 1965 etwa konstatierten die industriellen Unternehmer, der Arbeitsmarkt des Landes sei »leergefegt wie noch nie «. ${ }^{372}$ Fast zeitgleich klagte die Bundesregierung, in der Ministerialbürokratie

369 | Vgl. genaue Angaben über das erreichte Rentenniveau in: Protokoll über die Sitzung der GTK, 15.10.1963. In: Archiv Ver.di, Bestand Kluncker, 45.

370 | Vgl. zu dieser fehlenden Dynamisierung H. Jacobi in: Protokoll über die 9. Sitzung des HV, 9./10.11.1960. In: Archiv Ver.di, Bestand Kluncker, 45.

371 | Protokoll über die Sitzung der GTK, 15.10.1963. In: Archiv Ver.di, Bestand Kluncker, 45. Forderungen der Arbeitgeber, die »Überversorgung « zu beseitigen, erwähnte H. Jacobi schon auf der HV-Sitzung vom November 1960.

372 | Sozialpolitik im 5. Deutschen Bundestag. XVI. Jahresmitgliederversammlung [der Bundesvereinigung der Deutschen Arbeitgeberverbände] in Bad Godesberg, Köln 1966, S. 16. Die amtliche Statistik verzeichnete im September 1965 bundesweit rund 85.000 Arbeitslose, aber 720.000 den Arbeitsämtern gemeldete offene Stellen. 
fehle »qualifizierter Nachwuchs« und selbst bei Schreibkräften und Arbeitern bestehe eine "prekäre Personallage «. ${ }^{373}$

Für die Reform der Zusatzversorgung, die Bund und TdL im März 1965 mit ÖTV und DAG vereinbarten, ist dieser Hintergrund überragend wichtig: Der Tarifvertrag sollte dem Staat helfen, weiterhin Personal zu gewinnen, obwohl die Privatwirtschaft wegen der scharfen Konkurrenz um Arbeitskräfte vielfach deutlich höhere Löhne und Gehälter zahlte. Die Reform »demokratisierte« daher das Privileg, im Alter vor Einschränkungen des gewohnten individuellen Lebensstandards geschützt zu sein. Bislang hatten es de facto vor allem die Beamten genossen; nun wurde dieses Vorrecht wirklich konsequent auf die Arbeiter und Angestellten des Öffentlichen Dienstes ausgedehnt. ${ }^{374}$

Damit wirkte die Beschäftigung »beim Staat« langfristig noch sicherer, als sie es ohnehin schon war, d.h., die Tarifpartner stärkten mit ihrer Vereinbarung gezielt den sozialen Aspekt, der das öffentliche Image des Staatsdienstes schon seit langem dominierte. Aus der Sicht der Arbeitgeber hatte die Reform zudem den großen Vorteil, aktuell kaum zusätzliche Kosten zu verursachen, weil sie in den öffentlichen Etats eher in der übernächsten als bereits in der nächsten Legislaturperiode finanziell wirksam wurde. Nennenswerte politische Kritik an der Vereinbarung vom Frühjahr 1965 gab es daher nicht. ${ }^{375}$

Die Details der Reform waren - wie sich denken lässt - kompliziert. Im Kern gab es nun eine weitere Aufstockung der gesetzlichen Rente neben der älteren Zusatzversorgung. Die blieb erhalten, wurde aber deutlich preiswerter und langfristig damit finanziell auch unwichtiger, weil der Versicherungsbeitrag fast halbiert wurde. Der neu eingeführte dritte Bestandteil der Altersbezüge wurde vollständig von den Arbeitgebern bezahlt und regelmäßig an die allgemeine Einkommensentwicklung angepasst. Damit

373 | Die Kabinettsprotokolle der Bundesregierung, Bd. 18: 1965. Bearb. v. Josef Henke/Christoph Seemann, München 2008 (im Folgenden: Kabinettsprotokolle Bundesregierung 1965), S. 146 (Kabinettssitzung v. 24.3.1965).

374 | Vgl. zu diesem Zusammenhang: ÖTV-Geschäftsbericht 1964/67, S. 47.

375 | Zwar wurden die laufenden Renten nach Inkraftreten der Reform zum 1. Januar 1967 auf komplizierte Weise neu berechnet. Mehrheitlich ergaben sich dadurch aber keine höheren Bezüge. 1967 etwa wurden rund 55.000 der etwa 230.000 laufenden Renten »umgestellt«; in 82 Prozent der Fälle blieb die ausgezahlte Summe jedoch unverändert (Geschäftsbericht Versorgungsanstalt BundLänder 1967, S. 14). 
entstand für die Arbeiter und Angestellten der Öffentlichen Hand »eine dynamische Gesamtversorgung«. Sie war so gestaltet, dass schon nach fünf Jahren Arbeit »beim Staat« 35 Prozent des jeweiligen Verdienstes als dauerhafte Altersversorgung gesichert waren. In der gesetzlichen Rentenversicherung wurde dieser Wert hingegen erst erreicht, wenn der oder die Versicherte jahrzehntelang "geklebt« (also Beiträge gezahlt) hatte. ${ }^{376}$

Nach 35 Dienstjahren erhielten Arbeiter und Angestellte des Staates - wie Beamte - zudem künftig den vollen Satz von 75 Prozent des jeweils letzten Bruttoverdienstes. Zwar galt auf Drängen der Arbeitgeber eine Kappungsgrenze, die bei Gesamtbezügen von 900 DM monatlich gezogen wurde. Gekürzt wurde aber stets nur der beitragslose dritte Bestandteil der Altersversorgung; die Versicherungsleistungen blieben unangetastet. Ein zeitgenössischer Versicherungsexperte lobte diesen Tarifvertrag als »eine beachtliche sozialpolitische Leistung«: Deutliche Einschränkungen des individuellen Lebensstandards durch eine »Unterversorgung " werde es bei den Rentnern und Rentnerinnen des Staates in Zukunft nicht mehr geben. Die Gewerkschaften des Öffentlichen Dienstes sowie Bund und Länder hätten damit einen sozialen Standard gesetzt, der hoffentlich bald für alle Arbeitnehmer gelten werde. ${ }^{377}$ Heinz Kluncker äußerte sich ganz ähnlich: Er sah in der Zusatzversorgung »eine wesentliche Grundlage für soziale Regelungen in der $\mathrm{Zu}$ kunft« und meinte damit offensichtlich nicht nur den Öffentlichen Dienst. ${ }^{378}$

376 | Rentenversicherungsansprüche wurden seinerzeit durch Beitragsmarken belegt, die der Versicherte in ein persönliches Versicherungsheft einklebte. Daher die volkstümliche Formulierung, jemand habe viel oder auch zu wenig "geklebt«. Die Gewerkschaften benutzen (wie oben schon gezeigt wurde) das gleiche Verfahren, um die Beitragszahlungen ihrer Mitglieder zu dokumentieren.

377 | Reiner Rübsteck: Neuregelung der Zusatzversorgung im öffentlichen Dienst. In: Soziale Sicherheit 14 (1965), S. 147-148, hier: S. 148. Bei Überschreiten der 900-DM-Grenze wurden jeweils 20 Prozent des dritten, beitragslosen Teils der Gesamtbezüge gestrichen. Die beiden anderen Bestandteile der gesamten Rente blieben unangetastet; dies galt auch, wenn sie zusammen mehr als $900 \mathrm{DM}$ ergaben. Der Beitrag der Zusatzversorgungskasse sank von insgesamt 6,9 Prozent der Bruttobezüge auf 2,5 Prozent; der Arbeitnehmer zahlte nun 1,5 Prozent (statt zuvor 2,3 Prozent) seiner Bezüge (Geschäftsbericht Versorgungsanstalt Bund-Länder 1967, S. 3).

378 | So im April 1970 in seiner Rede auf der Festveranstaltung zum 25-jährigen Dienstjubiläum des Stuttgarter Oberbürgermeister Arnulf Klett in: 25 Jahre 
Diese Details sind ohne Frage recht spröde - aber gerade deshalb von Bedeutung für eine breit angelegte Geschichte der ÖTV. Sie belegen zum einem, wie dringlich die Gewerkschaft auf ausgefeiltes Expertenwissen angewiesen war, wenn sie in Tarifverhandlungen bestehen wollte. »Nur ausgezeichnete Kenner [...] können zu allen Fragen Stellung nehmen«, so hatten selbst die Mitglieder des Hauptvorstandes geklagt, als sie 1960 darüber berieten, wie die Zusatzversorgung sozial sinnvoll zu reformieren sei. ${ }^{379}$ Der Wissensstand der einfachen Mitglieder darf daher wohl als noch geringer gelten.

Zum anderen zeigt der Tarifvertrag zur Altersversorgung des Öffentlichen Dienstes vom März 1965 mit seinen komplexen Regelungen eindringlich, wie langfristig Gewerkschaften denken und handeln können. Für die große Mehrheit der Mitglieder, die im Jahr 1965 zur ÖTV gehörten, hatte der große sozialpolitische Erfolg ihrer Organisation persönlich keine Bedeutung: Sie profitierten kaum von den neu vereinbarten Regelungen, weil die ihre Wirkung ja erst langfristig entfalteten. Die Tatsache, dass die reformierte Ordnung der Zusatzversorgung überhaupt erst Anfang 1967 in Kraft trat, unterstrich den Langzeitcharakter dieses Projektes zusätzlich.

Die rentenpolitische Arbeit der ÖTV wurde schließlich auf den vorangegangenen Seiten auch deshalb genauer dargestellt, weil die 1965 vereinbarte spezielle Alterssicherung für Arbeiter und Angestellte des Staates in den 1970er Jahren von den Arbeitgebern immer schärfer als »skandalös« kritisiert wurde. Dieser Streit wird unten genauer geschildert. Allerdings lohnt es sich, schon an dieser Stelle an den sozialen Kontext zu erinnern, in dem die Rentenaufbesserung beschlossen wurde: Wie oben gezeigt wurde, gehörten die meisten ÖTV-Mitglieder zu den Bundesbürgern mit geringem Einkommen. Fast zwei Drittel von ihnen verdienten Mitte der 1960er Jahre weniger als 500 DM brutto pro Monat. ${ }^{380}$ Auch ein Rentenniveau von 75

Oberbürgermeister. Festschrift für Arnulf Klett, Stuttgart 1971, S. 125-126, hier: S. 126.

379 | Protokoll über die 9. Sitzung des HV, 9./10.11.1960. In: Archiv Ver.di, Bestand Kluncker, 45.

380 | Bayer/Streeck/Treu: Gewerkschaftsbewegung, S. 263. Allerdings ist dabei die oben beschriebene Unsicherheit über die »Beitragsehrlichkeit« vieler Mitglieder zu bedenken. 
Prozent bedeutete bei solchen Löhnen und Gehältern nichts anderes als eine sehr bescheidene Existenz.

So gesehen war die spezielle Rentenreform, die 1965 per Tarifvertrag für die Arbeiter und Angestellten des Staates beschlossen wurde, eigentlich nichts anderes als eine zur Tat gewordene Kritik an den oft genug unzulänglichen Renten der gesetzlichen Sozialversicherung, deren Zahlungen bei früheren Geringverdienern auch nach Einführung der »dynamischen« Alterssicherung keinen selbstbestimmten Ruhestand zuließen. ${ }^{381}$ Allerdings hat die ÖTV ihren tarifpolitischen Erfolg öffentlich nie in diesem Sinne präsentiert. Wenn es um die Altersversorgung ging, sah sie den Öffentlichen Dienst offensichtlich doch stark als ein geschlossenes soziales System. Damit übernahm die Organisation die Sichtweise ihrer Mitglieder: 1967 konstatierte das Tarifsekretariat, für die vom Staat beschäftigten Arbeiter verliere »der Bezug zu den Arbeitern in der Wirtschaft an Bedeutung. Es werden immer mehr Vergleiche mit den anderen Gruppen des öffentlichen Dienstes angestellt. ${ }^{382}$

Das Pensionssystem der Beamten blieb daher der Maßstab, mit dem die ÖTV die Renten der nicht-verbeamteten Mitarbeiter des Öffentlichen Dienstes bewertete. Ihr nächstes Ziel ergab sich damit fast wie von selbst: Da Bund und Länder begonnen hatten, die »Versorgungslücke« bis zu dem Anteil von 75 Prozent der jeweils letzten Bezüge, der zum Symbol für den »sicheren Lebensabend" geworden war, mit einem Zuschuss zu schließen, sollte nun die ältere, durch Beiträge der Arbeitnehmer teilfinanzierte Zusatzversorgung verschwinden. Unübersehbar diente die lebenslange Alimentierung des Beamten durch den Staat dabei als Vorbild. ${ }^{383}$

381 | $\mathrm{Zu}$ einer abwägenden Bilanz der Rentenreform vgl.: Hilpert: Wohlfahrtsstaat, S. 112-137. Grob gesagt bewirkte die Reform vor allem, dass die Einkommensunterschiede im Erwerbsleben nun stärker auch als Unterschiede im Rentenniveau auftraten. Von allgemeiner Altersarmut ließ sich nicht mehr sprechen; arme Rentner und vor allem arme Rentnerinnen gab es jedoch nach wie vor in erheblicher Zahl.

382 | Vermerk des Tarifsekretariats über Monatslöhne für Arbeiter, 3.5.1967. In: Archiv Ver.di, Bestand Kluncker, 12.

383 | Um es vorwegzunehmen: Ab 1973 wurde dann die gesamte Zusatzversorgung allein von den Arbeitgebern bezahlt. Siehe dazu S. $336 \mathrm{f}$. 


\section{Laufbahnen für Angestellte durch den "Bewährungsaufstieg" und ein Monatssalär auch für Arbeiter}

In den ersten fünf Jahren unter Heinz Klunckers Vorsitz erzielte die ÖTV zwei weitere strukturell wichtige tarifpolitische Erfolge. Wollte man es kurz machen, könnte ein Satz die entscheidenden Stichworte bieten: 1966 erreichte die Gewerkschaft, dass für Angestellte künftig ein »Bewährungsaufstieg« möglich war; 1969 setzte sie einen Tarifvertrag durch, der einen Monatslohn für die Arbeiter schuf. Leider sagen diese knappen Informationen kaum etwas aus. Bedeutung gewinnen sie nur im sozialen und historischen Kontext - er soll im Folgenden jeweils wenigstens knapp skizziert werden.

Hinter dem bürokratisch klingenden Begriff "Bewährungsaufstieg" etwa verbirgt sich eine kleine Revolution im Öffentlichen Dienst: Feste "Laufbahnen", die mit Sicherheit stets nach oben führten, hatte es bislang nur für Beamte gegeben. Mit dem Tarifvertrag, der den »Bewährungsaufstieg« einführte, entstand nun etwas sehr Ähnliches für Angestellte des Staates. Das "zweierlei Recht«, das die ÖTV beklagte, wurde damit zwar nicht beseitigt, die Grenze zwischen den beiden Sphären aber verschob sich.

Wenn die Deutschen immer sofort an "Sicherheit" dachten, sobald von Beamten die Rede war, dann ergab sich das nicht nur aus deren Unkündbarkeit und aus der guten Altersversorgung. In den beiden oberen Ebenen der Beamtenwelt, d.h. im »gehobenen Dienst« und im »höheren Dienst«, bedeutete der Amtseid seinerzeit stets den Einstieg in eine exakt vorgezeichnete berufliche und finanzielle Karriere, die noch mehr umfasste als regelmäßig gewährte Dienstalterszulagen. Dabei ging es im Einzelnen durchaus unterschiedlich hoch hinauf; die "Regelbeförderung« sorgte jedoch durch die Bank langsam, aber sicher für gewichtigere Amtsbezeichnungen und höhere Einkünfte. Formal existierte zwar kein Anspruch auf diesen Aufstieg; de facto aber war die individuelle Karriere doch als sicher anzusehen, obwohl ein renommierter Verwaltungsjurist dies streng missbilligend als »krypto-verfassungswidrige Entwicklung« geißelte. Sogar in der unteren Ebene der Beamtenhierarchie, im »einfachen Dienst«, gehörte seit den 1950er Jahren mindestens eine Beförderung zum sozialen Besitzstand der Beamten. ${ }^{384}$

384 | Walter Leisner: Das Leistungsprinzip. In: ders.: Beamtentum. Schriften zum Beamtenrecht und zur Entwicklung des öffentlichen Dienstes 1968-1991. 
Bei den Angestellten im Öffentlichen Dienst (von den Arbeitern ganz zu schweigen) sah das anders aus. Genau wie in der Privatwirtschaft kam eine Beförderung für sie stets nur zustande, wenn sie sich individuell auf eine freie Stelle bewarben und vom Arbeitgeber auch dafür ausgewählt wurden; feste Fristen oder gesicherte Ansprüche gab es dabei nicht. Die ÖTV meinte, dieser Zustand diskriminiere die beruflich höher qualifizierten Angestellten - und für dieses Urteil gab es gute Gründe. Schon seit 1950 vermehrte sich die Zahl der Angestellten im Staatsdienst rascher als die der Beamten und Arbeiter; in den 1960er Jahren trat dieser Trend dann sogar noch deutlicher hervor. ${ }^{385}$ Dabei veränderte sich auch das berufliche Profil der Angestellten im Öffentlichen Dienst: Zunehmend entstanden Stellen, die eine höhere Schulbildung und qualifizierteres Fachwissen voraussetzen. In einigen Sparten der Verwaltung - etwa in den Finanzämtern - übernahmen Angestellte teilweise sogar exakt die gleichen Aufgaben wie Beamte. Ihre Chancen auf ein berufliches Fortkommen aber blieben unsicher. ${ }^{386}$

Hrsg. v. Josef Isensee, Berlin 1995, S. 273-292, hier: S. 286 (dieser Text stammt aus dem Jahr 1971). Vgl. als knappen Abriss für die Beförderungspraxis etwa: Widerstand gegen den Bewährungsaufstieg. In: FAZ, 29.7.1965; Bewährungsaufstieg für die Angestellten des öffentlichen Dienstes. In: FAZ, 27.8.1965. Einen genaueren Einblick in dieses komplexe System, das Züge einer Geheimwissenschaft trug, gibt etwa: Geschäftsbericht des Hauptvorstandes der Deutschen Postgewerkschaft vom 1.7.1965 bis 30.6.1968, Frankfurt/Main 1968, S. 36-54.

385 | Vgl. etwa die Angaben in: Claus Schäfer/Rainer Skiba/Hartmut Tofaute: Personalausgaben und Einkommensfindung im öffentlichen Dienst, Köln 1975, S. 32. Auf der Basis dieser Zahlen wuchs die Gruppe der staatlichen Angestellten von 1960 auf 1966 um 27,9 Prozent. Bei den Beamten betrug der Zuwachs im gleichen Zeitraum 16,6 Prozent, bei den staatlich beschäftigten Arbeitern 18,0 Prozent.

386 | Ebd. Die Zahl der Angestellten im höheren und gehobenen Öffentlichen Dienst wuchs hiernach von 1960 auf 1966 um 44,6 Prozent. Bei den Beamten betrug der Zuwachs in diesen beiden Dienststufen gleichzeitig 26,4 Prozent. Zum Nebeneinander von Beamten und Angestellten, die weitgehend gleiche Arbeiten erledigten, vgl. etwa für Hessen die Angaben des Bundesangestelltensekretärs der ÖTV, Günther Stein. In: Angestellte fordern ihre Chance. In: FAZ, 17.6.1965, sowie allgemein auch: ÖTV-Geschäftsbericht 1968/71, S. 153 f. u. 164. Grundlegend zur Kritik an diesen Verhältnissen vgl. etwa: Eberhard Menzel: Die strukturelle Desorganisation des öffentlichen Dienstes in der Bundesrepublik. In: Die öffentliche Verwaltung 22 (1969), S. 513-526. 
Im Frühjahr 1965 beschloss der ÖTV-Hauptvorstand, diese Diskrepanz zwischen den individuellen Zukunftsaussichten von Beamten und staatlichen Angestellten in einer breit angelegten Kampagne öffentlich anzuprangern. Das Gremium verfasste einen »Offenen Brief« an die Bundesregierung und die anderen staatlichen Arbeitgeber, der "gleiches Recht" verlangte: Auch Angestellte müssten sichere berufliche Aufstiegschancen erhalten. Der »Bewährungsaufstieg« sollte das möglich machen: Wer gut arbeitete, erwarb nach diesem Modell das Recht, automatisch in die nächsthöhere Besoldungsgruppe aufzurücken. Die Wartezeit vor der sicheren Höhergruppierung wollte die ÖTV »je nach Wert der Tätigkeit" zwischen einem Jahr und fünf Jahren differenzieren; wie bei der »Regelbeförderung« der Beamten verlangsamte sich das Aufstiegstempo mit der fachlichen Qualifikation. ${ }^{387}$

In den Jahren 1965 und 1966 behandelte die Gewerkschaft diese Sache als ihre tarifpolitische Hauptaufgabe: Der »Bewährungsaufstieg" sei ein entscheidender Schritt hin zur »Festlegung moderner, besserer und gerechterer Tätigkeitsmerkmale« in den Tarifverträgen, die von den Arbeitgebern hartnäckig behindert oder sogar blockiert werde. Zwar hielt die ÖTV eine "gründliche Revision« der teilweise jahrzehntealten Stellen- und Arbeitsbeschreibungen im gesamten Öffentlichen Dienst für die bessere Lösung. Solange diese ausbleibe, sei der »Bewährungsaufstieg « aber immerhin doch ein geeigneter Ersatz für die »fehlende fortschrittliche Tarif- und Personalpolitik der öffentlichen Arbeitgeber «. ${ }^{388}$ Günther Stein, der Angestelltensekretär der ÖTV, sprach sogar von einer "Notwehr, um die Interessen unserer Mitglieder durchzusetzen ${ }^{389} \mathrm{Ihr}$ Projekt trug die Organisation in

387 | Offener Brief des ÖTV-HV an die Bundesregierung, 15.7.1965. In: Archiv Ver.di, Bestand Kluncker, 12. Die von der ÖTV vorgeschlagenen Wartefristen entsprachen Regelungen, die für die Beamten der Bundespost galten. Vgl.: Geschäftsbericht des Hauptvorstandes der Deutschen Postgewerkschaft vom 1. Juli 1968 bis 30. Juni 1971, Frankfurt/Main 1971, S. 144.

388 | Ebd. Vgl. auch: ÖTV-Geschäftsbericht 1964/67, S. 181. Hier wird der »Bewährungsaufstieg«als "Sofortmaßnahme« bezeichnet, die helfen könne, das viel größere Problem einer Generalrevision zu bewältigen. $\mathrm{Zu}$ den nur ansatzweise erfolgreichen Bemühungen der ÖTV in den frühen 1960er Jahren, die Tätigkeitsbeschreibungen für Angestellte an die gewandelte Berufswelt anzupassen, siehe schon S. 92.

389 | Günther Stein: Bewährungsaufstieg perfekt. In: ÖTV-Magazin 1966, H. 4, S. 3. 
die breitere Öffentlichkeit: An Kundgebungen und Demonstrationen in zahlreichen Großstädten, die terminlich mit dem Verhandlungsprozess abgestimmt wurden, beteiligten sich nach den Angaben der ÖTV insgesamt 40.000 Beschäftigte. ${ }^{390}$

Obwohl sich die Arbeitgeber anfänglich entschieden gegen den $\gg \mathrm{Be}-$ währungsaufstieg« sträubten, fanden sie doch zunehmend Gefallen an den Vorschlägen der Gewerkschaft. Zumal Bund und Länder, bei denen Beamte und Angestellte in der Tat häufiger Seite an Seite mit weitgehend den gleichen Arbeiten beschäftigt waren, kamen der ÖTV (wie auch der DAG, die vergleichbare Forderungen stellte) schrittweise entgegen. Allerdings beharrten TdL und Bundesregierung unnachgiebig darauf, die sichere Beförderung nur beruflich qualifizierten Angestellten einzuräumen. Zudem hielten sie die von der ÖTV vorgeschlagenen »Bewährungsfristen" generell für zu kurz und auch für zu undifferenziert. Gerade in den oberen Ebenen des Tarifgefüges, in denen eine Beförderung größere finanzielle Bedeutung hatte als bei stark weisungsgebundenen Tätigkeiten, wünschten sie sich einen deutlich langsameren Aufstieg in der Gehaltsskala. ${ }^{391}$

In langwierigen Verhandlungen entstand so ein äußerst komplizierter Kompromiss: Der im März 1966 unterzeichnete Tarifvertrag bezeichnete in dem gesamten, stark differenzierten System der siebzehn verschiedenen Vergütungsgruppen, die es für Angestellte im Öffentlichen Dienst gab, ganz genau jeweils die Stellen und Tätigkeiten, für die in Zukunft der »Bewährungsaufstieg" galt, sowie diejenigen, bei denen alles beim Alten blieb. Grob gesagt gab es eine tarifvertraglich fixierte Karriere nun für alle Angestellten des Staates, die mindestens eine fachbezogene Berufsausbildung absolviert hatten; geringer qualifizierte Angestellte und Quereinsteiger sowie alle Arbeiter blieben außen vor. Die Zeit, die vor der automatischen Höhergruppierung vergangen sein musste, betrug in keinem Fall weniger als zwei Jahre; bei Leitungsstellen konnte die berufliche »Bewährung« des Aspiranten sogar bis zu 15 Jahre dauern. ${ }^{392}$

390 | ÖTV-Geschäftsbericht 1964/67, S. 182.

391 | Vgl. den Abriss der Verhandlungen in: ebd., S. 115-117.

392 | Vgl. zusammenfassend: ebd.; die Details finden sich in: Tarifvertrag über den Bewährungsaufstieg für Angestellte des Bundes und der Länder vom 25. März 1966, Düsseldorf 1966, S. 12-46. Grob geschätzt hatten dank der Bestimmungen des Vertrages seinerzeit wohl 75 Prozent der Angestellten von Bund und 
Die ÖTV kritisierte solche langen Fristen und die neue Zweiteilung der Angestelltenschaft, sprach insgesamt aber doch von einem großen Erfolg: Mit dem »Bewährungsaufstieg« böten sich nun auch Angestellten des Staates Aufstiegsmöglichkeiten nach dem »Leistungsgrundsatz «. ${ }^{393}$

Gerade dieses Label passte allerdings nur schlecht zu den Formulierungen des Tarifvertrages. Als »bewährt " galt danach jeder Angestellte, der sich auf der aktuell besetzten Stelle den Arbeitsanforderungen "gewachsen gezeigt « hatte. ${ }^{394}$ In der codierten Sprache, die Personalverwaltungen in individuellen Arbeitszeugnissen verwandten, bezeichneten diese Worte einen Beschäftigten, der keine gravierenden Fehler gemacht hatte, aber auch nicht positiv aufgefallen war. Der »Leistungsgrundsatz«, den der Tarifvertrag über den »Bewährungsaufstieg« vom März 1966 zur Maxime erhob, fiel somit nicht sehr anspruchsvoll aus. Die konservative $F A Z$ wertete die Bestimmung resigniert als typisch für eine "Zeit der allgemeinen Gefälligkeit«, in der alle Arbeitgeber (auch die in Industrie und Gewerbe) »mit Blick auf die Arbeitsmarktlage« zu weitreichenden Zugeständnissen an die Beschäftigten bereit seien. ${ }^{395}$

Wenngleich die ÖTV einen anderen Eindruck zu erwecken versuchte: Gewerkschaften und Arbeitgeber hatten mit dem »Bewährungsaufstieg« de facto die "Regelbeförderung« der Beamten auf Teile der staatlichen Angestellten ausgedehnt - der sichere Aufstieg der Beamten aber erfolgte eben gerade nicht auf der Basis einer besonderen Eignung oder Leistung, sondern automatisch nach Zeitablauf. Zu dieser Ausweitung eines Beamtenprivilegs kam es, weil die unterschiedlichen Interessen der Tarifpartner so am einfachsten gemeinsam befriedigt wurden. Die ÖTV wünschte sich

Ländern Aussicht auf den »Bewährungsaufstieg« (Wer sich bewährt, kann aufrücken. In: FAZ, 17.2.1966).

393 | ÖTV-Geschäftsbericht 1964/67, S. 185; zur Kritik an den Fristen vgl.: ebd., S. 48, sowie: Günther Stein: Bewährungsaufstieg perfekt. In: ÖTV-Magazin 1966, H. 4, S. 3.

394 | Tarifvertrag, S. 1 ( $\$ 1$, Abs. 3).

395 | Friedrich Karl Fromme: Der Bewährungsaufstieg und sein Preis. In: FAZ, 3.3.1966. Vgl. als Hintergrund auch: Werner Möhl/Wolfgang Winterfeldt: Mitarbeiter-Bewertung. Maßstäbe und Methoden der Persönlichkeits- und Fähigkeitsbeurteilung, Bad Wörishofen 1968, S. 219 f. Hiernach war es eine gängige Praxis, in Arbeitszeugnissen zurückhaltende oder auch negative Urteile »durch das Weglassen positiver Formulierungen [zu] umschreiben«. 
dringend einen tarifpolitischen Erfolg, der vor allem den beruflich qualifizierten Angestellten im Öffentlichen Dienst zugutekam, um sich in der Konkurrenz mit der DAG gerade um diese wachsende Gruppe von Beschäftigten behaupten zu können. ${ }^{396}$ Zwar hätte die ÖTV eine grundlegende Revision der Stellen- und Arbeitsbeschreibungen präferiert, die mit Sicherheit für viele Angestellte zu einer Höhergruppierung geführt hätte. Bund und Länder aber verschleppten eine solche konsequente Modernisierung des Manteltarifvertrages; gleichzeitig wollten jedoch auch sie den Öffentlichen Dienst für beruflich qualifizierte Angestellte attraktiver gestalten. So wählten beide Seiten den vergleichsweise bequemen Ausweg, Angestellte in das System der »Regelbeförderung « einzubeziehen; gemeinsam verzichteten sie dabei auf den Versuch, das berufliche Fortkommen im Staatsdienst stärker an den "Leistungsgrundsatz" zu binden. Gerade die Arbeitgeber hatten offensichtlich keinerlei Interesse daran, die Beamtenschaft mit ihrer mächtigen Lobby aufzuscheuchen, indem sie begannen, Beförderungen bei den öffentlichen Angestellten jeweils von einer besonderen beruflichen Leistung abhängig zu machen: Da der Öffentliche Dienst ein eng zusammenhängendes juristisches und kommunikatives Gefüge darstellte, hätten Vorschriften für die Angestellten, die stark von der »Regelbeförderung «abwichen, zwangsläufig den Verdacht genährt, Gleiches sei womöglich auch für die Beamten geplant. Gerade das ohnehin unpopuläre und stark in die politische Defensive geratene Kabinett von Ludwig Erhard musste eine solche Debatte ernsthaft fürchten. ${ }^{397}$

396 | Vgl. dazu das ausdrückliche Bekenntnis der ÖTV, sie wolle und werde auch die Interessen von leitenden Angestellten vertreten. In: ÖTV-Geschäftsbericht 1964/67, S. 187.

397 | Zwar verlangten Bund und TdL in den Beratungen anfänglich, der Bewährungsaufstieg dürfe nur für Angestellte gelten, deren individuelle Leistungen »dauernd erheblich über den Durchschnittsleistungen« lägen (Über den Bewährungsaufstieg. In: FAZ, 29.9.1965). Allerdings ließen sie diese Forderung so rasch und so vollständig fallen, dass sich der Eindruck aufdrängt, der Punkt sei ihnen doch nicht sehr wichtig gewesen. Vgl. dazu: Aussicht auf Bewährungsaufstieg. In: FAZ, 14.1.1966; Bewährung und Aufstieg. In: FAZ, 16.2.1966. Im Bundeskabinett gab es keine Diskussionen über die Angelegenheit. Das Resultat der Verhandlungen etwa wurde dort kommentarlos zur Kenntnis genommen (Die Kabinettsprotokolle der Bundesregierung, Bd. 19: 1966. Bearb. v. Christine Fabian/Uta Rös- 
Recht besehen entstand der »Bewährungsaufstieg« also nicht nur, weil die ÖTV ihre Mitglieder für diese Forderung mobilisierte. Vielmehr verdankte sich die Regelung auch den Interessen der Beamten, denn indirekt zementierte der Tarifvertrag vom März 1966 einen wichtigen Teil der »hergebrachten Grundsätze«, nach denen die Welt der deutschen Beamten geregelt war und laut Grundgesetz ja auch geregelt sein sollte. ${ }^{398}$ Die ÖTV hat diesen Effekt nicht gewollt; sie hat ihn aber hingenommen, weil es ihr so gelang, beruflich qualifizierte Angestellte ohne eine grundlegende Reform der Manteltarifverträge mit rasch eintretenden Wirkungen individuell besser zu stellen.

Ein anderer Weg wäre durchaus möglich gewesen, denn für die Angestellten der Kommunen gab es nach 1966 keinen »Bewährungsaufstieg«, weil ausgerechnet die VKA, die in Tarifverhandlungen für den Öffentlichen Dienst doch stets als das schwächste Glied galt, von dieser Forderung der ÖTV grundsätzlich nichts wissen wollte: Sie schied schon frühzeitig aus den Beratungen aus, um eine Regelung durchzusetzen, die wirklich dem »Leistungsprinzip « entspreche. ${ }^{399}$

Wenn die Kommunalpolitiker in diesem Punkt personalpolitisch einen strikteren Kurs verfolgten als Bund und Länder, dann taten sie das im Wesentlichen aus finanziellen Gründen. In den Städten gab es zahlreiche Ämter, öffentliche Einrichtungen und Betriebe, die vorwiegend Angestellte beschäftigten. Gerade bei den stark expandierenden sozialen Diensten der Kommunen, also etwa in Kindertagesstätten, Altersheimen oder Krankenhäusern, hatte die Regelbeförderung der Beamten daher bislang keine große Bedeutung gehabt. Der »Bewährungsaufstieg« musste somit für die Personaletats der Städte deutlich gravierendere Folgen haben als für die Finanzen von Bund und Ländern. ${ }^{400}$

sel, München 2009 [im Folgenden: Kabinettsprotokolle Bundesregierung 1966], S. 120 f. [Kabinettssitzung v. 24.2.1966]).

398 | Vgl. zusammenfassend: Hans Fenske: Bürokratie in Deutschland. Vom späten Kaiserreich bis zur Gegenwart, Berlin 1985, S. 58-84.

399 | Aussicht auf Bewährungsaufstieg. In: FAZ, 14.1.1966.

400 | Beispielhaft kann man etwa die Personalverhältnisse in Frankfurt am Main heranziehen: 1965 beschäftigte die Stadt in ihren Kindertagesstätten 492 Angestellte und drei Beamte. In den Kinderheimen gab es 364 Angestellte und neun Beamte; in den Kliniken 1.609 Angestellte und 41 Beamte. Alle Zahlen aus: Eine untragbare Last. In: FAZ, 11.3.1966. 
Der Status quo wurde jedoch trotz dieser finanziellen Bedenken der Kommunen überwunden. In mühseligen und konfliktreichen Verhandlungen vereinbarten VKA und ÖTV binnen Jahresfrist eine »verbesserte Vergütungsstruktur«, die für zahlreiche beruflich höher qualifizierte städtische Angestellte deutliche finanzielle Verbesserungen mit sich brachte. Zwar handelte es sich selbst bei dieser Abmachung noch nicht um die umfassende Revision der veralteten Stellenbeschreibungen, die nach dem Urteil der Gewerkschaft längst überfällig war. Die ÖTV akzeptierte jedoch auch diesen zweiten »Ersatz« dafür ebenso wie zuvor bereits den »Bewährungsaufstieg " - was noch einmal deutlich macht, dass der neuartige beamtenähnliche Beförderungsmechanismus für die Angestellten bei Bund und Ländern zentral tatsächlich den Interessen der Arbeitgeber entsprach, die sich nicht trauten, Beamtenprivilegien auch nur indirekt in Frage zu stellen. ${ }^{401}$

Mit ihrem Pragmatismus, der in diesem Fall vor allem nach kurzfristig wirksam werdenden Einkommensverbesserungen für Angestellte des Staates strebte, war die Gewerkschaft also einerseits ohne Frage erfolgreich. Andererseits aber half der Tarifvertrag mit Bund und Ländern vom März 1966 eindeutig nicht bei der strukturellen Modernisierung des Öffentlichen Dienstes. Eher ist wohl das Gegenteil der Fall: Da sich die vertraglich festgelegten Beförderungen mit einem Blick auf den Stellenkegel und den vorhandenen Personalbestand auf Jahre hinaus recht präzise berechnen ließen, schrumptte mit der Reform in den Behörden und Ämtern der Länder und des Bundes zwingend der ohnehin nicht große Spielraum, der ungewöhnlich leistungsstarken Beschäftigten eine rasche Karriere ermöglichte. Bereits 1970 klagte das Bundesinnenministerium, die Personalräte im Öffentlichen Dienst setzten seit der Änderung durch den Tarifvertrag von 1966 »der Förderung junger, leistungsfähiger Kräfte Widerstand entgegen«, um Stellen für Beförderungen "nach dem Dienstalter« freizuhalten. ${ }^{402}$

Last but not least gelang der ÖTV im Frühjahr 1969 noch ein weiterer tarifpolitischer Erfolg, der nichts mit einer der üblichen Lohn- und Gehaltserhöhungen zu tun hatte: Die Arbeiter im Öffentlichen Dienst wurden künttig nicht mehr wöchentlich entlohnt. Vielmehr erhielten sie nun

401 | ÖTV-Geschäftsbericht 1964/67, S. 183.

402 | Erwägungen des Hauptabteilungsleiters III des BMdI zur Frage der Reformbedürftigkeit des Dienstrechtes, 25.9.1970. In: AdsD, HSA, 1/HSAA007647. 
einen Monatslohn. Das mag auf den ersten Blick wie eine Formalität wirken, die keine weiteren Worte lohnt. Tatsächlich aber besaß diese Neuerung sowohl symbolisch als auch praktisch große Bedeutung. Symbolisch ging es bei der Abschaffung der Wochenlöhne darum, eine wichtige soziale Markierung zu beseitigen, die traditionell dazu gedient hatte, die Arbeiter von den Angestellten und Beamten zu unterscheiden: Ihr »Lohn« wurde pro Tag oder pro Woche berechnet; das »Gehalt« der Angestellten und der Beamten galt hingegen immer für einen ganzen Monat, und es wurde zumindest den unkündbaren Staatsdienern sogar stets im Voraus gezahlt. Wie ein Delegierter auf dem ÖTV-Gewerkschaftstag von 1968 konstatierte, empfanden die Arbeiter diesen Unterschied nach wie vor als »Klassifizierung«, die sie gegenüber den Angestellten zurücksetze. ${ }^{403}$

Das Nebeneinander von Lohn und Gehalt gehörte zu einem ganzen Bündel von tariflichen Regelungen und rechtlichen Vorschriften, die in der Arbeitswelt des 19. und 20. Jahrhunderts pauschal alle Arbeiter schlechter stellten als die Angestellten. In der Bundesrepublik geriet diese Tradition der sozialen Hierarchisierung allerdings zunehmend in die Kritik und dank der Arbeit der Industriegewerkschaften - auch ins Wanken. Erinnert sei an den 16 Wochen dauernden Streik der Metallarbeiter in SchleswigHolstein im Winter 1956/57, der eine ungeschmälerte Lohnfortzahlung bei Krankheit, die es in Metallunternehmen bislang nur für Angestellte gegeben hatte, auch für Arbeiter durchsetzte. Gerade nach diesem Durchbruch wandelte sich das allgemeine gesellschaftliche Bewusstsein: Es galt nun zunehmend als modern, eher die Gemeinsamkeiten zwischen allen »Mitarbeitern« oder »Arbeitnehmern« als die Unterschiede zwischen Arbeitern und Angestellten zu betonen. ${ }^{404}$

403 | So der Delegierte Erwin Schneider (Stuttgart) in: Protokoll ÖTV-GT 1968, Bd. 1, S. 104. Vgl. auch allgemein: Hans Hofbauer: Zur sozialen Gliederung der Arbeitnehmerschaft. Arbeiter und Angestellte in der Gesellschaftshierarchie, Köln und Opladen 1965, insbes. S. $157 \mathrm{f}$.

404 | Vgl. etwa: Heinz Dedenig: Zur Frage der Angleichung von Arbeitern und Angestellten. In: Sozialer Fortschritt 18 (1969), S. 228-231. Gesetzlich gesichert wurde die einheitliche Lohnfortzahlung bei Krankheit erst im Juli 1969 durch ein Gesetz der Großen Koalition (Volker Hentschel: Geschichte der deutschen Sozialpolitik 1880-1980, Frankfurt/Main 1983, S. 183-185). 
Monatslöhne für Arbeiter aber gab es selbst in der zweiten Hälfte der 1960er Jahre nur in Ausnahmefällen in einzelnen Betrieben; Tarifverträge, in denen diese Form der Bezahlung für ganze Branchen oder Tarifgebiete bindend vorgeschrieben wurde, existierten nicht. ${ }^{405}$ Die ÖTV übernahm insofern die Rolle eines Vorreiters, als sie die öffentlichen Arbeitgeber im Mai 1967 in einer informellen Besprechung erstmals mit der Forderung konfrontierte, eine solche Abmachung vorzubereiten. Die reagierten einvernehmlich ausgesprochen freundlich und erklärten, auch sie hielten eine unterschiedliche Behandlung von Arbeitern und Angestellten "gesellschaftspolitisch und auch im Recht für überholt«. ${ }^{406}$

Als es wenig später dann konkret wurde, gab es allerdings doch noch Streit, denn der scheinbar rein formale Unterschied zwischen Wochenund Monatslohn hatte eine versteckte finanzielle Dimension, die Arbeitgeber und Gewerkschaft unterschiedlich beurteilten. Im Kern ging es der ÖTV mit ihrer Forderung nämlich darum, die »Einkommensschere« zwischen den Arbeitern und Angestellten im Öffentlichen Dienst wenn schon nicht zu schließen, dann doch wenigstens zu verringern. ${ }^{407}$ Die Details der Lohn- und der Gehaltsberechnung erklären, wie das funktionieren sollte und funktionieren konnte. Grob gesagt war der Lohn der Arbeiter stark "leistungsbezogen", das Gehalt der Angestellten (wie auch das der Beamten) hingegen »familienbezogen«: Diese erhielten höhere Kinder- und Ortszuschläge, die ihr Grundgehalt deutlich aufstockten. Arbeiter standen sich in dieser Beziehung schlechter und erreichten vergleichbare finanzielle

405 | Vgl. im Rückblick: Aloys Vogt: Der Monatslohn - ein neues Lohnmodell. In: Arbeit und Leistung 28 (1974), S. 101-109, hier: S. 103. Die hochprofitablen kommunalen Versorgungsunternehmen für Energie scheinen beim Monatslohn für Arbeiter die Rolle einer Avantgarde gespielt zu haben, der kaum jemand folgte. Die »Hamburger Elektrizitätswerke« (HEW) etwa zahlten schon seit 1935 einen Monatslohn; deren Berliner Pendant, die BEWAG, folgte 1938. Vgl.: Ernst Zander: Personalprobleme bei Rationalisierung und Automatisierung, Neuwied und Berlin 1967, S. 63 (zur HEW); Sozialbericht der Berliner Kraft- und Licht- (BEWAG)-Aktiengesellschaft, Berlin 1939, S. 5 f.

406 | Vermerk über die Besprechung mit Arbeitgebervertretern über ein neues Lohnsystem der Arbeiter im Öffentlichen Dienst, 17./19.5.1967. In: Archiv Ver.di, Bestand Kluncker, 12.

407 | Bericht des Tarifsekretariats über die Tarifverhandlungen, 17./18.1.1969. In: Archiv Ver.di, Bestand Kluncker, 13. 
Aufbesserungen daher nur durch weitere Zuschläge, etwa für erschwerte Arbeiten, Nachtschichten oder Wochenenddienste. Hinzu kam bei den Angestellten auch noch eine deutlich größere Steigerung des Grundgehaltes mit höherem Dienstalter. Bei langer Dienstzeit winkte einem Angestellten (wie auch einem Beamten) im Laufe der Jahrzehnte so selbst ohne den »Bewährungsaufstieg« ein Gehaltszuwachs von bis zu 25 Prozent gegenüber der Eingangsbezahlung. Bei den Arbeitern des Staates betrug dieses Anciennitäts-Plus, das selbstverständlich auch die Höhe der späteren Rentenbezüge beeinflusste, bestenfalls 5,5 Prozent. ${ }^{408}$

Ihre Rechtfertigung fand diese Differenz in einer grob pauschalisierenden Vorstellung, die aus dem 19. Jahrhundert stammte: Angestellte arbeiteten danach (genau wie Beamte) »geistig«, Arbeiter hingegen »körperlich«. Dementsprechend galt es als ausgemacht, dass der Angestellte bei seiner Tätigkeit im Büro und in der Verwaltung im Laufe der Jahre kontinuierlich zusätzliche Erfahrungen sammelte, die ihn für den Arbeitgeber »wertvoller" machten. Bei Arbeitern wurde ein solcher Wissenszuwachs nicht nur deutlich geringer angesetzt. Das Alter schwäche darüber hinaus - so die fast allgemein akzeptierte Ansicht, die für viele Berufe sicher auch berechtigt war - bei körperlich tätigen Menschen die Arbeitskraft. Deshalb sei es nicht gerechtfertigt, einen betagten Handarbeiter besser zu bezahlen als dessen jüngere Kollegen. ${ }^{409}$

Mit dem Monatslohn für Arbeiter wollte die ÖTV soziale Hierarchisierungen dieser Art abbauen: Lohn und Gehalt sollten künftig gleichermaßen »familienbezogen « gestaltet werden; auch die Progression nach dem Dienstalter müsse für Arbeiter nach vergleichbaren Regeln erfolgen wie bei den Angestellten. Zudem sollten viele der bislang individuell gewährten Leistungszuschläge für Arbeiter bei bestimmten Tätigkeiten dauerhaft

408 | Vgl. zu den Details: Niederschrift über die erweiterte Bezirksvorstandssitzung der ÖTV NRW II, 24.9.1970. In: AdsD, ÖTV-NW II, 5/ÖTVC022002 (hier die zitierten Begriffe); Vermerk des Referats D II 2, 4.12.1968. In: BArch Koblenz, B 106, 37703; ÖTV-Geschäftsbericht 1964/67, S. 213. Eine Zusammenstellung der Benachteiligungen auch in: ÖTV fordert ein neues Lohnsystem für die Arbeiter bei Bund, Ländern und Gemeinden. In: ÖTV-Arbeiter-Nachrichten 7 (1969), S. 1-9, hier: S. 2-5.

409 | Vgl. genau diese Argumentation zur Rechtfertigung des Unterschiedes in: Vermerk des Referats D II 2 zur Forderung der ÖTV auf Einführung eines Monatslohnsystems, 14.1.1969. In: BArch Koblenz, B 106, 37703. 
zum Bestandteil des Grundgehaltes werden und damit in die Progression nach dem Dienstalter eingehen. In der Quintessenz ging es der ÖTV darum, gerade die Angst vor schwindenden Kräften und sinkendem Verdienst zu bannen, die mit zunehmendem Alter bislang wie selbstverständlich zum Leben körperlich tätiger Menschen gehört hatte. ${ }^{410}$

Anfang 1969 machte die Gewerkschaft diese Angelegenheit zu ihrer »Hauptforderung«, die sie auf jeden Fall erfüllt sehen wollte. ${ }^{411}$ Die Arbeitgeber aber sperrten sich. Das von dem Sozialdemokraten Karl Schiller geführte Bundeswirtschaftsministerium etwa fürchtete, bei den körperlich tätigen Arbeitern werde man einen »leistungsmäßigen Abfall« erleben, wenn man sie mit fortschreitendem Alter genauso regelmäßig besser bezahle wie die Angestellten und die Beamten. Auch Finanzminister Strauß rief streng nach »leistungsbezogenen Löhnen «. ${ }^{412}$

Da ÖTV und Arbeitgeber bei der Kompromissfindung sehr versiert waren, entwickelten sie auch in diesem Fall eine Regelung, die für beide Seiten akzeptabel war. Bereits im Sommer 1969 verständigten sie sich grundsätzlich darauf, den Monatslohn einzuführen. ${ }^{413}$ Die nachfolgenden Detailverhandlungen zogen sich dann zwar noch mehr als zwölf Monate hin, so dass die Reform erst im Oktober 1970 wirksam wurde. Mit dem schließlich erreichten Resultat war die ÖTV jedoch hoch zufrieden: Sie meinte, es handle sich um ein Ergebnis, "wie es besser gar nicht sein konnte«. Die »sozialen Bestandteile«der Bezahlung sahen für Arbeiter nun genauso aus wie für Angestellte und Beamte. Dies galt auch für die $\mathrm{Zu}-$

410 | Verhandlungen über ein neues Lohnsystem im öffentlichen Dienst haben begonnen. In: ÖTV-Arbeiter-Nachrichten 7 (1969), S. 73-74.

411 | So resümierend BMdI Benda in: Kabinettsprotokolle Bundesregierung 1969, S. 76 (Kabinettssitzung v. 22.1.1969). Erste Forderungen, die auf einen Monatslohn abzielten, hatte bereits der Gewerkschaftstag von 1964 verabschiedet (Protokoll ÖTV-GT 1964, Anträge und Entschließungen, S. 85-87).

412 | Vgl. genauer: Vermerk über die Tarifverhandlungen über die Erhöhung der Löhne und Vergütungen im Öffentlichen Dienst, 5.12.1968. In: BArch Koblenz, B 106, 37702; Handschriftliche Notizen über die Abteilungsleiterbesprechung zur Frage der Monatslöhne für Arbeiter im Öffentlichen Dienst, 14.1.1969. In: BArch Koblenz, B 106, 37703.

413 | Verhandlungen über ein neues Lohnsystem im öffentlichen Dienst haben begonnen. In: ÖTV-Arbeiter-Nachrichten 7 (1969), S. 73-74, hier: S. 74 . Vgl. auch: ÖTV-Geschäftsbericht 1968/71, S. 87-89. 
schläge je nach Dienstalter. Bei der Umwandlung bisheriger Leistungszulagen in feste Lohnbestandteile setzte sich die ÖTV hingegen nur teilweise durch. In den Verhandlungen hatte die Gewerkschaft offen erklärt, sie sei bei diesem Punkt sehr flexibel, um die finanziellen Sorgen der Arbeitgeber zu lindern: »Entscheidend sei allein« das grundsätzliche Ja der Gegenseite zum geänderten Bezahlungsmodus. Zudem erfolgte die Umstellung auf den Monatslohn, die für alle Arbeiter im Staatsdienst deutliche Einkommensverbesserungen mit sich brachte, nicht auf einen Schlag, sondern in drei Stufen bis zum Herbst $1972 .^{414}$

Trotz solcher Zugeständnisse konnte sich die ÖTV berechtigt selbst dafür loben, dass sie »eine weitere Annäherung von Arbeitern und Angestellten« des Staates durchgesetzt hatte: Dank des neuen Monatslohns seien es die Arbeiter, die nun »den größeren Schluck aus der Pulle [...] nehmen« könnten. ${ }^{415}$ Zwar galt dies keineswegs so allgemein, wie die Gewerkschaft es darstellte, denn Staatsarbeiter, die vor der Reform mehrere verschiedene Leistungszulagen erhalten hatten, profitierten von der Umstellung deutlich weniger als solche, die keine besonderen Tätigkeiten erledigt hatten. Daraus erwuchs durchaus Unwillen an der Basis der Organisation. ${ }^{416}$ Schaut man vergleichend auf die Privatwirtschaft, dann konnte der Tarifvertrag zur Einführung der monatlichen Entlohnung aber dennoch als großer tarifpolitischer Erfolg gelten. Erst 1974 entstand in einer der großen Bran-

414 | Bericht des Tarifsekretariats über die Tarifverhandlungen für den Öffentlichen Dienst, 17./18.1.1969. In: Archiv Ver.di, Bestand Kluncker, 13. Eine Zusammenfassung der wichtigsten Resultate in: Es ist geschafft. In: ÖTV-ArbeiterNachrichten 8 (1970), S. 81-82; ÖTV-Geschäftsbericht 1968/71, S. 87-89. Zu den Streitigkeiten über Details vgl. auch: ÖTV wird Monatslohn durchsetzen. In: ebd., S. 41-42; Über den Monatslohn muss jetzt endgültig entschieden werden. In: ebd., S. 69. Die Dienstalterszulage wurde neunmal jeweils im Abstand von zwei Jahren gewährt; dabei sanken die Aufschläge von anfänglich 3,5 Prozent stufenweise auf schließlich 1,25 Prozent ab. Die ÖTV hatte sich zehn Zulagen von jeweils 3,5 Prozent gewünscht, nannte den Kompromiss aber »fortschrittlich«, weil er in jüngeren Jahren zu höheren Zuwächsen führte (ÖTV-Geschäftsbericht 1968/71, S. 88).

415 | So H. Kluncker im Interview in: Großer Schluck für die Arbeiter. In: Die Welt, 30.1.1969.

416 | Vgl. dazu: Niederschrift über die erweiterte Bezirksvorstandssitzung der ÖTV NRW II, 24.9.1970. In: AdsD, ÖTV-NW II, 5/ÖTVC022002. 
chen der Bundesrepublik, in der Chemieindustrie, eine erste vergleichbare Abmachung. ${ }^{417}$

Mit ihrer strukturell orientierten Tarifpolitik hat die ÖTV den Öffentlichen Dienst in den 1960er Jahren fraglos deutlich verändert: Der Beamtenstatus wurde in diesem Jahrzehnt immer stärker zum Modell für die sozialen Rechte der Arbeiter und der Angestellten, die für »den Staat« tätig waren. Die unkündbare Stellung spätestens nach einer Beschäftigungszeit von 15 Jahren auch für sie hatte die ÖTV bereits in den Jahren 1960/61 als ein einheitliches Recht erstritten; 1965 erfolgte der Einstieg in ein System der beamtenähnlichen Altersversorgung. Nur ein Jahr später galt dann das Laufbahnprinzip für große Teile der Angestellten. 1969 schließlich setzte die ÖTV den Monatslohn für Arbeiter durch, und damit gab es auch für sie Einkommensgewinne je nach dem Dienstalter, wie es sie zuvor bei Beamten und Angestellten gegeben hatte.

Mit all diesen Regelungen nutzte die ÖTV ihre gewerkschaftlichen Chancen im Interesse ihrer Mitglieder wie auch aller Staatsbeschäftigten so erfolgreich, dass der Öffentliche Dienst insgesamt den Bundesbürgern zunehmend als »ein Symbol für beruflichen Aufstieg, soziale Statusbildung und materielle Sicherheit« galt. ${ }^{418}$ Die Frage, ob sich aus ihren Erfolgen längerfristig vielleicht Probleme für den Öffentlichen Dienst insgesamt und damit auch für die Organisation ergeben könnten, hat die ÖTV-Führung in den 1960er Jahren offensichtlich nicht beschäftigt. Zumindest findet sich in den erhaltenen internen Dokumenten der Gewerkschaft kein Hinweis auf eine solche Debatte. Dabei lag zumindest ein Widerspruch offen zu Tage: Einerseits stritt die Gewerkschaft dafür, die Arbeiter und Angestellten des Öffentlichen Dienstes sozial immer stärker den Beamten gleichzustellen; andererseits aber verteidigte sie mit der Tarifautonomie vehement das Streikrecht der beim Staat beschäftigten Nicht-Beamten.

Fast alle bundesdeutschen Politiker und Juristen aber betrachteten es als legitim und selbstverständlich, dass die Beamten für ihre große soziale Sicherheit einen »Preis« zu zahlen hatten und deshalb auf Arbeitskämpfe verzichten mussten. Die allgemeine Öffentlichkeit teilte diese Sicht unein-

417 | Vogt: Monatslohn, S. 103.

418 | Hilpert: Wohlfahrtsstaat, S. 330 (den Beitrag der Gewerkschaften zu dieser Entwicklung nimmt die Autorin in ihrer Darstellung allerdings kaum in den Blick). 
geschränkt, und selbst der DGB verlangte zu diesem Zeitpunkt noch kein Streikrecht für die unkündbaren Staatsdiener. ${ }^{419}$ Gerade die großen Erfolge ihrer strukturellen Tarifpolitik also stellten die ÖTV vor ein programmatisches Dilemma: Wenn sie die Arbeiter und Angestellten im Öffentlichen Dienst zu Quasi-Beamten machen wollte und auch machte, wie konnte sie dann gleichzeitig deren Streikrecht für die Zukunft rechtfertigen und bewahren?

Auf diese berechtigte Frage hatte die Gewerkschaft in den 1960er Jahren keine Antwort; ja, sie begann überhaupt erst darüber nachzudenken, als die Tarifverträge, aus denen sich das Dilemma ergab, bereits unterschrieben waren. ${ }^{420} \mathrm{~W}$ ie viele der vorstehenden Kapitel gezeigt haben, war (und ist) Tarifpolitik unendlich komplizierte Detailarbeit. Daher kann die Vielzahl der verhandelten Themen und Regelungen leicht die Grundfragen und die "großen Linien « verdecken - und mit diesem Problem hatte die ÖTV in den Jahren zwischen 1964 und 1969 doch ernsthaft zu kämpfen. Sieht man von der Zusatzversorgung ab, dann strebte sie bei strukturell wichtigen Fragen vor allem nach kurzfristig wirkenden Erfolgen und steuerte daher eher »auf Sicht«.

Auch die Wirkungen ihrer Tarifpolitik für das allgemeine Image des Öffentlichen Dienstes bei den Bundesbürgern und in den Massenmedien scheint die ÖTV kaum bedacht zu haben. Mit diesem Ansehen aber stand es nicht zum Besten, weil gerade die Beamtenschaft ebenso beneidet wie scharf kritisiert wurde: Die unkündbaren Staatsdiener galten vielfach pauschal sowohl als sozial privilegiert wie auch als ineffizient, wenn nicht sogar als faul. Dabei zog insbesondere die sichere, leistungsunabhängige Karriere der Beamten heftige Kritik auf sich. ${ }^{421}$ Seit 1958 kannten zudem

419 | Als Zusammenfassung aus konservativer Sicht vgl.: Josef Isensee: Beamtenstreik. Zur rechtlichen Zulässigkeit des Dienstkampfes, Bad Godesberg 1971; kritisch gegenüber der »herrschenden Lehre« hingegen: Däubler: Streik. Zur Position des DGB vgl.: Thomas Ellwein: Gewerkschaften und öffentlicher Dienst. Zur Entwicklung der Beamtenpolitik des DGB, Opladen 1980, S. 96-99 u. 103.

420 | Als Versuch, das programmatische Dilemma zu lösen, entwickelte die Organisation in den 1970er Jahren ihr Modell eines einheitlichen Dienst- und Personalrechtes für den gesamten Öffentlichen Dienst. Siehe dazu unten Kapitel III. 421 | Vgl. etwa die Zusammenstellung von Pressestimmen in: Öffentliche Dienstleistungen - Vergeudung von Steuergeldern? Vorträge und Ansprachen auf der 7. beamtenpolitischen Arbeitstagung des DBB vom 14. bis 16. Januar 1965 auf 
auch die Bundesbürger »Parkinsons Gesetz«, das der Sozialwissenschaftler C. Northcote Parkinson einige Jahre zuvor in Großbritannien postuliert und werbewirksam nach seinem eigenen Namen benannt hatte: Danach wucherten bürokratische Apparate selbstzweckhaft vor sich hin, ohne damit leistungsfähiger zu werden. Empirisch ließ sich dieses angebliche Gesetz zwar leicht widerlegen; die eingängige These, der Staatsapparat diene vor allem sich selbst, wurde aber dennoch auch in der Bundesrepublik begeistert aufgegriffen und popularisiert. ${ }^{422}$

Die ÖTV, die parallel Beamte organisierte, wusste selbstverständlich von diesen Stimmen. Man kann aber nicht sagen, dass sie ihnen wirkungsvoll widersprochen hätte. Die Organisation ignorierte das Problem und verschärfte es, indem sie dazu beitrug, alle Beschäftigten des Staates mit beamtenähnlichen Rechten auszustatten.

Gerade der Tarifvertrag über den »Bewährungsaufstieg«, der ein besonders heftig kritisiertes soziales Privileg der Beamten auf die staatlichen Angestellten ausdehnte, kann als ein gutes Beispiel für diese Tarifpolitik dienen, die sich wenig für die Stellung des Öffentlichen Dienstes im gesamten sozialen und wirtschaftlichen System der deutschen Gesellschaft interessierte. Weil die Politiker mitspielten, funktionierte diese Strategie. Bündnispartner außerhalb des Staatsapparates aber ließen sich mit Erfolgen wie der sicheren Karriere für Angestellte oder auch der kostenlosen "Zusatzversorgung" schwerlich gewinnen.

Diese Schattenseite ihrer Arbeit nahm die Gewerkschaft jedoch erst später wahr. Wie unten gezeigt werden wird, musste die ÖTV in den 1970er

Bühler Höhe, Bad Godesberg 1965, S. 120-132, sowie: Heinrich Tötter: Die Beamten im Spiegel der Publizistik. In: Die Beamten und die Öffentlichkeit. Vorträge, Ansprachen und Diskussionen auf der 10. beamtenpolitischen Arbeitstagung des DBB vom 11. bis 13. Januar 1968 auf Bühler Höhe, Bad Godesberg 1968, S. 85-101. 422 | Vgl. zusammenfassend etwa: Carl Hermann Ule: Parkinsons Gesetz und die deutsche Verwaltung. Vortrag, gehalten vor der Berliner Juristischen Gesellschaft am 4. März 1969, Berlin 1960. Parkinsons Text war 1958 in deutscher Übersetzung publiziert worden (C. Northcote Parkinson: Parkinsons Gesetz und andere Untersuchungen über die Verwaltung, Düsseldorf 1958). Eine umfangreiche Kritik und Widerlegung findet sich in: Eckart Sturm: Die Entwicklung des öffentlichen Dienstes in Deutschland. In: Carl Hermann Ule (Hrsg.): Die Entwicklung des öffentlichen Dienstes. Berichte, Vorträge, Diskussionsbeiträge, Köln u. a. O. 1961, S. 1-285. 
Jahren mehrfach schmerzlich erleben, wie isoliert sie nicht nur in der allgemeinen Öffentlichkeit, sondern sogar innerhalb der bundesdeutschen Gewerkschaftsbewegung dastand, weil der Öffentliche Dienst insgesamt sozial als privilegiert galt. Der sprichwörtliche Pyrrhussieg hat zwar wohl einen anderen Charakter - insofern ist der Begriff an dieser Stelle verfehlt. Dennoch hat sich die ÖTV gerade mit den strukturell gewichtigen tarifpolitischen Erfolgen, die sie in den 1960er Jahren einfuhr, ein besonderes gewerkschaftliches Problem eingehandelt.

Da soziale Neuerungen in einem Segment des Öffentlichen Dienstes für die anderen Gruppen der Beschäftigten kaum folgenlos bleiben, profitierten letztlich auch die Beamten von dem Tarifvertrag, der den »Bewährungsaufstieg« der Angestellten einführte: Einvernehmlich sicherten CDU/ CSU und SPD als Partner in der Großen Koalition die routinemäßige Beamtenbeförderung im Mai 1969 erstmals per Gesetz einheitlich für Bund und Länder. Das bisherige Gewohnheitsrecht wurde damit einklagbar, denn Bundestag und Bundesrat beschlossen ausdrücklich, der individuelle Aufstieg in der Beamtenhierarchie dürfe »nicht an einem Mangel entsprechender Ämter« scheitern. ${ }^{423}$

Gleichzeitig plädierten Konservative und Sozialdemokraten für eine grundlegende Reform des Öffentlichen Dienstes, die gerade bei den Beamten und ihren besonderen Rechten beginnen müsse: Beförderungen sollten nur noch nach dem »Leistungsprinzip« erfolgen; das starre Laufbahnrecht sei zu lockern; es müsse generell leichter werden, vom Staatsdienst in die Privatwirtschaft und auch wieder zurück zu wechseln. ${ }^{424}$ Wort und Tat hat-

423 | Georg Anders: Zum neuen Entwurf eines Zweiten Besoldungsneuregelungsgesetzes. In: Die öffentliche Verwaltung 22 (1969), S. 81-92, hier: S. 82. Allerdings galt dies nur für den Aufstieg in das erste Beförderungsamt. Vgl. auch: Volker H. Heer: Beamtenbesoldung in der Bundesrepublik Deutschland. Entwicklung, Struktur, Problematik, Theorie, Frankfurt/Main und Zürich 1975, S. 23.

424 | Vgl. etwa: Einheitliches Dienstrecht - aber wie? In: FAZ, 8.11.1969; Reformpläne der SPD für den öffentlichen Dienst. In: ÖTV-Beamten-Nachrichten 14 (1969), S. 59-61; für CDU/CSU vgl.: Hans-Joachim Schäfer: Der öffentliche Dienst am Wendepunkt? In: Der Städtetag 22 (1969), S. 418-421, hier: S. 418. Inhaltlich waren diese Forderungen nicht neu. Bereits 1966 hatten sich im Bundestag alle Parteien dafür ausgesprochen, dass dem Leistungsprinzip bei Beamtenbeförderungen »mehr Geltung verschafft werden müsse« (Lücke bemüht sich um einheitliche Beamtenbesoldung. In: FAZ, 22.4.1966). 
ten bereits auf ähnliche Weise nicht zueinander gepasst, als die ÖTV 1966 den »Bewährungsaufstieg « für Angestellte erkämpfte. Daher war es nur konsequent, dass die Politiker diesen irreführenden Begriff nun in das Beamtenrecht übernahmen. Zumindest auf dem Papier war die oft kritisierte "Regelbeförderung« damit abgeschaff. De facto trieben die Arbeitgeber aber nur das Projekt weiter voran, das sie einige Jahre zuvor gemeinsam mit der ÖTV begonnen hatten: Sie sprachen von einer Modernisierung des Öffentlichen Dienstes und steuerten gleichzeitig in eine andere Richtung. Wenige Jahre später, als die Gewerkschaft ernsthaft daranging, über eine Neuordnung des Staatsdienstes nachzudenken, die sich nicht einfach nur am Status der Beamten orientierte, trat - wie im nachfolgenden Kapitel gezeigt wird - diese Abneigung der Arbeitgeber gegen wirklich neue Elemente im Recht des Öffentlichen Dienstes noch sehr viel deutlicher hervor. 


\section{Die »eigentliche Macht im Staat»?}

\section{Erfolge und vergebliche Mühen der ÖTV in den 1970er Jahren}

\section{Politischer Konsens und Dissens: Positionen der ÖTV in allgemeinen politischen Fragen in der sozialliberalen Ära}

\section{Die Ostkontakte der ÖTV nach 1969}

Mit dem Amtsantritt der ersten sozialliberalen Koalitionsregierung in Bonn im Oktober 1969 begann eine neue Phase in den Beziehungen zwischen der ÖTV und den Arbeitgebern im Öffentlichen Dienst. Da die Gewerkschaft und die SPD eng miteinander verflochten waren, blickte die ÖTV-Führung voller Sympathie auf die neue Bundesregierung: Heinz Kluncker sprach im Dezember 1969 in der Großen Tarifkommission ausdrücklich von »einer von vielen Gewerkschaftsmitgliedern erhofften Regierungskonstellation «. ${ }^{1}$ Ein Einklang der Interessen und Strategien blieb dennoch selten. Konflikte gab es vor allem (aber eben nicht nur) im Bereich der Tarifpolitik. Im Folgenden wird kurz an zwei anderen Beispielen gezeigt, wie unterschiedlich es trotz der politischen Nähe von SPD und ÖTV mit der Übereinstimmung zwischen der Gewerkschaft und der SPD-geführten Bundesregierung aussehen konnte.

Uneingeschränkt auf dem Kurs des Bonner Kabinetts lag die ÖTV bei der »Ostpolitik«. Der Grundsatz, man müsse den Status quo in Europa anerkennen, um ihn zu überwinden, wurde nach dem Oktober 1969 zur offiziellen politischen Richtlinie der bundesdeutschen Politik. Innenpolitisch musste sich die Koalition dabei nicht nur gegen den erbitterten Widerstand von CDU/CSU, von Vertriebenenverbänden und anderen rechtslastigen Interessengruppen, sondern auch gegen große Teile der Printmedien

1 | Sitzung der Großen Tarifkommission (GTK), 4.12.1969. In: AdsD, Depositum Kluncker, Reden und Referate November 1969-Februar 1972. 
durchsetzen. In dieser Auseinandersetzung, deren erhitzter Ton heute weitgehend vergessen ist, stand die ÖTV, gemeinsam mit den anderen DGBGewerkschaften, fest an der Seite der Regierung. ${ }^{2}$

Nach wie vor propagierte und pflegte die ÖTV auch eigene organisatorische Kontakte in den "Ostblock«, die den Verständigungskurs der offiziellen Außenpolitik unterstützen sollten. Bereits auf dem DGB-Bundeskongress Ende Mai 1969 hatte Heinz Kluncker verlangt, Gewerkschafter müssten trotz des gewaltsamen Endes des »Prager Frühlings« weiterhin als "Botschafter des guten Willens" gegenüber den osteuropäischen Staaten aktiv werden. Bloße Appelle zur Völkerverständigung reichten nicht aus, um den Frieden in Europa zu sichern: "Wenn wir Politik machen und nicht nur erdulden wollen, müssen wir mit unseren östlichen Nachbarn reden.« Dabei bezog der ÖTV-Vorsitzende ausdrücklich die DDR mit ein: »Wir müssen uns auch von der Illusion freimachen, wir könnten [...] die DDR ausklammern oder sogar umklammern. " $^{3}$

So nahm die ÖTV bereits im Jahr 1969 ihre eigenen Ostkontakte wieder auf. ${ }^{4}$ Nur gegenüber der DDR herrschte noch längere Zeit Funkstille. Gewerkschaftliche Begegnungen zwischen Bundesrepublik und DDR wurden erst möglich, als die beiden deutschen Staaten im »Grundlagenvertrag " im Sommer 1973 nach langen Verhandlungen einen Modus vivendi vereinbarten, der beide Seiten zur friedlichen Koexistenz verpflichtete. Daraufhin entstanden rasch auch Kontakte zwischen der ÖTV und der DDR-Gewerk-

2 | Vgl. dazu Heinz Kluncker in: Protokoll 7. Ordentlicher Gewerkschaftstag Berlin 1972 [der Gewerkschaft Öffentliche Dienste, Transport und Verkehr], Stuttgart 1972 (im Folgenden: Protokoll ÖTV-GT 1972), S. 48 u. 50 f. Rückblickend vgl. auch: Hemmer/Simon, Wirkung, S. 146.

3 | Protokoll des 8. Ordentlichen Bundeskongresses [des Deutschen Gewerkschaftsbundes], München, 18. bis 23. Mai 1969, Düsseldorf 1969, S. 464 u. 466. Allgemein zur Einbindung der gewerkschaftlichen Ostpolitik in die offizielle Außenpolitik nach 1969 vgl.: Stefan Müller: West German Trade Unions and the Policy of Détente (1969-1989). In: Moving the Social 52 (2014), S. 109-134.

4 | Zu den Ostkontakten der ÖTV nach 1969 vgl. etwa: ÖTV-Geschäftsbericht 1968/71, S. 32 f.; ÖTV-Geschäftsbericht 1972/75, S. 36f.; ÖTV: Geschäftsbericht 1976-1979. Hrsg. v. der Gewerkschaft Öffentliche Dienste, Transport und Verkehr - Hauptvorstand, Stuttgart 1980 (im Folgenden: ÖTV-Geschäftsbericht 1976/79), S. 45 (hiernach waren die Ost-West-Begegnungen mittlerweile »selbstverständlich geworden«). 
schaft für den Öffentlichen Dienst. Sie beschränkten sich allerdings stets auf die obere Führungsebene, weil die ostdeutschen Organisationen nur solche Begegnungen auf quasi diplomatischer Ebene wünschten. ${ }^{5}$ Auch eine Spionage-Affäre um Hans Faltermeier, der zum gHV der ÖTV gehörte und im Sommer 1976 zu zwei Jahren Gefängnis verurteilt wurde, weil er angeblich Kontakt zur DDR-Staatssicherheit gehabt hatte, brachte die ÖTV-Führung von ihrer Gesprächsbereitschaft nicht ab: Sie hielt weiterhin Kontakt zu den FDGB-Organisationen in Ost-Berlin. ${ }^{6}$

Der politische Ertrag dieser Beratungen ist schwer zu beurteilen. Wie in der offiziellen Außenpolitik, so trat bei den Gewerkschaften ebenfalls zunehmend Ernüchterung ein, weil der innere Wandel in den osteuropäischen Diktaturen, den man doch eigentlich anstoßen wollte, ausblieb. ${ }^{7}$ Dies gilt gerade für die letzte Phase des hier untersuchten Zeitraums, in der sich die Ost-West-Beziehungen vor allem durch Konflikte um Rüstungsfragen und den sowjetischen Einmarsch in Afghanistan wieder deutlich verschlechterten. Nachdem Heinz Kluncker im Januar 1981 mit einer Delegation des

5 | Konzeption für den Informationsbesuch einer Delegation des Zentralvorstandes der Gewerkschaft der Mitarbeiter der Staatsorgane und der Kommunalwirtschaft (GMSK) bei der Gewerkschaft ÖTV im DGB, 24.4.1976. In: BArch Berlin, SAPMO, DY 34, 25299. Mit anderen »Ostblock«-Gewerkschaften gab es hingegen einen Austausch von Jugend- und »Urlauber«-Gruppen. Vgl.: ÖTV-Geschäftsbericht 1972/75, S. 36 f.; ÖTV-Geschäftsbericht 1976/79, S. 45. Erst im Januar 1981 stand beim Besuch einer ÖTV-Delegation in Ost-Berlin auch ein Treffen mit einer Betriebsgruppe der Gewerkschaft aus der städtischen Verwaltung der »Hauptstadt der DDR « auf dem Programm (Konzeption für den Informationsaufenthalt einer Delegation des HV der ÖTV, 5.11.1980. In: BArch Berlin, SAPMO, DY 34, 25427). Berichte darüber konnten nicht ermittelt werden.

6 | Vgl. etwa: Zwei Jahre Gefängnis für Faltermeier. In: FAZ, 1.6.1976; Motiv unklar. In: Vorwärts, 3.6.1976. Das Urteil erging, obwohl der Prozess nicht geklärt hatte, was genau Faltermeier verraten haben sollte. Akten der DDR-Staatsicherheit über ihre Kontakte zu Faltermeier und die Bespitzelung Heinz Klunckers scheinen nicht mehr zu existieren. Auf Anfrage wurden mir von der BStU zwar viele Akten vorgelegt; keine davon aber enthielt Informationen über die Affäre. Vgl. zu Faltermeier und den Vorwürfen gegen ihn auch die umfangreiche Dokumentation, die der HV am 6. September 1974 an alle Mitarbeiter der Hauptverwaltung sowie an alle Bezirks- und Kreisverwaltungen verschickte. Ein Exemplar davon in: Archiv Ver.di, Bestand Kluncker, 53.

7 | Vgl. allgemein: Müller: Trade Unions, S. 125. 
ÖTV-Hauptvorstandes in Ost-Berlin erstmals mit dem FDGB-Vorsitzenden Harry Tisch beraten hatte, legte er die politische Messlatte jedenfalls sehr niedrig. Bei seiner Rückkehr äußerte er intern, die Begegnung habe als ein »kleiner warmer Hauch« vielleicht »ein ganz klein bißchen« dazu beigetragen, »jedenfalls das Klima nicht weiter vereisen zu lassen ${ }^{8}{ }^{8}$

Von einem »Bazillus der Freiheit«, der in den Osten getragen werden sollte, sprach Kluncker zu diesem Zeitpunkt nicht mehr. Stattdessen ging es nur noch darum, den Status quo zu bewahren. Allerdings kann man für die DDR ein anderes Fazit ziehen. Bei seinem Besuch im Januar 1981 begegnete der ÖTV-Vorsitzende in Ost-Berlin auf der Straße ganz kurz auch Menschen, die mit dem offiziellen Besuchsprogramm nichts zu tun hatten. Er wurde dabei freundlich begrüßt (»Dich kennen wir aus dem Westfernsehen«) und mit einem gewichtigen Wunsch konfrontiert: »Laßt uns nicht im Stich, laßt uns nicht alleine «? Wie diese Episode zeigt, waren Heinz Klunckers hartnäckige Bemühungen um gewerkschaftliche Kontakte in den »Ostblock« zumindest in der DDR vielleicht doch mehr als nur reine Symbolpolitik. Sie mögen (um Kluncker zu zitieren) »ein ganz klein bißchen« geholfen haben, im Herrschaftsbereich der SED ein Gefühl der nationalen Zusammengehörigkeit wachzuhalten, das die Partei in den 1970er und 1980er Jahren eigentlich doch zerstören wollte.

\section{Die Haltung der ÖTV \\ im Streit um die »Berufsverbote» im Öffentlichen Dienst}

Handelte die ÖTV in der »Ostpolitik« stets im Einklang mit der sozialliberalen Bundesregierung, so lag sie in einer anderen politischen Sache mit dem Kabinett für längere Zeit im Dissens. Dabei ging es um den »Extremisten-Erlass«, der - anders als die Außenpolitik - mit der Gewerkschaft und ihren Mitgliedern durchaus direkt zu tun hatte. Politisch war diese Angelegenheit für die ÖTV unter anderem deshalb wichtig, weil Teile ihrer Basis den Kurs kritisierten, den die Gewerkschaftsführung verfolgte: Sie forderten eine noch schärfere Haltung und deutlichere Kritik.

8 | Protokoll der 3. Sitzung des HV der ÖTV, 29./30.1.1981. In: AdsD, ÖTV, 5/ ÖTVB130080.

9 | So von Kluncker wiedergegeben in: Protokoll der 3. Sitzung des HV der ÖTV, 29./30.1.1981. In: AdsD, ÖTV, 5/ÖTVB130080. 
Als »Extremisten-Erlass« bezeichnete die Öffentlichkeit einen »Beschluss«, auf den sich Bundeskanzler Willy Brandt und die Regierungschefs aller Bundesländer am 9. Januar 1972 einigten, um sicherzustellen, dass im Öffentlichen Dienst keine Personen beschäftigt wurden, die nicht »jederzeit für die freiheitliche demokratische Grundordnung im Sinne des Grundgesetzes « eintraten. ${ }^{10}$ Im Prinzip bestätigten die Politiker damit nur eine Praxis, zu der sich die Bundesrepublik als "streitbare Demokratie« schon seit ihren Anfängen bekannte: Da die Weimarer Republik nach dem Urteil vieler Historiker auch deshalb gescheitert war, weil sie zahlreiche rechtsradikale Beamte - zumal unter den Richtern - hatte gewähren lassen, sollte es in der neuen Demokratie keine Staatsdiener mehr geben, die zu antidemokratischen politischen Bewegungen gehörten oder mit diesen sympathisierten. Bereits 1950 erließ die Bundesregierung Vorschriften, in denen dieser Grundsatz genauer geregelt wurde. ${ }^{11}$

Der Beschluss von 1972 hatte selbstverständlich aktuelle politische Hintergründe: Er reagierte auf die Polarisierungstendenzen, die sich in der Bundesrepublik seit Mitte der 1960er Jahre zeigten, und zielte sowohl auf Anhänger der rechtsradikalen NPD als auch auf Mitglieder und Sympathisanten der neu gegründeten »Deutschen Kommunistischen Partei« (DKP) und anderer weit links stehender Gruppierungen. Anders als der Beschluss von 1950, von dem die Öffentlichkeit kaum Notiz genommen hatte, entwickelte sich dessen Bekräftigung im »Extremisten-Erlass« von 1972 allerdings zu einem der am heftigsten umkämpften innenpolitischen Streitpunkte der 1970er Jahre. Wie schon bei den Notstandsgesetzen handelte es sich um eine Debatte, die fast ausschließlich im linken politischen Milieu stattfand, und die Kontrahenten stritten mit ähnlicher Erbitterung.

10 | Der Beschluss ist abgedruckt in: Hermann Borgs-Maciejewski (Hrsg.): Radikale im öffentlichen Dienst. Dokumente, Debatten, Urteile, Bonn-Bad Godesberg 1973, S. 9.

11 | Vgl. zu diesem Beschluss und der historischen Dimension dahinter im Überblick etwa: Hans-Helmuth Knütter: Verfassungsfeindliche Beamte in der Weimarer Republik. In: Wulf Schönbohm (Hrsg.): Verfassungsfeinde als Beamte? Die Kontroverse um die streitbare Demokratie, München und Wien 1979, S. 13-38; Peter Graf Kielmansegg: Von der Notwendigkeit und den Schwierigkeiten streitbarer Demokratie. In: ebd., S. 39-68. 
Die zahlreichen Kritiker, die der Erlass von 1972 auf den Plan rief, monierten vor allem zwei Punkte: Zum einen galt die Anforderung an die politische Gesinnung des Staatsdieners ausdrücklich auch für »Bewerber", die noch nicht im Öffentlichen Dienst beschäftigt waren. $\mathrm{Zu}$ diesen gehörten auch Juristen und Pädagogen, die nach ihrem Studium ein Referendariat beim Staat absolvieren mussten, um ihre Ausbildung dann mit dem Zweiten Staatsexamen zu beenden. Wurde ihnen dieses Referendariat wegen "verfassungsfeindlicher Aktivitäten" verweigert, fehlte ihnen trotz des Studiums ein berufsqualifizierender Abschluss. Eine Bürgerinitiative, die - mit starker Förderung durch die DKP - im Frühjahr 1973 entstand, sprach in solchen Fällen von »Berufsverbot« und prägte damit eines der wirkungsmächtigsten politischen Schlagworte dieses Jahrzehnts. ${ }^{12}$

Zum anderen ging es um die Frage, wer denn entschied, ob jemand einer Organisation mit "verfassungsfeindlichen Zielen" angehörte oder selbst "verfassungsfeindlichen Aktivitäten" nachging. Nach dem Gesetz entschied allein das Bundesverfassungsgericht, ob eine politische Organisation verfassungswidrige Ziele verfolgte und deshalb zu verbieten war; die juristischen Hürden für eine solche Entscheidung lagen hoch. Nun waren weder NPD noch DKP verboten; auch liefen gegen sie keine entsprechenden Verfahren in Karlsruhe - in der Praxis führte der "Extremisten-Erlass" nach 1972 aber dazu, dass etliche ihrer Mitglieder und Unterstützer durch einfache administrative Entscheidungen aus dem Staatsdienst entfernt oder aber gar nicht erst eingestellt wurden. Die juristische Debatte, ob dieses Vorgehen rechtlich zulässig oder unzulässig sei, entbrannte ebenso rasch wie der politische Streit, ob der Beschluss des Kanzlers und der Ministerpräsidenten nicht vielleicht mehr schade als nütze, weil er die »streitbare Demokratie« ins Zwielicht rücke. ${ }^{13}$

Ebenso wie die GEW, die Bahn- und die Postgewerkschaft konnte es auch die ÖTV kaum vermeiden, zu diesen Auseinandersetzungen Stellung zu beziehen, denn der Erlass bezog sich nicht nur auf Beamte, sondern ausdrücklich auch auf alle Arbeiter und Angestellten im Öffentlichen Dienst. ${ }^{14}$

12 | Vgl. etwa: Gerard Braunthal: Politische Loyalität und öffentlicher Dienst. Der »Radikalenerlaß«von 1972 und seine Folgen, Marburg 1992, S. 70.

13 | Vgl. dazu ausführlich: Dominik Rigoll: Staatsschutz in Westdeutschland. Von der Entnazifizierung zur Extremistenabwehr, Göttingen 2013, S. 335-457.

14 | Borgs-Maciejewski: Radikale, S. 9. 
Bereits 1972 entwickelte die ÖTV eine mit dem DGB abgesprochene offizielle Position zum »Extremisten-Erlass«, an der sie in den nachfolgenden Jahren konsequent festhielt. Im Mai 1972 bekannte sich Heinz Kluncker auf dem Gewerkschaftstag schon in seinem Rechenschaftsbericht einerseits ausdrücklich dazu, Verfassungsfeinde vom Staatsdienst fernzuhalten. Gleichzeitig erklärte er, der gerade erst ergangene Beschluss der Politiker sei schlicht überflüssig: "Die Regelungen in den Beamtengesetzen, in den Tarifverträgen und im Strafgesetzbuch reichen völlig aus, um Verfassungsfeinde im öffentlichen Dienst wirksam bekämpfen zu können." In diesem Zusammenhang bekräftigte der Vorsitzende die Zweifel, wie rechtsstaatlich die Gesinnungsüberprüfung der Staatsdiener sei: »Die Entscheidung darüber, wer verfassungsfeindlich handelt, muß [...] bei den dafür zuständigen Gerichten bleiben und darf nicht dem Ermessen der Behörden überlassen werden. [...] Man kann die Demokratie nicht dadurch verteidigen und sichern, daß man sie beseitigt. ${ }^{15}$ In einem Fernseh-Interview warnte Kluncker wenig später vor einer »law-and-order-Hysterie«: Die Auseinandersetzung mit radikalen politischen Bewegungen müsse "politisch erfolgen und nicht mit Rechtsmitteln ${ }^{16}{ }^{16}$

Gerade diese Warnung des ÖTV-Vorsitzenden erwies sich als ausgesprochen prophetisch: Der "Extremisten-Erlass« entpuppte sich in den nachfolgenden Jahren als ein umfangreiches Arbeitsbeschaffungsprogramm für den bundesdeutschen Verfassungsschutz. Bei allen Bewerbern und Bewerberinnen, die in den Öffentlichen Dienst eintreten wollten, suchten dessen Beamte nach Hinweisen auf »verfassungsfeindliche Aktivitäten«; gleichzeitig gab es immer wieder Ermittlungen gegen Beamte und gegen Arbeiter und Angestellte des Staates, die sich öffentlich für eine der neuen radikalen Parteien engagiert hatten oder einfach nur Mitglied waren. Besonders Basis und Umfeld der DKP standen dabei im Visier des Geheimdienstes. Der bürokratische Aufwand war enorm, die Zahl der Nichteingestellten und Entlassenen eher klein. ${ }^{17}$ Für die politische Atmosphäre in der Bundesrepublik

15 | Protokoll ÖTV-GT 1970, S. 60.

16 | Interview H. Kluncker in: »Kennzeichen D«, ZDF, gesendet am 13.7.1972, 21.45 Uhr, zit. nach dem Transkript in: Archiv Ver.di, Bestand Kluncker, 45.

17 | Bis 1989 summierte sich die Zahl der Überprüfungsverfahren auf 3,5 Millionen; im gleichen Zeitraum wurden 2.250 BewerberInnen abgelehnt und 250 Beamte entlassen (Braunthal: Loyalität, S. 9). 
hatte der Erlass dennoch fatale Folgen: Insbesondere unter jungen und gut ausgebildeten Deutschen verbreitete sich das Gefühl, man lebe in einem »repressiven Staat«, der die Meinungsfreiheit nicht mehr achte, wenn die etablierten Parteien und der gesellschaftliche Status quo grundlegend kritisiert wurden. $^{18}$

Mit ihrer früh vorgetragenen Kritik lag die ÖTV-Führung - ebenso wie der DGB und die GEW, die ähnliche Einwände erhoben - also genau richtig. Zur Genugtuung der Gewerkschaften erkannte auch die SPD recht rasch, dass sie 1972 im Streben um eine möglichst glaubwürdige Abgrenzung nach links eine Fehlentscheidung getroffen hatte. Gemeinsam mit den sozialdemokratischen Ministerpräsidenten bemühte sich die Bundesregierung um Schadensbegrenzung: Vor allem sollte die »Regelanfrage« an die Verfassungsschützer verschwinden, die alle Bewerber für den Öffentlichen Dienst pauschal unter Verdacht stellte. Ein entsprechender Gesetzentwurf scheiterte im Oktober 1975 jedoch an der CDU/CSU-Mehrheit im Bundesrat. Darauf erklärte die Bundesregierung, sie betrachte den Erlass von 1972 als »obsolet«. Politisch war damit aber wenig gewonnen: Da der Bund und die einzelnen Länder die Verfassungstreue ihrer Beschäftigten nun jeweils auf sehr unterschiedliche Weise überprüften, verstärkte sich das von Kritikern der "Berufsverbote« beklagte "Klima der Furcht" eher noch. ${ }^{19}$ Damit blieb die Kritik der Gewerkschaften weiter relevant. ${ }^{20}$

Auch die ÖTV beschäftigte sich in den 1970er Jahren immer wieder neu mit diesem Thema. Zwar war sie sich in der Ablehnung des "Extremisten-Erlasses" stets einig. Teile der Basis aber wünschten sich doch viel schärfere Worte als die, mit denen Heinz Kluncker den Erlass kritisierte. 1976 lagen dem Gewerkschaftstag elf verschiedene Anträge vor, die in ihren Formulierungen teilweise deutlich über die offiziellen Stellungnahmen hinausgingen. Initiatoren waren etwa die Konferenzen der beiden nordrhein-westfälischen Bezirke, die Bezirkskonferenz Hessen oder auch

18 | Schildt/Siegfried: Deutsche Kulturgeschichte, S. $291 \mathrm{f}$.

19 | Braunthal: Loyalität, S. 9. Zu dem Gesetzentwurf und seinem Scheitern vgl. ausführlich: Rigoll: Staatsschutz, S. 427-456.

20 | Vgl. für den DGB: Geschäftsbericht des Bundesvorstandes des Deutschen Gewerkschaftsbundes 1972 bis 1974, Düsseldorf 1975, S. 405-407; Geschäftsbericht des Bundesvorstandes des Deutschen Gewerkschaftsbundes 1975 bis 1977, Düsseldorf 1978, S. 377-381. 
die Kreisdelegiertenkonferenz München, d. h. einige der wichtigsten ÖTVUnterorganisationen. Mehrfach fiel darin das Wort »Berufsverbot«, das die ÖTV-Führung - wie auch der DGB - erklärtermaßen bewusst nicht verwendete, weil es sich um einen von der DKP kreierten Propagandabegriff handele. In der Diskussion bezeichnete ein Delegierter aus Bremen den Erlass von 1972 als »Verfassungsbruch«, der eine »tödliche politische Gefahr für uns alle« bedeute: In der Bundesrepublik breite sich die »Friedhofsstille eines totalitären Staates « aus. ${ }^{21}$

Auf dem Gewerkschaftstag 1980 wiederholte sich dieses Bild. Die Zahl der Anträge war auf 15 gestiegen; erneut benutzten alle Antragsteller das offiziell verpönte Wort von den »Berufsverboten«. Radikale Forderungen wurden formuliert. So verlangte etwa die hessische Bezirkskonferenz die sofortige Einstellung und »Rehabilitierung« aller abgelehnten Bewerber und aller entlassenen Beschäftigten. Einer der Debattenredner erklärte, der »Extremisten-Erlass« sei ein eigens zu diesem Zweck erfundenes Instrument für die "politische Entmündigung des Arbeitenden ${ }^{22}$

Die offizielle Position der ÖTV blieb von all diesen scharfen Anträgen und dramatischen Worten unberührt. Auf beiden Kongressen verabschiedete die deutliche Mehrheit der Delegierten letztlich Resolutionen, die den vergleichsweise moderat kritischen Kurs des geschäftsführenden Hauptvorstandes und auch der DGB-Führung stützten. Die bereits 1972 entwickelte Formulierung, spezielle Regelungen, wie man die Verfassungstreue der Staatsbeschäftigten zu prüfen habe, seien allein schon wegen der beamtenrechtlichen Bestimmungen schlicht »überflüssig«, wurde darin jedes Mal erneut bekräftigt. ${ }^{23}$

Für die Geschichte der ÖTV in den 1970er Jahren ist der folgenlose Streit um diese Beschlüsse dennoch nicht uninteressant. An ihm zeigt sich

21 | Protokoll 8. Ordentlicher Gewerkschaftstag Hamburg 1976 [der Gewerkschaft Öffentliche Dienste, Transport und Verkehr], 2 Bde., Stuttgart 1976 (im Folgenden: Protokoll ÖTV-GT 1976), Bd. 1, S. 333 f. (Jürgen Sönksen, Bremen); die Anträge finden sich in: ebd., Bd. 2, S. 116-126.

22 | [Protokoll] 9. Gewerkschaftstag Berlin 1980 [der Gewerkschaft Öffentliche Dienste, Transport und Verkehr], 2 Bde., Stuttgart 1980 (im Folgenden: Protokoll ÖTV-GT 1980), Bd. 1, S. 379 f. (Dieter Gabanyi, Augsburg); die Anträge finden sich in: ebd., Bd. 2, S. 147-161.

23 | Vgl.: Protokoll ÖTV-GT 1976, Bd. 1, S. 116 f. (Initiativantrag 125 A); Protokoll ÖTV-GT 1980, Bd. 2, S. 147 f. (Antrag 163). 
beispielhaft ein politischer Wandel innerhalb der Gewerkschaft: Die ÖTV rückte in diesem Jahrzehnt offensichtlich zumindest teilweise weiter nach links, als es ihrer eigenen Führung lieb war. Zwar mag dieser Trend gerade bei dem Thema der "Berufsverbote« vielleicht mächtiger wirken, als er es in der Realität tatsächlich war, weil die angeführten scharfen Proteste in dieser Sache wohl auch demonstrativen Charakter trugen. Wenn eine Bezirkskonferenz dazu Beschlüsse fasste, die der eigenen Verbandsleitung widersprachen, dann hatte das gewerkschaftspolitisch eher geringe Bedeutung. Zugleich aber tat es den Mitgliedern gut, die politisch wirklich weit links standen. Von reiner "Schaufensterpolitik« sollte man dennoch nicht sprechen. Die 1970er Jahre als das »rote Jahrzehnt« (Gerd Koenen) prägten und veränderten auch die ÖTV. Gerade im Kernbereich der gewerkschaftlichen Arbeit, in der Tarifpolitik und in den Lohn- und Gehaltsrunden, zeigte sich diese Veränderung. Das »Hauptgeschäft« der Gewerkschaft wurde, wie die folgenden Ausführungen zeigen werden, dadurch insofern noch schwieriger als zuvor, als die internen Streitigkeiten in der Organisation heftiger wurden.

\section{Geänderte Vorzeichen. Inflation und staatliche Konjunkturlenkung als neue Faktoren in der Tarifpolitik}

\section{Sozial gerecht oder "nivellierend «? Die Inflation und die "Sockel»- Strategie der ÖTV in den Lohn- und Gehaltsverhandlungen}

Im Winter 1969/70 führte die ÖTV erstmals Tarifverhandlungen für den Öffentlichen Dienst, in denen die Vertreter des Bundes von der neuen, SPDgeführten Koalition nominiert und instruiert wurden. Zwar fiel das Amt des Innenministers, der in diesen Runden traditionell als Verhandlungsführer der Arbeitgeber fungierte, an die FDP. Hans-Dietrich Genscher, der diese Position bis zum Mai 1974 bekleidete, hatte sich jedoch mit den Sozialdemokraten Karl Schiller und Alex Möller im Wirtschafts- und Finanzministerium abzustimmen. Zugleich unterstand er selbstverständlich der Kabinettsdisziplin und der Richtlinienkompetenz des Bundeskanzlers Willy Brandt. Welche Folgen diese ganz neue Konstellation für das Verhältnis zwischen der ÖTV und ihren Verhandlungspartnern in den Tarifrunden für den Öffentlichen Dienst haben würde, war eine offene Frage. 
Grundsätzlich hatte sich die Gewerkschaft zwar bereits positioniert. Das Credo der ÖTV, das Heinz Kluncker im Dezember 1969 in der Großen Tarifkommission formulierte, wurde oben schon zitiert: »unser Selbstverständnis verbietet jede Art von Disziplinierung«. Trotz aller politischen Sympathien für die sozialliberale Regierung hatte die ÖTV in dieser Angelegenheit nach den Worten des Vorsitzenden gar keine andere Wahl: Kluncker warnte, für sie als Einheitsgewerkschaft sei es »tödlich«, wenn bei den Mitgliedern "Zweifel an der Standfestigkeit und Unabhängigkeit« der Organisation gegenüber der sozialdemokratisch geführten Bundesregierung aufkämen. ${ }^{24}$ Im DGB-Bundesvorstand erklärte Kluncker ähnlich eindeutig, »Zurückhaltung in der Lohnpolitik« aus Rücksicht auf die SPD sei für ihn und die ÖTV »indiskutabel «. ${ }^{25}$

Nun handelt es sich bei diesen Sätzen zunächst einmal nur um Absichtserklärungen, denen die Praxis nicht zwingend gefolgt sein muss. Rekonstruiert man die Tarifrunden für den Öffentlichen Dienst nach 1969 auch mit internen Dokumenten, dann zeigt sich, dass Kluncker durchaus anders auftreten konnte, als es die zitierten Statements erwarten lassen. Ganz so eindeutig unabhängig agierte die ÖTV denn doch nicht. In der frühen Phase der sozialliberalen Koalition suchte der ÖTV-Vorsitzende vielmehr den direkten Kontakt mit der Bundesregierung - und dabei ging es ihm durchweg darum, Konflikte zu vermeiden. Mehrfach traf er sich im Kanzleramt mit Herbert Ehrenberg, dem Leiter der Abteilung »Wirtschafts-, Finanz- und Sozialpolitik« in der Regierungszentrale, der bis zum Wahlsieg der SPD als hauptamtlicher Funktionär der IG Bau - Steine - Erden gearbeitet hatte. Ihm gegenüber erklärte Kluncker im Sommer 1970 ausdrücklich, die ÖTV werde für den Öffentlichen Dienst »keine `Nachhok-Forderungen« stellen. Überhaupt sei sie "zu einer verantwortungsbewußten Führung der Tarifverhandlungen« bereit, ohne die Abschlüsse in der Privatwirtschaft - insbesondere die in der Metallindustrie - als »ein Präjudiz zu sehen ${ }^{26}{ }^{26}$

24 | Sitzung der Großen Tarifkommission (GTK), 4.12.1969. In: AdsD, Depositum Kluncker, Reden und Referate November 1969-Februar 1972.

25 | Der Deutsche Gewerkschaftsbund 1969-1975. Eingel. u. bearb. v. Klaus Mertsching, Bonn 2013, S. 295 (Sitzung des Bundesvorstandes, 7.7.1970).

26 | Vermerk H. Ehrenberg für den Bundeskanzler, 30.7.1970. In: BArch Koblenz, B 136,6589 . 
Einige Monate später gab sich Kluncker zuversichtlich, »die ÖTV-Forderungen in vertretbaren Grenzen halten zu können«, wenn Regierung und SPD-Fraktion geschlossen auf der Linie bleiben würden, »keinerlei zusätzliche Leistungen [...], auch keine Veränderung der Weihnachtszuwendung « zu versprechen. Für den Bundeskanzler notierte Ehrenberg direkt nach diesem Gespräch: »Ich habe sehr das Gefühl, daß auf Kluncker Verlaß ist, soweit er seine heterogene Gewerkschaft zusammenhalten kann, und werde permanent mit ihm Kontakt halten. $\aleph^{27}$ Im Sommer 1971 schließlich konferierte Kluncker mit Herbert Wehner, dem Vorsitzenden der SPDBundestagsfraktion. Gemeinsam mit den Chefs der Eisenbahner- und der Postgewerkschaft sowie der GEW sprach Kluncker dabei über Möglichkeiten, die kommende Tarifrunde für den Öffentlichen Dienst »in den Griff zu bekommen, um eine Konfrontation zwischen Regierung und Gewerkschaften zu vermeiden«. Um dieses Ziel zu erreichen, wollten die Gewerkschaftsführer »rechtzeitig die erforderliche Einflußnahme« einleiten. ${ }^{28}$

Allerdings sind diese Äußerungen des ÖTV-Vorsitzenden nur persönliche Absichtserklärungen. Heinz Kluncker selbst war zwar offensichtlich bereit, sich tarifpolitisch mit den erstmals in Bonn regierenden Sozialdemokraten abzustimmen. Wie der tatsächliche Verlauf der Tarifrunden beweist, reichte seine innerorganisatorische Macht jedoch nicht aus, um den Kurs der Gewerkschaft wirklich konsequent zu lenken. Die ÖTV und die sozialliberale Bundesregierung gerieten als Verhandlungspartner für den Öffentlichen Dienst daher schon in den ersten Jahren nach 1969 doch recht heftig aneinander. Im Frühjahr 1971 organisierte die Gewerkschaft sogar einen Streik, der heute weitgehend vergessen ist, obwohl er die Öffentlichkeit und die Regierung intensiv beschäftigte.

27 | Vermerk H. Ehrenberg für den Bundeskanzler, 16.10.1970. In: ebd. Den Kanzler selbst scheint Kluncker in seiner Funktion als ÖTV-Vorsitzender hingegen nur einmal persönlich getroffen zu haben. Dabei warnte Kluncker vor einem Erstarken der beruflichen Spartengewerkschaften, und er brachte mit allgemeinen Worten den Wunsch »nach noch engerem Kontakt mit der Partei zum Ausdruck« (W. Brandt an Helmut Schmidt u. Herbert Wehner, 31.7.1970, abgedr. in: Willy Brandt: Berliner Ausgabe. Bd. 7: Mehr Demokratie wagen. Innen- und Gesellschaftspolitik 1966-1974. Bearb. v. Wolther von Kieseritzky, Bonn 2001, S. 235-237).

28 | Herbert Wehner an Willy Brandt, 17.7.1971. In: AdsD, Willy Brandt-Archiv (WBA), Abt. 11.3, 21. 
Angetrieben wurden diese Konflikte von einem wirtschaftlichen Problem, das die reformfreudige SPD in ihren optimistischen Zukunftsplanungen nicht antizipiert hatte: Nach 1969 beschleunigte sich der Preisanstieg in der Bundesrepublik sehr stark. So verteuerte sich die private Lebenshaltung 1970 bereits um 3,5 Prozent (gegenüber 1,9 Prozent im Vorjahr). 1971 und 1972 lag die jährliche Teuerungsrate jeweils schon über fünf Prozent und 1973 dann sogar bei sieben Prozent. ${ }^{29}$ Erschreckt sprachen die Zeitgenossen von einer »galoppierenden Inflation«; Tipps für den Schutz der angeblich bedrohten Privatvermögen - etwa durch den Kauf von Immobilien und anderen Sachwerten - entwickelten sich zu einem beliebten Medienthema. ${ }^{30}$ Auch die ÖTV reagierte mit ihren Mitteln auf den raschen Preisanstieg, den die Bundesbürger in dieser Dimension noch nicht kannten: Sie veränderte die Grundstruktur ihrer Tarifforderungen, indem sie nun jeweils Geringverdiener besonders begünstigt sehen wollte. Die Bundesregierung wie auch Länder und Gemeinden hielten hingegen nichts von dieser Bevorzugung der unteren Lohngruppen. In allen Tarifrunden zwischen 1969/70 und 1972/73 wurde über diese Frage gestritten.

Gleichzeitig kamen die Arbeitgeber und die Gewerkschaft auch deshalb nicht einvernehmlich miteinander aus, weil die politisch Verantwortlichen in der Bundesregierung ebenfalls nach Wegen suchten, auf die inflationäre Entwicklung zu reagieren. Finanzielle Zurückhaltung des Staates galt als ein probates Mittel, den Preisanstieg zu bremsen. Zumal die Haushaltspolitik des Bundes - das mussten die Gewerkschaft und ihre Führung nach 1969 lernen - funktionierte auch unter einem sozialdemokratischen Kanzler nicht grundsätzlich anders als zuvor unter Politikern der CDU, weil der Personaletat im Rahmen der staatlichen Ausgaben nun einmal besonders wichtig war. Heinz Kluncker und Herbert Ehrenberg mögen gehofft haben, sie könnten als Sozialdemokraten gemeinsam die Tarifpolitik für den Öffentlichen Dienst konfliktfrei gestalten. Die wirtschaftliche Entwicklung aber ließ solcher Harmonie keine Chance. Weder die ökonomische »Globalsteuerung«, an der Karl Schiller als Wirtschaftsminister arbeitete, noch die unbestreitbar vorhandenen politischen Sympathien Heinz Klunckers für die neue Bundesregierung vermochten daran etwas zu ändern.

29 | Zahlen nach: Weiß: ÖTV, S. 116.

30 | Vgl. beispielhaft die achtteilige Serie: Wie schützt man sich vor Inflation? In: Wirtschaftswoche 25 (1971), H. 8-H. 15. 
Konkret verlangte die ÖTV seit 1969 in den Tarifverhandlungen jeweils einen "Sockelbetrag", der allen Beschäftigten gleichermaßen zustehen müsse. Im Streit um den »Teuerungsausgleich« hatte sie im September 1969 erstmals eine solche Einheitszahlung durchgesetzt. Abgewandelt durch unterschiedliche Kombinationen mit ergänzenden prozentualen Forderungen stand der "Sockel« nun jedes Jahr wieder neu auf dem tarifpolitischen Programm der Gewerkschaft. Er brachte Geringverdienern anteilig höhere Lohnzuschläge ein als besser bezahlten Beschäftigten, und gerade dieser ungleiche Effekt war der ÖTV wichtig, weil er gezielt auf die Inflation reagiere: Rasch steigende Lebenshaltungskosten, so argumentierte sie, träfen einkommensschwache Haushalte deutlich stärker als Gutverdiener, die kleinere Anteile ihres Etats für die lebensnotwendigen Dinge ausgaben. ${ }^{31}$

Bei den Arbeitgebern stieß die Einheitszahlung auf große Bedenken: Sie beklagten deren »nivellierenden Charakter «, der dem Leistungsprinzip widerspreche und $» z$ Unzufriedenheit bei den qualifizierten Arbeitnehmern « führe. ${ }^{32}$ Letztlich laufe der tarifliche "Sockel« darauf hinaus, »den Empfängern niedriger Einkommen die realen Einkommensverluste [durch die steigenden Preise - K.C.F.] voll auszugleichen, den Empfängern höherer Einkommen hingegen nur einen Bruchteil ihres Verlustes zu ersetzen«. Zudem seien pauschale Gehaltserhöhungen alles andere als sozial, weil sie kopfstarke Familien gegenüber Alleinstehenden und kinderlosen Ehepaaren benachteiligen. ${ }^{33}$

31 | Vgl. als Überblick: Weiß: ÖTV, S. 128-164. Der geforderte "Sockelbetrag« betrug $100 \mathrm{DM}$ (für 1970), $40 \mathrm{DM}$ (für 1971), $50 \mathrm{DM}$ (für 1972) und $70 \mathrm{DM}$ (für 1973). Weitere Details vgl. ebd.; sowie: ÖTV-Geschäftsbericht 1968/71, S. 82-124; ÖTV-Geschäftsbericht 1972/75, S. 84-91.

32 | In der Reihenfolge der Zitate: Hans-Dietrich Genscher im Interview in der Spätausgabe der »Tagesschau«, ARD, 21.12.1971 (ein Transkript in: Archiv Ver.di, Bestand Kluncker, 45); Vermerk über den Verlauf der Lohn- und Vergütungstarifverhandlungen, 12.1.1973. In: BArch Koblenz, B 106, 58588.

33 | Vermerk der Abt. I C 5 im Bundeskanzleramt, 16.1.1973. In: BArch Koblenz, B 106, 58588. Vgl. ähnlich auch: Niederschrift der außerordentlichen Mitgliederversammlung und Hauptausschuß-Sitzung der VKA, 12.1.1973. In: BArch Koblenz, B 367, 45; Karl-Heinz Kiefer an die FAZ-Redaktion, 1.2.1973. In: BArch Koblenz, B 222, 44. Kiefer war Geschäftsführer der TdL. Vgl. ferner: Sockelbeträge verfehlen ihren Zweck. In: Handelsblatt, 29.1.1973. Die Benachteiligung kopfstarker Familien ergab sich aus ihrer höheren Konsumquote. 
Prozentual ergaben sich durch einen pauschalen »Sockelbetrag« in der Tat deutlich voneinander abweichende Lohn- und Gehaltserhöhungen. 1970, als die Einheitszahlung mit 100 DM besonders groß ausfiel, schwankten der gesamte Vergütungszuwachs der Beschäftigten zwischen 14,5 und 8,3 Prozent des jeweiligen Bruttoverdienstes. ${ }^{34}$ Es spricht für die Durchsetzungskraft der ÖTV, dass es ihr trotz der grundsätzlichen Bedenken der Arbeitgeber viermal hintereinander gelang, eine "gespaltene Forderung" (d. h. eine Kombination von »Sockel« und linearer Lohnsteigerung) durchzusetzen. Mehrfach drohte sie dabei mit einer Urabstimmung und mit Streik; wiederholt betonte die Gewerkschaftsführung, der pauschal gewährte Betrag sei als Inflationsausgleich für sie »nicht verhandlungsfähig «. ${ }^{35}$

Heinz Kluncker stritt in diesen Tarifrunden loyal und engagiert für eine Forderung, die er selbst nicht teilte. Im Herbst 1969 hatte er sich in der krisenhaften Situation während der »wilden Streiks« zwar entschlossen hinter die Parole gestellt, ein pauschaler Zuschlag von 100 DM pro Monat für alle Beschäftigten des Staates sei wegen der Teuerung unerlässlich. In der fast direkt anschließenden Tarifrunde für 1970 erneuerte er diese Forderung, aber das ergab sich schlicht aus dem Stand der Dinge: Da die 300 DM für die letzten Monate des Jahres 1969 eine Sonderzahlung darstellten, die nicht in die Lohn- und Gehaltstabellen einging, hätte die Gewerkschaft mit jeder anderen Forderung einen bereits erstrittenen Erfolg wieder aufgegeben. ${ }^{36}$

34 | Weiß: ÖTV, S. 131.

35 | So Heinz Kluncker gleichlautend in: Interview im »Bericht aus Bonn«, ARD, 10.12.1971 (ein Transkript in: Archiv Ver.di, Bestand Kluncker, 45); Vermerk über den Verlauf der Lohn- und Vergütungstarifverhandlungen, 12.1.1973. In: BArch Koblenz, B 106, 58588. Allerdings war der "Sockel « in der Regel geringer bemessen, als die ÖTV es gefordert hatte. Nur in der Tarifrunde für 1970 konnte sie sich mit den geforderten $100 \mathrm{DM}$ ohne Abstriche durchsetzen; danach betrug die realisierte Pauschalzahlung 20 DM (für 1971, statt der geforderten 40 DM), 30 DM (für 1972, statt $50 \mathrm{DM}$ ) und $40 \mathrm{DM}$ (für 1973, statt $70 \mathrm{DM}$ ). Alle diese Abschlüsse wurden auf die Beamten übertragen, d.h. auch bei ihnen wurde der einfache Dienst bevorzugt. Vgl. dazu rückblickend: Krumsiek: Alle Jahre wieder, S. 332.

36 | Sitzung der Großen Tarifkommission (GTK), 4.12.1969. In: AdsD, Depositum Kluncker, Reden und Referate November 1969-Februar 1972. Vgl. auch Klunckers Äußerungen im Interview in: »Mit geringem Aufwand größtmöglichen Ärger«. In: Der Spiegel 24 (1970), H. 1/2, S. 32-33. Zu den komplizierten Details 
Eine wiederholte oder sogar zur tarifpolitischen Routine gemachte "Sockelei« hielt Kluncker jedoch für falsch. Allerdings sagte er das nie öffentlich, sondern immer nur intern, weil die Pauschale eine für die ÖTV ohnehin schwierige Frage - das Verhältnis von gutbezahlten und geringverdienenden Mitgliedern - berührte. Im Herbst 1970, als der Vorsitzende wegen einer schweren Lungeninfektion mehrere Wochen das Bett hütete, warnte Heinz Jacobi als sein Stellvertreter vor der Großen Tarifkommission, die »Nivellierung « der Lohnerhöhungen führe zu Verstimmung bei den besser bezahlten Angestellten: »Da kommt dann die Kritik, daß sie wieder einmal - na ja, ich will krass sagen - betrogen worden sind. Das muß man auch sehen." Sicher könne man sich über Gewerkschaftsmitglieder empören, die das hierarchische Gefüge der Lohn- und Gehaltstabellen unverändert lassen wollten, denn »von Abständen lebt man nicht«. Eine Organisation, die auch bei beruflich qualifizierten Beschäftigten stark sein wolle, könne deren Emotionen aber nicht ignorieren. Die Tarifkommission stimmte trotzdem mit deutlicher Mehrheit für eine weitere Pauschalzahlung im Forderungskatalog der ÖTV, weil dies den »Erwartungen der Mitgliedschaft« entspreche. ${ }^{37}$

Die Formulierung »in Teilen der Mitgliedschaft« hätte die Realität wohl besser getroffen. Dies zeigte sich, als die ÖTV im Herbst 1972 ihre tarifpolitische Strategie erstmals breit an der Basis diskutierte. So hatte es der Gewerkschaftstag zuvor im Juni beschlossen, um die Mitglieder stärker zu aktivieren. Bislang war die Frage, was genau in der kommenden Lohnrunde zu fordern sei, stets nur vom Tarifsekretariat, den hauptamtlichen Funktionären, dem gHV und abschließend dann von der Großen Tarifkommission beraten worden. Zum einen antwortete diese neue Praxis allgemein auf den stark politisierten Zeitgeist. "Mehr Demokratie wagen« - dieses Motto, das die erste Regierungserklärung von Willy Brandt dominierte, wurde in den Jahren nach 1969 nicht nur zum geflügelten Wort, sondern auch zum Anstoß für gesellschaftlichen Wandel auf breiter Front, weil viele jüngere

vgl.: ÖTV-Geschäftsbericht 1968/71, S. 84 f. Die Summe von 100 DM ergab sich aus einer Kopplung von prozentualer Forderung, einem einheitlichen Sockel von 70 DM sowie einer ergänzenden Zahlung für alle die Beschäftigten, bei denen ein Plus von 100 DM damit noch nicht erreicht war.

37 | Bericht des Tarifsekretariats Nr. 162/70, 24.11.1970. In: Archiv Ver.di, Bestand Kluncker, 18. 
Deutsche den Imperativ des Kanzlers als Auftrag an sich selbst verstanden. Mit ihren neuartigen Basisdiskussionen entsprach die ÖTV solchen Bedürfnissen. ${ }^{38}$

Zum anderen reagierte die ÖTV mit dem neuen Prozedere konkret auf Vorwürfe, die demokratischen Strukturen der Gewerkschaften seien nur eine Fassade, hinter der eine kleine Funktionärselite de facto fast uneingeschränkt herrsche. ${ }^{39}$ Diese Kritik, die von linken Akademikern stammte, hätte gestandene Gewerkschafter allerdings wohl wenig beeindruckt, wenn nicht die »wilden Streiks« vom September 1969 gewesen wären. Selbstgerechte Zufriedenheit mit den internen Strukturen der DGB-Verbände verbot sich seitdem sogar für Funktionäre, die eine straffe gewerkschaftliche Führung schätzten.

Den tariflichen »Sockel«, den seine Verfechter stets als besonders sozial lobten, beurteilten die ÖTV-Mitglieder nach wie vor sehr unterschiedlich. Im Bezirk Hessen, der den Auftrag zur breiten Basisdiskussion sehr ernst nahm, zeigten sich dabei überraschende interne Fronten: Gerade die Arbeiterausschüsse votierten 1972 mehrheitlich gegen eine weitere Pauschalzahlung; Mehrheiten fand dieser Vorschlag hingegen in den Gremien und Versammlungen, in denen Angestellte und Beamte dominierten. ${ }^{40}$ Die verkehrte Welt, die solche Beschlüsse scheinbar dokumentieren, erklärt sich aus dem Eigeninteresse der gewerkschaftlich organisierten Arbeiter, denn sie standen mehrheitlich nicht so weit unten in der Einkommenshierarchie, dass der Sockelbetrag sie begünstigte. Zumindest galt dies bei den überschaubaren Summen von meist weniger als 100 DM monatlich, die sich die widerstrebenden Arbeitgeber von der Gewerkschaft abhandeln ließen. In

38 | Vgl. zusammenfassend für die ÖTV: Weiß: ÖTV, S. 145-150; allgemein vgl.: Edgar Wolfrum: Die geglückte Demokratie. Geschichte der Bundesrepublik Deutschland von ihren Anfängen bis zur Gegenwart, Bonn 2007, S. 315 f.

39 | Vgl. vor allem: Hartmut Schellhoss: Apathie und Legitimität. Das Problem der neuen Gewerkschaft, München 1967. Erneuert wurde diese Kritik etwa in: Joachim Bergmann/Otto Jacobi/Walther Müller-Jentsch: Gewerkschaften in der Bundesrepublik. Gewerkschaftliche Lohnpolitik zwischen Mitgliederinteressen und ökonomischen Sachzwängen, Frankfurt/Main und Köln 1975, insbes. S. 292-295.

40 | Elf von 13 Kreisarbeiterausschüssen in Hessen sowie auch der Bezirksarbeiterausschuss votierten gegen eine »Sockel«-Forderung (BV Hessen an gHV, 21.11.1972. In: Archiv Ver.di, Bestand Kluncker, 19). 
dieser Größenordnung begünstigten pauschale Zahlungen tatsächlich fast ausschließlich gering qualifizierte Berufsanfänger im Öffentlichen Dienst (insbesondere, wenn sie ledig waren); länger gediente Arbeiter, die nicht mehr zu den unteren Lohngruppen gehörten, hatten hingegen von einer rein linearen Erhöhung der Bezüge teilweise deutlich mehr zu erwarten. Wer dennoch auf einem pauschalen Anteil im Forderungskatalog der ÖTV bestehe, so hieß es klipp und klar in einem »Arbeitspapier« der hessischen Bezirksleitung, stimme dafür, die Bezüge in den untersten Lohngruppen »auf Kosten der überwiegenden Mehrzahl der Arbeiter« überproportional zu erhöhen. ${ }^{41}$ Dennoch beschloss die Große Tarifkommission, die in dieser Sache immer noch das letzte Wort hatte, im Herbst 1972 unbeeindruckt ein weiteres Mal eine »gespaltene Forderung« aus »Sockel« sowie einer ergänzenden linearen Erhöhung, und die Arbeitgeber stimmten trotz starker Bedenken wiederum zu. ${ }^{42}$

Dieser Tarifvertrag für 1973 zog noch im gleichen Jahr eine zweite Verhandlungsrunde nach sich, wie es sie ganz ähnlich 1968 und 1969 schon einmal gegeben hatte. Der Preisanstieg entwickelte sich deutlich rascher als prognostiziert; wie im Spätsommer 1969 forderte die gewerkschaftli-

41 | Arbeitspapier zur Diskussion über die Tarifrunde 1972/73 mit der ÖTV-Mitgliedschaft in Hessen, o. D. In: ebd. Vgl. dort auch konkrete Berechnungen, bei denen eine lineare zwölfprozentige Erhöhung mit einer "gespaltenen Forderung« von 70 DM plus weiteren sechs Prozent verglichen und für einzelne Gehaltsgruppen berechnet wird. In Gruppe VI, Stufe 1 ergab sich z. B. alternativ eine Lohnerhöhung von 119,67 DM bei der linearen Variante bzw. von 99,34 DM bei der »gespaltenen Forderung«. Finanzielle Vorteile brachte ein »Sockel« nur für die Beschäftigten mit sich, die unterhalb der Lohngruppe IV eingruppiert waren. Ähnliche Resultate vgl. auch in: Ausarbeitung des Statistischen Amtes Dortmund »Erfüllen Sockelbeträge gegenwärtig ihren Zweck?«, September 1973. In: AdsD, ÖTV-NRW II, 5/ÖTVC603002.

42 | Weiß: ÖTV, S. 156. Vgl. ebd., S. 153-156, auch zusammenfassend zur Diskussion in Hessen. Allerdings galt es den Arbeitgebern als Erfolg, dass in den Verhandlungen nur der Sockelbetrag verändert wurde (gezahlt wurden 40 statt der verlangten $70 \mathrm{DM}$ ). Die von der ÖTV ergänzend verlangte sechsprozentige Erhöhung wurde hingegen sofort akzeptiert. Damit sei eine »weitergehende Umverteilung " verhindert worden und deshalb handele es sich um eine "Wende in der Tarifpolitik« für den Öffentlichen Dienst (Karl-Heinz Kiefer an die FAZ-Redaktion, 1.2.1973. In: BArch Koblenz, B 222, 44). 
che Basis in verschiedenen Branchen deshalb erneut eigenmächtig einen Inflationsausgleich trotz bestehender Friedenspflicht. ${ }^{43}$ Anders als bei den "wilden Streiks« im September 1969 war die ÖTV diesmal allerdings wachsam und von Anfang an im Bilde. Bereits im Juni 1973 warnte die Große Tarifkommission, die zu Beginn des Jahres vereinbarten Lohn- und Gehaltserhöhungen drohten zu »verblassen«, weil die Preise so rasant zulegten: Die Gewerkschaft müsse reagieren. ${ }^{44}$

Genau wie im Herbst 1968 benutzte die ÖTV erneut das "Weihnachtsgeld«, um ihre unruhige Basis zufrieden zu stellen. Diese Sonderzahlung zum Jahresende, die seit 1971 jeweils zwei Drittel der individuellen Monatsbezüge betrug, sollte noch im laufenden Jahr auf ein volles 13. Gehalt steigen. Heinz Kluncker und die anderen Mitglieder des gHV waren in dieser Sache von Anfang sehr engagiert, denn von einem weiteren pauschalen Teuerungszuschlag, wie er mit den 300 DM im Herbst 1969 gezahlt worden war, wollten sie grundsätzlich nichts wissen. Eindringlich forderte Heinz Kluncker alle ÖTV-Funktionäre auf, intern lautstark für die Forderung nach einem 13. Gehalt zu trommeln, von einer möglichen »Teuerungszulage« aber zu schweigen. ${ }^{45}$

Offensichtlich ging es hier erneut um die Frage, ob eine sozial »ausgleichende oder eine lineare Lohnerhöhung verlangt werden sollte - und die ÖTV-Führung positionierte sich dabei eindeutig im Lager der "Sockel«Gegner. An der Basis wurde zeitgleich unverändert heftig gestritten. Frustriert berichtete die Bezirksverwaltung NRW II, es sei in vielen Gremien und Betriebsgruppen »kaum noch möglich, eine gemeinsame Willensbildung« über die Lohnpolitik der ÖTV zu erreichen; Befürworter und Kritiker der pauschalen Erhöhungen lägen mit ihren Meinungen "grundsätzlich auseinander ${ }^{46}$

43 | Vgl. allgemein: Birke: Streiks, S. 274-304; Klaus Schroeder: Der Weg in die Stagnation. Eine empirische Studie zur Konjunkturentwicklung und Konjunkturpolitik in der Bundesrepublik von 1967-1982, Opladen 1984, S. 39-45.

44 | Zit. nach: Weiß: ÖTV, S. $161 \mathrm{f}$.

45 | Notizen von Hans Liersch über die Sitzung der GTK, 4.6.1973. In: AdsD, ÖTV-NRW II, 5/ÖTVC603002. Ganz ähnlich auch Klunckers Äußerungen in: Notizen von Hans Liersch über die Vorbesprechung der ÖTV-Verhandlungskommission, 12.9.1973. In: ebd.

46 | In der Reihenfolge der Zitate: Bezirksverwaltung NRW II an den Bezirksjugendausschuss NRW II, 22.6.1973. In: AdsD, ÖTV-NRW II, 5/ÖTVC022003; Pro- 
Tarifpolitisch waren die Weichen beim »Weihnachtsgeld" allerdings eindeutig gestellt: Bereits 1964 hatten die Tarifpartner die frühere Einheitszahlung abgeschafft. Von daher boten die von der galoppierenden Inflation angeschobenen Verhandlungen im Herbst 1973 der ÖTV-Führung eine willkommene Gelegenheit, auf einfache Weise zu einer linearen Lohn- und Gehaltserhöhung zu kommen. Zwar widersetzten sich die Arbeitgeber. Vor allem die Bundesregierung fürchtete die "Signalwirkung" steigender Bezüge im Öffentlichen Dienst noch im Jahr 1973 (in welcher Form auch immer), weil es »erhebliche Stabilitätsprobleme« nach sich ziehen könne, wenn die Privatwirtschaft ähnliche Zugeständnisse mache. ${ }^{47}$

Heinz Kluncker aber warnte, ohne eine rasche Zusage, noch 1973 das volle 13. Gehalt zu zahlen, könne die ÖTV »lokale Feuer« und vielleicht sogar "Flächenbrände« (d.h. »wilde Streiks« wie im September 1969) nicht verhindern: Die Verhandlungskommission erhalte beständig Anrufe von Betriebsgruppen, in denen sie immer nur mit der Frage konfrontiert werde: »Wie lange lasst Ihr Euch das eigentlich noch gefallen?«. Dieser Hinweis auf den »Druck« der Basis machte Eindruck: Die VKA gab klein bei, weil sie »örtliche Zugeständnisse« in einzelnen Städten fürchtete, und deshalb leisteten auch Bund und Länder keinen weiteren Widerstand. Bereits im Oktober 1973 erhielten die Beschäftigten des Öffentlichen Dienstes einen Abschlag auf ihr zusätzliches Monatsgehalt; im Dezember folgte dann der Rest der Summe. ${ }^{48}$

tokoll der gemeinsamen Sitzung des Bezirksvorstandes mit Mitgliedern des HV und des Beirats NRW II, 14.12.1973. In: ebd.

47 | BMdI an Bundeskanzler Willy Brandt, 10.7.1973. In: BArch Koblenz, B 136, 5204.

48 | In der Reihenfolge der Zitate: Tonbandabschrift der Tarifverhandlungen am 12./13.9.1973. In: AdsD, ÖTV, 5/ÖTVB412004 (H. Kluncker); Niederschrift über die außerordentliche Mitgliederversammlung und Hauptausschußsitzung der VKA, 12.9.1972. In: BArch Koblenz, B 376, 45 (VKA). Die Arbeitgeber hatten zunächst einen Stufenplan zur Einführung des vollen 13. Gehaltes vorgeschlagen; erst Ende 1974 sollten die 100 Prozent erreicht werden. Beschäftigte mit Kindern erhielten nach dem abgeschlossenen Tarifvertrag zu ihrem 13. Gehalt weitere 50 DM pro Kind. Die Abschlagszahlung im Oktober 1973 betrug 25 Prozent. Vgl. zu diesen Details auch: Notizen von Hans Liersch über die Tarifverhandlungen, 12./13.9.1973. In: AdsD, ÖTV-NRW II, 5/ÖTVC603002. Wie 1968 wurde diese tarifliche Abmachung erneut umgehend auf die Beamten übertragen (ÖTV-Geschäftsbericht 1972/75, S. 317). 
Einige Warnstreiks hatten Klunckers Drohung wirkungsvoll unterstützt. Vor allem Beschäftigte der Müllabfuhr legten dabei befristet die Arbeit nieder; betroffen waren vor allem die Großstädte München, Nürnberg, Köln, Hannover, Oberhausen, Leverkusen und Mönchengladbach sowie einige kleinere Gemeinden wie Celle und Wolfenbüttel. Bezeichnenderweise verlangten die Streikenden dabei allerdings durchweg einen pauschalen »Teuerungszuschlag«; vom 13. Monatsgehalt war hingegen nicht die Rede. In Frankfurt am Main streikten Müllarbeiter auf eigene Faust sogar noch für solch eine Forderung, als die ÖTV den Tarifvertrag über das volle zusätzliche Gehalt bereits unterschrieben hatte. ${ }^{49}$

Die tarifpolitische Logik der ÖTV-Führung überzeugte offensichtlich nach wie vor nur Teile der Organisation, und selbst Arbeitergremien wie die zahlreichen hessischen Kreisarbeiterausschüsse, die 1972 für lineare Lohnerhöhungen votiert hatten, trafen wohl keineswegs zwingend die gerade aktuelle Stimmung ihrer Basis. Was sozial gerecht sei, darüber konnten auch Gewerkschafter sehr unterschiedlich denken. Der rasche Preisauftrieb in den frühen 1970er Jahren, so scheint es, hat bei vielen Mitgliedern der ÖTV (und nicht nur bei ihnen) ein starkes Bedürfnis geweckt, Geringverdienern besonders zu helfen. Die komplizierten Details, die Experten exakt bestimmten und bedachten, spielten dabei keine Rolle; der "Sockel« überzeugte wohl vor allem emotional als ein scheinbar probates tarifpolitisches Mittel in Zeiten der Inflation..$^{50}$

49 | Vgl. die Aufstellung in: Weiß: ÖTV, S. 163a [!]. Erfolg hatten die Streikenden nur in Hannover: Hier gewährte die Stadt noch vor Beginn der Tarifverhandlungen über das Weihnachtsgeld pauschale Zulagen, die bei $300 \mathrm{DM}$ begannen und mit steigendem Einkommen bis auf 100 DM sanken. Die Streikenden hatten eine Einheitszahlung von 600 DM gefordert. Vgl. dazu: Aktenvermerk des Referats IV/3 für den Bundeskanzler, 12.9.1973. In: BArch Koblenz, B 136, 5204. Zu dem erfolglosen Frankfurter Streik, der bei Weiß nicht erwähnt wird, vgl.: Nach neun Uhr fährt kein Müllwagen mehr. In: FAZ, 28.9.1973. Der fast ganztägige Ausstand, der pauschal 300 DM zusätzlich durchsetzen sollte, wurde auf einer Personalversammlung beschlossen, an der 1.400 der insgesamt 1.800 Beschäftigten der Frankfurter Müllabfuhr teilnahmen; dieser Beschluss fiel, obwohl die anwesenden ÖTV-Vertreter eindringlich an die Friedenspflicht erinnerten.

50 | In der Tarifrunde für 1973 erhob der konservative Deutsche Beamtenbund die ersten öffentlichen Forderungen nach einer Pauschale. Wie die TdL notierte, habe diese Tatsache »den Gegnern des Sockelbetrages in der ÖTV [...] die Argu- 
Bei der ÖTV-Führung galt solche Gefühlspolitik als sehr gefährlich. Die Organisation müsse erkennen, warnte Heinz Kluncker vor dem gHV im September 1973, »daß die Welt für uns nicht mehr heil ist, daß wir latent [...] Getriebene sein können«, wenn die Furcht vor einer anhaltend starken Geldentwertung in den Gremien und an der Basis weiter wachse. Die Nachgiebigkeit von Kommunalpolitikern gegenüber streikenden städtischen Arbeitern erschien damit unversehens als eine Gefahr für die ÖTV: "Wenn einige Leute auf den Geschmack kommen, daß sie nur zu pfeifen brauchen [...], und dann Stadtverwaltungen zusammenbrechen«, dann könne rasch die Situation entstehen, dass die Lohnpolitik für die Öffentlichen Dienst künftig "an uns vorbei« laufe. ${ }^{51}$

Die Warnstreiks der großstädtischen Müllarbeiter und deren Forderungen nach einem einheitlichen Inflationsausgleich wirkten so fast wie ein Menetekel, das auch der ÖTV galt. Zwar hatten hauptberufliche und ehrenamtliche Funktionsträger (wie schon im Herbst 1969) in der Regel an diesen »spontanen « Arbeitsniederlegungen lenkend mitgewirkt. Anders als bei den damaligen "September-Streiks" beschlich die Gewerkschaftsführung diesmal jedoch wirklich ein ungutes Gefühl: Zumindest bei den Aktionen in Hannover, die tatsächlich zur Zahlung von pauschalierten Teuerungszuschlägen führten, hätten die Streikenden und die sozialdemokratisch dominierte Stadtverwaltung, so Kluncker, gemeinsam die Regie übernommen: "Wir saßen wie Hein Doofi dabei. ${ }^{52}$ Hinweise, wie man diese Situation für die Zukunft vermeiden könne, blieb der Vorsitzende jedoch schuldig, und auch die anderen gHV-Mitglieder hatten in dieser Hinsicht offenbar keine Ideen. So blickte die Gewerkschaftsführung ausgesprochen nervös auf ihre eigene Basis und auf deren Vertreter in wichtigen Gremien. Heinz Kluncker hielt erklärtermaßen nichts davon, das neue strategische Problem der ÖTV mit den Mitgliedern der Großen Tarifkom-

mentationsmöglichkeiten sehr stark beschnitten« (Karl-Heinz Kiefer an die FAZRedaktion, 1.2.1973. In: BArch Koblenz, B 222, 44).

51 | Tonbandabschrift der Vorberatungen vor den Tarifverhandlungen am 12./13.9.1973. In: AdsD, ÖTV, 5/ÖTVB412004.

52 | Ebd. Zur Rolle der ÖTV in den Müllarbeiter-Warnstreiks vgl. zusammenfassend: Aktenvermerk des Referats IV/3 für den Bundeskanzler, 12.9.1973. In: BArch Koblenz, B 136, 5204. 
mission zu beraten, denn diese seien »in einigen Fällen, ohne selbstgefällig zu sein, auch intellektuell überfordert «. ${ }^{53}$

Die rasche Einigung mit den Arbeitgebern über das volle 13. Monatsgehalt entschärfte die Situation zwar noch im September 1973. Für die Haltung der Gewerkschaftsführung in der nachfolgenden Tarifrunde, die bekanntlich in einem groß angelegten Streik der ÖTV gipfelte, waren die Ereignisse des Vorjahres jedoch höchst bedeutsam. Ohne das Gefühl, die interne Welt der Gewerkschaft sei »nicht mehr heil«, hätten Heinz Kluncker und der gHV die Organisation im Februar 1974 wohl kaum so zielstrebig in jenen Arbeitskampf geführt, der dann zu einer politischen Demütigung von Bundeskanzler Willy Brandt wurde. Wie zu zeigen sein wird, wollte die ÖTV-Führung die Eskalation gezielt auch deshalb, weil sie fürchtete, die Mitglieder würden ansonsten eigenmächtig handeln. ${ }^{54}$

Die von den Arbeitgebern so heftig beklagte "nivellierende Wirkung« der pauschalen Lohn- und Gehaltserhöhungen muss hingegen als Mythos gelten. Drei zu eins - so lautete 1967 das Verhältnis zwischen den Grundbezügen in der niedrigsten und in der höchsten Gehaltsgruppe im BAT; im Jahr 1974 war daraus eine Spanne von 2,9 zu eins geworden. Die von der ÖTV durchgesetzten tariflichen »Sockel« waren offensichtlich nicht so bemessen, dass sie die finanzielle Hierarchie des Öffentlichen Dienstes ernsthaft tangierten. ${ }^{55}$ Auch die finanzielle Kluft zwischen den Laufbahnen, die

53 | Tonbandabschrift der Vorberatungen vor den Tarifverhandlungen am 12./13.9.1973. In: AdsD, ÖTV, 5/ÖTVB412004.

54 | Aufmerksame Beobachter der wirtschaftlichen und sozialen Entwicklung hatten solch eine Situation schon frühzeitig vorausgesagt. Wie der renommierte Wirtschaftswirtschaftler Alfred Müller-Armack bereits 1970 notierte, bedrohten hohe Inflationsraten grundsätzlich die »Führungsfunktion « von Gewerkschaften, weil die Basis wegen der Teuerung besonders wirkungsvolle lohnpolitische Erfolge verlange: Unter Umständen müssten Gewerkschaftsführer in solchen Zeiten Forderungen stellen, von denen sie selbst nichts hielten (Alfred Müller-Armack: Ist die Inflation unser Schicksal? In: Die politische Meinung 5 (1970), H. 4, S. 1131, hier: S. 30).

55 | Berechnet nach: Aufstellung über die Entwicklung der Brutto- und Nettovergütungen bei Bund und Ländern 1967-1974, o. D. In: Archiv Ver.di, Bestand Kluncker, 46. Die Berechnung erfolgte jeweils für die Bruttobezahlung in der letzten Stufe der Grundvergütung unter Einbeziehung des Ortszuschlags 2. Bei der Nettobezahlung (berechnet für die Lohnsteuerklasse III) sank der Abstand von 
den »Höheren Dienst« und den »Gehobenen Dienst« privilegierte, blieb weitgehend unverändert. ${ }^{56}$

Dennoch hatten die Arbeitgeber durchaus berechtigten Grund zur Klage - und daraus erwuchs langfristig ein ernsthaftes Problem sowohl für die Beschättigten in den unteren Gehaltsgruppen als auch für die ÖTV. Kurz gesagt wirkten die pauschalen Lohnerhöhungen bei der Bruttobezahlung anders als bei den Nettobeträgen - und daran zeigt sich einmal mehr eindringlich, wie kompliziert das Geschäft der Tarifpolitik sein kann. Schaut man auf die Kosten der Arbeitgeber, dann verteuerte sich ein Beschäftigter in der niedrigsten Gehaltsgruppe X von 1967 auf 1974 um 84,4 Prozent; der Nettobetrag, der dem Arbeitnehmer ausgezahlt wurde, stieg hingegen nur um 68,6 Prozent. Einen so weiten Abstand zwischen Brutto- und Nettoeffekt gab es nur in den unteren Stufen, weil das deutsche Steuer- und Sozialrecht, das seinerzeit nur sehr niedrig angesetzte Freibeträge kannte, Geringverdiener nicht adäquat entlastete. ${ }^{57}$

Diesen Effekt haben in den frühen 1970er Jahren weder die Freunde noch die Kritiker einer sozial ausgleichenden Tarifpolitik bedacht. Dabei wäre gerade in diesem Punkt Aufmerksamkeit wichtig gewesen. Wenn die

2,60: 1 im Jahr 1967 auf 2,57:1 (1974). Auf längere Sicht ergaben sich allerdings durchaus auch deutlichere Angleichungen. Vgl. die äußerst gründliche Untersuchung für den Zeitraum 1960 bis 1980 in: Bernd Mettelsiefen/Lothar Pelz/Bernd Rahmann: Verdienststruktur im öffentlichen Sektor, Göttingen 1988, S. 187-205. Wegen der Feingliederung des Entlohnungssystems fiel die Annäherung im Einzelnen sehr unterschiedlich aus. Signifikant profitierten davon jüngere Beschäftigte in den unteren Besoldungsgruppen. Insgesamt hielten die Autoren den "Nivellierungseffekt« dennoch für unbedeutend: Die "statusgruppenbezogene Einkommenshierarchie« im Öffentlichen Dienst sei im Untersuchungszeitraum "nahezu unverändert" geblieben (ebd., S. 260).

56 | Vgl.: Detlef Merten: Zur Problematik der Gewährung einheitlicher Festbeträge bei Besoldungsanpassungen. In: Klaus König/Hans-Werner Laubinger/Frido Wegener (Hrsg.): Öffentlicher Dienst. Festschrift für Karl Hermann Ule zum 70. Geburtstag am 26. Februar 1977, Köln u. a. O. 1977, S. 349-381, hier: S. 379.

57 | Alle Angaben: Aufstellung über die Entwicklung der Brutto- und Nettovergütungen bei Bund und Ländern 1967-1974, o. D. In: Archiv Ver.di, Bestand Kluncker, 46. In der Mitte der Gehaltshierarchie (etwa in den Gruppen V A und VI B) betrug die Bruttoverteuerung 62,6 Prozent; die Nettovergütung wuchs um 60,1 Prozent. 
Öffentliche Hand (und nur sie) für gering qualifizierte Arbeiten besonders hohe Bruttobezüge gewährte, entstand ein Ungleichgewicht gegenüber den Löhnen für vergleichbare Tätigkeiten in der Privatwirtschaft, welches den sozial begünstigten Beschäftigten des Staates nicht nützte: Es bedrohte nämlich ihre Arbeitsplätze. Dennoch begleitete die Auseinandersetzung um tarifliche »Sockel« die ÖTV durch das ganze Jahrzehnt. Wie die Gewerkschaft dabei mit jener Gefahr umging, die sie selbst aus sozialen Motiven mit heraufbeschworen hatte, wird weiter unten noch ausführlich untersucht.

\section{Die wirtschaftliche "Globalsteuerung" der Bundesregierung und die Tarifautonomie}

Tarifpolitisch stritten sich die Arbeitgeber und die ÖTV zwischen 1969 und 1973 allerdings keineswegs nur über die vermeintliche »Nivellierung « der Löhne und Gehälter. Noch uneiniger waren sie sich über die ganz grundsätzliche Frage, wie stark die wirtschafts- und finanzpolitischen Planungen von Regierung und Parlament die Tarifverhandlungen im Öffentlichen Dienst prägen dürften. Die Frage war nicht neu; sie stellte sich nur nach dem Amtsantritt der sozialliberalen Koalition in Bonn mit zunehmender Dringlichkeit. Die »Globalsteuerung« des Wirtschaftslebens, um die sich das Wirtschaftsministerium unter Karl Schiller bemühte, geriet bereits in den frühen 1970er Jahren in eine schwere Krise, denn die Inflation machte dem selbstbewussten Minister hartnäckig einen Strich durch seine Berechnungen und Planungen: Die Preissteigerungsrate wuchs von Jahr zu Jahr; von "Stabilität«, die unverändert als höchst bedeutsam galt, konnte keine Rede sein. ${ }^{58}$

Dieser inflationäre Schub, der als Hintergrund der Tarifverhandlungen immer wichtiger wurde, ging auch auf staatliches Handeln zurück. Die Öffentliche Hand verhielt sich in den Jahren nach 1970, in denen die bundesdeutsche Wirtschaft noch einmal rasant wuchs, eher prozyklisch als antizyklisch, d.h., sie förderte den Boom mit seinen steigenden Preisen, statt ihn zu dämpfen. Eine starke Expansion des Öffentlichen Dienstes und der Staatsausgaben gehörte an zentraler Stelle zu den Faktoren, die wirt-

58 | Vgl. zusammenfassend: Nützenadel: Stunde, S. 344-352; Schanetzky: Ernüchterung, S. 112-139. 
schaftlich antreibend wirkten. Von 1969 bis 1974 wuchs die Zahl der Staatsbeschäftigten um 400.000 Köpfe auf mehr als 3,4 Millionen insgesamt. Die Personalausgaben stiegen um 55 Prozent und damit weitaus stärker als die verfügbaren Etats. Die öffentliche Verschuldung legte ebenso deutlich zu wie die "Staatsquote« (d.h. der Anteil am gesamten Sozialprodukt, den die Öffentliche Hand für sich beansprucht); der Anteil der Investitionen an den öffentlichen Haushalten aber sank. ${ }^{59}$

Es wäre viel zu einfach, an dieser Stelle von einer falschen oder auch nur fehlerhaften Politik der Bundesregierung und der SPD zu sprechen. Der Staatsapparat expandierte so stark, weil er in Bund, Ländern und Gemeinden durch politische Beschlüsse neue Aufgaben übernahm und bestehende Angebote ausbaute; die Staatsquote wuchs, weil bislang unzureichende soziale Hilfen und Transferleistungen (etwa für Kriegsopfer, die Empfänger von Sozialhilfe, Rentner und Landwirte) ebenfalls politisch gewollt deutlich verbessert wurden. So entstanden die meisten der neuen Arbeitsplätze im Staatsdienst in den Bereichen »Bildung « und »soziale Hilfen«, deren Ausbau von allen Parteien und von der großen Mehrheit der Bundesbürger gewünscht wurde. ${ }^{60}$ Da die Zuständigkeit für diese beiden Segmente des Öffentlichen Dienstes vor allem bei den Bundesländern und den Kommunen lag, ging das wirtschaftlich prozyklische Verhalten des Staates zentral auf ihr Konto. Die Bundesregierung versuchte seit 1970 zwar mehrfach, mit

59 | Als knappe Zusammenfassung vgl.: ebd., S. 122 f. Von 1969 auf 1974 wuchs die Staatsquote von 38,9 Prozent auf 43,4 Prozent. Ausführlicher vgl. etwa: Keller: Arbeitsbeziehungen, S. 79-105 (genaue Zahlenangaben S. 84). Die Zahl von 3,4 Millionen erfasst die Vollzeitbeschäftigten im »unmittelbaren« Öffentlichen Dienst (Bund, Länder und Gemeinden, inkl. Bundesbahn und Bundespost). Rund 600.000 Beschäftigte in weiteren öffentlichen Unternehmen (bis zu einem 50-prozentigen Besitzanteil der Öffentlichen Hand) sind noch dazu zu rechnen. Vgl. dazu sowie generell zu Berechnungen für den »mittelbaren« Öffentlichen Dienst (die Sozialversicherungsträger, die Sparkassen, die Rundfunkanstalten etc.) ausführlich: Claus Schäfer/Rainer Skiba/Hartmut Tofaute: Probleme des Öffentlichen Dienstes. In: WSI-Mitteilungen 27 (1974), S. 394-414. Unter weiter Auslegung des Begriffs »Öffentlicher Dienst« kommen die Autoren auf insgesamt 5,7 Millionen staatlich Beschäftigte (S. 404-406).

60 | Vgl. als Überblick etwa: Hans Günter Hockerts: Im Zenit der staatlichen Wohlfahrtsproduktion: Die Reformära 1966-1974. In: ders.: Der deutsche Sozialstaat. Entfaltung und Gefährdung seit 1945, Göttingen 2011, S. 181-201. 
"Stabilitätsprogrammen« gegenzusteuern; diese nicht sehr konsequent verfolgten Bemühungen verpufften jedoch weitgehend wirkungslos. ${ }^{61}$

CDU und CSU, die als Opposition im Bundestag die angeblich gänzlich »unverantwortliche" Haushalts- und Wirtschaftspolitik der Bundesregierung laut beklagten, halfen bei der Expansion des Staatsapparates nach 1969 also durchaus kräftig mit. Langfristig kostspielige »Strukturveränderungen« im Stellenkegel des Öffentlichen Dienstes beim Bund wie bei den Ländern, etwa durch pauschal höhere Eingangsgehälter, zusätzliche Beförderungsstellen und neuartige "Sonderlaufbahnen« für Polizisten, Steuerbeamte und Techniker, beschlossen die Parteien in der Regel ebenfalls einvernehmlich. ${ }^{62}$

Darüber hinaus versagte die wirtschaftliche »Globalsteuerung« auch deshalb, weil rasch steigende Preise in den frühen 1970er Jahren ein internationales Phänomen darstellten: Alle westlichen Industrieländer litten unter hohen Inflationsraten. ${ }^{63}$ Die Gründe dafür sind zu komplex, um auf einen einfachen Nenner gebracht zu werden. Der ungebremste Energie- und Rohstoffhunger der zunehmend miteinander konkurrierenden reichen Nationen spielte ebenso eine wichtige Rolle wie spekulative Währungsgeschäf-

61 | Vgl. dazu detailliert: Gerhard Mammen: Grundzüge differenzierter Stabilisierungspolitik in der Bundesrepublik Deutschland, Göttingen 1978, S. 73-97; als ein Beispiel für die Stabilitätsbemühungen der Bundesregierung vgl. etwa ihr entsprechendes Programm vom Mai 1973 und dazu: Schroeder: Weg, S. 40-44. Für das Wachstum des Öffentlichen Dienstes in einem dauerhaft CDU-geführten Bundesland vgl. etwa am Beispiel von Baden-Württemberg: Ute Steiner: Das Personal im Landeshaushalt. Entwicklung, Kosten, Einsparungen, Stuttgart 2002. Allein 1970 und 1971 entstanden hier 17.500 neue Stellen im Öffentlichen Dienst. Das entsprach einer Personalvermehrung von zehn Prozent in zwei Jahren (ebd., S. 11). Als lokales Beispiel vgl.: Walter Krummerey: Bestimmen Aufgaben, Organisation und Leistungen die Personalwirtschaft der Kommunalverwaltung? Versuch einer Antwort am Beispiel der Stadt Herne, Herne 1973.

62 | Vgl. als Überblick: Tarifpartner im öffentlichen Dienst vor schwieriger Verhandlungsrunde. In: FAZ, 1.10.1971. Speziell für die Beamten vgl. auch: ÖTV-Geschäftsbericht 1972/75, S. 323.

63 | So die Feststellung Schillers in: Die Kabinettsprotokolle der Bundesregierung, Bd. 23: 1970. Bearb. v. Christine Fabian/Uta Rössel, Berlin u.a. O. 2015. (im Folgenden: Kabinettsprotokolle Bundesregierung 1970), S. 363 (Kabinettssitzung v. 17.9.1970). Vgl. im Überblick auch: Müller-Armack: Inflation, S. 11-31. 
te, die auf den Zusammenbruch des international seit 1944 bestehenden Systems fester Wechselkurse setzten. Gerade die DM, die gegenüber dem Dollar und wichtigen europäischen Währungen im Interesse florierender deutscher Exporte trotz einer deutlichen Aufwertung im Jahr 1969 immer noch unterbewertet war, stand im Zentrum solcher Spekulationswellen. Damit floss viel ausländisches Kapital in die Bundesrepublik; der Geldumlauf beschleunigte sich. Gegen diesen »Inflationsimport« gab es kaum einen wirkungsvollen Schutz. ${ }^{64}$

Wichtig ist dieser internationale Hintergrund, weil zahlreiche ausländische Regierungen in ihrer Furcht vor den politischen Folgen der Inflation nach 1970 beherzt in den Markt und in die Tarifautonomie eingriffen: Preise und Löhne wurden staatlich reglementiert. Allein in den beiden ersten Jahren der neuen Dekade ergingen entsprechende Verordnungen oder Gesetze in den Niederlanden, in Schweden, Norwegen, Dänemark und Frankreich. Selbst die USA, das Kernland kapitalistischer Freiheit, verfügten im August 1971 öffentliche Kontrollen sowohl für Preiserhöhungen als auch für neue Tarifabschlüsse. ${ }^{65}$ Das Bundeskabinett aber scheute vor vergleichbaren Maßnahmen zurück, obwohl bei Meinungsumfragen mehr als zwei Drittel der Deutschen sogar für einen amtlichen Preisstopp votierten: Dieser Dirigismus, so meinte die Regierung, sei ordnungspolitisch falsch und ökonomisch hochproblematisch. Lediglich für Wohnungsmieten entstand ein kompliziertes System amtlicher Vorschriften, das deren Verteuerung bremsen sollte. ${ }^{66}$

64 | Das Zitat aus: Otmar Emminger: D-Mark, Dollar, Währungskrisen, Stuttgart 1986, S. 243. Vgl. zusammenfassend zu diesem Problem: Björn Alecke: Deutsche Geldpolitik in der Ära Bretton Woods, Münster 1999, S. 88-97; Carl-Ludwig Holtfrerich: Geldpolitik bei festen Wechselkursen 1948-1970. In: Deutsche Bundesbank (Hrsg.): 50 Jahre Deutsche Mark. Notenbank und Währung in Deutschland seit 1948, München 1998, S. 347-438, hier: S. 423-426.

65 | Vgl. den detaillierten Überblick in: Ausarbeitung des BMF, Abt. W I, über Preis- und Lohnkontrollen in Westeuropa und den USA, 4.9.1972. In: AdsD, HSA, 1/HSAA008329.

66 | Elizabeth Noelle/Erich Peter Neumann (Hrsg.): Jahrbuch der öffentlichen Meinung 1968 -1973, Allensbach und Bonn 1974, S. 359. Dieses Resultat erbrachte eine Umfrage im März 1971. Meinungen zu einem Lohnstopp haben die Meinungsforscher nicht untersucht. Im November 1971 entstand als Reaktion auf stark steigende Mieten durch ein Bundesgesetz das System der »ortsüblichen Ver- 
Angesichts dieser Selbstbeschränkung und angesichts der enttäuschenden Erfahrung, dass die Teuerung allen dämpfenden Maßnahmen des Wirtschaftsministeriums und der Bundesbank trotzte, gewannen die eigenen Ausgaben als ökonomisches Steuerungsinstrument immer größere Bedeutung für die Bundesregierung. ${ }^{67}$ Aus der Sicht des Wirtschaftsministeriums stellten die Tarifverträge für den Öffentlichen Dienst, die jeweils kurz nach Jahresbeginn ausgehandelt wurden und immer bundesweit galten, »eine gewisse Leitlinie« auch für die Lohnerhöhungen in der Privatwirtschaft dar; der wirtschaftswissenschaftliche Sachverständigenrat der Bundesregierung sprach sogar von einer »Signalwirkung «. ${ }^{68}$

Wer die Inflation bekämpfen wollte, der musste nach dieser Logik vor allem für möglichst niedrige Tarifabschlüsse der Öffentlichen Hand sorgen. Gelinge dies nicht, so erklärte Klaus-Dieter Arndt, Staatssekretär im Wirtschaftsministerium, im Herbst 1970, so werde sich in der Bundesrepublik eine inflationäre Mentalität ausbreiten: Dann entstehe ein »Basarkapitalismus in der Lohnpolitik, der alles nehme, was er kriegen könne, ohne auf die Konsequenzen zu achten ${ }^{69}$ Die ökonomischen Prognosen und »Orientierungsdaten«, mit denen das Wirtschaftsministerium die Öffentlichkeit und die Teilnehmer der »Konzertierten Aktion« ausstattete, verwandelten sich damit in eine Anleitung für das eigene Tun: Im Oktober 1970 beschloss das Kabinett, der nächste Tarifvertrag für die Arbeiter und

gleichsmieten«als eine Form der Preiskontrolle, das im Kern auch heute noch gilt. Vgl. dazu ausführlich: Karl Christian Führer: Die Stadt, das Geld und der Markt. Immobilienspekulation in der Bundesrepublik 1960-1985, Berlin und Boston 2016, S. 280-299. Zusammenfassend zur ablehnenden Haltung der Bundesregierung gegenüber Lohn- und Preiskontrollen vgl. etwa: Hans Tietmeyer: Möglichkeiten und Grenzen staatlicher Stabilisierungspolitik im marktwirtschaftlichen System der Bundesrepublik Deutschland. In: Stabilisierungspolitik. WSI-Forum vom 5. bis 7. Dezember 1973, Köln 1974, S. 218-240, hier: S. 229-237. Tietmeyer war Ministerialdirektor im BWiM.

67 | Kabinettsprotokolle Bundesregierung 1970, S. 135 (Kabinettssitzung v. 12.3.1970); S. 363 (Kabinettssitzung v. 17.9.1970).

68 | In der Reihenfolge der Zitate: Arndt warnt Gewerkschaften zur Vernunft. In: Handelsblatt, 9.10.1970; Sachverständigenrat zur Begutachtung der gesamtwirtschaftlichen Entwicklung, Konjunktur im Umbruch - Risiken und Chancen. Jahresgutachten 1970/71, Stuttgart und Mainz 1970, S. 81.

69 | Arndt warnt Gewerkschaften zur Vernunft. In: Handelsblatt, 9.10.1970. 
Angestellten im Öffentlichen Dienst müsse sich »wesentlich« an den Richtwerten des Wirtschaftsressorts orientieren. ${ }^{70}$

Den tarifpolitischen Fehdehandschuh, den ausgerechnet eine sozialdemokratisch geführte Regierung ihr damit vor die Füße warf, hat die ÖTV sofort aufgegriffen, obwohl sich Heinz Kluncker kurz zuvor bei einer Besprechung mit Herbert Ehrenberg im Kanzleramt noch betont konziliant gegeben hatte. Die Organisation wehrte sich mit einem Streik, der zwar auf einem »Nebenschauplatz«, d. h. nicht direkt im Öffentlichen Dienst, stattfand, aber dennoch grundsätzlich als gewerkschaftlicher Widerstand gegen »Lohnleitlinien« der Bundesregierung gemeint war: Ende Januar 1971 initiierte und organisierte die ÖTV einen Streik des Bodenpersonals der Deutschen Lufthansa, der zehn Tage dauerte. Nach den Worten Heinz Klunckers handelte es sich bei diesem Arbeitskampf um »eine Konfrontation, die gewollt war « - und das galt für beide Seiten. ${ }^{71}$

Als Hauptaktionär der Fluggesellschaft drängte der Bund die Unternehmensleitung zu einer Haltung, die dem Kabinettsbeschluss entsprach. Wie Journalisten notierten, wollte die Regierung damit »eine Probe aufs Exempel für die gesamte Lohnpolitik 1971 setzen «. ${ }^{72}$ Die ÖTV wiederum beobachtete bei den nicht fliegenden Beschäftigten der Lufthansa eine groBe Konfliktbereitschaft. Sie sorgten sich nicht nur - wie fast alle Bundesbürger - über die steigenden Preise, sondern hatten zudem ein besonderes Anliegen: Die Airline bezahlte ihre Beschäftigten »am Boden« deutlich weniger großzügig als das Personal, das in den Flugzeugen arbeitete. Diese Kluft belastete das Betriebsklima bereits seit langem; die rasche Teuerung verschärfte die Unzufriedenheit. Zugleich durfte sich die ÖTV gerade im unteren Segment dieser tariflichen Zwei-Klassen-Gesellschaft stark fühlen:

70 | Kabinettsprotokolle Bundesregierung 1970, S. $400 \mathrm{f}$. (Kabinettssitzung v. 22.10.1970). Vgl. auch: Rolf Seitenzahl: Einkommenspolitik durch konzertierte Aktion und Orientierungsdaten, Köln 1974, S. $138 \mathrm{f}$.

71 | Gewerkschaftlicher Situationsbericht von Heinz Kluncker vor dem ÖTVBeirat, 18.6.1971. In: AdsD, Depositum Kluncker, Reden und Referate November 1969-Februar 1972.

72 | Vgl. zusammenfassend den Bericht von H. Kluncker in: Protokoll ÖTVGT 1972, Bd. 1, S. 56. Das Zitat aus: Gebremster Höhenflug. In: Die Rheinpost, 30.1.1971. Seit 1953 gab es auch Privataktionäre bei der Lufthansa; Aktienmehrheit und Lenkung der Betriebsentwicklung lagen jedoch weiterhin klar bei der Öffentlichen Hand. 
Rund 5.000 Arbeiter und Angestellte von den insgesamt etwa 15.000 Angehörigen des Lufthansa-Bodenpersonals hatten sich der Gewerkschaft angeschlossen; im Frankfurter Flughafen, der als "Drehscheibe» und Hauptstandort der Lufthansa-Flotte besondere Bedeutung besaß, lag die Organisationsquote sogar bei 50 Prozent. Dazu kamen rund 1.600 Angestellte mit oft besonders qualifizierten Tätigkeiten bei der technischen Wartung der Maschinen, die der DAG angehörten. ${ }^{73}$

Die konkreten Prozentzahlen, um die Lufthansa und Gewerkschaft im Frühjahr 1971 stritten, wirken aus heutiger Sicht ziemlich erstaunlich: Der Arbeitgeber bot Lohn- und Gehaltserhöhungen von durchschnittlich 13,5 Prozent an; die ÖTV verlangte hingegen für einzelne Personalgruppen Aufbesserungen von bis zu 25 Prozent und auch im Durchschnitt noch ein Plus von 18 Prozent. ${ }^{74}$ Zwar fällt es auf den ersten Blick schwer, die Offerte der Unternehmensleitung für »stabilitätskonform« zu halten; tatsächlich aber handelte es sich unter den besonderen Bedingungen der Zeit sowie konkret für die Lufthansa doch um ein strategisch bestimmtes (d.h. mit Blick auf den Partner bewusst noch "zu niedrig« angesetztes) Angebot, wie es in Tarifverhandlungen allgemein üblich war. Die hohe Zahl entstand, weil auch die Lufthansa-Geschäftsführung das starke finanzielle Gefälle zwischen Kabinenbesatzungen und Bodenpersonal ausgleichen wollte.

Lässt man den betriebsspezifischen Konflikt beiseite, wie diese strukturellen Korrekturen »richtig« zu bemessen seien, dann bot die Lufthansa ihren nicht fliegenden Beschäftigten in der Tarifrunde für 1971 Lohn- und Gehaltsverbesserungen von acht Prozent an. Exakt diese Zahl hatte das Wirtschaftsministerium zuvor als Höchstgrenze für wirtschaftlich noch »angemessene« Lohnerhöhungen bezeichnet, weil sie sich aus der Teue-

73 | Zu der innerbetrieblichen Kluft zwischen fliegendem und Boden-Personal vgl. etwa: Peter Odrich: Der Streik bei der Lufthansa. In: FAZ, 1.2.1971; HansJoachim Deckert: Den Vogel abgeschossen. In: Mannheimer Morgen, 1.2.1971; Lutz Linke: Der Familienkrach brachte etwas ein: „Vater« rückt nun mehr Geld raus. In: Metall, 16.2.1971. Die Angaben zur gewerkschaftlichen Stärke nach: Die Lufthansa bereitet sich auf einen Streik vor. In: Westfalenpost, 29.1.1971; Die Lufthansa steht vor Sturz in ein Chaos. In: FR, 29.1.1971; Das Mißverständnis. In: Wirtschaftswoche 25 (1971), H. 7, S. 12-13, hier: S. 12. Insgesamt beschäftigte die Lufthansa Ende 1971 rund 22.000 Personen (Jahresbericht 1971 der Deutschen Lufthansa Aktiengesellschaft, Frankfurt/Main 1972, S. 13).

74 | Lufthansa-Streik lähmt Flugbetrieb. In: Bonner Rundschau, 30.1.1971. 
rungsrate und dem zu erwartenden Produktivitätszuwachs ergebe - und darin lag für die ÖTV die Provokation. Öffentlich erklärte Heinz Kluncker, »seine Gewerkschaft werde keine Lohnleitlinien akzeptieren, wer immer sie auch präsentiere«. Damit meinte er nicht nur Karl Schiller, sondern auch Verkehrsminister Georg Leber, den ehemaligen Chef der IG Bau, der sich öffentlich in den Tarifstreit eingemischt hatte. ${ }^{75}$

Die ÖTV-Mitglieder im Lufthansa-Bodenpersonal zeigten sich kampfbereit: In der Urabstimmung votierten 94,7 Prozent für einen Arbeitskampf. Die DAG, die ebenfalls zum Streik aufrief, schrammte hingegen nur knapp an einem gewerkschaftlichen Desaster vorbei: Mit 77,5 Prozent lag der Anteil der "Ja«-Stimmen bei ihren Mitgliedern nur 2,5 Punkte über dem nötigen Quorum. ${ }^{76}$ Am zehntägigen Ausstand beteiligten sich dann doch viele »DAGler«. Zwar streikten stets nur rund 5.000 der 15.000 Beschäftigten, die zum Bodenpersonal der Lufthansa gehörten; eine höhere Beteiligung aber war auch gar nicht nötig, weil der organisatorisch hochkomplexe Flugverkehr der Gesellschaft bereits bei dieser Zahl von Streikenden weitgehend stilllag. Auch 2.000 Neueintritte von Lufthansa-Beschäftigten allein in den Streiktagen konnte die ÖTV als Erfolg verbuchen. ${ }^{77}$

Die Presse berichtete intensiv, aber stark gewerkschaftskritisch. Zum einen gehörte die Lufthansa zu den Unternehmen, die in den Medien hohe Aufmerksamkeit genossen, weil an ihnen deutscher Nationalstolz hing.

75 | Attacken auf Leber und Lufthansa. In: SZ, 3.2.1971. Schiller und Leber (der höhere Defizite bei Post und Bahn fürchtete) hatten versucht, den oben zitierten Kabinettsbeschluss durch die präzise Zahl (8 Prozent) zu fixieren; Innenminister Genscher aber verlangte »flexible Verhandlungsmöglichkeiten« (Notiz über das Ministergespräch zur Vorbereitung der Tarifverhandlungen und der Besoldungsneuregelung, 16.11.1970. In: BArch Koblenz, B 136, 6589). Zu Lebers Intervention vgl. genauer: Lufthansa-Streik lähmt Flugbetrieb. In: Bonner Rundschau, 30.1.1971.

76 | Zahlen aus: Streik bei Lufthansa lähmt den Flugverkehr. In: Kölner StadtAnzeiger, 31.1.1971.

77 | Lufthansa-Flugplan wie anfangs der 60er Jahre. In: Handelsblatt, 2.2.1971. Heinz Kluncker sprach rückblickend von einem Streik, der »trotz vieler Improvisationen und trotz vieler Mängel in der Organisation« dank der Einsatzbereitschaft der Streikenden gelungen sei (Gewerkschaftspolitischer Situationsbericht von Heinz Kluncker vor dem ÖTV-Beirat, 18.6.1971. In: AdsD, ÖTV, 5/ÖTVB130054). Zu den Eintritten während des Streiks vgl.: ÖTV-Geschäftsbericht 1972/75, S. 211. 
Etliche Zeitungskommentare lasen sich daher so, als attackiere eine ökonomisch rücksichtlose Gewerkschaft ein Symbol deutscher Verlässlichkeit und Dynamik. Zudem saß Heinz Kluncker im Lufthansa-Aufsichtsrat: Wie konnte er da »eine Krise « des Unternehmens herbeiführen ${ }^{78}$ Darüber hinaus lag der prinzipielle Charakter der Auseinandersetzung offen zu Tage. Kurz vor Streikbeginn hatten die »Fünf Weisen« des Sachverständigenrates »den Staat« eindringlich gemahnt, er überfordere »die Verständnisfähigkeit der Öffentlichkeit«, wenn er als Arbeitgeber »seine eigenen Orientierungsdaten für die Lohnpolitik« nicht ernst nehme. ${ }^{79}$

In diesem »Nervenkrieg« behielt die ÖTV die Oberhand: Als die finanziellen Verluste der Lufthansa sich auf 25 Millionen DM summiert hatten, erreichte die Gewerkschaft mit Hilfe eines unparteiischen Vermittlers einen Tarifvertrag, der die Löhne und Gehälter des Bodenpersonals nach den Berechnungen der Gewerkschaft um durchschnittlich 15,9 Prozent verbesserte. Etwa 13 Prozent entfielen auf die »Grunderhöhung«, die sich die Bundesregierung bei acht Prozent gewünscht hatte. ${ }^{80}$ Hoch erfreut kommentierte Heinz Kluncker: „Unser Kampf war [...] vor allem ein Kampf gegen den Mißbrauch der gesamtwirtschaftlichen Orientierungsdaten. [...] Die Lufthansa und ihr Hauptaktionär mußten ihre Zahlenspiele in den Papierkorb werfen, weil die betroffenen Arbeitnehmer und ihre ÖTV nicht bereit waren, sie zu akzeptieren. $\aleph^{81}$

78 | Rudolf Bauer: Flugunfähig. In: Rheinische Post, 30.1.1971. Vgl. ähnlich auch: Lufthansa-Streik wozu? In: Christ und Welt, 29.1.1971; Ein Streik mit Folgen. In: Tagesspiegel (Berlin), 30.1.1971; sowie die Karikatur »Das war's«. In: Die Welt, 6.2.1971. Zur Bedeutung der Lufthansa als nationales Symbol vgl. etwa: HansJoachim Deckert: Den Vogel abgeschossen. In: Mannheimer Morgen, 1.2.1971; Peter Hornung: Bestreikte Lufthansa. In: Bayernkurier, 6.2.1971.

79 | Sachverständigenrat: Konjunktur, S. 81.

80 | Das Zitat aus: Bei der Lufthansa wird weiter gestreikt. In: SZ, 3.2.1971; Zahlen aus: Rolf Diekhof: ... und keinen Deut mehr. In: Die Zeit, 12.1.1971. Die Lufthansa sprach hingegen von einer durchschnittlichen Erhöhung um 14,8 Prozent. Die Angabe der ÖTV beruhe auf einem »Rechenfehler«. Die Rolle des Vermittlers hatte der Präsident des Bundesrechnungshofes Volkmar Hopf übernommen (Lufthansa-Streik endlich beendet. In: Bonner Rundschau, 8.2.1971). In ihrem Geschäftsbericht bezifferte die ÖTV den Abschluss dann sogar auf durchschnittlich 16,3 Prozent (ÖTV-Geschäftsbericht 1972/75, S. 211).

81 | Protokoll ÖTV-GT 1972, Bd. 1, S. 56. Weil sie fürchtete, den Personalkostenanteil nicht mehr stabil halten zu können, verfügte die Unternehmensleitung im 
Auf diese rundum positive Bilanz fiel kurz nach dem erfolgreich abgeschlossenen Arbeitskampf allerdings ein Schatten, der sich gewerkschaftspolitisch nicht als nebensächlich abtun ließ: Die Vereinigung Cockpit, die als spezielle Interessenvertretung von Lufthansa-Piloten die meisten dieser hochbezahlten Beschäftigten vereinte, beendete die Zusammenarbeit mit der ÖTV in Tarifangelegenheiten, denn ihr passten weder der Streik noch dessen Ziele, die vielen der Großverdiener in den Flugzeugen als nivellierend galten. Die ÖTV revanchierte sich, indem sie die Vereinigung zur "gegnerischen Organisation « erklärte, was auf einen Unvereinbarkeitsbeschluss hinauslief: Doppelmitgliedschaften in beiden Organisationen durfte es nun nicht mehr geben. De facto verlor in dieser Konfrontation vor allem die ÖTV: Sie verfügte seitdem kaum noch über Einfluss unter den Männern, die an der Spitze der Lufthansa-Gehaltshierarchie standen. ${ }^{82}$ In zugespitzter Form zeigten sich in dieser Episode die gewerkschaftspolitischen Probleme einer sozial angleichenden Tarifpolitik. Zwar lebte in der Tat niemand von »Abständen« bei Lohn und Gehalt - in der sozialen Realität gab es aber offensichtlich doch Beschäftigte, die von einer geringeren Spreizung bei der Bezahlung selbst dann nichts wissen wollten, wenn sie selbst dadurch gar keine finanziellen Nachteile erlitten. Der unbestreitbare Erfolg von 1971 hat die ÖTV daher auch geschwächt, weil die Lufthansa-Piloten, die sich um ihre besonders hervorgehobene Stellung sorgten, ihren Bund mit der Organisation kündigten. ${ }^{83}$

Juni 1971 auch in Reaktion auf den Tarifabschluss einen »Personaleinstellungsstopp« (Jahresbericht Lufthansa 1971, S. 9). Auch eine Dividende wurde - anders als in den Vorjahren - nicht ausgeschüttet (ebd., S. 5).

82 | Vgl. den Abriss der Auseinandersetzung durch H. Kluncker in: Protokoll ÖTV-GT 1972, S. 68, sowie: ÖTV-Geschäftsbericht 1972/75, S. 142. Im Jahr 1979 gab es in der ÖTV exakt 519 Mitglieder in der Berufsgruppe »Fliegendes Personal Luftfahrt", aber 15.573 Mitglieder, die zum Bodenpersonal gehörten (Übersicht der Mitgliederstatistik der Abteilungen im Sekretariat 2 im Zeitraum 1976 bis Juni 1979, o. D. In: AdsD, ÖTV, 5/ÖTVB130075). Pilotinnen kannte die Berufswelt seinerzeit noch nicht.

83 | Zum Streit zwischen der ÖTV und der Vereinigung Cockpit, die nach dem Bruch mit der ÖTV ein Kooperationsabkommen mit der DAG abschloss, vgl. auch noch: ÖTV-Geschäftsbericht 1976/79, S. 151. Ferner: Deutsche Angestellten-Gewerkschaft: Tätigkeitsbericht 1971-1975. Vorgelegt dem 11. Bundeskongress, Hamburg 1975, S. 74. Die Vereinigung hatte zu diesem Zeitpunkt 1.160 Mitglieder. 
Auf der großen Bühne der Tarifpolitik, auf der über die Arbeitsbedingungen im »richtigen« Öffentlichen Dienst verhandelt wurde, erneuerte sich derweil der Konflikt der ÖTV mit Bundeswirtschaftsminister Schiller. Der Sozialdemokrat, der im Frühjahr 1971 zusätzlich das Amt des Finanzministers übernahm und damit politisch noch größeren Einfluss genoss als zuvor, verschärfte den Ton sogar: Als »Superminister« wandelte er sich immer stärker zum Prediger öffentlicher Sparsamkeit, der lautstark gegen den steten Zuwachs bei den staatlichen Personalausgaben protestierte. »Stabilität beginnt beim Staat«, verkündete Schiller im Sommer 1971 vor Kommunalpolitikern der SPD. Die »Explosion der Personalkosten«, die zu Lasten der öffentlichen Investitionen gehe, müsse sofort ein Ende haben: »Eine stabilitätsgerechte Besoldungspolitik im öffentlichen Bereich ist das erste Gebot der nächsten Stunde für die Öffentliche Hand - aus gesamtwirtschaftlicher Sicht und aus der Sicht unserer Gesellschafts- und Reformpolitik. ${ }^{84}$ Wenig später warnte der Minister alle Gewerkschaften - und ungenannt vor allem die ÖTV - »durch pures Weiterpokern« gefährdeten sie in der aktuellen wirtschaftlichen Situation »die Leistungskraft unserer ganzen Wirtschaft«: Gerade der Öffentliche Dienst habe »ein eindeutiges Zeichen für eine stabilitätsgerechte Lohnpolitik« zu setzen. ${ }^{85}$

Schiller erwies sich mit diesen Äußerungen - je nach Sicht des Interpreten - entweder als beratungsresistent oder als Überzeugungstäter, dem es an politischen Alternativen mangelte. Kritik sowohl an den Konzepten als auch an der Praxis der »Globalsteuerung « und der »Konzertierten Aktion« entfaltete sich in der Bundesrepublik nach 1969 rasch in beeindruckender Fülle und Differenziertheit. Der Nachweis, dass die von Schiller versprochene konfliktfreie und angeblich rationale Lenkung der Wirtschaft durch seine »Orientierungsdaten« kaum funktionieren konnte, wurde dabei auf

84 In der Reihenfolge der Zitate: Karl Schiller: Stabilität beginnt beim Staat. In: ders.: Reden zur Wirtschafts- und Finanzpolitik und Stichworte, Bd. 9, Bonn 1971, S. 121-136, hier: S. 121, 126 u. 129 f. Schiller hielt diese Rede auf der Kommunalpolitischen Bundeskonferenz der SPD am 25. Juni 1971. Zum Rücktritt Alex Möllers, der die kreditfinanzierte Ausgabenpolitik der Bundesregierung nicht mehr mittragen wollte, und zu Schillers Ernennung zum Doppelminister vgl. etwa: Manfred Görtemaker: Geschichte der Bundesrepublik Deutschland. Von der Gründung bis zur Gegenwart, München 1999, S. 567-571.

85 | Rede Karl Schiller auf der Jahresmitgliederversammlung der BDA, 7.12.1971. In: Archiv Ver.di, Bestand Kluncker, 38. 
verschiedene Weise geführt. Ganz grundsätzlich argumentierten jene Kritiker, die einwandten, mit den "Zielprojektionen« in den Jahreswirtschaftsberichten vermenge das Ministerium auf wissenschaftlich fragwürdige Weise die Makroebene hochaggregierter volkswirtschaftlicher Zahlen mit der ökonomischen Mikroebene der Tarifverhandlungen. ${ }^{86}$ Eher auf die Praxis zielte der Einwand, solange Länder und Gemeinden nicht Teil der »Konzertierten Aktion« würden, fehlten in diesen Besprechungen volkswirtschaftlich wichtige Akteure, die das wirtschaftliche Handeln zumal der Öffentlichen Hand entscheidend mitbestimmten. ${ }^{87}$

Realpolitisch vielleicht noch überzeugender war schließlich der Gedanke, Schiller verhindere mit seinen öffentlich stets als »objektiv« präsentierten Zahlen genau das, was er erreichen wolle: Ohne es zu bedenken, setze er damit beide Tarifparteien, vor allem aber die Gewerkschaften, unter Druck, ihre Eigenständigkeit und Handlungsfähigkeit zu beweisen. Wer das ignoriere, der sei »konflikttheoretisch [...] naiv« ${ }^{88}$ Ausgerechnet die konservative Tageszeitung Die Welt vermutete bereits im Frühjahr 1971: ॥n Lohnverhandlungen könnte sich manche Gewerkschaft mit einem niedrigeren Abschluß zufrieden geben, wenn es nicht diese Orientierungsdaten gäbe«. Solange der Minister immer wieder versuche, »die Vormundschaft" über die Tarifpartner zu übernehmen, solange werde es zu "Gefahren an der Lohnfront« kommen. ${ }^{89}$ Ein Wirtschaftswissenschafter argumentierte wenig später, Schillers Vorgaben seien de facto »Ausgangspunkt der Verhandlungen [für Tarifverträge - K.C.F.] und nicht - wie beabsichtigt -

86 | Vgl. dazu ausführlich: Seitenzahl: Einkommenspolitik, S. 131-143.

87 | Otto Vogel: Konzertierte Aktion - Bericht über die Erfahrungen seit ihrem Bestehen, Köln 1970, S. 6. Vgl. auch: Ingo Schmidt: Ist die Konzertierte Aktion als konjunkturpolitisches Instrument geeignet? In: Zeitschrift für Wirtschafts- und Sozialwissenschaften 92 (1972), S. 421-439; Harold Rasch: Die »Konzertierte Aktion«: Bilanz eines gescheiterten Experiments. In: Der Betriebs-Berater 27 (1972), S. 1149-1152.

88 | Hermann Adam: Die Konzertierte Aktion in der Bundesrepublik, Köln 1972, S. 93. Vgl. ähnlich auch: Vogel: Konzertierte Aktion, S. 10 f.; Erich Hoppmann: Konzertierte Aktion und der »Rahmen der marktwirtschaftlichen Ordnung «. In: ders. (Hrsg.): Konzertierte Aktion. Kritische Beiträge zu einem Experiment, Frankfurt/Main 1971, S. 265-313, hier: S. 313.

89 | Kurt Steves: Das Dilemma der Lohnpolitik. In: Die Welt, 19.3.1971. Vgl. ähnlich auch: Müller-Armack: Inflation, S. 30. 
Zielgröße«, weil jeder Gewerkschaftsführer, der seinen Auftrag ernst nehme, alles tun werde, »um Lohnerhöhungen über diese Grenze hinaus zu realisieren ${ }^{90}{ }^{90}$

Schiller aber ignorierte diese Stimmen. Zunehmend klangen seine öffentlichen Stellungnahmen genauso wie die seines Amtsvorgängers Ludwig Erhard, dessen Appell-Politik er 1967 so spöttisch beurteilt hatte. Zwar sah der wirtschaftliche Hintergrund im Vergleich zu den 1950er und 1960er Jahren nun erheblich anders aus - die Forderungen des Wirtschaftsministers aber liefen für die Gewerkschaften ohne Frage auf das Gleiche hinaus. Heinz Kluncker antwortete daher einmal mehr mit Klartext: Die ÖTV, so sagte er in den Tarifverhandlungen für 1972, akzeptiere "weder haushaltspolitische Hemmnisse, Tabuzahlen, Schallmauern oder wie auch immer man sie bezeichnen mag, noch andersartige Lohnleitlinien. Wir kommen in freier Verantwortung als Tarifpartner zusammen, ohne dass die Gesetzgebung diesen Bereich der Tarifautonomie einzuschränken vermag. « ${ }^{91}$

Letztlich, so Kluncker, wolle der Wirtschaftsminister den Öffentlichen Dienst als »konjunkturpolitischen Lückenbüßer« benutzen. Damit missachte er die sozialen Interessen der Staatsbeschäftigten und auch die Notwendigkeit, qualifiziertes Personal zu halten und anzuwerben. Da die Privatwirtschaft oft deutlich übertariflich bezahle, während es für die Beschäftigten der Öffentlichen Hand nach wie vor keine "Lohndrift" gebe, müssten die Tarife für die Arbeiter und Angestellten des Staates nach eigenen Regeln gebildet werden. ${ }^{92}$ Zwar betonte Kluncker immer wieder, Tarifverhandlungen seien selbstverständlich durchweg Verhandlungen über

90 | Bernhard Külp: Zur Problematik der Tarifautonomie. In: Hamburger Jahrbuch für Wirtschafts- und Gesellschaftspolitik 17 (1972), S. 199-222, hier: S. 212 f. Hervorhebungen im Original.

91 | Rede Heinz Kluncker bei der Eröffnung der Tarifverhandlungen, 10.11.1971. In: Archiv Ver.di, Bestand Kluncker, 21. Vgl. auch: Kluncker: Keine Rücksicht auf die Etats. In: Handelsblatt, 24.9.1970.

92 | Transkript des Interviews von Heinz Kluncker in der Sendereihe »Das Interview zum Zeitgeschehen«, gesendet im Südwestdeutschen Rundfunk, 26.11.1973, 19 Uhr. In: Archiv Ver.di, Bestand Kluncker, 45. Vgl. auch: Kluncker: Keine Rücksicht auf Etats. In: Handelsblatt, 24.9.1970. Zur Lohndrift in der Privatwirtschaft vgl. etwa: Joachim Bretschneider: Niedrigere Lohndrift! In: Der Arbeitgeber 11 (1974), H. 1, S. 10-11. Hiernach lagen die effektiv gezahlten Löhne im Durchschnitt um 11,8 Prozent über den Tariföhnen. In der Sicht der Arbeitgeber waren 
einen »Ausgleich der Interessen« durch Kompromisse. Zugleich aber sei jeder Tarifvertrag doch ein »Ausfluß von Macht und nicht von Geist«: Wie die Einigung aussehe, entscheide sich in den Beratungen sowie eventuell im handfesten Konflikt (d.h. durch einen Streik), aber nicht durch Ratschläge von außen oder durch scheinbar objektive Orientierungsdaten. ${ }^{33}$ Eine Gewerkschaft, die anders agiere, könne nämlich gleich darauf verzichten, Forderungen zu stellen: »Entweder ist kein Geld da oder es paßt nicht in die Konjunktur oder wir haben Signalwirkung. ${ }^{94}$

Wer so dachte, der musste zwangsläufig auch die »Konzertierte Aktion" kritisieren. Wie oben gezeigt wurde, hatte die ÖTV dieses Gesprächsgremium, das der Minister mit wirtschaftlichen Daten und Prognosen versorgte, in der Wirtschaftskrise von 1966/67 durchaus positiv beurteilt. Seit dem Ende der Rezession wandelte sich die Sicht: Die Führung der ÖTV gewann immer stärker den Eindruck, Schiller gehe es in den Beratungen der »Aktion « verdeckt darum, die Tarifautonomie einzuschränken. Die Industriegewerkschaften und der DGB teilten diese Skepsis; die ÖTV aber drängte auf Handlungen, weil die Prognosen und Planungen des Ministers sie viel direkter tangierten als Organisationen, die mit Privatunternehmern verhandelten. ${ }^{95}$

Im März 1971 forderte Heinz Kluncker, die DGB-Verbände sollten nur dann weiter an den Sitzungen der "Konzertierten Aktion" teilnehmen, wenn die Bundesregierung verspreche, »alles zu unterlassen, was für Tarifverhandlungen Maßstäbe setzen könnte«. Da die anderen Gewerkschaftsführer nichts davon hielten, so konfrontativ vorzugehen, unterblieb jedoch ein entsprechender Beschluss. ${ }^{96}$ Enttäuscht drohte Kluncker daher direkt vor der nächsten Sitzung des Gremiums im Herbst 1971 in einer gewerk-

diese Lohnzuschläge »ein unabdingbares Instrument [...], das eine leistungsgerechte Entlohnung sicherstellen will« (ebd., S. 11).

93 | In der Reihenfolge der Zitate: Kluncker: Tarifautonomie, S. 214; Der Deutsche Gewerkschaftsbund 1969-1975, S. 915 (Bundesvorstandssitzung v. 30.9/1.10.1974). 94 | Tonbandabschrift der Tarifverhandlungen am 12./13.9.1973. In: AdsD, ÖTV, 5/ÖTVB412004.

95 | Vgl. als Beispiel für die vergleichsweise gelassene Sicht des DGB auf die »Konzertierte Aktion« die Äußerungen von Georg Neemann (Mitglied des DGB-Bundesvorstands) in: Gespräche ohne Folgen. In: Die Zeit, 12.3.1971.

96 | Der Deutsche Gewerkschaftsbund 1969-1975, S. 386 (Bundesvorstandssitzung v. 2.3.1971). Vgl. auch: S. 402 f. (Bundesvorstandssitzung v. 3.3.1971). 
schaftsinternen Vorbesprechung mit »einem spektakulären Austritt« der ÖTV aus der »Konzertierten Aktion«, wenn Vertreter der Bundesregierung »irgendwelche Prozentmargen« für wirtschaftlich angeblich gerade noch vertretbare Tariferhöhungen im Öffentlichen Dienst nennen sollten. ${ }^{97}$ Dieser Eklat blieb jedoch aus. Unversehens trat der Wirtschaftsminister gerade bei diesem Treffen argumentativ ungewöhnlich defensiv auf; insofern musste Kluncker nicht handeln. ${ }^{98}$

Möglicherweise haben Krisengespräche hinter den Kulissen geholfen, diese Entspannung herbeizuführen. So eine sozialdemokratische Geheimdiplomatie lässt sich zwar nicht nachweisen. Politisch wirkt es jedoch plausibel, dass jemand die Kontrahenten zur Mäßigung gedrängt haben muss: Ein Scheitern der »Konzertierten Aktion« auf offener Bühne durch Streit mit einer Gewerkschaft hätte der Regierung und der SPD mit Sicherheit schwer geschadet. ${ }^{99}$ Nach dem Herbst 1971 bemühten sich zudem beide Seiten auffällig intensiv darum, ihren Konflikt nicht mehr so prägnant und öffentlich auszutragen, wie sie das zuvor getan hatten. So wurden die für das jeweils nächste Jahr eingeplanten »Personalverstärkungsmittel « in den Haushaltsentwürfen der Bundesregierung fortan nicht mehr klar und deutlich ausgewiesen, sondern in Einzeletats »sorgfältig versteckt «. ${ }^{100}$

Gleichzeitig entwickelte die ÖTV Forderungskataloge, die sich »durch mangelnde Transparenz« auszeichneten und in ihren finanziellen Konsequenzen daher nur noch schwer zu bewerten waren. ${ }^{101}$ »Sockel«-Beträge passten gut in diese Strategie; dazu kamen Forderungen nach strukturellen Veränderungen in der Lohn- und Gehaltshierarchie oder neu bemessenen

97 | Kurzprotokoll der Vorbesprechung der Gewerkschaftsvertreter zur Sitzung der »Konzertierten Aktion«, 17.9.1971. In: Archiv Ver.di, Bestand Kluncker, 34.

98 | Protokoll der 21. Sitzung der "Konzertierten Aktion«, 17.9.1971. In: Archiv Ver.di, Bestand Kluncker, 34. Schiller sagte hier ausdrücklich, sowohl der Bundeshaushalt als auch die wirtschaftlichen »Orientierungsdaten« seines Ministeriums seien »keine Präjudizierung der Lohnentwicklung im öffentlichen Bereich«.

99 | Vgl. dazu grundlegend: Adam: Konzertierte Aktion, S. 93 f.

100 | Tarifpartner im öffentlichen Dienst vor schwieriger Verhandlungsrunde. In: FAZ, 1.10.1971.

101 | Im öffentlichen Dienst fressen Löhne die Reformen. In: Handelsblatt, 29.11.1971. Vgl. auch: Was die Kontrahenten verschweigen. In: Wirtschaftswoche 25 (1971), H. 46, S. 10-11. 
Zuschlägen. ${ }^{102}$ Arbeitszeitverkürzungen zogen ebenfalls verdeckte Kosten nach sich. In der Tarifrunde für 1972 spielte dieses Thema eine wichtige Rolle: In einem modellhaften Kompromiss einigten sich die Tarifparteien darauf, die 40-Stunden-Woche im Öffentlichen Dienst nach zweijähriger Wartezeit im Herbst 1974 einzuführen. ${ }^{103}$

Die Altersversorgung der Beschäftigten fand sogar noch weniger politische und mediale Aufmerksamkeit als die im Vergleich "handfeste "Frage der Arbeitszeit. Nur Experten registrierten die Aktivitäten der ÖTV auf diesem Feld und auch ihren Erfolg: Seit 1973 übernahmen die öffentlichen Arbeitgeber den Beitrag, den die Beschäftigten bislang für die Zusatzrenten der »Versorgungsanstalt« gezahlt hatten. Das entsprach für den einzelnen Versicherten einer verborgenen Lohn- und Gehaltserhöhung von immerhin fast einem Prozent. ${ }^{104}$ Bei ihrer offiziell erhobenen prozentualen

102 | Als Überblick über diese komplizierte Materie vgl. nur für die Arbeiter im Öffentlichen Dienst: ÖTV-Geschäftsbericht 1972/75, S. 116-121.

103 | Die Gewerkschaft hatte ursprünglich die Einführung zum 1. Januar 1973 gefordert. Vgl. hierzu: Weiß: ÖTV, S. 141-143. Die 42-Stundenwoche war - gemäß der Vereinbarung von 1969 - zum 1. Januar 1972 eingeführt worden. Vgl. auch: ÖTV-Geschäftsbericht 1972/75, S. 107. Beide tariflichen Abmachungen wurden jeweils für die Beamten übernommen. Die Festlegung, 1974 zur 40-Stunden-Woche überzugehen, war im Lager der Arbeitgeber durchaus umstritten: In der VKA etwa gab es Stimmen, die warnten, solche langfristig vereinbaren Zugeständnisse an die Gewerkschaft würden »in den Jahren, in denen sie wirklich wirksam werden, nicht honoriert" (Niederschrift über die außerordentliche Mitgliederversammlung und Hauptausschußsitzung der VKA, 7./8.1.1972. In: BArch Koblenz, B 376, 45). Der Ablauf der Tarifrunde für 1974 (siehe dazu weiter unten) bewies, wie berechtigt diese Warnung war.

104 | Vgl. zu den Details das Gutachten der »Treuarbeit«, einer Wirtschaftsprüfungsgesellschaft. In: VerBT, Drucksache 7/5569 (6.7.1976), hier: S. 62. Die Übernahme der Restbeiträge erfolgte in zwei Stufen zum 1. Juli 1972 (zu 50 Prozent) und vollständig dann zum 1. Juli 1973. In den Verhandlungen über diese Tarifreform, die bereits seit Herbst 1970 liefen, verlangte die ÖTV sogar, die Arbeitgeber sollten für die Arbeiter und Angestellten im Öffentlichen Dienst auch noch die Beiträge zur gesetzlichen Rentenversicherung übernehmen (Rede von Heinz Kluncker bei der Eröffnung der Tarifverhandlungen, 10.11.1970. In: Archiv Ver.di, Bestand Kluncker, 12). Wie ernst gemeint dies war, muss offenbleiben. Verhandlungen darüber hat es nicht gegeben. Ein entsprechender Tarifvertrag hätte ein Grundprinzip der gesetzlichen Rentenversicherung - die Teilung der Beiträge 
Forderung, die einen Dissens mit dem Wirtschaftsminister am deutlichsten dokumentierte, hielt sich die Gewerkschaft für das Jahr 1973 hingegen so stark zurück, dass die Arbeitgeber diese Zahl (plus sechs Prozent) gleich bei den ersten Beratungen akzeptierten. Die ÖTV war davon »überrascht", d.h. sie hatte sich verkalkuliert. Im Nachhinein sagte Heinz Kluncker zu der niedrig angesetzten Zahl sogar öffentlich: »Das scheint ein Fehler gewesen zu sein. « 105

Die nach wie vor bestehende politische Nähe von Partei und Gewerkschaft hat 1972 und 1973 offensichtlich so etwas wie eine Verabredung gestiftet, Eskalationen möglichst zu vermeiden. Auch der spektakuläre Rücktritt von Karl Schiller von seinen beiden Ministerposten im Sommer 1972 im Streit um die bundesdeutsche Währungspolitik half dabei, weil nun der am stärksten sendungsbewusste »Globalsteuerer« im Kabinett fehlte. Der neue Wirtschaftsminister Hans Friderichs von der FDP hielt als Liberaler nicht sonderlich viel von einer dauerhaft aktiv lenkenden Rolle des Staates im wirtschaftlichen Geschehen und blieb zudem eine politisch eher blasse Figur; Helmut Schmidt als Finanzminister vermied öffentliche Interventionen in die Tarifrunden für die Arbeiter und Angestellten des Staates. ${ }^{106}$

Der Grundkonflikt aber bestand unverändert fort: Die Bundesregierung blickte zunehmend besorgt und ratlos auf die weiter steigenden Teuerungsraten sowie auf die deutlich anwachsenden Staatsschulden; die ÖTV beharrte auf uneingeschränkter Tarifautonomie auch für die Arbeiter und Angestellten des Staates. Damit blieb das Verhältnis der Organisation zur SPD-Spitze problematisch. Eine tagespolitische Episode machte den Dissens im Herbst 1972 sehr deutlich: Durch wiederholten Protest zwang Heinz Kluncker im November den SPD-Vorstand, öffentlich den eigenen Parteisprecher Jochen Schulz bloßzustellen. Schulz hatte den Gewerkschaf-

zwischen Arbeitgeber und Arbeitnehmer - in Frage gestellt. Zu scharfen Protesten der privaten Arbeitgeber gegen die Forderung vgl.: Arbeitgeber fürchten ÖTV-Signale. In: Handelsblatt, 12.11.1970; Verbeamten? In: StZ, 12.11.1970.

105 | Kluncker: Lohnforderung garantiert nur Status quo. In: Handelsblatt, 18.1.1973. Wie oben schon erwähnt wurde, stimmten die Arbeitgeber dem Prozentsatz taktisch gezielt zu, um einen reduzierten Sockelbetrag aushandeln zu können. Siehe dazu weiter unten in diesem Kapitel.

106 | Vgl.: Weiß: ÖTV, S. 151 f. Zu Schillers Rücktritt vgl. knapp zusammenfassend: Wolfrum: Demokratie, S. 322; Alecke: Geldpolitik, S. 95. 
ten kurz nach dem Sieg der Partei bei der Bundestagswahl in einem Presseartikel »das Recht auf lautstarke Forderungen an diesen Staat und damit an uns alle« abgesprochen. Die Bundesregierung stehe »für das Volk insgesamt « und habe deshalb die Aufgabe, Ansprüche zurückzuweisen, die sie für falsch halte. Die ÖTV und ihr Vorsitzender wurden dabei ausdrücklich genannt. ${ }^{107}$

Kluncker fand diese Sicht der Dinge unerhört: »Herr Schulz macht das Recht einer Gewerkschaft auf Forderungen davon abhängig, daß diese Forderungen von der Regierung dieses Staates gutgeheißen werden. Eine solche Auffassung ist bisher nur in totalitären Staaten von der Staatspartei gegenüber der Staatsgewerkschaft vertreten worden.« Beschwichtigungen, Schulz habe nur seine persönliche Meinung publiziert, akzeptierte der ÖTV-Chef nicht: „Es handelt sich hier um einen Konflikt der SPD mit dem ÖTV-Hauptvorstand, der nicht gesprächsweise unter Genossen beizulegen ist." Erst eine offizielle Begegnung von Kluncker und Helmut Schmidt, dem stellvertretenden Parteivorsitzenden, bei der Schmidt erklärte, der Parteisprecher habe sich leider »im Ton vergriffen«, stiftete oberflächlich wieder Frieden. ${ }^{108}$

Auch der Streit um das 13. Monatsgehalt, in dem Regierung und Gewerkschaft im Herbst 1973 bei konkreten Tarifverhandlungen öffentlich wieder recht deutlich aneinandergerieten, war daher nur ein Vorgeplänkel für die heftige Auseinandersetzung, die fast unmittelbar danach begann. Mit einer weiteren Verschärfung der wirtschaftlichen Probleme brach das wohl ohnehin eher informelle Stillhalteabkommen zusammen, das im Herbst 1971 entstanden war. Es folgte mit einem bundesweiten Arbeitskampf der ÖTV im Frühjahr 1974 ein tarifpolitischer Streit, der lange nachwirken sollte.

107 | Jochen Schulz: Auf dem Teppich bleiben! In: SPD-Pressedienst 72/228, 28.11.1972.

108 | In der Reihenfolge der Zitate: Heinz Kluncker an den SPD-Parteivorstand, 29.11.1972; Heinz Kluncker an Holger Börner, 30.11.1972 (bei diesem Dokument handelt es sich um ein Telegramm; die Rechtschreibung wurde korrigiert). Beide in: AdsD, Depositum Kluncker, Stehordner 74. Zu dem Treffen Kluncker Schmidt vgl.: Presseerklärung der ÖTV, 4.12.1972. In: ebd. Zur öffentlichen Wahrnehmung der Affäre vgl. etwa: ÖTV-Chef kontert SPD-Sprecher. In: StZ, 1.12.1972; Die Mahnung, auf dem Teppich zu bleiben, erregt Gewerkschafter. In: Die Welt, 1.12.1972. 


\section{Ein gewerkschaftlicher Sieg zu viel? Der Streik im Öffentlichen Dienst im Frühjahr 1974}

\section{Der Bundeskanzler als Tarifpolitiker: Die Ziele und Fehler Willy Brandts in der Tarifrunde 1973/74}

Die wesentlichen Tatsachen sind wohlbekannt: Der Bundeskanzler erklärte im Winter 1973/74 mehrfach öffentlich, die nächste Lohn- und Gehaltserhöhung für den Öffentlichen Dienst müsse auf jeden Fall unter zehn Prozent liegen. Jedes zweistellige Ergebnis gefährde die öffentlichen Haushalte und die wirtschaftliche Stabilität der Bundesrepublik. Die ÖTV, die ein Plus von 15 Prozent sowie eine Mindestzahlung von 185 DM forderte, widersetzte sich. Langwierige Verhandlungen scheiterten; im Februar 1974 kam es zu einem bundesweiten Streik. Nach drei Tagen akzeptierten die Arbeitgeber in neuen Verhandlungen Einkommensverbesserungen von elf Prozent und einen Mindestbetrag von 170 DM. Durchschnittlich ergab sich so ein Plus von 12,1 Prozent; für besonders schlecht bezahlte staatliche Bedienstete machte der Lohnzuschlag dank der sozial ausgleichenden Komponente sogar bis zu 17 Prozent aus. ${ }^{109}$ Auch die Bundesregierung stimmte dem Abschluss zu, und damit beschädigte dieser Tarifvertrag nachhaltig das Renommee Willy Brandts. Gleichzeitig empörten sich Politiker aller Couleur und fast die gesamte bundesdeutsche Presse über die ÖTV, die sich angeblich rücksichtslos und unverantwortlich verhalten habe.

Diese Auseinandersetzung, die selbst in jenen Überblicksdarstellungen der bundesdeutschen Geschichte erwähnt wird, die sich ansonsten kaum oder nicht für die Gewerkschaften interessieren, ist in einer Fülle von Quellen dokumentiert. Akten der ÖTV und der Bundesregierung liegen ebenso vor wie eine fast unüberschaubare große Zahl von Presseberichten und Kommentaren. In den Erinnerungen zahlreicher Politiker, die da-

109 | So Klunckers Angaben in: Wortprotokoll der 10. Sitzung des Hauptvorstands [der ÖTV], 3./4.10.1974. In: AdsD, ÖTV, 5/ÖTVB130038. Die Bundesregierung berechnete die durchschnittliche Lohn- und Gehaltsverbesserung mit 12,24 Prozent (BMdI an den Präsidenten des Deutschen Bundestags, 14.3.1974. In: BArch Koblenz, B 106, 58593). Der Mindestbetrag brachte wohl etwas mehr als 40 Prozent der Beschäftigten im Tarifbereich des Öffentlichen Dienstes keine Vorteile, d. h. für sie kamen die elf Prozent zum Zuge. Die Angabe nach: Die Basis kritisiert den Tarifabschluss. In: StZ, 20.2.1974. 
mals mehr oder weniger direkt beteiligt waren, finden sich rückblickende Stellungnahmen und Deutungen; auch Journalisten sind seit 1974 vielfach auf diesen Streik und seine Resultate zurückgekommen. Insofern wäre es leicht, im Folgenden weit auszuholen und sehr genau ins Detail zu gehen.

Um den Rahmen dieses Buches nicht zu sprengen, muss jedoch ein pointierteres Vorgehen gewählt werden. ${ }^{110}$ Die Darstellung wird sich auf drei zentral bedeutsame Aspekte konzentrieren: Erstens soll untersucht werden, warum Willy Brandt als Bundeskanzler im Frühjahr 1974 den offenen Konflikt mit der ÖTV gesucht hat. Nichts am Verhalten der ÖTV in dieser Konfrontation war überraschend. Die Gewerkschaft tat genau das, was sie 1971 und 1972 sowie schon in früheren Jahren verlässlich getan hatte, wenn Politiker versuchten, präzise Vorgaben für die Tarifverhandlungen für den Öffentlichen Dienst zu machen: Sie protestierte, pochte auf die Tarifautonomie und wehrte sich mit all ihrer Kraft.

Warum also zog der Kanzler in eine Auseinandersetzung, die nur zu einer Eskalation führen konnte? Und: Warum riskierte er einen Streik, obwohl die schwache Position der Gemeinden bei Arbeitsniederlegungen von Müllmännern, Busfahrern oder Arbeitern in Elektrizitätswerken jedem bekannt war, der auch nur rudimentär über die Beziehungen von ÖTV und öffentlichen Arbeitgebern Bescheid wusste? Diese Fragen stellen sich umso dringlicher, als Brandt - wie gleich gezeigt wird - mehrfach von kompetenter Seite davor gewarnt wurde, sich so eindeutig als Opponent der ÖTV $\mathrm{zu}$ positionieren.

Zweitens soll exemplarisch dargestellt werden, was es konkret bedeutet, wenn eine Gewerkschaft zum Streik aufruft und einen umfassenden Arbeitskampf organisiert. Es handelt sich dabei nämlich - besonders bei einem bundesweiten Streik - um einen organisatorischen Kraftakt, der alle Ressourcen des Verbandes hart strapaziert und sein hauptamtliches Personal enorm belastet. Zudem erfordert ein Streik Aktivitäten auch der »einfachen « Gewerkschaftsmitglieder, die in ihrer Mehrheit ansonsten nur sporadisch in »ihrer" Organisation konkret mitarbeiten. Es entsteht ein nicht-alltäglicher Zustand (zumindest in einem Land wie der Bundesrepublik mit ihren vorwiegend friedlichen Arbeitsbeziehungen), der langwierig eingeübte Rollenverteilungen zwischen Führung und Basis in Frage stellt.

110 | Eine ausführliche Darstellung des Ablaufs der Ereignisse liegt ohnehin bereits vor. Vgl.: Weiß: ÖTV, S. 164-181. 
In diesem Zusammenhang wird zudem untersucht, was die drei Tage dauernden Arbeitsniederlegungen im Öffentlichen Dienst im Februar 1974 für die bundesdeutsche Gesellschaft und die Bürger bedeuteten. Handelte es sich tatsächlich um einen Streik, der »rücksichtslos « geführt wurde und das öffentliche Leben »lahmlegte«? Kann man wirklich von »äußerst wirksamen und unpopulären Streikaktionen « sprechen. ${ }^{111}$ Oder präsentiert die historische Erinnerung mit solchen Vokabeln einen Mythos, der sich bei einer nüchternen Prüfung verflüchtigt?

Drittens wird geprüft, ob der Tarifvertrag, den die ÖTV mit ihrem Streik durchsetzte, wirklich so eindeutig als wirtschaftlich verfehlt bewertet werden kann, wie Politik und Medien es meinten. Dieses rundum negative zeitgenössische Urteil ist ohne Abstriche Teil der allgemeinen historischen Erinnerung geworden und wird auch in Überblicksdarstellungen zur Geschichte der Bundesrepublik aufgegriffen. War der Abschluss in der Tat so »überhöht" und ökonomisch unsinnig, dass man von einer »unverantwortlichen Lohnerhöhung « sprechen muss, die den Inflationsprozess weiter anheizte? ${ }^{112}$ Stand der wirtschaftspolitische Kurswechsel der Bundesbank, die noch 1974 zu einer Strategie des knappen Geldes überging, wirklich in engem Zusammenhang mit dem Tarifvertrag für den Öffentlichen Dienst, weil die Mitglieder des Direktoriums in ihrer Rolle als »Währungshüter« meinten, der Abschluss habe endgültig ihre bereits älteren Zweifel an der gesamtwirtschaftlichen Vernunft der Gewerkschaften und an der stabilitätspolitischen Verlässlichkeit der Regierung bestätigt? ${ }^{\text {?13 }}$ Mit den Antworten auf diese Fragen soll ein differenziertes Bild dieser wichtigen Tarifauseinandersetzung entstehen, über die bislang sowohl die Zeitgenossen als auch die Historiker fast ausschließend stark pauschalisierend geurteilt haben.

111 | In der Reihenfolge: Klaus Harpprecht: Im Kanzleramt. Tagebuch der Jahre mit Willy Brandt, Reinbek 2000, S. 471; Wolfgang Streeck: Re-Forming Capitalism. Institutional Change in the German Political Economy, Oxford 2009, S. 114 (»a crippling strike«, so lautet die Formulierung); Fritz W. Scharpf: Sozialdemokratische Krisenpolitik in Europa, Frankfurt/Main und New York 1987, S. 167.

112 | Wolfrum: Demokratie: S. 335. Vgl. ähnlich auch: Schanetzky: Ernüchterung, S. 167; Faulenbach: Das sozialdemokratische Jahrzehnt, S. 399.

113 | Scharpf: Krisenpolitik, S. 167. Vgl. ähnlich auch: Streeck: Capitalism, S. 114. 
Sucht man nach den Motiven und Zielen des Bundeskanzlers in der Tarifrunde für den Öffentlichen Dienst für 1974, so ist zunächst zu betonen, wie ungewöhnlich Brandts Vorgehen war: Keiner seiner Amtsvorgänger hatte sich je so offen und massiv mit Kritik an der ÖTV exponiert. Solche Stellungnahmen waren bislang Sache des jeweiligen Innenministers oder auch des Wirtschafts- und Finanzministers gewesen. Die Leiter dieser drei Ressorts blieben im Winter 1973/74 jedoch alle im Hintergrund. Zwar saß Brandt bei den Beratungen in Stuttgart nicht mit am Verhandlungstisch; politisch aber hatte er sich selbst zum wichtigsten Opponenten der Gewerkschaft gemacht. Dieses Engagement ist auch insofern erklärungsbedürttig, als der Kanzler kein Fachmann für ökonomische Fragen war; für Wirtschaftspolitik interessierte er sich nur wenig. ${ }^{114}$

Dennoch setzte der Kanzler mit dem ganzen politischen Gewicht seines Amtes schon in der ersten Phase der Tarifrunde öffentlich und hoch offiziell ein Limit für den Einkommenszuwachs der Staatsbeschäftigten. Im Bundestag erklärte er Ende November 1973, die ÖTV-Forderung, Löhne und Gehälter um 15 Prozent zu erhöhen, könne »nicht verwirklicht werden. Über 10 Prozent, gar 15 Prozent, nachdem soeben erst das 13. Monatsgehalt beschlossen wurde - das läßt sich vernünftigerweise nicht darstellen. $\aleph^{115}$ Damit war die Marke von zehn Prozent in der Welt, die der Kanzler auch in den nachfolgenden Monaten mehrfach bekräftigte: Ein zweistelliger Abschluss verstoße gegen »die Interessen der Allgemeinheit«, weil er die Inflationsrate in vergleichbare Höhen treiben werde. ${ }^{116}$

Nun hatte der Grundgedanke hinter dieser Mahnung seinerzeit - salopp gesagt - bereits einen sehr langen Bart: Seit Ludwig Erhard gehörte das Argument, die wirtschaftliche Stabilität werde gefährdet, wenn der

114 | Das Nachrichtenmagazin Der Spiegel verspottete Brandt damals sogar als »Wirtschaftslaien«. Zit. nach: Gregor Schöllgen: Willy Brandt. Die Biographie, Berlin 2001, S. 198.

115 | Verhandlungen des Deutschen Bundestages. 7. Wahlperiode. Stenographische Berichte, Bd. 85, Bonn 1973, S. 3912.

116 Informationen des SPD-Fraktion im Deutschen Bundestag Nr. 152/74, 12.2.1974. In: AdsD, WBA, Abt. 8, 146. Vgl. auch: Harte Verhandlungen mit der ÖTV. In: FAZ, 9.1.1974; Brandt lehnt zweistellige Forderungen ab. In: StZ, 25.1.1974; Brandt nennt Lohnforderungen im öffentlichen Dienst überzogen. In: Die Welt, 31.1.1974; Wehner schlägt gestaffelte Tariferhöhungen vor. In: FAZ, 2.2.1974; Brandt warnt die Gewerkschaften. In: Weser-Kurier, 4.2.1974. 
Lohnzuwachs im Staatsdienst »zu hoch« ausfalle, zum Standardrepertoire der öffentlichen Arbeitgeber. Da es diesmal direkt vom Bundeskanzler in die Debatte gebracht wurde und Brandt dabei gleich eine konkrete Zahl nannte, wirkte es jedoch gewichtiger als je zuvor. Diese politische Dramatik verdankte sich nicht etwa einem unversehens erwachten persönlichen Interesse des Kanzlers an komplexen volkswirtschaftlichen Zusammenhängen. Brandt reagierte vielmehr auf die besondere ökonomische Situation im Winter 1973/74, die ihm, seinen Ministern und auch dem gesamten Parteivorstand der SPD als höchst gefährlich galt. Anlass dieser Sorgen war die sogenannte Ölkrise, die im Oktober 1973 begann: Wegen stark gedrosselter Fördermengen in den wichtigsten erdölproduzierenden Ländern stieg der Preis für Rohöl innerhalb weniger Wochen um mehr als 70 Prozent. Es folgte eine weitere fast kontinuierliche Verteuerung auf zuvor für undenkbar gehaltene Werte. ${ }^{117}$

Bekanntlich führte dieser gänzlich unerwartete Preissprung zu den vier sonntäglichen »Fahrverboten« im November und Dezember 1973, die den Bundesbürgern eine ungewöhnlich ruhige Adventszeit bescherten. Diese öffentlichkeitswirtsame Aktion, die de facto allerdings eher symbolisch als praktisch bedeutsam war, verbarg eine massive Unsicherheit der Bonner Politiker angesichts der neuen Herausforderung. Beratungen des SPD-Parteivorstandes in diesem Winter dokumentieren eine wachsende Krisenstimmung. Anfang Dezember 1973 warnte Helmut Schmidt seine Genossen, die wirtschaftliche Entwicklung sei fast unkalkulierbar - und damit müsse auch die politische Stabilität der Bundesrepublik als ernsthaft gefährdet gelten. Mitte Januar 1974 forderte der Wirtschaftspolitische Ausschuss des Parteivorstandes, die Bundesregierung solle sich »auf einen nicht unerheblichen Konjunktureinbruch einstellen«. Auch eine Arbeitsgruppe für »Innenpolitische Grundsatzfragen« im Bundeskanzleramt prognostizierte, »daß wegen der Knappheit des Produktionsfaktors Energie das gesamtwirtschaftliche Angebot 1974 rückläufig sein wird«. Gleichzeitig aber werde die Verteuerung des Erdöls (der die anderen Energiepreise folgten)

117 | Vgl. hierzu ausführlich: Jens Hohensee: Der erste Ölpreisschock 1973/74. Die politischen und gesellschaftlichen Auswirkungen der arabischen Erdölpolitik auf die Bundesrepublik Deutschland und Westeuropa, Stuttgart 1996. Als Überblick vgl. auch: Wolfrum: Demokratie, S. 335-340. 
zu einer »weiteren drastischen Erhöhung der Inflationsrate « führen. ${ }^{118}$ Die Anzeichen dafür mehrten sich: Sowohl im Dezember 1973 als auch im Februar 1974 lag das Niveau der allgemeinen Lebenshaltungskosten um fast acht Prozent über dem jeweiligen Vorjahresmonat. Für die Bundesrepublik waren das Rekordzahlen. ${ }^{119}$

Gleichzeitig bekannte sich die SPD unverändert zu den planerischen Konzepten des abgetretenen "Super-Ministers Karl Schiller: Gerade in der Krise sei die Politik aufgerufen, die Wirtschaft zu lenken. Gemeinsam erklärten die drei höchsten Gremien der Partei im Februar 1974 auf einer eigens dafür einberufenen gemeinsamen Sitzung: »Der Staat hat die Verantwortung für das erreichbare Optimum an Preisstabilität und für einen hohen Beschäftigungsstand.« Auch die praktische Schlussfolgerung für die Verhandlungen mit der ÖTV blieb dieser »kleine Parteitag« nicht schuldig: Die Öffentliche Hand brauche aktuell »Geld für beschäftigungssichernde und strukturverbessernde Investitionen«; Zurückhaltung bei Lohn- und Gehaltserhöhungen für die Staatsbediensteten sei deshalb absolut unerlässlich. ${ }^{120}$

Wenn sich der Bundeskanzler in der Tarifrunde für 1974 so ungewöhnlich offen als Gegner der ÖTV exponierte, handelte er also keineswegs isoliert: Mit ihm führte die SPD ihren politisch wichtigsten Mann in eine Auseinandersetzung, die aus Sicht der sozialdemokratischen Führungsgremien über den Erfolg der Bundesregierung und damit auch über die weiteren Aussichten der SPD als Regierungspartei entschied. An verbaler Unterstützung mangelte es dem Kanzler nicht. Bei internen Beratungen

118 | In der Reihenfolge der Zitate: Protokoll der Sitzung des SPD-Parteivorstandes, 7.12.1973. In: BArch Koblenz, N 1369, 1812; Hans-Jürgen Junghans an Willy Brandt, 14.1.1974. In: BArch Koblenz, N 1369, 1813; Vermerk der Arbeitsgruppe »Innenpolitische Grundsatzfragen« über lohnpolitische Aussagen im Jahresgutachten 1973 des Sachverständigenrates, 12.12.1973. In: BArch Koblenz, B 106, 58521.

119 | Im Jahresdurchschnitt 1973 hatte die Teuerungsrate noch 7,1 Prozent betragen. Vgl. Hermann Adam: Wirtschaftspolitik und Regierungssystem der Bundesrepublik Deutschland. Eine Einführung, Opladen 1991, S. 216.

120 | Kommuniqué über die gemeinsame Sitzung von Parteivorstand, Parteirat und Kontrollkommission der SPD, 9.2.1974. In: BArch Koblenz, N 1369, 1813. Ausführlicher entfaltet wird diese Konzeption in: Tietmeyer: Möglichkeiten, S. 218-240. 
bestärkte ihn nicht nur Helmut Schmidt; auch sozialdemokratische Landesregierungschefs wie etwa Hans Koschnik (Bremen) oder Peter Schulz (Hamburg) beteuerten ihre Loyalität. Schmidt, der sich nach seinem Wechsel in das Finanzressort rasch in die neue Rolle als führender Ökonom der Republik gefunden hatte, erläuterte, die steigenden Ölpreise wirkten in der Bundesrepublik wie eine importierte Teuerung. Deshalb sei »binnenwirtschaftliche Zurückhaltung« wichtiger als je zuvor. Peter Schulz riet, einen Arbeitskampf zu riskieren, um die ÖTV dann durch ein Angebot zum Einlenken zu zwingen, das nur den unteren Einkommensgruppen einen Lohnzuwachs von mehr als zehn Prozent bringe. Auch Hans Koschnik plädierte für ein solches gestaffeltes Angebot: Wichtig sei nur, den Durchschnitt der Lohn- und Gehaltserhöhungen unter zehn Prozent zu halten. Die sozialdemokratische Landesregierung von Nordrhein-Westfalen sah das genauso und plädierte ebenfalls für einen harten Kurs: »Ein Arbeitskampf werde die öffentliche Hand nicht umbringen. ${ }^{121}$ Hans Wertz, der Finanzminister des Landes (sowie Mitglied der ÖTV), erklärte öffentlich, ein Überschreiten der Zehn-Prozent-Marke sei ökonomisch »selbstzerstörerisch «. ${ }^{122}$ Mehrfache Beteuerungen von TdL und VKA, man werde auf jeden Fall der Verhandlungslinie der Bundesregierung folgen, kamen hinzu. ${ }^{123}$ Prominente CDU-Politiker wie Gerhard Stoltenberg, Ministerpräsident von SchleswigHolstein, und Kurt Biedenkopf, Generalsekretär der Partei, versicherten, die Christdemokraten stünden in dieser Auseinandersetzung fest an der

121 | Aufzeichnung über die Besprechung des Bundeskanzlers mit den Regierungschefs der Länder, 24.1.1973. In: BArch Koblenz, B 136, 5204. Das zweite Zitat von Finanzminister Hans Wertz (NRW) als Vertreter des Landes. Zur Kritik Koschniks, der auch Präsident des Deutschen Städtetages war, an den ÖTV-Forderungen vgl. auch: 7,5 Prozent nicht tragbar. In: Bremer Nachrichten, 11.1.1974. 122 | Nach dem Scheitern der Tarifverhandlungen wächst die Streikgefahr im öffentlichen Dienst. In: FAZ, 29.1.1974. Zur ÖTV-Mitgliedschaft von Wertz vgl.: Der öffentliche Dienst wartet mit Zahlen auf. In: Weser-Kurier, 5.2.1974.

123 | Vgl. etwa: Nicht mehr als 7,5 Prozent. In: StZ, 12.1.1974; Protokoll über das Ergebnis der Besprechung des Bundeskanzlers mit den Regierungschefs der Länder, 24.1.1974. In: BArch Koblenz, B 106, 58589; Bonn und die Länder wollen gemeinsam handeln. In: FAZ, 26.1.1974; Vorbericht der VKA-Geschäftsstelle für die außerordentliche Mitgliederversammlung, 2.2.1974. In: BArch Koblenz, B 376, 46; Aktenvermerk von BMdI Hans-Dietrich Genscher über den Telefonanruf von OB Arnulf Klett, 6.2.1974. In: AdsD, HSA, 1/HSAA010025. 
Seite des Kanzlers, den sie ansonsten doch lieber schnellstens gestürzt hätten. ${ }^{124}$

Selbst Außenstehende bestürmten Willy Brandt, unnachgiebig zu bleiben. Wichtige industrielle Arbeitgeberverbände wie der BDI und der VDA meldeten sich mit der Mahnung, die Marke von zehn Prozent dürfe keinesfalls überschritten werden; »Gesamtmetall«, die Interessenvertretung der bundesdeutschen Metallindustrie, warnte eindringlich vor einem hohen Sockelbetrag. ${ }^{125}$ Informell »beschworen« angeblich sogar die Vorsitzenden der IG Metall und der IG Chemie den Kanzler, »die Gehälter im öffentlichen Dienst unten zu halten, weil sie es ihren Arbeitern schuldig seien, 2 Prozent mehr herauszuholen « - und dann lasse sich die Inflation kaum noch eindämmen. In den verfügbaren Quellen sind gewerkschaftliche Interventionen dieser höchst ungewöhnlichen Art allerdings nicht nachweisbar. $^{126}$

Brandt scheint sich die Position, Lohnzurückhaltung sei das Gebot der Stunde, allerdings ohnehin stark zu eigen gemacht zu haben. Nach den Aufzeichnungen seines engen politischen Vertrauten Klaus Harpprecht fürchtete der Kanzler, »daß die Mentalität der Deutschen eine Inflationsrate über 10 Prozent nicht ertrage, daß damit die Demokratie als solche in Gefahr gerät «. ${ }^{127}$ Ein anderer Mitarbeiter Brandts notierte verwundert, "wie emotional die Argumentation« des Kanzlers in dieser Sache ausfiel. ${ }^{128}$ Die Weigerung der ÖTV, von ihren Forderungen abzulassen, verstand Brandt zunehmend als eine politische Machtprobe, in der es um nicht we-

124 | Weiß: ÖTV, S. 175.

125 | Telex von BDI und VDA an den Bundeskanzler, 11.2.1974. In: AdsD, HSA, 1/HSAA010025; Gesamtverband der metallindustriellen Arbeitgeberverbände an den Bundeskanzler, 12.2.1974. In: ebd.; Vermerk von Referat D III 1 für den BMdI über den Telefonanruf des Hauptgeschäftsführers des Gesamtverbandes, 11.2.1975. In: BArch Koblenz, B 106, 58589. Die Metallindustriellen argumentierten, ein hoher Sockel werde für die IG Metall zum tarifpolitischen Vorbild werden, und das gefährde die »Lohnruhe« in den Betrieben, weil die besserverdienenden Arbeiter sich dann benachteiligten fühlten. Konkret hielten die Metallarbeitgeber allenfalls einen Sockel von 150 DM noch für tragbar.

126 | Harpprecht: Kanzleramt, S. 472.

127 | Ebd.

128 | Reinhard Wilke: Meine Jahre mit Willy Brandt. Die ganz persönlichen Erinnerungen seines engsten Mitarbeiters, Stuttgart und Leipzig 2010, S. 233. 
niger als um die Zukunft der ganzen Bundesrepublik ging. Dabei betrachtete er Heinz Kluncker offensichtlich als persönlichen Kontrahenten, dem die Weitsicht des politischen Würdenträgers fehle. Anfang Februar 1974 kommentierte der Kanzler den Streit mit der ÖTV in der ihm eigenen, stets etwas wolkigen Sprache vor dem SPD-Parteivorstand mit den Worten: »Bei dieser Auseinandersetzung gehe es auch darum, daß jemand zeigen wolle, daß er letzten Endes mächtiger sei als derjenige, der durch das Mandat der Wähler sein Amt ausübe.« Das Amt des Bundeskanzlers sei jedoch »kein geringeres Mandat als das eines Gewerkschaftskongresses«. Namen wurden nicht genannt - aber das war in dieser Sache auch nicht nötig. ${ }^{129}$

Zwar gab es Sozialdemokraten, die Brandt ausdrücklich warnten, den Tarifstreit mit der ÖTV so stark politisch zu sehen und sich dabei auch noch so eindeutig gegen die Gewerkschaft zu stellen. So erhob Holger Börner, der Bundesgeschäftsführer der Partei, »schwerste Bedenken« gegen die Linie, die der Kanzler in dieser Sache in Übereinstimmung mit dem Parteivorstand und seinen wichtigsten Ministern verfolgte. Es handele sich bei dem Streit mit der ÖTV »um einen normalen Tarifkonflikt«, nicht um einen politischen Show-down mit machtversessenen Gewerkschaftern. Wer die Zehn-Prozent-Marke öffentlich so heftig propagiere, der fördere nur »eine allgemeine Krisenstimmung« und damit die Geschäfte der Opposition, die der SPD wegen der starken Teuerung wirtschaftspolitisches Versagen vorwarf. Börner empfahl dringend, der Kanzler solle sich auf die Position zurückziehen, er habe in der Kontroverse zwischen Gewerkschaft und öffentlichen Arbeitgebern die Verpflichtung, »beiden Seiten gerecht zu werden. Der Bundeskanzler ist keine Tarifpartei, [...] er hat in unserer Demokratie kein Recht zu dekretieren. « ${ }^{130}$

129 | Protokoll über die Sitzung des SPD-Parteivorstandes, 8.2.1974. In: BArch Koblenz, N 1369, 1813. Vgl. auch die Feststellung, Brandt habe den Tarifstreit als einen »Machtkampf mit Kluncker« angesehen, der entscheiden müsse, »wer in diesem Land regiert«. In: Wilke: Jahre, S. 231. Ähnlich auch: Alex Möller: Tatort Politik, München und Zürich 1982, S. 390.

130 | Holger Börner an Willy Brandt, 13.2.1974. In: AdsD, WBA, Abt. 11.3, 32. Auch Hans-Dietrich Genscher will Brandt gewarnt haben: Wenn der Kanzler öffentlich eine Grenze für eine »tragbare« Lohnerhöhung nenne, werde deren Überschreitung für die ÖTV zur »Prestigefrage« (Hans-Dietrich Genscher: Erinnerungen, Berlin 1995, S. 119 f.). 
Ähnlich eindringlich warnte Hans-Jochen Vogel, als langjähriger Münchner Oberbürgermeister einer der profiliertesten und erfahrensten Kommunalpolitiker der Partei, Brandt sei dabei, sich in den Tarifverhandlungen für den Öffentlichen Dienst »in eine ausweglose Situation manövrieren zu lassen«. Wenn die ÖTV einen Streik organisiere, seien die Arbeitgeber schon nach kurzer Zeit »zum Nachgeben gezwungen. Ich befürchte, daß damit auch ein Prestigeverlust für den Bundeskanzler verbunden wäre. ${ }^{131}$

Brandt aber ignorierte nicht nur diese Einwände - er übersah auch die Anzeichen dafür, dass die SPD ihm in seiner neuen Rolle als Vorkämpfer der öffentlichen Sparsamkeit keineswegs so geschlossen folgte, wie es die Voten der Parteigremien suggerierten. Rudi Arndt etwa, der Frankfurter Oberbürgermeister und einer der bekanntesten "Linken« in der Sozialdemokratie, erklärte öffentlich, die Bundesregierung agiere tarifpolitisch mit ihrem Kurs "viel mehr [als ein] Interessenvertreter der Unternehmer als der arbeitenden Volksmassen«. Willi Reiss, Stadtverordnetenvorsteher in der Mainmetropole und Vorsitzender der Frankfurter SPD, nannte das ZehnProzent-Limit »inakzeptabel ${ }^{132}$ Konkret planten die für die Frankfurter Finanzen zuständigen Sozialdemokraten für 1974 im Etat der Stadt eine Lohn- und Gehaltserhöhung von zwölf Prozent. ${ }^{133}$

Allerdings waren es nicht nur dezidiert linke Kräfte innerhalb der gerade seinerzeit stark von Flügelkämpfen geprägten Sozialdemokratie, die so dachten. Die SPD in Rheinland-Pfalz etwa gehörte keineswegs zu den besonders »roten« Parteigliederungen. Dennoch wandten sich die Mitglieder der Mainzer Landtagsfraktion einmütig mit der Bitte an den Parteivorsitzenden, eine Konfrontation mit der ÖTV zu vermeiden: Wegen der galoppierenden Teuerung sei es unsozial, auf einer einstelligen Lohn- und Gehaltserhöhung zu beharren. ${ }^{134}$

131 | Telex von Hans-Jochen Vogel an Willy Brandt, 23.1.1974. In: AdsD, HAS, 1/HSAA010025. Die Rechtschreibung im Zitat wurde korrigiert. Vogel war zu diesem Zeitpunkt Bundesminister für Raumordnung, Bauwesen und Städtebau.

132 | Arndt übt Kritik an Bonn. In: FR, 14.1.1974.

133 | Weiß: ÖTV, S. 174.

134 | SPD-Landtagsfraktion Rheinland-Pfalz an Willy Brandt, 24.1.1974. In: AdsD, WBA, Abt. 8, 33. 
Als die Auseinandersetzung mit der ÖTV tatsächlich bis zum Streik eskalierte, verlor Willy Brandt daher rasch gerade seine sozialdemokratischen Unterstützer. Insbesondere Politiker, die für die Geschicke der bundesdeutschen Großstädte zuständig waren, gingen dem Kanzler einer nach dem anderen von der Fahne. Der Hamburger Erste Bürgermeister Peter Schulz etwa, der kurz zuvor noch ausdrücklich zu einer harten Haltung geraten hatte, wechselte bereits die Seiten, als die ÖTV noch das Ergebnis ihrer Urabstimmung auszählte. Der Kanzler, so teilte Schulz nun mit, müsse ein neues, besseres Angebot machen, weil es durch den Arbeitskampf nur schwerer werde, »einen für die Arbeitgeber tragbaren Abschluß« zu erreichen. Vor allem fürchtete der Hanseat auf kommunaler Ebene »Solidarisierungen « von Sozialdemokraten mit den streikenden Arbeitern und Angestellten im Öffentlichen Dienst. ${ }^{135}$

Dafür, wie so etwas aussehen konnte, existierte zu diesem Zeitpunkt schon ein Exempel aus dem Stadtstaat Bremen: Just an dem Tag, an dem die Abstimmung der ÖTV-Mitglieder begann, vereinbarten sowohl die Stadtwerke Bremerhaven als auch die Verkehrsgesellschaft der Kommune an der Wesermündung für ihre Beschäftigten mit der Gewerkschaft einen neuen Tarifvertrag, der eine lineare Lohnerhöhung von zwölf Prozent, einen Mindestbetrag von 185 DM sowie ein pauschales Urlaubsgeld von 250 DM umfasste. Zwar handelte es sich dabei um Haustarifverträge, die formal mit den zentralen Verhandlungen für Bund, Länder und Gemeinden nichts zu tun hatten. Dennoch sandte dieser doppelte Abschluss in der Bremer Teilstadt ein eindeutiges Signal aus: Beide Unternehmen gehörten der Stadt; ihre Leitung und Lenkung lag wegen der jahrzehntelangen Alleinherrschaft der SPD in Bremen und Bremerhaven fest in den Händen von Sozialdemokraten. Hans Koschnik hatte sich als Regierungschef des Bundeslandes Bremen kurz zuvor noch entschieden dafür stark gemacht, dem Öffentlichen Dienst nur eine Lohn- und Gehaltserhöhung unter zehn Prozent zu gewähren - nun aber reichte seine politische Kraft offensicht-

135 | Bürgermeister Peter Schulz an Bundeskanzler Willy Brandt, 9.2.1974. In: AdsD, HSA, 1/HSAA010025. Das Ergebnis der Streik-Urabstimmung wurde am 10. Februar bekannt gegeben. 
lich noch nicht einmal aus, um die Führungsmannschaft rein städtischer Unternehmen im Streit mit der ÖTV auf Kurs zu halten. ${ }^{136}$

Helmut Schmidt als Bundesfinanzminister fiel hingegen in der letzten Phase der Tarifstreitigkeiten im Februar 1974 vor allem durch öffentliches Schweigen auf. Willy Brandt vermisste gerade seine politische Unterstützung, als der Streik am 11. Februar begann. Selbst noch im Rückblick notierte er pikiert: $\gg$ Der Finanzminister teilte diese Haltung [die Meinung, die Zehn-Prozent-Marke dürfe nicht überschritten werden - K.C. F.], hielt sich dann aber eher zurück und entschwand zu einer Konferenz nach Washington. ${ }^{137}$ Horst Ehmke, seinerzeit Bundesforschungsminister und als ehemaliger Chef des Kanzleramtes Willy Brandt eng verbunden, urteilte ähnlich: "Der `starke Mann< im Kabinett überließ Brandt die Niederlage. «" ${ }^{138}$

Den entscheidenden Stoß erhielt die Widerstandskraft des Kanzlers aber von dem Parteilinken Rudi Arndt. Nach Brandts Darstellung ließ sich der Frankfurter Oberbürgermeister bereits am ersten Streiktag in einer dramatischen Aktion während einer laufenden Kabinettssitzung telefonisch mit dem Regierungschef verbinden (»was so noch nie passiert war«), um offiziell mitzuteilen, die Stadt Frankfurt werde sich separat mit der ÖTV einigen, wenn die zentralen Verhandlungen nicht zügig zu einem allgemein gültigen Tarifvertrag führten. Die Gewerkschaft drohe damit, den Arbeitskampf in Frankfurt auch auf die Müllabfuhr auszuweiten, und

136 | Vgl. zu dem Abschluss: In Bremerhaven zahlen die Stadtwerke 12 Prozent. In: Weser-Kurier, 8.12.1974; Die Streikbereitschaft im öffentlichen Dienst wächst. In: FAZ, 8.2.1974; Verantwortungslos. In: ebd. Besonderheiten der Bremer Verfassung haben die Eigenwilligkeit der Bremerhavener Betriebe gefördert: Bremerhaven ist zwar Teil des Bundeslandes Bremen, bildet aber eine eigenständige Kommune mit eigenem Oberbürgermeister und eigenen kommunalen Organen. Zudem besitzt der Präsident des Bremer Senats (der als Ministerpräsident des Landes fungiert) keine politische Richtlinienkompetenz. Vgl. zu den Details etwa: Volker Kröning et al. (Hrsg.): Handbuch der Bremischen Verfassung, Baden-Baden 1991.

137 | Willy Brandt: Erinnerungen, erw. Ausgabe, Frankfurt/Main und Berlin 1992, S. 312. Schmidt nahm während der Streiktage an einer internationalen Konferenz zu energiepolitischen Fragen in Washington, D.C., teil.

138 | Horst Ehmke: Mittendrin. Von der Großen Koalition zur Deutschen Einheit, Reinbek 1996, S. 231. Ähnlich auch die Wertung in: Gunter Hofmann: Willy Brandt und Helmut Schmidt. Geschichte einer schwierigen Freundschaft, München 2012, S. $160 \mathrm{f}$. 
das könne der Magistrat nicht zulassen. Verbittert schrieb Brandt in seinen Memoiren: »Die Vorstellung von nicht abgeholten Mülltonnen schreckte die ängstlichen Stadtväter noch mehr als die Aussicht auf stillstehende Verkehrsmittel.«139 Am nächsten Tag übernahm das städtische Verkehrsunternehmen von Bremen den Tarifvertrag der kommunalen Betriebe in Bremerhaven, der den Forderungen der ÖTV sehr weit entgegenkam - und dieser Beschluss fiel ganz direkt in die Zuständigkeit Hans Koschniks. ${ }^{140}$

Zwar gab es für Brandt noch einmal politische Schützenhilfe: Am dritten Streiktag appellierte Bundespräsident Gustav Heinemann in einem offiziellen Schreiben »in dieser kritischen Stunde " an den Kanzler, "sich in Ihrer Verantwortung für das Gesamtwohl durch nichts zu Entscheidungen drängen zu lassen, welche die Ihnen einsichtigen Möglichkeiten der Bundesrepublik Deutschland, ihrer Länder und Gemeinden überschreiten«. Brandt machte diese Intervention umgehend öffentlich. ${ }^{141}$ Börners Warnung vor einer politischen Eskalation der Tarifverhandlungen mit der ÖTV wurde bei den wichtigsten Mitgliedern der sozialdemokratischen Führung offensichtlich auch zu diesem Zeitpunkt noch nicht ernst genommen. Heinemann dürfte kaum auf eigene Faust gehandelt haben - dafür war seine Aktion zu ungewöhnlich, denn mit ihr griff ein amtierender Präsident zum ersten Mal in der Geschichte der Bundesrepublik in eine laufende Tarifauseinandersetzung ein.

Die von Brandt erhoffte Wende blieb jedoch aus. In den Großstädten intensivierte die ÖTV den Arbeitskampf, und sie erklärte zudem, nun unbefristet zu streiken. Nach dem Vorbild Rudi Arndts drohten daraufhin zahlreiche Bürgermeister gegenüber der VKA mit einem Tarifabschluss auf eigene Faust. ${ }^{142}$ Bei den zentralen Verhandlungen in Stuttgart spielte die Zehn-Prozent-Marke daher schon keine Rolle mehr, als Gustav Hei-

139 | Brandt: Erinnerungen, S. 313.

140 | Weiß: ÖTV, S. 177. Koschnik war Mitglied des Aufsichtsrates der Bremer Straßenbahn.

141 | Bundespräsident Gustav Heinemann an Bundeskanzler Willy Brandt, 13.2.1974. In: BArch Koblenz, B 136, 5205. Zu Brandts öffentlichen Mitteilungen über das Schreiben vgl.: Streik bis zur Urabstimmung ausgesetzt. In: FAZ, 14.2.1974. 142 | Vgl. etwa: Streikbeschluss auf "unbestimmte Zeit« nach dem zweiten, erhöhten Angebot. In: FAZ, 13.2.1974; Aufzeichnung über die Besprechung des Bundeskanzlers mit den Regierungschefs der Länder und der Vertreter der öffentlichen Arbeitgeber, 13.2.1974. In: BArch Koblenz, B 136, 5204. 
nemann seinen Brief schrieb. Sogar ein Versuch der Bundesregierung, im Scheitern wenigstens noch einen Teilerfolg durchzusetzen, blieb erfolglos: Der von Brandt ins Spiel gebrachte Vorschlag, eine Kappungsgrenze in den Tarifvertrag einzufügen, die den gutverdienenden Angestellten etwas weniger Geld eingebracht hätte, scheiterte schon an internen Streitigkeiten der Arbeitgeber. Unter dem Druck der ÖTV, die erklärte, sie werde den Streik nur beenden, wenn Bund, Länder und Gemeinden gleichlautende Tarifverträge unterzeichneten, kam am frühen Abend des 13. Februar 1974 nach insgesamt 17 Verhandlungsstunden die oben schon knapp umrissene Einigung auf elf Prozent und den Mindestbetrag von 170 DM zustande. Heinz Kluncker nannte das einen »fairen Kompromiss«. Mit diesem Urteil stand er jedoch allein auf weiter Flur: Allgemein galt der Tarifvertrag als eine schwere politische Niederlage des Kanzlers. ${ }^{143}$

Willy Brandt teilte diese Sicht. Zwar meinte er auch rückblickend, er habe "den Sachverstand « und die "ökonomische Einsicht« auf seiner Seite gehabt; zugleich aber musste er einen »Ansehensverlust« für seine Person eingestehen, der »doch noch dramatischer aus[fiel] als erwartet « ${ }^{144}$ Tatsächlich beförderte der Stuttgarter Abschluss eine schon seit einiger Zeit laufende öffentliche Debatte über die angebliche Führungsschwäche

143 | Klunckers Urteil zit. nach: Streik bis zur Urabstimmung ausgesetzt. In: FAZ, 14.2.1974. Mehr zu den öffentlichen Reaktionen auf die Einigung noch unten in diesem Kapitel. Details zum Streit um die Kappungsgrenze (die Bundesregierung schlug dafür verschiedene Summen zwischen 300 und 400 DM vor) finden sich etwa in: Niederschrift über die 4. Mitgliederversammlung der TdL, 11. bis 13.2.1974. In: BArch Koblenz, B 106, 58590; Niederschrift über die außerordentliche Mitgliederversammlung und Hauptausschußsitzung der VKA, 11./12./13.2.1974. In: BArch Koblenz, B 376, 46; Ergebnisprotokoll der Ministerbesprechung im Bundeskanzleramt, 12.2.1974. In: BArch Koblenz, B 136, 5204; Aufzeichnung über die Besprechung des Bundeskanzlers mit den Regierungschefs der Länder und den Vertretern der öffentlichen Arbeitgeber, 13.2.1974. In: ebd. Die Kappungsgrenze entfiel aus zwei Gründen: Zum einen ließ sich damit bei Arbeitern und Angestellten nur vergleichsweise wenig Geld einsparen; zum anderen aber sperrten sich CDU und CSU gegen eine Absprache, einen Tarifvertrag mit einer Kappungsgrenze auf die Beamten zu übertragen (was finanziell wirklich nennenswerte Einsparungen erbracht hätte). Vgl. dazu auch: Merten: Problematik, S. 379 f.

144 | Brandt: Erinnerungen, S. $312 \mathrm{f}$. 
des Kanzlers. In persönlichen Aufzeichnungen aus dem Jahr 1974 klagte Brandt über die »unmögliche Haltung Klunckers« und vermerkte, er habe nach der Einigung mit der ÖTV »ernsthaft überlegt«, ob er von seinem Regierungsamt zurücktreten solle. ${ }^{145}$

Letztlich fühlte sich Brandt vor allem von seinen eigenen Genossen allein gelassen und verraten. ${ }^{146}$ Im Februar 1974 erklärte er in einem vertraulichen Hintergrundgespräch mit Journalisten, der »überhöhte« Abschluss sei das logische Resultat der Tatsache, dass in den Großstädten »die Freunde ein- und derselben Gewerkschaft auf der Seite der Fordernden und der Seite der Gebenden sitzen, woran ich nichts ändern kann«. Positiv sei das Resultat der Tarifrunde für 1974 allenfalls insofern, als die ÖTV wohl noch mehr durchgesetzt hätte, "wenn ich nicht relativ hart gegengehalten hätte«. Allerdings könne man als Politiker in Deutschland wegen der Ordnungsliebe der Bundesbürger keinen wirklich gravierenden Streik riskieren: „Es gibt Länder, die mit wesentlicheren Arbeitskämpfen, auch im öffentlichen Dienst, fertig werden, und nicht gleich meinen, der Staat gehe unter.«Brandts Schlussfolgerung aus den Erfahrungen, die er mit der ÖTV gemacht hatte, lautete kurz und knapp: "Man muß den Gemeinden das Recht nehmen, Tarifverträge abzuschließen. ${ }^{147}$

Der »Groll« des Kanzlers, den Klaus Harpprecht unmittelbar nach dem Streik registriert hatte, war offensichtlich auch fast vier Wochen später noch nicht verflogen. So entstand die verwegene Idee, die Kommunen von den Tarifverhandlungen für den Öffentlichen Dienst auszuschließen. Von der gewerkschaftlichen Macht der ÖTV wäre nicht viel übrig geblieben,

145 | Willy Brandt: Notizen zum Fall Guillaume. In: ders.: Berliner Ausgabe. Bd. 7, S. 508-537, hier: S. 530. In Brandts Memoiren heißt es noch unversöhnlicher, die "Selbstachtung« hätte ihm im Februar 1974 den Rücktritt "gebieten müssen« (Brandt: Erinnerungen, S. 313).

146 | Egon Bahr: »Das musst du erzählen.« Erinnerungen an Willy Brandt, Berlin 2013, S. $156 \mathrm{f}$.

147 | Auszug aus dem Informationsgespräch des Bundeskanzlers mit Redakteuren der »Zeit«, 22.2.1974. In: BArch Koblenz, B 136, 5204. Schon am 13. Februar hatte Brandt intern angekündigt: »Für die Zukunft behalte sich der Bund vor, ein anderes Verfahren der Zusammenarbeit mit den öffentlichen Arbeitgebern zu praktizieren.« (Aufzeichnung über die Besprechung des Bundeskanzlers mit den Regierungschefs der Länder und den Vertretern der öffentlichen Arbeitgeber, 13.2.1974. In: BArch Koblenz, B 136, 5204). 
wenn sich Brandt mit diesem Plan durchgesetzt hätte. ${ }^{148}$ Für politische Gedankenspiele unter der Überschrift »Was wäre gewesen, wenn ...» bietet der ÖTV-Streik von 1974 also reichen Stoff: Die Vorstellung, der erste sozialdemokratische Bundeskanzler hätte im offenen Streit mit der ÖTV auf sein Amt verzichtet, lässt sich dabei gegen die Möglichkeit stellen, Brandt könnte als der Politiker erinnert werden, der der zweitgrößten DGB-Gewerkschaft das Rückgrat brach.

Beide Varianten zeigen noch einmal deutlich das enorme politische Gewicht der Tarifrunde von 1974. Brandts Deutung, es habe sich um einen Konflikt zwischen ökonomischem Fachwissen und politischem Verantwortungsgefühl auf der einen Seite und selbstsüchtigem Unverstand auf der anderen Seite gehandelt, die viele zeitgenössische und spätere Kommentatoren übernommen haben, verfehlt allerdings den Kern der Sache und damit auch die wahre historische Bedeutung des Streiks: Mit dem Tarifpolitiker Willy Brandt scheiterte im Februar 1974 vielmehr das sozialdemokratische Konzept der "Globalsteuerung«, das im Zentrum des SPDReformprogramms für die 1970er Jahre stand.

Die ÖTV war dabei allerdings nur bei oberflächlicher Betrachtung der Kontrahent, der diese Niederlage verursachte. Eher sollte man die Auseinandersetzungen um die Tarifeinigung für den Öffentlichen Dienst als das Exempel verstehen, an dem unübersehbar deutlich wurde, wie grundlegend dieses Konzept mit den politischen und wirtschaftlichen Realitäten kollidierte. Mit ihren fast schon verzweifelten Versuchen, die selbst dekretierte Zehn-Prozent-Marke lohnpolitisch durchzusetzen, wollte die SPD-geführte Bundesregierung wenigstens ein Kernelement ihrer wirtschaftspolitischen Reformstrategie bewahren, die ansonsten kaum noch überzeugen konnte. Wie schon die Währungsspekulationen der frühen 1970er Jahre so bewies die von der OPEC gesteuerte Verteuerung des Erdöls einmal mehr, wie wenig sich die Bundesrepublik vor außenwirtschaftlichen Einflüssen schützen konnte. Gerade die globale Dimension des Wirtschaftslebens aber entzog sich der nationalstaatlich gedachten »Globalsteuerung«: Der scheinbar so mächtige moderne Interventionsstaat erwies sich in diesen Situationen als Spielball wirtschaftlicher Kräfte, die er nicht kontrollieren konnte. Die durchaus berechtigte Furcht vor einer drohenden Rezession

148 | Harpprecht: Kanzleramt, S. 473. Zu der Frage, was aus Brandts tarifpolitischem Reformvorstoß wurde, siehe S. 426-432. 
kam verstärkend hinzu: Umso hektischer suchte die Regierung nach Möglichkeiten, die Binnenkonjunktur zu beeinflussen. Einsparungen bei den öffentlichen Personalausgaben boten sich als »Hebel« dafür geradezu an, zumal die Experten im Kanzleramt und in den Ministerien offensichtlich fest daran glaubten, es gebe eine »Lohnführerschaft«: Frühzeitig vereinbarte Tariferhöhungen für nur eine Branche oder eine Gruppe von Beschäftigten würden zum Vorbild auch für andere Tarifabschlüsse und so zu einem Maßstab, der das ganze wirtschaftliche Geschehen prägen könne. ${ }^{149}$

Gezielte staatliche Sparsamkeit nach mehreren Jahren großzügig geführter Kassen war jedoch politisch in jedem Fall schwierig. In einem dezentralen System wie dem der Bundesrepublik mit seiner Vielzahl eigenständiger Akteure und einem schwach entwickelten Durchgriffsrecht der zentralen Instanz stieß eine einheitliche Ausgabenpolitik aller öffentlichen Instanzen, bei der es um Einsparungen ging, zwangsläufig auf große Widerstände. ${ }^{150}$ Dies galt zumal in einer Zeit starker Teuerung. Hohe Inflationsraten führen in einer freien Gesellschaft wohl zwingend zu verstärkten Verteilungskämpfen, weil der Preisanstieg bereits erreichte soziale Standards

149 | Die Frage, ob es diese "Lohnführerschaft« einzelner Gewerkschaften tatsächlich gab, lässt sich nicht eindeutig beantworten. Untersucht wurde sie bislang vor allem von Wirtschaftswissenschaftlern, die mit hochaggregierten Zahlen und ohne vergleichende Analysen einzelner Tarifrunden arbeiten. Bei gleichem Ansatz kommen sie zu unterschiedlichen Ergebnissen. Teilweise wird die Avantgarde-Rolle einzelner Verbände bejaht (konkret meist für die IG Metall); teilweise aber auch skeptisch beurteilt, weil die gesamtwirtschaftliche Situation wichtiger sei als eine Vorbild-Funktion einzelner besonders durchsetzungsfähiger Gewerkschaften. Vgl. etwa: Jochen Beckord: Lohnführerschaft und kollektive Lohnverhandlungen, Frankfurt/Main u.a.O. 1977 (entschieden für die Existenz der "Lohnführerschaft«); Christoph Deutschmann/Rudi Schmiede (unter Mitarbeit v. Berndt Kirchlechner/Helmut Reiniger): Lohnentwicklung in der Bundesrepublik 1960-1978. Wirtschaftliche und soziale Bestimmungsgründe, Frankfurt/Main und New York 1983, S. 293-295 (das skeptische Urteil); Arno Weigend: Lohndynamik und Arbeitsmarkt. Strukturelle Untersuchungen über die Bestimmungsfaktoren der Lohnentwicklung in der Bundesrepublik Deutschland, Frankfurt/ Main 1982, S. 225-228 (eine unentschlossene Kombination beider Sichtweisen).

150 | Vgl. etwa: Nützenadel: Stunde, S. 350 f.; Franz Holzheu: Nach der Konzertierten Aktion die mittelfristig orientierte Regelbindung. In: Finanzarchiv N. F. 33 (1974/75), S. 475-499, hier: S. 494. 
bedroht und Zukunftsängste um sich greifen. ${ }^{151}$ Das Konzept der »Globalsteuerung« leugnete solche Konflikte und Emotionen. Es beruhte vielmehr auf der Annahme, es gäbe in wirtschaftlichen Fragen »objektiv« richtige Rezepte, die allgemein zu akzeptieren seien, wenn nur Experten und Regierung gemeinsam dahinterstanden. Die soziale Wirklichkeit sah anders aus - und damit musste die »Globalsteuerung" gerade in der Krise versagen, in der sie sich bewähren sollte.

Der Streik der ÖTV demonstrierte diese Defizite unübersehbar und auf offener Bühne. Der Kanzler Willy Brandt scheiterte 1974 also nicht an der ÖTV, sondern an der programmatischen Selbstüberforderung der sozialdemokratischen Bundesregierung, die eine wirtschaftliche Allzuständigkeit beanspruchte, ohne zu bedenken, wie schlecht es um ihre Möglichkeiten stand, auch entsprechend zu handeln. Die erstaunliche Naivität, mit der Brandt in den Konflikt mit der ÖTV zog, bzw. auch seine Resistenz gegen Beratungen und Warnungen machten den Ausgang des Streites dann zusätzlich zu einem persönlichen Fiasko.

Umso drängender - so scheint es - war deshalb das Bedürfnis, rückblickend wenigstens verbal auf die Gewerkschaft und ihren Vorsitzenden einzuschlagen. Wenn die allgemeine Öffentlichkeit Heinz Kluncker lang anhaltend als den »Bösewicht« des Jahres 1974 erinnerte, der das Ansehen Willy Brandts ramponierte, dann verdankte er dieses Label - wie unten noch genauer zu zeigen ist - vor allem sozialdemokratischen Politikern, die dem Kanzler zur Hilfe eilten, als das sprichwörtliche Kind bereits in den Brunnen gefallen war. Indirekt verschleierte diese scharfe Kritik die wahre Niederlage: Die ÖTV geriet damit in die Rolle des Sündenbocks, d.h., die Klage über die angeblich rücksichtlose Gewerkschaft half, den Glauben zu bewahren, eine ökonomische »Globalsteuerung« sei selbstverständlich möglich, wenn nur die Empfehlungen der Fachleute beachtet würden.

151 | Die Inflation, die Deutschland nach 1914 erlebte, kann für diese Zusammenhänge als das eindringlichste historische Beispiel gelten. Vgl. dazu grundlegend: Gerald D. Feldman: The Great Disorder. Politics, Economics, and Society in the German Inflation, 1914-1924, New York und Oxford 1993. Die erodierende Kraft der Inflation zeigte sich in dieser Zeit etwa in mehreren Beamtenstreiks, d. h. in Arbeitskämpfen, die es in Deutschland noch nie zuvor gegeben hatte. Vgl. dazu: ebd., S. 169 f. u. $421 \mathrm{f}$. 


\section{Warum und wie die ÖTV im Frühjahr 1974 den Streik organisierte}

Der Streik vom Februar 1974, der für den ersten SPD-Bundeskanzler und das Kabinett in Bonn zu einer harten Bewährungsprobe wurde, stellte allerdings auch die ÖTV vor enorme Herausforderungen. Es fiel der Gewerkschaft keineswegs leicht, diesen Arbeitskampf zu organisieren - und das galt sowohl in praktischer wie auch in politischer Hinsicht. Wie oben angekündigt wird im Folgenden exemplarisch ausgeführt, was ein umfassender Streik sowohl für die dazu aufrufende Gewerkschaft als auch für betroffene Öffentlichkeit bedeutet.

Schon mit ihren Forderungen für das Jahr 1974 hatte sich die ÖTV sehr schwer getan. Erneut fußten sie auf einer breit angelegten Diskussion unter den Mitgliedern und Funktionären; erneut kollidierten in diesen Beratungen - wie schon in den beiden Jahren zuvor - die Befürworter einer linearen Lohn- und Gehaltserhöhung mit Kollegen und Kolleginnen, die wegen der raschen Teuerung für eine soziale Komponente eintraten. Diese Kontroverse fiel zudem noch schärfer aus als zuvor. Die ÖTV-Führung in Stuttgart und auch die meisten Bezirksleitungen hielten nichts von weiteren Forderungen, Geringverdiener müssten besonders bedacht werden. Heinz Wolf, der Chef der hessischen ÖTV, etwa erklärte in einem Rundschreiben an die unteren Gliederungen der Organisation unmissverständlich, die Erfahrungen mit den bisherigen "gespaltenen Forderungen" aus einer Prozentzahl und einem »Sockel« seien »überwiegend negativ«: Die Tarifverträge der letzten drei Jahre, die alle diesem Muster gefolgt waren, hätten die Erfolge der ÖTV bei den "Strukturverbesserungen« im Öffentlichen Dienst verwischt und förderten deshalb Tendenzen zur Entsolidarisierung. ${ }^{152}$ Ganz ähnlich argumentierte wenig später auch Heinz Kluncker im Namen des gHV im offiziellen Organ der Gewerkschaft. ${ }^{153}$

Dennoch riefen viele der aktiven Mitglieder unverändert nach einem weiteren lohnpolitischen »Sockel«. Oft führten die Debatten zu keinem klaren Meinungsbild. Im Bezirk Nordrhein-Westfalen II beispielsweise votierten sechs der zwölf Kreise für eine ausschließlich lineare Forderung; die anderen sechs wollten eine Prozentzahl mit einem einheitlichen Festbetrag

152 | Rundschreiben der ÖTV-Bezirksleitung Hessen zur Tarifrunde 1974, September 1973. In: AdsD, ÖTV-NRW II, 5/ÖTVC603002.

153 | Vgl. Weiß: ÖTV, S. 169. 
kombinieren. ${ }^{154}$ Die Große Tarifkommission, die einen offiziellen Forderungskatalog festzulegen hatte, stand am Ende der Mitgliederdiskussion daher vor einer höchst schwierigen Aufgabe: Sie musste rund 300 stark voneinander abweichende Einzelbeschlüsse auf einen Nenner bringen. ${ }^{155}$ Auf die geforderte Lohnverbesserung von 15 Prozent konnte sich die Kommission noch relativ einfach verständigen. Mit der sozialen Komponente aber tat sie sich schwer. Es entstand ein Kompromiss, der zwei verschiedene Formen des sozialen Ausgleichs miteinander kombinierte: Die ÖTV verlangte daher nach dem Willen der Tarifkommission, der Lohn- und Gehaltszuschlag müsse für jeden Beschäftigten mindestens 185 DM betragen; zugleich aber forderte sie auch noch ein gehaltsunabhängiges einheitliches Urlaubsgeld von $300 \mathrm{DM} .{ }^{156}$

Damit griff die Gewerkschaft ein Prinzip wieder auf, das im Öffentlichen Dienst bis 1964 für das »Weihnachtsgeld« gegolten hatte. Pauschale Einmalzahlungen dieser Art kamen Geringverdienern besonders stark zugute - und darum ging es der Tarifkommission: Die Forderung nach dem einheitlichen Urlaubsgeld sollte offensichtlich die Mitglieder besänftigten, die sich auch für 1974 einen weiteren »Sockel« gewünscht hatten. ${ }^{157}$ Die Medien nahmen diese besonders komplizierte Struktur der ÖTV-Wunschliste kaum wahr, weil ihnen allein schon die Zahl von 15 Prozent als Provokation galt. Wie sich zeigen sollte, legten hingegen viele Mitglieder der Gewerkschaft fast gleichgewichtig Wert auf alle drei Segmente des Forderungskatalogs.

154 | Rundschreiben Bezirk NRW II Nr. 83/73, 7.12.1973. In: AdsD, ÖTV-NRW II, 5/ÖTVC603001.

155 | Beschlussvorlage für die Große Tarifkommission, 28.11.1973. In: Archiv Ver.di, Bestand Kluncker, 1.

156 | Weiß: ÖTV, S. 168-170.

157 | Wichtig ist hier der auf den ersten Blick rein sprachliche Unterschied zwischen einem »Mindestbetrag « und einem »Sockel« ober »Festbetrag«: Der letztere wird an alle Beschäftigten gezahlt (kombiniert mit der prozentualen Erhöhung der vorherigen Bezüge); der Mindestbetrag ist hingegen nur für Geringverdiener bedeutsam, die zusätzlich Geld erhalten, wenn die prozentuale Erhöhung bei ihnen eine Summe unterhalb des Mindestbetrages ergibt. Diese Variante des Sozialausgleichs ist daher für die Arbeitgeber deutlich kostengünstiger als ein »Sockel«. Vgl. zu diesem Unterschied und der Möglichkeit, ihn zur Kompromissfindung in der Mitgliederdebatte zu nutzen: Rundschreiben Bezirk NRW II Nr. 83/73, 7.12.1973. In: AdsD, ÖTV-NRW II, 5/ÖTVC603001. 
Trotz oder auch gerade wegen der internen tarifpolitischen Querelen noch vor dem Beginn der eigentlichen Tarifverhandlungen ließ sich ein starkes Engagement der gewerkschaftlichen Basis konstatieren. Der Bezirk Hessen hatte schon Ende 1972 berichtet, das neue Verfahren der offenen Mitgliederdiskussion habe gemeinsam mit der generell stark politisierten Stimmung der Zeit die ÖTV neu beflügelt. Deutlich zeige sich ein »Wille zu Aktivitäten« und eine "gespannte Aufmerksamkeit« für die Aktionen der Gewerkschaftsführung. Für die Organisation sei dieses Engagement und Interesse einerseits sehr erfreulich. Andererseits aber ergäben sich daraus auch neue Probleme. "Kerngruppen der Mitgliedschaft in den Städten« erwarteten von der ÖTV eine strikte Linie gegenüber den Arbeitgebern: „Diese Kerngruppen sind nicht bereit, einen Tarifabschluß nachsichtig zu tolerieren, der den Erwartungen, die sie hegen, nicht entspricht. ${ }^{158}$

In der Tarifrunde für 1974 erneuerte sich diese Stimmung an der Basis. Gemeinsam verlangten die Vertrauensleute der Bezirke NRW I und II daher im Januar 1974, die Verhandlungen in Stuttgart dürften erst durch ein Votum der gesamten Organisation beendet werden: »Kein Tarifabschluß ohne Urabstimmung«, so lautete ihre Forderung. Erklärtermaßen wollten die ehrenamtlichen Funktionäre damit »die konsequente Durchsetzung« der ÖTV-Forderungen sicherstellen. ${ }^{159}$

Die ÖTV-Führung ließ diesen Beschluss, der sie unverhohlen unter Druck setzen wollte und der gegen die Satzung verstieß, unkommentiert. Die scharfen Töne gegenüber den Arbeitgebern, die Heinz Kluncker fast zeitgleich anschlug, zeigen jedoch, wie sehr sich die Spitze der Organisation bemühte, der Stimmung an der Basis zu entsprechen. »Eine zweistellige Zahl muß es sein, die erheblich höher ist als zehn Prozent«, sagte Kluncker in einem Fernsehinterview; die immer noch einstelligen Angebote des Tarifpartners bewertete er wahlweise als "Klamotte« oder als »blanken Hohn«. Durchweg betonte der Vorsitzende die soziale Bedeutung der starken Preissteigerungen: Er wisse nicht, wie »der kleinere und mittlere Einkommensbezieher [...] leben soll«, wenn es keinen adäquaten Infla-

158 | ÖTV-Bezirksleitung Hessen an gHV, 29.12.1972. In: Archiv Ver.di, Bestand Kluncker, 19.

159 | Beschluss der ÖTV-Vertrauensleute der Bezirke NRW I und II, 8.1.1974. In: AdsD, ÖTV-NRW II, 5/ÖTVC603001. 
tionsausgleich gebe. ${ }^{160}$ Da diverse Warnstreiks auf kommunaler Ebene die Arbeitgeber nicht beeindruckten, steuerte die Gewerkschaft seit Ende Januar offen einen Streik an. Die Urabstimmung wurde für den 7. und 8. Februar 1974 angesetzt. ${ }^{161}$

Mit diesem Beschluss begann für die Organisation und für alle ÖTVFunktionäre eine Zeit enormer Anspannung. Allein die Vorbereitung der bundesweiten Urabstimmung strapazierte den Apparat der ÖTV und ihre Finanzen auf das Äußerste. Innerhalb weniger Tage mussten rund 600.000 Stimmzettel gedruckt und verteilt werden. Dazu kamen Plakate mit dem Abstimmungsaufruf, Flugblätter, Mitgliederlisten und Formulare, auf denen das Abstimmungsergebnis festzuhalten war. Da insbesondere die kommunalen Betriebe, in denen die ÖTV traditionell stark war, viele »Gastarbeiter« und "Gastarbeiterinnen« beschäftigten, mussten Informationsund Agitationstexte übersetzt werden: Sie erschienen in fünf Fremdsprachen. Die Funktionäre vor Ort mussten geeignete Räumlichkeiten für die Stimmabgabe aussuchen und verbindlich für zwei Tage sichern; es galt, die durchgehende Besetzung der Abstimmungslokale an zwei ansonsten ganz normalen Arbeitstagen zu regeln. Für eine Organisation, die zuletzt 1958 bundesweit gestreikt hatte und deshalb »keine wesentlichen Erfahrungswerte« für den gewerkschaftlichen Ernstfall mehr besaß, war keiner dieser vorbereitenden Schritte eine Selbstverständlichkeit. Wie das Organisationsreferat in Stuttgart lobend festhielt, ging die Urabstimmung dennoch glatt über die Bühne, weil sowohl die Beschäftigten in der Hauptverwaltung als auch die haupt- und ehrenamtlichen Funktionsträger in den Bezirken, Kreisen und Betrieben teilweise »zu jeder Tages- und Nachtzeit« aktiv waren. ${ }^{162}$

160 | In der Reihenfolge der Zitate: Transkript des Interviews mit H. Kluncker in »Heute«, ZDF, gesendet am 22.1.1974, 19 Uhr. In: Archiv Ver.di, Bestand Kluncker, 45; »Unter diese Klamotte kriegen Sie keine Unterschrift«. In: StZ, 23.1.1974; Transkript des Interviews mit H. Kluncker in »Der Markt", ARD, gesendet am 26.1.1974, 21.45 Uhr. In: Archiv Ver.di, Bestand Kluncker, 45; »15 Prozent! Herr Kluncker, wo wollen wir landen?«. In: Bild (Hamburg), 5.2.1974.

161 | Weiß: ÖTV, S. 175. Zu den Warnstreiks (etwa in Stuttgart, Dortmund, Solingen, Hamburg, Hannover und Esslingen) vgl. etwa: Warnstreiks vor Verhandlungsbeginn. In: FAZ, 22.1.1974; Wehner schlägt gestaffelte Tariferhöhungen vor. In: FAZ, 2.2.1974; ÖTV erwartet klares Votum für Streik. In: FAZ, 7.2.1974.

162 | Auswertung des Organisationsreferats zu Urabstimmung und Streik, 21.8.1974. In: Archiv Ver.di, Bestand Kluncker, 8. Übersetzungen erschienen auf 
Während diese Arbeiten noch liefen, musste sich die ÖTV zugleich schon vorab konkret auf einen Streik einrichten, damit sie nach der Abstimmung (bei der sie mit einem starken Votum für den Arbeitskampf sicher rechnete), auch möglichst rasch handeln konnte. Da deutsche Gewerkschaften nun einmal sehr geordnete Institutionen sind, bestand auch diese Vorbereitung zu einem nicht unerheblichen Teil aus der Produktion von vielen Formularen, Dokumenten und anderen Hilfsmitteln. Es galt, Merkblätter für die Streikenden zu erstellen und Listen für deren Registrierung; Kontrollkarten und Auszahlungslisten warem ebenso anzufertigen wie Plaketten und Armbinden für Streikordner oder Formulare, mit denen sich erkrankte Streikende »abmelden « konnten. Zudem organisierte die Gewerkschaft die Weiterversicherung der aktiv Streikenden bei den Krankenkassen - was jeweils eine individuelle Vollmacht nötig machte. Insgesamt entstand so ein Konvolut von 15 verschiedenen Papieren für jedes Mitglied, das sich an dem Arbeitskampf beteiligte. ${ }^{163}$

Noch wichtiger und zugleich schwieriger war die finanzielle Ausstattung der regionalen und lokalen ÖTV-Niederlassungen. Die Streikunterstützung sollte in bar jeweils vor Ort ausgezahlt werden, d. h., die Hauptverwaltung musste in kurzer Zeit große Summen bundesweit verteilen.

Italienisch, Spanisch, Serbokroatisch, Griechisch und Türkisch (Vermerk über die Besprechung von gHV und Organisationsreferat über die Streikvorbereitung, 11.1.1974. In: AdsD, ÖTV, 5/ÖTVB412004). Die ÖTV ermittelte erstmals 1971 die Zahl ihrer Mitglieder, die keine deutschen Staatsbürger waren. Zu diesem Zeitpunkt waren es 10.500 bei 109.000 "ausländischen Arbeitnehmern«, die im Organisationsbereich der ÖTV beschäftigt waren. 1975 waren beide Zahlen gestiegen, nämlich auf 24.100 bzw. rund 133.000 (ÖTV-Geschäftsbericht 1968/71, S. 419; ÖTV-Geschäftsbericht 1976/1979, S. 521). Diese Globalzahlen sind nicht sonderlich aussagekräftig: Die »Gastarbeiter« waren für die ÖTV insofern besonders wichtig, als sie fast ausschließlich in kommunalen Betrieben arbeiteten, ohne die es keinen wirkungsvollen ÖTV-Streik geben konnte. Einige Zahlen, die einen hohen Anteil von »Gastarbeitern« in kommunalen Betrieben in Stuttgart für 1973 belegen, finden sich in: Die Großstadt ist auf fremde Hilfe angewiesen. In: StZ, 26.11.1973. Danach stellten Ausländer 81 Prozent der Arbeiter bei der Stuttgarter Straßenreinigung und 61 Prozent bei der Müllabfuhr. Auch von den Putzfrauen eines städtischen Krankenhauses kamen 60 Prozent aus dem Ausland.

163 | Eine Sammlung dieser Dokumente befindet sich in: Archiv Ver.di, Bestand Kluncker, 4. 
Mit unbürokratischer Hilfe der gewerkschaftseigenen »Bank für Gemeinwirtschaft" gelang auch dieser organisatorische Kraftakt: Fast 20 Millionen DM in kleinen Scheinen landeten binnen weniger Tage in den Zweigstellen der Gewerkschaft. ${ }^{164}$ Für den so bereits weitgehend vorbereiteten Arbeitskampf votierten am 7. und 8. Februar 1974 rund 91 Prozent der 455.00 ÖTV-Mitglieder, die an der Abstimmung teilnahmen. ${ }^{165}$

Diese hohe Streikbereitschaft in einer Tarifrunde, die der Bundeskanzler bewusst stark politisiert hatte, war keineswegs so erwartbar und selbstverständlich, wie viele Medienkommentatoren es seinerzeit meinten. Der heraufziehende Arbeitskampf richtete sich gegen Willy Brandt und die regierende SPD - an dieser Frontstellung konnte es keinen Zweifel geben. Die Partei und die ÖTV aber waren in den frühen 1970er Jahren noch enger miteinander verflochten, als sie es zuvor schon gewesen waren. Insofern ist das Resultat der Urabstimmung bemerkenswert und erklärungsbedürftig.

Organisatorisch eilte die SPD seit Mitte der 1960er Jahre von Erfolg zu Erfolg: Die Zahl ihrer Mitglieder wuchs deutlich. Diese für Parteiführung und -manager erfreuliche Tatsache veränderte die Organisation: Die frühe-

164 | Erfahrungsbericht der Hauptkasse zum Arbeitskampf im Öffentlichen Dienst, 12.6.1974. In: Archiv Ver.di, Bestand Kluncker, 8. Die Streikunterstützung war attraktiv ausgestaltet: Für jeden aktiven Streiktag erhielt ein ÖTV-Mitglied das 2,5-fache seines zuletzt gezahlten Monatsbeitrags. Auf diese Weise deckte die Unterstützung rund 70 Prozent des ausgefallenen Brutto-Tagesverdienstes. Allerdings galt das nur, wenn das Mitglied sich an die Regel gehalten hatte, ein Prozent des Monatsverdienstes als Beitrag abzuführen (Rundschreiben des ÖTV-Organisationssekretariats, 23.1.1974. In: Archiv Ver.di, Bestand Kluncker, 4). Zum Problem der mangelnden Beitragsehrlichkeit siehe bereits S. 165-173 sowie S. 403-408.

165 | In absoluten Zahlen waren 525.442 Mitglieder zur Urabstimmung aufgerufen. 70.683 davon stimmten nicht ab (mehrheitlich wohl, weil sie krank oder im Urlaub waren). Unter den abgegebenen Stimmen waren 38.102 Nein-Stimmen und 2.116 ungültige Voten (ÖTV-Pressedienst, Nr. 22/74, 10.2.1974. In: Archiv Ver.di, Bestand Kluncker, 1). Die Zahl der Abstimmungsberechtigten ergab sich aus dem Umstand, dass für die Beschäftigten der Sozialversicherungsträger wegen einer längeren Laufzeit des Tarifvertrags noch die Friedenspflicht galt. Zudem verzichtete die ÖTV schon in ihrer Satzung grundsätzlich auf Streiks der Arbeiter und Angestellten bei Polizei, Feuerwehr und Bundeswehr. Die dort beschäftigten Mitglieder stimmten daher nicht ab (Weiß: ÖTV, S. 176). 
re »Klassenpartei« der Arbeiter wurde immer stärker zu einer sozial »vielgestaltigen Volkspartei«, in der die Industriearbeiter nur noch eine Gruppe neben anderen darstellten. ${ }^{166}$ Viele der neuen Parteimitglieder gehörten zum Öffentlichen Dienst - und diese Tatsache galt der Parteispitze trotz ihrer Freude über die wachsende Zahl der Genossen rasch als bedenklich. Hans Apel, Bundestagsabgeordneter für einen der Hamburger Wahlkreise und Mitglied des Parteivorstandes, sorgte sich bereits im Frühjahr 1974, die SPD werde zunehmend zu einer »Partei des öffentlichen Dienstes« und dieser Wandel vergraule die sozialdemokratischen "Stammwähler« in der Arbeiterschaft. ${ }^{167}$

Apels Diagnose stimmte zumindest insofern, als Beschäftigte des Staates in den frühen 1970er Jahren auf unterer und mittlerer Hierarchieebene der SPD stark aktiv waren. Wie die Parteigeschäftsführung ermittelte, arbeiteten zu diesem Zeitpunkt mehr als die Hälfte der ehrenamtlichen Funktionsträger an der Basis der Organisation hauptberuflich im Öffentlichen Dienst. Beamte stellten allein 25 Prozent der Vorsitzenden in den Ortsvereinen und 33 Prozent der Leitungskräfte in den Unterbezirken. Dazu kamen staatliche Angestellte, und sie gehörten fast durchweg der ÖTV an: Rund 30 Prozent der SPD-Unterbezirksleiter waren Mitglied dieser Gewerkschaft. Unter allen Sozialdemokraten gab es die gleiche Doppelmitgliedschaft nur bei acht Prozent der Genossen. Missvergnügt konstatierten die Parteimanager ein "geradezu erdrückendes Übergewicht« kleinerer sozialer Gruppen in der Alltagsarbeit der SPD - und damit meinten sie vor allem die Beamten und andere Staatsdiener. ${ }^{168}$

166 | Faulenbach: Das sozialdemokratische Jahrzehnt, S. 744. Vgl. hierzu genauer: ebd., S. 275-280.

167 | Protokoll über die Sitzung des SPD-Parteivorstandes, 8.3.1974. In: BArch Koblenz, N 1369, 1813.

168 | Vermerk von Alfred Nau für Willy Brandt, Heinz Kühn, Helmut Schmidt und Herbert Wehner, 3.4.1974. In: AdsD, WBA, Abt. 11/3, 34. Der Anteil der ÖTVMitglieder an der Gesamtzahl der Parteimitglieder nach: Horst W. Schmollinger: Zur politisch-gesellschaftlichen Beteiligung von Gewerkschaftsmitgliedern: Gewerkschaften in Parteien, Kirchen und Vereinen. In: Ulrich Borsdorf et al. (Hrsg.): Gewerkschaftliche Politik: Reform aus Solidarität. Zum 60. Geburtstag von Heinz O. Vetter, Köln 1977, S. 135-157, hier: S. 142. Insgesamt waren 24 Prozent aller SPD-Genossen auch gewerkschaftlich organisiert. Die ÖTV und die IG Metall (7,5 Prozent) stellten dabei die beiden größten Gruppen. 
Der Tarifkonflikt zwischen der ÖTV und der sozialdemokratisch geführten Bundesregierung im Winter 1973/74 ist gerade auch vor diesem Hintergrund zu betrachten, zumal es in diesem Streit unübersehbar ganz direkt um das Ansehen Willy Brandts ging. Der Parteivorsitzende und Kanzler aber wurde von vielen Sozialdemokraten auf stark emotionale Weise persönlich verehrt: Bei den Mitgliedern übertraf seine Popularität die aller anderen führenden Genossen. ${ }^{169}$ Der Privatbrief eines verdienten Sozialdemokraten und ÖTV-Mitglieds aus Wuppertal, der Heinz Kluncker Ende Januar 1974 erreichte, gibt einen Einblick in die Loyalitätskonflikte, die sich aus dieser Konstellation ergeben konnten. In diesem Schreiben beklagt sich Alfred Dobbert, der in den 1950er Jahren Stadtverordneter sowie Vorsitzender des SPD-Bezirks Niederrhein gewesen war, als Klunckers "alter Freund und einer Deiner Förderer" empört bei dem nunmehrigen Gewerkschaftsvorsitzenden über den Kurs der Organisation. Die Lohnforderungen der ÖTV seien völlig »überspitzt« und ein Zugeständnis an radikale Kräfte; die Gewerkschaft gefährde mit ihren scharfen Attacken auf die Bundesregierung die politische Stabilität der Bundesrepublik: »Unsere junge deutsche Demokratie darf nicht zum Spielball Unvernünftiger werden, die Regierung Brandt nicht durch uns selbst Schaden erleiden. « ${ }^{170}$

Wir wissen nicht, wie viele Mitglieder der ÖTV vor dem Arbeitskampf und an den Streiktagen einen solchen Zwiespalt empfanden. Zumindest zeitweilig dürfte er sich angesichts der engen Verzahnung der beiden Organisationen doch wohl recht häufig gemeldet haben. Wenn dies so war, dann handelte es sich dabei allerdings offensichtlich fast durchweg nur um eine Begleiterscheinung der Tarifstreitigkeiten. Die Voten aller ÖTV-Gremien und die hohe Zustimmungsrate in der Urabstimmung sprechen in dieser Hinsicht eine eindeutige Sprache: Die Gewerkschaft insgesamt wollte im Frühjahr 1974 den Arbeitskampf, obwohl sie damit zwangsläufig den Bundeskanzler attackierte.

169 | Vgl.: Schöllgen: Willy Brandt, S. $198 \mathrm{f}$.

170 | Alfred Dobbert an H. Kluncker, 23.1.1974. In: AdsD, Depositum Kluncker, Stehordner 77. Zu Dobberts Biografie vgl. die Angaben in: Wolfgang Gärtner (Hrsg.): 60 Jahre Landtag Nordrhein-Westfalen. Das Land und seine Abgeordneten, Düsseldorf 2006, S. 233. Dobbert dürfte wohl zu den Sozialdemokraten gehört haben, die Klunckers Studium an der »Akademie für Gemeinwirtschaft» möglich machten. 
Für diese Geschlossenheit und Entschlossenheit gab es aus Sicht der „ÖTVler« einen guten Grund: Angesichts der starken Teuerung galten die Forderungen nach den 15 Prozent, dem hohen Mindestbetrag und dem einheitlichen Urlaubsgeld als moralisch und ökonomisch völlig berechtigt. Die wirtschaftliche Logik der Beschäftigten des Öffentlichen Dienstes unterschied sich damit radikal von den Annahmen und Schlussfolgerungen der Bundesregierung und der vielen wirtschaftswissenschaftlichen Experten, die gemeinsam die Litanei der Lohnzurückhaltung intonierten.

Diese ganz andere Deutung der wirtschaftlichen Situation ergab sich zum einem aus Skepsis gegenüber den düsteren Prognosen der Bundesregierung. Die ÖTV hielt den Preisanstieg im Energiesektor, der die Politiker mit Schrecken erfüllte, für ein vorübergehendes und künstlich geschaffenes Problem. Im Dezember 1973 erklärte die Gewerkschaft, die Regierung wolle die Arbeitnehmer mit Verzichtsparolen »für dumm verkaufen«: Ihre Krisenszenarien seien nicht fundiert und aktuell ohne Bedeutung, denn »von einer Krise kann gegenwärtig ja nicht die Rede sein«. Selbst noch im März 1974, als der Preis für ein Barrel Rohöl fast bei 13 Dollar lag (nach rund 2,5 Dollar vor dem »Ölpreisschock«) sagte Heinz Kluncker, hinter dieser Entwicklung stehe nichts anderes als »eine im größten Stil durchgeführte Preiserhöhungsaktion der Ölkonzerne ${ }^{171}$ Damit lag er zwar falsch - ein Versagen aber kann man ihm in diesem Punkt wohl allenfalls insofern vorwerfen, als der ÖTV-Vorsitzende mit seiner Bewertung ein populäres Fehlurteil übernahm, das seinerzeit gerade im linken Milieu der Bundesrepublik eifrig gehegt und gepflegt wurde. ${ }^{172}$

Zum anderen widersprach die Gewerkschaft dem Kanzler und den wirtschaftswissenschaftlichen Experten, weil sie die amtlich festgestellte Inflationsrate, die im Winter 1973/74 zwischen sieben und acht Prozent schwankte, für irreführend hielt. Bei dem offiziellen Index der Lebenshaltungskosten handelt es sich - wie auch bei zahlreichen anderen statisti-

171 | In der Reihenfolge: zit. nach Weiß: ÖTV, S. 172; Rede von H. Kluncker vor der HV zum Streik im Öffentlichen Dienst, 26.3.1974. In: Archiv Ver.di, Bestand Kluncker, 2. Die Preisangaben aus: Hohensee: Ölpreisschock, S. 79.

172 | Vgl. dazu ausführlich: Hohensee: Ölpreisschock, S. 161-173. Beispielhaft für die Missdeutung der steigenden Preise auf linker Seite vgl. etwa: Die Konzerne sitzen am Öldrücker. In: WdA, 23.11.1973; Profite von historischem Ausmaß. In: WdA, 30.11.1974. 
schen Angaben - um eine soziale Konstruktion, die mit vielen mehr oder weniger willkürlich festgelegten Definitionen arbeitet, um Vergleichbarkeit im zeitlichen Ablauf zu garantieren. Konkret beruhten (und beruhen) diese Zahlen auf einem präzise festgelegten Bündel einzelner Waren, Dienstleistungen und Preise, die als typisch für die Ausgaben »durchschnittlicher« Privathaushalte gelten. Mit der Erfahrungswelt vieler Bürger hat dieser amtliche "Warenkorb « jedoch nur bedingt etwas zu tun. Haushalte »mit geringem Einkommen« etwa gab es für die Statistiker qua Definition lediglich bei Rentnern und Sozialhilfeempfängern, aber nicht bei Arbeitnehmern; die Lebenshaltung von Familien mit Kindern wurde unter Voraussetzungen erfasst, die in der Alltagswelt sehr ungewöhnlich waren. Zudem reagiert die offizielle Statistik stets nur in mehrjährigen Rhythmen auf veränderte Präferenzen der Verbraucher. ${ }^{173}$ Gerade in Zeiten rasch steigender Preise kann sich daher eine Kluft zwischen der amtlichen festgestellten Teuerung und der im Alltag "gefühlten" Inflation auftun - und einen solchen inflationären Schub erlebte die Bundesrepublik ohne Frage spätestens seit 1969/70.

Zahlreiche Briefe, in denen Angehörige des Öffentlichen Dienstes im Januar 1974 beim Bundesinnenministerium gegen die mageren Lohn- und Gehaltsangebote der staatlichen Arbeitgeber protestieren, dokumentieren

173 | Vgl. als Einführung in diese Probleme etwa: Wilhelm Brachwitz: Zur statistischen Analyse der Veränderungen der Lebenshaltungskosten mit Hilfe von Preis-, Mengen- und »Reaktions«-Indizes. In: Allgemeines Statistisches Archiv 49 (1965), S. 233-245; Gerhard Heske: Preisstatistik. Grundlagen und Praxis der volkswirtschaftlichen Preisstatistik, Berlin 1992, insbes. S. 135-155. Konkret gab es in den Mehrpersonen-Haushalten mit "mittlerem « und "höherem « Einkommen, die den Statistikern die Zahlen lieferten, stets einen ungewöhnlich weiten Altersabstand zwischen den beiden Kindern, weil sich so die unterschiedlichen Verbrauchsmuster von Kleinkindern und Teenagern erfassen ließen. Der statistisch beschriebene Vierpersonenhaushalt mit mittlerem Einkommen repräsentierte daher lediglich drei Prozent aller realen bundesdeutschen Privathaushalte bzw. sieben Prozent aller Arbeitnehmerhaushalte (Dietrich Kunz/Manfred Euler: Möglichkeiten und Grenzen der laufenden Wirtschaftsrechnungen. In: Wirtschaft und Statistik 23 [1971], S. 321-326, hier: S. 321 f.). Auch erfasste die Statistik grundsätzlich keine Haushalte mit zwei erwerbstätigen Erwachsenen; die ausschließlich berücksichtigten Rentnerhaushalte mit zwei Personen waren deutlich seltener als alleinstehende Rentner (Heske: Preisstatistik, S. 143 f.). 
diese Alltagssicht auf die Teuerung. Ein Frau Harth aus Köln etwa, die bei der Stadtverwaltung arbeitete, verwies auf die mit Jahresbeginn gestiegenen Beiträge zur Renten- und Krankenversicherung: Wenn sie die von ihr dafür aufzubringenden Summen mit dem Preisauftrieb bei Lebensmitteln zusammenrechne, dann habe sich ihre Lebenshaltung eher um zehn als um die amtlichen sieben bis acht Prozent verteuert. Ein Techniker der Stadtentwässerung im hessischen Eschborn klagte zusätzlich auch noch über eine höhere Prämie für seine Auto-Haftpflichtversicherung, den gestiegenen Preis für das Zeitungsabonnement, die heraufgesetzte Rundfunkgebühr sowie vor allem über den starken Auftrieb bei den Energiekosten, der ihn als Berufspendler und Hauseigentümer mit einer Ölheizung besonders stark belaste. Insgesamt habe seine Familie allein im Januar 1974 mehr als zwölf Prozent höhere Ausgaben zu verkraften. Ein Hamburger Finanzbeamter beschwerte sich auf ähnliche Weise über die gestiegenen Preise für den öffentlichen Nahverkehr und die Bundesbahn. Der Bewohner einer rheinischen Kleinstadt schließlich meldete sich mit der Nachricht, die Kommune habe die Kanalgebühren für 1974 um 50 Prozent erhöht: »Was sind dagegen schon 10 oder 15 Prozent? Die Verwaltung gibt sich doch mit solchen Kleinigkeiten nicht ab. ${ }^{174}$

Wer so rechnete, für den lag die Bundesregierung mit ihrer Warnung, ein Lohnabschluss über zehn Prozent für den Öffentlichen Dienst werde auch die Inflationsrate auf diese Höhe treiben, ganz falsch: Mit ihrem Limit verweigerte sie den Beschäftigten vielmehr eine angemessene Kompensation für inflationäre Verluste, die bereits eingetreten waren und zu einem guten Teil politische Hintergründe hatten. Wie legitim so eine Rechnung war, gaben intern sogar Beamte des Kanzleramts zu. Ende Januar 1974 übermittelten sie dem Bundeskanzler diese Kalkulation: Berücksichtige

174 | In der Reihenfolge: Christa Harth (Köln) an BMdI, 18.1.1974; Manfred von Lucadou (Eschborn) an BMdI, 22.12.1973; Horst Haß (Hamburg) an BMdI, 19.1.1974; Josef Schulmeister (Lampertheim) an BMdI, 3.12.1973. Alle in: BArch Koblenz, B 106, 58594. Vgl. ebd. auch zahlreiche weitere vergleichbare Schreiben. Diese Akte enthält auch viele Briefe von ÖTV-Betriebsgruppen und -Betriebsräten mit ähnlichen Angaben und ähnlicher Argumentation. Weitere Schreiben dieser Art vgl. zudem in: BArch Koblenz, B 222, 1323. Die Vermutung liegt nahe, dass es gewerkschaftsintern wohl zumindest Anregungen gab, an das Ministerium zu schreiben. Die Wortwahl und Argumentation in den Briefen ist aber so unterschiedlich, dass eine zentral gesteuerte Kampagne ausgeschlossen werden kann. 
man die Steuerprogression und die steigenden Sozialabgaben, die jede Lohnerhöhung nach sich zog, dann sichere ein zwölfprozentiger Aufschlag auf das Bruttoeinkommen den Lohnabhängigen bei einer Inflationsrate von neun Prozent lediglich den schon vorhandenen realen Verdienst. Da viele Experten erwarteten, im gerade erst begonnenen Jahr werde dieser Rekordwert wegen der rapide steigenden Energiepreise erreicht oder sogar überschritten, rieten die Ministerialbeamten dem Kanzler damit indirekt, flexibler auf die Forderungen der ÖTV zu reagieren. ${ }^{175}$ Brandt aber ignorierte diesen Hinweis ebenso wie auch die Warnungen seiner Parteigenossen Holger Börner und Hans-Jochen Vogel. Das Sprichwort »Wer nicht hören will, der muss fühlen« könnte daher gut als Überschrift für den dreitägigen Arbeitskampf im Februar 1974 dienen.

Als sozial gerecht galten die 15 Prozent der ÖTV vielen Mitgliedern der Organisation zudem wegen einer anderen, sehr speziellen inflationären Entwicklung, die in der Bundesrepublik seit Anfang der 1970er Jahre wiederholt für öffentliche Empörung gesorgt hatte: In Landtagen, Stadtverordnetenversammlungen und auch im Bundestag beschlossen All-Parteien-Koalitionen einvernehmlich teilweise deutlich höhere Diäten für die Abgeordneten. Zweistellige Zuwachsraten waren dabei die Regel. Zeitgleich mit der Tarifrunde für den Öffentlichen Dienst im Winter 1973/74 beriet etwa der Bundestag über den Plan, das Gesamteinkommen der Abgeordneten durch aufgestockte Unkostenpauschalen um insgesamt 20 Prozent zu steigern. Statt 6.370 DM sollten künftig monatlich 7.680 DM gezahlt werden, die nach wie vor vollständig steuerfrei blieben. ${ }^{176}$

175 | Aktenvermerk (Langfassung) des Bundeskanzleramtes für den Bundeskanzler zur Vorbereitung seines Gesprächs mit den Gewerkschaften, 23.1.1974. In: AdsD, WBA, Abt. 8, 95. Eine sehr ähnliche Berechnung vgl. auch in: Heinz Michael: Schlechte Erfahrungen verderben gute Sitten. In: Die Zeit, 8.2.1974. Zu den Prognosen, die Inflation werde neun Prozent und mehr erreichen, vgl.: Ehmke: Mittendrin, S. 231.

176 | Vgl. etwa: Tiefer Griff in unsere Tasche? In: WdA, 25.1.1974. Tatsächlich beschlossen wurde diese Erhöhung allerdings erst im Sommer 1974, weil die ursprünglich für das Frühjahr geplante Abstimmung wegen starker öffentlicher Kritik auf Antrag der SPD verschoben wurde. Vgl. dazu: Nur vertagt: Das Gerangel um die Diäten der Abgeordneten. In: FAZ, 2.2.1974; Beamte im Parlament verdienen doppelt. In: FAZ, 21.6.1974. Zu vorangegangenen ähnlichen Beschlüssen in Landtagen und Stadtverordnetenversammlungen vgl. etwa: Höhere Diäten für 
Zwar ließen sich Beschlüsse dieser Art schon deshalb nicht direkt mit den jährlichen Tarifrunden vergleichen, weil sie nur in weiteren zeitlichen Abständen erfolgten und ausschließlich einen kleinen Personenkreis betrafen. Dennoch verletzten sie das Gerechtigkeitsgefühl vieler Bürger: Die Parlamentarier schienen dem Volk das Wasser zu predigen, während sie sich selbst großzügig Wein genehmigten. Wenn die staatlichen Arbeitgeber die Tarifrunde 1973/74 mit dem Angebot eröffneten, die Löhne und Gehälter um 7,5 Prozent zu erhöhen, konnten wohl gerade Angehörige des Öffentlichen Dienstes den Eindruck gewinnen, sie lebten in einer ZweiKlassen-Gesellschaft. ${ }^{177}$

Daher stritt keineswegs nur die ÖTV für die Forderung, die nächste Lohn- und Gehaltserhöhung müsse deutlich über zehn Prozent liegen. 14 Prozent mehr sowie ein einheitliches Urlaubsgeld von 400 DM verlangte die DAG, und selbst der stets betont staatstragend auftretende Deutsche Beamtenbund wollte in den Gehaltsabrechnungen ein Plus von zwölf Prozent sehen. Als die ÖTV ihre Urabstimmung vorbereitete, erklärte Alfred Krause, der DBB-Vorsitzende, öffentlich, es gebe in seiner Organisation und unter den Beamten allgemein »ein Gefühl der Solidarität« mit den beim Staat beschäftigten Arbeitern und Angestellten, die kurz vor einem Streik standen. ${ }^{178}$

Auch Nicht-Gewerkschafter empfanden offensichtlich so. Wegen der tief im kollektiven Gedächtnis verankerten Erfahrung von zwei großen Inflationen teilten zahlreiche Deutsche das Gefühl, es sei sozial völlig berechtigt, sich gegen Einkommensverluste durch rasch steigende Preise zu wehren. Nach den Ergebnissen repräsentativer Meinungsumfragen reagier-

niedersächsische Abgeordnete. In: FAZ, 17.1.1972; Landtag fast einmütig für Diätenerhöhung. In: FAZ, 23.2.1972; Höhere Dïaten. In: FAZ, 7.12.1972; Die Städte sind nicht sparsam. In: FAZ, 25.6.1973; Gemeinsam für höhere Diäten. In: FAZ, 4.12.1973; Mehr Geld für die Abgeordneten. In: FAZ, 12.12.1973.

177 | Vgl. etwa den anklagenden Bezug auf die Zuwachsrate bei den Diäten in: Horst Haß (Hamburg) an BMdI, 19.1.1974; Walter Dirks (Emden) an BMdI, 17.1.1974. Beide in: BArch Koblenz, B 106, 58594; Personalrat der Stadt Datteln an BMdI, 21.1.1974. In: BArch Koblenz, B 106, 58589.

178 | Zur DAG vgl.: Streik: »Wir sind keine impotenten Freier«. In: Der Spiegel 28 (1974) 6, S. 19-26, hier S. 20; Pressemitteilung des DBB, 29.1.1974. In: Archiv Ver.di, Bestand Kluncker, 1; Transkript des Interviews mit Alfred Krause, WDR III, 30.1.1974. In: ebd. 
te die Mehrheit der Bevölkerung daher keineswegs mit der Empörung, die Politiker und Medien artikulierten, als die ÖTV ihre 15-Prozent-Forderung stellte. Anfang Februar 1974 äußerten vielmehr 58 Prozent der Befragten "Verständnis« für die Gewerkschaft; lediglich 27 Prozent teilten das negative Urteil der Bundesregierung und fast der gesamten Presse. Als der Streik begonnen hatte, fiel diese Zustimmung sogar noch größer aus: Nun meinten 73 Prozent der Bürger, die Forderungen der ÖTV seien berechtigt; 61 Prozent bejahten auch die Arbeitsniederlegungen. Nur 30 Prozent verlangten von den Arbeitgebern einen »harten Kurs«. Wie sich denken lässt, hielt die Bundesregierung diese Zahlen strikt unter Verschluss. ${ }^{179}$

Die Gewerkschaft agierte daher zwar ohne zu wissen, wie viel Unterstützung sie in der Bevölkerung genoss, aber diese Informationslücke hatte zumindest anfangs keine Bedeutung für den Ablauf des Streiks. Spätestens seit Ende Januar 1974, als sie die Urabstimmung ansetze, war die ÖTV-Führung entschlossen, einen großangelegten Arbeitskampf zu riskieren. Wie zielstrebig sie dabei handelte, zeigt ihr höchst ungewöhnlicher strategischer Schachzug unmittelbar nach der Urabstimmung: Als deren Ergebnisse am 10. Februar vorlagen, rief der gHV die Mitglieder der Organisation umgehend zum Streik auf. Inhaltlich präsentierte die Verbandsführung den Ausstand in diesem Appell vor allem als Kampf gegen das "Lohndiktat« der Bundesregierung, das es "zu brechen« gelte. Noch am gleichen Tag mussten zahlreiche Stadt- und Staatstheater ihre Abendvorstellungen absagen, weil das mehrheitlich in der ÖTV organisierte technische Personal die Arbeit verweigerte. ${ }^{180}$

179 | Presse- und Informationsamt der Bundesregierung an Bundeskanzler Willy Brandt, 4.2.1974. In: AdsD, HSA, 1/HSAA010025; Aktenvermerk des Ministerbüros im BMdI, 13.2.1974. In: BArch Koblenz, B 106, 58589.

180 | Das Zitat aus dem Flugblatt »Wir rufen zum Streik« vom 10.2.1974; ein Exemplar davon in: Archiv Ver.di, Bestand Kluncker, 5. Zu den kurzfristig angesetzten Streikaktionen in den Theatern vgl. den Bericht über eine Beschwerde der Deutschen Bühnengenossenschaft in: Protokoll der 62. Sitzung des gHV, 18.2.1974. In: AdsD, ÖTV, 55/ÖTVB412007. Die Bühnengenossenschaft organisierte das künstlerische Personal der Theater. Sie beklagte sich mit dem Hinweis, viele Darsteller erhielten für ausgefallene Aufführungen keinen oder nur einen gekürzten Lohn. Auch an den nachfolgenden Streiktagen konnten viele Theater nicht bespielt werden. Vgl. genauer: Vergebliches Warten auf Straßenbahn und Bus. In: Weser-Kurier, 12.2.1974. 
Die Arbeitgeber hatten also keine Gelegenheit, auf das Votum der ÖTV-Mitglieder zu reagieren und eventuell ein neues Angebot zu machen, um doch noch eine Einigung herbeizuführen. Nach Heinz Klunckers Darstellung war dies ein zentrales Moment der ganzen Tarifrunde. Fast drei Jahre nach dem Arbeitskampf sagte er rückblickend vor dem ÖTV-Hauptvorstand: „Der Streik war 1974 u. a. erfolgreich, weil wir die Brüder in Bonn völlig überrascht haben. Die haben doch gedacht, durch einen Griff ans Telefon noch am Sonntagmorgen uns dazu zu bewegen, nochmals Luft zu geben. Als wir an diesem Sonntagmorgen den Streik der Presse verkündet haben, da bin ich doch gar nicht mehr ans Telefon gegangen für solche Seelenmassagen, sondern jeder Mann in der Organisation wußte, wir brauchen einen Arbeitskampf «. ${ }^{181}$

In der Tat durchkreuzte die ÖTV mit ihrem Vorpreschen offensichtlich das Kalkül des Bundeskanzlers und seiner engsten Mitarbeiter. Intern entrüstete sich Brandt über das »ungewöhnliche Verfahren« der Gewerkschaft; öffentlich sprach er sogar von »Verwunderung « und »Befremden ${ }^{182}$ Taktisch hatte die ÖTV-Führung offensichtlich genau richtig gehandelt - allerdings gelang dieser Coup nur, weil Willy Brandt als ihr wichtigster Kontrahent einmal mehr bewies, wie wenig er über Gewerkschaften wusste. Heinz Kluncker beendete seinen Rückblick auf den erfolgreichen Streik mit der nüchternen Feststellung: "Die Situation wird nicht wiederkehren. « ${ }^{183}$

Der dreitägige Streik, der am 11. Februar 1974 ernsthaft begann und am Abend des 13. Februars sein Ende fand, lässt sich selbst dann auf zwei verschiedene Weisen beschreiben, wenn man nur auf die ÖTV schaut. Zum einen gab es wirkungsvolle Arbeitsniederlegungen, die planvoll ausgeweitet wurden und stark in den Alltag vieler Bürger eingriffen. Zum anderen aber wuchsen gleichzeitig die Zweifel innerhalb der Organisation, wie

181 | Protokoll der 3. Sitzung des HV, 20./21.1.1977. In: AdsD, ÖTV, 5/ ÖTVB412009.

182 | In der Reihenfolge der Zitate: Kurzprotokoll über die Ministerbesprechung im Bundeskanzleramt, 10.2.1974. In: BArch Koblenz, B 136, 5205; Die Bundesregierung bietet neue Verhandlungen an. In: FAZ, 11.2.1974. Vgl. ähnlich auch noch: Auszug aus dem Informationsgespräch des Bundeskanzlers mit Redakteuren der »Zeit«, 22.2.1974. In: BArch Koblenz, B 136, 5204. Hier sprach Brandt von seiner »Enttäuschung « über den Schachzug der ÖTV.

183 | Protokoll der 3. Sitzung des HV, 20./21.1.1977. In: AdsD, ÖTV, 5/ ÖTVB412009. 
groß ihre Macht denn wirklich sei. Beide Entwicklungen hingen unlösbar miteinander zusammen, denn sie ergaben sich direkt aus der besonderen inneren Struktur der Gewerkschaft.

Nach den ersten, noch ganz punktuellen Arbeitsniederlegungen an den Stadt- und Staatstheatern am Abend des 10. Februar streikten am darauffolgenden Tag (einem Montag) bereits 140.000 Beschäftigte des Öffentlichen Dienstes. In fast allen bundesdeutschen Großstädten sowie in vielen mittelgroßen Kommunen lag der öffentliche Nahverkehr komplett still; vielfach (aber nicht durchgängig) streikten auch Arbeiter der Müllabfuhr und der Straßenreinigung. Am 12. Februar wuchs die Zahl der Ausständigen auf rund 200.000 (auch durch den jetzt fast vollständigen Ausstand der Müllmänner); der dritte Tag brachte einen weiteren Anstieg auf fast 250.000 . $\mathrm{Zu}$ diesem Zeitpunkt ruhte die Arbeit auch in Behörden wie etwa in den KFZ-Zulassungsstellen; Schulen und Ämter blieben geschlossen, weil sich die Hausmeister nicht mehr um die Heizung kümmerten. Zumindest in einigen Städten (etwa in Mainz und Saarbrücken) kam es stundenweise zu Stromsperren; die Fernwärme blieb teilweise aus. Auf mehreren Autobahnen bildeten sich Staus, weil Unfallstellen zwar abgesperrt, aber nicht mehr zügig geräumt wurden. ${ }^{184}$ Auf dem Frankfurter Flughafen mussten

184 | Vgl.: Außerordentliche Sitzung des gHV, 3.2.1974. In: Archiv Ver.di, Bestand Kluncker, 1 (mit den Planungen zum Ablauf des Streiks); Weiß: ÖTV, S. 177; Lagebericht über die Arbeitskampfmaßnahmen, 13.2.1974. In: BArch Koblenz, B 136, 5205 (mit den Zahlen der Streikenden); Mit dem Öfchen zum Dienst. In: FAZ, 12.2.1974; Streik-Mißbrauch. In: Wiesbadener Tageblatt, 12.2.1974; Müllsäcke werden zu Verkaufsschlagern. In: Weser-Kurier, 14.2.1974; 17.500 streikten in Hessen. In: Hessische Allgemeine Zeitung, 12.2.1974; Bericht der ÖTV-Bezirksverwaltung Saarbrücken, 9.10.1974. In: Archiv Ver.di, Bestand Kluncker, 8; Die ÖTV Hessen will Autobahnsperrung erreichen. In: FAZ, 12.2.1974. Die Stromsperre in Saarbrücken brachte die ÖTV in Konflikt mit der "Saarbrücker Zeitung«, deren Redaktion und Druckanlagen davon stundenlang stillgelegt wurden. Die Zeitung sprach von einem Angriff auf die Pressefreiheit: Die lokale Streikführung habe das Verlagshaus wegen kritischer Kommentare zu den ÖTV-Forderungen gezielt von der Energieversorgung abgeschnitten. Die Gewerkschaft bestritt diesen Vorwurf, zahlte aber schließlich außergerichtlich eine Entschädigung von knapp 30.000 DM »ohne Anerkennung einer Rechtspflicht«, um einen Prozess zu vermeiden. Vgl. hierzu: Bericht der Bezirksverwaltung Saarbrücken, 9.10.1974; ÖTVRechtsreferat an HV, 25.10.1974. Beide in: Archiv Ver.di, Bestand Kluncker, 8. 
die Passagiere ihr gesamtes Gepäck selbst zum Flugzeug tragen (bzw. es dort nach der Landung in Empfang nehmen), weil streikende Techniker die Förderbänder stillgelegt hatten. Auch die Rolltreppen und Fahrstühle im Gebäude blieben ohne Strom. Im Endeffekt entstanden so zahlreiche Verspätungen bei Starts und Landungen. ${ }^{185}$

Zudem gab es vom 11. bis zum 13. Februar Schwerpunktstreiks bei der Bundespost, zu denen die in Tarifsachen eng mit der ÖTV zusammenarbeitende Deutsche Postgewerkschaft aufgerufen hatte. Nimmt man eine flächendeckend durchgeführte zweistündige Arbeitspause am 13. Februar aus, an der sich rund 150.000 Arbeiter und Angestellte der Post beteiligten, dann handelte es sich aber eher um ergänzende Aktionen. Der Streikfonds der Postgewerkschaft war finanziell so schlecht ausgestattet, dass sie es sich schlicht nicht erlauben konnte, »eine große Anzahl streikender Mitglieder über längere Dauer hinweg finanziell zu unterstützen«. ${ }^{186}$

Ohne Frage gab es viele Bürger, die sich über diese Arbeitsniederlegungen im Öffentlichen Dienst empörten. Die ÖTV erhielt eine Fülle von bösen Briefen und Anrufen; mehrfach gab es Bombendrohungen gegen die Hauptverwaltung in Stuttgart. Einige Betroffene forderten Schadensersatz, etwa für die Kosten von Taxifahrten oder für einen Verdienstausfall wegen geplatzter Geschäftstermine. ${ }^{187}$ Von allgemeiner Wut aber kann

185 | Vgl. hierzu: Die ÖTV Hessen will Autobahnsperrung erreichen. In: FAZ, 12.2.1974; 17.500 streikten in Hessen. In: Hessische Allgemeine Zeitung, 12.2.1974. Die Lufthansa fühlte sich dennoch nicht ernsthaft geschädigt, merkte allerdings an, den verstärkten Einsatz des eigenen Personals bei der Gepäckabfertigung hätte sie nur eine Woche lang aufrecht erhalten können. Danach wären massive Betriebsstörungen aufgetreten (Erfahrungsbericht der Lufthansa über die Betriebsabwicklung während des Streiks im Öffentlichen Dienst, 29.3.1974. In: BArch Koblenz, B 106, 58589).

186 | Geschäftsbericht des Hauptvorstandes und des Gewerkschaftsausschusses der Deutschen Postgewerkschaft vom 1. Juli 1971 bis 30. Juni 1974. An den 11. Ordentlichen Gewerkschaftskongress in Hamburg, Congress-Centrum, 20. bis 26. Oktober 1974, Frankfurt/Main 1974 (im Folgenden: Geschäftsbericht DPG 1971/74), S. 204. Ein ausführlicher Überblick über die Tarifrunde aus der Sicht der DPG findet sich ebd., S. 185-214.

187 | Eine umfangreiche Sammlung von Protestbriefen findet sich in: Archiv Ver.di, Bestand Kluncker, 7 und 8. Zu den Bombendrohungen vgl.: Lagebericht über die Arbeitskampfmaßnahmen, 13.2.1974. In: BArch Koblenz, B 136, 5205. 
ganz offensichtlich nicht gesprochen werden. Die oben schon angeführte, nicht publizierte Meinungsumfrage belegt ein weit verbreitetes Verständnis in der Bevölkerung gerade auch nach Beginn der Aktionen. Zugleich berichteten die ÖTV-Betriebsgruppen von einer "erstaunlich entschlossenen Streikbereitschaft« unter den Mitgliedern. ${ }^{188}$ Darüber hinaus erwies sich der Arbeitskampf für die Gewerkschaft als ein hervorragendes Werbemittel: Innerhalb der drei Streiktage verzeichnete sie den Eintritt von fast 58.000 neuen Mitgliedern. ${ }^{189}$

Dennoch wuchs in der ÖTV-Führungsmannschaft mit jedem Streiktag die Unruhe: Unter den Funktionären, die an den zentralen Tarifverhandlungen in Stuttgart beteiligt waren, plädierte eine wachsende Gruppe dafür, sich zügig mit den Arbeitgebern zu einigen und dabei deutliche Abstriche am Forderungskatalog der Gewerkschaft hinzunehmen. Angeführt wurde diese Gruppe von Heinz Kluncker. Sowohl aus grundsätzlichen Erwägungen als auch aus pragmatischen Gründen wollte der Vorsitzende einen langen Ausstand auf jeden Fall vermeiden. Ein Arbeitskampf, so äuBerte Kluncker, sei prinzipiell »kein Mittel, mit dem der Gegner vernichtet werden soll. Wir wollen mit dem Streik einen Verteilungskonflikt lösen, der auf andere Weise zu unseren Ungunsten gelöst würde. Wenn wir aber die Tarifautonomie nicht selbst ad absurdum führen wollen, müssen wir die Tatsache akzeptieren, daß auch ein Streik mit einem Kompromiß endet.« ${ }^{190}$ Konkret ergab sich daraus die Schlussfolgerung: »15 Prozent können wir nicht erreichen. « $^{191}$

Gleichzeitig hielt Kluncker die ÖTV ohnehin für zu schwach für einen Sieg auf ganzer Linie. Mit den militärischen Metaphern, die gerne benutzt

188 | Vgl. zusammenfassend: Bericht des ÖTV-Bezirks NRW II für das Seminar "Auswertung und Diskussion der Tarifrunde 1973/74«, März 1974. In: AdsD, ÖTV-NRW II, 5/ÖTVC603001. Vgl. ebd. auch eine Sammlung der Einzelberichte, auf denen diese Zusammenfassung fußt.

189 | Notiz des Vorstandssekretariats 6, 15.3.1974. In: Archiv Ver.di, Bestand Kluncker, 5. Eine ähnliche Erfahrung machte auch die DPG: Sie nahm allein im Januar und Februar 1974 rund 20.000 neue Mitglieder auf (bei einem Gesamtbestand von 400.000 Mitgliedern) (Geschäftsbericht DPG 1971/74, S. 508 u. 502). 190 | Rede von H. Kluncker vor dem Hauptvorstand zum Streik im Öffentlichen Dienst, 26.3.1974, In: Archiv Ver.di, Bestand Kluncker, 2.

191 | So zit. in: Handschriftliche Notizen von Hans Liersch über die Tarifverhandlungen, 11./13.2.1974. In: AdsD, ÖTV-NRW II, 5/ÖTVC603003. 
werden, wenn von einem Streik die Rede ist, fragte er, »mit welchen Bataillonen" die Gewerkschaft denn "Bund und Länder in die Knie zwingen« solle: »Es hat sich doch herausgestellt, daß unser Organisationsverhältnis in diesen beiden Bereichen mehr als verbesserungsbedürftig ist. « ${ }^{192}$ In der Tat hatte die Urabstimmung aktuelle Zahlen geliefert, die eindeutig ausfielen. Die ÖTV war nach wie vor in kommunalen Betrieben und in vielen Gemeindeverwaltungen äußerst stark; unter den Arbeitern und Angestellten der Länder und besonders denen des Bundes zählte sie jedoch deutlich weniger Mitglieder. In städtischen Verkehrsbetrieben waren Organisationsquoten von 90 Prozent und mehr so häufig, dass sie als Regel gelten konnten, und auch in der "allgemeinen Kommunalverwaltung « dominierten die ÖTV-Kolleginnen und -Kollegen vielfach ganz eindeutig. In Düsseldorf und in Stuttgart etwa gehörten buchstäblich sowohl sämtliche Arbeiter und Arbeiterinnen als auch alle Angestellten der Stadt zur ÖTV; in Frankfurt am Main waren es immerhin »noch « 85,7 Prozent der Beschäftigten. ${ }^{193}$

Im Vergleich dazu verzeichnete die Gewerkschaft in den »allgemeinen Landesverwaltungen « typischerweise eher normale Mitgliederanteile zwischen 30 und maximal 40 Prozent; selten waren es mehr (wie in RheinlandPfalz mit 67 Prozent) oder auch weniger (wie in Bayern mit nur 18 Prozent). Ähnlich schlecht wie in Bayern sah es auch beim Bund aus: Von den 6.200 Arbeitern und Angestellten, die in Bonn die Bundesregierung unterstützten oder in anderen Bundeseinrichtungen arbeiteten, gehörten lediglich 18,5 Prozent zur ÖTV; bei den 1.111 nicht-verbeamteten Beschäftigten in der Bundesfinanzverwaltung galt dies sogar nur für sechs Prozent. ${ }^{194}$

192 | Rede von H. Kluncker vor dem Hauptvorstand zum Streik im Öffentlichen Dienst, 26.3.1974. In: Archiv Ver.di, Bestand Kluncker, 2.

193 | Vgl. die genaue Aufstellung in: Überblick über den Organisationsgrad im Bereich VKA (Gemeinden) nach den Protokollen der Urabstimmungen 1974, o. D. In: Archiv Ver.di, Bestand Kluncker, 2. Allerdings gab es in der allgemeinen Kommunalverwaltung auch einige Ausnahmefälle mit ungewöhnlich schlechten Organisationsquoten: Diese lag etwa in Köln nur bei 24,8 Prozent und betrug in Krefeld sogar nur 15,4 Prozent. Überlegungen zur Erklärung dieser Ausnahmen konnten in den durchgesehenen Unterlagen der ÖTV nicht ermittelt werden.

194 | Überblick über den Organisationsgrad im Bereich der Länder (TdL) nach den Protokollen der Urabstimmungen 1974, o.D.; Überblick über den Organisationsgrad im Bereich des Bundes nach den Protokollen der Urabstimmungen 1974, o. D. Beide in: Archiv Ver.di, Bestand Kluncker, 2. Die oben genannten Zah- 
Ausgerechnet der Bundesregierung, die in den Tarifverhandlungen als Hauptgegner der Gewerkschaft auftrat, konnte die ÖTV daher kaum direkt etwas anhaben. Zwar streikten in Bonn im Bundespresseamt die Beschäftigten, die Fernschreiben entgegennahmen und absetzten. Der äußerst umfangreiche »Nachrichtenspiegel«, den das Amt täglich für Regierung und Parlament zusammenstellte, schrumpfte damit auf kaum noch fünf Seiten. In einigen anderen Dienststellen blieben Büros ungeheizt oder Telefonanlagen lagen still. Zudem gab es keinen Fahrdienst für Minister und Staatssekretäre. Ein harter Streik sah sicher anders aus - gleichzeitig aber gab es keine ungenutzten Optionen, mehr Druck zu machen. ${ }^{195}$

Intern stritt sich die ÖTV-Delegation bei den Stuttgarter Tarifverhandlungen daher schon am zweiten und stärker noch am dritten Streiktag heftig über die Frage, was geschehen werde, wenn die Organisation den Arbeitskampf weiter fortsetzte, obwohl sie in den verschiedenen Segmenten des Öffentlichen Dienstes so ungleich vertreten war. Heinz Kluncker hatte dazu eine klare Meinung: Wer in der gegebenen Situation nicht auf die Arbeitgeber zugehe, der riskiere den Ausstieg von Bund und TdL aus den gemeinsamen Tarifverhandlungen für den Öffentlichen Dienst. Es sei aber immer Linie der Gewerkschaft gewesen, an der Tarifeinheit für Bund, Länder und Gemeinden festzuhalten. ${ }^{196}$

Zudem blickte die Leitung der ÖTV zunehmend besorgt auf die veröffentliche Meinung zu den Streikaktionen. Zwar war eine schlechte Presse für die Gewerkschaft überhaupt nichts Neues; qualitativ aber erreichte die Medienkritik an der ÖTV mit dem Arbeitskampf doch ein neues Niveau. Wie etwa die Berliner Bezirksleitung berichtete, zeichneten die Zeitungen in der Teilstadt in ihrer Streikberichterstattung unisono »ein Bild des Schreckens und des Verfalls« mit Schlagzeilen wie »Heute früh begann in

len für die allgemeinen Landesverwaltungen meinen jeweils nur den Organisationsgrad in den jeweiligen Landeshauptstädten.

195 | Vgl.: Ein Fahrstuhl streikte mit. In: Hessische Allgemeine Zeitung, 12.2.1974; Lagebericht über die Arbeitskampfmaßnahmen, 13.2.1974. In: BArch Koblenz, B 136, 5205; Harpprecht: Kanzleramt, S. 470.

196 | Vgl.: Handschriftliche Notizen von Hans Liersch über die Tarifverhandlungen, 11./13.2.1974. In: AdsD, ÖTV-NRW II, 5/ÖTVC603003; Rede von H. Kluncker vor dem Hauptvorstand zum Streik im Öffentlichen Dienst, 26.3.1974. In: Archiv Ver.di, Bestand Kluncker, 2. Zu der dramatisierenden Presseberichterstattung vgl. zusammenfassend auch: Kittner: Arbeitskampf, S. 676. 
Berlin das Chaos«. Auch die Bundesregierung registrierte bei einer umfassenden Auswertung der Presse, generell werde von den Massenmedien die »R̈̈cksichtslosigkeit« der ÖTV beklagt. ${ }^{197}$ Da die Organisation die oben zitierten Meinungsumfragen nicht kannte, fürchtete sie verständlicher Weise, ein Streik, der sich bis in die nachfolgende Woche hinziehe, werde sich "gegen uns aus[wirken], denn mindestens der Bund zieht die öffentliche Meinung auf seine Seite ${ }^{198}$

Darüber hinaus vermisste die ÖTV die Solidarität des DGB und der DGB-Gewerkschaften. Der Bezirk NRW II meldete der Hauptverwaltung in Stuttgart, die anderen Arbeitnehmerverbände im Ruhrgebiet hätten der streikenden ÖTV bestenfalls »in großem Abstand « beigestanden: »Nicht selten waren ihre politischen Bedenken gegen die Streikwirkung spürbar.« Deutlich unverblümter klagte die Kreisverwaltung Siegen über »das mangelnde solidarische Verhalten« der Kollegen und Kolleginnen aus anderen Gewerkschaften, »denn insbesondere die Mitglieder, Funktionäre, Sekretäre und der Bevollmächtigte der IG Metall haben den Arbeitskampf in einer Weise kritisiert, die nicht mehr zu vertreten ist«. Die ÖTV in Essen zeichnete ein ähnliches Bild und sprach von einer »ausgemachten Schweinerei ${ }^{199}$ Aus der DGB-Zentrale in Düsseldorf berichtete die FAZ, »hinter vorgehaltener Hand « äußerten sich viele Mitglieder des Bundes-Vorstandes sehr kritisch über die »Rücksichtslosigkeit ohnegleichen«, mit der die ÖTVFührung die Regierung behandle. ${ }^{200}$ Rückblickend beschrieb Heinz Klun-

197 | In der Reihenfolge der Zitate: Auswertung der Tarifrunde 1973/74 der ÖTVBezirksleitung Berlin, o. D. In: AdsD, ÖTV-NRW II, 5/ÖTVC603007 (die zitierte Schlagzeile erschien an 11.2.1974 in dem Boulevard-Blatt "BZ«); Auswertung des Presse- und Informationsamtes der Bundesregierung über das Presse-, Rundfunkund Fernseh-Echo auf den Tarifabschluss der ÖTV, 18.2.1974. In: AdsD, HSA, 1/ HSAA010026.

198 | Handschriftliche Notizen von Hans Liersch über die Tarifverhandlungen, 11./13.2.1974. In: AdsD, ÖTV-NRW II, 5/ÖTVC603003.

199 | In der Reihenfolge der Zitate: Zusammenstellung der Erfahrungsberichte zum Streik aus dem Bezirk NRW II, 29.5.1975. In: AdsD, ÖTV-NRW II, 5/ ÖTVC603007; Bericht der KV Siegen über den Streik 1974, 27.5.1974; Bericht der KV Essen, 29.3.1974. Beide in: AdsD, ÖTV-NRW II, 5ÖTVC603306.

200 | Neuer Inflationsstoß. In: FAZ, 14.2.1974. Äußerungen der Gewerkschaftsvorsitzenden Rudolf Sperner (IG Bau) und Adolf Schmidt (IG Bergbau) auf einer internen Besprechung mit Willy Brandt kurz vor dessen Rücktritt belegen die- 
cker diesen Dissens innerhalb des scheinbar doch so solidarischen Blocks der DGB-Gewerkschaften mit den Worten: „Wir haben nicht allzu viele Freunde. $\ll^{201}$

Und schließlich musste die ÖTV auch auf ihre Finanzen achten. Wie oben gezeigt wurde, konnte sie sich in dieser Hinsicht keineswegs mit der IG Metall vergleichen. Trotz einer zwischenzeitlich deutlich verbesserten finanziellen Situation war die ÖTV nach wie vor eine vergleichsweise »arme« Gewerkschaft. Die 20 Millionen DM, die für die Streikunterstützung vorab an die Geschäftsstellen gingen, entsprachen bereits einem Fünftel ihres gesamten Vermögens und fast einem Drittel der kurzfristig verfügbaren flüssigen Mittel. Grob gerechnet hätte ein Ausstand mit mehr als 200.000 streikenden Mitgliedern die Konten der ÖTV schon nach einer Woche weitgehend geleert. ${ }^{202}$ Sarkastisch kommentierte der Vorsitzende: »Bei solchen Größenordnungen kann man nicht einfach munter drauflos streiken. ${ }^{203}$ Gerade auf dem scheinbaren Höhepunkt ihrer Macht klafften Fremd- und Selbstwahrnehmung der ÖTV daher weit auseinander: Am dritten Streiktag meinten viele ihrer führenden Funktionäre, die Gewerkschaft brauche dringend einen raschen Tarifabschluss.

Von Einigkeit ließ sich in dieser Hinsicht aber nicht sprechen. Ein guter Teil der 17 Stunden dauernden Verhandlungsrunde, die in den Morgenstunden des 14. Februar schließlich zur Einigung der Tarifpartner führte, verging mit internen Streitigkeiten in der ÖTV-Delegation und in der Gro-

se Distanz: Beide sagten, die ÖTV trage wegen ihres Arbeitskampfes »Mitschuld an der für die Regierung ungünstigen Stimmung«. Zit. nach: Kemper: Loderer, S. 297. Heinz Kluncker nahm an dieser Besprechung nicht teil.

201 | Rede von H. Kluncker vor dem Hauptvorstand zum Streik im Öffentlichen Dienst, 26.3.1974. In: Archiv Ver.di, Bestand Kluncker, 2.

202 | Vgl. die Berechnungen in: Informationen der HVA Nr. 105/322 über eine mögliche Ausrufung eines ÖTV-Streiks, 9.2.1972. In: BStU, Archiv der Zentralstelle, MfS HVA, 11. Zur verbesserten Finanzsituation insgesamt siehe oben in diesem Kapitel.

203 | So im Rückblick in: Protokoll ÖTV-GT 1976, Bd. 1, S. 69. Insgesamt kostete der Arbeitskampf, der am ersten Streiktag mit »nur« 140.000 ausständigen Mitgliedern begonnen hatte, die ÖTV 18 Millionen DM; davon entfielen elf Millionen auf Streikunterstützungen (Rede von $\mathrm{H}$. Kluncker vor dem Hauptvorstand zum Streik im Öffentlichen Dienst, 26.3.1974. In: Archiv Ver.di, Bestand Kluncker, 2; Protokoll ÖTV-GT 1976, Bd. 1, S. 69). 
ßen Tarifkommission, welcher Kompromiss für die Basis der Organisation akzeptabel sei. Auf Drängen Heinz Klunckers einigte sich die Große Tarifkommission relativ rasch und problemlos darauf, die Forderung nach dem einheitlichen Urlaubsgeld fallen zu lassen, wenn die Arbeitgeber versprächen, über eine solche Sonderzahlung noch im Jahr 1974 separat neu zu verhandeln - was diese daraufhin zügig taten. ${ }^{204}$

Hart gerungen aber wurde über die Frage, ob die Gewerkschaft eher einen hohen Prozentsatz oder eine möglichst üppige Mindestzahlung verlangen sollte. Zumal die hessischen Delegierten forderten, der Tarifvertrag müsse unbedingt eine zwölfprozentige lineare Erhöhung enthalten; der Mindestbetrag sei aus ihrer Sicht hingegen »ohne Bedeutung«. Die Vertreter etlicher anderer Bezirke widersprachen und plädierten für eine prägnante soziale Komponente »im Tausch« gegen eine niedrigere Prozentzahl. Bei diesem Hin und Her ignorierten die Sprecher der Basis auch den Rat des ÖTV-Vorsitzenden: Heinz Kluncker war am Abend des 12. Februar offensichtlich bereit, einen Vertragsentwurf der Arbeitgeber zu akzeptieren, der ein Plus von 10,5 Prozent und einen Mindestbetrag von 160 DM vorsah. »Hessen und NRW II drohen!!«, vermerkte Hans Liersch, der Vorsitzende eben dieses nordrhein-westfälischen ÖTV-Bezirks, daraufhin in einem stichwortartigen Protokoll dieser internen Beratungen. Gezwungenermaßen zog Heinz Kluncker in eine weitere Verhandlungsrunde mit den Arbeitgebern, die - nach mehrfachen Unterbrechungen - gegen zwei Uhr am Morgen des nächsten Tages dann mit der Einigung auf elf Prozent und eine Mindestzahlung von 170 DM zum Abschluss kam. Auch die hessischen Delegierten verzichteten schließlich auf ihre Zwölf-ProzentForderung, da die Arbeitervertreter in der Tarifkommission gemeinsam er-

204 | Handschriftliche Notizen von Hans Liersch über die Tarifverhandlungen, 11./13.2.1974. In: AdsD, ÖTV-NRW II, 5/ÖTVC603003. Diese Verhandlungen im Herbst 1974 blieben erfolglos. Die ÖTV-Führung hatte nichts anderes erwartet, und sie wusste zugleich, dass zahlreiche kommunale Betriebe nach ihren Haustarifen bereits Urlaubsgeld zahlten. Ein Streik für ein allgemeines Urlaubsgeld war damit de facto fast unmöglich. Daher verschleierte die Vereinbarung über weitere Verhandlungen noch im gleichen Jahr nur den Verzicht der Gewerkschaft auf diesen Teil ihrer Forderungen (Notizen von Hans Liersch zur Urlaubsgeldforderung 1974, o.D. In: AdsD, ÖTV-NRW II, 5/ÖTVC603005). Erst 1977 konnte die ÖTV das Urlaubsgeld tatsächlich durchsetzen. Siehe dazu sowie zum raschen Ende der Verhandlungsrunde im Herbst 1974 weiter unten in diesem Kapitel. 
klärten, ein »Weiterstreiken für 12\% [sei] wertlos, da der erreichte Mindestbetrag meistens einen höheren Wert ergibt«. ${ }^{205}$

Die Nachgiebigkeit der Arbeitgeber, die den Abschluss in der skizzierten Form möglich machte, hatte die ÖTV gezielt gefördert: Über ihre Bezirksverwaltungen in Nordrhein-Westfalen verbreitete sie die Nachricht, sie wolle am kommenden Tag im Ruhrgebiet die Lieferung von Strom, Gas und Wasser einschränken. Hans Liersch notierte dazu kurz und knapp: »das war nur Bluff« ${ }^{206}$ Begeisterung kam in der Delegation der Gewerkschaft jedoch nicht auf, als sich zeigte, wie geschickt sie auch mit diesem Schachzug agiert hatte, der die Kommunalpolitiker einmal mehr besonders stark unter Druck setzte. Stattdessen lagen ihnen die nur ganz begrenzt bedeutsamen Haustarif-Verträge der Stadtwerke von Bremerhaven und der Bremer Straßenbahn den ÖTV-Vertretern in Stuttgart schwer im Magen: Gäbe es sie nicht, so hieß es in der abschließenden Diskussion der Großen Tarifkommission, dann würde der Stuttgarter Abschluss von den Mitgliedern sicher »als der größte Tariferfolg der ÖTV gefeiert werden«. So aber müsse man sich auf Kritik und Ärger gefasst machen, weil der zentrale Vertrag kein zwölfprozentiges Plus enthalte. ${ }^{207}$

\section{Nach der Einigung: Reaktionen auf den Tarifabschluss in der ÖTV sowie in Politik und Medien}

Der Sturm der Entrüstung, der in der ÖTV losbrach, als der Stuttgarter Kompromiss bekannt gegeben wurde, überraschte die Verbandsleitung dann allerdings doch: So vehement ablehnend hatte sie sich das Votum der Basis nicht vorgestellt. Die Kreisverwaltung Essen meldete etwa, die Basis vor Ort fordere den "unbefristeten totalen Streik«, um die bei Beginn der Tarifrunde beschlossenen Forderungen der ÖTV ohne Abstriche durchzusetzen; aus Hagen hieß es, die Mitglieder seien »entsetzt« über den Abbruch des Streiks und nicht bereit, »einen Tarifvertrag unter 12\% und ohne ein Angebot für Urlaubsgeld zu akzeptieren«. Der stellvertretende Betriebsratsvorsitzende der kommunalen Verkehrsbetriebe in Mainz ließ den

205 | Handschriftliche Notizen von Hans Liersch über die Tarifverhandlungen, 11./13.2.1974. In: AdsD, ÖTV-NRW II, 5/ÖTVC603003.

206 | Ebd.

207 | Ebd. 
ÖTV-Vorstand telefonisch wissen, der vereinbarte Abschluss sei nichts anderes als »eine Unverschämtheit«. Die Betriebsgruppe in der Kölner Schulverwaltung übermittelte per Telegramm diese Botschaft: »fuer $11 \%$ haben wir nicht gestreikt. ausrufezeichen. ${ }^{208}$ In Frankfurt am Main empfahl die ÖTV-Kreisdelegierten-Konferenz (mit nur zwei Gegenstimmen) allen Mitgliedern, bei der kommenden Urabstimmung über den Tarifvertrag mit »Nein« zu stimmen. Der Streik sei von der Verbandsspitze viel zu zaghaft geführt worden. ${ }^{209}$

Bei dem erneuten allgemeinen Mitgliedervotum am 20./21. Februar 1974 stimmte dann aber doch eine Mehrheit für die Annahme der Vereinbarung. Dieser Umschwung, der nach den vorangegangenen scharfen Protesten überraschend kam, lässt sich nicht präzise erklären. Möglicherweise hatten die empörten Kritiker die Mehrheit der Mitglieder unmittelbar nach der Einigung in Stuttgart schlicht übertönt, weil sie sich lauter und engagierter äußerten; möglicherweise verstanden viele Kollegen erst nach einiger Zeit, dass sie letztlich mehr als die elf Prozent Aufschlag erhielten. Zudem war die Option, den Streik nach einwöchiger Pause wiederaufzunehmen, eher theoretischer Art. Mit 62 Prozent »Ja«-Stimmen und 38 Prozent Ablehnungen erwiesen sich die ÖTV-Mitglieder allerdings als ungewöhnlich zerstritten. Ein genauerer Blick auf das Resultat zeigt zudem, wie missgestimmt insbesondere Arbeiter des Öffentlichen Dienstes waren. Gerade sie hatten den dreitägigen Streik im Wesentlichen getragen. Nun aber stimmten sie zu 42 Prozent gegen das Resultat, das sie selbst »erkämpft« hatten. Das nach dem ÖTV-Statut erforderliche Quorum von 51 Prozent

208 | In der Reihenfolge: Kreisverwaltung Essen an Zentrale Streikleitung, 13.2.1974; Kreisverwaltung Hagen an Zentrale Streikleitung, 13.2.1974; Aktennotiz Vorstandssekretariat Sechs, 13.2.1974; ÖTV-Betriebsgruppe Schulverwaltung Köln an die Zentrale Streikleitung, 13.2.1974. Alle in: Archiv Ver.di, Bestand Kluncker, 1. Vgl. ferner auch die Berichte der Bezirklichen Streikleitungen von Hessen, Baden-Württemberg und Weser-Ems an die Zentrale Streikleitung, jeweils vom 14.2.1974. In: ebd.

209 | Beschluss der Kreisdelegierten-Konferenz Frankfurt/Main, 19.2.1974. In: AdsD, ÖTV-NRW II, 5/ÖTVC 603004. Vgl. auch: Urabstimmung und Urabstimmung sind zweierlei Dinge. In: FAZ, 20.2.1974. Zu ähnlichen Beschlüssen von ÖTV-Gremien in Stuttgart sowie im Ruhrgebiet vgl.: Die Basis kritisiert den Tarifabschluß. In: StZ, 20.2.1974; Manche ÖTV-Mitglieder sind vom Streik-Ergebnis enttäuscht. In: WAZ, 20.2.1974; Urabstimmung völlig offen. In: WAZ, 21.2.1974. 
Zustimmung war zwar auch hier gegeben. Von einem eindeutigen Vertrauensbeweis für die Verbandsführung ließ sich jedoch nicht sprechen. ${ }^{210}$

Gleichzeitig wurde die Spitze der ÖTV von Medien und Politik scharf attackiert. In stark personalisierter Sicht sah die bundesdeutsche Presse den ÖTV-Vorsitzenden als eindeutigen Sieger des Streiks, der für seine Organisation einen triumphalen Erfolg errungen habe. Mit Jubel hatte das allerdings nichts zu tun. Klunckers Sieg war nach dem Urteil der Journalisten höchst bedenklich, wenn nicht sogar fast eine Katastrophe, die der Bundesrepublik und ihren Bürgern schweren Schaden zufügte. Für die FAZ, das konservative Flaggschiff der seriösen deutschen Presse, etwa hatte Kluncker mit dem Streik »Gewerkschaftsmacht demonstriert [...], wie kaum ein anderer zuvor«. Im Verhandlungsergebnis sah das Blatt »eine Niederlage für die Bürger, für die Volkswirtschaft, für die Autorität staatlicher Führung [...], für die Stabilität der Mark«. Die Wochenzeitung Die Zeit nannte die Lohnvereinbarung einen "Schock« und sprach von einer Erpressung des Staates durch die ÖTV. Der Spiegel erklärte, der Tarifabschluss beweise, »daß die Regierung nur so stark sein darf, wie ihre Bediensteten es zulassen «. ${ }^{211}$ Ähnlich dramatische Worte wählten nicht nur die Autoren nahezu aller anderen deutschen Printmedien, sondern auch die Kommentatoren im Fernsehen und im Radio. ${ }^{212}$

210 | Zusammenstellung der Ergebnisse der 2. Urabstimmung vom 20./21.2.1974, o. D. In: AdsD, ÖTV, 5/ÖTVB 412007. Die Wahlbeteiligung betrug 77 Prozent deutlich weniger als bei der vorangegangenen Urabstimmung über den Streik, an der sich etwas mehr als 90 Prozent der aufgerufenen Mitglieder beteiligt hatten. Im Bezirk Hessen stimmten mehr als 50 Prozent der Abstimmenden gegen die Annahme des Tarifvertrages. Vgl.: ÖTV, Post und Bahn stimmen Tarifabschluß zu. In: FAZ, 23.2.1974.

211 | Jürgen Eick: Mehr Macht als Verantwortung. In: FAZ, 20.2.1974; Dieter Piel: Wer soll das bezahlen? In: Die Zeit, 22.2.1974; Auf dem Wege in die Beamtenrepublik. In: Der Spiegel 28 (1974), H. 51, S. 28-41, hier: S. 28.

212 | Auswertung des Presse- und Informationsamtes der Bundesregierung über das Presse-, Rundfunk- und Fernseh-Echo auf den Tarifabschluss der ÖTV, 18.2.1974. In: AdsD, HSA, 1/HSAA010026. Vgl. auch: Walter Eberhardt/Bernd Rode/Herbert Steiner: Der Streik im öffentlichen Dienst 1974 im Spiegel der Presse, o. D. In: Archiv Ver.di, Bestand Kluncker, 11. Ausnahmen von der Regel sind so selten, dass sie es verdient haben, hier angeführt zu werden. Vgl. vor allem den Kommentar von Alfred Horné: »Tarifrunde 74: Die Gewerkschaften müssen zu- 
Dabei konnten Presse und Rundfunk Äußerungen prominenter Sozialdemokraten zitieren, die den Stuttgarter Tarifvertrag in Bausch und Bogen verwarfen. Hans Wertz beispielsweise nannte den Abschluss "unsinnig« und unverantwortlich, weil er die Öffentliche Hand „ganz zweifelsfrei« zu Steuererhöhungen zwingen werde; sein hessischer Amtskollege und Parteigenosse Heribert Reitz sprach sogar von einer »Tragödie« für Staat und Bürger. ${ }^{213}$ Erhard Eppler, Entwicklungshilfeminister in der Bundesregierung und einer der profilierten »Linken« in der SPD, empörte sich im März 1974 noch rückblickend über »die Demütigung des Kanzlers durch Kluncker«, die nicht nur Brandt, sondern der SPD insgesamt politisch schwer geschadet habe. Der Öffentliche Dienst der Bundesrepublik sei spätestens seit der Lohnerhöhung vom Februar 1974 eindeutig »überbezahlt« und es könne deshalb nur eine Frage der Zeit sein, bis »andere Gewerkschaften hier mit Heinz Kluncker ein Wort sprechen«, um diese ungerechte Privilegierung zu beenden. ${ }^{214}$

In den internen Debatten des Parteivorstandes klagte Hans Apel, seit dem Tarifabschluss gebe es eine "Verfilzungsdebatte in den Medien über das Verhältnis von SPD und ÖTV, die das Image der Partei ramponiere; Johannes Rau sekundierte mit dem Hinweis, die SPD gelte vielen Wählern wegen der engen Verflechtung der beiden Organisationen mittlerweile als "die Partei der öffentlichen Preise und Gebühren«. Beiden diente die Bürgerschaftswahl in Hamburg Anfang März 1974, bei der die Sozialdemokraten Stimmenverluste von rund zehn Prozentpunkten hinzunehmen hatten, als Beleg. Herbert Wehner und Helmut Schmidt bekannten sich ausdrücklich zu dieser Deutung. So erklärte Schmidt, die Hamburger Wahl sei ein

beißen«, gesendet im Bayerischen Rundfunk, 1. Hörfunkprogramm, 13.2.1974, 18.20 Uhr; ein Transkript in: AdsD, ÖTV, 5/ÖZVB130035. Der Autor verweist auf die Preissteigerungen und macht die Bundesregierung für den Arbeitskampf verantwortlich: »Wer die Arbeitnehmer und ihre Empfindungen so falsch einschätzt, der darf sich über einen gesalzenen Denkzettel nicht wundern.« Ungewöhnlich nüchtern und abwägend auch: Klaus Müller-Münter: Tarifpoker beendet. In: WAZ, 14.2.1974.

213 | SPD und FDP über Tarifabschlüsse besorgt. In: FR, 15.2.1974; Minister Reitz: Die Gewerkschaften ÖTV und DAG haben versagt. In: Gießener Anzeiger, 4.3.1974.

214 | »Sonst wird unser Staat ein Selbstbedienungsladen«. In: WAZ, 30.3.1974. 
»Denkzettel« der Wähler für den »de-facto-Rückzug dieser Partei aus der Mitte« - und damit meinte er auch den Stuttgarter Tarifabschluss. ${ }^{215}$

Konservative Politiker beteiligten sich natürlich ebenfalls an der Schelte für die ÖTV. Ministerpräsident Gerhard Stoltenberg ließ die Öffentlichkeit wissen, eine CDU-geführte Bundesregierung werde einen ähnlichen Konflikt mit einer streikenden ÖTV im Interesse der Allgemeinheit selbstverständlich »durchhalten«. Grundsätzlich dürfe es nicht mehr vorkommen, dass "Lohnleitlinien« der Regierung durch einen Streik beiseite gefegt würden. Notfalls müsse dies durch »gesetzliche Maßnahmen" sichergestellt werden. ${ }^{216}$ Ähnlich drohende Worte kamen im Herbst 1974 von Helmut Kohl, CDU-Vorsitzender und rheinland-pfälzischer Regierungschef: Arbeitsniederlegungen im Öffentlichen Dienst, mit denen Heinz Kluncker im Frühjahr »demonstriert habe, wer eigentlich die Macht in Händen halte, seien unerträglich und dürften sich nicht wiederholen «. ${ }^{217}$ Gesamtmetall, die Vereinigung der bundesdeutschen Metallunternehmer, schließlich beklagte »die totale Kapitulation der Arbeitgeber des Öffentlichen Dienstes« vor der ÖTV. ${ }^{218}$

Auch dieses Echo hatte die Führung der Gewerkschaft nicht in solcher Schärfe erwartet. In Zeitungsinterviews sagte Heinz Kluncker, er sei »erschrocken« über die öffentlichen Reaktionen auf den Tarifabschluss, und er beschwor den grundsätzlichen Charakter des Streiks: Die ÖTV habe mit dem Arbeitskampf die Tarifautonomie verteidigt, ohne die es keine soziale Marktwirtschaft, ja keine freie Gesellschaft gebe - und somit im Interesse der Allgemeinheit gehandelt. Wiederholt betonte er, der Streik habe nichts anderes möglich gemacht als einen Kompromiss, mit dem beide Seiten leben könnten. ${ }^{219}$

215 | Protokoll über die Sitzung des SPD-Parteivorstandes, 8.3.1974. In: BArch Koblenz, N 1369, 1813.

216 | Eine Art Taft-Hartley. In: Wirtschaftswoche 28 (1974), H. 18, S. 22.

217 | So Kohl auf einer Rede zum Abschluss des Landtagswahlkampfs in Hessen, zit. in: Mit Rückenwind nach Wiesbaden. In: FAZ, 25.10.1974.

218 | So der Bericht der Geschäftsführung für 1974, abgedruckt in: Peters: Verhandlung, S. 462.

219 | ÖTV will Urlaubsgeld in diesem Jahr. In: FAZ, 2.3.1974 (Zitat); Heinz Kluncker will an der Tarifautonomie festhalten. In: Handelsblatt, 14.3.1974. Als rückblickende Zusammenfassung dieser Position vgl. zudem: Heinz Kluncker: Partnerschaft muss einen Grundkonsens ermöglichen. In: Klaus Kinkel (Hrsg.): 
Damit stellt sich abschließend die dritte der oben aufgeworfenen grundlegenden Fragen zu dem Tarifkonflikt von 1973/74: Wie berechtigt war die scharfe Kritik von Politik und Medien am Streik, am Tarifabschluss und den Verhandlungspartnern und speziell an der ÖTV?

In der skizzierten Vorbereitung der Gewerkschaft auf die Tarifrunde und der Durchführung des Arbeitskampfes zeigte sich deutlich ein Aspekt, den fast alle zeitgenössischen Kommentatoren völlig ignorierten: Die ÖTV handelte bei ihrem Konfrontationskurs durchweg im Auftrag ihrer Mitglieder, d.h., sie erfüllte genau die Funktion, die Gewerkschaften in einer freien Gesellschaft haben. Dieser Punkt lässt sich sogar noch etwas schärfer formulieren: Mit Blick auf die Tarifrunde für 1974 hätte jedes alternative Verhalten der ÖTV-Führung massive Probleme innerhalb der Organisation nach sich gezogen. Die weitverbreitete Empörung an der Basis, als der Tarifvertrag auf dem Tisch lag, ist dafür ein beredter Beleg. Darüber hinaus handelte die Gewerkschaft offensichtlich sogar mit Zustimmung sehr vieler Bundesbürger; kritische Stimmen blieben in der Bevölkerung in der Minderheit. Der starke Preisanstieg im Jahr 1973, der mit der »Ölkrise« noch weiter zulegte, erklärt sowohl diese Sympathien als auch das starke Engagement der ÖTV-Mitglieder für die Forderungen der Organisation: Wegen der hohen Teuerungsrate galten die lohnpolitischen Rezepte der Bundesregierung als falsch und als sozial ungerecht.

Dieser demokratisch abgesicherte Charakter der ÖTV-Linie macht sie ökonomisch zwar nicht zwingend zu einem richtigen und erfolgversprechenden Programm. In einem gesellschaftlichen System, das auf dem freien Konflikt und Ausgleich politischer und wirtschaftlicher Interessen beruht, sollten solche Standpunkte aber ernst genommen und angemessen diskutiert werden. Mit seiner frühzeitigen Intervention in die Tarifverhandlungen versuchte Bundeskanzler Willy Brandt, genau diese Debatte zu verhindern. Insofern brach die ÖTV mit ihrem Arbeitskampf im Februar 1974 tatsächlich eine Lanze für die Freiheit nicht nur der Gewerkschaften. Diese grundlegende Bedeutung des Streiks zeigt sich gerade auch an der parteipolitisch motivierten Opposition im DGB und den Industriegewerkschaften.

In der Verantwortung. Hans-Dietrich Genscher zum Siebzigsten, Berlin 1997, S. 138-141. 
Es bleibt die Frage nach den allgemeinen ökonomischen Konsequenzen des Stuttgarter Tarifvertrages: Den zeitgenössischen Kritikern dieser Einigung galten sie schlichtweg als fatal. Auf den ersten Blick wirkt dieses Urteil in der Rückschau unmittelbar einleuchtend: Die Bundesrepublik erlebte in den Jahren 1974 und 1975 einen heftigen wirtschaftlichen Einbruch mit »Minuswachstum « und deutlich ansteigenden Arbeitslosenzahlen. ${ }^{220}$ Die Warnungen der Regierung vor »zu hohen« Lohnabschlüssen scheinen sich damit vollauf bestätigt zu haben. Schaut man genauer hin, dann zeigt sich aber ein etwas weniger eindeutiges Bild.

So betrug die Inflationsrate im Jahresdurchschnitt auch 1974 rund sieben Prozent - genau wie im Vorjahr. Seine Haltung im Tarifkonflikt mit der ÖTV hatte der Bundeskanzler aber immer mit dem Argument begründet, ein Lohn- und Gehaltsabschluss über zehn Prozent werde zu ebenfalls zweistelligen Teuerungsraten führen. Diese Wirkung stellte sich jedoch nicht ein, obwohl die Beschäftigten des Staates durchschnittlich doch etwas mehr als zwölf Prozent höhere Bezüge erhielten.

Offensichtlich war die Stuttgarter Vereinbarung im gesamten volkswirtschaftlichen Rahmen doch keine ökonomische Katastrophe, die unweigerlich einen Inflationsschub nach sich zog. Eher handelte es sich um einen ganz normalen Tarifvertrag. Der reale Einkommenszuwachs der Beschäftigten blieb in normalen Dimensionen: Berücksichtigt man die oben angeführte Berechnung des Bundeskanzleramtes, nach der eine zwölfprozentige Lohnerhöhung bei einer neunprozentigen Teuerung wegen der Steuerprogression und höherer Sozialabgaben nur den Kaufkraftschwund ausglich, dann brachte die Stuttgarter Einigung dank der im Verlauf des Jahres 1974 tatsächlich doch niedrigeren Inflationsrate den Staatsbediensteten zwar Gewinne - dieses Plus fiel mit durchschnittlich wohl vier Prozent jedoch weitaus bescheidener aus, als es die Zahlen im Tarifvertrag suggerieren. Als Wette auf die wirtschaftliche Zukunft war die Stuttgarter Vereinbarung daher keineswegs so abenteuerlich, wie die unterlegenen Politiker und die zeitgenössischen Kommentatoren in den Medien meinten. ${ }^{221}$

220 | Vgl. etwa: Wolfrum: Demokratie, S. 339.

221 | Rückblickend erklärte NRW-Finanzminister Wertz, das Ausbleiben der zweistelligen Inflationsraten sei wirtschaftlich nebensächlich. Entscheidend sei vielmehr, dass die Preissteigerungsrate 1974 »noch niedriger gewesen [wäre], wenn mehr tarifliche Disziplin bestanden hätte« (Handschriftliche Notizen von 
Wirklich bemerkenswert wurde die Abmachung vom Februar 1974 erst durch einen anderen und bereits älteren tarifpolitischen Erfolg der ÖTV: Im Oktober 1974 trat im Öffentlichen Dienst die zweistündige Arbeitszeitverkürzung auf nur noch 40 Stunden pro Woche in Kraft, die bereits 1972 vertraglich vereinbart worden war. Da der Staat seit dem Herbst 1973 gegen Jahresende zudem jeweils das vollständige 13. Monatsgehalt zahlte, gewann der Lohn- und Gehaltsabschluss vom Februar 1974 im Laufe des Jahres qualitativ doch einen anderen Charakter: Als sich das tarifpolitische Puzzle gegen Ende des Jahres erstmals vollständig zusammenfügte, ergab es einen deutlichen Wohlstandszuwachs und einen starken Kostenschub in den öffentlichen Personaletats, zumal alle drei Regelungen nach den dafür nötigen parlamentarischen Beschlüssen auch für die Beamten galten.

Gleichzeitig aber herrschte in der bundesdeutschen Gesellschaft ein starkes Krisengefühl. Wie sich nun zeigte, waren nämlich die oben zitierten Urteile der ÖTV-Führung über die angeblich geringe Bedeutung der »Ölkrise« falsch. Sie trivialisierten einen Vorgang, der tatsächlich ökonomisch von grundlegender Bedeutung war. Die überaus niedrigen Energiepreise, die es seit 1945 gegeben hatte, kehrten nicht zurück, und damit verloren die westlichen Wohlstands- und Industriegesellschaften ganz erheblich an wirtschaftlicher Dynamik. In weiter historischer Perspektive handelte es sich zwar um eine Normalisierung, die Wahrnehmung der Zeitgenossen aber sah anders aus. Unversehens gehörten die hochfliegenden Zukunftserwartungen der 1950er und 1960er Jahre der Vergangenheit an. Skepsis breitete sich aus; der Nachkriegsboom galt als endgültig vorbei. ${ }^{222}$

Gerade in dieser Phase des Umbruchs aber erzielte die ÖTV tarifpolitische Erfolge, die durchweg noch die älteren positiven Hoffnungen auf einen dauerhaften wirtschaftlichen Aufschwung dokumentierten. Für diese Koinzidenz wurde die Gewerkschaft nun öffentlich abgestraft: Die heftige Kritik, die sie in der Tarifrunde 1973/74 und auch noch lange danach auf sich zog, machte sie (die gerade in der Frage der Arbeitszeit sogar erst sehr spät gehandelt hatte) zur Hauptschuldigen.

Eher in einer Nebenrolle sehe ich die ÖTV in der Vorgeschichte der »monetaristischen Wende« der Bundesbank im Jahr 1974, die in der Ge-

Hans Liersch über die Tarifverhandlungen, 14.1.1975. In: AdsD, ÖTV-NRW II, 5/ ÖTVC603003).

222 | Vgl. knapp zusammenfassend etwa: Wehler: Gesellschaftsgeschichte, S. 60-64. 
schichte der Bundesrepublik einen bedeutsamen wirtschaftspolitischen Einschnitt bezeichnet. Der Augenschein wirkt zwar auch in dieser Sache zunächst recht überzeugend: Im Dezember 1974, als der Kombinationseffekt der ÖTV-Erfolge richtig deutlich wurde, verkündete das Direktorium der Bundesbank erstmals unzweideutig, sie werde auf die wirtschaftliche Entwicklung in der Bundesrepublik in Zukunft durch »Geldmengensteuerung« einwirken. Damit übernahmen die amtlichen »Währungshüter« der Bundesrepublik ein Konzept, das sich ausdrücklich gegen die wirtschaftspolitischen Rezepte des Keynesianismus richtete, zu denen sich die SPD und die von ihr geführte Bundesregierung nach wie vor bekannten. ${ }^{223}$ Wie erwähnt, gibt es Wirtschaftshistoriker, die den Beschluss der Bundesbank als direkte Reaktion auf die Tarifabschlüsse der Gewerkschaften und zumal der ÖTV in den Jahren 1973 und 1974 verstehen.

Mir scheint hier eine Zuspitzung vorzuliegen, die ein falsches Bild zeichnet. Zum einen wurde der Kurswechsel der Bank schon seit Ende der 1960er Jahre diskutiert und vorbereitet; zum anderen diente er erklärtermaßen vor allem dazu, die Bundesrepublik besser vor »außenwirtschaftlichen Störungen« wie etwa Währungsspekulationen oder stark steigenden Rohstoffpreisen zu schützen. ${ }^{224}$ Zwar hatte die Bundesbank bei ihrem Kurswechsel durchaus auch Gewerkschaften und Arbeitgeber im Auge: Die Tarifpartner, vor allem aber doch die Gewerkschaften, sollten durch das öffentlich deklarierte Geldmengenziel ihr früheres Vertrauen zurückgewinnen, »daß vertraglich vereinbarte Lohnerhöhungen nicht durch unkontrollierte Inflation wieder entwertet werden.« Wenn die Inflationsfurcht verschwinde, so argumentierte die Bundesbank, dann stärke das gerade die Tarifautonomie und deren Möglichkeiten zur »Herstellung eines vernünftigen sozialen Konsenses«. ${ }^{225}$

223 | Vgl. etwa: Helmut Schlesinger: Die Geldpolitik der Deutschen Bundesbank 1967-1977. In: Werner Ehrlicher/Dieter Duwendag (Hrsg.): Geld- und Währungspolitik im Umbruch. Internationale Erfahrungen des letzten Jahrzehnts, BadenBaden 1983, S. 59-83; Otmar Emminger: Deutsche Geldpolitik im Zeichen des Monetarismus. In: Peter Hampe (Hrsg.): Friedman contra Keynes. Zur Kontroverse über die Konjunktur- und Beschäftigungspolitik, München 1984, S. 43-66.

224 | Ebd., S. 57.

225 | Ebd., S. 63. 
Ende 1974 stand die Probe, ob dieses Konzept funktionieren konnte, noch aus. Die Rahmenbedingungen für Tarifverhandlungen aber hatten sich in diesem Jahr massiv und teilweise dauerhaft verändert. Zum einen übernahm die Bundesbank nun eine sehr viel aktivere und eigenständigere wirtschaftspolitische Rolle als zuvor. Zwangsläufig verloren damit »Lohnleitlinien« oder tarifpolitische Maximalzahlen der Bundesregierung, mit denen sich die ÖTV schon seit den frühen 1960er Jahren immer wieder neu herumgeschlagen hatte, deutlich an Bedeutung. Zum anderen aber unterschied sich die wirtschaftliche Situation des Landes grundlegend von der in den beiden ersten Nachkriegsjahrzehnten.

\section{Ein symbolischer Körper: Heinz Kluncker als «Gewerkschaftsboss»}

Ein Gewicht von 150 Kilo und mehr bei einer Körpergröße von 1,88 Meter darf man wohl ohne Zögern als exorbitant bezeichnen. Diese Masse brachte Heinz Kluncker in seinen schwersten Zeiten auf die Waage; zwischen 120 und 130 Kilo wog er in den 1970er Jahren wohl selbst in Phasen, in denen er stärker auf seine Ernährung achtete. ${ }^{26}$ Keine Frage - der ÖTVVorsitzende war ein sehr dicker Mann.

Gehört diese Feststellung in eine Geschichte der von ihm geleiteten Gewerkschaft? Oder handelt es sich dabei um eine anekdotische Nebensache, die von den wirklich wichtigen historischen Dingen ablenkt? In einer umfassend angelegten Darstellung der »Ära Kluncker« wäre es m. E. gleich aus zwei Gründen falsch, den ungewöhnlichen Körperumfang des Vorsitzenden einfach zu ignorieren. Erstens stand Heinz Kluncker in der öffentlichen Wahrnehmung spätestens seit Ende der 1960er Jahre ungewöhnlich eindeutig für »seine« Organisation. Er verkörperte die ÖTV so unmittelbar, dass es nur legitim ist, auch seinen Körper zu thematisieren: Ein wichtiges Element des Bildes würde fehlen, wenn davon nicht die Rede wäre, weil Kluncker als Person die öffentliche Wahrnehmung der Gewerkschaft prägte.

226 | Interview Elke Stierle, 17.12.2013. Rückblickend hat Kluncker selbst als sein höchstes Gewicht 159 Kilo angegeben (Rolf Bier: Kluncker: So war es wirklich. In: Bunte [1988], H. 46 [Magazin], S. 185). 
Zweitens will das vorliegende Buch ja auch eine politische Biografie Heinz Klunckers bieten. Sein enormes Gewicht ist dafür in einer Hinsicht sogar entscheidend bedeutsam: Es erklärt zwar nicht vollständig, aber doch zu einem guten Teil, warum er 1982 im Alter von nur 57 Jahren überraschend und ganz kurzfristig aus dem Amt schied. Daher gehört Klunckers Körper zwingend in eine Darstellung, die seine Arbeit für die Belange der ÖTV-Mitglieder würdigen möchte.

Wie viele sehr schwergewichtige Menschen hat Heinz Kluncker etliche Jahre gebraucht, bis die weit über 100 Kilo beisammen waren, die er fortan zu tragen hatte. Fotos von ihm aus den ersten Nachkriegsjahren zeigen eine normale Statur. 1964, bei seiner Wahl zum Chef der ÖTV, konnte man ihn zwar bereits mit dem etwas altmodischen Wort "wohlbeleibt« beschreiben; von richtiger Fettsucht ließ sich aber noch nicht sprechen. ${ }^{227}$ Gegen Ende des Jahrzehnts sah es dann schon ganz anders aus. Anfang 1971 nannte ein Journalist in einem Kluncker-Porträt erstmals ein genaues Gewicht (129 Kilo). Seitdem war »die bullige Statur « des Vorsitzenden immer wieder ein Thema, wenn die Presse über die ÖTV und ihren Chef berichtete. ${ }^{228}$ Kaum ein Artikel über die Gewerkschaft kam ohne einen Hinweis auf Klunckers enorme Leibesfülle aus - und damit wurde die Sache politisch.

Sicher lag es nahe, bei einem Mann, der nicht einfach nur sehr schwer, sondern zugleich hochgewachsen war, von einer "monumentalen Erscheinung« oder von einer "Art Naturereignis« zu sprechen. ${ }^{229}$ Die Journalisten nutzten mit solchen Formulierungen Klunckers große persönliche Wiedererkennbarkeit in der Reihe der ansonsten wenig charakteristischen bundesdeutschen Gewerkschaftsführer. Ebenso ironisch wie sprachlich gedrechselt bemerkte die $F A Z$, es käme »in unserer an markanten Umrissen armen Öffentlichkeit einer kaum zu rechtfertigenden Vergeudung physiognomischer Substanz« gleich, wenn Kluncker nicht zu einem führenden Gewerkschafter geworden wäre. In der Frankfurter Rundschau hieß es ein-

227 | Vgl. die Abbildungen in: Hemmer/Simon: Wirkung, S. 92 f., 107 u. 110 f.

228 | Carl-Christian Kaiser: Sprecher für Küchenfeen und Physiker. In: Die Zeit, 12.2.1971.

229 | Vetten: Riese, S. 52; Hermann Renner: Er macht Staatsverdiener aus den Staatsdienern. In: Die Welt, 11.2.1974. 
facher, aber mit ähnlicher Stoßrichtung, Kluncker sei »ein Mann so recht nach dem Geschmack von Karikaturisten «. ${ }^{230}$

In der Tat tauchte der ÖTV-Chef spätestens seit 1969 in zahlreichen politischen Karikaturen auf, die in der Regel immer dann in die Printmedien kamen, wenn Politiker und Gewerkschaft wieder über einen Tarifvertrag für den Öffentlichen Dienst berieten. Das Abbildungsmuster war dabei stets gleich: In der Gestalt von Heinz Kluncker erschien die Gewerkschaft als ebenso übermächtig wie unerschütterlich; ihre Kontrahenten wirkten demgegenüber durchweg machtlos und verschreckt. So trat Kluncker etwa als ein Riese, der sich zudem drohend die Ärmel aufkrempelt, einem winzig kleinen Minister in dessen Büro gegenüber; er konfrontierte den im Nikolaus-Kostüm auftretenden Hans-Dietrich Genscher mit einem gigantisch großen Schuh, auf dem die Tarifforderungen der Gewerkschaft stehen; er stürzte mit voller Wucht von oben auf den deutlich kleiner dargestellten Willy Brandt herab, oder er bedrohte als eine Lawine die gesamte Regierung, die als Seilschaft am steilen Berghang auftritt; er nahm - wiederum in Riesengestalt - den hilflos in seinen Armen zappelnden Genscher in den Schwitzkasten oder bestellte als offensichtlich alkoholisierter und erneut körperlich eindeutig dominanter Matrose an der Bar beim verängstigten Kanzler den Schnaps »mit den meisten Prozenten«. Einige dieser Zeichnungen hatten ein langes mediales Leben: Bei neuen Tarifrunden erschienen sie in vielen Zeitungen fast regelmäßig als Nachdruck. ${ }^{231}$

Auf nicht gerade subtile Weise vermittelten alle diese Karikaturen ein und dieselbe Botschaft: Die ÖTV war eine unkontrollierbare, nicht einzudämmende Macht, die rücksichtslos eigene Interessen durchsetzte. Die Leute von der schreibenden Zunft verstärkten und erweiterten diese Message, wenn sie ihren Lesern Heinz Kluncker als »Gewerkschaftsboss aus dem Bilderbuch« oder als »Elefanten im Porzellanladen« präsentierten und

230 | Hermann Rudolph: Heinz Kluncker, der Gewerkschafter aus dem Bilderbuch. In: FAZ, 7.2.1974; Winfried Didzoleit: Der flüsternde Riese: Kluncker. In: FR, 12.2.1974.

231 | Als Erstdruck erschienen die angesprochenen Motive jeweils in: Kieler Nachrichten, 27.9.1969; WAZ, 16.12.1969; Die Welt, 10.1.1970; Trierischer Volksfreund, 27.4.1982; Kölnische Rundschau, 8.1.1970; SZ, 9./10.11.1974. Sammlungen dieser und weiterer Karikaturen findet man in: Hemmer/Simon: Wirkung, S. $116 \mathrm{f}$; Eberhardt: Kluncker, S. $44 \mathrm{f}$. 
den ÖTV-Chef als einen »Machtfaktor« beschrieben, neben dem es in der Bundesrepublik »keinen gleichwertigen« gebe: »Wie arm ist dagegen der Kanzler dran, der ständig über alles Rechenschaft ablegen und sich für jeden Schritt verantworten muß« - so urteilte 1976 die Illustrierte Stern, die im politischen Spektrum der deutschen Presse eher auf der links-liberalen Seite als rechts einzuordnen war. Heinz Kluncker, so urteilte das Blatt abschließend, sei deshalb »der Größte [...] im ganzen Land «. ${ }^{232}$

Wenn sowohl die demokratischen inneren Strukturen der Gewerkschaften als auch deren eigentlich unschwer zu erkennende organisatorische und finanzielle Schwächen so konsequent übersehen oder auch geleugnet wurden, dann musste der schwergewichtige Heinz Kluncker wohl zwingend zum Symbol für Gewerkschaftsmacht an sich werden. Im Magazin Wirtschaftswoche hieß es 1981, es falle schwer, »Klunckers Körperfülle von seiner Machtfülle zu trennen«, denn seine Gewichtigkeit sei deren »angemessene Verpackung«. Im gleichen Atemzug bemerkte der Autor, Kluncker agiere in der Öffentlichkeit spätestens seit dem Streik von 1974 als »sein eigenes Markenzeichen« - und damit verwies er auf den modernen Charakter des eben beschriebenen Prozesses. ${ }^{233}$

Oben wurde zitiert, dass der ÖTV-Chef kurz nach seinem Amtsantritt verlangt hatte, eine Gewerkschaft müsse öffentlich ebenso leicht zu identifizieren sein wie eine »Markenartikelfirma«. In den 1970er Jahren war dieser Wunsch offensichtlich in Erfüllung gegangen, weil Kluncker selbst allgemein als Label der Organisation galt. Ebenfalls schon angeführt wurde die bewusste Entscheidung der ÖTV-Pressestelle, den Vorsitzenden in ihrer Medienarbeit stark in den Vordergrund zu stellen. Mit dieser Strategie hat die Organisation offensichtlich sehr erfolgreich, aber ungewollt ein recht zwiespältiges Image kreiert, weil der Körper des Vorsitzenden im Laufe der Zeit noch umfangreicher und damit noch suggestiver wurde. Zumindest Außenstehenden dürfte es da schwergefallen sein, sich gegen die simple

232 | In der Reihenfolge der Zitate: Hermann Rudolph: Heinz Kluncker, der Gewerkschafter aus dem Bilderbuch. In: FAZ, 7.2.1974; Eva Martens: Der Schreck in der Abendstunde. In: Die Zeit, 22.1.1982; Sievers: Kluncker, S.77-80. Als »Prototyp für einen Gewerkschafsboss« erscheint Kluncker in: Wenn es um mehr Lohn geht, kennt Kluncker keine Freunde. In: Die Welt, 11.6.1976.

233 | Georg Heller: Der sanfte Buhmann. In: Wirtschaftswoche 35 (1981), H. 13, S. 46 u. 50, hier: S. 46 . 
Assoziationskette zu wehren, die von Klunckers enormer Leibesfülle auf die Macht der ÖTV schloss.

Von zwiespältigen Wirkungen der Symbolfigur Heinz Kluncker muss man wohl auch deshalb sprechen, weil die Deutschen in den 1960er und 1970er Jahren begannen, anders über schwere Menschen zu denken, als sie das bisher getan hatten. In Zeiten, die noch keinen Überfluss an jederzeit verfügbaren und erschwinglichen Nahrungsmitteln kannten und in denen Familien den größten Teil ihres Einkommens für Lebensmittel aufwandten, stand gerade der schwergewichtige Mann für Wohlstand, ja sogar für Reichtum, und damit auch für Macht und Einfluss. ${ }^{234}$ Die Wohlstandsgesellschaft, die mit dem Nachkriegsboom in der eben noch schwer kriegszerstörten Bundesrepublik entstand, entwickelte jedoch einen anderen Blick: Das nun gewissermaßen demokratisierte Übergewicht galt als individuelles Problem, ja fast als charakterliches Versagen. »Wer dick ist, ist selber schuld «, dekretierte ein renommierter Medizinprofessor im Frühjahr 1973 mit großem Medienecho: Sehr schwere Menschen seien wie "Drogensüchtige«, die ihre Bedürfnisse nicht kontrollieren könnten. Zwei Jahre später blies Der Spiegel in einer Titelgeschichte mit der gleichen Botschaft zum »Kampf um die Pfunde«. Ein Kluncker-Foto als Negativbespiel illustrierte den Text. ${ }^{235}$

234 | Die politische Ikonographie der sozialistischen Arbeiterbewegung etwa setzte bei bildlichen Darstellungen von Unternehmern/Besitzbürgern und Proletariern stets auf den Kontrast zwischen Dick und Dünn. Ein Beispiel dafür sind die einschlägigen Karikaturen in der sozialdemokratischen Satirezeitschrift »Der Wahre Jacob«, vgl. u.a.: Ausgabe 22 im Jg. 53 (1932). Vgl. zur Verwendung von Symbolen in der Arbeiterkultur auch: Hans-Josef Steinberg: Satirische Zeitschriften der deutschen sozialistischen Arbeiterbewegung. In: Hans-Peter Harstick/ Arno Herzig/Hans Pelger (Hrsg.): Arbeiterbewegung und Geschichte. Festschrift für Shlomo Na'aman zum 70. Geburtstag, Trier 1983, S. 74-81; sowie Gottfried Korff: Rote Fahnen und geballte Faust. Zur Symbolik der Arbeiterbewegung in der Weimarer Republik. In: Dietmar Petzina (Hrsg.): Fahnen, Fäuste, Körper. Symbolik und Kultur der Arbeiterbewegung, Essen 1986, S. 27-60.

235 | In der Reihenfolge: Rainer Flöhl: Wer dick ist, ist selber schuld. In: FAZ, 7.4.1973; Kampf um die Pfunde. In: Der Spiegel 29 (1975), H. 39, S. 126-142, das Kluncker-Foto auf S. 129. Vgl. zum Hintergrund als Abriss: Georges Vigarello: The Metamorphoses of Fat. A History of Obesity, New York 2013. Als historischkulturwissenschaftliche Untersuchung zum Thema - trotz des anspruchsvollen 
Vor diesem Hintergrund ließ sich der mächtige Körper des ÖTVVorsitzenden noch schärfer antigewerkschaftlich deuten. "Die Beamten fressen den Staat«, so überschrieb wiederum Der Spiegel im Herbst 1974 einen ausführlichen Bericht über die stark gestiegenen Personalkosten der Öffentlichen Hand und »Klunckers neue Tarifrunde«. Auf der Titelseite prangte dazu ein großes Foto Klunckers, das - aus leichter Untersicht aufgenommen - seine Leibesfülle prägnant zur Geltung brachte. ${ }^{236}$ Die Welt, die ihr Verleger Axel Springer in den frühen 1970er Jahren zum rechtskonservativen Kampfblatt machte, wurde noch deutlicher: „Er ist, wie er ißt«, hieß es 1975 in einem persönlichen Porträt Klunckers. Die genauen Schlussfolgerungen blieben dann zwar dem Leser überlassen; fraglos aber waren Maßlosigkeit und Kontrollverlust die erwünschten Assoziationen. ${ }^{237}$ Da sich Symbole vielfältig nutzen lassen, können sie auch der Denunziation dienen - und genau in diesem Sinne nutzte ein großer Teil der bundesdeutschen Presse den ungewöhnlichen Körper des ÖTV-Vorsitzenden. Teils geschah dies ganz bewusst, teils wohl aber eher aus professioneller Bequemlichkeit, denn an dieser Gewerkschaft war nun einmal nichts so prägnant und wiedererkennbar wie ihr übergewichtiger Chef.

Als Person musste Heinz Kluncker selbstverständlich mit all den Problemen leben, die allzu viele Kilos auf Dauer zwingend mit sich bringen. Kurzatmigkeit selbst bei geringer körperlicher Belastung und eine enorme Schweißproduktion, die ihn zwang, bis zu dreimal täglich das Hemd zu wechseln, gehörten ebenso noch zu den harmlosen Folgen wie der Zwang, seine Anzüge in New York zu kaufen, weil die deutsche Konfektionsindustrie seinerzeit noch überhaupt nicht mit sehr massigen Kunden rechnete. ${ }^{238}$ Kluncker war ohne Frage für sein überschüssiges Gewicht selbst verant-

Titels - wegen willkürlich wirkender Lücken und einseitig ausgewählter Beispiele selbst als Essay eher unbefriedigend: Gilman L. Sander: Fat. A Cultural History of Obesity, Cambridge 2008.

236 | Die Beamten fressen den Staat. In: Der Spiegel 28 (1974), H. 51, Titelseite sowie die Artikel »Auf dem Weg in die Beamtenrepublik«, S. 28-41, u. »Selbstbedienungsladen derer, die drin sind? (Interview mit Bundespräsident Gustav Heinemann), S. 41-46.

237 | Die Macht des Mannes aus Muckertal. In: Die Welt, 12.9.1975.

238 | Da Kluncker gut verdiente und ohnehin oft in die USA reiste, war es für ihn kein Problem, seine Anzüge in dem Fachgeschäft »Fat Men Shop« auf der New Yorker 5th Avenue zu kaufen (Siegmar Schelling: Läßt die Muskeln spielen ... In: 
wortlich: Er aß sehr gern, sehr schnell und sehr viel. Ebenso verhielt es sich mit Wein. »Er konnte in einer Geschwindigkeit ein Glas leeren, das ist nicht möglich«, erinnert sich Elke Stierle. ${ }^{239}$ Ermahnungen zur Mäßigung beeindruckten Kluncker wenig: »Nur ein Mensch, der richtig ißt, könne auch richtig arbeiten«, sagte er Journalisten. Da er werktags in der Regel zwölf Stunden und mehr für die Gewerkschaft in Einsatz war und auch noch an den Wochenenden viele Amtsgeschäfte erledigte, stellte er sich selbst damit physiologisch fast eine Carte blanche aus. Auch gegenüber subtilerer Einflussnahme zeigte er sich immun. So versuchte Siegfried Bußjäger einmal gezielt, seinen Chef "zu beschämen, indem ich mindestens genauso viel gegessen habe wie er - aber das hat nicht funktioniert «. ${ }^{240}$

Zwar bemühte sich Kluncker in den 1970er Jahren auf ärztlichen Rat mehrmals, sein Gewicht zu verringern. Teilweise geschah das unter öffentlicher Anteilnahme: 1974 berichtete Bild gleich zweimal (sowohl im Januar als auch im Juli) über Diätkuren des ÖTV-Vorsitzenden. ${ }^{241}$ Er hungerte dabei unter medizinischer Anleitung in Kliniken und erzielte dennoch jeweils nur kurzfristige Erfolge. Schwer übergewichtigen Menschen empfahlen die Ärzte seinerzeit eine »Null-Diät«, d. h. den radikalen Verzicht auf fast jede Kalorienzufuhr für mehrere Tage oder Wochen. So ließ sich zwar ein rascher Gewichtsverlust erreichen. Längerfristig erwies sich dieses drastische Fasten jedoch als wenig nachhaltig, weil viele Patienten sehr schnell wieder stark zunahmen, wenn sie die Klinik verlassen hatten. ${ }^{242}$ Auch bei Heinz Kluncker trat dieser »Jo-Jo-Effekt« verlässlich ein. ${ }^{243}$

Welt am Sonntag, 27.1.1974). 1974 betrug Klunckers Brutto-Verdienst monatlich 5.134 DM (Vetten: Riese, S. 53).

239 | Interview Elke Stierle, 17.12.2013.

240 | Interview Siegfried Bußjäger, 1.4.2014.

241 | Der kranke ÖTV-Chef hat schon 10 Pfund abgenommen. In: Bild (Hamburg), 5.1.1974; ÖTV-Chef Kluncker nahm 40 Pfunde ab. In: Bild (Hamburg), 3.7.1974.

242 | Rainer Flöhl: Wer dick ist, ist selber schuld. In: FAZ, 7.4.1973. Bei solchen Kuren durfte der Patient neben Unmengen an Mineralwasser meist nur 100 Gramm Eiweiß pro Tag zu sich nehmen, um Muskelabbau zu verhindern. Zur Kritik an der »Null-Diät« und ihren geringen Erfolgsraten vgl. zusammenfassend: Gisela Küneweg: Stoffwechseländerungen bei Nulldiät, med. Diss., Universität Marburg 1980, S. 87-96.

243 | Interview Siegfried Bußjäger, 1.4.2014; Interview Elke Stierle, 17.12.2013. 
Er blieb so schwer, wie er war - und scheint die gesundheitlichen Schäden seit Mitte der 1970er Jahre achselzuckend akzeptiert zu haben. Im August 1979 erlitt er an seinem Schreibtisch in der Stuttgarter ÖTV-Zentrale einen Kreislaufkollaps. Er kam ins Krankenhaus; die Ärzte stabilisierten ihn und rieten, er müsse dringend wenigstens 40 Kilo Gewicht verlieren. ${ }^{244}$ Dazu ist es nicht gekommen. Bereits im Winter 1981/82 war Kluncker nur noch eingeschränkt bewegungsfähig, weil sein zu schwaches Herz den überaus massigen Körper nicht mehr ausreichend entwässern konnte. Wie Elke Stierle sagt, hatte sich Kluncker bereits im Januar 1982 zum Rücktritt entschlossen, weil er sich eingestehen musste, dass er die gerade abgeschlossenen Tarifverhandlungen für den Öffentlichen Dienst nur noch unter Qualen überstanden hatte. ${ }^{245}$

Einstweilen blieb dieser Entschluss jedoch geheim. Sowohl der kurz bevorstehende DGB-Bundeskongress, bei dem über die Nachfolge von Heinz Oskar Vetter entschieden wurde, als auch der zu dieser Zeit rasch eskalierende Skandal um die betrügerischen Geschäfte bei dem gewerkschaftlichen Baukonzern »Neue Heimat" hielten Kluncker auf dem Posten. In den Verhandlungen des DGB-Kongresses spielte der ÖTV-Vorsitzende zwar eine wichtige Rolle; gesundheitlich aber verschlechterte sich sein Zustand in diesen Tagen dramatisch. Hinter den Kulissen brach er im Berliner Kongresszentrum körperlich erneut zusammen, drängte die Ärzte aber, ihn mit "Spritzen und Tabletten« kurzfristig wieder fit zu machen. ${ }^{246}$

Das gelang offensichtlich. Wenig später aber zog sich Kluncker gezwungenermaßen ins Privatleben zurück. Anfang Juni 1982 informierte er die ÖTV-Führung und unmittelbar darauf auch die Öffentlichkeit über seine Entscheidung, zum 31. Juli 1982 als Gewerkschaftsvorsitzender abzutreten. Selbst Mitglieder des gHV waren überrascht, und sei es auch nur über den frühen Zeitpunkt der Ankündigung. Für den Hauptvorstand und die ÖTV insgesamt sowie für die Medien kam Klunckers Entscheidung ganz unerwartet. ${ }^{247}$

244 | Kluncker: Zusammenbruch am Schreibtisch. In: Bild (Hamburg), 7.8.1979. Zu diesem Zeitpunkt wog Kluncker nach eigener Aussage 159 Kilo.

245 | Interview Elke Stierle, 17.12.2013.

246 | Bier: Kluncker, S. 185. Zu Klunckers wichtiger Rolle bei der Entscheidung über Vetters Nachfolger siehe unten Kapitel IV.

247 | Interview Monika Wulf-Mathies, 7.4.2015. Zu den gewerkschaftspolitischen Hintergründen des Rücktritts siehe unten Kapitel IV. 
An ehrenden Worten in der Presse mangelte es nicht. Einmal mehr wurde er als »Prototyp « eines Gewerkschaftsführers und als unangefochten herrschender »Boss« der ÖTV gewürdigt. ${ }^{248}$ Die traurige, aber (wenn man es denn so sehen wollte) auch schon fast ironisch wirkende Wendung, dass sich Heinz Kluncker als die Inkarnation gewerkschaftlicher Übermacht unversehens gerade wegen der Körperfülle, die ihn zum Symbol gemacht hatte, letztlich als überaus schwach erwies, blieb hingegen unkommentiert.

\section{Gemischte Bilanz: Die innere Entwicklung der ÖTV in den 1970er Jahren}

\section{Ungelöste und gelöste Probleme: Der Ertrag der organisatorischen Reformen}

Ende 1974 konnte die ÖTV-Hauptverwaltung eine erfreuliche Zahl publizieren: Wie ihre Statistik auswies, hatte die Gewerkschaft in den vorangegangenen zwölf Monaten durchschnittlich etwas mehr als eine Million Mitglieder gezählt. Damit war nach langem Warten eine symbolisch bedeutsame Marke erreicht. Bereits 1963 hatte es 984.000 ÖTV-Kollegen und -Kolleginnen gegeben; die fast zum Greifen nahe Millionengrenze aber wollte in den nachfolgenden Jahren einfach nicht fallen. Bis 1970 kämpfte die ÖTV mit stagnierenden oder sogar leicht sinkenden Mitgliederzahlen. Erst danach ging es wieder voran; der Zuwachs hielt sich aber zunächst in Grenzen. So durfte sich die ÖTV erst nach 1974 berechtigt als Millionenorganisation bezeichnen. ${ }^{249}$

Die zweite Hälfte des Jahrzehnts brachte dann raschere und vor allem kontinuierliche Fortschritte: 1980 zählte die ÖTV bereits 1,15 Millionen

248 | In der Reihenfolge: Klunckers Rücktritt. In: StZ, 3.6.1982; Wulf Riemer: Der Boss löst Bestürzung aus. In: SZ, 3.6.1982. Zu den öffentlichen Reaktionen auf den Rücktritt siehe genauer auch unten Kapitel IV.

249 | ÖTV-Geschäftsbericht 1972/75, S. 591. Eine Statistik mit Stichtagszahlen jeweils zum Jahresende für den Zeitraum 1960 bis 1983 findet sich in: Hans-Joachim Meissner: Entgeltpolitik für den öffentlichen Dienst. Willensbildung, Entscheidungsprozesse, Ergebnisse und Korrekturperspektiven, Frankfurt/Main 1987, S. 212. Die zentrale EDV der ÖTV erfasste auch 1974 noch nicht alle Kreisverwaltungen und damit auch nicht alle Mitglieder: Ende des Jahres verzeichnete die zentrale Mitgliederdatei 715.000 Namen (ÖTV-Geschäftsbericht 1972/75, S. 610). 
Mitglieder. Sie gehörte damit zu der kleinen Gruppe unter den sechszehn DGB-Gewerkschaften, die in den 1970er Jahren deutlich gewachsen waren. ${ }^{250}$ Auch bei den Betriebsratswahlen - einem weiteren Gradmesser für gewerkschaftlichen Erfolg - schlug sich die ÖTV sehr gut: Obwohl Kandidaten ohne gewerkschaftliche Anbindung bei diesen Abstimmungen in den 1970er Jahren deutlich mehr Stimmen gewannen als zuvor, behauptete sich die ÖTV unangefochten als dominierende Kraft. So stellte sie bei den Wahlen im Jahr 1978 fast 80 Prozent aller Betriebsräte im Öffentlichen Dienst und in der Verkehrsbranche sowie 91 Prozent der Betriebsratsvorsitzenden. ${ }^{251}$

Die scharfe Kritik von Politikern und Medien, die der ÖTV spätestens seit dem Streik im Februar 1974 entgegenschlug, hat ihr als Interessenvertretung von Arbeitnehmern offensichtlich nicht geschadet. Gerade 1974 verzeichnete sie den stärksten Zuwachs an neuen Mitgliedern in ihrer ganzen Geschichte: fünf Prozent gegenüber 0,3 und 0,4 Prozent in den beiden vorangegangenen Jahren. Dieser plötzliche Sprung ist umso erstaunlicher, als es der Gewerkschaft zuvor kaum gelungen war, von der erheblichen Expansion des Öffentlichen Dienstes zu profitieren. Mehr als 400.000 neue Stellen entstanden - wie oben schon vermerkt wurde - im gesamten Staatsdienst zwischen 1969 und 1974; die ÖTV legte bis Ende 1973 (also in fünf Jahren) jedoch nur um knapp 37.000 Mitglieder zu. Allein im Jahr des Streiks summierten sich Neuaufnahmen und Abgänge hingegen zu einem Plus von rund 50.000 Beitragszahlern. ${ }^{252}$

Der gerade einmal dreitägige Streik, der die mächtig auftrumpfenden Arbeitgeber zum Nachgeben zwang, nutzte der Gewerkschaft - so scheint es - deutlich mehr als all die organisatorischen Reformen, die sie zwischen 1966 und 1968 beschlossen hatte. Damit sollen diese Bemühungen nicht

250 | Genaue Angaben und Tabellen in: Beate Kindler: Mitgliederentwicklung der Gewerkschaft ÖTV 1970 bis 1990. In: Archiv Ver.di, Bestand Kluncker, 40. 1978 wuchs die Zahl der DGB-Organisationen mit der Aufnahme der »Gewerkschaft der Polizei« auf 17. Siehe dazu genauer im nachfolgenden Unterkapitel.

251 | ÖTV-Geschäftsbericht 1976/79, S. 553 f. Betriebsräte entstanden in diesem Jahr im Organisationsbereich der ÖTV in 1.713 Dienststellen und Unternehmen; die Wahlbeteiligung betrug fast 85 Prozent. Nur 3,9 Prozent der gewählten Kandidaten gehörten zur DAG.

252 | Meissner: Entgeltpolitik, S. 213. Die Angaben beziehen sich auf die Stichtagsdaten jeweils zum Jahresende. 
entwertet werden. Ihre Berechtigung lässt sich nicht bestreiten - dennoch lieferten weder die oben skizzierte neue Organisationsstruktur, die stärker berufs- und betriebsorientiert gestaltet war, noch eine modernisierte Medien- und Öffentlichkeitsarbeit allein die Impulse, die nötig waren, um die Basis der ÖTV wirklich spürbar zu verbreitern. Der Satz von den notwendigen, aber letztlich nicht ausreichenden Voraussetzungen drängt sich beim Blick auf diese Entwicklung geradezu auf: Der Arbeitskampf war offensichtlich das beste Mittel, um abseits stehende Beschäftigte zum Eintritt in die Gewerkschaft zu bewegen. ${ }^{253}$

Allerdings gab es in den internen Debatten der ÖTV seinerzeit niemanden, der diesen Zusammenhang zwischen der tarifpolitischen Strategie und der organisatorischen Entwicklung herstellte. In Heinz Klunckers Amtszeit hat die Gewerkschaft bis 1982 im Öffentlichen Dienst nicht mehr gestreikt (wenn man von Warnstreiks absieht, die sich auf die Mitgliederzahlen kaum positiv auswirkten). Die ÖTV-Spitze hat sich eher sogar darum bemüht, weitere Arbeitsniederlegungen großen Stils zu vermeiden bzw. sie zögerte damit selbst dann, wenn größere Teile der Basis einen Streik forderten. Diese Furchtsamkeit (oder weniger scharf formuliert: diese starke Zurückhaltung) und ihre vielfältigen Gründe werden weiter unten noch erörtert. ${ }^{254}$

Eher indirekt, aber durchaus wirkungsvoll trug die organisatorische Entwicklung selbst dazu bei, dass die ÖTV nach 1974 nicht darüber nachdachte, wie sie Streiks strategisch für sich selbst nutzen konnte. Man sah sich (durchaus berechtigt) ohnehin auf gutem Wege; das Krisengefühl, das die organisatorischen Debatten und Reformen der 1960er Jahre angeschoben hatte, verschwand. Damit urteilte die Gewerkschaft auch recht gelassen über Strukturen und Aufgaben, die zuvor als problematisch bzw. als ungelöst gegolten hatten.

Beispielhaft zeigt sich der gelassenere Blick auf die eigenen Probleme etwa bei der Altersstruktur. Sorgte sich die ÖTV-Führung zuvor über die

253 | Die Gewerkschaft Ver.di als Nachfolgerin der ÖTV orientiert ihre Arbeit seit 2007 bewusst auch an diesem Zusammenhang. Vgl. dazu etwa: Andrea Kocsis: Erfolgreiche Tarifpolitik und guter Organisationsgrad - zwei Seiten einer Medaille. In: dies./Gabriele Sterkel/Jörg Wiedemuth (Hrsg.): Organisieren am Konflikt. Tarifauseinandersetzungen und Mitgliederentwicklung im Dienstleistungssektor, Hamburg 2013, S. 12-18.

254 | Siehe den nachfolgenden Abschnitt über die Tarifpolitik nach 1974. 
zunehmende »Vergreisung« der Organisation, so sprach Heinz Kluncker bereits 1972 von »der gesunden Altersstruktur der Mitgliedschaft«; vier Jahre später lobte er sogar die »sehr günstige Altersstruktur«. ${ }^{255}$ Dabei hatte sich de facto gegenüber dem vorangegangenen Jahrzehnt nichts grundlegend geändert. Anteilig stellten Rentner und Rentnerinnen nach wie vor fast konstant etwa elf bis dreizehn Prozent aller ÖTV-Mitglieder; die Gruppe der - im weiteren Sinne - »jugendlichen« Beitragszahler, die jünger als 25 waren, fiel in der Regel etwas kleiner oder bestenfalls genauso groß aus wie die der Alten. Auch der Mitgliederzuwachs nach 1974 führte - trotz etwas größerer Schwankungen bei den jungen Gewerkschaftern - nicht zu entscheidend anderen Verhältnissen, d. h., beide Alterskohorten entwickelten sich in absoluten Zahlen stets ungefähr in dem Tempo, in dem auch die gesamte Organisation stärker wurde..$^{256}$

Damit hat die Gewerkschaft in den 1970er Jahren offensichtlich ihren Frieden gemacht. Die Erfahrung, dass die betont bunte und »moderne" Imagekampagne, die in den Jahren um 1970 auf Berufsanfänger zielte, die Organisation letztlich nicht wirkungsvoller stärkte als die vergleichsweise biederen früheren Bemühungen um junge Menschen mag zu dieser neuen Gelassenheit beigetragen haben. Zudem wirkten andere Werbeaktionen stets nur begrenzt. Selbst wenn sie ungewöhnlich aufwendig vorbereitet und inszeniert wurden, erwiesen sie sich schon auf mittlere Sicht als ein Strohfeuer. ${ }^{257}$

255 | Protokoll ÖTV-GT 1972, S. 65; Protokoll ÖTV-GT 1976, Bd. 1, S. 76.

256 | Vgl. die Angaben in: ÖTV-Geschäftsbericht 1968/71, S. 424; ÖTV-Geschäftsbericht 1972/75, S. 592; ÖTV-Geschäftsbericht 1976/79, S. 677 f. Speziell für die Jugendlichen vgl. beispielhaft auch: Statistische Angaben zur Altersstruktur der ÖTV-Mitglieder im Bezirk NRW I 1975-1979, o. D. In: AdsD, ÖTV NRW I, Ordner 2.6. Bezirksjugendkonferenz 1979.

257 | Vgl. beispielhaft die Werbeaktion im Winter 1971/72. Sie wurde durch einen kostspieligen Auftrag an ein Meinungsforschungsinstitut vorbereitet, das »Unorganisierte und Fremdorganisierte« zu ihrer Sicht auf die ÖTV befragte. Kurzfristig scheint die von diesen Ergebnissen inspirierte Kampagne erfolgreich gewirkt zu haben: Der Mitgliederzuwachs im Jahr 1971 lag mit 1,7 Prozent deutlich höher als in den Vorjahren. Bereits 1972 aber sank er wieder auf 0,4 Prozent ab, obwohl die Aktion noch bis in den März des Jahres fortgeführt wurde (ÖTVGeschäftsbericht 1968/71, S. 40 f.). Details zu der erwähnten Studie konnten im Rahmen dieser Untersuchung nicht ermittelt werden. Zu den Kampagnen für Jugendliche siehe S. 191. 
Hinter diesen mageren Resultaten stand das Problem der Mitgliederfluktuation, das die ÖTV weiterhin begleitete. Sogar im Rekordjahr der Organisation 1974 ähnelte die Anwerbung neuer Gewerkschaftsmitglieder einer Sisyphusarbeit: Dank des Streiks unterzeichneten in diesem Jahr fast 110.000 Beschäftigte eine Beitrittserklärung zur ÖTV (58.000 davon - wie gesagt - allein im Februar); am Jahresende aber schrumpfte das Plus an Beitragszahlern auf »nur« noch 50.000 zusammen, weil die Organisation gleichzeitig 60.000 Mitglieder durch Tod, Austritt oder auch durch schlichtes »Verschwinden« verlor. ${ }^{258}$ Ähnlich wie bei der Frage der Altersstruktur scheint die Organisation auch mit Blick auf die Fluktuation an ihrer Basis in den 1970er Jahren ihre begrenzten Handlungsmöglichkeiten akzeptiert zu haben. 1972 klagte Heinz Kluncker auf dem Gewerkschaftstag zwar noch einmal über die kontinuierlichen Verluste an Mitgliedern, die "nach wie vor erheblich« seien. Danach aber wurde das Problem weder auf den nachfolgenden Kongressen noch in den Beratungen des Hauptvorstandes erneut angesprochen: Es galt nun offensichtlich als ein unvermeidliches Übel. ${ }^{259}$

Wirklich positiv entwickelte sich nach 1970 die Finanzsituation der ÖTV. Gerade in dieser Hinsicht fußte ihr gestärktes Selbstbewusstsein nicht auf der Neubewertung weitgehend unveränderter Probleme und Risiken, sondern auf neuen Tatsachen. Oben wurde gezeigt, wie massiv sich der finanzielle Spielraum der Gewerkschaft in den 1960er Jahren verengt hatte. Diese Notlage konnte die ÖTV in den 1970er Jahren hinter sich lassen. In ihrer Abrechnung für 1975 resümierte die Hauptkasse befriedigt, die Organisation verfüge über genügend Mittel, »um auch schwierige und kritische Situationen meistern zu können«; auf dem Gewerkschaftstag im Sommer 1976 erklärte Heinz Kluncker, die ÖTV sei »eine finanziell konsolidierte Organisation ${ }^{260}$

Tatsächlich war es der Gewerkschaft gelungen, wieder so zu wirtschaften, dass sie nicht mehr von der Hand in den Mund lebte. 1975 etwa konnte sie in ihrer Bilanz am Jahresende einen Überschuss von soliden zehn Pro-

258 | Vgl. genauer den Bericht in: Protokoll der 13. Sitzung des HV, 18./19.6.1975. In: AdsD, ÖTV, 5/ÖTVB130036.

259 | Protokoll ÖTV-GT 1972, S. 66.

260 | In der Reihenfolge der Zitate: Protokoll der 18. Sitzung des HV, 11.6.1976. In: AdsD, ÖTV, 5/ÖTVB130051; Protokoll ÖTV-GT 1976, Bd. 1, S. 78. 
zent ausweisen; in absoluten Zahlen blieben ihr 14,5 Millionen DM von den rund 145 Millionen DM, die sie eingenommen hatte. In den nachfolgenden Jahren blieb es bei diesem Verhältnis von Einnahmen und Ausgaben. Der Streikfonds füllte sich damit verlässlich; andere Rücklagen konnten ebenfalls regelmäßig gestärkt werden. ${ }^{261}$

Die Handlungsmöglichkeiten, die sie damit finanziell zurückgewann, verdankte die ÖTV einer strikten Ausgabenkontrolle und deutlich verbesserten Beitragszahlungen. Beides ließ sich als Erfolg verbuchen; beides aber war hart erkämpft und brachte für die Organisation auch Probleme mit sich. So war es für die Hauptkasse sicher sehr erfreulich, dass die Gewerkschaft nach 1970 in fast jedem Haushaltsjahr weniger Geld ausgab, als es der jeweilige Finanzplan vorgesehen hatte. ${ }^{262}$

Der konsequent knapp gehaltene Apparat stieß im Alltag aber offensichtlich auch an seine Grenzen, weil ehrenamtliche Arbeit den Einsatz professioneller Kräfte nur bedingt ersetzen konnte. Wiederholte Klagen einzelner Berufsgruppen, sie würden von der ÖTV mit ihren speziellen Interessen und Problemen nicht adäquat vertreten, belegen dieses Dilemma. So beschwerte sich ein Delegierter auf dem Gewerkschaftstag von 1972, es gebe keine nennenswerte Zielgruppearbeit der ÖTV für seine Berufsgruppe, die Feuerwehrmänner, obwohl diese 19.000 Mitglieder stellten und mit einem Organisationsgrad von 90 Prozent doch als gewerkschaftliche Vorbilder taugten. Ein Vertreter der medizinischen Berufe monierte, es fehlten aktuelle »berufspolitische Schriften« der Gewerkschaft für die Beschäftigten in den Krankenhäusern, wie es sie für andere Professionen schon seit längerem gebe. 1976 schließlich forderten gleich mehrere Vertreter medizinischer Berufe, die ÖTV müsse in den Kliniken präsenter sein und »aktiver werden ${ }^{263}$

261 | Die genauen Zahlen der Jahre 1975 bis 1978 in: ÖTV-Geschäftsbericht 1976/79, S. 686-692. Im Jahr 1964 hatte der Überschuss - wie oben gezeigt wurde - lediglich 1,7 Prozent der Einnahmen betragen.

262 | Vgl. ebd.; Heinz Kluncker in: Protokoll ÖTV-GT 1980, Bd. 1, S. 66.

263 | In der Reihenfolge: Protokoll ÖTV-GT 1972, S. 85-87 (der Delegierte Will Wolf, Frankfurt, für die Feuerwehrleute); ebd., S. 98 (der Delegierte Paul Schmidt, Augsburg, für das Gesundheitswesen); Protokoll ÖTV-GT 1976, S. 98 f. (Zitat; die Delegierte Annette Schwarzenau, Berlin), S. 103 (die Delegierten Peter Lippert und Bodo Fast, beide ebenfalls Berlin). 
Nun konnte eine Organisation, deren Basis so extrem unterschiedliche Gruppen umfasste, gewiss keine vollständige Harmonisierung der Interessen erreichen. Dennoch scheint die berufsspezifische Arbeit der ÖTV auch an einem Mangel an Personal und Geld gelitten zu haben. Die Feststellung des Vorsitzenden auf dem Kongress von 1980, die Gewerkschaft habe im vorangegangenen Jahrzehnt stets "sparsam gewirtschaftet«, kann insofern nicht uneingeschränkt als Erfolgsmeldung gelten. Zumindest einige der Delegierten urteilten noch schärfer: Sie monierten die »starre Sparsamkeit» der Hauptverwaltung oder klagten über »Pfennigfuchserei am falschen Ort«. Nach einer ungewöhnlich langen und kontroversen Debatte forderte der Gewerkschaftstag schließlich den Hauptvorstand auf, die Möglichkeiten für eine bessere personelle Ausstattung der Kreisverwaltungen zu prüfen. ${ }^{264}$

Ihre Gewinne erwirtschaftete die ÖTV in den 1970er Jahren allerdings nicht nur durch restriktiv gestaltete Etats. Weitaus wichtiger für den finanziellen Erfolg waren stärker sprudelnde Einnahmen dank zahlreicher neuer Mitglieder und höherer Beiträge. Vor allem der zweite dieser beiden Trends erklärt die gewandelte Kassenlage. In den 1960er Jahren war die ÖTV eine arme Gewerkschaft, weil ihre Mitglieder nur knauserig zahlten; nach 1970 wuchs der durchschnittliche Beitrag so deutlich, dass die Organisation ihre ökonomische Krise überwinden konnte. Die konkreten Zahlen sind an dieser Stelle entbehrlich, denn der Aufschwung lässt sich mit anderen Angaben besser belegen: Erstellt man eine Liste der Durchschnittsbeiträge, den die einzelnen DGB-Verbände jeweils von ihren Mitgliedern erhielten, dann verbesserte sich die ÖTV in dieser Statistik von »dem blamablen 12. Platz« (so die Bewertung durch Heinz Kluncker) im Jahr 1970 in rasantem Tempo auf den vierten Rang im Jahr $1978 .^{265}$

Da die Einkommen der Beschäftigten im Öffentlichen Dienst in dieser Zeit keineswegs stärker wuchsen als die der Arbeiter und Angestellten in den Privatbetrieben, entstand der statistische Sprung nach vorn offensichtlich durch zunehmende »Beitragsehrlichkeit«: Anders als zuvor führten vie-

264 | In der Reihenfolge der Zitate: Protokoll ÖTV-GT 1980, Bd. 1, S. 66 (H. Kluncker); Wolfgang Uhlenbrock (Duisburg), S. 432; Anni Kaufmann (Niederrhein), S. 435. Die gesamte Debatte vgl. in: ebd., S. 431-446. Die Antragskommission hatte empfohlen, den entsprechenden Antrag abzulehnen.

265 | Protokoll ÖTV-GT 1972, S. 62 (Zitat); ÖTV-Geschäftsbericht 1976/79, S. 679. 
le Mitglieder der ÖTV nun tatsächlich den prozentualen Anteil ihres Einkommens an die Gewerkschaft ab, den diese in ihrer Satzung verlangte. ${ }^{266}$ Allerdings geschah das keineswegs freiwillig. Die Organisation musste bei den Kollegen und Kolleginnen vielmehr hart nachfassen, um ihren Anspruch durchzusetzen - und viele Mitglieder reagierten sehr verärgert, als sie in dieser Form zur Kasse gebeten wurden.

Die Wende in der Finanzgeschichte der ÖTV begann Ende 1970. In diesem Monat beschloss der Beirat der Organisation (der zwischen den Gewerkschaftstagen als ihr höchstes Beschlussgremium fungierte) eine ganz neue Beitragsordnung. Die alte Tabelle, die Lohn- und Gehaltsgruppen bildete und diesen jeweils einen in DM angegebenen Monatsbeitrag gegenüberstellte, verschwand in der Versenkung. An ihre Stelle trat ab April 1971 die denkbar einfache Vorschrift, jedes Mitglied habe künftig dauerhaft ein Prozent der individuellen Bruttobezüge als Beitrag zu leisten. Diese Regel galt uneingeschränkt, während die Tabelle zuvor einen Höchstbeitrag festgelegt hatte, der gutverdienende Angestellte und Beamte entlastete. Ihrer Basis versprach die Organisation »bessere Leistungen« und eine schlagkräftigere ÖTV, denn »die Streikkasse [...] sitzt bei jeder Tarifverhandlung mit am Tisch«. Zugleich erklärte sie, gegenüber der alten Satzung bedeute die neue Version ja eine Beitragssenkung: Wer korrekt gezahlt habe, der werde nun entlastet. ${ }^{267}$

266 | Wie oben ausgeführt wurde, verlangte die Satzung seit 1963 einen Beitrag von durchschnittlich etwa 1,3 Prozent des Bruttogehalts. Allerdings ergab sich dieser Wert nur indirekt: Eine Beitragstabelle nannte absolute Zahlen für das Einkommen und den Monatsbeitrag (siehe oben Kapitel II). Zum empirischen Nachweis, dass die Löhne und Gehälter im Öffentlichen Dienst in etwa im Einklang mit den Tariflöhnen der Privatindustrie stiegen, vgl.: Deutschmann/Schmiede: Lohnentwicklung, S. 263-271.

267 | Gerechter Beitrag - Bessere Leistungen. In: ÖTV-Magazin 1971, H. 2, S. 3-7, hier: S. 4. Kinderzuschläge wurden nicht in den Bruttolohn einbezogen, auf den sich der Beitrag beziehen sollte, um Familienväter zu entlasten. Der mit der Reform abgeschaffte Höchstbeitrag betrug 1970 monatlich 15 DM für alle Beschäftigten, die mehr als 1.050 DM brutto im Monat verdienten. Heinz Kluncker, der wie alle festangestellten Funktionäre selbstverständlich Beiträge zu zahlen hatte, taugt als ein gutes Beispiel, um die finanzielle Bedeutung zu demonstrieren: Er verdiente damals rund 5.000 DM monatlich, musste nach der neuen Regel also 50 DM monatlich zahlen, statt zuvor 15 DM. 
Formal entsprach das den Tatsachen. Allerdings hatte bislang kaum ein ÖTV-Mitglied tatsächlich den ordnungsgemäßen Obolus entrichtet - und damit begannen die Probleme. Erschreckt berichteten etliche der unteren Verwaltungseinheiten, man habe trotz der Vorschriften »im Interesse der Erhaltung des Mitgliederbestandes und der Mitgliederwerbung « ungeprüft jeden Beitrag akzeptiert, den die Kollegen für sich selbst deklarierten; gehe man nun strikt und "mit Druck« vor, um die Ein-Prozent-Regel durchzusetzen, dann könne es an der Basis »zur restlosen Auslöschung ganzer Bereiche kommen. $^{268}$

Die ÖTV-Spitze hatte solche Proteste vorausgesehen und verlangte daher gar keine sofortige Umsetzung der neuen Satzung. Bis Anfang 1973 allerdings sollte eine Angleichung erfolgt sein. Es blieb den Kreisverwaltungen überlassen, wie sie dabei vorgingen und mit welchem Tempo individuell »zu niedrige« Beiträge auf den Satz von einem Prozent angehoben wurden. ${ }^{269}$

In der Praxis erwies sich jedoch selbst die Übergangsfrist von anderthalb Jahren als allzu optimistisch. Ein großer Teil der unteren Verwaltungsstellen blieb passiv, teils wohl, weil sie Austritte fürchteten, teils aber auch einfach deshalb, weil sie die zusätzliche Arbeit nicht bewältigen konnten. Als der Bezirk Nordrhein-Westfalen II die Umsetzung der neuen Vorschrift nach einem Jahr überprüfte, ermittelte er enttäuschende Ergebnisse: Nur 56 Prozent der Mitglieder in diesem kopfstärksten Regionalverband der ÖTV zahlten nach einer Kontrolle den satzungsgemäßen Beitrag; der große Rest bestimmte nach wie vor de facto selbst, was ihnen die Gewerkschaft wert war.

Zudem zeigten sich frappierende Unterschiede zwischen den einzelnen Kreisverwaltungen: Einige waren systematisch an alle Mitglieder herangetreten, andere hatten hingegen noch gar nichts getan. Auch Austritte wurden verzeichnet: Etwa 4.000 Kündigungen gingen wohl eindeutig auf Versuche zurück, die Ein-Prozent-Regel durchzusetzen. Das entsprach etwa

268 | In der Reihenfolge der Zitate: Entschließung der Fachgruppe Versorgungsverwaltung Hannover, 4.2.1971. In: Archiv Ver.di, Bestand Kluncker, 56; KV Siegburg an den gHV, 25.1.1971. In: ebd. Vgl. ähnlich auch: KV Hannover an den HV, 22.1.1971. In: ebd., sowie auch noch zahlreiche weitere Mitteilungen dieser Art.

269 | Protokoll ÖTV-GT 1972, S. 64. 
drei Prozent der Kollegen und Kolleginnen in der Ruhrregion. ${ }^{270}$ Diese Resultate dürfen wohl als repräsentativ für die ganze Organisation gelten. So ging der enttäuschend geringe Zuwachs an Mitgliedern, den die ÖTV in den Jahren 1972 und 1973 melden musste, offensichtlich auf eine ungewöhnlich starke Abwanderung zurück, weil doch etliche Beitragszahler die ÖTV unter den geänderten Bedingungen als »zu teuer« empfanden. ${ }^{271}$

Die Verbandsführung hielt dennoch entschlossen an ihrem Ziel fest, die neue Beitragsformel zur Realität zu machen. Da sie den Eindruck hatte, viele der Kreisverwaltungen gingen dabei zu zögerlich vor, wurde sie im Sommer 1973 selbst aktiv. Sie entwarf einen Fragebogen für die Beitragszahler, der genaue Angaben zur individuellen Tätigkeit und zur Besoldung verlangte. Zugleich informierte das Formular die Befragten, sie seien verpflichtet, sich "unverzüglich" bei der Gewerkschaft zu melden, wenn ihre persönliche Besoldung stieg. Die unteren Verwaltungsstellen sollten den Fragebogen flächendeckend verschicken und auf einer Antwort bestehen..$^{272}$

Zahlreiche der Funktionäre "vor Ort« antworteten jedoch mit Protesten: Mit dieser »Gehaltsschnüffelei« vertreibe die ÖTV die eigenen Mitglieder; es werde zu »Massenaustritten« kommen. Der Bezirk Bayern meldete, die Aktion werde »von dem weitaus größten Teil der Vertrauensleute abgelehnt«. Zur Begründung höre man immer wieder den Satz: "Ich bin nicht bereit, die Organisation zu zerstören.« Die Kreisverwaltung Wiesbaden warnte, wenn die ÖTV auf der Ein-Prozent-Regel bestehe, würden vor allem gutverdienende Angestellte und Beamte austreten, die sich ohnehin schon über die tarifpolitische "Sockelei« der Gewerkschaft ärgerten: Der fehlende Höchstbetrag bedeute nichts anderes, als dass die Elite des Öffent-

270 | Protokoll über die Bezirksvorstandssitzung NRW II, 24.5.1974. In: AdsD, ÖTV NRW II, 5/ÖTVC022003. Neueintritte glichen die 4.000 Kündigungen in der Mitgliederstatistik allerdings wieder aus. Zum unterschiedlichen Vorgehen der Kreisverwaltungen in der Beitragsfrage vgl. auch: Kassenbericht 1972. In: ÖTV-intern 1973, H. 6, S. 40-45, hier: S. 44 f.

271 | Das Plus stürzte von fast 17.000 zusätzlichen Mitgliedern im Jahr 1971 auf nur noch 3.892 (1972) und 2.914 (1973) ab. Berechnet nach: Meissner: Entgeltpolitik, S. 212.

272 | ÖTV-Geschäftsbericht 1972/75, S. 200. Ein Exemplar des Fragebogens in: Formular Nr. 1032, 6/73, o. D. In: Archiv Ver.di, Bestand Kluncker, 56. 
lichen Dienstes "von einer Mitgliedschaft [in der ÖTV - K.C.F.] praktisch ausgesperrt« werde. ${ }^{273}$

Heinz Kluncker und der gHV hielten jedoch Kurs. Verärgert wischte der Vorsitzende den Widerspruch der unteren Funktionäre beiseite: Er beweise nur, dass die Durchsetzung der Beitragsreform vielfach bislang "völlig vernachlässigt bzw. gar nicht erst in Angriff genommen wurde«. Umso wichtiger sei es, die Organisation weiterhin zur Aktivität zu zwingen. ${ }^{274}$

Der Fragebogen wurde daraufhin wohl tatsächlich flächendeckend verteilt. Ob die Mitglieder ihn dann durchweg auch ausfüllten und zurückschickten, ist damit jedoch nicht gesagt. Zudem gab es selbstverständlich keine Garantie für wahrheitsgemäße Angaben. Letztlich musste die ÖTV ihren Beitragszahlern nach wie vor vertrauen. Anders als in vielen Industriebetrieben, in denen die Lohnbuchhaltung neben den Sozialabgaben gleichzeitig den Gewerkschaftsbeitrag vom Gehalt abzog, gab es in dieser Hinsicht im Öffentlichen Dienst auch in den 1970er Jahren keine nennenswerte Kooperation zwischen Arbeitgebern und Gewerkschaft. ${ }^{275}$ Das Gefühl, viele Mitglieder nähmen die Satzung immer noch nicht ernst, blieb der ÖTV daher dauerhaft erhalten. Noch 1981 klagte der Hauptkassierer, es gebe mit Sicherheit »immer noch relativ viele Mitglieder«, die weniger als das vorgeschriebene eine Prozent zahlten. Es bleibe deshalb notwendig, beständig an die »Beitragsehrlichkeit« zu appellieren. So wurde die ÖTV nach jeder Tarifrunde erneut bei ihrer eigenen Basis vorstellig, um als Organisation angemessen an den finanziellen Erfolgen zu partizipieren, die sie für die Beschäftigten erstritten hatte. ${ }^{276}$

273 | In der Reihenfolge der Zitate: KV Osnabrück an BV Niedersachsen, 19.6.1973; BV Bayern an HV, 3.8.1976; KV Wiesbaden an HV, 31.8.1973. Alle in: Archiv Ver.di, Bestand Kluncker, 56. Vgl. ebd. auch noch zahlreiche weitere Protestschreiben.

274 | Auszug aus dem Protokoll über die Klausursitzung des gHV, 16./17.7.1973. In: Archiv Ver.di, Bestand Kluncker, 56.

275 | Die ÖTV setzte bei der Modernisierung ihres Beitragswesens in diesem Jahrzehnt fast ausschließlich auf das "Lastschriftverfahren«, d. h., die Mitglieder wurden aufgefordert, der Gewerkschaft eine Abbuchungsvollmacht für ihr Privatkonto zu erteilen. Genaue Kenntnisse über die jeweiligen Bezüge der Mitglieder ließen sich so nicht gewinnen. 1979 wurden rund 90 Prozent der Beiträge per Lastschrift eingezogen (ÖTV-Geschäftsbericht 1976/79, S. 696).

276 | Protokoll der 4. Sitzung des HV, 14./15.5.1981. In: AdsD, ÖTV, 5/ ÖTVB130082 B. Die Vermutung der Hauptkasse fußte auf der starken Spannung 
Die große Mehrheit der ÖTV-Mitglieder scheint die finanzielle Last des einprozentigen Beitrags in den 1970er Jahren aber akzeptiert zu haben. Anders ist der rasche Aufstieg der Organisation in der Skala der durchschnittlich gezahlten Gewerkschaftsbeiträge nicht zu erklären. Zudem beweist die positive Entwicklung der Mitgliederzahlen nach 1974, dass die starke Furcht vieler ÖTV-Funktionäre, jeder höhere Beitrag werde Kollegen zum Austritt treiben, doch überzogen war. Die Frage, ob sich die Mitgliedschaft »lohne« oder nicht, wurde offensichtlich nicht ausschließlich ökonomisch beurteilt. Eine Gewerkschaft musste deshalb keineswegs zwingend Samthandschuhe anlegen, wenn sie ihren Mitgliedern fordernd gegenübertrat. Diese Erfahrung machte die Organisation ebenfalls, als sie Ende der 1970er Jahre begann, säumige Mitglieder nicht einfach nur mehrfach zu mahnen, sondern bei Hartnäckigkeit auch zu verklagen: Weniger als fünf Prozent der vor Gericht gebrachten Schuldner verließen die Organisation; die übergroße Mehrheit aber zahlte und blieb. ${ }^{277}$

\section{Die neue soziale Struktur der Mitgliedschaft und ihre Konsequenzen für die ÖTV}

Nur in einer Hinsicht schädigte sich die ÖTV mit ihrem neuen Beitragssatz dann doch selbst: Als Beamtenorganisation befand sie sich in den 1970er Jahren deutlich auf einem absteigenden Ast - und dieser negative Trend hatte wohl direkt etwas mit der Ein-Prozent-Regel zu tun. Der konkurrierende Deutsche Beamtenbund nämlich forderte von seinen Mitgliedern deutlich weniger Geld und vertrat ohnehin bereits die Mehrheit der lebenslang gesicherten Staatsdiener. Diese Kombination von finanziellem Wettbewerb mit der Anziehungskraft der stärkeren Organisation scheint die ÖTV bei der Werbung um Beamte dauerhaft behindert zu haben. ${ }^{278}$

der Durchschnittsbeiträge zwischen den einzelnen Kreisverwaltungen. Bei einem Gesamtdurchschnitt von rund 18 DM monatlich unterschieden sich die lokalen Zahlen um bis zu 4,87 DM: Diese Differenz sei zu groß, um mit regional unterschiedlich hohen Löhnen erklärt zu werden. Zu den jährlichen Aktionen zur Anpassung der Beiträge vgl. etwa: ÖTV-Geschäftsbericht 1976/79, S. $674 \mathrm{f}$.

277 | ÖTV prozessiert gegen Tausende von Mitgliedern. In: StZ, 19.10.1979; Interview Siegfried Bußjäger, 1.4.2014.

278 | Vgl. die entsprechende Analyse bereits in: BV Bayern an HV, 3.8.1973. In: Archiv Ver.di, Bestand Kluncker, 56. Auf dem Gewerkschaftstag von 1976 mokier- 
Zudem existierte, wie erwähnt, die Gewerkschaft der Polizei. Auch sie war für ihre Mitglieder erheblich »billiger« als die ÖTV. Anders als der Beamtenbund stand sie dem DGB programmatisch mittlerweile sehr nahe; lediglich der anhaltende Widerstand der ÖTV verhinderte ihre Aufnahme in den Dachverband. ${ }^{279}$ Ein spezieller Korpsgeist, den offensichtlich viele Polizisten teilten, definierte die Berufsgewerkschaft. Die ÖTV hielt es für antiquiert, wenn sich Gewerkschafter so separierten, erfuhr aber gerade in den 1970er Jahren, dass die GdP ihr immer erfolgreicher Konkurrenz machte. Polizisten stellten offensichtlich einen nennenswerten Teil der Beamten, die nach 1970 die ÖTV verließen. ${ }^{280} 1978$ musste sich die ÖTV in diesem Wettstreit schließlich sogar ganz geschlagen geben: Der DGB akzeptierte den Aufnahmeantrag der GdP, um die Organisation an sich zu binden. Aus übergeordneten gewerkschaftspolitischen Gründen lenkte die ÖTV ein; zugleich empfahl sie allen Mitgliedern, die noch zu ihrer separaten Polizeisektion gehörten, in die neue 17. DGB-Gewerkschaft zu wechseln, mit der man in Stuttgart nun offiziell »befreundet« war. ${ }^{281}$ Die Abwanderung von Beamten aus der ÖTV nahm damit ein weiteres Mal zu.

te sich Heinz Kluncker über Konkurrenzorganisationen der ÖTV, die »mit einem miesen Gefälligkeitsbeitrag « auf Mitgliederjagd gingen (Protokoll ÖTV-GT 1976, Bd. 1, S. 465).

279 | Vgl. dazu etwa Heinz Kluncker in: Protokoll ÖTV-GT 1972, S. 67.

280 | Vgl. etwa: Die Gewerkschaften im Jahre 1972. In: Bericht des Deutschen Industrieinstituts zu Gewerkschaftsfragen 6 (1972), H. 1, S. 1-45, hier: S. 14.

281 | Vgl. zu diesem ganzen Komplex: Die Polizeigewerkschaft in den DGB? In: FAZ, 9.12.1977; Ernst Günther Vetter: Heimkehr der Polizeigewerkschaft in den Gewerkschaftsbund. In: FAZ, 10.12.1977; Robert Steiert: Gewerkschaft der Polizei verstärkt Einheitsgewerkschaften. In: GM 29 (1978), S. 289-296; ÖTV-Geschäftsbericht 1976/79, S. 21 u. 29 f. Die GdP hatte zu diesem Zeitpunkt etwa 140.000 Mitglieder. Von den rund 20.000 Beschäftigten bei der Polizei, die zum gleichen Zeitpunkt noch zur ÖTV gehörten, folgten etwa 13.000 dem Aufruf, in die GdP zu wechseln. Selbst Anfang 1979 zählte die ÖTV unter ihren Mitgliedern immer noch 8.000 Polizisten (Protokoll der 13. Sitzung des HV, 30./31.1.1979. In: AdsD, ÖTV, 5/ÖTVB130065). Hintergrund der Einigung zwischen GdP und ÖTV/DGB im Winter 1977/78 war der tarifpolitische Bruch zwischen der ÖTV und der DAG im Jahr 1976, die keine gemeinsamen Tarifverhandlungen mehr führten (siehe dazu oben). Nach Aufösung der Tarifgemeinschaft fürchteten ÖTV und DGB, die GdP könne sich der DAG annähern und mit ihr gemeinsam eine kopfstarke Tarifgemeinschaft bilden. Vgl. dazu den ausführlichen Kommentar von E.G. 
Ihre Zahl sank allerdings schon seit 1971 kontinuierlich. Ende 1980 zählte die Gewerkschaft etwas weniger als 93.000 verbeamtete Mitglieder; gegenüber dem Jahr 1971 war diese Berufsgruppe in der ÖTV um fast 19.000 Köpfe und damit um 17 Prozent geschrumpft. Den stärksten Einbruch gab es dabei bezeichnender Weise 1973, dem Jahr, in dem die ÖTV begann, ihren neuen Beitragssatz ernsthaft durchzusetzen. Wegen dieser Verluste stellten die Beamten in den frühen 1980er Jahren nur noch acht Prozent der ÖTV-Mitglieder statt etwas mehr als elf Prozent eine Dekade zuvor. ${ }^{282}$

Der Anspruch der Organisation, als solidarischer Bund für Arbeiter, Angestellte und Beamte gleichermaßen zu sprechen, schien gerade Beamten zunehmend zu missfallen. Zwar war die Angelegenheit in Wirklichkeit etwas komplizierter (denn auch die GdP war keine exklusive Beamtenorganisation); auf den ersten Blick aber wirkte die Selbstdarstellung der ÖTV vor dem Hintergrund der skizzierten Veränderungen doch fast zwingend deutlich großspuriger als in den 1950er und 1960er Jahren, in denen der Beamtenblock in der Gewerkschaft kontinuierlich gewachsen war.

Der organisatorische Aufschwung der ÖTV seit 1970 entstand vor allem, weil immer mehr Angestellte eintraten. Bei den Arbeitern gab es hingegen eine uneinheitliche Entwicklung: Auf leichte Verluste in den ersten Jahren der Dekade folgte eine deutliche Zunahme 1974/75, die aber rasch wieder von erneuten Rückgängen abgelöst wurde. Erst gegen Ende des Jahrzehnts stieg die absolute Zahl von Arbeitern und Arbeiterinnen in der ÖTV wieder kontinuierlich an. 1981 und 1982 lag sie bei rund 585.000 - und damit fast genauso hoch wie im Jahr 1966. Da auch der Öffentliche Dienst seit den 1960er Jahren intensive Bemühungen der Arbeitgeber erlebt hatte, gerade einfache, körperlich geprägte Tätigkeiten zu rationalisieren, auszugliedern oder ganz einzusparen, bezeichneten die Zahlen von 1981/82 einen großen Erfolg der ÖTV: Es gelang ihr, in einer schrumpfenden Gruppe von Beschäftigten ihre Position als Gewerkschaft noch weiter auszubauen. ${ }^{283}$

Innerhalb der Organisation aber ging der Arbeiteranteil zunehmend zurück: Schon seit 1978 stellten Arbeiter und Arbeiterinnen nur noch

Vetter (s.o.) sowie die Ausführungen von H. Kluncker in: 3. Sitzung des HV, 20./21.1.1977. In: AdsD, ÖTV, 5/ÖTVB130054.

282 | Berechnet nach: Meissner: Entgeltpolitik, S. 212.

283 | Die Zahlen nach: ebd. Zu Rationalisierung und Privatisierung im Öffentlichen Dienst siehe weiter unten in diesem Kapitel. 
knapp 50 Prozent aller Mitglieder (mit sinkender Tendenz) - statt mehr als 60 Prozent in den frühen 1960er Jahren. Gleichzeitig wurde die ÖTV immer deutlicher zu einer Gewerkschaft von Angestellten. Deren Zahl wuchs von rund 315.000 im Jahr 1970 auf 506.000 Ende 1982. Damit umfasste diese Berufsgruppe bereits 43 Prozent aller ÖTV-Mitglieder - kaum weniger als die der Arbeiter, die in den frühen Phasen der ÖTV-Geschichte stets erheblich größer gewesen war. ${ }^{284}$

Hinter dieser einschneidenden Veränderung stand nicht einfach nur eine erfolgreiche gewerkschaftliche Werbearbeit. Die ÖTV profitierte von der fortschreitenden »Tertiarisierung« der bundesdeutschen Wirtschaft, d. h. von der stark zunehmenden Zahl an Dienstleistungstätigkeiten sowie an verwaltenden Arbeiten in Büros. Zwar hat es den Wandel von der »Industriegesellschaft" in eine »Dienstleistungsgesellschaft", den viele Soziologen und Sozialhistoriker für die 1970er Jahren diagnostiziert haben, in so schematischer Form im deutschen Fall nicht gegeben. ${ }^{285}$ Dennoch expandierten in dieser Dekade insbesondere Wirtschaftsbereiche, um deren Beschäftigte sich die ÖTV bemühte: Der staatliche Verwaltungsapparat ist hier ebenso zu nennen wie das Gesundheitswesen und soziale Dienste. Besonders in den beiden zuletzt genannten Segmenten dominierten Angestellte - und dort verzeichnete die ÖTV ihre stärksten Zuwächse. ${ }^{286}$

Zugleich arbeiteten in diesen Berufsfeldern vor allem Frauen. Zwangsläufig wurde die ÖTV deshalb durch den Zustrom von Angestellten auch

284 | Zahlen nach und berechnet nach: Meissner: Entgeltpolitik, S. 212. 1970 hatte der Angestelltenanteil noch bei 32 Prozent gelegen.

285 | Vgl. etwa: Gerald Ambrosius: Agrarstaat oder Industriestaat - Industriegesellschaft oder Dienstleistungsgesellschaft? Zum sektoralen Strukturwandel im 20. Jahrhundert. In: Reinhard Spree et al. (Hrsg.): Geschichte der deutschen Wirtschaft im 20. Jahrhundert, München 2001, S. 50-69. Vgl. auch die kritischen Anmerkungen zu Problemen der Sozial- und Wirtschaftsstatistik in: Christian Girschner: Die Dienstleistungsgesellschaft. Zur Kritik einer fixen Idee, Köln 2003, insbes. S. 95-101.

286 | Protokoll ÖTV-GT 1980, Bd. 1, S. 96 (die Delegierte Annette Schwarzenau, Berlin). Zur starken Expansion des Öffentlichen Dienstes bei der vor allem von Frauen geleisteten sozialen Betreuung vgl. genauer: Gerald Kreißig/Johannes Hintzen: Zur Personalentwicklung der Kommunen, Köln 1975, S. 33 f.; Gerald Kreißig: Personalstand und Personalentwicklung bei Bund, Ländern und Gemeinden. In: Der Städtetag 35 (1982), S. 188-194. 
weiblicher. Seit 1970 nahm die Gewerkschaft kontinuierlich in jedem Jahr erheblich mehr Frauen als Männer auf; am Ende der Dekade verzeichnete sie 115.000 neu gewonnene Kolleginnen gegenüber 28.000 zusätzlichen männlichen Beitragszahlern. Der weibliche Anteil an allen Mitgliedern wuchs damit von 17,7 Prozent auf fast 26 Prozent zu Beginn des Jahres $1980 .{ }^{287}$ Da gerade junge Frauen eintraten, ergab sich in der Altersgruppe bis zum 25. Lebensjahr eine für die ÖTV (wie auch für fast alle anderen Gewerkschaften) ganz neue Geschlechterstruktur: Frauen stellten in dieser Kohorte ungefähr genauso viele Mitglieder wie die Männer. ${ }^{288}$

Indirekt verweisen diese spröden Zahlen auf eine weitere tiefgreifende Veränderung in der bundesdeutschen Gesellschaft: Mit der wirtschaftlichen »Tertiarisierung « wandelten sich die Muster, die bislang das Selbstbild von Frauen und die Praxis weiblicher Erwerbsarbeit geprägt hatten. Beschränkte sich die Berufstätigkeit im Leben von Frauen bislang typischerweise auf einige wenige Jahre zwischen dem Ende der Schulausbildung und der Heirat bzw. der Geburt des ersten Kindes, so arbeiteten viele Frauen nun zunehmend deutlich länger außer Haus. Teilweise orientierte sich ihre Lebensplanung sogar schon an dem Modell, den Beruf als dauerhafte persönliche "Berufung« zu verstehen (was den Anspruch auf eine Karriere mit einschloss), dem bislang fast nur Männer gefolgt waren.

Der Öffentliche Dienst spielte in diesem Emanzipationsprozess eine wichtige, vielleicht sogar entscheidende Rolle: Er öffnete sich weitaus rascher und bereitwilliger für Frauen, die langfristig einer qualifizierten Erwerbsarbeit nachgehen wollten, als die Privatindustrie. Zudem folgten die öffentlichen Arbeitgeber deutlich seltener der ebenso langlebigen wie schäbigen Tradition, Frauen selbst bei vergleichbarer Tätigkeit schlechter zu bezahlen als Männer. Im Vergleich mit Industrie und Gewerbe gab es im Staatsdienst deshalb eine »deutlich geringere Diskriminierung « von Frauen gegenüber Männern. ${ }^{289}$ Für Beamte existierte zudem seit 1969 eine besondere Form der Geschlechterpolitik, die viele Frauen begrüßten: Eine Be-

287 | Berechnet nach: Meissner: Entgeltpolitik, S. 212.

288 | Beate Kindler: Mitgliederentwicklung der Gewerkschaft ÖTV 1970 bis 1990, Archiv Ver.di, Bestand Kluncker, 40.

289 | Schäfer/Skiba/Tofaute: Personalausgaben, S. 108 (Zitat) sowie im Detail S. $36-42$ u. 70-72. Vgl. zu diesem Thema auch: Keller: Arbeitsbeziehungen, S. 290-293. 
amtin, die kleine Kinder hatte, konnte auf eigenen Wunsch sogar während eines längeren Zeitraums auf eine Teilzeitstelle wechseln. Teilzeitarbeit, die es bislang fast ausschließlich bei besonders einfachen Tätigkeiten (wie etwa bei Reinigungskräften) gegeben hatte, veränderte damit gravierend ihren sozialen Charakter. ${ }^{290}$ Zwar existierte auch »beim Staat « bei Weitem noch keine wirkliche Gleichberechtigung. Teilzeitarbeit etwa wurde zwar von vielen Frauen begrüßt; sie hatte aber insofern diskriminierende Effekte, als sie das Problem, Beruf und Familie zu vereinen, ausschließlich auf Kosten der Frauen »löste«. Darüber hinaus blieben Leitungsaufgaben (konkret: die Stellen im Höheren Dienst) eine männliche Domäne. Ein Anfang aber war gemacht. $^{291}$

Nun sind solche Wandlungen in der Arbeitswelt allenfalls eine Voraussetzung für gewerkschaftlichen Erfolg, aber keine Garantie dafür. Letztlich bleiben die starken Gewinne der ÖTV bei Angestellten und bei Frauen daher ein Verdienst der Organisation: Sie machte in den 1970er Jahren offensichtlich diesen beiden eng miteinander verknüpften Gruppen ein attraktives Angebot. Die konkurrierende DAG konnte von den Veränderungen in

290 | Zur Einführung der Teilzeitarbeit für Mütter zunächst nur für Beamtinnen vgl.: Silke Heinemann: Teilzeitbeschäftigung im öffentlichen Dienst. Entwicklung und Einflussfaktoren im intersektoralen und internationalen Vergleich, Frankfurt/Main 2002, S. 149-162. Tarifvertraglich wurden diese Regelungen erst 1994 gesichert (ebd., S. 144f.). Das veränderte soziale Wesen der Teilzeitarbeit nach der Reform vom 1969 zeigt sich schon daran, dass bereits im Jahr 1978 fast ein Drittel der erwerbstätigen Frauen, die einen Hochschulabschluss besaßen, auf Teilzeitstellen arbeiteten (Dorothee Müller-Hagen: Teilzeitarbeit. Chancen und Probleme. In: Der Arbeitgeber 31 [1979], S. 338-340, hier: S. 338).

291 | Die DGB-Gewerkschaften (und auch die ÖTV) standen der Teilzeitarbeit lange skeptisch oder sogar ablehnend gegenüber, weil sie vor allem deren Nachteile bei der sozialen Absicherung der Beschäftigten sahen und zudem auch nur vollbeschäftigte Arbeitnehmer für organisierbar hielten. Erst in den 1960er Jahren begann in dieser Hinsicht ein Wandel. Vgl. dazu: Christine von Oertzen/Almut Rietzschel: Das »Kuckucksei« Teilzeitarbeit. Die Politik der Gewerkschaften im deutsch-deutschen Vergleich. In: Gunilla-Friederike Budde (Hrsg.): Frauen arbeiten. Weibliche Erwerbstätigkeit in Ost- und Westdeutschland nach 1945, Göttingen 1997, S. 212-251, hier: S. 214-229. Speziell zur Haltung der ÖTV vgl. etwa: Hilde Just: Zur Teilzeitarbeit im öffentlichen Dienst. In: Frauen und Arbeit (1977), H. 4, S. 12-13. 
dieser Dekade hingegen bei Weitem nicht so stark profitieren. ${ }^{292}$ Darüber hinaus hätte sich die Erfolgsbilanz der ÖTV sogar noch glanzvoller präsentiert, wenn sie denn innerhalb des DGB wirklich die Zuständigkeit für den gesamten Öffentlichen Dienst besessen hätte. So aber führte die separate Existenz der GEW, die Lehrer und Hochschullehrer organisierte, dazu, dass die besonders stark wachsende Gruppe der Lehrerinnen organisatorisch für die ÖTV grundsätzlich tabu war. Der weibliche Anteil in der von Heinz Kluncker geführten Gewerkschaft stieg deshalb nach 1970 nicht so rasch und auch nicht so eindeutig, wie es angesichts der Wandlungen in der bundesdeutschen Berufswelt bei einem anderen Zuschnitt der »Verbandsgrenzen « im DGB gerade in diesem Jahrzehnt möglich gewesen wäre. ${ }^{293}$

Für die Frauenarbeit der ÖTV hatte der Zustrom an weiblichen Mitgliedern vielleicht auch deshalb weitaus weniger Konsequenzen, als man erwarten könnte. Wie oben gezeigt wurde, verzichtete die Gewerkschaft seit 1968 auf regelmäßige spezielle Frauenkonferenzen und auf eine offiziell deklarierte Frauenquote für die Gremien der Organisation, weil man meinte, der Gleichberechtigung der Geschlechter so besser zu dienen. Auf dem Gewerkschaftstag von 1972 wurde diese Entscheidung gerade von weiblichen Delegierten ausdrücklich noch einmal begrüßt: »Mit einem sogenannten Naturschutz für Frauen ist es nicht getan. ${ }^{294}$

292 | Die DAG gewann im Bereich »Öffentlicher Dienst« von 1970 auf 1982 insgesamt 35.290 neue Mitglieder, gegenüber einem Plus der ÖTV von 190.167 (ebenfalls nur bei den Angestellten). Zahlen berechnet nach: Meissner: Entgeltpolitik, S. 212 u. 215.

293 | Die GEW publizierte keine Zahlen zur Geschlechtsstruktur ihrer Mitgliedschaft. Sie wuchs von 120.000 Mitgliedern (1970) auf 159.000 (1980) bzw. auf 186.000 (1982). Eine spezielle Frauenarbeit kannte die Organisation seit 1974 nicht mehr; Kritik daran wurde erst auf dem Kongress von 1983 laut. Die Angaben aus: Gewerkschaft Erziehung und Wissenschaft, Geschäftsbericht 1968-1971, Frankfurt/Main 1972, S. 325; [Gewerkschaft Erziehung und Wissenschaft] Geschäftsbericht 1980-1983, Frankfurt/Main 1984, S. 193; [Gewerkschaft Erziehung und Wissenschaft] Gewerkschaftstag 1983. Angenommene Anträge, Frankfurt/Main 1984, S. 54-59, hier: S. 58 f.

294 | Protokoll ÖTV-GT 1972, S. 79 (die Delegierte Marie-Luise Smeets, Düsseldorf). Vgl. ähnlich auch Hilke Kleine-Frölke (HV-Mitglied), S. 92; Anneliese Wolf (HV-Mitglied), S. $94 \mathrm{f}$. 
Heinz Kluncker hielt die Reform ebenfalls für erfolgreich. 1976 dekretierte er: »Reglementierungen und Vorschriften sind im Interesse der Frauen ungeeignet. Ich bin überzeugt, unsere Kolleginnen werden sich dank ihrer Aktivität durchsetzen." Diesmal aber widersprach zumindest eine Frau. Eine Delegierte aus dem Bezirk Nordrhein-Westfalen II berichtete, gerade unter den weiblichen Mitgliedern wachse die »Unruhe« über ihre »unzulängliche Betreuung und Anhörung « durch die männlich dominierte Organisation. Indirekt forderte sie eine Revision der 1968 beschlossenen Regeln: »Man vergisst allzu leicht, daß alle gewerkschaftlichen gesellschaftlichen Initiativen auf großen Frauenkonferenzen entwickelt wurden. ${ }^{295}$ Im Getümmel des langen und anstrengenden Kongresses ging dieser Dissens allerdings unkommentiert unter.

Zumindest die Frauen, die innerhalb der Organisation im Bundesfrauenausschuss offiziell auf die weiblichen Belange zu achten hatten, aber fragten sich ebenfalls zunehmend, ob die ÖTV 1968 richtig entschieden habe. Im offiziellen Geschäftsbericht für die Jahre 1972 bis 1975 hatte der Ausschuss noch festgestellt, Veranstaltungen nur für Kolleginnen seien »nicht im Sinne gemeinschaftlicher gewerkschaftlicher Arbeit«. Der Report für die nachfolgenden vier Jahre argumentierte jedoch deutlich anders: Rein weibliche besetzte Konferenzen, so habe sich gezeigt, würden Frauen helfen, die Furcht zu überwinden, dass »ihr Wissen und ihre Kenntnisse über die Zusammenhänge von Gesellschaft und Arbeitswelt zu gering seien, um darüber mitreden zu können«. Das Frauensekretariat setze nun verstärkt auf Veranstaltungen, die Männer grundsätzlich ausschlossen. ${ }^{296}$

Schaut man auf die Beteiligung von Frauen an den wichtigsten Gremien der ÖTV, dann kann man für die 1970er Jahre wohl allenfalls dann von Fortschritten sprechen, wenn man den beklagenswert niedrigen Stand von 1968 als Maßstab akzeptiert. Von nur drei Prozent auf dem damaligen

295 | Protokoll ÖTV-GT 1976, Bd. 1, S. 77 (H. Kluncker) u. S. 139 (die Delegierte Waltraud Grass von der KV Märkischer Kreis). Auch schon 1972 hatte Marie-Luise Smeets (Düsseldorf) die konkrete Betreuung der weiblichen Mitglieder als ganz unzureichend kritisiert (vgl. Protokoll ÖTV-GT 1972, S. 79).

296 | In der Reihenfolge der Zitate: ÖTV-Geschäftsbericht 1972/75, S. 569; ÖTVGeschäftsbericht 1976/79, S. 671. Im zweiten Berichtszeitszeitraum hatte der Ausschuss insgesamt 15 reine Frauenkonferenzen durchgeführt - gegenüber vier in den Jahren 1972 bis 1975. 
Gewerkschaftstag stieg der Anteil der weiblichen Delegierten am »Parlament« der Gewerkschaft auf rund sechs Prozent 1972. Vier Jahre später war dies unverändert. 1980 war der Frauenanteil endlich stärker gestiegen: auf dann elf Prozent 1980. ${ }^{297}$ Auch damit aber waren die Frauen immer noch deutlich unterrepräsentiert. Wenn sie auf den Kongressen dennoch eine größere Rolle spielten als zuvor, so lag das an einigen der Kolleginnen, die sich selbstbewusst von alten Rollenklischees verabschiedeten. Offensichtlich hatte es die ÖTV mit Vertreterinnen einer neuen Frauengeneration zu tun: Sie sprachen auch zu Themen, die gar nichts mit "Frauenfragen« zu tun hatten, und sie traten mit ihren Kommentaren und Anträgen sogar mehrfach vor das Auditorium - was ansonsten ausschließlich die »Granden« der Organisation (d.h. die Kreisvorsitzenden oder die Mitglieder des gHV) taten. Dank dieser starken Aktivität fiel der weibliche Redeanteil an den Gewerkschaftstagen nun nicht mehr ganz so marginal aus wie noch $1968 .^{298}$

297 | Die genauen Zahlen: 5,7 Prozent 1972, 6,1 Prozent 1976, 10,6 Prozent 1980. In absoluten Zahlen wuchs die Gruppe der weiblichen Delegierten damit von 33 bzw. 37 auf 61. Alle Zahlen nach den jeweiligen Protokollen. Sie gelten jeweils nur für die tatsächlich anwesenden ordentlichen Delegierten. Zu den ebenfalls geringen Frauenanteilen an anderen ÖTV-Gremien siehe weiter unten. Lediglich bei der Kandidatur für Betriebsratswahlen gab es in der ÖTV für Frauen eine größere Chance. Sie stellten 1978 immerhin 19 Prozent der gewählten ÖTV-Betriebsräte (1.396 von 7.334 in absoluten Zahlen); 209 Frauen wurden sogar Betriebsratsvorsitzende. Berechnet nach: ÖTV-Geschäftsbericht 1976/79, S. 553 f. u. 671.

298 | So meldeten sich 1972 elf der insgesamt 33 weiblichen Delegierten zu Wort, neun davon sprachen mehrfach. Zwei Frauen (Heidemarie Pflanz, Berlin, und Sabine Eiermann, Gießen) kamen sogar auf die ganz ungewöhnlich hohe Zahl von sechs bzw. fünf Redebeiträgen. Beide sind wegen der politischen Tendenz ihrer Reden unschwer als Mitglieder oder doch zumindest als Sympathisantinnen der DKP oder einer anderen linken politischen Gruppierung zu erkennen. Pflanz nahm nur an diesem GT teil, Sabine Eiermann wurde auch 1976 wieder delegiert. Auf diesem GT sprachen zwar insgesamt nur neun weibliche Delegierte; acht davon aber standen mehrfach auf dem Podium. 1980 schließlich beteiligten sich 26 Frauen an der Diskussion, zehn redeten mehrfach. Alle Angaben ermittelt durch einen Abgleich der Namensliste der Delegierten mit der Rednerliste (bzw. für 1972 durch Durchsicht des gesamten Protokolls, weil die Namensliste keine Vornamen nennt). Sowohl für 1976 als für 1980 wurden die Redebeiträge von Monika Wulf-Mathies nicht berücksichtigt, weil sie als Kandidatin für den gHV (1976) bzw. als gHV-Mitglied (1980) einen besonderen Status hatte. Sie sprach 
Im Hauptvorstand der ÖTV und im politisch dominierenden gHV blieb hingegen alles beim Alten. In beiden Leitungsgremien spielten Frauen nach wie vor nur Nebenrollen. Im geschäftsführenden Vorstand ersetzte Monika Wulf-Mathies, die zuvor im Bundeskanzleramt in Bonn gearbeitet hatte, zwar seit 1976 die ausgeschiedene Hanna Simon. Als die einzige Frau im engsten Führungskreis der Gewerkschaft machte sie sich keine Illusionen über den Hintergrund ihrer Wahl: 1978 sagte sie rückblickend in einer Debatte des Hauptvorstandes, sie halte sich zwar uneingeschränkt für qualifiziert, glaube aber doch »ziemlich sicher«, dass sie vor allem deshalb nominiert und gewählt wurde, "weil Ihr Euch diese eine Repräsentationsfrau leisten wolltet [...], vielleicht auch leisten konntet, weil die Gefahr noch nicht so groß war, daß das einen Erdrutsch auslösen würde«. Auf die Dauer, so Wulf-Mathies weiter, schade sich die ÖTV aber selbst, wenn sie weiter so vorgehe. Die Organisation solle ganz generell die Mitarbeit von Frauen aktiver fördern und auch fordern: Es müsse zumindest eine "moralische Selbstverpflichtung« der Gewerkschaft geben, die weiblichen Mitglieder wirklich angemessen an allen Gremien zu beteiligen. ${ }^{299}$

Spätestens damit lag die Frage einer Frauenquote wieder auf dem Tisch. Obwohl die Satzung von 1968 in diesem Punkt immer noch galt, beschloss der gHV bei der Vorbereitung des Kongresses, der 1980 anstand, deren stillschweigende Revision. Zuvor hatte auch Heinz Kluncker erklärt, er sehe den geringen weiblichen Anteil in den ÖTV-Organen »mit Sorge «. ${ }^{300}$ Daraufhin »empfahl« der gHV den Bezirken, bei der Auswahl der Delegierten den weiblichen Anteil an allen Mitgliedern in der jeweiligen Region möglichst adäquat abzubilden. Mindesten fünf »Kolleginnen« aber müsse jeder Bezirk auf den Gewerkschaftstag entsenden. ${ }^{301}$

1980 siebenmal und zweimal auf dem Kongress von 1976 (Bewerbungsrede und Danksagung nach der Wahl).

299 | Protokoll der 9. Sitzung des HV, 11.5.1978. In: AdsD, ÖTV, 5/ÖTVB130062. Unter den 60 Mitgliedern des 1980 gewählten HV gab es vier Frauen (ein Anteil von 6,6 Prozent). Berechnet nach: Protokoll ÖTV-GT 1980, Bd. 2, S. 1027-1029. Nach wie vor waren alle Bezirksleiter männlich. Auch in den Gremien der Bezirke und Kreise spielten Frauen nur eine ganz untergeordnete Rolle. Vgl. hierzu: Claudia Pichl: Das Arbeitnehmer-Patriachat. Die Frauenpolitik der Gewerkschaften, Köln 1979, S. $96 \mathrm{f}$.

300 | Protokoll der 15. Sitzung des HV, 4.10.1979. In: AdsD, ÖTV, 5/ÖTVB130068. 301 | ÖTV-Geschäftsbericht 1976/79, S. 670. 
Die Antwort der Organisation fiel eindeutig aus: Statt der 158 Frauen, die dem Prozentsatz weiblicher Mitglieder entsprochen hätten, durften nur 61 weibliche Delegierte an dem Kongress teilnehmen. Acht der zwölf Bezirke hatten selbst die Minimalforderung des gHV ignoriert; mit einem Frauenanteil von immerhin 16 Prozent präsentierte sich der Bezirk Nordrhein-Westfalen II bereits als emanzipatorisch besonders engagiert. ${ }^{302}$ Appelle entfalteten offensichtlich nur eine sehr begrenzte Wirkung, wenn es darum ging, die Übermacht der Männer in gewerkschaftlichen Gremien zu brechen. Dennoch lehnte der Gewerkschaftstag ohne eine Debatte drei Anträge ab, Frauen seien zukünftig »bevorzugt« zu berücksichtigen, wenn haupt- und ehrenamtliche Positionen neu vergeben wurden. ${ }^{303}$ Insofern deutete 1980 noch nichts darauf hin, dass ausgerechnet die ÖTV nur zwei Jahre später, nach dem Rücktritt Heinz Klunckers, als erste DGB-Gewerkschaft überhaupt eine Frau - Monika Wulf-Mathies - in das Spitzenamt wählen würde. Wie es zu dieser überraschenden Entwicklung kam, wird unten genauer geschildert. Ausgerechnet der scheidende »Boss« der Organisation spielte dabei nämlich eine recht wichtige Rolle.

Wenn sich die ÖTV in der innerorganisatorischen "Frauenfrage « in den 1970er Jahren de facto kaum bewegte, so erklärt sich das auch aus dem letztlich geringen Interesse der männlichen Führungskräfte an diesem Problem. Zwar sprach Kluncker im Herbst 1979 von seiner »Sorge« über den zu niedrigen Anteil weiblicher Funktionsträger. Wesentlich wichtiger aber war für ihn der geringe Anteil einer anderen Gruppe in den Gremien der Organisation. Dem Vorsitzenden ging es um die Arbeiter: Deren nicht adäquate Vertretung müsse »sehr bedenklich stimmen«. ${ }^{304}$

Das Manko, das der Vorsitzende hier thematisierte, war nicht neu und es lag offen zu Tage: Auf den Gewerkschaftskongressen von 1976 und 1980 vertrat jeweils nur ein knappes Viertel der Delegierten die Arbeiter und Arbeiterinnen, die doch mehr als 50 Prozent der Mitglieder stellten. Im wichtigsten Entscheidungsorgan der ÖTV saßen zu fast 60 Prozent Ange-

302 | Berechnet nach den Namenslisten in: Protokoll ÖTV-GT 1980, Bd. 2, S. $1035-1050$.

303 | Vgl. die Anträge in: ebd., Bd. 2, S. 271-273 (sie stammten von der Bezirkskonferenz NRW I, der Kreisdelegiertenkonferenz Köln und der Bezirkskonferenz Niedersachsen); die Abstimmung in: ebd., Bd. 1, S. 431.

304 | Protokoll der 15. Sitzung des HV, 4.10.1979. In: AdsD, ÖTV, 5/ÖTVB130068. 
stellte; noch deutlicher überrepräsentiert waren die Beamten mit Anteilen von 19 Prozent (1976) bzw. von 17 Prozent (1980). In anderen Gremien sah es wohl nicht besser aus. ${ }^{305}$

Schlimmer noch: Die Gewerkschaftsführung fragte sich sogar, ob in den speziellen Ausschüssen, die ausschließlich mit Arbeitern besetzt werden sollten, um deren Interessen neben denen der Angestellten und Beamten adäquat zu artikulieren, wirklich Arbeiter saßen. 1978 forderte die Hauptverwaltung in Stuttgart die Bezirke auf, die personelle Zusammensetzung der Bezirksarbeiterausschüsse zu überprüfen. Offensichtlich sorgte sie sich, dort könnten vor allem Mitglieder das Wort führen, die selbst schon seit längerem nicht mehr zu den Arbeitern gehörten, weil sie sich zwischenzeitlich beruflich verbessert hatten. Auch in diesem Fall fiel die Antwort der Organisation eindeutig aus. Lediglich der Bezirk Bayern bestätigte, der Ausschuss bestehe tatsächlich nur aus Arbeitern; die übrigen elf Bezirke aber schwiegen. Diese Verweigerung einer Antwort verstand das zentrale Arbeitersekretariat der Gewerkschaft als Beweis, wie sehr es mit seiner Anfrage ins Schwarze getroffen habe. Erforderlich sei eine zügige »Bereinigung« der Arbeiterausschüsse: Die ÖTV stelle sich »ein Armutszeugnis aus« und sie werde »unglaubwürdig«, wenn selbst der Strang ihrer Selbstverwaltung, der den Arbeitern vorbehalten sei, von Angestellten oder sogar von Beamten durchsetzt sei. ${ }^{306}$

Mangels aussagekräftiger Quellen wissen wir nicht, was daraufhin geschah. Wie der Gewerkschaftstag von 1980 beweist, änderte sich so oder so aber nichts an der geringen Beteiligung von Arbeitern und Arbeiterinnen an den beruflich gemischten Gremien der Gewerkschaft. Vor allem diese Organe aber entschieden über die Politik der Organisation - und ausgerechnet die nach wie vor größte Gruppe der ÖTV-Mitglieder hatte dabei

305 | Zahlen berechnet nach: Protokoll ÖTV-GT 1976, Bd. 1, S. 94; Protokoll ÖTV-GT 1980, Bd. 1, S. 97. 1976 betrug der Arbeiteranteil exakt 23 Prozent; 1980 lag er mit 23,6 nur unwesentlich höher. Zu den anderen Gremien der ÖTV vgl. die Feststellung im Geschäftsbericht für die Jahre 1976 bis 1979, es sei der ÖTV generell nicht gelungen, »eine Zusammensetzung zu erreichen, die dem Stärkeverhältnis der Arbeiter entspricht« (ÖTV-Geschäftsbericht 1976/79, S. 95).

306 | Rundschreiben des Bundesarbeitersekretariats an die Bezirksarbeitersekretäre, 27.7.1978. In: AdsD, ÖTV NRW II, 5/ÖTVC301004. Die Frage nach der Besetzung war am 13.3.1978 versandt worden. 
dauerhaft wenig zu sagen. Monika Wulf-Mathies konstatiert rückblickend, »dass die eher geringe Zahl der Beamten immer sehr geschickt waren bei der Durchsetzung ihrer Interessen, auch innerhalb der ÖTV. Die Bedeutung der Beamtenausschüsse war immer größer als die der Arbeiterausschüsse. «07

Dieses Problem der ÖTV entstand offensichtlich, weil Gewerkschaften als demokratische Gebilde mit ausgefeilten internen Strukturen, Hierarchien und Entscheidungswegen nun einmal unweigerlich über den Austausch von Argumenten funktionieren: Sie leben von Worten, vor allem in persönlicher Rede sowie in geschriebener Form. Eloquenz und die Sicherheit, sich im kontroversen Gespräch behaupten zu können, aber gehören zu dem sozialen Kapital, das gesellschaftlich höchst ungleich verteilt ist. In Gruppen, die in dieser Hinsicht deutlich durchmischt sind, bilden sich daher rasch Strukturen, die diese Ungleichheit reproduzieren, zumal wenn die weniger eloquenten Mitglieder nicht aktiv gegen diese Rollenverteilung opponieren. Der Auswahlprozess, der so wenige Arbeiter auf die ÖTV-Gewerkschaftstage brachte, dürfte wohl ähnlich verlaufen sein. Nach Monika Wulf-Mathies' Urteil waren die Arbeiter in der ÖTV »relativ ungeschickt im Lobbying« und bei Bemühungen, »sich Rückhalt [in der Organisation] zu verschaffen, die dann Mehrheiten bewirkt hätten«. ${ }^{308}$

Allerdings, so ließe sich kritisch anmerken, hat die ÖTV wenig getan, um wirklich für Änderung zu sorgen. Letztlich hat sie die geringe innerorganisatorische Rolle der Arbeiter einfach hingenommen; im Vergleich agierte sie in der "Frauenfrage « sogar noch engagierter, wenn man von folgenlosen Klagen und wohlfeilen Lippenbekenntnissen einmal absieht. Paradoxerweise verfolgte die ÖTV als eine Organisation mit einem starken Arbeiteranteil daher eine Tarifpolitik, die vor allem von Angestellten und Beamten formuliert wurde. Dabei trugen die fortdauernden Forderungen nach gezielt sozial ausgleichenden Lohn- und Gehaltserhöhungen, die Geringverdiener besserstellen sollten, Züge einer sozialen Stellvertreter-Politik. Deren Hintergründe werden im Folgenden ebenso diskutiert wie ihre Folgen.

307 | Interview Monika Wulf-Mathies, 7.4.2015.

308 | Ebd. 


\section{Begrenzte Handlungsmöglichkeiten: Tarifverhandlungen für den Öffentlichen Dienst nach 1974}

\section{Ungünstige Bedingungen und der Wunsch der ÖTV nach möglichst konfliktfreien Tarifrunden}

Auf dem Höhepunkt der fast zwei Monate dauernden Streiks legten mehr als anderthalb Millionen Beschäftigte des Öffentlichen Dienstes die Arbeit nieder. In den Großstädten wuchsen die Berge des nicht abgefahrenen Mülls, der in Parks und auf anderen Grünflächen notdürftig zwischengelagert wurde. Viele Krankenhäuser behandelten nur noch besonders dringliche Notfälle, weil Techniker und Hilfskräfte streikten; zahlreiche kommunale Behörden schlossen dauerhaft ihre Türen. Der Unterricht an Schulen und Universitäten fiel fast flächendeckend aus, weil die Gebäude mitten in einem ungewöhnlich kalten Winter ungeheizt blieben. Teilweise konnten Tote nicht begraben werden, weil sogar städtische Friedhöfe bestreikt wurden. Der sozialdemokratische Regierungschef, der öffentlich ein Fünf-Prozent-Limit für Lohnerhöhungen deklariert hatte, um die Inflationsrate nach unten zu drücken, mochte dennoch keine Krise erkennen: Andere Nationen, so sagte er der Presse, würden angesichts solcher $\mathrm{Zu}$ stände nicht von einem Chaos sprechen. Mit dieser Bemerkung, die große öffentliche Empörung erregte, grub er sich wohl selbst sein politisches Grab - zumal der Arbeitskampf schließlich auch noch mit einem Lohnabschluss von 14 Prozent zu Ende ging. Bei der wenig später folgenden Parlamentswahl triumphierte die Oppositionsführerin, die im Wahlkampf versprach, die Macht der Gewerkschaften deutlich zu beschneiden. Nach Erhebungen von Meinungsforschern stimmte sogar jeder Dritte der organisierten Arbeitnehmer für ihr Programm.

Der solchermaßen skizzierte Streik mit seinen gravierenden politischen Konsequenzen gehört nicht in die bundesdeutsche Geschichte. Er ereignete sich im Frühjahr 1979 in Großbritannien und brachte dort Margaret Thatcher und ihre Konservative Partei an die Regierung. ${ }^{309}$ Der Winter des

$\mathbf{3 0 9}$ | Vgl. aus der Fülle der Literatur etwa: John Shepherd: „Crisis? What Crisis?« The Callaghan Government and the British »Winter of Discontent«, Manchester 2013, insbes. S. 82-129; Robert Taylor: The Trade Union Question in British Politics. Government and Unions since 1945, Cambridge/MA 1993, S. 257-260 (hier die Angabe zum Wahlverhalten der Gewerkschaftsmitglieder); Kenneth 
Missvergnügens«, den die Briten seinerzeit erlebten, fügt sich als Hintergrund dennoch sinnvoll auch in eine Untersuchung ein, die nach der Entwicklung der ÖTV fragt. Trotz der vielen Unterschiede zwischen den politischen Systemen und gewerkschaftlichen Traditionen in Großbritannien einerseits und der Bundesrepublik andererseits wirkt der britische Arbeitskampf doch wie eine noch einmal dramatisch gesteigerte Wiederholung des Streits, den die ÖTV und Willy Brandt als Bundeskanzler im Februar 1974 miteinander ausgefochten hatten: Auch auf der britischen Insel zeigte sich das enorme Konfliktpotenzial, das im Verhältnis zwischen Gewerkschaften für den Öffentlichen Dienst und Inhabern der Regierungsmacht selbst dann besteht, wenn die beiden Seiten politisch eng miteinander verbunden sind.

In der Bundesrepublik kam es nach 1974 bis zum Beginn des nachfolgenden Jahrzehnts allerdings zu einer ganz anderen Entwicklung als in Großbritannien: Die ÖTV und die öffentlichen Arbeitgeber gingen zumindest öffentlich vielmehr ausgesprochen vorsichtig miteinander um. Sie strebten erklärtermaßen nach möglichst konfliktfreien und damit "geräuschlosen « Tarifverhandlungen. Wie oben schon angedeutet wurde, ergab sich dieser weitgehend friedliche Verlauf zu einem guten Teil schon deshalb, weil die ÖTV bereits kurz nach dem Streik realisierte, wie stark die »Ölkrise« die wirtschaftliche Situation der Bundesrepublik tatsächlich auf Dauer veränderte. Die bislang gewohnten Wachstumsraten, so hieß es im Juni 1974 in einem Beschluss des ÖTV-Bezirksvorstanden NRW II, seien für die Zukunft nicht mehr zu erwarten: »Die Grenzen des Machbaren und Erreichbaren werden für uns sichtbar.« ${ }^{310}$

1975 verstärkte sich dieses Gefühl, das Ende einer Epoche erlebt zu haben. Der wirtschaftliche Einbruch übertraf die Rezession von 1967; die Zahl der Arbeitslosen erreichte mit anderthalb Millionen einen neuen Re-

O. Morgan: Callaghan. A Life, Oxford 1997, S. 653-676; Charles Moore: Margaret Thatcher. The authorized Biography, Bd. 1: Not for Turning, London 2013, S. 397-400. Wegen der kleinteiligen Struktur des Ensembles britischer Gewerkschaften wurden die Arbeitsniederlegungen im Öffentlichen Dienst von verschiedenen Gewerkschaften organisiert. Es handelte sich also nicht um einen einheitlichen Streik mit einem einheitlichen Forderungskatalog.

310 | Beschluss des Bezirksvorstandes NRW zur tarifpolitischen Situation, 12.6.1974. In: AdsD, ÖTV NRW II, 5/ÖTVC022003. 
kordwert. Sinkende Steuereinnahmen und die stark anwachsenden Kosten für soziale Hilfen vertieften die Krise der öffentlichen Haushalte, die bereits in den letzten Jahren des Wirtschaftsbooms begonnen hatte. 1975 lag das Finanzierungsdefizit im Bundesetat nicht mehr bei drei Milliarden bzw. zehn Milliarden DM wie in den Jahren 1973 und 1974, sondern schon am Jahresanfang bei 40 Milliarden. Auch in den Ländern und Gemeinden wuchsen die Haushaltslöcher weiter an. Zwar ging die Teuerungsrate sowohl in diesem Jahr wie auch danach deutlich zurück. Doch selbst dieser unbestreitbare Erfolg im Kampf gegen das bislang größte wirtschaftliche Problem der Bundesrepublik, den die Bundesbank mit ihrer neuen Methode der »Geldmengensteuerung « maßgeblich mitverantwortete, konnte die weit verbreitete Krisenstimmung jedoch nicht bannen. ${ }^{311}$

So galten die Arbeitslosenzahlen allgemein als höchst bedenklich, weil sie trotz der wieder verbesserten Konjunkturdaten nach 1976 nicht wieder auf den gewohnten, sehr niedrigen Stand absanken. Zudem traf Erwerbslosigkeit nun erstmals auch junge Menschen, die ihre Ausbildung oder die Schule abgeschlossen hatten. Gerade dieses ganz neue Problem weckte intensive politische und soziale Ängste. Im Herbst 1976 konstatierte Heinz Kluncker vor dem ÖTV-Hauptvorstand, in der Bundesrepublik gebe es mittlerweile eine »strukturelle Arbeitslosigkeit«, die selbst mit einem wieder stärker werdenden Wirtschaftswachstum nicht verschwinden werde. ${ }^{312}$

Die ÖTV-Führung reagierte, indem sie ihre Funktionäre und Mitglieder auf schwierigere Zeiten einschwor. Da der hartnäckig stabile »Sockel« von Arbeitslosen - so Kluncker - durch »eine weltweite wirtschaftliche Kri-

311 | Als Überblick vgl. etwa: Thomas Ellwein: Krisen und Reformen. Die Bundesrepublik seit den sechziger Jahren, München 1989, S. 47-56; Wolfrum: Demokratie, S. 335-355. Die Inflationsrate sank von 7,1 Prozent 1973 bis auf 2,7 Prozent 1978 kontinuierlich. Ab 1979 (4,1 Prozent) stieg sie wieder an. Vgl.: Statistisches Bundesamt, Preise. Verbraucherpreisindizes für Deutschland. Lange Reihen ab 1948, Wiesbaden Juli 2016, S. 4. Die genannten Zahlen zum Finanzierungsdefizit im Bundeshaushalt aus: Horst Clemens: Der öffentliche Dienst im Sparprogramm der Regierungskoalition. In: Zeitschrift für Beamtenrecht 23 (1975), S. 333-341, hier: S. 333.

312 | Protokoll der 2. Sitzung des HV, 14./15.10.1976. In: AdsD, ÖTV, 5/ ÖTVB130054. Zum Hintergrund vgl. etwa: Thomas Raithel: Jugendarbeitslosigkeit in der Bundesrepublik Deutschland. Entwicklung und Auseinandersetzung während der 1970er und 1980er Jahre, München 2012. 
se« verursacht sei, stünden alle Gewerkschaften vor neuen tarifpolitischen Herausforderungen.$^{313}$ Konkret veränderte sich etwa der Blick der ÖTV auf die öffentlichen Haushalte und deren Defizite. Hatte die Gewerkschaft bislang sehr entschieden darauf beharrt, für die Staatsfinanzen seien allein die Politiker verantwortlich, korrigierte sie nun stillschweigend ihre Position. Der Bezirk Hessen erklärte den ÖTV-Vertrauensleuten und Betriebsräten im September 1975: »Die öffentlichen Haushalte lassen eine erhebliche Ausweitung des Personalkostenanteils derzeit nicht mehr zu. Dies zu bestreiten, wäre nicht nur unrealistisch, sondern würde uns mit Sicherheit in einen nicht mehr überbrückbaren Gegensatz zu allen anderen DGB-Gewerkschaften bringen.« Die ÖTV dürfe deshalb künftig gegenüber ihrer Basis auch "unpopuläre Aussagen" nicht scheuen; die Zeit der »Fensteranträge«, in denen Mitgliederversammlungen offensichtlich unrealistische Forderungen formulierten, sei endgültig vorbei. ${ }^{314}$

Auch Heinz Kluncker wurde fast zeitgleich sehr deutlich. »Die Haushaltssituation, insbesondere die des Bundes, ist katastrophal«, schrieb er in einem Rundbrief, der ungewöhnlicher Weise direkt per Post an jedes einzelne ÖTV-Mitglied versandt wurde: Es bestehe »ein objektiver Zwang zum Sparen«. Die Gewerkschaft habe nun vor allem die Aufgabe, dafür zu sorgen, dass Einsparungen in den öffentlichen Etats für die Beschäftigten des Staates »sozial vertretbar" ausfielen. Dabei markierte der Vorsitzende gleich mehrere rote Linien: Die ÖTV werde weder einen Lohn- und Gehaltsverzicht noch eine "Lohnpause« akzeptieren; auch "Sonderopfer«, die nur im Öffentlichen Dienst gelten sollten, dürfe es nicht geben. ${ }^{315}$ Ansonsten aber trat die Organisation betont bescheiden auf: Öffentlich sagte Kluncker, die Gewerkschaft werde sich »auf die Sicherung des Realeinkommens konzentrieren ${ }^{316}$ Auf die verwunderte Frage von Journalisten, ob er mit solchen

313 | Protokoll der 3. Sitzung des HV, 20./21.1.1977. In: AdsD, ÖTV, 5/ ÖTVB130054.

314 | ÖTV-Bezirk Hessen Landesdienst Nr. 2/75, September 1975. In: Archiv Ver.di, Bestand Kluncker, 23.

315 | Rundbrief H. Kluncker an die ÖTV-Mitglieder, 30.8.1975. In: Archiv Ver.di, Bestand Kluncker, 23.

316 | Erklärung von H. Kluncker auf der Pressekonferenz, 12.9.1975. In: Archiv Ver.di, Bestand Kluncker, 36. Vgl. sehr ähnlich auch schon: Kluncker zur Einführung eines Schlichtungsverfahrens bereit. In: FAZ, 9.11.1974; Kluncker: Noch kein Säbelrasseln. In: Die Welt, 9.11.1974. 
Formulierungen nicht mangelnden gewerkschaftlichen Kampfgeist beweise, reagierte der ÖTV-Vorsitzende betont gelassen: Es sei die »Pflicht« einer Gewerkschaftsführung, »den Mitgliedern deutlich zu machen, wie groß der eigentliche Spielraum ist [...]. Und das haben wir getan. «17

Diese defensive Position ergab sich allerdings nicht einfach nur aus den geänderten wirtschaftlichen Rahmenbedingungen. Zwar handelte die ÖTV in der Krisensituation nach 1974 getreu den Traditionen der deutschen Gewerkschaften, die sich immer als pragmatisch arbeitende und konstruktive wirtschaftliche Kraft definiert hatten. Zugleich aber trugen die Erfahrungen und die Folgen des Streiks vom Februar 1974 stark dazu bei, dass die Organisation nun deutlich anders auftrat als zuvor: Gerade der scheinbar triumphale Erfolg, den sie errungen hatte, machte sie in den nachfolgenden Tarifrunden so vorsichtig. Die Tarifpolitik der ÖTV hätte sich daher wahrscheinlich auch dann signifikant verändert, wenn der ökonomische Einbruch im Jahr 1975 weniger stark ausgefallen wäre.

Oben wurde schon vermerkt, wie konsterniert, ja erschrocken die Gewerkschaft auf das vehement negative Medienecho reagierte, das sie nach dem Arbeitskampf im Frühjahr 1974 erntete. Der Eindruck der ÖTV-Führung, sie werde öffentlich an den Pranger gestellt, weil Politik und Presse einander dabei beständig bestärkten, wich auch nicht, als der Streik zunehmend in die Vergangenheit rückte. Mit Willy Brandts Rücktritt vom Amt des Bundeskanzlers im Mai 1974 entstand nämlich ein retrospektiver Blick auf die Auseinandersetzung zwischen dem Kanzler und der ÖTV, der die Affäre um den DDR-Spion Günter Guillaume in den Hintergrund drängte: Der Streik galt nun als die "wahre« Ursache hinter Brandts Demission. Der FDP-Bundestagsabgeordnete Otto Graf Lambsdorff (keineswegs ein politischer Freund des gescheiterten Regierungschefs) nannte Kluncker öffentlich den »Kanzler-Killer« - und diese Invektive blieb haften. ${ }^{318}$ Spätestens seit dem Mai 1974 konnte jeder, der die angeblich allzu mächtigen bundesdeutschen Gewerkschaften kritisieren wollte, seine Anklage mit

317 | Transkript des Interviews von H. Kluncker mit dem Deutschlandfunk, gesendet 30.12.1975, 7.20 Uhr. In: Archiv Ver.di, Bestand Kluncker, 45.

318 | Kluncker war der Kanzler-Killer. In: Handelsblatt, 30.5.1974. Als Belege für die Langlebigkeit der Formulierung vgl. etwa: Erika Martens: Der Schreck in der Abendstunde. In: Die Zeit, 22.1.1982, sowie selbst noch den kurzen Nachruf auf Kluncker in: Der Spiegel 59 (2005), H. 17, S. 190. 
einem Hinweis auf die ÖTV ohne weitere argumentative Mühen scheinbar überzeugend verifizieren.

Allein mit einer anhaltend negativen Presse hätte die Gewerkschaft allerdings wohl umgehen können - schließlich war sie solche Töne schon seit langem gewohnt. Zusätzliches Gewicht aber gewann das politische und mediale "Kesseltreiben" gegen die ÖTV, weil zahlreiche Stimmen in der Bundesrepublik unmittelbar nach dem Streik im Februar 1974 für eine Reform des Streikrechts plädierten. Dabei ging es durchweg darum, im Öffentlichen Dienst künftig Arbeitskämpfe grundsätzlich zu unterbinden. Den Anstoß für diese Debatte lieferte eine vornehmlich mit prominenten Juristen besetzte »Studienkommission für die Reform des öffentlichen Dienstrechtes«, die im Auftrag der Bundesregierung arbeitete und ihren Abschlussbericht ablieferte, als die Tarifverhandlungen im Winter 1973/74 gerade begannen. Arbeitsniederlegungen in öffentlichen Betrieben mit Monopolcharakter wie etwa im Nahverkehr werteten die Experten in ihrem Text als »Nötigung«, die vor allem sozial schwache Bürger träfe, »die auf die öffentlichen Leistungen in besonderem Maße angewiesen sind. Der Staat kann daher nicht zulassen, daß die Funktionszuverlässigkeit seiner Leistungssysteme durch seine eigenen Personalkräfte in Frage gestellt wird. ${ }^{319}$

Zwar schwiegen sich die offiziell bestellten Gutachter vornehm darüber aus, was denn konkret geschehen müsse, um ihre apodiktischen Wertungen praktisch wirksam zu machen. Diese Lücke schloss sich nach dem Streik vom Februar jedoch fast wie von selbst: Sowohl Politiker als auch zahlreiche weitere Juristen und Interessenorganisationen wie etwa der »Bund der Steuerzahler« sowie Arbeitskreise der CDU und die sogenannten Fünf Weisen im wirtschaftlichen "Sachverständigenrat« der Bundesregierung riefen unisono nach einem Streikverbot für alle Beschäftigten von Bund, Ländern und Gemeinden. Deren Löhne und Gehälter sollten künftig entweder in obligatorischen und bindenden Schlichtungsverfahren oder aber sogar überhaupt nur noch von unabhängigen Expertengremien festgelegt werden. Die von Willy Brandt bevorzugte Idee, lediglich die Kommunen

319 | Studienkommission für die Reform des öffentlichen Dienstrechtes: Bericht der Kommission, Baden-Baden 1973, S. 348. Klunckers Formulierung vom »Kesseltreiben« in: Protokoll der außerordentlichen Sitzung des HV, 11.9.1975. In: AdsD, ÖTV, 5/ÖTVB130036. 
von den Tarifverhandlungen für den Öffentlichen Dienst auszuschließen, wirkte da im Vergleich fast schon wieder liberal - und auch sie blieb in der Diskussion, als Brandt vorzeitig aus dem Amt schied. ${ }^{320}$

Bedenkenlose Denunziationen der ÖTV waren Teil dieser Debatte. Die umfangreichen Notdienste in lebensnotwendigen Betrieben etwa, zu denen sich die Gewerkschaft bei ihren Streiks verpflichtete, blieben durchweg unerwähnt. Der angesehene Bonner Staatsrechtler Josef Isensee ging sogar so weit, die ÖTV indirekt als antidemokratische Kraft zu bezeichnen. Sein Satz "Souverän ist, wer über die Müllabfuhr entscheidet « wurde in der Einleitung der vorliegenden Studie schon zitiert. Mit diesen Worten wollte der Professor keineswegs witzig sein. Er warnte vielmehr, die Tarifautonomie im Öffentlichen Dienst sei der »Hebel zur Errichtung des Gewerkschaftsstaates«, und zog daraus die Schlussfolgerung: "Allein das gesetzliche Regelungsverfahren [für die Löhne und Gehälter der staatlichen Arbeiter und Angestellten - K.C. F.] entspricht dem demokratischen Prinzip.«Weil der Staat die allgemeinen Interessen vertrete und betreue, habe er ein Recht, von allen seinen Mitarbeitern »stetige, unbedingte Dienstbereitschaft« zu verlangen. ${ }^{321}$

Hochrangige Sozialdemokraten zeigten keine Scheu, sich aktiv an dieser Diskussion zu beteiligen, deren Teilnehmer der ÖTV ganz grundlegend ans Leder wollten. Dies galt nicht nur für Rolf Krumsiek, Oberstadtdirektor in Wuppertal (sowie Mitglied der SPD und der ÖTV), der in der VKA eine prominente Rolle spielte. Auch Bundespräsident Gustav Heinemann

320 | Vgl. als Beiträge zu dieser Debatte neben den oben schon zitierten Forderungen von Gerhard Stoltenberg und Helmut Kohl etwa: Bernd Rüthers: Gewerkschaftsmacht gegen Staatsmacht? In: FAZ, 23.2.1974; Peter Hanau: Streiks im öffentlichen Dienst. In: Zeitschrift für Rechtspolitik 7 (1974), S. 111-114; Gerhard Wacke: Im öffentlichen Dienst gibt es kein Streikrecht. In: FAZ, 3.4.1974; Rolf Borell: Die Personalausgaben der Gebietskörperschaften, Wiesbaden 1974, S. 80; Stellungnahme des Arbeitskreises "Öffentlicher Dienst« der CDA zu den Thesen des CDU-Bundesfachausschusses »Innenpolitik« zur Reform des Öffentlichen Dienstes, 4.5.1974. In: BStU, Archiv der Zentralstelle, MfS-HA XX, 22597; Sachverständigenrat zur Begutachtung der gesamtwirtschaftlichen Entwicklung: Vollbeschäftigung für morgen. Jahresgutachten 1974/75, Stuttgart und Mainz 1974, Tz. 348, S. 138. In kritischer Perspektive vgl. zu dieser Debatte auch: Schäfer/ Skiba/Tofaute: Personalausgaben, S. 96-103.

321 | Isensee: Tarifvertrag, S. 28-37, die Zitate in der Reihenfolge auf S. 35, 37 u. 29. 
sowie Helmut Schmidt als frisch ernannter neuer Kanzler profilierten sich mit Einwänden gegen das Streikrecht der staatlichen Arbeiter und Angestellten. Heinemann erklärte bei einer hochoffiziellen Festveranstaltung, die das 25 Jahre alte Grundgesetz feierte, die »Verquickung der Interessenvertretung der Bediensteten draußen mit Interessenten drinnen bis in die Parlamente und Rathäuser hinein sei auf die Dauer untragbar«. Schmidt hielt sich vor den Medien zwar bedeckt. Intern aber sagte er doch, er sehe die "Stellung und Rolle des öffentlichen Dienstes [...] als ein gesamtgesellschaftliches Problem, das auf dem Wege sei, ein verfassungsrechtliches Problem zu werden«. Änderungen seien dringend nötig, auch wenn dabei »erhebliche Probleme im gewerkschaftlichen Raum auftauchen können«. Diese Worte fielen, als der Kanzler kurz nach seiner Wahl erstmals offiziell mit Vertretern des DGB-Bundesvorstandes konferierte. Bezeichnenderweise widersprach keiner der anwesenden Gewerkschafter - der ÖTV-Vorsitzende aber fehlte bei dieser Unterredung. Heinz Klunckers oben schon zitierte Feststellung, es gebe bei den anderen DGB-Verbänden »nicht allzu viele Freunde« der ÖTV, traf offensichtlich nach wie vor ins Schwarze. ${ }^{322}$

In der bedrängten politischen Situation, in die sie nach dem Streik vom Februar 1974 geriet, sah die ÖTV nur eine Möglichkeit sich zu wehren: Sie akzeptierte eine Schlichtungsvereinbarung, die es zwischen ihr und den staatlichen Arbeitgebern bislang nicht gegeben hatte. Diese Lücke war einerseits ungewöhnlich, weil Abkommen dieser Art bei den Industriegewerkschaften schon seit langem existierten. ${ }^{323}$ Andererseits aber hatten bis-

322 | In der Reihenfolge: Niederschrift über die 143. Zusammenkunft der Oberstadtdirektoren aus NRW, 26.3.1974. In: AdsD, ÖTV NRW II, 5/ÖTVB412018 (hier Krumsieks nicht näher erläuterte Forderung, das Streikrecht im Öffentlichen Dienst müsse »eingeschränkt« werden); Heinemann: Wirklichkeit auf die Verfassung hin entwickeln. In: FAZ, 25.5.1974; Der Deutsche Gewerkschaftsbund 1969-1975, S. 865-872, hier: S. 872 (Gespräch des Bundeskanzlers mit dem DGBBundesvorstand, 18.5.1974). Warum Kluncker an dieser politisch wichtigen Besprechung nicht teilnahm, die nach Schmidts Willen ausdrücklich die "positive Grundeinstellung der Regierung gegenüber den Gewerkschaften« demonstrieren sollte, ließ sich im Rahmen dieses Projektes nicht eindeutig klären. Offiziell galt er offensichtlich schlicht als »entschuldigt«, weil verhindert.

323 | Der DGB hatte sich bereits 1954 mit den industriellen Arbeitgeberverbänden auf eine »Musterschlichtungsvereinbarung« geeinigt, die - mit einigen Ände- 
lang weder die ÖTV noch Bund oder TdL und VKA ein Schlichtungsprozedere vermisst: In keiner ihrer vielen Tarifverhandlungen seit der Gründung der Bundesrepublik war darüber auch nur mit einem Wort geredet worden. Nach dem Arbeitskampf von 1974 galt die Angelegenheit jedoch plötzlich als äußerst wichtig. Sowohl die TdL als auch die VKA plädierten noch im Sommer des Jahres für ein Abkommen dieser Art, weil so eine »Objektivierung der Tarifverhandlungen im öffentlichen Dienst« erreicht werden könne. $^{324}$

$\mathrm{Zu}$ diesem Zeitpunkt allerdings hatten sich die Bundesregierung und die ÖTV-Führung insgeheim schon längst verständigt. Bereits Anfang April 1974 vereinbarte Heinz Kluncker im persönlichen Gespräch mit Willy Brandt grundsätzlich, künftig auch in den Lohn- und Gehaltsverhandlungen für die Arbeiter und Angestellten des Staates ein Schlichtungsverfahren möglich zu machen. Nur der kurz darauf folgende Rücktritt des Kanzlers verhinderte einen raschen Abschluss. ${ }^{325}$ Helmut Schmidt setzte die Angelegenheit dann zügig wieder auf die Tagesordnung. In seinem Auftrag erarbeitete der Hamburger Innensenator Heinz Ruhnau einen detaillierten Entwurf, der sich stark an den bereits älteren Schlichtungsabkommen für die Metallindustrie und die Seeschifffahrt orientierte. Es folgten Detailverhandlungen mit der Spitze der ÖTV, für die »absolute Vertraulichkeit« vereinbart wurde. Gerade der Gewerkschaftsführung war

rungen - von den meisten Gewerkschaften übernommen wurde. Unterschiedlich geregelt wurde vor allem die Frage, ob nach gescheiterten Verhandlungen automatisch ein Schlichtungsverfahren stattfinden musste. Ganz ohne Schlichtungsabkommen blieben - neben dem Öffentlichen Dienst - nur die Textilindustrie und der Bergbau. Als Überblick vgl. etwa: Gerhard Boldt: Zur Gestaltung des Schlichtungsverfahrens bei kollektiven Arbeitsstreitigkeiten in der Bundesrepublik Deutschland. In: Simone David-Constant/Lucien François/Micheline Jamoulle (Hrsg.): En Hommage à Paul Horion, Liege 1972, S. 69-87.

324 | Niederschrift über die 102. Mitgliederversammlung u. Hauptausschußsitzung der VKA, 28.6.1974. In: BArch Koblenz, B 367, 26. Fast identisch im Wortlaut: Vermerk der TdL-Geschäftsstelle für das Gespräch mit BMdI Maihofer, 25.7.1974. In: BArch Koblenz, B 222, 1323.

325 | So die rückblickende Darstellung in: Vermerk von Referat IV/3 für den Bundeskanzler, 3.7.1974. In: BArch Koblenz, B 136, 5205. Die Unterredung von Brandt und Kluncker fand hiernach am 2.4.1974 statt. Direkte Nachweise dafür konnten im Rahmen dieses Projektes nicht ermittelt werden. 
Verschwiegenheit höchst wichtig: Die Beratung sollte »in der ÖTV nicht bekannt werden «. 326

Dieser Wunsch belegt den stark politischen Charakter der Schlichtungsvereinbarung. Wenn Tarifpartner einen Vertrag dieser Art abschlieBen, einigen sie sich darauf, Streiks zu erschweren, denn nach gescheiterten Verhandlungen kann als nächste Stufe des Konflikts nun erst noch eine weitere Beratungsrunde unter dem Vorsitz unparteiischer Experten folgen. Zwangsläufig verlängert sich so die »Friedenspflicht« der Tarifparteien um mehrere Wochen oder sogar um Monate, und damit ergibt sich gerade für die Gewerkschaften die Frage, ob sie noch auf die Streikbereitschaft ihrer Mitglieder setzen können. Der Streik (wie auch die Aussperrung) wird im Tarifgeschehen so eindeutig zur Ultima Ratio. In einer stark konsensorientierten Gesellschaft wie der Bundesrepublik hatte die Schlichtungsidee genau deshalb so viele Freunde unter bürgerlichen Sozialpolitikern und unter den Arbeitsrichtern. ${ }^{327}$

Tatsächlich konnten Urabstimmung und Streik der ÖTV nach den Regelungen des Entwurfs von Heinz Ruhnau um bis zu drei Monate verzögert werden, denn künftig hatte jede Tarifpartei das Recht, nach gescheiterten Verhandlungen ein Schlichtungsverfahren in Gang zu setzen. Erst nach diesen zwölf Wochen musste die neue Verhandlungsrunde zwingend abgeschlossen sein; so lange galt auch die tarifliche Friedenspflicht. ${ }^{328}$ Wegen dieser Regelungen war die »Vertraulichkeit« der Verhandlungen für die ÖTV-Spitze so wichtig: Offensichtlich fürchtete Heinz Kluncker, er könne beschuldigt werden, die tarifpolitische Handlungsfreiheit der Gewerkschaft zu beschneiden, wenn so kurz nach dem Streik vom Februar 1974 bekannt wurde, dass er mit den Arbeitgebern über ein Schlichtungs-

326 | Vermerk der Gruppe I/3 für den Bundeskanzler, 8.8.1974. In: BArch Koblenz, B 136, 5205. Vgl. zu dieser Angelegenheit auch: Heinz Ruhnau an Bundeskanzler Helmut Schmidt, 1.7.1974. In: ebd.

327 | Vgl. exemplarisch: Boldt: Gestaltung, S. 85-87 (der Autor war Präsident des Bundesarbeitsgerichts); Bernd Rüthers: Arbeitsrecht und politisches System, Frankfurt/Main 1973, S. 130. Kritisch hingegen die Perspektive in: Kittner: Arbeitskampf, S. 676.

328 | Vgl. zu den Details den Entwurf in: Heinz Ruhnau an Bundeskanzler Helmut Schmidt, 1.7.1974. In: BArch Koblenz, B 136, 5205. Das schließlich vereinbarte Abkommen übernahm diese Regelungen weitgehend unverändert. Vgl.: ÖTV-Geschäftsbericht 1972/75, S. $108 \mathrm{f}$. 
abkommen verhandelte. So wie die Dinge lagen, ließ sich zudem parteipolitische Rücksichtnahme vermuten: Das Urteil, die Schlichtung sei »der Preis«, den die ÖTV zahlen musste, weil sie dem sozialdemokratischen Kanzler so hartnäckig die Stirn geboten hatte, drängte sich nach der Vorgeschichte geradezu auf.

Dem überzeugten Sozialdemokraten Heinz Kluncker dürfte die unbestreitbar pazifizierende Wirkung einer Schlichtungsvereinbarung zwar wohl gerade nach den Ereignissen vom Frühjahr 1974 nicht ernsthaft unangenehm gewesen sein. Weitaus wichtiger aber war für ihn doch die bedrohliche Debatte, wie die Tarifautonomie für die Beschäftigten des Staates eingeschränkt werden könne: Im persönlichen Gespräch mit dem neuen Bundeskanzler erklärte Kluncker im September 1974, er verhandle über das Schlichtungsabkommen vor allem deshalb, um autoritäre »Reformen« zu verhindern, die den Arbeitgebern direkt oder indirekt das Recht zugestehen wollten, künftig nicht nur die Bezüge der Beamten, sondern auch die Löhne und Gehälter seiner Arbeiter und Angestellten durch politischen Beschluss festzusetzen. ${ }^{329}$

So wie Kluncker es sich gewünscht hatte, erfuhren die Öffentlichkeit und die Basis der ÖTV erst von den Beratungen zwischen der Gewerkschaftsführung und den Arbeitgebern, als das Schlichtungsabkommen bereits weitgehend ausgehandelt war. Vor der Presse sagte Klunker nun, er befürworte die Vereinbarung, um »Bestrebungen, die Tarifautonomie einzuschränken, den Boden [zu] entziehen «. ${ }^{330}$ In der Großen Tarifkommission betonte er, der Vertrag entspreche genau seinen Vorstellungen: Vor allem gebe es keinen Schlichtungszwang, wie ihn andere Gewerkschaften vereinbart hatten. Zudem führten die neuen Beratungen unter unparteiischer Leitung immer nur zu einem Vorschlag, über den beide Tarifparteien dann frei entscheiden durften. Die Handlungsfreiheit der ÖTV bleibe damit uneingeschränkt bestehen. Die versammelten Tarifexperten sahen das wohl genauso: Sie begrüßten die Vereinbarung ohne jeden Einwand.

329 | Handschriftlicher Vermerk von Bundeskanzler Helmut Schmidt, 23.9.1974. In: AdsD, HSA, 1/HSAA009389.

330 | Kluncker zur Einführung eines Schlichtungsverfahrens bereit. In: FAZ, 9.11.1974. 
Auch in anderen Gremien oder aus der Organisation heraus sind keine kritischen Stimmen dokumentiert. ${ }^{331}$

Dieses Schweigen einer Gewerkschaft, die noch kurz zuvor mit starker Beteiligung der Basis erfolgreich gestreikt hatte, zu einer tarifpolitisch nun wirklich grundsätzlich wichtigen Frage kennzeichnet offensichtlich den inneren Zustand der Organisation seit dem Frühjahr 1974. Medien und Politik sahen die ÖTV auf dem Höhepunkt gewerkschaftlicher Macht; hinter deren Kulissen aber herrschte Katzenjammer - und dies galt gerade in den großstädtischen Versorgungsbetrieben, in denen die Gewerkschaft organisatorisch besonders stark war. Ohne deren Belegschaften aber konnte die ÖTV keinen wirkungsvollen Arbeitskampf durchführen. Der vorsichtige tarifpolitische Kurs, den die Gewerkschaft seit 1974 verfolgte, erklärt sich auch durch diese schlechte Stimmung im Kern ihrer Basis. „Keine Streikbereitschaft", so lautete im Dezember 1974 kurz und knapp das Fazit von Hans Liersch, dem Vorsitzenden des größten ÖTV-Bezirks NordrheinWestfalen II. Besonders die Arbeiter der Müllabfuhren, deren Streik für den Arbeitskampf im Frühjahr so entscheidend wichtig gewesen sei, hätten den Stuttgarter Tarifabschluss immer noch nicht akzeptiert. "Wir lassen uns nicht mehr vor den Karren spannen«, so laute nun ihre Parole. ${ }^{332}$

Ganz ähnlich berichteten auch die Bezirke Hessen und Bayern. "Stimmung tief, Lage ernst, Erwartungen zurückgesteckt« meldete im Telegrammstil die ÖTV in Nürnberg; die Kreisleitung Erlangen vermerkte, die kommunalen Arbeiter weigerten sich, weiterhin "für andere die Kastanien aus dem Feuer zu holen«. Von »Mutlosigkeit« war in dem Bericht aus Co-

331 Notizen von Hans Liersch über die Sitzung der GTK, 12.12.1974. In: AdsD, ÖTV NRW II, 5/ÖZVC603003. Zwar gab es auf dem Gewerkschaftstag von 1976 zwei Anträge, das Abkommen zu kündigen, weil es Arbeitskämpfe behindere. Sie stammten von der Kreisdelegiertenkonferenz Mannheim und der Bundesjugendkonferenz. Beide Anträge wurden ohne Diskussion abgelehnt (Protokoll ÖTV-GT 1976, Bd. 2, S. 336f. [die Anträge] sowie Bd. 1, S. 480 [die Abstimmung]). Als ein Beispiel für sogar zwei verpflichtende Schlichtungsrunden (zunächst ohne und bei immer noch ausbleibender Einigung dann mit unparteiischer Leitung) vgl. das entsprechende Abkommen der Gewerkschaft Nahrung - Genuss - Gaststätten und die Angaben dazu in: Tiemann: Mehr Frauen, S. 7.

332 | Notizen von Hans Liersch zur Tarifrunde 1975, o. D. [Ende 1974]. In: AdsD, ÖTV NRW II, 5/ÖTVC603005. 
burg die Rede; in Straubing registrierten die ÖTV-Funktionäre »zunehmendes Desinteresse und eine gefährliche Lethargie«. ${ }^{333}$

Zwar hatten seinerzeit alle Gewerkschaften mit zaghaften Stimmungen zu kämpfen. Die Rezession und die gestiegenen Arbeitslosenzahlen erschreckten die Mitglieder gerade der Industriegewerkschaften; auftrumpfende Forderungen fanden keinen Widerhall mehr. ${ }^{334}$ Bei der ÖTV aber kam Ärger über den Kurs der Verbandsführung hinzu: Weite Teile der Basis haderten immer noch damit, dass der Stuttgarter Tarifabschluss ihnen kein Urlaubsgeld eingebracht hatte. Die verabredeten weiteren Verhandlungen über diesen Punkt noch im gleichen Jahr fanden im Oktober 1974 zwar statt. Dabei verweigerten die Arbeitgeber jedoch jedes Entgegenkommen und die ÖTV-Führung gab daraufhin sofort klein bei. Intern rechtfertigte Heinz Kluncker diesen Kurs mit politischen Argumenten. So warnte er im Hauptvorstand, die ÖTV riskiere Streit mit ihren »Brudergewerkschaften« im DGB, wenn sie, »koste es, was es wolle, unbeschadet ob Arbeitslosigkeit und Kurzarbeit, in ihrem Bereich jetzt anfangen wollte, das Urlaubsgeld zu popularisieren«. Die Bundesregierung drohe damit, die für 1975 geplante Steuerreform zu verschieben (die gerade Geringverdiener finanziell entlasten sollte), wenn die ÖTV nicht auf ihre Forderung verzichte. Die Reaktion in den anderen DGB-Verbänden "wäre dann katastrophal «. 335

Im kleineren Kreis setzte der Vorsitzende zudem einen zweiten und noch gewichtigeren politischen Akzent: Nach dem Februar-Streik und den öffentlichen Reaktionen auf den Tarifvertrag könne kein Politiker nur

333 | Kurzbericht über Meinungsäußerungen der hessischen Kreisverwaltungen, 27.1.1975. In: Archiv Ver.di, Bestand Kluncker, 23; Stimmungsbild der Bezirksverwaltung Bayern zur Tarifbewegung im öffentlichen Dienst 1975, 13.2.1975. In: AdsD, ÖTV NRW II, 5/ÖTVC603003.

334 | Vgl. im Überblick: Die Gewerkschaften im Jahre 1975. In: Gewerkschaftsreport 9 (1975), H. 1, S. 1-29, insbes. S. 13; Walther Müller-Jentsch: Wirtschaftskrise und Gewerkschaftspolitik. In: Otto Jacobi/Walther Müller-Jentsch/Eberhard Schmidt (Hrsg.): Gewerkschaften und Klassenkampf. Kritisches Jahrbuch, Frankfurt/Main 1975, S. 10-17 (hier freilich in marxistischer Perspektive anklagend als politisches Versagen der Verbandsführungen gedeutet).

335 | In der Reihenfolge der Zitate: Wortprotokoll der 10. Sitzung des HV, 3./4.10.1974. In: AdsD, ÖTV, 5/ÖTVB130038; Notizen von Hans Liersch zur Urlaubsgeldforderung 1974, o. D. In: AdsD, ÖTV-NRW II, 5/ÖTVC603005 (zum Zusammenhang mit der Steuerreform). 
wenige Monate später erneut der ÖTV nachgeben, »ohne sein Gesicht zu verlieren«. Wessen Gesicht hier vor allem gemeint war, musste nicht erklärt werden: Gerade ihr Sieg im tarifpolitischen Streit mit dem ersten sozialdemokratischen Bundeskanzler beschnitt die Handlungsfreiheit der Organisation gegenüber Willy Brandts Nachfolger. ${ }^{336}$ Helmut Schmidt selbst war sich dessen wohl sehr bewusst: Wie Journalisten aus Bonn kolportierten, sagte der neue Kanzler zumindest »in privater Runde« ganz unverblümt, »der ÖTV-Chef könne es sich schon aus Staatsraison nicht leisten, ein zweites Mal an einem Kanzlerstuhl zu sägen«. ${ }^{337}$

Die deutlichen Stimmenverluste der SPD bei der Bürgerschaftswahl in Hamburg und auch bei den Landtagswahlen in Hessen sowie in Niedersachsen, die alle noch im Jahr 1974 stattfanden, intensivierten diese politischen Bedenken. Glaubt man den West-Spionen der DDR-Staatssicherheit, dann einigten sich die Führungen von DGB, IG Metall und ÖTV im Herbst 1974 hinter den Kulissen, die »zugespitzte Lage der Bundesregierung nicht durch unüberlegte Maßnahmen und überhöhte Lohnforderungen der Gewerkschaften noch weiter zu komplizieren ${ }^{338}$ Zwar fehlen andere Dokumente, die eine Absprache dieser Art bestätigen; politisch aber wirkt sie gerade am Ende des sehr bewegten Jahres 1974 ohne Frage plausibel. Eher ließe sich vielleicht sogar fragen, ob die drei Sozialdemokraten Heinz Os-

336 | Ebd.

337 | An der Lohn-Front beginnt der Clinch. In: Welt am Sonntag, 14.9.1975.

338 | Information der HVA Nr. 113/129 über die Haltung der DGB-Führung und maßgeblicher Funktionäre von IG Metall und ÖTV zu aktuellen gesellschaftspolitischen Fragen, 10.12.1974. In: BStU, Archiv der Zentralstelle, MfS HVA, 113. Ein Hinweis auf angeblich bevorstehende Beratungen zwischen Kluncker und Loderer im September 1974, in denen es um »Vorabstimmungen« für die nächste Tarifrunde gehe, findet sich in: Vermerk Referat IV/3 für den Bundeskanzler, 3.7.1974. In: AdsD, HSA, 1/HSAA006948. Weiteres dazu konnte im Rahmen dieses Projektes nicht ermittelt werden. Bei der Hamburger Bürgerschaftswahl im März 1974 verlor die SPD mehr als 10 Prozentpunkte und damit (erstmals seit 1957) auch die absolute Mehrheit der Parlamentssitze. In Niedersachsen und in Hessen fielen ihre Verluste mit etwa drei Punkten kleiner aus. Dennoch war insbesondere die Wahl in Hessen politisch bedeutsam: Hier wurde die CDU erstmals seit Gründung des Landes zur stärksten Partei (47 Prozent gegenüber den 43 Prozent der SPD). In allen drei Ländern blieb die SPD durch Koalitionen mit der FDP jedoch an der Regierung. 
kar Vetter, Eugen Loderer und Heinz Kluncker wirklich erst eine gemeinsame Unterredung brauchten, um sich so zu verständigen.

Bereits in der Tarifrunde für den Öffentlichen Dienst für 1975 jedenfalls herrschte zwischen der ÖTV und den staatlichen Arbeitgebern ein neuer, sehr entspannter Ton. Mehrfach vertagten sich die Unterhändler einvernehmlich, ohne überhaupt konkret geworden zu sein. Dieser schleppende Gang der Beratungen war gewünscht: Beide Seiten wollten sich »von ihrer Lohnführerrolle befreien«, d.h., künftig sollte allein die Privatwirtschaft jeweils am Jahresanfang die tarifpolitische Bühne beherrschen. ${ }^{339}$

Der ÖTV war dieses Ziel so wichtig, dass sie im Herbst 1974 sogar versuchte, es gleich »mit der Brechstange« durchzusetzen: Der Schlichtungsvereinbarung wollte sie zunächst nur dann zustimmen, wenn sich die Arbeitgeber im Gegenzug bereit erklärten, den laufenden Lohn- und Gehaltstarifvertrag bis Ende März 1975 zu verlängern. Eine Einmalzahlung sollte den Verlust ausgleichen, den die Beschäftigten durch die verschobene Lohnerhöhung erlitten. Dazu kam es zwar nicht, weil die Arbeitgeber die Absicht dahinter unschwer erkennen konnten: In der Pauschale verbarg sich das Urlaubsgeld, das sie strikt ablehnten. Deshalb gab es keine "Gegengabe« des Tarifpartners für die Unterschrift der ÖTV unter das Schlichtungsabkommen. ${ }^{340}$ Der zögerliche Gang der Tarifrunde, in der die Arbeitgeber lange kein konkretes Angebot formulierten, hatte dann aber doch den gewünschten Effekt: Die Beratungen für den Öffentlichen Dienst standen nicht mehr so stark im Blickpunkt der Öffentlichkeit, weil die IG Metall und die Unternehmer dieser Branche zum gleichen Zeitpunkt bereits kurz vor einem Abschluss standen. ${ }^{341}$

Zudem vereinbarten ÖTV und staatliche Arbeitgeber für 1975 einen Tarifvertrag mit einer Laufzeit von 13 Monaten; 1977 wiederholten sie die-

339 | Vermerk Referat IV/3 für den Bundeskanzler, 3.7.1974. In: AdsD, HSA, 1/ HSAA006948.

340 | Vgl. hierzu: Handschriftlicher Vermerk von Bundeskanzler Helmut Schmidt, 23.9.1974. In: AdsD, HSA, 1/HSAA009389; Aktenvermerk Referat IV/3 für den Bundeskanzler, 23.9.1974. In: ebd. (Zitat).

341 | Vgl. zu diesem Effekt etwa: Winfried Didzoleit: Mit Volldampf voraus geht er nicht in die Tarifrunde. In: FR, 16.11.1974; Kluncker will nicht Vorreiter sein. In: SZ, 14.12.1974; Konziliant und nüchtern in die zweite Tarifrunde. In: FAZ, 16.1.1975; Christian Millack: Das neue Besoldungsrecht. In: Zeitschrift für Beamtenrecht 23 (1975), S. 177-185, hier: S. 181. 
ses Vorgehen ein weiteres Mal. Der breite Rücken der IG Metall, die nach wie vor jeweils schon vor Beginn des neuen Jahres mit der ersten ihrer regionalen Verhandlungsrunden begann, verbarg das Tarifgeschehen für den Öffentlichen Dienst nun noch besser. ${ }^{342}$ Gewerkschaftlich ging die ÖTV nach Heinz Klunckers Urteil damit kein Risiko ein: Im Hauptvorstand sagte er im Frühjahr 1979, er glaube nicht, »daß es eine Regierung, auf welcher Ebene auch immer, geben kann, die ihren Tarifbevollmächtigten den Auftrag gäbe, die IG Metall offensichtlich und öffentlich zu korrigieren «. ${ }^{343}$ Zudem ließen die »Haushaltslage und die gegenwärtige Stimmungslage der öffentlichen Meinung « der ÖTV nach seinem Urteil ohnehin keine andere Wahl: Sie könne sich nur schaden, wenn sie erneut »die Lohnführung« übernehme. ${ }^{344}$ Im Frühjahr 1976 signalisierte er dem Bundeskanzleramt intern, er wünsche sich im Interesse der Gewerkschaft wiederum »eine möglichst schnelle und geräuschlose Tarifrunde «. ${ }^{345}$

Die Lohn- und Gehaltstarifverträge für den Öffentlichen Dienst in den Jahren 1975 bis 1979 lassen sich daher in zumindest einer Hinsicht denkbar knapp gemeinsam charakterisieren: Bei jeder dieser Aufstockungen erreichte die ÖTV geringere Prozentzahlen als die IG Metall, während die anteiligen Zuwächse für die Metaller und für den Öffentlichen Dienst zuvor seit den späten 1960er Jahren stets fast identisch gewesen waren. Mit den von ihr erstrittenen Lohnabschlüssen belegte die ÖTV unter den DGB-Verbänden deshalb seit 1975 durchweg nur noch mittlere Plätze auf der Skala gewerkschaftlicher Erfolge. ${ }^{346}$

342 | Vgl.: ÖTV-Geschäftsbericht 1972/75, S. 92; ÖTV-Geschäftsbericht 1976/79, S. 109, sowie im Überblick: Rolf Krumsiek: Alle Jahre wieder, S. 333.

343 | Protokoll der 13. Sitzung des HV, 30./31.1.1979. In: AdsD, ÖTV, 5/ ÖTVB130065.

344 | Protokoll der außerordentlichen Sitzung des HV, 11.9.1975. In: AdsD, ÖTV, 5/ÖTVB130036.

345 | Aktenvermerk Referat IV/B für den Bundeskanzler, 21.1.1976. In: AdsD, HSA, 1/HSAA010027.

346 | Vgl. hierzu etwa: Aktenvermerk des Abteilungsleiter Referat IV zur Tarifrunde 1976 im Öffentlichen Dienst, 30.12.1975. In: AdsD, HSA, 1/HSAA010027; Aktenvermerk der Abt. Z B 4 für den BMdI für die Aussprache über die bevorstehenden Lohn- und Vergütungstarifverhandlungen für den öffentlichen Dienst beim Bundeskanzler, 23.2.1979. In: BArch Koblenz, B 136, 15821 (hier der Rückblick auf die Tarifrunden seit 1975 im Vergleich mit den Abschlüssen der IG 
Stillschweigend akzeptierte die Gewerkschaft in diesen Jahren also eine Lohnleitlinie der besonderen Art: Sie entstand nicht durch politischen Beschluss, sondern verdankte sich der Tarifautonomie in einem florierenden Zweig der bundesdeutschen Industrie. Das Vorbild der IG Metall nahm die ÖTV-Führung dabei sehr ernst. Im Herbst 1979, als die größte deutsche Gewerkschaft einmal ungewöhnlich lange brauchte, um ihren Forderungskatalog zusammenzustellen, empfahl Heinz Kluncker intern ausdrücklich,

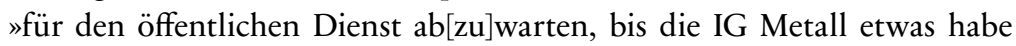
verlauten lassen «. ${ }^{347}$ Auch die staatlichen Arbeitgeber schätzten die Vorreiterrolle der Metallbranche: Ein Jahr zuvor waren sie es gewesen, die ihr Angebot absichtlich hinauszögerten, weil »in dem praktisch allein relevanten Metallbereich noch keine Daten gesetzt worden sind«; ebenfalls 1979 bewerteten die Tarifexperten der Bundesregierung den Lohnabschluss der IG Metall als »ein eindeutiges Signal« für »die Marschrichtung des Bundes «. ${ }^{348}$

Für die Öffentliche Hand erbrachte diese tarifpolitische Strategie den gewünschten Effekt: Sie half, den Anstieg der Personalkosten bei Bund, Ländern und Gemeinden abzubremsen. Die Zuwachsraten lagen nun deutlich niedriger als in der ersten Hälfte der 1970er Jahre. ${ }^{349}$ Allerdings verdankte sich dieser Effekt auch aktiven Sparmaßnahmen, etwa durch den Abbau finanziell bedeutsamer Sonderrechte der Beamten, durch verzögerte Beförderungen, Einstellungsstopps und betriebliche Rationalisierung und sogar durch die Privatisierung bestimmter Arbeiten, für die bislang der Öffentliche Dienst zuständig gewesen war. Wegen dieser verschiedenen parallelen Entwicklungen lässt sich nicht genau berechnen, wie stark der

Metall). Speziell für die Tarifrunde 1977 vgl. den detaillierten Vergleich mit den Resultaten der IG Metall in: Projektgruppe Gewerkschaftsforschung: Tarifpolitik 1977. Darstellung und Analyse der Tarifbewegung in der Metallverarbeitenden, der Chemischen und der Druckindustrie sowie im Öffentlichen Dienst, Frankfurt/Main und New York 1978, S. 257-270, insbes. S. $262 \mathrm{f}$.

347 | Protokoll der 15. Sitzung des HV, 4.10.1979. In: AdsD, ÖTV, 5/ÖTVB130068. 348 | In der Reihenfolge der Zitate: Aktenvermerk der Abt. Z B 4 für das Chefgespräch der öffentlichen Arbeitgeber, 13.3.1978; Aktenvermerk der Abt. Z B 4 für den BMdI für die Aussprache über die bevorstehenden Lohn- und Vergütungstarifverhandlungen für den öffentlichen Dienst beim Bundeskanzler, 23.2.1979. Beide in: BArch Koblenz, B 136, 15821.

349 | Vgl. etwa: Aktenvermerk von Referat D III 1 für den Minister, 9.5.1977. In: BArch Koblenz, B 106, 97908. 
Staat finanziell profitierte, weil die Lohn- und Gehaltserhöhungen für den Öffentlichen Dienst nach 1975 durchweg moderat ausfielen. ${ }^{350}$

Noch einmal deutlich diffuser fiel das Resultat bei der ÖTV aus. Für ihr Verhalten in der Tarifrunde für 1975 erntete sie zwar - zum ersten Mal nach langen Jahren - anerkennende Medienkommentare. Journalisten entdeckten und lobten plötzlich den »Staatsmann Kluncker«; sie sprachen von einem "guten Ende im Tarifstreit« oder auch von einem "Zeichen nicht nur wirtschaftlicher, sondern vor allem von politischer Vernunft«. ${ }^{351}$ Von einem neuen Image der ÖTV und ihres Vorsitzenden lässt sich dennoch nicht sprechen. Bereits 1976 fielen die Urteile vieler Zeitungen wieder unverhohlen unfreundlich aus, weil die Gewerkschaft für dieses Jahr besonders dringlich eine sozial ausgleichende Lohn- und Gehaltserhöhung verlangte. 1977 ergab sich genau das gleiche Bild. ${ }^{352}$ Auch Karikaturen, in denen der schwergewichtige Heinz Kluncker die angeblich stets »unersättliche« ÖTV symbolisierte, erschienen nach wie vor. ${ }^{353}$

Die Mischung von wirtschaftlichem Pragmatismus, politisch motivierter Rücksichtnahme auf den zweiten sozialdemokratischen Bundeskanzler

350 | Zu Rationalisierung und Privatisierung siehe genauer weiter unten in diesem Kapitel.

351 | In der Reihenfolge der Zitate: Joachim Sobotta: Staatsmann Kluncker. In: Rheinische Post, 18.2.1975; Geklärt. In: Deutsches Allgemeines Sonntagsblatt, 23.2.1975; Hans Riehl: Signal der Vernunft. In: tz (München), 19.2.1975. Ähnlich vgl. auch: Peter Gillies: Die Tarifparteien haben gelernt. In: Die Welt, 19.2.1975; Hans D. Barbier: Dicht an der Richtzahl. In: SZ, 19.2.1975; Hans-Henning Zencke: Solidarisch. In: WAZ, 19.2.1975; Hans-Jörg Sottorf: Maßvoll. In: Göttinger Tageblatt, 19.2.1975; Kurt Becker: Die Kraftprobe. In: Kölner Stadt-Anzeiger, 19.2.1975; Abschluss der Vernunft. In: StZ, 18.2.1975.

352 | Vgl. etwa: ÖTV bleibt hart. In: Bild (Hamburg), 10.4.1976; Er klunckert mal wieder. In: Die Welt, 10.4.1976; Unbelehrbarer Kluncker. In: FAZ, 10.4.1976; Die ÖTV langt zu. In: StZ, 16.11.1976; Was Klunckers »soziale Akzente« kosten würden. In: Handelsblatt, 18.11.1976; Heinz Melder: Öffentliche Hand - offene Hand. In: Die Welt, 8.2.1977; Vergeblicher Ruf an Kluncker. In: SZ, 8.2.1977; Nun auch Urlaubsgeld? In: FAZ, 26.2.1977.

353 | Vgl. beispielhaft die Zeichnung des renommierten Karikaturisten Horst Haitzinger in: Badische Zeitung, 11.2.1977, die Kluncker als hungrigen Esser an einem winzig kleinen Tisch zeigt. Trotz seiner bildfüllenden Figur verlangt Kluncker, »nicht wieder eine so winzige Portion« serviert zu bekommen, weil er »ja nur noch Haut und Knochen« sei. 
und Anpassung an die Streikunlust gerade in den wichtigsten Gruppen ihrer Basis, die hinter der defensiven Strategie der ÖTV stand, hielt die Organisation dennoch auf Kurs. Zwar regte sich auf dem Gewerkschaftstag von 1976 deutlich Unwille, als gleich zwei Sozialdemokraten mit Regierungsverantwortung - der Bundeskanzler und der Hamburger Bürgermeister Hans-Ulrich Klose - die ÖTV für ihre »Kooperation« in den ökonomisch nun so schwierigen Zeiten lobten. Schmidt hob die »Verantwortung für das Ganze« hervor, die sich in den beiden letzten Tarifrunden im Verhalten der Gewerkschaft gezeigt habe. Klose sagte sogar, der Hamburger Senat habe ein Sparprogramm für den Öffentlichen Dienst der Hansestadt aufgelegt, das "gegen den geschlossenen Widerstand der ÖTV nicht zu machen gewesen« wäre: »Aber es hat diesen ÖTV-Widerstand nicht gegeben." Stattdessen habe die Gewerkschaft »den Willen zur Zusammenarbeit und die Einsicht in bestimmte Notwendigkeiten« bewiesen. Wirkungsvolle Sparmaßnahmen im Staatsapparat könne die Politik eben »nur mit einer richtigen Gewerkschaft wie der ÖTV zusammen durchziehen. Sonst geht es überhaupt nicht. « ${ }^{354}$

In der allgemeinen Debatte protestierten mehrere Delegierte scharf gegen Würdigungen dieser Art. Heinz Wolf, der hessische Bezirksvorsitzende, sprach von »Gegnerpropaganda und betonte, Gewerkschaften seien grundsätzlich »für das große Ganze nicht zuständig«. Hans Schwalbach, Vorsitzender im ÖTV-Bezirk Nordwest, empfand Kloses Worte »wie eine kalte Dusche«; ein Delegierter aus Dortmund meinte, »engagierte Gewerkschafter« könnten solch ein Lob nur »energisch zurückweisen«. ${ }^{355}$ Trotz (oder vielleicht doch eher: gerade wegen) der fast schon provozierenden Worte von Hans-Ulrich Klose ging der Gewerkschaftstag rasch zur Routine über: Eine grundlegende tarifpolitische Debatte über die vorsichtige Verhandlungsführung der Verbandsspitze fand 1976 nicht statt.

354 | Protokoll ÖTV-GT 1976, Bd. 1, S. 21 (H. Schmidt) u. S. 19f. (Klose). Schmidts Formulierung kann man als bewusst gewählte politische Spitze verstehen, denn Willy Brandt hatte im Tarifstreit im Frühjahr 1974 mehrfach gefordert, die ÖTV solle »Verantwortung vor dem Ganzen« zeigen und den Abschluss unter zehn Prozent akzeptieren. Vgl. etwa: Brandt mahnt Tarifpartner erneut. In: Weser-Kurier, 2./3.2.1974.

355 | In der Reihenfolge: ebd., S. 113 f., 135 u. 110 (Rainer Schellbach, Dortmund). 


\section{Verborgene Konflikte und Blockaden: Das tarifpolitische "Moratorium" der Arbeitgeber und seine Folgen}

Wie wichtig es der ÖTV-Führung war, die Tarifrunden für den Öffentlichen Dienst möglichst "geräuschlos« durchzuführen, zeigte sich auch daran, dass die Verbandsführung keinen Versuch unternahm, ihre eigene Basis oder die Öffentlichkeit für einen anderen Streit zu interessieren, den sie abseits der jährlichen Lohn- und Gehaltsrunden mit den öffentlichen Arbeitgebern austrug. Er blieb eine Angelegenheit, von der lediglich Experten etwas wussten, obwohl sich das Bild von den weitgehend einvernehmlichen Tarifbeziehungen im Öffentlichen Dienst in den Jahren nach 1975 durchaus gravierend verändert, wenn man auf diese Auseinandersetzung schaut.

Konkret ging es um die Manteltarifverträge für die Arbeiter und Angestellten des Staates, in denen etwa die verschiedenen beruflichen Tätigkeiten, Zulagen und Karrierewege in Abgrenzung gegeneinander geregelt waren. Das innere Gefüge des Öffentlichen Dienstes ergab sich weitgehend aus diesen Abmachungen. Gerade in einer Arbeitswelt, die sich mit dem Vormarsch der elektronischen Datenverarbeitung rapide wandelte, kam ihnen große Bedeutung zu. Dennoch herrschte in den Manteltarifverträgen für den Öffentlichen Dienst nach dem Willen der Arbeitgeber seit 1974 absoluter Stillstand. Im Dezember des Jahres beschlossen Bundesregierung und TdL einvernehmlich ein "Moratorium « für Verhandlungen über diese länger laufenden Tarifverträge. 1977 erneuerten sie ihre Entscheidung. Da auch die Kommunen den Beschluss respektierten, gab es de facto bis 1979 keine nennenswerten Veränderungen dieser Abmachungen; erst 1978 begannen Arbeitgeber und ÖTV überhaupt wieder mit Gesprächen über neue Manteltarifverträge, die zum Leidwesen der Gewerkschaft allerdings nur »schleppend« verliefen. ${ }^{356}$

Mit dem »Moratorium« verfolgten Bund und Länder eine doppelte Absicht. Zum einen ging es um handfeste finanzielle Interessen. Zum anderen und eher im Verborgenen aber führten sie den tarifpolitischen Stillstand

356 | Vgl. im Überblick: ÖTV-Geschäftsbericht 1976/79, S. 101-103 u. 121 f. (Zitat: S. 102). Die ursprüngliche Vereinbarung für das "Moratorium« mit ihrer finanziellen Argumentation findet sich in: Gemeinsame Erklärung der Bundesregierung und der Regierungen der Bundesländer, 19.12.1974. In: BArch Koblenz, B 222, 1324. 
bei den strukturell orientierten Tarifverträgen auch herbei, um die ÖTV in einer grundlegend wichtigen Sache auszubremsen, die der Gewerkschaft als der zukunftsorientierte Kern ihrer ganzen Tarifpolitik galt. Als Organisation, die Beamte, Angestellte und Arbeiter gleichermaßen vertrat und "Standesverbände" wie etwa den Beamtenbund oder die DAG für anachronistische Relikte des 19. Jahrhunderts hielt, hatte die ÖTV immer gegen die starren internen Hierarchien und Privilegien im Öffentlichen Dienst opponiert: Nach ihren Vorstellungen sollte der moderne Staat alle seine Beschäftigten gleichbehandeln. ${ }^{357}$

So klar dieses Ziel war, so sehr erschöpfte sich der Versuch der ÖTV, es zu erreichen, lange jedoch in einer Ad-hoc-Politik, die in vielen Einzelschritten nach und nach zumindest einige Sonderrechte der Beamten und auch der Angestellten abbaute. Ein konsequent durchdachter konzeptioneller Rahmen aber fehlte. Er entstand erst in den Jahren 1969/70, als die ÖTV gemeinsam mit dem DGB ein Programm entwickelte, das dem Öffentlichen Dienst ein einheitliches Personal- und Dienstrecht geben sollte. Vor allem ging es den Gewerkschaften darum, allen Arbeitnehmern des Staates die Möglichkeit zu geben, ihre Lohn- und Arbeitsbedingungen aktiv mitzugestalten. Die Beamten sollten so aus ihrer Abhängigkeit von Entscheidungen des "Dienstherrn « befreit werden. Zwar besaßen sie das Koalitionsrecht, gewerkschaftlich handeln aber durften sie nicht. Bund, Länder und Gemeinden mussten ihre Beamten nur »anhören«, bevor politisch über die Gehälter und die Arbeitsbedingungen entschieden wurde; das Streikrecht blieb ihnen grundsätzlich verwehrt. Diesen "Sonderstatus« der Beamten wollten ÖTV und DGB mit dem einheitlichen Dienstrecht aus der Welt schaffen: Nur so sei eine "qualitätsorientierte Modernisierung des öffentlichen Dienstes« möglich, die »antiquierte Formen der Über- und Unterordnung" überwinde und die "noch verbliebenen hierarchischen Strukturen im öffentlichen Dienst« aufbreche. ${ }^{358}$

Allerdings ging es dabei nicht darum, den "Stand « der deutschen Berufsbeamten einfach abzuschaffen. Tradition und Grundgesetz machten

357 | Siehe dazu schon S. 31.

358 | Heinz Kluncker: Für ein einheitliches Dienstrecht. In: ÖTV-Beamten-Nachrichten 15 (1970) 1, S. 1. Zum Anteil der DGB-Beamtenabteilungen am Konzept des einheitlichen Dienstrechtes vgl. zusammenfassend: Ellwein: Gewerkschaften, S. 100-103. 
eine so radikale Reform fast unmöglich - das mussten auch Gewerkschafter akzeptieren, die versuchten, weit in die Zukunft zu planen. Deshalb entwickelten DGB und ÖTV ein Modell, wie man den Beamten zum selbstbestimmten Arbeitnehmer mache könne, ohne ihn gleich in einen ganz normalen Angestellten zu verwandeln. ${ }^{359}$ Es kam nicht zu einem einheitlichen Dienstrecht, weil ÖTV und DGB keinen Partner fanden, der an dem Konzept dauerhaft interessiert gewesen wäre. Walter Eberhardt, der langjährige enge Mitarbeiter Heinz Klunckers in der ÖTV-Hauptverwaltung, urteilt rückblickend, die Gewerkschaft habe insbesondere den politischen Mut der SPD weit überschätzt. ${ }^{360}$ Bei den Beamten nämlich regten sich lautstarke Gegner des einheitlichen Dienstrechtes, die in dieser Berufsgruppe viel Applaus fanden. Da alle Bundestagsparteien intensiv um die Stimmen der Beamten und ihrer Familien warben, trat keine von ihnen wirklich ernsthaft für die Reform ein. ${ }^{361}$

Mit dem Arbeitskampf von 1974 war die Idee eines Streikrechts für Beamte dann politisch eindeutig tot. Die oben skizzierte Debatte, ob es im Öffentlichen Dienst überhaupt Arbeitsniederlegungen geben dürfe, stellte ganz andere Weichen - und das »Moratorium« der Arbeitgeber bei neuen Manteltarifverträgen aus dem Herbst des Jahres schrieb diese Kursänderung dann eindeutig fest: Wer sich weigerte, über weitere Schritte zur Gleichbehandlung von Arbeitern und Angestellten des Staates zu sprechen, der sah offensichtlich überhaupt keine Notwendigkeit, darüber hinaus auch noch

359 | Grob gesagt wollten DGB und ÖTV zwischen einem dienstlichen »Statusrecht" und einem »Folgerecht« unterscheiden: Das erstere sollte es den öffentlichen Arbeitgebern erlauben, bestimmte Beschäftigte des Öffentlichen Dienstes wegen ihrer hoheitlichen Bedeutung weiterhin besonders eng an sich zu binden. Das »Folgerecht« war dann jedoch einheitlich für den ganzen Öffentlichen Dienst konzipiert, d.h., die Regeln der Tarifautonomie sollten künftig auch dann gelten, wenn über die Gehälter und die konkreten Arbeitsbedingungen der Beamten beraten wurde. Als knappe Zusammenfassung vgl. etwa: Schäfer/Skiba/Tofaute: Personalausgaben, S. 90-109.

360 | Interview Walter Eberhardt, 16.11.2013.

361 | Vgl. exemplarisch etwa die engagierte Verteidigung des Status quo in: Jörg Jung: Die Zweispurigkeit des öffentlichen Dienstes. Eine Untersuchung über die Veränderungen der Personalstruktur im öffentlichen Dienst und die Verankerung des Berufsbeamtentums im Grundgesetz, Berlin 1971. Zusammenfassend zum Scheitern der Dienstrechtsreform vgl. auch: Rigoll: Staatsschutz, S. 238-242. 
die besondere Stellung der Beamten in Frage zu stellen. So hielt der Öffentliche Dienst in den 1970er Jahren fast schon demonstrativ sogar an arbeitsrechtlichen Relikten aus dem 19. Jahrhundert fest, die in vielen Sparten der Privatwirtschaft längst beseitigt waren: Arbeiter des Staates etwa mussten nach wie vor jeweils sofort ein ärztliches Attest vorlegen, wenn sie sich krankmeldeten - bei Angestellten und Beamten wollte der Arbeitgeber die Krankschreibung hingegen stets erst nach drei Fehltagen sehen. ${ }^{362}$

Wie gesagt diente das "Moratorium« gleichzeitig konkreten finanziellen Interessen der Arbeitgeber: Sie wollten tarifliche Höhergruppierungen vor allem im expandierenden Segment der Angestellten vermeiden, weil dieses Aufrücken ganzer Gruppen im Gehaltsgefüge für sie sehr kostspielig sein konnte. Zwar gab es in den Ländern durchaus Politiker, die diesen gewollten tariflichen Stillstand skeptisch beurteilten. Der Öffentliche Dienst, so meinten sie, könne nur dann erfolgreich um qualifizierte Arbeitskräfte werben, wenn er mit seinen Stellenbeschreibungen auf neue technische Entwicklungen reagiere. Zudem belaste es die »Beziehungen« zur ÖTV, wenn die Arbeitgeber ausgerechnet Veränderungen abblockten, die der Gewerkschaft so am Herzen lagen, weil sie mit der DAG um die Gunst der besser ausgebildeten Angestellten konkurrieren musste. Die von der Bundesregierung unnachgiebig vorgetragenen finanziellen Argumente verhinderten jedoch eine Korrektur der Entscheidung von 1974. ${ }^{363}$

In der Tat nahm die ÖTV insbesondere Fragen der Eingruppierung bei den Angestellten sehr wichtig. Nach ihrer Zählung gab es im Öffentlichen Dienst bereits im Jahr 1977 mehr als 80 verschiedene Berufsgruppen, deren Tätigkeitsbeschreibungen stark überholt waren. ${ }^{364}$ So protestierte die Gewerkschaft mehrfach gegen das »Moratorium» der Arbeitgeber. Allerdings

362 | Dieser Unterschied verschwand erst im Dezember 1979 mit den ersten Resultaten der wieder aufgenommenen Manteltarifverhandlungen. Vgl.: ÖTV-Geschäftsbericht 1976/79, S. 121 f. Zur Situation in der Privatwirtschaft vgl. als Überblick: Herfried Heisler: Die tarifvertragliche Angleichung der Rechtsstellung von Arbeitern und Angestellten. In: Franz Jürgen Säcker/Ernst Zander (Hrsg.): Mitbestimmung und Effizienz. Humanität und Rationalität der Produktionsstruktur in mitbestimmten Unternehmen, Stuttgart 1981, S. 341-349.

363 | Vgl. zusammenfassend: Vermerk der TdL-Geschäftsstelle für das Spitzengespräch, 26.5.1975. In: BArch Koblenz, B 222, 1323.

364 | Aktenvermerk des Referats D III 1 über das Tarif-Spitzengespräch am 17.5.1977, 22.5.1977. In: BArch Koblenz, B 106, 97908. 
tat sie das doch stets eher halblaut und ohne großen Nachdruck. Ihre $\mathrm{Zu}$ rückhaltung in dieser Frage hatte einen Grund: Die Arbeitgeber stellten nämlich eine strategisch genau überlegte Bedingung für neue Gespräche über die Manteltarifverträge und wollten solche Beratungen nur führen, wenn die ÖTV gleichzeitig einem Abbau der Zusatzversorgung für die Beschäftigten des Öffentlichen Dienstes zustimme oder doch zumindest darüber verhandle.

Oben wurde skizziert, wie diese ergänzende Altersrente für Arbeiter und Angestellte des Staates entstand und wie sie sich stufenweise von einer Versicherung in eine beitragslose, dynamisch gestaltete Versorgung verwandelte. Wie gezeigt wurde, konnte sie unter bestimmten Bedingungen zu Altersbezügen führen, die dem letzten Nettoeinkommen des Rentners bzw. der Rentnerin vor dem Ausscheiden aus dem Berufsleben entsprachen oder sogar noch höher lagen. ${ }^{365}$ Trotz einer 1967 eingeführten »Kappungsgrenze« existierte diese »Überversorgung« nach wie vor. Allerdings wollten die Arbeitgeber sie in den 1970er Jahren nicht mehr hinnehmen - und deshalb verbanden sie diese hochkomplexe Angelegenheit in einer Art Junktim mit der ganz anders gelagerten Frage neuer Manteltarifverträge. Die ÖTV aber verwahrte sich »kompromisslos« gegen grundlegende Änderungen am System der Zusatzversorgung: Sie stelle »ein Jahrhundertwerk« dar und gehöre zu ihren größten sozialen Erfolgen. So ging es bis 1980 weder in der einen noch in der anderen Sache wirklich voran. ${ }^{366}$

Dieser »faktische Stillstand des Tarifgeschäfts" neben den jährlichen Lohnrunden konnte der ÖTV nicht gefallen. ${ }^{367}$ Dennoch hat sie wenig ge-

365 | Siehe S. 268-273 u. 336f.

366 | In der Reihenfolge der Zitate: ÖTV-Geschäftsbericht 1976/79, S. 123 (Beschluss der GTK vom 1.7.1978); Protokoll ÖTV-GT 1980, Bd. 1, S. 166 (der Delegierte Rudolf Kanne, Braunschweig). Zusammenfassend zu dieser Angelegenheit, die hier bewusst nur ganz kursorisch dargestellt wird, weil Details bei der Zusatzversorgung durchweg äußerst kompliziert sind, vgl. etwa: ÖTV-Geschäftsbericht 1976/79, S. 122-126. Umfangreiches Material zu dem erwähnten Junktim der Arbeitgeber vgl. etwa in: BArch Koblenz, B 106, 97908 u. 97909. Zur ablehnenden Haltung der ÖTV gegenüber den Änderungswünschen der Arbeitgeber an der Zusatzversorgung vgl. auch: Versuch sozialer Demontage. In: ÖTV-Magazin 1977, H. 8, S. 12.

367 | Das Zitat (eine Zustandsbeschreibung des BMdI) aus: Aufzeichnung über das Gespräch mit H. Kluncker, 4.7.1978. In: BArch Koblenz, B 106, 97909. Ganz ähnlich auch die Feststellung in: ÖTV-Geschäftsbericht 1976/79, S. 101. 
tan, um Bewegung zu erreichen, ja, sie hat sogar darauf verzichtet, die Blockade der Arbeitgeber öffentlich zu kritisieren. Offensichtlich fürchtete sie, die sprichwörtlichen schlafenden Hunde zu wecken, denn bei solchen Protesten hätte sie zwingend öffentlich auch erklären müssen, warum sie die Forderungen der Arbeitgeber bei der Zusatzversorgung so strikt ablehnte. Angesichts der scharfen Kritik, die der Gewerkschaft und auch dem Öffentlichen Dienst allgemein seit dem Streik von 1974 entgegenschlug, war das jedoch eine höchst undankbare und vielleicht sogar unlösbare Aufgabe.

De facto verteidigte die ÖTV ein soziales Sicherungssystem, das nach dem Urteil von Experten deutlich großzügiger ausgestaltet war als die Altersversorgung »normaler« Rentner. In mancher Hinsicht übertraf es sogar die Absicherung der Beamten. Für die Arbeiter und Angestellten des Staates, die in den Ruhestand wechselten, konnten sich auf diese Weise sehr erfreuliche soziale Vorteile ergeben. Von Gerechtigkeit aber ließ sich nicht sprechen - zumal wenn man vergleichend auf die gesetzlich versicherten Beschäftigten von Industrie und Gewerbe schaute, die typischerweise den Gürtel deutlich enger schnallen mussten, wenn sie in den Ruhestand gingen. ${ }^{368}$ Ausgerechnet ein früherer Erfolg also hemmte die Gewerkschaft

368 | Als genauen Vergleich der verschiedenen Sicherungssysteme vgl. vor allem den Bericht der Wirtschaftsprüfungsgesellschaft "Treuarbeit« vom Dezember 1976 in: VerBT, Drucksache 7/5569 (6.7.1976), zu den Vorteilen der Zusatzversorgung vgl. hier insbes. S. 9, 26-28, 42-45, 62 f. u. 139-156, zum Versorgungsniveau in der Gesetzlichen Rentenversicherung (GRV) vgl. ebd. S. 38. Im Fazit urteilten die Wirtschaftsprüfer, die Zusatzversorgung sei »beachtlich« besser als die Alterssicherung der Beamten und der GRV-Rentner (S. 45). Ihre Vorteile ergaben sich zum einen, weil sich der Rentenanspruch in der Zusatzversorgung weitgehend aus den gesamten Bezügen (inklusive aller Zulagen und des 13. Monatsgehaltes) errechnete, während es bei den Beamten zahlreiche "nicht ruhegehaltsfähige« Teile der Gesamtbezüge gab. Dazu kamen komplizierte versicherungsmathematische Details. So bevorzugte die Zusatzversorgung kurioserweise am deutlichsten Arbeiter und Angestellte, die relativ spät (konkret: nach dem 30. Lebensjahr) in den Öffentlichen Dienst eintraten, zuvor aber schon Rentenansprüche in der GRV erworben hatten: Sie erreichten schon nach knapp 20 Dienstjahren das Versorgungsniveau der Beamten (75 Prozent der letzten Nettobezüge) (ebd., S. 45). Allerdings lieferte die »Treuarbeit« nur Modellrechnungen. Sie untersuchte also nicht, wie häufig eine »Überversorgung « tatsächlich existierte. Der Bundesrechnungshof ermittelte für 1974 durch eine Stichprobe, dass bei rund 40 Prozent der überprüften Fälle die letzten Nettobezüge erreicht oder überschritten wurden. 
nach 1975 in ihrer tarifpolitischen Arbeit: Die Privilegien, die sie selbst in den Jahren des wirtschaftlichen Booms für die Beschäftigten erkämpft hatte, banden ihr nun die Hände, weil die Arbeitgeber unter geänderten wirtschaftlichen Bedingungen nach Tauschgeschäften und Kompensationen strebten. ${ }^{369}$

Das finanzielle Motiv für diese neue Strategie der Arbeitgeber lässt sich exakt beschreiben: Allein von 1970 auf 1975 steigerten sich die jährlich geleisteten Rentenzahlungen in der Zusatzversorgung für den Öffentlichen Dienst von rund 400 Millionen auf fast 1,2 Milliarden DM. Da die Zahl der Rentner und Rentnerinnen, die von der VBL Geld erhielten, gleichzeitig nur um 42 Prozent wuchs, muss die Verdreifachung der Auszahlungen auf deutlich erhöhte Bezüge aller Versorgungsempfänger zurückgehen. ${ }^{370}$ Auch nach 1975 setzte sich diese Entwicklung fort: Die ausgezahlten Summen wuchsen erheblich stärker als die Zahl der bewilligten Renten. 1980 summierten sich die gewährten Zusatzrenten bereits auf etwas mehr als 2,2 Milliarden DM. ${ }^{371}$

Wie die Stichprobe entstand und wie umfangreich sie war, wurde dabei jedoch nicht mitgeteilt (VerBT, Drucksache 7/5849 [26.10.1976], S. 19).

369 | Offensichtlich hatte aber auch die Politik kein Interesse daran, die Besonderheiten der Zusatzversorgung öffentlich groß zu thematisieren. Das eben erwähnte Gutachten der »Treuarbeit«, das dafür viel Material bot, etwa wurde zwar dem Bundestag vorgelegt. Dort aber überwiesen es die Regierungsparteien (ohne Protest der Opposition) ohne Debatte sofort an den Innenausschuss. Politische Wirkungen entfaltete das Gutachten nicht (Verhandlungen des Deutschen Bundestages. 7. Wahlperiode. Stenographische Berichte, Bd. 99, Bonn 1976, S. 18537). Als eine der seltenen öffentlichen Thematisierungen der Zusatzversorgung und der »Überversorgung« in dieser Zeit vgl.: Mehr Rente als Gehalt. In: OffenbachPost, 29./30.1.1977.

370 | Berechnet nach: Friedmar Fischer/Werner Siepe: 80 Jahre Zusatzversorgung der VBL. Dokumentation. Zahlen, Daten und Fakten von 1970 bis 2050, Hamburg 2014, S. 29 (die Versorgungsausgaben) u. S. 21 f. (die Zahlen der ausgezahlten Renten). Die oben genannten Zahlen in DM sind aus den Angaben in Euro in der angegebenen Quelle zurückberechnet. 1975 zahlte die Versorgungsanstalt des Bundes und der Länder (VBL), der sich auch die meisten Kommunen angeschlossen hatten, insgesamt 344.900 Renten.

371 | 1980 zahlte die VBL rund 460.000 Renten. Berechnet nach: ebd. Die Zahl der Renten war mithin seit 1975 um 33,7 Prozent gestiegen, während sich die Rentenzahlungen gleichzeitig um fast 90 Prozent erhöht hatten. 
Mit dieser in der Tat sehr dynamischen Entwicklung hatten die Arbeitgeber offenbar überhaupt nicht gerechnet, als sie sich 1965 darauf einließen, die Zusatzversorgung nach dem Vorbild der gesetzlichen Rente künftig regelmäßig an die Entwicklung der Löhne und Gehälter anzupassen. Da die Arbeiter und Angestellten des Staates seit 1973 zudem keine eigenen Beiträge mehr in die Kasse der VBL zahlten, musste die Öffentliche Hand die stark steigende Last allein tragen. ${ }^{372}$

Das tarifpolitische Patt, in dem Arbeitgeber und Gewerkschaft seit dem »Moratorium« des Bundes und der Länder vom Herbst 1974 verharrten, konnte daher zwangsläufig nicht auf Dauer bestehen. Auf Seiten der Arbeitgeber wuchs der Unwille über die Kosten der Zusatzversorgung; in der ÖTV verärgerte der Stillstand bei neuen beruflichen Eingruppierungen gerade Mitglieder mit höherer Qualifikation. Fast schon verständnisvoll notierten die Tarifexperten des Innenministeriums im Sommer 1978, die ÖTV-Führung stehe mittlerweile doch unter zunehmendem Druck ihrer Basis, zumal sie seit 1974 »keine besonderen gewerkschaftlichen Erfolge in den Lohnrunden« mehr vorweisen könne, die sich als »Kompensation« für die ausbleibenden neuen Manteltarifverträge präsentierten ließen. ${ }^{373}$ So gesehen waren die weitgehend "geräuschlosen« Lohn- und Gehaltstarifverhandlungen, die im Öffentlichen Dienst in der zweiten Hälfte der 1970er Jahre aufeinander folgten, auch so etwas wie eine von der ÖTV und den Arbeitgebern gemeinsam errichtete Fassade, hinter der sie ihre Uneinigkeit in grundlegenden Fragen verbargen, die zugleich aber doch umso baufälliger wurde, je länger sie stand.

372 | Allerdings wurde die Zusatzversorgung - anders als die gesetzliche Rente seit 1957 - auch nach der Reform von 1965/67 nicht ausschließlich auf dem Wege der Kostenumlage finanziert. Sie griff nach wie vor auf angesparte »Anwartschaften« aus der vorangegangenen Zeit zurück. Zu den wiederum höchst komplizierten Details vgl. das Gutachten der »Treuarbeit« (VerBT, Drucksache 7/5569, 6.7.1976, S. 62 f.).

373 | Aufzeichnung über das Gespräch mit H. Kluncker, 4.7.1978. In: BArch Koblenz, B 106, 97909. 


\section{Noch einmal: "Sockel» oder nur Prozente? Der anhaltende Streit um sozial ausgleichende Komponenten in der ÖTV-Tarifpolitik}

Eine auf mittlere Sicht durchaus vergleichbare Sprengkraft besaß auch noch ein anderer prinzipieller tarifpolitischer Dissens, von dem die allgemeine Öffentlichkeit ebenfalls kaum etwas mitbekam: der Streit um sozial ausgleichende Anpassungen der Löhne und Gehälter. Er erneuerte sich nach 1974 in jeder Tarifrunde und entzweite unverändert nicht nur Arbeitgeber und Gewerkschaft, sondern auch die ÖTV-Mitglieder untereinander. Seit 1972 ergab sich der Forderungskatalog der Gewerkschaft ja jeweils aus einem breit angelegten Diskussionsprozess, an dem sich alle Mitglieder beteiligen konnten.

An dieser Praxis änderte sich auch nach 1974 nichts. Zwar gab es in der Organisation etliche Stimmen, die das Verfahren kritisierten. Grob gesagt standen sich dabei zwei Gruppen gegenüber. Einerseits gab es Rufe, die Gewerkschaftsführung solle die Debatte straffer lenken, weil unrealistische Forderungen, die an der Basis "nach Gefühl« formuliert wurden, nur in Frustration enden könnten. Andererseits aber existierten auch genau entgegengesetzte Vorstellungen: Heinz Kluncker sowie die anderen Mitglieder des gHV sollten öffentlich zu tarifpolitischen Fragen strikt schweigen, bis alle unteren Gliederungen der ÖTV und abschließend dann die Mitglieder der Großen Tarifkommission darüber entschieden hatten. Besonders Zahlen, die Kluncker in Interviews nannte, würden von den einfachen Mitgliedern als Vorentscheidung verstanden, die ihre Mitsprache überflüssig mache. ${ }^{374}$

Der Gewerkschaftstag 1976 entschied diesen Dissens durch einen Formelkompromiss: Die ÖTV-Spitze wurde beauftragt, künttig jeweils »Informationsmaterial über die ökonomische, finanzielle und soziale Entwicklung« bereit zu stellen, um die Basisdiskussion möglichst sachlich zu halten. Was damit genau gemeint war, blieb jedoch offen. Allerdings versicherte der Vorsitzende ausdrücklich, es gehe bei dem neuen Prozedere nicht da-

374 | Vgl. als paradigmatisch für diese beiden Positionen den Antrag der Bezirkskonferenz Hamburg einerseits sowie den Antrag der Bezirkskonferenz Hessen andererseits. In: Protokoll ÖTV-GT 1976, Bd. 2, S. 310 f. (hier das Zitat) u. S. 308 (Hessen). Zahlreiche weitere, jeweils leicht unterschiedliche Anträge in dieser Sache in: ebd., S. 308-315. 
rum, die Debatte verdeckt zu lenken, sondern um »mehr Aktivität und mehr Demokratie ${ }^{375}$

In der Tat nahm die ÖTV die Befragung ihrer Basis sehr ernst, obwohl die Führung der Organisation deren Resultate zunehmend als problematisch empfand. Die Mitglieder nämlich unterstützten eine Tarifpolitik, die Geringverdiener im Öffentlichen Dienst bevorzugen sollte. In der ersten Tarifrunde nach dem Streik von 1974 erhob die Gewerkschaft erneut eine dreigeteilte Forderung, in der eine Prozentzahl (plus sechs Prozent) mit einem »Sockel« (50 DM) und einem pauschal zu zahlenden Urlaubsgeld (300 DM) kombiniert wurde. 1976 sollte es nach dem Beschluss der Großen Tarifkommission sogar ausschließlich einen einheitlichen Lohn- und Gehaltszuschlag von $135 \mathrm{DM}$ monatlich für alle Beschäftigten geben. Auch in den drei nachfolgenden Jahren verlangte die ÖTV, der neue Tarifvertrag müsse jeweils ein sozial ausgleichendes Element enthalten. Zwar wurde die soziale Komponente etwas abgeschwächt, weil sie nur noch aus dem Urlaubsgeld (d.h. aus einer Einmalzahlung) bestand. Aber die Gewerkschaft wollte die Geringverdiener im Öffentlichen Dienst auch damit stärker begünstigen als die besser bezahlten höheren Angestellten und Beamten. ${ }^{376}$

Diese starke Fixierung auf ungleich gestaltete Einkommensgewinne befremdete gerade Sozialdemokraten, die auf Seiten der öffentlichen Arbeitgeber Verantwortung trugen. So kommentierte Helmut Schmidt den ÖTVBeschluss für 1976 intern mit den Worten, die ÖTV erhebe damit eine Forderung, die bei Privatunternehmern keinesfalls durchgesetzt werden könne. Er fürchte deshalb, »daß die anderen Gewerkschaften wie Chemie und IG Metall und Bau eines Tages sagen, jetzt platzt uns der Kragen, jetzt wollen wir mal unsere Rechnung aufmachen«. Horst Ehmke, ein Vertreter des linken Parteiflügels, bestätigte die Zustandsbeschreibung des Kanzlers: Im persönlichen Gespräch habe ihm Franz Steinkühler von der baden-

375 | In der Reihenfolge der Zitate: Protokoll ÖTV-GT 1976, Bd. 2, S. 306 f. (der Antrag des HV, der ohne Änderung angenommen wurde) u. Bd. 1, S. 447 (H. Kluncker). In der Debatte erklärte Kluncker, der gHV werde »Orientierungshilfen« für die Mitgliederdebatte geben, »Aber bitte hängt uns keinen totalen Maulkorb um!« (ebd.).

376 | Vgl. als Überblick: ÖTV-Geschäftsbericht 1972/75, S. 91-93; ÖTV-Geschäftsbericht 1976/79, S. 106-113. 
württembergischen IG Metall gesagt, die ÖTV-Forderung sei "ganz unmöglich bei uns zu machen«. 377

In einem Brief an Heinz Kluncker griff Schmidt wenig später noch zu einem anderen Argument: Jeder Mindestbetrag treibe die Lohnkosten gerade für gering qualifizierte Arbeiten beim Staat in die Höhe. »Als altes ÖTV-Mitglied sehe ich aber natürlich auch die Gefahr, daß sich dadurch die Basis für unsere Organisation verengen könnte. ${ }^{378}$ In den Tarifverhandlungen für 1977 schließlich wurde der oben schon einmal erwähnte sozialdemokratische Kommunalpolitiker Rolf Krumsiek als Sprecher der VKA noch deutlicher. In Reaktion auf das von der ÖTV erneut verlangte Urlaubsgeld von pauschal 300 DM für alle staatlichen Arbeiter und Angestellten »drohte [er] mit weiteren Privatisierungsmaßnahmen, die vor allem den unteren Einkommensbezieher träfen «.379

Nun gab es in der ÖTV nach wie vor erklärte Gegner von Einheitsforderungen, die mit ihrer Meinung nicht hinter dem Berg hielten. Als die Bezirksvorsitzenden im November 1974 über die kommende Tarifrunde berieten, votierten vier dieser zwölf führenden Funktionäre - nämlich die Leiter der durchweg kopfstarken und organisatorisch wichtigen Bezirke NRW I, Hessen, Bayern und Berlin - für eine reine Prozentforderung. Heinz Hackbarth, der Vertreter der Berliner ÖTV, kritisierte dabei ausdrücklich das von den Freunden der »Sockel«-Politik gern vorgebrachte

377 | Protokoll der Gemeinsamen Sitzung von Parteivorstand, Parteirat und Kontrollkommission, 20.2.1976. In: AdsD, SPD-Parteivorstand, 2/PVAS0000640. Persönlich allerdings verteidigte Ehmke sozial ausgleichende Tarifforderungen: Er bitte darum, »nicht dies Prinzip als solches anzugreifen«, weil es ein Thema sei, »an dem man SPD-Positionen vertreten kann«. Ein Beschluss wurde auf der Sitzung nicht gefasst. Ehmke vertrat als direkt gewählter Abgeordneter seit 1969 den Wahlkreis Stuttgart III; Franz Steinkühler war seit 1972 Bezirksleiter im IG Metall-Bezirk Baden-Württemberg.

378 | Helmut Schmidt an H. Kluncker, 18.4.1976. In: AdsD, HAS, 1/HSAA010027. Ergänzend verweist Schmidt auch hier auf die Gefahr, dass die »Sockel«-Strategie der ÖTV zu "Spannungen in der Zusammenarbeit« unter den DGB-Gewerkschaften führen könne. Reaktionen Klunckers auf diesen Brief konnten im Rahmen dieses Projektes nicht ermittelt werden. Schmidt bat in seinem Schreiben ausdrücklich um eine Antwort.

379 | Notizen [von Hans Liersch?] über die Tarifverhandlungen, 10.2.1977. In: AdsD, ÖTV-NRW II, 5/ÖTVC301003. 
Argument, wegen der Teuerung müsse man die Geringverdiener besonders fördern: »Er selbst halte nichts von der klassenkämpferischen These, wonach das Brot für die Kleinen teurer sei. ${ }^{380}$ Heinz Wolf berichtete kurz darauf, die »Funktionskörper der großen Kreisverwaltungen« in dem von ihm geführten Bezirk Hessen seien »durchweg Sockelgegner«. Der Widerstand der Arbeitgeber gegen die wiederum "gespaltene« Forderung der Organisation aktiviere die Funktionäre daher nicht. Vielmehr gebe es »hämische Bemerkungen, die ÖTV habe die Lage durch ihre Forderungsstruktur selbst verschuldet ${ }^{3}{ }^{381}$

1977 schließlich konstatierte Wolf, die Mitgliederdiskussion über die Tarifpolitik werde nach wie vor »mit viel Emotion und Erbitterung geführt«. Eine Liste mit den lokal beschlossenen Forderungen aus dem Bezirk NRW II für das gleiche Jahr verzeichnet stark divergierende Vorstellungen: Einige Kreisverwaltungen wünschten sich hohe Pauschalsummen; andere wollten hingegen nur eine Prozentzahl ohne jedes ausgleichende Element akzeptieren. ${ }^{382}$ Fast zeitgleich warnte Heinz Hackbarth im Hauptvorstand der Organisation erneut vor weiteren nicht-linearen Lohnerhöhungen: Im West-Berliner Öffentlichen Dienst betrage der Stundenlohn einer festangestellten Putzfrau aktuell 8,62 DM und damit verdiene sie fast so viel wie ein Facharbeiter in der Berliner Elektroindustrie, der laut Tarifvertrag 8,82 DM pro Stunde bekam. Reinigungskräfte in Privatfirmen der Branche

380 | Notizen von Hans Liersch über die Sitzung des gHV mit den Bezirksvorsitzenden, 4.11.1974. In: AdsD, ÖTV NRW II, 5/ÖTVC603003.

381 | Kurzbericht der Bezirksverwaltung Hessen über Meinungsäußerungen der hessischen Kreisverwaltungen zum Ergebnis der Tarifverhandlungen am 14.1.1975, 27.1.1975. In: ebd.

382 | Das Zitat aus: ÖTV-Hessen aktuell Nr. 6/77, 20.10.1977 (ein Exemplar dieser Mitgliederinformation in: Archiv Ver.di, Bestand Kluncker, 14); Vorstellungen der Kreisverwaltungen im Bezirk NRW II zur Tarifrunde 1977, o.D. In: AdsD, ÖTV NRW II, 5/ÖTVC6003011. So verlangten etwa die Kreisverwaltungen von Bottrop und Witten Festbeträge von 175 bzw. 170 DM; die Kreisverwaltung Rheine hingegen votierte für eine Forderung von 7,5 Prozent. Eine ähnliche Aufstellung mit noch stärker voneinander abweichenden Forderungen für die Tarifrunde 1975 findet sich in: Forderungen der einzelnen Kreisverwaltungen im Bezirk NRW II, o.D. [Jan. 1975]. In: ebd., 5/ÖTVC6003010. Vgl. auch die Klage eines GT-Delegierten über die Mitgliederdiskussion als »Wirrwarr« in: Protokoll ÖTVGT 1976, Bd. 1, S. 134 (Klaus del Tedesco, Kassel). 
erhielten an der Spree erheblich geringere Löhne, und sie würden zudem fast ausschließlich nur zwei bis drei Stunden pro Tag beschäftigt, damit für sie keine Sozialversicherungsbeiträge anfielen. Zwar verurteilte Hackbarth solche Arbeitsverträge als »Machenschaften « - dennoch resümierte er, dass Reinigungsarbeiten im Öffentlichen Dienst in Berlin mehr als doppelt so teuer waren wie bei Privatfirmen. Logischerweise werde diese Diskrepanz noch weiter wachsen, wenn die ÖTV an ihrer sozial ausgleichenden Tarifpolitik festhalte. ${ }^{383}$

Trotz all dieser Warnungen, die sowohl intern laut wurden als auch von außen kamen, bildeten sich in den Mitgliederdiskussionen der Gewerkschaft auch in der zweiten Hälfte der 1970er Jahre immer wieder neu Mehrheiten für nichtlineare Lohnerhöhungen. Zwar wirkte dabei das bereits ältere Argument, die Inflation schädige besonders Geringverdiener, weiter fort. Auch Heinz Kluncker griff darauf zurück, wenn er die ÖTV-Forderungen öffentlich präsentierte und verteidigte. ${ }^{384}$ Zusätzlich gewann die "Sockel«-Strategie nach 1974 allerdings eine stark politische Dimension, die sie in dieser Form noch nicht gehabt hatte, als die Teuerungsraten in den Jahren nach 1969 wirklich rasant gewachsen waren: Sie entwickelte sich immer stärker zum Beweis einer linken Gesinnung.

Mit dem Mitgliederzuwachs nach 1974 scheinen sich die internen Debatten in der ÖTV deutlich verändert zu haben. Die Gewerkschaft erlebte in dieser Zeit den Zustrom neuer Kolleginnen und Kollegen, deren politische Sozialisation in der Phase der Studentenproteste nach 1967/68 und in den ersten, reformfreudigen Regierungsjahren Willy Brandts stattgefunden hatte. Viele von ihnen brachten ziemlich genaue Vorstellungen davon mit, was eine Gewerkschaft zu tun und zu leisten habe. Ähnlich wie in anderen DGB-Gewerkschaften und in der SPD kann man von einer Wiederbelebung sozialistischer Ideale und dezidiert kapitalismuskritischer Einstellungen sprechen. Zwar blieb die Zahl dieser »neuen Linken« in der Millionenorganisation der ÖTV immer begrenzt. Dennoch gewannen sie rasch Einfluss, weil sie sich aktiv und selbstbewusst in die Gewerkschafts-

383 | Protokoll der 3. Sitzung des HV, 20./21.1.1977. In: AdsD, ÖTV, 5/ ÖTVB130054.

384 | Vgl. etwa: Kluncker fordert unterschiedslos 135 Mark mehr für alle Beschäftigten im öffentlichen Dienst. In: FAZ, 14.1.1976; Rede von H. Kluncker bei Eröffnung der Tarifverhandlungen, 10.2.1977. In: Archiv Ver.di, Bestand Kluncker, 24. 
arbeit »einbrachten« (um eines der Lieblingswörter dieser Zeit zu benutzen). ${ }^{385}$

Wie dieses Engagement wirken konnte, beschrieb Heinz Kluncker im Frühjahr 1977 dem Hauptvorstand am Bespiel einer tarifpolitischen Mitgliederdiskussion in München, an der er selbst als Gast teilgenommen hatte. Der Vorsitzende hatte diese Debatte als ziemlich absurde Veranstaltung erlebt: 30 der insgesamt 37 Redner und Rednerinnen votierten für einen Festbetrag von 250 DM, obwohl es der ÖTV im Vorjahr noch nicht einmal gelungen war, die weitaus geringere Summe von 135 DM durchzusetzen. Mehrheitlich kamen diese Freunde eines weiteren und noch viel höheren »Sockels« aus den Bereichen »Erziehung, Wissenschaft, Kindergärtnerinnen [und] Sozialarbeiter«. Nach Klunckers Urteil repräsentierten sie »keine 5 Prozent der Mitglieder in diesem Kreisverband «; die Vertreter der kopfstarken Bereiche (d. h. besonders die aus den kommunalen Versorgungsbetrieben) meldeten sich mit abweichenden Meinungen hingegen erst ganz am Ende der Debatte zu Wort. Zudem verlangte die lautstarke Minderheit eine Abstimmung, die den tarifpolitischen Kurs der Kreisverwaltung festlegen sollte: »Das ging auf Messers Schneide, daß dieser Antrag abgewimmelt wurde«. Der Willensbildungsprozess an der Basis, so das Fazit des Vorsitzenden, drohe zum Problem zu werden, weil »die schweigende Mehrheit zu Hause sitzt«, während kleine Gruppen die Versammlungen "mit Emotionen« dominierten. ${ }^{386}$

Heinz Wolf in Hessen hatte offenbar ganz ähnliche Erfahrungen gemacht, denn er warnte einige Monate später vor »Verbalradikalismus" in der Mitgliederdiskussion: Gerade die Arbeiter der kommunalen Betriebe, ohne die es keinen erfolgreichen Streik der ÖTV geben könne, seien »nur unvollkommen« beteiligt, wenn über die Forderungen für die nächste Ta-

385 | Zum Hintergrund vgl. etwa: Gerd Koenen: Das rote Jahrzehnt. Unsere kleine deutsche Kulturrevolution, Köln 2001; Andreas Kühn: Stalins Erben, Maos Söhne. Die Lebenswelt der K-Gruppen in der Bundesrepublik der 70er Jahre, Frankfurt/Main 2005; Anton Stengl: Zur Geschichte der »K-Gruppen«. Marxisten-Leninisten in der BRD der siebziger Jahre, Frankfurt/Main 2011. Vgl. zu parallelen Entwicklungen in der SPD: Faulenbach: Das sozialdemokratische Jahrzehnt, S. 275-280 u. 774.

386 | Protokoll der 3. Sitzung des HV, 20./21.1.1977. In: AdsD, ÖTV, 5/ ÖTVB130054. 
rifrunde beraten werde: Diese Versammlungen dürften nicht "zum Reservat sich elitär gebärdender Debattierkreise werden « ${ }^{387}$

Im Herbst 1979 wurde Wolf in einem Bericht an Heinz Kluncker noch deutlicher. Er klagte über die dominante Selbstdarstellung von »Kolleginnen und Kollegen aus dem Gesundheits- und Sozialbereich« sowie aus der Kommunal- und Landesverwaltung in den internen Debatten der Gewerkschaft. Wegen »des permanenten Schweigens unserer klassischen Mitglieder und deren Anfälligkeit für Emotionen« gelinge es kleinen Gruppen besonders engagierter und eloquenter linker Mitglieder immer wieder, kaum durchdachte tarifpolitische Positionen durchzusetzen. Dadurch verändere sich das ganze innere Gefüge der Organisation: »Mehr und mehr ziehen sich auch in unserem Bezirk bisher aktive Mitglieder und Funktionäre aus unseren klassischen Mitgliederbereichen zurück bzw. fangen an zu schweigen.« Besonders bedenklich fand Wolf dabei, dass die neuen Aktivisten der Gewerkschaft in seiner Sicht eine »die da oben-Haltung" kultivierten, die sich gegen die ÖTV-Führung (und damit konkret wohl auch gegen ihn selbst) richtete: In ihrer Vorstellung sollten allein die Mitglieder über den Forderungskatalog der Gewerkschaft entscheiden. Mit solchen »basisdemokratischen Schwarmgeistern« könne man aber keine erfolgreiche Tarifpolitik betreiben. ${ }^{388}$

Bei Heinz Kluncker fand der hessische Bezirksvorsitzende mit seinen Klagen sicher ein offenes Ohr. Bereits ein Jahr zuvor hatte der Vorsitzende konstatiert, es gebe in den ÖTV-Organisationsbereichen Sozialarbeit, Gesundheitswesen und Universitäten mittlerweile einen nennenswerten Einfluss besonders linker Mitglieder: Sie stammten aus der 1968 neu gegründeten »Deutschen Kommunistischen Partei« (DKP), die stark von der SED abhängig war und auch von ihr finanziert wurde, sowie aus diversen maoistisch inspirierten »K-Gruppen«, von denen der »Kommunistische Bund Westdeutschland « (KBW) die aktivste und größte (oder besser: die noch am wenigsten kleine) war. Gleichzeitig seien dies auch die Abteilungen in der ÖTV, in denen am häufigsten und am lautstärksten Festbeträge und andere Instrumente einer sozial ausgleichenden Tarifpolitik verlangt würden. ${ }^{389}$

387 | ÖTV-Hessen aktuell Nr. 6/77, 20.10 .1977 (ein Exemplar dieser Mitgliederinformation in: Archiv Ver.di, Bestand Kluncker, 14).

388 | Heinz Wolf an H. Kluncker, 9.11.1979. In: AdsD, Depositum Kluncker, Stehordner 80 .

389 | Protokoll der 12. Sitzung des HV, 24.11.1978. In: AdsD, ÖTV, 5/ÖTVB130065. 
Einerseits beschrieben Kluncker und Heinz Wolf mit den zitierten Berichten sicher reale Veränderungen innerhalb der ÖTV. So agierten in den 1970er Jahren in anderen DGB-Verbänden ebenfalls überschaubare, aber sehr aktive Gruppen von weit links stehenden Mitgliedern, die wenig bis nichts vom »revisionistischen« Kurs der Gewerkschaftsführungen hielten und den Anspruch erhoben, die »wahren Interessen« der Werktätigen zu artikulieren. ${ }^{390}$ Wenn dabei offen anti-demokratische Positionen vertreten wurden oder das Prinzip der Einheitsgewerkschaft gefährdet erschien, wehrten sich die Organisationen, indem sie die besonders radikalen Linken ausschlossen. Auch die ÖTV verfuhr so. ${ }^{391}$

Andererseits aber wäre es viel zu einfach, die Tarifpolitik der Gewerkschaft in dieser Dekade nur mit dem Überengagement sendungsbewusster Exponenten der neuen revolutionären Linken zu erklären. Anders als der hessische Bezirksvorsitzende hütete sich Heinz Kluncker vor dieser Simplifizierung: Im Hauptvorstand erklärte er ausdrücklich, es sei ganz falsch, jeden Verfechter der »Sockel«-Strategie »als KBW-inspiriert zu diffamieren «. ${ }^{392}$

Berichte der Kreis- und Bezirksverwaltungen über die Mitgliederdebatten im Winter 1978/79 belegen, wie recht der Vorsitzende damit hatte. Nur der Bezirk Weser-Ems, der zugleich über eine »sehr geringe Beteiligung« an den Versammlungen klagte, vermerkte eine Dominanz kleiner Gruppen

390 | Speziell für die DKP vgl. etwa: Manfred Wilke/Hans-Peter Müller: SED-Politik gegen die Realitäten. Verlauf und Funktion der Diskussion über die westdeutschen Gewerkschaften in SED und KPD/DKP 1961 bis 1972, Köln 1991; Emil-Peter Müller: Die Bündnispolitik der DKP. Ein trojanisches Pferd, Köln 1982, S. 102-119. $\mathrm{Zu}$ den K-Gruppen und ihrer Gewerkschaftsarbeit vgl. etwa: Michael Steffen: Geschichten vom Trüffelschwein. Politik und Organisation des Kommunistischen Bundes 1971 bis 1991, Berlin u. a. O. 2002, S. 135; Kühn: Stalins Enkel, S. 142.

391 | Bezogen auf die Gesamtzahl der Mitglieder blieben die Ausschlüsse extrem selten. In den fünf Jahren von 1976 bis 1979 kam es zu insgesamt 186 Ausschlüssen aus politischen Gründen und wegen gewerkschaftsschädigenden Verhaltens. 134 davon trafen Mitglieder des KBW, die typischerweise ein besonders starkes »revolutionäres« Selbstbewusstsein an den Tag legten (ÖTV-Geschäftsbericht 1976/79, S. 79-81). Als Überblick auch für die anderen DGB-Verbände vgl. (aus marxistischer Sicht) auch: Rainer Erb: Gewerkschaftsausschlüsse in den 70er Jahren. In: Jacobi/Müller-Jentsch/Schmidt: Gewerkschaftspolitik, S. 166-175.

392 | Protokoll der 3. Sitzung des HV, 20./21.1.1977. In: AdsD, ÖTV, 5/ ÖTVB130054. 
bei diesen Beratungen. Ansonsten war davon nicht die Rede. Hessen meldete sogar stolz (aber ohne weitere Details), fast zwei Drittel aller Mitglieder in der Region hätten an Veranstaltungen teilgenommen, auf denen der Forderungskatalog für die kommende Tarifrunde besprochen wurde. ${ }^{393}$ Bei so starker Beteiligung taugt der nicht genauer geregelte und damit für Zufallsmehrheiten durchaus anfällige Prozess der Mitgliederdiskussion nicht, um die Tendenz dieser Willensbildung zu erklären. ${ }^{394}$

So bleibt zu erklären, warum die sozial ausgleichende Tarifpolitik in der ÖTV so ungebrochen populär war. Auch für das Jahr 1979 beschloss die Große Tarifkommission ja erneut eine "gespaltene Forderung (konkret für ein Lohnplus von 6,5 Prozent und eine Erhöhung des pauschal gezahlten Urlaubsgeldes um ebenfalls einheitliche $250 \mathrm{DM}$ ). Dabei hatte die Gewerkschaftsspitze - wie im Vorjahr - in ihren Informationsmaterialien nur eine Prozentzahl vorgeschlagen. Außerdem warnte Heinz Kluncker erstmals

393 | Bericht der Bezirksverwaltung Weser-Ems, o. D. [Feb. 1979]; Bezirksverwaltung Hessen an gHV, 16.2.1979. Beide in: Archiv Ver.di, Bestand Kluncker, 26. Vgl. ebd. auch zahlreiche weitere Berichte von Bezirks- und Kreisverwaltungen.

394 | Die Mitgliederdiskussion war ja kein »einheitliches Meinungsbildungsverfahren«, sondern ein offensichtlich sehr unterschiedlich verlaufendes Prozedere, in dem die ÖTV-Gliederungen jeweils vor Ort entschieden, wie sie vorgingen. Selbst in dem vergleichsweise kleinen und damit noch gut überschaubaren saarländischen Bezirk wusste die Zentrale nicht genau, was in den Versammlungen der Betriebsgruppen im Einzelnen geschah (Bezirksverwaltung Saar an gHV, 9.2.1979. In: Archiv Ver.di, Bestand Kluncker, 26 [hier auch das Zitat]). Dieser Bericht konstatierte: "Inwieweit die Mitglieder ihre Meinung zur Forderungsempfehlung überhaupt und wie einbringen, kann nicht analysiert werden, weil dazu keine aussagefähigen oder repräsentativen Tatsachen bekannt sind.« Es erscheint kaum vorstellbar, dass dies in den deutlich größeren anderen Bezirken der ÖTV nicht gegolten haben soll. Offensichtlich kämpften auch andere DGBOrganisationen mit vergleichbaren Problemen. So beschloss die Gewerkschaft Handel, Banken und Versicherungen schon 1976, allen ihren Mitgliedern einen Fragebogen vorzulegen, der verschiedene Tarifforderungen auflistete. So sollte eine umfassende Befragung möglich werden, ohne eine aufwendige Urabstimmung durchzuführen. In der ÖTV-Führung stieß dieses Vorgehen auf scharfe Ablehnung. Heinz Kluncker sah darin ein »unmögliches Unterfangen«: Durch die Befragung werde es zu einer "unverbindlichen Anforderungsinflation« kommen. So aber könne man keine aussichtsreiche gewerkschaftliche Tarifpolitik betreiben (Protokoll der 3. Sitzung des HV, 20./21.1.1977. In: AdsD, ÖTV, 5/ÖTVB130054). 
öffentlich vor weiteren besonderen Verbesserungen für Geringverdiener: Wenn die ÖTV sie durchsetze, dann nur »um dem Preis, daß in den Bereichen, in denen viele Beschäftigte der untersten Lohngruppen tätig sind, zunehmend privatisiert würde«. Die solidarisch gemeinte Forderung schädige letztlich gerade die Mitarbeiter des Staates, die »einfachste Tätigkeiten « verrichteten und für die gleiche Arbeit außerhalb des Öffentlichen Dienstes »erheblich weniger« erhielten. ${ }^{395}$ Die klaren Worte des Vorsitzenden blieben im Prozess der demokratischen Meinungsbildung in der Organisation jedoch ungehört.

Diese Tatsache verweist auf ein tiefer liegendes Problem der ÖTV. Vor dem Hintergrund der besonderen sozialen Struktur des beruflich so disparaten Öffentlichen Dienstes liegt es nämlich nahe, die von den Mitgliedern der Gewerkschaft so hartnäckig präferierte nichtlineare Tarifstrategie als eine Politik zu verstehen, die gar nicht so sehr gezielt den Geringverdienern dienen sollte, sondern vielmehr in einer sehr verallgemeinernden Art und Weise »die da oben« ins Auge nahm: Es ging der ÖTV-Basis darum, den finanziellen Vorsprung der gut bezahlten Staatsbediensteten zu verringern.

Gewerkschaftliches Handeln nützt generell selbst den Arbeitnehmern, die nicht organisiert sind, weil der Tarifvertrag auch auf sie angewendet wird. Über diese Trittbrettfahrer-Effekte ärgerten sich alle Gewerkschaften. ${ }^{396}$ In der ÖTV aber besaß das Problem ein besonders starkes emotionales Gewicht. Wie oben gezeigt wurde, fiel die Spannbreite der Löhne und Gehälter im Öffentlichen Dienst ungewöhnlich weit aus: Sie erfasste auch Spitzeneinkommen von mehr als 10.000 DM monatlich, die nach Heinz Klunckers Worten in der Privatwirtschaft »überhaupt nicht tarifvertrag-

395 | »Wir sind keine Koalitionspartner der Regierung«. In: Der Stern 32 (1979), H. 3, S. 88-92, hier: S. 88. Klunckers öffentliche Äußerungen in dieser Angelegenheit waren allerdings alles andere als konsequent. In der Tarifrunde für 1980 dementierte er wiederum in einem Presseinterview (in: „Überhaupt keine Veranlassung für einen Afghanistan-Abschlag«. In: Die Welt, 1.3.1980) den oben zitierten Satz mit den Worten: »Aber das Tariflohnniveau im öffentlichen Dienst ist nicht die Ursache für Privatisierungen."

396 | Die in allen DGB-Organisationen periodisch immer wieder neu aufkommenden (letztlich aber stets abgelehnten) Forderungen nach exklusiver Geltung der Tarifverträge nur für Gewerkschaftsmitglieder zeigen diesen Unwillen. Für die ÖTV vgl. solche Anträge etwa in: Protokoll ÖTV-GT 1972, S. 634 f.; Protokoll ÖTV-GT 1976, Bd. 2, S. 320 f.; Protokoll ÖTV-GT 1980, Bd. 2, S. 348. 
lich geregelt werden, sondern allenfalls in Aufsichtsratspräsidien zurecht gemauschelt werden ${ }^{397}$

Zudem übernahmen Bund, Länder und Gemeinden die Lohn- und Gehaltsabschlüsse, die sie mit der ÖTV vereinbarten, in den 1970er Jahren durchweg ohne Abstriche für die Beamten. ${ }^{398}$ Der Arbeitskampf im Februar 1974 hatte also jenen Staatsbeschäftigten ebenfalls ein höheres Einkommen gesichert, die selbst gar nicht streiken durften; sogar die Minister, mit denen sich die ÖTV herumstritt, und auch der Bundeskanzler, der ihr so hart zusetzte, erhielten am Ende mehr Geld, weil sich die Gewerkschaft den tarifpolitischen Vorgaben der Regierung so entschlossen widersetzte. Zudem erledigten hochrangige Beamte sowie Angestellte im gehobenen Dienst abseits der politischen Führungsebene vielfach beruflich Aufgaben, die in Privatbetrieben in die Zuständigkeit der Unternehmensführung fielen - zugleich aber gehörten sie zu den Arbeitnehmern, die von den Tarifverträgen profitierten.

Die ÖTV-Basis scheint diese sehr spezielle Struktur zunehmend als ungerecht empfunden zu haben. Der Personalrat eines nordrhein-westfälischen Krankenhauses erklärte bei den Beratungen über die tariflichen Forderungen im Frühjahr 1977 ausdrücklich, es seien stets »nur die Arbeiter, Angestellten und Beamten der unteren bis mittleren Einkommen", die sich für die ÖTV-Forderungen einsetzten. Das Leitungspersonal der Klinik bemühe sich hingegen nach Kräften, »den Lohnkampf mit Hilfe des besonderen Dienstrechts zu behindern und zu unterdrücken«. Deshalb seien rein lineare Tarifforderungen im Öffentlichen Dienst geradezu absurd: Schließlich würden »in keinem Industriezweig die Bezüge der Manager durch den Tarifkampf der Arbeiter bestimmt ${ }^{399}$

397 | „Wir sind keine Koalitionspartner der Regierung«. In: Der Stern 32 (1979), H. 3, S. 88-92, hier: S. 88 f.

398 | Vgl. hierzu: Krumsiek: Alle Jahre, S. 332.

399 | Personalrat des Verbandskrankenhauses Schwelm an die ÖTV-Kreisverwaltung Gevelsburg, 1.2.1977. In: Archiv Ver.di, Bestand Kluncker, 26. Vgl. als weitere Beispiele für diese Argumentation auch die Entschließung der hessischen Mitglieder der GTK vom 24.3.1977, abgedr. in: ÖTV-Hessen Aktuell, Nr. 3/77, 28.3.1977 (ein Exemplar in: AdsD, ÖTV NRW II, 5/ÖTVC603013); Bericht der Abt. Nahverkehr der Kreisverwaltung Dortmund an die Hauptabt. Nahverkehr beim ÖTV-HV, 4.1.1979. In: Archiv Ver.di, Bestand Kluncker, 26. 
Da keineswegs nur die besonders weit links stehenden ÖTV-Mitglieder so dachten, verhielt sich die ÖTV-Spitze im tarifpolitischen Richtungsstreit zwischen den Freunden und den Gegnern der »Sockel«-Strategie so vorsichtig. In diesem Sinne verstehe ich jedenfalls den Hinweis Heinz Klunckers vor dem Hauptvorstand, die Frage, ob lediglich eine Prozentzahl oder auch ein Mindestbetrag gefordert werde, sei für ihn »nicht ideologisch motiviert, sondern praktisch politisch bezogen«: Die Einheit der Organisation war offenbar nur zu wahren, wenn die Führung die moralisch-ökonomischen Emotionen der aktiven Gewerkschaftsmitglieder respektierte, obwohl sie doch sehr wohl um die Gefahren wusste, die daraus gerade für die Beschäftigten in den untersten Lohngruppen entstanden. ${ }^{400}$

Forderungen zu stellen ist für eine Gewerkschaft immer der leichtere Teil im Geschäft der Tarifverhandlungen. Es folgt unweigerlich das Pflichtprogramm, mit den anderen Tarifparteien um eine Einigung zu ringen. In den Jahren nach 1974 eckte die ÖTV mit ihrer sozialen Orientierung in diesen Gesprächen zunehmend an. Widerspruch erntete sie dabei nicht nur bei den Arbeitgebern, sondern zunehmend auch bei der DAG, mit der sie in Tarifangelegenheiten trotz einiger Meinungsverschiedenheiten bislang weitgehend problemlos zusammengearbeitet hatte. Diese Gemeinsamkeit in der konkreten gewerkschaftlichen Arbeit zerbrach 1976, und damit endeten zunächst einmal auch alle Hoffnungen, die beiden Gewerkschaften könnten ihre organisatorische Konfrontation beenden, um die solidarische Kraft der Arbeitnehmer im Öffentlichen Dienst gegenüber den staatlichen Arbeitgebern zu stärken. Die ÖTV hat diesen Bruch bewusst herbeigeführt - was einmal mehr beweist, wie wichtig die sozial ausgleichende Tarifstrategie für sie selbst war.

In den frühen 1970er Jahren standen sich ÖTV und DAG programmatisch in vieler Hinsicht sehr nah, weil der stark links geprägte Zeitgeist der Jahre nach 1968 auch die in Hamburg residierende Angestelltengewerkschaft veränderte. Einvernehmlich konstatierten Delegationen der DAG und des DGB im Mai 1974 ihre "fast völlige Übereinstimmung in gesellschaftspolitischen Fragen«. Dies geschah auf einem Treffen, das nach dem Willen beider Seiten die Chancen für eine Integration der DAG in den DGB ausloten sollte. Trotz programmatischer Harmonie fanden die beiden

400 | Protokoll der 13. Sitzung des HV, 30./31.1.1979. In: AdsD, ÖTV, 5/ ÖTVB130065. 
Seiten aber nicht zueinander, denn »in organisatorischen Fragen [...] waren die Vorstellungen vollkommen konträr «. ${ }^{401}$

Realisten dürfte dieses Resultat nicht überrascht haben. Die DAG, deren Mitgliederzahlen seit den frühen 1960er Jahren eher stagnierten als wuchsen, wäre zwar wohl durchaus bereit gewesen, sich als eigenständige Organisation dem DGB anzuschließen. Genau dies aber lehnte der Dachverband unter Heinz Oskar Vetter entschieden ab, denn eine berufsständische Gewerkschaft wie die DAG, die Angestellte aller Sparten und Branchen zusammenfasste, hätte auch nach dem Eintritt in den DGB weiterhin im Organisationsbereich fast aller anderen DGB-Verbände »gewildert«. Zumal die ÖTV und die ebenfalls zum DGB gehörende Gewerkschaft Handel, Banken und Versicherungen (HBV) forderten de facto nichts anderes als eine Selbstauflösung der DAG, wenn sie von deren Integration in den DGB sprachen: Sie wollten die Mitglieder der Hamburger Organisation »übernehmen«, weil ansonsten das für den DGB zentral wichtige Prinzip »ein Wirtschaftsbereich - eine Gewerkschaft« de facto kaum noch gegolten hätte. ${ }^{402}$

Diese Selbstabschaffung eines Verbandes mit immerhin rund 450.000 Mitgliedern aber musste allein schon wegen der Eigeninteressen der DAGFunktionäre als äußerst unwahrscheinlich gelten. Das Treffen im Frühjahr 1974 endete daher mit dem Fazit, »daß alle weiteren Bemühungen, in nächster Zeit zu einem Abbau der organisatorischen Unterschiede zwischen DAG und DGB zu kommen, voraussichtlich ergebnislos verlaufen werden ${ }^{4}{ }^{403}$

401 | Bericht über das Gespräch DGB-DAG am 30.5.1974 in Hannover, 11.6.1974, abgedr. in: Der Deutsche Gewerkschaftsbund 1969-1975, S. 797 f. Heinz Kluncker gehörte zu der DGB-Delegation.

402 | Vgl. hierzu etwa: Kluncker für Eingliederung der DAG in Gewerkschaftsbund. In: Die Welt, 28.6.1972; Klunckers Kuchen. In: Wirtschaftswoche 28 (1974), H. 19, S. 20; Dritter Weg. In: Der Spiegel 28 (1974), H. 20, S. 41. Zu den Mitgliederzahlen der DAG vgl. Hans-Peter Müller: Die Deutsche Angestellten-Gewerkschaft im Wettbewerb mit dem DGB. Geschichte der DAG 1947-2001, Baden-Baden 2011, S. 332 u. 464.

403 | Der Deutsche Gewerkschaftsbund 1969-1975, S. 797. Konkret wäre für eine Selbstauflösung der DAG eine Vier-Fünftel-Mehrheit der Stimmen auf einem Gewerkschaftstag nötig gewesen. Nach dem zitierten Bericht war sich die DAG-Leitung sicher, dass sie ein solches Votum "nicht erhalten würde«. 
Zwangsläufig bemühte sich die nun wieder auf sich selbst verwiesene Angestelltengewerkschaft seitdem verstärkt darum, ihre Eigenständigkeit zu demonstrieren - und dafür benutzte sie gezielt auch das Feld der Tarifpolitik. Von der »Sockel«-Strategie der ÖTV hatte der Hamburger Verband bereits vor dem gescheiterten Gespräch mit dem DGB im Mai 1974 nur wenig gehalten: Genau wie die Arbeitgeber klagte auch die DAG über deren angeblich »nivellierende« Folgen. Diese Kritik artikulierte die Organisation nun jedoch weitaus entschiedener als zuvor. Bereits 1975 berichtete die HBV, die DAG habe ihr in der letzten Lohn- und Gehaltsrunde für das Versicherungsgewerbe lautstark eine "Nivellierungspolitik« vorgeworfen. In den Tarifverhandlungen habe sich daher eine »einheitliche Front von Arbeitgebern und DAG « gebildet. ${ }^{404}$ In der Chemieindustrie scherte die Hamburger Organisation sogar aus den bislang stets gemeinsam geführten Tarifgesprächen aus: Sie verlangte - und bekam - separate Beratungen mit den Arbeitgebern. Anschließend lieferten sich DAG und IG Chemie eine giftige öffentliche Kontroverse, in der von gewerkschaftlicher Einheit nichts mehr zu spüren war. ${ }^{405}$

In der Tarifrunde für 1976 richteten sich die Profilierungsbemühungen der DAG dann gegen die ÖTV. Deren Forderung, die Löhne und Gehälter im Öffentlichen Dienst sollten einheitlich um 135 DM pro Monat erhöht werden, fiel vor dem Hintergrund der mittlerweile schon traditionsreichen Debatten über die »nivellierende« Wirkung nichtlinearer Tarifabschlüsse allerdings fast schon provozierend aus: Da die DAG erklärtermaßen nicht daran dachte, sich nach den Vorstellungen der ÖTV in den DGB einzugliedern, benutzte nun auch die ÖTV die Tarifpolitik, um die Distanz zwischen den beiden Organisationen zu betonen. Die Hamburger Reaktion ließ nicht auf sich warten. In öffentlichen Erklärungen, die per Flugblatt in den Betrieben bekannt gemacht wurden, verwahrte sich die DAG scharf gegen die »Leistungsfeindlichkeit« der ÖTV-Strategie. Wer eine für alle Beschäftigten gleich große pauschale Lohnerhöhung durchsetzen wolle, der

404 | Auszug aus dem Protokoll des Tarifpolitischen Ausschusses des DGB vom 10.7.1975, o. D. In: Archiv Ver.di, Bestand Kluncker, 49.

405 | Vgl. hierzu: Der Kampf zwischen den Gewerkschaften. In: Die Welt, 9.12.1975. Weil sich die DAG durch scharf kritische Formulierungen in der Mitgliederzeitschrift der IG Chemie beleidigt fühlte, beantragte sie erfolgreich eine einstweilige Verfügung gegen die Auslieferung des Magazins. 
bestrafe »die Leistungsbereitschaft und den Arbeitswillen« der beruflich qualifizierten Angestellten. Mit der DAG sei so etwas nicht zu machen: "Die Gehaltspolitik der DAG basiert auf dem Leistungsprinzip. « 406

Die Tarifverhandlungen, die nach diesem gewerkschaftsinternen Vorgeplänkel begannen, verliefen für die ÖTV wenig erfreulich. Bei den Arbeitgebern stieß sie mit ihrer Einheitsforderung auf geschlossene Ablehnung; auf die Streikbereitschaft der Basis aber konnte sie nach wie vor nicht vertrauen. Gleichzeitig inszenierte der DAG-Vorsitzende Heinz Grothegut die von ihm geführte Organisation vor den Fernsehkameras erfolgreich als selbstbewussten Widerpart der ÖTV. Verärgert distanzierte sich Heinz Kluncker daraufhin öffentlich von der »irren Leistungsideologie« der DAG. ${ }^{407}$

Nach gescheiterten Verhandlungen begann die erste Schlichtung in der Tarifgeschichte des bundesdeutschen Öffentlichen Dienstes. Sie endete mit einer Empfehlung, die eine Prozentzahl (plus fünf Prozent) mit einem Mindestbetrag von 75 DM kombinierte. Während die ÖTV den Vorschlag ablehnte, nahm die DAG ihn an. In erneuten Beratungen mit den Arbeitgebern musste die nach wie vor verzagt agierende ÖTV-Führung schließlich nachgeben: Sie akzeptierte eine nur leicht überarbeitete Version der Schlichtungsempfehlung, obwohl sie noch kurz zuvor erklärt hatte, der Einheitsbetrag sei für sie essenziell wichtig. ${ }^{408}$ Eine Handlungsalternative

406 | In der Reihenfolge der Zitate: Flugblatt des DAG-Landesverbandes Niedersachsen-Bremen, 23.1.1976. In: Archiv Ver.di, Bestand Kluncker, 49; Der Kampf zwischen den Gewerkschaften. In: Die Welt, 9.12.1975 (zit. wird hier der DAGVorsitzende Hermann Brandt). Vgl. zusammenfassend aus der Perspektive der DAG auch: Gerhard Halberstadt: Die Angestellten und ihre Gewerkschaft. Stationen einer bewegten Geschichte, Freiburg 1991, S. $290 \mathrm{f}$.

407 | Vgl. den rückblickenden Bericht in: Am Ende die Gleichberechtigung? In: SZ, 14.6.1976.

408 | Als Abriss vgl.: ÖTV-Geschäftsbericht 1976/79, S. 106 f.; Deutsche Angestellten-Gewerkschaft: Tätigkeitsbericht 1975/79. Vorgelegt dem 12. Bundeskongress, Hamburg 1979 (im Folgenden: DAG-Tätigkeitsbericht 1975/79), S. 96. Zur strikt ablehnenden Haltung der Arbeitgeber gegenüber der Einheitsforderung und dem Schlichtungsverfahren vgl. genauer: Tarifrunde 1976 im öffentlichen Dienst. In: Gewerkschaftsreport 10 (1976), H. 2, S. 21-25. In dem schließlich auch von der ÖTV akzeptierten Tarifvertrag stieg der Mindestbetrag auf 85 DM; gleichzeitig aber wurden in den Vertrag eher versteckte Änderungen am Ortszuschlag einge- 
fehlte, weil »nicht alle regionalen Gliederungen der ÖTV ihre Entschlossenheit, notfalls für diese berechtigte Forderung zu kämpfen, deutlich genug demonstriert« hatten. Mit anderen Worten: Der interne Dissens, welche grundlegende tarifpolitische Strategie die Gewerkschaft verfolgen solle, lähmte die Organisation, wenn es wirklich ernst wurde. ${ }^{409}$

Erneut zeigten sich gerade die engagierten ÖTV-Mitglieder sehr enttäuscht. Ein Antrag auf dem wenig später stattfindenden Gewerkschaftstag, der unter anderem von Heinz Wolf (selbst gar kein Freund der sozial ausgleichenden Tarifstrategie) unterstützt wurde, vermerkte kritisch, die ÖTV züchte "Lethargie« an ihrer Basis und wachsendes »Mißtrauen« gegenüber den Funktionären, weil sie sich nicht erkennbar gegen einen Tarifvertrag gewehrt habe, der so grundlegend von ihren ursprünglichen Forderungen abwich. ${ }^{410}$

Der Beschluss des Kongresses, die Tarifgemeinschaft mit der DAG zu kündigen und künftig nur noch allein mit den Arbeitgebern zu verhandeln, reagierte im doppelten Sinne auf den Verlauf dieser Tarifberatungen. Die DAG hatte sich so widerspenstig verhalten, dass die ÖTV mit Blick auf den Hamburger Verband berechtigt von einer "gegnerischen Organisation« sprechen konnte. Zudem lehnte die DAG einheitliche Tarifverträge

baut, durch die das Plus für die Arbeitgeber »nahezu kompensiert« wurde (Rundschreiben der Arbeitsrechtlichen Vereinigung der Gemeinden und gemeinwirtschaftlichen Unternehmen in Nordrhein-Westfalen, 12.4.1976. In: AdsD, ÖTV NRW II, 5/ÖTVC603012).

409 | Flugblatt der ÖTV-Bezirksleitung Hessen, 11.4.1976. In: AdsD, ÖTV NRW II, 5/ÖTVC603014. Nach dieser Darstellung hatten sich nach dem Schlichtungsverfahren nur die Bezirke Hessen und Baden-Württemberg dafür ausgesprochen, eine Urabstimmung vorzubereiten. Beide Bezirke votierten auch gegen den ausgehandelten Abschluss.

410 | Protokoll ÖTV-GT 1976, Bd. 2, S. 312-314 (Zitate: S. 313). Dieser Initiativ-Antrag 374 A wollte die ÖTV daher verpflichten, künftig eine »Mitgliederbefragung« durchzuführen, wenn die GTK einem Tarifvertrag zustimmte, der »in besonders gravierendem Umfange« von der Ursprungsforderung abwich. Der Gewerkschaftstag lehnte den Antrag »mit großer Mehrheit« als nicht praktizierbar und als nicht satzungskonform ab. Vgl. die Diskussion (mit der Begründung des Antrags durch Heinz Wolf) und die Abstimmung in: ebd., Bd. 1, S. 458-460. Scharfe Kritik am Verlauf der Tarifrunde übte auch der Delegierte Rainer Schellbach (Dortmund). Vgl.: ebd., S. $111 \mathrm{f}$. 
für Arbeiter und Angestellte ab, d.h. sie stellte sich auch gegen das ÖTVProjekt, ein einheitliches Personalrecht zu schaffen, das die traditionelle „Kragenlinie« ignorierte. Deshalb, so sagte Heinz Kluncker, dürfe die DAG künftig »nicht mehr am gleichen Verhandlungstisch" sitzen wie die ÖTV. ${ }^{411}$

Aber die DAG hatte wohl nicht ganz unrecht, als sie erklärte, die ÖTV habe diese Konfrontation auch deshalb herbeigeführt, weil sie den Ärger ihrer eigenen Basis über den Tarifabschluss für 1976 begrenzen wollte: Es gehe der ÖTV-Führung gar nicht so sehr um »sachliche gewerkschaftspolitische Auseinandersetzungen ", sondern eher darum, »ihr Abgehen von der nivellierenden Sockel- und Festbetragspolitik" in den Hintergrund zu drängen. ${ }^{412}$ Die eigene Truppe an internen Streitigkeiten zu hindern, indem man den Konflikt mit einem äußeren Konkurrenten oder Gegner intensiviert, ist in der Tat eine traditionsreiche Strategie in der Geschichte der menschlichen Gruppenbildung - und im Fall der ÖTV hat sie im Sommer 1976 gut funktioniert. Der Gewerkschaftstag beschäftigte sich nur am Rande mit dem problematischen letzten Tarifabschluss; dem Bruch der Tarifgemeinschaft stimmten die Delegierten hingegen mit nur einer Gegenstimme zu. ${ }^{413}$

Wie oben schon angedeutet wurde, zahlte die ÖTV für diese Entscheidung organisatorisch einen durchaus hohen Preis: Sie musste 1977/78 die von ihr bislang verhinderte Integration der GdP in den DBG akzeptieren, weil der DGB-Hauptvorstand eine eventuelle Annäherung zwischen GdP und DAG unbedingt verhindern wollte, und damit zugleich auf ihre eigene Abteilung für Beschäftigte der Polizei verzichten. Da die DAG eifrig dabei war, um gewerkschaftliche Partner für ein »Anti-DGB-Kartell« zu werben, bestand in dieser Hinsicht in der Tat dringender Handlungsbedarf. ${ }^{414}$

Für die Tarifrunden mit Bund, Ländern und Gemeinden hatte das Ende der ÖTV-DAG-Tarifgemeinschaft hingegen geringere Folgen, als man

411 | Protokoll ÖTV-GT 1976, Bd. 1, S. 474f.; der Antrag ist wiedergegeben in: ebd., Bd. 2, S. $333 \mathrm{f}$.

412 | DAG-Tätigkeitsbericht 1975/79, S. 91.

413 | Protokoll ÖTV-GT 1976, Bd. 1, S. 478 f.

414 | Vgl. hierzu etwa: »Closed Shop« für Arbeiter. In: Vorwärts, 21.10.1976; Verhandeln nach der G-Formel. In: Die Zeit, 26.11.1976; DAG sammelt Standesorganisationen für ein Anti-DGB-Kartell. In: FR, 25.11.1976; Tarifgemeinschaft gegen ÖTV-Monopol. In: SZ, 30.10.1976. 
vielleicht vermuten würde. Da die Arbeitgeber inhaltlich abweichende Verträge mit den beiden Organisationen strikt ablehnten, um die »Einheit des Tarifrechts« zu erhalten, wurde zwar der Verhandlungsgang komplizierter und schwerfälliger. Das eindeutige organisatorische Übergewicht der ÖTV garantierte ihr in diesem neuen Prozedere zeitgleicher separater Beratungen jedoch verlässlich eine dominierende Rolle. Am Ende standen deshalb stets gleichlautende Abmachungen, bei deren Entstehung die DAG nach wie vor nur eine Nebenrolle spielte. ${ }^{415}$

Allerdings stellte die ÖTV in den Jahren 1977 bis 1979 nur noch Tarifforderungen, in denen die "soziale Komponente" deutlich weniger wog als in den vorangegangenen Verhandlungsrunden: Durchweg ging es nun nur noch um ein einheitliches Urlaubsgeld (bzw. für 1978 um eine neue Ordnung der Urlaubsdauer, die Bezieher geringer Einkommen begünstigte). ${ }^{416}$

1977 rückte die Gewerkschaft das Urlaubsgeld ganz in das Zentrum ihres Forderungskatalogs. Seit 1974 hatte sie es immer wieder erfolglos gefordert. Zudem erhielten mittlerweile mehr als 80 Prozent der Beschäftigten in der Privatwirtschaft eine solche Einmalzahlung. Deren Einführung auch im Öffentlichen Dienst sei deshalb ein »Gebot der Gerechtigkeit «. ${ }^{417}$ Bewusst verzichtete die ÖTV damit darauf, bei der Erhöhung der monatlichen Bezüge noch einen weiteren »Sockel« oder einen Mindestbetrag zu verlangen. Wie Heinz Kluncker dem Hauptvorstand erklärte, müsse man

415 | Zur Festlegung der Arbeitgeber auf das Prinzip der Tarifeinheit vgl. bereits: Vermerk der Abt. D III für das Chefgespräch mit TdL und VKA, 10.2.1976. In: BArch Koblenz, B 106, 97908. Konkrete Schilderungen der neuen, komplizierten Parallelverhandlungen vgl. etwa in: Die »DAG-Maus« schlägt hart zurück. In: SZ, 30.10.1976; Die öffentlichen Arbeitgeber lassen sich breitschlagen. In: Handelsblatt, 22.11.1976; Krumsiek: Alle Jahre, S. $332 \mathrm{f}$.

416 | Die Urlaubsdauer sollte künftig nicht mehr (wie bisher) nach Lohn- und Gehaltsgruppen, sondern nur nach dem Lebensalter gestaffelt sein. De facto bedeutete dies einen besonderen Wohlstandzuwachs für die unteren Lohngruppen, die von der geltenden Regelung benachteiligt wurden. Diese Forderung wurde anders als der Lohnzuwachs, der in dem abgeschlossenen Tarifvertrag von den geforderten 7,5 auf 4,5 Prozent sank - fast ohne Abstriche durchgesetzt. ÖTV-Geschäftsbericht 1976/79, S. $110 \mathrm{f}$.

417 | Rede von H. Kluncker bei Eröffnung der Tarifverhandlungen, 10.2.1977. In: Archiv Ver.di, Bestand Kluncker, 24. 
so vorgehen, weil sich die sozial ausgleichende Tarifpolitik in den letzten Tarifrunden zunehmend als stark konfliktträchtig erwiesen habe. Dabei verwies er ausdrücklich auf Kontroversen mit den anderen DGB-Organisationen: »Wenn ein solcher Mindestbetrag Wirkungen zeigen soll, muß er so hoch angesiedelt sein, daß wir damit die ganzen Industriegewerkschaften kopfscheu machen. « $^{418}$

Das Urlaubsgeld, das die ÖTV 1977 tatsächlich in der Höhe von 150 DM für jeden Beschäftigten durchsetzte und das 1979 dann auf 300 DM stieg, führte die alte "Sockel«-Strategie also in deutlich abgeschwächter Form weiter. Ihre sozial ausgleichende Funktion war der Gewerkschaft aber sehr wichtig. Gegenüber den Arbeitgebern betonte Heinz Kluncker deshalb, die ÖTV sehe die neue pauschale Zulage dezidiert nicht als „Einstieg« in ein 14. Monatsgehalt: »Das Urlaubsgeld müsse für alle und immer einheitlich sein. $\ll^{419}$

Die Frage, ob die Gewerkschaft damit genug tat, um das Gerechtigkeitsbedürfnis ihrer Basis zu befriedigen, muss allerdings wohl als offen gelten. Die 300 DM entsprachen in der untersten Stufe der BAT-Hierarchie im Jahr 1979 zwar einer Einkommenserhöhung um 1,3 Prozent der Jahresgesamtbezüge, während dieses Plus (bei gleichem Familienstand und gleichem Dienstalter) in der höchsten Gehaltsgruppe nur 0,4 Prozent ausmachte. Der Urlaub des Geringverdieners, der brutto rund 23.000 DM im Jahr erhielt, dürfte sich dennoch deutlich von der Ferienreise des besonders gutverdienenden Angestellten unterschieden haben, denn der verdiente im gleichen Zeitraum insgesamt 73.000 DM. Bei den Nettobeträgen dürfte die Differenz zudem angesichts der Realitäten des damaligen deutschen Steuersystems wohl noch etwas kleiner ausgefallen sein. ${ }^{420}$ Ob Mitglieder

418 | 3. Sitzung des HV, 20./21.1.1977. In: AdsD, ÖTV, 5/ÖTVB130054. Vgl. auch: Wie Maihofer im Tarifpoker gegen das Umfallen kämpft. In: Die Welt, 26./27.2.1977; Nun auch Urlaubsgeld? In: FAZ, 26.2.1977.

419 | So bereits zit. in: Niederschrift über die außerordentliche Mitgliederversammlung und Hauptausschusssitzung der VKA, 14.1.1975. In: BArch Koblenz, B 376, 46. Zu den Details der durchgesetzten Regelung vgl.: ÖTV-Geschäftsbericht 1976/79, S. 109 u. 113. Die genannten Summen galten für alle vollbeschäftigten Arbeiter und Angestellten der Öffentlichen Hand; Teilzeitbeschäftige und Auszubildende erhielten weniger. Kinderzuschläge gab es nicht.

420 Berechnet nach den Zahlen in: Bericht des Tarifsekretariats Nr. 80/79, 14.12.1979. Berechnet werden hier die Bezüge der beiden Gruppen für einen ver- 
der ÖTV, die dem Leitungspersonal in Behörden und Ämtern ohnehin deren Funktion als Vorgesetzte übel nahmen, einen "sozialen Akzent" dieser Größenordnung als ausreichend akzeptierten, erscheint doch sehr fraglich.

Insgesamt verdeckten die unbestreitbaren Erfolge, die der ÖTV mit ihrer Tarifpolitik auch noch nach 1974 gelangen, somit mehrere nur mühsam kontrollierte Konflikte. Mit den Arbeitgebern lag die Gewerkschaft sowohl in der Frage der Manteltarifverträge als auch bei der Zusatzversorgung grundsätzlich über Kreuz. Der anhaltende Streit, ob lineare oder sozial ungleiche Lohn- und Gehaltserhöhungen zu fordern seien, entzweite Mitglieder und Funktionäre; zudem entfremdete eine deutlich sozial ausgleichend orientierte Tarifpolitik die DAG, und sie förderte darüber hinaus auch noch die Kritik der industriellen DGB-Verbände an der ÖTV.

Allerdings ist selbst diese Liste noch nicht vollständig: Abseits der weitgehend "geräuschlos" verlaufenden Lohn- und Gehaltsrunden der Jahre 1975 bis 1979 hatte die ÖTV auch noch mit einer neuen tarifpolitischen Herausforderung zu kämpfen: Seit 1974 bemühten sich die staatlichen Arbeitgeber hartnäckig darum, ihre Personalkosten abzubauen. Dabei intensivierten sie schon zuvor begonnene betriebliche Rationalisierungsmaßnahmen so deutlich, dass sich durchaus von einem qualitativen Wandel sprechen lässt. Gleichzeitig »erfanden« sie ein ganz neues kostensenkendes Mittel: Bestimmte Arbeiten ließ der Staat nun zunehmend von Privatfirmen und deren Beschäftigten erledigen; das damit zuvor befasste eigene Personal wurde entweder umgesetzt oder aber entlassen. Insbesondere auf kommunaler Ebene begann sich der Öffentliche Dienst damit deutlich zu verändern.

heirateten Beschäftigten ohne Kinder, der jeweils die letzte Stufe der Grundvergütung und den Ortszuschlag in der Gruppe S, 2. Stufe, erhielt. Eine ähnliche Berechnung vgl. auch schon in: Was Klunckers »soziale Akzente« kosten würden. In: Handelsblatt, 18.11.1976. 


\section{Rationalisierung und Privatisierung im Öffentlichen Dienst in den 1970er Jahren}

\section{"Schreibdamen« und andere Opfer betrieblicher Effizienzsteigerung}

An Fürsorge ließ es der Arbeitgeber nicht mangeln. Das neue Großraumbüro, das die Bremer Sozialbehörde im Jahr 1971 für die Beschäftigten ihres Schreibdienstes einrichtete, erhielt eine große Sitzecke sowie eine Küche mit Kühlschrank. Den Teppichboden, der verlegt wurde, durften die 19 Stenotypistinnen, die dort künftig nebeneinander arbeiten sollten, gemeinsam auswählen. Trotz solcher Investitionen versprach sich die Behördenleitung deutliche finanzielle Einsparungen, denn der Umzug bedeutete für die Schreibkräfte, die zuvor jeweils in kleineren Gruppen von bis zu vier Personen in getrennten Büros und auf verschiedenen Etagen des Gebäudes gesessen hatten, eine grundlegende neue Organisation ihrer Tätigkeit: Die »Schreibdamen« wurden von ihren Vorgesetzten nun nicht mehr zum Diktat gebeten. Stattdessen erhielten sie Tonbänder, von denen sie die zu schreibenden Texte abhörten. Büroboten übernahmen deren Anlieferung sowie auch die Verteilung der erstellten Schriftstücke. Wie eine betriebswirtschaftliche Analyse ergeben hatte, konnte die Behörde insgesamt acht Stellen für Stenotypistinnen einsparen, weil die Produktivität des Schreibdienstes deutlich wachsen werde, wenn man auf ein stenografisch protokolliertes Diktat und auf den persönlichen Kontakt zwischen den Sekretärinnen und den Vorgesetzten verzichtete. Mit diesem Projekt folgte die Bremer Amtsleitung einem Konzept, das der Bundesrechnungshof im Frühjahr 1970 allen staatlichen Verwaltungseinrichtungen empfohlen hatte. Die amtlichen Rechnungsprüfer hatten zuvor ihren eigenen Schreibdienst reformiert und dabei 40 Prozent der Stellen eingespart. ${ }^{421}$

In der Praxis verursachte die Neuordnung in der Bremer Sozialbehörde dann allerdings erhebliche Probleme. Überrascht stellten die Verant-

421 | Alle Angaben zu Bremen nach dem Bericht von Manfred Riebe, Personalratsvorsitzender der Behörde. In: Jochen Fuhrmann: Rationalisierung in der Verwaltung, Köln und Frankfurt/Main 1977, S. 50-58. Die Empfehlungen des Bundesrechnungshofes veröffentlicht in: Bemerkungen des Bundesrechnungshofes zur Bundeshaushaltsrechnung für das Haushaltsjahr 1967, 26.2.1970. In: Verhandlungen des Deutsche Bundestages. 6. Wahlperiode. Anlagen zu den stenographischen Berichten, Bd. 137, Bonn 1970, Drucksache 559, S. 32-34. 
wortlichen fest, dass sich die meisten der "Schreibdamen« mit dem neuen Büro und der neuen Arbeitsorganisation nicht anfreunden wollten: Nur fünf der 19 verbliebenen Frauen behielten ihre Vollzeitstellen; alle anderen bewarben sich weg, oder aber sie forderten für sich eine Teilzeitbeschäftigung. Da der Arbeitsmarkt der Bundesrepublik seinerzeit noch stark von Konkurrenz der Arbeitgeber um Bewerber geprägt war, bereitete es erhebliche Mühen, die Lücken zu schließen. Die erhoffte Beschleunigung der Schreibarbeiten stellte sich zudem erst nach mehreren Monaten ein. Anfangs wuchsen die Fehlerquoten der »Schreibdamen« deutlich an (nicht zuletzt, weil viele von ihnen neu waren); Schriftstücke mussten teilweise mehrmals korrigiert werden. So verzögerten sich Briefe der Behörde um bis zu fünf Wochen. Zwar verschwand dieser Rückstau im Laufe der Zeit. Die Sekretärinnen aber blieben dauerhaft unzufrieden: Sie klagten über Monotonie, eine deutlich intensivierte Arbeitslast und Isolation. Um zumindest das letzte dieser Probleme zu lindern, erhielt daraufhin jede von ihnen nachträglich ein Telefon am Arbeitsplatz. Zudem erging in der Behörde die offizielle Weisung, »die Diktierenden sollten auch ruhig mal in den Schreibdienst gehen, auch ruhig mal sprechen, auch dann, wenn sie keinen dienstlichen Auftrag haben ${ }^{4}{ }^{422}$

Nach dem Urteil der ÖTV veränderte sich damit jedoch nichts zum Positiven: Die »Streßsituation« der Schreibkräfte habe sich mit der Umorganisation ihrer Arbeit massiv verschlechtert. Von zentralen Schreibdiensten der eben beschriebenen Art hielt die Gewerkschaft deshalb gar nichts: Der berufliche Alltag der Sekretärinnen reduziere sich an solchen Arbeitsplätzen auf »eine monotone, krankmachende Fließbandarbeit an Schreibgeräten«, bei der »der Mensch nur noch Sklave der Maschine zu sein scheint«, während sie zuvor eine »Mischtätigkeit« mit starken kommunikativen Anteilen erledigt hatten. ${ }^{423}$ Betriebswirtschaftlich galten diese Probleme jedoch als nebensächlich. So forderte der Bundesrechnungshof 1975 erneut, die staatlichen Verwaltungen sollten ihre Schreibarbeiten zentralisieren. Langfristig lasse sich das damit befasste Personal dank der Effi-

422 | M. Riebe. In: Fuhrmann: Rationalisierung, S. 54.

423 | In der Reihenfolge der Zitate: ebd., S. 57; Hilde Just: Darstellung der Politik für die Arbeitnehmerinnen aus der Sicht der Gewerkschaft ÖTV. In: Frauen und Arbeit (1977), H. 5, S. 6-8, hier: S. 7. Vgl. auch: Schreibdienst muß human bleiben. In: ÖTV-Magazin 1977, H. 12, S. 12. 
zienzgewinne so um fast 50 Prozent reduzieren. Zudem brauche der Staat als Arbeitgeber dann keine Sekretärinnen mit Stenographie-Kenntnissen mehr - was eine geringere Entlohnung rechtfertige. ${ }^{424}$

Das Konzept der Rechnungsprüfer von 1975 entsprach also exakt ihrem Vorschlag von 1970. Deutlich verändert aber hatte sich die Begründung für die verlangte Reform: 1970 reagierte der Plan vor allem auf den Arbeitskräftemangel in der Bundesrepublik, der es auch dem Staat schwer machte, Beschäftigte anzuwerben. 1975 aber ging es dezidiert darum, Personalkosten einzusparen: Frei werdende Stellen im Schreibdienst sollten so lange nicht mehr neu besetzt werden, bis die Zahl der Sekretärinnen deutlich geschrumpft war. ${ }^{425}$

Wenn die staatlichen Rechnungsprüfer ihr bereits etwas älteres Rationalisierungsprojekt mit einer neuen Rechtfertigung noch einmal vorstellten, so geschah dies keineswegs zufällig gerade 1975. Generell bezeichnet dieses Krisenjahr einen Einschnitt in der Geschichte des Öffentlichen Dienstes in der Bundesrepublik. War er in den vorangegangenen Jahren des politischen Reformeifers noch einmal deutlich erweitert worden, so begann nun ein neuer Abschnitt: Politisch galt es jetzt als höchst wichtig, die staatlichen Ausgaben "zu konsolidieren «, und dabei fassten Vertreter aller Parteien zentral die Personalkosten der Öffentlichen Hand ins Auge.

In Bund, Ländern und Gemeinden verlangten die jeweils politisch Verantwortlichen fast unisono "Sparsamkeit« gerade in den Personaletats der Behörden und der staatlichen Betriebe. Absichtserklärungen dieser Art besaßen zwar schon eine lange Tradition; neu waren jedoch die vielen Versuche, sie auch praktisch umzusetzen. Ende 1974 verfügte die Bundesbahn - nach wie vor der größte Staatsbetrieb - einen sofortigen unbefristeten Einstellungsstopp. Selbst bestehende frei werdende Posten sollten unbesetzt bleiben, um die Belegschaft schrittweise um 60.000 Köpfe zu verkleinern. Fast zeitgleich konzipierte und verabschiedete die sozialliberale Koalition in Bonn ein auf mehrere Jahre angelegtes Sparprogramm, das den Bundesbeamten bestimmte Zulagen und Sonderzahlungen kürzte.

424 | Just: Darstellung, S. 7. Ein Hinweis auf die entbehrlichen StenographieKenntnisse und den sich daraus ergebenden Kostenvorteil fand sich auch schon in den »Bemerkungen« des Rechnungshofes von 1970 in: VerBT, Anlagen, Bd. 137, Drucksache 559, S. 33.

425 | Just: Darstellung, S. 7. 
1975 beschloss die SPD als Regierungspartei in Hamburg, für drei Jahre keine neuen Stellen im Öffentlichen Dienst des Stadtstaates mehr zu schaffen. Da der Staat als Arbeitgeber im Herbst 1974 allgemein von der 42- auf die 40-Stunden-Woche übergegangen war, lief diese Entscheidung darauf hinaus, jedem der Beschäftigten im Hamburger Staatsdienst in der verkürzten Arbeitszeit weiterhin das gleiche Arbeitsvolumen abzuverlangen. Rationalisierungsmaßnahmen wollte der Senat hingegen deutlich intensivieren. So hoffte er, »die Chance des Sparenmüssens [zu] nutzen, um das [...] Problem der Effizienz im öffentlichen Dienst« anzugehen. Vergleichbare Beschlüsse kamen nicht nur in Berlin und vielen anderen Großstädten zustande. Im Ruhrgebiet verpflichteten sich vielmehr auch mittelgroße und kleinere Gemeinden, künftig in ihrem Personaletat zu kürzen. ${ }^{426}$ Die skizzierte Geschichte des Zentralen Schreibdienstes in der Bremer Sozialbehörde war somit nur ein frühes Beispiel für einen Trend, mit dem sich die ÖTV nach 1975 intensiv beschäftigen musste.

Angestoßen wurden all diese Sparpläne von den wachsenden Sorgen der Politiker, die über die öffentlichen Haushalte entschieden. Wie erwähnt hatten sich alle Gebietskörperschaften in den frühen 1970er Jahren in großem Stil verschuldet. Diese immer schon umstrittene Kreditaufnahme galt nun, da sich die ökonomischen Zukunftsaussichten der Bundesrepublik eintrübten, vollends als höchst bedenklich. Besonders in den Kommunen breitete sich die Furcht aus, die Öffentliche Hand werde finanziell handlungsunfähig. Tatsächlich konnten zahlreiche Großstädte schon zu diesem Zeitpunkt ihre bislang aufgelaufenen Kredite nicht mehr aus den laufenden Einnahmen verzinsen und tilgen, d.h., sie mussten entweder neue Schulden machen, um die alten Verpflichtungen zu bedienen, andere Ausgaben kürzen oder aber Rücklagen auflösen und Vermögenswerte

426 | Vgl. in der Reihenfolge: Die Bundesbahn will drastisch sparen. In: FAZ, 8.11.1974; Clemens: Der öffentliche Dienst, S. 333-341; Rolf Dieckmann: Aufgabenkritik in einer Großstadtverwaltung unter besonderer Berücksichtigung Hamburgs, Berlin 1977, S. 189-192; Hans-Ulrich Klose: Hamburgs Zukunft sichern. Regierungserklärung am 29. Januar 1975 vor der hamburgischen Bürgerschaft, Hamburg 1975, S. 20 (Zitat); Sparprogramm des Berliner Senats. In: FAZ, 4.11.1976; Haushaltskonsolidierung bleibt Problem Nr. 1. In: Der Städtetag 30 (1977), S. 17-24; Niederschrift über die 11. Sitzung des Personalausschusses des Nordrhein-Westfälischen Städte- und Gemeindebundes, 29.10.1976. In: Archiv Ver.di, Bestand Kluncker, 52. 
mobilisieren. Gleichzeitig flossen nur noch rund 1,5 Prozent der gesamten Kommunalausgaben in neue Investitionsvorhaben. Der Schuldendienst verschlang hingegen bereits elf Prozent. Gegenüber den frühen 1960er Jahren war dieser Haushaltsposten nun fast doppelt so gewichtig wie zuvor, während die Investitionsquote im gleichen Zeitraum zwei Drittel ihres Anteils verloren hatte. ${ }^{427}$

Angesichts dieser Situation hätte die Frage entstehen können, ob der Staat nicht vielleicht in dem Sinne unterfinanziert sei, dass er nur unzureichend am wachsenden Wohlstand der bundesdeutschen Gesellschaft partizipierte. Die kontinuierlich wachsende Bedeutung der Lohnsteuer, die vornehmlich durch die Erwerbsarbeit der vielen Normalverdiener entstand, für die gesamten staatlichen Einnahmen sowie der korrespondierende anteilige Rückgang an Steuern, die von Kapitaleigentümern und anderen wirklich vermögenden Bundesbürgern aufgebracht wurden, wiesen gemeinsam in diese Richtung. Tatsächlich aber entwickelte sich eine ganz andere Diskussion: Der Staat - so der Tenor - »überfordere« die Finanzkraft der Bürger und der Unternehmen. Er gebe zu viel Geld aus und müsse deshalb zum Sparen gezwungen werden. ${ }^{428}$

427 | Bruno Weinberger: Ein markanter Einschnitt. In: Der Städtetag 29 (1976), S. 1; Die Finanznot der Gemeinden und Städte nimmt weiter zu. In: FAZ, 8.1.1976. Die Angaben zu den Anteilen der Investitionen und des Schuldendienstes nach: Elsner: Gemeindefinanzsystem, S. 106. Vgl. exemplarisch auch die Angaben zu Hannover in: Haushaltskonsolidierung bleibt Problem Nr. 1. In: Der Städtetag 30 (1977), S. 17-24, hier: S. 21. Eine Änderung der Steuergesetze durch den Bundestag, die Anfang 1970 in Kraft trat, hat die skizzierte negative Entwicklung entscheidend gefördert: Die Lohnsteuer der abhängig Beschäftigten wurde seitdem jeweils in dem Wohnort des einzelnen Arbeitnehmers erhoben - und nicht mehr dort, wo er oder sie arbeitete. Davon profitierten alle Gemeinden im Umfeld der Metropolen, in denen Berufspendler lebten. Den Großstädten entging das Geld; auf den Kosten für die Infrastruktur, ohne die es die tägliche An- und Abreise der Vorstädter nicht geben konnte, blieben sie hingegen sitzen. Vgl. zusammenfassend zur ökonomischen Überforderung der Städte nach 1970 etwa: Hans Heuer: Die veränderte ökonomische Basis der Städte. In: Jürgen Friedrichs (Hrsg.): Die Städte in den 80er Jahren. Demographische, ökonomische und technologische Entwicklungen, Opladen 1980, S. 23-47; speziell zum Problem der Lohnsteuer vgl.: Klose: Zukunft, S. 5 f.

428 | Vgl. hierzu etwa die vieldiskutierten Thesen in: Wolfgang Streeck: Gekaufte Zeit. Die vertagte Krise. Frankfurter Adorno-Vorlesungen 2012, Berlin 2013. 
Die Schnelligkeit, mit der diese Deutung Mitte der 1970er Jahre in Politik und Medien fast allgemein akzeptiert wurde, ist alles andere als selbstverständlich. Noch 1973 hatte die von der Bundesregierung eingesetzte Studienkommission für die Reform des Staatsdienstes ausdrücklich konstatiert, der Staatsapparat und die Staatsausgaben seien seit 1960 deshalb so stark gestiegen, weil die Öffentliche Hand in Bereichen investiert habe, »die für das gesamtwirtschaftliche Wachstum und den gesellschaftlichen Fortschritt zunehmende Bedeutung « besäßen. ${ }^{429}$

In der öffentlichen Debatte gab es solches Lob nach 1974 dann kaum noch zu hören. Mit seiner oben schon kurz erwähnten Titelgeschichte »Die Beamten fressen den Staat« vom November des Jahres prägte der Hamburger Spiegel den neuen Diskurs. Auch Politiker, die kurz zuvor noch selbst aktiv die Expansion des Öffentlichen Dienstes vorangetrieben hatten, schlugen in diese Kerbe. Die staatlichen Personalausgaben, so erklärte der Vorstand des Deutschen Städtetags bereits 1975, müssten sinken, »wenn nicht der Staat, wenn nicht das Gemeinwohl Schaden nehmen soll«. Im SPD-Parteirat herrschte im Februar 1976 Einigkeit, es sei politisch unabdingbar, gerade diesen Etatposten bei Bund, Ländern und Gemeinden »in den Griff zu bekommen«. Lothar Späth, der Fraktionsvorsitzende der regierenden CDU in Baden-Württemberg, bezeichnete die Höhe der staatlichen Lohn- und Gehaltsaufwendungen wenig später als »langfristig lebensgefährlich «. ${ }^{430}$

Die Massenmedien bekräftigten und verstärkten diese Wertungen; Sachbücher, die den bundesdeutschen Staatsapparat als "aufgebläht" und ineffizient beschrieben, fanden offenbar verlässlich Käufer und Leser. ${ }^{431}$ Gleich-

429 | Studienkommission: Bericht, S. 133.

430 | In der Reihenfolge der Zitate: Erwin Schleberger: Warten auf die Dienstrechtsreform. In: Der Städtetag 28 (1975), S. 455; Sitzung des SPD-Parteirates, Parteivorstandes und der Kontrollkommission, 20.2.1976. In: AdsD, SPD-Parteivorstand, 2/PVAS0000640; Späth: Einfluss der Tarife für Etat lebensgefährlich. In: StZ, 3.11.1976.

431 | Vgl. beispielhaft die verschiedenen Publikationen des SPD-MdB Ulrich Lohmar, der öffentlichkeitswirksam von einen »Klassenkampf der Staatsbürokratie gegen die private Gesellschaft« sprach: Ulrich Lohmar: Staatsbürokratie. Das hoheitliche Gewerbe. Deutsche Aspekte eines neuen Klassenkampfes, München 1978; ders.: Klassenkampf der Staatsbürokratie gegen die private Gesellschaft. In: Aus Politik und Zeitgeschichte 29 (1979), B 15/17, S. 3-8; ders.: Ersticken wir an der 
zeitig entwickelten Experten zahlreiche Konzepte und Pläne, wie der Öffentliche Dienst kostengünstiger arbeiten könne. Neben arbeitsorganisatorischen Reformen wie etwa den zentralen Schreibdiensten empfahlen sie insbesondere die Einführung der elektronischen Datenverarbeitung, um massenhaft zu erledigende Routineaufgaben stark zu beschleunigen. ${ }^{432}$

Technisch und arbeitsorganisatorisch scheint der Öffentliche Dienst daraufhin in der zweiten Hälfte der 1970er Jahre tatsächlich deutlich in Bewegung geraten zu sein. Allerdings ist es nicht möglich, dazu wirklich präzise Angaben zu machen. Rationalisierung entsteht jeweils vor Ort, d.h. für spezifische Arbeiten im einzelnen Betrieb oder sogar nur in einer einzelnen Abteilung. Von Fall zu Fall können sich dabei gravierende Unterschiede ergeben; zumal die Frage, wie sich Arbeitsabläufe verändern, wenn neue Geräte oder Techniken benutzt werden, entzieht sich weitgehend pauschalen Urteilen. ${ }^{433}$ Auch den Zeitgenossen war daher unklar, was Rationalisierung für sie selbst konkret bedeuten könnte - und gerade dieser vage Cha-

Bürokratie?, Köln 1980. Vgl. ferner: Frieder Lauxmann: Was sind uns die Beamten wert?, Stuttgart 1974; Borell: Personalausgaben; Herbert König: Dynamische Verwaltung. Bürokratie zwischen Politik und Kosten, Stuttgart 1977; Heiner Geißler: Alternativen zu einer verbürokratisierten Gesellschaft. In: ders. (Hrsg.): Verwaltete Bürger - Gesellschaft in Fesseln, Frankfurt/Main 1978, S. 121-130.

432 | Vgl. als Literaturüberblick etwa: Herbert König: Zur Effizienz öffentlichen Handelns im Spiegel der nationalen und internationalen Diskussion. In: Die Verwaltung 13 (1980), S. 57-76; Hannes Rehm: Wirtschaftlichkeit und Sparsamkeit im öffentlichen Sektor. In: ebd., S. 77-92. Die Ausbreitung der EDV im betrieblichen Alltag der 1970er Jahre ist weitgehend unerforscht. So lässt sich nur vermuten, dass sich zumal das gesamte Rechnungswesen und die Kontenführung in dieser Zeit wohl grundlegend verändert haben. Ende 1975 beschlossen z. B. die Länderfinanzminister ein gemeinsames Programm, die Finanzämter durch Einführung der "automatischen Datenverarbeitung « umzugestalten. Vgl. dazu den Bericht des Bundesrechnungshofes in: VerBT, Drucksache 7/5849 (26.10.1976), S. 72 f. Einige präzise Angaben zum Ausbau der EDV finden sich etwa in: Werner Ruckriegel: Computersysteme in der öffentlichen Verwaltung aus anwendungsbezogener Sicht. In: Erwin Grochla/Wolfgang Starke/Werner Ruckriegel: Computer-Verbundsysteme in Wirtschaft und Verwaltung, Dortmund 1976, S. 43-60. 433 | Vgl. hierzu etwa: Eduard Gaugler et al.: Rationalisierung und Humanisierung von Büroarbeiten. Studie im Auftrag des Bayerischen Staatsministeriums für Arbeit und Sozialordnung, Ludwigshafen 1980, insbes. S. 385-389; Harald Burglin: Angestellte - das große Rationalisierungspotential in Büros und Verwaltungen. 
rakter des Phänomens scheint zu einer negativen Grundstimmung bei den Beschäftigten geführt zu haben. 1976 diskutierte der ÖTV-Gewerkschaftstag über einen Antrag, der die Gewerkschaft aufforderte, sich stärker in die öffentlichen Rationalisierungs- und Effizienzdebatten einzumischen: Dies sei »eine der größten Aufgaben« der Organisation, weil »die Kolleginnen und Kollegen Angst vor den Folgen der Rationalisierung haben «. ${ }^{434}$

Wie alle deutschen Gewerkschaften bekannte sich auch die ÖTV ausdrücklich zum technischen Fortschritt und zu dessen Nutzung im Arbeitsalltag. Mit der englischen Eisenbahner-Gewerkschaft, die es bei der Elektrifizierung des britischen Bahnverkehrs durchgesetzt hatte, dass die nicht mehr benötigten Heizer weiterhin auf den Lokomotiven mitfuhren, wollte die ÖTV deshalb keinesfalls verglichen werden. ${ }^{435}$ Zudem bejahte sie das Ideal einer möglichst effizienten öffentlichen Verwaltung. Ihr Modell eines einheitlichen Dienst- und Personalrechtes etwa propagierte die Gewerkschaft ausdrücklich mit dem Versprechen, die Leistungskraft von Behörden und Ämter werde mit dieser Reform deutlich steigen. ${ }^{436}$

Soziale Verschlechterungen für Beschäftigte durch technische und arbeitsorganisatorische Reformen und Entlassungen aber lehnte die Gewerkschaft ab: Wenn der Arbeitgeber rationalisiere, dann sei er verpflich-

In: Ursula Schumm-Garling (Hrsg.): Angestellte und Gewerkschafen. Neue Trends und neue Antworten, 2. überarb. Aufl., Köln 1991, S. 180-189, insbes. S. 181-185. 434 | Protokoll ÖTV-GT 1976, Bd. 1, S. 328 (der Delegierte Heinz Eid, Stuttgart). Der entsprechenden Antrag der Kreisdelegiertenkonferenz: ebd., Bd. 2, S. 109113. Anders als von der Antragskommission empfohlen wurde dieser Antrag nicht als »Material« an den HV überwiesen (was die Sache de facto als weniger wichtig markierte), sondern »mit übergroßer Mehrheit « beschlossen (ebd., Bd. 1, S. 331). In mancher Hinsicht verschärfte der Beschluss die 1968 verabschiedete Resolution, denn nun verwahrte sich die ÖTV erstmals ausdrücklich gegen »Leistungskontrollen« des Arbeitgebers und gegen »Personalplanungs- und Personalführungssysteme, welche nur der Arbeitsintensivierung und Disziplinierung dienen« (ebd., Bd. 2, S. 110).

435 | Vgl. etwa expressis verbis die Delegierten Günther Schackow und Wolfgang Clotten (beide: Berlin) in: Protokoll ÖTV-GT 1968, Bd. 1, S. 274 u. 294.

436 | Vgl. etwa: Kluncker: Dienstrecht, S. 1; ders.: Sozialpolitische Probleme der Entstaatlichung. In: Horst Hanusch (Hrsg.): Reform öffentlicher Leistungen. Beiträge zur Entstaatlichung. Ein Kolloquium der Universität Augsburg in Memmingen, Baden-Baden 1978, S. 77-93, hier: S. 80 f. 
tet, die sozialen Interessen der davon konkret betroffenen Mitarbeiter zu wahren. Mit dieser Position, die sie auf dem Gewerkschaftstag von 1968 formuliert hatte, prägte die ÖTV erfolgreich die »Rationalisierungsschutzabkommen«, die sie in den Jahren 1970 und 1971 mit Bund, Ländern und Gemeinden aushandelte. Vergleichbare Verträge setzten zeitlich parallel auch fast alle anderen DGB-Gewerkschaften durch; im Vergleich enthielt die Abmachung für den Öffentlichen Dienst aber ungewöhnlich weit reichende Vorschriften, die betroffenen Arbeitnehmern ihre vorherigen Bezüge sicherten. ${ }^{437}$

Gleichzeitig entstand unter Federführung des DGB ein ausgefeiltes gewerkschaftliches Programm zur »Humanisierung der Arbeitswelt«, das die defensiv angelegten Rationalisierungsschutzabkommen der einzelnen Verbände in eine umfassende und langfristig angelegte soziale Reformstrategie einband: Sie wollte das Berufsleben aller abhängig Beschäftigten verbessern, ihre Selbstbestimmung fördern und Prozesse der beruflichen Dequalifikation durch eine zunehmende Arbeitsteilung und den vermehrten Einsatz von Maschinen verhindern. ${ }^{438}$

437 | Vgl.: ÖTV-Geschäftsbericht 1968/71, S. 74; ÖTV-Geschäftsbericht 1976/79, S. 127. Die entsprechenden Verträge veröffentlicht in: ÖTV: Wortlaut der überbezirklichen Tarifverträge des Jahres 1970, Stuttgart 1971, Bd. 1, S. 856-864 (für Gemeindearbeiter); ÖTV: Wortlaut der überbezirklichen Tarifverträge des Jahres 1971, Stuttgart 1972, S. 1244-1251 (für Arbeiter und Angestellte bei Bund, Ländern und Gemeinden gemeinsam). Zu den Abkommen der anderen DGBOrganisationen vgl. etwa: Fritz Böhle/Burkart Lutz: Rationalisierungsschutzabkommen. Wirksamkeit und Probleme. Untersuchungen zur Vermeidung sozialer Härten bei technischen und wirtschaftlichen Veränderungen, Göttingen 1974.

438 | Vgl. etwa: Heinz Oskar Vetter: Humanisierung der Arbeitswelt als gewerkschaftliche Aufgabe. In: GM 24 (1973), H. 1, S. 1-11; ders. (Hrsg.): Humanisierung der Arbeit als gesellschaftspolitische und gewerkschaftliche Aufgabe. Protokoll der Konferenz des Deutschen Gewerkschaftsbundes vom 16. bis 17. Mai 1974 in München, Frankfurt/Main und Köln 1974, insbes. S. 201-219. Fast zeitgleich förderte das Bundesforschungsministerium unter dem Sozialdemokraten (und früheren IG Metall-Funktionär) Hans Matthöfer etliche betriebliche Modellversuche zur »Humanisierung des Arbeitslebens« und deren sozialwissenschaftliche Begleitung. Vgl. als Überblick: Werner Abelshauser: Nach dem Wirtschaftswunder. Der Gewerkschafter, Politiker und Unternehmer Hans Matthöfer, Bonn 2009, S. 288-296. 
Anders als noch in den 1960er Jahren war die ÖTV daher sowohl programmatisch als auch mit Blick auf ihre innerbetrieblichen Handlungsmöglichkeiten gut aufgestellt, wenn es im nachfolgenden Jahrzehnt darum ging, gewerkschaftlich auf Rationalisierungsplanungen der Arbeitgeber zu reagieren. Ihre Erfolge blieben dennoch begrenzt. Zwar bescheinigte sich die Gewerkschaft selbst eine gute Arbeit: Im Öffentlichen Dienst habe es so gut wie keine Entlassungen wegen betrieblicher und technischer Neuerungen gegeben; zudem sei es ihr auch gelungen, die Einkommen der betroffenen Beschäftigten weitgehend ungekürzt zu erhalten. ${ }^{439}$

Allerdings garantierte ein gleichbleibender Lohn keineswegs zwingend die Zufriedenheit eines umgesetzten Mitarbeiters auf seinem neuen Arbeitsplatz. Schon am Beispiel der »Schreibdamen« in der Bremer Sozialbehörde, die lieber kündigten, als den ganzen Tag lang nur noch Tonbanddiktate abzutippen, zeigte sich eindringlich, wie vielfältig die Faktoren sein konnten, die darüber entschieden, ob ein Arbeitsplatz als attraktiv oder als untragbar belastend galt. ${ }^{440}$

Darüber hinaus verhinderte ein Rationalisierungsschutzabkommen immer nur die materielle Schlechterstellung bereits beschäftigter Kolleginnen und Kollegen. Neu hinzukommenden Kräften konnte es grundsätzlich nicht helfen. Ebenso frei war der Arbeitgeber, und zwar auch dann, wenn er entschied, Stellen nicht wieder neu zu besetzen, die durch die »natürliche Fluktuation« frei wurden: Gegen diesen schleichenden Abbau von Arbeitsplätzen konnte sich die Gewerkschaft nicht wehren. Ihr Anspruch auf »die soziale Beherrschung und Kontrolle unternehmerischer Rationali-

439 | ÖTV-Geschäftsbericht 1976/79, S. 127. 1968 hatte ein Delegierter auf dem Gewerkschaftstag hingegen noch berichtet, »Lohnminderungen" seien bei Rationalisierungsmaßnahmen »das Hauptproblem der Betriebs- und Personalräte« (Protokoll ÖTV-GT 1968, Bd. 1, S. 328 [Georg Büttner, Nürnberg]).

440 | Ein anderes Beispiel dafür wurde bereits auf dem ÖTV-Kongress von 1968 vorgestellt: Ein Delegierter aus Düsseldorf berichtete dort über das Schicksal der etwa 60 Kassierer, deren Arbeit überflüssig wurde, als der lokale Energieversorger sein Finanzwesen nur noch elektronisch und bargeldlos gestaltete. Zwar wurden sie bei gleichen Bezügen im Betrieb umgesetzt. Die ihnen zugewiesene Arbeit als Pförtner im Drei-Schicht-Dienst erwies sich jedoch als völlig ungeeignet: "Die Leute sind uns seelisch vor die Hunde gegangen« (ebd., S. 329 [Karl Zelosko, Düsseldorf]). 
sierungsmaßnahmen« ließ sich daher von vornherein allenfalls bruchstückhaft verwirklichen. ${ }^{441}$

Praktische Probleme kamen hinzu. Die zuständigen Betriebsräte wurden vielfach erst spät über geplante innerbetriebliche Veränderungen informiert; teilweise hielt der Arbeitgeber sie trotz des geltenden Schutzabkommens sogar ganz außen vor. Auch fiel es den gewählten Vertretern der Belegschaft oft schwer, den meist detaillierten und konkreten Projekten der Betriebs- oder Amtsleitungen eigene Vorstellungen entgegenzusetzen. Selbstkritisch konstatierte die ÖTV 1983 in einem Bericht über ihre Erfahrungen mit Rationalisierungen, bei den betroffenen Beschäftigten herrsche vielfach ein »Gefühl von Hilflosigkeit« und eine »Grundstimmung von Ohnmacht und Übergangenwerden«. Letztlich zeige sich, dass die Personalräte innerbetriebliche Umstrukturierungen »zwar verzögern, in aller Regel aber nicht verhindern« könnten. ${ }^{442}$

Wie Soziologen anhand von Interviews mit betroffenen Arbeitnehmern in Kommunalbehörden ermittelten, bedeuteten neue Techniken und neu organisierte Arbeitsabläufe fast durchweg ein schärferes Tempo und den Zwang, sich bei der Arbeit stärker zu konzentrieren. Immerhin 44 Prozent der Befragten sahen für sich selbst aber auch Vorteile, etwa weil physisch anstrengende Arbeiten oder reine Routinetätigkeiten entfielen. Rund 30 Prozent zogen hingegen ein negatives Fazit: Ihr Arbeitsalltag habe sich durch die Rationalisierung verschlechtert. ${ }^{443}$ Ganz ähnlich fiel das Ergebnis aus, wenn man die vor allem körperlich arbeitenden Beschäftigten der

441 | Ingrid Scheibe-Lange: Rationalisierung in der Praxis gewerkschaftlicher Gegenwehr. In: WSI-Mitteilungen 33 (1980), S. 480-489, hier: S. 480. Vgl. ähnlich auch schon: Klaus Düll/Dieter Sauer: Rationalisierung im öffentlichen Dienst. In: GM 26 (1975), H. 2, S. 37-46.

442 | Christine Dörner/Wolfgang Roos: Rationalisierung und elektronische Datenverarbeitung, Stuttgart 1983, S. 56. Zur Feststellung, die Personalräte würden oft auch ganz übergangen, vgl.: Franz Holländer: Vorwort. In: ebd., S. 5. Holländer war Mitglied im gHV der ÖTV. Ähnlich auch das Fazit in: Gerhard Armanski et al.: Rationalisierung in der öffentlichen Verwaltung. Ursachen, Auswirkungen, Widerstand, Frankfurt/Main und New York 1983, insbes. S. 280-304. 443 | Ebd., S. 295. Für diese Studie wurden rund 500 Beschäftigte in zehn verschiedenen Behörden in vier Städten befragt. In allen diesen Ämtern waren in den zwei Jahren vor der Befragung arbeitsorganisatorische und/oder technische Rationalisierungsmaßnahmen durchgeführt worden. 
Stadtreinigung ins Auge fasste: Einerseits erleichterten neue Fahrzeuge und Hebeeinrichtungen ihre Arbeit; andererseits mussten sie in gleicher Zeit nun größere Müllmengen bewegen. Von den Betriebsräten, die in dieser Sache befragt wurden, gab ein Drittel an, vor der Modernisierung sei die Tätigkeit bei der Müllabfuhr angenehmer gewesen. ${ }^{444}$

Bessere Arbeitsbedingungen durch Rationalisierungsmaßnahmen waren aber durchaus möglich. Dies gilt wohl gerade für die hier untersuchten Jahre, denn vielfach klagten die Betroffenen über eher banale Probleme, die nur entstanden, weil die Planer die innerbetrieblichen Neuerungen nicht alltagspraktisch durchdachten. Die Verwaltungsangestellten, die nun vor den "Datensichtgeräten" einer EDV-Anlage arbeiten mussten, saßen vielfach an völlig improvisierten Arbeitsplätzen, bei denen die technische Apparatur, der Schreibtisch, der Stuhl und die Beleuchtung nicht zusammenpassten. Die körperlichen Probleme, die daraus fast unweigerlich entstanden, waren ebenso unangenehm wie vermeidbar. ${ }^{445}$

Kurzfristig nicht beheben ließ sich hingegen der technologisch höchst unzulängliche Stand der zeitgenössischen Bildschirmtechnik. Aus der Sicht der Gegenwart, in der "Screens« nicht nur den Arbeitstag, sondern (in verschiedener Größe) selbst noch die Freizeit vieler Menschen beherrschen, wirkt es zwar befremdlich, wie häufig und intensiv seinerzeit über die Arbeit an solchen Geräten geklagt wurde. Die lichtschwachen und in "Bernsteinfarbe« ermüdend vor sich hin blinkenden Apparaturen der damaligen Zeit machten ihre Bedienung jedoch schon nach wenigen Stunden in der Tat äußerst anstrengend und belastend: »Augenbeschwerden, Kopfschmerzen und Nervosität« waren häufige Folgen. ${ }^{446}$

444 | Rolf Jansen/Reinhard Rudat: Stadtreinigung in der Bundesrepublik Deutschland. Die betrieblichen Rahmenbedingungen und die Arbeitssituation der Betroffenen, Dortmund 1978, S. 52 f. Befragt wurden die Betriebsräte von 180 Stadtreinigungsunternehmen. Vgl. ausführlich auch: Hauptvorstand der Gewerkschaft Öffentliche Dienste, Transport und Verkehr (Hrsg.): Rationalisierung und ihre Auswirkungen im Bereich der Stadtreinigung (Müllabfuhr). Beispiel Stadtreinigung Neumünster, Stuttgart 1983.

445 | Vgl. dazu: Gaugler: Rationalisierung, S. 394 f.; Armanski: Rationalisierung, S. 296 f.; Dörner/Roos: Rationalisierung, S. $27 \mathrm{f}$.

446 | Armanski: Rationalisierung, S. 298. Vgl. auch: Dörner/Roos: Rationalisierung, S. 34 . 
Mit dem ambitionierten Programm, das Arbeitsleben zu »humanisieren«, hatten die Rationalisierungsmaßnahmen, die es in den 1970er Jahren in vielen Behörden und öffentlichen Betrieben gab, also doch eher nur am Rande zu tun. Wenn überhaupt, dann ergaben sich Vorteile und Entlastungen im Arbeitsalltag für die Beschäftigten offensichtlich lediglich »nebenbei« und immer nur insoweit, als »sie nicht im Konflikt mit Rationalisierungsüberlegungen « und Kosteneinsparungen standen. ${ }^{447}$

Auch scheint die ÖTV den Prozess in den einzelnen Betrieben doch eher bremsend begleitet als aktiv mitgestaltet zu haben. Vielfach schöpften die Betriebsräte noch nicht einmal die ihnen zugestandenen Anhörungsund Mitspracherechte voll aus. Sie waren - so scheint es - immer schon dann zufrieden, wenn der Arbeitgeber weiterhin allen Betroffenen den zuvor gezahlten Lohn garantierte. Allerdings gab es wohl auch keinen Druck von der Basis, der die Personalvertreter gezwungen hätte, sich nun auch noch für die konkrete Arbeitssituation zu interessieren. Glaubt man den Ergebnissen der seinerzeit empirisch forschenden Soziologen, dann sahen sich die meisten Behördenmitarbeiter bei Umgestaltungen des Arbeitsplatzes und der Arbeitsabläufe von vornherein als machtlose Objekte ihrer Vorgesetzten. Diese Mutlosigkeit gegenüber denen »da oben« zeigten sie dann auch gegenüber der Gewerkschaft und dem Betriebsrat - um sich anschließend dann aber doch zu beklagen, ihre Interessen seien nicht wirkungsvoll vertreten worden. ${ }^{448}$

Unter solchen Voraussetzungen blieb der ÖTV nur eine sehr undankbare Rolle. Zum einen war ihr Einfluss auf die Details des Geschehens trotz

447 | Gaugler: Rationalisierung, S. 389. Vgl. ähnlich auch: Burglin: Angestellte, S. 185. Vgl. auch allgemein das sehr skeptische Fazit über den Erfolg des »Humanisierungsprogramms« in: Reimar Birkwald: Humanisierung der Arbeitswelt - Anspruch und Wirklichkeit. Eine Zwischenbilanz aus gewerkschaftlicher Sicht. In: Lutz von Rosenstiel/Max Weinkamm (Hrsg.): Humanisierung der Arbeitswelt vergessene Verpflichtung? Eine kritische Bestandsaufnahme anlässlich einer Fachtagung des Kolping-Bildungswerkes, Stuttgart 1980, S. 179-185. Der Autor war Leiter der Abteilung Tarifpolitik in der Hauptverwaltung der IG Metall.

448 | Armanski: Rationalisierung, S. 301-303. Rund die Hälfte der für diese Studie Befragten waren ÖTV-Mitglieder; in vier der zehn untersuchten Ämter lag der Organisationsgrad sogar bei 80 Prozent. Dennoch waren nur 15 Prozent der Befragten mit der Arbeit ihrer Betriebsräte im Zuge der Rationalisierung zufrieden; die Vertrauensleute erhielten sogar nur von zehn Prozent ein Lob (ebd., S. 302 f.). 
des Rationalisierungsschutzabkommens de facto eng begrenzt. Sie konnte soziale Nachteile für direkt betroffene Beschäftigte begrenzen; ansonsten aber entschieden die Arbeitgeber. Darüber hinaus wurde die Gewerkschaft bei betrieblichen Umstrukturierungen dafür mitverantwortlich gemacht, dass im Öffentlichen Dienst nach wie vor sehr hierarchisch geplant und entschieden wurde. Zwar fehlte es nicht an Ratschlägen von Experten, gerade bei Rationalisierungen sei eine »mitarbeiterorientierte Führung« durch die Amts- oder Betriebsleitung unerlässlich. ${ }^{449}$ Trotzdem sah die Praxis offensichtlich typischerweise ganz anders aus - und ihre Frustration darüber luden die Beschäftigten dann auch noch bei der Gewerkschaft ab.

\section{Eine neue Epoche beginnt: Die frühe deutsche Privatisierungsdebatte und ihre Konsequenzen}

Zusätzlich kompliziert wurde die Frage, wie sich die ÖTV bei innerbetrieblichen Rationalisierungsmaßnahmen verhalten solle, durch die zeitgleiche Debatte über Privatisierungen im Öffentlichen Dienst. Schon in einem ganz praktischen Sinne hing beides eng zusammen. Oftmals diskutierten Politiker und Arbeitgeber eine mögliche Privatisierung bestimmter Aufgaben und Tätigkeiten alternativ mit geplanten Veränderungen der Arbeitsabläufe in Behörden und staatlichen Betrieben, die Personal und Kosten einsparen sollten; teilweise drohten sie mit einer Privatisierung, wenn der Öffentliche Dienst die ins Auge gefassten Arbeiten nicht deutlich effizienter erledige.

Gleichzeitig aber war das Konzept der Privatisierung noch weit mehr als nur ein strategisch eingesetztes Instrument, das störrische Beschäftigte des Staates und ihre Gewerkschaft disziplinieren sollte. Mit diesen Forderungen, der Öffentliche Dienst solle bestimmte Aufgaben nicht mehr selbst erledigen, sondern an private Betriebe abgeben, kündigte sich in der Bundesrepublik vielmehr schon in den Jahren nach 1975 ein wirtschafts- und gesellschaftspolitischer Paradigmenwechsel an, der alle westlichen Gesellschaften seit 1979/80 bis in unsere Gegenwart hinein prägte: Es handelte sich dabei um Vorboten der »era of liberalization«, die den Nachkriegskonsens, ein sozialstaatlich eingehegter Kapitalismus garantiere Demokratie,

449 | Vgl. etwa: Zander: Personalprobleme, S. 118-125; Gaugler: Rationalisierung, S. 403 f. (Zitat). 
Wohlstand und die bürgerlichen Freiheiten am verlässlichsten, durch den Glauben an die segensreichen Wirkungen der freien Konkurrenz ersetzte. Folgerichtig hat sich der Staat in dieser Zeit, die mit den Wahlsiegen von Margaret Thatcher und Ronald Reagan in Großbritannien und in den USA unübersehbar begann, zunehmend selbst entmachtet und der Privatwirtschaft immer größere Freiheiten eingeräumt. ${ }^{450}$

Die ÖTV hat die grundlegende Bedeutung dieser Angelegenheit frühzeitig erkannt. Nach dem Prinzip »Wehret den Anfängen« arbeitete sie intensiv daran, argumentativ die Gedanken zu widerlegen, die hinter den Privatisierungsforderungen standen; selbst in scheinbar nur nachrangig wichtigen Segmenten des Öffentlichen Dienstes hat sie sich zudem intensiv gegen die ersten Experimente mit privat erledigten Arbeiten gewehrt. Mangelnde Wachsamkeit kann man der Organisation daher keinesfalls vorwerfen. Dennoch fiel ihre Erfolgsbilanz wohl noch ungünstiger aus als bei Rationalisierungsmaßnahmen.

Dieser Misserfolg ergab sich zum einen schlicht deshalb, weil die Arbeitgeber frei über Privatisierungen entscheiden konnten: Das Rationalisierungsschutzabkommen für den Öffentlichen Dienst erwähnte solche Maßnahmen nicht. Dementsprechend besaßen die Betriebsräte kein kodifiziertes Mitspracherecht. ${ }^{451}$ Zum anderen aber entwickelte die Privatisierungsdebatte rasch einen stark politisch-ideologischen Charakter. Dabei befand sich die ÖTV - wie alle Kritiker des neuen Glaubens an den freien Markt - zunehmend in der Defensive, denn der Zeitgeist präferierte deutlich eine Abkehr von den Grundprinzipien der sozialstaatlich geprägten Nachkriegszeit. Die Frage, warum sich dieser Wandel international so rasch und so grundlegend vollzog, wird von der Geschichtswissenschaft bereits seit einiger Zeit intensiv diskutiert. Viele dieser Studien argumentieren stark politik- und ideengeschichtlich. Der Siegeszug der Privatisierungsideologie bleibt so letztlich rätselhaft, weil er ausschließ-

450 | Alasdair Roberts: The Logic of Discipline. Global Capitalism and the Architecture of Government, Oxford 2010, S. 3. Als Überblick in internationaler Perspektive vgl. auch: Monica Prasad: The Politics of Free Markets. The Rise of Neoliberal Economic Policies in Britain, France, Germany and the United States, Chicago und London 2006; Christian Caryl: Strange Rebels. 1979 and the Birth of the 21st Century, New York 2013.

451 | ÖTV-Geschäftsbericht 1976/79, S. 127 f. 
lich aus sich selbst heraus erklärt wird: Die Existenz der Lehre führt zu ihrem Erfolg. ${ }^{452}$

Am Beispiel der Bundesrepublik in den Jahren nach 1975 lässt sich hingegen deutlich zeigen, wie sehr konkrete und gelöste wirtschaftliche Probleme halfen, die Überzeugungskraft des neuen gesellschaftspolitischen Paradigmas zu stärken. Besonders die unbewältigten Krisen im System der staatlichen Dienstleistungen spielten in diesem Zusammenhang eine wichtige Rolle.

Bekanntlich stammt das Konzept, das die "era of liberalization « international prägte, aus der akademischen Welt der USA. Allgemein hat sich dafür der Begriff »Neoliberalismus" durchgesetzt. Auch in der Bundesrepublik bürgerte sich diese Bezeichnung ein, obwohl sie im nationalen Kontext eigentlich schon vergeben war: Unter den deutschen Ökonomen hatten sich ausgerechnet die Gründungsväter der Sozialen Marktwirtschaft als neoliberal bezeichnet. ${ }^{453}$ Die amerikanische Gedankenschule gleichen Namens vertrat in vieler Hinsicht radikal andere Positionen. Sie hielt Staatsinterventionen in den wirtschaftlichen Wettbewerb grundsätzlich für fragwürdig: Letztlich erfülle der freie Markt alle gesellschaftlichen Bedürfnisse stets am effektivsten. Seit 1971 lagen die beiden wichtigsten populär gehaltenen Werke der »Chicago School«, die den Neoliberalismus dieser Observanz propagierten, auch auf Deutsch vor. ${ }^{454}$

452 | Vgl. beispielhaft neben der eben schon angeführten Arbeit von Roberts etwa: Roger E. Backhouse: The Rise of Free Market Economics: Economists and the Role of the State since 1970. In: Steven G. Medema/Peter Boettke (Hrsg.): The Role of Government in the History of Economic Thought, Durham und London 2005, S. 355-392; Jeff Madrick: The Age of Greed. The Triumph of Finance and the Decline of America, 1970s to the Present, New York 2011; Thomas Borstelmann: The 1970s. A New Global History from Civil Rights to Economic Inequality, Princeton und Oxford 2012.

453 | Vgl. als treffende Zusammenfassung: Gustav Seibt: Was bedeutet eigentlich das Wort neoliberal? Eine Erinnerung. In: SZ, 30.4.2015.

454 | Gemeint sind: Friedrich A. von Hayek: Die Verfassung der Freiheit, Tübingen 1971 (als »The Constitution of Liberty« bereits 1960 erschienen); Milton Friedman: Kapitalismus und Freiheit, Stuttgart 1971 (als "Capitalism and Freedom" bereits 1962 publiziert). Die Bezeichnung »Chicago School« entstand, weil Hayek und Friedman beide an der University of Chicago unterrichteten. 
Eine praktische Nutzanwendung ihrer zunächst sehr allgemein formulierten Lehren auf das Ensemble der öffentlichen Dienstleistungen entwickelten die neuen Neoliberalen erst im Laufe der 1970er Jahre. Staatlich garantierte Versorgungsmonopole etwa für Strom, Gas und Wasser oder auch beim großstädtischen Nahverkehr dienten in ihrer Sicht vor allem den Politikern, die das Monopol regulierten, und den Wählern, deren Interessen die Politiker im Auge hatten, sowie unter Umständen den Unternehmen, die sich nicht um den Wettbewerb kümmern mussten, und vermittelt deren Beschäftigten. Die Politiker nützten die aus ihrem Amt abgeleitete Entscheidungsfreiheit, um die Leistungen und Preise des Monopolunternehmens nach dem Gusto ihrer Stammwähler zu gestalten; die Betriebe selbst aber würden zu ökonomischen »Nischen«, in denen kein Effizienzund Gewinndruck herrsche. Den Preis dafür zahlte nach dieser Analyse die Allgemeinheit - sowohl im wörtlichen Sinne durch überhöhte Gebühren oder unnötige Steuerforderungen als auch indirekt etwa durch mangelnden Service und schlechte Leistungen, weil die Betriebe kaum gezwungen seien, um ihre Kunden zu werben. ${ }^{455}$

Damit dementierten die amerikanischen Neoliberalen so ziemlich alle zentralen Annahmen, auf denen das gerade in Deutschland so wirkungsmächtige und populäre Konzept der staatlichen "Daseinsvorsorge" beruhte. Empirisch stand dieser Frontalangriff allerdings auf recht wackeligen Beinen. Die »Chicago School « gehörte zu dem stark theoretisch und mathematisch orientierten Zweig der Wirtschaftswissenschaft, d.h., sie arbeitete vor allem mit Modellannahmen und hoch abstrakten Gleichungen, die mathematisch auf der Basis einiger weniger konkreter Beispiele durchgerechnet wurden. Studien, die öffentliche und private Versorgungsunternehmen wirklich umfassend miteinander verglichen und auch die

455 | Als hilfreiche Zusammenfassung vgl.: Michel Ghertman: The Puzzle of Regulation, Deregulation und Reregulation. In: Claude Ménard/Michel Ghertman (eds.): Regulation, Deregulation, Reregulation. Institutional Perspectives, Cheltenham 2009, S. 351-373. Formuliert wurde die skizzierte Sicht erstmals 1971 von George Stigler sowie von Sam Peltzman. Vgl.: George Stigler: Economic Theory of Regulation, wieder abgedruckt in: ders.: The Citizen and the State. Essays on Regulation, Chicago und London 1975, S. 114-141; Sam Peltzman: Pricing in Public and Private Enterprises. Electric Utilities in the United States. In: Journal of Law and Economics 14 (1971), S. 109-147. 
dabei zu überwindenden methodischen Probleme bedachten, fehlten hingegen. ${ }^{456}$

Ihr politisch-ideologischer Charakter hat der neuen Lehre nicht geschadet. Spätestens nachdem Friedrich von Hayek und Milton Friedman als deren wichtigste Propheten in den Jahren 1974 und 1976 jeweils den wirtschaftswissenschaftlichen Nobelpreis erhalten hatten, dominierte die Kritik an regulierenden Eingriffen des Staates international den öffentlichen Diskurs. ${ }^{457}$ Auch Politiker begannen, die neoliberalen Ideen aufzugreifen. In den USA etwa beseitigte die Administration von Präsident Jimmy Carter (einem Demokraten) bereits 1975/76 traditionsreiche Wettbewerbsbeschränkungen im Lkw-Fernverkehr, die zuvor immer mit den Interessen der Allgemeinheit begründet worden waren. Es folgten rasch weitere Beschlüsse dieser Art, etwa für den Flugverkehr, bei der Post und auch im Bankwesen. ${ }^{458}$

Zeitgleich meldeten sich Freunde eines möglichst freien Wettbewerbs auch in der Bundesrepublik immer lautstärker zu Wort. Eine wichtige Rolle spielte dabei die CDU, die im Bundestag auf den Oppositionsbänken saß, gleichzeitig aber doch einige Bundesländer und viele Kommunen regierte. 1975 beschloss sie auf ihrem Parteitag, die Staatstätigkeit dürfe in Deutschland auf keinen Fall noch weiter ausgebaut werden; eher sei ein Abbau anzustreben. Vor allem die Kommunalpolitiker der Union hatten diesen Beschluss initiiert. ${ }^{459}$ Zumindest einigen Christdemokraten ging er jedoch nicht weit genug. Die Junge Union verlangte bereits ein Jahr später ausdrücklich die Privatisierung des gesamten Öffentlichen Nahverkehrs, um eine umfassende »Entstaatlichung« der bundesdeutschen Gesellschaft

456 | Ghertman: Puzzle, S. 357. Zu den methodischen Problemen, die Aufgaben und Leistungen öffentlicher und privater Dienstleistungs- und Versorgungsunternehmen miteinander zu vergleichen, vgl. etwa: Charles Beat Blanckart: Privatisierung öffentlicher Dienstleistungen. Beurteilungs- und Entscheidungsprobleme. In: ders./Monika Faber (Hrsg.): Regulierung öffentlicher Unternehmen, Königstein/Taunus 1982, S. 171-182.

457 | Borstelmann: 1970s, S. 128-130.

458 | Ebd., S. 148-160.

459 | Vgl. genauer zu den parteipolitischen Debatten über diese Frage: Helmuth Fluhrer: Weniger Staat - Mehr Privat. Die Befürworter im kommunalen Bereich, München 1984, S. 115-135. 
einzuleiten. ${ }^{460}$ Die Hamburger Bürgerschaftsabgeordnete Birgit Breuel profilierte sich ebenfalls öffentlich erfolgreich als eine scharfe Kritikerin des angeblich ebenso "übermächtigen" wie leistungsschwachen Öffentlichen Dienstes. Der Staat als »Mammutanbieter von Gütern und Leistungen«, so forderte sie, dürfe keine Zukunft mehr haben, denn er erdrücke »individuelle Gestaltungsfreiheit, mindert Effizienz und lähmt Eigeninitiative«. ${ }^{461}$

Diese anfangs auch in der CDU noch stark umstrittene Position setzte sich nach 1975 in der Partei trotz des hinhaltenden Widerstandes des Arbeitnehmerflügels erstaunlich schnell durch. Bereits 1979 hieß es in dem neuen Grundsatzprogramm, das sich die Christdemokraten auf ihrem Parteitag in Ludwigshafen gaben, die Versorgung der Bürger mit Gütern und Dienstleistungen solle »soweit wie möglich dem Wettbewerb privater Anbieter überlassen bleiben«. Der Bürger gewinne bei solcher Konkurrenz größere "Freiräume«, bessere Leistungen und auch finanzielle Vorteile, denn "Monopolbildungen" durch politische Beschlüsse gingen immer auf seine Kosten. ${ }^{462} \mathrm{Im}$ gleichen Jahr beschloss die CDU-Landesregierung von Niedersachsen ein Programm zur umfassenden »Entstaatlichung« der Dienstleistungen, die von der Öffentlichen Hand erbracht wurden. Auch vor Museen, Schulen und Universitäten wollte die Regierung dabei nicht haltmachen. Zuständig für die "Erzeugung eines Privatisierungsdrucks« im weitverzweigten System der Landesministerien, Behörden und Ämter war Birgit Breuel, die nach dem eindeutigen Wahlsieg der niedersächsischen CDU im Jahr zuvor das Amt der Wirtschaftsministerin in Hannover übernommen hatte. ${ }^{463}$

Allerdings handelte es sich bei der Idee, der Staatsapparat solle durch Privatisierungen schrumpfen, in der zweiten Hälfte der 1970er Jahre kei-

460 | Junge Union fordert Grundsatz-Debatte. In: FAZ, 11.10.1976; Vorschläge zur Gesellschaftspolitik. In: ebd. Vgl. auch: Kommunalpolitisches Programm der Union vorgelegt. In: FAZ, 25.8.1976; Wilhelm Oelert: Reprivatisierung des öffentlichen Personennahverkehrs, wo und wie? In: Der Personenverkehr 27 (1976), S. 108-114.

461 | Birgit Breuel: Es gibt kein Butterbrot umsonst. Gedanken zur Krise, den Problemen und Chancen unserer Wirtschaft, Düsseldorf und Wien 1976, S. $138 \mathrm{f}$. 462 | Mehr Wettbewerb bei öffentlichen Dienstleistungen, Bonn 1979, S. 1 u. 3.

463 | Hannover will große Entstaatlichung. In: FR, 26.10.1979. Ein ausführliches Programm der Ministerin in: Birgit Breuel: Den Amtsschimmel absatteln. Weniger Bürokratie - mehr Bürgernähe, Düsseldorf und Wien 1979. 
neswegs um ein reines CDU-Projekt. Bereits im Dezember 1975 konstatierte Heinz Kluncker vor dem ÖTV-Hauptausschuss, neben Christdemokraten und FDP-Politikern würden durchaus auch Sozialdemokraten in diese Richtung denken. Politisch gebe es deshalb »kein Patentrezept«, wie sich die Gewerkschaft wehren könne. ${ }^{464}$ Tatsächlich war kurz zuvor ein Positionspapier der SPD bekannt geworden, über das der Parteivorstand noch beriet. Darin fanden sich zahlreiche Vorschläge, wie man die staatlichen Personalkosten abbauen könne; auch Privatisierungen wurden dabei nicht ausgeschlossen. Zwar ruderte die Parteiführung rasch zurück, als ÖTV und DGB scharf protestierten: Es habe sich nur um einen unverbindlichen Entwurf gehandelt. ${ }^{465}$ Bereits 1976 fiel dann zumindest auf lokaler Ebene dennoch ein ganz anderer Beschluss: In West-Berlin erklärte die regierende SPD, sie werde auch Privatisierungen defizitärer kommunaler Dienstleistungen und Betriebe prüfen, um den notleidenden Etat der Stadt zu entlasten. ${ }^{466}$

Anders als die CDU zog die Sozialdemokratie allerdings eine enge Grenze für Maßnahmen dieser Art: Die zentral wichtigen öffentlichen Versorgungsleistungen wollte sie grundsätzlich nicht für den freien Wettbewerb öffnen. Zurückziehen sollte sich der Staat als Anbieter und Arbeitgeber allenfalls in Randbereichen des Öffentlichen Dienstes. ${ }^{467}$ Die starke Stellung der SPD in den bundesdeutschen Großstädten und damit auch im Deutschen Städtetag sowie in der VKA sorgte dafür, dass sich beide Organisationen diese Haltung zu eigen machten. Seit 1976 empfahl der Städtetag ganz offiziell, »Hilfstätigkeiten« im Öffentlichen Dienst wie etwa die Pflege von Grünflächen oder die Reinigung von öffentlichen Gebäuden

464 | Anlage zum Protokoll der 15. Sitzung des HV, 9./10.12.1975. In: AdsD, ÖTV, 5/ÖTVB130036.

465 | Vgl. hierzu etwa: Streit um soziale Demontage. In: Die Zeit, 1.8.1975; Stellungnahme von Heinrich Jacobi zur SPD-Studie, 24.7.1975. In: Archiv Ver.di, Bestand Kluncker, 35 .

466 | Sparprogramm des Berliner Senats. In: FAZ, 4.11.1976.

467 | Vgl. beispielhaft: Leistungen für Bedürftige bleiben kommunal. In: FAZ, 29.11.1976; Arndt erläutert sozialdemokratischen Freiheitsbegriff. In: FAZ, 11.12.1976; Reitz: Privatisierung kein Allheilmittel. In: FAZ, 2.11.1976; Große Brocken, kleine Brocken und das Rosinenprinzip. In: FAZ, 21.10.1976 (hier ist für München von »Annextätigkeiten« im Öffentlichen Dienst die Rede, die privatisiert werden könnten). 
könnten problemlos privatisiert werden. Ferner sei genau zu prüfen, ob die Kommune wirklich eigene Betriebe wie Druckereien, Wäschereien in Krankenhäusern, Pfandleihen oder Beerdigungsinstitute und Gärtnereien brauche. ${ }^{468}$

Die FDP als Regierungspartner der Sozialdemokraten in der Bonner Koalitionsregierung diskutierte die gleiche Frage hingegen zunehmend ähnlich grundsätzlich wie die CDU. Als Partei, die vor allem den gewerblichen Mittelstand und die Freiberufler vertreten wollte, sympathisierte sie prinzipiell mit jeder Forderung, die staatliche Kompetenzen eingrenzte. Zudem trauten sich die Liberalen nach 1975 zunehmend, diese weltanschauliche Prägung notfalls auch im offenen Konflikt mit der SPD zu dokumentieren. ${ }^{469}$ Sie benutzten das Thema der Privatisierung nun gezielt, um sich programmatisch von den Sozialdemokraten abzusetzen. So kokettierten Birgit Breuel und der FDP-Generalsekretär Günter Verheugen im Januar 1980 auf einer öffentlichen Diskussionsveranstaltung in Bonn ausführlich mit ihrer gemeinsamen, koalitionspolitisch aber eigentlich doch inopportunen Abneigung gegen staatliche Dienstleistungen. Zuvor hatte die CDU-Politikerin einmal mehr ihr Programm einer umfassenden »Entstaatlichung « vorgestellt und dabei auch konkret verlangt, allen defizitären öffentlichen Betrieben künftig jede Subvention zu verweigern, um sie zugunsten privater Anbieter »vom Markt verschwinden zu lassen«. Verheugen stimmte demonstrativ zu. ${ }^{470}$

Feine Unterschiede im Verständnis dessen, was eine Privatisierung staatlicher Tätigkeiten konkret bedeute, über die sich die Politiker stritten, waren für die ÖTV ganz unwichtig: Sie lehnte die Idee grundsätzlich ab und vertrat diese Position auch mit Vehemenz öffentlich. Bereits auf dem Gewerkschaftstag von 1976 dominierte das Thema die Debatten. Nicht weniger als elf Anträge verschiedener Gremien und Bezirke verurteilten jeden Abbau

468 | Deutscher Städtetag: Privatisierung öffentlicher Aufgaben, Köln 1976, S. 42-44. 1986 erneuerte der Städtetag diesen Beschluss. Vgl.: Deutscher Städtetag: Möglichkeiten und Grenzen der Privatisierung öffentlicher Aufgaben, Köln 1986, S. 58-62.

469 | Vgl. etwa: Prasad: The Politics, S. 167.

470 | Gerhart Rudolf Baum et al.: Privatisierung - Gewinn für wen?, Bonn 1980, S. 161 (das Zitat von B. Breuel) sowie S. 171-173 u. 176f. (Breuel und Verheugen zu ihrer Übereinstimmung). 
des Öffentlichen Dienstes zugunsten privater Firmen. Solch ein Rückzug des Staates, so hieß es in dem schließlich exemplarisch »mit übergroßer Mehrheit« angenommenen Antrag, belaste »die schwächeren Glieder der Gesellschaft in unsozialer Weise«, weil gewinnorientierte Privatunternehmer ihre Kunden langfristig stärker zur Kasse bitten würden als öffentliche Unternehmen, die dem Allgemeinwohl verpflichtet seien. Gerade bei einer Privatisierung bislang öffentlicher Monopole drohe eine solche Entwicklung. Geschädigt seien zudem die Beschäftigten: Für sie bedeute eine Privatisierung unweigerlich »Lohndruck und schlechtere Arbeitsbedingungen ${ }^{4}{ }^{471}$

Einer der übrigen Anträge, die alle als »Material« an den Hauptvorstand überwiesen wurden, umriss die Position der ÖTV noch sehr viel eindeutiger als eine Antwort auf die neuen neoliberalen Lehren: »Privates Gewinnstreben kann dem Wohl der Allgemeinheit nicht gerecht werden. ${ }^{472}$ Ähnlich prinzipiell argumentierte 1978 die ÖTV in Niedersachsen, als sie sich gegen das Programm der neuen Wirtschaftsministerin des Landes wehrte: Birgit Breuel und all den anderen Freunden der Privatisierung gehe es mit ihrer »Entstaatlichungsideologie« um eine »Übersteigerung des Wettbewerbs zum gesellschaftlichen Prinzip«, bei der die Interessen der sozial Schwachen auf der Strecke bleiben müssten. ${ }^{473}$ Heinz Kluncker formulierte genauso scharf: Privatisierung nach den »Ideologien von Milton Friedman« führe zu einem »Ausverkauf des Sozialstaates«, der mit der »Sozialverpflichtung des Grundgesetzes« nicht vereinbar sei. ${ }^{474}$ Friedmans Lob der freien Konkurrenz, die angeblich ganz von selbst dem Wohl der Allgemeinheit

471 | Protokoll ÖTV-GT 1976, Bd. 2, S. 99. Das Votum des Kongresses in: ebd., Bd. 1, S. 328. Die gesamten Anträge gegen Privatisierungen (Nr. 112 bis 122) in: ebd., Bd. 2, S. 92-109.

472 | Ebd., Bd. 2, S. 104 (der Antrag der Bezirkskonferenz NRW I).

473 | Hans Joachim Mertsch: Die Stellung der Gewerkschaften zur Privatisierung öffentlicher Aufgaben. In: Wolfgang Bönig (Hrsg.): Der öffentliche Sektor und sein Einfluss auf die Volkswirtschaft. Zur Effizienz fiskalpolitischer Maßnahmen. Tagung vom 26. bis 28. Mai 1978, Loccum 1978, S. 97-113, hier: S. 98. Mertsch war stellvertretender Bezirksvorsitzender der ÖTV Niedersachsen.

474 | In der Reihenfolge der Zitate: ÖTV wirft Albrecht Ausverkauf des Sozialstaats vor. In: Die Welt, 12.1.1980; Kluncker will keinen Kummer machen. In: Quick (1981), H. 12, S. 15. Vgl. ähnlich auch die von der ÖTV herausgegebene Broschüre: Peter Kalmbach: »Mehr Markt - weniger Staat« - eine neokonservative 
diente, gehe vollständig in die Irre. Ein schwacher Staat, so Kluncker, sei nur im Interesse der Wohlhabenden. Alle anderen Bürger aber könnten auf die staatliche »Daseinsvorsorge " nicht verzichten: »Lebensqualität, Wirtschaftswachstum und öffentliche Dienstleistungen hängen untrennbar miteinander zusammen. « $^{475}$

Dieser grundsätzliche Charakter der bereits 1975 intensiv einsetzenden bundesdeutschen Privatisierungsdebatte verdient es, festgehalten zu werden. Die meisten der eben zitierten Äußerungen fielen, als Margaret Thatcher in Deutschland noch ganz unbekannt war. Großbritannien gilt gemeinhin als das europäische Land, in dem der amerikanische Neoliberalismus zuerst Fuß fasste. Tatsächlich aber spielte die Idee, öffentliche Dienstleistungen zu privatisieren, in der britischen Öffentlichkeit und in den politischen Debatten des Landes vor 1979/80 nur eine ganz geringe Rolle, weil selbst die Konservative Partei kaum davon sprach. ${ }^{476}$ Wie gezeigt wurde, verhielt sich das in der Bundesrepublik ganz anders. Insofern begann die vielleicht wichtigste politisch-ideologische Kontroverse der neueren Zeitgeschichte, die das Verhältnis von Staat und »den Märkten« mit langwierigen Folgen neu definierte, außerhalb der USA wohl nicht in England, sondern eher in Deutschland. ${ }^{477}$

Offensive. Darstellung und Kritik gegenwärtiger Revisionsversuche der Rollenverteilung zwischen Staat und Markt, Stuttgart 1981, insbes. S. 26.

475 | Heinz Kluncker: Die Rolle öffentlicher Unternehmen und ihrer Beschäftigten als Teil des öffentlichen Dienstes. In: Friedhelm Farthmann et al.: Arbeitnehmer in öffentlichen und gemeinwirtschaftlichen Unternehmen. 6. Wissenschaftliche Tagung über Gemeinwirtschaft in Bergneustadt vom 28. bis 30. März 1979, Baden-Baden 1980, S. 97-107, hier: S. 98.

476 | Prasad: The Politics, S. 102 u. 123. Anders verhielt es sich mit der »denationalization«, d. h. mit der Reprivatisierung verstaatlichter Industrien und Branchen wie etwa der Stahlindustrie und dem Bergbau, die eine Labour-Regierung nach dem Zweiten Weltkrieg in Staatseigentum überführt hatte.

477 | Als Berichte über diesen Debatten vgl. auch: Peter Becker: Es geht nicht allein um Privatisierung. In: FAZ, 17.12.1975; Privatunternehmer für öffentliche Aufgaben? In: FAZ, 27.3.1976; Die Automatik öffentlicher Verschwendung. In: FAZ, 20.5.1976; Große Brocken, kleine Brocken und das Rosinenprinzip. In: FAZ, 21.10.1976; Erwin Schleberger: Die Zauberformel Privatisierung. In: Der Städtetag 29 (1976), S. 121; Ludwig Mülhaupt/Jürgen Gornass: Zum Problem der Privatisierung im öffentlichen Bereich. In: Der Städtetag 30 (1977), S. 360-365; Detlef 
Die ÖTV hat die zentrale weltanschauliche Bedeutung der Privatisierungsforderungen früh erkannt und dementsprechend mit sehr grundsätzlichen politischen Einwänden darauf reagiert. Den Trend der öffentlichen Debatte konnte sie dennoch nicht umdrehen: Auch in der Bundesrepublik gewann die staatsfeindliche Haltung der amerikanischen Neoliberalen immer mehr einflussreiche und eloquente Anhänger. Vor allem die Presse adaptierte deren Lehren zunehmend mit unkritischer Begeisterung. ${ }^{478}$

Die Gründe für diese Entwicklung sind komplex und kaum auf einen Nenner zu bringen. Mit Sicherheit handelte es sich auch um eine intellektuelle Modeerscheinung. Der neomarxistisch geprägte Geist der Jahre nach »68«alterte mit seinen Verfechtern und damit schwang das Pendel des Zeitgeistes - wie so oft bei solchen Veränderungen - in die entgegengesetzte

Bischoff/Karl-Otto Nikusch (Hrsg.): Privatisierung öffentlicher Aufgaben. Ausweg aus der Finanzkrise des Staates?, Berlin und New York 1977 (mit zahlreichen Dokumenten); Wolfgang Däubler: Privatisierung - Speerspitze der Gegenreform? In: Hans Pornschlegel/Herbert Scholz (Hrsg.): Arbeitswissenschaft in der Gesellschaftspolitik, Berlin 1978, S. 173-184; Heinrich Siedentopf: Privatisierung öffentlicher Aufgaben - Begriff und Formen. In: VOP 2 (1980), S. 62-72.

478 | Ein aussagekräftiges Indiz dafür ist etwa die ordnungspolitische Kehrtwende, die Der Spiegel 1980 vollzog. In diesem Jahr publizierte das Hamburger Magazin, dem man wohl eine meinungsbildende Kraft zuschreiben darf, eine Serie seiner Wirtschaftsredakteurin Renate Merklein (sie gehörte zu den wenigen Spiegel-Autoren, die ihre Artikel namentlich kennzeichnen durften), in der die bundesdeutsche Ordnung durchgehend mit neoliberalen Argumenten scharf kritisiert wurde. 1982 folgte eine zweite Serie, die noch grundsätzlicher für mehr Selbstverantwortung der angeblich staatlich entmündigten Bürger argumentierte. Beide Serien erschienen auch als Taschenbuch. Vgl.: Renate Merklein: Griff in die eigene Tasche. Hintergeht der Bonner Sozialstaat die Bürger?, Reinbek 1980 (auf S. 109 f. mit einem positiven Bezug auf Hayeks »Verfassung der Freiheit«); dies.: Die Deutschen werden ärmer. Staatsverschuldung, Geldentwertung, Machteinbußen, Arbeitsplatzverluste, Reinbek 1982. Die wirtschaftswissenschaftliche Dissertation Merkleins, mit der sie 1967 an der Universität Hamburg promoviert wurde, steht hingegen noch ganz in der Tradition sozialstaatlichen Denkens. Vgl.: dies.: Soziale Sicherheit im Wirtschaftswachstum. Beziehungen zwischen Maßnahmen zur sozialen Sicherheit und dem wirtschaftlichen Wachstumsprozeß, Wirtschafts- und sozialwissenschaftliche Diss., Universität Hamburg 1969, insbes. S. 32-49 u. 121 f. 
Richtung. ${ }^{479}$ Desillusionierung kam hinzu: Der ökonomischen und gesellschaftlichen »Globalsteuerung « durch den planenden Staat gelang es nicht, die krisenhaften Entwicklungen in vielen wirtschaftlichen Bereichen nach dem »Ölpreisschock« aufzuhalten; auch das soziale Problem der Arbeitslosigkeit trotzte diversen kostspieligen Konjunkturprogrammen der Bundesregierung. ${ }^{480}$ Darüber hinaus profitierten die neoliberalen Staatskritiker in den 1970er Jahren entscheidend von gravierenden Problemen im System der staatlichen »Daseinsvorsorge«.

"Die öffentliche Wirtschaft steht mit dem Rücken an der Wand und der Wind bläst ihr ins Gesicht - mit dieser Feststellung eröffnete die Fachzeitschrift »Öffentliche Wirtschaft und Gemeinwirtschaft« ihren Jahrgang 1977. ${ }^{481}$ Ökonomisch stand es fraglos schlecht um das System der öffentlichen Dienstleistungen. Hohe laufende Defizite gab es keineswegs nur in kulturellen Einrichtungen wie Theatern und Museen, in denen solche Verluste seinerzeit noch als selbstverständlich galten, weil subventionierte Eintrittspreise das kulturelle Engagement der Kommunen bewiesen. Wie der Deutsche Städtetag wenige Monate zuvor durch eine umfassende Umfrage bei fast 300 Kommunalverwaltungen ermittelt hatte, verzeichneten von den vielen städtischen Dienstleistungsbetrieben einzig die städtischen Elektrizitätswerke nennenswerte Gewinne. Zumindest im Durchschnitt wenigstens noch knapp kostendeckend wirtschafteten Betriebe, die Abfall und Abwässer entsorgten. Bei allen anderen kommunalen Unternehmen und Dienstleistungen aber blieb die Vorschrift der Gemeindeordnung, Gebühren und Preise seien mindestens so zu bemessen, dass keine Defizite entstanden, unbeachtet. Teilweise hatten die Zahlungen der Kunden eher symbolische Bedeutung: Die öffentlichen Schwimmbäder etwa deckten lediglich ein Fünftel ihrer jährlich entstehenden Kosten durch Einnahmen an den Kassen; bei den Volkshochschulen reichten die Kursgebühren kaum für 15 Prozent der Aufwendungen. Nur ein Prozent bezahlten die Eltern,

479 | Kalmbach: Markt, S. 31.

480 | Vgl. etwa: Winfried Süß: Der keynesianische Traum und sein langes Ende. Sozioökonomischer Wandel und Sozialpolitik in den siebziger Jahren. In: Konrad H. Jarausch (Hrsg.): Das Ende der Zuversicht? Die siebziger Jahre als Geschichte, Göttingen 2008, S. 120-137, hier: S. 123 f. u. 126-128.

481 | Gottfried Schneider: Schritte nach vorn. In: Öffentliche Wirtschaft und Gemeinwirtschaft 26 (1977), S. 1. 
deren Kinder spezielle städtische Schulbusse benutzten, durch die von ihnen geforderte Gebühr. ${ }^{482}$

Finanziell besonders schwer wogen die hohen Defizite, die jedes Jahr neu bei den städtischen Verkehrsbetrieben und den Krankenhäusern anfielen. Diese Verluste waren zwar nicht neu. Es gab sie schon seit den 1960er Jahren (bei Bus und Straßenbahn teilweise sogar noch länger); allerdings intensivierte sich die negative Entwicklung zusehends. So gelang es auch mit einer 1972 in Kraft getretenen Neuordnung der Krankenhausfinanzierung nicht, die Einnahmen und Ausgaben der Kliniken auszugleichen. Zwar gab es auf regionaler und lokaler Ebene nun politisch beschlossene Pläne, die eine stete Expansion des stationären Gesundheitswesens verhindern sollten. Wirksame Kontrollen und Anreize für die Klinikleitungen, den Plan auch einzuhalten, fehlten jedoch. Für die Patienten entstanden so zahlreiche Vorteile. So mussten sie etwa selbst auf dem Land in der Regel nicht weit fahren, um ein Krankenhaus aufzusuchen; in den Großstädten gab es sogar ein Überangebot an Betten. Gleichzeitig aber war das System insofern »betriebswirtschaftlich unsinnig«, als es zwingend zu steigenden Defiziten führte. ${ }^{483}$ Gegen Ende des Jahrzehnts gaben die öffentlich finanzierten Krankenhäuser jährlich rund 16,6 Milliarden DM aus; gleichzeitig aber betrugen ihre Einnahmen (inklusive der gesetzlich fixierten laufenden Zuschüsse im System der »dualen Finanzierung« durch Krankenkassen und Staat) nur 12,5 Milliarden DM. Lediglich weitere Subventionen aus öffentlichen Kassen, Buchhaltungstricks der Kliniken und versteckte

482 | Erwin Schleberger: In Sachen Privatisierung. In: Der Städtetag 29 (1976), S. 690-692.

483 | Theo Thiemeyer: Öffentliche und gemeinwirtschaftliche Unternehmen als Erkenntnisobjekt der Betriebswirtschaftslehre und als volkswirtschaftliches Instrument. In: Peter Eichhorn (Hrsg.): Betriebswirtschaftliche Erkenntnisse für Regierung, Verwaltung und öffentliche Unternehmen. 25 Jahre Öffentliche Betriebswirtschaftslehre an der Universität Mannheim, Baden-Baden 1985, S. 125143, hier: S. 140. Vgl. ausführlicher auch: Peter Rosenberg: Möglichkeiten der Reform des Gesundheitswesens in der Bundesrepublik Deutschland, Göttingen 1975, insbes. S. 220-225; Heinz Naegler: Auswirkungen des gültigen Krankenhausfinanzierungs- und Preisrechts auf die Krankenhausbetriebsführung. In: Zeitschrift für öffentliche und gemeinwirtschaftliche Unternehmen 4 (1981), S. 302-316. 
Sparmaßnahmen etwa bei der Instandhaltung von Gebäuden und Geräten hielten diesen hoch defizitären medizinischen Apparat in Bewegung. ${ }^{484}$

Fortlaufend wachsende Verluste entstanden auch im Öffentlichen Nahverkehr. Zwar gelang es den meisten dieser Unternehmen (anders als in den 1960er Jahren, in denen die neue Massenmotorisierung zu sinkenden Fahrgastzahlen geführt hatte) seit den frühen 1970er Jahren, wieder mehr Fahrkarten zu verkaufen, obwohl die Ticketpreise wiederholt teilweise deutlich erhöht wurden. Der gleichzeitige Kostenanstieg aber machte solche Erfolge betriebswirtschaftlich stets wieder zunichte. Allein von 1972 auf 1976 wuchs das jährliche Defizit der städtischen Busse und Straßenbahnen von insgesamt 1,1 Milliarden DM auf 5,2 Milliarden - bei weiterhin »steigender Tendenz«. ${ }^{485}$

Zahlreiche Gemeinden konnten allein ihre Verluste im Nahverkehr selbst mit dem gesamten Gewinn des kommunalen Stromversorgers nicht mehr ausgleichen. ${ }^{486}$ Damit verwandelte sich das System der kommunalen Dienstleistungen vollends in eine gravierende Belastung für die ohnehin defizitären städtischen Haushalte: Rechnete man die Einnahmen und Ausgaben aller Betriebe dieser Art zusammen, dann erreichten sie gemeinsam

484 | Die Zahlen (für 1979) aus: Manfred Schlick: Ziele und Möglichkeiten der Privatisierung auf kommunaler Ebene, Bonn 1986, S. 47. Vgl. grundsätzlich auch: Martin Sommer: Organisation des Krankenhauswesens. In: VOP 2 (1980), S. 427-430.

485 | Zahlen aus: Weimer: Arbeitsproduktivität, S. 80 (1971); Alexander van der Bellen: Öffentliche Unternehmen zwischen Markt und Staat, Köln 1977, S. 89. Vgl. knapp zusammenfassend auch: Rainer Willecke: ÖPNV im Spannungsfeld zwischen Eigenwirtschaftlichkeit und Subvention. In: Der Personenverkehr 27 (1976), S. 105-107.

486 | Vgl. dazu etwa die Angaben für West-Berlin und Bremerhaven in: Hans Liehr: Eigenbetriebe in Berlin - Leistung Tag und Nacht - Aber zu welchem Preis? In: Der Städtetag 28 (1975), S. 687-690, hier: S. 689; Geschäftsbericht 1974 der Bremerhavener Versorgungs- und Verkehrsgesellschaft, der Stadtwerke Bremerhaven und der Verkehrsgesellschaft Bremerhaven, Bremerhaven 1975, S. 8. Genaue Angaben zu der uneinheitlichen Entwicklung in Bremen in: Heinz-Josef Bontrup: Untersuchung der wirtschaftlichen Entwicklung der Stadtwerke Bremen AG und der Bremer Straßenbahn AG unter Anwendung einer externen Bilanzanalyse, Bremen 1989, S. 53. Zwischen 1975 und 1982 gab es hier vier Jahre mit einem Gesamtdefizit, aber auch drei Jahre mit kleineren Gewinnen. 
im Jahr 1979 eine Kostendeckungsquote von nur 9,3 Prozent. Insgesamt zahlten die Kommunen in diesem Jahr 18,29 Milliarden DM aus ihren allgemeinen Etats, um die Defizite ihrer Dienstleistungs- und Versorgungsbetriebe abzudecken. ${ }^{487}$

Schließlich kämpften auch die beiden größten staatlichen Betriebe, die Bundesbahn und die Bundespost, mit großen Problemen. So eilte die Bahn in den 1970er Jahren von Rekorddefizit zu Rekorddefizit. Bei der Post verhielt es sich zwar insofern etwas anders, als sie nach langen Jahren mit Verlusten ab 1975 wieder Jahresüberschüsse erwirtschaftete. Dieses Plus entstand jedoch nur, weil das Monopolunternehmen seinen gewinnträchtigen Telefondienst für die Kunden, die Ortsgespräche führten, konsequent so stark verteuerte, dass die weiterhin auflaufenden Verluste fast aller anderen Postdienste wieder mehr als ausgeglichen wurden. Da lag der Vorwurf nahe, das Unternehmen nutze seine Monopolstellung aus. Zudem wuchs die ohnehin schon milliardenschwere Schuldenlast der Post trotz der wieder erlangten Profitabilität im laufenden Geschäft unverändert weiter an, auch weil ihre neue Tarifpolitik im Telefonbereich hohe Investitionen für technische Umstellungen erforderte. ${ }^{488}$

Ohne diesen dichten Wald tiefroter Zahlen bei den öffentlichen Dienstleistungen hätte es die neoliberale Programmatik der »Chicago School « in der Bundesrepublik sicher deutlich schwerer gehabt, Wirkung zu entfalten. Die ÖTV aber weigerte sich, das Defizitproblem als ein ernstes Problem der Gemeinwirtschaft zu diskutieren. Konkret argumentierte sie etwa beim Öffentlichen Nahverkehr mit dem "gesellschaftlichen Nutzen«, der entstehe, wenn Fahrten mit Privatautos vermieden würden: So gebe es weniger Dreck und Lärm. Deshalb sei es falsch, die Zahlungen der Passagiere als »wesentli-

487 | Schlick: Ziele, S. 50.

488 | Vgl. für die Post etwa: Rainer Pausch: Zur Frage der Privatisierung von Verwaltungstätigkeiten - dargestellt am Beispiel der Deutschen Bundespost. In: Zeitschrift für öffentliche und gemeinwirtschaftliche Unternehmen 1 (1978), H. 3, S. 61-72; Karl-Heinz Neumann/Urs Schweizer/Carl-Christian von Weizsäcker: Tarifpolitik im Telekommunikationsbereich. Eine Wohlfahrtsanalyse, Bonn 1981. Die Verteuerung entstand vor allem dadurch, dass nun erstmals auch für Ortsgespräche eine Zeittaktung eingeführt wurde. Zur Bahnkrise vgl. zusammenfassend etwa: Ernst Haar: Der gemeinwirtschaftliche Auftrag der Deutschen Bundesbahn. In: Zeitschrift für öffentliche und gemeinwirtschaftliche Unternehmen 5 (1982), S. 151-169. 
chen Kostendeckungsfaktor « zu behandeln: Die Fahrpreise im Öffentlichen Nahverkehr müssten konsequent »bedarfsgerecht" gestaltet werden, d.h. möglichst niedrig liegen, um Kunden anzulocken. ${ }^{489}$ Auch im Gesundheitswesen seien betriebswirtschaftliche Kosten-Nutzen-Analysen - so die ÖTV - ganz fehl am Platz: Gerade der Medizinbetrieb dürfte sich »nur an sozialstaatlichen und humanitären Gesichtspunkten« orientieren. ${ }^{490}$

Diese Positionen waren nicht neu: Verfechter einer umfassenden staatlichen "Daseinsvorsorge « hatten seit dem 19. Jahrhundert immer auf den Nutzen verwiesen, den die Allgemeinheit dank der öffentlichen Dienstleistungen selbst dann gewinne, wenn einzelne dieser Betriebe defizitär arbeiteten. Das ökonomische, politische und soziale Umfeld, in dem diese Argumentation vorgetragen wurde, sah in der zweiten Hälfte der 1970er Jahre allerdings deutlich anders aus als noch kurz zuvor. Der Wachstumsoptimismus der beiden vorangegangenen Dekaden war verschwunden; die stetig wachsenden Schulden der Öffentlichen Hand galten parteiübergreifend als ein gravierendes politisches Problem, das dringend gelöst werden müsse. Auch die Wähler teilten ganz offensichtlich zunehmend diese Sicht. ${ }^{41}$

Gleichzeitig lieferten alle Bemühungen, die Leistungen öffentlicher Unternehmen für das gesellschaftliche Wohl genauer zu beschreiben und auch ökonomisch zu berechnen, nur unbefriedigende Resultate: Es fehlten "Sozialbilanzen«, die schlüssig bewiesen, wie gemeinnützig diese Betriebe wirklich waren. ${ }^{492}$ Wenn die ÖTV - wie viele andere Gegner der neuarti-

489 | In der Reihenfolge der Zitate: Karl-Heinz Hoffmann: Öffentlicher Nahverkehr braucht Priorität. In: Öffentliche Wirtschaft und Gemeinwirtschaft 24 (1975), S. 20-21; Vorrang dem öffentlichen Nahverkehr. Materialien zur Nahverkehrskonzeption der Gewerkschaft ÖTV, Stuttgart 1972, S. 43.

490 | So Heinz Kluncker im Interview in: »An Haupt und Gliedern modernisieren«. In: StZ, 14.11.1970. Vgl. auch: Heinz Kluncker: Gesundheitspolitik als gewerkschaftliche Aufgabe. In: Gesundheitspolitik. Perspektiven und Beschlüsse der Gewerkschaft ÖTV, Stuttgart 1977, S. 5-9; Monika Wulf-Mathies: Perspektiven der Gewerkschaft ÖTV zur Gesundheitspolitik. In: ebd., S. 19-27.

491 | Vgl. hierzu etwa: Hans-Jürgen Krupp: Möglichkeiten und Grenzen der Staatstätigkeit. In: Gottfried Bombach/Bernhard Gahlen/Alfred E. Ott (Hrsg.): Möglichkeiten und Grenzen der Staatstätigkeit, Tübingen 1982, S. 1-51, hier: S. $40 \mathrm{f}$.

492 | Vgl. zusammenfassend etwa: Karl Oettle: Betriebserfolge in der privaten und in der öffentlichen Wirtschaft. In: ders.: Grundfragen öffentlicher Betriebe I. 
gen Staatskritik - zu diesen Wandlungen und Problemen schwieg, so blieb sie einen wichtigen Teil der Antwort schuldig, der in der gegebenen Situation nötig gewesen wäre, um überzeugend auf die Herausforderung durch den Neoliberalismus zu reagieren. ${ }^{493}$

Verlässt man die Ebene der programmatischen Debatte und fragt, was in der Bundesrepublik nach 1975 in Sachen der Privatisierung konkret geschehen ist, dann ist einerseits ein Scheitern zu konstatieren: Eine echte »Entstaatlichung« hat nicht stattgefunden. Selbst Birgit Breuel konnte als niedersächsische Wirtschaftsministerin in dieser Hinsicht nur eine magere Bilanz vorweisen, obwohl sie politisch von Ernst Albrecht, dem Ministerpräsidenten des Landes, durchaus unterstützt wurde. Frustriert bezeichnete sie selbst im Rückblick die praktischen Resultate ihrer Politik als »unbefriedigend«: Im Kabinett, in den Ämtern und Behörden, sogar selbst in ihrer eigenen Partei, der CDU, habe es fast durchweg "Blockaden« gegeben, wenn es galt, konkret bislang öffentlich erledigte Arbeiten und Dienstleistungen an Privatunternehmer abzugeben. Verantwortlich dafür seien unter anderem »Ressortegoismus«, die Furcht gewählter Politiker, für Arbeitsplatzverluste »vor Ort« verantwortlich gemacht zu werden, und »die Angst, einen Steuerungsmechanismus aus der Hand geben zu müssen«. Deshalb habe es trotz der Stimmenmehrheit der allein regierenden CDU im niedersächsischen Landtag nach 1977 und trotz ihrer eigenen ideologischen Linientreue keine »konsequente Politik der Marktöffnung« gegeben.

Ausgewählte Aufsätze zur Zielsetzung, Führung und Organisation öffentlicher Betriebe, Baden-Baden 1976, S. 37-54; van der Bellen: Unternehmen, S. 110-113.

493 | Mit ihrer Weigerung, das Defizitproblem ernst zu nehmen, stand die ÖTV allerdings nicht allein. Vgl. als Statements gegen den Neoliberalismus, die zu diesem Komplex schwiegen, etwa: Herbert Krüger: Die »Lebensluft « des Öffentlichen Dienstes. In: Walter Leissner (Hrsg.): Das Berufsbeamtentum im demokratischen Staat. Beiträge zum Dienstrecht und zur Dienstrechtsreform, Berlin 1975, S. 101119 (insofern ein Extrembeispiel, weil hier gerade die Defizite das gemeinnützige Wesen der öffentlichen Dienstleistungen »beweisen«). Auch die DAG vollzog erst nach einer Kostenexplosion im Gesundheitswesen Anfang der 1980er Jahre einen Schwenk und erkannte erstmals ein nicht mehr zu ignorierendes Defizitproblem im Gesundheitswesen an. Dabei gestand sie die kostenmindernde Wirkung der Selbstbeteiligung ein, beharrte aber darauf, dass für den Kostenausgleich in bestimmten Bereichen des Gesundheitswesens gegebenenfalls der Staat zuständig bleiben müsse. Vgl.: Müller: Deutsche Angestellten-Gewerkschaft, S. 142. 
Dieses Fazit gilt bis weit in die 1980er Jahre hinein auch für die ganze Bundesrepublik. ${ }^{494}$

Andererseits aber handelte es sich bei den frühen deutschen Privatisierungsdebatten keineswegs nur um einen rein theoretischen Streit. In einigen wenigen Segmenten des Öffentlichen Dienstes erfolgte tatsächlich schon in den 1970er Jahren so etwas wie ein Rückbau, der Privatunternehmern neue Geschäfte ermöglichte. Am wichtigsten waren dabei zwei Bereiche, die beide etwas mit Schmutz zu tun haben, sich ansonsten aber doch deutlich voneinander unterscheiden: die kommunale Müllabfuhr und Reinigungsarbeiten in öffentlichen Gebäuden. Dazu kam drittens ein kleines und sehr spezielles Segment staatlicher Arbeiten: die Aufgabe, die Fahrrinnen zu den deutschen Seehäfen sowohl auf hoher See als auch in Küstennähe und in den Flüssen kontinuierlich von Schlick und Schlamm zu befreien. ${ }^{495}$

494 | In der Reihenfolge der Zitate: Birgit Breuel: Der Mensch lebt nicht von Umsatzzahlen. Wie ich Politik verstehe, Herford 1987, S. 39 f. u. 20. Vgl. ähnlich auch schon das kritische Fazit in: Klaus Kemper: Eine Frau, die vieles ändern will. In: FAZ, 16.3.1981. Zur inkonsequenten Privatisierungspolitik auch der von Helmut Kohl geführten Bundesregierung nach 1982 vgl. etwa: Fritz Knauss: Privatisierung in der Bundesrepublik Deutschland 1983-1990. Bilanz und Perspektiven, Köln 1990.

495 | Ein weiterer Bereich bleibt hier unberücksichtigt, weil er die ÖTV kaum betraf: Zahlreiche Kommunen privatisierten in den 1970er Jahren den städtischen Schlachthof. Da die dort beschäftigten Arbeitnehmer von der Gewerkschaft Nahrung - Genuss - Gaststätten vertreten wurden, fielen diese Ausgliederungen nicht in die Zuständigkeit der ÖTV. Zudem hatten sie einen sehr speziellen Hintergrund: Das System der Fleischproduktion und -vermarktung veränderte sich seit den 1960er Jahren grundlegend durch Fortschritte der Kühltechnik. Damit entfiel die Notwendigkeit, Schlachttiere lebend in die Städte zu transportieren; es entstanden neue und hochmoderne Schlachthöfe direkt in den ländlichen Produktionsgebieten. Auf diesen Wandel, der die städtischen Schlachthöfe in Defizite stürzte, mussten auch die Kommunalverwaltungen reagieren. Mitte der 1980er Jahre waren bereits 49 kommunale Schlachthöfe privatisiert worden. Die Zahl aus: Deutscher Städtetag: Möglichkeiten, S. 104f.; zu Einzelbeispielen vgl. etwa: Fluhrer: Staat, S. 84-89; Bischoff/Nikusch: Privatisierung, S. 192-202 (beide zu Köln); Arbeitsgemeinschaft Selbständiger Unternehmer (Hrsg.): So wird privatisiert! Eine Handlungsanleitung, Bonn 1983, S. 36-38 (Andernach). 
Bei einem genaueren Blick auf diese drei Bereiche zeigt sich rasch, wie unzureichend die soziale Realität mit den stereotypen Begriffen und Wertungen zu beschreiben ist, die von den Kontrahenten im »Glaubenskrieg« zwischen Neoliberalen einerseits und Verfechtern der traditionsreichen staatlichen "Daseinsvorsorge« andererseits durchweg vorgetragen wurden (und werden). Privatisierungen haben - ähnlich wie Rationalisierungsmaßnahmen - stets spezielle und komplexe Hintergründe; auch ihre sozialen Wirkungen lassen sich keineswegs pauschal als entweder positiv oder negativ beschreiben. ${ }^{496}$

Dabei mögen die Privatisierungen bei der Müllabfuhr zunächst einmal wie ein Stück wirken, das hervorragend in die Lehrbücher der beiden konkurrierenden Denkschulen passt. Kommunale Unternehmen dieser Art zahlten in den späten 1970er Jahren um 45 bis 75 Prozent höhere Löhne als Privatbetriebe der gleichen Branche. Gleichzeitig verzeichneten die letzteren durchweg solide Gewinne, während die öffentliche Stadtreinigung, wie erwähnt, typischerweise noch nicht einmal kostendeckend arbeitete. ${ }^{497}$ Neoliberale Staatskritiker konnten diese groben Angaben benutzen, um die von ihnen behauptete "systembedingte Effizienzunterlegenheit des Staates « in wirtschaftlichen Dingen anschaulich zu belegen - Verteidigern des bundesdeutschen Status quo boten sie sich hingegen an, um über den "Lohndruck« zu klagen, der den Arbeitern der gewinnorientierten Privatwirtschaft das Leben schwer mache. ${ }^{498}$

496 | Die Formulierung von »Glaubenskrieg« aus: Siedentopf: Privatisierung, S. 64. Die Verschiedenartigkeit konkreter Privatisierungsmaßnahmen betont auch ein neuerer Literaturüberblick: Marcel vom Lehn: Geschichte eines Sachzwangs: Privatisierung als historischer Prozess. In: NPL 58 (2013), S. 59-76.

497 | Die Zahlen berechnet nach: Werner Böcker: Privatisierung öffentlicher Aufgaben. In: Deutscher Städtetag (Hrsg.): Im Dienst deutscher Städte 1905-1980. Ein kommunales Sachbuch zum 75. Jubiläum, Stuttgart 1980, S. 89-102, hier: S. 98. Zur Finanzlage der städtischen Betriebe siehe die Angaben oben; einen stolzen Hinweis auf die positive Ertragslage der Privatfirmen vgl. hingegen in: Verband privater Stadtreinigungsbetriebe an den Direktor des Mannheimer Stadtreinigungsamtes Heinrich Irmisch, 12.2.1976 (Kopie). In: Archiv Ver.di, Bestand Kluncker, 52.

498 | Renate Röhl: Privatisierung öffentlicher Aufgaben. Ein Überblick, Kiel 1982, S. 51 (die neoliberale Sicht); Protokoll ÖTV-GT 1976, Bd. 2, S. 99 (die gewerkschaftliche Position). 
Tatsächlich lagen die Dinge etwas komplizierter. So entstand die Diskrepanz der Löhne zu einem großen Teil schon deshalb, weil öffentliche und private Müllabfuhren in anderen regionalen Räumen agierten und auch nicht direkt miteinander konkurrierten, da sie jeweils ja mit regionalen Monopolrechten ausgestattet waren. Fast alle deutschen Städte, die mehr als 30.000 Einwohner zählten, besaßen ein eigenes Unternehmen für diese Aufgabe; Privatbetriebe arbeiteten hingegen vor allem in noch kleineren Gemeinden und »auf dem Land « sowie gelegentlich auch noch in den Randgebieten der Großstädte. ${ }^{499}$ Daher bezeichnete der ordnungspolitisch scheinbar so signifikante Einkommensunterschied zwischen den Müllarbeitern in kommunalen und in nicht-öffentlichen Unternehmen nur den ganz normalen Abstand zwischen den Löhnen in den Städten (zumal in den Ballungsgebieten) einerseits sowie in eher strukturschwachen Regionen andererseits, der auf die abweichenden Lebenshaltungskosten reagierte.

Auch die im Vergleich offenbar tatsächlich geringere betriebliche Effektivität der kommunalen Müllbetriebe hatte komplexe Hintergründe. In Dörfern und Kleinstädten war das Geschäft, den Abfall einzusammeln und zu entsorgen, in vieler Hinsicht erheblich schwieriger als in Großstädten: Die Fahrzeuge mussten deutlich weitere Wege zurücklegen, bis sie gefüllt waren; die Abladestation war typischerweise ebenfalls nicht so rasch zu erreichen wie in Ballungsgebieten. Der Gewinn der Privatunternehmen, die

499 | Vgl. hierzu genauer: Helmut Orth/H. Schulz: Städtereinigung in kommunaler oder privater Hand? In: Kommunalwirtschaft (1977), S. 11-17, hier: S. 11 f.; Hartmut Tofaute: Zur Privatisierung öffentlicher Dienstleistungen. Die Übertragung öffentlicher Leistungen und Funktionen auf Private (Privatisierung). Eine Darstellung politischer, ökonomischer, gesellschaftlicher und arbeitnehmerorientierter Gesichtspunkte, Stuttgart 1977, S. 59-63. Insgesamt gab es in der Bundesrepublik in den 1970er Jahren rund 1.600 private Stadt- und Straßenreinigungsbetriebe; sie sammelten und transportierten - in der Regel auf der Basis von jeweils zehn Jahre lang laufenden Lizenzverträgen - den Müll von etwa 30 Millionen Bundesbürgern. Die Lagerung und Entsorgung von Müll war gesetzlich als öffentliche Aufgabe definiert und wurde daher generell von öffentlichen Einrichtungen übernommen. Angaben nach: Werner Sauerborn/Heiner Minssen: Gewerkschaftliche Probleme der Privatisierung öffentlicher Dienstleistungen. In: WSI-Mitteilungen 30 (1977), S. 383-393, hier: S. 393; Orth/Schulz: Städtereinigung, S. 12 (zu den Lizenzen). 
ja gerade außerhalb der Städte agierten, war daher alles andere als selbstverständlich: Rechnete man die Umsatzsteuer, die sie (anders als die öffentlichen Betriebe) zahlen mussten, ebenso ein wie die Gewinnerwartungen der Eigentümer oder Aktionäre, dann lagen ihre Betriebskosten bei gleicher Abfallmenge zwingend um etwa 20 bis 25 Prozent höher als die Aufwendungen der kommunalen Müllabfuhr - und dabei ist der Vorteil der geringeren Löhne bereits eingerechnet. ${ }^{500}$

Wenn sie trotz dieser Hürde Gewinne einfuhren, dann gelang ihnen das wohl vor allem, weil sie rascher investierten, um gezielt die jeweils modernsten Geräte einzusetzen, und bewusst deutlich geringere Aufwendungen machten, um Störungen und Verzögerungen im Betriebsablauf etwa durch kaputte Maschinen oder einen hohen Krankenstand zu vermeiden. ${ }^{501}$ Öffentliche Betriebe scheinen deutlich gemächlicher und vorsichtiger investiert und geplant zu haben. Trotz der an sich günstigeren Rahmenbedingungen für das Geschäft der Müllabfuhr arbeiteten sie deshalb betriebswirtschaftlich teilweise deutlich schlechter. Die ÖTV kannte dafür konkrete Beispiele. So entsorgte beispielsweise die Städtische Müllabfuhr im schwäbischen Heilbronn in den frühen 1970er Jahren mit jedem ihrer Fahrzeuge täglich den Abfall von rund 800 Haushalten. Bei gleichem Personaleinsatz (ein Fahrer, zwei Müllmänner) hätte diese Zahl jedoch bei 1.500 liegen können, wenn die Kommune in die moderne Technik investiert hätte, die private Unternehmen im Umland der Stadt bereits benutzten. ${ }^{502}$

Schlechtes Management kam selbstverständlich keineswegs nur in öffentlichen Betrieben vor - die gesamte moderne Wirtschaftsgeschichte sähe

500 | Orth/Schulz: Städtereinigung, S. 12 f.

501 | Vgl. dazu: Böcker: Privatisierung, S. 99; Tofaute: Privatisierung, S. 71 f; Verband privater Stadtreinigungsbetriebe an den Direktor des Mannheimer Stadtreinigungsamtes Heinrich Irmisch, 12.2.1976 (Kopie). In: Archiv Ver.di, Bestand Kluncker, 52.

502 | So im Rückblick die Darstellung in: ÖTV-KV Heilbronn/Schwäbisch Hall an HV, Sekretariat 1, 28.11.1975. In: Archiv Ver.di, Bestand Kluncker, 52. Die vor diesem Hintergrund auch in Heilbronn diskutierte Privatisierung der Müllabfuhr blieb jedoch aus: Die Stadt investierte selbst und rechnete daher für 1976 mit einer Rendite, die über das hinausging, was die Privatbetriebe erwirtschafteten. $\mathrm{Zu}$ einer ähnlichen Entscheidung auch in München im Jahr 1981 (bei einer deutlichen Mehrheit der CSU im Stadtrat) vgl.: Fluhrer: Staat, S. 87. 
sonst anders aus. Allerdings gab es im System der öffentlichen Dienstleistungsbetriebe doch Strukturen, die eine schwache Leitung begünstigten. Insofern war die mangelnde Effektivität und Ertragskraft vieler kommunaler Müllunternehmen dann eben doch auch ordnungspolitisch erklärbar. Diesen Zusammenhang hätte die ÖTV problemlos anschaulich illustrieren können. In einem internen Memorandum aus dem Frühjahr 1976 für Heinz Kluncker erklärte das Hauptvorstands-Mitglied Kurt Jäger, die Leitung der kommunalen Stadtreinigung genieße - anders als etwa die Führung der Stadtwerke - nur geringes soziales Ansehen. Dementsprechend handele es sich »um typische Dienstposten für die Belohnung - manchmal auch Unterbringung im Sinne von >Abschieben - von Parteifreunden, Personalratsvorsitzenden und anderen Funktionären, viel häufiger aber noch für die Versetzung von Beamten, die sich auf anderen Dienstposten als nicht geeignet erwiesen « hätten. Sowohl mit ihren Kenntnissen als auch mit ihrer Einsatzbereitschaft sei es deshalb oft nicht weit her. Darüber hinaus versandeten viele Initiativen für betriebliche Verbesserungen im schwerfälligen Beratungs- und Entscheidungsprozedere der kommunalen Selbstverwaltung. Ausdrücklich konstatierte der Gewerkschaftsfunktionär, die Gewinne der privaten Abfallunternehmen stammten »nicht aus Lohndrückerei«: Sie böten eine angemessene Entlohnung und Sozialleistungen, die denen öffentlicher Betriebe entsprächen. ${ }^{503}$

Jäger, der das Geschäftsfeld offensichtlich gut kannte, hielt es zwar problemlos für möglich, die von ihm beschriebenen Probleme zu vermeiden, ohne aus der Müllabfuhr gleich ein Privatunternehmen zu machen. Dieser Weg sei für die Kommunalpolitiker aber deutlich langwieriger und auch schwieriger als die Entscheidung, sich des städtischen Betriebes ganz zu entledigen. Besonders kleinere Gemeinden wählten lieber den einfacheren Pfad - und sei es nur, weil sie die hohen Kosten für eine moderne technische Ausstattung des kommunalen Unternehmens scheuten. ${ }^{504}$

503 | Diskussionsbeitrag von Kurt Jäger zur Privatisierung der Müllabfuhr, 27.2.1976. In: Archiv Ver.di, Bestand Kluncker, 52. Vgl. ähnlich auch schon: Stellungnahme der Abt. Kommunale Fuhrpark- und Stadtreinigungsbetriebe zu Privatisierungstendenzen in der Stadtreinigung, o. D. [Nov. 1975]. In: Archiv Ver.di, Bestand Kluncker, 50.

504 | Ebd. Ein Müllwagen auf dem Stand der modernen Technik kostete 1977 zwischen 140.000 und 180.000 DM (Orth/Schulz: Städtereinigung, S. 13). 
Im konkreten Einzelfall - so zeigt sich am Beispiel der Stadtreinigung trat der politisch-ideologische Charakter der Privatisierungsdebatte rasch hinter Fragen zurück, die nicht mehr sehr viel mit einem »Glaubenskrieg« zu tun hatten: War es möglich, den kommunalen Betrieb konsequent rational zu organisieren? Ließ sich sicherstellen, dass nur fachlich kompetente Leitungskräfte bestellt wurden? Konnte ein öffentlicher Betrieb ähnlich frei und rasch über Investitionen entscheiden wie ein Privatbetrieb? Kurt Jäger hielt - wie gesagt - positive Antworten für möglich; einschränkend fügte er dann aber doch hinzu, die nötigen Änderungen seien nur möglich, wenn auch die ÖTV bereit sei, ergebnisoffen über einige ihrer »Tabus« zu diskutieren. Dabei dachte er offensichtlich vor allem an den Widerstand der Organisation gegen betriebliche Rationalisierungsmaßnahmen und an die Skepsis vieler Mitglieder gegenüber neuen Arbeitstechniken. ${ }^{505}$

Auf lokaler Ebene scheint die Gewerkschaft bei den kommunalen Müllbetrieben in den späten 1970er Jahren durchaus bereit gewesen zu sein, nicht eisern am innerbetrieblichen Status quo festzuhalten. Offensichtlich prüften nach 1975 zahlreiche Gemeindeverwaltungen die Effizienz gerade dieser Unternehmen. Sowohl der Verband der privaten Stadtreinigungsbetriebe als auch große Wirtschaftsberatungsfirmen, die bei ihrer Suche nach neuen Geschäftspartnern in dieser Zeit den Staat als solventen Auftraggeber entdeckten, förderten diesen Trend mit eigenen Initiativen. Beschlüsse, die Müllabfuhr tatsächlich zu privatisieren, sind hingegen nur in Ausnahmefällen für einige Kleinstädte und Landkreise dokumentiert. ${ }^{506}$ Wenn die Gewerkschaft bei solchen Prüfungen höhere Leistungsanforderungen für die Beschäftigten des kommunalen Unternehmens akzeptierte, so tat sie das eindeutig, um eine Privatisierung zu verhindern. Von linker

505 | Diskussionsbeitrag von Kurt Jäger zur Privatisierung der Müllabfuhr, 27.2.1976. In: Archiv Ver.di, Bestand Kluncker, 52.

506 | Vgl. die Hinweise in: Böcker: Privatisierung, S. 97. Die ÖTV-Kreisverwaltung Heilbronn/Schwäbisch-Hall berichtete im November 1975, die große Wirtschaftsberatungsfirma "Wibera« reise »derzeit durch die Lande und preist ihre Dienste an « (ÖTV-KV Heilbronn/Schwäbisch Hall an HV, Sekretariat 1, 28.11.1975. In: Archiv Ver.di, Bestand Kluncker, 52). Als konkretes Beispiel für eine Privatisierung vgl. etwa: Werner Sauerborn: Fallstudie über die Privatisierung der Müllabfuhr im Landkreis Göttingen. In: Hauptvorstand der Gewerkschaft Öffentliche Dienste, Transport und Verkehr (Hrsg.): Zur Privatisierung öffentlicher Dienstleistungen, H. 3, Stuttgart 1977, S. 7-48. 
Seite kam dennoch der Vorwurf, die ÖTV betreibe eine "präventive Rationalisierung « und das bedeute nichts anderes, als »den Teufel mit Beelzebub auszutreiben ${ }^{5} .{ }^{507}$

Vor womöglich noch unangenehmeren Handlungsalternativen sah sich die Gewerkschaft in den Fällen, in denen der Staat darüber nachdachte, die Reinigungsarbeiten in öffentlichen Gebäuden nicht mehr von eigenem Personal erledigen zu lassen. So stand für die betroffenen Putzfrauen weit mehr auf dem Spiel als für die Müllmänner bei einer Privatisierung der Stadtreinigung. Gleichzeitig symbolisierten speziell die Reinigungskräfte, die im System der staatlichen Dienstleistungen auf den ersten Blick nur eine ganz randständige Bedeutung hatten, exemplarisch ein Grundprinzip der öffentlichen »Daseinsvorsorge«, das in Deutschland seit der Weimarer Republik allgemein akzeptiert worden war: Wenn über sie und ihre Arbeitsbedingungen gestritten wurde, dann ging es um die Funktion des Öffentlichen Dienstes als »Vorbild« für die Privatwirtschaft. Anders, als man es vielleicht vermuten würde, zeigte sich die weltanschauliche Dimension schon der frühen deutschen Privatisierungsdebatte somit gerade dann besonders deutlich, wenn sie die gering qualifizierte Arbeit von Putzfrauen thematisierte.

Genau wie beim Thema »Müllabfuhr« entstand der Gedanke, der Staat solle bei Reinigungsarbeiten nicht mehr selbst wirtschaften, im Wesentlichen durch eine ökonomische Diskrepanz: Die regelmäßige Säuberung von Büros, Ämtern und Schulen kam die Öffentliche Hand deutlicher billiger, wenn Privatfirmen diese Aufgabe erledigten. Bei vergleichbaren Arbeiten waren eigene Putzfrauen in den späten 1970er Jahren häufig mehr als doppelt so teuer wie Fremdkräfte; in Einzelfällen erreichte der Preisunterschied aber auch bis zu 160 Prozent. ${ }^{508}$

Diese große Kluft hatte spezielle Ursachen - und insofern bestätigt sich an diesem Beispiel erneut die oben postulierte Regel, jede Privatisierung habe auch eine ganz eigene Geschichte. Ihren enormen Kostenvorsprung gewannen die Privatbetriebe, die - anders als ihre Pendants in der Müll-

507 | Sauerborn/Minssen: Probleme, S. 393. Konkret bezog sich dieser Vorwurf auf das öffentliche Müllunternehmen im Landkreis Pinneberg (bei Hamburg): Hier hatte die ÖTV offensichtlich den Beschluss mitgetragen, den Personalbestand bei gleichem Arbeitsanfall von 54 auf 45 Köpfe zu verkleinern.

508 | Vgl. genaue Zahlen in: Böcker: Probleme, S. 97. 
branche - vor allem in den Städten aktiv waren und daher als direkte Konkurrenz zur Verfügung standen, weil sie keine "normalen« Arbeitgeber waren: Sie beschäftigten fast nur Teilzeitkräfte, die lediglich zwei bis 2,5 Stunden täglich arbeiteten und deshalb nicht der Sozialversicherungspflicht unterlagen. ${ }^{509}$

Die Öffentliche Hand hingegen kannte keine solchen »Minijobs«, die Mitte der 1970er Jahre einen Verdienst von etwa 300 bis 370 DM monatlich erbrachten. Sie beschäftigte auch ihr Reinigungspersonal (de facto handelte es sich um eine fast ausschließlich weibliche Berufsgruppe) nach den Tarifverträgen für Arbeiter und Arbeiterinnen im Staatsdienst. Damit war die staatlich beschäftigte Putzfrau arbeitslosen-, kranken- und rentenversichert; sie hatte Anspruch auf Urlaub und (seit 1979) auf Urlaubsgeld sowie anteilig auf das 13. Monatsgehalt. Bei längerer Beschäftigung konnte sie zudem in den Genuss der zusätzlichen Alterssicherung kommen. In einigen Bundesländern erhielten Putzfrauen, die Büros in den Ministerien säuberten, offensichtlich sogar eine ähnliche "Ministerialzulage« wie die dort tätigen Beamten. ${ }^{510}$

Alle diese Kosten fielen bei den privaten Reinigungsfirmen nicht an. Darüber hinaus zahlten sie Stundenlöhne, die - wenn denn der Tarifvertrag beachtet wurde - um etwa 30 Prozent niedriger lagen als »beim Staat«. Zwar setzten zumindest die wenigen größeren Betriebe in diesem Geschäftszweig bei der Reinigung von Fluren und anderen großen Flächen auch moderne Maschinen ein, während die Putzfrau im Öffentlichen Dienst selbst solche Arbeiten typischerweise noch mit Besen, Wassereimer und Feudel erledigen musste. ${ }^{511}$ In der Gesamtschau aber konnten die Pri-

509 | Vgl. dazu etwa: Just: Teilzeitarbeit, S. 12; sowie ausführlich: Tofaute: Privatisierung, S. 90-95; Heiner Minssen: Fallstudie über die Privatisierung der Gebäudereinigung bei der Stadt Hildesheim. In: Hauptvorstand der Gewerkschaft Öffentliche Dienste, Transport und Verkehr (Hrsg.): Zur Privatisierung öffentlicher Dienstleistungen, H. 3, Stuttgart 1977, S. 49-77, hier: S. 62 f. 1976 trat die Versicherungspflicht ab einem Monatseinkommen von 387,50 DM ein.

510 | Vgl. etwa die Angaben für Hessen in: Putzfrauen wirbeln Staub auf. In: FAZ, 15.6.1976.

511 | Zu den Lohnunterschieden vgl. die Angaben für Nordrhein-Westfalen und Hamburg für 1979 in: Horst Wilhelm Wamper: Möglichkeiten der Privatisierung technischer Leistungen in Mittelzentren, dargestellt am Beispiel der Stadt Geilenkirchen, wirtschafts- u. sozialwiss. Diss., TH Aachen 1984, S. 74. Siehe auch schon 
vatbetriebe ihre Dienste vor allem deshalb so billig anbieten, weil bei ihnen deutlich geringere Lohnkosten anfielen. Dieser Vorteil entstand vor allem durch die vom Gesetzgeber geschaffene Möglichkeit, "geringfügig« Beschäftigte nicht sozial abzusichern sowie zusätzlich durch die äußerst schwache gewerkschaftliche Position in der Branche der privaten Gebäudereiniger, die es vielen Arbeitgebern möglich machte, untertarifliche Löhne zu bezahlen. ${ }^{512}$

Grundsätzlich sah die ÖTV in der sehr viel besseren Position der staatlich beschäftigten Putzfrauen gar kein Problem. Im Gegenteil: Nach ihrem Verständnis erfüllte der Öffentliche Dienst gerade mit diesen Unterschieden gegenüber der Welt der Privatwirtschaft seinen gesellschaftlichen Auftrag, "mit vorbildlichen Arbeitsbedingungen [...] auch soziale Normen zu setzen«. Zudem beweise sich am Beispiel der Reinigungskräfte die sozial positive Wirkung einer starken berufsübergreifenden Gewerkschaft: Sie helfe als Verbund eben auch gering qualifizierten Beschäftigten wie den Putzfrauen, die gegenüber den Arbeitgebern keine nennenswerte Verhandlungsmacht besaßen. Das Geschäftsmodell der privaten Reinigungsfirmen lehnte die Gewerkschaft hingegen kompromisslos ab: Dort beschäftigte Frauen würden unter »frühkapitalistischen Bedingungen« arbeiten; die dafür verantwortlichen Unternehmer seien »Sklavenhändler plus Telefon«, die ihr Geld mit »der Ausbeutung der sozial Schwächsten« verdienten. ${ }^{513}$

Die Vorstellung, der Öffentliche Dienst habe im Wirtschaftsleben eine sozialpolitische »Vorbildfunktion« auch für Privatbetriebe, war bereits im späten Kaiserreich entstanden. In der Weimarer Republik gehörte sie bereits fest zu dem Gedankengebäude, das die umfassend angelegte »Daseinsvorsorge« zumal der deutschen Kommunalverwaltungen legitimierte.

die Angaben für West-Berlin (S. 451f.). Zu den Arbeitsbedingungen vgl. etwa den farbigen Bericht für die Universität Saarbrücken in: Aktennotiz des ÖTVVorstandssekretariats 1 über Besprechungen in Saarbrücken, 7.3.1977. In: Archiv Ver.di, Bestand Kluncker, 52. Untertarifliche Löhne waren in der Branche der Gebäudereiniger wohl sehr häufig; genauere Informationen dazu aber fehlten. Vgl. den allgemeinen Hinweis darauf in: Wamper: Möglichkeiten, S. 75.

512 | Böcker: Probleme, S. 98.

513 | So H. Kluncker in: Protokoll ÖTV-GT 1976, Bd. 1, S. 71. Ähnlich auch seine Bemerkungen in: Protokoll ÖTV-GT 1980, Bd. 1, S. 512 f. 
Insofern berief sich die ÖTV mit ihren eben zitierten Stellungnahmen nur auf anerkannte deutsche Traditionen. ${ }^{514}$

Allerdings erntete sie im veränderten politischen und sozialen Klima der späten 1970er Jahre damit erstmals grundsätzlichen Widerspruch. Birgit Breuel, die selbsternannte Vorkämpferin der aus den USA importierten neoliberalen Ideen, etwa hielt überhaupt nichts von einem besonderen sozialen Auftrag der öffentlichen Betriebe für ihre eigenen Beschäftigten: Er lasse sich nur verwirklichen, wenn es keinen freien Wettbewerb gebe - und dafür zahle letztlich immer der Verbraucher die Zeche. Noch schärfer und konkreter formulierte es 1981 der CDU-Wirtschaftsrat: Wenn der Staat beispielsweise seine Putzfrauen deutlich besserstelle als die Privatwirtschaft, dann handele es sich dabei um nichts anderes als um eine "Ausbeutung der Masse der Arbeitnehmer durch die Arbeitnehmer im öffentlichen Dienst«, denn letztlich stamme das Geld für deren "zu gute« Bezahlung aus den Steuereinnahmen. Die ÖTV, die solche Privilegien verteidige, beweise mit ihrer Haltung ein »mittelalterlich-zunftmäßiges Besitzstanddenken ${ }_{.}^{515}$

Zwar antwortete die Gewerkschaft mit ähnlich grundsätzlichen Argumenten, indem sie die emanzipatorischen Wirkungen weiblicher Erwerbsarbeit beschwor. Wer das Geschäftsmodell der privaten Gebäudereiniger unterstütze, der akzeptiere, dass Frauen »in alte Abhängigkeiten und gesellschaftliche und familiäre Rollenklischees« zurückfielen, denn der »Minilohn« für den »Minijob« ermögliche »keine eigenständige Lebensführung«. Zudem drohe den Frauen im Alter wegen der fehlenden Rente die Sozialhilfe - und so verursache das »rein betriebswirtschaftlich orientierte Kal-

514 | Vgl. zu dieser Vorbildfunktion etwa: Fritz Naphtali (Hrsg.): Wirtschaftsdemokratie. Ihr Weg, Wesen und Ziel. Hrsg. im Auftrag des Allgemeinen Deutschen Gewerkschaftsbundes, Berlin 1928, S. 68 f.; Richard Sternberg-Raasch: Die soziale Bedeutung der kommunalen Betriebe für die Arbeitnehmer. In: Reichsarbeitgeberverband Deutscher Gemeinden und Kommunalverbände, Bericht über das 10 . Geschäftsjahr (1. April 1929 bis 31. März 1930), Berlin 1930, S. 55-59, hier: S. 57 u. 59; Walther Pahl/Kurt Mendelsohn (Bearb.): Handbuch der öffentlichen Wirtschaft. Hrsg. v. Vorstand des Gesamtverbandes der Arbeitnehmer der öffentlichen Betriebe und des Personen- und Warenverkehrs, Berlin 1930, S. 8.

$\mathbf{5 1 5}$ | Gerd Habermann/Rolf W. Mühlmann: Privatisierung - warum? Ein Plädoyer gegen die ausufernde Staatstätigkeit, Hannover 1981, S. 38 f. Breuels Position vgl. etwa in: Baum: Privatisierung, S. 161. Vgl. auch: Mehr Wettbewerb bei öffentlichen Dienstleistungen, Bonn 1979, S. 6. 
kül« der Unternehmer langfristig Kosten für die Allgemeinheit. Darüber hinaus schädige es die Kassen der Sozialversicherungen, wenn Teilzeitbeschäftigte normale Arbeitnehmer ersetzten. ${ }^{516}$

Die Meinung überzeugter Neoliberaler war mit solchen Einwänden allerdings nicht zu erschüttern. In einer freien Gesellschaft, so hieß es in der eben schon einmal zitierten Publikation des CDU-Wirtschaftsrates, müsse es möglich sein, auch nur für nur wenige Stunden pro Woche und ohne Sozialversicherungspflicht einer Erwerbsarbeit nachzugehen. Solche Kurzzeitjobs entsprächen einem Bedürfnis vieler Frauen, die Kinder und Familie versorgten, aber doch etwas zum Haushaltsetat beitragen wollten. Kleine Rentenansprüche in einer fernen Zukunft seien unter solchen Umständen für die Frauen hingegen völlig uninteressant. ${ }^{517}$

Zumindest mit der letzten Feststellung lag die CDU wohl richtig: In der Tat fehlte es den privaten Reinigungsbetrieben nicht an Personal, das die kurze Arbeitszeit gerade auch deshalb schätzte, weil der Lohn dafür nach der Regel »Brutto gleich Netto« ungeschmälert blieb. Alltagspraktisch und ökonomisch war diese Haltung durchaus verständlich: Eine Putzfrau, die volle drei Stunden pro Werktag arbeitete, lag mit ihren Nettobezügen nur um 50 DM über dem Verdienst ihrer Kollegin, die einen versicherungsfreien "Minijob« erledigte, obwohl die versicherte Beschäftigte im Monat 25 Stunden länger geputzt hatte. ${ }^{518}$

Wenn man nicht rein utilitaristisch entschied, dann verbargen sich hinter der scheinbar ganz banalen Frage, ob öffentliche Gebäude besser von staatlich oder privat Beschäftigten gereinigt werden sollten, mithin gleich mehrere überraschend diffizile Probleme und Grundsatzentscheidungen. Diese tiefere Dimension der Privatisierungsdebatte brachte der ÖTV seinerzeit durchaus Vorteile: Vor allem ihr Argument, versicherungspflichtige Beschäftigungen dienten sowohl der individuellen gesellschaftlichen Teil-

516 | Jürgen H. Mendner/Werner Sauerborn (unter Mitwirkung v. Dorothee Möller): Privatisierung - Angriff auf den Sozialstaat. Eine Untersuchung über die Folgen für die Arbeitnehmer als Bürger, Beschäftigte und Steuerzahler am Beispiel Niedersachsens, Stuttgart 1983, S. $209 \mathrm{f}$.

517 | Habermann/Mühlmann: Privatisierung, S. 43. Vgl. auch: Deutscher Industrie- und Handelstag: Praxisleitfaden Privatisierung, Bonn 1984, S. 83.

518 | So die Angaben für 1976 in: Minssen: Fallstudie, S. 62 f. Vgl. auch: Wamper: Möglichkeiten, S. 75. 
habe wie auch der Allgemeinheit, berührte sich eng mit Grundpositionen der SPD. Der Deutsche Städtetag, dessen Gremien von sozialdemokratischen Kommunalpolitikern dominiert wurden, beschloss ausdrücklich, es dürfe kein »Lohn- und Versicherungsdumping " geben, wenn der Staat dazu übergehe, Hilfstätigkeiten wie etwa die Putzarbeiten von privater Seite erledigen zu lassen. ${ }^{519}$

Mit der Realität hatte dieser Beschluss allerdings wohl nur bedingt etwas zu tun. Viele Kommunen experimentierten in den Jahren nach 1975 mit einer Privatisierung von Reinigungsarbeiten - und dabei prüften die politisch Verantwortlichen oft nicht sehr genau, ob das offiziell unerwünschte „Dumping« wirklich ausblieb. Die Welle solcher Beschlüsse lässt sich leicht erklären. Zum einen handelte es sich um eine Angelegenheit, die kaum öffentliche Aufmerksamkeit fand, weil sie die Bürger - anders als etwa die Privatisierung der Müllabfuhr - nicht direkt betraf. Die politischen Hürden für eine Entscheidung waren daher weitaus niedriger. Zum anderen aber ging es durchaus um nennenswerte Summen. Durchschnittlich entfielen bei den bundesdeutschen Kommunen etwa drei Prozent der gesamten Verwaltungsausgaben auf Reinigungsarbeiten. Das mag wenig eindrucksvoll wirken, aber dieser Eindruck schwindet, wenn man erfährt, dass etwa der Stadtstaat Hamburg im Jahr 1975 insgesamt 141 Millionen DM ausgab, um seine Gebäude und Büros sauber zu halten. Im deutlich kleineren Bremen waren es immerhin noch 80 Millionen DM. Beide Summen entstanden fast ausschließlich durch die Personalkosten. Da die Privatbetriebe versprachen, um 40 bis 50 Prozent billiger zu arbeiten, lockte hier ein Einsparungspotenzial, das angesichts der grassierenden roten Zahlen in den Etats kaum ein Stadtkämmerer ignorieren mochte. ${ }^{520}$ Druck der öffentlich bestellten Rechnungsprüfer kam hinzu: Sowohl der Bundesrechnungshof als auch dessen Pendants bei den Bundesländern sowie die Rechnungsprü-

519 | Erklärung des Deutschen Städtetages zur Privatisierung öffentlicher Aufgaben, 7.1.1976. In: Archiv Ver.di, Bestand Kluncker, 52.

520 | Arbeitsgemeinschaft Selbständiger Unternehmer: So wird privatisiert!, S. 42 (die allgemeine Prozentabgabe, hier für 1978/79); Tofaute: Privatisierung, S. 77 (die Angabe für Hamburg); Hauptvorstand der Gewerkschaft Öffentliche Dienste, Transport und Verkehr (Hrsg.): Zur Privatisierung öffentlicher Dienstleistungen, H. 3, Stuttgart 1977, S. 32 (die Angabe für Bremen). Den Satz von drei Prozent bestätigt auch: Wamper: Möglichkeiten, S. 67. 
fungsämter der Kommunen forderten seit 1975 wiederholt dezidiert Einsparungen in den öffentlichen Etats durch eine stärkere »Fremdreinigung «. ${ }^{521}$

Präzise Angaben, was genau daraufhin in den Kommunen und bei Bund und Ländern geschah, liegen auf dem gegenwärtigen Forschungsstand nicht vor. Typischerweise scheinen Teilprivatisierungen erfolgt zu sein, d.h., die Öffentliche Hand vergab einen Teil der anfallenden Arbeiten an Privatfirmen (etwa indem Neubauten grundsätzlich nicht mehr öffentlich gereinigt wurden). Darüber hinaus aber lässt sich kaum etwas Allgemeines sagen. Offensichtlich verlief die Entwicklung im Einzelnen sehr unterschiedlich. Einige Kommunen weiteten die "Fremdreinigung" gezielt immer weiter aus und stellten daher keine neuen »eigenen« Putzfrauen mehr an. ${ }^{522}$

In anderen Fällen aber gab es auch ganz andere Entwicklungen: In Hamburg beispielsweise beschlossen die regierenden Sozialdemokraten bereits im Frühjahr 1976, die erst im Vorjahr begonnene Vergabe von Reinigungsarbeiten an Privatfirmen wieder zu beenden. Den Anlass dafür bot unter anderem die von der ÖTV aufgedeckte Tatsache, dass 34 von den 37 Unternehmen, die seitdem im Auftrag der Stadt in öffentlichen Gebäuden putzten, ihre Beschäftigten an der Wahl eines Betriebsrates gehindert hatten. Ganz ähnlich gegen eine weitere »Fremdreinigung « entschieden später auch der Bremer Senat und der Magistrat von Oberhausen. ${ }^{523}$

521 | Vgl. im Rückblick die »Unterrichtung« des Bundesrechnungshofes für 1977 in: VerBT, Drucksache 8/3238 (8.10.1979), S. 68 f.; Putzfrauen wirbeln Staub auf. In: FAZ, 15.6.1976 (für entsprechende Forderungen des hessischen Landesrechnungshofes); Aktennotiz des ÖTV-Vorstandssekretariats 1 über Besprechungen in Saarbrücken, 7.3.1977 (für die Stadt Saarbrücken und die Universität). In: Archiv Ver.di, Bestand Kluncker, 52. Vgl. zum Hintergrund auch: Heinrich Siedentopf/ Klaus-Dieter Grunwald: Die kommunale Rechnungsprüfung. Bestandsaufnahme und Verbesserungsvorschläge, Wiesbaden 1976, S. 73-75. Hier wird der Übergang von der »Gesetzmäßigkeits- zur Wirtschaftlichkeitsprüfung « als eine der aktuellen Hauptaufgaben der kommunalen Rechnungsprüfung bezeichnet.

522 | Als lokale Beispiele vgl. etwa: Wamper: Möglichkeiten, S. 63-69; Heinz Kühnert: Reinigung der Schulgebäude - ein finanzträchtiges Kapitel im städtischen Haushalt. In: Kommunalwirtschaft (1977), S. 390-391 (für Solingen).

523 | Vgl. dazu: Tofaute: Privatisierung, S. 79f. (für Hamburg); Hauptvorstand der ÖTV: Privatisierung, S. 32 f. (für Bremen); Rationalisierung kostet die Stadt 1,1 Millionen mehr. In: WAZ, 9.2.1980 (für Oberhausen). 
Allerdings durften sich die ÖTV und die öffentlich beschäftigten Putzfrauen wohl auch in diesen Fällen nur bedingt freuen. So beschloss die von der SPD dominierte Stadtverordnetenversammlung von Oberhausen die vollständige »Rekommunalisierung« ihrer Reinigungsarbeiten ausdrücklich mit der Absicht, nun eine zentrale Gebäudereinigung einzurichten, die den gesamten städtischen Putzdienst "zentralisieren und rationalisieren« sollte. In Bremen bedeutete der Verzicht der Stadt auf eine weitere Auftragsvergabe ebenfalls keine Rückkehr zum früheren Status quo: Das Arbeitspensum der Putzfrauen wurde deutlich erhöht. ${ }^{524}$ An der Universität in Saarbrücken schließlich verpflichtete sich der Personalrat (der selbstverständlich vornehmlich mit ÖTV-Mitgliedern besetzt war) in einer ähnlichen Situation, eine Reorganisation der Reinigungsarbeiten mitzutragen, deren Ziel es war, »eine ähnliche Wirtschaftlichkeit zu erzielen, wie sie beim Einsatz privater Unternehmen erreicht wird «. ${ }^{525}$

Eine Privatisierung blieb in diesem Fall aus - die Frage, wer im Nebeneinander von Privatbetrieben und öffentlichen Unternehmen Vorbild für wen sein sollte, wurde aber dennoch ganz anders beantwortet, als es in der traditionellen deutschen Lehre von der staatlichen "Daseinsvorsorge« vorgesehen war. Insofern steht diese Vereinbarung aus Saarbrücken modellhaft für die neuen Rahmenbedingungen, unter denen sich das System der öffentlichen Dienstleistungen und der kommunalen Betriebe seit Mitte der 1970er Jahre weiterentwickeln musste.

Wie stark die politisch-ideologischen Argumente wirken konnten, die der amerikanische Neoliberalismus zur Verfügung stellte, zeigte sich besonders deutlich schließlich in dem dritten Segment, in dem die frühe deutsche Privatisierungsdebatte noch in Heinz Klunckers Jahren als ÖTV-Vorsitzender konkrete Wirkungen entfaltete: in der »Nassbaggerei«, die großen Schiffen die Fahrrinnen in die deutschen Seehäfen freihielt. Die Fachbezeichnung dieses kleinen, nur einigen Experten bekannten Geschäftsfelds mag ein wenig unernst, ja fast etwas kindlich klingen, doch dieser Eindruck täuscht: Es handelt sich um ein höchst wichtiges und sehr umsatzträchtiges Aufgabengebiet. Allein der Bund gab im Haushaltsjahr 1980 1,24 Milliarden DM für solche Räumarbeiten aus, bei denen hoch-

524 | In der Reihenfolge: Oberhausen reinigt städtisch. In: WAZ, 12.2.1980; Hauptvorstand der ÖTV: Privatisierung, S. 34.

525 | Ebd., S. 24. 
spezialisiertes Gerät eingesetzt werden musste. Weiteres Geld kam aus den Etats der Küstenländer und der Hafenstädte. ${ }^{526}$

Einen guten Teil der so bezahlten Baggerarbeiten erledigte die Öffentliche Hand selbst in staatseigenen Betrieben. Der Bund etwa beschäftigte rund 350 Personen im Schichtdienst auf sechs schwimmenden Schaufelbaggern. Näher an der Küste und in den Seehäfen selbst agierten Landesund Kommunalbetriebe. Allein im Hafen von Emden in Niedersachsen etwa zählte die landeseigene Nassbaggerei 120 Mitarbeiter. ${ }^{527}$

Doch auch Privatbetriebe übernahmen solche Aufträge. Die wenigen wirklich großen Bauunternehmen, die es in der Bundesrepublik gab, besaßen auch die für solche Arbeiten nötigen Maschinen und geschultes Personal. Dennoch herrschte auf diesem speziellen Markt keine Konkurrenz. Seit dem späten 19. Jahrhundert teilten sich Privatunternehmer und öffentliche Regiebetriebe die staatlichen Gelder für die Nassbaggerei an den deutschen Küsten vielmehr im stillen Einverständnis: Der Staat erledigte die Aufgabe, vorhandene Fahrrinnen dauerhaft frei zu halten; Privatbagger kamen hingegen immer dann zum Einsatz, wenn die Zufahrtswege weiter vertieft oder ganz neu angelegt wurden. Da die internationale Handelsschifffahrt seit den frühen 1950er Jahren immer größere Schiffe mit immer mehr Tiefgang einsetzte, ließ sich gerade in dieser Zeit mit solchen Ausbauprojekten in den flachen deutschen Küstengewässern ebenso verlässlich viel Geld verdienen wie mit der Instandhaltung. ${ }^{528}$

Diese für beide Seiten bequeme Rollenteilung wollten die privaten Tiefbaubetriebe in den 1970er Jahren allerdings nicht mehr akzeptieren. Sie verlangten zunehmend dringlich einen Anteil an den kontinuierlichen

526 | Die Summe aus: Tagesdienst der SPD-Bundestagsfraktion, 6.3.1980. In: BArch Koblenz, B 108, 69189.

527 | Zahlen (ebenfalls für 1980) aus: Vermerk der Abt. Binnenschifffahrt und Wasserstraßen des Bundesverkehrsministeriums (BVM), 27.4.1981. In: BArch Koblenz, B 108, 69191; Jürgen H. Mendner/Werner Sauerborn: Privatisierung um jeden Preis. Die Politik der Niedersächsischen Landesregierung am Beispiel der Nassbaggerei im Emder Hafen, Hannover 1982, S. $11 \mathrm{f}$.

528 | Zusammenfassend zu dieser Struktur vgl. etwa: Aktenvermerk der Abt. W 1 des BVM über Möglichkeiten einer Verbesserung der Unterhaltungsbaggerei im Seebereich, 17.10.1973. In: BArch Koblenz, B 108, 69186; Aktenvermerk der Abt. Binnenschifffahrt und Wasserstraßen des BVM, 27.4.1981. In: BArch Koblenz, B $108,69191$. 
Räumarbeiten in bereits vorhandenen Fahrrinnen. Hinter diesen Forderungen stand zum einen ein skeptischer Blick in die Zukunft: Weitere großzügige Ausbauaufträge, so fürchtete die Baubranche, werde es bei den Wasserstraßen wohl allein schon wegen der zunehmenden Finanzprobleme der Öffentlichen Hand nicht geben. ${ }^{529}$ Zum anderen fand der lange Bauboom, den die Bundesrepublik seit ihrer Gründung erlebt hatte, mit dem wirtschaftlichen Einbruch von 1974 fast schlagartig ganz allgemein sein Ende. Insbesondere der Wohnungsbau brach stark ein. Dauerhaft verlässlich anfallende Aufgaben gewannen in dieser neuen Krise auch für Großunternehmen betriebswirtschaftlich eine viel größere Bedeutung als zuvor. ${ }^{530}$

Wie begehrlich die Baubranche auf die öffentlichen Gelder für die »Unterhaltungsbaggerei« schaute, zeigte sich daran, dass sie in dieser Sache gemeinsam handelte: Im Oktober 1975 legte ein Konsortium, das von den vier größten bundesdeutschen Baufirmen geführt wurde, dem Verkehrsministerium und dem Bundestag ein konkretes Angebot vor, den bundeseigenen Baggerbetrieb mit all seinen Maschinen und dem gesamten Personal zu übernehmen. Das vorhandene Gerät wollten die Baubetriebe nach dem Zeitwert bezahlen; zugleich versprachen sie, die Löhne und Arbeitsbedingungen der Beschäftigten nicht zu verschlechtern. Der Staat als Auftraggeber der neuen Privatfirma sollte dennoch dank der »unstreitig stärkeren Initiative und Flexibilität der Unternehmer« einen mindestens zehnprozentigen Kostenvorteil gewinnen. Grob gerechnet, entsprach das einer Einsparung im Bundesetat von etwa 50 Millionen DM pro Jahr. ${ }^{531}$

Mit diesem Angebot begann ein jahrelanges Tauziehen zwischen der Bauwirtschaft und ihren Lobbyisten auf der einen sowie dem sozialdemo-

529 | Vgl. etwa die entsprechenden Bemerkungen zu diesen Befürchtungen in: ÖTV-Informationen für den Wasserbau, 27.2.1979. In: AdsD, ÖTV-NRW II, 5/ ÖTVC301004; Aktenvermerk der Abt. Binnenschifffahrt und Wasserstraßen des BVM, 27.4.1981. In: BArch Koblenz, B 108, 69191.

530 | Vgl. als zeitgenössische Zusammenfassung etwa: Peter Leclergue: Am Ende einer Höllenfahrt. In: FAZ, 10.3.1976.

531 | Hauptverband der Deutschen Bauindustrie an den Haushaltsausschuss des Deutschen Bundestages, 27.11.1975. In: BArch Koblenz, B 108, 69187. Vgl. zusammenfassend auch: Mendner/Sauerborn: Privatisierung, S. 54f. Das Konsortium wurde konkret von den großen Baufirmen Hochtief, Strabag, Holzmann und Grün \& Bilfinger dominiert (ebd., S. 62). 
kratisch geführten Bundesverkehrsministerium, den Experten der Wasserstraßenverwaltung und auch der ÖTV auf der anderen Seite. Beide Blöcke stritten um die Zustimmung der Politiker, die im Bundestag und seinen Fachgremien über die Verwendung der öffentlichen Gelder entschieden. In dieser Auseinandersetzung bildeten komplexe Fachfragen und ordnungspolitische Lehrsätze rasch ein schwer zu entwirrendes Geflecht. Die Privatbetriebe inszenierten die Angelegenheit zunehmend als einen grundsätzlichen ordnungspolitischen, ja weltanschaulichen Konflikt: Es gehe darum, dass der Staat »das Prinzip der Subsidiarität« ernst nehme (d.h. alle Arbeiten an Privatfirmen vergebe, die er nicht zwingend selbst erledigen müsse), sowie darum, exemplarisch »die mangelnde Leistungsfähigkeit einer bürokratischen Planwirtschaft gegenüber einer am Markt orientierten sozialen Wettbewerbswirtschaft« zu beweisen. ${ }^{532} \mathrm{Zu}$ ihrer Unterstützung mobilisierten die Baubetriebe die Industrie- und Handelskammern in den Küstenregionen: In einer gemeinsamen Eingabe an den Bundestag mahnten die Kammern, die Nassbaggerei müsse durch Privatisierungen so umgestaltet werden, dass »die marktwirtschaftliche Ordnung der Bundesrepublik« gewahrt sei. ${ }^{533}$

Die Beamten des zuständigen Verkehrsministeriums und der Wasserstraßenverwaltung operierten hingegen vor allem mit ökonomisch-pragmatischen Argumenten. Die von der Bauindustrie versprochenen zehnprozentigen Einsparungen beeindruckten die staatlichen Experten überhaupt nicht. Aus ihrer Sicht konnte der bundeseigene Regiebetrieb für den Staatshaushalt weit größere Vorteile erwirtschaften. Allerdings musste er dazu konsequent rationalisiert werden - und das hieß in der Praxis vor allem: Er

532 | Stellungnahme der Privatfirmen zu der Stellung des BVM betr. den Nassbagger-Regiebetrieb, Okt. 1979. In: BArch Koblenz, B 108, 69188. Vgl. auch die jeweils namentlich gezeichneten Artikel des Bau-Lobbyisten Arthur Pukall in der FAZ: Privatunternehmen statt Regiebetriebe. In: FAZ, 31.8.1977; Die Industrie arbeitet erfolgreicher. In: FAZ, 23.2.1978; Privatisierung in den Mühlen der Politik. In: FAZ, 30.4.1980; Bürokraten weigern sich zu sparen. In: FAZ, 4.5.1981, Die Schwierigkeiten der Privatisierung - an einem Beispiel dargestellt. In: FAZ, 8.6.1982.

533 | Oldenburgische Industrie- und Handelskammer an den Vorsitzenden des Haushaltspolitischen Ausschusses des Bundestags, Heinrich Müller, 10.5.1979. In: BArch Koblenz, B 108, 69188. Diese Stellungnahme erfolgte ausdrücklich in Übereinstimmung mit allen anderen küstennahen Kammern. 
brauchte neue, leistungsfähigere Maschinen. ${ }^{534}$ Das eigens in Auftrag gegebene Gutachten einer Wirtschaftsberatungsfirma bestätigte dieses Urteil: Eine Privatisierung des Staatsbetriebes könne nur dann empfohlen werden, wenn »nicht beabsichtigt [sei], das Rationalisierungspotential auszuschöpfen und die erforderlichen Investitionsmittel zur Verfügung zu stellen «. ${ }^{535}$

Nur nebenbei verwiesen die Ministerialbeamten auf den unlösbaren ordnungspolitischen Widerspruch im Vorhaben der privaten Baubetriebe: Ihre Forderung, der Staat solle einen öffentlichen Betrieb ohne Ausschreibung und ohne Konkurrenz verschiedener Bieter an ein Konsortium der wichtigsten bundesdeutschen Baufirmen verkaufen, habe mit den Grundprinzipien einer "am Markt« orientierten Wettbewerbswirtschaft nichts zu tun und verstoße damit gegen bundesdeutsche Gesetze und gegen Vorschriften der EWG. ${ }^{536}$

Tatsächlich fürchteten die vier Großkonzerne, die das Konsortium dominierten, gerade die freie Konkurrenz und die unternehmerische Initiative, für die sie angeblich doch stritten. In den Niederlanden nämlich existierten kapitalstarke Baufirmen, die sich ganz auf die Nassbaggerei spezialisiert hatten und deshalb nicht nur umfangreiches Know-how, sondern auch die modernsten und leistungsfähigsten Maschinen anbieten konnten. Von einem Wettbewerb, der dazu hätte führen können, dass die Bundesaufträge für die »Unterhaltungsbaggerei« an ausländische Betriebe gehen, wollten die deutschen Baufirmen daher zumindest auf mittlere Sicht nichts wissen: Ihr Konsortium, so erklärten sie, sei als befristetes Instrument mit dem Ziel gedacht, die inländischen Betriebe zu stärken. Nach Ablauf von drei Jahren könne man dann daran denken, den deutschen Markt im Rahmen einer offenen Ausschreibung für die internationale Konkurrenz zu öffnen. ${ }^{537}$

534 | Vgl. etwa: Stellungnahme des Referats W 8 zur Übernahme des Nassbagger-Regiebetriebes, 23.12.1975. In: BArch Koblenz, B 108, 69187.

535 | Betriebswirtschaftlicher Vergleich der Betriebskosten für die Unterhaltung der seewärtigen Wasserstraßen, ausgearbeitet von der Kraft-Wegenstein AG, Sept. 1979. In: BArch Koblenz, B 108, 69188.

536 | Stellungnahme des Referats W 8 zur Übernahme des Nassbagger-Regiebetriebes, 23.12.1975. In: BArch Koblenz, B 108, 69187.

537 | Vgl. etwa: Hauptverband der Deutschen Bauindustrie an den Haushaltsausschuss des Deutschen Bundestages, 27.11.1975; ders. an dens., 1.3.1976; Akten- 
Einmal mehr zeigt sich an diesen Details, wie wenig die einprägsamen Floskeln der neoliberalen Lehre von der angeblich systemisch bedingten staatlichen Ineffizienz und den Segnungen des kapitalistischen Wettbewerbs weiterhalfen, wenn konkret über eine Privatisierung öffentlicher Arbeiten zu entscheiden war. Wenn sie es denn wollten, konnten sich die dafür zuständigen Politiker vielmehr in detaillierte Aufstellungen vertiefen, in denen die Kosten, Betriebsleistungen und Amortisationsaussichten verschiedener Baggermodelle verglichen wurden, die man anschaffen konnte, um den bundeseigenen Regiebetrieb zu modernisieren. Interventionen des privaten Konsortiums, das solche Investitionen scharf kritisierte und unversehens auch ein neues Angebot vorlegte, das nun Einsparungen von 25 Prozent versprach, machten die Sache für Laien zwar nicht einfacher. ${ }^{538} \mathrm{Im}$ Bundesverkehrsministerium stieß aber auch diese verbesserte Offerte auf große Skepsis, weil die Privatbetriebe selbst auf Nachfrage nicht überzeugend erklären konnten, wie sie den Kostenvorteil konkret erreichen wollten. ${ }^{539}$

Dennoch errang die Bauwirtschaft in dieser Sache nach jahrelangen Mühen tatsächlich einen Erfolg. Im März 1980 beschloss der Haushaltsausschuss des Bundestages mehrheitlich, der Bund solle die "Unterhaltungsbaggerei« im Laufe der kommenden drei Jahre an Privatfirmen abgeben. Die Öffentlichkeit nahm davon keine Notiz, obwohl es sich um eine politische Sensation handelte: Der Beschluss kam zustande, weil zwei der drei FDP-Abgeordneten, die in dem Gremium saßen, mit den Oppositionspar-

vermerk der Abt. Binnenschifffahrt und Wasserstraßen des BVK, 14.3.1981. Alle in: BArch Koblenz, B 108, 69187.

538 | Vgl. als nur ein Beispiel für die detaillierten Vergleiche etwa: Stellungnahme des Referats W 8 zur Übernahme des Nassbagger-Regiebetriebes, 23.12.1975. In: BArch Koblenz, B 108, 69187. Kompliziert wurde die Angelegenheit, weil in der Nassbaggerei zwei grundlegend verschiedene Baggertypen benutzt wurden (und werden): Schaufel-Kettenbagger und Saugbagger, deren Vorzüge und Nachteile schwer vergleichbar sind. Vgl. einige Angaben dazu etwa in: A.[lfred] Welte: Moderne Schwimmbagger. In: Hansa 111 (1974), S. 604-620; Hans Laucht: Gefahren einer Privatisierung. In: ÖTV-Magazin 1978, H. 2, S. 17-18.

539 | Sachstandsbericht von Referat BW 22, 10.3.1981. In: BArch Koblenz, B 108, 69190. Zum neuen Angebot des Konsortiums vgl. zusammenfassend: Mendner/ Sauerborn: Privatisierung, S. 58. 
teien CDU und CSU stimmten. Damit verlor die sozialliberale Koalition erstmals seit 1969 ihre Mehrheit in einem parlamentarischen Gremium. ${ }^{540}$

Schlagartig verwandelte sich die Nebensache damit in eine Angelegenheit, die auf oberster politischer Ebene beraten wurde. Bundeskanzler Helmut Schmidt höchstpersönlich entschied in Absprache mit Herbert Wehner und Wolfgang Mischnick, den Fraktionsvorsitzenden der beiden Koalitionsparteien, die SPD solle klein begeben, um den Frieden im Regierungsbündnis zu bewahren. In hektischen Detailverhandlungen, an denen das Konsortium der Baufirmen direkt beteiligt war, entstand ein Kompromiss, der den Beschluss des Haushaltsausschusses leicht korrigierte: Nicht die kompletten Bundesmittel, sondern nur ein Drittel davon sollte nun - ohne Ausschreibung - an die privaten Baubetriebe fließen. Nach Ablauf der drei Jahre wollte man dann prüfen, wie weiter zu verfahren sei. Im Dezember 1981 nahm der Haushaltsausschuss diesen korrigierten Plan an - mit den Stimmen der meisten SPD-Abgeordneten. ${ }^{541}$

Wenig später gelang es Birgit Breuel in Niedersachen nach langem Streit mit ihrer eigenen Partei, das gleiche Vorgehen bei den Baggerarbeiten im Hafen von Emden durchzusetzen. Auch in diesem Fall erfolgte eine Privatisierung ohne echten Wettbewerb: Zwar gab es eine Ausschreibung - deren Konditionen aber waren gezielt so gestaltet, dass der Auftrag de facto nur an eine bestimmte Firma gehen konnte, die bereits vor der offiziellen Entscheidung neues Gerät für die anfallenden Arbeiten gekauft hatte. Dem landeseigenen Betrieb hatte das Kabinett in Niedersachsen hingegen die Hände gebunden: Die Regierung sperrte bereits parlamentarisch bewilligte Haushaltsmittel in Höhe von neun Millionen DM, die dafür gedacht waren, die stark überalterten Gerätschaften zu ersetzen, mit denen im Emdener Hafen gearbeitet wurde. Das zuständige Wasser- und

540 | Ebd.

541 | Vgl. zu den Details: Sachstandsbericht von Referat BW 22, 10.3.1981; Vermerk des Referats BW 22 über die 4. Besprechung mit der Vereinigung der Nassbagger-Unternehmungen, 4.3.1981; Bericht des Abteilungsleiters der Abt. Binnenschifffahrt und Wasserstraßen des BVK an den Minister, 16.3.1981 (hier die Informationen über die Entscheidung des Bundeskanzlers). Alle in: BArch Koblenz, B 108, 69190; Aktenvermerk des Abteilungsleiters, 27.4.1981. In: BArch Koblenz, B 108, 69191. Zur politischen Dimension der Sache und zum Beschluss von 1981 vgl. auch: Mendner/Sauerborn: Privatisierung, S. 58-60; Arthur Pukall: Die Schwierigkeit der Privatisierung - an einem Beispiel dargestellt. In: FAZ, 8.6.1982. 
Schifffahrtsamt hatte diese Investition entschieden befürwortet: Mit dem neuen Bagger, der zwei Maschinen ersetzen sollte, die aus den Jahren 1915 und 1925 stammten, könne der Regiebetrieb die anfallenden Kosten für die »Unterhaltungsbaggerei« im Jadebusen um jährlich zwölf Millionen DM senken. ${ }^{542}$ Als sie schließlich auch den Beschluss zur Teilprivatisierung in Emden durchgesetzt hatte, bescheinigte sich die Wirtschaftsministerin selbst erfreut einen Erfolg in ihrem Kampf, "den Staat endlich von den Aufgaben zu befreien, die im Wettbewerb und in Eigenverantwortung viel besser wahrgenommen werden können«. Zudem spare das Land Niedersachsen jährlich rund zehn Millionen DM. ${ }^{543}$

Die ÖTV, die sowohl den Streit in den Bundestagsgremien als auch die Kontroverse in Niedersachsen mit zahlreichen Plädoyers für eine Rationalisierung und Modernisierung der öffentlichen Betriebe begleitet hatte, kommentierte den Ausgang mit der bitteren Feststellung, es handele sich in beiden Fällen um Entscheidungen, bei denen "Sachfragen völlig in den Hintergrund gedrängt« worden seien: Um ideologischen Lehrsätzen von der Überlegenheit privat geführter Betriebe zu genügen, lasse die Politik bei der Nassbaggerei »fragwürdige Experimente« zu. Alle Versprechungen, man könne durch die geplanten Privatisierungen öffentliche Gelder einsparen, fußten auf ungenauen und fragwürdigen Berechnungen. ${ }^{544}$ In einem Aktenvermerk kam der zuständige Abteilungsleiter im Bundesverkehrsministerium im März 1981 zu einem ganz ähnlichen Urteil: Es sei im Haushaltsausschuss des Bundestages »bei dem Reizthema `Privatisierung`

542 | Vgl. ausführlich zu den komplizierten Details: Mendner/Sauerborn: Privatisierung, S. 13-34.

543 | Breuel: Mensch, S. 37.

544 | ÖTV-Hauptvorstand an die Mitglieder des Haushaltsausschusses des Deutschen Bundestages, 12.3.1981. In: BArch Koblenz, B 108, 69190. Zusammenfassend vgl.: Werner Sauerborn: Regiebetrieb ist wirtschaftlicher. In: ÖTV-Magazin 1982, H. 4, S. 21-22. Vgl. auch schon: Laucht: Gefahren, S. 17-18; ÖTV-Informationen für den Wasserbau, 27.2.1979. In: AdsD, ÖTV-NRW II, 5/ÖTVC301004; Birgit Breuel gesprächsbereit. In: FAZ, 17.1.1980; Vermerk des Persönlichen Referenten des Staatssekretärs im BVM über ein Gespräch mit Heinz Kluncker, 30.1.1981. In: BArch Koblenz, B 108, 69190. Birgit Breuel vermerkte rückblickend »massivsten Widerstand « der ÖTV in Niedersachsen gegen ihre Pläne bei der Nassbaggerei (Breuel: Mensch, S. 37). 
bisher nicht möglich [gewesen], vertieft und emotionslos zu argumentieren.$^{545}$

Wie sich beim Blick auf die Details zeigt, besaß die in praktischer Hinsicht nur marginal bedeutsame Frage, wie die »Unterhaltungsbaggerei« für die deutsche Schifffahrt wirtschaftlich zu gestalten sei, politisch und symbolisch in der Bundesrepublik in den Jahren um 1980 eine überraschend große Bedeutung. Zumal der Privatisierungsbeschluss im Haushaltsgremium des Bundestages vom März 1980, bei dem CDU/CSU und FDP erstmals gemeinsam abstimmten, kündigte bereits das Jahr 1982 an, in dem die FDP die sozialliberale Koalition verließ, um politisch mit der Union zusammenzuarbeiten.

Das folgende Kapitel, das die Tarifrunden für den Öffentlichen Dienst nach 1979/80 untersucht, belegt genauer, wie sehr sich dieser Bruch ebenfalls seit 1979/80 noch in weiterer Hinsicht vorbereitete. Das Klima, in dem diese Verhandlungen stattfanden, unterschied sich massiv von dem der vorangegangenen Jahre. Es ist deshalb gerechtfertigt, schon für diese Zeit bis zum Ende der sozialliberalen Koalition von einem neuen Abschnitt in der Geschichte auch der ÖTV zu sprechen.

545 | Bericht des Abteilungsleiters der Abt. Binnenschifffahrt und Wasserstraßen des BVK an den Minister, 16.3.1981. In: BArch Koblenz, B 108, 69190. 



\section{Krise der Tarifpolitik}

Die ÖTV in der letzten Phase der sozialdemokratischen Ära 1980 bis 1982

\section{Eine verunsicherte Gewerkschaft: Die Stimmung in der ÖTV zu Beginn des neuen Jahrzehnts}

\section{Umfassende Unzufriedenheit: Der Gewerkschaftstag 1980 als Ventil für die "Frustration mehrerer Jahre"}

Im Laufe der Beratungen verwandelte sich der Kongress fast in ein Tribunal: Jeder der Delegierten, die im Juni 1980 auf dem Gewerkschaftstag der ÖTV unmittelbar nach dem Rechenschaftsbericht von Heinz Kluncker das Wort ergriffen, äußerte sich negativ über die Strategie und die Leistungen der Organisation in den vorangegangenen vier Jahren. Dabei hatte sich der Vorsitzende in seiner Bilanz bereits ungewöhnlich selbstkritisch gegeben. Ohne auf Details einzugehen, sprach Kluncker von »Fehleinschätzungen und Pannen« in der Tarifpolitik, aus denen »wir [...] alle gemeinsam [...] lernen müssen «. ${ }^{1}$

Diese verklausulierte Mahnung zu solidarischer Kritik nahm den Vertretern der Basis allerdings nicht den Wind aus den Segeln. Den Reigen der Kritiker eröffnete ein Delegierter aus Hagen, der sich über die »Halbherzigkeit« empörte, mit der die Verbandsführung in der letzten Tarifrunde agiert habe: Für dieses Verhalten des gHV und auch der Großen Tarifkommission könne "kein Verständnis von den Kollegen erwartet werden«. Andere Redner äußerten sich ganz ähnlich. Es sei nötig, »auf dem Gebiet der Tarifpolitik ein Vertrauensverhältnis wiederherzustellen«, weil die Gewerkschaftsführung dieses Vertrauen in den Jahren seit dem letzten Gewerkschaftskongress verspielt habe. Sie berichteten von »einer großen Resignation innerhalb der Mitglieder«; die »Stimmung gegenüber der ÖTV« in den Betrieben könne

1 | Protokoll ÖTV-GT 1980, Bd. 1, S. 59. 
nur noch als »mies« bezeichnet werden und auch die Mitglieder seien höchst unzufrieden: "Sie fühlen sich verarscht. $\aleph^{2}$ Für 1980 habe die ÖTV-Führung eigenmächtig einen Lohn- und Gehaltstarifvertrag akzeptiert, »der die Kollegen vor den Kopf schlägt« und deshalb die unteren Funktionäre der Organisation ebenfalls »unmöglich gemacht« habe: Sie seien nun die »Watschenhansel« sowohl der Gewerkschaftsbasis als auch der nichtorganisierten Arbeitnehmer und sollten dennoch weiterhin für die Organisation werben. ${ }^{3}$

Harro Sachße, einem der ehrenamtlichen Mitglieder des Hauptvorstandes, platzte in diesem Trommelfeuer aus Klagen und Beschwerden schließlich der Kragen. Der Ton, den die Delegierten gegenüber der ÖTV-Führung anschlugen, so gab er zurück, sei »unerträglich«: Die Gewerkschaftsführung lasse sich in ihrer Tarifpolitik durchweg davon leiten, "was durchsetzbar ist, und zwar durchsetzbar nicht nur von außen, sondern auch von innen her, aus der Organisation heraus«. Heinz Kluncker argumentierte in seinem Schlusswort genauso: Wer fordere, die ÖTV solle in den Tarifrunden für den Öffentlichen Dienst fordernder und aggressiver auftreten, der müsse die Frage beantworten, ob die "Kampfbereitschaft" in allen Bereichen des Staatsdienstes wirklich gleichermaßen gegeben sei. Kluncker hielt diese Einheitlichkeit nicht für gegeben - und auch im Frühjahr 1980 habe sie nicht existiert: »Es gibt noch zu viele Kollegen in unserer ÖTV, die gerne streiken lassen und selbst keine Bereitschaft zu einem dauerhaften Arbeitskampf mitbringen.« Unter solchen Bedingungen könne die Organisation nur vorsichtig auftreten. Anschließend bemühte sich der Vorsitzende aber um eine versöhnliche Perspektive: Die scharfe Kontroverse, für die es in der Geschichte der Organisation kein Vorbild gab, habe die ÖTV als eine »Kampfgemeinschaft « gestärkt, »die Lebensverhältnisse ändern und keine Tarifschusterei betreiben will «. ${ }^{4}$

Der Ärger vieler Delegierter über die Führungsmannschaft der eigenen Organisation war allerdings immer noch nicht verraucht. Als der Kongress

2 | In der Reihenfolge der Zitate: Werner König (Hagen), ebd., S. 87; Uta Landsberg (Berlin), S. 94; Erwin Eisenhut (Stuttgart), S. 99; Dieter Pallokat (Berlin), S. 104.

3 | In der Reihenfolge der Zitate: Gerold Schaub (Darmstadt), ebd., S. 108; KarlHeinz Josten (Hannover), S. 118; Horst Dralle (Hannover), S. 181.

4 | In der Reihenfolge der Zitate: H. Sachße, ebd., S. 106; H. Kluncker, ebd., S. 211 u. $212 \mathrm{f}$. 
die Mitglieder des gHV für die kommenden vier Jahre wählte, fiel der offiziell benannte Kandidat für den einzigen neu zu vergebenen Sitz durch: Ein Konkurrent, der sich erst unmittelbar vor der Abstimmung vorstellte, erhielt mehr Stimmen. Wie Heinz Wolf anschließend in persönlichen Briefen an Heinz Kluncker berichtete, ging es bei dieser Wahl kaum um die beiden Personen. Vielmehr habe es hinter den Kulissen des Kongresses unter den Delegierten Absprachen gegeben, »den Mitgliedern des gHV [...] einen sogenannten Denkzettel zu erteilen«. Nur deshalb sei der von der Verbandsführung protegierte Bewerber gescheitert. Versteckt dokumentiere der Wahlgang daher die »Frustration mehrerer Jahre« über die Tarifpolitik der ÖTV, die nicht nur bei vielen Mitgliedern, sondern gerade auch bei den unteren Funktionsträgern der Gewerkschaft herrsche. ${ }^{5}$

Diese schlechte Stimmung speiste sich in der Tat nicht nur aus akutem Ärger über die soeben abgeschlossene Tarifrunde, sondern auch aus längerfristig gewachsenen Enttäuschungen. Keineswegs neu war etwa die 1980 von mehreren Delegierten wieder vorgetragene Kritik, die ÖTV-Führung dominiere und lenke die tarifpolitische Diskussion an der Basis, in der die Forderungen der Organisation formuliert wurden, viel zu stark durch präzise Vorgaben und durch ihre Öffentlichkeitsarbeit. Da die Gewerkschaft ihren Vorsitzenden so intensiv als ihr »Gesicht« einsetzte, zielte dieser Vorwurf direkt auf Heinz Kluncker. Ein Delegierter aus Stuttgart etwa erklärte: Bei »vielen Mitgliedern« und in »der gesamten Öffentlichkeit« herrsche

5 | In der Reihenfolge der Zitate: Heinz Wolf an Heinz Kluncker, 18.6.1980; ders. an dens., 4.7.1980. Beide in: AdsD, Depositum Kluncker, Stehordner 80. Der offizielle Kandidat war Karl-Heinz Jungmann, der seit 1977 die ÖTV-Kreisverwaltung Frankfurt/Main leitete; der ad hoc aufgestellte Gegenkandidat war Karl-Heinz Werner, seit 1968 Bundesbeamtensekretär in der Stuttgarter Hauptverwaltung. Im zweiten Wahlgang, in dem keine absolute Mehrheit der Stimmen mehr erforderlich war, erreichte Werner 315 Stimmen, Jungmann erhielt 294 Stimmen. Den Wahlverlauf und die Vorstellung der beiden Bewerber vgl. in: Protokoll ÖTV-GT 1980, Bd. 1, S. 261-266. Beide Bewerber waren SPD-Mitglieder; Jungmann war mit seinerzeit 36 Jahren deutlich jünger als der 55 Jahre alte Werner. Heinz Wolf hielt Werner gewerkschaftspolitisch für "äußerst schwach«; dessen Wahlerfolg betrachtete der hessische Bezirksvorsitzende auch als "persönliche Niederlage für mich«, weil es ihm trotz vieler Gespräche nicht gelungen sei, ein einheitliches Votum der hessischen Delegierten für Jungmann zu erreichen (so in seinem Brief vom 18.6.1980). 
die Überzeugung, man höre die offizielle Position der ÖTV, »wenn sich der Bildschirm mit unserem Vorsitzenden Kollegen Kluncker füllt«. Daher sei es ein Unding, dass der gHV die Basisdebatte jedes Jahr neu mit öffentlich bekanntgegebenen Empfehlungen einleite. Letztlich gebe es für die einfachen Mitglieder so gar keine echte Entscheidungsfreiheit. ${ }^{6}$

Neben dieser Kritik an der innerverbandlichen Demokratie standen Einwände gegen zwei konkrete tarifpolitische Entscheidungen der vorangegangenen Jahre. Sie betrafen spezielle Fragen und hatten daher selbst innerhalb der Gewerkschaft nur geringe Aufmerksamkeit gefunden, als die ÖTV die nun so negativ bewerteten Regelungen unterzeichnet hatte. Zum einen ging es dabei um die Bezahlung von Auszubildenden und Praktikanten im Bereich der Krankenpflege. Im Frühjahr 1977 hatte die ÖTV die Forderung der öffentlichen Arbeitgeber akzeptiert, diese Vergütungen für alle neu beginnenden Kräfte künftig geringer zu bemessen als zuvor. Eine angehende Krankenpflegerin etwa erhielt nun im dritten Lehrjahr nur noch zwei Drittel der Eingangsvergütung, die nach absolvierter Ausbildung in dieser Berufsgruppe gezahlt wurde, während sie bislang 75 Prozent erhalten hatte. In den ersten beiden Lehrjahren fiel dieser Abstand noch größer aus. ${ }^{7}$

Die Beschäftigung eines Praktikanten oder einer Auszubildenden kam die Kliniken seitdem also günstiger; wer unter den neuen Bedingungen in dieses Berufsfeld einstieg, stand sich hingegen finanziell schlechter als derjenige, der vor 1977 begonnen hatte. Nun war es selbstverständlich höchst ungewöhnlich, dass eine Gewerkschaft nicht protestierte, sondern zustimmte, wenn eine unveränderte Arbeit künftig geringer entlohnt wurde. Wenn die ÖTV-Führung in diesem Fall dennoch nachgab, so tat sie das, weil sie auf ein Versprechen der Arbeitgeber setzte: Würden die Vergütungen abgesenkt, so hatten diese in den Verhandlungen erklärt, könne die Zahl der Ausbildungsplätze für Pflegekräfte deutlich vermehrt werden.

6 | Protokoll ÖTV-GT 1980, Bd. 1, S. 100 (Erwin Eisenhut, Stuttgart). Vgl. ähnlich auch die Bemerkungen von Manfred Kanzleitner (Stuttgart), ebd., S. 84 f.; Uta Leitner (Berlin), S. 92; Dieter Pallokat (Berlin), S. 103.

7 | Die Beispielszahlen für die Krankenpflegerin nach den Angaben der Delegierten Annette Schwarzenau (Berlin) in: Protokoll ÖTV-GT 1980, Bd. 1, S. 95. Die fünf verschiedenen Verträge, in denen die neue Bezahlung geregelt wurde, publiziert in: ÖTV: Wortlaut der überbezirklichen Tarifverträge des Jahres 1977, Stuttgart 1978, Bd. 1, S. 288-298. 
In Zeiten einer starken Jugendarbeitslosigkeit sei es ein solidarischer Akt, so zu handeln. Dennoch lehnte gerade die ÖTV-Gewerkschaftsjugend den Vorschlag der Arbeitgeber strikt ab: „Die Schaffung von mehr Ausbildungsplätzen darf nicht auf Kosten der Vergütung und Qualität der Berufsausbildung erfolgen. ${ }^{8}$

Die Tarifexperten der Gewerkschaft in der zuständigen Verhandlungskommission und in der gHV aber ignorierten diese Position. Sie beriefen sich auf Stimmen innerhalb der ÖTV, die Organisation solle sich um mehr Ausbildungsplätze im Öffentlichen Dienst bemühen, und trösteten sich zusätzlich mit der Erwartung, die finanzielle Schlechterstellung neuer "Azubis« und neuer Praktikanten in der Krankenpflege werde dank der zu erwartenden Lohn- und Gehaltszuwächse in den nächsten jährlichen Tarifrunden in absoluten Zahlen rasch überwunden. Solch ein Verzicht sei akzeptabel, wenn es darum gehe, arbeitslosen Schulabgängern zu helfen. ${ }^{9}$

Auf dem Kongress von 1980 zogen mehrere Delegierte hingegen ein negatives Resümee: Die ÖTV sei den Arbeitgebern »auf den Leim gegangen«, denn diese hätten das "vage Versprechen« von 1977, in den Kliniken mehr Ausbildungsplätze zu schaffen, nicht eingehalten. Siegfried Merten, der für den gHV auf diese Kritik reagierte, widersprach nur insofern, als er auf ein vermehrtes Angebot von Praktikantenstellen verwies: »Trotzdem gestehen wir zu: Das war ein schwerer Brocken, den wir da geschluckt haben. Dafür tragen wir heute noch die Verantwortung. ${ }^{10}$

Noch spezieller war die retrospektive Kritik an einer weiteren, bereits etwas älteren Abmachung unter den vielen speziellen Tarifverträgen, die ÖTV und Arbeitgeber seit dem letzten Gewerkschaftstag von 1976 vereinbart hatten. Sie regelte sehr detailliert ein soziales Zugeständnis der Arbeitgeber an die Beschäftigten: Wer erkrankte kleine Kinder oder andere engste Angehörige pflegen musste, der konnte im Öffentlichen Dienst bei weiterlaufenden Bezügen zeitlich befristet von der Arbeit freigestellt werden. Änderungen im BAT sowie in den Manteltarifverträgen für die beim

8 | ÖTV-Geschäftsbericht 1976/79, S. 394.

9 | Vgl. zusammenfassend Siegfried Merten in: Protokoll ÖTV-GT 1980, Bd. 1, S. 200 f. Vgl. als Beispiel für die Sorgen wegen der Jugendarbeitslosigkeit: Zusätzliche Ausbildungsplätze schaffen! In: ÖTV-Magazin 1977, H. 5, S. 3.

10 | In der Reihenfolge der Zitate: Protokoll ÖTV-GT 1980, Bd. 1, S. 90 f (Lothar Bauer, Dortmund), S. 95 (Annette Schwarzenau, Berlin), S. 201 (S. Merten). 
Staat beschäftigten Arbeiter hatten diesen Anspruch 1979 neu festgesetzt und von zuvor 14 Arbeitstagen auf lediglich sechs Tage verkürzt. Zudem war die Freistellung nun nur noch dann möglich, wenn ein Kind im Alter von bis zu 14 Jahren zu versorgen war. Wie wiederum mehrere Delegierten berichteten, wurden diese Verschlechterungen »von den Kollegen einfach nicht akzeptiert«: Der alte Rechtszustand müsse wieder gelten. ${ }^{11}$

In der Tat hatte die ÖTV den drängenden Arbeitgebern auch in dieser Sache nachgegeben. Sie tat das, weil die Angelegenheit kurz zuvor erstmals gesetzlich geregelt worden war: Der Bundestag weitete das bislang nur tarifvertraglich gesicherte soziale Privileg einiger weniger Berufsgruppen auf alle Lohnabhängigen aus. Allerdings beschlossen die Parlamentarier dabei Regelungen, die in den Details deutlich hinter den Standards des Öffentlichen Dienstes zurückblieben. Im Streit mit ihren Tarifpartnern, der daraufhin begann, widersetzte sich die ÖTV zwar erfolgreich deren Forderung, die gesetzlichen Bestimmungen eins zu eins für die Beschäftigten des Staates zu übernehmen. Einige Abstriche an den alten Verträgen musste sie jedoch akzeptieren. Auch retrospektiv hielt der gHV die Kritik der Delegierten deshalb für nicht gerechtfertigt: Tarifpolitik funktioniere nun einmal nicht ohne Kompromisse. Angesichts der ohnehin zahlreichen negativen Stimmen in Medien und Politik über den Öffentlichen Dienst und seine angeblich skandalösen Privilegien sei solche Flexibilität gerade in der aktuellen Situation unverzichtbar. ${ }^{12}$

\section{Eine "Niederlage« der ÖTV? Der Lohn- und Gehaltsabschluss für 1980 in der Kritik des Gewerkschaftstages}

Genauso uneinig wie in den eben skizzierten Aspekten waren sich die ÖTVFührung und die Vertreter der Basis schließlich auch bei der Beurteilung der Lohn- und Gehaltstarifverträge für 1980. Erst dieser Dissens erklärt den ungewöhnlich scharfen Ton der Kritik auf dem Gewerkschaftskongress,

11 | Vgl. etwa: ebd., S. 92 (Uta Landsberg, Berlin - Zitat) sowie auch: Dieter Pallokat (Berlin), S. 104; Helga Hirsch (Hamburg), S. 125, und die Anträge dazu in: ebd., Bd. 2, S. 466-468. Zuvor hatten die Tarifverträge für den Öffentlichen Dienst die Freistellung auch zugelassen, wenn im Haushalt lebende Eltern erkrankt waren.

12 | Vgl.: ebd., Bd. 1, S. 199f. (Siegfried Merten) sowie allgemein auch Heinz Kluncker, S. 58. 
denn diese Abmachungen betrafen ja alle Angehörigen des Öffentlichen Dienstes - auch die Beamten, da die Arbeitgeber die ausgehandelten tariflichen Verbesserungen in jenem Jahr wieder für sie übernahmen. Folgt man den Delegierten, die sich dazu äußerten, dann meinten viele Mitglieder, die Gewerkschaft habe in der gerade abgeschlossenen Tarifrunde eine "Niederlage« erlitten - und dieser Misserfolg gehe auf das Konto der ÖTVFührungsmannschaft und der Großen Tarifkommission, weil sie die Basis nicht zum Streik aufgerufen hatten. Heinz Kluncker wurde dafür persönlich verantwortlich gemacht: "wir haben lautstark gepfiffen, und Du hast ohne Verbesserung des Angebots Freitagnacht abgeschlossen «. ${ }^{13}$

Mit ihrer Hauptforderung war die Gewerkschaft in den Tarifverhandlungen tatsächlich nicht durchgedrungen. Nach dem Willen der befragten Mitglieder ging es der ÖTV auch 1980 vor allem um eine sozial ausgleichende Komponente: Sie koppelte ihre Forderung nach neunprozentigen Lohn- und Gehaltserhöhungen mit einem Mindestbetrag von 180 DM und bezeichnete gerade diese Summe als essenziell wichtig. Anders als in den direkt vorangegangenen Jahren, in denen (wie oben gezeigt) das soziale Element in der ÖTV-Tarifpolitik etwas in den Hintergrund gerückt war, stand ein besonders deutliches finanzielles Plus für die geringer bezahlten Beschäftigten des Staates damit wieder ganz im Zentrum der gewerkschaftlichen Forderungen. Erklärend verwies die ÖTV vor der Öffentlichkeit erneut auf die allgemeine Teuerung, die Geringverdiener besonders stark belaste. $^{14}$

Ähnlich vertraut wie diese Begründung war Eingeweihten auch die Vorgeschichte der für 1980 erhobenen Forderung: Sie ergab sich aus den Diskussionen und Beschlüssen in den unteren Ebenen der Organisation, obwohl die Führungsspitze einen anderen Kurs befürwortete. Zumal Heinz Klun-

13 | Protokoll ÖTV-GT 1980, Bd. 1, S. 100 (Erwin Eisenhut, Stuttgart). Vgl. ähnlich auch die anderen zu Beginn dieses Kapitels bereits angeführten und zitierten Delegierten.

14 | Vgl. etwa: Kluncker: 180 Mark Sockelbetrag bedeutet für viele plus neun Prozent. In: Die Welt, 18.12.1979; Kluncker macht's nicht billiger. In: WAZ, 18.12.1979; Kluncker-Paket fürs Schaltjahr. In: Aachener Volkszeitung, 18.12.1979. Einen Überblick über den gesamten Forderungskatalog findet man in: ÖTV: Geschäftsbericht 1980-1983. Hrsg. v. der Gewerkschaft Öffentliche Dienste, Transport und Verkehr - Hauptvorstand, Stuttgart 1984 (im Folgenden: ÖTV-Geschäftsbericht 1980/83), S. $135 \mathrm{f}$. 
cker warnte intern, wer weitere nicht-lineare Lohnerhöhungen verlange, der fördere die Privatisierungen im Öffentlichen Dienst. Die Basis - oder vielleicht besser: deren aktiver Teil - entschied jedoch wiederum anders. Nach einem einstimmigen Beschluss der Großen Tarifkommission für die 180 DM präsentierte Kluncker den neuen Mindestbetrag vor der Öffentlichkeit daher als den Kern der ÖTV-Forderungen. ${ }^{15}$

Dabei war der Vorsitzende wohl gerade über diese Summe recht unglücklich: Sie lag höher als all die anderen Mindest- oder Sockelbeträge, die die ÖTV bislang gefordert hatte. Fast schon demonstrativ bekannte sich die Organisation damit zu einem tarifpolitischen Grundprinzip, das die Arbeitgeber seit Jahren scharf kritisierten. Dieses Auftrumpfen der Gewerkschaft gerade in der Tarifrunde für 1980 war allgemeinpolitisch durchaus bemerkenswert, denn im Herbst des Jahres stand die nächste Bundestagswahl an, die über das weitere Schicksal der zunehmend zerstrittenen sozialliberalen Koalition in Bonn entschied. Um die Brisanz von Streiks im Öffentlichen Dienst so kurz vor einer Wahl wussten - zumal nach den Ereignissen in Großbritannien im Jahr zuvor - selbstverständlich alle Beteiligten.

Wie Akten des Bundesinnenministeriums belegen, blickte auch die ÖTV-Führung sorgenvoll auf die kommende Tarifrunde. In Vorgesprächen mit Vertretern der Bundesregierung und der Länder drängte Heinz Kluncker bereits im November 1979, die Arbeitgeber sollten frühzeitig ihren "guten Willen« beweisen, um einen möglichst konfliktfreien Ablauf der Verhandlungen zu garantieren. Konkret wünschte er sich einen rasch zu vereinbarenden Tarifvertrag, der die Sparförderung der Arbeitgeber für die Beschäftigten des Öffentlichen Dienstes deutlich verbessern sollte: Gäbe es diesen Abschluss noch vor Beginn des neuen Jahres, dann werde das Zugeständnis der Arbeitgeber in der ÖTV zu einer »Mäßigung bei der Formulierung der Lohnforderungen« führen. Politisch sei dies im Interesse beider Seiten: »Man solle sich beiderseits 1980 ein Fiasko ersparen. ${ }^{16}$

15 | Vgl. den retrospektiven Überblick durch Kluncker selbst in: Protokoll der 3. Sitzung des HV, 29./30.1.1981. In: AdsD, ÖTV, 5/ÖTVB130080. Vgl. auch: Kluncker spricht laut von Streik. In: FR, 3.3.1980; Kluncker riskiert eine Machtprobe. In: StZ, 24.3.1980.

16 | In der Reihenfolge der Zitate: Vermerk über die Besprechung der Staatssekretäre, 26.11.1979; Vermerk über das Spitzengespräch Bund/TdL/VKA - ÖTV, 
Die Tarifpartner aber verweigerten sich: Als ein »Instrument der Einkommensanpassung " gehöre auch eine verbesserte Sparförderung in die allgemeinen Lohnverhandlungen. Zudem könne der Vorsitzende ja nicht garantieren, dass die ÖTV nach einem ersten Erfolg tatsächlich bescheiden auftreten werde. ${ }^{17}$ Die tarifliche Morgengabe der Arbeitgeber, die sich Heinz Kluncker gewünscht hatte, blieb daher aus; die Mitgliederdiskussion in der ÖTV, die sich wegen fehlender Quellen nicht detailliert nachzeichnen lässt, führte zu dem oben skizzierten Forderungskatalog.

In den offiziellen Tarifverhandlungen, die Anfang März 1980 begannen, verwahrten sich die öffentlichen Arbeitgeber - wie es zu erwarten gewesen war - gerade gegen den Mindestbetrag von $180 \mathrm{DM}$ und das damit angestrebte besondere finanzielle Plus für die unteren Lohn- und Gehaltsgruppen: Es sei »leistungshemmend « und zwinge sie auf mittlere Sicht zu »kostspieligen Entzerrungen« der immer stärker nivellierten Vergütungshierarchie. ${ }^{18}$ In diesem Streit gerieten die Tarifpartner nach den eher unauffällig ausgefochtenen Tarifrunden der vorangegangenen Jahre erstmals

8.11.1979. Beide in: BArch Koblenz, B 136, 15822. Die besonderen Zahlungen der Arbeitgeber als Beitrag zur "Vermögensbildung « der Arbeitnehmer gab es im Öffentlichen Dienst seit 1970: Pro Monat betrugen sie 13 DM, die auf ein Sperrkonto gingen und Einzahlungen des Arbeitnehmers ergänzten. Diese Summe war seitdem unverändert geblieben; in der Privatwirtschaft wurde 1980 hingegen vielfach bereits deutlich mehr gezahlt (meist 39 DM, oft aber auch schon 52 DM pro Monat). Auch das BMdI gab daher zu, die Forderung der ÖTV (konkret verlangte die Gewerkschaft 52 DM als neue Summe) sei »im Prinzip berechtigt" (so in der oben angeführten Besprechung der Staatssekretäre). Die genannten Zahlen aus: Aktenvermerk der Abt. D III/1 des BMdI über vermögenswirksame Leistungen im Öffentlichen Dienst, 9.11.1979. In: ebd. Heinz Kluncker vermied im Übrigen öffentlich ganz bewusst den offiziellen Begriff der »Vermögensbildung«: Man betreibe »Etikettenschwindel«, wenn man eine "Sparförderung« so benenne (Transkript des Interviews mit Heinz Kluncker in »Bilanz«, ZDF, gesendet am 30.6.1976, 20.15 Uhr. In: Archiv Ver.di, Bestand Kluncker, 45).

17 | Vermerk über die Besprechung der Staatssekretäre, 26.11.1979. In: ebd.

18 | Vermerk der Unterabteilung ZB im Bundeskanzleramt, 29.2.1980. In: BArch Koblenz, B 136, 15822. Vgl. ferner: Vermerk des Referats 132, 10.3.1980; Aufzeichnung über das Ergebnis des ersten Ministergespräches zur Tarifrunde 1980 im Öffentlichen Dienst, 5.3.1980. Beide in: BArch Koblenz, B 136, 15822. Protokoll der Lohn- und Vergütungstarifverhandlungen für den Öffentlichen Dienst, 7.3.1980. In: BArch Koblenz, B 222, 1332. 
wieder durchaus heftig aneinander. Nach dem 25. März kam es in mehreren Großstädten für jeweils einige Stunden zu Warnstreiks im Öffentlichen Nahverkehr, bei anderen kommunalen Versorgungsbetrieben sowie in einigen Ämtern und Behörden. Mancherorts beteiligten sich zahlreiche Beschäftigte: 7.000 waren es etwa in Köln, 1.500 in Hamburg und 1.000 in Frankfurt am Main. ${ }^{19}$

Die Arbeitgeber hielten diese Arbeitsniederlegungen für illegal, weil nach ihrer Interpretation zu diesem Zeitpunkt noch die Friedenspflicht galt, und auch die ÖTV sprach offiziell durchweg von »spontanen« Aktionen. De facto dürften die jeweiligen Ortsgruppen der Gewerkschaft und die lokalen Funktionäre jedoch das ihre getan haben, um die kollektiven Ausstände möglich zu machen. ${ }^{20}$ In der bundesdeutschen Presse erntete die ÖTV wegen dieser Warnstreiks einmal mehr scharf negative Kommentare: Sie schädige die Bürger, weil sie »nur so aus Spaß an der eigenen Durchsetzungsfähigkeit« trotz guter Gegenargumente der Arbeitgeber unnachgiebig versuche, einen sozial ausgleichenden Abschluss zu erreichen. ${ }^{21}$

Da ein Arbeitskampf zu drohen schien, befasste sich - nach einer mehrjährigen Pause - erstmals wieder der Bundeskanzler persönlich mit den Details der Tarifstreitigkeiten für den Öffentlichen Dienst. Helmut Schmidt erwies sich auch bei dieser Gelegenheit als ein Mann der klaren Worte: Es dürfe keinen Abschluss geben, der bei der allgemein geltenden Prozentzahl höher liege als die 6,8 Prozent, auf die sich die IG Metall mit ihren Tarif-

19 | Die Zahlen aus: Meldung der Führungs- und Lagezentrale des BMdI, 27.3.1980. In: BArch Koblenz, B 222, 1333. Vgl. auch die Angaben in: Pressedienst der ÖTV Hessen, Nr. 7/80, 26.3.1980. In: Archiv Ver.di, Bestand Kluncker, 26, sowie ferner: "Spontis« an der Streikfront. In: Handelsblatt, 27.3.1980; Warnstreiks - nur Ärger. In: Bonner Rundschau, 27.3.1980.

20 | Vgl. etwa den scharfen Protest des BMdI gegen das "rechtswidrige Verhalten« der Ausständigen in: Presseerklärung des BMdI, 27.3.1980. In: Archiv Ver.di, Bestand Kluncker, 26. Ein Hinweis auf die Beteiligung der lokalen ÖTV-Spitzen findet sich in: Meldung der Führungs- und Lagezentrale des BMdI, 27.3.1980. In: BArch Koblenz, B 222, 1333.

21 | Verlust des Augenmaßes. In: Der Tagesspiegel (Berlin), 6.4.1980. Vgl. ganz ähnlich auch: Klunckers Strategie. In: Rheinischer Merkur, 28.3.1980; Tarif-Poker wie eh und je. In: Saarbrücker Zeitung, 28.3.1980; Ohne Vernunft. In: FAZ, 28.3.1980, Kluncker »sockelt«. In: Rheinische Post, 24.3.1980; Teurer Prinzipienstreit. In: Handelsblatt, 25.3.1980. 
partnern bereits geeinigt hatte. Eine soziale Komponente sei akzeptabel, auch um der ÖTV entgegenzukommen; sie dürfe aber insbesondere die Bezüge der beim Staat beschäftigten Arbeiter nicht dauerhaft noch weiter nach oben führen, denn deren Verdienste seien »im Vergleich zum gewerblichen Bereich« schon gegenwärtig »viel zu hoch«. Einen Einigungszwang sah der Kanzler nicht: »Notfalls müsse auch ein Scheitern der Verhandlungen in Kauf genommen werden. " Im Übrigen wolle er, »wenn notwendig«, über die ganze Angelegenheit gerne persönlich mit Heinz Kluncker sprechen. ${ }^{22}$ Auf einer zweiten Besprechung wenig Tage später erwähnte der Kanzler noch eine zweite Möglichkeit, die ÖTV zu bremsen: Es müsse »Kontakt« mit der IG Metall »in dem Sinne aufgenommen werden, daß von dort aus auf Kluncker eingewirkt wird «, keinen Abschluss anzustreben, der über die letzten Lohnabschlüsse in der gewerblichen Wirtschaft hinausgehe. ${ }^{23}$

$\mathrm{Ob}$ es daraufhin eine Beratung zwischen dem Kanzler und dem ÖTVVorsitzenden und/oder auch Interventionen durch die Führung der IG Metall bei Heinz Kluncker gegeben hat, lässt sich nicht sagen. Allerdings bemühte sich die Spitze der ÖTV gerade nach den Warnstreiks sehr intensiv um eine Einigung in letzter Minute. Offensichtlich war es ihr wichtig, den Pfad zu vermeiden, der sowohl zu einer Schlichtung als auch zur Urabstimmung und dann weiter zu Streiks führte. Die erhöhte Sparförderung der Arbeitgeber, über die man kurz zuvor noch ergebnislos gesprochen hatte, wurde nun Teil einer Paketlösung, auf die sich die Tarifparteien schließlich am 28. März 1980 nach einer der üblichen Marathon-Verhandlungsrunden einigten. Wie Heinz Kluncker hinterher intern wie öffentlich erklärte, handelten die versammelten Fachleute der Gewerkschaft und die Mitglieder der Großen Tarifkommission unter dem Eindruck, sowohl die Bundesregierung als auch die TdL seien bereit, aus den gemeinsamen Tarifverhandlungen auszuscheren, um einen Arbeitskampf zu riskieren. Die »Einheitlichkeit des öffentlichen Dienstes bei den Tarifabschlüssen« sei für die ÖTV aber unverzichtbar: Die Gewerkschaft stehe »in der Verantwortung«,

22 | Aufzeichnung über das Ergebnis des Ministergesprächs beim Bundeskanzler zur Tarifrunde im Öffentlichen Dienst, 19.3.1980. In: BArch Koblenz, B 136, 15822 .

23 | Aufzeichnung über das Ergebnis des Ministergesprächs beim Bundeskanzler zur Tarifrunde im Öffentlichen Dienst, 26.3.1980. In: ebd. 
diese Übereinstimmung zu bewahren. ${ }^{24}$ Die Haltung des Bundeskanzlers scheint der Gewerkschaftsspitze also bekannt gewesen zu sein - wie sie kommuniziert wurde, muss jedoch offenbleiben.

So entstand der auf dem Gewerkschaftstag dann scharf kritisierte Abschluss, den die Große Tarifkommission nach eindringlich werbenden Worten Heinz Klunckers mit Zwei-Drittel-Mehrheit akzeptiert hatte. Unter den vielen komplizierten Kompromissen, die im Laufe der Tarifgeschichte schon für den Öffentlichen Dienst entstanden waren, gebührt dieser Abmachung wohl ein Ehrenplatz auf der Rangliste der nur noch für Experten verständlichen Verträge. Lediglich auf den ersten Blick war das Resultat leicht zu fassen: Neben einer prozentualen Erhöhung der Löhne und Gehälter um 6,3 Prozent stand ein Mindestbetrag von 110 DM pro Monat, der in jedem Fall erreicht werden musste. Wer genauer hinschaute und sich im speziellen Vokabular der Tarifverträge auskannte, entdeckte allerdings, dass sich diese Regelung von den Mindest- oder Sockelbeträgen unterschied, die in früheren Abmachungen vereinbart worden waren. Bei den speziellen Zuschlägen, die auch dem Geringverdiener die 110 Mark sicherten, handelte es sich nämlich um "zusätzliche Zahlungen«, die lediglich für zwölf Monate gewährt wurden. Sie verschwanden also wieder, wenn der Tarifvertrag ablief, während alle vorherigen Mindestzahlungen das Tarifgefüge jeweils dauerhaft verändert hatten. ${ }^{25}$

Diesen Unterschied, der auf Uneingeweihte wahrscheinlich wie eine juristische Haarspalterei wirkte, betrachteten die Arbeitgeber als großen Erfolg. Öffentlich erklärte Bundesinnenminister Gerhart Baum (FDP), die »elende Sockelei« im Öffentlichen Dienst sei damit endlich beendet. ${ }^{26}$ Wie sich denken lässt, präsentierte und bewertete Heinz Kluncker den Abschluss ganz anders. Es gebe ja eine wirkungsvolle soziale Komponente:

24 | Protokoll ÖTV-GT 1980, Bd. 1, S. 57. Vgl. auch H. Kluncker in: Protokoll der 3. Sitzung des HV, 29./30.1.1981. In: AdsD, ÖTV, 5/ÖTVB130080.

25 | Vgl. zu den Details: ÖTV-Geschäftsbericht 1980/83, S. 136f. Zudem waren diese "zusätzlichen Zahlungen« auch nicht "gesamtversorgungsfähig«, d.h., sie hatten keine Bedeutung für die spätere zusätzliche Altersrente der staatlichen Arbeiter und Angestellten.

26 | Baum erfreut, daß die »elende Sockelei« im öffentlichen Dienst vermieden wurde. In: Die Welt, 31.3.1980. 
Wer weniger als 1.750 DM brutto im Monat verdiente, der erhalte dank des Tarifabschlusses ein Lohnplus von bis zu 7,8 Prozent. ${ }^{27}$

Nüchtern betrachtet handelte es sich bei der Abmachung vom 28. März 1980 um einen mühsam ausgehandelten Kompromiss, der so kompliziert konstruiert war, dass wohl nicht nur Außenstehende, sondern auch die direkt betroffenen Arbeitnehmer kaum noch beurteilen konnten, welche Seite denn "gewonnen « hatte. ${ }^{28}$ Der starke Unwille, den die Delegierten kaum drei Monate später auf dem Gewerkschaftstag der ÖTV artikulierten, beweist daher vielleicht vor allem, wie unpopulär diese Tarifpolitik geworden war, in der Experten immer komplexere Detailregelungen aushandelten, um stets beiden Seiten doch noch »irgendwie« gerecht zu werden. Wie eine Vertreterin der ÖTV-Basis klagte, entstanden so Tarifverträge, die »teilweise kaum noch verständlich « seien. ${ }^{29}$

Gleichzeitig fühlten sich die Beschäftigten des Staates offensichtlich auf neuartige Weise unsicher und sozial ungeschützt. Ein Delegierter aus Berlin benannte die Faktoren, die dafür verantwortlich waren: »Nullstellenplan [d.h.: Einstellungsstopps], Rationalisierung, Veränderung von Arbeitsinhal-

27 | Im Schwitzkasten. In: Hannoversche Allgemeine Zeitung, 29.3.1980.

28 | Vgl. dazu die treffenden Worte in: Waldemar Schäfer: Kein K.o. für Kluncker. In: Handelsblatt, 1.4.1980. Der fast schon gewundene Kompromisscharakter zeigt sich etwa an den Bestimmungen für eine zweite soziale Komponente, die den Mindestbetrag von 110 DM ergänzte: Der Vertrag erhöhte die oben schon erwähnte Sparförderung der Arbeitgeber (die immer eine Eigenleistung des Arbeitnehmers voraussetzte) nur für Geringverdiener. Sie erhielten bei einem Bruttoeinkommen von bis zu 1.900 DM nun 26 DM statt der sonst gezahlten 13 DM Sparförderung pro Monat. Fast schon absurderweise wurden die zusätzlichen 13 DM allerdings ein Jahr direkt als "persönliche Zulage« ausgezahlt. Erst nach dieser Zeit sollten sie dann - wie üblich - auf das gesperrte Konto für die »Vermögensbildung« gehen, d. h., de facto handelte es sich für ein Jahr eben nicht um einen Teil der auf lange Sicht konzipierten Sparförderung, sondern um einen Lohnzuschlag, der nur nicht so deklariert wurde. Bei solchen Regelungen ließ sich wohl berechtigt von "gewissen Verrenkungen« der Tarifpartner (so Schäfer in dem genannten Artikel) sprechen, die gemeinsam unbedingt eine Einigung erreichen wollten. Zu den Details der Regelung vgl.: ÖTV-Geschäftsbericht 1980/83, S. 138.

29 | Uta Landsberg (Berlin). In: Protokoll ÖTV-GT 1980, Bd. 1, S. 93. Eine ähnliche Klage vgl. auch schon in: Protokoll ÖTV-GT 1976, Bd. 1, S. 123 (der Delegierte Reinhard Lehmann, Berlin). 
ten, Minderung der Wertigkeit der Arbeit durch neue Technik berühren inzwischen fast alle Bereiche auch des öffentlichen Dienstes.«Die Gewerkschaft aber sei gerade in diesen Fragen zu passiv: Sie solle und müsse »agieren, nicht reagieren«, wenn sie wirklich die Interessen der Beschäftigten wahren wolle. ${ }^{30}$

Der Vorwurf, auf den sich alle der Kritiker einigen konnten, die im Sommer 1980 auf dem Gewerkschaftstag sprachen, kann wohl lauten: Die Organisation habe sich nicht erst in der Lohnrunde für 1980, sondern bereits in den vorangegangenen Jahren tarifpolitisch verzettelt. Um der ungewöhnlich selbstkritischen Debatte eine positive Perspektive zu geben, entwickelte eine Gruppe der Delegierten, in der Heinz Wolf offensichtlich eine führende Rolle übernahm, einen Initiativantrag, der den gHV aufforderte, künftig klare Prioritäten für die tarifpolitische Arbeit der Organisation zu entwickeln, die sich an dem »Einsatzwillen einer breiten Mitgliedschaft« orientieren sollten: "Man muß in bestimmten Situationen wissen, wohin die Reise geht.« Bei dieser Schwerpunktsetzung sollte die Führung insbesondere »tarifpolitische Maßnahmen zur Arbeitsplatzsicherung« im Auge behalten. Erklärtermaßen sollte so die »Überschaubarkeit« der ÖTV-Tarifpolitik wiederhergestellt werden: »Es kann einfach nicht mehr so sein, daß die zuständigen Funktionäre des Tarifsekretariats Tarifverträge ausarbeiten und abschließen, ohne daß wir überhaupt wissen, wohin der Hase gegangen ist und was daraus wird.«Die Versammlung stimmte dem Antrag nach kurzer und kaum kontroverser Debatte mit großer Mehrheit zu. ${ }^{31}$

Trotz der vielen scharfen Worte, die gefallen waren, endete der Kongress also in versöhnlicher Stimmung. Recht besehen hatte die ÖTV ihre interne Uneinigkeit mit dem zitierten Beschluss allerdings nicht gelöst, sondern wohl eher noch intensiviert. So stärkte der Gewerkschaftstag die tarifpolitische Macht des gHV, obwohl von der Basis der Organisation doch schon seit einigen Jahren beständig die Klage kam, sie werde bei der

30 | Dieter Pallokat (Berlin). In: Protokoll ÖTV-GT 1980, Bd. 1, S. 104.

31 In der Reihenfolge der Zitate: Heinz Wolf (als Sprecher der Antragsteller), ebd., S. 496; Harro Sachße (HV), ebd., S. 500. Der Antrag in: ebd., Bd. 2, S. 325; die Abstimmung in: ebd., Bd. 1, S. 508. In der Debatte hatte nur ein Delegierter gegen den Antrag gesprochen: Georg Backhaus (Hamburg) warnte als einer der Vertreter der Beschäftigten in der privaten Transport- und Verkehrssparte, die ÖTV werde sich mit dieser Stärkung des gHV selbst »Fesseln anlegen« (ebd., S. 502). 
Planung der jährlichen Tarifrunden zu wenig beteiligt. Zudem enthielt die Formulierung von den zentral wichtigen »Maßnahmen zur Arbeitsplatzsicherung« indirekt eine klare Absage an weitere Mindest- oder Sockelbeträge, die - wie oben gezeigt wurde - unbestreitbar dazu beigetragen hatten, dass gering qualifizierte Handarbeiten im Öffentlichen Dienst deutlich besser bezahlt wurden als in der Privatwirtschaft. In der Privatisierungsdebatte spielte dieser Zusammenhang bekanntlich eine zentrale Rolle. Die sozial ausgleichenden Komponenten, die Geringverdienern besonders zugute kamen, aber lagen den Gewerkschaftsmitgliedern, die sich an der basisdemokratischen Debatte über die Tarifpolitik der Organisation beteiligten, ganz offensichtlich nach wie vor besonders am Herzen.

Klunckers Formulierung, die ÖTV sei eine »Kampfgemeinschaft«, die keine "Tarifschusterei« mehr betreiben wolle, war daher ohne Frage mehr Wunschdenken als Realität. Wie sehr dieses skeptische Urteil zutraf, trat gerade in den beiden letzten Tarifrunden zu Tage, die noch in die insgesamt achtzehn Jahre dauernde "Ära Kluncker« gehören. Sowohl in den Beratungen für 1981 als auch für 1982 stand die ÖTV vor ganz neuen Herausforderungen: Nicht sie selbst, sondern die Arbeitgeber, die ihre Personalkosten senken wollten, bestimmten die Verhandlungen durch drohend vorgetragene Forderungen. Mit dem üblichen Prozedere der Tarifrunden für den Öffentlichen Dienst hatte dieser Ablauf bereits 1981 nur noch wenig zu tun - und 1982 kam es dann sogar zu einer ganz neuen Frontstellung.

\section{2. "Der Herr schütze uns vor unseren Freunden«: Der Konflikt der ÖTV mit der SPD-Regierung Nordrhein- Westfalens in den Tarifverhandlungen für 1981}

\section{Verkehrte Welt in der Tarifpolitik}

Heinz Kluncker ließ jede diplomatische Rücksichtnahme fahren. Wahrscheinlich wurde er auch sehr laut. Das »Tänzchen«, das die Arbeitgeber in der aktuellen Tarifrunde mit ihm und der ÖTV aufführten, müsse sofort ein Ende haben, so polterte der Gewerkschaftsvorsitzende am 20. März 1981 auf einem Treffen der Verhandlungskommissionen: »Meine Herren, wenn das so weitergeht, dann wird sich der Hauptvorstand der ÖTV nicht mehr in der Lage sehen, mit der TdL Tarifverhandlungen zu führen.« Er werde den zuständigen Gremien der ÖTV empfehlen, mit den Landesre- 
gierungen künftig nur noch auf Bezirksebene zu verhandeln - und dann bleibe in der Tariflandschaft des Öffentlichen Dienstes nichts mehr beim Alten: »Wir werden uns dann bezirklich hochschaukeln«.32

Diese Drohung verband Kluncker mit einem scharfen Angriff auf Johannes Rau, den Ministerpräsidenten Nordrhein-Westfalens, der zwar nicht persönlich anwesend war, die Tarifverhandlungen aber öffentlich mehrmals mit ÖTV-kritischen Anmerkungen begleitet hatte. Nach Klunckers Urteil versuchte Rau »die Autorität und den guten Willen« der ÖTV zu untergraben. Deshalb trage der sozialdemokratische Landespolitiker die Verantwortung für das "Chaos" und die "sozialen Spannungen«, die bei Streiks in öffentlichen Versorgungsbetrieben gerade »in den Städten des Reviers« unweigerlich entstehen würden. Dann könne sich Rau zudem das gerade erst verabschiedete "Haushaltsstrukturgesetz « seiner Regierung, das auf den Abbau der staatlichen Personalkosten zielte, »in die Haare massieren lassen«. Kluncker fügte hinzu: »Sie sollen sich bloß nicht einbilden, daß das für Nordrhein-Westfalen billiger wird. ${ }^{33}$

Mit dieser Attacke schlug der ÖTV-Vorsitzende im Frühjahr 1981 verbal bereits zum zweiten Mal auf den sozialdemokratischen Ministerpräsidenten des bevölkerungsreichsten Bundeslandes ein. Schon bei der offiziellen Eröffnung der Tarifgespräche am 6. März hatte sich Kluncker ungewöhnlich giftig über Rau geäußert: Da der Politiker öffentlich gerne wortreich über seinen protestantischen Glauben sprach und von der Presse deshalb oft als »Bruder Johannes« tituliert wurde, verspottete ihn Kluncker (ohne den Namen direkt zu nennen, aber doch unmissverständlich auf Rau gemünzt) als "moralinsauren Prediger, um nicht zu sagen Pharisäer«, der Verständigung im Munde führe, gleichzeitig aber doch »in unerträglicher Weise« die Grundprinzipien der Tarifautonomie in Frage stelle. ${ }^{34}$

32 | Wortprotokoll der Erklärung von Heinz Kluncker in den Tarifverhandlungen für den Öffentlichen Dienst, 20.3.1981, als Anhang enthalten in: BMdI, TdL und VKA an Ministerpräsident Johannes Rau, 20.3.1981. In: BArch Koblenz, B 136, 15823.

33 | Ebd.

34 | Rede von H. Kluncker zur Eröffnung der Plenarrunde in den Tarifverhandlungen für den Öffentlichen Dienst, 6.3.1981. In: AdsD, Depositum Kluncker, Stehordner 81 . 
So aggressive Töne hatte es - soweit wir wissen - in den Tarifgesprächen für den Öffentlichen Dienst in der Geschichte der Bundesrepublik noch nie gegeben. Nach Klunckers Drohungen in der zweiten Verhandlungsrunde zeigte sich Bundesinnenminister Gerhart Baum bestürzt: Die »Spannung« zwischen der ÖTV und dem Düsseldorfer Kabinett, so schrieb der FDP-Politiker aus Stuttgart an Johannes Rau, sei »einem zu erzielenden Verhandlungsergebnis nicht förderlich «. ${ }^{35}$ In einem vertraulichen Telefongespräch bat Baum den Ministerpräsidenten noch am gleichen Tag eindringlich »um Zurückhaltung «. ${ }^{36}$

So erstaunlich wie Klunckers bewusst auch persönlich gemeinte Attacken auf einen der prominentesten Sozialdemokraten in der Bundesrepublik war ihr konkreter Anlass. Der ÖTV-Vorsitzende empörte sich derart emotional, weil die nordrhein-westfälische Regierung im Frühjahr 1981 tarifpolitisch »verkehrte Welt" spielte: Das Landeskabinett forderte, die Löhne und Gehälter der Staatsbediensteten um einen für Arbeiter, Angestellte und Beamte gleich hohen Einheitsbetrag zu erhöhen. Nach dem vorangegangenen jahrelangen Streit um die angeblich »nivellierenden« Folgen der Mindest- oder Sockelbeträge, die von der ÖTV gefordert wurden, trug diese Kehrtwende der politisch einflussreichen NRW-Regierung fast schon etwas absurde Züge - allerdings lässt sich das Gleiche auch über die Reaktion der Gewerkschaft sagen, denn Heinz Kluncker drohte den Arbeitgebern am 20. März 1981 mit einer Entwicklung, die er selbst nur ein halbes Jahr zuvor auf dem ÖTV-Kongress noch als verhängnisvoll bezeichnet hatte. Nun aber sollte sein Satz, die ÖTV sei verpflichtet, die Einheitlichkeit der Tarifabschlüsse im Öffentlichen Dienst zu erhalten, unversehens nicht mehr gelten.

In der Tarifrunde für 1981 - so zeigt die eben skizzierte politische Rochade - geschah offensichtlich etwas Neues. Die wohleingeübten Rollen der Tarifparteien verloren ihre klaren Konturen; neue Strategien und Verhandlungstricks wurden erprobt. Diese Entwicklung, die sich im nachfolgenden Jahr sogar noch weiter beschleunigte, hatte - wie sich denken

35 | BMdI, TdL und VKA an Ministerpräsident Johannes Rau, 20.3.1981. In: BArch Koblenz, B 136, 15823.

36 | Aktenvermerk von Referat 132 des BMdI zur Unterrichtung an den Gruppenleiter, den Abteilungsleiter und den Chef des Bundeskanzleramtes, 23.3.1981. In: BArch Koblenz, B 136, 15823. 
lässt - einen konkreten ökonomischen Hintergrund: Die konjunkturelle Lage der Bundesrepublik verdüsterte sich wieder, und damit gewann das Problem der wachsenden Defizite in den öffentlichen Etats und der damit eng verbundenen staatlichen Schuldenwirtschaft noch einmal deutlich an politischem Gewicht.

Wie bereits 1973/74 begann die Krise erneut mit stark steigenden Energiekosten: Dem ersten »Ölpreisschock« folgte ein zweiter, der bewies, wie rasch man bei Rohöl und Benzin Preisen nachtrauern konnte, die eben noch als exorbitant hoch gegolten hatten. Die Bundesrepublik litt dabei gleich doppelt. Sie war von Energieimporten abhängig, die nun deutlich teurer bezahlt werden mussten. Da es sich um eine internationale Krise handelte, verschlechterten sich zugleich die Absatzchancen der Exportindustrie, ohne die das Land ökonomisch nicht florierte. Damit sanken auch die Steuereinnahmen von Bund, Ländern und Gemeinden, während die ohnehin hohen Arbeitslosenzahlen und auch die Ausgaben für Arbeitsmarktpolitik weiter wuchsen. ${ }^{37}$

All diese Probleme wogen politisch besonders schwer, weil die Hoffnung, der Staat könne so einen wirtschaftlichen Einbruch mit kreditfinanzierten Investitions- und Förderprogrammen in einen Boom verwandeln, in der zweiten Hälfte der 1970er Jahre weitgehend verkümmert war. Wer nach dem Misserfolg der vorangegangenen Konjunkturprogramme in der neuen Krise weiter auf die Rezepte des Keynesianismus setzen wollte, der musste sich den Vorwurf anhören, wider besseres Wissen unbelehrbar zu sein. $^{38}$

Aus verschiedenen Gründen bündelten sich die Sorgen der Bundesrepublik, die der zweite »Ölpreisschock« auslöste, vor allem in NordrheinWestfalen. Das Ruhrgebiet kämpfte ohnehin wirtschaftlich und sozial im-

37 | Vgl. etwa: Peter König: Ölpreisschocks und makroökonomische Anpassungsprozesse zwischen Industrieländern, Konstanz 1990; Klaus Matthies: Anfälligkeit der Industrieländer gegenüber Ölschocks. Vergangenheit und Perspektiven, Hamburg 1992.

38 | Vgl. zusammenfassend als zeitgenössische Stimme etwa: Thilo Sarrazin: Das Lächeln der Sphinx - oder: Die Staatsverschuldung und die Krise der Globalsteuerung. In: Aus Politik und Zeitgeschichte 31 (1981) B 38, S. 3-23. Der Autor, der bekanntlich noch eine lange politische und publizistische Karriere vor sich hatte, gehörte seinerzeit als Referatsleiter im Bundesfinanzministerium zu den allgemein anerkannten sozialdemokratischen Finanzexperten. 
mer noch mit den Folgen, die der Niedergang des Steinkohlen-Bergbaus ausgelöst hatte und immer noch bewirkte. Eine Krise der Stahl- und Eisenindustrie kam hinzu; zugleich war der Landesetat durch milliardenschwere Subventionen für die wenigen verbliebenen Zechen besonders belastet. ${ }^{39}$ Eine steuerpolitische Maßnahme der Bundesregierung sorgte zudem dafür, dass auch die Städte an Rhein und Ruhr mit Beginn des neuen Jahrzehnts vor besonders großen finanziellen Sorgen standen. Nach einer Änderung im System der Gewerbesteuer, die zum 1. Januar 1980 in Kraft trat, sprudelte ihre Haupteinnahmequelle deutlich spärlicher als zuvor: Einzelne Kommunen verloren bis zu 40 Prozent des bisherigen Aufkommens aus der Gewerbesteuer. ${ }^{40}$ Anfänglich sprang ihnen das Land helfend bei; schon im Sommer 1981 aber beschloss das Kabinett in Düsseldorf, das selbst mit massiv steigenden Defiziten kämpfte, die Abschaffung dieser Ausgleichszahlungen. ${ }^{41}$

Da die SPD die meisten nordrhein-westfälischen Großstädte (insbesondere im Ruhrgebiet) regierte und seit 1980 im NRW-Landtag eine absolute

39 | Vgl. etwa: Heinz Schaefer: Zur Entwicklung der regionalen Produktionsstrukturen. In: Nordrhein-Westfalen in der Krise - Krise in Nordrhein-Westfalen? Tagungsband zum RWI-Symposium vom 24. und 25.10.1984, Berlin 1985, S. 3955; Klaus Mackscheidt: Der öffentliche Haushalt in Nordrhein-Westfalen - ein Schicksalsbuch der Nation? In: Hans Günther Meissner (Hrsg.): Spannungsfelder im Marketing, Dortmund 1990, S. 9-27.

40 | 1980 verschwand die »Lohnsummensteuer«, die als eine Ergänzung der Gewerbesteuer bislang auf kommunalen Beschluss hin erhoben werden durfte. Sie orientierte sich sowohl an der Zahl der vor Ort vorhandenen Arbeitsplätze als auch am lokalen Lohn- und Gehaltsniveau. Ihre Abschaffung war als Anreiz für Großbetriebe gedacht, neue Arbeitsplätze zu schaffen. Gerade im Ruhrgebiet blieb diese Wirkung jedoch aus; zugleich hatten sich die Gemeinden dort besonders stark auf diese spezielle Form der Gewerbesteuer gestützt. Zu den Details und Hintergründen vgl. etwa: Die Gemeinden sehen sich als Opfer der Steuerreform. In: FAZ, 1.8.1978; Im Ruhrgebiet helles Entsetzen. In: FAZ, 2.8.1978 (beide Artikel mit Bezug auf den Beschluss zur Abschaffung der Steuer zum 1.1.1980); Gratwanderung am Rande des Abgrunds. In: Der Städtetag 32 (1979), S. 85-94, hier: S. 85-88; Die Städte in den achtziger Jahren. Ein Bericht über die Mitgliederversammlung des Städtetages Nordrhein-Westfalen am 30. Januar 1980 in Recklinghausen, Köln 1980, S. 120-123.

41 | Die Finanzlage Nordrhein-Westfalens ist schlechter als die des Bundes. In: FAZ, 9.7.1981. 
Mehrheit besaß, war es vor allem diese Partei, die auf die sich mehrenden finanziellen Hiobsbotschaften im ehemaligen wirtschaftlichen Kraftzentrum der Bundesrepublik reagieren musste. Zum großen Ärger der ÖTV dachten die Sozialdemokraten dabei vor allem an Sparmaßnahmen im Öffentlichen Dienst. Diether Posser, der Finanzminister des Landes, trug entsprechende Forderungen und Vorschläge massiv vor die Öffentlichkeit. Weil es für sie kein Risiko gebe, den Arbeitsplatz zu verlieren - so dekretierte Posser etwa im Oktober 1980 -, müssten die Beschäftigten des Staates generell und dauerhaft »am Ende der Lohnzuwächse« stehen. ${ }^{42}$ Wenig später beschloss das Düsseldorfer Kabinett nicht nur eine sechsmonatige Einstellungs- und Beförderungssperre, sondern auch den Wegfall verschiedener sozialer Leistungen für öffentlich Beschäftigte, die nicht durch Tarifverträge gesichert waren. Sparpläne ähnlicher Art entwickelten auch die Kommunen. ${ }^{43}$

Vor diesem Hintergrund begann die Lohn- und Gehaltsrunde für den Öffentlichen Dienst für 1981 - und im Jahr darauf sah es nicht anders aus, da die kurzfristig erreichten Einsparungen durch all die Einstellungsstopps, Nachbesetzungs- oder Beförderungssperren sich durchweg nur »im marginalen Bereich" bewegten. ${ }^{44}$ Aus dieser Erfahrung erklärt sich zu einem guten Teil der fast schon missionarische Eifer, mit dem gerade sozialdemokratische Landes- und Kommunalpolitiker nach 1980 für eine möglichst harte Haltung der öffentlichen Arbeitgeber gegenüber der ÖTV stritten.

42 | Beamte gehören ans »Ende der Lohnrunde«. In: FAZ, 27.10.1980.

43 | Vgl. etwa: Keine neuen Stellen in Düsseldorf. In: FAZ, 13.10.1980; Der EtatEntwurf in Nordrhein-Westfalen muß korrigiert werden. In: FAZ, 26.11.1980; Milliarden-Loch im Düsseldorfer Haushalt. In: FAZ, 4.12.1980; Der Schuldendienst der Regierung Rau übersteigt sogar die Kreditaufnahme. In: FAZ, 23.7.1981; Nordrhein-Westfalen muß noch mehr sparen. In: FAZ, 31.10.1981; Posser spart die Hälfte des Landeshaushaltes. In: FAZ, 13.1.1982; Die Regierung Rau vor neuen Defiziten. In: FAZ, 6.3.1982. Für die Kommunen vgl. zahlreiche Beispiele in: Wolfgang Gernert: Analyse von Haushaltsreden in nordrhein-westfälischen Gemeinden 1983, Essen 1983.

44 | Vgl. dazu genauer: Johannes Werner Schmidt: Überlegungen zu einzelwirtschaftlichen Konsolidierungsstrategien für öffentliche Haushalte. In: Peter Eichhorn/Günter Sieber (Hrsg.): Rationalisierungsreserven in öffentlichen Verwaltungen und öffentlichen Unternehmen, Köln 1985, S. 11-19, hier: S. 15. Dieses Fazit umfasst auch die Sparbemühungen in den Jahren nach 1975. 
Der erste Zug in der neuen tariflichen Partie gehörte im Winter 1980/81 allerdings noch der Gewerkschaft (im Jahr darauf galt dann selbst diese Regel nicht mehr): Öffentlich forderte sie im Dezember 1980 eine siebenprozentige Lohn- und Gehaltserhöhung. Sozial ausgleichende Elemente fehlten - was es bei der ÖTV seit den späten 1960er Jahren nicht mehr gegeben hatte. ${ }^{45}$ Vorangegangen war die nun schon traditionsreiche Basisdebatte. Sie verlief zumindest insofern ergebnisoffener als in den Vorjahren, als es erstmals keine Pressekonferenz gegeben hatte, auf der Heinz Klucker vorab die tarifpolitischen Überlegungen des gHV vorstellte. Dessen Vorschläge wurden ausschließlich intern kommuniziert; gegenüber der Presse behandelte Kluncker die Angelegenheit hingegen "wie eine Geheimsache«. ${ }^{46}$

Indem sie sich so verschwiegen gab, reagierte die ÖTV-Spitze auf den erwähnten Vorwurf, wegen der starken Medienpräsenz des Vorsitzenden seien ihre offiziell stets so bezeichneten »Empfehlungen« für die Mitglieder de facto eher Direktiven. Nach Klunckers rückblickendem Urteil erwies sich sein Verzicht auf Presseerklärungen und Interviews als hilfreich: Die internen Kritiker, die meinten, es gebe in der ÖTV in konkreten tarifpolitischen Fragen keine echte Mitbestimmung der Basis, seien »um einiges stiller geworden ${ }^{4}{ }^{47}$

Unter Ausschluss der Öffentlichkeit versuchte Heinz Kluncker im Herbst 1980 allerdings wohl intensiver als je zuvor, die Mitgliederdiskussion durch klare Vorgaben und unzweideutige Warnungen zu lenken. Wie schon im Krisenjahr 1975, so zeichnete der Vorsitzende erneut ein ausgesprochen düsteres Bild sowohl der wirtschaftlichen Lage als auch der Erfolgsaussichten der ÖTV. Vor der Großen Tarifkommission erklärte er im Oktober 1980, in den kommenden Lohnrunden werde es wegen der schwächelnden Konjunktur und der hohen Arbeitslosigkeit nur noch Abschlüsse »mit begrenztem Volumen« geben. Politisch wehe der Wind der ÖTV direkt ins Gesicht: »Der allgemeine Druck gegen die Staatsverschuldung wird zunehmen«; die Forderung nach Privatisierung öffentlicher Unternehmen und Dienstleistungen finde immer mehr Beifall »in der veröffentlichen Meinung« und bei allen Parteien. Selbst von Sozialdemokraten habe es

45 | ÖTV-Geschäftsbericht 1980/83, S. 139. Die Lohn- und Gehaltstarifverträge liefen Ende Februar 1981 aus; die Erhöhung sollte also ab März 1981 greifen.

46 | Kluncker sucht den Beifall der Basis. In: Die Welt, 17.12.1980.

47 | Protokoll der 6. Sitzung des HV, 1./2.10.1981. In: AdsD, ÖTV, 5/ÖTVB130084. 
dazu schon »manche schwachsinnig-dümmliche oder auch boshafte Erklärung" gegeben. Lohnpolitisch sei für die ÖTV daher mehr als ein "Schritthalten« mit den Einkommenszuwächsen in der Privatwirtschaft nicht zu erreichen. Sicher könne man bei einer solchen Strategie von »Anspruchslosigkeit« sprechen - Alternativen aber sah Kluncker nicht. ${ }^{48}$

Offenbar wurden die meisten Funktionäre der Organisation erfolgreich auf diese Linie eingeschworen. Der Bezirk Hessen etwa forderte, »alle ehren- und hauptamtlichen Funktionäre, die Verantwortung für die Organisation tragen «, müssten die Basisdebatte auf die Frage konzentrieren, »was politisch erreichbar und durchsetzbar ist«. Es gelte deshalb die Regel: »keine zusätzlichen Nebenforderungen« neben einer prozentualen Lohn- und Gehaltserhöhung. Um das gewünschte Ergebnis zu erreichen, empfahl der Bezirksvorstand, die Mitgliederdiskussion strikt auf die einzelnen Betriebe und Verwaltungsstellen zu konzentrieren. Die »sogenannten Vertrauensleute-Vollversammlungen der Kreisverwaltungen", die sich in den Vorjahren offensichtlich eigenmächtig etabliert hatten, um tarifpolitisch mitzureden, sollte es hingegen nicht mehr geben: Die ÖTV, so schrieb Heinz Wolf ausdrücklich in seinem eigenen Namen, brauche derartige "Happenings" nicht. ${ }^{49}$

Einmal mehr fehlen genauere Informationen darüber, wie der organisationsinterne Meinungsbildungsprozess im Einzelnen ablief, an dessen Ende die von der Großen Tarifkommission im Dezember 1980 beschlossene Sieben-Prozent-Forderung stand. Einheitlichkeit aber war auch nach dem offiziellen Ende der Debatte nicht garantiert. Wie Mitglieder des Hauptvorstandes berichteten, kam es trotz aller Mühen der Führungsmannschaft an der Basis immer noch zu "emotionalen Meinungsbildungen" und zu Mehrheiten für Sockel- oder Mindestbeträge: Angesichts der aktuellen ökonomischen Lage und der Erfahrungen mit solchen Forderungen in den vorangegangenen Jahren sei dies »ein ganz erschreckender Vorgang ${ }^{50}{ }^{50}$

48 | Rede H. Kluncker vor der GTK, 27./28.10.1980. In: AdsD, Depositum Kluncker, Stehordner 80. Ein Protokoll der anschließenden Debatte in der Tarifkommission konnte in den für dieses Projekt durchgesehenen Akten nicht ermittelt werden. 49 | Bezirksleitung Hessen an gHV, 10.12.1980. In: Archiv Ver.di, Bestand Kluncker, 27. Bei diesem Dokument handelt es sich um ein Telex. Die Rechtschreibung wurde stillschweigend korrigiert.

50 | Protokoll der 3. Sitzung des HV, 29./30.1.1981. In: AdsD, ÖTV, 5/ÖTVB130080. 
Wenn Heinz Kluncker seine interne Mahnung zu strikter gewerkschaftlicher Realpolitik im Januar und Februar 1981 mehrfach eindringlich wiederholte, so tat er das offensichtlich, weil er um die Geschlossenheit der ÖTV bangte. Zusatzforderungen (etwa nach einem höheren Urlaubsgeld oder mehr Urlaub), so warnte er, würden die ÖTV »ins Abseits stellen«, weil Politik und Presse die Beschäftigten des Staates ohnehin für sozial privilegiert hielten. Wer Mindestbeträge verlange, der programmiere »die nächste Niederlage der Gewerkschaft ÖTV in der Bewertung aller Mitglieder«, weil ein weiterer Sockel realistischer Weise nur in einer Größenordnung durchzusetzen sei, die den meisten gewerkschaftlich organisierten Staatsbeschäftigten gar nicht nütze. ${ }^{51}$ Im Februar schließlich warnte Kluncker unmissverständlich vor einem Arbeitskampf. Ein Scheitern der Verhandlungen bedeute für die ÖTV ein unkalkulierbares "Abenteuer«, weil die Organisation nicht sicher sein könne, die nötige 75-Prozent-Mehrheit für einen Streik zu bekommen. Eine Rede vor der Großen Tarifkommission beendete er deshalb mit der Aufforderung: "Laßt die Kirche im Dorf, sorgt, daß wir den Status quo halten ${ }^{52}$

Während die ÖTV-Führung alles in ihrer Macht Stehende tat, um einmal mehr eine möglichst "geräuschlose« Tarifrunde für den Öffentlichen Dienst zu garantieren, verhielten sich einige Vertreter der öffentlichen Arbeitgeber ganz anders. Besonders die nordrhein-westfälische Landesregierung suchte bewusst den Konflikt mit der ÖTV. Bereits im Dezember 1980 trat Ministerpräsident Johannes Rau mit ebenso ungewöhnlichen wie konkreten Vorschlägen an seine Amtskollegen in den anderen Bundesländern heran: Nicht in den dafür zuständigen Gremien der TdL, sondern hochoffiziell im Bundesrat sollten die Regierungschefs eine gemeinsame Position für die bevorstehenden Lohn- und Gehaltsverhandlungen beschließen. Ziel müsse es sei, entweder eine Verlängerung des noch laufenden Tarifvertrages um sechs Monate (d. h.: eine »Lohnpause« in dieser Zeit) durchzusetzen oder aber die nächste Gehaltserhöhung auf eine absolute Summe zu begrenzen, die für alle Bediensteten gleich sei. Nur so könne

51 | Ebd. Kluncker nennt hier die Summe von 150 DM monatlich: Nur ein Mindestbetrag dieser Größe bringe der Mehrheit der ÖTV-Mitglieder überproportionale Zuwächse.

52 | Rede H. Kluncker vor der GTK, 25./26.2.1981. In: AdsD, Depositum Kluncker, Stehordner 81 . 
ein »aus betriebswirtschaftlicher Sicht« vertretbarer Tarifabschluss erreicht werden. Angesichts der sicheren Arbeitsplätze im Öffentlichen Dienst seien die finanziellen Einbußen, die sich aus seinen Vorschlägen ergaben, für die Beschäftigten "zumutbar ${ }^{53}$

Und damit nicht genug: Rau begann, auch öffentlich für eine Einheitszahlung zu werben; Finanzminister Posser und Friedhelm Farthmann, der Arbeitsminister des Landes, sekundierten. Im Januar 1981 votierte die SPD-Fraktion im Düsseldorfer Landtag mit deutlicher Mehrheit für diesen Vorschlag. Schließlich wurde eine Summe genannt: Einheitlich 80 DM monatlich sollte jeder Staatsdiener als Lohn- oder Gehaltserhöhung bekommen. ${ }^{54}$ Gleichzeitig fuhr Farthmann, der als Vorsitzender der »Arbeitsgemeinschaft für Arbeitnehmerfragen« (AfA) in der SPD quasi offiziell für den Gewerkschaftsflügel der Partei sprach, öffentlich scharfe Attacken auf die sozialen Privilegien der Staatsbediensteten. Die "Regelbeförderung" im Öffentlichen Dienst etwa nannte er »skandalös«: Die AfA verlange den "Abbau« dieser gesicherten Karrieren, weil es für Arbeiter in der Privatwirtschaft nichts Vergleichbares gebe. ${ }^{55}$

Diese tarifpolitischen Querschüsse von sozialdemokratischer Seite kamen für die ÖTV offensichtlich völlig überraschend. Verwundert verwies Heinz Kluncker auf den Widerspruch, der sich hinter der angebotenen Einheitszah-

53 | Fernschreiben des Ministerpräsidenten von NRW an den Bundeskanzler und die Ministerpräsidenten der Länder Baden-Württemberg, Berlin, Bremen, Hamburg, Hessen, Niedersachsen, Rheinland-Pfalz, Saarland und Schleswig-Holstein, 17.12.1980. In: BArch Koblenz, B 136, 15823. Vgl. auch: Rau sieht Sparmöglichkeiten im öffentlichen Dienst. In: FAZ, 19.12.1980.

54 | Vgl. zusammenfassend den Bericht von Hans Liersch in: Protokoll der 3. Sitzung des HV, 29./30.1.1981. In: AdsD, ÖTV, 5/ÖTVB130080.

55 | Arbeiter haben viel mehr Nachteile als Angestellte und Beamte. In: FR, 12.2.1981. Wie die FAZ schrieb, war Farthmann im NRW-Kabinett die treibende Kraft insbesondere hinter der Forderung nach einem Einheitsbetrag (Rau sieht Sparmöglichkeiten im öffentlichen Dienst. In: FAZ, 19.12.1980). Farthmann, der vor seinem Wechsel in die Politik lange als wirtschaftspolitischer Experte für den DGB gearbeitet hatte, plädierte in einem fast zeitgleich publizierten Buch in allgemeinen Formulierungen für eine Tarifpolitik, die »neue und auch sozialpolitisch richtige Akzente für die Zukunft"setzen müsse (Friedhelm Farthmann: Entscheidungsjahre. Leben zwischen Freiheit und Ordnung, Düsseldorf und Wien 1980, S. 115). 
lung verbarg: „Der härteste Widerstand gegen jede Art von sozialer Komponente wurde bisher von den Arbeitgeberspitzen in NRW geleistet. Dies gilt sowohl für die TdL als auch für die VKA. ${ }^{56}$ Von Raus Vorschlägen wollte die Gewerkschaft grundsätzlich nichts wissen: Der Ministerpräsident fordere ein "Sonderopfer« von den Staatsbediensteten. Deren Löhne und Gehälter aber seien keine "finanzielle Manövriermasse« für sparwütige Finanzpolitiker, sondern die angemessene Entlohnung für geleistete Arbeit, die beide Tarifparteien gemeinsam in frei ausgehandelten Verträgen vereinbart hätten. ${ }^{57}$

Mit der Frage, warum die SPD-Genossen an Rhein und Ruhr in der Tarifrunde für 1981 plötzlich ganz anders handelten als zuvor, hielt sich die Führungsmannschaft der ÖTV nicht lange auf. Sie fand sehr rasch eine Antwort, die an den sozialdemokratischen Politikern kaum noch ein gutes Haar ließ: Johannes Rau und seine Mitstreiter legten es aus Sicht Heinz Klunckers und anderer wichtiger Funktionäre der Gewerkschaft darauf an, "Streit zwischen die Arbeitnehmer« zu tragen, um die ÖTV »auseinander zu treiben« oder sogar zu »zerreißen «. ${ }^{58}$ Diese Interpretation erklärt den hochemotionalen Ton, den die Gewerkschaft in ihrer Gegenwehr anschlug. So empörte sich Heinz Kluncker vor dem Hauptvorstand wörtlich über »die Dreckigkeit des Vorgehens der Landesregierung NRW«; Reinhold Mosch, Vorsitzender des ÖTV-Bezirks NRW I, sprach von »Unverfrorenheit« und forderte, die Organisation solle »mit der gleichen Rigorosität [...] draufhauen« wie Rau oder Farthmann. Kurt Schneider, ehrenamtliches Hauptvorstands-Mitglied aus Baden-Württemberg, benutzte ähnliche Vokabeln und rief: »Der Herr schütze uns vor unseren Freunden« ${ }^{59}$

Öffentlich nannte Heinz Kluncker die tarifpolitischen Initiativen des nordrhein-westfälischen Ministerpräsidenten »dümmlich, fahrlässig und gefährlich«; die Kritik Farthmanns am Öffentlichen Dienst bewertete der ÖTV-Vorsitzende als "perfide«. Ein lokaler Funktionär, der Gewerkschaftsvorsitzende in Oberhausen Gerhard Martin, schließlich meinte abfällig, von dem Regierungschef des wichtigsten Bundeslandes solle man doch

56 | Protokoll der 3. Sitzung des HV, 29./30.1.1981. In: AdsD, ÖTV, 5/ÖTVB130080.

57 | Proteste gegen Raus Pläne. In: FAZ, 20.12.1980.

58 | So Klunckers Formulierungen in der Tarifrunde am 20.3.1981. Zit. nach dem Wortprotokoll in: BMdI, TdL und VKA an Ministerpräsident Johannes Rau, 20.3.1981. In: BArch Koblenz, B 136, 15823.

59 | Protokoll der 3. Sitzung des HV, 29./30.1.1981. In: AdsD, ÖTV, 5/ÖTVB130080. 
wohl erwarten, »daß er auch denken kann« - und er erinnerte Rau drohend an den ÖTV-Streik von 1974, der Heinz Kluncker seinen Ruf als »KanzlerKiller« eingetragen hatte: »Kluncker kann auch ein $\gg$ Rau-Killer« sein. $\aleph^{60}$

Äußerungen dieser Art waren mit Sicherheit nicht im Sinne der ÖTVFührung, die einen Streik für unrealistisch und gefährlich hielt. Intern arbeitete allerdings auch Heinz Kluncker mit historischen Reminiszenzen an den Arbeitskampf im Februar 1974, wenn er über die neue konfrontative Haltung gerade seiner sozialdemokratischen Verhandlungspartner sprach. Ende Januar 1981 erklärte er dem Hauptvorstand, die für die Tarifpolitik zuständigen SPD-Politiker legten es darauf an, die ÖTV in einen Arbeitskampf zu treiben, den die Gewerkschaft kaum gewinnen könne, weil »einige ein Trauma haben, uns das noch einmal heimzuzahlen, was wir ihnen 1974 angetan haben«. Ausdrücklich zählte Kluncker Bundeskanzler Helmut Schmidt zu dieser Gruppe. Gleichzeitig sprach der ÖTV-Vorsitzende aber von einer »Einheitsfront gegen uns", die von linken Sozialdemokraten wie etwa Erhard Eppler bis ganz nach rechts zu dem CSU-Vorsitzenden und bayerischen Ministerpräsidenten Franz-Josef Strauß reiche: »Im Grunde sind das die gleichen Brüder, wenn auch mit unterschiedlicher Kappe« ${ }^{61}$

So umzingelt sah sich die ÖTV-Führung unter anderem deshalb, weil sie sich in ihrem Streit mit wichtigen sozialdemokratischen Politikern einmal mehr von den anderen DGB-Organisationen allein gelassen fühlte. Nach Klunckers Worten handelten Johannes Rau und seine Mitstreiter bis hinauf zum Bundeskanzler mit »der stillschweigenden Duldung anderer DGB-Gewerkschaften«. Hans Liersch, der Chef des wichtigen ÖTV-Bezirks NRW II, bestätigte dieses Urteil. Vor dem Hauptvorstand berichtete er ebenfalls im Januar 1981 über seine persönlichen Versuche, bei den Ruhrgebietsorganisationen der IG Metall, der IG Bergbau und Energie sowie der IG Bau - Steine - Erden um Unterstützung für die ÖTV-Proteste gegen die Sparpolitik der Landesregierung im Öffentlichen Dienst zu werben. Erfreuliche Erfahrungen machte Liersch dabei nicht: »Ich will Euch das ersparen, was ich dort alles gehört habe.« Zwar zeigten die hauptamtlichen Funktionäre mehrheit-

60 | In der Reihenfolge der Zitate: Kluncker: Dümmliche Gesetze. In: FR, 5.2.1981; Die ÖTV bläst zum Gefecht. In: NRZ, 6.2.1981; Gewerkschafter schlägt einen recht harten Kurs ein. In: WAZ, 6.2.1981 (die beiden letzten Artikel mit abweichenden Zitaten aus einer Rede von G. Martin).

61 | Protokoll der 3. Sitzung des HV, 29./30.1.1981. In: AdsD, ÖTV, 5/ÖTVB130080. 
lich Verständnis; zugleich aber hätten sie »im Innenverhältnis ihrer Gewerkschaft so große Schwierigkeiten, ihre Truppen für uns zu mobilisieren, weil die Vorurteile gegen den öffentlichen Dienst generell so tiefgreifend sind, daß sie dagegen einfach nicht mehr ankämpfen«. Andere Vorstandsmitglieder hatten offenbar Ähnliches erlebt: Das »ständige Einhämmern« von Politikern und Medien auf die angeblich skandalösen Privilegien der Staatsbediensteten präge die Stimmung selbst unter Gewerkschaftsmitgliedern; dieser »Spaltpilz« gedeihe so prächtig, dass man als Beschäftigter der Öffentlichen Dienstes fast schon »zum Türken Deutschlands « geworden sei. ${ }^{62}$

Vollends hilflos wurde die ÖTV in der Sicht ihrer Führung aber erst durch die interne Uneinigkeit der Organisation. Wie Heinz Kluncker vor der Großen Tarifkommission sagte, gab es unter den ÖTV-Mitgliedern selbst noch im Februar 1981 »eine breite Stimmung« gegen den offiziellen Forderungskatalog für die Tarifverhandlungen. Zuvor hatte er im Hauptvorstand gewarnt, der Vorschlag der NRW-Landesregierung, die nächste Lohnerhöhung als Einheitsbetrag zu zahlen, bedeute für die ÖTV »innerorganisatorische Spannungen, deren Umfang und Ausmaß wir noch gar nicht richtig einschätzen können «. ${ }^{63}$

Wie Berichte von der Basis aus Nordrhein-Westfalen zeigen, steckte die ÖTV tatsächlich in einer höchst unangenehmen Zwickmühle: Zahlreiche Kreisverwaltungen meldeten, insbesondere die Arbeiter und Angestellten der kommunalen Versorgungsbetriebe, ohne die es im Öffentlichen Dienst keinen rasch wirkenden Ausstand geben konnte, seien mehrheitlich nicht bereit, für die verlangten sieben Prozent zu streiken. Allenfalls ein hoher Mindestbetrag (genannt wurden Summen zwischen 120 und 180 DM pro Monat) könne sie mobilisieren - gerade dafür aber wollte die ÖTV-Führung auf gar keinen Fall fechten. Vor allem aus kleineren Gemeinden kamen darüber hinaus sogar ganz negative Nachrichten: Die Mitglieder seien verunsichert; Resignation mache sich breit. ${ }^{64}$

62 | Ebd. Die letzten Zitate von Harry Fuchs und Reinhold Mosch.

63 | In der Reihenfolge der Zitate: Rede H. Kluncker vor der GTK, 25./26.2.1981. In: AdsD, Depositum Kluncker, Stehordner 81; Protokoll der 3. Sitzung des HV, 29./30.1.1981. In: AdsD, ÖTV, 5/ÖTVB130080.

64 | Vgl. die Liste der Meldungen in: Ergebnisse der Anfrage betr. Arbeitskampfbereitschaft, 3.2.1981. In: AdsD, ÖTV, 5/ÖTVC603022. Ferner: Vorsitzender des Bezirksarbeiterausschusses NRW II an die Bezirksleitung NRW II, 17.2.1981. In: ebd. 


\section{Ein «blaues Auge» der ÖTV: Der tarifpolitische Kompromiss für 1981}

Unter so ungemein negativen Vorzeichen - so sollte man denken - konnte die Tarifrunde für 1981 eigentlich nur zu einem gewerkschaftlichen Desaster werden. Tatsächlich aber kam es dann doch gar nicht so schlimm. Als der Tarifvertrag unterzeichnet war, konstatierte Heinz Kluncker intern, die ÖTV sei »insgesamt mit einem blauen Auge davongekommen « ${ }^{65}$ Diesen glimpflichen Ausgang verdankte die Organisation allerdings kaum eigener Stärke oder auch nur den eingangs zitierten Drohungen ihres Vorsitzenden. Zumindest in einem der für das Resultat der Tarifrunde zentral wichtigen Punkte hatte sich die Leitung der Gewerkschaft vielmehr erfolgreich selbst Angst eingejagt: Die "Einheitsfront« der Arbeitgeber, der sie sich gegenübersah, existierte nicht.

Diese Fehldeutung begann bereits bei der Frage, warum die regierenden nordrhein-westfälischen Sozialdemokraten unversehens für einen Einheitsbetrag warben, den die öffentlichen Arbeitgeber bislang immer als »nivellierend« abgelehnt hatten. Heinz Kluncker und die anderen Mitglieder der ÖTV-Spitze verstanden diesen Vorschlag - wie gesagt - als tarifpolitische Ranküne, als einen raffiniert ausgedachten Versuch, Zwietracht zwischen Führung und Basis der ÖTV zu säen. Dabei unterstellten sie den SPD-Politikern auch Rachsucht, die noch aus dem Jahr 1974 datiere.

Nun hatte der unglückliche vorzeitige Rücktritt Willy Brandts die überzeugten Sozialdemokraten Johannes Rau, Diether Posser und Friedhelm Farthmann sicher nachhaltig geschmerzt. Dennoch wirkt es stark übertrieben, solche Emotionen als Motiv für die politisch äußerst überraschende Kehrtwende einer ganzen Landesregierung zu verstehen. Betrachtet man das weitere sozial- und gesellschaftspolitische Umfeld in der Bundesrepublik seit den späten 1970er Jahren, dann wird - denke ich - ein anderer Hintergrund sichtbar: Mit dem Modell einer nicht-linearen Lohn- und Gehaltserhöhung im Öffentlichen Dienst beteiligten sich die drei führenden Männer im NRW-Kabinett an einer Debatte über den Begriff "Solidarität" und dessen praktische Bedeutung im Alltag, die seinerzeit das ganze linke Milieu in der Bundesrepublik beschäftigte. Dabei ging es zentral darum, sozial ausgleichende Maßnahmen auch zur Aufgabe des einzelnen Bürgers zu machen, weil der mit den beständig wachsenden Defiziten in den öffent-

65 | Protokoll der 4. Sitzung des HV, 14./15.5.1981. In: AdsD, ÖTV, 5/ÖTVB130082 B. 
lichen Kassen kämpfende Staat an die Grenzen seiner Handlungsmöglichkeiten stoße.

Gleichermaßen Anstoß wie wichtiges Element in dieser Debatte war der sogenannte Grottian-Plan, für den der Berliner Politologie-Professor Peter Grottian bereits seit 1978 mit bemerkenswert breitem Echo warb: Nach seinen Vorstellungen sollten gutbezahlte Staatsbedienstete wie Richter, Studienräte und Professoren auf etwa ein bis zwei Prozent ihrer Bezüge verzichten, damit die Öffentliche Hand neue Arbeits- und Ausbildungsplätze einrichten konnte. In Kombination mit einer abgesenkten Eingangsbesoldung im Höheren Dienst, so meinte der Akademiker, würden Mittel für 120.000 bis 225.000 zusätzliche Arbeitsplätze frei - und dieses Angebot sei angesichts der hohen Arbeitslosenzahlen gerade auch bei jungen Menschen dringend nötig. ${ }^{66}$

In leicht abgewandelter Form präsentierte Grottian sein Modell im Frühjahr 1981 erneut. Der prominente linke SPD-Bundestagsabgeordnete Peter Conradi und 32 andere Parlamentarier nicht nur aus der SPD, auch Norbert Blüm als Chef der CDU-Sozialausschüsse sowie die Vorsitzenden einiger Wohlfahrtsverbände unterstützten ihn. Dieser neue "GrottianPlan« forderte eine »Nullrunde« für alle jene Beschäftigten im Öffentlichen Dienst im Jahr 1981, deren Jahresbezüge über 50.000 DM brutto lagen. Die eingesparten Steuergelder sollten für 60.000 neue Stellen ausreichen. ${ }^{67}$

Der überraschende Vorstoß von Johannes Rau und seinen beiden Ministern zugunsten einer Einheitszahlung fiel nicht nur zeitlich mit diesem Vorschlag zusammen: Er entsprang auch den gleichen Überlegungen und war zudem sehr viel präziser als die verschiedenen Varianten des »GrottianPlans«. Finanztechnisch gehörte die Idee des Berliner Professors wohl eher zu den Milchmädchenrechnungen; zudem blieb durchweg unklar, wie sie eigentlich konkret verlässlich umgesetzt werden sollte, weil Grottian

66 | Vgl. etwa: Es kann nur noch schlimmer werden. In: Der Spiegel 32 (1978), H. 23, S. 65-73, hier: S. 73. Zu Grottians Biografie vgl. die Angaben in: Der Professor für das Politische. In: taz, 8.6.2007.

67 | Peter Grottian: Öffentlicher Dienst: Für neue Arbeitsplätze wäre das Geld schon da. In: FR, 18.3.1981. Vgl. auch: Peter Grottian: Gehaltsstopp 50000 Mark? In: FAZ, 19.2.1981 (ein Leserbrief des Autors); Offener Brief von Peter Conradi und anderen an BMdI Gerhart Baum, 7.4.1981. In: Archiv Ver.di, Bestand Kluncker, 27; Sparen im öffentlichen Dienst - wie und auf wessen Kosten? In: FAZ, 4.5.1981. 
immer von einem freiwilligen Verzicht der gutbezahlten Staatsbediensteten auf individueller Basis sprach. Solche offenen Fragen gab es bei den Vorschlägen der nordrhein-westfälischen Regierung nicht; die soziale Begründung aber war die gleiche. Johannes Rau monierte daher mehrfach öffentlich, die ÖTV verhalte sich »unsozial« gegenüber den Arbeitslosen, wenn sie sich gegen die pauschale Lohn- und Gehaltserhöhung sperre. Die aktuellen wirtschaftlichen Probleme seien nur zu überwinden, wenn die Öffentliche Hand ihre Investitionen ausweite. Dazu müsse man bei konsumtiven Ausgaben wie Löhnen und Gehältern sparen. ${ }^{68}$

Trotz dieser noblen Rechtfertigung war die Einheitszahlung bei den Arbeitgebern aber keineswegs konsensfähig. Über diese Tatsache wurde in den ÖTV-Gremien im Winter 1980/81 überraschend wenig gesprochen. Die "Einheitsfront«, über die Heinz Kluncker klagte, existierte auch an anderer Stelle gar nicht. Die Bundesregierung etwa forderte in internen Beratungen, »keine Positionen aufzubauen, die doch aufgegeben werden müssen«. Die von Nordrhein-Westfalen vorgeschlagenen 80 DM für alle Beschäftigten oder die Forderung nach einer »Lohnpause« im Öffentlichen Dienst, so notierte das Bundeskanzleramt, machten es Heinz Kluncker »angesichts einer kritischen und schon mit der Lohnrunde [19]80 unzufriedenen ÖTV-Basis schwer«, die Gewerkschaftsmitglieder auf realistische Ziele einzuschwören. ${ }^{69}$

Franz-Josef Strauß, der als Rechtsaußen der bundesdeutschen Innenpolitik für viele Sozialdemokraten und Gewerkschafter das personifizierte Böse darstellte, nutzte die Gelegenheit, sich als Freund der Beamten und aller Staatsbediensteten zu profilieren. Öffentlich versicherte er der ÖTVFührung, er habe "volles Verständnis« für ihre Proteste gegen geplante

68 | Kluncker: Dümmliche Gesetze. In: FR, 5.2.1981. Akten der NRW-Ministerien, die genauer über die politischen Hintergründe der Vorschläge von Johannes Rau informieren, standen für dieses Projekt nicht zur Verfügung. Auf Anfrage des Verfassers konnte das Nordrhein-Westfälische Landesarchiv in seinen Beständen keine thematisch einschlägigen Akten zur Tarifrunde für 1981 ermitteln (Auskunft an KCF v. 3.2.2014). Die edierten Protokolle des Landeskabinetts helfen in dieser Sache nicht weiter, da es sich um rein auflistende Ergebnisprotokolle handelt.

69 In der Reihenfolge der Zitate: Aufzeichnung über das Ergebnis des Ministergesprächs beim Bundeskanzler zur Tarifrunde im Öffentlichen Dienst, 4.3.1981; Vermerk von Referat 132 für den Chef des Bundeskanzleramts, 30.1.1981. Beide in: BArch Koblenz, B 136, 15823. 
»Sonderopfer« der Mitarbeiter von Bund, Ländern und Gemeinden: Die finanziellen Probleme der Öffentlichen Hand dürften »nicht allein auf dem Rücken der Angehörigen des öffentlichen Dienstes« gelöst werden. Intern verwahrte sich Strauß gegen die »leistungsfeindliche Gleichmacherei und Nivellierung«, die sich aus den nordrhein-westfälischen Planungen ergebe. ${ }^{70}$ Der von Johannes Rau geforderte offizielle Beschluss im Bundesrat blieb daher aus; die TdL legte sich vielmehr darauf fest, ohne eine vorab ausgehandelte einheitliche Position in die Tarifverhandlungen zu gehen. ${ }^{71}$

Einig waren sich die Arbeitgeber nur in zwei Punkten. Zum einen strebten sie geschlossen nach einem Tarifabschluss, der im Gesamtergebnis die aktuelle Inflationsrate von 4,5 Prozent nicht ausgleichen dürfe. Wegen »des fehlenden Arbeitsplatzrisikos" auch der Arbeiter und Angestellten des Staates sei es angesichts der hohen Arbeitslosenzahlen nötig, bei den Lohn- und Gehaltserhöhungen einen »Abstand« zwischen dem Öffentlichen Dienst und der Privatwirtschaft zu halten. Zum anderen kam erneut das Thema der »Überversorgung « für die Rentnerinnen und Rentner aufs Tapet, die im Öffentlichen Dienst gearbeitet hatten. Der hessische Ministerpräsident Holger Börner etwa erklärte, es sei »unerträglich«, dass es die Rentenbezüge in voller Höhe des alten Lohnes dank der Zusatzversorgung immer noch gebe, während das Rentenniveau »für die Masse der Arbeitnehmer« nicht zuletzt wegen des zurückgekehrten Problems der Arbeitslosigkeit schon in naher Zukunft deutlich sinken werde. Helmut Schmidt machte sich diese Position ausdrücklich zu eigen: Man müsse in dieser Sache »öffentlichen Druck« auf die ÖTV ausüben und »notfalls sogar nach gesetzlichen Abhilfemöglichkeiten suchen «. ${ }^{72}$

Die Verhandlungen über neue Lohn- und Gehaltstarifverträge, die nach dem langen Vorgeplänkel schließlich im März 1981 ernsthaft begannen, verliefen dann weitaus weniger ungewöhnlich, als es angesichts der Vorge-

70 | In der Reihenfolge der Zitate: Strauß versteht Kluncker. In: FR, 31.12.1980; Ministerpräsident Franz-Josef Strauß an Ministerpräsident Johannes Rau, 30.12.1980. In: BArch Koblenz, B 136, 15823 (die Rechtschreibung dieses Fernschreibens wurde stillschweigend korrigiert).

71 | Vorstand der TdL an den Ministerpräsidenten von Baden-Württemberg, 8.1.1981. In: BArch Koblenz, B 222, 1334.

72 | Ergebnisprotokoll der Besprechung des Bundeskanzlers mit den Regierungschefs der Länder, 13.3.1981. In: BArch Koblenz, B 136, 15823. 
schichte zu erwarten gewesen war. Nach einem bereits vielfach erprobten Modell verzögerten die Tarifparteien die Beratungen in stillschweigendem Einvernehmen erst einmal durch folgenlose Treffen in Stuttgart, weil sie noch auf den ersten Tarifabschluss für die Metallindustrie warteten. ${ }^{73} \mathrm{Zu}$ mindest im Bundesinnenministerium wurden auch die scharfen Töne, die Heinz Kluncker - wie oben zitiert - dennoch nach einiger Zeit gegenüber den Arbeitgebern anschlug, nicht ernst genommen. Der ÖTV-Vorsitzende agiere eigentlich »sehr moderat« und mit stetem Blick auf die allgemeine Öffentlichkeit: „Er möchte der Presse keine Gelegenheit geben, über den öffentlichen Dienst 'herzufallen`« Gleichzeitig aber müsse er Rücksicht auf die Stimmung in der Gewerkschaft nehmen: »Der aufgestaute Ärger in der ÖTV, insbesondere beim Landesverband NRW, konnte von Kluncker nicht mehr gebremst werden."Seine Drohungen seien daher im Wesentlichen nur »Theaterdonner«, der die eigenen Mitglieder beeindrucken solle - auch um zu beweisen, dass die ÖTV »nicht als `Trittbrettfahrer der IG Metall« handele. ${ }^{74}$

In der Schlussphase der Verhandlungen, als das Resultat der Metallindustrie (ein Plus von 4,9 Prozent, das erst nach einem Streik im Tarifbezirk Württemberg-Baden vereinbart wurde) bereits vorlag, gab es in Stuttgart dann allerdings doch noch echten Streit. Offensichtlich standen die Verhandlungen Ende April 1981 kurz vor dem Scheitern, weil sich die Tarifparteien nicht einigen konnten, ob der »Abstand « gegenüber der Privatwirtschaft - den die ÖTV schon seit 1975 grundsätzlich akzeptierte - mit einem linearen Abschluss über 4,2 Prozent (so das nach langen internen Beratungen entstandene Angebot der Arbeitgeber) oder 4,3 Prozent (die Forderung der ÖTV) richtig bemessen sei. Gegenüber der Großen Tarifkommission sprach Heinz Kluncker bereits von Urabstimmung und Streik: »Wir können nicht mit 4,2 Prozent nach Hause kommen. ${ }^{75}$

73 | Vgl. dazu: Aktenvermerk von Referat 132 des BMdI über die Tarifverhandlungen für den Öffentlichen Dienst, 6.3.1981; Aktenvermerk, 19.3.1981; Aktenvermerk, 13.4.1981. Alle in: BArch Koblenz, B 136, 15823.

74 | In der Reihenfolge der Zitate: Aktenvermerk von Referat 132 über die zweite Runde bei den Tarifverhandlungen für den Öffentlichen Dienst, 23.3.1981; Aktenvermerk von Referat 132, 30.4.1981. Beide in: BArch Koblenz, B 136, 15823.

75 | Handschriftliche Notizen [von Hans Liersch?] über die Sitzung der GTK, 29.4.1981. In: AdsD, ÖTV NRW II, 5/ÖTVC603022. 
Einer der im Tarifgeschäft handelsüblichen Kompromisse half den Kontrahenten schließlich im letzten Moment aus der Klemme: Die ÖTV erhielt die 4,3 Prozent, auf die sie so großen Wert legte; zugleich aber gab es für die bereits vergangenen Monate März und April 1981 für jeden Beschäftigten eine rückwirkende Lohn- und Gehaltserhöhung von pauschal $60 \mathrm{DM}$ pro Monat. Alle Beteiligten konnten so ihr politisches Gesicht wahren: Die Arbeitgeber bekamen einen Abschluss, der in der gesamten zwölfmonatigen Laufzeit unter 4,3 Prozent lag; die nordrhein-westfälische Landesregierung hatte ihren Einheitsbetrag zumindest ansatzweise durchgesetzt, und auch die zahlreichen Freunde tariflicher Sockel in der ÖTV wurden bedient. Für gutbezahlte Staatsbeschäftigte bedeutete der Tarifvertrag allerdings finanzielle Verluste: Ihr Gehaltsplus betrug weniger als vier Prozent; für sie fiel der »Abstand « gegenüber den Einkommenszuwächsen in der Metallindustrie also doch recht deutlich aus. Wie das Bundesinnenministerium notierte, akzeptierte die ÖTV-Führung dieses versteckte Resultat, weil sie fürchtete, die Arbeitgeber könnten die tariflichen Regelungen ansonsten nicht eins zu eins auf die Beamten übertragen: Eine solche "Abkoppelung« der unkündbaren Staatsdiener von den Entwicklungen im Tarifbereich wolle die Gewerkschaft unbedingt vermeiden. ${ }^{76}$

Heinz Kluncker sprach insgesamt dennoch vom zitierten »blauen Auge« der ÖTV. Für die Zukunft aber sah er richtiggehend Schwarz: In der nächsten Tarifrunde werde die Frage der Zusatzversorgung im Zentrum stehen (die 1981 noch ausgeklammert blieb, weil sie in gesonderten Tarifverträgen mit längeren Laufzeiten geregelt war): Die ÖTV müsse dann »mit großer Zähigkeit, großer Beharrlichkeit und Konsequenz« kämpfen, um eine »Demontage« der besonderen Alterssicherung für Arbeiter und Angestellte des Öffentlichen Dienstes zu verhindern. ${ }^{77}$

Im Kern lag der ÖTV-Chef mit dieser Prognose völlig richtig: Die ÖTV musste im Winter 1981/82 in der Tat besonders hartnäckig gegen die Arbeitgeber streiten. Allerdings ging es dabei gar nicht um die »Überver-

76 | Aktenvermerk von Referat 132 für den Bundeskanzler zur Übernahme des Tarifabschlusses 1981 auf die Beamten, 3.6.1981. In: BArch Koblenz, B 136, 15823. Als Bestätigung des unter vier Prozent liegenden Resultats bei höherem Einkommen vgl. die Angaben von H. Kluncker in: Protokoll der 4. Sitzung des HV, 14./15.5.1981. In: AdsD, ÖTV, 5/ÖTVB130082 B.

77 | Protokoll der 4. Sitzung des HV, 14./15.5.1981. In: AdsD, ÖTV, 5/ÖTVB130082 B. 
sorgung« der Rentner und Rentnerinnen. Im Zentrum der Streitigkeiten stand vielmehr ein Versuch ihres Tarifpartners, die Löhne und Gehälter aller Beschäftigten zu kürzen - und wegen der Besonderheiten des Öffentlichen Dienstes handelte es sich dabei keineswegs nur um eine Forderung. Vielmehr hatten die Arbeitgeber in dieser Sache selbst schon gehandelt, bevor die ÖTV überhaupt ins Spiel kam.

\section{Der erste Abwehrkampf: Die Lohn- und Gehaltskürzungen im Öffentlichen Dienst in der "Operation 82« und die ÖTV}

\section{Ein ganz neuer Schachzug: Die Beamtenbesoldung als tarifpolitischer Hebel der Arbeitgeber}

Zu Beginn der im Winter 1981/82 sehr ungewöhnlich verlaufenden Tarifverhandlungen für den Öffentlichen Dienst stand ein Beschluss der Bundesregierung. Bereits Anfang September 1981 verabschiedete das Kabinett ein umfassendes Paket von finanziellen Sparmaßnahmen, das neben vielen anderen Maßnahmen auch die Besoldung der Bundesbeamten kürzte. Die Parlamentsfraktionen der beiden Regierungsparteien SPD und FDP stimmten zu - trotz großer Unruhe unter den sozialdemokratischen Abgeordneten: Sie brauchten fast acht Stunden Beratungszeit, um zu einem positiven Votum über das geplante »Haushaltsstrukturgesetz« zu kommen. ${ }^{78}$

Insgesamt wollte die Regierung durch Gesetzesänderungen und Mittelkürzungen rund 25 Milliarden DM für die kommenden drei Haushaltsjahre einsparen. Für diesen Versuch gab es ohne Frage Anlass genug: Mit dem zweiten »Ölpreisschock « verschlechterten sich nicht nur die ökonomischen Aussichten der Bundesrepublik ganz allgemein. Auch die Krise der öffentlichen Haushalte verschärfte sich; in Gemeinden und Bundesländern wie beim Bund drohten neue Rekorddefizite. 50 Milliarden DM betrug die prognostizierte Unterdeckung für 1982 allein im Bundeshaushalt, d.h., das Sparprogramm - das umfangreichste seiner Art in der Geschichte der Bundesrepublik - sollte nur helfen, die jährliche Neuverschuldung unge-

78 | Vgl. etwa: Koalitions-Fraktionen billigen Sparbeschlüsse der Regierung. In: FAZ, 9.9.1981. Als detaillierten Überblick über die geplanten Maßnahmen vgl. etwa: Konsolidieren, Begrenzen, Einsparen: Was das Bonner »Sparpaket« enthält. In: FAZ, 12.11.1981. 
fähr weiter auf dem Niveau zu halten, das in den vorangegangenen Jahren erreicht worden war. Steuererleichterungen für Unternehmerinvestitionen sollten gleichzeitig helfen, die Entstehung neuer Arbeitsplätze zu fördern. ${ }^{79}$

CDU und CSU als Opposition bemängelten den Entwurf des »Haushaltsstrukturgesetzes" als völlig unzureichend: Zumal der Abbau der staatlichen Ausgaben erfolge viel zu zaghaft. ${ }^{80}$ Dennoch gab es auf der Sparliste der Regierung gleich mehrere Punkte, mit denen sich die Sozialdemokraten sehr schwer taten, weil damit soziale Leistungen eingeschränkt wurden. Die Handschrift der FDP prägte das geplante Gesetz deutlich stärker als die früheren Versuche der sozialliberalen Koalition, den Bundeshaushalt finanziell zu »konsolidieren«. So sollten etwa sowohl das Kindergeld als auch die staatliche Unterstützung für Schüler und Studenten aus einkommensschwächeren Familien (das BAföG) gekürzt werden. ${ }^{81}$

Demgegenüber fand die geplante Senkung der Beamtenbezüge weder in der SPD und in ihrer Bundestagsfraktion noch in den anderen Parteien, den parlamentarischen Gremien oder der breiten Öffentlichkeit große Aufmerksamkeit. Pro Kopf sollte dieser Einkommensverzicht mit etwas weniger als einem Prozent der Gesamtbesoldung moderat ausfallen; gekürzt wurde ein spezieller Teil der Beamtengehälter, der Ortszuschlag, während das Grundgehalt unangetastet blieb. Den meisten Bundesbeamten droh-

79 | Vgl. etwa: Schuldenberg wächst weiter. In: FR, 4.5.1981; Die meisten RuhrStädte sind finanziell am Ende. In: FAZ, 23.9.1981; Mit neuen Schulden die alten bezahlen. In: FAZ, 13.8.1981; Der Schuldendienst der Regierung Rau übersteigt schon die Kreditaufnahme. In: FAZ, 13.8.1981; Jeden Tag 25 Millionen Mark Schulden. In: FAZ, 5.11.1981.

80 | Zur Kritik der CDU/CSU vgl. etwa: Kiep: Keine Solidierung mit diesem Finanzplan. In: FAZ, 24.9.1981, sowie ausführlich auch die Rede des schleswigholsteinischen Ministerpräsidenten Gerhard Stoltenberg (CDU) im Bundesrat am 25.9.1981 in: Verhandlungen des Bundesrates 1981. Stenographische Berichte von der 495. Sitzung am 30.1.1981 bis zur 507. Sitzung am 18.12.1981, Bonn 1981, S. 280-286.

81 | $\mathrm{Zu}$ den SPD-internen Widerständen vgl. etwa: Koalitions-Fraktionen billigen Sparbeschlüsse der Regierung. In: FAZ, 9.9.1981, sowie die kritische Rede des linken SPD-Abgeordneten Manfred Coppik im Bundestag am 12.11.1981, der seine Ablehnung des Entwurfs begründete. In: Verhandlungen des Deutschen Bundestages. 9. Wahlperiode. Stenographische Berichte, Bd. 119, Bonn 1981, S. $3665-3667$. 
te so ein finanzieller Verlust von monatlich 16 bis etwa 30 DM. Erst in der kleinen Gruppe der »B«-Besoldeten, die ganz an der Spitze der staatlichen Gehaltspyramide standen, ergaben sich deutlich höhere Summen von 100 DM pro Kopf und mehr. Unter den zahlreichen Sparprojekten der Regierung war dies ein Punkt von scheinbar ganz untergeordneter Bedeutung: Im Bundeshaushalt 1982 sollten durch die Kürzung 164 Millionen DM eingespart werden. ${ }^{82}$

Diese Zahl führte allerdings in die Irre. So erwartete das Kabinett erklärtermaßen, Länder und Gemeinden würden den Beschluss, der nach dem Gesetzentwurf bereits zum 1. Januar 1982 wirksam werden sollte, übernehmen (für die formal eigenständigen Staatsunternehmen Bundesbahn und Bundespost mit ihren zahlreichen Beamten galt selbstverständlich das gleiche). Allein analoge Beschlüsse der Länder und Kommunen erhöhten die Summe der eingesparten öffentlichen Gelder nach den Berechnungen der Bundesregierung auf 604 Millionen DM; mehr als die Hälfte davon kam den Ländern zugute, da sie besonders viele Beamte beschäftigten. ${ }^{83}$

Selbst damit aber war die Wirkungskraft des Regierungsbeschlusses noch nicht erschöpft: Er kürzte wegen einer tarifrechtlichen Besonderheit, die es nur im Öffentlichen Dienst gab, auch die Besoldung der staatlichen Angestellten. Gerade dieser »Gleichtakt von Beamten- und Tarifbereich» beim Abbau der Bezüge, den das »Haushaltsstrukturgesetz« selbst gar nicht ansprach, war dem Kabinett wichtig. Zum einen ging es so um eine doch ganz andere Summe, nämlich um etwa 1,2 Milliarden DM eingesparte staatliche Personalkosten allein für 1982, wenn man die vermiedenen Ausgaben von Bund, Ländern und Gemeinden zusammenrechnete. Zum an-

82 | Die Zahlenangaben aus: Aktenvermerk der Abt. IV des Arbeitsministeriums Nordrhein-Westfalen, 18.9.1981 (Abschrift). In: BArch Koblenz, B 376, 197 (die individuellen Verluste); Vermerk des Referat 132 für den Chef des BKA und den Bundeskanzler, 11.1.1982. In: BArch Koblenz, B 136, 31897 (die Einsparsumme). Im komplizierten System der staatlichen Besoldung diente der Ortszuschlag, der das Grundgehalt ergänzte, dazu, lokale Unterschiede der Lebenshaltungskosten auszugleichen. In der Regel war er der finanziell bedeutsamste unter den vielen verschiedenen Zuschlägen, aus denen sich die Gesamtbesoldung eines Beamten zusammensetzen konnte.

83 | Vermerk des Referat 132 für den Chef des BKA und den Bundeskanzler, 11.1.1982. In: BArch Koblenz, B 136, 31897. 
deren aber hoffte die Regierung, »Zeichen für die Tarifrunde 1982 in allen Bereichen [zu] setzen «, indem sie selbst nicht nur für die Beamten, sondern gleich auch noch für die Angestellten im Staatsdienst vorab schon Fakten schuf. $^{84}$

Öffentlich argumentierten die Kabinettsmitglieder und die Sprecher der Koalitionsfraktionen zwar anders, wenn sie diese intern »Operation 82« genannte Maßnahme erläuterten. Sie sprachen von ihrer Absicht, die Sparmaßnahmen sozial ausgewogen zu gestalten, von Solidarität mit den Arbeitslosen und allgemein von der Notwendigkeit, das Investitionsklima in der Bundesrepublik zu verbessern. ${ }^{85}$ Vieles in den Planungen des Kabinetts erinnerte bezeichnender Weise an den »Grottian-Plan«, der zeitgleich immer noch diskutiert wurde. Allerdings fehlte eine Zusage, die eingesparten Gelder in neue Ausbildungsplätze oder Stellen zu investieren, und die sollte es auch nicht geben: Ein wesentliches Ziel des »Haushaltsstrukturgesetzes« war es, die Personalkosten des Bundes zu senken.

Insbesondere das Argument von der sozialen Balance war sicher durchaus ernst gemeint. Zugleich aber sollte die so unscheinbar wirkende Kürzung der Beamtenbesoldung versteckt als eine allgemein gültige Lohnleitlinie der Bundesregierung wirken. Politiker wie Ludwig Erhard, Karl Schiller oder Willy Brandt hatten zuvor allesamt vergeblich versucht, die Gewerkschaften - und zumal die ÖTV - mit einer solchen Vorgabe zu disziplinieren. Das Kabinett Helmut Schmidts verfolgte 1981/82 dennoch das gleiche Ziel, ging dabei aber einen ganz anderen Weg. Es verzichtete auf moralisierende Mahnungen zum »Maßhalten« ebenso wie auf scheinbar wissenschaftlich exakt erstellte Ratschläge, die informell beraten wurden, oder ex cathedra bekanntgemachte Prozentzahlen und setzte ganz auf das Kleingedruckte im hochkomplexen deutschen Tarifrecht, um die Weichen für eine Senkung der Reallöhne zu stellen, die möglichst nicht nur für die Beschäftigten des Staates gelten sollte.

Dreh- und Angelpunkt des ganzen Vorhabens, allen öffentlich Beschäftigten per Regierungsbeschluss und Gesetz die Bezüge zu kürzen, war die enge Verzahnung der Beamtenbesoldung mit den Tarifverträgen für die

84 | Ebd.

85 | Vgl. etwa die Rede des SPD-Abgeordneten Eugen Glombig im Bundestag am 12.11.1981 in: Verhandlungen des Deutschen Bundestages. 9. Wahlperiode. Stenographische Berichte, Bd. 119, Bonn 1981, S. 3681-3685. 
Angestellten des Staates, die ÖTV und DAG mit williger Kooperation der Arbeitgeber in den 1960er Jahren entwickelt und ausgebaut hatten. Konkret enthielt der Bundes-Angestelltentarifvertrag (BAT) einen Passus, nach dem die Ortszuschläge, die den staatlichen Angestellten zustanden, denen der Beamten entsprechen sollten. In den Zeiten der Hochkonjunktur, aus denen der Paragraph stammte, sicherte diese Regelung eine gemeinsame Aufwärtsentwicklung der Beamten- und der Angestelltengehälter. Nun aber drehte die Bundesregierung den Spieß um: Die Kürzung der Ortszuschläge für die Beamten, die sie rechtlich unanfechtbar beschließen konnte, griff nach dem BAT zwingend auch bei den Angestellten. Im Bundesetat wurden diese Einsparungen bei den Gehältern der Angestellten mit dem »Haushaltsstrukturgesetz« daher für 1982 gleich fest eingeplant. ${ }^{86}$

Schwieriger wurde es nur bei den Arbeitern und Arbeiterinnen der Öffentlichen Hand. Zwar erhielten sie ebenfalls Ortszuschläge; diese aber wurden nicht als selbständiger Lohnbestandteil ausgewiesen und ließen sich daher nicht separat kürzen. Anders war es bei den Laufbahnzulagen - allerdings nahm der Tarifvertrag, der sie regelte, keinen Bezug auf das Beamtenrecht. Der Arbeitgeber, der die Löhne der staatlichen Arbeiter kürzen wollte, brauchte also in jedem Fall neue Verträge, die er mit den Gewerkschaften aushandeln musste. Dieses Problem hielt die Bundesregierung jedoch für lösbar: Sei der Gehaltsabbau für die Beamten und die staatlichen Angestellten erst einmal per Gesetz beschlossen und vollzogen, dann werde man die Gewerkschaften schon dazu bringen, die gleiche Kürzung auch bei den staatlichen Arbeitern zu akzeptieren. Die ja ohnehin starke Kritik am Öffentlichen Dienst in allen Medien werde dabei ebenso helfen wie das Argument von der sozialen Gerechtigkeit bei krisenbedingten Einsparungen. ${ }^{87}$

Da der Tarifvertrag über die Laufbahnzulagen für die Arbeiter mit nur einmonatiger Frist zum Jahresende 1981 gekündigt werden konnte und in dieser Abmachung keine »Nachwirkung« vereinbart worden war (d. h.

86 | Geregelt war dies in $\$ 29$ BAT. Zu den komplizierten rechtlichen Details vgl. ausführlich: Finanzministerium NRW an den Chef der Staatskanzlei NRW, 18.9.1981 (Abschrift). In: BArch Koblenz, B 376, 197, sowie auch schon: ÖTV-Geschäftsbericht 1961/63, S. $218 \mathrm{f}$.

87 | Vgl. zusammenfassend: Vermerk des Referats 132 für den Chef des BKA und den Bundeskanzler, 11.1.1982. In: BArch Koblenz, B 136, 31897. 
die Zulagen entfielen nach einer Kündigung, wenn kein neuer Vertrag abgeschlossen wurde), bot sich den Arbeitgebern zudem ein einfach zu gehender Weg, die ÖTV in dieser Sache durch eigenes Handeln unter Druck zu setzen. Perspektivisch hoffte die Regierung, die Ein-Prozent-Kürzung könne vollständig realisiert sein, bevor die allgemeinen Lohn- und Gehaltsverträge für den Öffentlichen Dienst zum 1. März 1982 ausliefen. Solch ein Auftakt hätte die Tarifrunde - auch in der Privatwirtschaft - ohne Frage stark geprägt. ${ }^{88}$

Taktisch war diese »Operation 82« zweifellos geschickt konzipiert. Die kurze Kündigungsfrist für die Zulagenverträge der Arbeiter erlaubte es der Regierungskoalition, das parlamentarische Verfahren für die Ein-ProzentKürzung im Rahmen des »Haushaltsstrukturgesetzes « abzuschließen, ohne handfeste Protestaktionen der ÖTV fürchten zu müssen: Juristisch gesehen konnten sich die Beamten ohnehin nicht wehren, und dies galt im vorliegenden Fall auch für die Angestellten - die Arbeiter aber unterlagen noch der Friedenspflicht.

Für die ÖTV-Führung kam dieser Plan ihres Tarifpartners im September 1981 offensichtlich völlig überraschend. Kurz zuvor erst hatte sie sich in einer Frage bewegt, die das Klima in den Tarifverhandlungen für den Öffentlichen Dienst seit Jahren schwer belastete: Nach langem Widerstand akzeptierte die ÖTV eine erste Reform in der Zusatzversorgung für die Arbeiter und Angestellten des Staates, bei der es um die »Überversorgung« ging. In Verhandlungen mit den Arbeitgebern hatte die Gewerkschaft deren Forderung zugestimmt, die Anrechnungs- und Kürzungsregeln, die im Beamtenrecht galten, wenn ein Pensionär verschiedene Altersbezüge erhielt, künftig für die Versicherten der Zusatzversorgung zu übernehmen. Diese Änderung - in der Sicht der Arbeitgeber nichts anderes als »der deutliche und richtungsweisende Einstieg in den Abbau der Überversorgung «stand Mitte September 1981 auf der Tagesordnung des Verwaltungsrates der Versorgungsanstalt. Sie wurde wie vereinbart beschlossen; auch die ÖTV-Vertreter hoben dafür die Hand. ${ }^{89}$

88 | Zu den rechtlichen Details vgl. wiederum ausführlich: Finanzministerium NRW an den Chef der Staatskanzlei NRW, 18.9.1981 (Abschrift). In: BArch Koblenz, B 376, 197.

89 | Rundschreiben der VKA-Geschäftsstelle, 17.9.1981. In: BArch Koblenz, B 376, 197. Die Änderung war ab dem 1. Januar 1982 gültig. Zu den - wieder einmal - 
Wenn die Gewerkschaft in diesem Punkt nachgab, obwohl sie die Zusatzversorgung in ihrer bestehenden Form bislang doch immer entschlossen verteidigt hatte, so tat sie das wohl ausschließlich aus taktischen Gründen. Im Januar des Jahres hatten sich alle Parteien im Bundestag in fast identischen Formulierungen klar gegen die »Überversorgung « gewandt und Reformen verlangt. Auch der Sprecher der SPD stimmte dabei mit ein: Altersbezüge von 100 Prozent und mehr des letzten Nettoverdienstes seien »ungerecht gegenüber allen anderen Sozialversicherten « und deshalb »skandalös«. Ausdrücklich versicherte der Abgeordnete, solche üppigen Altersbezüge seien »keine sozialdemokratische Absicht und Politik« - was ihm aus den Reihen der CDU den Zuruf eintrug: „Überzeugt mal den Kluncker! « ${ }^{90}$ In der gleichen Debatte sagte Innenminister Baum, die »Überversorgung« der staatlichen Arbeiter und Angestellten sei »nicht erträglich [...]. Das paßt nicht in die Landschaft, in der wir uns heute befinden. Das muß geändert werden. «"1

Offenbar beschloss die ÖTV-Führung daraufhin, einen Kampf aufzugeben, der wohl tatsächlich nicht mehr zu gewinnen war. Internes Quellenmaterial dazu fehlt. Die Vermutung liegt aber nahe, dass sie hoffte, die Verhandlungsposition der ÖTV in der kommenden Lohn- und Gehaltsrunde zu verbessern, wenn sie den Arbeitgebern vorab in einem seit Jahren strittigen Punkt entgegenkam. Umso größer war dann der Schrecken, als der Tarifpartner unvermittelt auf Konfrontationskurs ging, während der

sehr komplizierten Details vgl. ausführlich: Wolfgang Philipp: Das Phänomen der Überversorgung. In: FAZ, 2.4.1982. In der Sicht der ÖTV war das Problem der »Überversorgung« mit der Reform endgültig bereinigt (Siegfried Merten: Da läßt sich keine Mark einsparen. In: ÖTV-Magazin 1981, H. 9, S. 13-14).

90 | Verhandlungen des Deutschen Bundestages. 9. Wahlperiode. Stenographische Berichte, Bd. 117, Bonn 1981, S. 812 (der Abgeordnete Klaus-Dieter Kühbacher). Noch im Sommer 1980 hatte Heinz Kluncker die SPD in deren Parteiorgan aufgefordert, sich von der Forderung auf Beseitigung der »Überversorgung « zu distanzieren: »ich kann mir beim besten Willen nicht vorstellen, daß Sozialdemokraten eine soziale Demontage anstreben" (Geblieben ist ein hoher Leistungsdruck. In: Vorwärts, 19.6.1980). Vgl. als Hintergrund der Bundestagsdebatte auch den scharf negativen Artikel zur »Überversorgung « in: Skandalöse Überversorgung im öffentlichen Dienst. In: SZ, 5.11.1981.

91 | Verhandlungen des Deutschen Bundestages. 9. Wahlperiode. Stenographische Berichte, Bd. 117, Bonn 1981, S. 815. 
bisher am stärksten störende Stein des Anstoßes noch aus dem Weg gerollt wurde.

Das geplante »Haushaltsstrukturgesetz« versetzte die ÖTV-Spitze jedenfalls bereits im September 1981 in helle Aufregung. Der Hauptvorstand versammelte sich zu einer seiner sehr seltenen Sondersitzungen, als das Bundeskabinett den Entwurf des »Haushaltsstrukturgesetzes« gerade erst offiziell verabschiedet hatte. Heinz Kluncker fand dabei scharfe Worte sowohl allgemein für das Sparpaket als auch speziell für die geplante Ein-ProzentKürzung: Das Gesetz sei »sozial unausgewogen« und widerspreche deshalb dem »sozialdemokratischen Grundanspruch«; der projektierte Lohn- und Gehaltsabbau bei den Beschäftigten des Staates bedeute eine »Kampfansage an die Gewerkschaften und ein Infragestellen der Tarifautonomie«. Die Bundesregierung wolle das Beamtenrecht und den BAT nutzen, um den Öffentlichen Dienst zur »tarifpolitische[n] Schule der Nation « zu machen. ${ }^{92}$

Eine einstimmig verabschiedete Entschließung machte diesen Protest öffentlich. Der Text verwahrte sich vehement gegen jedes "Sonderopfer» der Staatsbediensteten und bezeichnete das Vorgehen der Regierung als »schamlos«: Mit ihrem Versuch, die Ein-Prozent-Kürzung per Gesetz zu dekretieren, beweise das sozialliberale Kabinett »ein gebrochenes Verhältnis zu den Arbeitnehmern dieser Gesellschaft « und zur Tarifautonomie. Sogar eine gewichtige historische Parallele wurde gezogen: Der Regierungsplan erinnere an die »Methoden Brüningscher Sparpolitik «. ${ }^{93}$

Was die scharf formulierte Entschließung (selbstverständlich) verschwieg, war die Unsicherheit der gesamten ÖTV-Führung, wie sich die Organisation wehren könne. Diese Selbstzweifel saßen tief. Heinz Kluncker fürchtete, die ÖTV stehe vor einer »Zerreißprobe«; Harro Sachße aus Berlin konstatierte: »Eine so vertrackte Situation habe er in seiner ganzen Funktionärstätigkeit noch nicht erlebt. ${ }^{94}$ Der gesamte Hauptvorstand

92 | Protokoll der außerordentlichen Sitzung des HV, 7.9.1981. In: AdsD, ÖTV, 5/ÖTVB130083. Vgl. auch: Alle Sonderlasten für Beschäftigte des öffentlichen Dienstes abgelehnt. In: ÖTV-Magazin 1981, H. 10, S. 4-5.

93 | Entwurf der Entschließung des ÖTV-Hauptvorstandes zu den Sparvorhaben der Bundesregierung im Haushalt 1982, 6.9.1981. In: Archiv Ver.di, Bestand Kluncker, 28. Vgl. auch: ÖTV will sich Sparbeschlüssen widersetzen. In: SZ, 9.9.1981. 94 | Verwirrender Weise gibt es für die HV-Sitzung am 7. September 1981 zwei unterschiedliche Protokolle in verschiedenen Akten der ÖTV: die eben zitierte 
teilte Klunckers negatives Urteil über das Sparpaket der Bundesregierung. Auch sahen alle der versammelten ÖTV-Funktionäre in der Ein-ProzentKürzung einen Versuch, die Tarifautonomie über das Beamtenrecht auszuhebeln. Die Organisation müsse dessen Gelingen unbedingt verhindern. Aber niemand war sich sicher, wie es um die Chancen der ÖTV stand, in dieser Auseinandersetzung zu gewinnen.

Die Nachrichten, welche Stimmung bei den Mitgliedern der Gewerkschaft und allgemein bei den Beschäftigten des Staates herrsche, die auf der außerordentlichen Hauptvorstands-Sitzung vorgetragen wurden, ergaben kein einheitliches Bild. Vermerkte einer der ehrenamtlichen Funktionäre "gewaltige Unruhe«, sahen andere überhaupt keine Streikbereitschaft, eine »resignative Grundstimmung« oder doch zumindest »konträre Auffassungen«. Mehrmals berichteten Vertreter der Basis, Gewerkschaftsmitglieder zeigten »Verständnis dafür, daß gespart werden müsse«, oder aber sie teilten sogar die in der Bevölkerung weit verbreitete Vorstellung, die Personalkosten hätten »den Staat an den Rand des Ruins gebracht«. Für die nicht gewerkschaftlich organisierten Kollegen gelte das sogar noch stärker. ${ }^{95}$ Diese höchst unterschiedlichen Aussagen ließen nur einen Schluss zu: Die selbst so empörte und kampfbereite ÖTV-Führung war nicht in der Lage, ihre gewerkschaftliche Macht sicher zu beurteilen.

Gab es in dieser Hinsicht wenigstens Hoffnung, die Streikbereitschaft werde noch entstehen, wenn die Gewerkschaft erst umfassend erkläre, worum es gehe, so waren sich Heinz Kluncker und die anderen Hauptvorstands-Mitglieder gleichzeitig sicher, dass die ÖTV in einem ernsthaften Konflikt über die Ein-Prozent-Kürzung ganz allein stehen werde: Auf Unterstützung der Industriegewerkschaften, so das einhellige Urteil, brauche man nicht zu hoffen. Wie Kluncker berichtete, dominiere im DGB und

Version, die von einer »außerordentlichen Sitzung« spricht, und eine zweite, ausführlichere Version, in der die übliche Zählung der HV-Sitzungen beibehalten wurde. In der zweiten Variante handelte es sich daher um die 5. Sitzung des HV. Da dieser Text ausführlicher ist, wird er im Folgenden ebenfalls zitiert. Auch die beiden Formulierungen oben stammen aus dieser Version: Protokoll der 5. Sitzung des HV, 7.9.1981. In: AdsD, ÖTV, 5/ÖTVB130068.

95 | Zitiert werden in der Reihenfolge der Äußerungen: Friedhelm Heymann (NRW II), Hans Schwarz (Rheinland-Pfalz), Kurt Schneider (Baden-Württemberg), Otto Stettner (Bayern), noch einmal O. Stettner sowie Heinz Hackbarth (Bezirksvorsitzender Berlin). Alle Zitate nach: ebd. 
in den Führungen der anderen DGB-Organisationen, die keine Beschäftigten des Öffentlichen Dienstes vertraten, die Furcht, bei einem Scheitern der Sparbeschlüsse werde die zunehmend brüchige Regierungskoalition von SPD und FDP zerbrechen - und dann bekomme man eine von der CDU geführte Bundesregierung, die »noch Schlimmeres « beschließen werde. ${ }^{96}$

Zumal bei einem Streik gegen den Kürzungsbeschluss, so warnte Kluncker, könne die ÖTV den anderen Gewerkschaften »als Totengräber dieser Regierung mit Vergleichen zu 1974« gelten. Dann drohe ein »Kesseltreiben« gegen die ÖTV gerade im DGB. Sympathie in den Medien und in der Öffentlichkeit werde es ebenfalls nicht geben: So negativ, wie die Stimmung gegenüber den Staatsbeschäftigten nun einmal sei, müsse man mit dem Vorwurf rechnen, »die ÖTV wäre nichts anderes als ein brutaler Interessenvertreter des privilegierten öffentlichen Dienstes [...], wenn man sich berechtigt wehre«. So endete die Hauptvorstandssitzung in höchst unsicherer Stimmung: Einerseits gab es »keine Patentrezepte«, was zu tun sei; andererseits aber teilten alle Anwesenden die Auffassung, es müsse zwingend etwas geschehen, denn sonst sei es mit der Glaubwürdigkeit der ÖTV vorbei. $^{97}$

Aus verschiedenen Gründen befand sich die Gewerkschaft in der Tat in einer höchst unangenehmen Situation. Nicht zuletzt zeigte sich im Herbst 1981 erneut, wie stark die Ereignisse von 1974 die ÖTV immer noch hemmten und belasteten: Solange in Bonn ein Sozialdemokrat regierte, bedrohte sie im Konfliktfall mit gewerkschaftlichen Aktionen fast zwangsläufig immer dessen Ansehen und Macht mit. Insofern war das im Frühjahr 1974 entstandene »Trauma«, das Heinz Kluncker im Vorjahr bei den führenden Männern der SPD diagnostiziert hatte, eben auch ein Trauma der ÖTV. Die Endzeitstimmung, die in den Jahren 1981 und 1982 zunehmend über der sozialliberalen Koalition in Bonn hing, löste dieses Problem keineswegs, sondern intensivierte es wohl eher noch, weil die Regierungsmacht der SPD ohnehin schon stark gefährdet war.

Berücksichtigt man zudem, wie skeptisch die Gewerkschaftsspitze über die Stimmung ihrer eigenen Basis urteilte und wie vertrackt die tarifrechtliche Situation aussah, dann wirkte ein Erfolg der ÖTV ganz un-

96 | Protokoll der außerordentlichen Sitzung des HV, 7.9.1981. In: AdsD, ÖTV, 5/ ÖTVB130083.

97 | Ebd. 
wahrscheinlich. Nur kurz nach ihrem halb verborgenen Misserfolg in der Tarifrunde für 1980 schien der Organisation im Winter 1981/82 zum ersten Mal in ihrer Geschichte eine echte Niederlage zu drohen.

\section{Ein gewerkschaftlicher "Triumph«? Der Ausgang der "Operation 82" - und einige unangenehme Wahrheiten über die begrenzte Macht der ÖTV}

Diese Niederlage blieb jedoch aus: Nach einigem Hin und Her haben die Arbeitgeber schließlich auf ihren Versuch verzichtet, eine Lohn- und Gehaltskürzung im Öffentlichen Dienst per Gesetz durchzusetzen. Für die Presse war dies ein weiterer "Triumph" der ÖTV und ihres Vorsitzenden: »Man fühlt sich an 1974 erinnert, als ein Kanzler Brandt am `Klotz Kluncker scheiterte. ${ }^{98}$ Wenn sie solche Wertungen benutzten, übersahen die Journalisten allerdings, wie wenig die Gewerkschaft durch das Nachgeben der Arbeitgeber konkret gewann: De facto war damit noch nicht einmal deren Forderung nach niedrigeren Löhnen vom Tisch. Zudem entdeckte die ÖTV ausgerechnet in den Streitigkeiten, die zu ihrem zweiten angeblichen "Triumph" führten, dass sie in Tarifauseinandersetzungen für die Beschäftigten des Öffentlichen Dienstes nur unter ganz bestimmten Bedingungen gewerkschaftlich kraftvoll agieren konnte - und diese Voraussetzungen waren keineswegs selbstverständlich gegeben.

Im Kern gewann die ÖTV in der Auseinandersetzung um die »Operation 82 « zwar keine grundsätzlich neuen Erkenntnisse über die Grenzen ihrer Macht. Bekanntlich aber macht es doch einen großen Unterschied, wenn bislang eher diffus wahrgenommene Probleme sich plötzlich nicht mehr in den Hintergrund drängen lassen, sondern erstmals klar und deutlich bestimmt werden müssen und auch bestimmt werden können. Dies geschah, als die ÖTV im Frühjahr 1982 einen Streik vorbereitete. Ganz ähnlich wie der Arbeitskampf von 1974, so hatte auch der letzte Erfolg in der Amtszeit Heinz Klunckers für das Selbstverständnis der Gewerkschaft Folgen, die kaum zu dem Begriff »Triumph" passen wollen.

Aber der Reihe nach: Zunächst einmal ließ sich die »Operation 82« für die Bundesregierung sehr vielversprechend an. TdL und VKA bekannten sich ebenfalls zu der Ein-Prozent-Kürzung; die parlamentarische Beratung

98 | In der Reihenfolge der Zitate: Konfuser Kürzungs-Rückzug. In: SZ, 8.2.1982; Heinz Kluncker vor der metallenen Meßlatte. In: Die Welt, 8.2.1982. 
des »Haushaltsstrukturgesetzes« in Bundestag und Bundesrat ging trotz heftiger Auseinandersetzungen über Einzelpunkte (wie etwa die Kürzung des Kindergeldes) und trotz eines Vermittlungsverfahrens zwischen der Länderkammer und dem Bundestag zügig über die Bühne. Keine der vielen Änderungen an dem Gesetzentwurf, die von den Abgeordneten und den Ministerpräsidenten durchgesetzt wurden, betraf die abgesenkten Ortszuschläge für Beamte und staatliche Angestellte. ${ }^{99}$

Bruchlinien zeigten sich nur hinter den Kulissen. Viele Kommunalpolitiker fühlten sich von der Bundesregierung »überfahren«, weil die VKA von dem Sparpaket erst erfuhr, als sich das Kabinett darüber schon ganz einig war. Im Präsidium des kommunalen Dachverbandes gab es daher skeptische Stimmen: Die Ein-Prozent-Kürzung »bringe viel Ärger und wenig Geld«. Öffentlich allerdings beteuerten sowohl die Gemeinden als auch die Bundesländer, sie stünden uneingeschränkt hinter dem Regierungsbeschluss. ${ }^{100}$

In einem informellen »Spitzengespräch« zwischen Heinz Kluncker und dem Bundesinnenminister sowie Vertretern von TdL und VKA Mitte September 1980 in Bonn erklärte der ÖTV-Vorsitzende erneut, die Gewerkschaft betrachte das »Haushaltsstrukturgesetz« als Versuch, die Tarifautonomie im Öffentlichen Dienst einzuschränken und damit als »Kampfansage«; dieses Gespräch endete mit einer »Verhärtung« der Positionen: Die Bundesländer kündigten an, sie planten im Übrigen auch noch, die Eingangsbesoldung der Länderbeamten deutlich zu kürzen. Dabei wurden Zahlen zwischen sechs und 14 Prozent genannt. ${ }^{101}$

99 | Vgl. etwa: Die unionsregierten Länder lehnen das Gesetzespaket zum Haushalt ab. In: FAZ, 28.11.1981; Der Bundestag verabschiedet die Spargesetze. In: FAZ, 11.12.1981; Gesetzgebung zur Sanierung des Bundeshaushaltes abgeschlossen. In: FAZ, 19.12.1981.

100 | Auszug aus dem Protokoll der 9. Präsidiumssitzung der VKA, 14.9.1981. In: BArch Koblenz, B 376, 197. Das Präsidium beschloss ausdrücklich, die VKA dürfe "nichts tun, was ihr den Vorwurf einbringen könnte, die Kommunen stünden nicht hinter den Sparbeschlüssen« (ebd.). Für die TdL vgl.: Öffentlicher Dienst: Beamte vergiften. In: Der Spiegel 35 (1981) H. 42, S. 110.

101 | So Heinz Klunckers Bericht in: Protokoll der 7. Sitzung des HV, 10./11.12.1981. In: AdsD, ÖTV, 5/ÖTVB130087. Als Zusammenfassung aus der Sicht der Arbeitgeber vgl.: Rundschreiben der VKA-Geschäftsstelle, 17.9.1981. In: BArch Koblenz, B 376, 197. 
Die Gewerkschaft verlegte sich daraufhin auf Methoden der Geheimdiplomatie. Nach seinen eigenen Angaben traf sich Heinz Kluncker im Oktober 1981 zweimal unter vier Augen mit Bundeskanzler Helmut Schmidt, um über die geplante Ein-Prozent-Kürzung zu reden; parallel führte Siegfried Merten zahlreiche Gespräche mit Mitgliedern der Bundestagsfraktionen sowie mit wichtigen Personen in TdL und VKA. Man geht wohl nicht fehl, wenn man vermutet, dass Merten dabei vor allem mit Sozialdemokraten zusammenkam, denen er ins Gewissen redete. ${ }^{102}$

Was genau hinter den Kulissen geschah, lässt sich nicht rekonstruieren. Eindruck aber scheinen Kluncker und Merten durchaus gemacht zu haben: Anfang November 1981 erwirkte die SPD einen offiziellen Koalitionsbeschluss, die Ortszuschläge für die Beamten und staatlichen Angestellten zwei Monate später zu kürzen als zunächst geplant. Der Gehaltsabbau sollte nun erst zum 1. März 1982 wirksam werden - genau an dem Tag, an dem die nächste Lohn- und Gehaltstarifrunde für den Öffentlichen Dienst offiziell begann. Mit dieser Verschiebung, so erklärte Innenminister Baum, hoffe man, »die Voraussetzungen« für eben jene Verhandlungen zu verbessern. ${ }^{103}$

Einerseits durfte die ÖTV diesen Beschluss, dem sich TdL und VKA wiederum anschlossen, durchaus als einen ersten Erfolg verbuchen. Andererseits aber beharrten die Arbeitgeber in der Sache doch nach wie vor unverändert auf ihrer Position. Bei der befristeten Aussetzung der Kürzung handelte es sich - recht besehen - um eine rein taktische Maßnahme, um einen »Verfahrenstrick«. So sagte es Heinz Kluncker in einem weiteren Spitzengespräch am 5. November 1981: Der Tarifpartner vermeide es durch die Verzögerung, mit einem Gesetz in die laufenden Tarifverträge für die Angestellten im Öffentlichen Dienst einzugreifen und entziehe sich so einer Diskussion, ob dieser Part des »Haushaltsstrukturgesetzes« juristisch überhaupt zulässig sei. Die einseitige Kürzung der Ortszuschläge aber sei immer noch geplant und deshalb gebe es für die Beschäftigten nach wie vor keine gleichberechtigte Mitsprache über ihre Entlohnung. Der geringe Umfang der vorgesehenen Einkommensverluste, so der Vorsitzende, sei irrelevant,

102 | Ebd. Zu den persönlichen Treffen zwischen Kluncker und Schmidt konnten im Rahmen dieses Projektes keine Dokumente ermittelt werden.

103 | Aktenvermerk der VKA-Geschäftsstelle über das Spitzengespräch in Bonn, 5.11.1981. In: BArch Koblenz, B 376, 197. 
denn es gehe um das Prinzip: »Nach der gegenwärtigen Willensbildung in der ÖTV werde es keinen neuen Lohn- und Gehaltstarifvertrag geben, wenn ein Eingriff des Gesetzgebers nicht von Beginn an ausgeschlossen werde.« Gleichzeitig betonte Kluncker, die Gewerkschaft sperre sich nicht gegen einen Lohnabschluss, der die schwierige Haushaltslage berücksichtige: Sie werde die aktuellen finanziellen und wirtschaftlichen Probleme »verantwortungsbewußt« berücksichtigen. Die Vertreter der Arbeitgeber zeigten sich jedoch unbeeindruckt. Auch sie argumentierten sehr grundsätzlich. Innenminister Gerhart Baum etwa erklärte, es gehe »wohl nicht an«, dass die ÖTV versuche, »den Gesetzgeber zu unterlaufen« ${ }^{104}$

Es folgten offensichtlich weitere informelle Gespräche zwischen der ÖTV-Führung und Mitgliedern der Bundesregierung sowie der Koalitionsfraktionen. Auch der DGB-Bundesvorstand schaltete sich ein. Eine Annäherung aber blieb aus. Die Arbeitgeber kündigten die Zulagenverträge für die beim Staat beschäftigten Arbeiter; sie blieben also bei ihrem Plan, die Ein-Prozent-Kürzung für den gesamten Öffentlichen Dienst durchzusetzen. Daraufhin kündigte die ÖTV ihrerseits zum gleichen Termin alle Verträge über die Zulagen für Angestellte, die nicht im BAT geregelt waren. Bei einem Treffen mit den SPD-Bundestagsabgeordneten drohte Heinz Kluncker den Sozialdemokraten zudem »mit einem härteren Arbeitskampf als $1974 \ll .{ }^{105}$

Seit Ende November 1981 trug er diese Warnung wiederholt auch öffentlich vor. Nur ein endgültiger Verzicht der Arbeitgeber auf die EinProzent-Kürzung noch vor dem 1. März 1982 könne die drohende Konfrontation verhindern: Anderenfalls sei die ÖTV entschlossen, bereits im Januar oder Februar zum Streik aufzurufen, um »die Nervenzentren der öffentlichen Strom-, Wasser- und Gas-Versorgung lahmzulegen «. ${ }^{106}$ Mitte

\section{4 | Ebd.}

105 | So Kluncker wörtlich in: Protokoll der 7. Sitzung des HV, 10./11.12.1981. In: AdsD, ÖTV, 5/ÖTVB130087. Zu den gegenseitigen Kündigungen der Zulagenverträge vgl. zusammenfassend: Rundschreiben der VKA-Geschäftsstelle, 29.1.1982. In: BArch Koblenz, B 376, 198.

106 | Dieser Streik soll die Versorgungszentren lahmlegen. In: FAZ, 26.11.1981. Vgl. auch: Kluncker: Sparbeitrag nur im Rahmen von Tarifverhandlungen. In: FAZ, 25.11.1981; Entweder Verzicht auf Kürzungen oder Streik. In: Handelsblatt, 22.12.1981; Kluncker stellt ein Ultimatum. In: SZ, 24.12.1981. Vgl. auch schon: 
Dezember begann die Gewerkschaft, sich ganz konkret auf einen Arbeitskampf vorzubereiten. Wie schon 1974 handelte es sich dabei erneut um einen organisatorischen Kraftakt, der viel Geld verschlang. Allein für die Urabstimmung wurden insgesamt 900.000 Stimmzettel in drei verschiedenen Varianten gedruckt und verteilt, weil die Beschäftigten von Bund, Ländern und Gemeinden jeweils separat befragt werden mussten. Die zahlreichen anderen Papiere - von den Kontrollkarten über die Vollmacht zur Weiterversicherung und den Hinweisen, wie ein Streikender sich zu verhalten habe - entstanden ebenfalls in kurzer Zeit in hohen Auflagen. ${ }^{107}$ Alle Bezirks- und Kreisleitungen erhielten zusätzliche Telefonanschlüsse, um die organisationsinterne Kommunikation zu verbessern; ein System der »Schnellverteilung« von Flugblättern und anderem Informationsmaterial wurde aufgebaut. ${ }^{108}$

Nach der Erinnerung seines Mitarbeiters Walter Eberhardt hat Heinz Kluncker in dieser Zeit ernsthaft überlegt, ob er aus der SPD austreten solle, weil ihn das Vorgehen der Bundesregierung so empörte. Zugleich aber sei er sich »sehr unsicher« gewesen, was die ÖTV mit ihrem Widerstand gegen das "Haushaltsstrukturgesetz « bewirken könne. ${ }^{109}$ Wie Kluncker selbst gegenüber dem Hauptvorstand ausführte, erschwerte gerade ihr erster Teilerfolg den eigenen Abwehrkampf: Eine »direkte Beeinträchtigung der Tarifautonomie« gebe es nach der Verschiebung der Gehaltskürzung auf Anfang März nicht mehr und deshalb stehe es um die »Mobilisierungsfähigkeit« der ÖTV nun nicht mehr so gut, »als wenn ab dem 1. Januar von den Arbeitgebern zugeschlagen worden wäre «. ${ }^{110}$

Müllberge auf Hamburgs Straßen und Warnstreiks in den Behörden? In: Bild (Hamburg), 26.11.1981 (hier bezogen auf Warnstreiks).

107 | Aktennotiz über die Drucksachen für Urabstimmung und Streik, 16.12.1981. In: Archiv Ver.di, Bestand Kluncker, 30. Konkret wurden 650.000 Stimmzettel für den Bereich der Gemeinden gedruckt, 150.000 für den Bereich Länder und 100.000 für den Bereich Bund. Zu den anderen Papieren, die meist in einer Auflage von 600.000 Stück gedruckt wurden, vgl. ebd.

108 | Vgl. ausführlich die rückblickende Darstellung in: Aktennotiz des Vorstandssekretariats 6 (Organisations-Sekretariat) über die organisatorische Vorbereitung für Urabstimmung und Streik, 19.2.1981. In: Archiv Ver.di, Bestand Kluncker, 30.

109 | Interview Walter Eberhardt, 16.12.2013.

110 | Protokoll der 7. Sitzung des HV, 10./11.12.1981. In: AdsD, ÖTV, 5/ ÖTVB130087. 
Aus den Orts- und Betriebsgruppen der Organisation kamen nach wie vor höchst unterschiedliche Nachrichten über die Stimmung der Mitglieder. ${ }^{111} \mathrm{Zu}$ den zahlreichen führenden Funktionären, die keine Streikbereitschaft erkennen konnten, gehörte der Vorsitzende selbst. Viele ÖTVMitglieder, so Kluncker, würden die entrüsteten Proteste der Gewerkschaft gegen die Forderung der Bundesregierung nicht verstehen. "Macht nicht so ein Theater, der öffentliche Dienst ist schon im Schußfeld genug«, diese Meinung höre er immer wieder, zumal in den für die ÖTV so wichtigen nordrhein-westfälischen Bezirken. ${ }^{112}$

Da die Düsseldorfer Landesregierung im Herbst 1981 fast zeitgleich mit ihrem Bekenntnis zu der geplanten Ein-Prozent-Kürzung weitere, eigene Sparmaßnahmen für den Öffentlichen Dienst in Nordrhein-Westfalen beschloss, hatten die Beschäftigten des Landes und ihre Gewerkschaft in der Tat auch noch andere gewichtige Sorgen: Das SPD-Kabinett wollte in den kommenden Jahren rund 7.000 Stellen (durch Nutzung der »natürlichen Fluktuation«) streichen und hatte deshalb die Neubesetzung frei werdender Posten untersagt. ${ }^{113}$

Die Vorbereitungen für eine Urabstimmung aber liefen weiter - begleitet von den der Gewerkschaft nun schon sattsam bekannten katastrophischen Warnungen in den Medien, die bei einem Streik ein »Chaos" in den Großstädten voraussahen und die ÖTV der »Erpressung« bezichtigten. ${ }^{114}$ Mit Flugblättern, die sich vor allem an die Mitglieder der anderen DGB-Verbände wandten, versuchte die ÖTV dagegen zu halten: Sie kämpfe gegen »staatlich verordnete Arbeitsbedingungen und Einkommen« und

111 | Vgl. etwa die Erklärungen von Harro Sachße (Berlin), Kurt vom Bauer (NRW I) und Kurt Schneider (Baden-Württemberg) in: ebd.

112 | Rede H. Kluncker auf der Sitzung des gHV mit den Bezirksvorsitzenden, 27.1.1982. In: Archiv Ver.di, Bestand Kluncker, 28.

113 | Vgl. genauer: Rundschreiben der ÖTV NRW II, November 1981. In: AdsD, ÖTV NRW II, 5/ÖTVC603024. Die 7.000 Stellen entsprachen etwa zwei Prozent aller Stellen im Landesdienst Nordrhein-Westfalens.

114 | Vgl. etwa: Einer gegen alle. In: Die Welt, 7.1.1982; Eberhard Maseberg: Klunckers alte Kleider. In: Deutsches Allgemeines Sonntagsblatt, 15.1.1982; »Bei Lohnkürzung wird gestreikt«. In: Saarbrücker Zeitung, 18.1.1982; Wolf Gunter Brügmann: Kampf ums Prinzip. In: FAZ, 18.1.1982; Erika Martens: Der Schreck in der Abendstunde. In: Die Zeit, 22.1.1982. 
gegen die "Willkür« der Politiker, die von den Beschäftigten des Öffentlichen Dienstes ein "Sonderopfer « forderten. ${ }^{115}$

Ende Januar 1982, wenige Tage vor der für den 3. Februar geplanten Urabstimmung der ÖTV-Mitglieder, trafen die streitenden Parteien erstmals direkt in offiziellen Verhandlungen aufeinander. Formal berieten sie über die gekündigten Zulagen-Tarifverträge; de facto ging es jedoch ganz allgemein um die Ein-Prozent-Kürzung und deren Zusammenhang mit der kommenden Lohn- und Gehaltsrunde. Die ÖTV errang in diesen Beratungen einen unerwarteten Erfolg - allerdings erwies sich bei einem zweiten Blick, wie sehr auch diese erneute Konzession der Gegenseite taktischen Charakter trug. Insofern handelte es sich abermals um ein Resultat, das die Gewerkschaft vor neue Probleme stellte.

Der Vorgang an sich war in Tarifstreitigkeiten für den Öffentlichen Dienst nicht neu: Bei den Besprechungen in Stuttgart am 28. Januar 1982 scherten die Gemeinden aus der bislang geschlossenen Front der Arbeitgeber aus. Konkret erklärten die Vertreter der VKA, sie würden die Ortszuschläge für Beamte und Angestellte auch im März »freiwillig « weiter in alter Höhe auszahlen. So könne dann eine normale, nicht vorbelastete Tarifrunde für die Arbeiter und Angestellten der Kommunen beginnen, in der über alle Lohn- und Gehaltsfragen zu sprechen sei. Damit war die Forderung der ÖTV, die Arbeitgeber müssten auf die dekretierte Kürzung verzichten, zumindest von den Gemeinden erfüllt. Der Presse galt Heinz Kluncker deswegen gleich als der eindeutige »Punktsieger« der Stuttgarter Beratungen. ${ }^{116}$

De facto aber traf die VKA - wie gesagt - wohl eher eine taktische Entscheidung. So erklärte sie in Stuttgart, sie werde in den kommenden Beratungen auf niedrigere Löhne dringen, weil »auch nach ihrer Meinung die Beschäftigten im öffentlichen Dienst einen Beitrag zur Begrenzung der öffentlichen Ausgaben leisten müssen $\ll{ }^{117}$ Ein gemeinsames Kommu-

115 | Flugblatt »ÖTV-Informationen für Mitglieder in den Gewerkschaften des Deutschen Gewerkschaftsbundes«, Januar 1982, ein Exemplar in: Archiv Ver.di, Bestand Kluncker, 29.

116 | Heinz Henkel: Punktsieger Kluncker. In: SZ, 30.1.1982. Zu den Planungen, die Urabstimmung am 3. Februar durchzuführen, vgl.: Notizen von Hans Liersch über die gHV-Sitzung, 15.1.1982. In: AdsD, ÖTV NRW II, 5/ÖTVC603024.

117 | Rundschreiben der VKA-Geschäftsstelle, 29.1.1982. In: BArch Koblenz, B 376, 198. 
niqué von VKA und ÖTV, über dessen Formulierung die beiden Seiten zehn Stunden lang gestritten hatten, stellte den Verzicht der Gemeinden auf die Ein-Prozent-Kürzung daher ausdrücklich unter »Vorbehalt «. ${ }^{118}$ Intern erläuterte die Geschäftsführung des Kommunalverbandes, sie habe mit der ÖTV einen »Kompromiss« geschlossen, der vor allem den Städten nütze: Die Friedenspflicht der Kommunalbeschäftigten gelte nun wieder; das »Gesamtpaket « für die künftigen Löhne und Gehälter, über das man ab März mit der Gewerkschaft verhandeln werde, könne die Finanznöte der öffentlichen Haushalte besser berücksichtigen als isolierte Beschlüsse über einzelne Lohnbestandteile. ${ }^{119}$

Für den, der hinter die Kulissen der internen Beratungen unter den Arbeitgebern schauen konnte, dürfte die VKA-Entscheidung vom 28. Januar 1982 nicht sehr überraschend gekommen sein. Bereits im September des Vorjahres, als die Bundesregierung ihren Plan der Ein-Prozent-Kürzung entwickelte, hatten die Kommunen erklärt, die Arbeitgeber würden mit weiteren Lohnabschlüssen, bei denen der Öffentliche Dienst - wie in den Vorjahren und wie zumal 1981 - hinter den Tarifergebnissen der Privatwirtschaft zurückbleibe, besser fahren: »Das spare viel Geld« und werde von den Mitarbeitern im Staatsdienst eher akzeptiert, »als wenn ihnen etwas weggenommen wird «. ${ }^{120}$

Auch nach dem »Kompromiss« zwischen ÖTV und VKA war der Konflikt der Tarifparteien also nur vertagt, aber nicht beigelegt - und das unterschied diesen Beschluss der Kommunen grundsätzlich von all den anderen Entscheidungen, mit denen sich die VKA in Tarifverhandlungen für den Öffentlichen Dienst zuvor gegen Bund und Länder gestellt hatte. Die Reaktion von TdL und Bundesregierung entsprach ebenfalls nicht dem gewohnten Verlauf: Sie schwenkten nicht - wie sonst - auf den Kurs der Gemeinden ein, sondern hielten kategorisch an der im »Haushaltsstruktur-

118 | Bericht von Referat 132 des Bundeskanzleramtes über die Verhandlungen mit der ÖTV, 29.1.1982. In: BArch Koblenz, B 136, 31897. Der Streit entstand, weil die VKA eine »Verrechnung« ankündigen wollte. Der »Vorbehalt« als abgeschwächte Formulierung fand schließlich die Zustimmung der ÖTV.

119 | Rundschreiben der VKA-Geschäftsstelle, 29.1.1982. In: BArch Koblenz, B 376, 198.

120 | Auszug aus dem Protokoll der 9. Präsidiumssitzung der VKA, 14.9.1981. In: BArch Koblenz, B 376, 197. 
gesetz« fixierten Kürzung der Ortszuschläge zum 1. März 1982 fest. Das SPD-Kabinett von Nordrhein-Westfalen ging sogar noch einen Schritt weiter: Nur wenige Tage nach der Stuttgarter Tarifrunde diskutierte es über eine Initiative des Landes im Bundesrat, noch weitere Zulagen der Beamten und auch deren Urlaubsgeld zu kürzen. Insgesamt sollte so ein Gehaltsabbau um fünf Prozent erreicht werden. ${ }^{121}$

Der vermeintliche »Punktsieger« von Stuttgart stand daher im Februar 1982 vor einer noch schwierigeren Situation als zuvor: Im Gemeindebereich konnte die Gewerkschaft nicht mehr zum Streik aufrufen; Bund und Länder aber blieben auf ihrem konfrontativen Kurs. Die bereits vollständig vorbereitete Urabstimmung wurde hastig abgeblasen, um neu zu prüfen, ob und wie die ÖTV einen wirkungsvollen Arbeitskampf organisieren könne, der ganz ohne die Arbeiter und Angestellten der Kommunen auskommen musste. Mit Hilfe ihrer Mitgliederdatei suchte die Gewerkschaft nach möglichen Streikschwerpunkten; ergänzend wurden die Orts- und Bezirksverwaltungen noch einmal befragt. Ein Streik war gewünscht - und zwar ein Streik nach dem Grundsatz: »Je härter und umfassender - desto kürzer. ${ }^{122}$

Zwischen diesem Wunsch und den Möglichkeiten der Gewerkschaft lag allerdings eine weite Kluft. Auf einer Sitzung des Organisationssekretariats in der Stuttgarter Hauptverwaltung mit Vertretern der Bezirke, auf der alle verfügbaren Informationen über die Schlagkraft der ÖTV abseits der Gemeinden zusammengetragen wurden, entstand ein düsteres Bild. Fasst man die zahlreichen Berichte zusammen, dann verzeichnete die Organisation nur in den Arbeitsämtern so viele Mitglieder, dass ein wirkungsvoller Streik garantiert zu sein schien. Vor diesem Schritt aber zuckte die ÖTV-Führung zurück, fürchtete sie doch den »Zorn der Arbeitslosen« und

121 | Vermerk des Finanzministeriums NRW über Sparmaßnahmen im Öffentlichen Dienst, 7.2.1982. In: AdsD, ÖTV NRW II, 5/ÖTVB603023. Dieser Vermerk wurde der ÖTV-Organisation in Nordrhein-Westfalen offensichtlich hinter den Kulissen zugespielt. Zur unnachgiebigen Position von Bund und TdL in den Stuttgarter Verhandlungen vgl.: Rundschreiben der VKA-Geschäftsstelle, 29.1.1982. In: BArch Koblenz, B 376, 198.

122 | Notizen von Hans Liersch zu einem möglichen Arbeitskampf, o. D. [Februar 1982]. In: AdsD, ÖTV NRW II, 5/ÖTVC603024. Zur Absage der Urabstimmung vgl.: Protokoll der Sitzung des Vorstandsekretariats 6 (Organisations-Sekretariat), o. D. [Februar 1982]. In: Archiv Ver.di, Bestand Kluncker, 30. 
damit zugleich einen gravierenden Schaden an ihrem ohnehin schon nicht gerade günstigen öffentlichen Image. In den Bezirksleitungen gab es zudem offensichtlich starke »Skrupel«, gerade diese staatlichen Einrichtungen stillzulegen. ${ }^{123}$

Ließe man die Arbeitsämter außen vor, dann aber wäre bei der ÖTV ohne die Gemeindemitarbeiter »weitgehend die Luft raus«. Zwar zählten die meisten Hausmeister in staatlichen Schulen zu den Mitgliedern der Organisation. Ob man deren Herrschaft über die Heizungsanlagen nutzen sollte, um den Schulbetrieb lahmzulegen, und ob man so wirklich zu einem »harten« Arbeitskampf kam, der die Arbeitgeber beeindruckte, das war unter den versammelten Funktionären jedoch heftig umstritten. In den Landesministerien ging, wie mehrfach berichtet wurde, abseits einiger technischer Dienste und der Fahrbereitschaften in der Regel "gar nichts«. Etwas besser sah es wohl in Bonn aus; zugleich aber waren die meisten dieser "Kollegen« und »Kolleginnen« in den Bundesministerien nach den Worten des zuständigen Berichterstatters »natürlich gleichzeitig noch Parteifreunde«. Persönlich merkte er an, die gewerkschaftliche Solidarität dieser Mitglieder solle in der aktuellen Situation besser "ganz zurückhaltend" beurteilt werden. Als potenzielle Streikschwerpunkte blieben der Gewerkschaft daher nur nachrangig bedeutsame Einrichtungen von Bund und Ländern wie etwa die Eichämter oder die Zentrale der Bundesmonopolverwaltung für Branntwein in München. ${ }^{124}$

Siegfried Bußjäger, der die Versammlung als Vertreter des gHV leitete, formulierte gegen Ende der langen Debatte ein eindeutiges Fazit: »die Lage ist nahezu hoffnungslos«. Die ÖTV müsse sich eingestehen, dass sie nur dann eine starke Gewerkschaft sei, wenn sie es mit allen drei Gruppen der öffentlichen Arbeitgeber gleichzeitig zu tun habe. Ohne die Tarifgemeinschaft ihrer Verhandlungspartner fehle der ÖTV hingegen das »Durchsetzungsvermögen [...], das wir haben müssen «. ${ }^{125}$

In der Krise klein beizugeben, kam für die Gewerkschaft jedoch selbstverständlich nicht in Frage. Die Urabstimmung wurde erneut angesetzt, diesmal für den 10. Februar und nur für die ÖTV-Mitglieder, die beim Bund und

123 | Protokoll der Sitzung des Vorstandsekretariats 6 (Organisations-Sekretariat), o. D. [Februar 1982]. In: Archiv Ver.di, Bestand Kluncker, 30.

124 | Ebd.

125 | Ebd. 
den Ländern beschäftigt waren. ${ }^{126}$ Nach Lage der Dinge stand die Verbandsführung bei dieser Abstimmung vor einer echten Zitterpartie: Niemand war sich sicher, ob in beiden Gruppen die jeweils nötige Zustimmung von mindestens 75 Prozent für einen Arbeitskampf zustande kommen werde. ${ }^{127}$

Diese doppelte Nagelprobe blieb der Gewerkschaft - wie gesagt - dann allerdings erspart. Überraschend erklärten Bundesregierung und TdL auf einem weiteren Treffen der Tarifpartner am 5. Februar 1982, sie wollten sich dem Vorgehen der VKA nun doch anschließen: Die Kürzung der Ortszuschläge ab März werde für die Beamten durch einen zeitgleich eingeführten neuen Zuschlag wieder ausgeglichen; bei den Angestellten zahle man freiwillig weiter. Ähnlich wie die Gemeinden verwiesen auch Bund und Länder jedoch ausdrücklich auf ihren "Vorbehalt der Verrechnung", d.h., an ihrer "Kürzungsabsicht" hielten sie fest. Befriedigt konstatierten die zuständigen Experten im Bundeskanzleramt, der Beschluss habe unmittelbar "zu einer wesentlichen Verbesserung des Verhandlungsklimas" geführt. Die ÖTV akzeptierte die Erklärung ihrer Verhandlungspartner, und damit galt die Friedenspflicht nun auch wieder für die Beschäftigten von Bund und Ländern. ${ }^{128}$

Vorangegangen waren intensive Beratungen vor allem innerhalb des Bundeskabinetts, die man zu einem guten Teil wohl als Auseinandersetzung zwischen SPD und FDP verstehen darf. Bereits am 27. Januar hatte in Bonn ein Ministergespräch unter dem Vorsitz von Helmut Schmidt stattgefunden, in dem deutlich wurde, wie uneinig sich die Regierungspartner waren: Während der Bundeskanzler meinte, Arbeitgeber und Gewerkschaft sollten in der Frage der Ein-Prozent-Kürzung "aufeinander zugehen«, weil bei dem Beschluss darüber »im Sommer 1981 von beiden Seiten Fehler gemacht worden seien«, warnten Innenminister Baum und Vizekanzler

\section{6 | Ebd.}

127 | Rede H. Kluncker auf der Sitzung des gHV mit den Bezirksvorsitzenden, 27.1.1982. In: Archiv Ver.di, Bestand Kluncker, 28.

128 | Aktenvermerk von Referat 132 über den Ablauf der Verhandlungen mit der ÖTV am 5. Februar 1982, 8.2.1982. In: BArch Koblenz, B 136, 31897. Zur praktischen Umsetzung des Beschlusses durch ein »Vorschaltgesetz« für das »Haushaltsstrukturgesetz« vgl. etwa: Helmut Herles: Mierscheidt und andere Absurditäten. In: FAZ, 16.2.1982; Die Besoldungskürzungen aus dem Haushaltsgesetz herausnehmen? In: FAZ, 3.3.1982. 
Hans-Dietrich Genscher, ein »Nichtvollzug« der Kürzung zum 1. März könne der Bundesregierung »leicht als Schwäche ausgelegt werden «. ${ }^{129}$

Dieser zunächst noch offen gelassene Konflikt wurde Anfang Februar mit dem eben skizzierten Beschluss entschieden. Nach Presseinformationen geschah dies auf höchster politischer Ebene in einer Beratung nur von Schmidt, Genscher und Baum unmittelbar vor dem Zusammentreffen mit der ÖTV. Die letztlich wohl von ihm persönlich durchgesetzte Korrektur des »Haushaltsstrukturgesetzes« brachte dem Kanzler durchaus Ärger ein. Gemeinschaftlich protestierten die finanzpolitischen Experten der beiden Regierungsparteien, die im Haushaltsausschuss des Bundestags saßen: Mit ihrer einsamen Entscheidung seien der Kanzler und die beiden FDP-Minister dem Parlament »in den Rücken gefallen«; die mühsam erarbeiteten Sparbeschlüsse würden so »wertlos gemacht«, denn schließlich entstehe nun der Eindruck, »daß es der ÖTV unter Vorsitz Klunckers möglich gewesen sei, die Gesetzgebung des Bundestages entscheidend zu beeinflussen«. Allerdings brachte eine Vereinbarung der beiden Fraktionsführungen, die Angelegenheit öffentlich nicht weiter zu diskutieren, die koalitionsinternen Dissidenten rasch wieder zum Schweigen. ${ }^{130}$

Wie erwähnt verstand auch die Tagespresse den Beschluss von Bundesregierung und Bundesländern als eindeutigen Sieg der ÖTV. Dabei war zum einen in der Sache aber noch gar nichts entschieden - und zum anderen lässt sich darüber hinaus wohl berechtigt fragen, ob der Bundeskanzler nicht in Wirklichkeit vor allem deshalb auf die einseitige Ein-Prozent-Kürzung verzichtete, weil er die ÖTV-Führung nicht noch weiter schwächen wollte. Zwar wusste man in der Bonner Ministerialbürokratie offensichtlich nicht genau, wie negativ die Gewerkschaft ihre Streikmöglichkeiten einschätzte. Furcht vor einem Arbeitskampf wird in den überlieferten Regierungsakten zum Tarifkonflikt 1981/82 aber nirgends deutlich. ${ }^{131}$

129 | Aufzeichnung über das Ergebnis des Ministergesprächs beim Bundeskanzler zur Tarifrunde im Öffentlichen Dienst, 27.1.1982. In: BArch Koblenz, B 136, 31897.

130 | In der Koalition Streit um die Aufhebung des Ein-Prozent-Abschlags bei den Beamten. In: FAZ, 11.2.1981.

131 | Vgl. vor allem die umfangreichen Papiere des Referats 132 im Bundeskanzleramt, in denen ein eventueller Streik durchweg sehr nüchtern behandelt wird. In: BArch Koblenz, B 136, 31897. 
Der höchst ungewöhnliche Beschluss der Bundesregierung, ein für sie politisch zentral bedeutsames Gesetz, das noch gar nicht in Kraft getreten war, vorab zu korrigieren, kann daher durchaus als eine Art Freundschaftsdienst gegenüber der bedrängt dastehenden Spitze der ÖTV gedeutet werden: Zumindest der Arbeitskampf, der die Gewerkschaft nach Lage der Dinge wohl eher öffentlich bloßgestellt als gestärkt hätte, konnte so entfallen. Ein persönlicher Kontakt zwischen dem Kanzler und Heinz Kluncker, der offensichtlich leicht herzustellen war, wenn es um wichtige Dinge ging, mag geholfen haben, diese Lösung zu finden - aber das ist eine Vermutung, die sich nicht verifizieren lässt.

Da Urabstimmung und Streik mit der Erklärung der Arbeitgeber vom 5. Februar 1982 überflüssig wurden, begann im März und April eine Lohnund Gehaltstarifrunde, die scheinbar ganz nach den üblichen Regeln verlief. Die Beratungen führten jedoch zu keiner einvernehmlichen Lösung. Es folgte auf Verlangen der Arbeitgeber ein Schlichtungsverfahren, an dessen Ende ein Kompromissvorschlag der beiden unparteiischen Schlichter stand, den ÖTV und Arbeitgeber Ende April schließlich billigten.

Die ÖTV akzeptierte für das Jahr 1982 letztlich einen Abschluss, der Bund, Länder und Gemeinden finanziell insofern zufrieden stellte, als die Löhne und Gehälter der öffentlichen Arbeiter und Angestellten real unter den Vorjahresstand sanken. Auch lag das Gesamtergebnis (ein Plus von 3,15 Prozent bei einer zwölfmonatigen Laufzeit) um etwa einen Prozentpunkt niedriger als das Durchschnittsresultat in den Tarifabschlüssen für die Privatwirtschaft. Zufrieden konstatierte Helmut Schmidt im Kabinett: »Das wesentliche Einsparziel im öffentlichen Dienst sei erreicht. «132

Intern urteilte Heinz Kluncker ganz ähnlich: Die vereinbarten Verträge bedeuteten »keine Reallohnsicherung«. Mehr sei jedoch nicht zu erreichen gewesen: »Ich sehe keine Möglichkeit, die ÖTV in ein Abenteuer zu stürzen.« Immerhin habe sich die Gewerkschaft in einer für sie sehr schwierigen Situation aber noch gut behauptet. »Kein Sieg - für keine Seite«, so lautete sein Fazit. ${ }^{133}$

132 | So auf der 74. Kabinettssitzung am 28. April 1982. Einzusehen in: Kabinettsprotokolle Online, www.bundesarchiv.de/cocoon/barch/0000/k/k1982k/kap1_1, letzter Zugriff: 4.2.2016.

133 | Notizen [von Hans Liersch?] über die Sitzung der GTK, 29.4.1982. In: AdsD, ÖTV NRW II, 5/ÖTVC603024. Der Tarifvertrag sprach von einem Plus von 3,6 
Damit hatte Kluncker zumindest insofern recht, als der Tarifabschluss der Gewerkschaft keine offensichtliche Niederlage bereitete: Der Abbau der Reallöhne, den die Regierung erreichen wollte, fand zwar statt; er erfolgte aber nur versteckt und auch nicht per Gesetz, sondern nach den Regeln der Tarifautonomie. Ebenso versteckt blieb ein weiterer Erfolg der Arbeitgeber: Indem sie dem Einigungsvorschlag der Schlichter zustimmte, verpflichtete sich die ÖTV zu einer noch im gleichen Jahr beginnenden Verhandlungsrunde zum Abbau der »Überversorgung«. Nach Lage der Dinge konnte die Gewerkschaft den Arbeitgebern dabei keinen wirkungsvollen Widerstand mehr entgegensetzen. ${ }^{134}$ Zudem beschlossen die Arbeitgeber nur kurz nach dem Ende der langen Tarifverhandlungen, die Beamtengehälter im Jahr 1982 erst mit dreimonatiger Verzögerung an die neuen Tarifverträge für den Öffentlichen Dienst anzupassen, d. h., sie sparten bei dieser Gruppe der Beschäftigten noch einmal zusätzlich Geld ein. ${ }^{135}$

Die Lohn- und Gehaltstarifrunde für 1982 endete also genauso, wie sie begonnen hatte: mit einem Beweis, dass die Finanznot der Öffentlichen Hand den Umgang der Politiker mit den Arbeitnehmern im Staatsdienst gravierend veränderte. Sogar die den staatlichen Arbeitgebern zuvor stets so wichtige Einheit von »Beamten- und Tarifbereich« war nun nicht mehr selbstverständlich gesichert. Die Regeln, an denen sich die ÖTV in ihrer Arbeit für die Beschäftigten im Öffentlichen Dienst seit den 1950er Jahren orientiert hatte, verloren offensichtlich stark an Bedeutung - und darauf reagierte die Gewerkschaft: So gab es in den neu ausgehandelten Tarifver-

Prozent (bei einer Forderung von 6,5 Prozent). Diese Erhöhung galt aber erst ab dem 1. Mai 1982. Für die vorangegangenen Monate März und April erhielten die Beschäftigten eine Einmalzahlung von 40 DM. Vgl.: ÖTV-Geschäftsbericht 1980/83, S. 140 f. Mit 20 DM pro Monat lag das sozial ausgleichende Element der Abmachung niedriger als je zuvor, d.h., es dürfte nur ganz wenigen Beschäftigten eine insgesamt überdurchschnittliche Lohnerhöhung gebracht haben. $\mathrm{Zu}$ den Details vgl. auch: Schlichterspruch im öffentlichen Dienst angenommen. In: FAZ, 30.4.1982.

134 | Vgl. zu den Details der im Sommer 1983 verabschiedeten neuen Version der Zusatzversorgung, die keine Gesamtversorgung mehr zulassen sollte, die über 90 Prozent des Nettoarbeitsentgelts hinausging: ÖTV-Geschäftsbericht 1980/83, S. 162-165. Diese Bestimmungen traten zum 1. Januar 1985 in Kraft.

135 | Zur heftigen Kritik der Beamtenverbände, der ÖTV und des DGB vgl. etwa: Kritik an Besoldungserhöhung zum 1. August. In: FAZ, 8.2.1982. 
trägen für die Gehaltszulagen der Angestellten keinen Verweis mehr auf das Beamtenrecht. In den Beratungen hatte die ÖTV noch unnachgiebig auf dieser Forderung bestanden. ${ }^{136}$

Indem die Gewerkschaft damit die auf der Hand liegenden Lehren aus der »Operation 82 « zog, verabschiedete sie sich allerdings indirekt von der Hoffnung auf ein einheitliches Dienstrecht, das die Beamten zu Arbeitnehmern mit normalen Rechten machen sollte. Mit den neuen Zulageverträgen verzichtete die ÖTV auf ihre Strategie, dieser Reform den Weg zu bereiten, indem sie Beamten- und Tarifrecht miteinander verzahnte. Stillschweigend stufte sie ihr Langzeitprojekt damit auf die Stufe einer reinen Forderung herab, die mit der konkreten gewerkschaftlichen Arbeit nichts mehr zu tun hatte. Da die Idee der Dienstrechtsreform eng mit den Neuordnungsplänen der späten 1960er und frühen 1970er Jahre zusammenhing, bezeichnete das Jahr 1982 also auch in dieser Hinsicht den Schlusspunkt einer Epoche.

\section{Weichenstellungen unmittelbar vor dem Rücktritt: Heinz Klunckers gewerkschaftliche Arbeit in den letzten Monaten seiner Amtszeit}

\section{Der „Neue Heimat»-Skandal und die Wahl des neuen DGB-Vorsitzenden}

Im Winter 1981/82 stand es um Heinz Klunckers Gesundheit - wie oben geschildert wurde - äußerst schlecht. Zugleich aber war der ÖTV-Chef sowohl in der Gewerkschaft als auch in Verhandlungen mit den Arbeitgebern fast ununterbrochen stark gefordert: Der Tarifstreit im Öffentlichen Dienst begann ungewöhnlich früh, nämlich schon im September 1981, und er endete mit der Annahme des Schlichterspruchs erst Ende April 1982. Bereits im Januar des Jahres fasste Kluncker wohl den Entschluss, sein Amt vorzeitig abzugeben, weil er sich den Belastungen und Anforderungen, die der ÖTV-Vorsitz mit sich brachte, gesundheitlich nicht mehr gewachsen fühlte. Erst Anfang Juni aber informierte er den ÖTV-Vorstand. Er blieb auf dem

136 | Vermerk von Referat 132 über die Tarifrunde im Öffentlichen Dienst, 8.2.1982. In: BArch Koblenz, B 136, 31897; Rede H. Kluncker zur Eröffnung der Tarifverhandlungen, 12.3.1982. In: Archiv Ver.di, Bestand Kluncker, 46. 
Posten, obwohl ihn seine Ärzte immer eindringlicher aufforderten, sofort auszuscheiden.

Dieses Pflichtbewusstsein trotz stark schwindender Kräfte und tatsächlich wohl akut drohender Lebensgefahr zeigte Kluncker, weil es für einen prominenten und öffentlich stark präsenten Gewerkschaftsführer, wie er es war, kaum einen ungünstigeren Zeitpunkt als das Frühjahr 1982 geben konnte, um überraschend zurückzutreten. Während sich die Tarifstreitigkeiten für den Öffentlichen Dienst immer noch weiter hinzogen, entwickelte sich nämlich zusätzlich seit Februar einer der größten politischen Skandale in der Geschichte der Bundesrepublik zu einer schweren Belastung für den DGB und die gesamte bundesdeutsche Gewerkschaftsbewegung. Gemeint sind die Enthüllungen über die finanziellen Machenschaften, mit denen sich die Geschäftsführer des gewerkschaftseigenen Baukonzerns »Neue Heimat« (NH) hinter der gemeinnützigen Fassade des Unternehmens schamlos persönlich bereichert hatten. Heinz Kluncker war in dieser Affäre, die das öffentliche Ansehen der Gewerkschaften schwer ramponierte, gleich doppelt gefordert. Er saß seit langen Jahren im Aufsichtsrat der NH; zudem musste er als eines der wichtigsten Mitglieder des DGB-Bundesvorstandes mit darüber beraten, wie der gewerkschaftliche Dachverband in der Krise reagieren sollte, um zu retten, was zu retten war.

Bekanntlich begann die öffentliche Aufarbeitung der vielen Dinge, die bei der NH im Argen lagen, Anfang Februar 1982 mit einer Titelgeschichte des Hamburger Spiegel. Es folgten zwei weitere umfangreiche Enthüllungsgeschichten des Magazins, die zeigten, wie groß der Millionenschaden war, den die NH-Manager mit ihrer persönlichen Raffgier angerichtet hatten. ${ }^{137}$ Auch der DGB-Vorsitzende Heinz Oskar Vetter und Eugen Loderer, Chef der IG Metall, gerieten in diesem Skandal ins Zwielicht: Sie hatten sich privat an speziellen Baugesellschaften der NH beteiligt, die einen Anleger auch ganz ohne Eigenkapital zum Immobilienbesitzer machten, weil sie öffentliche Subventionen und die Steuersparmöglichkeiten der gutverdienenden Bundesbürger konsequent ausnutzten. Dabei geschah zwar nichts Illegales; mit den hehren gewerkschaftlichen Idealen der sozialen Gerechtigkeit und der Solidarität mit den Schwachen ließ sich diese sehr speziel-

137 | Vgl. vor allem: Peter Kramper: NEUE HEIMAT. Unternehmenspolitik und Unternehmensentwicklung im gewerkschaftlichen Wohnungs- und Städtebau 1950-1982, Stuttgart 2008, S. 596-606. 
le Form der Vermögensbildung, die der Konzern nur seinen Mitarbeitern und anderen "Insidern" angeboten hatte, aber ganz offensichtlich nicht vereinbaren. ${ }^{138}$

Hinter all diesen unappetitlichen Enthüllungen der Journalisten, die auf einzelne Personen zielten, ließ sich der wahre und viel größere NHSkandal im Frühjahr 1982 erst erahnen: Das riesige Unternehmen mit seinen mehr als 200.000 Wohnungen allein in der Bundesrepublik war stark unterkapitalisiert, in zahlreiche hochriskante spekulative Auslandsgeschäfte verstrickt und katastrophal überschuldet. Hinter dieser Schieflage stand die bedenkenlose Expansionsstrategie der Unternehmensführung, die gemeinnützige und gewinnorientierte Aktivitäten intransparent miteinander vermengte und plump ein ewiges Wachstum der Baubranche voraussetzte. Die Aufarbeitung dieser Probleme sollte den DGB und die deutsche Öffentlichkeit noch auf Jahre hinaus intensiv beschäftigten. Zunächst einmal aber ging es vor allem um Personen und um individuelle Verantwortung.

Als langjähriger NH-Aufsichtsrat war Heinz Kluncker zwar ganz direkt Teil des »Neue Heimat«-Skandals; ein persönliches Fehlverhalten aber konnte ihm niemand vorwerfen. So hatte der ÖTV-Vorsitzende als einziger der 20 Aufsichtsräte zumindest bei einigen Gelegenheiten kritische Fragen zu den Auslandsgeschäften des Konzerns gestellt, die mit dem gemeinnützigen Auftrag eines Gewerkschaftsunternehmens wenig bis gar nichts zu tun hatten. 1977 sprach er von "gravierenden Fehlern« des NH-Managements; im Dezember 1979 warf er Albert Vietor, dem zentralen Mann des Konzerns, sogar "arglistige Täuschung "vor, weil dieser die Risiken der internationalen Projekte verschleiert hatte. In beiden Fällen ließ sich Kluncker allerdings besänftigten; seine Kritik blieb letztlich folgenlos. ${ }^{139}$ Da der Aufsichtsratsvorsitzende Heinz Oskar Vetter den Kurs der NH-Führung ohne Wenn und Aber bejahte und verteidigte, verfügte Heinz Kluncker in dieser Sache allerdings nur über geringe Handlungsmöglichkeiten. ${ }^{140}$

138 | Ebd., S. 596f. Vgl. auch: Vetter hat etwa 200.000 Mark angelegt. In: FAZ, 19.2.1982.

139 | In der Reihenfolge der Zitate: Andreas Kunz (Hrsg.): Die Akte NEUE HEIMAT. Krise und Abwicklung des größten Wohnungsbaukonzerns Europas 1982-1998, Frankfurt/Main und New York 2003, Bd. 1, S. 55 (zitiert wird aus der Einleitung des Herausgebers); Kramper: NEUE HEIMAT, S. 564.

140 | Kramper: NEUE HEIMAT, ebd. 
Von den finanziellen Durchstechereien Vietors und seiner Kollegen in der NH-Geschäftsführung wusste Kluncker nichts, da sie vor dem Aufsichtsrat noch aufwendiger verborgen wurden als der spekulative Charakter der vielen ausländischen Investitionen. Auch an den fragwürdigen steuersparenden Baugesellschaften der NH hatte sich der ÖTV-Vorsitzende nicht beteiligt. Überhaupt unterschied sich Kluncker radikal von einem Mann wie Albert Vietor - außer der Herkunft aus bescheidenen Verhältnissen, dem SPD-Parteibuch und der Mitgliedschaft in einer DGB-Gewerkschaft gab es zwischen ihnen keine Gemeinsamkeit. Nach Monika Wulf-Mathies' Erinnerung war der NH-Chef Heinz Kluncker bereits "zutiefst zuwider«, als Vietor allgemein noch höchstes Ansehen genoss. ${ }^{141}$ Der Baumanager war ein selbstherrlicher Autokrat, der wie selbstverständlich stets seinen eigenen Vorteil im Auge hatte und so durch seine Arbeit für ein gemeinnütziges Unternehmen zu richtigem Reichtum kam. In den frühen 1980er Jahren verzeichnete Vietor Jahreseinkünfte von 1,6 Millionen DM; standesgemäß zog er sich nach seinem tiefen Fall vom Amt des NH-Geschäftsführers im Frühjahr 1982 umgehend in seine Villa im Tessin zurück. ${ }^{142}$

Heinz Kluncker hingegen lebte auch noch in den Jahren, in denen er als Vorsitzender der ÖTV monatlich zunächst etwa 5.000 DM und später (ab 1980) dann sogar fast 10.000 DM brutto im Monat verdiente, wie ein ganz normaler bundesdeutscher Kleinbürger. Er bewohnte mit Frau und zwei Kindern ein bescheidenes, gemietetes Reihenhaus am Stuttgarter Stadtrand, in dem er das enge Treppenhaus wegen seiner Leibesfülle in den 1970er Jahren zunehmend nur noch mit Mühe passieren konnte. ${ }^{143}$ Den Sommerurlaub verbrachte die ganze Familie stets am gleichen Ort, in einem fest aufgebockten Wohnwagen an der jugoslawischen Adriaküste, ohne Klimaanlage oder anderen Komfort. Großzügig war Kluncker, wenn es um Essen und Trinken ging; auch Freunde und Gäste bewirtete er liebend gern und ohne Blick auf die Kosten. ${ }^{144}$

141 | Interview Monika Wulf-Mathies, 7.4.2015.

142 | Kramper: NEUE HEIMAT, S. 598 f. Vietor war Mitglied der IG Bau - Steine -Erden, hat aber niemals ein Gewerkschaftsamt bekleidet. Er machte seine gesamte Karriere innerhalb der NH. Vgl.: ebd., S. 104-108.

143 | Interview Hajo Graf Vitzthum, 14.6.2014. Vgl. auch die verwunderten Bemerkungen zu Klunckers bescheidenem Wohnhaus in: Vetten: Riese, S. 53.

144 | Interview Elke Stierle, 17.12.2013. 
Die Raffgier Vietors und der anderen NH-Manager haben den ÖTVChef wohl auch deshalb persönlich tief getroffen, weil diese als Leiter eines besonders großen gewerkschaftlichen Unternehmens das ungeschriebene, aber doch recht präzise umrissene sozialdemokratische Ethos so radikal ignorierten. Kluncker fand in dem NH-Skandal jedenfalls rasch seine Rolle: Er drängte auf rückhaltlose Aufklärung und forderte personelle Konsequenzen selbst dann, wenn kein justiziables Fehlverhalten vorlag. Vor dem ÖTV-Hauptvorstand sagte er im Februar 1982, »seine Linie« im Umgang mit dem Skandal laute »restlose Aufklärung und konsequentes Handeln ${ }^{145}{ }^{145}$ Mit dieser Haltung leistete er der deutschen Gewerkschaftsbewegung wohl einen wichtigen Dienst, denn Kluncker half so im Frühjahr 1982 maßgeblich, die Berufung des Mannes zu verhindertn, der bereits offiziell für das Amt des DGB-Vorsitzenden nominiert worden war.

Als einzigen Kandidaten für die Nachfolge Heinz Oskar Vetters, der wegen seines Alters auf dem kommenden DGB-Kongress im Mai nicht wieder kandidieren wollte, benannte der DGB-Bundesvorstand Anfang März 1982 Alois Pfeiffer, den langgedienten wirtschaftspolitischen Referenten des gewerkschaftlichen Dachverbandes und ehemaligen Vorsitzenden der Gartenbau-Gewerkschaft. Pfeiffer aber gehörte zu den gutverdienenden Gewerkschaftsfunktionären, die sich an einem der trickreich konstruierten steuersparenden Bauprojekte der NH beteiligt hatten. Da der NH-Skandal im Laufe der Zeit immer größere Dimensionen annahm und sich zudem herausstellte, dass Pfeiffer seine Baubeteiligung im Wert von 100.000 DM ohne einen Pfennig Eigenkapital erworben hatte, empfand Heinz Kluncker diese von ihm anfänglich noch mitgetragene Personalentscheidung zunehmend als falsch: Persönlich drängte er Pfeiffer, »aus moralischen Gründen« auf die Kandidatur zu verzichten. ${ }^{146}$

Der DGB-Funktionär aber sperrte sich; schließlich habe er nichts Gesetzwidriges getan. Erst als Kluncker den stellvertretenden IG Metall-Vorsitzenden Hans Mayr (der den erkrankten und selbst in die Affäre verstrickten Eugen Loderer vertrat) auf seine Seite zog, gab Pfeiffer nach: ÖTV und IG Metall stellten gemeinsam mehr als 50 Prozent der Delegierten auf dem kommenden DGB-Bundeskongress, der den Nachfolger Vetters zu wählen

145 | Protokoll der 8. Sitzung des HV, 11.2.1982. In: AdsD, ÖTV, 5/ÖTVB130087. 146 | Große Schweinerei. In: Der Spiegel 36 (1982), H. 11, S. 27. Vgl. auch: DGB über Vetter-Nachfolge uneins. In: FAZ, 12.3.1982. 
hatte. ${ }^{147}$ So konnte die Versammlung im Mai 1982 mit Ernst Breit, dem bisherigen Chef der Postgewerkschaft, einen neuen DGB-Vorsitzenden wählen, der nichts mit den Affären um die "Neue Heimat« zu tun hatte. Heinz Kluncker, der mit letzter Kraft an diesem Kongress teilnahm, setzte direkt nach der Wahl Breits ein öffentlich stark wirkendes Zeichen: Er überreichte dem frisch Gewählten vor den versammelten Fotografen einen großen Besen und machte damit »handgreiflich« deutlich, wie wichtig es für den neuen DGB-Vorsitzenden sein werde, das NH-Debakel aufzuklären und zu bereinigen. ${ }^{148}$

Wie fast alle Beteiligten konnte Heinz Kluncker seinerzeit nicht ahnen, wie lange sich diese Arbeiten danach noch hinzogen. Sie reichten bis weit in die 1990er Jahre und kosteten die DGB-Organisationen insgesamt die exorbitante Summe von rund einer Milliarde DM. Wichtiger vielleicht noch: Das traditionsreiche Konzept der Gemeinwirtschaft, das seine Verfechter als notwendiges Korrektiv für die strikt profitorientierte private Erwerbswirtschaft präsentierten, verlor in der langen und sehr konfliktreichen Aufarbeitung des NH-Skandals massiv an Überzeugungskraft. ${ }^{149}$ Gerade die ÖTV stand damit vor einer programmatischen Herausforderung, denn die öffentlichen Betriebe, die für ihre gewerkschaftliche Arbeit so wichtig waren, legitimierten sich entscheidend durch die gemeinwirtschaftlichen Lehren. Die Frage, wie die Gewerkschaft in dieser Situation reagierte, gehört aber bereits in eine andere Untersuchung.

\section{Ein Nachfolger oder eine Nachfolgerin? Der scheidende Heinz Kluncker und die Wahl des neuen ÖTV-Vorsitzenden}

In der Satzung der ÖTV wurde der Chef der Organisation nur ein einziges Mal erwähnt: Paragraph 23 bestimmte, der Vorsitzende sei Mitglied des Hauptvorstandes, und er gehöre zusammen mit den beiden Stellvertretern und vier weiteren Vorstandsmitgliedern auch dem gHV an. Dabei aber blieb es. Regelungen, wie etwa Kandidaten für die Leitung der Organisation nominiert werden sollten, fehlten. Selbst die Frage, wie der Vor-

147 | Gewisses Opfer. In: Der Spiegel 36 (1982), H. 13, S. 32; Breit einstimmig für die Nachfolge Vetters nominiert. In: FAZ, 26.3.1983.

148 | Vgl. etwa: Der alte und der neue Vorsitzende. In: FAZ, 21.5.1982.

149 | Vgl.: Kramper: NEUE HEIMAT, S. 600-606. 
sitzende zu wählen sei, beantwortete sich nur indirekt durch Paragraph 25, der die Aufgaben des Gewerkschaftstages festlegte: Seine Delegierten bestimmten die Mitglieder des Hauptvorstandes. Wie seinerzeit in der Bundesrepublik noch allgemein üblich, kannte das Dokument keine weiblichen Würdenträger in der Organisation: Laut Satzung gab es in der ÖTV einen »Vorsitzenden« sowie selbstverständlich auch nur einen »Chefredakteur«, einen »Leiter der Hauptkasse« und sogar einen »Bundessekretär für Frauen ${ }^{150}$

Das große öffentliche Aufsehen, das die Wahl von Monika Wulf-Mathies zur Nachfolgerin Heinz Klunckers im September 1982 erregte, ist auch vor dem Hintergrund der traditionsreichen und damals noch kaum kritisch geprüften kulturellen Prägung zu sehen, die hinter dieser Wortwahl in der ÖTV-Satzung stand. Mit Wulf-Mathies übernahm erstmals eine Frau den Vorsitz einer bundesdeutschen Gewerkschaft - und das geschah gleich noch in der zweitgrößten DGB-Organisation. Ihre Wahl bezeichnete daher eine wichtige Etappe in der langen Geschichte, in der die vom Grundgesetz so leichthin postulierte Gleichberechtigung von Frauen und Männern in der Bundesrepublik schrittweise tatsächlich zur sozialen Realität wurde. In seiner Rolle als scheidender ÖTV-Vorsitzender hat Heinz Kluncker durchaus einiges dafür getan, um diese historisch bedeutsame Wahl möglich zu machen: Als er vor dem Hauptvorstand seinen Rücktritt ankündigte, schlug Kluncker gleichzeitig Monika Wulf-Mathies als Kandidatin für das frei werdende Amt vor, obwohl er damit die Pläne eines seiner engsten Kollegen in der ÖTV-Führung durchkreuzte.

Wäre es dabei um die Konkurrenz zwischen zwei Männern gegangen, dann müssten sich rückblickend wohl nur Gewerkschaftshistoriker für Klunckers Vorgehen interessieren. ${ }^{151}$ Wulf-Mathies aber war die einzige

150 | Vgl. etwa: Protokoll ÖTV-GT 1972, S. 749 f. Auch die Geschäftsordnung der ÖTV-Gewerkschaftstage schwieg zu der Frage, wie Kandidaten für die Leitungspositionen auszuwählen waren.

151 | Wie gesagt stand in der Satzung der ÖTV nichts über ein Recht des Vorsitzenden, bei der Wahl seines Nachfolgers mitzureden. Kluncker praktizierte hier ein offensichtlich nicht fixiertes Vorrecht, von dem er selbst 1964 profitiert hatte: Adolph Kummernuss hatte ihn vor dem Hauptvorstand im Februar 1964 als Kandidaten für den Vorsitz präsentiert (Protokoll über die 10. Sitzung des HV, 6./7.2.1964. In: AdsD, ÖTV, 5/ÖTVB130011). 
Frau an der Spitze der ÖTV - und damit gewann Klunckers Plädoyer für sie eine ganz andere Bedeutung. Allerdings kann Heinz Kluncker wohl dennoch nur sehr bedingt als ein Vorkämpfer der gelebten Gleichberechtigung gelten. Er tat im Sommer 1982 gewissermaßen das historisch Sinnvolle und Richtige aus eher prosaischen organisationspolitischen Gründen, die allenfalls nebenbei etwas mit der hehren Idee der Frauenemanzipation zu tun hatten.

Wie wahrscheinlich in allen großen Organisationen existierte selbstverständlich auch in der ÖTV so etwas wie eine interne Hierarchie des Personals hinter der übermächtigen Figur des Vorsitzenden, von der die Öffentlichkeit wenig oder gar nichts wusste. Als potenzieller Nachfolger Klunckers galt in dieser Hierarchie im Jahr 1982 eindeutig Siegfried Merten, gHV-Mitglied seit 1972 und seit 1976 zugleich einer der beiden Stellvertreter des Vorsitzenden: Er konnte auf eine jahrzehntelange Karriere in der Gewerkschaft zurückblicken, verfügte über breite Erfahrungen in Tarifverhandlungen und war zudem ein exzellenter »Netzwerker« innerhalb der komplizierten Organisation der ÖTV. ${ }^{152}$ Er gehörte - wie Kluncker - zum Jahrgang 1925 und durfte mit 54 Jahren damals also durchaus noch beanspruchen, in »den besten Jahren« zu stehen. Auch sein Habitus erinnerte an den des scheidenden Vorsitzenden: Öffentlich pflegte Merten nach dem Urteil der Wochenzeitschrift Die Zeit den »alten Haudegen-Stil« eines aggressiv auftretenden Gewerkschaftsführers, den Heinz Kluncker so erfolgreich kultiviert hatte. ${ }^{153}$

Wulf-Mathies hingegen war eine »Seiteneinsteigerin«, eine promovierte Germanistin, die nach dem Regierungsantritt der SPD in der Bonner Ministerialbürokratie rasch Karriere gemacht hatte, und mit seinerzeit 40 Jahren zudem deutlich jünger als Merten. ${ }^{154}$ Der ÖTV gehörte sie seit 1971 an; erst seit 1976 arbeitete sie als hauptberufliche Funktionärin der Organisation. Heinz Kluncker hatte sie im Mai 1975 auf dem DGB-Kongress in Hamburg persönlich kennengelernt. Zwar war dieser Kontakt wohl »eher ein $\mathrm{Zu}$ -

152 | Interview Hajo Graf Vitzthum, 7.4.2015.

153 | Erika Martens: Ein Mann und eine Frau stellen sich zur Wahl. In: Die Zeit, 17.9.1982. Klunckers zweiter Stellvertreter Karl Heinz Hoffmann kam als CDUMitglied für die Nachfolge in einer so SPD-nahen Organisation wie der ÖTV aus realpolitischen Gründen selbstverständlich nicht in Frage.

154 | Ebd. 
falk«; er führte aber dazu, dass der ÖTV-Vorsitzende die bestens etablierte Bonner Regierungsdirektorin spontan fragte, ob sie nicht in die Stuttgarter Gewerkschaftszentrale wechseln wolle. Erfahrungen mit aktiver Gewerkschaftsarbeit hatte Wulf-Mathies zuvor nur in der ÖTV-Betriebsgruppe im Bundeskanzleramt gesammelt, für die sie unter anderem als Vertrauensfrau und als Personalrätin tätig gewesen war. Auf Klunckers überraschendes Angebot reagierte sie zunächst mit der Bitte um Bedenkzeit; erst als der ÖTV-Chef nach langen Wochen des Schweigens noch einmal nachhakte, sagte sie zu. Trotz offensichtlicher Skepsis unter den Delegierten wegen ihrer nicht sehr breiten gewerkschaftlichen Erfahrungen wählte der ÖTVKongress sie rund ein Jahr später dann direkt in den gHV ${ }^{155}$

Ihren Start als Gewerkschaftsfunktionärin beschreibt sie selbst rückblickend als nicht ganz einfach, auch weil der Vorsitzende sich im Alltag für sie doch nur bedingt als »helfende Hand« auf dem Weg in das neue Arbeitsfeld erwies. Dennoch profilierte sie sich rasch: Zuständig war sie vor allem für den medizinischen Bereich, der zu den stark wachsenden Sparten in der ÖTV gehörte; inhaltlich bemühte sie sich, in der öffentlichen Arbeit der Gewerkschaft stets die positive gesellschaftliche Bedeutung des Öffentlichen Dienstes stark hervorzuheben, um den weitverbreitenden Klagen über dessen angebliche Privilegien entgegenzuarbeiten. ${ }^{156}$ Auf dem Gewerkschaftstag 1980 mit dem besten Stimmenergebnis aller gHV-Mitglieder wiedergewählt, gehörte sie spätestens seitdem zu den wichtigsten Personen in der Verbandsspitze. ${ }^{157}$

Allerdings war sie damit noch keineswegs gleich eine potenzielle Nachfolgerin Klunckers. Als der schwerkranke Vorsitzende sie im Juni 1982 erst

155 | Interview Monika Wulf-Mathies, 7.4.2015. An dem DGB-Bundeskongress hatte Wulf-Mathies als von der Bundesregierung entsandte Gastdelegierte teilgenommen. In ihrer Bewerbungsrede auf dem Gewerkschaftstag im Juni 1976 bemühte sich Wulf-Mathies intensiv, den Vorwurf zu entkräften, sie sei gewerkschaftlich zu unerfahren. Vgl.: Protokoll ÖTV-GT 1976, Bd. 1, S. 258-260. Sie erhielt 477 Ja-Stimmen bei 92 Nein-Stimmen und 17 Enthaltungen (ebd., S. 261). 156 | Ebd.

157 | Wulf-Mathies erhielt 534 Ja-Stimmen (sechs mehr als Heinz Kluncker); Siegfried Merten kam hingegen nur auf 448 Ja-Stimmen (Protokoll ÖTV-GT 1980, Bd. 1, S. 270 u. 257. Auch bei der Zahl der Nein-Stimmen schnitt Wulf-Mathies mit 55 Stimmen besser ab als Heinz Kluncker (65 ablehnende Voten), Merten (157 Nein-Stimmen) und alle anderen gHV-Mitglieder. 
intern und unmittelbar darauf auch öffentlich als Kandidatin benannte, machte Kluncker vielmehr »die Sensation [...] perfekt«, die seine Rücktrittserklärung ja ohnehin schon hervorrief: Sein Vorschlag kam für die Mitglieder des Hauptvorstandes ebenso »völlig unvorbereitet« wie der Amtsverzicht. In der Folge gab es »erhebliche Unruhe« nicht nur im Hauptvorstand, sondern auch unter den Bezirksvorsitzenden und in den unteren Gliederungen der ÖTV, weil zahlreiche Funktionäre Siegfried Merten doch für den besseren Kandidaten hielten. ${ }^{158}$

Der stellvertretende Vorsitzende selbst teilte diese Sicht. Heinz Kluncker hatte seine überraschende Personalempfehlung im Hauptvorstand nur sehr summarisch begründet: Wulf-Mathies habe im Unterschied zu Merten an der Spitze der ÖTV eine »langjährige Perspektive« und sei zudem bestens eingearbeitet. Warum Letzteres für Merten nun nicht gelten sollte, blieb ebenso unklar wie die Frage, wieso Kluncker die elf Jahre Berufsleben, die sein Stellvertreter seinerzeit noch vor sich hatte, nicht für eine »langjährige Perspektive« hielt. Zugleich sagte Kluncker, er votiere für Wulf-Mathies auch "auf die Gefahr hin, einen Freund zu verlieren«, und obwohl er sich bewusst sei, »daß ich hier verletze, Gefühle mißachte. Ich tue dies nach sorgfältiger Überlegung. « ${ }^{159}$

Fragt man Klunckers damalige engste Mitarbeiter, welcher Art seine damals nicht näher erläuterten Überlegungen denn waren, dann erklären sie einheitlich, der scheidende Vorsitzende habe seinem Stellvertreter das höchste Amt der ÖTV nicht zugetraut: Kluncker hielt Merten für zu sprunghaft und für zu beeinflussbar. Daher sei er bei der Regelung seiner Nachfolge vor allem darauf bedacht gewesen, die Wahl von Siegfried Merten zu verhindern. Wulf-Mathies wurde von ihm nominiert, weil er ihr noch die besten Erfolgsaussichten bei dieser nicht ganz einfachen Operation zutraute. ${ }^{160}$

Auch Monika Wulf-Mathies konstatiert in der Rückschau: »ich war sicher nicht seine Wunschkandidatin«. Sie selbst rechnete zunächst nur damit, man werde sie bei Klunckers Ausscheiden (das sie schon seit eini-

158 | Erika Martens: Ein Mann und eine Frau stellen sich zur Wahl. In: Die Zeit, 17.9.1982.

159 | Protokoll der 9. Sitzung des HV, 2.6.1982. In: AdsD, ÖTV, 5/ÖTVB130088. 160 | Interview Walter Eberhardt, 16.12.2013; Interview Siegfried Bußjäger, 1.4.2014; Interview Hajo Graf Vitzthum, 7.4.2014. 
ger Zeit über kurz oder lang erwartete) »aus schlechtem Gewissen« wohl zur neuen Stellvertreterin des nächsten Vorsitzenden wählen. ${ }^{161}$ Die Nominierung, die Kluncker selbstverständlich vor seinem Auftritt im Hauptvorstand unter vier Augen mit ihr besprochen hatte, nahm sie aus zwei Gründen an: zum einem weil sie Merten als gewerkschaftlich »rückwärtsgewandt« empfand, als einen »Bizeps-Gewerkschafter«, dessen Auftreten nicht mehr zu den gewandelten Strukturen im Öffentlichen Dienst und in der ÖTV passte; zum anderen um weibliche Gleichberechtigung nicht nur allgemein und abstrakt einzufordern, sondern sie als Herausforderung auch persönlich anzunehmen, wenn sich die Chance dafür bot. ${ }^{162}$

Die Frage, ob die Delegierten des außerordentlichen Gewerkschaftstages, der Klunckers Nachfolge regeln musste, diesen Mut honorieren würden, ließ sich selbst am Morgen des 29. September 1982 noch nicht eindeutig beantworten, als der Kongress in Wiesbaden zusammentrat. Siegfried Merten kandidierte gegen Wulf-Mathies, und damit stand die Gewerkschaft zum ersten Mal in ihrer Geschichte vor einer Kampfabstimmung über die Person ihres Vorsitzenden. Überraschender Weise lief die Wahl dann zügig ab: Bereits bei der zweiten Abstimmung erhielt Wulf-Mathies die absolute Mehrheit der Stimmen. Mit Heinz Kluncker und seinen personalpolitischen Planungen hatte dieser Ausgang wohl nur noch wenig zu tun. Die Organisation überraschte sich vielmehr selbst, indem sie so klar gegen den Kandidaten votierte, der für ein gewerkschaftliches »Weiter so" stand. Eine schwache Rede von Merten, die sich fast ausschließlich mit der Vergangenheit beschäftigte, und ein souveräner Auftritt von Wulf-Mathies mit klug gewählten Ankündigungen für die weitere Arbeit der Gewerkschaft mögen etliche zuvor noch unentschlossene Delegierte bewogen haben, für die Kandidatin zu stimmen - zumal Merten so tat, als sei die ÖTV in den vorangegangenen Jahren äußerst erfolgreich gewesen. Damit ignorierte er die Krisenstimmung innerhalb der Organisation. ${ }^{163}$

Letztlich aber dokumentierte die ÖTV mit ihrer Entscheidung für Wulf-Mathies doch vor allem auch die Tatsache, dass sie nicht mehr die Gewerkschaft war, die im Sommer 1964 Heinz Kluncker zum Vorsitzen-

161 | Interview Monika Wulf-Mathies, 7.4.2015.

162 | Ebd.

163 | Protokoll Außerordentlicher Gewerkschaftstag Wiesbaden 1982. Hrsg. v. der ÖTV, Stuttgart o. J., S. 22-25. 
den gewählt hatte: Als eine von Angestellten dominierte Organisation, die gerade Frauen und beruflich besser qualifizierte Beschäftigte als neue Mitglieder gewann, stand ihr die Führung durch Wulf-Mathies "gut zu Gesicht«. Auf den Abschied von Heinz Kluncker folgte also ein in die Zukunft weisender Neuanfang. Dies ergab sich zwar eher aus Zufall als aus einer langfristig vorausschauenden Personalplanung - aber das nimmt der Wahl von 1982 nichts von ihrer historischen Bedeutung.

Als die neue ÖTV-Vorsitzende am 29. September 1982 gewählt wurde, befand sich die politische Landschaft der Bundesrepublik bereits mitten in dem Umbruch, auf den die langen Jahre des Bundeskanzlers Helmut Kohl folgten. Im Streit über die »Haushaltskonsolidierung « und die wirtschaftspolitischen Hauptziele der Bundesregierung hatte die FDP Anfang des Monats die sozialliberale Koalition aufgekündigt und ihre Minister aus dem Kabinett abgezogen; gemeinsam planten CDU/CSU und FDP bereits die Abwahl Helmut Schmidts durch ein konstruktives Misstrauensvotum. Wenig später saßen die Sozialdemokraten im Bundestag dann tatsächlich auf den Oppositionsbänken; in seiner Regierungserklärung sprach der neue christdemokratische Bundeskanzler von einer umfassenden »Wende«, die er innenpolitisch durchsetzen wolle. Zwangsläufig tangierte dieser Regierungswechsel die ÖTV ganz direkt, weil die Tarifverhandlungen für den Öffentlichen Dienst nun erstmals wieder unter anderen politischen Vorzeichen stattfanden als in den Jahren seit 1969 - aber auch das ist bereits eine andere Geschichte, die hier nicht mehr zu untersuchen ist. 



\section{Schlussbetrachtung}

In diesem Buch sollte die Frage nach der Macht der ÖTV in einem doppelten Sinne geprüft werden: Es galt, sowohl den tarifpolitischen Einfluss der Organisation auf die Verhandlungspartner in der Ära Heinz Kluncker als auch die innerorganisatorische Entscheidungskraft des Vorsitzenden zwischen 1964 und 1982 darzustellen und zu untersuchen. Versucht man in diesem Sinne eine Zusammenfassung, dann liegt es nahe, zunächst die Rolle des Vorsitzenden innerhalb der von ihm geführten Gewerkschaft zu thematisieren, denn ein Chef, der - wie gezeigt - selbst dann noch ein gewichtiges Wort mitredet, wenn es um seine eigene Nachfolge geht, scheint doch tatsächlich über große Macht zu verfügen. Trifft also das von Journalisten geprägte Wort von der ÖTV als einer »Kluncker-Gesellschaft« zu? ${ }^{1}$

In der hier vorgelegten Untersuchung finden sich zwar durchaus etliche Informationen und Teilresultate, die eine positive Antwort auf diese Frage begründen könnten. Zumal personalpolitisch besaß Heinz Kluncker offensichtlich erhebliche Gestaltungsmöglichkeiten, die er auch intensiv nutzte. Selbst eher gering entwickelter gewerkschaftlicher "Stallgeruch" war dabei kein Hindernis, wenn es nach Klunckers Urteil ansonsten "passte«. Die Mitglieder des geschäftsführenden Hauptvorstandes und des Hauptvorstandes, den beiden Führungsgremien der ÖTV zwischen den Gewerkschaftstagen, wurden zwar jeweils von den Kongressdelegierten gewählt. Bei diesen Wahlen aber konnte Klunckers Fürsprache stark helfen: Wenn Monika Wulf-Mathies ihre Gewerkschaftskarriere 1976 gleich als Mitglied im gHV starten konnte, dann verdankte sie den ihr damit erwiesenen Vertrauensvorschuss wohl entscheidend der Tatsache, dass der Vorsitzende sie persönlich als neue Führungskraft »angeworben" hatte und unterstützte.

1 | Warten auf den DGB. In: Die Zeit, 20.6.1980. 
Auf ähnliche Weise dürfte Kluncker bereits die Wahl Karl Heinz Hoffmanns in den gHV im Jahr 1968 gefördert haben - und Hoffmann besetzte sogar gleich die Position des stellvertretenden Vorsitzenden, obwohl er die ÖTV intern nicht wirklich kannte.

Der größer besetzte Hauptvorstand schließlich kann nach den überlieferten Wortprotokollen durchaus als ein Gremium gelten, das dem Vorsitzenden folgte: Auf seinen Sitzungen wurde zwar sehr viel geredet, aber wenig gestritten, geschweige denn nach kontroverser Debatte etwas beschlossen. ${ }^{2}$ So finden sich nur höchst selten profilierte Äußerungen des Vorsitzenden; Kluncker ließ vor allem die anderen reden. Oft beschränkte er sich konsequent auf die Rolle, die Sitzung formal zu leiten. Paradoxerweise dokumentiert nach meiner Meinung gerade diese starke Zurückhaltung seine politisch dominante Position innerhalb der ÖTV-Führung: So neutral konnte sich nur ein Vorsitzender verhalten, der die Fäden sicher in seiner Hand wusste. Da Kampfkandidaturen für die Sitze in gHV und HV auf den Gewerkschaftstagen nicht üblich waren, verdankte sich die personelle Zusammensetzung der Gewerkschaftsspitze wohl generell stark der ordnenden Hand des Vorsitzenden. Genau belegen lässt sich dieser Einfluss jedoch nicht. ${ }^{3}$

Aus dem politisch homogenen Charakter der ÖTV-Führungsgremien ergaben sich für den Vorsitzenden Handlungsspielräume, die er nach seinen Überzeugungen nutzen konnte. Besonders die »Ostpolitik« der ÖTV, die in den Jahren nach 1964 in der öffentlichen Wahrnehmung der Organisation eine große Rolle spielte, kann stark als ein persönliches Projekt Heinz Klunckers gelten. Weder die Gewerkschaftsbasis noch die diversen Instanzen der verbandsinternen Demokratie wurden damit groß befasst. Da offener Widerspruch ausblieb, entwickelte die ÖTV dank der Initiativen

2 | Eine Ausnahme, auf die ich aus Platzgründen in der vorstehenden Untersuchung nicht eingehen konnte, ist hier zu vermerken: Die kontroverse Debatte über die Risiken von Atomkraftwerken erreichte in den späten 1970er Jahren auch die Führungsgremien der ÖTV. Vgl. etwa: 3. Sitzung des HV, 20./21.1.1977. In: AdsD, ÖTV, 5/ÖTVB130054; 5. Sitzung des HV, 11./12.5.1977. In: AdsD, ÖTV, 5/ÖTVB130036. Als Abriss vgl.: Markus Mohr: Die Gewerkschaften im Atomkonflikt, Münster 2001.

3 | Der Wahlgang auf dem Gewerkschaftstag 1980 mit zwei Bewerbern für einen HV-Sitz und dessen organisationspolitischer Hintergrund wurde oben als einzige Ausnahme vermerkt. 
ihres Vorsitzenden intensive Kontakte zu Gewerkschaftsverbänden in den sozialistischen Diktaturen Osteuropas und später dann auch in der DDR.

Großen Einfluss besaß Heinz Kluncker offensichtlich auch im weiteren Kreis der ÖTV-Funktionsträger und bei den engagiert mitarbeitenden »einfachen« Mitgliedern. Die in den späten 1970er Jahren mehrfach vorgetragenen Klagen, es könne keine wirklich freie Mitgliederdebatte über den Forderungskatalog für die kommende Tarifrunde geben, wenn der Chef die Vorstandsempfehlung dafür vorab schon öffentlich präsentierte, belegt eindringlich, wie schwer Klunckers Worte innerhalb der Organisation wogen.

Trotz all dieser Feststellungen ist es aus meiner Sicht dennoch verfehlt, die ÖTV der 1960er und 1970er Jahre als »Kluncker-Gesellschaft« zu bezeichnen. In der Tarifarbeit, dem Kernbereich der gewerkschaftlichen Bemühungen, verfolgte die Gewerkschaft keineswegs eine Politik nach dem Gusto ihres Vorsitzenden. Vielmehr zeigt sich gerade an diesem Feld exemplarisch, wie komplex die Beziehungen zwischen Führung, Funktionären und Basis ausfielen und wie sehr die innerorganisatorische Meinungsbildung als ein Prozess verstanden werden muss, in dem um Kompromisse gerungen wurde und in der die Führung danach strebte, die an der Basis dominierenden Ansichten möglichst schon vorab zu berücksichtigen.

Wie gezeigt stritt die ÖTV seit 1967/68 fast jedes Jahr neu wieder über die tarifpolitische Grundsatzentscheidung, ob sie lineare oder sozial ausgleichende Lohn- und Gehaltserhöhungen fordern solle. In dieser Dauerdebatte entstanden rasch recht stabile Fronten: Die Verbandsführung um Heinz Kluncker und auch viele der Bezirksfunktionäre lehnten eine sozial differenzierte Lohnpolitik ab, weil sie meinten, mit einer Bevorzugung der schlechter bezahlten Beschäftigten fördere man vor allem die neoliberalen Attacken auf den vor Konkurrenz geschützten Öffentlichen Dienst; unter den Mitgliedern, die sich an den internen Debatten über den Forderungskatalog beteiligten, bildeten sich dennoch immer wieder Mehrheiten für »Sockel«- oder Festbetrags-Forderungen.

Verantwortlich dafür waren emotional geprägte Vorstellungen von sozialer Gerechtigkeit, die im links dominierten politischen Klima der Zeit ohnehin florierten und angesichts der zeitweise hohen Preissteigerungen in den Jahren nach 1968/69 zusätzlich legitim wirkten. Diese Stimmung erwies sich als so stark, dass die Verbandsspitze begann, sie zu antizipieren: Mehrfach integrierte die ÖTV-Führung sozial ausgleichende Elemente in ihre offizielle Empfehlung für die kommende Tarifrunde, die der Mit- 
gliederdiskussion einen Rahmen geben sollte. Wiederholt musste Heinz Kluncker als der Verhandlungsführer der ÖTV daher mit den Arbeitgebern über tarifpolitische Wünsche streiten, die er selbst für problematisch, wenn nicht sogar für falsch hielt. Um die innergewerkschaftliche Demokratie, die linke Kritiker der DGB-Organisationen in den 1970er Jahren als stark defizitär bezeichneten, kann es so schlecht nicht gestanden haben, wenn in der zweitgrößten bundesdeutschen Gewerkschaft solche Ergebnisse möglich waren. ${ }^{4}$

Auch im Arbeitskampf erwies sich die scheinbar so dominante Macht Heinz Klunckers als eng begrenzt. Im Frühjahr 1974 hätte der Streik im Öffentlichen Dienst ein zügigeres Ende gefunden, wenn es nach den Vorstellungen des ÖTV-Vorsitzenden gegangen wäre; erst das gegenteilige Votum der Großen Tarifkommission erzwang weitere Zugeständnisse der Arbeitgeber. Den so erreichten Tarifabschluss hielten viele Streikende trotzdem immer noch für unzureichend. Offensichtlich ging es dabei keineswegs nur um entgangene materielle Vorteile, sondern auch um einen anderen Blick auf den Streik als tarifpolitisches Kampfinstrument. Heinz Kluncker verstand Tarifverträge vorrangig als Dokumente einer Partnerschaft mit den Arbeitgebern. Von daher war es für ihn selbstverständlich, dass auch ein Streik zu einem Kompromiss mit den Vertragspartnern führen musste. Wie sich im Februar 1974 zeigte, erwarteten viele ÖTV-Mitglieder hingegen einen uneingeschränkten Sieg, d.h. einen Vertrag, der den Forderungen der Gewerkschaft zumindest in den zentralen Punkten eins zu eins entsprach. Die abwägende, strategische Sicht der Verbandsführung auf den Arbeitskampf war ihnen fremd. Gerade der scheinbar so eindrucksvolle »Triumph« der ÖTV über Bundeskanzler Willy Brandt hinterließ daher innerhalb der Organisation Unfrieden und Enttäuschung.

Ein solcher Konflikt zwischen Hoffnungen der Basis und Einschätzungen der Verbandsführung während eines großen Streiks war historisch weder neu noch ÖTV-spezifisch, hingegen kann der anhaltende Richtungsstreit um lineare oder sozial differenzierte Tarifforderungen insofern als eine Besonderheit der ÖTV gelten, als er sowohl aus strukturellen als auch aus politischen Gründen in dieser Gewerkschaft besonders heftig ausgetragen wurde. Im Öffentlichen Dienst fiel zum einen die Spanne zwischen

4 | Als nur ein Beispiel solcher Kritik vgl. etwa: Bergmann/Jacobi/Müller-Jentsch: Gewerkschaften, insbes. S. 292-297. 
den verschiedenen Einkommensgruppen so weit aus, dass eine für alle Beschäftigten gleiche prozentuale Steigerung von Lohn und Gehalt leicht sozial ungerecht wirken konnte. Zum anderen veränderte das »rote Jahrzehnt« der 1970er Jahre gerade weite Teile des Öffentlichen Dienstes. Seine stark erweiterten fürsorgerischen und betreuenden Aufgaben wurden von neu eingestellten Beschäftigten übernommen, die sich dem sozialen und politischen Reformgeist der Zeit vielfach stark verpflichtet fühlten. Dieser Wandel prägte die ÖTV spätestens seit den frühen 1970er Jahren: Zum Leidwesen der ÖTV-Führung nahm die interne tarifpolitische Diskussion damit den Charakter einer stark weltanschaulich gefärbten Debatte an, in der linksorientierte Angestellte und Beamte entscheiden wollten, was im sozialen Interesse geringverdienender Arbeiter liege.

Von all diesen Spannungen innerhalb der ÖTV, die Klunckers persönliche Macht stark einschränkten, nahm die breite Öffentlichkeit in seiner Amtszeit kaum Notiz - und gerade diese Wahrnehmungslücke bezeichnet nach meinem Urteil eine große Leistung des Gewerkschaftsführers. Es gelang Heinz Kluncker nicht nur, die intern vielfältig fraktionierte sowie sozial und politisch noch weiter auseinanderstrebende ÖTV in den 1970er Jahren als solidarische Interessengemeinschaft für alle Beschäftigten des Öffentlichen Dienstes zusammenzuhalten und sie immer wieder neu auf eine gemeinsame Tarifpolitik zu verpflichten. Darüber hinaus wirkte er als öffentliche Person stets so prägnant und stark, dass Fragen nach den inneren Konflikten der von ihm geführten Organisation in den Medien gar nicht aufkamen. Dieser doppelte Erfolg ist umso bemerkenswerter, als Kluncker biografisch keineswegs als ein spontan überzeugender Repräsentant des Öffentlichen Dienstes gelten konnte. Seine eigenen beruflichen Erfahrungen in diesem speziellen Segment der bundesdeutschen Arbeitswelt fielen - wie gezeigt wurde - recht bescheiden aus. Die Formulierung von der ÖTV als einer »Kluncker-Gesellschaft«, die für die Zeitgenossen so überzeugend wirkte, belegt, wie weitgehend es ihm jedoch gelang, dieses Manko vergessen zu machen.

Stark zu differenzieren ist nach den Ergebnissen der vorgelegten Studie ferner das Bild einer übermächtigen ÖTV, der die öffentlichen Arbeitgeber kaum etwas entgegensetzen konnten. Zwar zählte die ÖTV zumal in der ersten Hälfte des hier untersuchten Zeitraums ohne Frage zu den DGBOrganisationen mit großer Streikmacht: Der hohe gewerkschaftliche Organisationsgrad in fast allen kommunalen Versorgungsbetrieben sicherte 
ihr vielfältige Möglichkeiten, die Arbeitgeber unter Druck zu setzen, denn ein Stillstand im öffentlichen Nahverkehr, bei der Müllabfuhr oder in den Elektrizitätswerken störte in kürzester Zeit den reibungslosen Ablauf des großstädtischen Alltags. Politiker, die sich den Wählern als fürsorgliche "Stadtväter« und effiziente Verwalter präsentieren wollten, hatten daher ein großes Interesse, Konflikte mit der ÖTV möglichst rasch durch tarifpolitische Zugeständnisse beizulegen. ${ }^{5}$

Dennoch sollte man die Risiken und Probleme nicht unterschätzen, vor denen die ÖTV stand, wenn ein Tarifkonflikt im Öffentlichen Dienst bis zu einem Streik zu eskalieren drohte. Da Arbeitgeber und Gewerkschaft stets zentral miteinander verhandelten, ging es für die Gewerkschaft immer um die Aufgabe, einen überregionalen Arbeitskampf zu organisieren, der zahlreiche Mitglieder tangierte. Allein schon das Prozedere, die Basis über einen Streik abstimmen zu lassen, belastete die ÖTV finanziell wie personell ganz erheblich; ihr Streikfonds fiel zudem eher klein aus und reichte daher nicht, um einen längeren Ausstand mit vielen Streikenden zu finanzieren. Der Arbeitskampf war und blieb daher auch für die ÖTV in

5 | Zumindest gilt dies, wenn sowohl ein gleiches Wahlrecht wie auch eine hohe Wahlbeteiligung gegeben sind. Historisch gesehen sind beide Voraussetzungen keineswegs selbstverständlich - was alle zeitgenössischen Kritiker übersahen, die von einer angeblich risikolosen »Erpressung« der Kommunalpolitiker sprachen, wenn die ÖTV Streiks in städtischen Versorgungsbetrieben organisierte. Eine Stadtverwaltung hingegen, die nur sozial besser gestellten Teilen der Bevölkerung verantwortlich ist, kann mit einer solchen Arbeitsniederlegung unter Umständen sehr gelassen umgehen. Als Beispiel dafür taugt einer der ersten großen Streiks im Öffentlichen Dienst in Deutschland: der mehr als zehn Wochen dauernde Ausstand der städtischen Müllarbeiter in Kiel im Sommer 1909. Der Magistrat, der dank des höchst undemokratischen Kommunalwahlrechts jener Zeit nur von bürgerlichen Parteien getragen wurde, verweigerte jedes Zugeständnis an die für höhere Löhne streikenden Arbeiter, obwohl während des Ausstandes nicht nur Mülleimer, sondern auch die »Fäkalieneimer« der zahlreichen Haushalte stehen blieben, die nicht an die Kanalisation angeschlossen waren. Der Streik wurde schließlich erfolglos abgebrochen. Vgl. dazu etwa: Emil Dittmer: Streik und Aussperrung der Gemeindearbeiter in Kiel. In: Correspondenzblatt der Generalkommission der Gewerkschaften Deutschlands 19 (1909), Nr. 27, S. 418; Furtwängler: ÖTV, S. 200-202; Wolfgang Kügel: Gemeindearbeiterschaft, Stadtverwaltung und gewerkschaftliche Organisation in Deutschland 1896-1921, phil. Diss., Universität München 1989, S. 214-224. 
tariflichen Auseinandersetzungen die Ultima ratio, die keineswegs selbstverständlich zum strategischen Arsenal der Verbandsführung gehörte.

Die besonderen politischen Strukturen der Zeit kamen jeweils hinzu. So modifizierten sich die Konfliktlinien in den 1970er Jahren. Wie sich in den Tarifrunden für den Öffentlichen Dienst nach dem erfolgreichen Streik von 1974 zeigte, profitierte die ÖTV nur sehr bedingt von ihrer engen Verbindung mit der SPD als regierender Partei im Bund, in wichtigen Bundesländern und in den meisten deutschen Großstädten. Anders, als es die meisten zeitgenössischen Kommentatoren meinten, erwies sich die Nähe von Partei und Gewerkschaft für die ÖTV vielmehr sogar als ein Hindernis: Mit einem vergleichbar konfrontativ geführten Arbeitskampf und einem weiteren Tarifabschluss, der Politiker und Medien auf ähnliche Weise eingeladen hätte, von einer schweren Niederlage der Arbeitgeber zu sprechen, riskierte die Gewerkschaft unter den gegebenen Umständen negative politische Folgen für die SPD, die Heinz Kluncker und die anderen Sozialdemokraten in der ÖTV-Führung in schwere Konflikte gestürzt hätten.

Darüber hinaus konnte sich die ÖTV kaum auf Unterstützung durch die anderen DGB-Gewerkschaften und deren Mitglieder verlassen. Eher herrschte in diesen Organisationen eine negativ aufgeladene Stimmung gegen den Öffentlichen Dienst, dessen Beschäftigte und auch gegen deren Gewerkschaft. Der Arbeitskampf von 1974, in dem die ÖTV mit Bundeskanzler Willy Brandt zu dessen Schaden über Kreuz lag, spielte bei diesen Emotionen eine wichtige Rolle; wichtiger noch (gerade an der Basis der Industriegewerkschaften) waren jedoch Vorurteile gegenüber den Staatsbediensteten, die pauschal als sozial privilegiert galten. Auch das höchst negative Presseecho auf den Streik und den Tarifabschluss von 1974 hat die ÖTV durchaus erschreckt und somit dazu beigetragen, dass die Organisation ausgerechnet nach ihrem größten Erfolg tarifpolitisch über mehrere Jahre hin eher vorsichtig agierte.

In der zweiten Hälfte der 1970er Jahre und vollends dann nach 1980 wurde zudem immer deutlicher, wie stark der Zusammenhang zwischen den Tarifabschlüssen für den Öffentlichen Dienst einerseits und den Staatsausgaben und dem Stand der öffentlichen Verschuldung andererseits die Handlungsmacht der ÖTV begrenzte: In dem Maße, in dem das Thema der Staatsverschuldung an politischer Bedeutung gewann, geriet die ÖTV unter neue Rechtfertigungszwänge, wenn sie die Arbeitgeber mit kost- 
spieligen Forderungen konfrontierte. Gewerkschaftsmacht - so zeigt sich gerade an dieser letzten Phase der "Ära Kluncker« - ergibt sich keineswegs zwingend und keineswegs allein aus einem hohen Organisationsgrad in wichtigen Unternehmen. In den Belegschaften der kommunalen Versorgungsbetriebe war die ÖTV Ende der 1970er Jahre noch genauso stark wie zu Beginn des Jahrzehnts. Nicht nur das konjunkturelle, sondern auch das politische Umfeld aber hatte sich massiv verändert - und damit stand die gewerkschaftliche Arbeit nun unter ganz anderen, eher negativen Vorzeichen. Dies erklärt mit, warum die intensiven Bemühungen der ÖTV, die "neoliberal« inspirierten ersten Privatisierungen öffentlicher Arbeiten in der Bundesrepublik zu verhindern, weitgehend erfolglos blieben.

Schließlich sollte man auch deshalb besser nicht von einer Übermacht der ÖTV gegenüber den Arbeitgebern sprechen, weil die Gewerkschaft ihre starke Position in der Tarifpolitik für den Öffentlichen Dienst paradoxerweise zu einem guten Teil einer Entscheidung ihrer Tarifpartner verdankte. In den konfliktreichen Verhandlungen im Winter 1981/82 trat dieser ansonsten verborgene Zusammenhang offen zu Tage: Wenn es keine gemeinsamen Verhandlungen mit Bund, Ländern und Gemeinden über gleichlautende Tarifverträge für alle drei Segmente des Öffentlichen Dienstes gab, dann sah es mit der Durchsetzungskraft der ÖTV doch ganz anders aus als in all den vorangegangenen Tarifrunden. Gegenüber dem Bund und den Landesregierungen war die Gewerkschaft fast machtlos, weil sie einer Streikdrohung keine wirkungsvollen Taten folgen lassen konnte; nur bei den Gemeinden verfügte sie über vielfältige Möglichkeiten, die Arbeitgeber im Konfliktfall stark unter Druck zu setzen. Zu einer Gewerkschaft, die wirkungsvoll für alle Beschäftigten des bundesdeutschen Staates kämpfte, wurde die ÖTV also nur, weil die Arbeitgeber dem Grundsatz folgten, in Bund, Ländern und Gemeinden müssten inhaltlich identische Tarifverträge gelten, und weil sie deren Bestimmungen dann auch noch auf die Beamten übertrugen.

Mit diesen Entscheidungen verfolgten die Arbeitgeber selbstverständlich eigene Interessen: Sie wollten Abwerbungen innerhalb des Öffentlichen Dienstes verhindern. Da der Staat - anders als Privatunternehmen - stets nur tariflich zahlte, sicherte er sich so exakt kalkulierbare Personalkosten; zudem schützte er sich vor allzu starker Personalfluktuation. Hinter dieser Politik der Tarifeinheit stand - wiederum selbstverständlich - vor allem die Sorge, besonders qualifizierte Beamte und leitende Angestellte 
könnten von verschiedenen öffentlichen Arbeitgebern konkurrierend umworben werden. Sie kam aber auch der großen Gruppe der weniger gut ausgebildeten Angestellten sowie allen Arbeitern zugute, die »beim Staat" und in öffentlichen Betrieben beschäftigt waren - eben weil es die von den Arbeitgebern gewollte Tarifeinheit der ÖTV möglich machte, ihre starke Stellung gegenüber den kommunalen Arbeitgebern auch für die Interessen der Angestellten und Arbeiter von Bund und Ländern zu nutzen. Die Gemeinschaft der öffentlichen Arbeitgeber also half der ÖTV durchaus entscheidend, sich zu der Gewerkschaft zu entwickeln, die sie in den 1960er und 1970er Jahren wurde.

Das Bild der übermächtigen und nicht zu bremsenden ÖTV, das Politik und Medien im Untersuchungszeitraum beständig neu entwarfen, entsprach mithin aus verschiedenen Gründen keineswegs der Realität. Gewerkschaftlich war die Organisation unter Heinz Klunckers Vorsitz dennoch ohne Frage sehr erfolgreich. Drei soziale Errungenschaften sind in einer Gesamtschau besonders hervorzuheben. Erstens gelang es der ÖTV in den 1960er Jahren, den Einkommensabstand zwischen den Beschäftigten der florierenden bundesdeutschen Industrie und den Mitarbeitern des Staates zu beseitigen, welcher die große Masse der beruflich nicht besonders gut qualifizierten Arbeiter und Angestellten im Öffentlichen Dienst sowie die einfachen Beamten sozial bislang deutlich benachteiligt hatte. Die Gewerkschaft korrigierte damit eine Gehaltsstruktur, die in den Jahren der Weltwirtschaftskrise nach 1929 entstanden war, zum Teil aber sogar schon aus der Zeit der ersten schweren Inflation in Deutschland in der gerade erst gegründeten Weimarer Republik datierte. In den 1970er Jahren konnte dieser mühselige schrittweise Anpassungsprozess als abgeschlossen gelten: Seit dem Tarifabschluss vom Februar 1974 erklärte auch die ÖTV, es gebe für die Beschäftigten des Staates bei den Löhnen und Gehältern im Vergleich mit der Privatwirtschaft keinen Nachholbedarf mehr. Der Öffentliche Dienst beschäftigte seinerzeit insgesamt fast vier Millionen Menschen, von denen die meisten eine Familie versorgten. Ohne die Gleichstellung dieser bedeutenden Zahl von Arbeitnehmern wäre die Entwicklung der deutschen Gesellschaft zu einer Gemeinschaft von auf historisch ganz neue Weise materiell gut lebenden und gut abgesicherten Bürgern unvollständig geblieben.

Zweitens stritt die ÖTV unter Heinz Klunckers Führung erfolgreich gegen eine ganze Reihe von überkommenen Regelungen, die Arbeiter des 
Staates deutlich schlechter stellten als Angestellte und Beamte. Solche Markierungen der »Kragenlinie«, die den vermeintlich geringeren Wert körperlicher Arbeit gegenüber "geistigen« Tätigkeiten perpetuierten, gab es im Öffentlichen Dienst Anfang der 1960er Jahre noch in vielen Formen, etwa bei den Regelungen zur Krankmeldung und beim Urlaubsanspruch oder durch den Unterschied zwischen »Lohn« und »Gehalt«. Mit ihrem hartnäckigen Kampf gegen diese antiquierten Normen, die in vielen Industriebetrieben zeitgleich bereits weitgehend abgebaut waren, leistete die Gewerkschaft ohne Frage einen wichtigen Beitrag zur Modernisierung des Öffentlichen Dienstes.

Drittens gelang es der ÖTV in dem hier untersuchten Zeitraum, die Altersversorgung der Arbeiter und Angestellten des Staates erheblich zu verbessern. Der in mehreren Schritten vollzogene Ausbau der bereits älteren Zusatzversorgung für alle nicht-verbeamteten Beschäftigten im Öffentlichen Dienst bedeutete für diese in ihren Jahren im Ruhestand einen erheblichen Wohlstandszuwachs, der insofern besonders schwer wog, als gleichzeitig die allgemeine Lebenserwartung wuchs. Das Problem, im Alter mit deutlich sinkendem Einkommen rechnen zu müssen, verlor damit für die Arbeiter und Angestellten der Öffentlichen Hand deutlich an Bedeutung.

Gerade dieser Erfolg, der weit über die vergleichbaren tarifpolitischen Errungenschaften der Industriegewerkschaften in der Alterssicherung der Beschäftigten hinausging, erwies sich für die ÖTV jedoch als zweischneidige Sache. Da ein kleiner Teil der aus dem Berufsleben ausscheidenden Arbeiter und Angestellten des Staates dank der neuen Regeln besser versorgt wurden als selbst die Beamten, nahmen Politiker und Medien zunehmend Anstoß an der Zusatzversorgung. Sie wurde zum Symbol für die angebliche Privilegierung der Staatsbeschäftigten und weckte sozialen Neid; die Arbeitgeber nutzten diese Emotionen immer wieder neu, um die ÖTV tarifpolitisch unter Druck zu setzen. Zwar wehrte sich die Gewerkschaft nach Kräften. Noch in der letzten Phase der »Ära Kluncker« aber gab die ÖTV dann doch nach: In der Hoffnung, so die Forderungen der Arbeitgeber nach Lohn- und Gehaltskürzungen im Öffentlichen Dienst abfangen zu können, akzeptierte die Gewerkschaft im Sommer 1981 einen Abbau der »Überversorgung « für ausscheidende Arbeiter und Angestellte, den sie bislang stets mit dem Argument verweigert hatte, es gebe in dieser Sache gar keinen Handlungsbedarf. 
Auch die Rücknahme eines älteren Erfolges gehörte somit zur Geschichte der ÖTV in den Jahren, in denen die Gewerkschaft von Heinz Kluncker geführt wurde. Gescheitert ist sie zudem mit ihrem Plan, ein einheitliches Dienstrecht zu initiieren, das für staatlich beschäftigte Arbeiter und Angestellte ebenso wie für Beamte gelten sollte. In der tarifpolitischen Bilanz der ÖTV für die Jahre 1964 bis 1982 muss das Ausbleiben dieser Reform als ein bedeutsamer Negativposten gelten, verstand die Gewerkschaftsspitze das Konzept, dessen Details mit erheblichem intellektuellen Aufwand entwickelt worden waren, doch als den wichtigsten Beitrag der ÖTV zur gesellschaftspolitischen Zukunftsdebatte in der Bundesrepublik. Bündnispartner aber fand sie nicht: An den »hergebrachten Grundsätzen« des deutschen Beamtentums hat sich die Gewerkschaft trotz all ihrer anderen Erfolge die Zähne ausgebissen.

Angesichts der innenpolitisch traditionell starken Stellung der deutschen Beamtenverbände war dieser Ausgang zwar nicht überraschend. Zugleich aber zeigt sich daran ein doppeltes Problem, das die gewerkschaftliche Tarifpolitik grundsätzlich stark erschweren kann: Der komplizierte Charakter arbeitsrechtlicher Bestimmungen jenseits der Frage, wie hoch Lohn oder Gehalt ausfallen, und die juristisch geprägte Sprache der Tarifverträge, die ohne Expertenwissen teilweise kaum verständlich sind, können es sehr schwer machen, die Basis der Organisation zu mobilisieren und dann auch noch der breiteren Öffentlichkeit zu erklären, was die Gewerkschaft fordert. Das Konzept des einheitlichen Dienstrechts kann wohl mit Recht als Musterbeispiel für eine stark »abgehobene« Tarifpolitik gelten, die mit dem beruflichen Alltag der einfachen Mitglieder wenig zu tun hat, der strategisch planenden Gewerkschaftsführung aber doch sehr wichtig ist. Wenn gerade dieser Langzeitplan der ÖTV recht sang- und klanglos unterging, dann hatte das Resultat nicht zuletzt damit zu tun, dass es in der deutschen Arbeitswelt wohl kaum ein komplizierteres und spröderes Feld gibt als das Verhältnis zwischen den Tarifverträgen für die Arbeiter und Angestellten des Staates und dem Dienstrecht für die Beamten.

Korrigiert man die Übertreibungen und Simplifizierungen der vielen zeitgenössischen Kommentatoren und Kritiker, dann erscheint die ÖTV in den Jahren der »Ära Kluncker« mithin als eine recht normale Gewerkschaft: Ihr organisatorisches Wachstum war keineswegs selbstverständlich gesichert; sie kämpfte mit internen Ungleichgewichten und verwaltungstechnischen Problemen; sie stritt immer wieder vehement über ihren ta- 
rifpolitischen Kurs, musste mit großen Streiks sehr vorsichtig sein und vollbrachte in den jährlichen Verhandlungsrunden mit den Arbeitgebern keine Wunder. Wer mag, kann von einer »Entzauberung« sprechen.

Nach meinem Urteil wirkt die ÖTV der 1960er und 1970er Jahre jedoch gerade in dieser Gestalt erst wirklich beeindruckend. Ihre Geschichte zeigt exemplarisch, wie schwierig und wie wertvoll gewerkschaftliche Arbeit ist, wie sehr sie - trotz der unbestreitbar großen Macht der Gewerkschaftsspitze - als kollektive Aktion gesehen werden muss, die vom Engagement vieler Menschen lebt. Sie zeigt zudem, wie stark Ökonomie, Politik und Gesellschaft auf eine Gewerkschaft einwirken, wie sehr dieses höchst komplexe Umfeld die Organisation mit all ihren Handlungen prägt und wie zwingend Gewerkschaftsarbeit daher immer wieder neu formuliert werden muss, wenn sie erfolgreich für die sozialen Belange der Beschäftigten streiten soll. Wer eine Gesellschaftsgeschichte der Bundesrepublik schreiben will, der sollte seine Aufmerksamkeit daher gerade auch auf die Gewerkschaften, ihre Tarifpolitik und deren Kontext richten. Die hier vorgelegte Geschichte der ÖTV unter dem Vorsitz Heinz Klunckers hat - so hoffe ich - bewiesen, wie reich der Ertrag sein kann, wenn man eine Gewerkschaft derart in den Blick nimmt. 


\section{Literatur}

25 Jahre Oberbürgermeister (1971). Festschrift für Arnulf Klett. Stuttgart. Abelshauser, Werner (2009): Nach dem Wirtschaftswunder. Der Gewerkschafter, Politiker und Unternehmer Hans Matthöfer. Bonn.

Abresch, Mirko/Leunig, Sven (2012): 1962-1969: Dominanz föderaler Konflikte. In: Leunig, Sven/Träger, Hendrik (Hrsg.): Parteipolitik und Landesinteressen. Der deutsche Bundesrat 1949-2009. Münster, S. 79106.

ACON[-Gesellschaft für Werbung und Kommunikation] (o.J.): Werbung für eine Gewerkschaft. Broschüre. Köln.

Adam, Hermann (1972): Die Konzertierte Aktion in der Bundesrepublik. Köln.

Adam, Hermann (1991): Wirtschaftspolitik und Regierungssystem der Bundesrepublik Deutschland. Eine Einführung. Opladen.

Alber, Jens (1989): Der Sozialstaat in der Bundesrepublik 1950-1983. Frankfurt/Main.

Albers, Willi (1958/59): Aufgabe und Stellung der Gemeinden im Finanzsystem der gesamten Öffentlichen Hand. In: Finanzarchiv N.F. 19, S. 399-426.

Alecke, Björn (1999): Deutsche Geldpolitik in der Ära Bretton Woods. Münster.

Altrichter, Helmut (2013): Kleine Geschichte der Sowjetunion 1917-1991. 4. aktualis. u. erw. Aufl. München.

Ambrosius, Gerold (2001): Agrarstaat oder Industriestaat - Industriegesellschaft oder Dienstleistungsgesellschaft? Zum sektoralen Strukturwandel im 20. Jahrhundert. In: Spree, Reinhard (Hrsg.): Geschichte der deutschen Wirtschaft im 20. Jahrhundert. München, S. 50-69. 
Ambrosius, Gerold (2009): Regulierung öffentlicher Dienstleistungen in historischer Perspektive. In: Regulierung. Referate einer vom Wissenschaftlichen Beirat des Bundesverbandes Öffentlicher Dienstleistungen am 6./7. Februar 2008 veranstalteten Tagung. Berlin, S. 18-38.

Ambrosius, Gerold (2012): Hybride Eigentums- und Verfügungsrechte. Öffentlich-private Kooperationen in systematisch-theoretischer und historisch-empirischer Perspektive. Berlin.

Amedick, Sigrid (2000): Altersversorgung in einer Leistungsverwaltung: das Beispiel der bayerischen Staatseisenbahnen 1844-1914. In: Wunder, Bernd (Hrsg.): Pensionssysteme im öffentlichen Dienst in Westeuropa (19./20. Jh.). Baden-Baden, S. 55-75.

Anders, Georg (1969): Zum neuen Entwurf eines Zweiten Besoldungsneuregelungsgesetzes. In: Die öffentliche Verwaltung 22, S. 81-92.

Appelius, Stefan (1999): Heine. Die SPD und der lange Weg zur Macht. Essen.

Arbeitsgemeinschaft Selbständiger Unternehmer (Hrsg.) (1983): So wird privatisiert! Eine Handlungsanleitung. Bonn.

Armanski, Gerhard/Dörner, Christine/Mendner, Jürgen H./Oppelt, Wolfgang/Roos, Wolfgang (1983): Rationalisierung in der öffentlichen Verwaltung. Ursachen, Auswirkungen, Widerstand. Frankfurt/ Main und New York.

Arndt, Helmut (Hrsg.) (1969): Lohnpolitik und Einkommensverteilung. Verhandlungen auf der Tagung des Vereins für Socialpolitik, Gesellschaft für Wirtschafts- und Sozialwissenschaften, in Berlin 1968. Berlin.

Backhouse, Roger E. (2005): The Rise of Free Market Economics: Economists and the Role of the State since 1970. In: Medema, Steven G./ Boettke, Peter (eds.): The Role of Government in the History of Economic Thought. Durham und London, S. 355-392.

Bahr, Egon (2013): „Das musst du erzählen.« Erinnerungen an Willy Brandt, Berlin.

Baring, Arnulf (in Zusammenarbeit mit Manfred Görtemaker) (1982): Machtwechsel. Die Ära Brandt-Scheel. Stuttgart.

Bartsch, Heinz (1968): Die Aufgaben der Gewerkschaft der Mitarbeiter der Staatsorgane und der Kommunalwirtschaft bei der Gestaltung des entwickelten gesellschaftlichen Systems des Sozialismus in der DDR. Referat auf der III. Zentraldelegiertenkonferenz. Berlin (DDR). 
Baum, Gerhart Rudolf et al. (1980): Privatisierung - Gewinn für wen? Bonn.

Bayer, Hermann/Streeck, Wolfgang/Treu, Eckbert (1981): Die westdeutsche Gewerkschaftsbewegung in Zahlen. Ein Datenhandbuch zur organisatorischen Entwicklung ausgewählter Industrie- und Berufsverbände 1960-1975. Königstein/Taunus.

Becker, Jens/Jentsch, Harald (2007): Otto Brenner. Eine Biografie. Göttingen.

Beckord, Jochen (1977): Lohnführerschaft und kollektive Lohnverhandlungen. Frankfurt/Main u.a.O.

Beginn und Aufstieg (1960). 10 Jahre Gewerkschaft der Polizei 1950-1960. Zusammengest. u. bearb. von Klaus Hübner. Hamburg.

van der Bellen, Alexander (1977): Öffentliche Unternehmen zwischen Markt und Staat. Köln.

Bender, Gerd (2012): Tarifautonomie, Regulierte Selbstregulation, Korporatismus. Eine Skizze. In: Collin, Peter/Bender, Gerd/Ruppert, Stefan/ Seckelmann, Margrit/Stolleis, Michael (Hrsg.): Regulierte Selbstregulierung im frühen Interventions- und Sozialstaat. Frankfurt/Main, S. 53-67.

Benz, Winfried (1969): Beamtenverhältnis und Arbeitsverhältnis, Stuttgart.

Bergmann, Joachim/Jacobi, Otto/Müller-Jentsch, Walther (1975): Gewerkschaften in der Bundesrepublik. Gewerkschaftliche Lohnpolitik zwischen Mitgliederinteressen und ökonomischen Sachzwängen. Frankfurt/Main und Köln.

Bier, Rolf (1988): Kluncker: So war es wirklich. In: Bunte, H. 46/1988 (Magazin), S. 185.

Bierfelder, Wilhelm (1972): Personalführung und Personalverwaltung in alten Gleisen? In: Genscher, Hans-Dietrich et al.: Der öffentliche Dienst am Scheideweg. Bonn, S. 77-121.

Birke, Peter (2007): Wilde Streiks im Wirtschaftswunder. Arbeitskämpfe, Gewerkschaften und soziale Bewegungen in der Bundesrepublik und Dänemark. Frankfurt/Main und New York.

Birkwald, Reimar (1980): Humanisierung der Arbeitswelt - Anspruch und Wirklichkeit. Eine Zwischenbilanz aus gewerkschaftlicher Sicht. In: Rosenstiel, Lutz von/Weinkamm, Max (Hrsg.): Humanisierung der Arbeitswelt - vergessene Verpflichtung? Eine kritische Bestandsaufnah- 
me anlässlich einer Fachtagung des Kolping-Bildungswerkes. Stuttgart, S. 179-185.

Bischoff, Detlef/Nikusch, Karl-Otto (Hrsg.) (1977): Privatisierung öffentlicher Aufgaben. Ausweg aus der Finanzkrise des Staates? Berlin und New York.

Blanckart, Charles Beat (1982): Privatisierung öffentlicher Dienstleistungen. Beurteilungs- und Entscheidungsprobleme. In: ders./Faber, Monika (Hrsg.): Regulierung öffentlicher Unternehmen. Königstein/Taunus, S. 171-182.

Böcker, Werner (1980): Privatisierung öffentlicher Aufgaben. In: Deutscher Städtetag (Hrsg.): Im Dienst deutscher Städte 1905-1980. Ein kommunales Sachbuch zum 75. Jubiläum. Stuttgart, S. 89-102.

Böhle, Fritz/Lutz, Burkart (1974): Rationalisierungsschutzabkommen. Wirksamkeit und Probleme. Untersuchungen zur Vermeidung sozialer Härten bei technischen und wirtschaftlichen Veränderungen. Göttingen.

Boldt, Gerhard (1972): Zur Gestaltung des Schlichtungsverfahrens bei kollektiven Arbeitsstreitigkeiten in der Bundesrepublik Deutschland. In: David-Constant, Simone/François, Lucien/Jamoulle, Micheline (eds.): En Hommage à Paul Horion. Liege, S. 69-87.

Bongard, Willi (1963): Männer machen Märkte. Mythos und Wirklichkeit der Werbung. Oldenburg und Hamburg.

Bongers, Hans M. (1967): Deutscher Luftverkehr. Entwicklung, Politik, Wirtschaft, Organisation. Versuch einer Analyse der Lufthansa. Bad Godesberg.

Bontrup, Heinz-Josef (1989): Untersuchung der wirtschaftlichen Entwicklung der Stadtwerke Bremen AG und der Bremer Straßenbahn AG unter Anwendung einer externen Bilanzanalyse. Bremen.

Borell, Rolf (1974): Die Personalausgaben der Gebietskörperschaften. Wiesbaden.

Borgs-Maciejewski, Hermann (Hrsg.) (1973): Radikale im öffentlichen Dienst. Dokumente, Debatten, Urteile. Bonn-Bad Godesberg.

Born, Claudia (1997): Das Ei vor Kolumbus. Frauen und Beruf in der Bundesrepublik Deutschland. In: Budde, Gunilla-Friederike (Hrsg.): Frauen arbeiten. Weibliche Erwerbstätigkeit in Ost- und Westdeutschland nach 1945. Göttingen, S. 46-61. 
Borries-Pusback, Bärbel von (2002): Keine Hochschule für den Sozialismus. Die Gründung der Akademie für Gemeinwirtschaft in Hamburg 1945-1955. Opladen.

Borstelmann, Thomas (2012): The 1970s. A New Global History from Civil Rights to Economic Inequality. Princeton und Oxford.

Brachwitz, Wilhelm (1965): Zur statistischen Analyse der Veränderungen der Lebenshaltungskosten mit Hilfe von Preis-, Mengen- und »Reaktions«-Indizes. In: Allgemeines Statistisches Archiv 49, S. 233-245.

Brandt, Willy (1992): Erinnerungen. Erw. Ausgabe, Frankfurt/Main und Berlin.

Brandt, Willy (2001): Berliner Ausgabe. Bd. 7: Mehr Demokratie wagen. Innen- und Gesellschaftspolitik 1966-1974. Bearb. v. Wolther von Kieseritzky. Bonn.

Brauer, Max (1955): Grundfragen der öffentlichen Wirtschaft. In: Bekenntnis zur öffentlichen Wirtschaft. Kundgebung des Deutschen Gewerkschaftsbundes »Grundfragen der öffentlichen Wirtschaft« am 24. Juni 1955 im Städtischen Saalbau, Essen. Düsseldorf.

Braunthal, Gerard (1992): Politische Loyalität und öffentlicher Dienst. Der »Radikalenerlaß« von 1972 und seine Folgen. Marburg.

Bretschneider, Joachim (1974): Niedrigere Lohndrift! In: Der Arbeitgeber 11, H. 1, S. 10-11.

Breuel, Birgit (1976): Es gibt kein Butterbrot umsonst. Gedanken zur Krise, den Problemen und Chancen unserer Wirtschaft. Düsseldorf und Wien.

Breuel, Birgit (1979): Den Amtsschimmel absatteln. Weniger Bürokratie mehr Bürgernähe. Düsseldorf und Wien.

Breuel, Birgit (1987): Der Mensch lebt nicht von Umsatzzahlen. Wie ich Politik verstehe. Herford.

Bröckling, Ulrich (2007): Das unternehmerische Selbst. Soziologie einer Subjektivierungsform. Frankfurt/Main.

Brücher, Bodo (1995): Die sozialistische Jugendbewegung Deutschlands. Politisch-pädagogisches Konzept und Realität sozialistischer Jugendund Erziehungsarbeit in den Nachkriegsjahren. Werther.

Bruhn, Claus-Jürgen (1993): Tariffähigkeit von Gewerkschaften und Autonomie. Eine Kritik der Mächtigkeitslehre des Bundesarbeitsgerichtes. Berlin. 
Die Bundesversammlungen 1949-1994 (1999). Eine Dokumentation aus Anlaß der Wahl des Bundespräsidenten am 23. Mai 1999. Bonn.

Burglin, Harald (1991): Angestellte - das große Rationalisierungspotential in Büros und Verwaltungen. In: Schumm-Garling, Ursula (Hrsg.): Angestellte und Gewerkschafen. Neue Trends und neue Antworten. 2. überarb. Aufl. Köln, S. 180-189.

Buschak, Willy (2002): Edo Fimmen. Der schöne Schein von Europa und die Globalisierung. Eine Biografie. Essen.

Campbell, George A. (1965): The Civil Service in Britain, London.

Capelle, Karl-Hermann (1952a): Wissenswertes von der Akademie und den ehemaligen Studenten 1951/52. In: Mitteilungen der Akademie für Gemeinwirtschaft in Hamburg, H. 1 (März), S. 15-24.

Capelle, Karl-Hermann (1952b): Die Akademie für Gemeinwirtschaft an der Arbeit. In: Akademie für Gemeinwirtschaft in Hamburg. Ihre Aufgaben und ihre Arbeitsweise. Hamburg, S. 63-80.

Caryl, Christian (2013): Strange Rebels. 1979 and the Birth of the 21st Century. New York.

Civil Service Pay Research Unit (1958): First Annual Report 1957, London. Clemens, Horst (1975): Der öffentliche Dienst im Sparprogramm der Regierungskoalition. In: Zeitschrift für Beamtenrecht 23, S. 333-341.

Däubler, Wolfgang (1970): Der Streik im öffentlichen Dienst. Tübingen.

Däubler, Wolfgang (1978): Privatisierung - Speerspitze der Gegenreform? In: Pornschlegel, Hans/Scholz, Herbert (Hrsg.): Arbeitswissenschaft in der Gesellschaftspolitik. Berlin, S. 173-184.

Dedenig, Heinz (1969): Zur Frage der Angleichung von Arbeitern und Angestellten. In: Sozialer Fortschritt 18, S. 228-231.

Deutsche Angestellten-Gewerkschaft (1975). Tätigkeitsbericht 1971-1975. Vorgelegt dem 11. Bundeskongress. Hamburg.

Deutsche Angestellten-Gewerkschaft (1979). Tätigkeitsbericht 1975/79. Vorgelegt dem 12. Bundeskongress, Hamburg.

Der Deutsche Gewerkschaftsbund 1956-1963 (2005). Bearb. v. Jens Hildebrandt unter Mitarbeit v. Boris Schweitzer. Bonn.

Der Deutsche Gewerkschaftsbund 1964-1969 (2006). Bearb. v. Wolther von Kieseritzky. Bonn.

Der Deutsche Gewerkschaftsbund 1969-1975 (2013). Eingel. u. bearb. v. Klaus Mertsching. Bonn. 
Deutscher Industrie- und Handelstag (1984): Praxisleitfaden Privatisierung. Bonn.

Deutscher Städtetag (1976): Privatisierung öffentlicher Aufgaben. Köln.

Deutscher Städtetag (1986): Möglichkeiten und Grenzen der Privatisierung öffentlicher Aufgaben. Köln.

Deutschmann, Christoph/Schmiede, Rudi (unter Mitarbeit v. Berndt Kirchlechner/Helmut Reiniger) (1983): Lohnentwicklung in der Bundesrepublik 1960-1978. Wirtschaftliche und soziale Bestimmungsgründe. Frankfurt/Main und New York.

Dieckmann, Rolf (1977): Aufgabenkritik in einer Großstadtverwaltung unter besonderer Berücksichtigung Hamburgs. Berlin.

Dittmer, Emil (1909): Streik und Aussperrung der Gemeindearbeiter in Kiel. In: Correspondenzblatt der Generalkommission der Gewerkschaften Deutschlands 19, Nr. 27, S. 418.

Dörner, Christine/Roos, Wolfgang (1983): Rationalisierung und elektronische Datenverarbeitung. Stuttgart.

Dörre, Klaus (2006): Gewerkschaftseliten nach 1945 - Kontinuität und Wandel der Führungsgruppen deutscher Gewerkschaften: Das wiederbelebte Interesse an den gewerkschaftlichen Führungsgruppen. In: Mitteilungsblatt des Instituts für soziale Bewegungen, Bd. 35, S. 7-27.

Düll, Klaus/Sauer, Dieter (1975): Rationalisierung im öffentlichen Dienst. In: GM 26, H. 2, S. 37-46.

Eberhardt, Walter et al. (Bearb.) (1995): Heinz Kluncker. Ein Porträt zum siebzigsten Geburtstag. Hrsg. v. der Gewerkschaft Öffentliche Dienste, Transport und Verkehr. Stuttgart.

Edelmann, Heidrun (1999): Privatisierung als Sozialpolitik. »Volksaktien« und Volkswagenwerk. In: Jahrbuch für Wirtschaftsgeschichte 1999, Bd. 1, S. 55-72.

Ehmke, Horst (1996): Mittendrin. Von der Großen Koalition zur Deutschen Einheit. Reinbek.

Ellwein, Thomas (1980): Gewerkschaften und öffentlicher Dienst. Zur Entwicklung der Beamtenpolitik des DGB. Opladen.

Ellwein, Thomas (1989): Krisen und Reformen. Die Bundesrepublik seit den sechziger Jahren. München.

Elsner, Hermann (1979): Das Gemeindefinanzsystem. Geschichte, Ideologie, Grundlagen. Köln u.a.O. 
Emminger, Otmar (1984): Deutsche Geldpolitik im Zeichen des Monetarismus. In: Hampe, Peter (Hrsg.): Friedman contra Keynes. Zur Kontroverse über die Konjunktur- und Beschäftigungspolitik. München, S. $43-66$.

Emminger, Otmar (1986): D-Mark, Dollar, Währungskrisen. Stuttgart.

Erb, Rainer (1978): Gewerkschaftsausschlüsse in den 70er Jahren. In: Jacobi, Otto/Müller-Jentsch, Walther/Schmidt, Eberhard (Hrsg.): Gewerkschaftspolitik in der Krise. Kritisches Gewerkschaftsjahrbuch 1977/78. Berlin, S. 166-175.

Farthmann, Friedhelm (1980): Entscheidungsjahre. Leben zwischen Freiheit und Ordnung. Düsseldorf und Wien.

Faulenbach, Bernd (2010): Das sozialdemokratische Jahrzehnt. Von der Reformeuphorie zur Neuen Unübersichtlichkeit. Die SPD 1969-1982. Bonn.

Der FDGB (1962). Erfüllungsgehilfe der SED. Hrsg. v. Bundesvorstand des Deutschen Gewerkschaftsbundes, Frankfurt/Main.

Felberg, Bruno (1972): Das Wohngeld. Eine Untersuchung seiner wirtschaftlichen und sozialen Bedeutung und ein Vergleich mit anderen Subventionen. Bonn.

Feldman, Gerald D. (1993): The Great Disorder. Politics, Economics, and Society in the German Inflation, 1914-1924. New York und Oxford.

Fenske, Hans (1985): Bürokratie in Deutschland. Vom späten Kaiserreich bis zur Gegenwart. Berlin.

Filbinger, Hans (1978): Regierungsplanung - Euphorie und Wirklichkeit. In: Schwebler, Robert (Hrsg.): Jahre der Wende 1968-1978. Bestandsaufnahme eines Jahrzehnts. Alex Möller zum 75. Geburtstag. Karlsruhe, S. 95-105.

Fink, Carole K. (2014): Global Cold War. An international History. Boulder.

Fischer, Friedmar/Siepe, Werner (2014): 80 Jahre Zusatzversorgung der VBL. Dokumentation. Zahlen, Daten und Fakten von 1970 bis 2050. Hamburg.

Fischer, Stefanie (2014): Ökonomisches Vertrauen und antisemitische Gewalt. Jüdische Viehhändler in Mittelfranken 1919-1939. Göttingen.

Fluhrer, Helmuth (1984): Weniger Staat - Mehr Privat. Die Befürworter im kommunalen Bereich. München. 
Fontaine, Laurence (2006): Bemerkungen zum Kaufen als soziale Praxis. Feilschen, Preise festlegen und Gütern ersteigern in frühneuzeitlichen Europa. In: Historische Anthropologie 14, S. 334-348.

Forsthoff, Ernst (1938): Die Verwaltung als Leistungsträger. Stuttgart und Berlin.

Forsthoff, Ernst (1958): Die Daseinsvorsorge und die Kommunen. Ein Vortrag. Köln.

Frese, Birgit (2000): Anstöße zur sozialen Reform. Hans Katzer, die Sozialausschüsse und ihre Vorschläge zur Schaffung einer partnerschaftlichen Wirtschaftsordnung. Phil. Diss., Universität Düsseldorf.

Friedman, Milton (1971): Kapitalismus und Freiheit. Stuttgart.

Führer, Karl Christian (1995): Mieter, Hausbesitzer, Staat und Wohnungsmarkt. Wohnungsmangel und Wohnungszwangswirtschaft in Deutschland 1914-1960. Stuttgart.

Führer, Karl Christian (Hrsg.) (2004a): Tarifbeziehungen und Tarifpolitik in Deutschland im historischen Wandel. Bonn.

Führer, Karl Christian (2004b): Tarifbeziehungen und Tarifpolitik als Gegenstand der Geschichtswissenschaft. In: ders.: Tarifbeziehungen und Tarifpolitik, S. 7-25.

Führer, Karl Christian (2004c): Von der Selbstbestimmung der Tarifparteien zur staatlichen Verantwortung für die Lohnbildung. Das tarifliche Schlichtungswesen des Baugewerbes in der Weimarer Republik 1924-1932. In: ders.: Tarifbeziehungen und Tarifpolitik, S. 64-113.

Führer, Karl Christian (2008): Medienmetropole Hamburg. Mediale Öffentlichkeiten 1930-1960. Hamburg.

Führer, Karl Christian (2012): Schuld und »Selbstbesinnung«. Axel Springers Bild-Zeitung und die Juden in den 1950er und 1960er Jahren. In: Backhaus, Fritz/Belkin, Dimitrij/Gross, Raphael (Hrsg.): Bild dir dein Volk! Axel Springer und die Juden. Göttingen, S. 17-25.

Führer, Karl Christian (2016): Die Stadt, das Geld und der Markt. Immobilienspekulation in der Bundesrepublik 1960-1985. Berlin und Boston.

Fuhrmann, Jochen (1977): Rationalisierung in der Verwaltung. Köln und Frankfurt/Main.

Furtwängler, Franz Josef (1962): ÖTV. Geschichte einer Gewerkschaft. 3. erw. Aufl. Stuttgart.

Gärtner, Wolfgang (Hrsg.) (2006): 60 Jahre Landtag Nordrhein-Westfalen. Das Land und seine Abgeordneten. Düsseldorf. 
Gaugler, Eduard/Althauser, Ulrich/Kolb, Meinulf/Mallach, Angelika (1980): Rationalisierung und Humanisierung von Büroarbeiten. Studie im Auftrag des Bayerischen Staatsministeriums für Arbeit und Sozialordnung. Ludwigshafen.

Geertz, Clifford (1979): Suq: The Bazar Economy in Sefrou. In: ders./ Geertz, Hildred/Rosen, Lawrence: Meaning and Order in Marroccan Society. Cambridge/MA u. a. O., S. 123-244.

Geißler, Heiner (1978): Alternativen zu einer verbürokratisierten Gesellschaft. In: ders. (Hrsg.): Verwaltete Bürger - Gesellschaft in Fesseln. Frankfurt/Main, S. 121-130.

Gelsner, Kurt (1985): Der Marburger Bund. Chronik der organisierten Krankenhausärzte. Frankfurt/Main.

Genscher, Hans-Dietrich (1995): Erinnerungen. Berlin.

Gerfin, Harald (1969): Ausmaß und Wirkung der Lohndrift. In: Lohnpolitik und Einkommensverteilung. Verhandlungen auf der Tagung des Vereins für Socialpolitik, Gesellschaft für Wirtschafts- und Sozialwissenschaften in Berlin 1968. Berlin, S. 472-522.

Gernert, Wolfgang (1983): Analyse von Haushaltsreden in nordrheinwestfälischen Gemeinden 1983. Essen.

Geschäftsbericht 1962, 1963 und 1964 des Vorstandes der IG Metall für die Bundesrepublik Deutschland (1965). Frankfurt/Main.

Geschäftsbericht 1974 der Bremerhavener Versorgungs- und Verkehrsgesellschaft, der Stadtwerke Bremerhaven und der Verkehrsgesellschaft Bremerhaven (1975). Bremerhaven.

Geschäftsbericht der IG Bau - Steine - Erden für die Bundesrepublik Deutschland [19]63/65 (1966). Frankfurt/Main.

Geschäftsbericht der Versorgungsanstalt des Bundes und der Länder 1967 (1970). Karlsruhe.

Geschäftsbericht der Versorgungsanstalt des Bundes und der Länder (VBL), Karlsruhe, für die Geschäftsjahre 1963 bis 1966 (1967). Karlsruhe.

Geschäftsbericht des Bundesvorstandes des Deutschen Gewerkschaftsbundes (1965). 1962 bis 1. Halbjahr 1965. Düsseldorf.

Geschäftsbericht des Bundesvorstandes des Deutschen Gewerkschaftsbundes (1968). 2. Halbjahr 1965 bis 1968. Düsseldorf.

Geschäftsbericht des Bundesvorstandes des Deutschen Gewerkschaftsbundes 1972 bis 1974 (1975). Düsseldorf. 
Geschäftsbericht des Bundesvorstandes des Deutschen Gewerkschaftsbundes 1975 bis 1977 (1978). Düsseldorf.

Geschäftsbericht des Hauptvorstandes der Deutschen Postgewerkschaft vom 1.7.1965 bis 30.6.1968 (1968). Frankfurt/Main.

Geschäftsbericht des Hauptvorstandes der Deutschen Postgewerkschaft vom 1. Juli 1968 bis 30. Juni 1971 (1971). Frankfurt/Main.

Geschäftsbericht des Hauptvorstandes und des Gewerkschaftsausschusses der Deutschen Postgewerkschaft vom 1. Juli 1971 bis 30. Juni 1974 (1974). An den 11. Ordentlichen Gewerkschaftskongress in Hamburg, Congress-Centrum, 20. bis 26. Oktober 1974. Frankfurt/ Main.

Die Gewerkschaft Erziehung und Wissenschaft (1954). Ihr Aufbau, ihre Probleme, ihr Kampf und ihre Erfolge. Oberhausen.

Gewerkschaft Erziehung und Wissenschaft (1972): Geschäftsbericht 1968-1971. Frankfurt/Main.

[Gewerkschaft Erziehung und Wissenschaft] (1984a): Geschäftsbericht 1980-1983. Frankfurt/Main.

[Gewerkschaft Erziehung und Wissenschaft] (1984b): Gewerkschaftstag 1983. Angenommene Anträge. Frankfurt/Main.

Ghertman, Michel (2009): The Puzzle of Regulation, Deregulation und Reregulation. In: Ménard, Claude/Ghertman, Michel (eds.): Regulation, Deregulation, Reregulation. Institutional Perspectives. Cheltenham, S. 351-373.

Girschner, Christian (2003): Die Dienstleistungsgesellschaft. Zur Kritik einer fixen Idee. Köln.

Gleitze, Bruno (1963): Die Lohndrift als Konjunkturindikator. In: Nemitz, Kurt/Becker, Richard (Hrsg.): Gewerkschaft, Wirtschaft, Gesellschaft. Beiträge zu wirtschaftlichen und gesellschaftlichen Gegenwartsfragen. Köln, S. 81-92.

Gniesmer, Friedrich (1980): Der Weg zur und mit der GdP. In: Die deutsche Polizei. Ihre Geschichte, ihre Gewerkschaft. Daten, Fakten, Meinungen. 30 Jahre Gewerkschaft der Polizei 1950-1980. Hilden, S. 1-59.

Görtemaker, Manfred (1999): Geschichte der Bundesrepublik Deutschland. Von der Gründung bis zur Gegenwart. München.

Gompers, Samuel (1987): The Samuel Gompers Papers. Vol. 2: The Early Years of the American Federation of Labor, 1887-90. Edited by Stuart B. Kaufman. Urbana and Chicago. 
Gundelach, Herlind (1983): Die Sozialausschüsse zwischen CDU und DCG. Selbstverständnis und Rolle 1949-1966. Phil. Diss., Universität Bonn.

Haar, Ernst (1982): Der gemeinwirtschaftliche Auftrag der Deutschen Bundesbahn. In: Zeitschrift für öffentliche und gemeinwirtschaftliche Unternehmen 5, S. 151-169.

Habermann, Gerd/Mühlmann, Rolf W. (1981): Privatisierung - warum? Ein Plädoyer gegen die ausufernde Staatstätigkeit. Hannover.

Halberstadt, Gerhard (1991): Die Angestellten und ihre Gewerkschaft. Stationen einer bewegten Geschichte. Freiburg.

Hale, Norman M. (1973): Großbritannien. In: Kaiser, Josef H./Mayer, Franz/Ule, Carl (Hrsg.): Recht und System des öffentlichen Dienstes. Frankreich, Großbritannien, Italien, Japan, Niederlande. Baden-Baden, S. 93-154.

Hanau, Peter (1974): Streiks im öffentlichen Dienst. In: Zeitschrift für Rechtspolitik 7, S. 111-114.

Hanson, Charles/Jackson, Sheila/Miller, Douglas (1982): The Closed Shop. A Comparative Study in Public Policy and Trade Union Security in Britain, the US and West Germany. London.

Harpprecht, Klaus (2000): Im Kanzleramt. Tagebuch der Jahre mit Willy Brandt. Reinbek.

Harden, Heinz-Dieter/Friedrichs, Hans (1982): Das Collective-Bargaining-Modell von Pen. In: Wirtschaftswissenschaftliche Studien 11, S. 145-151.

Hauptvorstand der Gewerkschaft Öffentliche Dienste, Transport und Verkehr (Hrsg.) (1977): Zur Privatisierung öffentlicher Dienstleistungen. H. 3. Stuttgart.

Hauptvorstand der Gewerkschaft Öffentliche Dienste, Transport und Verkehr (Hrsg.) (1983): Rationalisierung und ihre Auswirkungen im Bereich der Stadtreinigung (Müllabfuhr). Beispiel Stadtreinigung Neumünster. Stuttgart.

Hausmann, Marc (2012): Vor dem dritten Staatsbankrott? Der deutsche Schuldenstaat in historischer und internationaler Perspektive. 2. durchges. Aufl. München.

Haustein, Werner (1944): Fragen der allgemeinen und betrieblichen Sozialpolitik bei der Reichsbahn. In: Archiv für Eisenbahnwesen 66, S. 165-224. 
Hayek, Friedrich A. von (1971): Die Verfassung der Freiheit. Tübingen.

Heer, Volker H. (1975): Beamtenbesoldung in der Bundesrepublik Deutschland. Entwicklung, Struktur, Problematik, Theorie. Frankfurt/Main und Zürich.

Heinemann, Silke (2002): Teilzeitbeschäftigung im öffentlichen Dienst. Entwicklung und Einflussfaktoren im intersektoralen und internationalen Vergleich. Frankfurt/Main.

Heisler, Herfried (1981): Die tarifvertragliche Angleichung der Rechtsstellung von Arbeitern und Angestellten. In: Säcker, Franz Jürgen/Zander, Ernst (Hrsg.): Mitbestimmung und Effizienz. Humanität und Rationalität der Produktionsstruktur in mitbestimmten Unternehmen. Stuttgart, S. 341-349.

Heller, Georg (1981): Der sanfte Buhmann. In: Wirtschaftswoche 35, H. 13, S. 46 u. 50.

Hemmer, Hans-Otto/Simon, Hartmut (Hrsg.) (2000): Auf die Wirkung kommt es an. Gespräche mit Heinz Kluncker. Frankfurt/Main.

Hentschel, Volker (1983): Geschichte der deutschen Sozialpolitik 18801980. Frankfurt/Main.

Hentschel, Volker (1996): Ludwig Erhard. Ein Politikerleben. München.

Heske, Gerhard (1992): Preisstatistik. Grundlagen und Praxis der volkswirtschaftlichen Preisstatistik. Berlin.

Hesselbach, Walter (1963): Die gemeinwirtschaftlichen Unternehmen im Wettbewerb. In: Nemitz Kurt/Becker, Richard (Hrsg.): Gewerkschaft Wirtschaft - Gesellschaft. Beiträge zu wirtschaftlichen und sozialen Gegenwartsfragen. Köln, S. 107-124.

Heubeck, Georg (1970): Entwicklung der Beamtenpensionen im Vergleich zu anderen Arten der Alters- und Hinterbliebenenversorgung. Bad Godesberg.

Heubeck, Georg (1974): Die Versorgung im öffentlichen Dienst - gestern heute - morgen. Bad Godesberg.

Heuer, Hans (1980): Die veränderte ökonomische Basis der Städte. In: Friedrichs, Jürgen (Hrsg.): Die Städte in den 80er Jahren. Demographische, ökonomische und technologische Entwicklungen. Opladen.

Hildebrandt, Jens (2010): Gewerkschaften im geteilten Deutschland. Die Beziehungen zwischen DGB und FDGB vom Kalten Krieg bis zur Neuen Ostpolitik 1955 bis 1969. St. Ingbert. 
Hill, Robert (1925): Streiks in gemeinnützigen Betrieben. In: Kaskel, Walter (Hrsg.): Koalitionen und Koalitionskampfmittel. Berlin, S. 149-156.

Hilpert, Dagmar (2012): Wohlfahrtsstaat der Mittelschichten? Sozialpolitik und gesellschaftlicher Wandel in der Bundesrepublik Deutschland (1949-1975). Göttingen.

Hirche, Kurt (1961a): Das Experiment der Volksaktie. Köln.

Hirche, Kurt (1961b): Gewerkschafter im Bundestag. In: GM 12, S. 641651.

Hirche, Kurt (1965): Gewerkschafter im 5. Deutschen Bundestag. In: GM 16, S. 705-712.

Hockerts, Hans Günter (2011): Im Zenit der staatlichen Wohlfahrtsproduktion: Die Reformära 1966-1974. In: ders.: Der deutsche Sozialstaat. Entfaltung und Gefährdung seit 1945. Göttingen, S. 181-201.

Hofbauer, Hans (1965): Zur sozialen Gliederung der Arbeitnehmerschaft. Arbeiter und Angestellte in der Gesellschaftshierarchie. Köln und Opladen.

Hofbauer, Hans/Schuster, Lothar/Dadzio, Werner (1968): Die Arbeitssuchenden in der Bundesrepublik Deutschland im Frühjahr 1968. In: Mitteilungen aus der Arbeitsmarkt- und Berufsforschung 1, H. 4, S. 177-197.

Hoffmann, Karl-Heinz (1975): Öffentlicher Nahverkehr braucht Priorität. In: Öffentliche Wirtschaft und Gemeinwirtschaft 24, S. 20-21.

Hofmann, Gunter (2012): Willy Brandt und Helmut Schmidt. Geschichte einer schwierigen Freundschaft. München.

Hohensee, Jens (1996): Der erste Ölpreisschock 1973/74. Die politischen und gesellschaftlichen Auswirkungen der arabischen Erdölpolitik auf die Bundesrepublik Deutschland und Westeuropa. Stuttgart.

Holtfrerich, Carl-Ludwig (1998): Geldpolitik bei festen Wechselkursen 1948-1970. In: Deutsche Bundesbank (Hrsg.): 50 Jahre Deutsche Mark. Notenbank und Währung in Deutschland seit 1948. München, S. 347438.

Holzheu, Franz (1974/75): Nach der Konzertierten Aktion die mittelfristig orientierte Regelbindung. In: Finanzarchiv N. F. 33, S. 475-499.

Hoppmann, Erich (1971): Konzertierte Aktion und der Rahmen der marktwirtschaftlichen Ordnung«. In: ders. (Hrsg.): Konzertierte Aktion. Kritische Beiträge zu einem Experiment. Frankfurt/Main.

Horné, Alfred (1959): Der beklagte Sieg. Gespräche über die Mitbestimmung. Villingen. 
Hotz, Matthäus (1926): Die soziale Betätigung der Deutschen Reichspost. Berlin.

Huber, Berthold (2012): Franz Steinkühler - einer von uns. In: Schabedoth, Hans-Joachim/Schaaf, Peter (Hrsg.): Franz Steinkühler. Einer von uns. Marburg, S. 8-12.

Huch, Burkhardt/Dolezalek, Carl Martin (Hrsg.) (1978): Angewandte Rationalisierung in der Unternehmenspraxis. Ausgewählte Beiträge zum 75. Geburtstag von Kurt Pentzlin. Düsseldorf und Wien.

Hülsbruch, Hans-Joachim (1961): Die Gestaltung der Beamtengehälter seit der Währungsumstellung. Eine volkswirtschaftliche Untersuchung. Wirtschaftswiss. Diss., Hochschule für Wirtschafts- und Sozialwissenschaften Nürnberg.

In letzter Stunde (1968). Reden, Diskussionen und Beschluß der außerordentlichen Hauptversammlung des Deutschen Städtetages am 26. November 1968 in Bonn. Stuttgart und Berlin.

Isensee, Josef (1971): Beamtenstreik. Zur rechtlichen Zulässigkeit des Dienstkampfes. Bad Godesberg.

Isensee, Josef (1975): Der Tarifvertrag als Gewerkschafts-Staats-Vertrag. In: Leisner, Walter (Hrsg.): Das Berufsbeamtentum im demokratischen Staat. Beiträge zum Dienstrecht und zur Dienstrechtsreform. Berlin, S. 23-45.

Jahnz, Alfred (1971): Die Neuregelung der zusätzlichen Alters- und Hinterbliebenenversorgung im öffentlichen Dienst. Kommentar zur Satzung der Versorgungsanstalt des Bundes und der Länder (VBL). 3. neu bearb. Aufl. Stuttgart.

Jahrbuch 1964/65 (1966). Geschäftsbericht der Gewerkschaft Nahrung, Genuss, Gaststätten. Hamburg.

Jahresbericht 1971 der Deutschen Lufthansa Aktiengesellschaft (1972). Frankfurt/Main.

Jahresbericht der Bundesvereinigung der Deutschen Arbeitgeberverbände (1964). 1. Dezember 1963-30. November 1964. Vorgelegt der Mitgliederversammlung in Bad Godesberg am 2. Dezember 1964. Düsseldorf.

Jansen, Rolf/Rudat, Reinhard (1978): Stadtreinigung in der Bundesrepublik Deutschland. Die betrieblichen Rahmenbedingungen und die Arbeitssituation der Betroffenen. Dortmund. 
Jung, Jörg (1971): Die Zweispurigkeit des öffentlichen Dienstes. Eine Untersuchung über die Veränderungen der Personalstruktur im öffentlichen Dienst und die Verankerung des Berufsbeamtentums im Grundgesetz. Berlin.

Just, Hilde (1977a): Zur Teilzeitarbeit im öffentlichen Dienst. In: Frauen und Arbeit, H. 4, S. 12-13.

Just, Hilde (1977b): Darstellung der Politik für die Arbeitnehmerinnen aus der Sicht der Gewerkschaft ÖTV. In: Frauen und Arbeit, H. 5, S. 6-8.

Die Kabinettsprotokolle der Bundesregierung (1984). Bd. 2: 1950. Bearb. v. Ulrich Enders/Konrad Reiser. Boppard.

Die Kabinettsprotokolle der Bundesregierung (1988). Bd. 4: 1951. Bearb. v. Ursula Hüllbüsch. Boppard.

Die Kabinettsprotokolle der Bundesregierung (1989a). Bd. 5: 1952. Bearb. v. Kai von Jena. Boppard.

Die Kabinettsprotokolle der Bundesregierung (1989b). Bd. 6: 1953. Bearb. v. Ulrich Enders/Konrad Reiser. Boppard.

Die Kabinettsprotokolle der Bundesregierung (1993). Bd. 7: 1954. Bearb. v. Ursula Hüllbüsch/Thomas Trumpp. Boppard.

Die Kabinettsprotokolle der Bundesregierung (2000). Bd. 10: 1957. Bearb. v. Ulrich Enders/Josef Henke. München.

Die Kabinettsprotokolle der Bundesregierung (2002). Bd. 11: 1958. Bearb. v. Ulrich Enders/Christoph Schawe. München.

Die Kabinettsprotokolle der Bundesregierung (2004). Bd. 14: 1961. Bearb. v. Ulrich Enders/Jörg Filthaut. München.

Die Kabinettsprotokolle der Bundesregierung (2005). Bd. 15: 1962. Bearb. v. Uta Rössel/Christoph Seemann. München.

Die Kabinettsprotokolle der Bundesregierung (2006). Bd. 16: 1963. Bearb. v. Ulrich Enders/Christoph Seemann. München.

Die Kabinettsprotokolle der Bundesregierung (2008). Bd. 18: 1965. Bearb. v. Josef Henke/Christoph Seemann. München.

Die Kabinettsprotokolle der Bundesregierung (2009). Bd. 19: 1966. Bearb. v. Christine Fabian/Uta Rössel. München.

Die Kabinettsprotokolle der Bundesregierung (2010). Bd. 20: 1967. Bearb. v. Walter Naasner/Christoph Seeman. München.

Die Kabinettsprotokolle der Bundesregierung (2011). Bd. 21: 1968. Bearb. v. Christian Fabian/Uta Rössel. München. 
Die Kabinettsprotokolle der Bundesregierung (2012). Bd. 22: 1969. Bearb. v. Walter Naasner/Christoph Seemann. München.

Die Kabinettsprotokolle der Bundesregierung (2015). Bd. 23: 1970. Bearb. v. Christine Fabian/Uta Rössel. Berlin u.a.O..

Käppner, Joachim (2010): Berthold Beitz. Die Biographie. Berlin.

Kaiser, Christian (2006): Korporatismus in der Bundesrepublik Deutschland. Eine politikfeldübergreifende Übersicht. Marburg.

Kalmbach, Peter (1981): »Mehr Markt - weniger Staat« - eine neokonservative Offensive. Darstellung und Kritik gegenwärtiger Revisionsversuche der Rollenverteilung zwischen Staat und Markt. Stuttgart.

Kassel, Brigitte (Hrsg.) (2001): ... letztlich ging es doch voran! Zur Frauenpolitik der ÖTV 1949-1989. Stuttgart.

Kassel, Brigitte (2004): Differenz und Gleichheit. Zur Zeitpolitik der Gewerkschaft ÖTV als Geschlechterpolitik 1948-1989. In: Führer: Tarifbeziehungen und Tarifpolitik, S. 201-223.

Keller, Berndt (1978): Lohnbestimmung im öffentlichen Dienst. In: Wehling, Hans-Georg (Hrsg.): Arbeitskonflikte in der Bundesrepublik. Fachwissenschaftliche Analysen, Unterrichtsempfehlungen. Opladen, S. 44-52.

Keller, Berndt (1983): Arbeitsbeziehungen im öffentlichen Dienst. Tarifpolitik der Gewerkschaften und Interessenpolitik der Beamtenverbände. Frankfurt/Main und New York.

Kemper, Klaus (2003): Eugen Loderer und die IG Metall. Biografie eines Gewerkschafters. Filderstadt.

Kielmansegg, Peter Graf (1979): Von der Notwendigkeit und den Schwierigkeiten streitbarer Demokratie. In: Schönbohm, Wulf (Hrsg.): Verfassungsfeinde als Beamte? Die Kontroverse um die streitbare Demokratie. München und Wien, S. 39-68.

Kittner, Michael (2005): Arbeitskampf. Geschichte, Recht, Gegenwart. München.

Klein, Beatrix/Bilz, Fritz/Ehlert, Klaus (1996): »Im Prinzip sind wir uns doch einig.« 50 Jahre ÖTV in Köln 1946-1996. Köln.

Kleßmann, Christoph (1997): Zwei Staaten, eine Nation. Deutsche Geschichte 1955-1970. 2. überarb. u. erw. Aufl. Bonn.

Klose, Hans-Ulrich (1975): Hamburgs Zukunft sichern. Regierungserklärung am 29. Januar 1975 vor der hamburgischen Bürgerschaft. Hamburg. 
Klotzbach, Kurt (1982): Der Weg zur Staatspartei. Programmatik, praktische Politik und Organisation der deutschen Sozialdemokratie 19451965. Berlin.

Kluncker, Heinz (1958): Arbeitszeitverkürzung auch im öffentlichen Dienst. In: Die Quelle 9, S. 453-454.

Kluncker, Heinz (1960): Der Lohn- und Gehaltsstreit im Öffentlichen Dienst. In: Die Quelle 11, S. 106-107.

Kluncker, Heinz (1961): Die Tarifsituation im öffentlichen Dienst. In: Die Quelle 12, S. 152-153.

Kluncker, Heinz (1962): Tarifautonomie im öffentlichen Dienst bleibt gewahrt. In: Die Quelle 13, S. 300-301.

Kluncker, Heinz (1965): Hintergründe einer Reise. In: Die Quelle 16, S. 438-439.

Kluncker, Heinz (1966): Gewerkschaftliche Ostkontakte. In: ÖTV-Magazin, H. 1, S. 29-32.

Kluncker, Heinz (1968): Kommt es zu einer Neuorientierung der gewerkschaftlichen Ostpolitik? In: Der Volkswirt 22, H. 35, S. 23.

Kluncker, Heinz (1970): Für ein einheitliches Dienstrecht. In: ÖTV-Beamten-Nachrichten 15, H. 1, S. 1.

Kluncker, Heinz (1973): Tarifautonomie im Widerstreit der Interessen. In: Flohr, Heinz/Lompe, Klaus/Neumann, Lothar F. (Hrsg.): Freiheitlicher Sozialismus. Beiträge zu seinem heutigen Selbstverständnis. Bonn, S. 213-216.

Kluncker, Heinz (1977): Gesundheitspolitik als gewerkschaftliche Aufgabe. In: Gesundheitspolitik. Perspektiven und Beschlüsse der Gewerkschaft ÖTV. Stuttgart, S. 5-9.

Kluncker, Heinz (1978): Sozialpolitische Probleme der Entstaatlichung. In: Hanusch, Horst (Hrsg.): Reform öffentlicher Leistungen. Beiträge zur Entstaatlichung. Ein Kolloquium der Universität Augsburg in Memmingen. Baden-Baden, S. 77-93.

Kluncker, Heinz (1980): Die Rolle öffentlicher Unternehmen und ihrer Beschäftigten als Teil des öffentlichen Dienstes. In: Friedhelm Farthmann et al.: Arbeitnehmer in öffentlichen und gemeinwirtschaftlichen Unternehmen. 6. Wissenschaftliche Tagung über Gemeinwirtschaft in Bergneustadt vom 28. bis 30. März 1979. Baden-Baden, S. 97-107. 
Kluncker, Heinz (1997): Partnerschaft muss einen Grundkonsens ermöglichen. In: Kinkel, Klaus (Hrsg.): In der Verantwortung. Hans-Dietrich Genscher zum Siebzigsten. Berlin, S. 138-141.

Knauss, Fritz (1990): Privatisierung in der Bundesrepublik Deutschland 1983-1990. Bilanz und Perspektiven. Köln.

Knütter, Hans-Helmuth (1979): Verfassungsfeindliche Beamte in der Weimarer Republik. In: Schönbohm, Wulf (Hrsg.): Verfassungsfeinde als Beamte? Die Kontroverse um die streitbare Demokratie. München und Wien.

Kocsis, Andrea (2013): Erfolgreiche Tarifpolitik und guter Organisationsgrad - zwei Seiten einer Medaille. In: dies./Sterkel, Gabriele/Wiedemuth, Jörg (Hrsg.): Organisieren am Konflikt. Tarifauseinandersetzungen und Mitgliederentwicklung im Dienstleistungssektor. Hamburg, S. 12-18.

Koenen, Gerd (2001): Das rote Jahrzehnt. Unsere kleine deutsche Kulturrevolution. Köln.

König, Herbert (1977): Dynamische Verwaltung. Bürokratie zwischen Politik und Kosten. Stuttgart.

König, Herbert (1980): Zur Effizienz öffentlichen Handelns im Spiegel der nationalen und internationalen Diskussion. In: Die Verwaltung 13, S. 57-76.

König, Peter (1990): Ölpreisschocks und makroökonomische Anpassungsprozesse zwischen Industrieländern. Konstanz.

Korff, Gottfried (1986): Rote Fahnen und geballte Faust. Zur Symbolik der Arbeiterbewegung in der Weimarer Republik. In: Petzina, Dietmar (Hrsg.): Fahnen, Fäuste, Körper. Symbolik und Kultur der Arbeiterbewegung. Essen, S. 27-60.

Kramper, Peter (2008): NEUE HEIMAT. Unternehmenspolitik und Unternehmensentwicklung im gewerkschaftlichen Wohnungs- und Städtebau 1950-1982. Stuttgart.

Krause, Alfred (1968): Staat und Staatsdienst heute. Bad Godesberg.

Kraushaar, Wolfgang (2008): Die Furcht vor einem »neuen 33«. Protest gegen die Notstandsgesetzgebung. In: Geppert, Dominik/Hacke, Jens (Hrsg.): Streit um den Staat. Intellektuelle Debatten in der Bundesrepublik 1960-1980. Göttingen, S. 135-150.

Kreißig, Gerald/Hintzen, Johannes (1975): Zur Personalentwicklung der Kommunen. Köln. 
Kreißig, Gerald (1982): Personalstand und Personalentwicklung bei Bund, Ländern und Gemeinden. In: Der Städtetag 35, S. 188-194.

Kreutzer, Susanne (2004): »Eine Schwester schaut nicht auf die Uhr«. Zur Arbeitszeitpolitik der Gewerkschaft Öffentliche Dienste, Transport und Verkehr (ÖTV) in der Krankenpflege 1949-1960. In: Führer: Tarifbeziehungen und Tarifpolitik, S. 175-200.

Kreutzer, Susanne (2005): Vom »Liebesdienst« zum modernen Frauenberuf. Die Reform der Krankenpflege nach 1945. Frankfurt/Main.

Kreutzer, Susanne (2006): »Der Aufstieg findet nicht statt«. Frauen und Führungspositionen in der Gewerkschaft Öffentliche Dienste, Transport und Verkehr (ÖTV) in den 1950er und 1960er Jahren. In: Mitteilungsblatt des Instituts für Soziale Bewegungen, S. 167-177.

Kröning, Volker/Pottschmidt, Günter/Preuß, Ulrich K./Rinken, Alfred (Hrsg.) (1991): Handbuch der Bremischen Verfassung. Baden-Baden.

Krüger, Herbert (1975): Die »Lebensluft« des Öffentlichen Dienstes. In: Leissner, Walter (Hrsg.): Das Berufsbeamtentum im demokratischen Staat. Beiträge zum Dienstrecht und zur Dienstrechtsreform. Berlin, S. 101-119.

Krummerey, Walter (1973): Bestimmen Aufgaben, Organisation und Leistungen die Personalwirtschaft der Kommunalverwaltung? Versuch einer Antwort am Beispiel der Stadt Herne. Herne.

Krumsiek, Ralf (1978): Alle Jahre wieder. In: Der Städtetag 31, S. 332-335.

Krupp, Hans-Jürgen (1982): Möglichkeiten und Grenzen der Staatstätigkeit. In: Bombach, Gottfried/Gahlen, Bernhard/Ott, Alfred E. (Hrsg.): Möglichkeiten und Grenzen der Staatstätigkeit: Tübingen, S. 1-51.

Kügel, Wolfgang (1989): Gemeindearbeiterschaft, Stadtverwaltung und gewerkschaftliche Organisation in Deutschland 1896-1921. Phil. Diss., Universität München.

Kühn, Andreas (2005): Stalins Erben, Maos Söhne. Die Lebenswelt der KGruppen in der Bundesrepublik der 70er Jahre. Frankfurt/Main.

Kühnert, Heinz (1977): Reinigung der Schulgebäude - ein finanzträchtiges Kapitel im städtischen Haushalt. In: Kommunalwirtschaft, S. 390-391.

Külp, Bernhard (1965): Lohnbildung im Wechselspiel zwischen politischen und wirtschaftlichen Kräften. Berlin.

Külp, Bernhard (1965a): Streik und Streikdrohung. Ihre Rolle in der Volkswirtschaft und im Sozialprozeß. Berlin. 
Külp, Bernhard (1969b): Tarifverhandlungen: Strategie und Taktik. In: Arndt: Lohnpolitik, S. 157-173.

Külp, Bernhard (1972): Zur Problematik der Tarifautonomie. In: Hamburger Jahrbuch für Wirtschafts- und Gesellschaftspolitik 17, S. 199-222.

Küneweg, Gisela (1980): Stoffwechseländerungen bei Nulldiät. Med. Diss., Universität Marburg 1980.

Kuhlmann, Werner (1960): Unser Weg. In: Beginn und Aufstieg. 10 Jahre Gewerkschaft der Polizei 1950-1960. Hamburg, S. 15-21.

Kummernuss, Adolph (1953): Gewerkschaft und Polizei. In: Der Bürger und seine Polizei. Vorträge im Rahmen der Arbeitstagung »Woche der Polizei«, veranstaltet von der ÖTV in der Michael-Rott-Schule Mosbach/Baden im Januar 1953. Stuttgart, S. 76-94.

Kunz, Andreas (Hrsg.) (2003): Die Akte NEUE HEIMAT. Krise und Abwicklung des größten Wohnungsbaukonzerns Europas 1982-1998. 2 Bde. Frankfurt/Main und New York.

Kunz, Dietrich/Euler, Manfred (1971): Möglichkeiten und Grenzen der laufenden Wirtschaftsrechnungen. In: Wirtschaft und Statistik 23, S. 321-326.

Laucht, Hans (1978): Gefahren einer Privatisierung. In: ÖTV-Magazin, H. 2, S. 17-18.

Lauschke, Karl (1998): »Störenfriede«. Der Einfluss der 68er-Bewegung auf die betriebliche und gewerkschaftliche Interessenvertretung. Das Beispiel der Dortmunder ÖTV. In: Westfälische Forschungen 48, S. 333-358.

Lauschke, Karl (2000): Die ÖTV in Dortmund. Lokale Gewerkschaftsgeschichte der Nachkriegszeit. Ein fälliger Perspektivenwechsel. In: Mitteilungsblatt des Instituts für Soziale Bewegungen, S. 141-158.

Lauschke, Karl (2004): Weder Kämpfer noch Bürokrat oder Dienstleister. Zum Wandel der Gewerkschaftsfunktionäre in der zweiten Hälfte des 20. Jahrhunderts. In: Kösler, Till/Stadtland, Helke (Hrsg.): Vom Funktionieren der Funktionäre. Politische Interessenvertretung und gesellschaftliche Integration in Deutschland nach 1933. Essen, S. 221-238.

Lauschke, Karl (2007): Der Wandel in der betrieblichen und gewerkschaftlichen Interessenvertretung nach den westdeutschen Septemberstreiks. In: Gehrke, Bernd/Horn, Gerd-Rainer (Hrsg.): 1968 und die Arbeiter. Studien zum "proletarischen Mai« in Europa. Hamburg, S. 76-91.

Lauxmann, Frieder (1974): Was sind uns die Beamten wert? Stuttgart. 
Lehn, Marcel vom (2013): Geschichte eines Sachzwangs: Privatisierung als historischer Prozess. In: NPL 58, S. 59-76.

Lehnert, Detlef (1991): Kommunale Politik, Parteiensystem und Interessenkonflikte in Berlin und Wien 1919-1932. Wohnungs-, Verkehrs- und Finanzpolitik im Spannungsfeld von städtischer Selbstverwaltung und Verbandseinflüssen. Berlin.

Leisner, Walter (1971): Beamtenstreik? Das »Schwedische Modell« auf dem Prüfstand. Hintergründe und Lehren des schwedischen Beamtenstreiks 1971. Bonn-Bad Godesberg.

Leisner, Walter (1995): Das Leistungsprinzip. In: ders.: Beamtentum. Schriften zum Beamtenrecht und zur Entwicklung des öffentlichen Dienstes 1968-1991. Hrsg. v. Josef Isensee. Berlin, S. 273-292.

Lieb, Peter (2014): Unternehmen Overlord. Die Invasion in der Normandie und die Befreiung Westeuropas. München.

Liehr, Hans (1975): Eigenbetriebe in Berlin - Leistung Tag und Nacht Aber zu welchem Preis? In: Der Städtetag 28, S. 687-690.

Lindlar, Ludger (1997): Das mißverstandene Wirtschaftswunder. Westdeutschland und die westeuropäische Nachkriegsprosperität. Tübingen.

Lösche, Peter/Walter, Franz (1989): Zur Organisationskultur der sozialdemokratischen Arbeiterbewegung in der Weimarer Republik. Niedergang der Klassenkultur oder solidargemeinschaftlicher Höhepunkt? In: GG 15, S. 511-536.

Löwisch, Manfred (1980): Zulässiger und unzulässiger Arbeitskampf im öffentlichen Dienst. Ein Vergleich der Rechtslage in den USA und in der Bundesrepublik Deutschland. Heidelberg und Karlsruhe.

Lohmar, Ulrich (1978): Staatsbürokratie. Das hoheitliche Gewerbe. Deutsche Aspekte eines neuen Klassenkampfes. München.

Lohmar, Ulrich (1979): Klassenkampf der Staatsbürokratie gegen die private Gesellschaft. In: Aus Politik und Zeitgeschichte 29, B 15/17, S. 3-8.

Lohmar, Ulrich (1980): Ersticken wir an der Bürokratie? Köln.

Luhmann, Niklas (2010): Politische Soziologie. Hrsg. v. André Kieserling. Berlin.

Lutz, Egon (1969a): Ostpolitiker aus Passion: Heinz Kluncker. In: Mühlbradt/Lutz: Zwang, S. 104-109. 
Lutz, Egon (1969b): Zwischen Kampf und Kooperation - Kritische Bemerkungen aus gewerkschaftlicher Sicht. In: Mühlbradt/Lutz: Zwang, S. 145-167.

Mackscheidt, Klaus (1990): Der öffentliche Haushalt in Nordrhein-Westfalen - ein Schicksalsbuch der Nation? In: Meissner, Hans Günther (Hrsg.): Spannungsfelder im Marketing. Dortmund, S. 9-27.

Madrick, Jeff (2011): The Age of Greed. The Triumph of Finance and the Decline of America, 1970s to the Present. New York.

Mammen, Gerhard (1978): Grundzüge differenzierter Stabilisierungspolitik in der Bundesrepublik Deutschland. Göttingen.

Marx, Stefan (Bearb.) (2013): Der Kreßbronner Kreis. Die Protokolle des Koalitionsausschusses der ersten Großen Koalition aus CDU, CSU und SPD. Düsseldorf.

Matthies, Klaus (1992): Anfälligkeit der Industrieländer gegenüber Ölschocks. Vergangenheit und Perspektiven. Hamburg.

McPherson, William H. (1971): Public Employee Relations in West Germany. Ann Arbor.

Meis, Walter (1952): Einige Betrachtungen über die Leistungen der Absolventen der Akademie für Gemeinwirtschaft. In: Mitteilungen der Akademie für Gemeinwirtschaft in Hamburg, H. 2 (Dezember), S. 27-33.

Meissner, Hans-Joachim (1987): Entgeltpolitik für den öffentlichen Dienst. Willensbildung, Entscheidungsprozesse, Ergebnisse und Korrekturperspektiven. Frankfurt/Main.

Mendner, Jürgen H./Sauerborn, Werner (1982): Privatisierung um jeden Preis. Die Politik der Niedersächsischen Landesregierung am Beispiel der Nassbaggerei im Emder Hafen, Hannover.

Mendner, Jürgen H./Sauerborn, Werner (unter Mitwirkung v. Dorothee Möller) (1983): Privatisierung - Angriff auf den Sozialstaat. Eine Untersuchung über die Folgen für die Arbeitnehmer als Bürger, Beschäftigte und Steuerzahler am Beispiel Niedersachsens. Stuttgart.

Menze, Hubert (1963): Markttransparenz in Theorie und Wettbewerbsrecht. In: Wirtschaft und Wettbewerb 13, S. 578-590.

Menzel, Eberhard (1969): Die strukturelle Desorganisation des öffentlichen Dienstes in der Bundesrepublik. In: Die öffentliche Verwaltung 22, S. 513-526.

Merklein, Renate (1969): Soziale Sicherheit im Wirtschaftswachstum. Beziehungen zwischen Maßnahmen zur sozialen Sicherheit und dem 
wirtschaftlichen Wachstumsprozeß. Wirtschafts- und sozialwissenschaftl. Diss., Universität Hamburg.

Merklein, Renate (1980): Griff in die eigene Tasche. Hintergeht der Bonner Sozialstaat die Bürger? Reinbek.

Merklein, Renate (1982): Die Deutschen werden ärmer. Staatsverschuldung, Geldentwertung, Machteinbußen, Arbeitsplatzverluste. Reinbek.

Merten, Detlef (1977): Zur Problematik der Gewährung einheitlicher Festbeträge bei Besoldungsanpassungen. In: König, Klaus/Laubinger, Hans-Werner/Wegener, Frido (Hrsg.): Öffentlicher Dienst. Festschrift für Karl Hermann Ule zum 70. Geburtstag am 26. Februar 1977. Köln u. a. O., S. 349-381.

Merten, Siegfried (1981): Da läßt sich keine Mark einsparen. In: ÖTV-Magazin, H. 9, S. 13-14.

Mertsch, Hans Joachim (1978): Die Stellung der Gewerkschaften zur Privatisierung öffentlicher Aufgaben. In: Bönig, Wolfgang (Hrsg.): Der öffentliche Sektor und sein Einfluss auf die Volkswirtschaft. Zur Effizienz fiskalpolitischer Maßnahmen. Tagung vom 26. bis 28. Mai 1978. Loccum, S. 97-113.

Mettelsiefen, Bernd/Pelz, Lothar/Rahmann, Bernd (1988): Verdienststruktur im öffentlichen Sektor. Göttingen.

Metzler, Ernst (1928): Die Arbeiter und Angestellten der Deutschen Reichspost in ihrer besonderen Rechtsstellung. Diss. Leipzig.

Meyer, August (1999): Hitlers Holding. Die Reichswerke »Hermann Göring«. Überarb. u. aktualis. Aufl. München.

Mintert, David Magnus (2006): Distanz zum Unrecht durch Bindungen an das sozialistische Milieu und die Tradition der Sozialdemokratie am Beispiel Wuppertals. In: Kunze, Rolf-Ulrich (Hrsg.): Distanz zum Unrecht 1933-1945. Methoden und Probleme der deutschen Widerstandsforschung. Konstanz, S. 127-158.

Millack, Christian (1975): Das neue Besoldungsrecht. In: Zeitschrift für Beamtenrecht 23, S. 177-185.

Minssen, Heiner (1977): Fallstudie über die Privatisierung der Gebäudereinigung bei der Stadt Hildesheim. In: Hauptvorstand der Gewerkschaft ÖTV: Privatisierung, S. 49-77.

Möhl Werner/Winterfeldt, Wolfgang (1968): Mitarbeiter-Bewertung. Maßstäbe und Methoden der Persönlichkeits- und Fähigkeitsbeurteilung. Bad Wörishofen. 
Möller, Alex (1962): Neuordnung des Finanzausgleichs zwischen Bund, Ländern und Gemeinden. In: Kommunale Finanzreform. Hannover.

Möller, Alex (1982): Tatort Politik. München und Zürich.

Mohr, Markus (2001): Die Gewerkschaften im Atomkonflikt, Münster.

Mommsen, Hans/Grieger, Manfred (1996): Das Volkswagenwerk und seine Arbeiter im Dritten Reich. Düsseldorf.

Moore, Charles (2013): Margaret Thatcher. The Authorized Biography. Vol. 1: Not for Turning. London.

Mooser, Josef (1984): Arbeiterleben in Deutschland 1900-1970. Klassenlagen, Kultur und Politik. Frankfurt/Main.

Morgan, Kenneth O. (1997): Callaghan. A Life. Oxford.

Mühlbradt, Werner/Lutz, Egon (1969): Der Zwang zur Sozialpartnerschaft. Hintergründe der Zusammenarbeit von Gewerkschaften und Arbeitgebern. Neuwied und Berlin.

Mülhaupt, Ludwig/Gornass, Jürgen (1977): Zum Problem der Privatisierung im öffentlichen Bereich. In: Der Städtetag 30, S. 360-365.

Müller, Emil-Peter (1982): Die Bündnispolitik der DKP. Ein trojanisches Pferd. Köln.

Müller, Gloria (1991): Strukturwandel und Arbeitnehmerrechte. Die wirtschaftliche Mitbestimmung in der Eisen- und Stahlindustrie 1945-1975. Essen.

Müller, Hans-Peter (2011): Die Deutsche Angestellten-Gewerkschaft im Wettbewerb mit dem DGB. Geschichte der DAG 1947-2001. Baden-Baden.

Müller, Karl Valentin (1957): Die Angestellten in der hochindustrialisierten Gesellschaft. Köln und Opladen.

Müller, Stefan (2014): West German Trade Unions and the Policy of Détente (1969-1989). In: Moving the Social 52, S. 109-134.

Müller-Armack, Alfred (1970): Ist die Inflation unser Schicksal? In: Die politische Meinung 5, H. 4, S. 11-31.

Müller-Hagen, Dorothee (1979): Teilzeitarbeit. Chancen und Probleme. In: Der Arbeitgeber 31, S. 338-340.

Müller-Jentsch, Walther (1975): Wirtschaftskrise und Gewerkschaftspolitik. In: Jacobi, Otto/Müller-Jentsch, Walther/Schmidt, Eberhard (Hrsg.): Gewerkschaften und Klassenkampf. Kritisches Jahrbuch. Frankfurt/ Main, S. 10-17. 
Nachtmann, Walter (1996): 100 Jahre ÖTV. Die Geschichte einer Gewerkschaft und ihrer Vorläuferorganisationen. Bd. 1: Geschichte. Bd. 2: Biographien. Frankfurt/Main.

Naegler, Heinz (1981): Auswirkungen des gültigen Krankenhausfinanzierungs- und Preisrechts auf die Krankenhausbetriebsführung. In: Zeitschrift für öffentliche und gemeinwirtschaftliche Unternehmen 4, S. 302-316.

Naphtali, Fritz (Hrsg.) (1928): Wirtschaftsdemokratie. Ihr Weg, Wesen und Ziel. Hrsg. im Auftrag des Allgemeinen Deutschen Gewerkschaftsbundes. Berlin, S. 68-69.

Nelson, Walter B./Stone, Gerald W./Swint, J. Michael (1981): An Economic Analysis of Public Sector Bargaining and Strike Activity. In: Journal of Labor Research 2, S. 77-98.

Neumann, Karl-Heinz/Schweizer, Urs/Weizsäcker, Carl-Christian von (1981): Tarifpolitik im Telekommunikationsbereich. Eine Wohlfahrtsanalyse. Bonn.

Neumark, Fritz (1966): Probleme und Aspekte einer Finanzreform. In: Die Finanzreform und die Gemeinden. Stuttgart u.a.O., S. VII-XVI.

Neundorfer, Ludwig (1961): Die Angestellten. Neuer Versuch einer Standortbestimmung. Stuttgart.

Nicolaysen, Rainer (2002): Der lange Weg zur VolkswagenStiftung. Eine Gründungsgeschichte im Spannungsfeld von Politik, Wirtschaft und Wissenschaft. Göttingen.

Noelle, Elizabeth/Neumann, Erich Peter (Hrsg.) (1974): Jahrbuch der öffentlichen Meinung 1968-1973. Allensbach und Bonn.

Nützenadel, Alexander (2005): Stunde der Ökonomen. Wissenschaft, Politik und Expertenkultur in der BRD 1949-1974. Göttingen.

Öffentliche Dienstleistungen - Vergeudung von Steuergeldern? (1965): Vorträge und Ansprachen auf der 7. beamtenpolitischen Arbeitstagung des DBB vom 14. bis 16. Januar 1965 auf Bühler Höhe. Bad Godesberg.

Oeftering, Heinz (1954): Die Unternehmungen des Bundes. In: Grundfrage der öffentlichen Wirtschaft. Ergebnisse einer Arbeitstagung. Stuttgart.

Oelert, Wilhelm (1976): Reprivatisierung des öffentlichen Personennahverkehrs, wo und wie? In: Der Personenverkehr 27, S. 108-114.

Oertzen, Christine von/Rietzschel, Almut (1997): Das »Kuckucksei« Teilzeitarbeit. Die Politik der Gewerkschaften im deutsch-deutschen Vergleich. In: Budde, Gunilla-Friederike (Hrsg.): Frauen arbeiten. Weibliche 
Erwerbstätigkeit in Ost- und Westdeutschland nach 1945. Göttingen, S. 212-251.

Oettle, Karl (1976): Betriebserfolge in der privaten und in der öffentlichen Wirtschaft. In: ders.: Grundfragen öffentlicher Betriebe I. Ausgewählte Aufsätze zur Zielsetzung, Führung und Organisation öffentlicher Betriebe. Baden-Baden, S. 37-54.

Orth, Helmut/Schulz, H. (1977): Städtereinigung in kommunaler oder privater Hand? In: Kommunalwirtschaft, S. 11-17.

Osterhammel, Jürgen (2009): Die Verwandlung der Welt. Eine Geschichte des 19. Jahrhunderts. München.

Osterkamp, K.[arl] (1950): Die wirtschaftliche Lage der Arbeitnehmer im öffentlichen Dienst. In: Öffentlicher Dienst, Transport und Verkehr 2, S. 250-251.

[ÖTV] (o.J.): Geschäftsbericht der Gewerkschaft Öffentliche Dienste, Transport und Verkehr für das Jahr 1949. Hrsg. v. Hauptvorstand. Stuttgart o. J. [1950].

ÖTV (1952): Geschäftsbericht 1949-1951. Hrsg. v. der Gewerkschaft Öffentliche Dienste, Transport und Verkehr - Hauptvorstand, 3 Bde.: Teil 1 und Teile 2 (Abschnitt A und Abschnitt B). Stuttgart.

ÖTV (1954): Geschäftsbericht 1952-1954. Hrsg. v. der Gewerkschaft Öffentliche Dienste, Transport und Verkehr - Hauptvorstand. Stuttgart.

ÖTV (1958): Geschäftsbericht 1955-1957. Hrsg. v. der Gewerkschaft Öffentliche Dienste, Transport und Verkehr - Hauptvorstand. Stuttgart.

ÖTV (1961): Geschäftsbericht 1958-1960. Hrsg. v. der Gewerkschaft Öffentliche Dienste, Transport und Verkehr - Hauptvorstand. Stuttgart.

ÖTV (1964): Geschäftsbericht 1961-1963. Hrsg. v. der Gewerkschaft Öffentliche Dienste, Transport und Verkehr - Hauptvorstand. Stuttgart.

ÖTV (1968): Geschäftsbericht 1964-1967. Hrsg. v. der Gewerkschaft Öffentliche Dienste, Transport und Verkehr - Hauptvorstand. Stuttgart.

ÖTV (1972): Geschäftsbericht 1968-1971. Hrsg. v. der Gewerkschaft Öffentliche Dienste, Transport und Verkehr - Hauptvorstand. Stuttgart.

ÖTV (1976): Geschäftsbericht 1972-1975. Hrsg. v. der Gewerkschaft Öffentliche Dienste, Transport und Verkehr - Hauptvorstand. Stuttgart.

ÖTV (1980): Geschäftsbericht 1976-1979. Hrsg. v. der Gewerkschaft Öffentliche Dienste, Transport und Verkehr - Hauptvorstand. Stuttgart.

ÖTV (1984): Geschäftsbericht 1980-1983. Hrsg. v. der Gewerkschaft Öffentliche Dienste, Transport und Verkehr - Hauptvorstand. Stuttgart. 
ÖTV (1953): Wortlaut der überbezirklichen Tarifverträge des Jahres 1952. Stuttgart.

ÖTV (1955): Wortlaut der überbezirklichen Tarifverträge des Jahres 1954. Stuttgart.

ÖTV (1956): Wortlaut der überbezirklichen Tarifverträge des Jahres 1955. Stuttgart.

ÖTV (1965): Wortlaut der überbezirklichen Tarifverträge des Jahres 1964. Stuttgart.

ÖTV (1968a): Wortlaut der überbezirklichen Tarifverträge des Jahres 1967. Stuttgart.

ÖTV (1971): Wortlaut der überbezirklichen Tarifverträge des Jahres 1970. 2 Bde. Stuttgart.

ÖTV (1972a): Wortlaut der überbezirklichen Tarifverträge des Jahres 1971. Stuttgart.

ÖTV (1978): Wortlaut der überbezirklichen Tarifverträge des Jahres 1977, 2 Bde. Stuttgart.

Pahl, Walther/Mendelsohn, Kurt (Bearb.) (1930): Handbuch der öffentlichen Wirtschaft. Hrsg. v. Vorstand des Gesamtverbandes der Arbeitnehmer der öffentlichen Betriebe und des Personen- und Warenverkehrs. Berlin.

Parkinson, C. Northcote (1958): Parkinsons Gesetz und andere Untersuchungen über die Verwaltung. Düsseldorf.

Pausch, Rainer (1978): Zur Frage der Privatisierung von Verwaltungstätigkeiten - dargestellt am Beispiel der Deutschen Bundespost. In: Zeitschrift für öffentliche und gemeinwirtschaftliche Unternehmen 1, H. 3, S. 61-72.

Peltzman, Sam (1971): Pricing in Public and Private Enterprises. Electric Utilities in the United States. In: Journal of Law and Economics 14, S. 109-147.

Pelz, Lothar (1984): Theorie und Empirie des Collective Bargaining und die Verdienstdynamik des öffentlichen Sektors. Oldenburg.

Pentzlin, Kurt (1973): Die organisierte Unzufriedenheit. Eine »Rolle« der Gewerkschaften. Stuttgart.

Peters, Jürgen (Hrsg.) (2003): In freier Verhandlung. Dokumente zur Tarifpolitik in der Metallindustrie 1945 bis 2002. Bearb. u. eingel. v. Holger Gorr. Bd. 2. Göttingen. 
Pichl, Claudia (1979): Das Arbeitnehmer-Patriachat. Die Frauenpolitik der Gewerkschaften. Köln.

Pirker, Theo (1960): Die blinde Macht. Die Gewerkschaftsbewegung in Westdeutschland. Zweiter Teil: 1953-1960. Weg und Rolle der Gewerkschaften im neuen Kapitalismus. München.

Pirker, Theo (1965): Die Gewerkschaft als Versicherungsbetrieb. In: Horné, Alfred (Hrsg.): Zwischen Stillstand und Bewegung. Eine kritische Untersuchung über die Gewerkschaft in der modernen Industriegesellschaft. Frankfurt/Main, S. 7-17.

Plumpe, Werner (2004): Tarifsystem und innerbetriebliche Konflikte in der Weimarer Republik. In: Führer: Tarifbeziehungen und Tarifpolitik, S. 26-63.

Poiger, Uta G. (2000): Jazz, Rock and Rebels. Cold War Politics and American Culture in a Divided Germany. Berkeley.

Prasad, Monica (2006): The Politics of Free Markets. The Rise of Neoliberal Economic Policies in Britain, France, Germany and the United States. Chicago and London.

Preller, Ludwig (1963): Lohnpolitik in gesamtwirtschaftlicher Betrachtung. In: Nemitz, Kurt/Becker, Richard (Hrsg.): Gewerkschaft - Wirtschaft - Gesellschaft. Beiträge zu wirtschaftlichen und sozialen Gegenwartsfragen. Köln, S. 206-217.

Der private Haushalt in der Bundesrepublik Deutschland 1960/61 (1965). Statistische Daten zu ausgewählten Strukturdaten. Köln und Opladen.

Projektgruppe Gewerkschaftsforschung (1978): Tarifpolitik 1977. Darstellung und Analyse der Tarifbewegung in der Metallverarbeitenden, der Chemischen und der Druckindustrie sowie im Öffentlichen Dienst. Frankfurt/Main und New York.

[Protokoll DGB 1962] Protokoll 6. Ordentlicher Bundeskongress [des Deutschen Gewerkschaftsbundes], Hannover, 22. bis 27. Oktober 1962. Düsseldorf 1963.

[Protokoll DGB 1969] Protokoll des 8. Ordentlichen Bundeskongresses [des Deutschen Gewerkschaftsbundes], München, 18. bis 23. Mai 1969. Düsseldorf 1969.

[Protokoll Gründungstagung] Protokoll über die Verhandlungen der Gründungstagung des Gesamt-Verbandes der Arbeitnehmer der öffentlichen Betriebe und des Personen- und Warenverkehrs. Berlin 1929. 
[Protokoll GT HBV 1968] Protokoll des 7. Ordentlichen Gewerkschaftstages der Gewerkschaft Handel, Banken und Versicherungen 15. September bis 20. September 1968 in Bremen. Bochum 1969.

[Protokoll GT IG Bau 1963] Protokoll über den 6. Ordentlichen Gewerkschaftstag der Industriegewerkschaft Bau - Steine - Erden für die Bundesrepublik Deutschland, Kongreßhalle Berlin vom 24. bis 29. Juni 1963. Frankfurt/Main o.J.

[Protokoll GT IG Bau 1966] Protokoll über den 7. Ordentlichen Gewerkschaftstag der Industriegewerkschaft Bau - Steine - Erden für die Bundesrepublik Deutschland, Stadthalle Bremen vom 20. bis 25. Juni 1966. Frankfurt/Main 1966.

[Protokoll GT IG Bau 1972] Protokoll über den 9. Ordentlichen Gewerkschaftstag der Industriegewerkschaft Bau - Steine - Erden für die Bundesrepublik Deutschland, Rheingoldhalle Mainz vom 25. Bis 30. September 1972. Frankfurt/Main o.J.

[Protokoll GT IG Druck 1965] Protokoll des 7. Ordentlichen Gewerkschaftstages [der IG Druck und Papier] 1965, vom 26. September bis 2. Oktober 1965 in Berlin. Berlin o.J.

[Protokoll GT IG Druck 1968] Protokoll des 8. Ordentlichen Gewerkschaftstages der Industriegewerkschaft Druck und Papier, Koblenz 1968. Frankfurt/Main 1968.

[Protokoll GT Textil 1963] Protokoll des 8. Ordentlichen Gewerkschaftstages der Gewerkschaft Textil - Bekleidung vom 16. bis 20. September 1963 in Hannover. Düsseldorf 1963.

[Protokoll GT Textil 1965] Protokoll des 9. Ordentlichen Gewerkschaftstages der Gewerkschaft Textil - Bekleidung vom 11.-15.10.1965 in der Liederhalle in Stuttgart. Düsseldorf 1966.

[Protokoll ÖTV 1949] Protokoll des Vereinigungs-Verbandstages der Gewerkschaften des Öffentlichen Dienstes, Transport und Verkehr, Stuttgart, den 28. bis 30. Januar 1949. Stuttgart 1949.

[Protokoll ÖTV-GT 1952] Protokoll des 1. Ordentlichen Gewerkschaftstages der Gewerkschaft Öffentliche Dienste, Transport und Verkehr vom 18. bis 22. Februar 1952 in Hamburg. Stuttgart 1952.

[Protokoll ÖTV-GT 1955] Protokoll des 2. Ordentlichen Gewerkschaftstages der Gewerkschaft Öffentliche Dienste, Transport und Verkehr vom 3. bis 7. Mai 1955 in Frankfurt/Main. Stuttgart 1956. 
[Protokoll ÖTV-GT 1958] Protokoll des 3. Ordentlichen Gewerkschaftstages der Gewerkschaft Öffentliche Dienste, Transport und Verkehr vom 1. bis 6. Juni 1958 in München. Stuttgart 1959.

[Protokoll ÖTV-GT 1961] Protokoll des 4. Ordentlichen Gewerkschaftstages der Gewerkschaft Öffentliche Dienste, Transport und Verkehr vom 25. Juni bis 1. Juli 1961 in Berlin. Stuttgart 1962.

[Protokoll ÖTV-GT 1964] Protokoll des 5. Ordentlichen Gewerkschaftstages der Gewerkschaft Öffentliche Dienste, Transport und Verkehr vom 28. Juni bis 4. Juli 1964 in Dortmund. Stuttgart 1965.

[Protokoll ÖTV-GT 1968] Protokoll 6. Ordentlicher Gewerkschaftstag München 1968 [der Gewerkschaft Öffentliche Dienste, Transport und Verkehr]. 2 Bde. Stuttgart 1968.

[Protokoll ÖTV-GT 1972] Protokoll 7. Ordentlicher Gewerkschaftstag Berlin 1972 [der Gewerkschaft Öffentliche Dienste, Transport und Verkehr]. Stuttgart 1972.

[Protokoll ÖTV-GT 1976] Protokoll 8. Ordentlicher ÖTV-Gewerkschaftstag Hamburg 1976 [der Gewerkschaft Öffentliche Dienste, Transport und Verkehr]. 2 Bde. Stuttgart 1976.

[Protokoll ÖTV-GT 1980] 9. Gewerkschaftstag Berlin 1980 [der Gewerkschaft Öffentliche Dienste, Transport und Verkehr]. 2 Bde. Stuttgart 1980.

[Protokoll ÖTV-GT 1982] Protokoll Außerordentlicher Gewerkschaftstag Wiesbaden 1982. Hrsg. v. der Gewerkschaft Öffentliche Dienste, Transport und Verkehr, Stuttgart o.J.

Quellen zur Geschichte der deutschen Gewerkschaftsbewegung im 20. Jahrhundert (1996). Bd. 11. Der Deutsche Gewerkschaftsbund 1949 bis 1956. Bearb. von Josef Kaiser. Bonn.

Quellen zur Geschichte der deutschen Gewerkschaftsbewegung im 20. Jahrhundert (2005). Bd. 12. Der Deutsche Gewerkschaftsbund 19561963. Bearb. von Jens Hildebrandt unter Mitarb. von Boris Schwitzer. Bonn.

Raithel, Thomas (2012): Jugendarbeitslosigkeit in der Bundesrepublik Deutschland. Entwicklung und Auseinandersetzung während der 1970er und 1980er Jahre. München.

Ramm, Thilo (1961): Die Parteien des Tarifvertrags. Stuttgart.

Ramm, Thilo (1964): Der wilde Streik. In: Arbeit und Recht 12, S. 353-362. 
Rasch, Harold (1972): Die »Konzertierte Aktion«: Bilanz eines gescheiterten Experiments. In: Der Betriebs-Berater 27, S. 1149-1152.

Rehbock, Annette (1989): Soziologisches Wissen und gewerkschaftliche Organisation, Gewerkschaftliche Bildungsarbeit in den siebziger Jahren. Münster.

Rehm, Hannes (1980): Wirtschaftlichkeit und Sparsamkeit im öffentlichen Sektor. In: Die Verwaltung 13, S. 77-92.

Reulecke, Jürgen (1985): Geschichte der Urbanisierung in Deutschland. Frankfurt/Main.

Riehl-Heyse, Herbert (1980): An Kluncker kommt niemand vorbei. In: Playboy 9, H. 9, S. 108-110 u. 170-175.

Rigoll, Dominik (2013): Staatsschutz in Westdeutschland. Von der Entnazifizierung zur Extremistenabwehr. Göttingen.

Roberts, Alasdair (2010): The Logic of Discipline. Global Capitalism and the Architecture of Government. Oxford.

Röhl, Renate (1982): Privatisierung öffentlicher Aufgaben. Ein Überblick. Kiel.

Roseman, Mark (1992): Recasting the Ruhr, 1945-1958. Manpower, Economic Recovery and Labour Relations. New York.

Rosenberg, Peter (1975): Möglichkeiten der Reform des Gesundheitswesens in der Bundesrepublik Deutschland. Göttingen.

Ruckriegel, Werner (1976): Computersysteme in der öffentlichen Verwaltung aus anwendungsbezogener Sicht. In: Grochla, Erwin/Starke, Wolfgang/Ruckriegel, Werner: Computer-Verbundsysteme in Wirtschaft und Verwaltung. Dortmund, S. 43-60.

Rübsteck, Reiner (1965): Neuregelung der Zusatzversorgung im öffentlichen Dienst. In: Soziale Sicherheit 14, S. 147-148.

Rüthers, Bernd (1973): Arbeitsrecht und politisches System. Frankfurt/ Main.

Sachverständigenrat zur Begutachtung der gesamtwirtschaftlichen Entwicklung (1970): Konjunktur im Umbruch - Risiken und Chancen. Jahresgutachten 1970/71. Stuttgart und Mainz.

Sachverständigenrat zur Begutachtung der gesamtwirtschaftlichen Entwicklung (1974): Vollbeschäftigung für morgen. Jahresgutachten 1974/75. Stuttgart und Mainz.

Sander, Gilman L. (2008): Fat. A Cultural History of Obesity. Cambridge. 
Sarrazin, Thilo (1981): Das Lächeln der Sphinx - oder: Die Staatsverschuldung und die Krise der Globalsteuerung. In: Aus Politik und Zeitgeschichte 31, B 38, S. 3-23.

Sauer, Paul (2003): Arnulf Klett. Ein Leben für Stuttgart. Stuttgart.

Sauerborn, Werner (1977): Fallstudie über die Privatisierung der Müllabfuhr im Landkreis Göttingen. In: Hauptvorstand der Gewerkschaft ÖTV: Privatisierung, S. 7-48.

Sauerborn, Werner (1982): Regiebetrieb ist wirtschaftlicher. In: ÖTV-Magazin, H. 4, S. 21-22.

Sauerborn, Werner/Minssen, Heiner (1977): Gewerkschaftliche Probleme der Privatisierung öffentlicher Dienstleistungen. In: WSI-Mitteilungen 30, S. 383-393.

Schäfer, Claus/Skiba, Rainer/Tofaute, Hartmut (1974): Probleme des Öffentlichen Dienstes. In: WSI-Mitteilungen 27, S. 394-414.

Schäfer, Claus/Skiba, Rainer/Tofaute, Hartmut (1975): Personalausgaben und Einkommensfindung im öffentlichen Dienst. Köln.

Schäfer, Gerhard (1988): Soziologie zwischen Faschismus und Restauration. In: Waßner, Rainer (Hrsg.): Wege zum Sozialen. 90 Jahre Soziologie in Hamburg. Opladen, S. 147-168.

Schäfer, Hans-Joachim (1969): Der öffentliche Dienst am Wendepunkt? In: Der Städtetag 22, S. 418-421.

Schaefer, Heinz (1985): Zur Entwicklung der regionalen Produktionsstrukturen. In: Nordrhein-Westfalen in der Krise - Krise in Nordrhein-Westfalen? Tagungsband zum RWI-Symposium vom 24. und 25.10.1984. Berlin, S. 39-55.

Schanetzky, Tim (2007): Die große Ernüchterung. Wirtschaftspolitik, Expertise und Gesellschaft in der Bundesrepublik Deutschland 1966 bis 1982. Berlin.

Scharf, Günter (1987): Geschichte der Arbeitszeitverkürzung. Der Kampf der deutschen Gewerkschaften um die Verkürzung der täglichen und wöchentlichen Arbeitszeit. Frankfurt/Main.

Scharpf, Fritz W. (1987): Sozialdemokratische Krisenpolitik in Europa. Frankfurt/Main und New York.

Scheibe-Lange, Ingrid (1980): Rationalisierung in der Praxis gewerkschaftlicher Gegenwehr. In: WSI-Mitteilungen 33, S. 480-489.

Schellhoss, Hartmut (1967): Apathie und Legitimität. Das Problem der neuen Gewerkschaft. München. 
Schelsky, Helmut (1952): Die politische Bedeutung der soziologischen Studien an den sozialen Hochschulen. In: Die Akademie für Gemeinwirtschaft in Hamburg. Ihre Aufgaben und ihre Arbeitsweise. Hamburg, S. 29-50.

Schelsky, Helmut (1982): Funktionäre. Gefährden sie das Gemeinwohl? Stuttgart.

Schildt, Axel/Siegfried, Detlev (2009): Deutsche Kulturgeschichte. Die Bundesrepublik - 1945 bis zur Gegenwart. München.

Schiller, Karl (1968): Konjunkturpolitik auf dem Wege zu einer Affluent Society. In: Schwebler, Robert/Föhrenbach, Walter (Hrsg.): Jahre der Wende. Festgabe für Alex Möller zum 65. Geburtstag. Karlsruhe, S. 61-72.

Schiller, Karl (1971): Stabilität beginnt beim Staat. In: ders.: Reden zur Wirtschafts- und Finanzpolitik und Stichworte. Bd. 9. Bonn, S. 121-136.

Schiller, Karl (2007): Gewerkschaften als Verbündete der Wirtschaftspolitik. In: ders.: Wachstum, Stabilität, Gleichgewicht. Vorträge, Reden, Aufsätze. Hrsg. v. Detlef W. Prinz. Berlin, S. 207-243.

Schilling, Florian (1984): Der Einigungsprozess bei Tarifverhandlungen. Eine Darstellung am Beispiel der Tarifrunde 1978 in der bundesdeutschen Metallindustrie. Berlin.

Schleberger, Erwin (1975): Warten auf die Dienstrechtsreform. In: Der Städtetag 28, S. 455.

Schleberger, Erwin (1976a): Die Zauberformel Privatisierung. In: Der Städtetag 29, S. 121.

Schleberger, Erwin (1976b): In Sachen Privatisierung. In: Der Städtetag 29, S. 690-692.

Schlesinger, Helmutn(1983): Die Geldpolitik der Deutschen Bundesbank 1967-1977. In: Ehrlicher, Werner/Duwendag, Dieter (Hrsg.). Geld- und Währungspolitik im Umbruch. Internationale Erfahrungen des letzten Jahrzehnts. Baden-Baden, S. 59-83.

Schleyer, Hanns Martin (1963): Arbeitgeber-Maßnahmen beim Lohnkonflikt in der Metallindustrie. In: Die gesamtwirtschaftliche Koordinierung der Lohn- und Sozialpolitik. Geschäftsführerkonferenz der Bundesvereinigung der Deutschen Arbeitgeberverbände am 17. und 18. Mai 1963 in Baden-Baden. Düsseldorf, S. 38-44.

Schleyer, Hanns Martin (1964): Tarifautonomie in der Praxis. In: Tarifautonomie in gesamtwirtschaftlicher Verantwortung. Geschäftsführer- 
konferenz der Deutschen Arbeitgeberverbände vom 4.-6. Juni 1964 in Berlin. Düsseldorf, S. 16-29.

Schlick, Manfred (1986): Ziele und Möglichkeiten der Privatisierung auf kommunaler Ebene. Bonn.

Schmidt, Alfons (1971): Entwicklung und Bedeutung der Gemeindefinanzen in der BRD mit einem Vergleich dreier strukturtypischer Gemeinden: 1950-1968. Rechtswiss. Diss., Universität Freiburg (Schweiz).

Schmidt, Ingo (1972): Ist die Konzertierte Aktion als konjunkturpolitisches Instrument geeignet? In: Zeitschrift für Wirtschafts- und Sozialwissenschaften 92, S. 421-439.

Schmidt, Johannes Werner (1985): Überlegungen zu einzelwirtschaftlichen Konsolidierungsstrategien für öffentliche Haushalte. In: Eichhorn, Peter/Sieber, Günter (Hrsg.): Rationalisierungsreserven in öffentlichen Verwaltungen und öffentlichen Unternehmen. Köln, S. 11-19.

Schmollinger, Horst W. (1977): Zur politisch-gesellschaftlichen Beteiligung von Gewerkschaftsmitgliedern: Gewerkschaften in Parteien, Kirchen und Vereinen. In: Borsdorf, Ulrich et al. (Hrsg.). Gewerkschaftliche Politik: Reform aus Solidarität. Zum 60. Geburtstag von Heinz O. Vetter. Köln, S. 135-157.

Schnapp, Günther (1960): Zehn Jahre Arbeit und Kampf um die Rechte der Polizeibediensteten. In: Beginn und Aufstieg. 10 Jahre Gewerkschaft der Polizei 1950-1960. Hamburg, S. 33-62.

Schneider, Gottfried (1977): Schritte nach vorn. In: Öffentliche Wirtschaft und Gemeinwirtschaft 26, S. 1.

Schneider, Johann (1979): Gewerkschaften im öffentlichen Dienst. Interessen und Interessenkonstellationen. In: Bergmann, Joachim (Hrsg.): Beiträge zur Soziologie der Gewerkschaften. Frankfurt/Main, S. 111-142.

Schneider, Michael (1986): Demokratie in Gefahr? Der Konflikt um die Notstandsgesetze: Sozialdemokratie, Gewerkschaften und intellektueller Protest (1958-1968). Bonn.

Schneider, Michael (1989): Kleine Geschichte der Gewerkschaften. Ihre Entwicklung in Deutschland von den Anfängen bis heute. Bonn.

Schoefer, Sabine (2000): Strategie statt Notwehr. Organisationsentwicklung in den Gewerkschaften am Beispiel der ÖTV. Münster.

Schöllgen, Gregor (2001): Willy Brandt. Die Biographie. Berlin. 
Schönhoven, Klaus (1980a): Expansion und Konzentration. Studien zur Entwicklung der freien Gewerkschaften im Wilhelminischen Deutschland 1890 bis 1914. Stuttgart.

Schönhoven, Klaus (1980b): Selbsthilfe als Form der Solidarität. Das gewerkschaftliche Unterstützungswesen im Deutschen Kaiserreich bis 1914. In: Archiv für Sozialgeschichte 20, S. 147-193.

Schönhoven, Klaus (2002): Arbeitskonflikte in Konjunktur und Rezension. Gewerkschaftliche Streikpolitik und Streikverhalten der Arbeiterschaft vor 1914. In: ders.: Arbeiterbewegung und soziale Demokratie in Deutschland. Ausgewählte Beiträge. Hrsg. v. Hans-Jochen Vogel/ Michael Ruck. Bonn, S. 165-182.

Schönhoven, Klaus (2004): Wendejahre. Die Sozialdemokratie in der Zeit der Großen Koalition 1966-1969. Bonn.

Schörken, Rolf (2004): Die Niederlage als Generationserfahrung. Jugendliche nach dem Zusammenbruch der NS-Herrschaft. Weinheim und München.

Schreiber, Folkert (1964): Personal und Personalausgaben. In: Der Städtetag 17, S. 534-535.

Schreml, Alfons/Dietl, Josef (1960): Die Berechnung der gemeindlichen Schuldengrenze. München.

Schroeder, Klaus (1984): Der Weg in die Stagnation. Eine empirische Studie zur Konjunkturentwicklung und Konjunkturpolitik in der Bundesrepublik von 1967-1982. Opladen.

Schuckart, Rainer (2008): Kontinuitäten einer konservativen Staatsrechtslehre. Forsthoffs Positionen in der Weimarer Republik, im Dritten Reich und in der Bundesrepublik. In: Glienke, Stephan Alexander/Paulmann, Volker/Perels, Joachim (Hrsg.): Erfolgsgeschichte Bundesrepublik? Die Nachkriegsgesellschaft im langen Schatten des Nationalsozialismus. Göttingen, S. 85-114.

Schüler, Manfred et al. (1964): Zur Finanzreform in der Bundesrepublik Deutschland. Tatsachen, Probleme und Möglichkeiten. Hannover.

Seitenzahl, Rolf (1974): Einkommenspolitik durch konzertierte Aktion und Orientierungsdaten. Köln.

Shepherd, John (2013): „Crisis? What Crisis?« The Callaghan Government and the British »Winter of Discontent«. Manchester.

Siedentopf, Heinrich (1980): Privatisierung öffentlicher Aufgaben - Begriff und Formen. In: VOP 2, S. 62-72. 
Siedentopf, Heinrich/Grunwald, Klaus-Dieter (1976): Die kommunale Rechnungsprüfung. Bestandsaufnahme und Verbesserungsvorschläge. Wiesbaden.

Siegfried, Detlef (2000): Zwischen Aufarbeitung und Schlußstrich. Der Umgang mit der NS-Vergangenheit in den beiden deutschen Staaten 1958 bis 1969. In: Schildt, Axel/Siegfried, Detlef/Lammers, Karl Christian (Hrsg.): Dynamische Zeiten. Die 60er Jahre in den beiden deutschen Gesellschaften. Hamburg, S. 77-113.

Sievers, Leo (1976): Wenn Kluncker will, stehen alle Räder still. In: Der Stern 29, H. 24, S.77-80.

Sölter, Arno (1975): Der unvollständige Wettbewerbsbegriff. Zur Bedeutung von Markttransparenz und Marktinformationsverfahren für den Wettbewerbsprozess. Heidelberg.

Sommer, Martin (1980): Organisation des Krankenhauswesens. In: VOP 2, S. 427-430.

Sozialbericht der Berliner Kraft- und Licht- (BEWAG)-Aktiengesellschaft (1939). Berlin.

Sozialpolitik im 5. Deutschen Bundestag (1966). XVI. Jahresmitgliederversammlung [der Bundesvereinigung der Deutschen Arbeitgeberverbände] in Bad Godesberg. Köln.

Spaethen, Rolf (1961): Grundlagen einer modernen Sozialpolitik für Angestellte. Rede auf der Festveranstaltung aus Anlass des 1. Mai 1961 in der Beethoven-Halle in Bonn. Hamburg.

Spernol, Boris (2008): Notstand der Demokratie. Der Protest gegen die Notstandsgesetze und die Frage der NS-Vergangenheit. Essen.

Stamp, Friedrich (1997): Arbeiter in Bewegung. Die Geschichte der Metallgewerkschaften in Schleswig-Holstein. Malente.

Steffen, Michael (2002): Geschichten vom Trüffelschwein. Politik und Organisation des Kommunistischen Bundes 1971 bis 1991. Berlin u.a.O.

Stein, Günter (1961): Der Bundesangestelltentarifvertrag (BAT) im öffentlichen Dienst. In: Die Quelle 12, S. 111-112.

Stein, Günther (1966): Bewährungsaufstieg perfekt. In: ÖTV-Magazin, H. 4, S. 3 .

Steinberg, Hans-Josef (1983): Satirische Zeitschriften der deutschen sozialistischen Arbeiterbewegung. In: Harstick, Hans-Peter/Herzig, Arno/ Pelger, Hans (Hrsg.): Arbeiterbewegung und Geschichte. Festschrift für Shlomo Na'aman zum 70. Geburtstag. Trier, S. 74-81. 
Steiner, Ute (2002): Das Personal im Landeshaushalt. Entwicklung, Kosten, Einsparungen. Stuttgart.

Stengl, Anton (2011): Zur Geschichte der »K-Gruppen«. Marxisten-Leninisten in der BRD der siebziger Jahre. Frankfurt/Main.

Sternberg-Raasch, Richard (1928): Die Bedeutung der Kommunen als Arbeitgeber und ihre besonderen Probleme. Berlin.

Sternberg-Raasch, Richard (1930): Die soziale Bedeutung der kommunalen Betriebe für die Arbeitnehmer. In: Reichsarbeitgeberverband Deutscher Gemeinden und Kommunalverbände: Bericht über das 10. Geschäftsjahr (1. April 1929 bis 31. März 1930). Berlin, S. 55-59.

Stier, Bernhard (1998): Staat und Strom. Elektrifizierung in Preußen zwischen Staatswirtschaft und nationaler Strukturpolitik 1910-1940. In: Kaufhold, Karl Heinrich/Sösemann, Bernd (Hrsg.): Wirtschaft, Wissenschaft und Bildung in Preußen. Zur Wirtschafts- und Sozialgeschichte Preußens vom 18. bis zum 20. Jahrhundert. Stuttgart, S. 111-137.

Stier, Bernhard (1999): Staat und Strom. Die politische Steuerung des Elektrizitätssystems in Deutschland 1890-1950. Ubstadt-Weiher.

Stigler, George (1975): Economic Theory of Regulation. In: ders.: The Citizen and the State. Essays on Regulation. Chicago und London, S. 114-141.

Strauß, Franz Josef (1978): Die Finanzreform 1969. In: Schwebler, Robert (Hrsg.): Jahre der Wende 1968-1978. Bestandsaufnahme eines Jahrzehnts. Alex Möller zum 75. Geburtstag. Karlsruhe, S. 43-53.

Streeck, Wolfgang (1981): Gewerkschaftliche Organisationsprobleme in der sozialstaatlichen Demokratie. Königstein/Taunus.

Streeck, Wolfgang (2009): Re-Forming Capitalism. Institutional Change in the German Political Economy. Oxford.

Streeck, Wolfgang (2013): Gekaufte Zeit. Die vertagte Krise. Frankfurter Adorno-Vorlesungen 2012. Berlin.

Studienführer der Akademie für Gemeinwirtschaft Wintersemester 1948/49 und Sommersemester 1949 (o.J.). Hamburg.

Studienkommission für die Reform des öffentlichen Dienstrechtes (1973): Bericht der Kommission. Baden-Baden.

Sturm, Eckart (1961): Die Entwicklung des öffentlichen Dienstes in Deutschland. In: Ule, Carl Hermann (Hrsg.): Die Entwicklung des öffentlichen Dienstes. Berichte, Vorträge, Diskussionsbeiträge. Köln u.a. O., S. 1-285. 
Sturm, Roland (1998): Staatsverschuldung. Ursachen, Wirkungen und Grenzen staatlicher Verschuldungspolitik. Opladen.

Süß, Winfried (2008): Der keynesianische Traum und sein langes Ende. Sozioökonomischer Wandel und Sozialpolitik in den siebziger Jahren. In: Jarausch, Konrad H. (Hrsg.): Das Ende der Zuversicht? Die siebziger Jahre als Geschichte. Göttingen, S. 120-137.

Tarifvertrag über den Bewährungsaufstieg für Angestellte des Bundes und der Länder vom 25. März 1966 (1966). Düsseldorf.

Taylor, Robert (1993): The Trade Union Question in British Politics. Government and Unions Since 1945. Cambridge/MA.

Thiemeyer, Theo (1985): Öffentliche und gemeinwirtschaftliche Unternehmen als Erkenntnisobjekt der Betriebswirtschaftslehre und als volkswirtschaftliches Instrument. In: Eichhorn, Peter (Hrsg.): Betriebswirtschaftliche Erkenntnisse für Regierung, Verwaltung und öffentliche Unternehmen. 25 Jahre Öffentliche Betriebswirtschaftslehre an der Universität Mannheim. Baden-Baden, S. 125-143.

Tiemann, Irmgard (1977): Mehr Frauen in die Tarifkommissionen. In: Frauen und Arbeit, H. 2, S. 6-7.

Tietmeyer, Hans (1974): Möglichkeiten und Grenzen staatlicher Stabilisierungspolitik im marktwirtschaftlichen System der Bundesrepublik Deutschland. In: Stabilisierungspolitik. WSI-Forum vom 5. bis 7. Dezember 1973. Köln, S. 218-240.

Tilly, Richard H. (1995): Städtewachstum, Kommunalfinanzen und Munizipalsozialismus in der deutschen Industrialisierung. Eine vergleichende Perspektive 1870-1913. In: Reulecke, Jürgen (Hrsg.): Die Stadt als Dienstleistungszentrum. Beiträge zur Geschichte der »Sozialstadt« in Deutschland im 19. und frühen 20. Jahrhundert. St. Katharinen, S. 125-152.

Tötter, Heinrich (1968): Die Beamten im Spiegel der Publizistik. In: Die Beamten und die Öffentlichkeit. Vorträge, Ansprachen und Diskussionen auf der 10. beamtenpolitischen Arbeitstagung des DBB vom 11. bis 13. Januar 1968 auf Bühler Höhe. Bad Godesberg, S. 85-101.

Tofaute, Hartmut (1977): Zur Privatisierung öffentlicher Dienstleistungen. Die Übertragung öffentlicher Leistungen und Funktionen auf Private (Privatisierung). Eine Darstellung politischer, ökonomischer, gesellschaftlicher und arbeitnehmerorientierter Gesichtspunkte. Stuttgart.

Trottenberg, Wilhelm (1995): Bundeswehr und Gewerkschaften (19451966). Ende einer hundertjährigen Feindschaft. Hamburg. 
Ule, Carl Hermann (1960): Parkinsons Gesetz und die deutsche Verwaltung. Vortrag, gehalten vor der Berliner Juristischen Gesellschaft am 4. März 1960. Berlin.

Ullmann, Hans-Peter (1995): Das Deutsche Kaiserreich, 1871-1918. Frankfurt/Main.

Verhandlungen des Deutschen Bundestages (1952). 1. Wahlperiode. Stenographische Berichte, Bd. 13. Bonn.

Verhandlungen des Deutschen Bundestages (1962). 4. Wahlperiode. Stenographische Berichte, Bd. 50. Bonn.

Verhandlungen des Deutschen Bundestages (1963). 4. Wahlperiode. Stenographische Berichte, Bd. 52. Bonn.

Verhandlungen des Deutschen Bundestages (1966). 5. Wahlperiode. Stenographische Berichte, Bd. 65. Bonn.

Verhandlungen des Deutsche Bundestages (1970). 6. Wahlperiode. Anlagen zu den stenographischen Berichten, Bd. 137. Bonn.

Verhandlungen des Deutschen Bundestages (1973). 7. Wahlperiode. Stenographische Berichte, Bd. 85. Bonn.

Verhandlungen des Deutschen Bundestages (1976). 7. Wahlperiode. Stenographische Berichte, Bd. 99. Bonn.

Verhandlungen des Deutschen Bundestages (1981a). 9. Wahlperiode. Stenographische Berichte, Bd. 117. Bonn.

Verhandlungen des Deutschen Bundestages (1981b). 9. Wahlperiode. Stenographische Berichte, Bd. 119. Bonn.

Verhandlungen des Bundesrates 1967. Stenographische Berichte von der 304. Sitzung am 10. Februar 1967 bis zur 318. Sitzung am 15. Dezember 1967. Bonn 1967.

Verhandlungen des Bundesrates 1981. Stenographische Berichte von der 495. Sitzung am 30.1.1981 bis zur 507. Sitzung am 18. Dezember 1981. Bonn 1981.

Vetten, Horst (1974): Der leise Riese. In: Der Stern 27, H. 4, S. 50-55.

Vetten, Horst (1980): Ein Boss, kein Proletarier. In: Manager-Magazin 10, H. 9, S. 76.

Vetter, Heinz Oskar (1973): Humanisierung der Arbeitswelt als gewerkschaftliche Aufgabe. In: GM 24, H. 1, S. 1-11.

Vetter, Heinz Oskar (Hrsg.) (1974): Humanisierung der Arbeit als gesellschaftspolitische und gewerkschaftliche Aufgabe. Protokoll der Konfe- 
renz des Deutschen Gewerkschaftsbundes vom 16. bis 17. Mai 1974 in München. Frankfurt/Main und Köln.

Vigarello, Georges (2013): The Metamorphoses of Fat. A History of Obesity, New York.

Vogel, Hans-Jochen (1962): Die kommunalen Unternehmen in der Marktwirtschaft. Köln.

Vogel, Otto (1970): Konzertierte Aktion - Bericht über die Erfahrungen seit ihrem Bestehen. Köln.

Vogel, Reiner (1988): Hermann Höcherl. Annäherungen an einen politischen Menschen. Regensburg.

Vogt, Aloys (1974): Der Monatslohn - ein neues Lohnmodell. In: Arbeit und Leistung 28, S. 101-109.

Vorrang dem öffentlichen Nahverkehr (1972). Materialien zur Nahverkehrskonzeption der Gewerkschaft ÖTV. Stuttgart.

Wamper, Horst Wilhelm (1984): Möglichkeiten der Privatisierung technischer Leistungen in Mittelzentren, dargestellt am Beispiel der Stadt Geilenkirchen. Wirtschafts- u. sozialwiss. Diss., TH Aachen.

Weber, Jürgen/Tylkowski, Otto (Hrsg.) (1988): Controlling - eine Chance für öffentliche Unternehmen und Verwaltung. Stuttgart.

Weber, Max (2013): Wirtschaft und Gesellschaft. Soziologie. Unvollendet 1919-1920. Hrsg. v. Knut Borchardt/Edith Hanke/Wolfgang Schluchter. Tübingen.

Weber, Petra (2010): Gescheiterte Sozialpartnerschaft - Gefährdete Republik? Industrielle Beziehungen, Arbeitskämpfe und der Sozialstaat. Deutschland und Frankreich im Vergleich (1918-1933/39). München.

Wehler, Hans-Ulrich (2009): Deutsche Gesellschaftsgeschichte. Bundesrepublik und DDR 1949-1990. Bonn.

Weigend, Arno (1982): Lohndynamik und Arbeitsmarkt. Strukturelle Untersuchungen über die Bestimmungsfaktoren der Lohnentwicklung in der Bundesrepublik Deutschland. Frankfurt/Main.

Weinberger, Bruno (1966): Das quantitative Problem der Gemeindefinanzreform. In: Die Finanzreform und die Gemeinden. Stuttgart u.a.O., S. 71-109.

Weinberger, Bruno (1976): Ein markanter Einschnitt. In: Der Städtetag 29, S. 1.

Weinhauer, Klaus (2004): Sozialpartnerschaft, autoritärer Staat und Innere Sicherheit. Gewerkschaftliche Interessenvertretung in der nordrhein- 
westfälischen Polizei von den 1950er Jahren bis Anfang der 1970er Jahre. In: Führer: Tarifbeziehungen und Tarifpolitik, S. 224-246.

Weiß, Gerhard (1978): Die ÖTV. Politik und gesellschaftspolitische Konzeptionen der Gewerkschaft ÖTV von 1966 bis 1976. 2. Aufl. Marburg.

Weißer, Ulfried (2015): Die Bundesrepublik Deutschland. Ein Erfolgsprojekt. Berlin.

Weitbrecht, Hansjörg (1969): Effektivität und Legitimität der Tarifautonomie. Eine soziologische Untersuchung am Beispiel der deutschen Metallindustrie. Berlin.

Welsch, Johann (1980): Globalsteuerung in der Bundesrepublik Deutschland. Köln.

Welte, A.[lfred] (1974): Moderne Schwimmbagger. In: Hansa 111, S. 604620.

Wilke, Manfred/Müller, Hans-Peter (1971): SED-Politik gegen die Realitäten. Verlauf und Funktion der Diskussion über die westdeutschen Gewerkschaften in SED und KPD/DKP 1961 bis 1972. Köln.

Wilke, Reinhard (2010): Meine Jahre mit Willy Brandt. Die ganz persönlichen Erinnerungen seines engsten Mitarbeiters. Stuttgart und Leipzig.

Willecke, Rainer (1976): ÖPNV im Spannungsfeld zwischen Eigenwirtschaftlichkeit und Subvention. In: Der Personenverkehr 27, S. 105-107.

Wilms, Ernst Helmut (1968): Probleme einer konjunkturgerechten Gestaltung der Gemeindefinanzen. Rechts- u. staatswiss. Diss., Universität Freiburg/Breisgau.

Winkler, Heinrich August (1984): Von der Revolution zur Stabilisierung. Arbeiter und Arbeiterbewegung in der Weimarer Republik 1918 bis 1924. Berlin und Bonn.

Wohlfahrtspflege und Gesundheitsfürsorge in Barmen (1929). Hrsg. v. Städtischen Wohlfahrts- und Jugendamt Barmen. Düsseldorf.

Wolfrum, Edgar (2006): Die 60er Jahre. Eine dynamische Gesellschaft. Darmstadt.

Wolfrum, Edgar (2007): Die geglückte Demokratie. Geschichte der Bundesrepublik Deutschland von ihren Anfängen bis zur Gegenwart. Bonn.

Wulf-Mathies, Monika (1977): Perspektiven der Gewerkschaft ÖTV zur Gesundheitspolitik. In: Gesundheitspolitik. Perspektiven und Beschlüsse der Gewerkschaft ÖTV. Stuttgart, S. 19-27.

Zander, Ernst (1967): Personalprobleme bei Rationalisierung und Automatisierung. Neuwied und Berlin. 
Zehn Jahre ÖTV 1949-1959 (1969). Berichte, Bilder, Dokumente. Über Ziele und Wirken einer großen Gewerkschaft. Stuttgart.

Zentner, Christian (1966): Das Verhalten von Georg Leber, analysiert unter dem Aspekt seiner macht-politischen Bedeutung für die deutsche Gewerkschaftsbewegung und die Sozialdemokratische Partei Deutschlands. Mainz.

Zimmermann, Elisabeth (1961): Der Beruf der Krankenschwester. Seine Entwicklung in den letzten 80 Jahren unter besonderer Berücksichtigung Bayerns und seiner Probleme in der Gegenwart. München.

Zimmermann, Rüdiger (1996): 100 Jahre ÖTV. Die Geschichte einer Gewerkschaft und ihrer Vorläuferorganisationen. Biografien. Frankfurt/ Main.

Zörner, Hendrik (1989): Die Gewerkschaft ÖTV in Wuppertal von 19451987. Wuppertal.

Zwanzig Jahre ÖTV (1966). Daten, Zeugnisse, Meinungen aus 20 Jahren Gewerkschaftsarbeit. Red. bearb. v. Werner Haak. Stuttgart. 



\section{Abkürzungen}

ADGB Allgemeiner Deutscher Gewerkschaftsbund

AdsD Archiv der sozialen Demokratie (der Friedrich-Ebert-Stiftung)

AfA Arbeitsgemeinschaft für Arbeitnehmerfragen (der SPD)

BAföG Bundesausbildungsförderungsgesetz

BArch Bundesarchiv

BAT Bundes-Angestelltentarifvertrag

BDI Bundesverband der Deutschen Industrie

BMdI Bundesministerium des Innern

BMF Bundesministerium der Finanzen

BStU Bundesbeauftragter für Unterlagen des Staatssicherheitsdienstes der ehemaligen Deutschen Demokratischen Republik

BWiM Bundeswirtschaftsministerium

BZ Berliner Zeitung

CDU Christlich Demokratische Union Deutschlands

DAG Deutsche Angestellten-Gewerkschaft

DBB Deutscher Beamtenbund

DDR Deutsche Demokratische Republik

DGB Deutscher Gewerkschaftsbund

DIHT Deutscher Industrie- und Handelstag

Diss. Dissertation

DKP Deutsche Kommunistische Partei

DM Deutsche Mark

DPG Deutsche Postgewerkschaft

DStT Deutscher Städtetag

EWG Europäische Wirtschaftsgemeinschaft

FAZ Frankfurter Allgemeine Zeitung

FDGB Freier Deutscher Gewerkschaftsbund (der DDR) 
FDJ Freie Deutsche Jugend

FDP Freie Demokratische Partei

FR Frankfurter Rundschau

GdP Gewerkschaft der Polizei

GEW Gewerkschaft Erziehung und Wissenschaft

GG Geschichte und Gesellschaft

gHV Geschäftsführender Hauptvorstand

GM Gewerkschaftliche Monatshefte

GRV Gesetzliche Rentenversicherung

GT Gewerkschaftstag

GTK Große Tarifkommission

HAB Hamburger Abendblatt

HV Hauptvorstand

HSA Helmut Schmidt-Archiv

IG Industriegewerkschaft

IÖD Internationale der Öffentlichen Dienste

ITF Internationale Transportarbeiter-Föderation

KBW Kommunistischer Bund Westdeutschland

KPD Kommunistische Partei Deutschlands

$\mathrm{KZ} \quad$ Konzentrationslager

Nato North Atlantic Treaty Organization

NRW Nordrhein-Westfalen

NS Nationalsozialismus

NWDR Nordwestdeutscher Rundfunk

NDR Norddeutscher Rundfunk

NH Neue Heimat (gewerkschaftseigener Baukonzern)

NPL Neue Politische Literatur

NRZ Neue Rhein-Zeitung

ÖTV Gewerkschaft Öffentliche Dienste, Transport und Verkehr

QGG Quellen zur Geschichte der deutschen Gewerkschaften im 20. Jahrhundert

SED Sozialistische Einheitspartei Deutschlands

SPD Sozialdemokratische Partei Deutschlands

StA HH Staatsarchiv Hamburg

StZ Stuttgarter Zeitung

SZ Süddeutsche Zeitung

taz die tageszeitung 
TdL Tarifgemeinschaft deutscher Länder

u. a.O. und andere Orte

UdSSR Union der Sozialistischen Sowjetrepubliken

USA United States of America

VBL Versorgungsanstalt des Bundes und der Länder

VEBA Vereinigte Elektrizitäts- und Bergwerks AG

VC Vereinigung Cockpit

VDA Verband der Automobilindustrie e.V.

VDF Verband Deutscher Flugleiter

ver.di Vereinte Dienstleistungsgewerkschaft

VerBT Verhandlungen des Deutschen Bundestages

VKA Vereinigung der kommunalen Arbeitgeberverbände

VOP Verwaltungsführung, Organisation, Personalwesen

VW Volkswagen

WAZ Westdeutsche Allgemeine Zeitung

WBA Willy Brandt-Archiv

WdA Welt der Arbeit

WDR Westdeutscher Rundfunk 


\section{Politikwissenschaft}
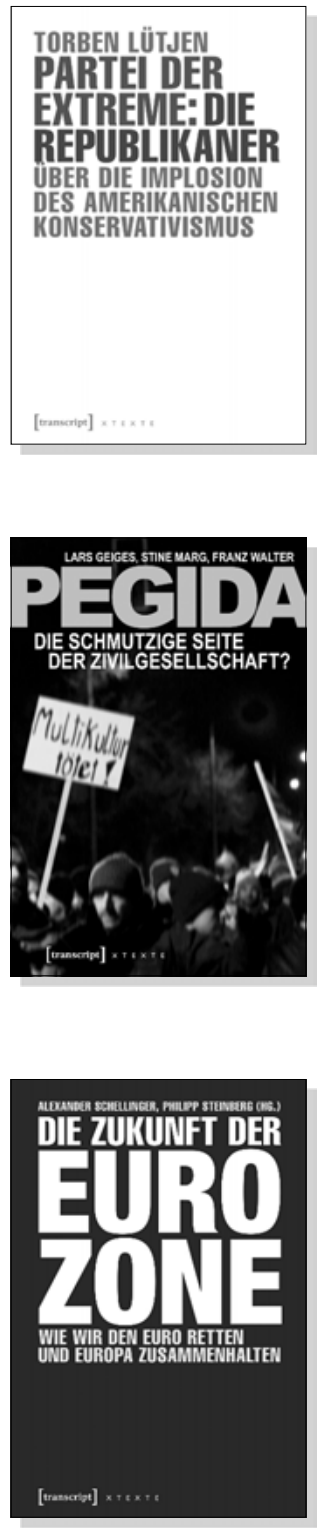

\section{Torben Lütjen}

Partei der Extreme: Die Republikaner Über die Implosion

des amerikanischen Konservativismus

Oktober 2016, 148 S., kart., 14,99 € (DE),

ISBN 978-3-8376-3609-3

E-Book: $12,99 €(D E)$, ISBN 978-3-8394-3609-7

EPUB: $12,99 €(D E)$, ISBN 978-3-7328-3609-3
Lars Geiges, Stine Marg, Franz Walter

\section{Pegida}

Die schmutzige Seite der Zivilgesellschaft?

2015, 208 S., kart., farb. Abb., 19,99€ (DE),

ISBN 978-3-8376-3192-0

E-Book: $14,99 €(D E)$, ISBN 978-3-8394-3192-4

EPUB: $14,99 €(D E)$, ISBN 978-3-7328-3192-0

Alexander Schellinger, Philipp Steinberg (Hg.)

Die Zukunft der Eurozone

Wie wir den Euro retten

und Europa zusammenhalten

Oktober 2016, 222 S., kart., 19,99€ (DE),

ISBN 978-3-8376-3636-9

E-Book: $17,99 €(\mathrm{DE})$, ISBN 978-3-8394-3636-3

EPUB: $17,99 €(\mathrm{DE})$, ISBN 978-3-7328-3636-9 


\section{Politikwissenschaft}
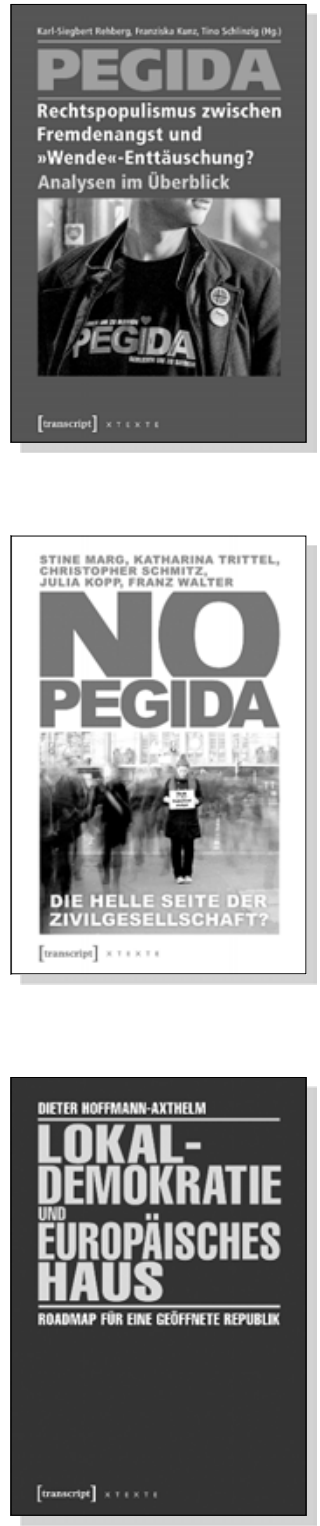

Karl-Siegbert Rehberg, Franziska Kunz, Tino Schlinzig (Hg.) PEGIDA - Rechtspopulismus zwischen Fremdenangst und »Wende«-Enttäuschung? Analysen im Überblick

September 2016, 384 S., kart., 29,99€ (DE), ISBN 978-3-8376-3658-1

E-Book: $26,99 €(\mathrm{DE})$, ISBN 978-3-8394-3658-5

EPUB: $26,99 €(\mathrm{DE})$, ISBN 978-3-7328-3658-1

Stine Marg, Katharina Trittel, Christopher Schmitz, Julia Kopp, Franz Walter NoPegida

Die helle Seite der Zivilgesellschaft?

März 2016, 168 S., kart., 19,99€ (DE),

ISBN 978-3-8376-3506-5

E-Book: $17,99 €(\mathrm{DE})$, ISBN 978-3-8394-3506-9

EPUB: $17,99 €(\mathrm{DE})$, ISBN 978-3-7328-3506-5

Dieter Hoffmann-Axthelm

Lokaldemokratie und Europäisches Haus

Roadmap für eine geöffnete Republik

Oktober 2016, 114 S., kart., 17,99€ (DE),

ISBN 978-3-8376-3642-0

E-Book: $15,99 €(\mathrm{DE})$, ISBN 978-3-8394-3642-4 
